\title{
Archaeological Data Recovery at Fish Creek Slough Site (41DL436)
}

David L. Nickels

Follow this and additional works at: https://scholarworks.sfasu.edu/ita

Part of the American Material Culture Commons, Archaeological Anthropology Commons, Environmental Studies Commons, Other American Studies Commons, Other Arts and Humanities Commons, Other History of Art, Architecture, and Archaeology Commons, and the United States History Commons

Tell us how this article helped you.

This Article is brought to you for free and open access by the Center for Regional Heritage Research at SFA ScholarWorks. It has been accepted for inclusion in Index of Texas Archaeology: Open Access Gray Literature from the Lone Star State by an authorized editor of SFA ScholarWorks. For more information, please contact cdsscholarworks@sfasu.edu. 


\section{Archaeological Data Recovery at Fish Creek Slough Site (41DL436)}

\section{Licensing Statement}

This is a work for hire produced for the Texas Department of Transportation (TxDOT), which owns all rights, title, and interest in and to all data and other information developed for this project under its contract with the report producer. The report may be cited and brief passages from this publication may be reproduced without permission provided that credit is given to TxDOT and the firm that produced it. Permission to reprint an entire chapter, section, figures or tables must be obtained in advance from the Supervisor of the Archeological Studies Branch, Environmental Affairs Division, Texas Department of Transportation, 125 East 11th Street, Austin, Texas, 78701 


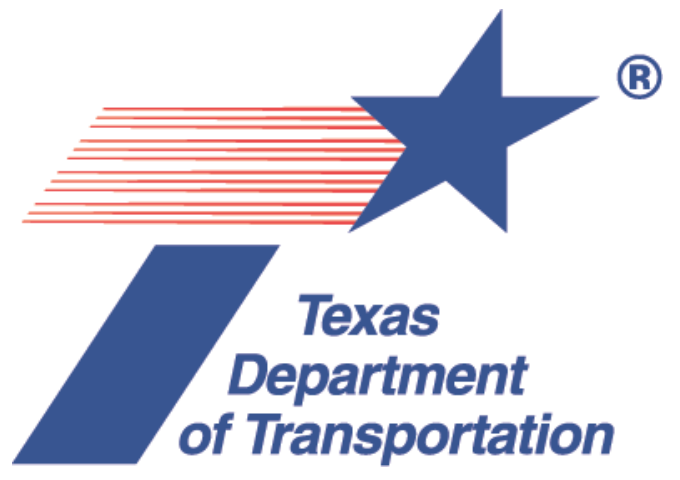

Archaeological Data Recovery at Fish Creek Slough Site (41DL436)

\section{Dallas County, Texas}

edited by David L. Nickels 



\section{Archaeological Data Recovery at the Fish Creek Slough Site (41Dl436), Dallas County, Texas}

Draft

edited by

David L. Nickels

with contributions by

James T. Abbott, David O. Brown, Kenneth M. Brown, Joel Butler, Linda Scott Cummings, Phil Dering, Jon Dowling, Timothy Figol, Charles D. Frederick, Robert G. Howells, Jodi A. Jacobson, Mervyn Kontrovitz, Mary Malainey, Raymond P. Mauldin, David L. Nickels, Kathryn Puseman, Timothy E. Riley, W. Nicholas Trierweiler, Barbara Winsborough, and Chad Yost

James T. Abbott and W. Nicholas Trierweiler, Co-Principal Investigators

Prepared for

Texas Department of Transportation

CSJ 0918-45-608

Contract No. 579-09-SA006

Work Authorization No. 57-1004SA1002

Texas Antiquities Permit No. 5764

Archeological Studies Program Report No. 170

by

AmaTerras ENVIRONMENTAL, INC.

Austin, Texas

December 2014 


\title{
Copyright (C) 2014
}

Texas Department of Transportation (TxDOT)

This is a work for hire produced for the Texas Department of Transportation (TxDOT), which owns all rights, title, and interest in and to all data and other information developed for this project under Contract 579-09-SA006. Brief passages from this publication may be reproduced without permission provided that credit is given to TxDOT and AmaTerra Environmental, Inc. Permission to reprint an entire chapter, section, figures or tables must be obtained in advance from the Supervisor of the Archeological Studies Program, Environmental Affairs Division, Texas Department of Transportation, 125 East 11th Street, Austin, Texas 78701. Copies of this publication have been deposited with the Texas State Library in compliance with the State Depository Requirement.

\author{
Printed by \\ Ginny's Printing
}

published by:

Texas Department of Transportation

Environmental Affairs Division

Archeological Studies Program

Scott Pletka, Ph.D., Supervisor

Archeological Studies Program Report No. 170

and

AmaTerra Environmental, Inc.

Technical Report No. 76

AmaTerra Project No.. 062-039

ISBN\# 978-1-935545-37-8

(C) 2014 by AmaTerra Environmental, Inc.

4009 Banister Lane, Suite 300

Austin, Texas 78704 


\section{Abstract}

The Fish Creek Slough site (41DL436) is a well stratified, multi-component, open campsite situated on an alluvial terrace on the west bank of Fish Creek in Dallas County, Texas. Discovered in 2005, the site contains an abundance of faunal material, charcoal, and burned clay within multiple, discrete stratified zones. The site was evaluated by the Texas Department of Transportation (TxDOT ) as eligible for listing in the National Register of Historic Places. Because the site was within the right-of-way for a planned road and bridge construction project, and as directed by the National Historic Preservation Act of 1966, TxDOT elected to undertake archaeological data recovery excavations to mitigate adverse effects to the site.

In October of 2010, AmaTerra Environmental, Inc. conducted archaeological data recovery excavations at the site under TxDOT contract no. 579-09-SA006. Mechanical stripping was conducted within a $6 \times 20-\mathrm{m}$ trench in 3-5-cm cuts down to 200 centimeters below the modern ground surface and exposed 43 burned zones, other features, and artifact concentrations. In addition to 285 cubic meters of soil removed mechanically, an additional 17.75 cubic meters was excavated within 107 hand-dug units. Collected and analyzed items included more than 8,700 faunal specimens, 43 pieces of chipped stone, and 206 fire-cracked rocks. Samples were collected for macrobotanical, magnetic susceptibility, $\mathrm{pH}$, carbon, and malacology, pollen, diatom, phytolith, and ostracod assays and selected specimens of fire-cracked rock were analyzed for the presence of starches and lipids.

Thirty-nine radiocarbon dates accepted as valid helped define four discrete occupational components with the earliest occupation probably occurring as early as AD 1025, and the last occupation probably as late as AD 1865. Geoarchaeological analyses show that the stratigraphic sequence accumulated rapidly, separating and preserving the discrete occupations in good context. Analysis of the exceptionally robust and well-preserved faunal assemblage provides evidence for interpretation of change through time in social structure, site spatial occupations, and diet and subsistence. Of special note, within the occupation zones dating to the Protohistoric and Historic periods, metal cut marks on bone suggest an increased reliance on European-introduced technology. 


\section{Table of Contents}

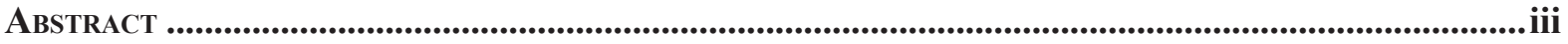

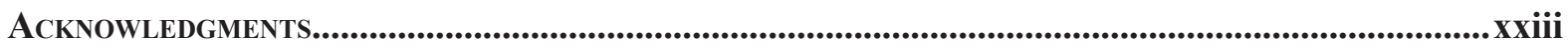

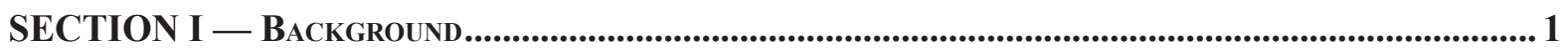

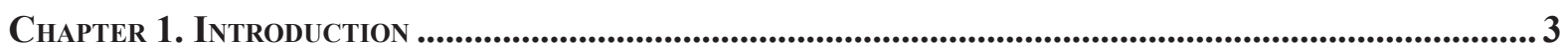

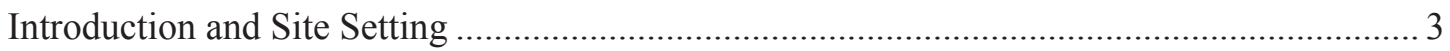

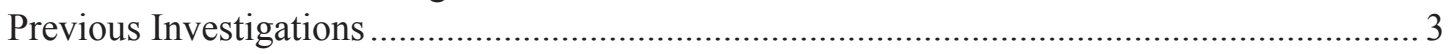

Data Recovery Scope of Work and Data Collected ......................................................... 5

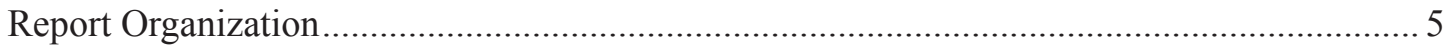

Chapter 2. Environmental Setting and Cultural Background ................................................... 7

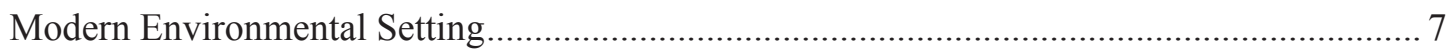

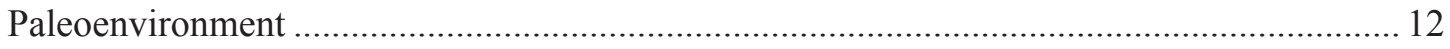

Cultural Context and Chronology ............................................................................ 13

Chapter 3. Research Design ................................................................................................................ 37

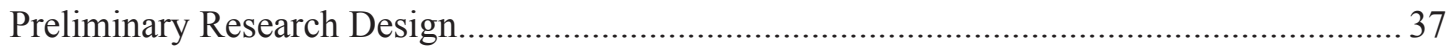

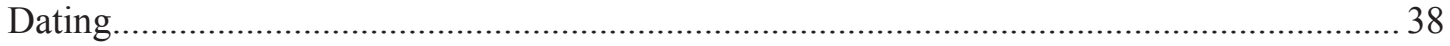

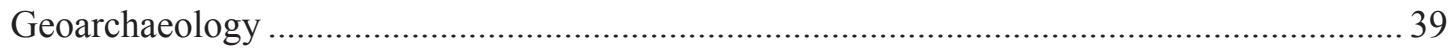

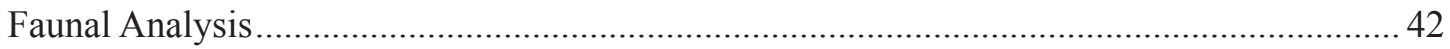

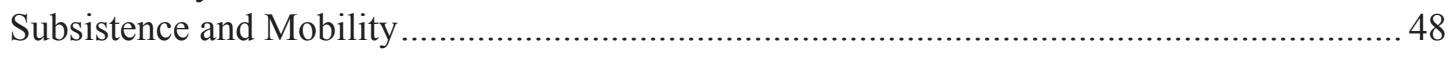

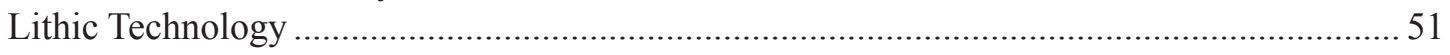

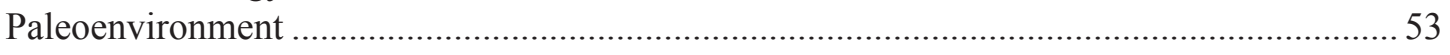

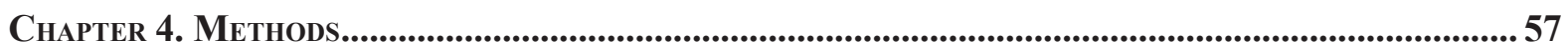

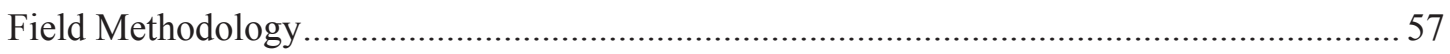

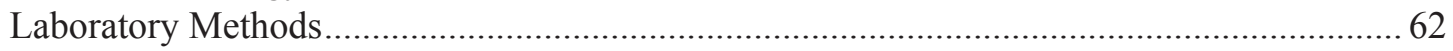

SECTION II — GEOARCheology Site Integrity ANd Radiocarbon Dating ................................. 65

Chapter 5. Geoarchaeology of 41Dl436, Dallas County, Texas ............................................. 67

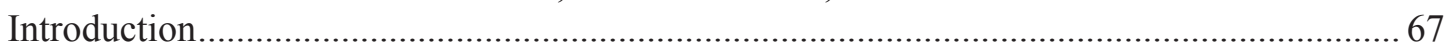

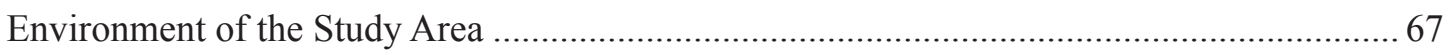

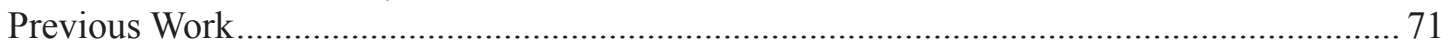

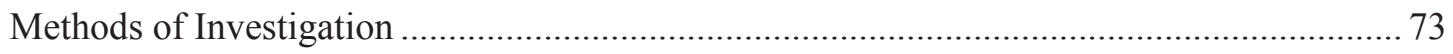

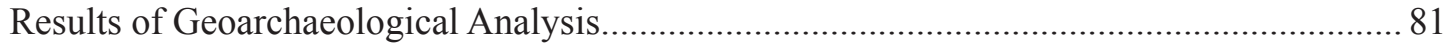

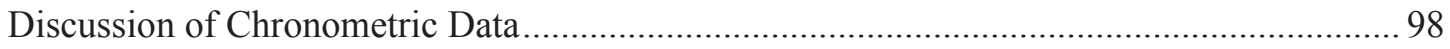

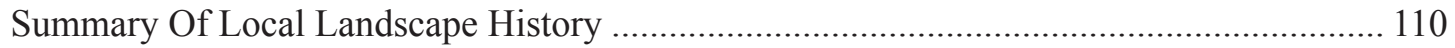

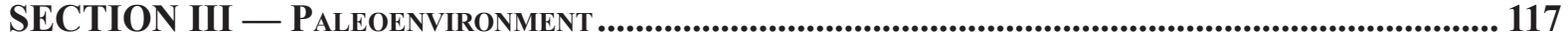

Chapter 6. Snails, Peaclams, and Freshwater Limpets................................................................. 119

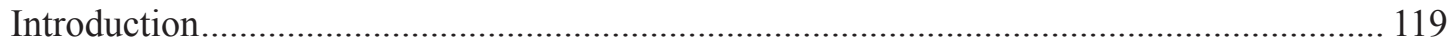

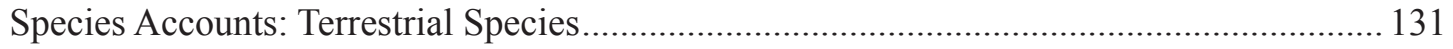

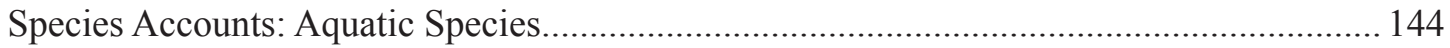

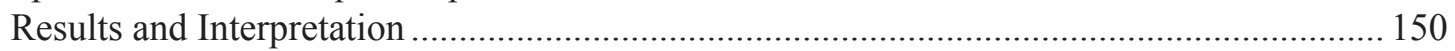

Chapter 7. Mussel Shell Species .................................................................................................. 165

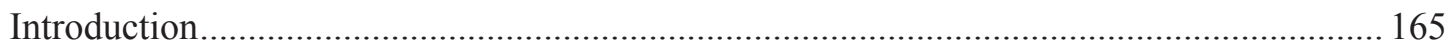

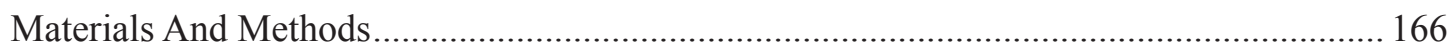




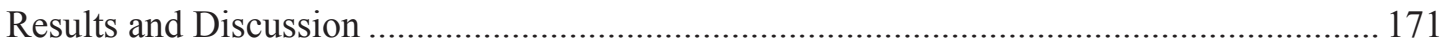

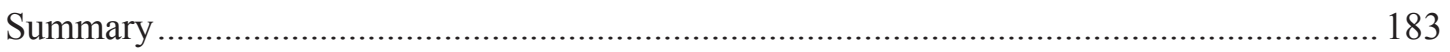

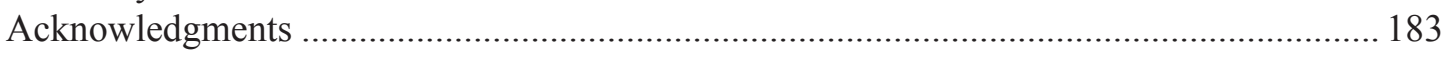

Chapter 8. Analysis and Evaluation of Isotope Data from Mussel Shells ................................. 189

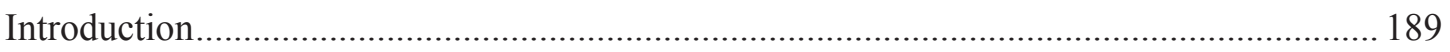

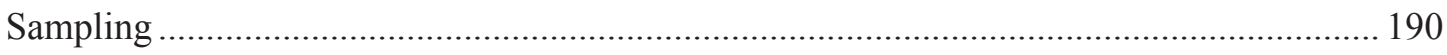

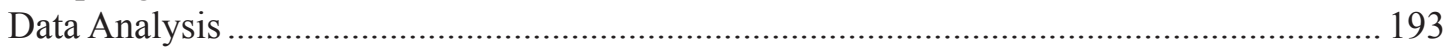

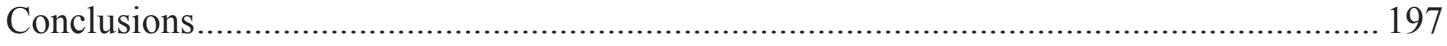

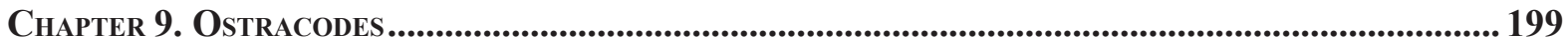

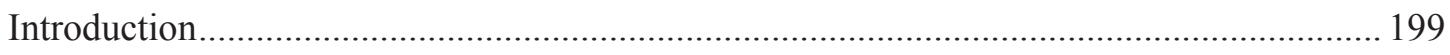

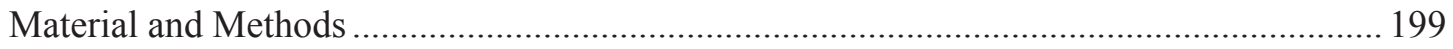

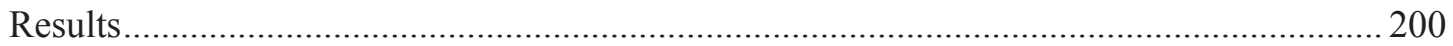

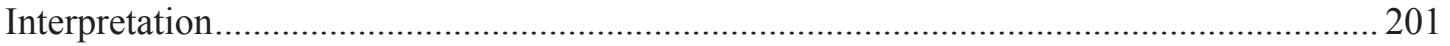

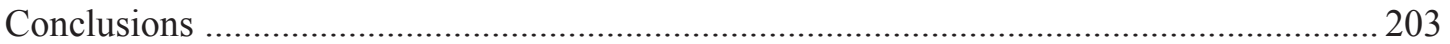

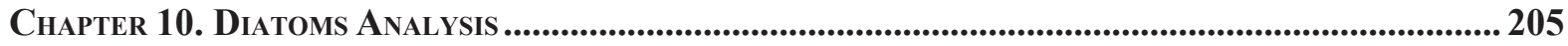

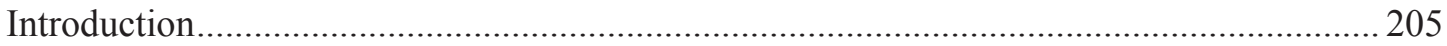

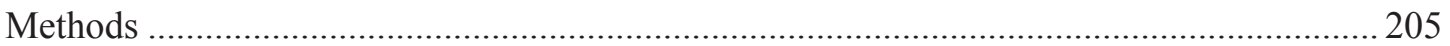

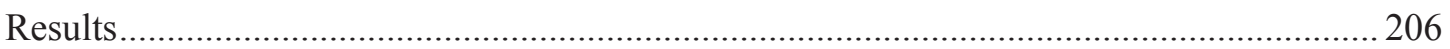

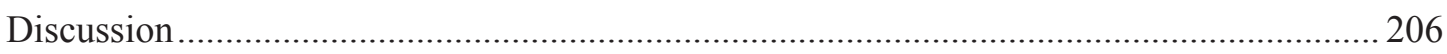

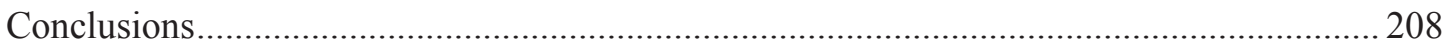

Chapter 11. Pollen, Phytolith, and Macrofloral Analyses and AMS Dating ........................ 211

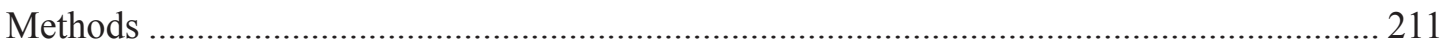

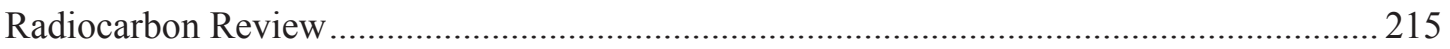

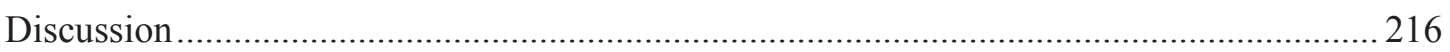

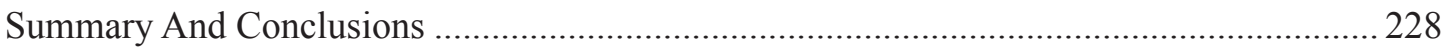

SECTION IV — Cultural and Environmental Manifestations............................................... 243

Chapter 12. Analysis of Lipid Residues Extracted from Fire-Cracked Rocks........................... 245

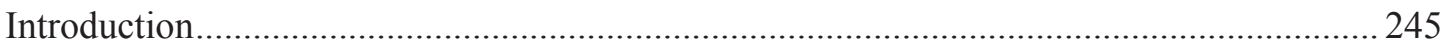

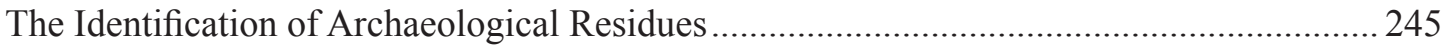

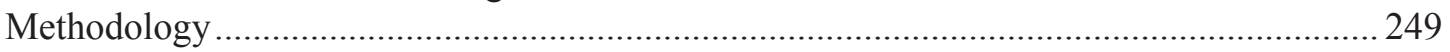

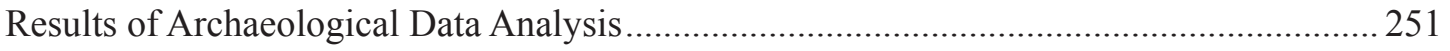

Chapter 13. Microfossil Analysis of Fire-Cracked Rock Samples.............................................. 255

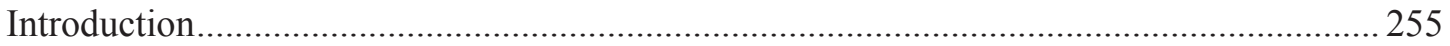

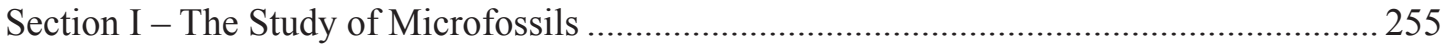

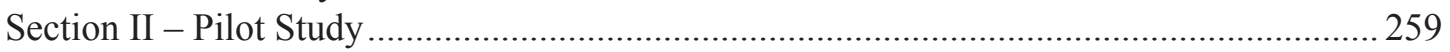

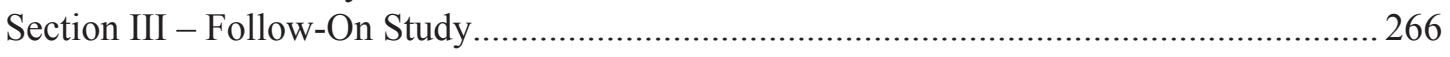

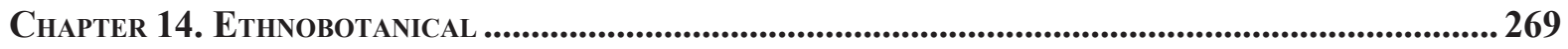

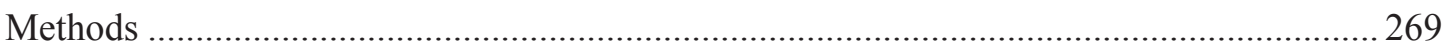

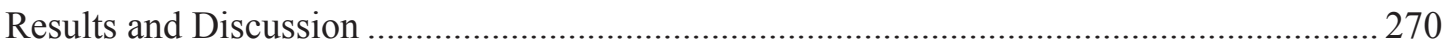

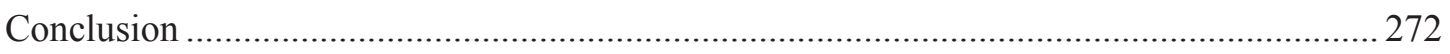

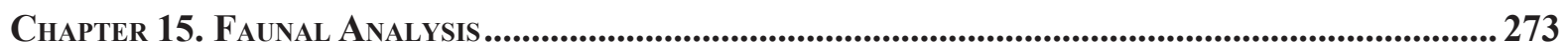

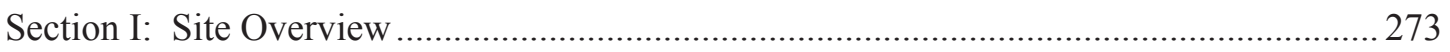

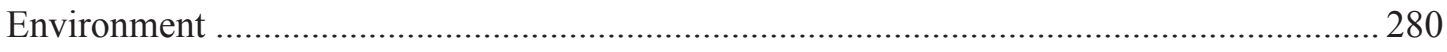

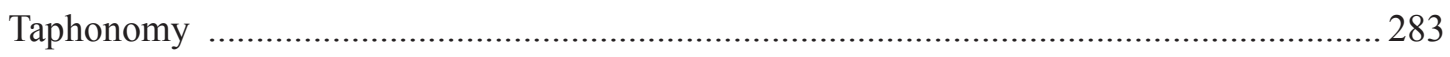

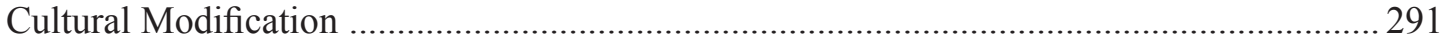

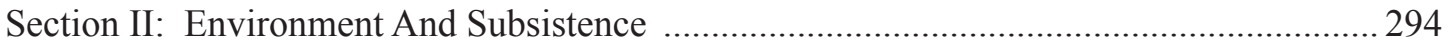




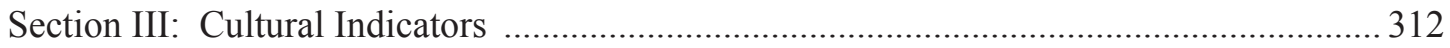

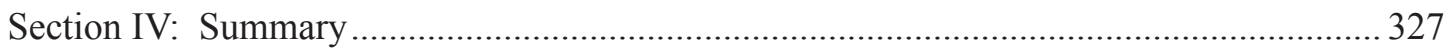

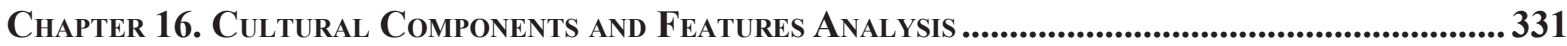

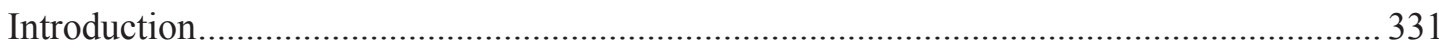

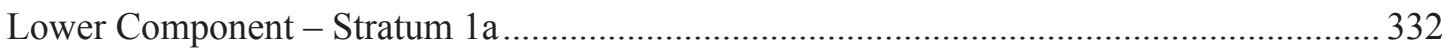

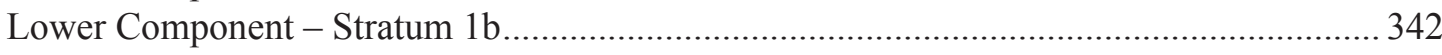

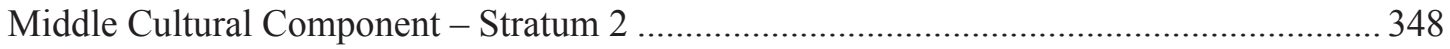

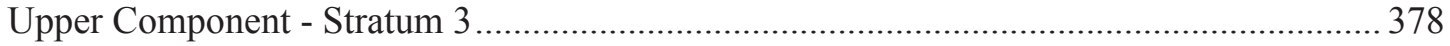

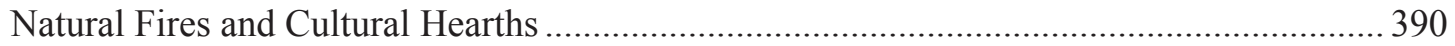

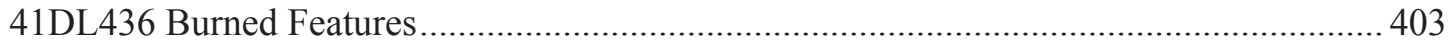

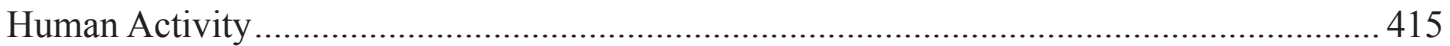

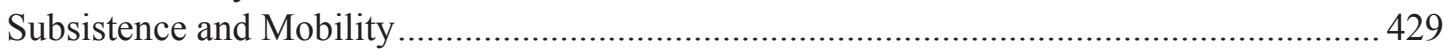

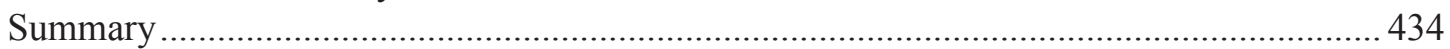

Technology, Subsistence and Mobility Patterns at 41DL436 ............................................ 436

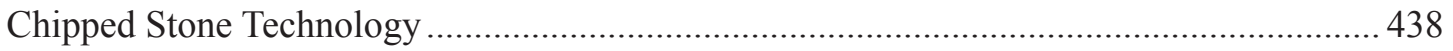

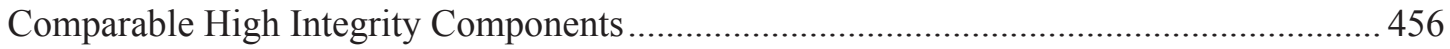

Summary and Conclusions of Later Prehistoric and Protohistoric Occupants ...................... 466

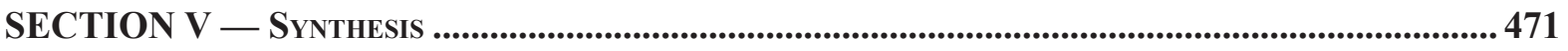

Chapter 17. Paleoenvironmental Climate and Biota ............................................................ 473

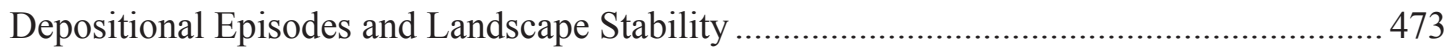

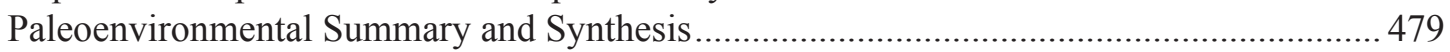

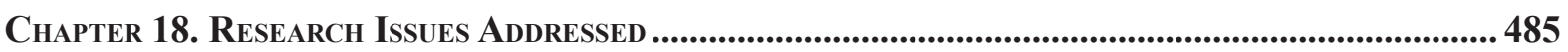

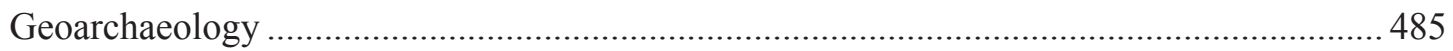

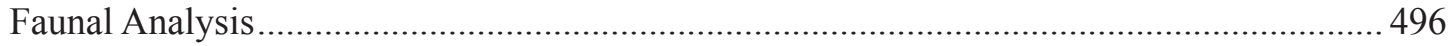

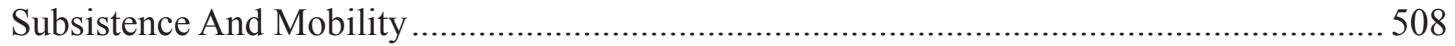

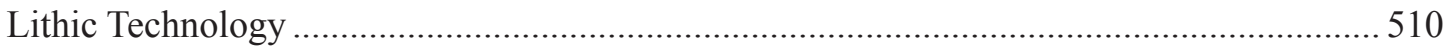

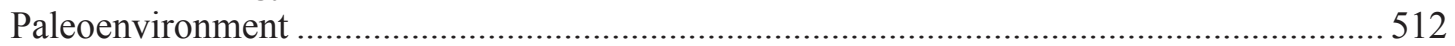

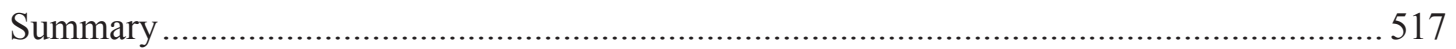

Chapter 19. Summary, Conclusions and Recommendations ..........................................................5 519

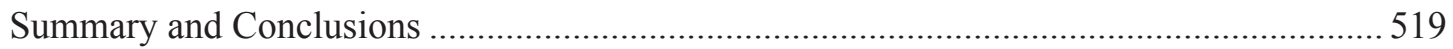

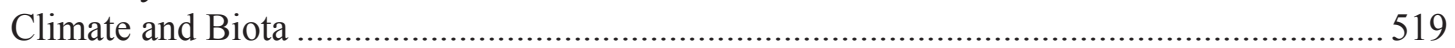

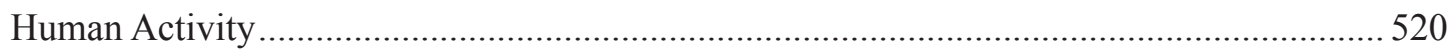

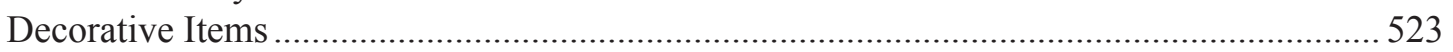

Cultural Affiliations and Named Native American Groups ................................................. 523

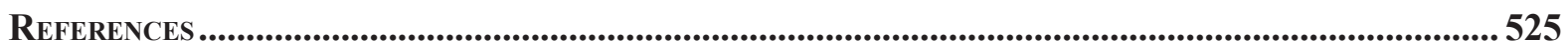

Appendix A - Soil Micromorphological Observations

Appendix B - Radiocarbon Data Sheets

Appendix C - Artifact Catalogs

Appendix D - Soil Susceptibility

Appendix E - Comparable Component Ages

Appendix F - Raw Materials

Appendix G - Faunal Data

Appendix H - Microfloral and Microcharcoal Radiocarbon Data SheEts

Appendix I - Bone Collagen Radiocarbon Dating 


\section{List of Figures}

Figure 1-1. Location of the Fish Creek Slough site in southwestern Dallas County............................................

Figure 2-1. Ecoregions of Texas as defined by Gould et al. 1960; adapted by TPWD (2011a)...........................8

Figure 2-2. Biotic provinces of Texas (Blair 1950; adapted by TPWD 2010c) ....................................................

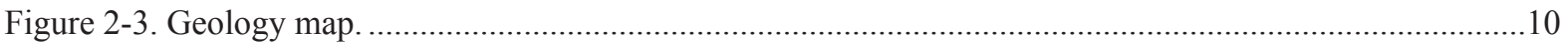

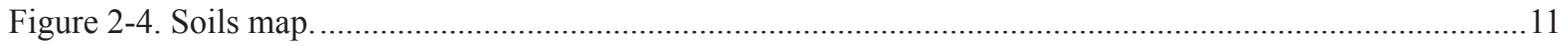

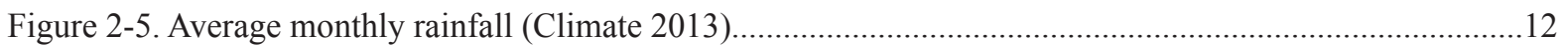

Figure 2-6. Average monthly temperatures (Climate 2013) .............................................................................12

Figure 2-7. Texas Paleoclimate data and its effects (adapted from Nickels et al. 2010). .....................................13

Figure 2-8. Paleoclimate data interpretations from the Vara Daniels site (41TV1364) in Austin, Texas (from

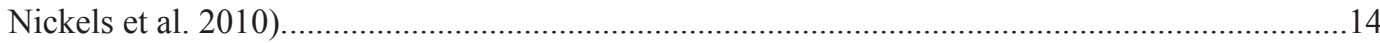

Figure 2-9. Locations of place names discussed in the text........................................................................

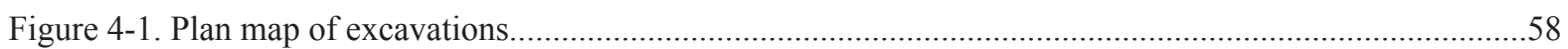

Figure 4-2. Gradall stripping began in the grid north end of the trench. ........................................................59

Figure 4-3. In some cases, burned zones were brushed with a push broom to better delineate the extent of the zone before excavations began (facing grid north) ……...............................................................59

Figure 4-4. Excavations in progress; facing grid north.

Figure 4-5. Excavations in progress; note stepped benches on both sides of the main excavation block (facing

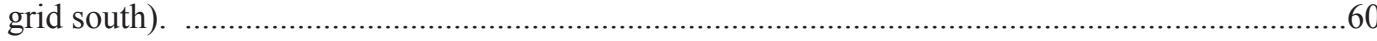

Figure 4-6. Excavation block in grid north portion of trench; facing grid northeast............................................61

Figure 4-7. Control Unit 49 in grid west wall of the trench; facing west. .........................................................61

Figure 5-1. Location and geological setting. Map adapted from the Geologic Atlas of Texas, Dallas Sheet. ......68

Figure 5-2. Map of local landforms and local topography superimposed on aerial photograph of the site. Contour interval is $2 \mathrm{ft}$.

Figure 5-3. Map of soils in the vicinity of 41DL436, from USDA-NRCS Web Soil Survey................................70

Figure 5-4. Reproduction of sketch map from Oksanen et al. (nd) with the approximate location of the data

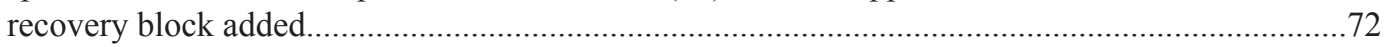

Figure 5-5. View of BT1 during the June phase of work, looking north....................................................73

Figure 5-6. View of Section GW-1 showing the offset at the safety bench....................................................75

Figure 5-7. Static and exploded views of hand excavation units within the data recovery block, coded by

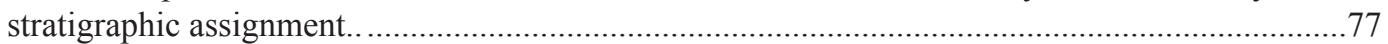

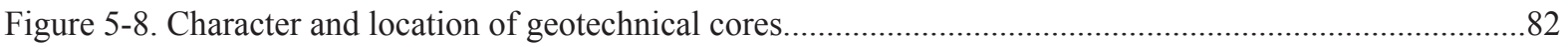

Figure 5-9. Typical profile of soil capping the higher ( $\mathrm{T}_{1 \mathrm{~A}}$ terrace) ...................................................................85

Figure 5-10. Photomosaic and schematic profile of eastern wall of excavation block.......................................87

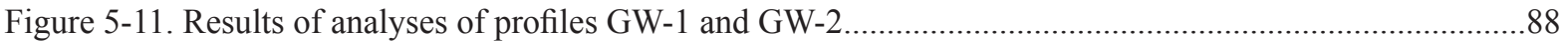

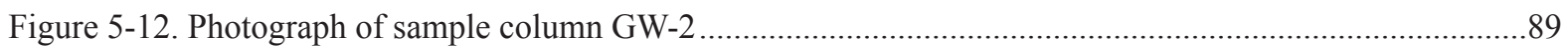

Figure 5-13. Graph of probability calibrated radiocarbon ages on charcoal and one bone from 41DL436, organized according to position in the block..............................................................................92

Figure 5-14. Photograph and sketch of tree throw feature at the Unit 1a-Unit $1 \mathrm{~b}$ contact...................................94 
Figure 5-15. Examples of ripples and crossbedding in silts and loams in the deposits of 41DL436.

Figure 5-16. Photograph showing soft, incipient carbonate nodules developing in stratified silts and fine sands of Unit 2 (arrows)

Figure 5-17. Looking down on convolute bedding structures at depth in the channel swale, exposed in the deep probe trench more than $4 \mathrm{~m}$ below the surface

Figure 5-18. Figure illustrating the relationship between measurement error and accuracy of calibrated ages..101

Figure 5-19. Schematic profile of east wall of block, showing approximate stratigraphic context of radiocarbon ages. Error values have been omitted for legibility.

Figure 5-20. Plot of prior and post-facto probability distributions resulting from Bayesian analysis. 107

Figure 5-21. Probability plot of samples from the northernmost $5 \mathrm{~m}$ of the block, arranged by approximate depth below datum.

Figure 5-22. Model of local landscape development at the Fish Creek Slough Site.

Figure 5-23. Alternative model of local landscape development at the Fish Creek Slough Site.....

Figure 6-1. Plan of Excavation.

Figure 6-2. Unit 49 Profile.

Figure 6-3. Examples of Material Recovered From the Snail Samples.

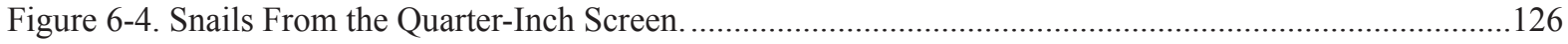

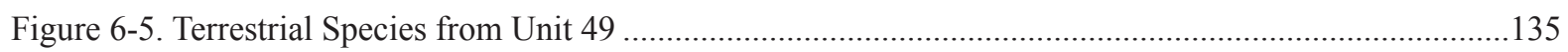

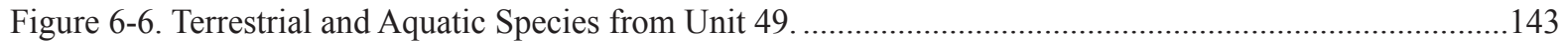

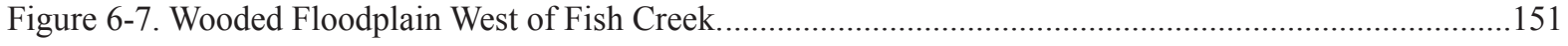

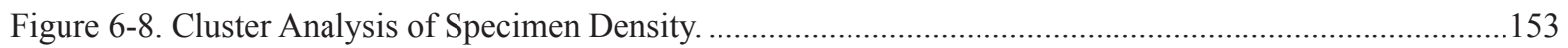

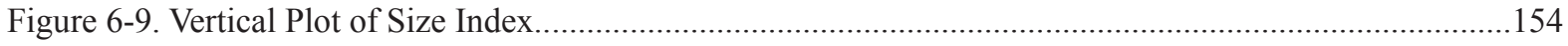

Figure 6-10. Most Common Species in Depositional Unit 1 .............................................................

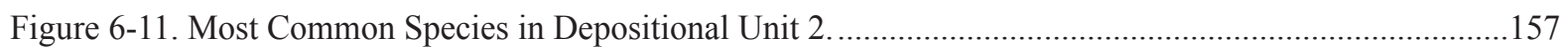

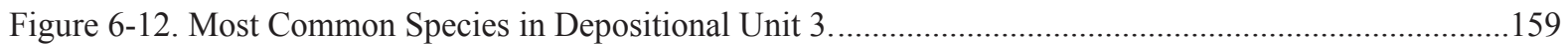

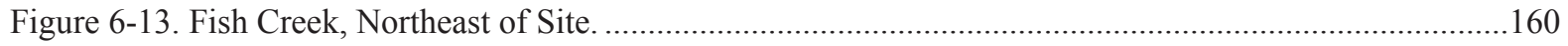

Figure 6-14. Depositional Units Plotted on PDSI Timeline for Data Cell 180............................................162

Figure 7-1. Elements and regions of a representative freshwater mussel (Family Unionidae) valve. ..............171

Figure 7-2. Louisiana Fatmucket (Lampsilis hydiana) male and female......................................................173

Figure 7-3. Louisiana fatmucket (Lampsilis hydiana) female..............................................................173

Figure 7-4. Louisiana fatmucket (Lampsilis hydiana) male and female specimens from sites in eastern

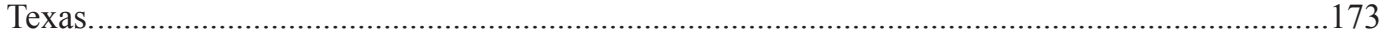

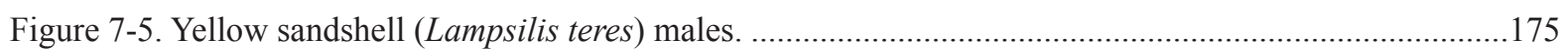

Figure 7-6. Yellow sandshell (Lampsilis teres) male and female from sites in eastern Texas.........................175

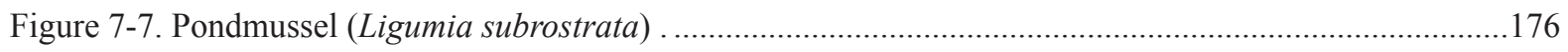

Figure 7-8. Pondmussel (Ligumia subrostrata) male and female from the Blue River, Oklahoma..................176

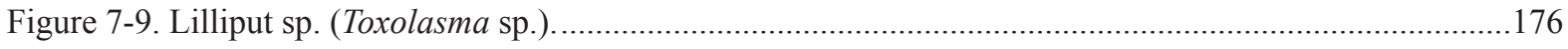

Figure 7-10. Texas lilliput (Toxolasma texasense) female.....................................................................177

Figure 7-11. Texas lilliput (Toxolasma texasense) male and female from southeastern Texas and lilliput (T. parvum) from Wisconsin.

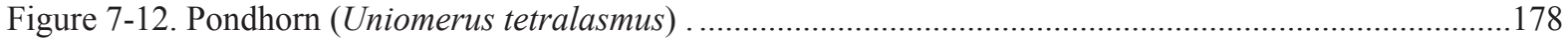


Figure 7-13. Pondhorn (Uniomerus tetralasmus) (above top) from Central Texas and tapered pondhorn (U. declivis) (above bottom) from north-eastern Texas.

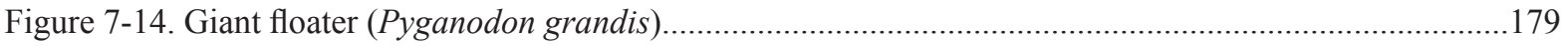

Figure 7-15. Giant floater (Pyganodon grandis) from the Trinity River drainage, Texas. .................................179

Figure 7-16. Bankclimber (Plectomerus dombeyanus) from Lake Livingston, Texas. ......................................180

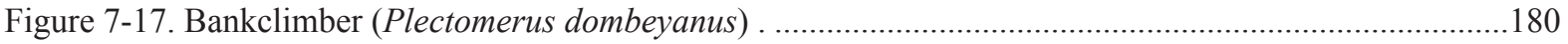

Figure 7-18. Pistolgrip (Quadrula verrucosa) male (above bottom) and female (above top) from eastern Texas.

Figure 7-19. Pistolgrip (Quadrula verrucosa).

Figure 7-20. This unidentified fragment, may have come from a large washboard (Megalonaias nervosa) specimen, but diagnostic features are lacking.

Figure 7-21. This fragment was attacked by a predator during its life, but survived and continued to grow......183

Figure 7-22. This specimen (right) shows clear indication of human manipulation of the valve indicated by a series of parallel grooves etched into the nacre between the pallial line and ventral margin of the valve.

Figure 7-23. Louisiana fatmucket (Lampsilis hydiana) umbos showing typical double-looped or V-shaped beak sculpture.

Figure 7-24. Louisiana fatmucket (Lampsilis hydiana) have double-looped or V-shaped beak sculpture

Figure 7-25. Yellow sandshell (Lampsilis teres) umbo showing typical double-looped or V-shaped beak sculpture.

Figure 7-26. Yellow sandshell (Lampsilis teres) umbo with double-looped or V-shaped beak sculpture. .185

Figure 7-27. Pondmussel (Ligumia subrostrata) umbo showing typical double-looped or V-shaped beak sculpture.

Figure 7-28. Pondmussel (Ligumia subrostrata) umbo that is strongly pointed and with beak sculpture that has a fine double-looped or V-shaped pattern that extends well into the posterior field along the posterior ridge.

Figure 7-29. Giant floater (Pyganodon grandis) umbo showing typical double-looped pattern.........................185

Figure 7-30. Giant floater (Pyganodon grandis) umbos with the typical double-looped sculpture pattern........186

Figure 7-31. Lilliput sp. (Toxolasma sp.) umbo.

Figure 7-32. Lilliput (Toxolasma parvum) (above left) and Texas lilliput (T. texasense) (above right) umbos showing more numerous single-looped ridges in Texas lilliput, which are angled over the posterior ridge area in both species.

Figure 7-33. Pondhorn (Uniomerus tetralasmus) umbo showing a single-looped sculpture pattern typical of the species

Figure 7-34. Pondhorn (Uniomerus tetralasmus) umbo with a single-looped sculpture pattern that is evenly curved and does not angle back more sharply over the posterior ridges

Figure 8-1. Locations of Units 93, 95, 103, 104 and Feature 11.

Figure 10-1. Representative Diatom Taxa.

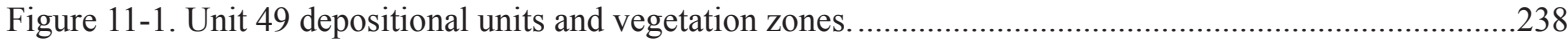

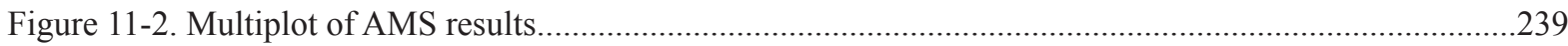

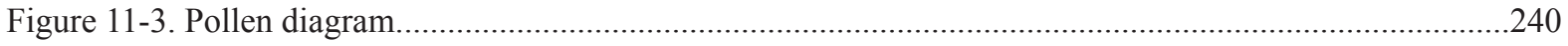

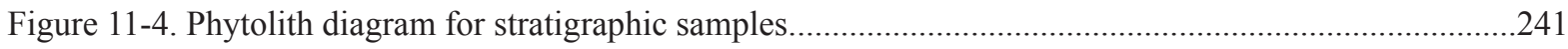

Figure 11-5. Selected phytolith, starch and sponge spicule micrographs from stratigraphic samples. .242 


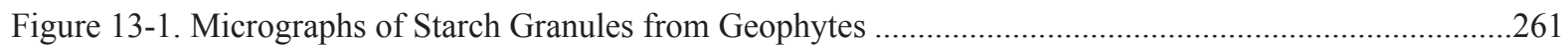

Figure 13-2. Micrographs of Starch from seeds and meristem .................................................................262

Figure 13-3. Cross-Polarized Light Micrographs of Starch Granules from Grass Seeds....................................263

Figure 13-4. Micrographs of unknown Starch Granules from FCR ……....................................................264

Figure 13-5. Micrographs of unknown starch granule type $\mathrm{G}$ and amyloplasts recovered from FCR sample

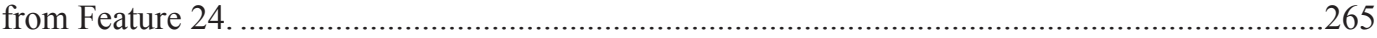

Figure 13-6. Micrographs of poaceae phytoliths recovered from fire cracked rock.............................................268

Figure 15-1. Distribution by Class of bone recovered during Data Recovery...................................................277

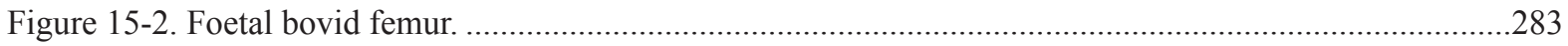

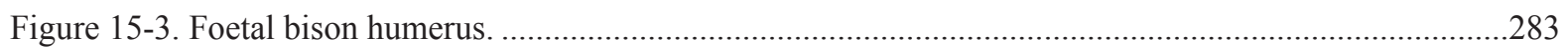

Figure 15-4. Stratum 2 (Field Lot \# 256) Bison mandibular 3rd molar..........................................................283

Figure 15-5. Distribution of skeletal fragments for bovids and cervids. .......................................................285

Figure 15-6. Distribution of forelimb and hindlimb skeletal fragments for mule deer, white-tailed deer, and

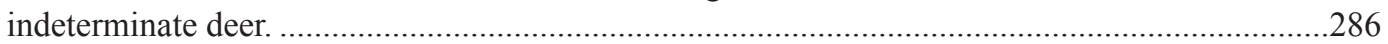

Figure 15-7. Average Utility (from Jacobson 2000) Distribution for Deer Elements.........................................287

Figure 15-8. Distribution of elements by utility ranking and species for deer bone recovered...........................287

Figure 15-9. Average Utility (from Emerson 1990) Distribution for Bison Elements. .....................................289

Figure 15-10. Distribution of bison elements by utility ranking. .................................................................28

Figure 15-11. Stratigraphic profile with Stratum 1a highlighted. ………............................................................294

Figure 15-12. Distribution of species NISP in Stratum 1a by habitat niche. ....................................................297

Figure 15-13. Frequency of aquatic species to terrestrial species in Stratum 1a. ..............................................297

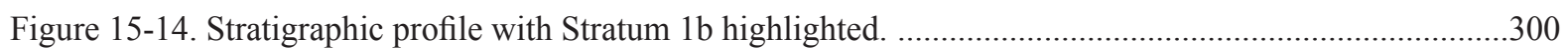

Figure 15-15. Distribution of species NISP in Stratum 1b by habitat niche. ................................................301

Figure 15-16. Frequency of aquatic species to terrestrial species in Stratum 1b. ............................................301

Figure 15-17. Distribution of species NISP in Stratum $1 \mathrm{~b}$ by habitat niche with wetland/aquatic removed .......301

Figure 15-18. Distribution of deer bone elements by utility ranking in Stratum 1b........................................302

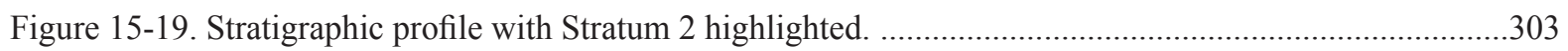

Figure 15-20. Distribution of species NISP in Stratum 2 by habitat niche....................................................305

Figure 15-21. Frequency of aquatic species to terrestrial species in Stratum 2 ...............................................305

Figure 15-22. Distribution of skeletal fragments for bovids and cervids recovered from Stratum 2. ................306

Figure 15-23. Distribution of deer bone elements by utility ranking in Stratum 2. ..........................................306

Figure 15-24. Stratigraphic profile with Stratum 3 highlighted. ........................................................................307

Figure 15-25. Distribution of species NISP in Stratum 3 by habitat niche. ..................................................309

Figure 15-26. Frequency of aquatic species to terrestrial species in Stratum 3. ................................................310

Figure 15-27. Summary of Species Habitat Distributions by Strata. ................................................................311

Figure 15-28. Summary of Species Habitat Distributions by Strata with Aquatic Resources Removed. ...........311

Figure 15-29. Stratum 1a (Field Lot \#255) bison thoracic vertebra with cuts.................................................313

Figure 15-30. Stratum 1a (Field Lot \#255) bison thoracic vertebra with cuts. .................................................314

Figure 15-31. Stratum 1a (Field Lot \#255) bison thoracic vertebra with cuts....................................................

Figure 15-32. Stratum 1a (Field Lot \#285) juvenile deer bone with stone tool cuts.........................................314 
Figure 15-33. Stratum 1b (Field Lot \# 354) deer radius. .314

Figure 15-34. Stratum 1b (Field Lot \# 354) deer radius. 315

Figure 15-35. Stratum 1b (Field Lot \#394) deer frontal bone with cuts.

Figure 15-36. Stratum 1b (Field Lot \#394) deer frontal bone with cuts - microscopic view of one of the cuts from Figure 15-35.

Figure 15-37. Stratum 1b (Field Lot \# 391) medium-large mammal longbone with series of cuts.

Figure 15-38. Stratum 1b (Field Lot \#391) medium-large mammal longbone stone tool cuts under microscope.

Figure 15-39. Stratum 2 (Field Lot \# 280) bison femur with series of cut marks and striking platform.

Figure 15-40. Stratum 2 (Field Lot \# 280) bison femur with series of cut marks and striking platform close-up of Figure 15-39.

Figure 15-41. Stratum 2 (Field Lot \# 280) bison femur with series of cut marks microscopic view of Figure 39 - note metal knife cut marks.

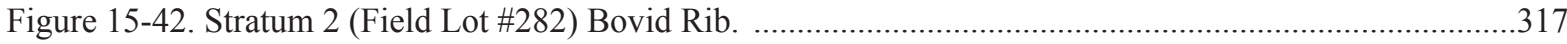

Figure 15-43. Stratum 2 (Field Lot \#282) Bovid Rib microscopic view of Figure 15-42 ...............................317

Figure 15-44. Stratum 2 (Field Lot \#282) Bovid Rib microscopic view. .........................................................

Figure 15-45. Stratum 3 (Field Lot \# 8) large mammal fragment microscopic view - metal knife cuts. ..........317

Figure 15-46. Distribution of Bone Fragmentation across Strata...................................................................

Figure 15-47. Distribution of Bone Fragmentation across Strata with indeterminate bone removed................319

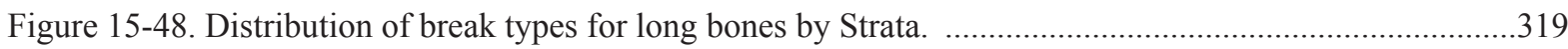

Figure 15-49. Stratum 2 (Field Lot \# 84) articulated bison radius, carpals, and phalanges. Note radius exhibits spiral fracture at end at far right of photograph (See Figure 48). ...............................320

Figure 15-50. Stratum 2 (Field Lot \#84) bison radius from Figure 47. Note spiral fracture. ..........................320

Figure 15-51. Stratum 2 (Field Lot \# 303) Bison mandible with browning and micro fractures. Also note eruption of permanent premolar replacing deciduous tooth.

Figure 15-52. Stratum 1b (Field Lot \#390) Deer metacarpal awl/punch. Note striations on tip and twist break.

Figure 15-53. Stratum 1b (Field Lot \# 391) Deer metacarpal with impact break on posterior surface. 324

Figure 15-54. Stratum 2 (Field Lot \#303) Bison humerus with birdshot. .325

Figure 15-55. Stratum 2 (Field Lot \#303) bison humerus with birdshot, note impact. ..................................325

Figure 15-56. Stratum 2 (Field Lot\# 280) abraded long bone expedient tool. ...............................................326

Figure 15-57. Stratum 2 (Field Lot \#280) Distal bison ulna abraded-expedient bone tool. 326

Figure 15-58. Stratum 2 (Field Lot \# 280) Distal bison ulna abraded-expedient bone tool from Figure 57 articulated with bison radius recovered with same Field Lot.

Figure 15-59. Stratum 3 (Field Lot \#1) Bison femur with intentional asphaltum splatter......

Figure 15-60. Stratum 3 (Field Lot \#1) close-up of Bison femur with intentional asphaltum splatter ..............327

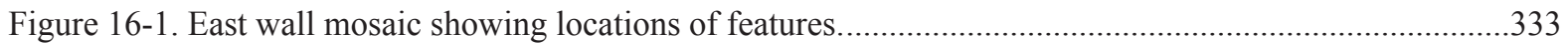

Figure 16-2. Planview of lower cultural component (Stratum 1) units and features......................................335

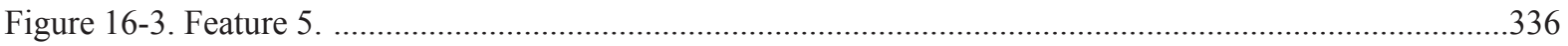

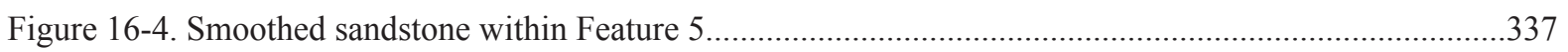

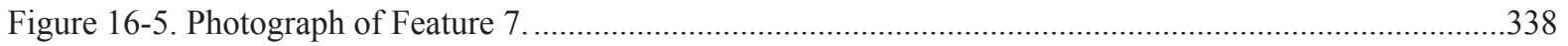


Figure 16-6. Feature 11 in Unit 95, Level 2; Unit 94 in foreground, Unit 95 in background, prior to beginning

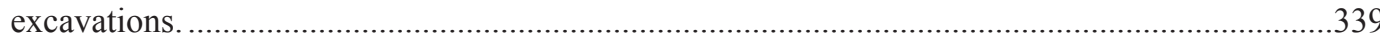

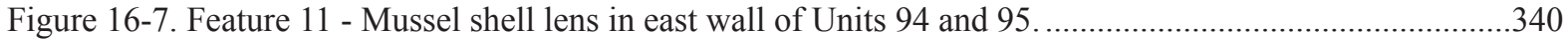

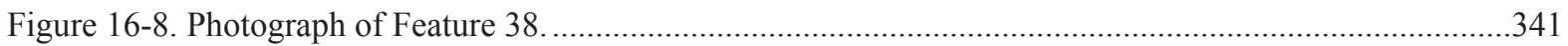

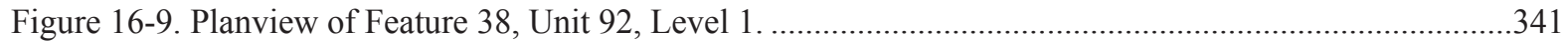

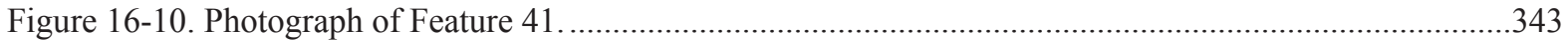

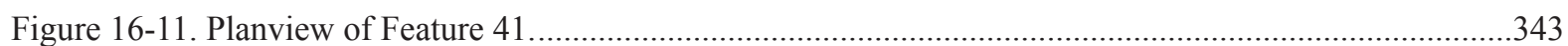

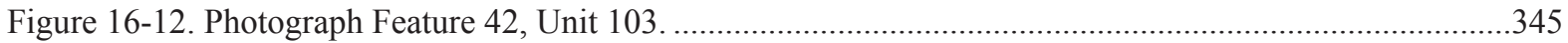

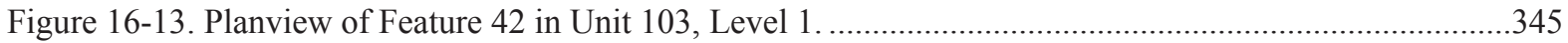

Figure 16-14. Calicite chunk with crystals found in the lower component, Stratum 1a/b divide. .....................347

Figure 16-15. Middle Component (Stratum 2) excavation units and features inclusive to Stratum 2 and the

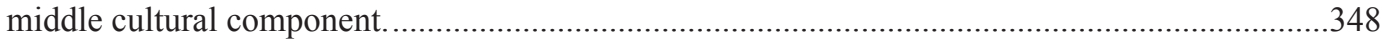

Figure 16-16. Feature 1 in Unit 54, as it was initially uncovered with a Gradall scrape................................350

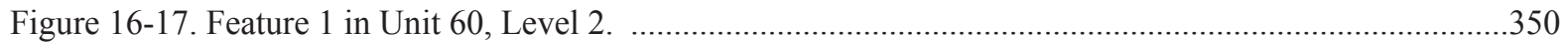

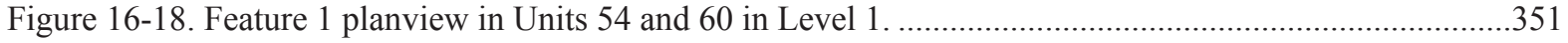

Figure 16-19. Evolving shape of Feature 1 as excavations progressed in Unit 60 to Level 2.........................351

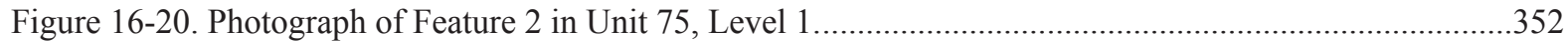

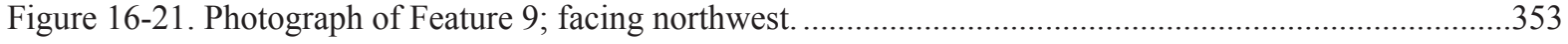

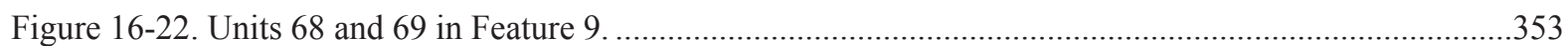

Figure 16-23. Smoothed sandstone recovered from Feature 9, Unit 76, Level 1.........................................354

Figure 16-24. Photograph of Feature 12; west wall of Gradall trench. ....................................................355

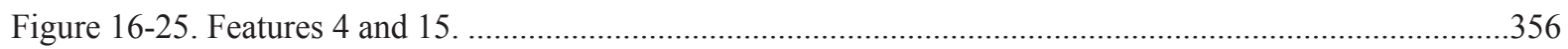

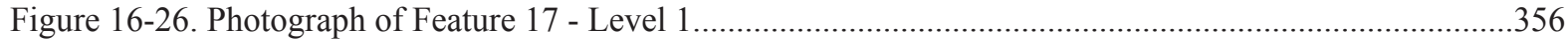

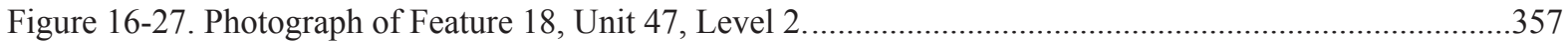

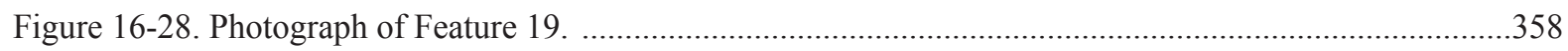

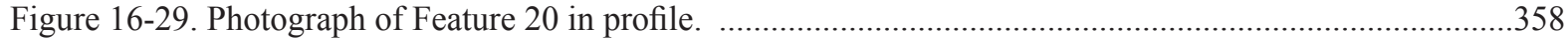

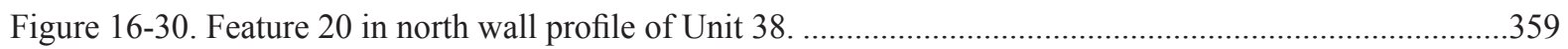

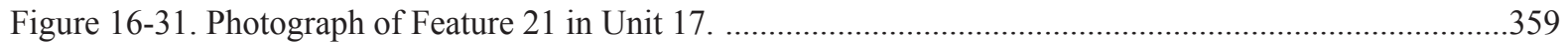

Figure 16-32. Plan view of the three components designated Feature 21 .............................................360

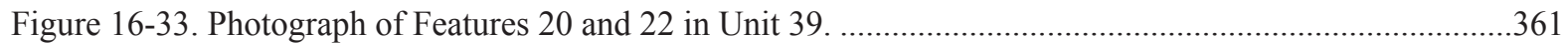

Figure 16-34. Photograph of the upper portion of Feature 23 in Unit 24 ................................................361

Figure 16-35. Feature 24; photograph taken after bone and bifacial tool removed......................................362

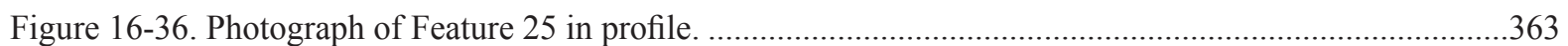

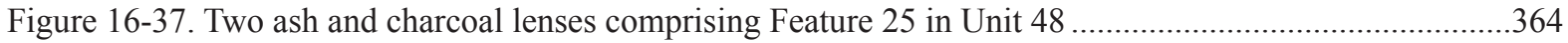

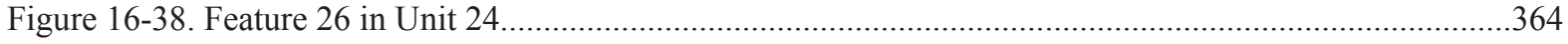

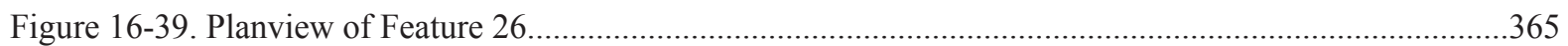

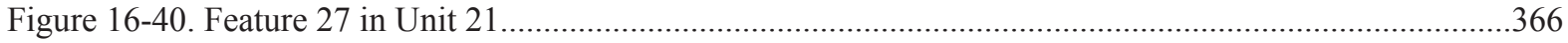

Figure 16-41. Photograph of Feature 28 halved; 0-10 cmbd, with top of feature pedestaled. .........................366

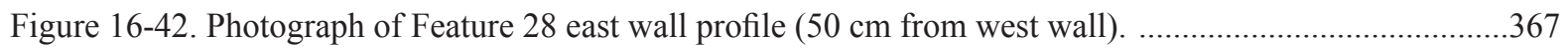

Figure 16-43. Photograph of Feature 28 extension into Gradall trench wall .........................................367 


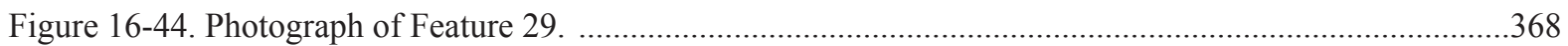

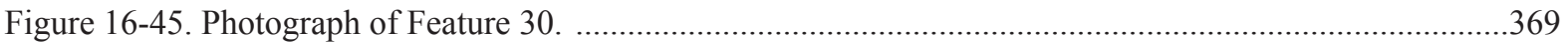

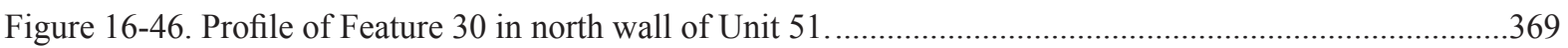

Figure 16-47. Photograph showing locations of Units 52, 53, and 62 relative to the entire extent of

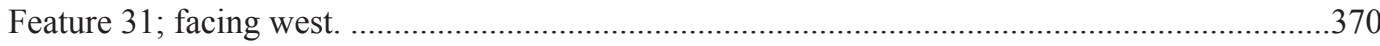

Figure 16-48. Photograph of Feature 31 in Units 52, 53, and 62; facing east. .................................................371

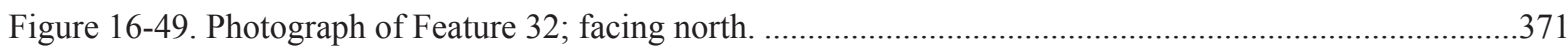

Figure 16-50. North wall profile of Features 30 and 32 in Unit 56................................................................372

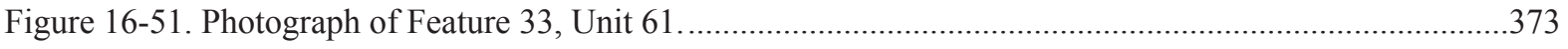

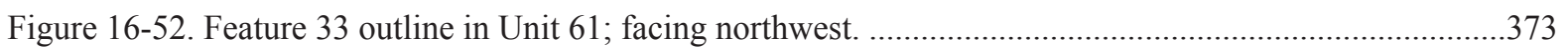

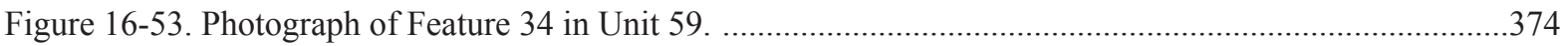

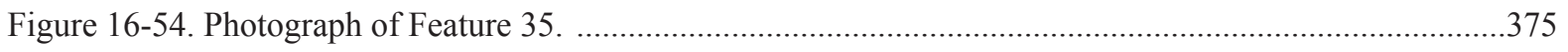

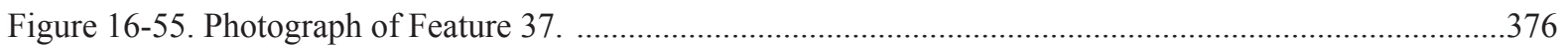

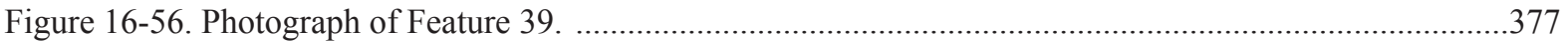

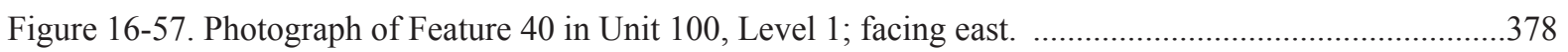

Figure 16-58. Excavation units and features within the upper cultural component (Stratum 3)........................379

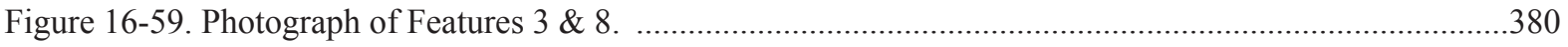

Figure 16-60. Upper $10 \mathrm{~cm}$ of Feature 4 pedestaled in Unit 6 before it was further excavated an additional

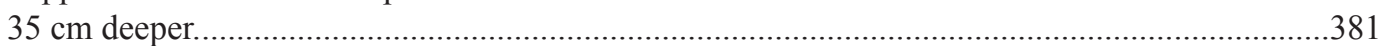

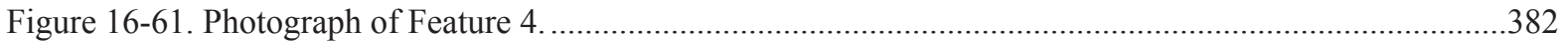

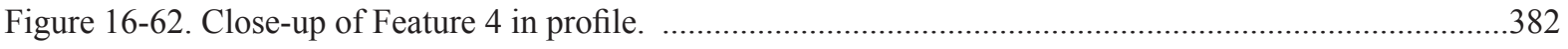

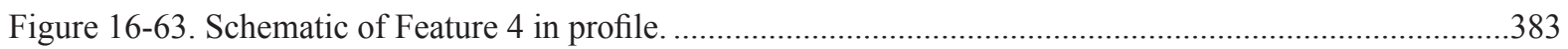

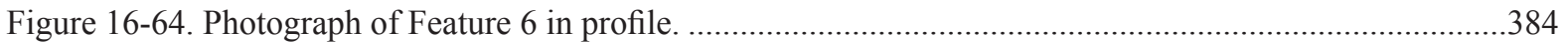

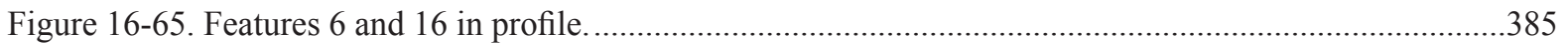

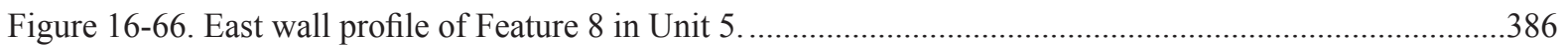

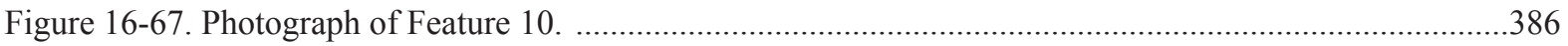

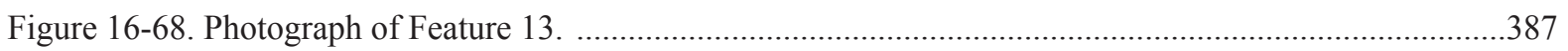

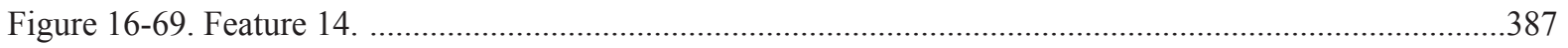

Figure 16-70. Photograph of Feature 16 in relation to Feature 6 .................................................................38

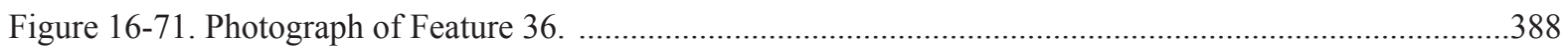

Figure 16-72. Photograph of Feature 36 in profile. …………..............................................................................389

Figure 16-73. Rib bone in Unit 1; arrow point was recovered directly beneath the bone. .................................389

Figure 16-74. Photograph showing both faces of an arrow point found in Unit 1. ............................................389

Figure 16-75. Burning trees downed in the 2006 Mount Laguna Fire near San Diego, California. ....................393

Figure 16-76a-d. Four oxidized earth patches following Little Venus Fire in 2006........................................394

Figure 16-77. Planview and cross section of a 'phantom heath' created by the Little Venus Fire in 2006, and

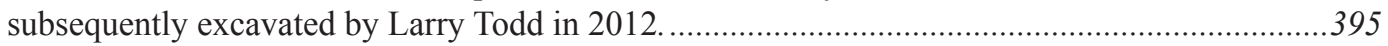

Figure 16-78. Mustang Fire tree burn in northeastern Utah with ash layer, burnt limb, outer rock "ring" at approximate extent of roots, and central burnt trunk charcoal........................................................396

Figure 16-79. Hypothetical excavation profile of the 'phantom hearth' shown in Figure 16-78 above, as

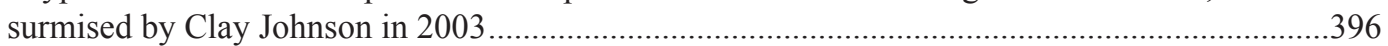




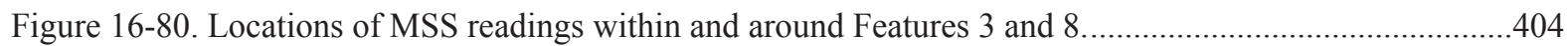

Figure 16-81. Moving averages of Magnetic Soil Susceptibility values in and around Features 3 and 8. ........405

Figure 16-82a. Locations of MSS readings $20 \mathrm{~cm}$ below the top of Feature $4(20 \mathrm{cmbd})$ in Unit $6 \ldots \ldots \ldots \ldots \ldots \ldots . . . .405$

Figure 16-82b. Chart showing MSS values inside and outside the upper $20 \mathrm{~cm}$ of Feature 4; sorted by MSS value (Y value). .406

Figure 16-83. Chart showing MSS values outside and inside of Feature 4. 406

Figure 16-84. Locations of MSS readings on top of Feature 6, and $10 \mathrm{cmbd}$ around the feature in Unit 8, Level 1 .......

Figure 16-85. Chart showing the MSS values on top of Feature 6, as well as $10 \mathrm{~cm}$ below the top. ................408

Figure 16-86. Profile of Feature 6 showing locations of MSS columns............................................................408

Figure 16-87. Moving average of MSS values inside and outside of Feature 6 ...............................................409

Figure 16-88. Photograph of Feature 28 in Unit 46A showing locations and values of MSS readings. .............411

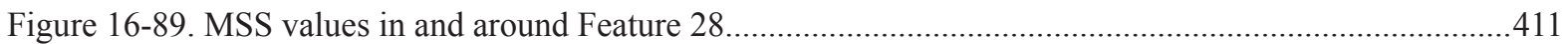

Figure 16-90. Planview of Feature 31 showing locations of MSS readings taken............................................412

Figure 16-91. MSS values within Feature 31. ............................................................................................

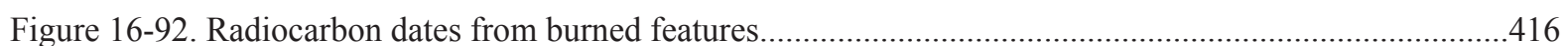

Figure 16-93. Turtle, bison \& cow/bison, and white tailed deer presence/absence in the lower cultural component (Stratum 1) units

Figure 16-94. Locations of hearth features and possible hearth features within the lower cultural component.

Figure 16-95. Turtle, bison \& cow/bison, and white tailed deer presence/absence in the middle cultural component (Stratum 2) units.

Figure 16-96. Locations of hearth features and possible hearth features within the middle cultural component.

Figure 16-97. Turtle, bison \& cow/bison presence/absence in the upper cultural component (Stratum 3) units

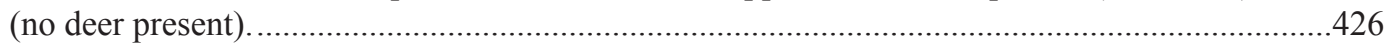

Figure 16-98. Locations of features in the upper cultural component..........................................................428

Figure 16-99. Hunter-Gatherer subsistence and settlement pattern model.......................................................431

Figure 16-100. Characterization of a foraging subsistence-settlement system..................................................432

Figure 16-101. Characterization of a collector subsistence-settlement system ..................................................433

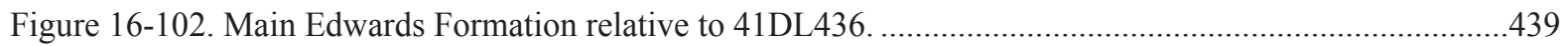

Figure 16-103. Ephemeral line of Edwards Formation exposures west of 41DL436.....................................439

Figure 16-104. Comparable age components discussed in the text...................................................................450

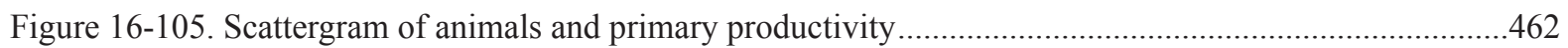

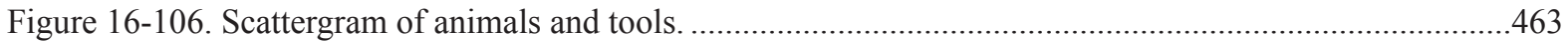

Figure 16-107. Scattergram of primary productivity and ethobotanical remains ................................................464

Figure 16-108. Scattergram of tools and charred ethnobotanical remains ..........................................................465 


\section{List OF TABLES}

Table 2-1. Cultural time periods in the North-Central Texas Archaeological Region (adapted from Lintz et al. 2008).

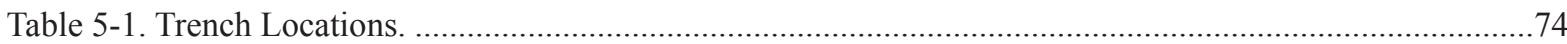

Table 5-2. Radiocarbon Ages (excluding Microcharcoal and Seeds Dated in Conjunction with Pollen Study). 103

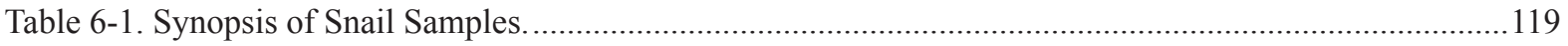

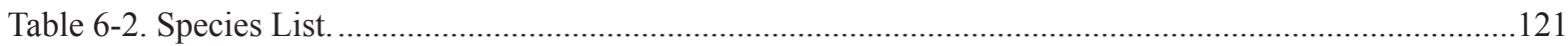

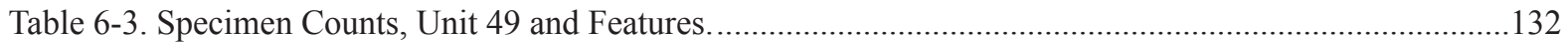

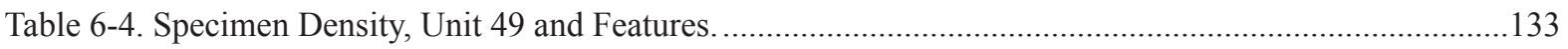

Table 6-4. Specimen Density, Unit 49 and Features (continued),.................................................................134

Table 7-1. Freshwater mussel (Family Unionidae) shell remains recovered at designated depths and from scraped materials at the Fish Creek Slough Site (41DL436), Dallas County, Texas, October 2010.

Table 7-2. Freshwater Mussels (Family Unionidae) Reported in Historic (less than 1980) and Recent (greater than 1979) Records from the Trinity River Drainage of Dallas, Denton, Collin, and Tarrant Counties, Texas

Table 7-3. Freshwater Mussel (Family Unionidae) Shell Remains Recovered at Designated Levels (UA = Unavailable) at the Fish Creek Slough Site (41DL436), Dallas County, Texas, 2010.

Table 7-4. Freshwater Mussel (Family Unionidae) Shell Remains Listed by Total Number (N) of Specimens,

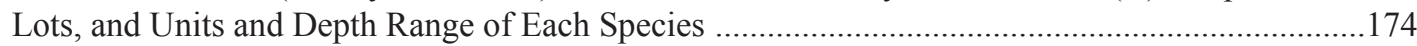

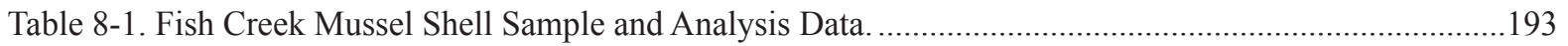

Table 8-2. Fish Creek T-Test $\delta 180$ Significance Matrix. ....................................................................................194

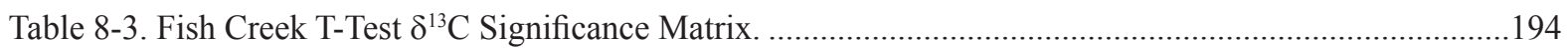

Table 8-4. Means, Standard Deviations, and Ranges of Fish Creek Slough Site Isotope Values........................195

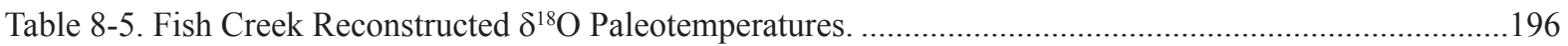

Table 9-1. Ostracodes Valve Count and Presence or Absence of Other Taxa at Each Depth. .............................200

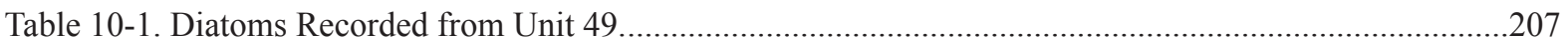

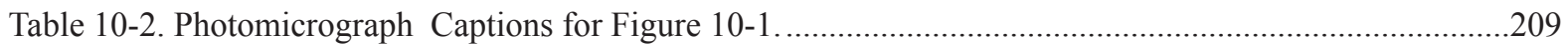

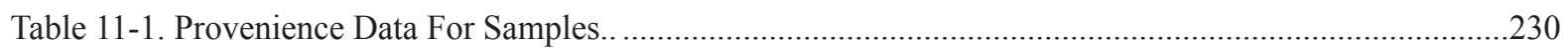

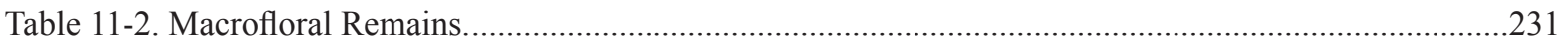

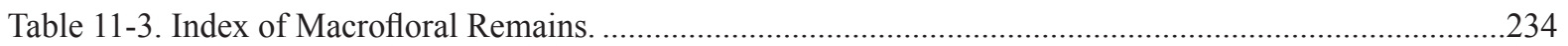

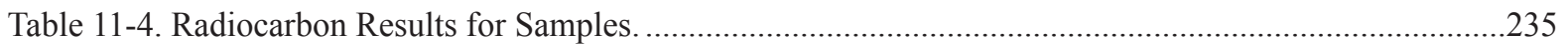

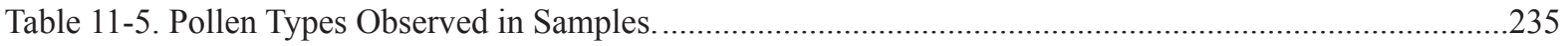

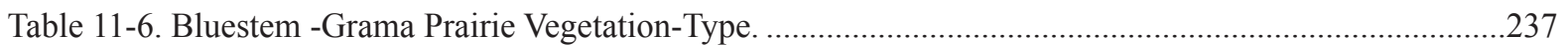

Table 12-1. Summary of Average Fatty Acid Compositions of Modern Food Groups Generated by Hierarchical Cluster Analysis.

Table 12-2. Criteria for the Identification of Archaeological Residues Based on the Decomposition Patterns of Experimental Cooking Residues Prepared in Pottery Vessels.........................................................247

Table 12-3. Known Food Sources for Different Types of Decomposed Residues. .............................................251

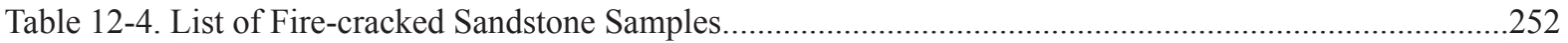


Table 12-5. Lipid Composition of Residue 11EC 1 Extracted from Fire-Cracked Rock. .................................252

Table 12-6. Biomarker and TAG Distributions in Lipid Residues with Insufficient Fatty Acids.....................254

Table 13-1. Measurements of Starch Granules from Modern Botanical References.......................................260

Table 13-2. Measurements of Starch Granules from FCR Samples. ........................................................263

Table 13-3. Fire-cracked Rock samples Analyzed in the Follow-on Study..............................................267

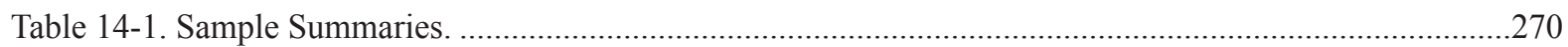

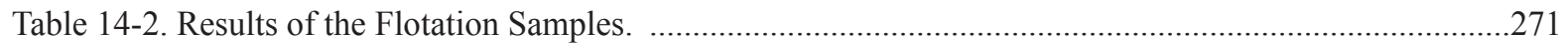

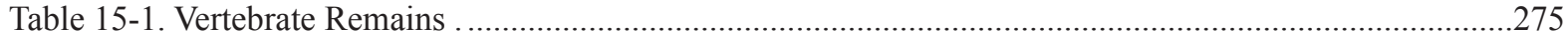

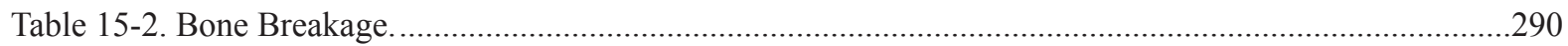

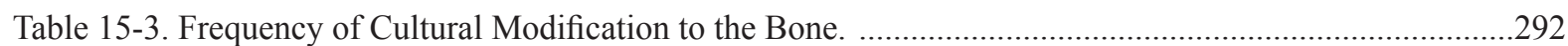

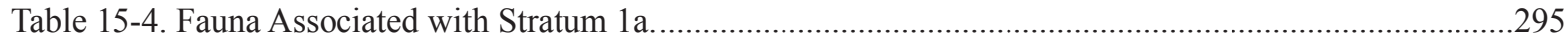

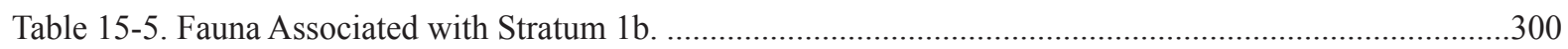

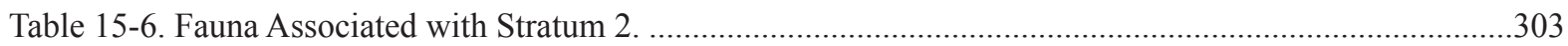

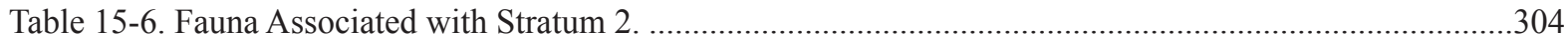

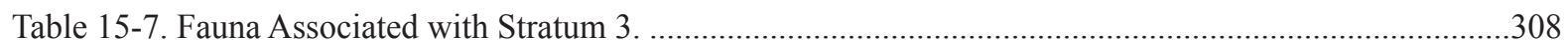

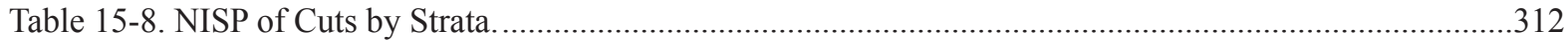

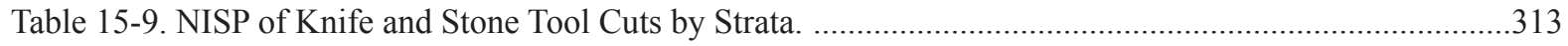

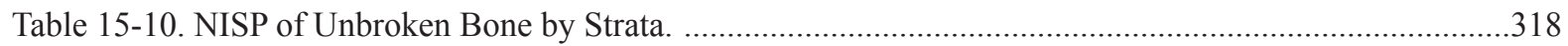

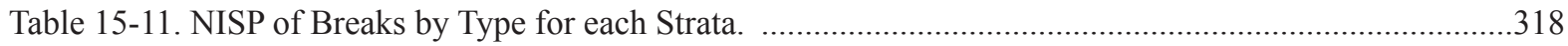

Table 15-12. Frequency of Occurrence of Localized Browning by NISP per Strata......................................322

Table 15-13. Distribution of Burned Bone by Level of Thermal Alteration and Strata. ..................................322

Table 15-14. Tool and other Cultural Modifications by Strata............................................................324

Table 15-15. Direct Evidence and Indirect Evidence for Human Modification of Bone by Strata. ...................327

Table 16-1. List of Features and Radiocarbon Dates for the Lower Cultural Component. .................................336

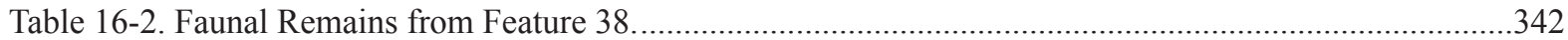

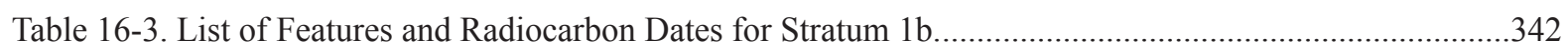

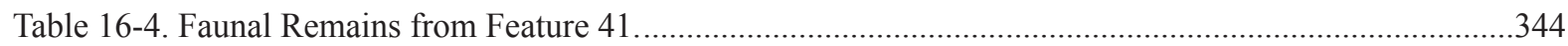

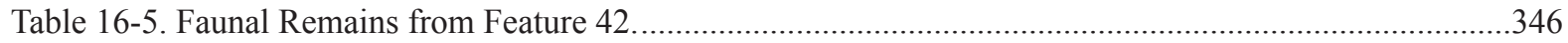

Table 16-6. List of Features and Radiocarbon Dates for the Middle Cultural Component (Stratum 2).............349

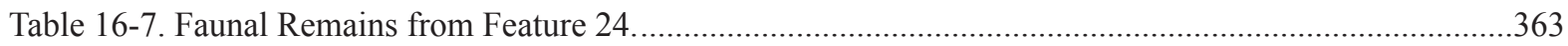

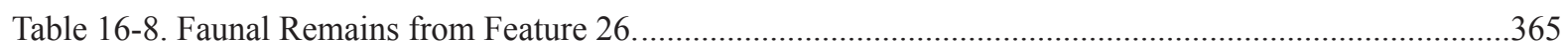

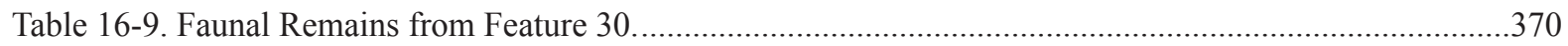

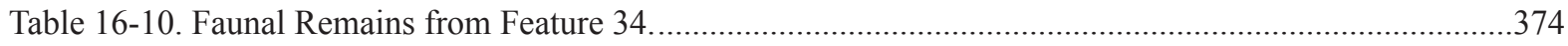

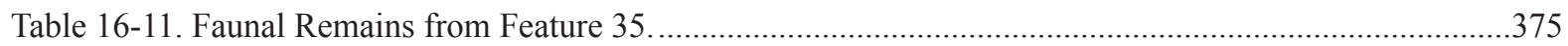

Table 16-12. List of Features, Unique Item, and Radiocarbon Dates for the Upper Cultural Component..........379

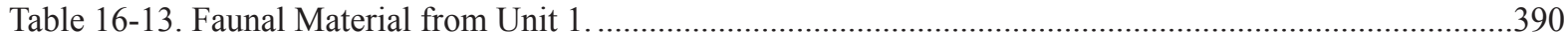

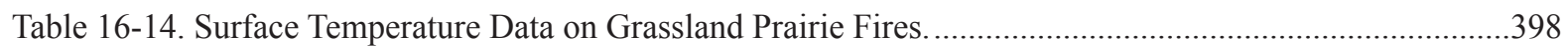

Table 16-15. Surface Temperatures of Fires as Recorded by Bellomo (1990; 1992)......................................398

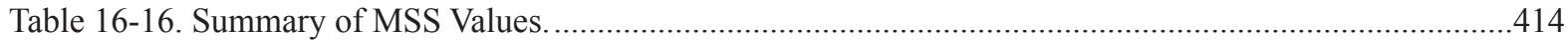


Table 16-17. Key Points That Have Been Made in this Discussion. ...........................................................434

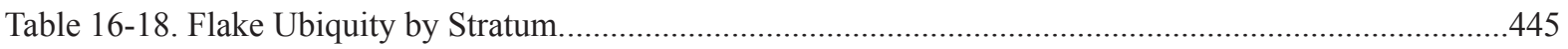

Table 16-19. Flake Types (Both Complete and Incomplete). ....................................................................445

Table 16-20. Total Number of Flakes Versus Broken Flakes.................................................................445

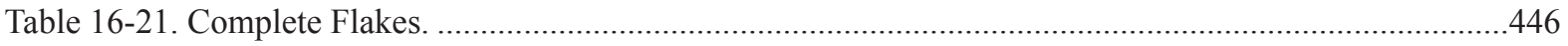

Table 16-22. Presence/Absence of Common Named Fauna.......................................................................448

Table 16-23. Comparable Age Components Considered for Comparison......................................................456

Table 16-24. Effective Temperatures for the Counties with Comparable Age Components...........................458

Table 16-25. Mean Annual precipitation, Effective Temperature, and Primary Production Values in the Areas

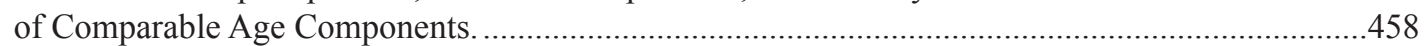

Table 16-26. Tool Assemblage Variety (presence/absence) at Comparable Age Components.........................459

Table 16-27. Consolidated Listing of Fauna, Mussel Shell, and Snail Groups from Comparable Cultural

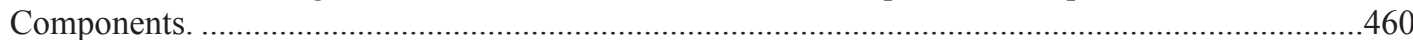

Table 16-28. Animal Groups Found at Comparable Cultural Components.................................................460

Table 16-29. Presence/absence of Charred, Edible Plant Remains from Comparable Cultural Components.....461

Table 16-30. Relative Lengths of Occupations by Groups at Ten Toyah Components. .................................467

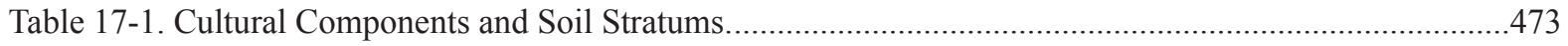

Table 17-2. Synthesized Results of Charred Plant Remains in Pilot Study Floatation Samples....................475

Table 17-3. Synthesized Results of Ostracode Analysis of Pilot Study Samples from Unit 49 .....................476

Table 17-4. Synthesized Results of Diatom Analysis of Samples from Unit 49........................................476

Table 17-5. Synthesized Results of Pollen and Phytolith Analysis of Samples from Unit 49........................477

Table 18-1. Actual and Expected Frequencies of Faunal Remains...........................................................501 


\section{ACKnowledgments}

As expected, an undertaking of this magnitude involves a large number of professionals whose contributions have been immense. We attempt here to recognize these individuals, but if there are some we miss, we apologize; the slight was certainly not intentional.

For their advocacy, which was very instrumental in the difficult decision to proceed to data recovery on a site that had as yet yielded no clear-cut artifacts other than a few modified bones, we would be remiss if we did not credit Dr. Jodi Jacobson (TRC) and Rachel Feit (AmaTerra) for their astute recognition of the site's potential despite its dearth of cultural material found during the initial survey discovery.

Overall success of this venture is due in large part to the management and archaeological staff at the Texas Department of Transportation's (TxDOT) Environmental Affairs Division, and in particular Dr. Scott Pletka (Supervisor of Archaeological Studies), Eric Oksanen (Staff Archaeologist), and Barbara Hickman (Staff Archaeologist).

The environmental and maintenance staff of TxDOT's Dallas District, and in particular Robert Hall (Environmental Specialist), Jay McCurley (Environmental Specialist), and Dan Perge (Transportation Engineer Supervisor) were instrumental in ensuring we were accommodated during all three investigations at the site, and enthusiastically assisted in many way.

Geo-Marine, Inc., archaeologists Duane Peter and Melissa (Missi) Green, and the crew of the Lisa Hopwood, Brett Lang, Janet Neissner, and Olga Torres ensured the June 2010 investigations were conducted in a thorough and professional manner.

Ama Terra field archaeologists who are to be commended for their hard work, professionalism, cohesive determination, and great attitudes during the October 2010 excavations are Crew Chief Jon Dowling, and crew members in alphabetical order-Bruce Darnell, Iakov Doumanoff, Shannon Smith, Noel Steinle, Jesse Todd, and Emory Worrell.

There are few professional Gradall operators who can approach the expertise of Charles (Charlie) Burns. After observing Charlie's enthusiasm for a few days, we surmised that if he had had his druthers, Charlie would have been an archaeologist. His keen eye was vigilantly watching for artifacts and features as he carefully and skillfully exposed them with the Gradall. Day in and day out, Charlie was constantly improving our working environment by moving dirt so to not interrupt ongoing hand excavations, constructing berms to keep water from inundating the deep trench, or simply clearing surrounding vegetation.

We thank Dr. Alston Thoms of Texas A\&M who more than once provided sage advice, as well as source information on thermal features and starches. As we have in the past, we once again turned to Dr. Raymond Mauldin of the Center for Archaeological Research at The University of Texas at San Antonio (UTSA) for his wise counsel on evaluating burned features and for providing journal articles on the same. 
Clay Johnson, recently of the Ashley National Forest in Utah enthusiastically allowed use of his photographs and drawing of burned features from the Mustang Fire in Utah. The same credits are well deserved by Dr. Lawrence Todd of Colorado State University for allowing use of his photographs and drawings of burned features from the Little Venus Fire in Wyoming.

Processing of malacology and floatation samples was accomplished in part by Molly Palmison. Dr. Dean Henderson provided advice on fish scales, and Dr. Robert McMahon freely consulted on ancylids.

Archaeologists Antonio Padilla and Jimmy Barrera collected the raw material samples from Fish Creek when they very well could have been doing something different on a hot Saturday.

As always, Consulting Geoarchaeologists Dr. Charles Frederick and Brittney Gregory provided expert analysis and sage counsel in interpreting geoarchaeological issues at the site.

We thank Mike Quigg for proofing and providing comments on the faunal analysis, as well as Shannon Gray and Trisha-Ann Gonzales who helped with figures and double checking references. In addition, we gratefully acknowledge the Vertebrate Paleontology Lab at the University of Texas at Austin for the use of their collection.

Individuals and organizations who provided assistance in dating the site are Darden Hood and (Beta Analytic, Inc.), Alex Cherkinsky (Center for Applied Isotope Studies, University of Georgia), Dr. Linda Scott Cummings (Paleo Research Inc.), and Dr. Raymond Mauldin (UTSA).

The many illustrations and graphics were professionally put together by Joel Butler, with assistance from Dan Rose, both of Ama Terra, and Jim Abbott of TxDOT.

The lady who laboriously and expertly molded multiple report formats into one, and graciously put up with our many changes along the way is Editor Margo Gregory of AmaTerra; thank you, Margo.

Finally, we recognize one of those laborers who most often is not acknowledged during a large project such as this one - that being the accountant. Everything is fine as long as everyone is getting paid, and all the accounts are credited properly and on time, but without an individual who's minute attention to detail is lacking, that fast moving train can quickly come off the track. In that regard, Erin Mace, we all thank you for keeping the train on the track. 


\section{SECTION I \\ BACKGROUND}




\section{Chapter 1}

\section{INTRODUCTION}

\section{David L. Nickels and W. Nicholas Trierweiler}

\section{InTRoduction and Site Setting}

In October of 2010, Ecological Communications Corporation (EComm $)^{1}$, under contract No. 579-09-SA006 with the Texas Department of Transportation (TxDOT), conducted archaeological data recovery excavations at site 41DL436-also known as the Fish Creek Slough site—in Dallas County, Texas.

The site is a stratified multi-component Late Prehistoric, Protohistoric, and Historic open campsite situated on the west bank of Fish Creek, in the City of Grand Prairie, Dallas County, Texas (Figure 1-1). The site is buried within Holecene fluvatile terrace deposits made up of sand, silt, and clay. It is situated within the Fort Worth Prairian ecotone between the Cross Timbers Ecological Region, and the Prairies, in the north Texas Blackland Prairie region. Typical riparian hardwood vegetation along Fish Creek includes oak, elm, and hackberry. However, the area is rapidly being modified by modern development.

\section{Previous Investigations}

Site 41DL436 was discovered in 2005 by Hicks and Company (Feit and Campbell 2005) during an archaeological survey conducted in advance of the construction of an extension of Lake Ridge Parkway and a bridge over Fish Creek. Investigations of the site at that time revealed an abundance of faunal material, charcoal, and burned clay within two discrete stratified zones, and National Register of Historic Places (NRHP) testing was recommended.

Following extended negotiations between the landowner and the City of Grand Prairie who eventually purchased the property, TxDOT geoarchaeologist James Abbott and archaeologist Eric Oksanen returned with a crew to the site in June 2010 and conducted additional trenching and hand excavations. Basically, the TxDOT investigations confirmed the findings and recommendations of Hicks and Company (Oksanen et al. n.d.). However, by that time the contract letting to begin road and bridge construction was imminent. Therefore, TxDOT elected to forgo formal NRHP testing and instead undertake a data recovery effort.

Ama Terra archaeologists and TxDOT's Abbott and Oksanen subsequently conducted Gradall trenching, geoarchaeological sampling, and extensive hand excavations at the site in October 2010. The 2010 data recovery effort resulted in mitigating any adverse effect to the portion of the site that will be impacted by construction.

1 In January 2012, EComm was acquired by AmaTerra Environmental, Inc. 
This figure has been redacted due to site sensitive information.

Figure 1-1. Location of the Fish Creek Slough site in southwestern Dallas County. 


\section{Data Recovery Scope of Work and Data Collected}

Mechanical stripping with a Gradall and targeted hand excavations were employed to rapidly expose and sample several burned zones and any other features or artifact concentrations encountered. Stripping within a $6 \times 20-\mathrm{m}$ trench was conducted in thin, 3-5-cm cuts, to 200 cmbs. Stripping of the block occurred systematically to facilitate documentation of spatial patterning in burned zones, other features, and isolated occurrences of bone, fire-cracked rocks, charcoal stains, and mussel shells. Forty-three cultural and non-cultural features were documented.

In total, approximately 285 cubic meters $\left(\mathrm{m}^{3}\right)$ of soil were removed mechanically, with an additional $17.75 \mathrm{~m}^{3}$ excavated by hand from 107 units during this project. In addition to Gradall scraping, and extensive 1-x-1-m excavations, field investigations conducted by Ama Terra included site mapping, and the collection of macrobotanical, magnetic susceptibility, $\mathrm{pH}$, carbon, and malacology samples, as well as bulk soil for pollen, diatom, phytolith, and ostracod subsamples. All fire-cracked rocks were collected, with selected pieces analyzed for the presence of starches and lipids.

One bulk soil sample was collected according to natural unit to the extent possible from each hand-excavated level for future processing. A total of 257 soil magnetic susceptibility readings were taken in selected profiles, as well as horizontally across and within the upper few centimeters of selected burned clay and hearth features and their surrounding matrices. A total of 95 flotation samples were collected from in and around features, and following flotation in the Ama Terra laboratory in Austin, selected light fraction samples were further analyzed.

The site is unique due in large part to its robust and very well preserved faunal assemblage. A total of 8,702 pieces of fauna was collected and analyzed. Other samples and cultural material collected and analyzed included 186 pieces of charcoal from the 1/4-inch screen and 54 from flotation samples, 43 pieces of chipped stone, and 206 fire-cracked rocks greater than one inch in size. In addition, Ama Terra staff took 372 photographs using digital cameras and mapping was conducted using a Total Data Station (TDS). Finally, the artifacts, field notes, forms, photographs, and drawings were turned over to TxDOT for permanent curation at TARL.

\section{REPORT Organization}

This report is structured within five main parts. The first part, Chapters $1-4$, provides the environmental and cultural background, a research design, and methodological background for the excavation project. The second part, Chapter 5, includes a discussion of the radiocarbon dates, geoarchaeology, and overall site integrity. The third part, Chapters 6-11, includes reports from various analysts with a focus on interpreting the paleoenvironment. The discussions in the fourth part, Chapters 12-16, provide an in-depth treatise of the cultural manifestations at the site. The final part consists of Chapters 17-19. These discussions integrate the various threads of the results, address research issues, summarize, and present conclusions. Finally, a series of appendices present the results of a raw material study, summarize various datasets, and include the artifact catalogs. 


\section{Chapter 2}

\section{EnVironmental Setting AND Cultural Background}

\section{David L. Nickels and Jon Dowling}

Site 41DL436 is located in the city of Grand Prairie, Dallas County, Texas. It is situated on the south bank of Fish Creek, a tributary of the West Fork of the Trinity River, east of the Tarrant County line. Elevation at the site is approximately 490 feet above mean sea level, and gently slopes to the northeast. During our excavations at the site in October 2010, the modern channel of Fish Creek was deeply incised, exposing a 3-4-meter (m) cutbank.

\section{Modern Environmental Setting}

\section{Ecological Regions}

Site 41DL436 is located within the Blackland Prairies Region of north central Texas. The Blackland Prairies Region consists of nearly level to gently rolling topography, and covers approximately 11.5 million acres from Grayson and Red River Counties in northeast Texas to Bexar County in the south-central region of the state. Elevations range from 300 to 800 feet above mean sea level. Blackland soils that occur in the region are so named due to the uniform dark-colored calcareous clay component of the typical mollisols. These soils are interspersed with gray acid sandy loams. This highly fertile region has been widely used for agriculture, although use of the land for ranching has become increasingly popular (Gould 1975; McMahan 1984; Hatch 1990).

More specifically, 41DL436 is situated within the Fort Worth Prairie sub-region, an ecotone between the Cross Timbers Ecological Region, and the Prairies (Gould et al. 1960; TPWD 2011a [Figure 2-1]). The topography varies from gently rolling, to hilly, to deeply dissected. Rapid surface drainage is typical throughout the region.

The area was named the "Cross Timbers" by travelers who traveled from west to east through the area about as early as 1772 . To both the east and west of this area was generally open prairie, but the timbered area in between the prairie areas became known as the "Cross Timbers." Since then, microcosms of the region have been significantly changed by the movement of people into towns and cities, and the fragmentation of once continuous habitat into smaller land holdings; such is the case with the City of Grand Prairie and the immediate area of 41DL436 (TPWD 2011b). 


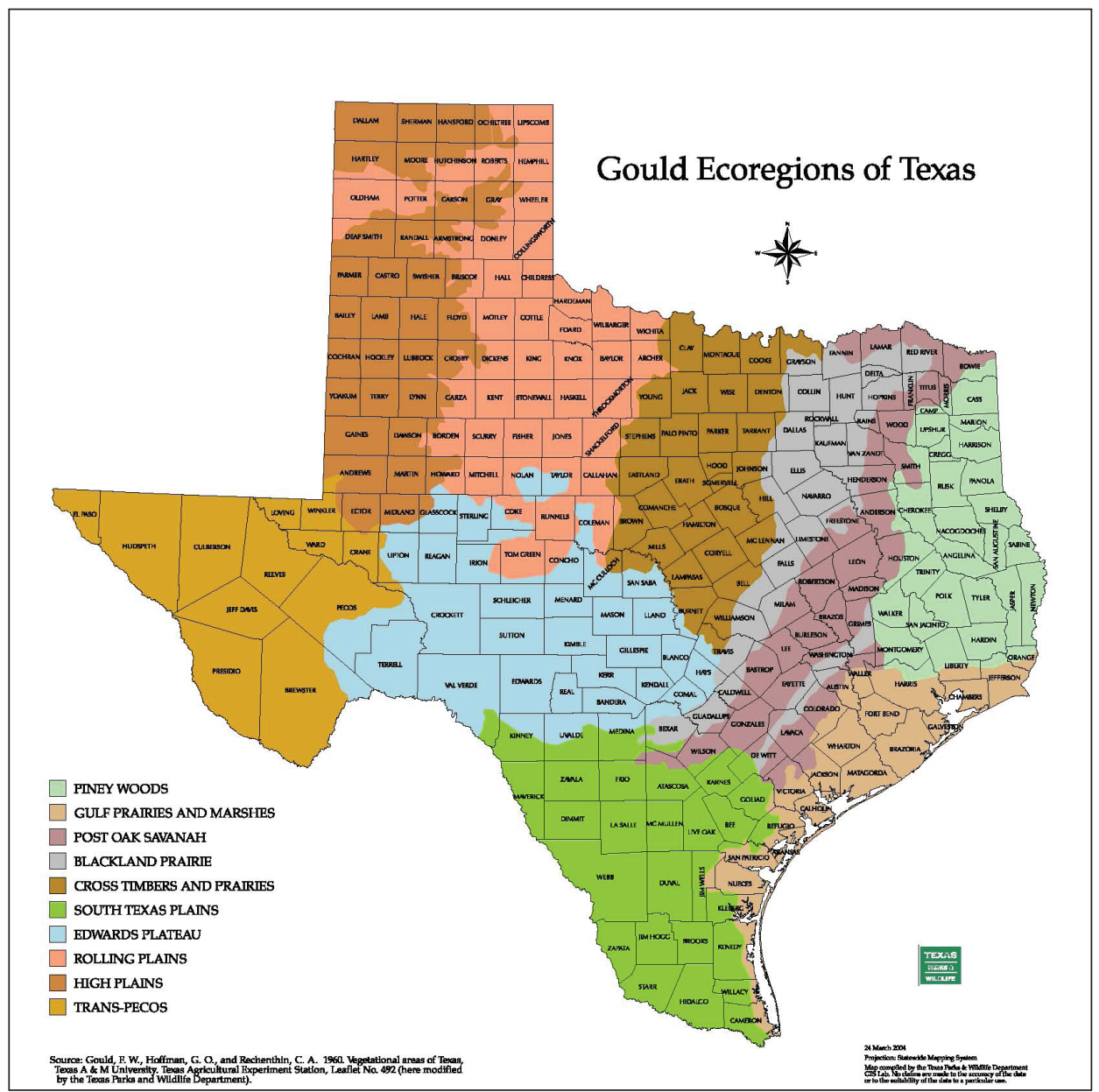

Figure 2-1. Ecoregions of Texas as defined by Gould et al. 1960; adapted by TPWD (2011a).

\section{Fauna}

Site 41DL436 is situated within the Texan biotic province of Texas as defined by Blair (1950 [Figure 2-2]). Until about the past 150 years, game in the Cross Timbers area was abundant with buffalo, bear, deer, antelope, wild boars, partridges, and turkeys (TPWD 2011b). When Blair published his Biotic Provinces of Texas (1950) some 60 years ago, one could expect to see mammals such as the Virginia opossum (Didelphis virginiana), the eastern mole (Scalopus aquaticus), fox squirrels (Sciurus niger), Louisiana pocket gophers (Geomys breviceps), fulvous harvest mice (Reithrodontomys fulvescens), white-footed mice (Peromyscus leucopus), hispid cotton rats (Sigmodon hispidus), eastern cottontails (Sylvilagus floridanus) and swamp rabbits (S. aquaticus).

Rodents often seen on the grasslands included the thirteen-lined ground squirrels (Spermophilus tridecemlineatus), hispid pocket mice (Chaetodipus hispidus), deer mice (Peromyscus maniculatus) and black-tailed jackrabbits (Lepus californicus).

Frogs and toads that would have been common are the Hurter's spadefoot (Scaphiopus holbrookiihurteri), the Gulf Coast toad (Bufo valliceps), the Woodhouse's toad (Bufo 
woodhousii), the gray treefrog (Hyla versicolor/chrysoscelis), the green treefrog (Hyla cinerea), a bullfrog (Rana catesbeiana), the southern leopard frog (Rana sphenocephala) and the eastern narrowmouth toad (Microhylla carolinensis). Once again, due to the ever-expanding cities of Fort Worth, Dallas, Grand Prairie, and others, the disruption of broad and continuous natural habitats that were the homes of selected species have been dissected, so that if they now exist within the populated areas, they do so in relict ecosystems.

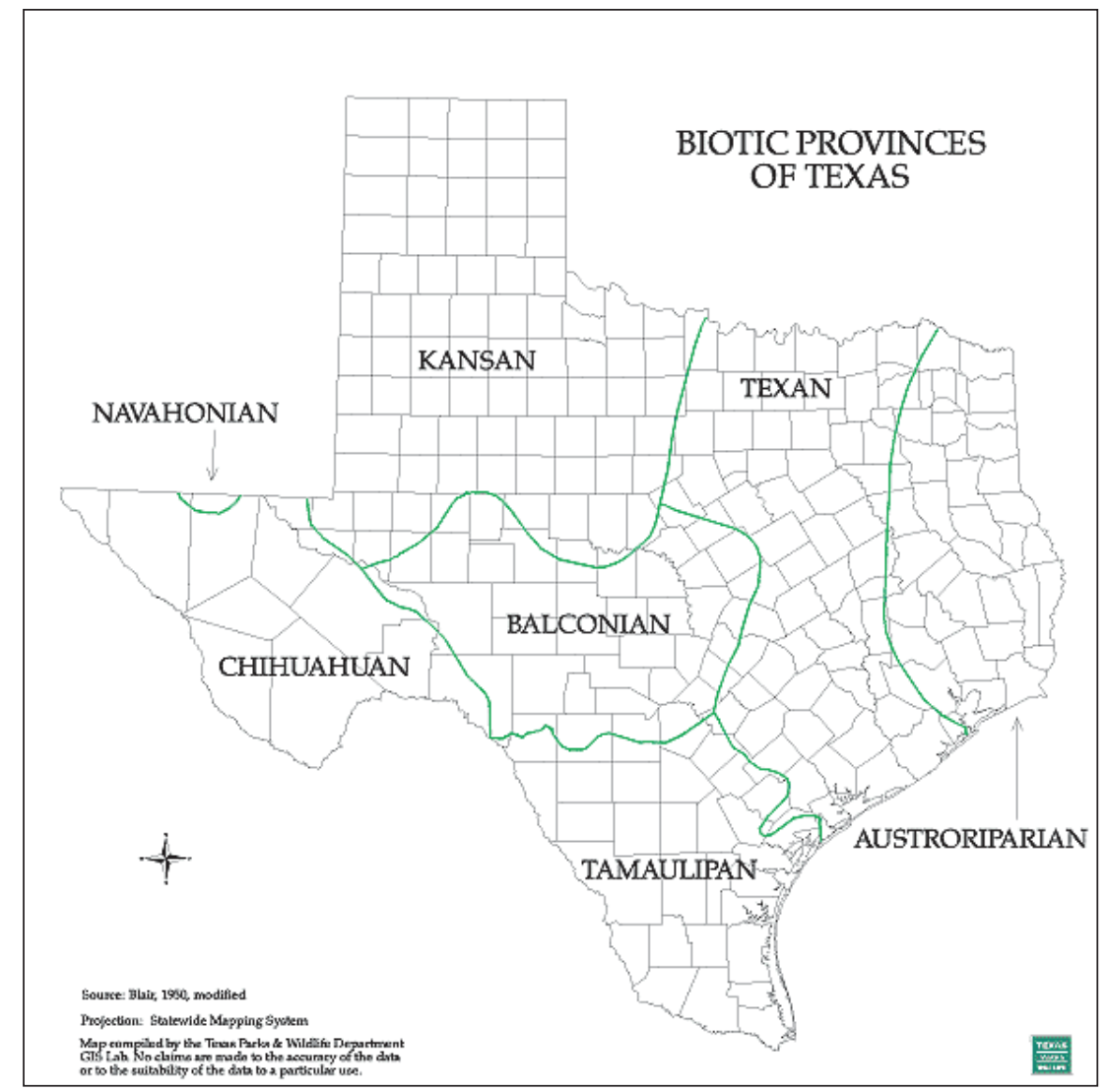

Figure 2-2. Biotic provinces of Texas (Blair 1950; adapted by TPWD 2010c).

\section{Flora}

Oldfield vegetation habitats are common in this area, consisting primarily of native grassland species as well as invasive brush and trees, in addition to a mixture of grasses, forbs, shrubs, vines, and trees from encroaching habitats. Herbaceous species found in Oldfield environments include Bermuda Grass, silver bluestem, Oldfield threeawn (Aristida oligantha), johsongrass, giant ragweed, western ragweed, goldenrod (Solidago spp.), common sunflower (Helianthus spp.) and cactus. Trees common in this area include mesquite (Prosopis glandulosa) and Ash juniper (Juniperus ashel). 
Riparian Woodland areas within the project area are situated along Fish Creek with vegetation consisting mostly of green ash (Fraxinus pennsylvanica), western soapberry (Sapindus drummondii), American elm (Ulmus Americana), black willow (Salix nigra) and cedar elm (Ulmus Crassifolia). Other species include green briar (Smilax nona-nox), poison ivy (Toxicodendron radicans), and wood oats (Chamanthium latifolium) common in the understory (Gould et al. 1960; McMahan 1984).

The Mixed Hardwood/Juniper Woodland vegetation types include nine to 30-foot tall trees, typically cedar elm, American elm, green ash, osage orange (Maclura pornifera) and ashe (Burnelia lanuginose), hackberry (Celtis laevigata), chinaberry (Melia azedarach), and mesquite (Prosopis glandulosa). Under the 50-100 percent canopy coverage is an understory of giant ragweed (Ambrosia trifida), yucca (Yucca spp.), prickly pear (Opuntia spp.), crotons (Croton spp.), little bluestem (Schizachyrium scoparium), silver bluestem (Bothriochloa laguroides), rescuegrass (Bromus unioloides), sideoats grama (Bouteloua curtipendula), wood oats, goldenrod (Solidago spp.), saw greenbrier, Virginia creeper (Parthenocissus quinquefolio), and poison ivy (Gould et al. 1960; McMahan 1984).

\section{Geology and Soils}

The geological formation at 41DL436 is mapped as fluvatile terrace deposits (Qt), made up of Pleistocene gravel, sand, silt, and clay (Barnes 1972/1988). However, as will be discussed by Jim Abbott and Charles Frederick in Chapter 5, the terrace deposits at 41DL436 are much younger, dating to the late Holocene (Figure 2-3).

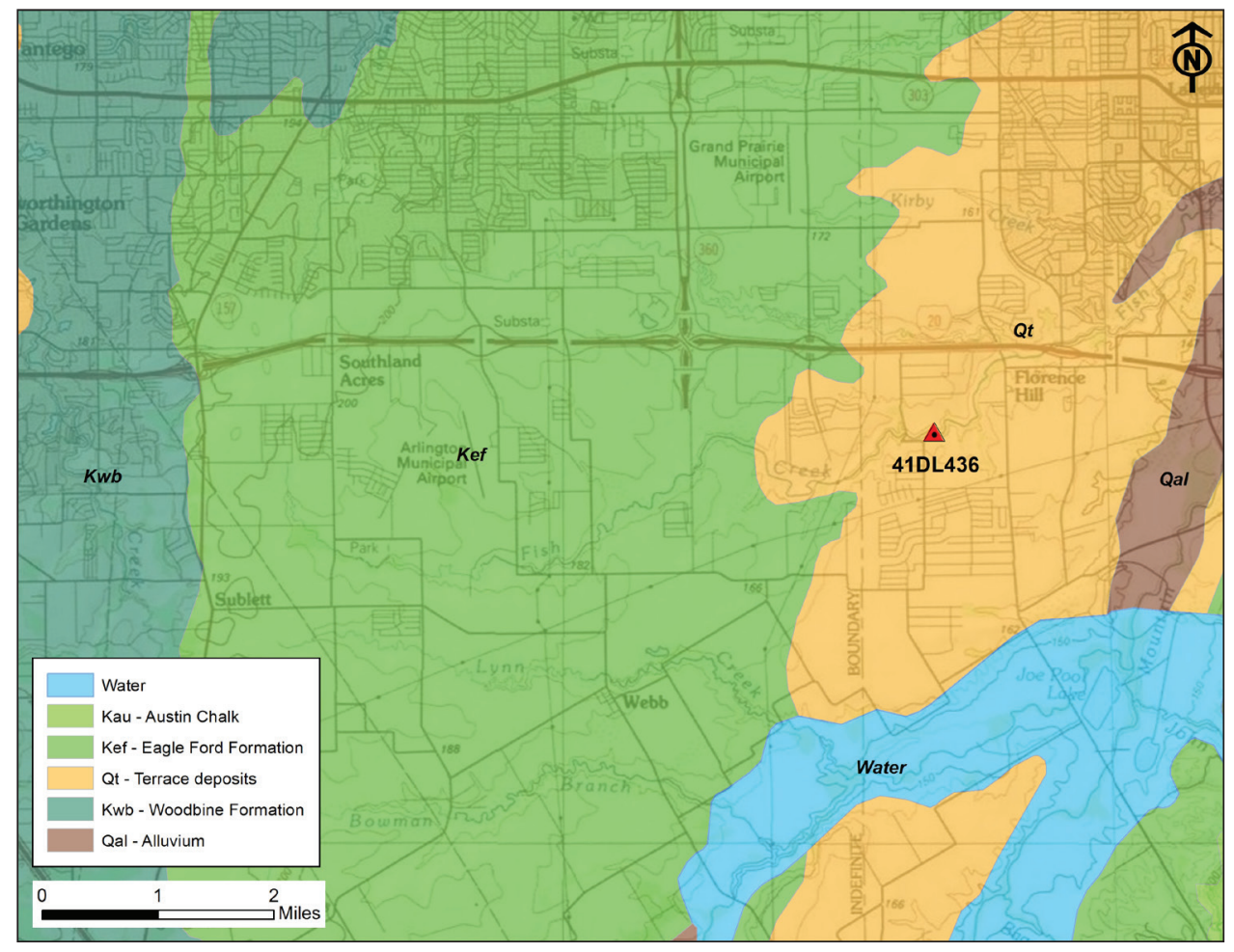

Figure 2-3. Geology map. 
Soils at the site, and within the surrounding area are discussed in great detail in Chapter 5. Suffice it to say here, that Frio silty clays makes up the upper terrace deposits where the excavations occurred (Figure 2-4). These deep soils are commonly found on nearly level flood plains in Dallas County, and are frequently flooded one or more times during a normal year. Nevertheless, the floodwaters are generally shallow, and of short duration. A typical soil pedon of Frio silty clay consists of a surface layer of moderately alkaline, dark grayish brown silty clay in the upper seven inches. Between 7-46 inches, is the same except it transitions to a very dark grayish brown. From about 46-74 inches below the surface, it is still moderately alkaline, but brown, silty clay loam (Coffee et al. 1980; Websoil 2011).

This figure has been redacted due to site sensitive information.

Figure 2-4. Soils map.

\section{Climate}

The average annual rainfall in Dallas County is just over 36 inches (Maxwell 2011). The average annual rainfall in the Dallas-Fort Worth area from 1971-2000 is illustrated in Figure 2-5. The monthly high average is just over five inches in May, with monthly low averages of around two inches occurring in January, July, and August (Climate 2013).

Figure 2-6 depicts the average monthly temperatures during the period 1971-2000 (Climate 2013). The lowest average monthly temperature occurs in January, at $36^{\circ} \mathrm{F}$, with the highest in July, at $95^{\circ} \mathrm{F}$ (Maxwell 2011). 


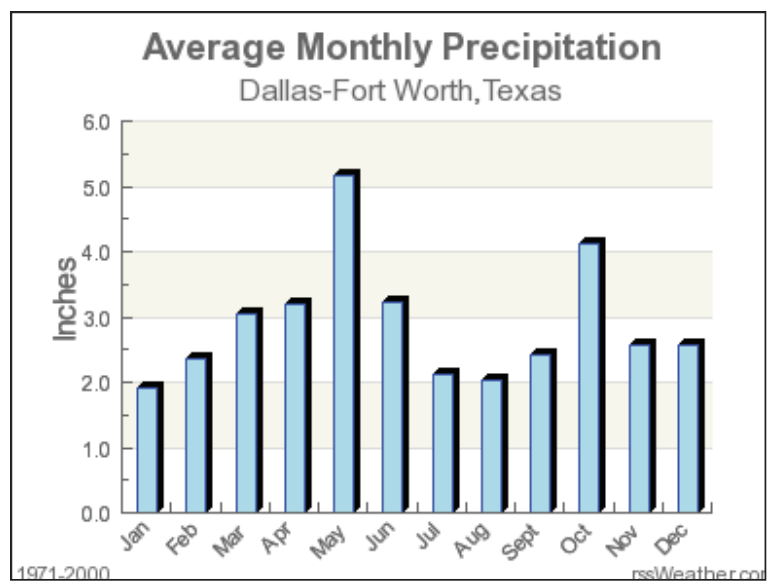

Figure 2-5. Average monthly rainfall (Climate 2013).

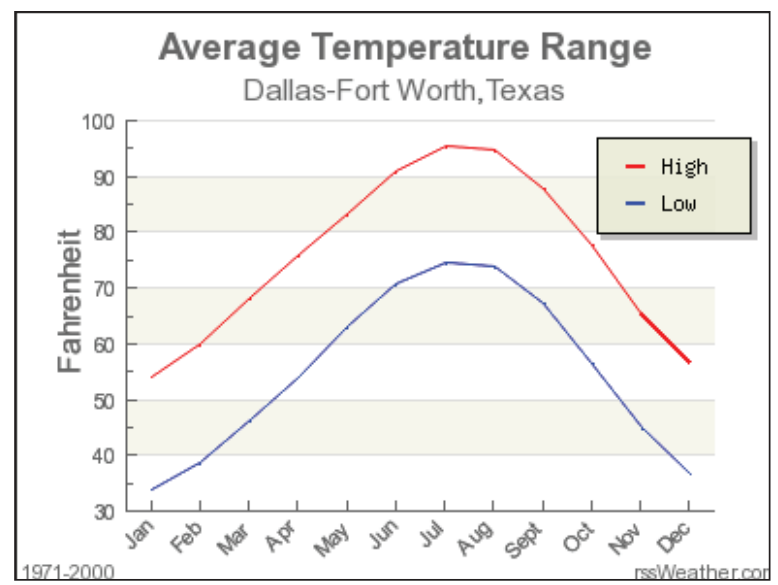

Figure 2-6. Average monthly temperatures (Climate 2013).

\section{Paleoenvironment}

An interpretation of multiple datasets derived from different paleoecological sources can be not only contentious and conflicting, but also somewhat confusing. Perhaps the most complete and continuous record with corroborating multiple lines of evidence comes from Bastrop and Kerr counties in Central Texas: Boriack Bog arboreal pollen (Bousman 1998), Patschke grass pollen (Camper 1991), Hall's Cave microfauna (Collins 1995; Toomey and Stafford 1994; Toomey et al. 1993). Until recently, it was believed that the Patschke Bog data was skewed by the intrusion of marsh grasses. However, by eliminating marsh taxa pollen counts from Camper's Patschke Bog samples, Raymond Mauldin has demonstrated a close correlation to the grass data from Boriack (Mauldin et al. 2003). In addition, oxygen isotope data from mussel shells and snail species recovered from the Vara Daniels site (41TV1364) in Austin have most recently contributed to what we know about the Early Holocene paleoclimate (Nickels et al. 2010).

Figures 2-7 and 2-8 illustrate these datasets. In addition, following Collins (2004), we have illustrated bison presence/absence (Dillehay 1974), and Collins' (2004) soil deposition, erosion, and soil formation sequences. The data illustrated in Figures 10 and 11 generally indicate that the waning of the Pleistocene, or late glacial period, marked a transition from a cooler, wetter environment ending around $9000 \mathrm{BP}$. The climate steadily grew warmer and drier, and more seasonal, with intermittent moist periods through about $4000 \mathrm{BP}$. The microfauna data indicate that there was a transition to a wetter climate for the next 3,000 years, but that seems to conflict with the pollen analysis from the two bogs, suggesting that it may have been slightly drier during that time, decreasing the arboreal canopy while increasing the grasslands available. Closer to 41DL436, stable carbon isotope data from 41TR170 on the Clear Fork of the Trinity River suggest a shift from warm and dry conditions to cooler and wetter conditions about 1,000 years ago (Lintz et al. 2008:58-61).

Although the two datasets also conflict with each other in evaluating the climate over the past 1,000 years, recent excavations at 41DL436 should help untangle these conflicts. Historically, 


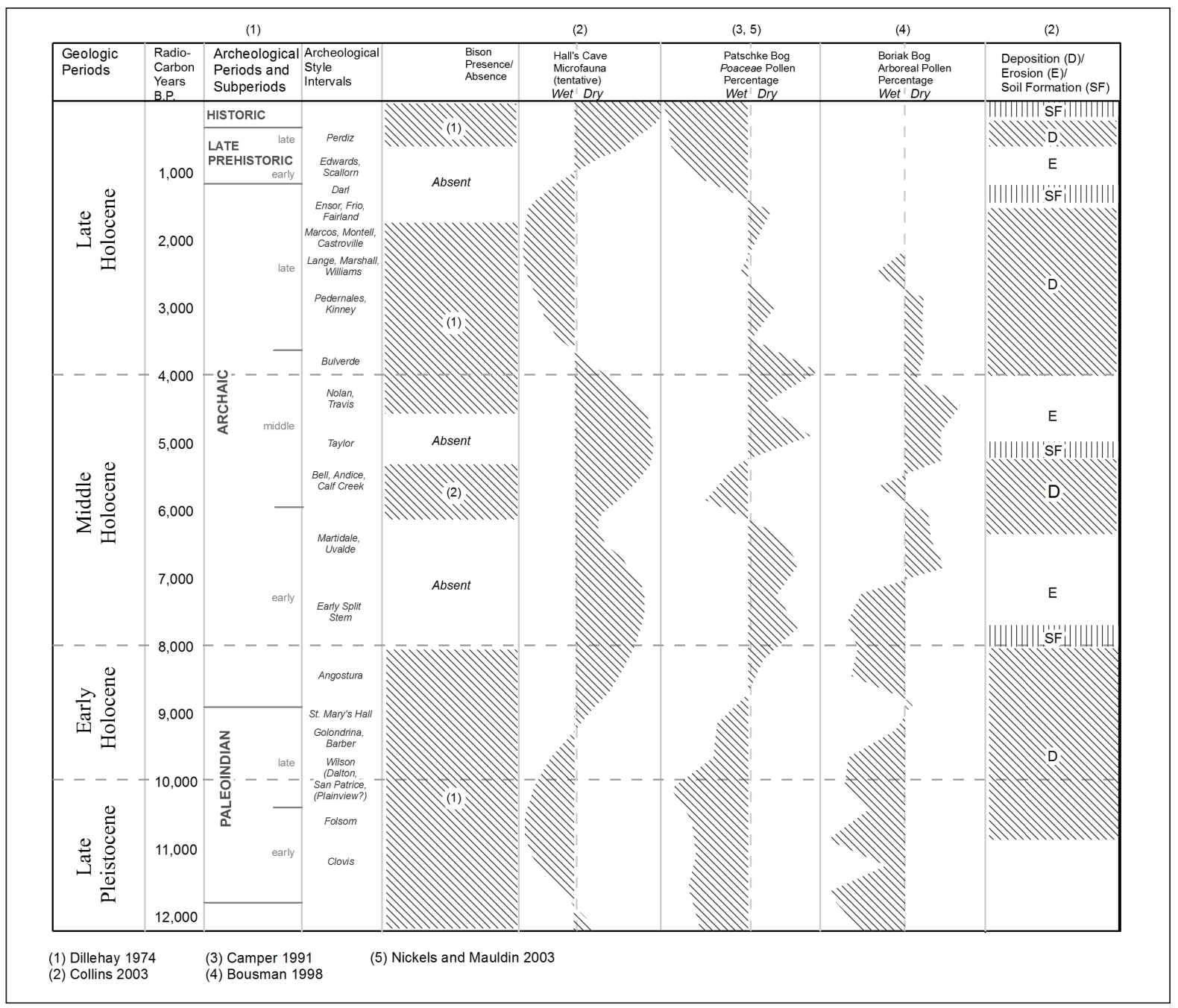

Figure 2-7. Texas Paleoclimate data and its effects (adapted from Nickels et al. 2010).

changes have been induced by human intervention through the clearing of wooded areas along the rivers for construction purposes, pumping more water for irrigation which has lowered water tables, and overgrazing by livestock. Although there are still many seeps, springs, and streams in the area, they most probably flowed with greater abundance during wetter intervals than exist at the present time, providing an abundant resource for prehistoric occupants.

\section{Cultural Context and Chronology}

Site 41DL436 is situated within the North-central Texas Archaeological Region (Perttula 2004:7). Although still poorly understood because of the lack of excavations conducted on well stratified and intact archaeological sites within the region, there are three periods that have most succinctly been defined by Dan Prikryl (1990) in his synthesis of geomorphology and archaeology along the Elm Fork of the Trinity River. They are the Palaeoindian period, the Archaic, the Late Prehistoric. Duane Peter and Dan McGregor (1988) further identified a Protohistoric period from their investigations at Joe Pool Lake that should be added to this 


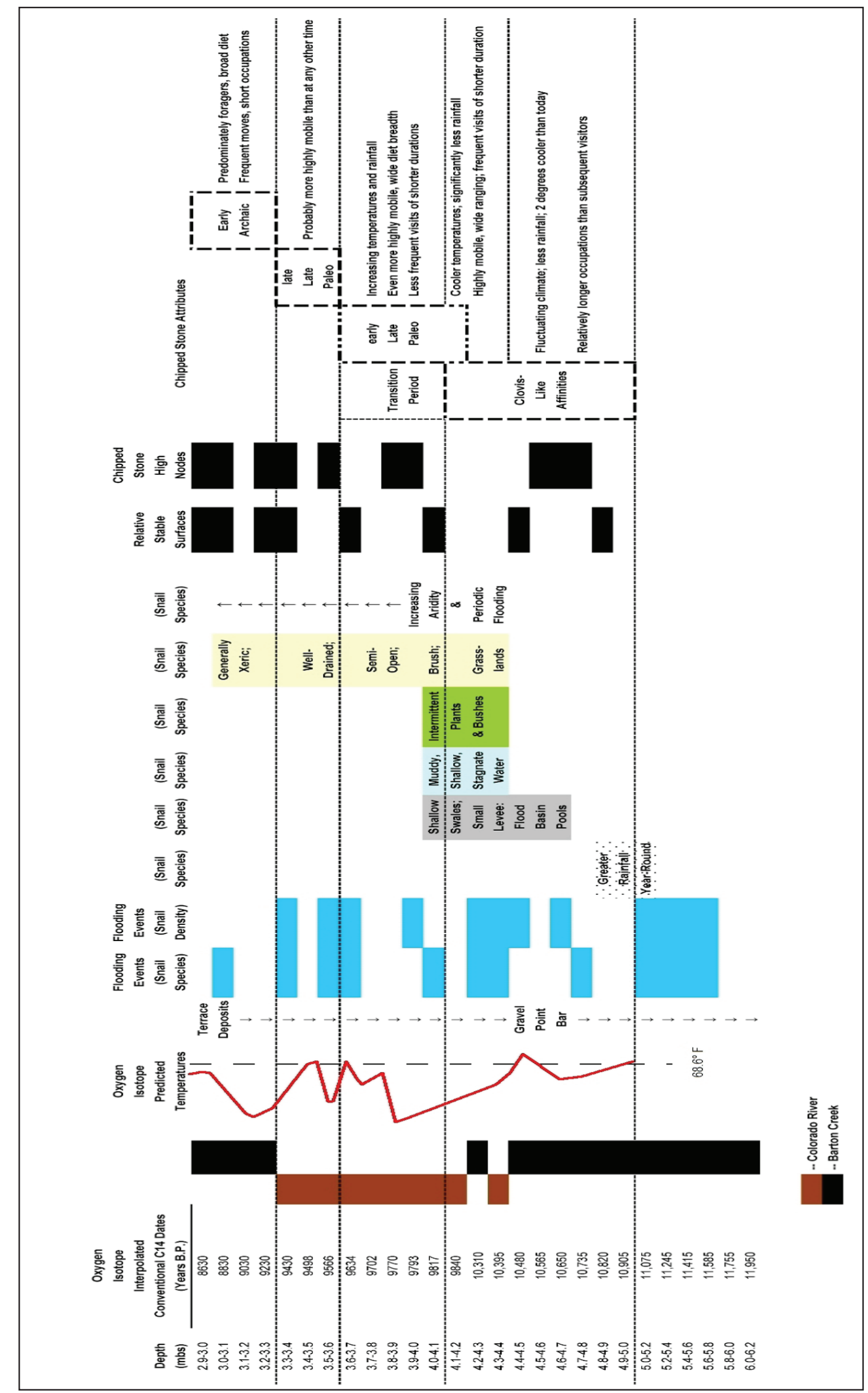

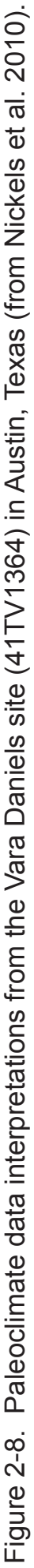


sequence. The sequence is shown in Table 2-1; all dates presented in 'years BP' are years before $\mathrm{AD} 1950$, when radiocarbon dating was refined.

Table 2-1. Cultural time periods in the North-Central Texas Archaeological Region (adapted from Lintz et al. 2008).

\begin{tabular}{ccc}
\hline Cultural Period & Interval & BC / AD \\
\hline Paleoindian & pre-8500 BP & pre-6550 BC \\
\hline Early Archaic & $8500-6000$ BP & $6550-4050$ BC \\
\hline Middle Archaic & $6000-3500$ BP & $4050-1550$ BC \\
\hline Late Archaic & $3500-1250$ BP & 1150 BC-AD 700 \\
\hline Late Prehistoric I & $1250-750$ BP & AD 700-1200 \\
\hline Late Prehistoric II & $750-250$ BP & AD 1200-1700 \\
\hline Protohistoric & $350 / 250-150$ BP & AD 1600/1700-1800
\end{tabular}

\section{Pre-Clovis}

Although humans may have inhabited North America before 11,500 BP, solid evidence does not as of yet support their existence. The argument that artifacts recovered from Levi Rockshelter in Travis County are older than Paleoindian (Alexander 1983:133-145) is not supported because the radiocarbon dates are not clustered, and there are no distinct artifact and extinct fauna assemblages within well-defined stratigraphy (Collins 1995:380-381). Other sites where assemblages are purportedly pre-Clovis include Friesenhahn Cave (Krieger 1964) and the Waco Mammoth Site (Fox et al. 1992). Human behavior is inferred on stone artifacts from Friesenhahn Cave, and mammoth bones at the Waco Site. However, problems of context or dating exist at both sites (Collins 1995:380-381). The Gault Site in Bell County, Texas has provided by far the largest Clovis assemblage in all of North America, and with artifacts stratigraphically beneath the known Clovis component, likely has the best chances of providing conclusive evidence for a pre-Clovis culture in Texas (Adavasio and Page 2002:292-294; Collins 2009; Collins and Brown 2000).

\section{Paleoindian}

The first undisputed evidence of human habitation in North America is known as the Paleoindian period and dates from 11,500-8000 BP in north-central Texas and the Southern Great Plains (Prikryl 1990; Hofman 1989:29-45; Story 1990). Similarly, the Paleoindian period dates from 11,500-8500 BP in central Texas (Collins 1995) where a higher number of well-stratified sites have been recorded. The South Great Plains were defined by changes in climatic conditions and subsistence patterns more so than projectile point technologies which are indicators of change in Central Texas; however, these regions will be referenced as well for a more complete over view of north-central Texas's prehistory since undisturbed Paleoindian sites near the Trinity River Valley are rare (Meltzer 1987). The close of the Pleistocene period is characterized by small bands of nomadic big game hunters with a lithic technology consisting of Clovis, Folsom, Dalton, Scottsbluff, Golondrina, and Plainview projectile points. Typically, Paleoindian projectile points were lanceolate-shaped and often fluted to facilitate hafting to 
foreshafts of wooden spears. Atlatls, or spear-throwers, were utilized by Paleoindian groups to more effectively bring down large game such as mammoth, mastodons, bison, camel, and horse (Black 1989). Known Clovis sites in Texas include kill sites, quarries, caches, open campsites, ritual sites, and burials (Collins 1995:381-383; Hester 1995:433-436).

Several sites dating to the Paleoindian Period are found throughout north-central Texas. One of the oldest Paleoindian sites in this region is arguably the Aubrey Clovis Site (41DN479), located in Denton County, Texas. The Aubrey Clovis Site has been carbon dated to 11,550 BP (Ferring 2001). A wide variety of lithic material, which originated in distant locations, was found at 41DN479 under roughly eight meters of alluvium on the Elm Fork floodplain. This lithic material was used to fashion a wide variety of tools such as blade tools, flake tools, Clovis points, end scrapers, and gravers (Ferring 2001). The Lewisville Lake Site (41DN71) contained 27 hearth features, an ephemeral lithic scatter in a near-surface context, and one Clovis point (Crook and Harris 1957, 1958; Story 1990:182-184).

Both the Horn Shelter No. 2 Site (41BQ46) and the Waco Mammoth Site yielded Paleoindian deposits. The Horn Shelter No. 2 Site revealed 27 strata of human occupation which yielded numerous features and several Clovis and Folsom projectile points. The Waco Mammoth Site also exhibited materials from the Paleoindian period (Fox et al. 1992). Some notable Clovis age sites have been recorded further north which include the Sam Kaufman site in Red River County (41RR18), which included a Paleoindian age hearth feature 1.8 meters below the ground surface (Kenmotsu and Perttula 1993). The Roy Young site (41LR36) in Lamar County yielded a single Clovis point, as did a site in Grayson County, Texas (Story 1990). In central Texas, the Gault Site (41BL323) in Bell County, has contributed to over 90 percent of the world's Clovis artifacts. Materials from this site may eventually provide conclusive evidence for a pre-Clovis culture in Texas as well (Adavasio and Page 2002:292-294; Collins and Brown 2000).

Recent research has suggested that the Paleoindian reliance on large game was not as pronounced as previously thought. In addition to megafauna, Paleoindian groups also harvested small game such as deer, turtle, mice, raccoons, and frogs (Collins 1995:381).

The latter portion of the Paleoindian Period saw stylistic changes in projectile point technology. Dalton, Scottsbluff and Golondrina traditions gradually replace Clovis and Folsom fluted technology types. These projectile types were wide spread, but occurred in higher densities in the High Plains and Central Texas (Meltzer and Bever 1995).

Environmental data suggests that the Paleoindian climate was wetter and cooler than it is today (Mauldin and Nickels 2001; Toomey et al. 1993). The climate gradually shifted to drier and warmer conditions as the Early Holocene approached (Bousman 1998). Studies indicate that it is highly unlikely that Paleoindian hunters caused the extinction of large game (Cannon and Meltzer 2004; Grayson and Meltzer 2002). As climatic conditions changed, megafauna began to die out, directing Paleoindian subsistence strategies towards small game hunting and plant foraging during the rise of the Archaic Period. 


\section{Archaic}

The Archaic Period immediately follows the Paleoindian Period and is typically divided into the Early, Middle, and Late Archaic subperiods. Generally the Archaic Period is characterized by a more intensive reliance on local floral and faunal resources. The Archaic period in north-central Texas is tentatively dated between 8500-2700 BP (Prikryl 1990). The Archaic period sees an increase in the number of projectile point styles (Collins 1995). The archaeological record also suggests a heavier reliance on food processing and a wider variety of site functions, as well as more localized geographic distributions of artifacts. Increasingly complex settlement systems, increased population sizes, gradually decreasing mobility, and development of distinct group territories define the Archaic period in north-central Texas (Prikryl 1990). These circumstances may have compelled Archaic populations of the Cross Timbers and prairie areas of northcentral Texas to diversify hunting and gathering strategies based on bottomland resources of the rivers and tributaries, and bison hunting along the plains (Hofman 1989). Archaeological endeavors along the West Fork of the Trinity River suggest that primary contexts for Early and Middle Archaic sites are likely to be identified only under deeply buried deposits of flood plain alluvium (Peter and McGregor 1988; Yates and Ferring 1986).

\section{Early Archaic}

Prikryl (1990) dates the Early Archaic from approximately 8500-6000 BP and suggests a lack of regional differences in terms of adaptive patterns during this time. In the North Texas region, subsistence data during the Early Archaic is scarce (Ferring and Yates 1997) and high integrity. Early Archaic components in north central Texas have not been identified. Projectile point styles in Central Texas began to transition around $8000 \mathrm{BP}$ from unstemmed to stemmed varieties such as Martindale and Uvalde (Black 1989). Early Archaic projectile point styles in north-central Texas included early split-stemmed varieties and possibly Angostura (Prikryl 1990; Story 1990). The dwindling megafauna populations led to a shift in focus from large game to smaller game such as deer, fish, and plant material (Black 1989).

\section{Middle Archaic}

The Middle archaic dates roughly from around $6000-3500 \mathrm{BP}$ and the climate shift to a warmer drier climate that began in the Early Archaic continued to persist into the Middle Archaic, although as the Middle Archaic continued conditions became more mesic (Albert and Wyckoff 1984), leading to the development of the Cross Timbers physiographic region (Prikryl 1990). Prikryl's (1990) research into the archaeological data from the lower Elm Fork of the Trinity River reveals that all Middle Archaic sites recorded prior to 1990 were situated on the first terrace above stream flood plains, with 55 percent along the Elm Fork itself. This settlement pattern suggests that Middle Archaic peoples utilized terraces along major drainages. Additionally, Prikryl's studies revealed a complete lack of burned rock middens in the lower Elm Fork region. Burned rock middens are a very common feature in Central Texas, and a number of theories have been posited in order to attempt to explain there absences in the lower Elm Fork region. One reason for the lack of burned rock middens in the area may be because the plant foods utilized in areas where burned rock middens occur with frequency were not 
common in the area Prikryl focused on. A second interpretation focuses on the link between burned rock middens and the processing of acorns, which some believe requires limestone in order to leach the acids from the acorns. The bedrock found in the oak savannahs of north Texas is typically sandstone and is chemically inert (Prikryl 1990). Lastly, it is quite possible that groups in central and north central Texas developed distinct adaptations (Prikryl 1990), and the distribution of dart points supports this interpretation. For example, point types that are commonly found in association with burned rock midden features such as Nolan, Travis, and Bulverde are absent from Prikryl's study area. Projectile points commonly found in the lower Elm Fork region include Carrollton, Wells, and the Basal-Notched group that includes Calf Creek, Bell, and Andice points (Prikryl 1990). Several important sites have been found in the north Texas region that date to the Middle Archaic. The R. W. Watts Site Number 2 (41CP14) in Camp County which exhibited dense midden deposits and burned rock features dated to the Middle and Late Archaic, with possible earlier components (McKay et al. 2003:14). The Wild Bull Site in Henderson County (41HE61) contained Middle and Late Archaic lithic assemblages and a burned rock feature (McKay et al. 2003:14). The Calvert Site in the Trinity Valley of Denton Creek (41DN103) (Ferring and Yates 1997) yielded a burial, hearths, and an unmixed assemblage of artifacts and fauna. Investigators at the site suggested that the climate may have been drier, and that the homogeneity of artifact types with adjacent regions might indicate that Middle Archaic groups participated in broader cultural interactions (Ferring and Yates 1997:305).

\section{Late Archaic}

Prikryl places the Late Archaic period from 3500-1250 BP and observes at least three increases in site frequency relative to the Middle Archaic period (1990). The Late Archaic in the northcentral Texas region is characterized by an increase in the number of sites, a greater distribution of sites over the landscape, and decreased mobility (Prikryl 1990).

Ferring (1986) suggests that the climate during the Late Archaic was even more mesic than in the previous Early and Middle Archaic periods, although the West Fork paleosol that developed in the latter part of the Late Archaic in the Upper Trinity Basin may be evidence of a wetter climatic regime. It has also been hypothesized that population densities increased dramatically during the Late Archaic, possibly due to changing environmental conditions, new subsistence strategies, technological innovations, reduced group mobility, or the increased accumulation of cultural knowledge. However, as groups began to specialize in the procurement of resources available, mobility and cultural interactions with neighboring groups may have decreased. This may be indicated in the more diverse tool technologies and subsistence patterns. Projectile point style varieties show an increase. Projectile points characterizing a Late Archaic component include Ellis, Ensor, Palmillas, Yarbrough, Kent, and Gary points. Other styles include Castroville, Elam, Dallas, Edgewood, Godley, Marshall, and Trinity points (Prikryl 1990; Story 1990). Prikryl's (1990) studies on population densities supports increases in populations in the region during the Late Archaic. Prikryl found that Late Archaic sites were 3.5 times more numerous than were sites dating to the Middle Archaic. This discrepancy is telling, but does not rule out the fact that there may be many more Middle Archaic sites; they just have not yet been located. 
The lithic material used for tool manufacture in the Late Archaic suggests a decrease in group mobility as compared to earlier periods (Skinner 1981; Prewitt 1983). Prikryl (1990) found that 62 percent of the projectile points found within his area of study (the Lower Elm Fork) were made from materials obtained locally, specifically Ogallala quartzite. Prikryl (1990) postulated the theory that the Late Archaic period in the upper Trinity River basin was characterized by a decline in the use of local chert, although the Fort Worth area near the Clear and West Forks of the Trinity River remained unexplored.

The frequency of open campsites seems to have increased during this time, but the scale of the sites tends to be smaller. Smaller game and plant materials continued to be an important component to Late Archaic subsistence strategies. This evidence is supported by the presence of lithic tools associated with plant processing activities (Brownlow et al. 1999). Late Archaic deposits along the Denton Creek drainage indicate an increased reliance on freshwater shellfish, suggesting a possible decreased availability of large game, decreasing territory size, or resource specialization (Anthony and Brown 1994). Several important sites dating to the Late Archaic have been documented in this region of Texas. The Joe Pool Lake site (Peter and McGregor 1988) and the Lake Ray Roberts site (Ferring and Yates 1997; Prikryl and Yates 1987), located in Dallas County provide important information to this period. Assemblages at these sites suggest that small bands of foraging hunters and gatherers occupied a locality for a limited time and then reoccupied other sites on a seasonal basis exploiting deer, rabbit, turtle, and freshwater mussel shell along the way (Ferring and Yates 1997:6). Other important Late Archaic sites include the Sister Grove Creek Site in Collin County (Lynott 1975), and the Hurricane Hill site (41HP106) in Hopkins County (Perttula 1999).

\section{Late Prehistoric}

The beginning of the Late Prehistoric period in the upper Trinity River basin falls roughly between 1300-250 BP. Research at Lake Ray Roberts suggests that regional exchange of technological information, rather than environmental change, likely explains the shift from Late Archaic lifeways to Late Prehistoric (Ferring and Yates 1997:305). Both Lynott (1977) and Prikryl (1990) agree on the division of the Late Prehistoric into an early and late phase based on arrow point and ceramic technologies. The early phase dates from 1300-800 BP, and reflects a continuation of the foraging subsistence system of the preceding Late Archaic. Assemblages are characterized by sand and grog tempered ceramics and by Scallorn, Steiner, Catahoula, and Alba arrow points (Lynott 1977; Prikryl 1990). The introduction of the bow and arrow enabled prehistoric hunters to harvest prey from greater distances more safely, and required less room to maneuver than atlatls so hunters could conceal themselves in brush. Similarly to other temporal periods, known sites appear to have occurred on terraces, although roughly one-third are known to be situated on the floodplain. The climate is also believed to have become drier around 1000 BP (Prikryl 1990). Climate stress and the presence of ecotones may have contributed to the large numbers of sites located on the Cross-Timbers/Blackland Prairie boundary. Prikryl argues that the regionalization observed during the early phase of the Late Prehistoric shifts to one of greater mobility or trade with neighboring groups (Prikryl 1990). 
The late phase reflects Southern Plains influences and occurred from 750-250 BP (Prikryl 1990). It is associated with the appearance of Nocona Plain ceramics of the Henrietta focus, unstemmed triangular points (Fresno, Maud, Washita, and Harrell), and the Perdiz point (Lynott 1977; Prikryl 1990). This period also exhibits some evidence of horticulture and bison procurement. As bison herd sizes increased, hunter gatherers became more reliant on them for subsistence (Baugh 1986; Prewitt 1981; Suhm 1957; Yates 1982). In north-central Texas, this phase demonstrates prominent influence from settled agricultural peoples to the north and east. The dry climatic conditions experienced during the early phase, continued during the late phase, contributing to short grasslands which bison herds fed on. This may account for the increase in Bison remains during this period. Terrace sites are the dominant site type, mostly occurring along the Cross Timbers/Blackland Prairie boundary. A high density of sites was recorded along that margin at the Aquilla Lake Site (Brown 1987a, 1987b).

Excavations at the Cobb-Pool site (41DL148) at Joe Pool Lake have contributed to our understanding of the Late Prehistoric period. House structures, roasting pits, Alba points, burned corn, and grog-tempered ceramics were documented at this site indicating significant adaptive transitions during the middle of the Late Prehistoric period (Peter and McGregor 1988). Data from the Ray Roberts project suggests that regional traditions which emerged during the last phase of the Late Prehistoric did so independently of the Plains or East Texas Woodlands cultures (Ferring and Yates 1997:305; Story 1990).

\section{Protohistoric}

The time period between roughly AD 1550-1800 in north-central Texas is referred to as the Protohistoric Period. From the mid-AD 1500s, Europeans entered Texas only sporadically and did not settle there until around AD 1700 (Webb 1952). First European contact on the Texas coast most likely began with the landing of Cabeza de Vaca and the Narvaez expedition survivors in 1528. Reliable historical information for the Trinity River basin during the Protohistoric period is somewhat limited, and it is not well understood which aboriginal groups resided in north-central Texas during this temporal period. Limited data suggest that Caddoan language speakers, possibly members of the Wichita Confederacy, occupied the area. Caddo groups, including the Kichai, Ionis, and Tonkawa Indians, are known to have occupied the lands within north Texas. Tribes consisting of the Wichita, Taovayas, Tawakoni, Yscani, Waco, and Kichai are believed to have entered the Southern Plains in an effort to avoid hostile groups like the Osage (Webb and Carroll 1952:904). Groups with more abbreviated occupation in this region include the Comanche, Kiowa, and Lipan Apache. More sedentary Plains Villagers of the Wichita Confederacy tended to leave behind a more substantial archaeological presence. These materials typically included arrow points (Fresno, Harrell, and Washita types), thick end scrapers, T-shaped perforators, bifacial gun flints, bison hoes, elbow pipes, Womak Engraved pottery, metal knives, horse tack, shot, kettle fragments, trade beads, and various European ceramics.

The ancestral Wichitas and Kichais emigrated from the northeastern woodlands onto the Great Plains, settling in the Arkansas River valley in today's Kansas and Oklahoma. They survived by raising corn, squash, beans, pumpkins and melons in fields near the streams, and 
by hunting bison, antelopes, rabbits, prairie chickens, grouse, quail, deer, bears, and turkeys on the plains and in the Cross Timbers. In the Spring and Summer, they lived in scattered villages in roundhouses constructed of poles and straw. Come Fall, they ventured onto the plains to hunt buffalo while living in tepees made of skins. Occasionally, they would come into contact with Osages on the east, or Apaches on the west, resulting nearly always in small-scale battles (Smith, F. T. 2000:3-6).

Perkins and Baugh (2008:384) view the onset of the Wichita protohistoric period as beginning with the interregional actions brought on by the collapse of large settlement systems to the east and west of the Plains, causing intermingling of the Wichita among various tribes, and terminating in A.D. 1846 with the onset of the processes of colonization and an initial reservation treaty with the United States.

The Athaspascan language is generally what differentiates the Apaches from other Native American Tribes. Athaspascan is the most widely spoken language among Native Americans in all of North America. In the region of Texas and New Mexico, the Texas Apaches, or Lipanes are recognized as eastern Apaches with a distinct linguistic division, and thus historians generically refer to the tribes and bands that have inhabited this region for centuries simply as “Apaches" (Dunn 1911:201-202).

\section{0-1650}

Spanish contact with Southern Plains Indians occurred from both the east and the west in the 1500s. The Wichitas on the Southern plains at this time consisted of two groups. The first groups numbered about 150,000 and were comprised of the Taovayas, the Tawakonis, the Guichitas, and the Kichais. The second group numbered roughly 50,000, and were named the Iscanis (Smith, F. T. 2000:8).

It could be, that in 1542 following the death of Spanish explorer Hernando de Soto, the remainder of his party may have reached the Trinity River area after crossing the Red River, but this cannot be confirmed (Strickland 1942; Williams 1942). In 1540, Hernando de Alvarado, a captain in the Coronado Expedition, encountered two Wichitas at Pecos Pueblo in New Mexico. By this time the Wichitas were very much actively trading bison by-products and bois d'arc wood with the Puebloans, in return for farm goods, obsidian, and turquoise. The two Wichitas at Pecos Pueblo were Ysopete, and one called the Turk. Learning from the Turk that there were large villages with large structures to the east (probably Mississippian moundbuilders), the Spaniards apparently misunderstood that these possible riches were located in Quivira, the Wichita homeland at the time. This sparked Coronado to proceed onto the plains in 1541 in search of Quivira, encountering both Athapaskan Apaches and Wichita Iscanis (Flint and Flint 1997).

The final Spanish expedition to the Wichita homeland occurred in 1601, when explorer Juan de Oñate led 80 soldiers, two priests, and a number of Indian servants to Quivira, along with greater than 700 horses and mules, an unspecified number of oxen, and four cannons. After a long battle with the Wichita Iskanis, Oñate and his were party were lucky to make it out of 
Quivira (in modern-day Kansas), relatively unscathed (Smith, F. T. 2000:14). The Wichitas were basically left alone by Europeans until two Frenchmen contacted them in 1719. By this time the Wichitas had successfully adapted to the use of horses left by the Spaniards for hunting and warfare, but they were otherwise unsettled. That is, their numbers had been ravaged by diseases such as smallpox, measles, and cholera, and enemy tribes were constantly forcing them southward. Fortunately, the French provided them with trade goods, including firearms, powder, and bullets. "Perhaps no more than twenty thousand Wichitas remained in 1719, down from approximately two hundred thousand in 1541" (Smith, F. T. 2000:16).

According to T. R Fehrenbach (1974:82-85), "The origin of the horse on the Great Plains of America is no mystery. The horse came from the Spanish, who in the sixteenth century, conquered all of Mexico and pushed up into the present southwestern states". More specifically, the first modern horses were brought into North America when Cortez invaded Mexico in the early 1500s. The Spanish then continued to invade north into what is today New Mexico and west Texas so that by 1540 Coronado invaded the Hopi and Zuni pueblos using Afro-Asian horses termed 'mustangs'.

Although the laws of New Spain forbid Indians to use horses or firearms, the Spanish ranchers moving northward from central Mexico and into the American southwest in the late 1500s chose to ignore those laws. Instead they provided horses to their Indian servants. Some of those same horses through whatever means passed into the hands of Indian groups who refused to submit to Spanish control, and who remained wild roving bands. By 1550, Spanish soldiers encountered these Indian bands mounted on Spanish mustangs in northern Mexico, but it is unclear whether or not that by the late 1500s, horse breeding and trade among Indian groups was likely common up and down the Rio Grande, as well as into the untamed areas of New Mexico, Texas, and north into southern Colorado.

Fehrenbach thinks otherwise, and even though Coronado's expedition into New Mexico, northern Texas, and Kansas in the 1540s lost several horses, they were likely geldings and therefore could not have produced horse stock for the Indians. Instead, Ferhenbach posits that horse herds in New Mexico had their beginnings in 1598 when Spanish Governor Don Juan de Oñate crossed the Rio Grande at today's El Paso with among other animal stock, 300 Spanish (mustang) mares and colts.

It was then that the local Pueblo Indians who did not have horses and who were mainly farmers were subdued and enslaved. It was then that the Spanish introduced the horse to the local Pueblo Indians and taught them how to ride and care for horses, so that the Pueblo Indians (Indios) could help care for the large herds of cattle, sheep, and goats that the Spanish brought with them and bred. It was during this same time that some Indios rebeled against this Spanish enslavement and escaped on horseback into the countryside, and undoubtedly encountered the Apaches and Athapaskan groups a little farther north in New Mexico and in western Texas. The Apaches were plains hunters and fighters. They were undoubtedly eager to acquire horses from the Pueblo Indian escapees, but breeding a few in small numbers was apparently a skill they had little interest in. Instead, the aggressive Apache quickly learned the art of stealing horses from both the Puebloans and the Spanish. Fehrenbach (1974:86) opines that by the Spanish 
wanting to protect the Pueblos, they further incited war with the Apache, who had a history of harassing and fighting the generally non-aggressive Pueblo farmers.

"As for the Apache, they used dogs to drag travois with teepee covers, food, and other belongings until they acquired the horse. "The addition of horses to Lipan life (during the second half of the seventeenth century) enabled them to move camp, follow the herds, and kill the buffalo with much more dispatch and efficiency than they had ever been able to do afoot" (Newcomb 1993:114). "By the 1650s, Spanish accounts show that mounted Apaches were raiding Spanish-Amerindian settlements in New Mexico, running off with cattle and horses. One such raid, in 1659, carried off three hundred horses" (Fehrenbach 1974:86).

In sum then, it would appear that the Spanish provided horses first to Pueblo Indians beginning in 1598, and shortly thereafter the Apache acquired a few of those horses first from escaped Pueblo Indians, but after quickly understanding the advantage of using horses in both war and hunting, began stealing horses both from the local Pueblos and Spanish ranchers with abandon.

If there had not been the Pueblo Revolt of 1680, horses would still have had a big impact, but probably not as quickly. As discussed above, by 1680, the Apaches had begun acquiring large numbers of horses, and undoubtedly realizing the overwhelming tactical advantages that swift, mounted Apache warriors had over Puebloan farmers and docile herds of nomadic bison on the plains, would have most assuredly kept them in ravenous pursuit of horses at all costs. The Pueblo Revolt simply allowed for two things: (1) the abandonment of horse remudas throughout the region, (2) unimpeded access and "easy pickings" to the horse herds by the Apaches without counter aggression from either the Spanish or the Puebloans.

According to Rupert Richardson (1996:6), no one can say for sure when the Comanches first acquired horses, and he surmises that the initial stock was either stallions and mares that had escaped from the remuda of the early Spanish explorers; or they may have been stolen from Mexican settlements. The first known and documented account was in 1724, when a French explorer in Kansas observed the Comanche demonstrating excellent horsemanship apparently already learned from years of experience. Regardless, most researchers would agree that the Comanches used horses the best even though they got them after other tribes. By the 1870s in Texas, the Comanches found that "Good horses were most easily obtained in the settlements of the frontier white people..." (Richardson 1996:7). There are many references to the expert horsemanship of the Comanche. Ferhenbach (1974:132-149) says that the Comanche simply possessed a different mindset based on ancient spiritual beliefs, and a belief that they were destined by a Supreme Being to rule the earth, and referred to themselves as "The People." As such, they were 'driven' and destined to make use of the horse as a means to this end.

\section{0-1770}

In the late 1600s and early 1700s, Spanish priests and soldiers, and French traders vied for control of lands and trade with Native Americans from the Arkansas River to the Rio Grande (Figure 2-9). "Around 1700, Spanish Texas was invaded from the north by some groups of related Indians, known today as the Wichitas. These semi-sedentary tribes were the Wichita 
proper, including the Taovayas, Tawakonis, Wacos, and Kichais. "The Wacos, Tawakonis, Taovayas, Wichita proper, and some minor groups are closely related linguistically, with only minor dialectual differences distinguishing them. Their essentially common language, termed Wichita, is one of four languages of the Caddoan stock, the others being Pawnee, Caddo, and Kichi. If there were once cultural differences which distinguished these various Wichita subgroups they have long since been forgotten" (Newcomb 1993:248). In the seventeenth and eighteenth centuries the Wichitas were consistently being forced south from the High Plains by Osages encroaching from the northeast, and who were armed with rifles supplied by Europeans, as well as by hostile Comanches who were encroaching from the northwest and the headwaters of the Arkansas River. To their advantage, by this time the Wichitas had acquired horses from southwestern New Mexico" (Newcomb 1993:248).

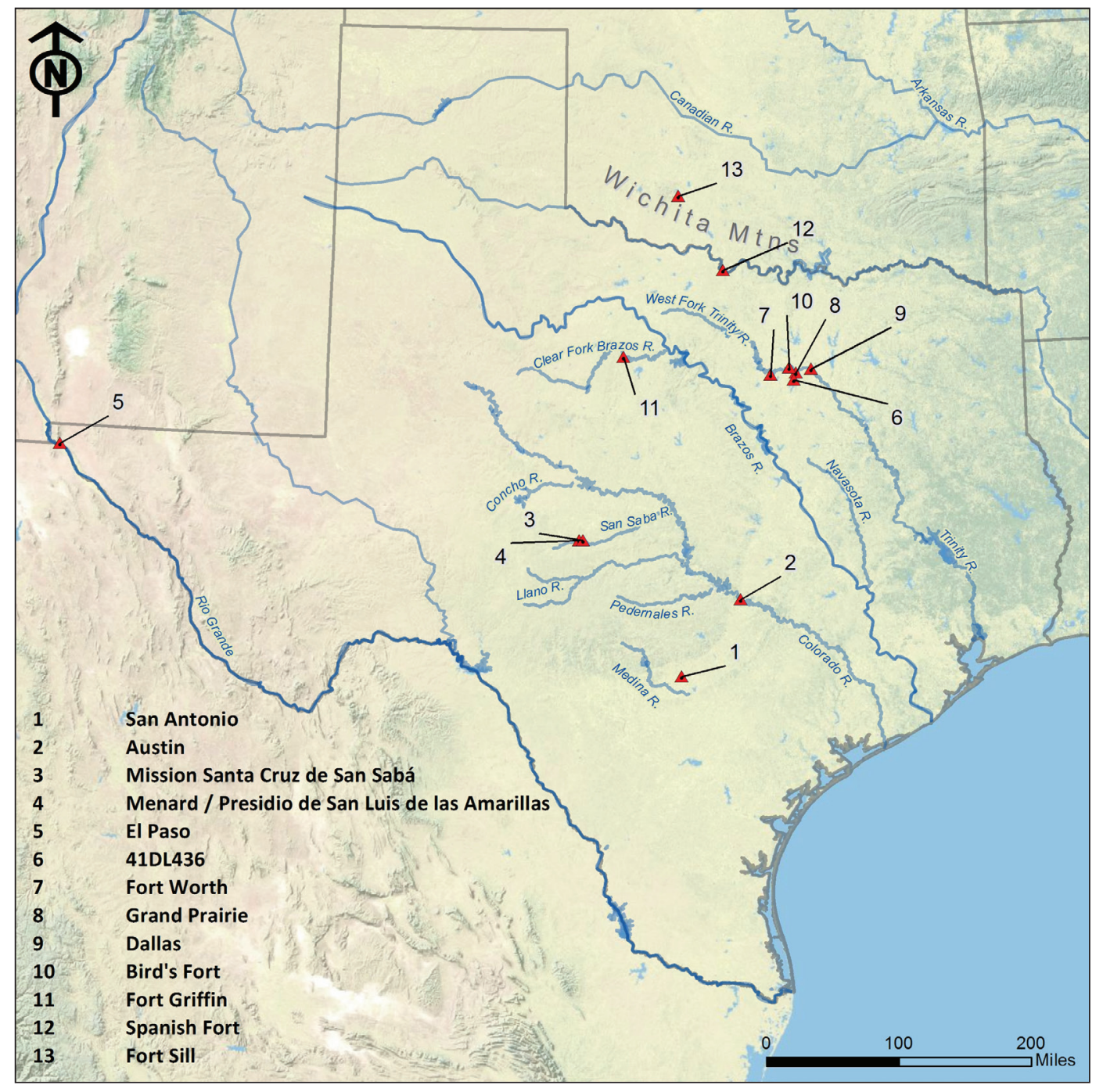

Figure 2-9. Locations of place names discussed in the text. 
In 1747, French traders succeeded in concluding a Wichita-Comanche allaince, and within a decade the Wichitas (Taovayas) had founded a substantial settlement and trading center on the Red River. The Wichitas' headquarters, and the major crossroads of the eighteenth-century southern plains, was at Spanish Fort on the Red River" (Newcomb 1993:23, 249), roughly 135 miles north-northwest of the Fish Creek Slough site (41DL436).

"At the dawn of historic times in east and northeast Texas and adjacent portions of Louisiana, Arkansas, and Oklahoma, lived about two dozen tribes of Caddo Indians" (Newcomb 1993:23). When the French first encountered the Caddos in northeast Texas late in the 1600s, the tribe numbered perhaps 8,000 in all, with agricultural villages as far northeast as beyond the Trinity River and to around the big bend of the Red River (John 1975:164-165). It seems quite likely then, that French trade goods, to include metal utensils, knives, and firearms reached westward along both the Trinity and Red River basins by about 1700, if not earlier. Native American groups to the west and northwest of the Caddos in the early seventeenth century were the Tonkawans, Wichitas, and the Kichais. These groups who occupied the region around 41DL436 were enemies of the Caddoans. Roving Tonkawan bands frequently invaded the western Caddo settlements, and by about 1650, the Apaches did the same. Notably, in preparing for war, the Caddo war party "... lived for a week in a special house, fasting, praying, dancing, planning, recruiting; at their departure the house was burned" (John 1975:166). Although agriculture was an important part of Caddoan subsistence, they relied on wild fruits and nuts, as well as a wide variety of terrestial game animals and fish. In addition, the westernmost Caddoans had always relied upon bison to some extent, and had likely on occasion traded goods with their western neighbors (John 1975:168).

"Between 1500 and 1700 the name Jumanos was used to identify at least three distinct peoples of the Southwest and South Plains. They include the Tompiro-speaking Pueblo Indians in Salinas, a nomadic trading group based around the Rio Grande and Río Conchos, and the Caddoan-speaking Wichitas along the Arkansas River and Red River basins. The Jumanos were buffalo hunters and traders, and played an active role as middlemen between the Spanish colonies and various Indian tribes" (Hickerson 1996; Hackett 1941).

In the seventeenth century, the Jumanos conducted long distance trade between the pueblos of New Mexico and eastern and northeastern Texas. By 1632, they had established a trading camp near the confluence of the Concho and Colorado rivers, and as Hickerson (1994) points out, there are many tributaries between the Colorado and Trinity rivers. It seems likely that these would have provided opportune trade routes to the area around 41DL436, before the trade routes were effectively blocked by the invading Apaches around 1680. The Jumano traders initially brought such items as textiles, turqouise, and pottery from the pueblos in New Mexico to the western edge of the Caddo near the lower Trinity River in exchange for bows. Later, the Jumanos traded metal goods and horses obtained from the Spanish frontier in New Mexico, as well as buffalo meat and hides hunted along the way (John 1975:170; Hackett 1941). Thus, it is a distinct possibility that in the 1600 s, these same goods were traded up the Trinity River and its tributaries with the Tonkawas, Wichitas, and Kichais in the vicinity of 41DL436. 
Nevertheless, three major Indian tribes who have become known as "Overlords of the Southern Plains" were the Comanches, Kiowas, and Kiowa Apaches. These tribes were nomadic buffalo hunters who ranged over hundreds of miles and practiced little or no agriculture. They had mastered the horse sometime prior to 1750" (Hamilton 1988:11; Roe 1955).

During the 1600s and 1700s, the Apaches in Texas became known principally as the "Lipan Apaches" (Dunn 1911: 201-202), and that name has continued to this day in historic writings. The Lipans were first documented by the Spanish as occupying an area on the upper reaches of the Colorado, Brazos, and Red rivers. However, the ever encroaching Comanches pushed the Lipans south so that by 1732, they were living along the San Saba, Llano, and Pedernales River valleys, with some being pushed even as far south as the Medina and Rio Grande. It could be, that the Lipan Apache, although mounted on horseback by this time, were reportedly without firearms (Dunn 1911:202-203), and thus were severely at a disadvantage to those Indians who had been trading with Europeans and Anglo-Americans for arms and ammunition. Nevertheless, they were apparently equipped with good horses, iron stirrups, iron arrow points, and iron dart points. Despite their handicap of not possessing firearms prior to 1750, the Lipan Apache were a fierce foe to be avoided on the plains during buffalo season, when many Indian bands were there competing for the same resource (Dunn 1911:222).

However, an apparently more fierce enemy emerged from the north to harass and consistently force the Apaches as well as other Indians southward from the Southern Plains and the rich buffalo hunting grounds. This more fierce fighting force would be the Comanches. "The period between 1725 to 1750, therefore, was one of gradual shifting to the south. As the Comanches continued to press hard upon the Apaches, the latter gave way before them, remaining in their new location until the renewed pressure was exerted by their enemy. The key to Apache migration and policy during this period, especially of the latter part, may be found primarily in the hostility of the Comanches" (Dunn 1911:265).

Despite encroachment by the Apaches and Comanches in the late 1600s and early 1700s, it appears that the Wichitas and Kichais were still very much a presence in the region. For example, in 1719, during a reconnaissance of the upper Red River, French explorer Du Rivage “... encountered several wandering bands, including the principal Tonkawan groups, who lived mainly by hunting buffalo. All the Indians had welcomed the Frenchman very cordially. Two Kichais accompanied Du Rivage...” on his return trip (John 1975:213).

The Taovaya (Towash, Tawehash, Teguayos, Toayas, Taouaizes, Tahuayases, Aijados), a Wichita group probably originally from Kansas and southern Nebraska, was forced by Osage and Comanche pressure into southern Oklahoma and northern Texas in the eighteenth century. In 1719 Jean Baptiste Bénard de la Harpe found Taovaya, Tawakoni, and Yscani Indians on the lower Canadian in present Oklahoma, and by 1759 the Taovayas were in a more or less permanent settlement on upper Red River near present Spanish Fort. They were one of the "Nations of the North" that gave the Spanish much trouble in the eighteenth century, participating in the raid on the mission of San Sabá de la Santa Cruz in 1758 and successfully defending their village against the retaliatory expedition led by Diego Ortiz Parrilla in 1759. In 
1772, through the efforts of Athanase de Mézières, a nominal peace was established between the Spanish and the Wichitas (John 1975).

A similar account of the Taovayas and Spanish Fort has been provided by Jelks (1996a): "The Taovaya, a Wichita group probably originally from Kansas and southern Nebraska, was forced by Osage and Comanche pressure into southern Oklahoma and northern Texas in the eighteenth century. In 1719 Jean Baptiste Bénard de la Harpe found Taovaya, Tawakoni, and Yscani Indians on the lower Canadian in present Oklahoma, and by 1759 the Taovayas were in a more or less permanent settlement on upper Red River near present Spanish Fort. Taovaya economy was similar to that of other plains tribes-joint dependence upon agriculture and bison hunting, with fairly permanent settlements, except for semi-nomadic hunting parties that followed the herds. The best and most detailed descriptions of the Taovaya Indians were made by De Mézières, who found them cultivating large fields of corn, beans, melons, gourds, and tobacco. They raised enough surplus crops to carry on extensive trade with the Comanches, who provided horses and captives in exchange for the agricultural products."

By the mid-to-late 1700s, John (1975) notes shifts in occupied areas. She also notes that by 1756, the Taovayas-Wichita group occupied a large encampment on both sides of the Red River (Spanish Fort) north of the 41DL436 area. By 1772, the Wichitas had established a large settlement on the upper Brazos River west of 41DL436, and the Tawakonis and Iscanis were occupying the Trinity River area downstream from 41DL436 (John 1975:200; see also, Cortés 1799:86-87). Herbert Bolton (1914) and Elizabeth John (1982) surmise that the encampment also referred to as Spanish Fort was occupied from about 1757 to 1812.

By the 1750s, the Apaches had taken hold of the Southern Plains with a vengeance. By 1799, all of the Apache nations had access to firearms, particularly the Mescaleros, Llaneros, and Lipanes. Notably, the Lipanes were particularly skillful in firing from horseback with accuracy. Although as stated previously, up until that time the Spanish government prohibited dealing in arms and ammunition to any Indians on the frontier, it was well known that the English and Anglo-Americans were trading guns and ammunition in exchange for furs. The use of firearms by the Apaches as well as other tribes was limited only to the extent of a lack of ammunition or the ability to repair them. Even those arms that could not be repaired were often fashioned into metal blades, knives, arrow points, and other tools (Cortés 1799:69-71; John 1975).

The greatest peaceful pastime for the Apache was hunting. During large hunts they would frequently employ the use of fire to herd and encircle game. The numerous burned areas discovered at the Fish Creek Slough site (41DL436; see Chapter 16) could possibly represent these tactics. In 1799, Lieutenant José Cortés of the Spanish Army describes an Apache hunt that took place in nearby proximity to their arch rivals, the Comanche, as follows:

"Our subject is the hunt in which they usually seek white-tailed deer, mule deer, pronghorns, javelinas, porcupines, mountain lions, bears, wolves, coyotes, hares, and rabbits. They reconnoiter the plains, valleys, hills, and mountains which they frequent, and by the tracks and signs that they find they determine the abundance of game existing in the area of search. The captain with the best reputation chooses and orders the day 
for the undertaking, and selects the spots where the different team of archers-some on foot and others mounted - who are to act as beaters should be in place by dawn, and the locations to be covered by those who are to serve throughout as lookouts to protect against enemy attacks. Only the most reliable ones are entrusted with this duty. In this way, at dawn they have surrounded an area whose circumference usually reaches four, five, or six leagues. The signal to begin the beating and close in is given by smoke signals, to which task riders are assigned. The operation begins by setting fire to the grass and vegetation all around the circle. Since they are all in their respective positions for this purpose, with torches made from dried palmilla bark at the ready, it is only a moment before one sees in flames the entire circle that is to be beaten. At the same moment they begin to yell and make noise. The game flees but finds no escape, and finally falls into the hands of such clever adversaries. This type of hunt is done only when the hay and grass are dry. In the rainy season, when they cannot burn the vegetation, they set up encirclements next to rivers and arroyos. They begin the beating with the preparations discussed above, and end up with the same yelling in this second type of hunt, tightening their chosen circle to the very last" (Cortés 1799:67-68).

Lieutenant Cortés goes on to say that "The most irreconcilable hatred that the Apaches hold, and the war that they carry on most tenaciously, are against the Comanche Indians. This hatred is as old as the nations themselves, and the war is waged with utmost vigor by the groups nearest to them ... (one group being the Lipanes)." Lieutenant Cortés (1799:76) surmises that this hatred has stemmed from their long perceived exclusive rights to buffalo hunting grounds.

In reconciliation to the warlike and aggressive Apaches, the French called for an alliance between the Apaches and the French allies. Those French allies being the Comanches, the Kichais, the Tawakonis, the Iscanis, the Osages, and others. An advantage to the Apaches would be their ability to openly trade for goods that were heretofore only available to the French allies. An implicit advantage to the French allies would be the supposed cessation of raiding and pillaging by the Apaches (John 1975:337-338). However, an ample supply of trade goods previously available to frontier French traders was interrupted by the French and Indian War (1754-1763) between France and Great Britain, but fought primarily in America between Great Britain and French colonies (John 1975:338; e.g. Anderson 2005).

Although the Wichita villages were predominantly tethered to the upper Arkansas River region at the time, their inability to secure firearms for ten years from the French during their ongoing wars with the Osage was significant. In the meantime, the British continued to supply the Osages with weapons. This ultimately forced the Wichita to abandon their lands along the Arkansas, and re-locate further south to the Red River in lands wrested from the Apache. These groups included the dominant Taovaya Wichita band, as well as the lesser Iscanis. Thus, in the mid-1750s, the okonitsa ("one who locates") of the Taovaya band selected an area on both sides of the Red River, at the western edge of the Cross Timbers, as an ideal location for their village (Spanish Fort). Other smaller bands re-settled farther to the southeast, along the Sabine River (John 1975:338-339). It is well established that by the 1740s, the French were trading with Indian tribes in northeast Texas, to include those along the lower Trinity and Sabine 
rivers, with the French providing powder, shot, muskets, cloth, blankets, razors, and knives. Later, in the 1750s, the Spanish would provide the same (John 1975:344-347).

The Taovayas had fought the Apaches for their newly occupied land along the Red River, and remained vengeful. In that regard, they sought an alliance with the feared Comanche tribe who had raised havoc in New Mexico, and were quickly taking over the High Plains region from the west and northwest. Not to be outdone, although the Taovayas were generally a settled and farming society, they were also very much accomplished in warfare (John 1975:341-342). Their pursuit of their arch nemesis, the Apaches, led to an eventual conflict with the Spanish in 1758 at Mission Santa Cruz de San Sabá near the modern-day city of Menard, Texas. By that time, French traders were known to be trading arms and ammunition to various Indian groups now mounted on horses, and which the Spanish viewed as threats, especially the troublesome Norteños - a general term applied to the Comanche, Wichita, and their allies (Weddle 1964:91, $105)$.

Although the Comanches, Kiowas, and Kiowa Apaches had been staunch enemies, around 1790, these groups had formed an alliance, and together they migrated from the north onto the Southern Plains. By 1824, the Wichitas, the Wacos, and a few Tawakonis and Kichais numbering perhaps 2,600 occupied the area between the Red River and modern-day Austin. Although these groups were generally of Caddoan stock, they were friends and allies with the Comanches, and by 1840, the Comanches most likely predominated the area (Richardson 1996:19). The Comanches ruled the plains, but the Apaches ruled the hills and mountainous areas. Although the Wichitas, the Wacos, and a few Tawakonis and Kichais whose homeland the Comanches had infiltrated were generally semi-sedentary agriculturalists raising corn and vegetables, as well as seasonal hunters, the Comanches would have none of that; the Comanches were by nature long range hunters. Lieutenant W. A. Trimble reported that in 1817 , the game had almost disappeared from the lower Red River area, and it was not until you reached the upper Trinity and Brazos rivers that buffalo, elk, deer, wild cows, hogs, and horses were abundant on the vast prairies. He further notes that although the Comanche pursed the buffalo herds from south to north in the Spring, and then from north to south in the Winter. Although the Comanche were at that time the largest and most warlike tribe, in 1820 alone, they lost roughly 4,000 members to small pox (Morse 1822:256-260). Meanwhile, along the western and southwestern peripheries of these Comanches lands, or Comanchería, were Lipan, Mescalero, Jicarilla, and Faraon Apaches with whom the Comanches were generally at war (Richardson 1996:20).

"In addition to being angered by Spanish intrusion, the Comanches and their allies detested the Apache. This animosity was the result of earlier competition for land and resources, at which the aggressive Apache had been very successful. As the Comanche swept into Texas from the northwest, they found willing allies in the Wichita, Tonkawa, and other tribes who had been bullied by the Apache. When the Spaniards chose to establish a mission for the Apache at San Sabá, they automatically became the enemies of the Comanche and other "Norteño" groups who detested the Apache" (Hall 2014). 
The Norteños attacked the San Sabá Mission equipped with firearms, swords, armor and other European weapons, killed nearly all of the inhabitants, and burned the mission (Weddle 1964; Hindes et al. 1995). Albeit months later, in retaliation, Colonel Diego Ortiz Parilla, Commander of the nearby Presidio de San Luis de las Amarillas led an "army" northward to wreak vengeance upon the Norteños. In addition to 360 presidial soldiers and civilian volunteers, Parilla's "army" consisted of 176 Indians recruited from the Spanish missions in northern Mexico and San Antonio. Of the Indians, 134 were Apache scouts and guides. He also brought with him approximately 1,500 horses and several hundred mules. Unfortunately for the Spaniards, the abundant supply of horses and mules would ultimately end up in the hands of the Norteños, who by this time had retreated and learned of the expedition, and were well fortified on the Red River (Weddle 1964:118).

On October 2, 1759, Colonel Parilla and his untrained army encountered a Tonkawa-Yojuane encampment (ranchería) near present-day Fort Griffin and the Clear Fork of the Brazos River, in modern-day Shackleford County. Parilla's army soundly defeated the Yojuane, and articles, horses, and mules found after the battle provided clear evidence that the Yojuane had participated in the massacre at Mission San Sabá. Forty-five (or fifty-five) Tonkawa-Yojuane were reportedly killed and 149 were taken captive. Others fled to join the main Tonkawa tribe (John 1975:350; Weddle 1964, 1968).

Colonel Parilla then proceeded north guided by Tonkawa-Yojuane prisoners toward the Wichita-Taovayas' stronghold on the Red River, otherwise known as "Spanish Fort," some 17 miles north of modern-day Nocona, and roughly 135 miles north-northwest of the Fish Creek Slough site (41DL436). Morrell (1996) posits that Spanish Fort was located in modern-day Montague County one mile south of the Red River and states "The Taovayan village known as Spanish Fort was fortified with entrenchments, wooden stockades, and a moat and protected by some 6,000 Indians flying the French flag. After a four-hour battle the Spanish retreated. They even left their baggage train and two cannon." However, Ed Jelks (1996b) has argued that the Spanish Fort Sites were a series of fortified villages stretching for several miles along the Red River, and Lathel Duffield (1965) discusses the archaeological results and problems associated with discovering the true location of Spanish Fort. In any case, in late 1759, Parilla's army was soundly defeated by the Wichita-Taovayas and their allies, forcing his retreat back to San Antonio, and leaving behind two cannons which the Taovaya secured (Weddle 1964:118-143).

\section{0-1800}

By the 1770s, marauding hostile Indian tribes and bands in the 41DL436 region, along the Trinity River included the Ietan Comanches, Tapcayas, Tawakonis, Iscanis, Kichais, and Tonkawas. However, even these groups were forced to abandon their hunting grounds for a period of time in the early 1770s, caused by an onslaught of the dreaded Osage from the north (Ewers 1969; John 1975:385-388). When the Spanish attempted peaceful negotiations with the Norteños in 1772, the Kichais numbered only thirty households, with a total of 80 men. They were industrious farmers, gatherers of wild fruits and nuts, and left their village in the winters to hunt buffalo. In return for buffalo hides, they traded for firearms (John 1975:409). 
The Iscanis dwelt 20 miles west of the Kichais on scattered farms. In 1772, the Iscani warriors wre only 60 in number. The Tawakonis lived in two villages, one of which was located roughly 18 miles west of the Iscanis, on the opposite side of the Trinity River. This village numbered 36 houses and 120 warriors. During the same time frame, approximately 150 Tonkawa warriors and their families ranged between the Trinity and the Brazos, having absorbed their kindred Yojuanes and Mayeyes bands. The Tonkawas were scorned by other Norteño groups who by this time had generally settled into farming villages, with annual hunting parties to hold them through the winters. The Tonkawas were still looked upon as thieves and vagabonds, living solely from hunting, and trading buffalo and deer hides to the Tawakonis (John 1975:409-410).

By 1772, the Osages had invaded from the north, forcing the western-most Taovayans with roughly 600 warriors, and their occasional allies the Comanches, to flee from the western edge of the Cross Timbers region along the Red River westward further upstream near the headwaters of the Red River. At the same time, the Wichitas retreated to the Brazos River, some 150 miles southwest of the Taovayas, and roughly 275 miles upstream from the Tawakonis (John 1975:411).

Elizabeth John (1975:490-491) illustrates the presence of two Taovayas-Wichita settlements just south of the Red River, and roughly 160 miles northwest of the Fish Creek Slough site (41DL436) in 1776, indicating that the Taovayas had by that time returned to their homeland following the Osage invasion. Recording in his journal an expedition from Santa Fe to the Taovaya Villages in 1787, José Mares described three villages. The first contained 23 lodges, the second 40, and the third, which was on the opposite side of the Red River, contained 27. A few leagues to the south, he came upon a village of Comanches trading with the French, and noted that the Comanches had also been at one of the Taovaya villages (Loomis and Nasatir 1967:296-297). When explorer Pedro Vial arrived at the Taovaya's Spanish Fort in 1788, he observed two villages within a half league of each other, and both consisting of about 17 huts made of straw. Villagers at both places were raising maize, kidney-beans, watermelons, and pumpkins (Loomis and Nasatir 1967:322). In Pedro Vial's 1789 report of his expeditions, he noted that Englishmen in Arkansas were trading rifles, powder, musket balls, and other arms to the Indians, and he recommended that a military post be established in the area of the Taovayas in order to protect travelers and shipments between Santa Fe and Natchitoches, Louisiana from the 'savage nations'. He further noted that the Taovaya were raising corn, beans, squashes, and melons, while hunting buffalo, deer, bears, and wild boars, and the rivers were full of fish, beavers, and nutrias (Loomis and Nasatir 1967:350).

\section{Historic}

The historic period begins with more formal European-American settlement of the continent. In response to the continuous threat of Apache and Comanche raiders, as well as the French incursion into East Texas, a series of Spanish missions and presidios were erected in Texas during the eighteenth century. Eventually, the newly independent Mexican government began granting empresario contracts to allow more prominent Anglo settlement to facilitate development throughout the territory. The Republic of Texas (1836-1845) later encouraged development, also offering land grants and at least some protection by Texas Rangers from 
marauding Indians. Prior to the early 1840s, the area that we know today as Dallas, Fort Worth, and Grand Prairie was an Indian vestige rarely visited by whites.

\section{0-1900s}

The newly formed Texas Republic in 1836 did not know how to effectively deal with the Indian attacks on white settlements, yet the Wichitas were suffering severe losses at the hands of the Texans. The Wichita tribes were forced to re-locate their villages in the mid-1830s. One group of both Tawakanis and Wacos settled near the mouth of the Wichita on the Red River, in present-day Clay County, Texas. A second group of both Tawakanis and Wacos settled north of the Red River in Oklahoma. In May 1835, the Kaichi village on the lower Trinity River was burned by Americans, forcing the Kichais to move upstream to the West Fork of the Trinity (modern-day Wise County) near the Western Cross Timbers area. Their occupation lasted about three years at that location, when in 1838 they were once again forced to re-locate southwestward to the Brazos River. Upon abandonment of the site on the West fork of the Trinity by the Kichais, the immediate was taken over by two Tawakoni groups who constructed a village. Three years later, in the Summer of 1841, Texas Rangers destroyed a small village that had been constructed by Wacos on Village Creek (modern-day Tarrant County) forcing the Wacos to re-locate to also re-locate to the West fork of the Trinity, some $6 \mathrm{~km}$ from the Tawakonis. Their occupations of those sites were once again, relatively short-lived. Both the Tawakonis and Wacos were forced to abandon the West Fork of the Trinity in 1844, and joined the Kichais on the Brazos. The Tawakonis and Taovayas later moved to Oklahoma and settled on Cache Creek, a tributary of the Wichita River (Smith, F. T. 2008). Notably, when Lieutenant Randolph Marcy observed their village in 1852, he reported that despite a lack of metal tools, the Taovayas were raising corn, pumpkins, beans, and melons (Marcy 1852). The Taovayas settled on the eastern edge of the Wichita Mountains in Oklahoma (Smith, F. T. 2000:135-136).

Although the the Taovayas and related Wichita Indians were officially re-located to Oklahoma as a result of a treaty with the United States in 1835 (Jelks 1996a), other Indian bands remained in the upper Trinity River region, and depredations continued. For example, in 1835, A band of Kichai Indians were known to be raiding white settlements on the Navasota River in east Texas. Following a heated battle, they were pursued all the way to their new encampment near the headwaters and forks of the Trinity River (Cox 2008:44-45; Wilbarger 1889:218-219).

J. W. Wilbarger (1889:195) reports that in 1837, a party of eight Texans who had survived Indian attacks; lost their horses, foodstuffs, blankets, and horses; and greased their wounds with buffalo grease approached the area that is now modern-day Dallas and encountered a Kickapoo Indian encampment there.

In 1838, three horses were stolen by an Indian raiding party in present-day Fannin County in northeast Texas. A volunteer company of whites mounted an expedition and after marching for three days, encountered the thieves and their Indian village on the West Fork of the Trinity. All but one of the horses were recovered, and several Indian scalps were taken by one of the white men. This battle took place at the location of what would later be called Bird's Fort, near present-day Fort Worth (Wilbarger 1889:426-429). 
The area around 41DL436 was included in The Peters Colony, one of the largest land grants in Texas history. In 1841, eleven Englishman and nine Americans petitioned the government of Texas to act as empresarios to settle families in Texas; among them were four with the surname of Peters, and one a son-in-law of the Peters. Under an initial contract, the first 600 families were to settle in portions of what is today Cooke, Denton, Grayson, and Collin counties. Each family was to receive 640 acres, and 320 acres to each single man over the age of seventeen, provided they built a good cabin and cultivated at least 15 acres (Connor 1959).

In November 1841, the area was to be settled under the terms of a second contract allowing for settlement of another 200 families. This included the multiple forks of the Trinity River, and thus before there was a Dallas, that area was known as the "Forks of the Trinity." In 1848, Dr. Ferdinand Roemer (1935) described the area as gently undulating prairies with thick and tall carpet grasses and wildflowers broken occasionally by mesquite and live oak mottes, and was occasionally referred to as the "Eldarado, the Three Forks of the Trinity". At that time, in order to oversee the venture, the empresarios organized the troubled, short-lived, and subsequently reorganized Texas Agricultural, Commercial and Manufacturing Company in Louisville, Kentucky (Connor 1959).

In the 1840s, the Waco on Village Creek Indian tribe occupied much of present-day Tarrant County, and the Shawnee occupied the Grayson and Cook County region. In addition, scattered bands roamed the upper tributaries of the Trinity. The Waco on Village Creek tribe caused the most problems for attempted early white settlement. Following a failed attempt by Major Jonathan Bird to rout the tribe from Waco Village in 1840, in 1841, General Edward Tarrant raided the village, destroyed their crops, and effectively broke up the village. A feeble attempt to establish a military outpost and civil settlement on the site, known as "Bird's Fort" failed in part due to continued Indian depredations, and the site was abandoned in 1842 (Connor 1959).

In 1842, 12 families that settled in the "Cross Timbers Settlement" in Fannin County were displaced and their crops and cattle abandoned due to Indian raids. Although, later that year 40 more families moved into the area and reported that they and their possessions were being left undisturbed by the Delaware Indians hunting around them. Although the Trinity River was touted as a means to reach the area, navigation by flat-bottomed steamers was impossible, and few immigrants came up the Trinity River. The contracts to settle new families under the nowdefunct and generally inept Texas Agricultural, Commercial and Manufacturing Company were assumed by the organization of the Texas Emigration and Land Company. By 1844, the Peters Colony boasted 381 colonists, 197 heads of families, and 184 single men (Connor 1959).

Indian atrocities in the 1840s required the use of militia forces, and the Texas Rangers served as a protective unit in the 1840 s. To wit, Captain James Bourland commanded a company of Texas Rangers on the headwaters of the Trinity River for about six months in 1841, followed by Captain Alexander Webb who commanded Bird's Fort from September 1841-March 1842 (Stopka and Black 2014). The Rangers' continued service in the vicinity of the headwaters through 1849 was supported by a petition from settlers in the area to the Lt. Governor at the time (Cox 2008:125-126). 
By the latter part of the nineteenth century most of the remaining Caddoes had settled in Louisiana near present-day Shreveport. However, with the sale of Louisiana Territory under the Louisiana Purchase in 1804, the Caddoes were now lawfully under the jurisdiction of the United States. Under an 1835 treaty, the Caddoes agreed to sell their lands to the U.S. and then moved westward into Spanish held northeast Texas. Unfortunately for them, at this inopportune time Texas won her independence from Spain, and the Caddoes found themslves once again unwanted in their new homelands. The Mexican government then saw an advantage to courting the Caddoes in an effort to overthrow the Texas government. In response, the U.S. government plied the Caddoes with arms and ammunition. This scheme however backfired, and the Caddoes used the arms and ammunition to raid and pillage villages and white settlers in Texas. In compromise, "In September, 1843, at Bird's Fort on the Trinity river, a treaty was concluded between the Republic of Texas and a number of Indian tribes - Caddoes, Delawares, Shawnees, and the Wichita subtribes - by which it was agreed that the Indians and Texas would thereafter live in friendship" (Newcomb 1993:348).

In 1844, Charles Elliot traveled overland from Fort Houston in modern-day Anderson County, northwest to the modern-day Dallas area, in Dallas County. In the area of 41DL436, he described the prairies as abundant in wild grasses, as well as wheat, rye, oats, red clover, cayenne pepper, flax, and indigo. An abundance of buffalo and wild horses was also observed, along with native trees such as plum, mesquite, pecan, cedar, bois d'arc, hackberry, elm, black walnut, persimmon, a wide variety of oaks, cottonwood, sycamore, willow, and locust. In addition, he noted a variety of wild grape and other vines, but perhaps most notably, he states that "In the vicinity of Dallas we found some cornfields in a very flourishing condition, prospects of good crops flattering" (Hollen 1956:320-322). Possibly appropos to the many burned areas discovered at the Fish Creek Slough site (41DL436; see Chapter 16), in Caddoan agricultural practices "Fire was at least occasionally employed to burn over old fields and perhaps to assist in clearing new ones" (Newcomb 1993:293).

Sporadic gains by whites in settling the area were not infrequently stymied by Indian depredations, increasing significantly in the spring of 1845. For example, roughly 25 Indians that were likely either Creeks or Cherokees crossed the Red River and near a settlement on the east fork of the Trinity, scalped a young boy on Rowlett Creek, and killed and scalped a man and his son on Little Mineral Creek in modern-day Grayson County. On Wilson Creek in present-day Collin County, a band of Caddoes supposedly stole a horse, but when caught, blamed it on the Wichitas. Although reports of thievery of cattle and horses by local Indian bands and tribes were common in 1845, settlers continued to farm, with corn being the major crop (Connor 1959).

The Comanche peoples for the most part loved peace, and were generally allied with the bands and tribes such as the Wichitas, Wacos, Tawakanis, Tonkawas, and Lipan Apaches in the north Texas area around 41DL436 and the South Texas Plains. "As the white men pressed against them and white men surveyed their villages and hunting grounds, there was nothing for them to do but withdraw and seek new homes in the Comanche range to the west of them" (Richardson 1996:83). 
The Comanches may have loved peace, but they loved their hunting lands more, so that by the 1850s when encroaching white settlers from the east began settling the region and increasingly pushed other Indian bands into their area, the Comanches were more than ready to push back. An additional problem faced by the Comanches at the same time was the thievery by Indians other than Comanches, but invariably blamed on the Comanches. To wit, "The Wichitas were the most arrant horse thieves on all the border (between Oklahoma and Texas). Unscrupulous white traders offered a ready market for such horses as they cared to sell; and the Texas supply never failed them. It seems the Wacos and Tawakonis were nearly as bad as the Wichitas. The merciless pressure from white settlers finally forced these last two bands to seek a home with their Wichita kinsmen north of the Red River, from which point they continued to raid the Texas border" (Richardson 1996:83). Pressures from encroaching whites and potentially Indian adversaries only sufficed to lessen the amount of bison in the area between 1830-1860, traditionally a staple of sustenance for the Comanches' existence. In 1846 alone, approximately 100,000 buffalo and cow hides were shipped from the Southern Plains to markets in Canada and the eastern U.S. (Richardson 1996:86).

Despite the raiding and pillaging that had occurred in Texas by many Indian tribes and bands, by 1850 , the misery and poverty of Indians in Texas had reached crisis proportions. The Texas government had to face facts; either the government provide for the starving Indians, or continue to be at constant war with them. As for the Comanches, they had had enough, with more than one chief pleading for a permanent place in Texas where they could settle and maybe even begin an agricultural way of life (Richardson 1996:107). Their requests were granted; one reservation consisting of eight leagues was laid out on the Brazos River near the mouth of the Clear Fork for the various smaller tribes, and a second reservation of four leagues on the Clear Fork was designated for occupation only by the Comanches (Richardson 1996:108; see also, Smith, F. T. 1996).

However, the Comanches and other Indians soon found that reservation life was not what they expected, and even their reservation was being overrun with white settlers and intrusive Indian groups. Although a series of treaties had been signed in the 1850 s and 1860 s between the Comanches and the United States government, in the eyes of the Comanches all the treaties had been broken. As such, the Comanches thought it only justified that they renewed, and continued war with the whites. Not yielding to the continuous onslaught of white settlers and the resultant forced intrusion of their claimed lands by other Indians, the Comanches retaliated in the way they only knew best from centuries of survival; they fought back, raiding, stealing, pillaging, and killing or capturing white settlers and intrusive Indians. For example, a young white boy, Clinton Smith, was captured by the Comanches near San Antonio in 1869. His narrative recounts that in the 1870s the Comanche band of roughly 200 that he was with encountered thousands of Apaches, Cheyennes, Kiowas, Lipans, Kickapoos, and others in the area south of Fort Sill, Oklahoma on their way to obtain supplies from the government. Captive Smith and the Comanches camped about 50 miles south of Fort Sill while some of them went to the fort. After receiving their ration of hardtack, sugar, coffee, guns, and ammunition, the Comanches then "... went back to our old haunts" of stealing horses and cattle. Heading south, Smith clearly remembers crossing "... the two Trinity rivers" and heading for the settlements (Smith C. L. 1995:120-124). It was not until 1874 that the backs of the renegade Comanches, Apaches, 
and Kiowas were broken in pitched battles with the U.S. army under command of Lieutenant Colonel Ranald Mackenzie that culminated in the Red River War. Even following the defeat and subsequent movement of the majority of the renegades to the Fort Sill reservation, several bands continued to move throughout northern Texas. However, within a few years' time all but a few had surrendered and straggled into the reservation (Wallace 1993).

As for the Wichitas' five main groups (Kichais, Tawakonis, Iscanis, Guichitas, Taovayas), when they first encountered Frenchmen in 1719, their tribe numbers were estimated at 20,000. From that time forward, their numbers were decimated by a combination of disease, and seemingly constant warfare. Being pushed from all sides during this period by warring Indian bands and tribes, the French and Spanish, and Anglo-Americans, the remaining few Wichita bands were forced to move from northern Oklahoma and southern Kansas, to central Texas, and finally southwestern Oklahoma. By 1901, the tribe numbered only about 350 (Smith, F. T. 2008:413-414).

The area around present-day Dallas was attractive to many of these settlers because of a natural ford on the Trinity River and populations in this locale soon grew. After becoming the Republic of Texas in 1836 following the decisive Battle at San Jacinto, the territory later joined the United States in 1845. Shortly after the onset of the Civil War, Grand Prairie was initially established as "Dechman" by settler Alexander McRae Dechman in 1863. Despite the large numbers of troops that Texas committed to the American Civil War, the Confederate State of Texas was only involved in five engagements with the Union army. In 1876, Dechman traded half his of his vast property to T\&P Railroad to ensure the railroad entered the area. The railroad named the depot "Dechman." The first church in the area was the Good Hope Cumberland Sabbath School established in 1870 by Rev. Andrew Hayter. The church was later named the West Fork United Presbyterian Church which is still active. The first U.S. Post Office in this area opened in 1877 under the name "Deckman" rather than "Dechman" due to a handwriting legibility issue. After the Postal Service had adopted the "Deckman" name, confusion ensued from the T\&P Railroad designation of Grand Prairie which was based on maps drawn in the 1850 s that described the area as "the grand prairie of Texas". In response to this confusion, the Postal Service named the post office Grand Prairie. Following Reconstruction, the Texas and Pacific Railway from Sherman to Fort Worth and the Missouri, Kansas and Texas to Dallas, were completed in 1881, providing this region with steady railway access. The town of Grand Prairie eventually grew to a city by 1909. During World War II, Grand Prairie forged a long history with the military and aviation industry which contributed greatly to its development (Maxwell 1996). 


\title{
Chapter 3
}

\section{Research Design}

\author{
David L. Nickels, James T. Abbott, Jodi A. \\ Jacobson, and W. Nicholas Trierweiler
}

The research design for data recovery at 41DL436 was developed in three stages. An original (September 2010) research design was developed in a preliminary stage to guide the field work and initial analyses (Trierweiler and Nickels 2010). Following that, additional research questions were developed that would lead to a pilot study whereby selected samples were sent to various specialists. Based upon the results of the pilot study, additional research questions were developed. These stages of development and a total of 15 primary research questions are expanded upon below.

\section{Preliminary Research Design}

The preliminary research design presented five research questions. These were as follows.

1. What is the depositional history at 41DL436?

a. What energy conditions are represented by the deposits?

b. What is the potential for site preservation?

2. Are archaeological deposits representing occupational debris preserved?

a. Are the deposits primary or secondary?

b. What activities are represented?

c. Is spatial patterning representing the distribution of activity loci preserved?

d. What is the relationship between occupational intensity, group size, and archaeological signature?

3. Does the sequence of burned surfaces represent agricultural/horticultural use of the site?

4. What information can be obtained regarding subsistence?

5. What is the potential for retrieving paleo-environmental information?

Each of these research questions was accompanied by discussion, data requirements, and expectations. The original research design also included a plan for field work, a burial treatment plan, and an outline of public outreach elements. The field work plan was implemented from October 5 through 29, 2010. Upon completion of the field work phase, AmaTerra conducted preliminary laboratory processing of the collected artifacts and samples, and identified a limited number of samples for initial assays as pilot studies to guide the development of this amended research design. 
Fieldwork and pilot studies analyses successfully addressed each of the original five questions. However, based upon the results of the pilot studies, the research design was then significantly amended to focus on eight main research domains. These include 15 primary research questions and approximately 60 subsidiary questions. The eight research domains are as follows.

1) Dating

2) Geoarchaeology

3) Faunal Analysis

4) Burning Replication

5) Human Activity

6) Subsistence and Mobility

7) Lithic Technology

8) Paleoenvironment

\section{$\underline{\text { DATING }}$}

Following the fieldwork and an initial round of radiocarbon dating, it was apparent the stratigraphy within the 41DL436 excavation block was very distinct and well-defined. Accordingly, 19 of the 22 radiocarbon dates were chronologically ordered as expected within layered strata. Potentially however, two of those three did not fit in vertical chronological order within relatively layered strata. The first is associated with Feature 1, a burned area on the slope of the paleochannel. Although it appears to lie within Unit 2, a radiocarbon date of 890 BP suggests it is of Unit 1 age. The second is associated with Feature 41, a fire-cracked rock feature that is obviously based in older, Unit 1 sediments, but the radiocarbon assay results of 360 BP suggests it is of Unit 2 age.

Twenty of the 22 radiocarbon dates during the first round of dating were in association with features. While the dating of features is important from an archaeological standpoint, sequential dating of a continuous vertical column from which soil samples and subsamples were analyzed for malacology, pollen, phytoliths, diatoms, and ostracods would allow for: (1) a refined continuum of sequential dates, (2) a finite interpretation of the paleoenvironment and sediment aggregation through time, (3) if the results do not provide a stacked, sequential chronological order, they even so may aid in interpreting other questions that may arise regarding soil depositional events and sequences at the site, as well as cultural material analytical units. It is noted that microcharcoal was present in all 10 of the samples analyzed from Control Unit 49 during the pilot study.

Question 1: Cultural and Geoarchaeological Chronologies, and Site Integrity. Can the site be more confidently dated both archaeologically and geologically? 


\section{Subsidiary Questions}

1.1 Are two radiocarbon dates received thus far out of sequence as they appear relative to soil strata?

1.2 What are the implications for fine-grained microcharcoal dates in a sequential, vertical column in correlation with subsamples that can provide significant paleoenvironmental information?

1.3 Can fine-grained dating be used to correlate environmental changes and soil deposition rates with possible cultural changes through time?

1.4 Can fine-grained dating be used to correlate environmental changes and soil deposition to the availability of raw material through time?

1.5 Can fine-grained dating be used to correlate environmental changes with subsistence practices through time?

\section{Data to be Evaluated}

- Microcharcoal dating of sediment samples from Unit 49, Levels 1-20.

- Additional macrocharcoal dates from Unit 49 as available.

- Additional charcoal dates from contexts in association with Features 1 and 41.

\section{Geoarchaeology}

Site 41DL436 is stratified in a terrace of Fish Creek, a tributary of Mountain Creek and, ultimately, the Trinity River. As a result of previous work, the degree of preservation of sedimentary structures and bone at 41DL436 was recognized to be remarkable. Geoarchaeological work conducted during the data recovery phase was designed to characterize these deposits to understand their structure and geometry, origin, age, and post-depositional modification.

At this point, the basic stratigraphy of site 41DL436 is well understood. There are three principal depositional units exposed in the excavation block. The oldest of these (Unit 1) is a relatively homogeneous silty deposit with a thick organic soil (PS2) that is tentatively correlated with Ferring's West Fork paleosol, although it appears to be on the extreme young age of this common stratigraphic marker. It is associated with a distinct paleochannel that is believed to represent the primary channel of Fish Creek at the time. This unit is succeeded by a very different deposit termed Unit 2 . Unit 2 consists of distinctly stratified silts, clay loams, and thin sands that aggraded under a distinctly altered depositional regime. These deposits fill the paleochannel and drape the adjacent floodplain, and therefore document the early stages of sedimentation during and after the avulsion of the channel. This unit terminates with the onset of a depositional hiatus that allowed a weak paleosol (PS1) to form across the terrace and in the shallow depression marking the paleochannel. Unit 3 aggraded on top of this paleosol. Like Unit 2, it is characterized by thin-bedded silts, clay loams, and fine sands. It fills the paleochannel depression completely, and is capped with a moderately developed surface soil. 
Analysis has focused on refining the stratigraphy, and identifying the stratigraphic unit associated with each unit/level, to assist with the identification of analytical units. The following geoarchaeological topics will be addressed during analysis of 41DL436:

Question 2: Depositional Context and Chronostratigraphy. What is the depositional context of the site matrix at 41DL436? What is the timing of these depositional events?

\section{Subsidiary Questions}

2.1 What is the sequence of depositional and erosional events and periods of stability that are represented by the deposits? How can these events be characterized?

2.2 How consistent is the corpus of chronometric data? What processes or other explanations are possible to explain apparent discrepancies in the sequence of ages?

2.3 What is the scale of the avulsion event represented in the site sediments?

2.4 How does this sequence compare with other sites of similar age that have been investigated in the region?

2.5 How does it compare with the regional model proposed by Ferring (1994)?

\section{Data to be Evaluated}

- Field information, including photographs, sketches, and notes.

- Chronometric dates from site strata.

- Textural, chemical, and magnetic susceptibility analysis of the sedimentary sequence.

- Micromorphological characterization of site sediments.

- Relevant published information on other sequences in the area.

\section{Discussion}

As stated above, the basic outline of this information is relatively well understood. Reporting will consist of explicating and documenting the macrostratigraphy in terms of its age and depositional character, and augmenting the discussion with the results of the micromorphology study.

Question 3: Soil Development. What is the character of soil development at Site 41DL436?

\section{Subsidiary Questions}

3.1 How does soil development differ between the two paleosols? What are the implications for the manner of their formation? What are the implications for the local climate and environments?

3.2 What was the character of drainage during each period of pedogenesis? What are the implications of pedogenic iron compounds and carbonates? 


\section{Data to be Evaluated}

- Field information, including photographs, sketches, and notes.

- Textural, chemical, magnetic susceptibility analysis and micromorphological characterization of soils.

\section{Discussion}

The focus of this topic will be on the character of the two paleosols and what they imply for the soil-forming environment during these two closely-spaced intervals of soil formation. The lower soil is relatively homogeneous except at its upper boundary, where initial indications of a changing depositional regime are manifest as lighter colored sandy and silty laminae interstratified in the dark matrix. The upper soil, in contrast, is distinctly laminated throughout. The investigation will draw on macroscopic and microscopic data to compare and contrast these two pedological environments.

Question 4: Site Integrity. What implications does the depositional sequence have for the integrity of archaeological and paleoecological data recovered from 41DL436?

\section{Subsidiary Questions}

4.1 What are the expectations for vertical integrity and mixing?

4.2 What are the implications for horizontal integrity?

4.3 What is the implication of the physical and chemical environment for the compositional integrity of the assemblage?

\section{Data to be Evaluated:}

- Field information, including photographs, sketches, and notes.

- Textural and micromorphological data.

- Artifact distribution and weight data.

\section{Discussion}

This topic will draw on data generated above to discuss the degree to which the recovered assemblages are trustworthy in terms of mixing (vertical integrity), representative of cultural patterning (horizontal integrity), and preservation of different artifact classes (termed compositional integrity here). The latter question includes such topics as artifact winnowing, chemical decomposition, and physical sorting, and the degree that they could have contributed to the character of the assemblage. These latter topics are relevant because of the unusual character of the recovered assemblage, particularly the paucity of recovered stone tools and debitage related to stone tool manufacture.

Question 5: Burn Zones. What can be deduced about the numerous zones of burned and reddened sediment observed during testing and data recovery? 


\section{Subsidiary Questions:}

5.1 What is the distribution of these burns?

5.2 What is their morphology? How big are they?

5.3 Are they cultural features (hearths)?

5.4 Are they features resulting from regional burns?

5.5 What is the potential that they represent intentionally-set fires?

5.6 What types of temperatures and durations are necessary to form such features?

\section{Data to be Evaluated}

- Field information, including photographs, sketches, and notes. Micromorphological characterization of burns.

- Possible replicative experiments to determine the temperature and duration of burning necessary to replicate the burns.

\section{Discussion}

One of the aspects of the site that was used to justify data recovery was the presence of multiple large burned zones. One of the working hypotheses going into testing was that these burns were the consequence of intentional burns, perhaps for agricultural clearing. As the data recovery cleared larger areas, it became clear that most of the burned zones were relatively restricted in size, and that other activities were clearly being conducted at the site. Nevertheless, the possibility remains that many of these burns represent "hot spots" where a higher than average amount of fuel (for example, a shrub) resulted in more intense burning. Another possibility is that some of the burns represent unprepared hearths (i.e., fires built on an open surface); however, several of the features were discovered mantling sloping paleosurfaces, making such a use unlikely in these cases. A final possibility is that some of the burns, at least, represent natural (or unintentional) wildfires. The purpose of this research topic is to explore the data potential of these features and their relationship to other aspects of the site. Although it is unlikely that we will resolve the origin of any of the features conclusively, the exercise is warranted because these burns are an important aspect of the site, and the potential to develop testable hypotheses and expectations is relatively good.

\section{Faunal Analysis}

Site 41DL436 is a well-stratified site with known contexts dating from the modern/historic period to approximately 700 years ago. Previous investigations at the site revealed excellent preservation of organic remains and evidence of butchery. Lithic artifact presence during earlier investigations was negligible, and even data recovery resulted in a paucity of nonorganic artifacts. Bone, shell, and botanical material, however, were numerous and remarkably preserved. Zooarchaeological studies conducted during the data recovery phase were designed to determine species variability, human subsistence strategies, taphonomic processes, and cultural use of bone. 
Due to the well-dated stratified nature of the site, there is the potential to analyze faunal material from multiple components allowing for intra-site comparison within a temporal framework. The majority of archaeological sites within Texas either have poor bone content due to extensive breakage for marrow and bone grease extraction, highly acidic soils, or other cultural and/or taphonomic factors. The rare exception for preservation at 41DL436 could provide useful data to answer not only relevant site specific questions, but which could also be extrapolated to inform regional questions concerning mobility, subsistence strategies, environmental change, division of labor, and non-subsistence use of bone.

Question 6: Species Presence. What do the species present at the site relay about the availability of resources within the area of 41DL436?

\section{Subsidiary Questions}

6.1 Does the presence or absence of certain species at the site, notably bison, indicate shifts in environmental conditions affecting the availability of certain prey?

6.2 Does the availability of certain prey species change over time?

6.3 Are there indicators for seasonal variability of resources at the site? Or do the species present indicate that the site was utilized only at certain times of the year while exploiting particular resources?

6.4 Is there enough variability in species present to indicate possible divisions of labor whereby larger animals (bison, deer) were "hunted" by able-bodied members of a group and smaller or slower prey species (turtle, fish) were "gathered?"

6.5 How do the presence of certain species, specifically bison, fit in with regional models (Creel 1990, 1991; Lynott 1979)

\section{Data to be Evaluated}

- Field information, including horizontal and vertical associations.

- Chronometric dates from associated strata.

- Identifications and analysis of bones recovered from the sites including indicators of age at death.

- Relevant published information on other temporally similar sites with adequate faunal analysis in the area.

\section{Discussion}

One of the aspects of the site used to justify data recovery was identification of bison at the site. Bison presence and use in north-central Texas is still only minimally understood. A relatively diverse sample of other species (white-tailed deer, Odocoileus sp., jackrabbit, Ornate box turtle, red-eared slider, bird, and osteichtheyes so far) have been identified from the site already. Microfauna from the site was recovered during flotation but had not yet been identified. 
Presence of bison, along with other species, suggests the site could provide information on environmental conditions in Dallas County during the past 700 years and aid in understanding how shifts in the availability of resources may have affected human prey choices and subsistence strategies. The stratification and numerous dates throughout the stratigraphic associations can be used to detail whether there were any changes in prey availability over time.

Question 7: Subsistence Strategies. What are the implications for prey choice versus prey availability at 41DL436? What degree of bone present is due to natural versus cultural circumstances?

\section{Subsidiary Questions}

7.1 As the location of the site is along a creek, what degree of fauna present indicates aquatic versus terrestrial resource procurement?

7.2 Are there indicators for cultural breakage or butchering on the bone?

7.3 Do skeletal part frequencies indicate on-site killing and butchering of species, transport of higher utility elements to the site from a separate kill location, or killing on-site with removal of higher utility body parts for consumption elsewhere?

7.4 Does the degree and type of bone fragmentation indicate processing of bone for marrow and/or grease?

7.5 In the levels where high biomass species are present, i.e. bison, are there indicators for low species diversity indicating a specialized hunting strategy?

\section{Data to be Evaluated}

- Field information, including horizontal and vertical associations.

- Identifications and analysis of bones recovered from the sites including bone breakage, butchery modification marks (cut, chop, impact, etc...), and skeletal part frequency data.

- Relevant published information on other temporally similar sites with adequate faunal analysis in the area or region.

\section{Discussion}

One of the aspects of the site used to justify data recovery was the presence of well-preserved faunal remains with indications of human butchering, notably cut marks for meat removal and percussion impacts with spiral fractures as evidence for marrow processing. Furthermore, in the absence of lithics or other artifacts, skeletal part frequencies can inform as to whether the site was indeed a task-oriented camp which was re-used or whether occupation had more depth. If utilized as a task-oriented camp, bone breakage can verify what portions of the animals were being utilized and inform as to what level of dietary stress occupants were under (e.g. taking the time to process not just meat but marrow yet not bone grease and whether marrow processing occurred for all bones, or just those with the greatest return). While some bone is clearly cultural in nature, field recovery indicated other bone scatters may have a non-cultural 
association. Processing on bones, fragmentation, and skeletal part frequencies can be used to differentiate what may have been consumed or utilized by people by what remains are noncultural. Cross-checking of data based on vertical and horizontal associations would aid in clarification.

Question 8: Taphonomy. Given the preservation at the site, what indications are there for pre and post depositional alteration to the bone? Is it possible to differentiate between cultural and natural associations of the bone?

\section{Subsidiary Questions}

8.1 As there are indications of burn zones at the site, does the burned bone recovered at the site inform as to whether the burns were associated with cultural events (prolonged exposure or evidence of high temperature) or with natural events (low temperature and fast burning fires associated with wildfires).

8.2 Does the degree of bone weathering indicate bones were exposed for some time prior to deposition by a natural flooding event, or is the degree of weathering consistent with quick burial potentially indicating more prolonged use of the site.

8.3 While well-preserved, bone at the site is broken. What is the degree of fresh versus dry breaks on the bone? Do the breaks represent a natural death and post-depositional breakage or are the breaks indications of marrow processing?

8.4 What degree of the bone has been scavenged by carnivores or rodents? Does rodent scavenging indicate use of the bone while still fresh (rat or mouse gnawing) or scavenging of the bone long after death after bone has dried out (squirrel gnawing).

\section{Data to be Evaluated}

- Field information, including horizontal and vertical associations.

- Identifications and analysis of bones recovered from the sites including bone breakage, weathering, degree of thermal alteration, and indications of animal scavenging data.

- Relevant published information on other temporally similar sites with adequate faunal analysis in the area or region.

\section{Discussion}

Given the riparian location and ephemeral nature of the occupations, it may be difficult to differentiate cultural and non-cultural bone presence. One of the unique elements of the site was a series of burn zones within the stratigraphy of the site. Whether the burn zones are associated with cultural features (hearths) or natural burns is unknown. The degree and association of thermally altered bone could inform as to whether it was associated with the burned zones and whether the bone was exposed to a fast burning low temperature fire (wildfire), prolonged exposure (greater than 25 minutes) to a low temperature fire (camp-fire) or to a high-temperature (greater than 450 degrees Celcius) fire (hearth). In addition, evidence of butchering marks on 
burned bone or presence of only typical "prey species" (versus commensal or pest species) with evidence of thermal alteration in association with burn zones could help clarify the interpretation. Weathering and animal modification of bone could provide information on preburial exposure time and inform to site use and function (kill-site, short-term camp, seasonal camp, etc...).

Question 9: Cultural Use of Bone. What implications are there for use of animal bone beyond a representation of subsistence and consumption of a food resource?

\section{Subsidiary Questions}

9.1 Given the paucity of lithic and other organic artifacts recovered from the site, are there indications for use of and/or on-site manufacturing of bone tools? What function did the bone tools serve and what percentage of the assemblage do they represent?

9.2 Were bones modified for use not just as tools but as decorative and/or ritualistic items (eg., bone beads, pendants, etc.)?

9.3 Are markings (eg., asphaltam, red staining) on bone from the site intentional decoration, functional (localized heating for breakage) or an incident of natural phenomena?

Data to be Evaluated

- Field information, including horizontal and vertical associations.

- Identifications and analysis of bones recovered from the sites including bone modification data.

- Relevant published information on other temporally similar sites with adequate faunal analysis in the area or region.

\section{Discussion}

Typically, the acidic conditions of soil, especially alluvial sediments, would limit the preservation of bone. Furthermore, the recurrent burial events by alluvial sediments has resulted in situ preservation of material usually encountered only in surficial disturbed contexts. Given the excellent preservation of organic material and the undisturbed context of the site, a more actualistic relationship between bone and lithic presence at short-term use campsites could be determined through the analysis of material recovered. The paucity of worked lithic artifacts indicates a probable highly curated tool model within a region with poor

lithic resource availability. Cultural reliance on bone artifacts could be better understood along with the supplemental role bone tool use and manufacture played in a lithic sparse framework. 


\section{Burning Replication}

Experiments conducted by Mauldin and Figueroa (2006) demonstrated that measuring magnetic susceptibility values of sediments may have the potential to identify cultural versus natural features. Theoretically, changes in mass-specific susceptibility values should be relative to heating temperatures of a given sample. Mauldin (1998:128-130) has demonstrated that post-firing temperatures in caliche hearths average between $300^{\circ} \mathrm{C}$ and $600^{\circ} \mathrm{C}$ for as much as six hours after firing. In addition, mineralogical changes that occur most commonly when sediments are heated between $300^{\circ} \mathrm{C}$ and $600^{\circ} \mathrm{C}$ may be reflected in magnetic susceptibility values when these same sediments are reheated (Crowther 2003; Dearing 1999).

Assuming subsistence cooking subsistence practices were consistent across 41DL436, and the site was repeatedly used as a short-term logistical activity site, then presumably hearth temperatures should have been relatively consistent. How these temperatures would compare to natural surface burns of downed vegetation is unclear, and a comparative study of temperature ranges in all of the burned clay patches could lend itself to distinguishing groupings.

Question 10: Magnetic Susceptibility Values as Indicators of Subsistence Practices. How do temperatures in cultural hearth features compare to natural surface burns of downed vegetation?

\section{Subsidiary Questions}

10.1 How do magnetic susceptibility values taken at 41DL436 compare to replicated, experimental surface burns and hearth features?

10.2 Can magnetic susceptibility values reliably be used to differentiate between cultural hearth features and natural burns that have occurred on previously exposed surfaces at 41DL436?

10.3 Can magnetic susceptibility values be reliably correlated with hearth stone and clay cooking temperatures, and thus infer subsistence items that were heated, cooked, boiled?

10.4 If magnetic susceptibility values correlate with temperatures in replicated, experimental, firings, do they provide the results that either corroborate, or conflict with the results of lipid and starches analyses?

\section{Data to be Evaluated}

- Field magnetic susceptibility data collected from in and around burned features.

- Clay hearth replication experimental studies.

- Tree burn replication studies.

- Range fire surface temperature data. 


\section{Human Activity}

Cultural remains at the site include features as well as faunal remains and chipped stone. However, lithic resources are scarce and may not be appropriate indicators of overall activity. An initial assessment indicates that cultural materials are horizontally and vertically discrete within well-stratified sediments and soils. Thus, the discrete depositional and cultural layers appear to represent gizements that can provide for ordered comparisons between repeated, both short term and long term occupations (Collins 1995). Depositional stratification at this site is fine-grained to the extent that individual occupation events can possibly be bracketed to isolate discrete behavioral episodes. Elsewhere, sharply defined stratification has enabled clear demarcation and tracing of individual occupation events (e.g., 41RN169 [Treece et al. 1993]). The burned zones and well-preserved bedding at 41DL436 provide a similar opportunity to define and trace prehistoric occupations.

Question 11: Occupation Periods and Activities. Can discrete occupations be teased out of the archaeological record? Can human activity within those discrete occupations be well defined?

\section{Subsidiary Questions}

11.1 Are occupation surfaces discrete and well-defined?

11.2 Are activities occurring at the site spatially isolated?

11.3 What do these activities imply in terms of subsistence and mobility through time?

\section{Data to be Evaluated}

- Attributes regarding feature type, size, and vertical and horizontal distribution at 41 DL436.

- Comparison of like features from other similar sites within the region.

- Study of spatial patterning of all cultural material relative to features at 41DL436 and similar sites.

\section{SubSistence AND Mobility}

\section{Theoretical Considerations}

Data obtained from the study of plant remains, starches, lipids, and faunal remains can be applied to optimal foraging theoretical models to infer both subsistence diet breadth and mobility patterns through time (e.g., Kelly 1983, 1988, 1995). Research into the relationships between hunters and gatherers and their environment is seeded in two paradigms; that of Cultural Ecology and Behavioral Ecology. Cultural ecology is based on the premise that cultural and social organizations will adapt to their environment. Steward $(1968,1969)$ believed that technological adaptation to the environment shaped social organizations, and that "The social environment, as contrasted with the natural environment, is also a factor in shaping the nature 
of any society but its role is minimal in most of these cases." (1969:188). Thus to Steward, subsistence technology was the core of culture (Kelly 1995:42).

Behavioral ecology is based on the premise that cultural and social organization will evolve through Darwinian natural selection. In essence, behavioral ecologists posit that specific activities or actions have developed through an unintentional evolutionary process whereby humans subconsciously evaluate their ability to survive in certain environments. Furthering their position, behavioral ecologists believe that hunter-gatherer behavior, and thus cultural change is dependent upon the food resources available in the environment (Kelly 1995:52-53). Behavioral ecologists agree that human behavior is based on rational choices, but go beyond and state that natural selection fixes, alters, or maintains the rational choices. Evolutionary theory argues that individuals will methodically forage to optimize their rate of return. Some evolutionists argue that hunter-gatherers will maximize their rate of foraging efficiency, or food intake when: (1) starving (2) specific nutrients are in short supply (3) time is limited (4) foraging is risky or dangerous (5) more food equals more production (Kelly 1995:39-64).

Optimal Foraging Theory is grounded in the behavioral ecology paradigm which assumes that individuals are responsible for their behavior, that through a natural selection process they subconsciously make decisions about the cost and benefits of their actions, and as a result they will always seek to optimize return benefits over the costs involved. Optimal foraging theory is based on the four basic concepts involved in foraging: goals, calories, constraints, and options. The goal of hunter-gatherers is to maximize foraging efficiency, considering the efforts involved in searching for, and handling (processing) resources; calories represent the energy that can be derived from the available resources; constraints represent the availability of resources, or the ability to digest them; and options represent the decisions on whether or not to take the resources that are encountered. In Optimal Foraging Theory the cost-versus-benefits applies particularly to foraging and collecting behavior. Optimal foraging models developed by behavioral ecologists rely on a material means with which to measure productivity; most frequently benefits are measured in terms of caloric return per hour of work (Kelly 1995:39-64). The stage is then set to discuss three models of optimal foraging theory: linear programming, diet-breadth, and patch-choice.

\section{Linear Programming}

Linear programming is more or less a forerunner of diet-breadth and patch-choice, and will not be dealt with in detail. Suffice it to say that the linear programming model was immediately popular because it allowed anthropologists to insert variables in the costs of pursuing and processing game to model hunter-gatherer subsistence. However, linear programming was considered inflexible in that it did not consider that hunter-gathers may choose alternate resources when moving from one patch to another, or that they may take other game when in pursuit of a specified one; also, the linear programming did not allow for separating search costs from processing (handling) costs. 


\section{Diet-Breadth}

The diet-breadth model (MacArthur and Pianka 1966) assumes that hunter-gathers will increase the breadth of their diet to meet caloric requirements. It assumes that they will maximize their efficiency by pursuing and taking the higher ranked resources first, then progressively lower ranked resources as needed. Ranking is based upon the number of kilocalories per hour produced relative to the mean dietary return rates, in return for the cost of obtaining them. The opposite is true also; when higher or equal ranked resources become available they will be taken and lower ranked resources will be dropped from the diet. Thus, the increase or decrease in the diet of the variety or breadth of plants and animals implies the name "diet-breadth model". This model assumes that the availability of resources is homogeneous, and that all resources will be encountered at random. The model is preferred over the linear programming model because it allows one to separate search from handling costs, and it allows for the ranking of resources.

\section{Patch-Choice}

The patch-choice model (Charnov 1976) assumes that patches of abundant resources are heterogeneously available across the landscape in patches, and that like the diet-breadth model, hunter-gatherers will encounter patches at random. This model suggests that patches of abundant resources will be exploited until they are either depleted or until they reach a point of diminishing return relative to moving to another patch. This model considers travel time between patches, but also assumes that caloric return rates are maximized as a benefit of mapping onto food patches.

\section{Lipid Study}

Although research of this nature in archaeological contexts has thus far been somewhat limited in Texas, the results of the pilot study indicate the potentially significant information that can be obtained with further study. Finding residues from either deer, bison, or javelina are not surprising, given the very large quantity of faunal remains excavated at this site. However, notably, evidence of plant residues were found in all three specimens analyzed. Phil Dering found no evidence of charred plant remains other than a grape seed and wood charcoal. Yet the discovery of plant residues in all three of the pilot study's three lipid samples complements Timothy Riley's discovery of starches in all of the six FCR specimens he analyzed during the pilot study. Thus, it appeared that more information on the ubiquity and intensity of plant processing in burned rock hearths could best be gained by the submission of additional FCR specimens for analysis.

\section{Starches Study}

Although research of this nature in archaeological contexts had thus far been extremely limited in North America, and had not been heretofore attempted at all in the Blackland Prairie region of northern Texas, the results of the pilot study indicated the potentially significant information that could be obtained with further study. In essence, the bulk of the resources are well known, 
but there is a lack of information on the microfossils, as well as the carbohydrate content (starch vs. fructan) from these resources.

Question 12: Subsistence Practices. What information can be obtained regarding subsistence?

\section{Subsidiary Questions}

12.1 What are the results of pilot studies on plant remains, faunal remains, lipid analysis, and starches analysis?

12.2 In order to provide an optimum return, what additional samples, and in what quantities should be submitted for more complete studies?

\section{Data to be Evaluated}

- The results of a complete study of the faunal remains.

- Lipid data from a study of additional fire-cracked rock samples from confidently dated hearth feature contexts.

- Starches data from additional fire-cracked rock samples from securely dated hearth feature contexts.

- Botanical fieldwork for the purpose of harvesting seasonal specimens, and then cooking them using traditional methods.

\section{LITHIC TEChNOLOGY}

Forty-three pieces of chipped stone were recovered during excavations at 41DL436. These are very sparse in numbers, and although theoretical models are apropos, in our opinion, the scant few lithics recovered at this stie do not lend themselves to theoretical interpretations.

\section{Subsistence}

The study of hunter-gatherer stone tool morphology characterizes the technology involved in making them, and how archaeologists interpret the variances in technology and assemblage formation suggest variances in subsistence and mobility patterns. Many researchers (e.g., Wilmsen 1968; Binford 1980, 1991; Weissner 1982a,b,c) have outlined the relationship of tool production to subsistence patterns and risks. The foremost hypotheses relating hunter-gatherer subsistence strategies to stone tool production are those of Binford $(1973,1979)$ and Bleed (1986). Bousman (1993) later synthesized their explanations and subsequent criticisms, and associated tool assemblages with the cost of production.

\section{Mobility}

The link between technology and mobility is difficult; different scales of mobility are affected by access to raw materials, costs of resource procurement, etc. The link between mobility and stone tool assemblages lies within a continuum of arguments, primarily those of Binford's 
(1980, 1983) forager versus collector subsistence models, relative to Bleed's (1986) and Bousman's (1993) arguments that increased bifacial technology is representative of increased mobility, and Schiffer's (1975) argument that a longer occupation span will result in an increase in the quantity and variety of stone tools used and discarded at the site (but see also, Hayden 1986). Essentially, foragers have high residential mobility compared to collectors, they tend to move to a known primary food source, and although their tools display great task flexibility, their tool assemblages are limited in variety. On the other hand, collectors move less frequently than foragers, they send out hunters to encounter a variety of prey, and return to the base camp. Thus, the collectors' variety in tool assemblages used to process a greater variety of prey is also greater.

\section{Lithic Raw Material}

Despite a relatively high level of effort in terms of hand-excavated sediments and soils, only a paucity of chipped stone was recovered, and all of those were small pieces. In addition, only small fire-cracked sandstone hearths were discovered, while some features documented may have been cultural hearths without the use of rocks as a heating element. Finally, only tiny naturally occurring gravels were observed within the excavation block, and none were observed in the modern-day cutbank of Fish Creek. All these factors suggest possibly: (1) raw material was perhaps not available during certain periods of occupation, (2) if raw material was immediately available, the inhabitants preferred not to use stone as a heating element, (3) tools were fashioned from other than stone, either by a scarcity of stone, or by preference.

Question 13: Lithic Analysis. What information can be obtained from a study of the lithic assemblage?

\section{Subsidiary Questions}

13.1 Can chipped stone assemblages be assigned to discrete occupations?

13.2 What types of stone tools are in the assemblage?

13.3 What types of lithic debitage are in the assemblage?

13.4 What types of lithic technological variability can be derived from the assemblage?

13.5 What types of stone tools does the debitage assemblage imply were being manufactured or re-sharpened at the site?

Data to be Evaluated

- Data from a detailed study of the lithics collected from the site. 
Question 14: Availability of Lithic Raw Material. Was stone not available during certain occupation periods?

\section{Subsidiary Questions}

14.1 Why were more pieces of chipped stone not recovered during the excavations?

14.2 What type of raw material was used to make stone tools?

14.3 What type of raw material was used in hearths as heating elements?

14.4 What geologic formations that could contribute as a raw material source are either in the immediate area of the site, or lie upstream?

14.5 How does the potential for raw material exposure compare to the paleoenvironment and the rates of aggradation at the site through time?

\section{Data to be Evaluated}

- A study of geologic atlas sheets, as well as lithic data from similar sites in the region.

- Geoarchaeological data obtained from 41DL436, to include sedimentation rates.

- Paleoenvironmental data from 41DL436 as well as from similar sites in the region.

- Data from the results of a raw material study; obtained from additional fieldwork to obtain lithic samples from exposures along Fish Creek, Elm Creek and their tributaries.

\section{Paleoenvironment}

At present, the paleoenvironmental record in north-central Texas is very poorly understood. However, the results obtained from pilot studies on phytoliths, pollen, ostracods, mussel shells, and snails are very productive and encouraging.

\section{Snail Species}

The preservation of snails in the five malacology samples examined during the pilot study was excellent. Interpretation of the snail data is that the site area was covered with a "...mosaic of scattered trees or small groves interspersed with more open, grassy areas". The water in Fish Creek was sluggish, slow-moving, and turbid. It had a muddy bottom, and supported an abundance of aquatic vegetation. In general, the interpretations from the snail data corroborate the interpretations from the mussel shell, phytolith, and pollen studies.

\section{Mussel Shell Species}

Overall, the mussel shells were very well preserved. Among the 1,426 valves and fragments examined, remains of eight, and possibly as many as 11 unionid taxa were discovered. In general, the specimens present suggest that the immediate area was periodically inundated with slowly flowing water, and at times became a ponded or backwater area with a soft mud or sandy 
bottom. One species present suggests a high-water event creating a stream-side oxbow. One shell (Yellow sandshell) identified as clearly incised by humans was recovered from stratum 2, and is associated with a radiocarbon date of $360 \pm 25$ B.P. A second shell (Washboard) that may have been transported for use at the site as a scoop or plate was also found.

\section{Ostracods}

Paleoenvironmental interpretations based on pilot study ostracode species recovered from the samples, as well as the absence of ostracode remains, possibly suggest varying and cyclical periods of possible flooding periods or events. The few recovered suggest possible periods where the site was not flooded, but was dry enough to create a stable surface appropriate for human occupation. Nevertheless, the pilot study of ostracode remains demonstrated that although there are ostracodes present, their preservation is not sufficient to yield significant paleoenvironmental information.

\section{Pollen and Phytoliths}

Overall, there was remarkable pollen and phytolith preservation in the ten samples submitted for the pilot study. Based upon the large quantities and wide variety of species found, marked changes in the environment were observed through time, and could be separated into four separate zones. The paleoenvironmental interpretations based on the pollen and phytolith taxa observed in the samples suggest varying and cyclical periods of flooding periods or events. As well, they offer the possibility that the growth of some grasses may have been encouraged for human consumption. However, as will be discussed in later chapters, these studies are not without problems when compared to other paleoenvironmental indicators.

In sum, the pilot study of pollen and phytolith remains demonstrated that: (1) pollen and phytoliths were observed in every sample submitted, (2) the preservation is very good in all levels, and (3) the results are sufficient to yield significant paleoenvironmental information. That being the case there is a similar likelihood of discovering pollen and phytoliths within samples not analyzed during the pilot study.

\section{Mussel Shell Isotopes}

Isotope data obtained from ten samples analyzed during the pilot study yielded a relatively strong separation between two groups from different areas of the site, suggesting that important proxy information might be gleaned from a broader analysis. In addition, the results provided proxy information regarding changes in temperature through time.

Question 15: Paleoenvironmental Information. What is the potential for retrieving paleoenvironmental information? 


\section{Subsidiary Questions}

15.1 What significant information was obtained from the pilot studies that should be pursued with additional samples analysis, so to provide the optimum data necessary to interpret the paleoenvironment at 41DL436 through time?

15.2 Based upon the results of the pilot studies, what sample analyses provided the least amount of information?

15.3 How can depositional trends be attributed to the relative robustness or decline in sample ubiquities through time?

\section{Data to be Evaluated}

- Additional data that can be obtained by the analysis of additional samples that have demonstrated a capability to provide significant and valuable information for interpreting paleoenvironmental changes.

- Sediment depositional rates through time. 


\section{Chapter 4 \\ MeTHODS}

\section{David L. Nickels}

This chapter provides a discussion of the field and laboratory methods during the excavations, as well as subsequent analysis and curation of the cultural material recovered. The methods employed throughout the project were a direct result of those research questions and testing strategies proposed in the initial research design and scope of work. In total, approximately $285 \mathrm{~m}^{3}$ of soil were removed mechanically, with an additional $17.75 \mathrm{~m}^{3}$ dug by hand from 107 units during this project. All fieldwork was conducted in full compliance with applicable OSHA and utility regulations. Upon completion of the fieldwork, including the State's geoarchaeological work, all excavations were backfilled using a Gradall.

\section{Field Methodology}

During the period October 5 through 29,2010 AmaTerra conducted data recovery at 41DL436 in Dallas County. Prefield operations included a thorough review of the data from previous testing projects at the site and in the surrounding region. In addition to Gradall scraping, and extensive 1 x 1-m excavations, field investigations conducted by AmaTerra included site mapping, and the collection of macrobotanical, magnetic susceptibility, $\mathrm{pH}$, carbon, and malacology samples, as well as bulk soil for pollen, diatom, phytolith, and ostracod subsamples. All fire-cracked rocks were collected, with selected pieces analyzed for the presence of starches and lipids.

Prior to conducting the field work, AmaTerra prepared and submitted a Texas Antiquities Committee (TAC) permit application, an initial research design, and a fieldwork plan for conducting the data recovery. The fieldwork plan and initial research design included provisions for between $10 \mathrm{~m}^{3}$ and $30 \mathrm{~m}^{3}$ of hand excavation, depending upon what was found. The TAC permit application incorporated the fieldwork plan and initial research design, and included all the necessary signatures for forwarding to the Texas Historic Commission. A phone call was made to 1-800-DIG-TEST, and clearance was received from all utility companies before fieldwork commenced.

\section{Site Visit}

In September 2010, Co-Principal Investigators Nicholas Trierweiler and James Abbott, Project Archaeologist David Nickels, and TxDOT/UTSA staff archaeologist Eric Oksanen visited the site to review field work that had previously been done, as well as the field work to be conducted during this project. Specifically, Abbott and Oksanen pointed out the locations of their backhoe trenches and test units during their June 2010 test excavations (Oksanen 2010), and site datums previously established by TxDOT and Hicks \& Company were relocated. Next, the footprint 
of a 9 x 20-m excavation trench, plus a 15-m Gradall entrance ramp, were laid out using tape measures and pin flags. The purpose of the block was to target the lowest flood terrace surface (T1), yet, the block was situated to minimize root disturbance and facilitate dirt management, to the extent possible (Figure 4-1).

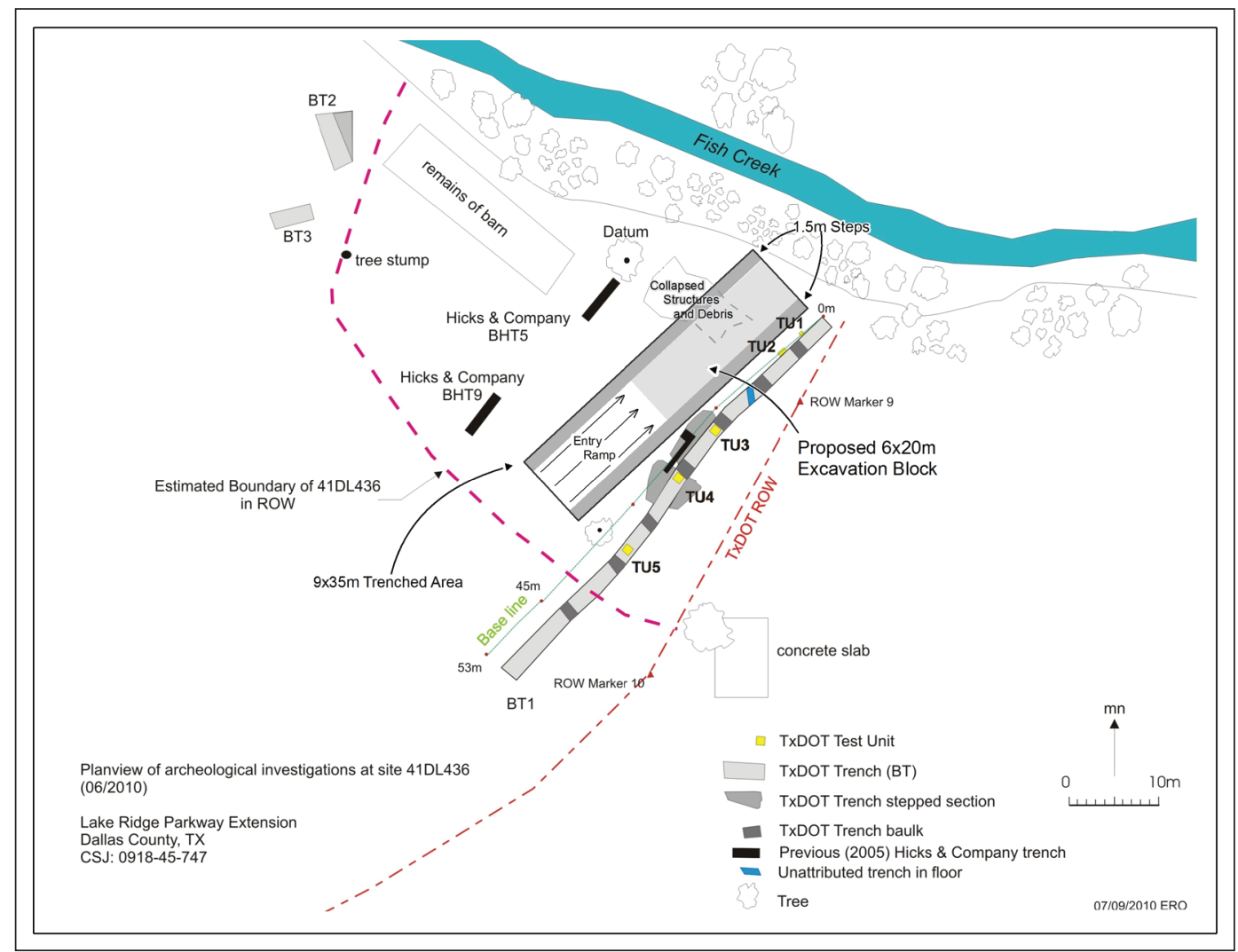

Figure 4-1. Plan map of excavations.

\section{Gradall Trench Excavations}

The data recovery investigations at 41DL436 consisted of mechanical stripping and targeted hand excavations designed to rapidly expose and sample several burned zones and any other features or artifact concentrations encountered. The excavations were based on a gradall block measuring approximately $9 \times 35 \mathrm{~m}$, including a recovery block measuring approximately $6 \mathrm{~m}$ (4 bucket widths) x $20 \mathrm{~m} ; 1.5-\mathrm{m}$ benches on each long side; and accommodation for a ramp for gradall access at one end.

Gradall stripping began on the grid north end of the trench, nearest Fish Creek (Figure 4-2). Stripping was conducted in thin, 3-5-cm cuts, and monitored stripping then occurred from 0 $\mathrm{cm}$ to $200 \mathrm{cmbs}$. Stripping of the block occured systematically to facilitate documentation of spatial patterning in burned zones.

When a burned strata was encountered, it was exposed in natural strata to the extent possible, and minimally hand cleaned where necessary to document patterns and extents of burning. As 
described below, all of these strata were mapped using a Total Data Station, and many were excavated by hand.

In addition to burned zones, scraping the surface in thin cuts exposed the tops of both cultural and non-cultural features, as well as isolated occurrences of bone, firecracked rocks, charcoal stains, and mussel shells. As these were encountered, pin flags were set to outline the area or feature to be further investigated by hand. Gradall stripping in that immediate area was halted until they could be fully documented. In some cases, large burn zones were first brushed with a floor brush to better delineate their horizontal extent (Figure 4-3).To maximize use of both Gradall and field crew time, and minimize down time, the Gradall would be shifted to another area of the block while the field crew documented the features and isolated finds. Nevetherless, localized stripping was practiced so to avoid areas within the block that would be significantly deeper than other parts of the block.

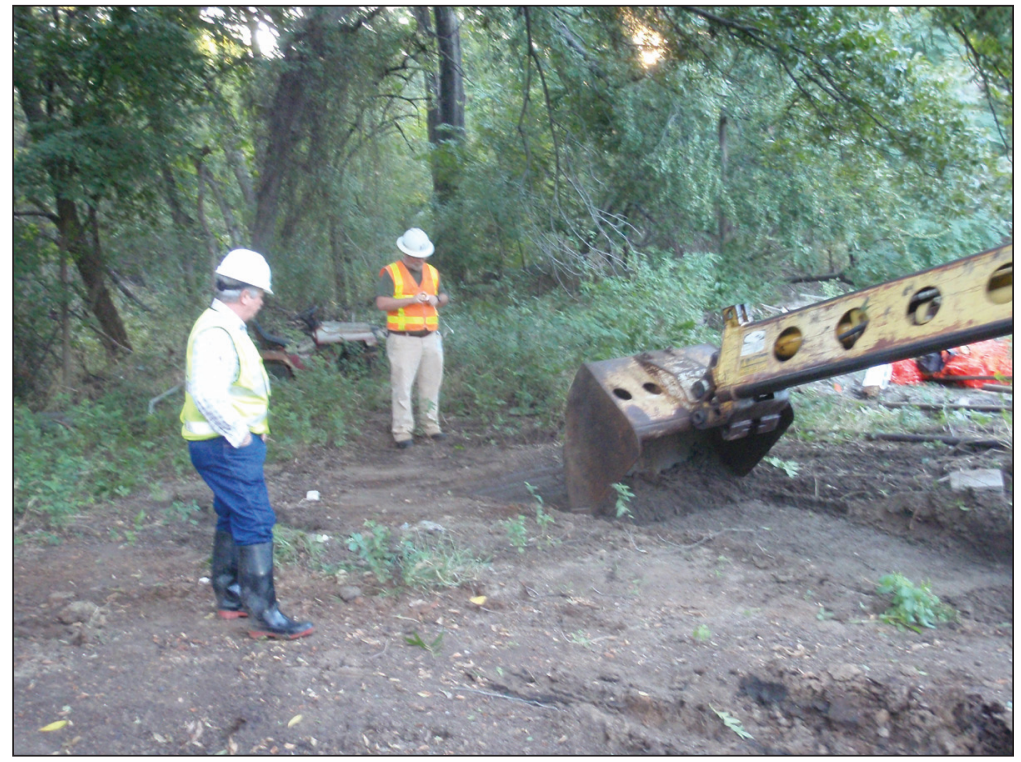

Figure 4-2. Gradall stripping began in the grid north end of the trench.

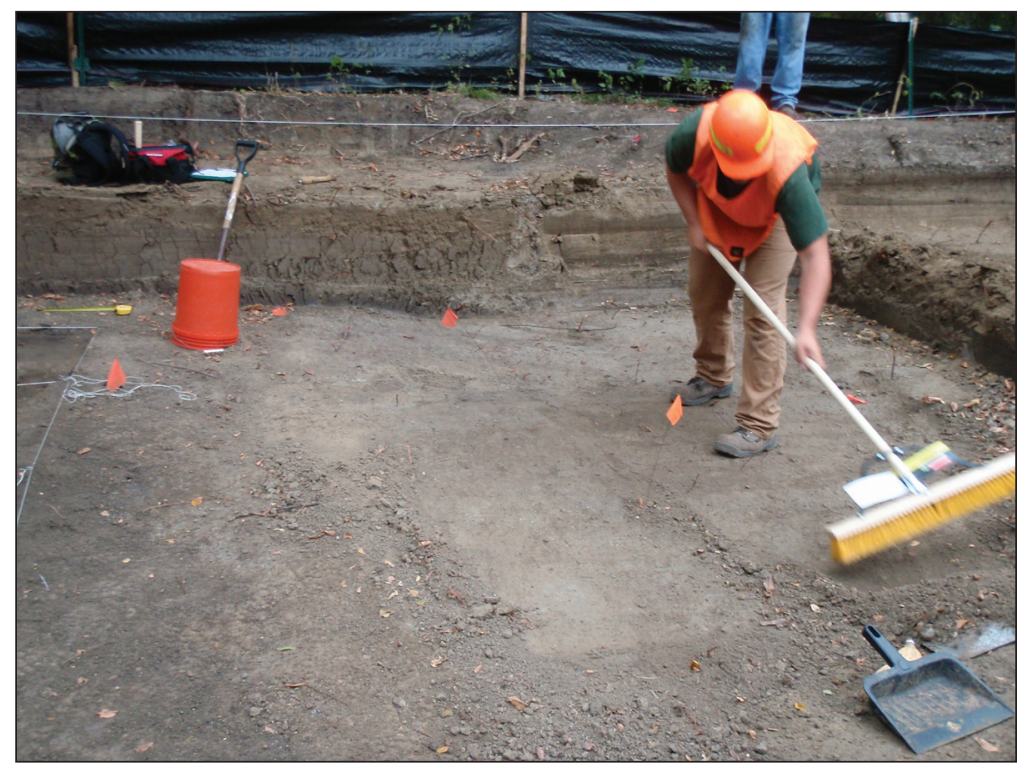

Figure 4-3. In some cases, burned zones were brushed with a push broom to better delineate the extent of the zone before excavations began (facing grid north).

\section{Mapping}

A Total Data Station (TDS) was used extensively every day throughout the fieldwork. Unit locations and levels, original ground surface, topography of burned surfaces and other traceable buried surfaces, cultural and natural feature locations, and the like were recorded using the TDS. A permanent datum was established on the modern surface off the grid north end of the 
trench, and a backsight point was established at $176^{\circ}$ from magnetic north. Both the datum and backsight points were set using 3/8-inch rebar in concrete. The datums previously established by TxDOT and Hicks \& Company were mapped to provide linkage with the excavations from those two projects. In addition, the locations of the TxDOT trench and hand units were re-located, and they were mapped with the TDS. The modern surface, buildings, utility poles, etc. in the surrounding area were also mapped.

Mapping data was downloaded from the data collector to a database spreadsheet loaded onto a computer hard drive by the GIS technician at the AmaTerra office in Austin. The data was checked for accuracy and maps were produced using Arcview software.

\section{Hand Excavation Units}

Hand-excavated units were employed to sample burned zones, cultural features, artifact concentrations, and other phenomena of interest. In general, hand-excavated units were limited to 2-3 levels to focus on burned zones and features only, and were dug in either natural levels or arbitrary $10-\mathrm{cm}$ levels. The volume of each unit level was recorded to control for variations introduced by natural levels. Depending upon the feature uncovered, at the discretion of the Project Archaeologist either single units were opened for excavation, or block excavations with multiple units were undertaken

(Figures 4-4-4-6).

Hand units were dug with both shovels and trowels, and

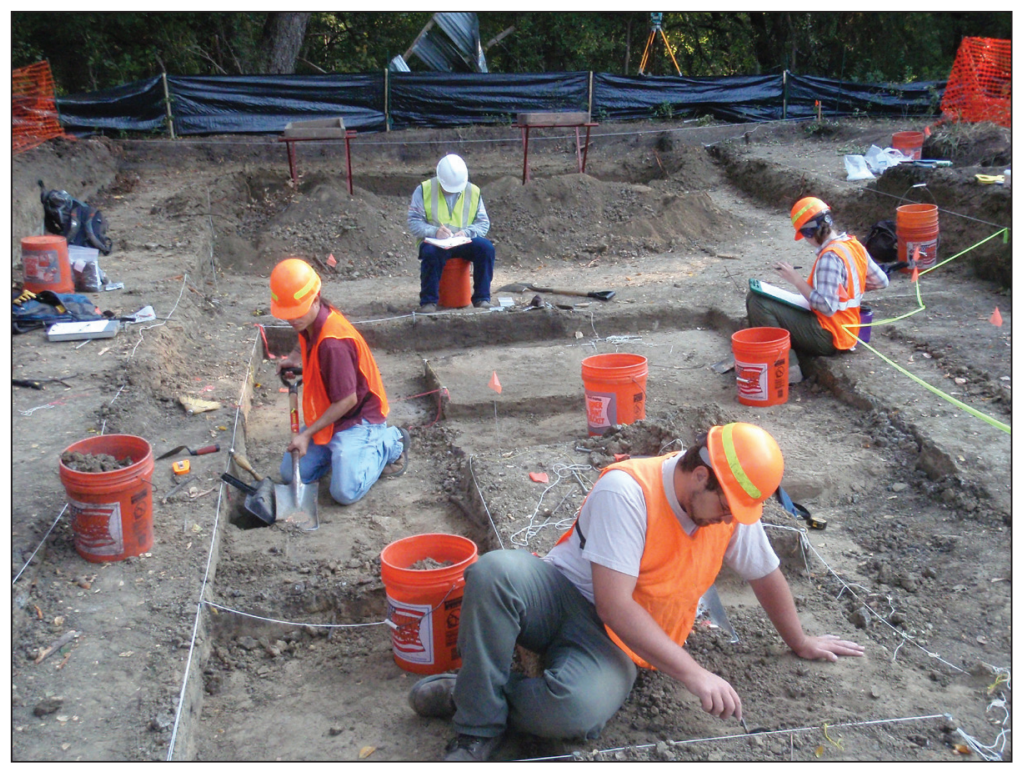

Figure 4-4. Excavations in progress; facing grid north.

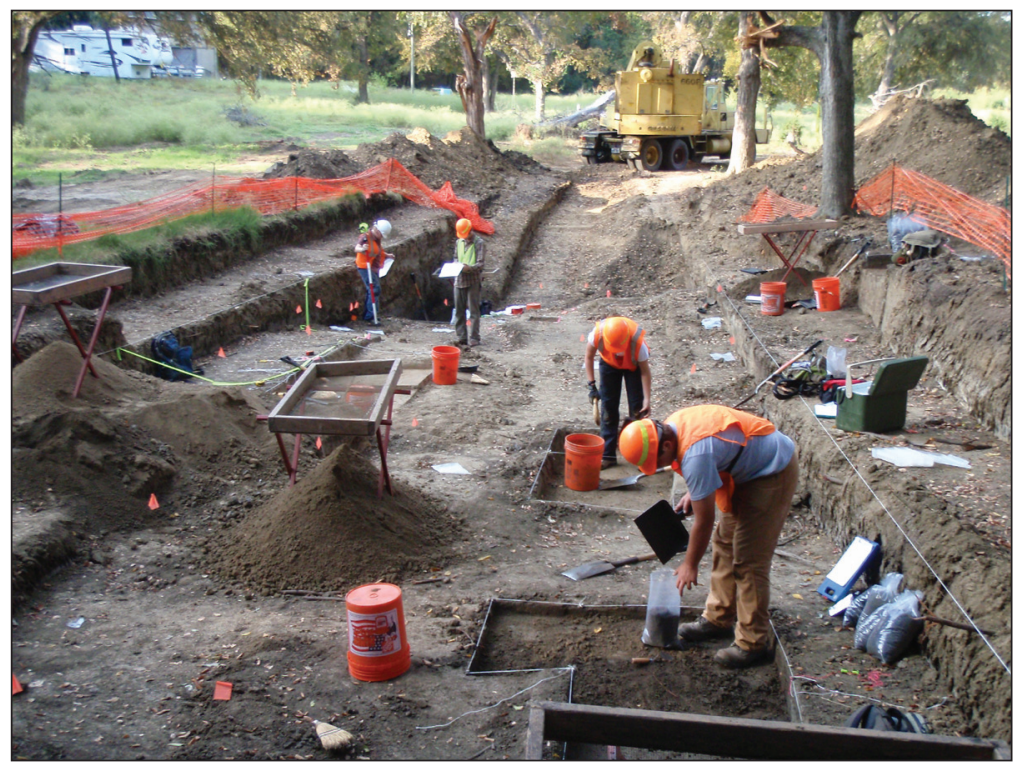

Figure 4-5. Excavations in progress; note stepped benches on both sides of the main excavation block (facing grid south). 


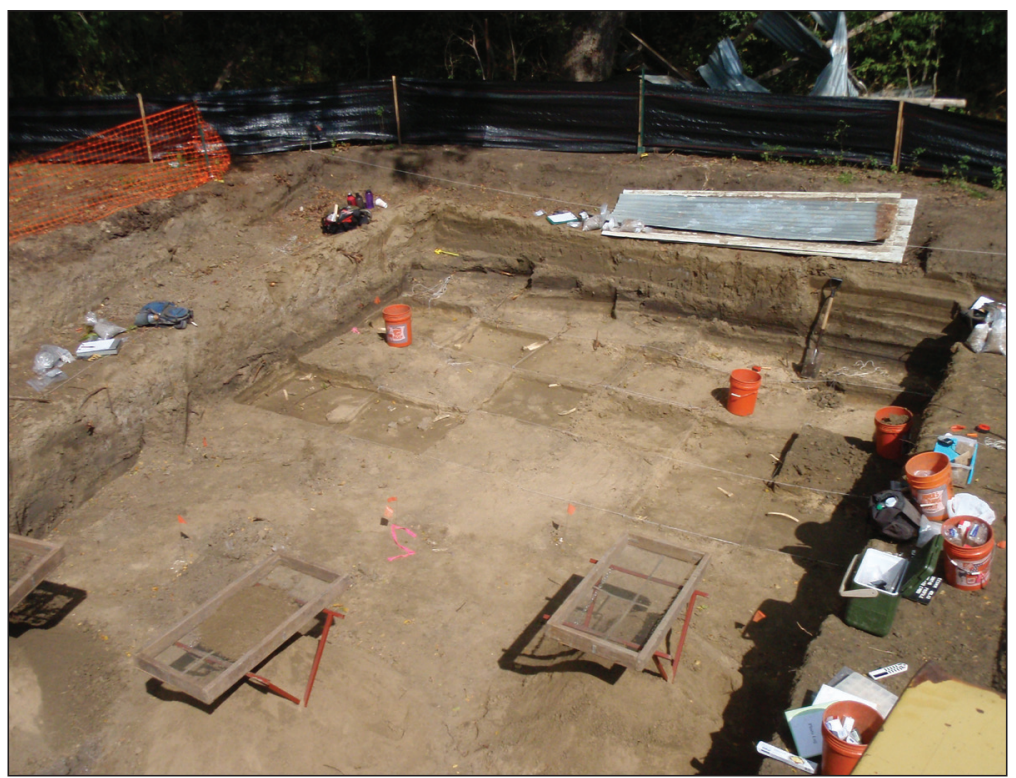

Figure 4-6. Excavation block in grid north portion of trench; facing grid northeast.

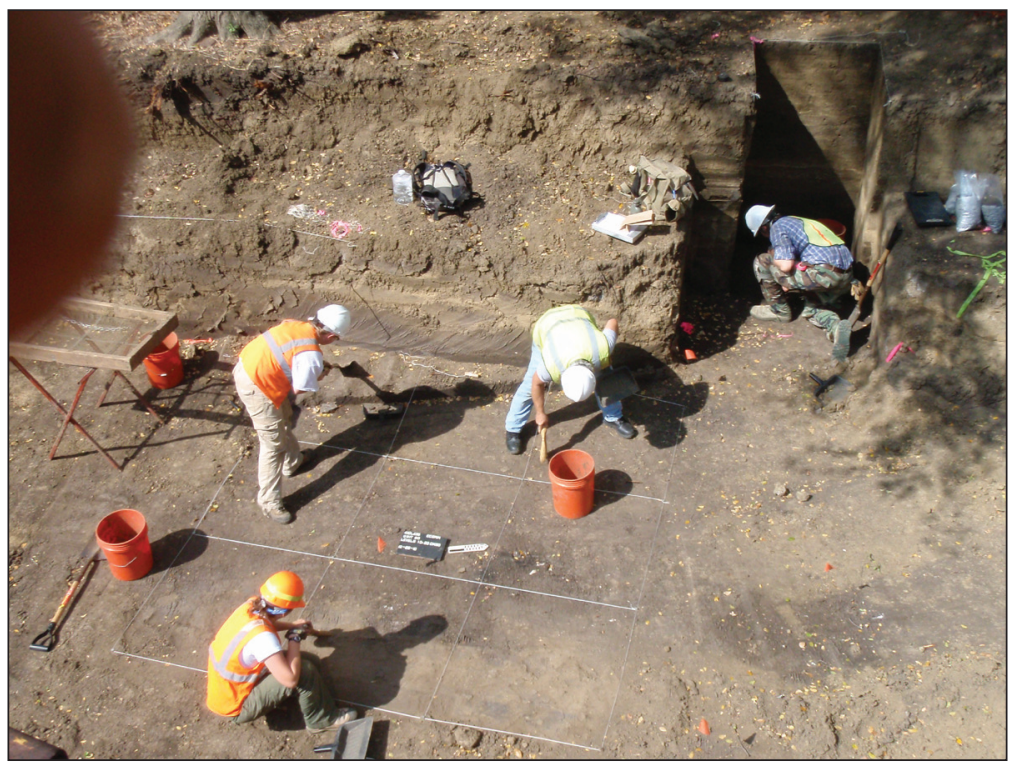

Figure 4-7. Control Unit 49 in grid west wall of the trench; facing west.

all sediments and soils were passed through $1 / 4$-inch mesh, using generally accepted archaeological techniques. The size and distribution of hand-excavated levels were determined by the PA or PI, so that they would be adequate to address questions identified in the preliminary research design. To provide control, a 1 x 1-m unit (Unit 49) (Figure 4-7) was excavated along the grid west trench wall.

Each unit was identified in numerical sequence as assigned by the Project Archaeologist. Normally, one crew member was assigned to each unit. Unit datums were established at trench bottom surface at the time, in the highest corner of the unit. Feature numbers were assigned when identified. They were cross-sectioned, profiles and plan views were drawn, and photographs taken. With the exception of special samples, all excavated material was screened through 1/4-inch mesh.

\section{Collection Procedures}

All fire-cracked rocks, natural pebbles and gravels, fauna, seeds, and chipped stones found both in situ and in the $1 / 4$-inch screen were collected. These were collected in either paper or plastic bags, and assigned a field lot number from a lot log maintained in the field. The collection bags were labeled with the assigned lot number and provenience. These procedures applied to both material collected from unit excavations, as well as isolated finds uncovered in a Gradall cut. Bags of material recovered from units bear the unit number and excavation level, while bags 
of material recovered from a Gradall surface, but not excavated, bear the northing, easting, and elevation as recorded with the TDS.

When present, charcoal was collected in an amount sufficient to at least obtain an Accelerated Mass Spectrometry (AMS) date. When charcoal was discovered in bulk mass, a discretionary sample size was collected. All charcoal samples were collected using a clean trowel, and placed in aluminum foil bearing the lot number and provenience. Lot and provenience information was also recorded on all other special samples collected from hand-excavated units, including floatation, pollen, and fire-cracked rocks for lipid analysis.

\section{Sampling}

An extensive program of bulk soil sampling for flotation recovery was employed. One $10 \mathrm{x}$ $10-\mathrm{cm}$ soil sample was collected according to natural unit to the extent possible from each hand-excavated level for future processing. In addition, floatation samples were collected from all feature contexts, and soil samples for malacology analysis were collected from every $10-\mathrm{cm}$ level in the hand-excavated control unit (Unit 49). Subsamples were to be taken from the $10 \times 10-\mathrm{cm}$ soil sample collected from Unit 49 for phytolith, diatom, and pollen analysis. Although technically not considered as samples, burned clay/daub was collected as potentially cultural material.

\section{Magnetic Soil Susceptibility}

A total of 257 magnetic soil susceptibility were taken using a hand-held meter, and the readings recorded on a standard form. Our standard procedure was to take readings in a gridded fashion horizontally across occupation surfaces and features. In addition, readings were taken in 5-cm increments from a vertical column in the east wall of a control unit (Unit 49). The data were later recorded in a computer database.

\section{Photographs}

AmaTerra staff took 372 photographs using digital cameras. Photographs were recorded on standard AmaTerra photograph forms in the field. In addition to photographing general excavation activities, particular attention was given to features, profiles, and plan views.

\section{LABORATORY METHODS}

Artifacts collected in the field were brought to the AmaTerra lab in Austin where they were washed, sorted, and catalogued. 


\section{Flotation Samples}

A total of 95 flotation samples were collected from in and around features. Each sample consisted of on average, four liters of sediment. The samples were processed outside the AmaTerra laboratory in Austin. The sediments were poured into plastic buckets, clean water added, and the mixture gently stirred by hand to bring the light fraction to the water's surface. The floated material was then gently skimmed off the surface or poured through a tightly woven chiffon cloth fitted into a fine wire mesh kitchen colander. The cloth with the light fraction on it was then removed and allowed to dry indoors under clean conditions. After drying, selected light fraction was then placed in paper letter envelopes and sent to Dr. Philip Dering of the Shumla School in Comstock, Texas.

\section{Chipped, Ground, and Battered Stone}

The processing of lithic artifacts began with washing and sorting into debitage and tool categories during a preliminary analysis. Tool categories used were projectile points, bifaces, unifaces, cores, battered or hammered stone, and ground stone. Counts were made of the various lithic categories, and data were then entered on an Excel Spreadsheet.

\section{Fire-cracked Rock}

All fire-cracked rock was collected for analysis. A total of 206 rocks greater than one inch from features and isolated contexts were counted and weighed, and examined for material type (e.g., sandstone, quartzite, chert, petrified wood).

\section{Charcoal}

A total of 186 charcoal samples were collected in the field, either in situ, or from the $1 / 4$-inch screen. An additional 54 samples were recovered from either floatation samples or from bulk sediment samples collected for malacology analysis. Selected charcoal samples were then submitted for radiocarbon analysis by the Center for Applied Isotope Studies at the University of Georgia, or by Beta Analytic in Florida.

\section{Faunal Remains}

Faunal material was gently washed, air dried, and placed in labeled bags. The remains and an accompanying inventory were then transported to Jodi Jacobson at TxDOT for further analysis.

\section{Snails and Mussel Shells}

All mussel shells were collected from the hand-excavated units, and a grab sample was collected from a mussel shell lens (Feature 11) in the lower levels of the trench. All mussel shells collected were mailed to Bob Howells for analysis. In turn, selected mussel shells were 
sent to David Brown for isotope analysis. All snails observed in the excavation units and $1 / 4$-inch screens were collected. In addition, a vertical bulk sediment column was collected from the control unit (Unit 49), specifically for analysis by Ken Brown. The methods of analyses for both mussel shells and snails can be found elsewhere in this report.

\section{Lipids and Starches}

Selected fire-cracked rocks were submitted to Timothy Riley for starch analysis, and to Mary Malainey for lipid analysis. The methods of analyses for both can be found elsewhere in this report.

\section{Diatoms, Ostracods, Phytoliths, and Pollen}

Selected sediment sub-samples were sent for analysis. Diatom samples were submitted to Barbara Winsborough, ostracods to Mervin Kontravitz, and phytoliths and pollen to Linda Scott Cummings. Their reports can also be found elsewhere in this volume.

\section{Curation}

Artifacts processed in the AmaTerra laboratory were washed, air-dried, and stored in archivalquality bags. Acid-free labels were placed in all artifact bags. Each bag was labeled with a provenience or corresponding lot number. Tools from all excavations were labeled with permanent ink and covered by a clear coat of acrylic. Artifacts from each investigation were separated by class and stored in acid-free boxes. Boxes were labeled with standard labels. Heavy fraction, light fraction, and other samples (e.g. 14C) were also placed in acid-free boxes.

Field notes, forms, photographs, and drawings were placed in labeled folders. Photographs, slides, and negatives were placed in archival-quality sleeves and stored in acid-free boxes. Documents and forms were printed on acid-free paper. A copy of the site report and all computer disks pertaining to this project are stored in archival boxes and curated with the field notes and documents. All were turned over TxDOT, for subsequent permanent curation at TARL. 


\section{SECTION II \\ GeonrCheology Site Integrity and Radiocarbon Dating}




\title{
Chapter 5 \\ GEOARCHAEOLOGY OF 41DL436, Dallas County, Texas
}

\author{
James T. Abbott \\ with contributions by Charles D. Frederick
}

\section{INTRODUCTION}

This report describes geoarchaeological observations made in conjunction with the last two phases of work at the Fish Creek Slough site (41DL436) in Dallas County, Texas. It describes the project area and the work performed; summarizes the stratigraphy, sedimentology, and pedogenic character of deposits; and addresses geoarchaeological questions that were articulated prior to data recovery and in the research design for analysis and reporting of data recovery investigations at the site. This analysis supports the archaeological interpretations by describing the character of the landscape that was occupied by prehistoric inhabitants, characterizing the manner and the speed at which this landscape evolved, and addressing the implications of this data for the spatial and stratigraphic integrity of interbedded archaeological remains.

\section{EnVironment of The Study Area}

The study area is situated in the city of Grand Prairie, north of Joe Pool Lake in southwestern Dallas County (Figure 5-1). The site is situated on the south bank of Fish Creek a short distance east of the Tarrant County line. Fish Creek is a moderately-sized tributary of Mountain Creek, in the watershed of the West Fork of the Trinity River. It heads in eastern Tarrant County and flows approximately $20 \mathrm{~km}$ east-northeast to its confluence with Mountain Creek. The site lies within the Blackland Prairie natural region, and the vegetation in the valley is mapped as cropland (McMahan et al. 1984), although urban development is encroaching from all sides. Vegetation in the vicinity of the site consists of a typical riparian assemblage of diverse hardwoods, including oak, elm, and hackberry, modified by rural development (primarily animal pens) and suburban encroachment (see Chapter 2).

Fish Creek consists of a narrow, moderately meandering channel incised 5-6 $\mathrm{m}$ below its floodplain and 15-20 m below the elevation of the surrounding "upland." According to the Geologic Atlas of Texas (see Figure 5-1), this upland actually consist of high fluvial terraces associated with Mountain Creek. The floodplain lies at a local elevation of approximately 490-500 feet amsl, and can be subdivided into an upper $\left(\mathrm{T}_{1 \mathrm{~A}}\right)$ surface between approximately 495 and $500 \mathrm{ft}$ amsl and a lower $\left(\mathrm{T}_{1 \mathrm{~B}}\right)$ surface between 490 and $495 \mathrm{ft}$ (Figure 5-2). The contact 


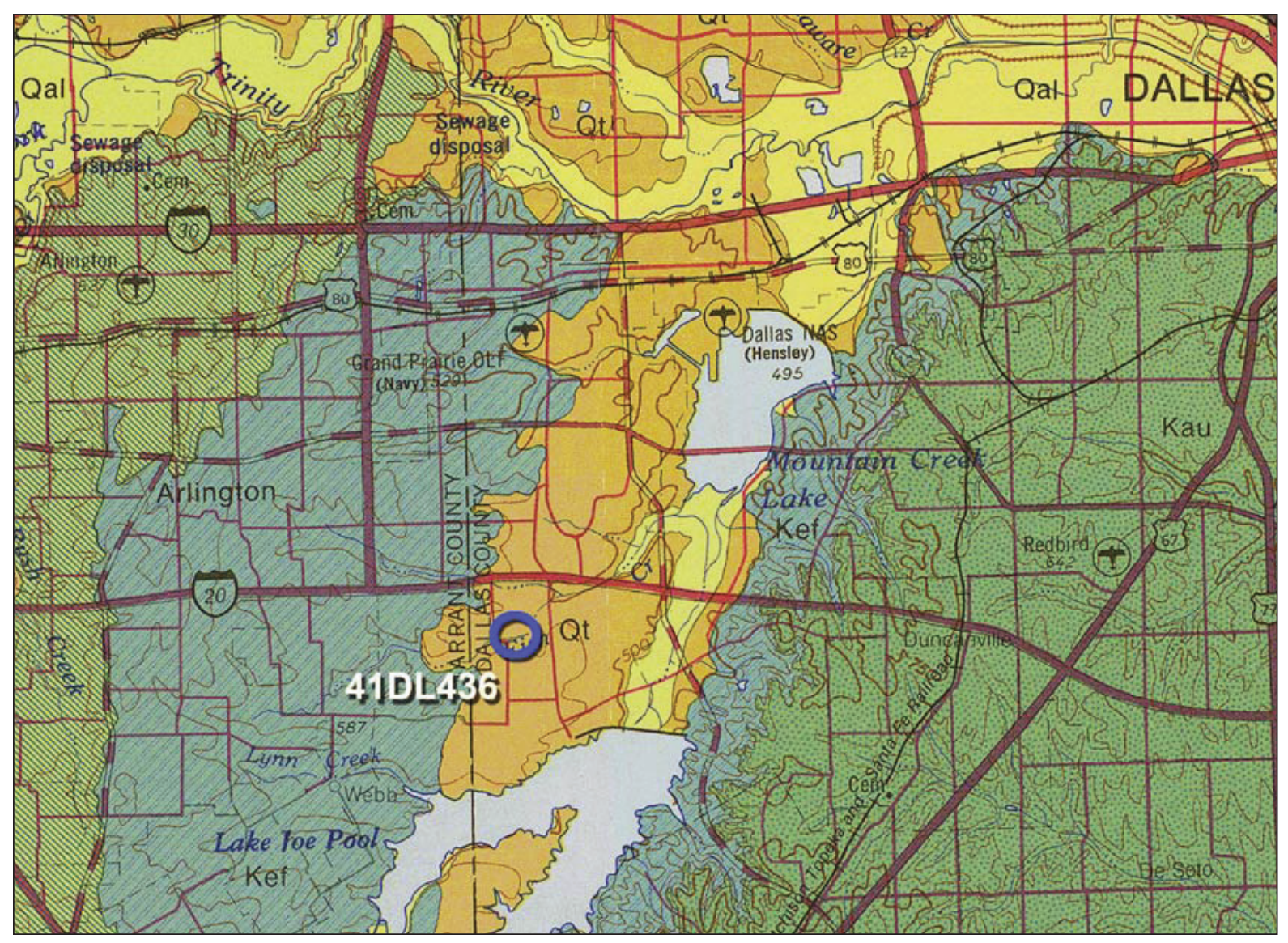

Figure 5-1. Location and geological setting. Map adapted from the Geologic Atlas of Texas, Dallas Sheet.

between these two surfaces is typically subtle. Topography in this figure is based on Lidar survey of the area by the North-Central Texas Council of Governments, and was used to infer the position of terrace boundaries. The former channel illustrated in Figure 5-2 is inferred based on these topographic contours and stratigraphic work conducted at the site (see below).

There is no USGS stream discharge data available for Fish Creek, but it is likely that flow is intermittent given its position in the overall drainage system. Soils in the vicinity are typical of the Blackland Prairie setting. Mapped soils include Frio silty clay in the axis of the valley; Altoga silty clay on the higher of the two terraces associated with Fish Creek on the south side of the stream and the relatively steep southern valley wall; Silawa fine sandy loam and Sunev clay loam on the higher Fish Creek terrace on the north side of the stream; and Crockett fine sandy loam, Houston Black clay, and Silawa fine sandy loam on the high Pleistocene terrace/ upland (Soil Survey Staff n.d.; Figure 5-3). Of these soils, only Frio silty clay and Altoga silty clay are mapped in the immediate vicinity of the site. Frio soils are classified as Cumulic Haplustolls (Mollisols), and exhibit a typical A1-A2-A3-A4-Bk profile developed in weakly stratified, very dark to dark grayish brown (10YR 4/2 to 5/2) silty clay, clay loam, and silty clay loam. Altoga silty clay soils are Udic Haplustepts (Inceptisols), and exhibit a typical Ap-Bk1Bk2-BCk developed in light brownish gray to very pale brown silty clay. Neither of these 
This figure has been redacted due to site sensitive information.

Figure 5-2. Map of local landforms and local topography superimposed on aerial photograph of the site. Contour interval is $2 \mathrm{ft}$. 
This figure has been redacted due to site sensitive information.

Figure 5-3. Map of soils in the vicinity of 41DL436, from USDA-NRCS Web Soil Survey. Key to soil mapping units: 1 = Altoga silty clay, 5 to $12 \%$ slopes, eroded; 37 = Frio silty clay, frequently flooded; 61 = Silawa silty loam, 3 to $8 \%$ slopes; 70 = Sunev clay loam, 1 to $3 \%$ slopes.

described series are a good match for the highly stratified, silty to fine sandy alluvium actually observed on site (see below).

Alluvial deposits in the Dallas area were studied by Ferring (1990; 1994; 2000), who defined a series of fills of middle Pleistocene to late Holocene age in the upper Trinity Basin. This sequence is the standard point of reference for alluvial stratigraphic studies in this part of the state. The fills identified by Ferring include a series of older deposits stranded at elevation and forming elevated terraces (the Irving, Coppell, and Carrollton Formations, which form the Stewart Creek, Hickory Creek, and Denton Creek terraces, respectively) and a series of stacked, late Pleistocene to late Holocene fills separated by bounding paleosols beneath the modern floodplain (including the Aubrey, Sanger, and Pilot Point formations, and post-Pilot Point deposits that occur in proximity to channels and are not formally named). While Sanger and (particularly) Aubrey deposits are relatively deeply buried and rarely exposed, Pilot Point alluvium is often exposed at the surface in distal parts of the Trinity floodplain, and buried by 
recent alluvium in more proximal locations. It is typically capped by a prominent paleosol, termed the West Fork soil by Ferring (1994) that is a common stratigraphic marker used at sites in the region (e.g., Lintz et al. 2008; Peter and Harrison 2011). Although Ferring's work focuses on the trunk streams and larger tributaries (e.g., Denton Creek), recent stratigraphic work at sites on smaller tributaries in the region (e.g., Abbott 2011; Frederick 2011) suggests that Ferring's model provides a good basis for interpreting the sequence of Holocene fills, but that architectural relationships among these units are sometimes quite different than the "layer cake" arrangement common in the trunk stream valley.

\section{Previous Work}

Site 41DL436 was recorded by archaeologist Rachel Feit in August, 2005 (Feit \& Campbell 2005). It was "defined by abundant bone, charcoal, burned clay, and hackberry seeds buried within two discrete stratified zones within a very active alluvial floodplain." Zones of apparent cultural debris were encountered at approximately 100-175 cm below surface in three different backhoe trenches. This material consisted of disarticulated faunal material, including bos/bison, turtle, rodent, and unidentified large mammal contained in stratigraphic zones of charcoal and burned clay. Approximately 14 percent of the 200-odd fragments of faunal material collected exhibited burning or charring, and two localized ash concentrations were designated as features. No lithic debris or burned rock was noted. Feit and Campbell noted the absence of lithic material, but concluded that this lack is not unusual in the area and recommended that the "preserved faunal material, baked clay, charcoal, burned seeds and other plant material" were indicative of prehistoric cultural activity and merited formal National Register of Historic Places testing. No geoarchaeological assessment was conducted in conjunction with this initial survey.

Following the 2005 Hicks \& Co. investigation, work on the project lapsed for several years because right of entry (ROE) for testing was not given by the owner, and the archaeological project languished (although NEPA clearance was obtained based on refusal of right of entry). In May 2010, the situation changed. TxDOT ENV was notified that the parcel had been purchased by the city of Grand Prairie, ROE had been obtained, and that letting was planned for September 2010. It was quickly apparent that this schedule was insufficient to allow for traditional testing, analysis, and tribal coordination. In order to meet the project schedule, TxDOT's Archaeological Studies Supervisor Scott Pletka asked archaeologist Eric Oksanen (a UTSA employee serving as an in-house TxDOT contractor) and geoarchaeologist Jim Abbott (TxDOT ENV) to conduct an emergency evaluation of the site the following week to determine whether additional work was warranted, and if so, what form it should take. Work to accomplish this goal was conducted on June 22-25, 2010 by Abbott and Oksanen, assisted by field crew furnished by Geo-Marine, Inc. This brief investigation confirmed the Hicks \& Co. conclusions, and highlighted the sparse and dispersed character of the remains.

Accordingly, in order to meet the project schedule, a decision was made to treat the site as if it were eligible to the NRHP, bypass formal NRHP eligibility testing, and proceed to staged data recovery. Oksanen et al. (n.d.) recommended that data recovery was warranted, but that because the cultural strata were distributed in low concentrations in stratified alluvium, it 
should be designed to identify and target cultural strata in a large, mechanically-excavated block. This work was conducted in the fall of 2010 .

The geoarchaeological analysis of 41DL436 is based on fieldwork conducted during the June 2010 evaluation and the October 2010 data recovery. Much like the parable of the blind men and the elephant, these two periods of investigation revealed different aspects of site stratigraphy, and both will be drawn on in the following discussion. The focus, however, will be on deposits exposed in the mitigation block. Figure 5-4 illustrates the approximate location of survey and test trenches and the mitigation block.

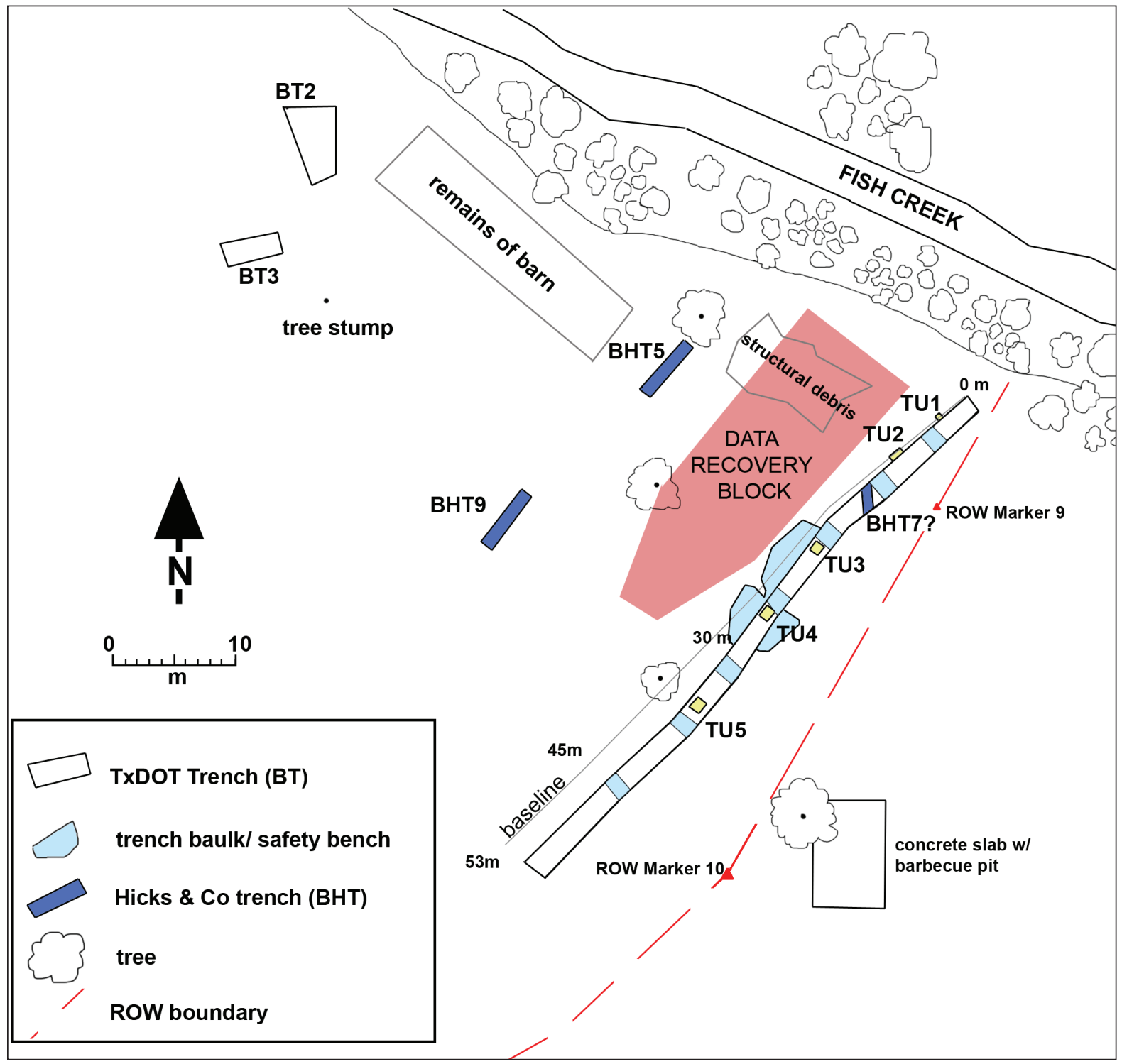

Figure 5-4. Reproduction of sketch map from Oksanen et al. (nd) with the approximate location of the data recovery block added. 


\section{MeThODS OF INVESTIGATION}

\section{June 2010 Field Evaluation}

The purpose of this phase of work was to increase the amount of information available in the most expeditious manner possible to (1) determine if additional work was in fact necessary, given that no conclusive artifacts had been found during survey (although bone, charcoal, and burned earth was noted, it could have been non-cultural); and (2) if so, to plan more effectively for the data recovery effort. The evaluation was performed in a relatively restricted time period and without much opportunity for detailed planning-Abbott and Oksanen were notified on Thursday, June 17, that an emergency effort to assess the site was needed, and fieldwork was begun on Tuesday, June 22 and completed Friday June 25. Consequently, emphasis was placed on mechanical excavation to expose a cross-section of the site, coupled with limited hand excavation to obtain controlled samples of materials.

Trenching was conducted with a Badger-brand Excavator with a smoothbladed, 5-ft bucket. The principal sample unit consisted of a single trench excavated across the $\mathrm{T}_{1 \mathrm{~B}}$ floodplain from near the channel up onto the proximal part of the $T_{1 \mathrm{~A}}$ terrace. Although, designated $\mathrm{BT} 1$, this $54 \mathrm{~m}$ trench was subdivided into eight segments by backing the excavator up about a meter farther than the boom could reach to leave preserved balks, which facilitated entry and crossing of the trench (Figure 5-5). Each segment of BT1 was approximately 5-8 m long, with the depths of individual segments ranging approximately $1.2-2$ $\mathrm{m}$ (excavation of individual segments was continued to a depth of at least $1.8 \mathrm{~m}$ except where burned zones noted in the floor were targeted for hand excavation). Where

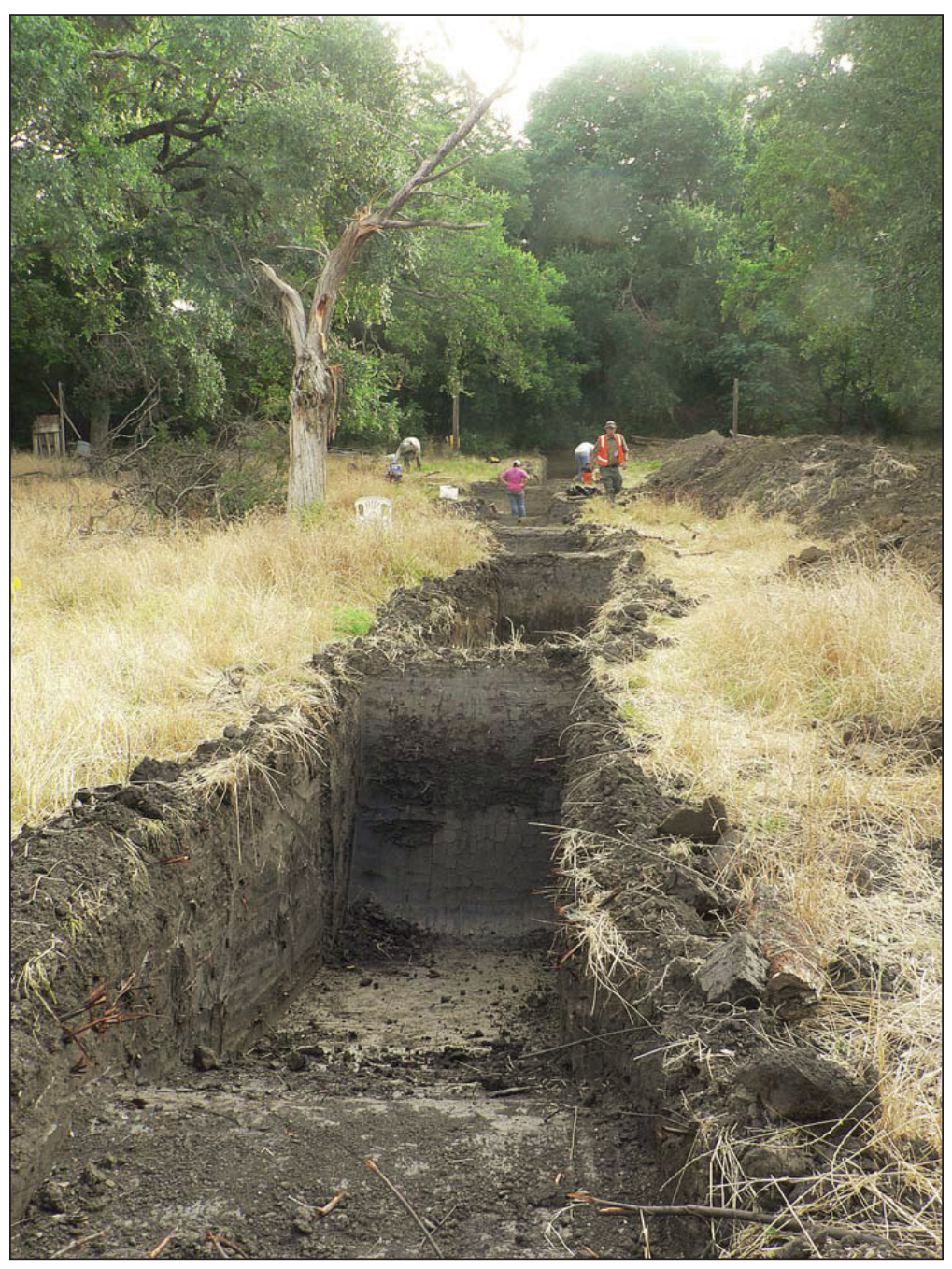

Figure 5-5. View of BT1 during the June phase of work, looking north. 
warranted by trench depth, safety benches were excavated along one or both walls of individual segments. Four stratigraphic columns were cleaned and described at intervals along BT1 to capture the variability of the exposed deposits.

In addition to the long trench, two additional trenches (BT2, BT3) were excavated at the western edge of the site. Trenching in the middle of the site was impeded by a series of large, felled trees. Because Hicks \& Co had already trenched in this part of the site, because the character of the site deposits observed in the new trenches matched the Hicks \& Co. descriptions so closely, and because it would have required too much of the limited field time available to move the trees out of the way, trenching was focused on the relatively open eastern side of the ROW (see Figure 5-4). Table 5-1 lists the UTM location of evaluation-phase trench corners and units. UTM measurements were made with a Trimble GeoExplorer GPS and post-processed to obtain accuracy of approximately $\pm 1 \mathrm{~m}$.

All hand excavation efforts during the June evaluation were focused on BT1. Hand units consisted of a mix of relatively small $(50 \times 50 \mathrm{~cm} ; 50 \times 100 \mathrm{~cm})$ stratigraphic tests that sampled the exposed sediment column from the surface to the base of the trench (TP1 and TP2) and $1 \times 1 \mathrm{~m}$ excavation units that targeted specific strata exposed at the bottom of the trench (TP3-TP5).

Table 5-1. Trench Locations.

\begin{tabular}{|c|c|c|c|c|}
\hline Location & UTM Zone & Northing & Easting & Comments \\
\hline Trench 2, SE corner & $14 S$ & 3615942 & 685080 & \\
\hline Trench 2, NE corner & $14 S$ & 3615950 & 685080 & \\
\hline Trench 2, NW corner & $14 S$ & 3615950 & 685077 & \\
\hline Trench 2, SW corner & $14 S$ & 3615942 & 685079 & \\
\hline Trench 3, SE corner & $14 S$ & 3615937 & 685075 & exposes $S$ edge of debris pile \\
\hline Trench 3, NE corner & $14 S$ & 3615939 & 685076 & exposes $\mathrm{S}$ edge of debris pile \\
\hline Trench 3, NW corner & $14 S$ & 3615940 & 685072 & exposes $S$ edge of debris pile \\
\hline Trench 3, NE corner & $14 S$ & 3615938 & 685072 & exposes $\mathrm{S}$ edge of debris pile \\
\hline Trench 1, SE corner & $14 S$ & 3615891 & 685103 & \\
\hline Trench 1, SW corner & $14 S$ & 3615893 & 685102 & \\
\hline Trench 1, NW corner & $14 S$ & 3615930 & 685139 & \\
\hline Trench 1, NE corner & $14 S$ & 3615929 & 685141 & \\
\hline Unit $1(50 \times 50 \mathrm{~cm})$ & $14 S$ & 3615928 & 685137 & on $\mathrm{W}$ wall of BT1, Segment 1 \\
\hline Unit $2(50 \times 100 \mathrm{~cm})$ & $14 S$ & 3615925 & 685134 & on $\mathrm{W}$ wall of BT1, Segment 2 \\
\hline Unit $3(1 \times 1 \mathrm{~m})$ & $14 S$ & 3615919 & 685126 & in floor of BT1, Segment 4 \\
\hline Unit $4(1 \times 1 \mathrm{~m})$ & $14 S$ & 3615914 & 685123 & in floor of BT1, Segment 5 \\
\hline Unit $5(1 \times 1 \mathrm{~m})$ & $14 S$ & 3615907 & 685116 & in floor of BT1, Segment 6 \\
\hline TxDOT ROW Stake 9 & $14 S$ & 3615919 & 685138 & eastern ROW \\
\hline NW corner concrete slab & $14 S$ & 3615896 & 685125 & $\begin{array}{l}\text { Slab measuring approx } 12 \mathrm{x} \\
20 \mathrm{ft} \text { w/ brick barbecue grill }\end{array}$ \\
\hline TxDOT ROW Stake 10 & $14 S$ & 3615891 & 685118 & eastern ROW \\
\hline
\end{tabular}




\section{October 2010 Data Recovery}

Data recovery at the Fish Creek Slough site consisted of mechanized excavation of a large block ( $9 \times 20 \mathrm{~m}$; narrowing to $6 \times 20 \mathrm{~m}$ below approximately 1-m bgs) with $1.5 \mathrm{~m}$ safety benches and a 10-m (approx.) ramp. Most data recovery work conducted at 41DL436 was performed when the geoarchaeologist was not present. Geoarchaeological sampling and documentation of the mitigation block was conducted during three visits on October 5, 14, and 27-30, 2010, (although very little data was collected during the first visit), supplemented with a systematic effort by the field crew to sample sediment from hand excavation units. The first two visits by the geoarchaeologist were made to observe excavation progress, and the third was made to sample and document the completed block. As described in detail elsewhere (Chapter 3), excavation of the block involved mechanical stripping with a gradall until cultural material was noted, followed by establishment and excavation of hand units to expose and document those materials. Geoarchaeological documentation was based primarily on examination of vertical profiles created as the block was excavated, supplemented with a deep probe trench excavated into the base of the block after all other work was completed.

The upper west wall profile was documented and sampled during the October 14 visit. This composite profile, designated Geoarchaeological Witness Section One (GW-1), was situated along the west wall of the safety bench and the main block about $8 \mathrm{~m}$ south of the northwest corner (although the block was not oriented with cardinal directions, for simplicity all references in this chapter assume that the block was oriented with the long axis $\mathrm{N}-\mathrm{S}$ and the ramp at the southern end). The upper 1 $\mathrm{m}$ of the profile (approx.) was on the sidewall of the bench, and the remaining $35 \mathrm{~cm}$ (approx.) was offset approximately $150 \mathrm{~cm}$ on the main block wall (Figure 5-6). A section of the wall approximately $1 \mathrm{~m}$ wide was cleaned, profiled and described according to criteria of Olson 1976 and Schoeneberger et al. 2002. Local elevations were recorded relative to a string level set into the wall, and a series of sixteen $8 \mathrm{~cm}^{3}$ sediment samples were obtained from the

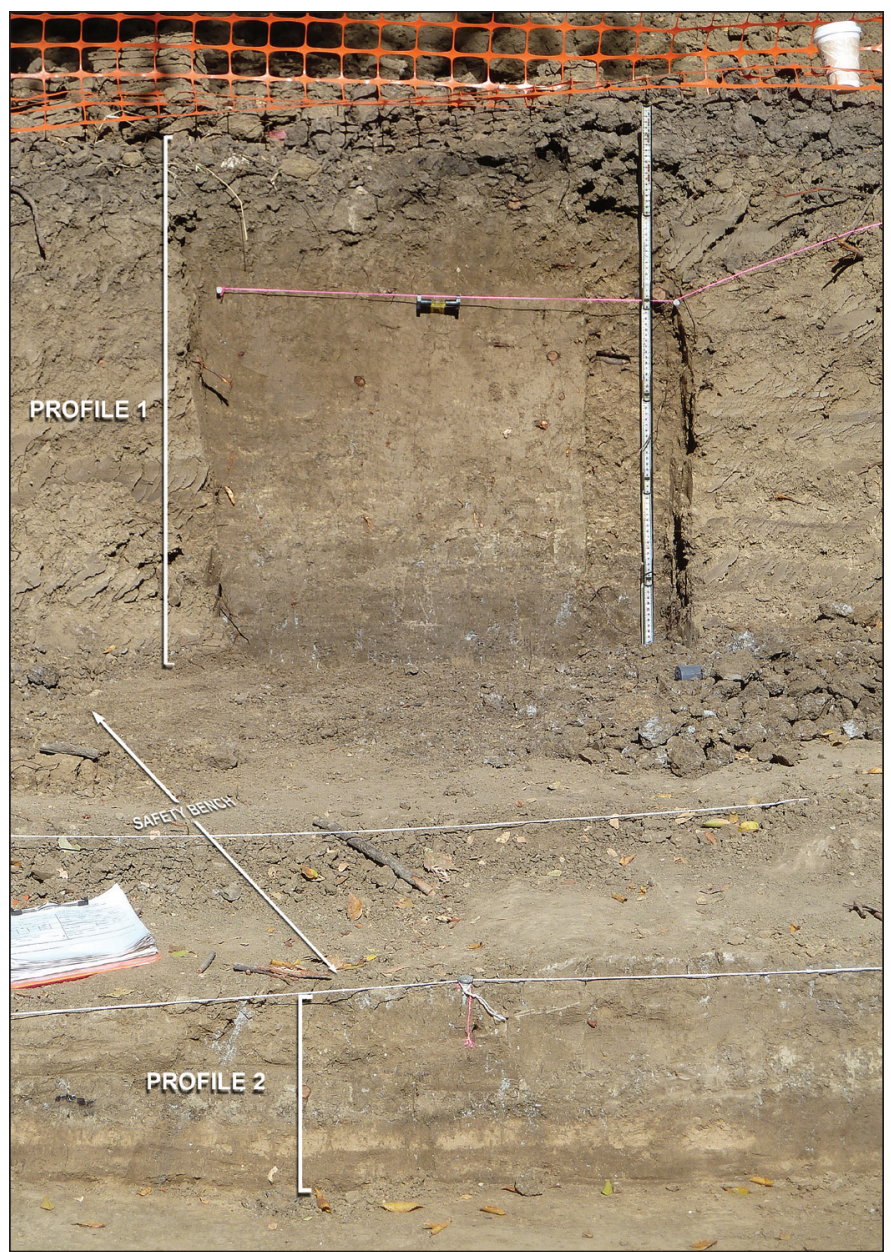

Figure 5-6. View of Section GW-1 showing the offset at the safety bench. 
profiles at increments of approximately $10 \mathrm{~cm}$ (in a few cases, the depth was adjusted to avoid cutting across boundaries reflecting changes in sediment character). The samples were collected in clear, 2 x 2 x 2-cm plastic boxes (internal dimension) designed for magnetic susceptibility sampling. The elevation of the reference nail was later recorded by the total station and the elevations were referenced to the remainder of the site.

From October 27-30, work focused on describing and documenting the margins of the mitigation block. Initially, all exposed walls in the block were examined, and Unit 49 (a $1 \times 1-\mathrm{m}$ unit excavated from the surface to 2-m bgs on the western margin of the block) was profiled. When the crew finished primary excavation, a deep probe trench was excavated in the center of the block to expose deeper deposits, and the northern and eastern walls of the block and accessible parts of the deep probe were thoroughly cleaned, strung with string levels at $50 \mathrm{~cm}$ depth intervals, photographed in overlapping frames for photomosaic preparation, and carefully drawn. Depths were based on reference nails established at known elevations with the total station used for control of excavation units. A single column of $8 \mathrm{~cm}^{3}$ cube samples (GW2) was taken at intervals of 5-10 $\mathrm{cm}$ from the surface to approximately $3.4 \mathrm{~m}$ below the surface (arbitrary elevation 99.6-96.3 m). In addition, five blocks of sediment were collected for thin section analysis. Three of these were taken from various depths in the wall of Unit 49 (the 2-m hand unit). The other two were from the east wall; one was from a distinct fired feature, and one sampled a distinct stratum of mussel shell and charcoal.

Upon completion of the work, the data were compiled and stratigraphic units were identified based on the profiles of the marginal walls. The total station data was then used to create a rotatable, three-dimensional map of unit locations using Google SketchUp (Figure 5-7). To resolve some software issues encountered in this process, level thicknesses were standardized at the closest increment of $5 \mathrm{~cm}$, all corners of each unit were assigned the same elevation, and initial unit elevations were standardized to the closest increment of $5 \mathrm{~cm}$ relative to the vertical datum. The completed model, available radiocarbon ages, and field description of the sediments were then used to assign each unit-level to one of the three principal stratigraphic units (and, where possible, subunits) defined from the walls of the block. This data was then provided to the Project Archaeologist for use in final definition of analytical units.

\section{Analytical Methods}

by Charles D. Frederick and James T. Abbott

The physical properties of the site were documented primarily through analysis of the two columns of magnetic susceptibility cube samples described above (GW-1 and GW-2, consisting of 82 samples) and five micromorphology samples. Analyses conducted on the cube samples included magnetic susceptibility, particle size analysis, organic carbon content, calcium carbonate content, iron content, soil $\mathrm{pH}$, and stable carbon isotope analysis. Magnetic susceptibility was determined using 2-cm cubes collected and packed in the field. Although these samples were not passed through a $2-\mathrm{mm}$ sieve to remove coarse clasts, rock fragments larger than sand were exceedingly rare in the deposit and are not considered a factor in the 


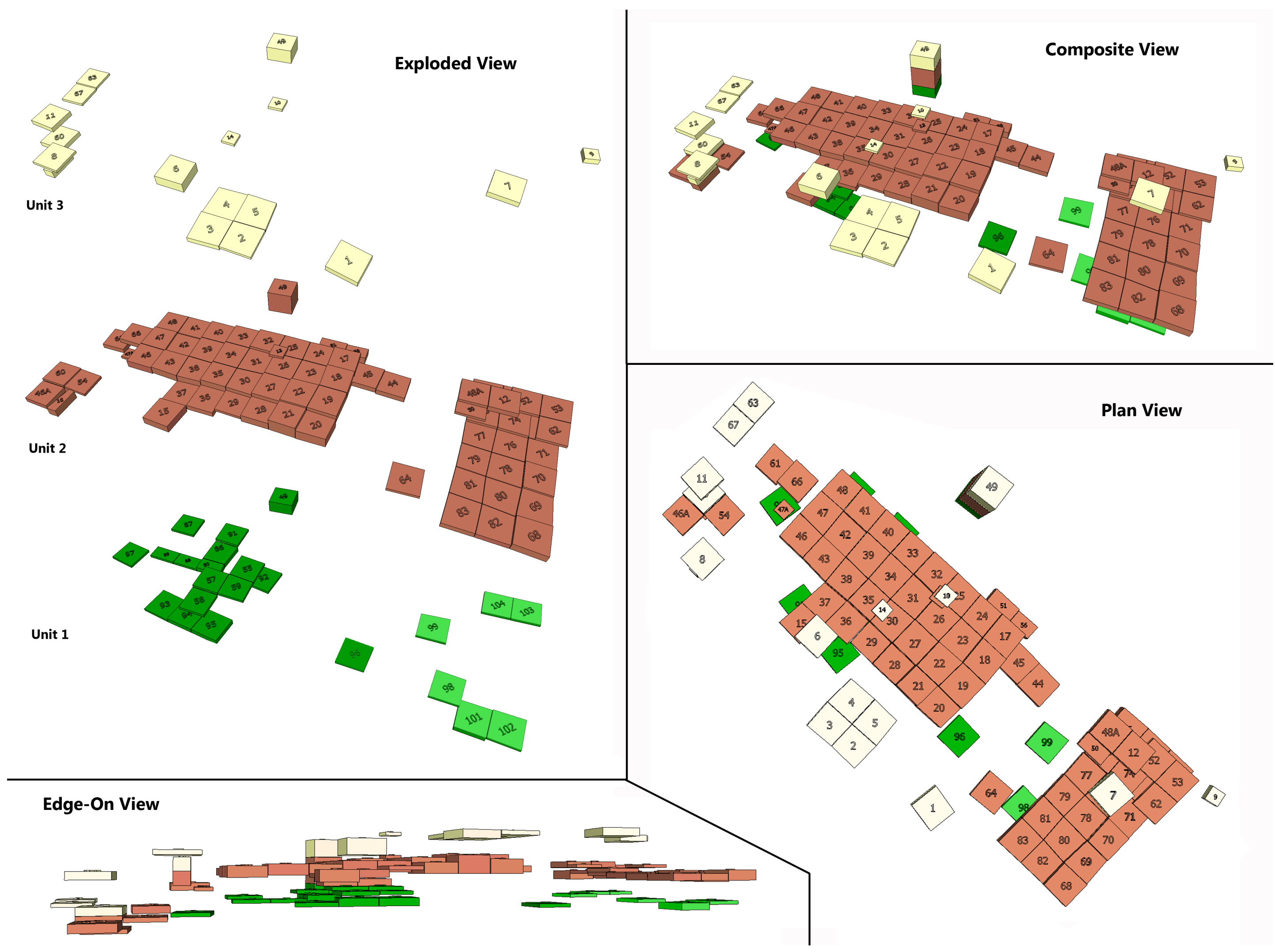

Figure 5-7. Static and exploded views of hand excavation units within the data recovery block, coded by stratigraphic assignment. Light yellow = Unit 3; brown $=$ Unit 2; pale green = Unit $1 \mathrm{~b}$; dark green $=$ Unit $1 \mathrm{a}$. Views are screen shots of a rotatable, dynamic model of unit locations prepared from TDS data in Google Sketch-Up. 
This page is intentionally left blank. 
measurements. After magnetic susceptibility was measured, each cube was opened and subsampled to provide material for the remaining analyses.

\section{Magnetic Susceptibility}

Magnetic susceptibility is a general measure of the degree to which a sample may be magnetized, and provides basic information on the magnetic mineralogy of the sample, which may vary owing to a variety of factors, such as depositional processes, soil development, and human occupation. The general application of magnetic susceptibility in archaeological studies has been discussed in detail by Dalan (2008) and Dalan and Bannerjee (1998). Frequency dependent magnetic susceptibility was calculated on cube samples to detect the concentration of ultrafine $(<0.03 \mu \mathrm{m})$ superparamagnetic ferromagnetic minerals occurring as crystals produced by biochemical processes in soil (Dearing 1999). Each cube was weighed, and the low frequency $(470 \mathrm{~Hz} ; \chi$ if $)$ and high frequency $(4700 \mathrm{~Hz} ; \chi$ hf) magnetic susceptibility was measured at the 0.1 setting on a Bartington MS2 meter using an MS2b sensor. The mass corrected magnetic susceptibility $(\chi 1 \mathrm{f})$ and coefficient of frequency dependency $(\mathrm{Cfd})$ were then calculated. The coefficient of frequency dependency $(\chi \mathrm{fd})$ is the percentage difference in magnetic susceptibility measured at low and high frequency:

$$
\chi \mathrm{fd}=((\chi \text { lf }-\chi \text { hf }) / \chi \text { lf }) \times 100
$$

Elevated values of $\chi$ fd (greater than approximately 10 percent (Gale and Hoare 1991:213)) are indicative of increased concentrations of fine-grained ferromagnetic minerals such as maghemite and magnetite in topsoils (Dearing et al. 1996).

\section{Particle Size Analysis (Texture)}

The particle size distribution (or texture) of each sample was determined on a Beckman-Coulter LS 13-320 multi-wavelength laser sizer. Samples were first subsampled, and then placed in a small beaker on a hot plate to which concentrated (30 percent) hydrogen peroxide was added in order to remove organic matter and a five percent solution of sodium hexametaphosphate was added to disperse the fine fraction. Samples were brought to a boil and then left on the hot plate until the reaction had ceased or the color of the sediment had changed, at which point they were removed from the hot plate, cooled and then measured on the LS-13-320. The results of these analyses are presented as percentages of sand, silt and clay, as well as in the form of descriptive statistics that are presented in phi units (a negative log base 2 conversion of millimeters). In the phi system, sands exhibit phi values between 0 and 4 , silts between 4 and 9 , and clay $>9$ phi. The USDA soil texture class for each sample was determined using the Soil Texture calculator provided by the NRCS website (NRCS n.d. c).

\section{Calcium Carbonate Equivalent (CCE)}

Calcium carbonate equivalent content (\%CCE) was calculated using a Chittick apparatus according to the following method. A small split (either $1.7 \mathrm{~g}$ or $0.85 \mathrm{~g}$, depending on the apparent carbonate content) of each sample was finely ground and passed through a $0.075-\mathrm{mm}$ 
sieve, weighed, placed into a 250-ml Erlenmayer flask, and connected to the Chittick apparatus. The liquid level in the measuring burette was then set to $-10 \mathrm{ml}$, the stopcock was closed so no gas could leave the system, and the leveling bulb was dropped to establish a vacuum inside the flask. At this point, the temperature and barometric pressure in the room were recorded. Then, $10 \mathrm{ml}$ of 50 percent strength (approximately $6 \mathrm{~N}$ ) hydrochloric acid was introduced into the flask, which was agitated intermittently until the reaction had ceased. At this point, the leveling bulb was raised until the liquid levels in the bulb and burette were equal, the volume of gas evolved was measured, and the calcium carbonate equivalent was calculated according to the method of Dreimanis (1962).

\section{Organic Carbon and Stable Carbon Isotopes}

The stable carbon isotopic composition of soil organic matter was determined by the Stable Isotope Research Unit, Department of Crop and Soil Science, at Oregon State University Corvalis, Oregon. Samples were first decalcified by reaction with hydrochloric acid, rinsed repeatedly, oven dried, and then finely ground.

The organic carbon for each sample was determined by calculating the amount of carbon dioxide released during combustion at $1000^{\circ} \mathrm{C}$ in a Carlo Erba NC2100 Elemental Analyzer (EA). The carbon dioxide was then passed through a heated column of copper and separated from nitrogen on a gas chromatograph column, and sent to the mass spectometer in a helium stream for measurement. To calculate percent carbon the mass spectrometer records the area under the curve for the carbon dioxide peak. Standards with known amounts of carbon are analyzed in each daily run, and the relationship between peak area, known percent carbon, and sample mass are used to calculate the percent carbon of unknown samples.

For stable isotope determination the finely powdered sample was weighed into tin capsules that were then flash combusted at $1700^{\circ} \mathrm{C}$ in the presence of a pulse of oxygen which converted all the carbon to CO2. The resulting CO2 was then carried to a PDZ-Europa 20/20 Isotope Ratio Mass Spectrometers by a capillary interface. The PDZ-Europa 20/20 has a precision of $+0.2 \%$ $13 \mathrm{C}$ at natural abundance levels.

\section{Soil pH}

Soil $\mathrm{pH}$ was measured on Mettler-Toledo bench top $\mathrm{pH}$ meter using a 2.5:1 water:soil ratio. Samples were mixed with water and allowed to stand for four hours at room temperature before measuring. The sensor was rinsed with distilled water and allowed to stabilize between each measurement.

\section{Extractable Iron}

Dithionite-Citrate Extractable Iron was performed using the methods of Holmgren (1967; Burt 2004:636-637 Method 6C4). For this method, $1.000 \pm 0.001$ gram of finely ground ovendry soil was placed in a 250 erlenmeyer flask, mixed with 2 grams of sodium dithionite, 20 grams of sodium citrate and $125 \mathrm{ml}$ of water and shaken overnight on a reciprocating shaker. 
After removal from the shaker 10 drops of saturated sodium chloride solution was added as a flocculant and the flask and the contents diluted to $250 \mathrm{ml}$ using a graduated cylinder. The solution was then shaken and left to stand for two hours, after which $0.25 \mathrm{ml}$ of the solution was pipetted to a graduated test tube, and $10 \mathrm{ml}$ water added. A small spatula was used to add a pinch of sodium dithionite and sodium citrate to the test tube, after which $0.5 \mathrm{ml}$ of a 0.25 percent solution of orthophenanthroline was added, and then a pipette was used to make the solution to $25 \mathrm{ml}$. The tube was then capped, shaken and left to stand for one hour for an orange color to develop, after which $10 \mathrm{ml}$ was transferred to a quartz cuvette and the concentration of iron was measured at $508 \mathrm{nM}$ using a Hach 2700 spectrophotmeter. The standard curve for the analysis was constructed from a $100 \mathrm{ppm}$ standard iron solution made dissolving 0.7023 ferrous ammonium sulfate in $20 \mathrm{ml}$ of $0.6 \mathrm{~N}$ hydrochloric acid, and then diluted to one liter in a volumetric flask. Aliquots of this standard solution were then used to prepare $25 \mathrm{ml}$ standard solutions of $5,10,25,50$ and $100 \mathrm{ppm}$ iron and the color developed for these as for the unknown sample, described above. Weight percent iron was obtained by dividing the mg iron by the weight of soil used (1 gram) and then divided by 10 . The weight percent Fe2O3 was obtained by multiplying the weight percent iron by 1.42 (Burt 2004: 636-637).

\section{Results of Geoarchaeological ANalysis}

\section{Stratigraphic Overview}

Although the localized stratigraphy exposed in the block excavation is well understood at this point, understanding of the broader stratigraphic setting of 41DL436 is less precise. Two gross stratigraphic units were noted in the trenches excavated during the exploratory phase of work in June, 2010. The majority of BT1, and the entirety of BT2 and BT3, exposed recent alluvial overbank deposits of Fish Creek underlying the T1B terrace, while the upper end of BT1 extended across the gentle terrace riser to the slightly higher $\left(\mathrm{T}_{1 \mathrm{~A}}\right)$ surface. Although the elevation of the two surfaces differs by less than a meter, the character of soil development indicated that the deposits underlying the higher surface are substantially older than those beneath the lower surface. All of the potential cultural material discovered during the first phase of work consisted of bone and burned strata associated with the more recent, stratified fill beneath the $\mathrm{T}_{\text {в }}$ surface. This fill was initially interpreted as rapidly aggraded overbank and natural levee deposits associated with Fish Creek, and was correlated with Ferring's Recent (post-Pilot Point) fill. Although the general age of these deposits was confirmed by subsequent work, data compiled since the report of the June work has established that the sediments were actually deposited in and adjacent to an abandoned channel of Fish Creek following an avulsion event (see below).

No cultural material was noted in association with the older fill, which was initially interpreted as a cumulic soil (the West Fork soil) representing slow aggradation of a deposit correlative with Ferring's Pilot Point alluvium. However, more detailed topographic and borehole data compiled since the report of the June work was completed suggests that this correlation is probably simplistic. Nevertheless, because the fill (or fills) underlying the $\mathrm{T}_{1 \mathrm{~A}}$ terrace were not addressed during the data recovery effort, the nature of the sequence remains relatively poorly understood. 
In the Trinity trunk system, where Ferring's allostratigraphic model was developed, the Pilot Point alluvium is either exposed at the floodplain surface or buried by a few meters of recent stratified alluvium; typically, the recent alluvium is present in proximity to the modern channel, while the Pilot Point is at the surface in more distal parts of the floodplain. This is very similar to the relationship between the older $\left(\mathrm{T}_{1 \mathrm{~A}}\right)$ and younger $\left(\mathrm{T}_{1 \mathrm{~B}}\right)$ fills at 41DL436. However, in the Trinity valley, the Pilot Point alluvium is stacked on a succession of (primarily) vertically aggraded Holocene and Late Pleistocene fills in a deep valley system (Ferring 1994). Detailed topographic and borehole data obtained for the 41DL436 vicinity suggest that this is not the case in the relatively small tributary valley of Fish Creek. Rather, it appears that the valley fill consists of inset lateral accretion deposits that represent a system that is cutting laterally and incising into the substrate, resulting in a style of alluvial architecture where younger units are laterally inset into older units. Evidence for this consists of the following:

- Detailed (2 ft contour) topography compiled from LIDAR data by the North Texas Council of Governments (NTCOG) (Figure 5-8) indicates several different constructional alluvial surfaces are present in the valley at elevations $12-26 \mathrm{ft}(3.6-8 \mathrm{~m})$ above the channel. In addition to the $\mathrm{T}_{1 \mathrm{~B}}\left(490-494 \mathrm{ft}\right.$ amsl, or 16-20 ft above the channel) and $\mathrm{T}_{1 \mathrm{~A}}(494-500 \mathrm{ft}$ amsl, or 20-24 ft above the channel), there is a low floodplain ( $\left.\mathrm{T}_{0}\right)$ on the point bars at 486-490 $\mathrm{ft}$ amsl (12-16 ft amsl) and a probable $\mathrm{T}_{2}$ terrace remnant downstream at 498-405 $\mathrm{ft}$ amsl. Stacked architecture, as is characteristic of the Trinity, would result in a relatively level, valley-filling floodplain.

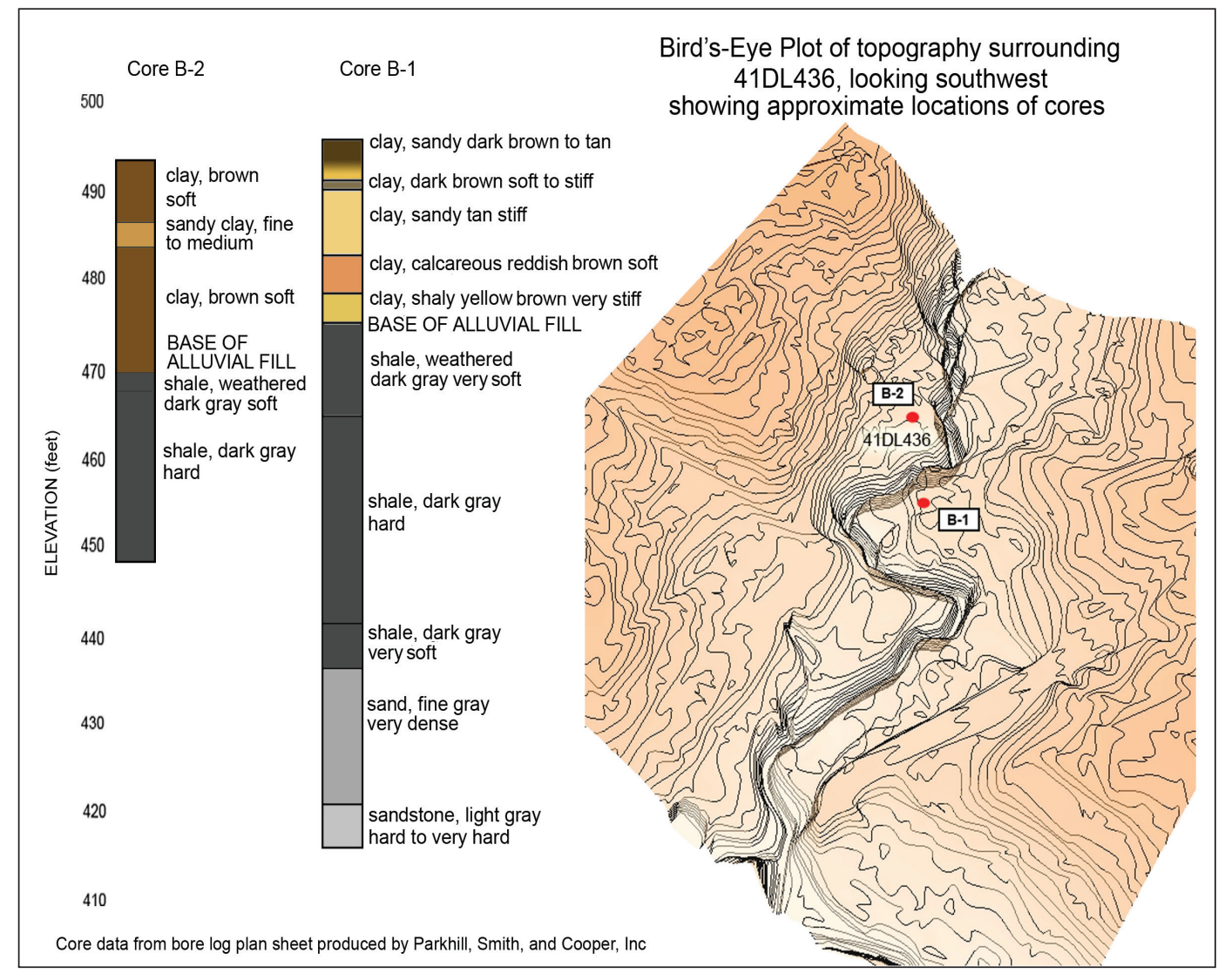

Figure 5-8. Character and location of geotechnical cores. 
- Core data compiled for the project (Bureau Veritas 2008; see Figure 5-8) indicates that the fill beneath the $\mathrm{T}_{1 \mathrm{~A}}$ surface north of the channel rests on bedrock at $(478.5 \mathrm{ft}$ amsl), while the base of the $\mathrm{T}_{1 в}$ fill is at $470 \mathrm{ft}$. This demonstrates that several meters of incision occurred between the deposition of sediments on the north side of the valley and the recent deposits on the south. Equally telling, the sequences of sediments recorded in the two core logs bear no resemblance to each other, and the higher (and presumably older) of the two cores records the presence of a reddened, calcareous fill at depth. Such reddish fills are common in the Late Pleistocene record in central Texas (e.g., Blum and Valastro 1989; Nordt 1992), where alluvial fills of this age are commonly perched on low benches above the stream. Although reddening is not noted in the Aubrey fill, the roughly time-equivalent unit in Ferring's Trinity sequence, its stratigraphic position at the base of the modern valley fill would have assured that it has been largely saturated for most of the Holocene, inhibiting oxidation.

- The soil developed in the exposed cumulic soil on the $\mathrm{T}_{1 \mathrm{~A}}$ surface near the site includes relatively large carbonate nodules in the B horizon (see below). These nodules, which are hard compound structures up to about a centimeter in size, do not occur in Ferring's description of the West Range soil. Nodules of this size are generally considered to represent a relatively protracted period of pedogenesis (see discussion below and in Abbott 2001), suggesting that this soil may have begun to form considerably earlier than the initiation of Pilot Point deposition in the Trinity valley (roughly $4.5 \mathrm{ka}$ ).

It should be noted that the sequence of deposits preserved in the Fish Creek valley does not necessarily represent direct climatic forcing of alluvial behavior. Although examples of such behavior have been convincingly argued in Texas (e.g., Blum 1989; Ferring 1994), climatic forcing of stream behavior is a complex topic, because landscape responses are often nonsynchronous, spatially varied, and governed by differing response thresholds (Bull 1991). Although extant evidence suggests that significant changes in regional climate occurred during the Late Pleistocene and Holocene, the preserved sequence could be the result of climate forcing, simple autocyclic variation in the character and loci of sedimentation due to migration of stream meanders in a slowly entrenching system, or (more likely) a combination of these intrinsic and extrinsic factors.

In contrast to the lingering uncertainty surrounding the $T_{1 \mathrm{~A}}$ terrace deposits, the $\mathrm{T}_{1 \mathrm{~B}}$ terrace deposits exposed by the data recovery excavations are well understood. These deposits consist of discrete, well preserved depositional strata that are well-dated, and reflect a relatively clear (albeit complex) depositional history. The Gradall block excavated for data recovery was situated to target the younger fill, where all the potential cultural material had been noted previously. Based on exposure in the block, this younger deposit was subdivided into two informal stratigraphic units based on a thin intercalated paleosol. In addition, a third, previously unseen informal stratigraphic unit was detected at depth in the data recovery block. This unit is older than the highly stratified material, but younger than the sediment(s) underlying the $\mathrm{T}_{1 \mathrm{~A}}$ terrace. 
The three stratigraphic units exposed in the excavation block were designated Units 1 through 3 (from oldest to youngest). Because the deposits noted beneath the $\mathrm{T}_{1 \mathrm{~A}}$ surface during testing were not exposed in the block, they were not included in the nomenclature developed for the data recovery stratigraphy. These older deposits are briefly described below, followed by a discussion of the deposits in the block excavation.

\section{Deposits beneath the $T_{1 \mathrm{~A}}$ Terrace}

The $\mathrm{T}_{1 \mathrm{~A}}$ terrace was addressed archaeologically only during the 2005 survey by Hicks \& Co. and the June 2010 evaluation phase. Because it was not associated with buried cultural material, the field description of the soil is not supported by laboratory analysis, and the unit remains undated.

Figure 5-9 illustrates a typical profile exposed at the upslope end of BT1, in an area mapped as Altoga silty clay. Altoga soils are typical of sloping erosional uplands in the Blackland Prairies. Although they are characterized by moderate to relatively prominent calcic horizons with "medium and coarse calcium carbonate concretions" (USDA n.d.b.), Altoga soils are classified as Inceptisols (Udic Haplustepts) because they exhibit a weak epipedon (Ap-Bk profile) due to pronounced sheet erosion. As the photo illustrates, the A horizon of the soil underlying the $\mathrm{T}_{1 \mathrm{~A}}$ terrace in BT1 is far from weak. Rather, it is approximately $75 \mathrm{~cm}$ thick, not counting the veneer of grayish, pebbly slopewash or the $35-\mathrm{cm}$ thick, transitional ABk horizon. This is quite thick for an organic A horizon, and suggests that the soil is either overthickened due to protracted deposition of organic sediment or as a result of vertic mixing (or both).

The thin veneer of somewhat gravelly clay capping the sequence represents colluviallyreworked sediments, and grades into the feather edge of the younger fill downslope. This veneer is very dark grayish brown to very dark brown, exhibits a moderate to strong blocky structure, and contains prominent carbonate filaments on ped faces. Given its thickness and general character, it is possible that this stratum is the result of plowing of the terrace surface during the historic period, but conclusive evidence for this (e.g., furrow cuts, plow-pan) was not observed in the exposed profile. Another distinct possibility is that it represents the same episode of Late Holocene erosion in the basin identified in the pollen study (see below and Chapter 11).

The underlying Bk horizon is characterized by dark brown massive clay containing similarly colored, hard, compound carbonate nodules. A few of these nodules are up to a centimeter in size, while most are considerably smaller. All exhibit an irregular knobby surface reflecting their origin as fused clusters of smaller nodules. No carbonate filaments, films or powdery matrix carbonate was noted in the horizon, suggesting that the nodules are probably residual features. No cultural material of any type was noted in association with this older fill by Hicks \& Company or during the June 2010 evaluation. The unit was not sampled during data recovery. 




Figure 5-9. Typical profile of soil capping the higher ( $\mathrm{T}_{1 \mathrm{~A}}$ terrace).

\section{Deposits Exposed in the Block Excavation and Deep Probe}

Three basic allostratigraphic depositional units, designated Units 1-3 from oldest to youngest, were identified in the mitigation block and the deep probe trench excavated into the floor of the block. Two of these units were further subdivided in the profile (into Units $1 \mathrm{a}$ and $1 \mathrm{~b}$, and $2 \mathrm{a}$ and $2 \mathrm{~b}$, respectively), but these fine subdivisions proved difficult to correlate with the hand excavation units. Figure 5-10 illustrates the eastern wall of the block excavation, both in photomosaic format and in schematic form with the units defined. Even casual examination of this figure quickly reveals the basic geometry of the sequence of units: Unit 1 represents a relatively homogeneous, buried alluvial fill deposited as a floodplain soil on the margin of a relatively deep channel, Unit 2 represents a highly stratified deposit that partially fills and overtops this channel before stabilizing and allowing a thin paleosol to develop, and Unit 3 
represents an initially stratified deposit that completely fills the channel and further builds up the floodplain surface before again stabilizing and allowing the weak surface soil to form. The following discussion fleshes out this sequence, and provides detail on the characteristics of each fill unit and their implications for preservation of the archaeological record.

Figure 5-11 illustrates analytical data from two stratigraphic columns collected in the block excavation. Column GW-1 was collected from the western block wall during the October 14 trip, and extends from the surface to a depth of approximately $135 \mathrm{cmbs}$ (the depth of excavation at the time). Although treated as a single column, the samples were actually offset by approximately $1.5 \mathrm{~m}$ at the safety bench (see Figure 5-6). Column GW-2 was collected on October 30 after the hand excavation had been completed, and extends through the deposits to a depth of approximately $3.2 \mathrm{~m}$ below the surface. This depth includes the main block and the deep probe trench excavated into the floor of the block. This column actually had two offsets, one of approximately $1.5 \mathrm{~m}$ at the safety bench and one of approximately $2 \mathrm{~m}$ at the base of the main block (Figure 5-12).

One of the first tasks of the geoarchaeological analysis was to use available data, including the geomorphic profiles, level and feature records, and photographs, to correlate and assign each hand excavation unit level to the depositional sequence for use by the Project Archaeologist in defining archaeological components. Although each of the hand excavation units was assigned to one of the primary depositional strata, it was generally not possible to confidently correlate and assign the hand excavation units to a particular unit subdivision. Consequently, Units $2 \mathrm{a}$ and $2 \mathrm{~b}$ were not subdivided, and excavation units belonging to Unit $1 \mathrm{~b}$ were identified primarily based on direct radiocarbon evidence and position in the block (see discussion of Unit $1 \mathrm{~b}$ below).

\section{Unit 1}

Unit 1 is the deepest deposit exposed in the block excavation. It was not discovered during the earlier evaluation phase in June, but came to light in the deeper part of the block excavation. Unit la consists of a relatively uniform, dark gray-brown loam that grades down into a sandy loam with depth. It is subdivided into Unit 1a, which represents the majority of the fill, and Unit $1 \mathrm{~b}$, which consists of a thin, northward dipping and thickening wedge of sediment that caps the unit (see Figure 5-10). Both units were relatively lightly excavated by hand. Unit $1 \mathrm{~b}$ is represented by a total of 8 levels (Units 98-99 and 101-104), while Unit 1a is represented by 27 unit levels, several of which represent $1 \times 0.50$ units. Paleosol 2, the deeper of the two paleosols defined on site, is developed through and welds both subunits into a single, overthickened floodplain soil. However, this pedogenesis was clearly penecontemporaneous with the aggradation of Unit 1 and does not represent a significant depositional hiatus in the sequence.

\section{Unit 1a}

Unit la was exposed between approximately 98-96.25 $\mathrm{m}$ (relative to the arbitrary 100-m datum) in the eastern wall of the block and the deep probe trench. The unit clearly extended deeper into 



Figure 5-10. Photomosaic and schematic profile of eastern wall of excavation block. 


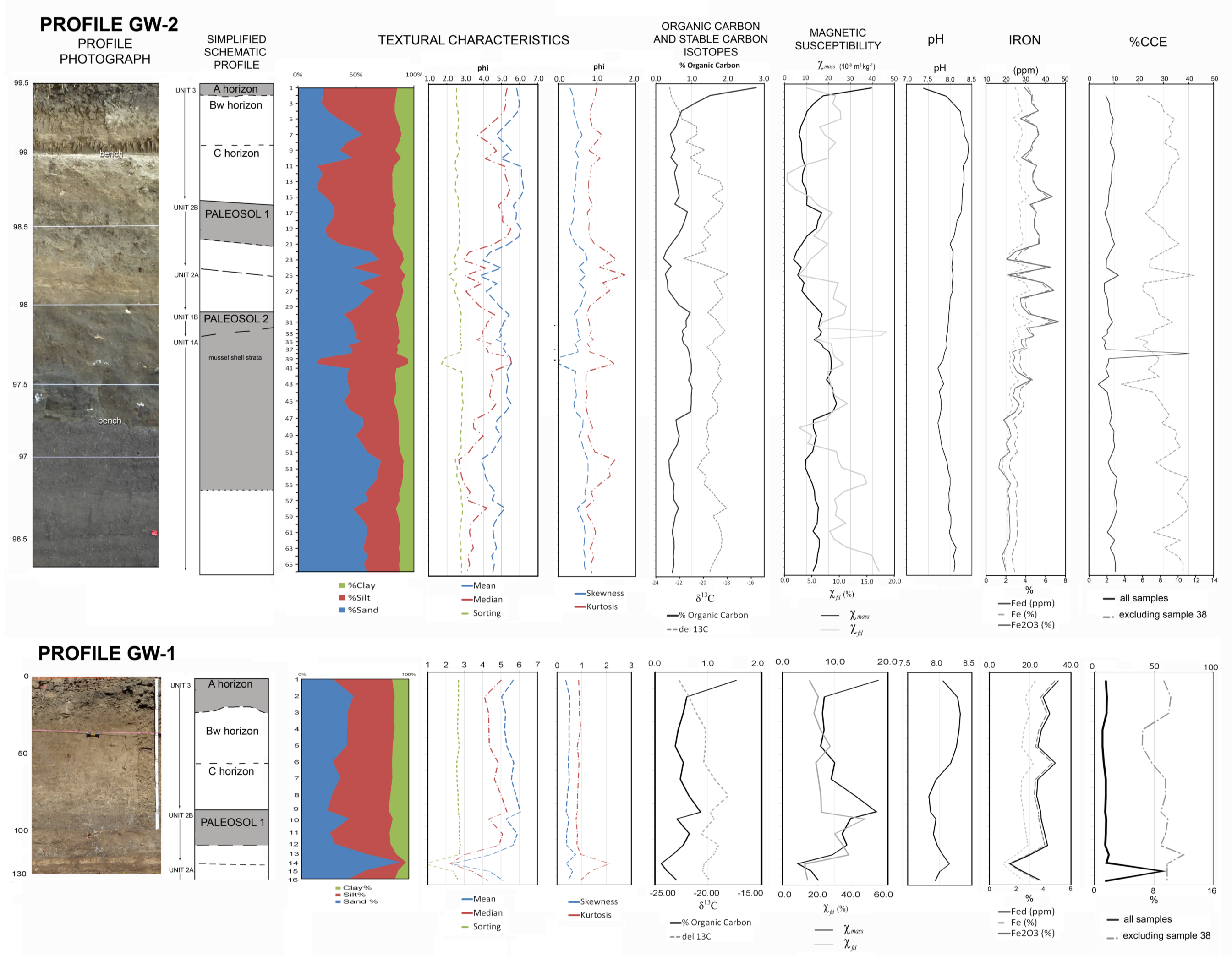

Figure 5-11. Results of analyses of profiles GW-1 and GW-2. 


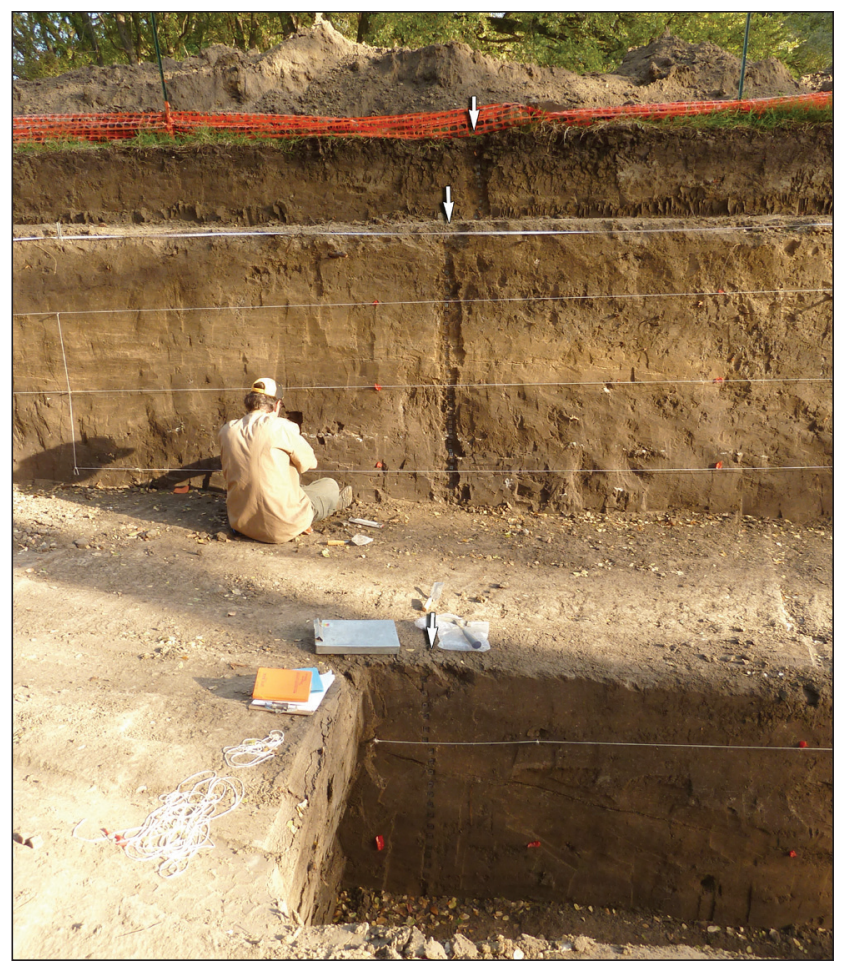

Figure 5-12. Photograph of sample column GW-2 (note arrows showing column offsets). the floodplain fill, but the trench was discontinued to permit safe entry and documentation of the exposed profile. Accordingly, the lower boundary of the unit is undefined. The upper boundary is defined with its contact with Unit $1 b$ (in the northern part of the block) and Unit 2 (in and adjacent to the paleochannel in the central part of the block). Unit 1 is not present at the southern end of the block.

The exposed $1.75 \mathrm{~m}$ profile of Unit 1a grades from a thick, very dark brown (10YR 2/2) to very dark gray (10YR 3/1), massive silt loam (locally silty clay loam) Akb horizon (97.95 to 97.25 $\mathrm{m})$, through a dark grayish brown $(2.5 \mathrm{Y}$ $4 / 2)$, massive sandy loam ABkb horizon (97.25-96.85 m), into a dark gray (10YR 4/1), massive loam to sandy loam Bkb horizon (96.85-96.3 m). The Ak-ABk horizon sequence is approximately 110 $\mathrm{cm}$ thick, and the transition between horizons is gradual. The most distinguishing characteristics of Unit 1a are its uniformity of color (10YR 2/1 to 3/2), lack of soil structure, and absence of preserved sedimentary structures. There are 1-2 percent prominent thick $\mathrm{CaCO}_{3}$ filaments in the $\mathrm{Akb}$ and $\mathrm{ABkb}$ horizons, and 2-4 percent in the Bkb horizon, but their visibility is limited in cut faces due to the lack of pedality. The entire unit is friable to very friable. There are very few roots, and only the occasional small (large insect-scale) krotovina. A few small, dispersed helical snail shells were noted in the Bkb horizon, but inclusions are primarily concentrated in a thin (approximately $20 \mathrm{~cm}$ ) zone of presumed culturally-related mussel shell in the middle of the A horizon, roughly $50 \mathrm{~cm}$ below the top of the unit. This shell lens extends for at least $4 \mathrm{~m}$ along the profile and slopes at a very shallow angle ( $<5^{\circ}$ degrees) to the south. Other cultural and potential cultural inclusions include localized, flat-lying burned strata and bone fragments, which are dispersed through the upper meter (approximately) of the fill.

Laboratory analysis of the unit (see Figure 5-11) suggests that the upper Akb horizon is dominated by loam, with some samples grading to silt loam or sandy loam, while the lower Akb horizon and Bkb horizon are predominantly sandy loam. Even though both horizons exhibit filaments that probably represent ongoing carbonate enrichment, the Akb horizon appears to be slightly decalcified in comparison with the $\mathrm{Bkb}$ (although the calcium-carbonate equivalent percentage (C.C.E.) of $\mathrm{Akb}$ and Bkb sediment samples averages 9.6 percent and 9.9 percent respectively, the average of the Akb is artificially elevated by one anomalous reading of 40 percent C.C.E. When that sample is excluded, the Akb average falls to a C.C.E. of 7.7 percent, suggesting that the upper unit is slightly decalcified. 
Organic carbon is somewhat elevated in the A horizon, but is still quite modest, ranging between approximately 0.36 percent and 1 percent organic carbon. In comparison, the modern soil has a maximum of approximately 2.8 percent organic carbon, but this falls rapidly to approximately 0.6 percent organic carbon $30 \mathrm{~cm}$ below the surface. The distribution of organic carbon through Unit 1a indicates several subtle peaks that may reflect relict stratification. The most striking trend is a sudden reduction from values of nearly 1 percent to values of less than 0.6 percent at the Ak-ABk boundary, but it is also interesting that the values through the mussel shell strata are relatively low (0.73-0.76 percent) while those underlying it are relatively high (greater than 0.9 percent), suggesting that the mussel shell rests on a stable surface that has been obscured by welding of more recent cumulic sediments.

Magnetic susceptibility measures also hint at relict stratification. The simple low frequency measure $\left(\chi_{\text {mass }}\right)$, closely tracks the measured organic matter content through the unit, but the ratio between high frequency and low frequency measures $(\chi \mathrm{fd})$ reveals several prominent spikes in the lower ABk and Bk (see Figure 5-11). Interestingly, the various forms of extractable iron show relatively low concentration throughout the unit, suggesting that overall iron mobility (primarily those resulting from anoxic processes during saturation) was probably relatively low. Soil $\mathrm{pH}$ is moderately alkaline and relatively stable, ranging approximately $7.7-8$ in the $\mathrm{Akb}$ and $\mathrm{ABkb}$ horizons and 7.95-8.15 in the Bkb horizon.

Two micromorphological samples extracted from Unit 1 were examined by Frederick (see Appendix A). Sample 3 was taken from the wall of Excavation Unit 49, in the west wall of excavation block, immediately below the contact with Unit 2, while Sample 5 was taken from the east wall of the excavation block and included the prominent, stratified mussel shell feature (Feature 11). The latter clearly represents Unit 1a, while the former could represent either subunit. Neither of these samples exhibited evidence of primary sedimentary structures, and both consisted of primarily subangular to subrounded quartz, with minor sedimentary rock inclusions, in a dark brown micromass. Both samples are dominated by excrement pedofeatures reflecting the almost total reworking of the sediment by earthworms and other microfauna. However, the earthworm pellets are densely packed and difficult to discern, and there is little evidence of developing pedality (soil structure). Dispersed fragments of charcoal were common in both samples, and charcoal, burned and unburned mussel shell, bone fragments, and snail shells were noted in the $2-3 \mathrm{~cm}$ thick occupation zone represented by the mussel shell in Sample 5. Both samples also exhibited secondary carbonate pedofeatures, including hollow-cored filaments and occasional fine nodules. Excrement pedofeatures dominate the fabric except in proximity to the mussel shell of Feature 11, where worm movement was impeded by the shell layer.

The upper boundary of Unit 1a defines the ground surface at the time the unit was abandoned. This interface slopes away in both directions from a high point in the middle of the block. To the south, the contact dips into an infilled stream channel at an average angle of approximately $34^{\circ}$ degrees (probably coincidentally, this is precisely the angle of repose for dry sand), extending to a depth of at least $95.66 \mathrm{~m}$ (roughly $2.4 \mathrm{~m}$ below the top of the unit). This sharply bounded paleochannel cuts across the floor of the block at an angle, intersecting the east wall of the block at approximately $15 \mathrm{~m}$ south and the west wall at approximately $18 \mathrm{~m}$ south of the north 
wall. Sediments above this boundary represent Unit 2a. To the north, the surface of Unit 1a dips irregularly at an inclination of approximately 2-4 degrees toward the modern channel. The sediments above this boundary represent the wedge of Unit 1b, which thins irregularly from approximately $50 \mathrm{~cm}$ maximum depth to pinch out against the highest part of Unit 1a.

The origin of this more gently-inclined paleosurface is almost certainly erosional. Although stream floodplains often develop a similar topography due to the deposition of coarse material as flooding waters leave the channel, that is not the case here. This is indicated quite clearly by the mussel shell bed in the upper part of the Unit 1a (Feature 11), which dips very gently toward the paleochannel and not away from it, as would be the case if the unit had aggraded as a natural levee. This suggests that the top of the unit was scoured as the system shifted from deposition of Unit 1a to Unit 1b. The seven accepted radiocarbon ages from Unit 1a range from $500 \mathrm{BP}$ (AD 1406-1444) to $1090 \mathrm{BP}$ (AD 893-997 and AD 1004-1012) (Figure 5-13). An additional age of $1920 \pm 30 \mathrm{BP}$ (AD 20-130) obtained on a mussel shell from Feature 11 is rejected. Dating of the overall sequence is discussed more thoroughly in a subsequent section.

In summary, Unit 1a consists of a sandy to loamy alluvial unit deposited on a vegetated point bar. Radiocarbon dates on Unit 1a samples suggest that it aggraded relatively slowly through the latest Holocene, and terminated with a transition to Unit $1 \mathrm{~b}$ sometime after $500 \mathrm{BP}$. At least one occupation, manifest as an extensive scatter of freshwater mussel shell, is stratified within the upper part of the unit. The termination of Unit 1a deposition represents the beginning of a significant hydraulic shift in the Fish Creek system, as discussed further below.

\section{Unit 1b}

Unit $1 \mathrm{~b}$ consists of a wedge of very dark loam and sandy loam that is welded to the surface of Unit 1a. It is bounded by its contact with Unit 2 at the top and with Unit 1a at its base. It is thickest at the northern end of the unit and pinches out at the highest point adjacent to the channel. Unit $1 \mathrm{~b}$ only occurs in the northern part of the excavation block.

The overall color of Unit $1 \mathrm{~b}$ is slightly lighter than Unit 1a (typically 10YR3./1), and interbedded primary depositional features composed of lighter brown (10YR 4/3 to 10YR 5/2) sands and loamy sands are rare to common at different points in the profile. Overall, however, Unit $1 \mathrm{~b}$ resembles Unit 1a far more than the overlying units, and the boundary between the two subunits is not always visually apparent. Unfortunately, it was not present at the location of either section GW-1 or GW-2, so no laboratory data is available from the Unit. It is very similar to Unit 1a, however, in terms of texture, color, consistence, and carbonate morphology.

Preserved sedimentary features in Unit $1 \mathrm{~b}$ consist of isolated ripple laminae composed of brown fine sand encased in the darker gray-brown sediment (lenticular bedding), overprinted with bioturbation structures (primarily insect-scale) that disrupt the structures and contacts. These features are generally isolated, but occur in concentration within a larger lenticular bedform preserved between approximately $6.5 \times 8.5 \mathrm{~m} \mathrm{~S}$ in the east profile (see Figure 5-10). Where these paler brown ripples are present in Unit $1 \mathrm{~b}$, distinguishing the Unit 1a/1b boundary 

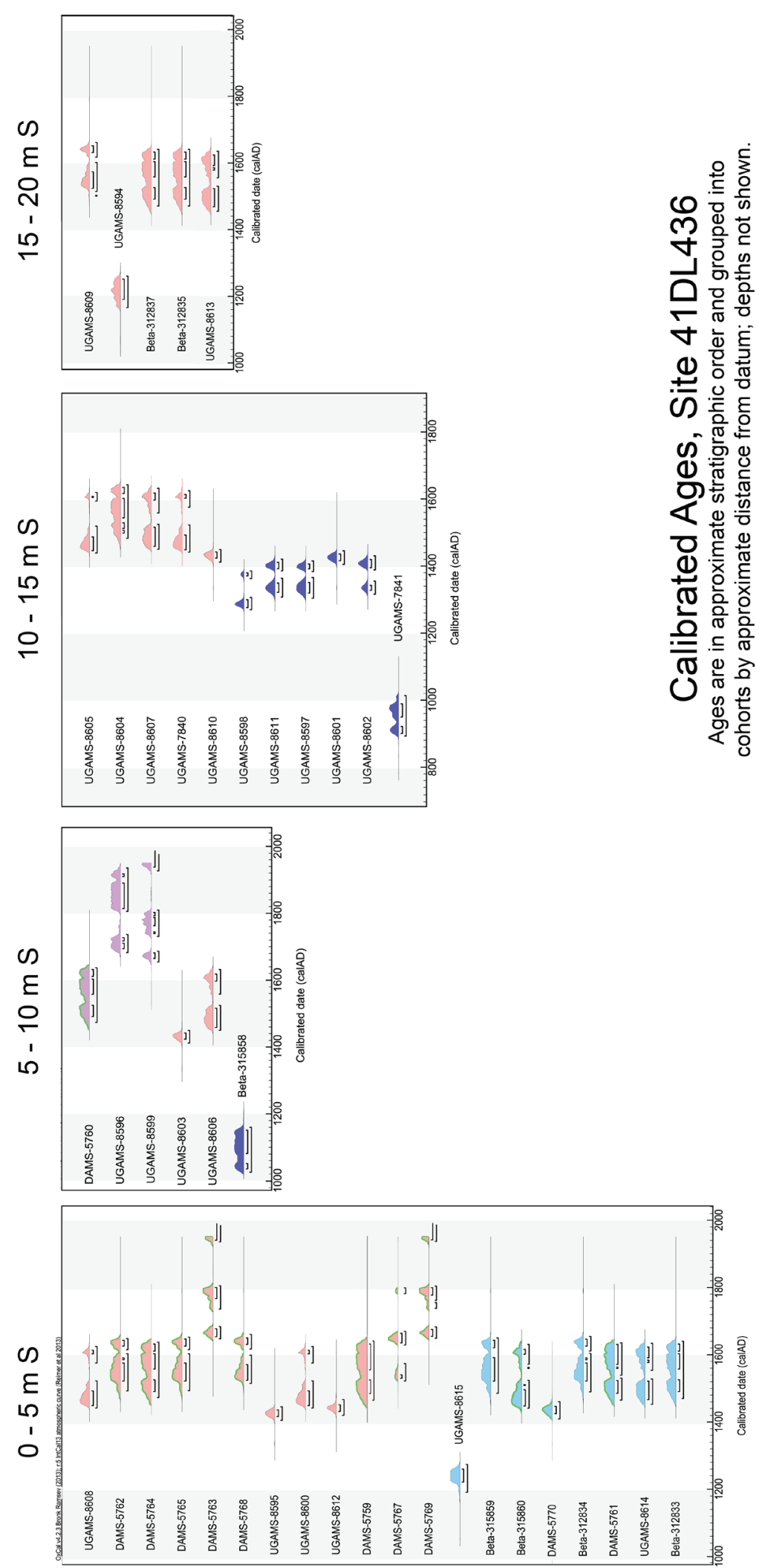

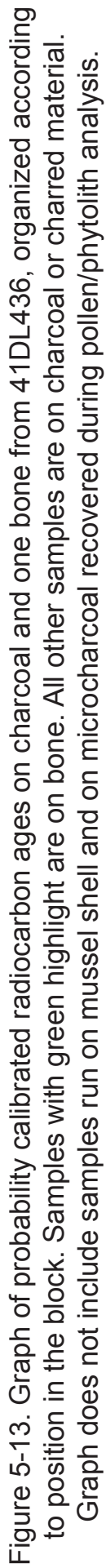


is relatively straight-forward; where they are absent, the boundary between the two subunits is extremely subtle.

In addition to the depositional features, which represent the input of lighter colored sands and loams during floods, there is a very distinct feature interpreted as a probable tree throw preserved in the east wall of the block at the contact between Unit 1a and 1b (Figure 5-14; see also Figure 5-10). This feature is a deep $(50 \mathrm{~cm}+)$ asymmetric pit with charcoal, ash, and burned earth in the bottom overlain by an offset paleodepression. The pit is intruded from the Unit 1a paleosurface, and is infilled with similar sediment with occasional pale sandy interbeds. Because of its asymmetry in shape, offset from the infilled pit in the paleosurface, and naturally-stratified fill, it is believed to represent a small tree throw (a pit produced when a tree is uprooted). However, the presence of charcoal, ash, and burned earth in the pit indicated that the tree was burned in addition to being uprooted, and it is very possible that the feature represents a byproduct of human activity.

Units $1 \mathrm{~b}$ and $1 \mathrm{a}$ are very similar and clearly related. In fact, the two units were no0t perceived as discrete units until the walls were scraped and profiled after primary excavation had concluded. Given this similarity, it is considered likely that the majority of the sediment making up Unit $1 \mathrm{~b}$ was derived from scour of Unit 1a, as the channel destabilized and prepared to avulse. Radiocarbon ages from the unit, however, are far from straightforward. Seven charcoal samples and two bone collagen samples were dated from Unit 1b. They ranged in age from 800 BP-300 BP, with seven of the samples dating to between 390-300 BP (calibrated ages between AD 1440-1650). In addition, one bone collagen sample yielded an age of $469 \pm 31$ BP (AD 1409-1460), and a radiocarbon age on mussel shell yielded an age of $1000 \pm 30 \mathrm{BP}$ (AD 990-1150). Interpretation of the ages from the unit is addressed below.

\section{Unit 2}

Unit 2 consists of a series of highly stratified sediment packets draped across the floodplain and in the abandoned channel. It contains a number of interstratified cultural lenses and features, including many dispersed bones and localized burns which clearly demarcate discrete paleosurfaces in the fill. This unit was the primary focus of hand excavations, and is represented by 158 unit levels representing 72 different excavation units.

Unit 2 is bounded at the bottom by its contact with Units 1a/1b (PS2). Within the paleochannel, the base of the deposits is not defined, and it may grade into channel sands associated with Unit 1 with no visible disconformity. The upper contact is defined by its contact with Unit 3 , and supports a weak cumulic paleosol with an A-C profile (PS1). In profile, Unit 2 is subdivided into two subunits (Unit 2a and Unit $2 \mathrm{~b}$ ) based on a very thick and prominent sandy bed with an erosional base; however, this contact (and hand units associated with them) could not be confidently identified in the hand unit records, and they are treated as a single analytical unit. The character of depositional strata in these two subunits are indistinguishable, suggesting they formed under the same general conditions. 


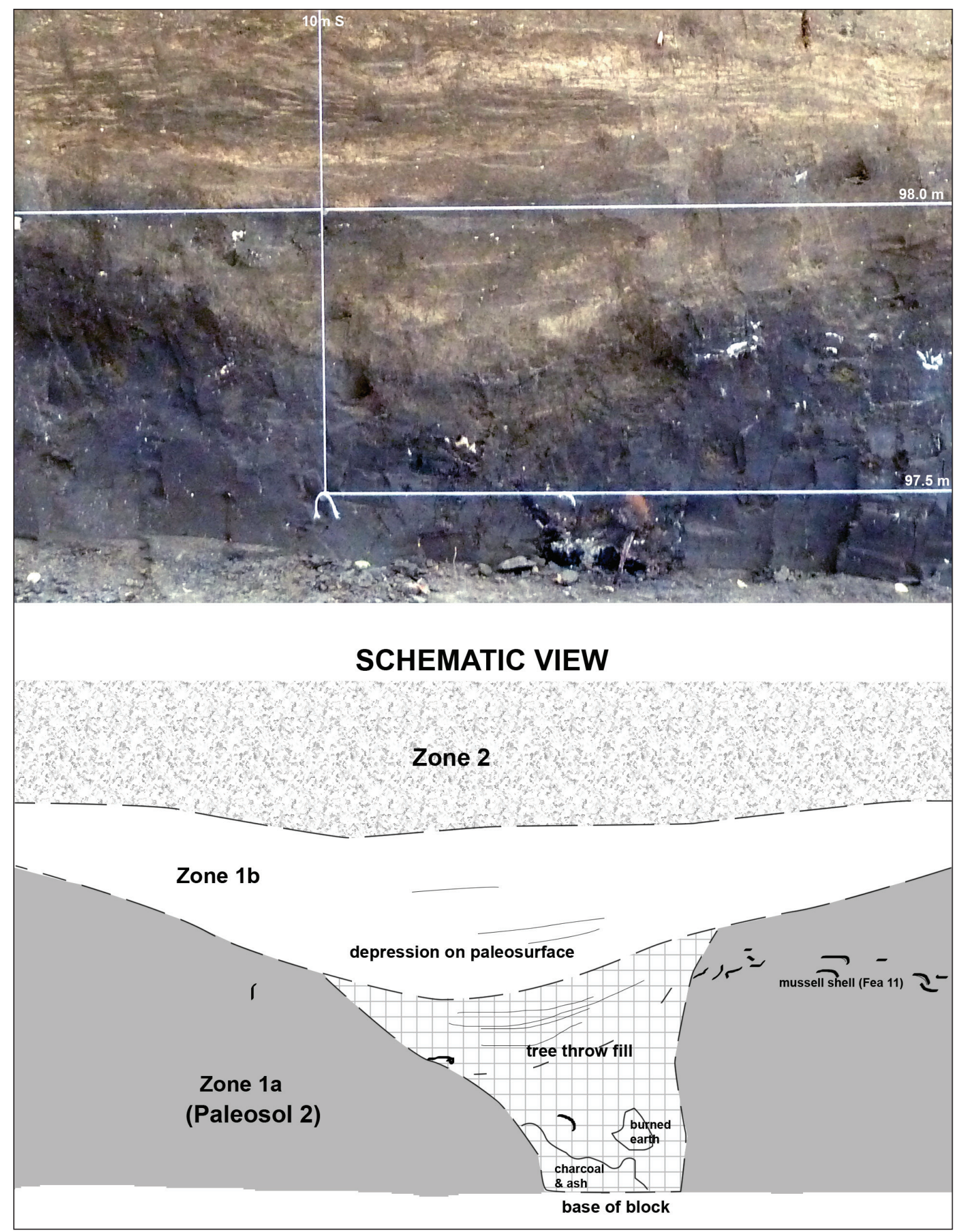

Figure 5-14. Photograph and sketch of tree throw feature at the Unit 1a-Unit 1b contact. 
Unit 2 reflects a sequence of silts and sands aggraded rapidly in a sediment-rich environment and sealed with minimal opportunity for reworking by burrowing organisms. Textural data (see Figure 5-11) indicate a system dominated by very fine sands and coarse silts and preserving detailed primary stratigraphy, resulting in distinctly varying proportions of sand and silt. There is also considerable variability apparent in soil iron, which is probably indicative of the deposition of channel sediments that had been subject to ongoing saturation (and therefore iron mobility) as well as iron mobilization in the site deposits following their deposition. Organic carbon and magnetic susceptibility is relatively low and unremarkable, while soil $\mathrm{pH}$ is consistently between 8.0-8.2. The upper part of the sequence exhibits a shift to a siltdominated environment, and PS1 is characterized by subtle but unmistakable increases in organic carbon and magnetic susceptibility.

The majority of Unit 2 exhibits prominent primary bedforms that reflect the articulation of brown and grayish brown silts and loams (10YR 4/2 to 10YR 5/3) with pale brown (10YR 6/2 to $10 \mathrm{YR} 6 / 3$ ) very fine sands and sandy loams. There are occasional thick (up to approximately $10 \mathrm{~cm}$ ), laterally continuous beds of laminated and ripple bedded sands and silts, but most of the unit consists of flaser (sand with muddy interbeds) and lenticular (mud with sandy interbeds) bedded sands and silts that are intimately interdigitated (Figure 5-15; see also Figure 5-10). These deposits are between approximately $50 \mathrm{~cm}$ and $125 \mathrm{~cm}$ thick as they drape across the floodplain and at least two meters thick in the channel. There are occasional clear burrow traces that interrupt the bedding. Small woody roots are occasionally present, but are not common. Carbonate films and filaments are common, particularly on the darker loamy sediments. In
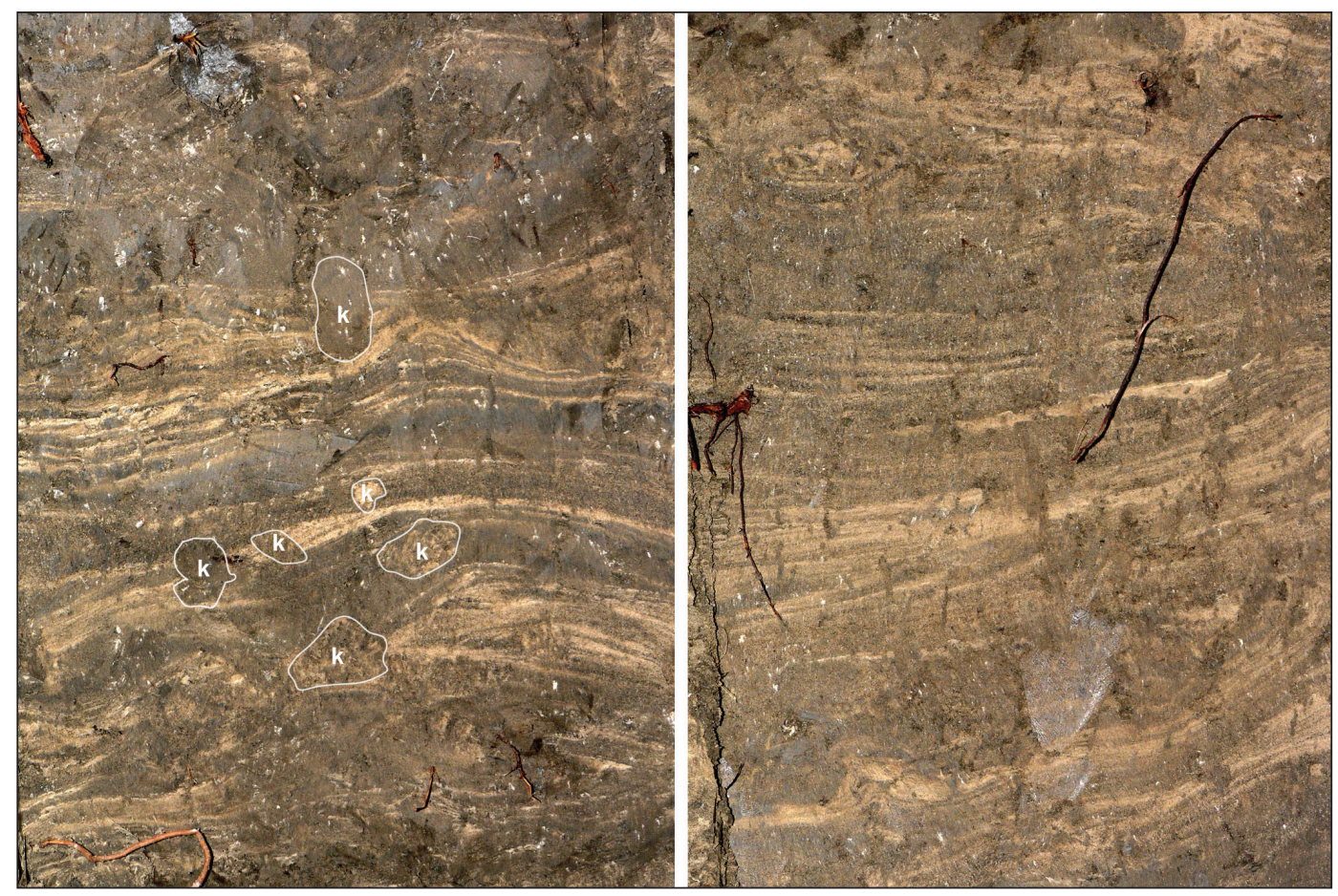

Figure 5-15. Examples of ripples and crossbedding in silts and loams in the deposits of 41DL436. Photographs are from the second phase of preliminary investigation in June 2010. Features marked with "k" in left pane are krotovina. Similar krotovina and root traces can be discerned in the right panel, but are not highlighted to allow the reader to draw their own conclusions. 
addition, small and relatively soft carbonate nodules are common locally, particularly in the infilled channel, and appear to be associated (at least in part) with bedding planes and former root traces (Figure 5-16).

The most noticeable characteristic of Unit 2 when viewed in section is the remarkable preservation of primary sedimentary structures. Root traces, concentrations of Celtis macrocarps in former rodent burrows, and broken depositional strata clearly suggest that the unit was turbated to a degree, but the degree of mixing appears minimal compared to most archaeological sites in alluvial

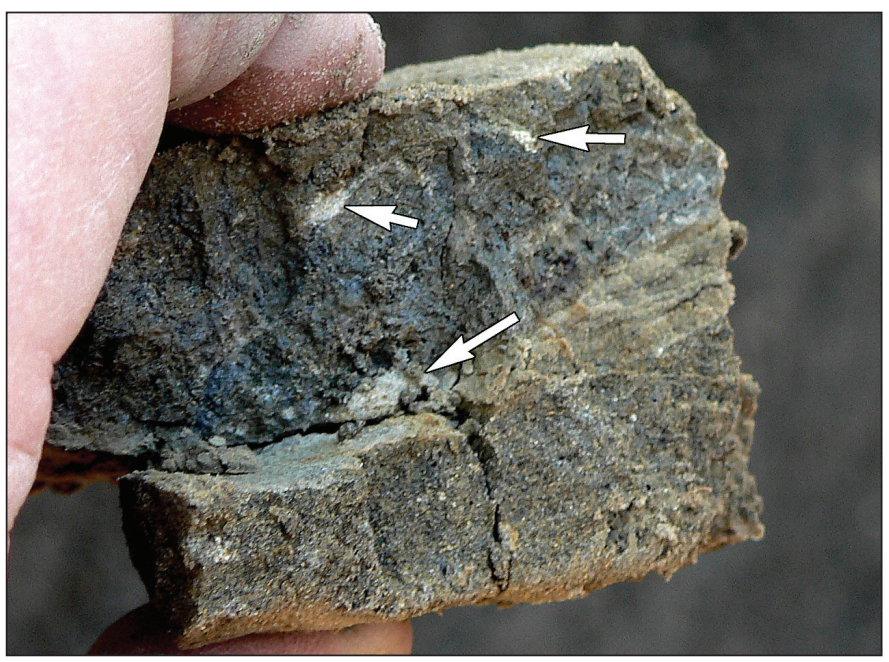

Figure 5-16. Photograph showing soft, incipient carbonate nodules developing in stratified silts and fine sands of Unit 2 (arrows). Carbonate filaments are also visible in finer grained material (upper right). deposits. In contrast, it is postdepositional disturbance features that are most prominent in thin section, particularly in finer-grained beds (see Frederick, this volume). Two samples were examined from Unit 2; one from the profile of Unit 49 on the west wall of the block, and one from a distinct burned zone just below the top of the unit in the channel swale. However, description of this latter sample focused on the characteristics of the burn rather than the matrix that hosted it, so this discussion is based primarily on the sample from Unit 49. At a microscopic level, primary stratification is apparent in "tonal variation" across the slide, but the dominant features apparent are excrement pedofeatures, vughs, and similar evidence of disturbance and reworking by microfauna. The basic constituents of the slide - subrounded quartz, minor sedimentary rock fragments, and a dark groundmass with a speckled b-fabric - are similar to the material noted in Unit 1. The prominence of microscopic disturbance features in this rapidly aggraded unit are testament to the speed with which organisms colonized and began to transform the alluvial sediments.

The deep probe excavated into the base of the block exposed sediments in the lower part of the abandoned channel. These sediments were extremely wet and could not be examined in any detail for safety reasons. However, observations of the cut floor of the trench suggest that somewhere below $96.5 \mathrm{~m}$, ripple bedding gave way to convolute bedding characterized by multiple fluid escape structures up to $30 \mathrm{~cm}$ in diameter (Figure5-17). These concentric structures, which represent bubble-like intrusions of laminated sediment, are typical of environments where high volumes of fluid-rich sediment are introduced very quickly (Reineck \& Singh 1980). Under pressure from the weight of overlying deposits, this fluid escapes in plumes that drag associated sediments upward, creating the concentric pattern seen in the trench floor. 
Twenty-three samples associated with Unit 2 were dated by the radiocarbon method. These ages range 208-500 BP, but ages from Unit $1 \mathrm{~b}$ indicate that the unit probably aggraded during the latter half of this time period. Discussion of the sequence follows description of Unit 3.

\section{Unit 3}

Unit 3 consists of material accumulated since Unit 2 was abandoned. Its lower boundary is the top of Paleosol 1, and its upper boundary is the modern ground surface. It is represented by 34 unitlevels, several of which were smaller than $1 \times 1 \mathrm{~m}$. Thickness of the unit varies from about $60-100 \mathrm{~cm}$ on the floodplain to almost two meters in the paleochannel. Unit 3 supports

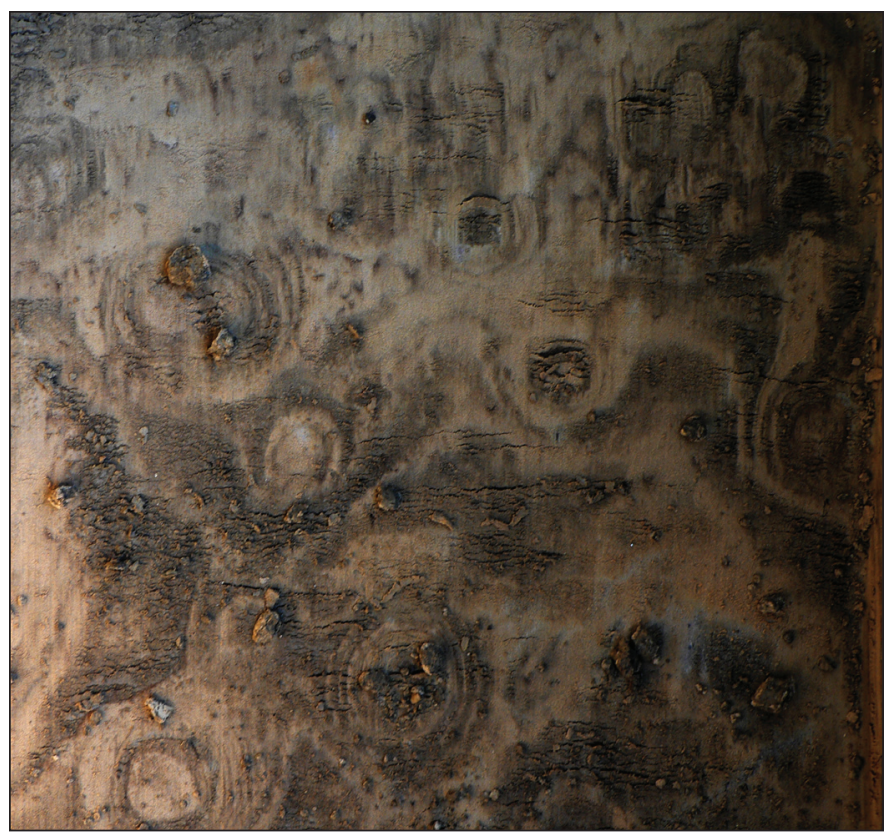

Figure 5-17. Looking down on convolute bedding structures at depth in the channel swale, exposed in the deep probe trench more than $4 \mathrm{~m}$ below the surface. These structures are indicative of dewatering (fluid escape) of rapidly deposited sediments. a relatively weakly developed A-Bw-C soil profile developed in silt loam and silty clay. The lowest part of the profile consists of silty loam with disrupted lenses of coarse silt and fine sand. As in Unit 2, the lighter colored materials are distinctly coarser grained, but sand is limited and the contrast here is between coarse silt on the one hand and silty loam and silty clay loam on the other. Individual lenses and couplets are highly disrupted by bioturbation, but laterally traceable as zones of similar sediments $1-3 \mathrm{~cm}$ thick, and remnant internal laminations and occasional crossbedding is often preserved in these thin zones. Visually, the lowest part of Unit 3 is similar to Unit 2, but it is markedly finer from a textural perspective. Calcium carbonate filaments are common, particularly in the darker, finer-grained sediments (10YR 3/1 to 10YR4/2), but no fine nodules were noted.

In the upper 40-60 $\mathrm{cm}$ of the section, primary stratification has been obliterated by soil development, forming a soil with an A-Bw profile. The textural data from profile GW-2 shows a dramatic increase in sand content above about $60 \mathrm{cmbs}$, while the GW-1 column it exhibits a much more modest increase. This shift clearly represents relict stratigraphic conditions, not changes wrought by soil development.

The Bw horizon consists of a massive to very weak blocky structured, dark grayish brown (10YR 4/2) silt loam with occasional weak carbonate filaments. The A horizon is about 20-30 $\mathrm{cm}$ thick and consists of very dark gray (10YR 3/1) to very dark grayish brown (10YR 3/2), fine blocky to granular structured silt loam. Organic carbon concentration and magnetic 
susceptibility are both several times higher in the upper Bw and A horizon than in the remainder of the profile, and $\mathrm{pH}$ is markedly more neutral. There is also a clear trend toward a more C3-dominated carbon isotope signature in the upper soil, increasing from about-18\%o a meter below the surface to $-23 \%$ at the surface in both GW-1 and GW-2.

One micromorphological sample was analyzed from the base of Unit 3 in the TP49 profile (see Appendix A). It revealed a distinctly laminated sequence of coarse (fine sand and coarse silt) and fine (dominantly silt) beds. The coarse beds have been reworked by fauna to a degree, but retain a fair degree of primary graded bedding. The fine beds, in contrast, have been almost completely reworked by soil fauna. Interestingly, mixing of the two types of beds appears limited. Three radiocarbon samples were recovered from features relatively high in Unit 3. Two samples on charcoal yielded ages of $110 \pm 25$ and $190 \pm 25$ BP, respectively, while a bone sample yielded a collagen age of $340 \pm 24 \mathrm{BP}$.

\section{Discussion of Chronometric Data}

Site 41DL436 represents a remarkably well-preserved Late Holocene stratigraphic sequence, and to date has yielded a sequence of 48 radiocarbon ages ranging from $5955 \pm 25 \mathrm{BP}$ to $110 \pm$ 25 BP. However, a few of these ages can be dismissed outright based on weight of the evidence considerations, and a surprisingly large number of others are considered to be slightly too old due to the use of old wood as a fuel source. This discussion considers the results of this dating program and its implication for the age of the site. To assure that the reader has sufficient background to follow the arguments, it begins with a basic discussion of radiocarbon dating as a technique. The reader is cautioned that this is a very limited introduction, and encouraged to review more thorough treatments of this complex topic (e.g., Libby 1955; Aitken 1974; Bradley 1985; Bowman 1990).

As devised by Libby (1955), standard radiocarbon dates are calculated based on a measured ratio between the proportion of normal isotopic carbon $\left({ }^{12} \mathrm{C}\right)$ and the radioactive isotope of carbon $\left({ }^{14} \mathrm{C}\right)$, both of which exist in the environment. All organisms incorporate both types of carbon into their molecular structure as a part of respiration and nutrient uptake, but upon death radiocarbon begins to decay to ${ }^{14} \mathrm{~N}$; therefore, the older a sample is, the smaller the proportion of ${ }^{14} \mathrm{C}$ relative to ${ }^{12} \mathrm{C}$. Using the known rate of decay from ${ }^{14} \mathrm{C}$ to ${ }^{14} \mathrm{~N}$ (like all radioactive elements, this rate is expressed as a time period in which half of the radioactive atoms can be expected to decay, and termed the radioactive element's half-life), the initial proportion of atmospheric ${ }^{14} \mathrm{C}$ in a sample, and the current proportion of ${ }^{14} \mathrm{C}$, it is possible to calculate the time elapsed since the organism represented quit incorporating new organic matter into the sample (usually this equates to when the organism died, but there are important exceptions, including trees; see below). In Libby's day, beta particles (electrons) released by nuclear decay were counted over a period of days or weeks, and the amount of ${ }^{14} \mathrm{C}$ was determined statistically based on expectations derived from the half-life. That process (radiometric dating) is still used, but has been largely supplanted by direct measurement of the proportion of ${ }^{12} \mathrm{C}$ and ${ }^{14} \mathrm{C}$ using an accelerator mass spectrometer (AMS dating) because much smaller samples can be dated. All of the ages in this study were dated with the AMS method. 
Raw radiocarbon ages are expressed in terms radiocarbon years before present (RYBP or simply BP). However, the "present" referred to is not actually the present, but rather AD 1950. This is a convention of reporting, and is done to provide comparability among ages. Radiocarbon assays are expressed with an error factor representing a one standard deviation (represented by the lower-case Greek letter sigma, or $\sigma$ ) spread about a Poisson probability curve; e.g. $1000 \pm 50 \mathrm{BP}$. Thus, there is a 68 percent statistical probability that the true age is within one standard deviation of the measured age (in the above example, between 950-1050 BP), a 95 percent probability that it is within two standard deviations (900-1100 BP), and a 99 percent probability that it is within three standard deviations (850-1150 BP). Of course, this means that there is one in 100 chance that the true age of any sample is more than three standard deviations away from the measured age.

"Calibration" refers to the conversion of a radiocarbon date from the radiocarbon scale to a calendrical age. This is accomplished statistically based on calibration against a correction curve constructed from samples of known age, to compensate for variations in atmospheric ${ }^{14} \mathrm{C}$. A variety of curves are available, but a standard curve for atmospheric (non-marine) samples has been recently agreed on (IncCal09; Reimer et al. 2009), and is used here. By convention, the two standard deviation spread is typically used in calibration, yielding a date spread that is statistically correct nineteen times out of twenty.

The preceding summary may seem simplistic, and it is. A number of the assumptions of the original radiocarbon method have been shown to be inaccurate, and corrections for them have been incorporated into analysis. For example, Libby originally calculated a half-life of carbon of 5568 years, while it is now estimated more accurately at $5730 \pm 40$ years. This is accounted for in calibration, but for reasons of comparability with previous ages, reported radiocarbon ages continue to use the original Libby half-life - this is the so-called "conventional" age, because the Libby half-life is being used by convention, even though it is understood to be less accurate.

A second basic assumption of the Libby equation is that the proportion of atmospheric radiocarbon has been constant. Again, this assumption is now known to be false - the proportion of atmospheric radiocarbon has fluctuated in response to changes in solar activity (cosmic ray bombardment of the upper atmosphere is primarily responsible for creating radiocarbon isotopes in the first place, so changes in the intensity of cosmic rays and in the character of the earth's magnetic field affect the their overall concentration) and climatically-driven changes in the rate of exchange between the atmosphere and terrestrial and marine carbon reservoirs. Dating samples of the last few centuries is further complicated by the tremendous release of "dead" carbon from fossil fuels since the dawn of the industrial revolution in Europe (the "Suess Effect") and dramatic increases in the concentration of atmospheric radiocarbon due to atmospheric testing of thermonuclear bombs since the late 1940s (Bradley 1984). The latter effect is so pronounced that radiocarbon dating of materials younger than the mid-1940s is not tenable.

Another key assumption of Libby's radiocarbon method is that atmospheric radiocarbon is taken up and incorporated by organisms in direct proportion to its atmospheric concentration. 
Again, this is known to be wrong - not all organisms incorporate carbon in equilibrium with the global reservoir, and most organisms take up the isotopically lighter $\left({ }^{12} \mathrm{C}\right)$ version of carbon preferentially in a process termed fractionation. Fortunately, those same organisms also fractionate a third isotope of carbon $-{ }^{13} \mathrm{C}$ - in a constant ratio with ${ }^{14} \mathrm{C}$. Because ${ }^{13} \mathrm{C}$ is stable and does not decay, the ratio between ${ }^{12} \mathrm{C}$ and ${ }^{13} \mathrm{C}$ can be used to determine the original ratio of ${ }^{12} \mathrm{C}$ and ${ }^{14} \mathrm{C}$ in a sample and correct the age for the fractionation effect. This yields what is known as a "corrected" age. Calibration is based on this corrected age.

Reservoir effects - that is, differences in the initial ratio between ${ }^{12} \mathrm{C}$ and ${ }^{14} \mathrm{C}$ due to differences in the source that the organism draws the carbon from-can be more difficult to deal with. There are a number of approaches to dealing with reservoir effects, particularly when they are predictable (e.g., marine samples drawing carbon from the ocean have their own curves), but in other cases (e.g., snails living in - and incorporating dead carbon from-limestone terrain), the effects can only be approximated. This type of error is generally termed the "hard water effect" because it is particularly prevalent in limestone terrain where isotopically dead carbon derived from geological carbonate minerals is dissolved in groundwater and used by resident organisms.

It is a characteristic of radiocarbon calibration curves that some parts of the curve are inherently more accurate than others. When atmospheric radiocarbon was relatively stable, the slope of the curve is such that calibration is relatively straight-forward. During periods when the atmospheric concentration of radiocarbon was in flux, however, the curve "flattens out" and doubles back on itself, and the likelihood of multiple intercepts (places where the sample's measured age crosses the curve more than once) increases markedly. In these areas of the curve, increasing the precision of the measurement (as expressed by the standard error) does not result in a proportionate increase the accuracy of the calibrated date. For example, Figure 5-18 illustrates the calibrated age of one of the samples dated during this study, Beta312833 , using its measured error ( $+30 \mathrm{BP})$ and a simulated error one third the size $( \pm 10 \mathrm{BP})$. As the figure shows, decreasing the error estimate has significant implications for the precision of the radiocarbon age (the 2 sigma or 95 percent confidence range improves precision by 66 percent, from 120 years to 40 years) but much less effect on the accuracy of the calibrated age (the 95 percent confidence range improves from 190 years to 145 years, an improvement of only approximately 23 percent).

Dating of the Fish Creek Slough Site was accomplished in a series of submissions to four different radiocarbon laboratories, with the results of earlier runs used to refine the selection of samples for subsequent submissions. Although a small suite of ages on microcharcoal and mussel shell is older (and, in the case of the microcharcoal, stratigraphically reversed; see Chapter 11), plausible radiocarbon ages from the Fish Creek Slough Site range from $110 \pm$ $25 \mathrm{BP}$ to $1090 \pm 25 \mathrm{BP}$, with approximately 75 percent of these assays younger than $500 \mathrm{BP}$. The two ages on mussel shell (Beta-318254 and Beta-318255) are substantially older than associated ages on charcoal and bone from the same strata, and are interpreted as dates evincing a significant hard water error and rejected. The deepest age in the microcharcoal sequence (PRI-11-68-241) is consistent with other ages from the top of Unit 1a, but the remaining ages from higher in the same column are dramatically older and stratigraphically reversed; they are 


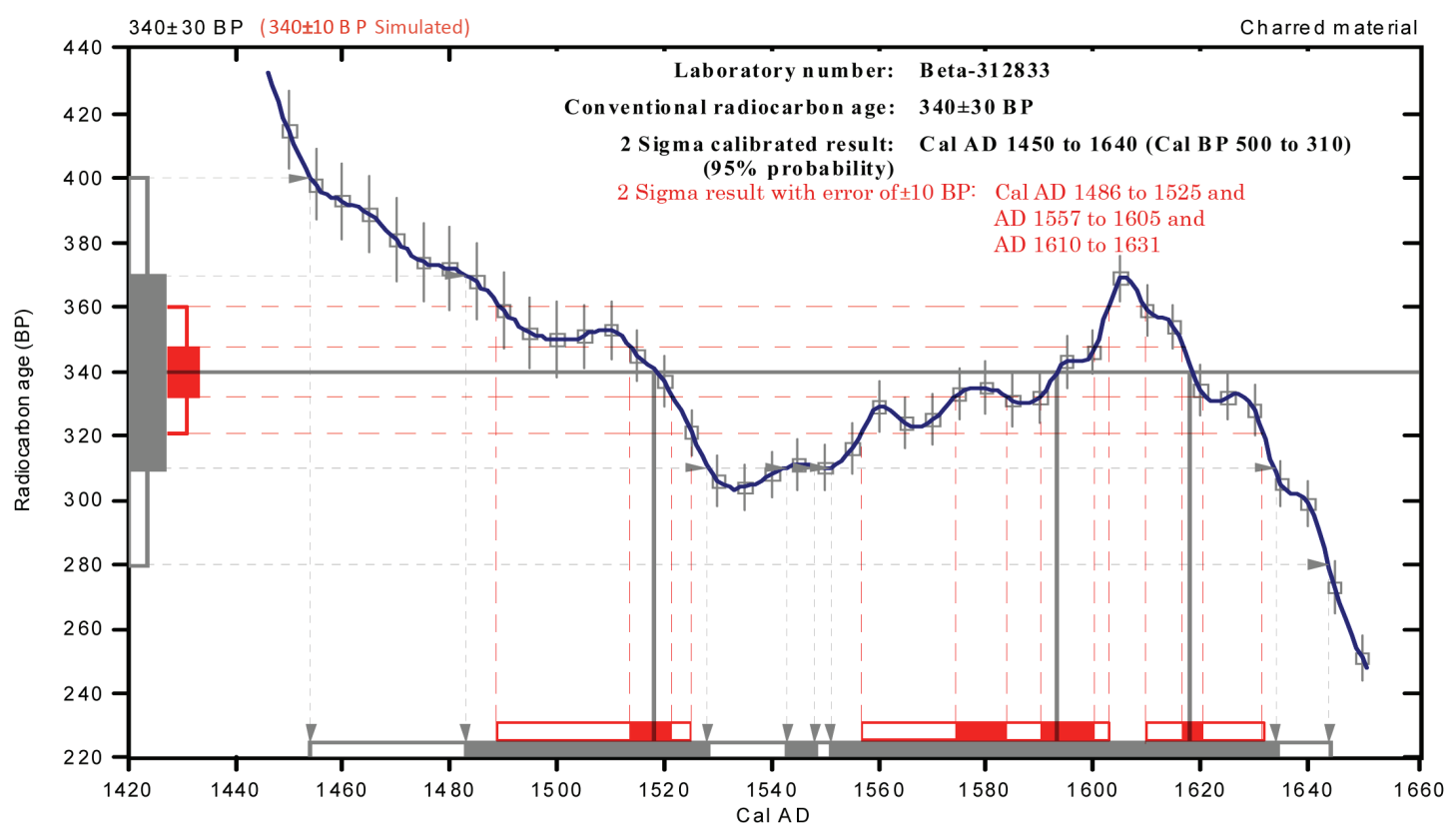

Figure 5-18. Figure illustrating the relationship between measurement error and accuracy of calibrated ages. Gray ranges represent the calibrated age resulting from the measured error of plus or minus 30 years, while red ranges illustrate a simulation of the effect of improving the error estimate to plus or minus 10 years.

interpreted as fluvially-reworked materials, and the ages are similarly rejected. The remaining ages are "accepted" for purposes of discussion, but a number of others are slightly older than expected and considered to likely represent dating of older organic material.

Figure 5-19 illustrates the approximate context of ages obtained during the study by extrapolating samples obtained in the block onto the eastern profile (see also Figure 5-13), excluding the microcharcoal samples and two rejected ages on mussel shell. Because the stratigraphy across the block is far from planar, and in fact slopes a few degrees to the east, the locations shown in Figure 5-19 are only an approximation presented so the reader can visualize the complexities of the radiocarbon sequence. Table 5-2 lists all ages and their contexts and associations. As is immediately apparent, the data suggests that the site deposits aggraded quickly during the last millennium. This involves a time period when the radiocarbon calibration curve is quite unstable, largely as a result of the accelerating release of dead carbon from fossil fuel use in Europe; as a consequence, the statistical precision of individual radiocarbon ages from this period suffers.

Even so, there are a number of interesting aspects to the suite of ages. With the exception of an anomalous (and rejected) age on mussel shell (Beta-318254), the Unit 1a sample consists of eight ages representing a calibrated timespan of approximately 560 years (AD 893-AD 1450) and an elevation range of $1.6 \mathrm{~m}$. These are both the widest ranging and least perplexing ages obtained. The oldest age was collected from the deep probe trench, nearly a meter below the remaining ages at an elevation of $96.47 \mathrm{~m}$ (relative to the arbitrary $100-\mathrm{m}$ datum). Excluding this deep age, all Unit 1a samples were collected from features or material scatters between 


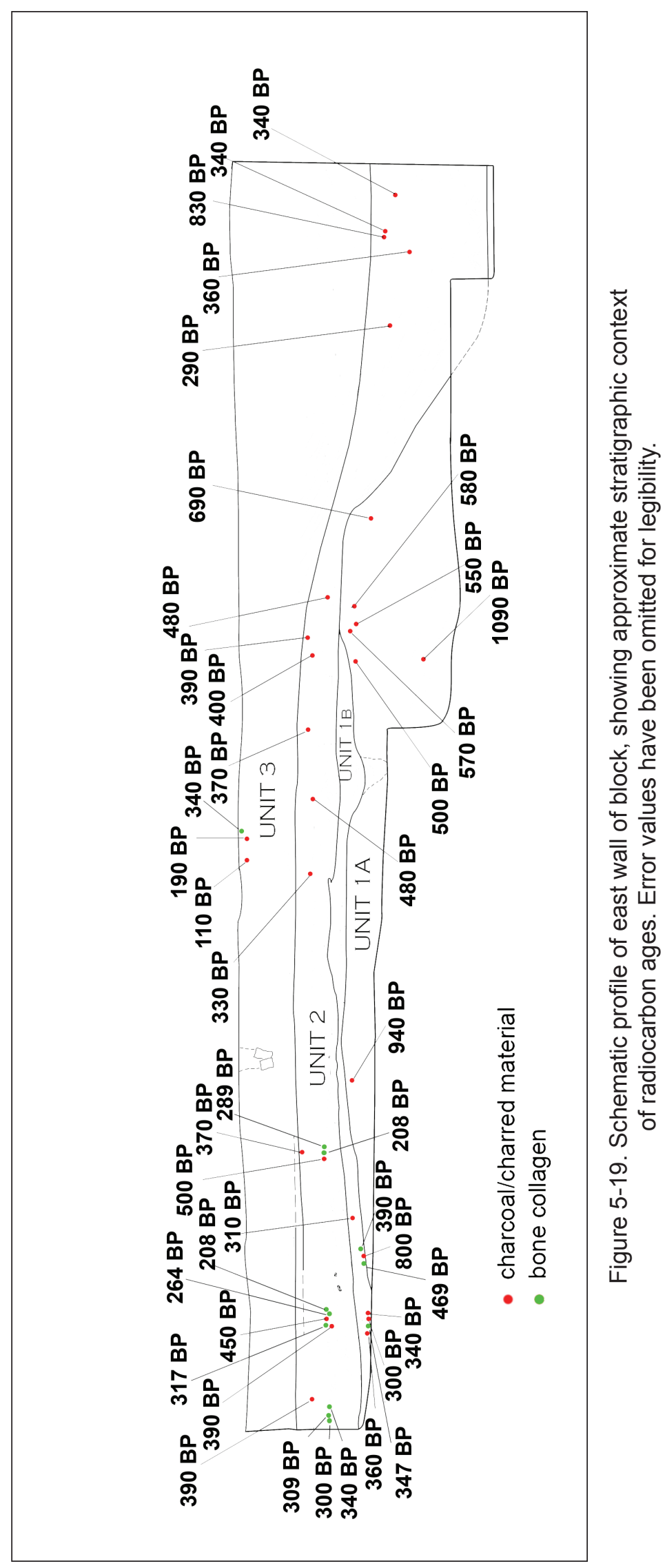




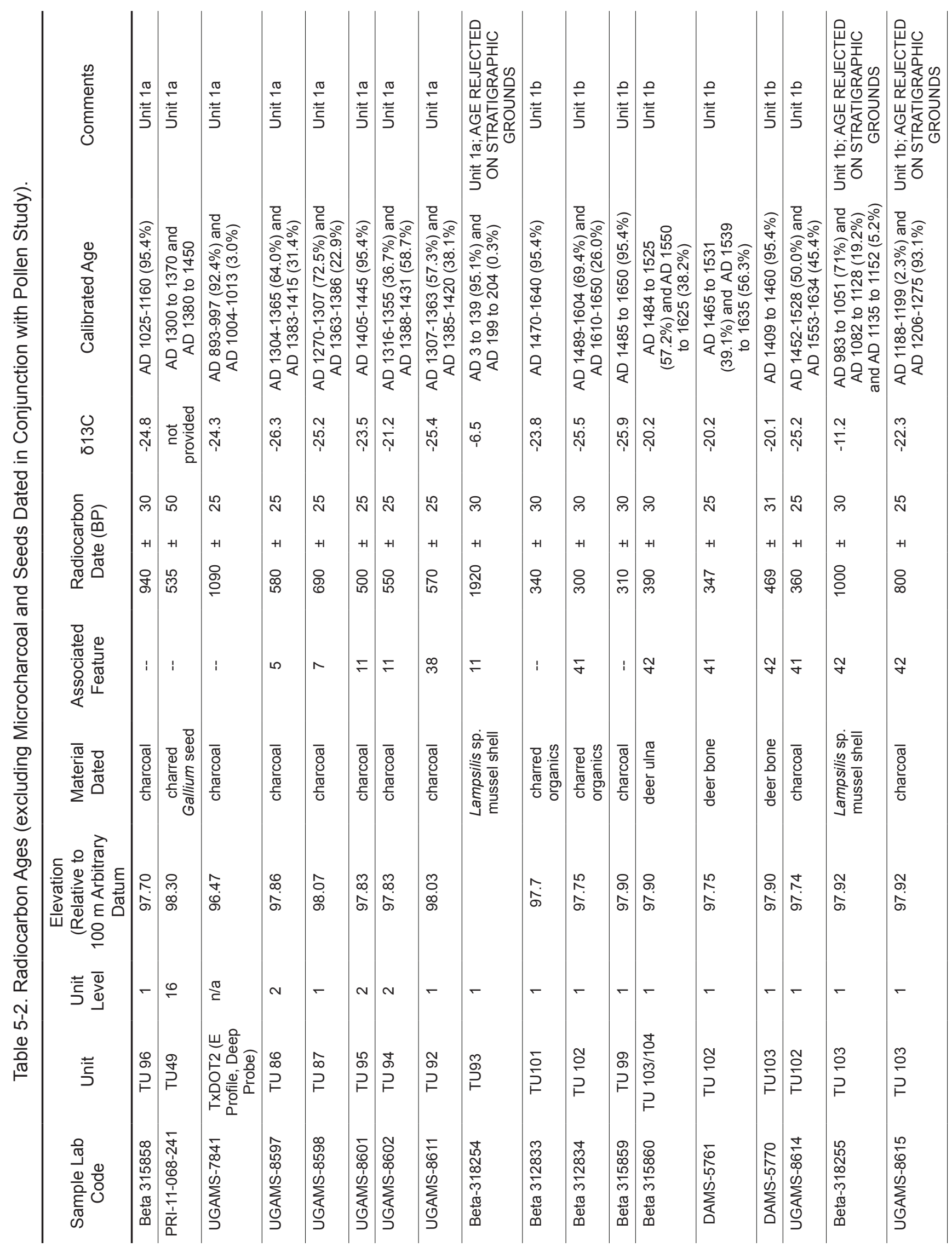




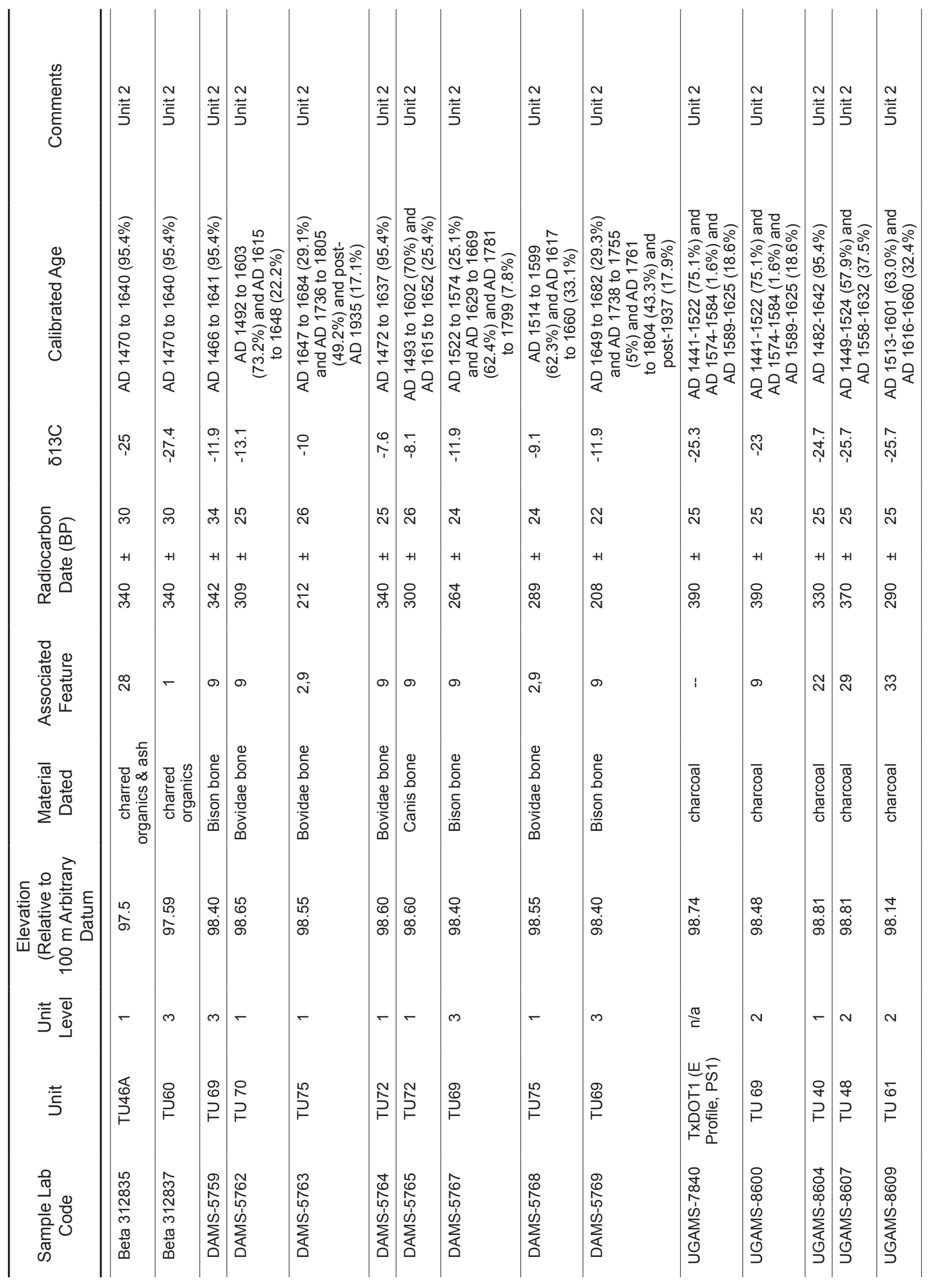




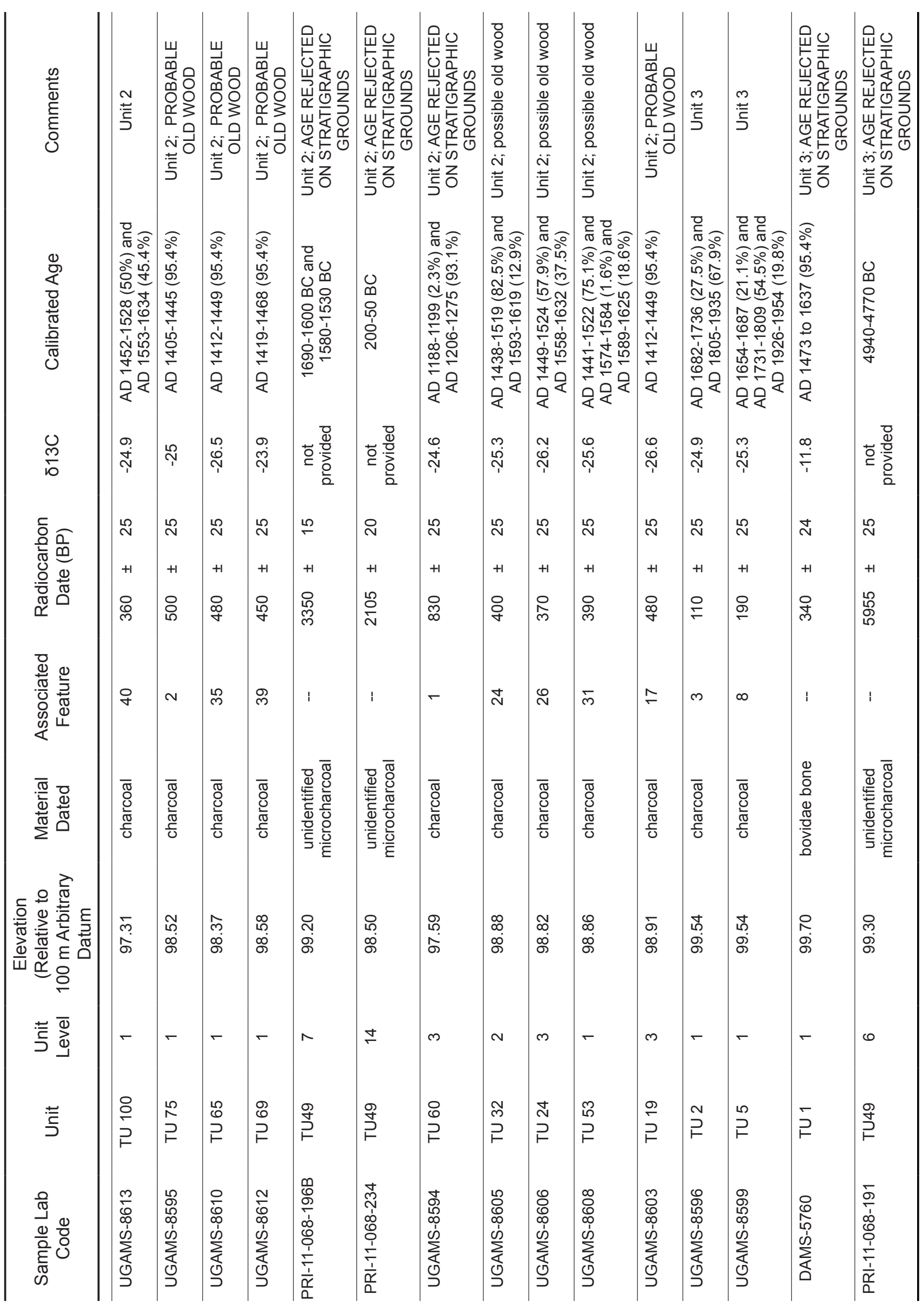


98.3-97.7 $\mathrm{m}$ bd. Overall, the ages of these samples average approximately $625 \mathrm{BP}$, and range 500-940 BP. However, five of the ages fall between 500-580 BP, including a sample from Features 5, a sample from Feature 38, and two samples from Feature 11. Collectively, these ages are consistent with slowed deposition near the end of the phase, which is in turn consistent with a transition from predominantly lateral accretion (point bar growth) to vertical accretion (overbank flooding).

With the exception of two obvious outliers (Beta 318255 - another mussel shell age - and UGAMS-8615), Unit $1 \mathrm{~b}$ includes six accepted ages with intercepts varying by less than 100 radiocarbon years (390 BP-300 BP) and one slightly older age (470 BP). Collectively, the seven accepted charcoal ages span a calibrated range of slightly more than 200 years, from AD 1440 to AD 1650. These accepted ages are nearly indistinguishable from the large suite from Unit 2, which spans 255 calibrated years (AD 1405-1660).

In an attempt to improve the accuracy of the suite of charcoal ages, the data were subjected to Bayesian statistical analysis using the program OxCAL 4.17 (Bronk Ramsey 2009). Standard radiocarbon analysis uses statistical probability to arrive at ages for individual samples based on their radiocarbon content. Baysian statistics provide a variety of mechanisms to further refine these estimates by comparing multiple samples and using what is known about their context and interrelationships to refine the age estimates (Steel 2000; Bronk Ramsey 2008; 2009). For example, given a stacked suite of ages A, B, C, and D from an alluvial deposit, one knows not only the measured ages, but that A should predate $\mathrm{B}$, which should predate $\mathrm{C}$, etc., based on the position of the samples in the stratigraphic sequence. Alternatively, one might not know the order of individual samples, but that the group of samples from Stratigraphic Unit A should precede those from stratigraphic unit B, etc. Bayesian statistics provide a mechanism to compare calibrated age probabilities (termed likelihoods in Bayesian parlance) against what can be assumed based on other known information (e.g., statigraphy, artifact style, etc.) the Bayesian prior model - to develop what are termed posterior probability densities that "take account of both the depositional model and the actual age measurements made" (Bronk Ramsey 2008).

Figure 5-20 illustrates the outcome of the analysis, which was run in OxCAL 4.17 using a Sequence model on 29 accepted charcoal ages. Although the analysis was able to narrow the probabilities considerably, more than a third of the ages exhibited an unacceptably low agreement index, a statistic produced by OxCAL that provides a measure of the degree of agreement between the prior and posterior distributions (this is shown on the figure with red probability curves). Bronk Ramsey suggests caution when the agreement index falls below 60; many of the thirteen samples flagged in the initial run had agreement indices below 10, and several were below 0.5. Examination of the graph reveals that the net effect of the Bayesian statistic was to push all of the probabilities for Unit 2 and particularly Unit $1 \mathrm{~b}$ to the same extreme end of their distribution. This is simply not a likely scenario.

The problem with the Bayesian analysis is clearly due to the presence of outliers - that is, samples that are not representative of the target event. Although several obvious outliers interpreted as intrusive remains were identified (see Figure 5-20) and excluded from the 


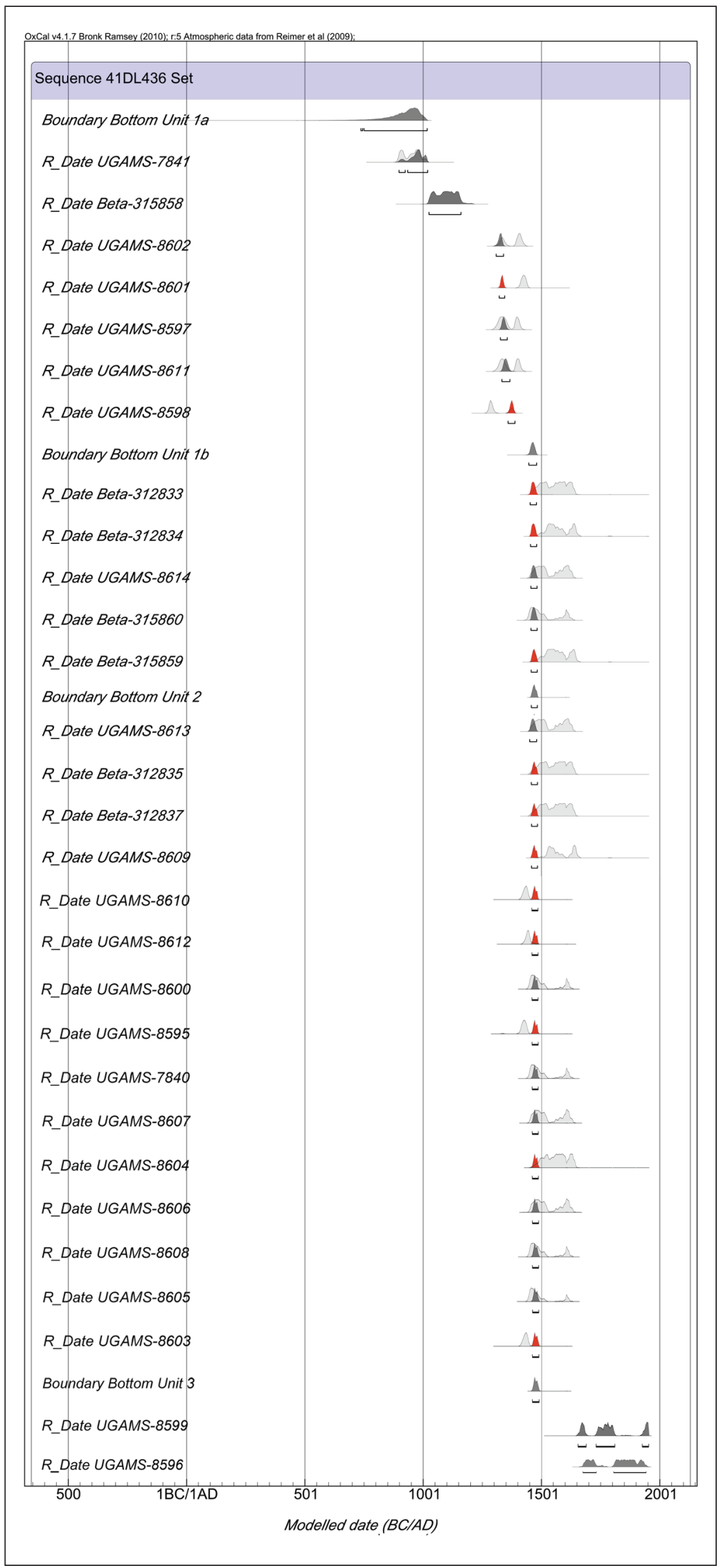

analysis, many dates were retained that are outliers in a Bayesian sense. Given the very tight clustering of ages from Units $1 b$ and 2 , this is not particularly surprising. However, the very fact that these ages are stratified through more than a meter of accumulated sediment demonstrates that they are not representative of a single targeted event.

One of the problems endemic to archaeology and stratigraphy alike is that the dating medium (the organic material being dated) is not always representative of the dating target (the event being dated). This is one of the most thorny issues in dating using the radiocarbon method, and the prime reason that radiocarbon dates need interpretation and should never be accepted at face value. One of the most common causes of this disjunction between the medium and the target is the so-called old wood problem (Schiffer 1987). Put simply,

Figure 5-20. Plot of prior and post-facto probability distributions resulting from Bayesian analysis. The Bayesian analysis is not believed to be reliable due to the inclusion of many ages on old wood. 
the age obtained from a radiocarbon date does not actually reflect the date of burning (the target), but rather the date that the carbon atoms that are dated were incorporated into the organism in the first place. In short lived species, this is not a problem, because the span of carbon incorporation is much shorter than the resolution of the dating method. In longer lived taxa like trees, however, this can introduce significant problems. In trees, active growth (and therefore incorporation of new carbon) occurs in the outer ring, just beneath the bark-older rings do not exchange carbon with the atmosphere. In other words, dates on carbonized tree wood - all else being equal — will tend to overestimate the age of the target event (burning). The degree to which this matters is a function of many different factors (Smart and Hoffman 1988). Obviously, the age of the tree canopy has an effect, as does the accessibility of dead wood. Many riparian trees are good self-pruners, dropping dead branches useful as firewood on a regular basis, while other trees do not tend to drop dead branches and therefore become useful as a fuel source for typical hunter-gatherers only after the tree dies. Also, because fire tends to consume the outer part of a branch first, wood preserved as charcoal tends to be the older, inner wood (Schiffer 1987). At the same time, hunter-gatherers will tend to use smaller parts of the tree first; even when dead, hunter-gatherers using stone tools are unlikely to use large trunk sections (where the oldest wood in a living tree resides) as fuel until they are already in an advanced state of decomposition.

While intrusion of charcoal often occurs in archaeological sites (e.g., through feature construction; root burns; or burrowing intrusions by rodents, insects, and earthworms), the intensity of this activity is reflected in the degree of destruction of primary depositional structures. At 41DL436, these structures are largely obliterated in Unit 1a and the upper part of Unit 3, but are remarkably well-preserved (at the macro level, anyway) in Unit 2 and the lower part of Unit 3, and rare but relatively intact in Unit 1b. These latter units include zones where the problematic assays are concentrated. For these reasons, all ages from the stratigraphic sequence at 41DL436 cannot be given equal weight - more recent ages from each unit are more likely to approximate the true age of deposition.

Accepted ages obtained from Unit 1a vary from 1090 BP to 500 BP, including the seven ages described above and an age of $535 \pm 50 \mathrm{BP}$ on a single gallium sp. seed from the top of Unit 1 in the pollen column (PRI-11-068-241; see Chapter 11). This is consistent with the generally young appearance of the unit (primarily its lack of pedogenic structure) and the preservation and characteristics of incorporated microfossils (see Chapter 6), and are considered to provide a reasonable estimate of the age of the unit. However, the relatively consistent ages from the wedge-shaped Unit $1 \mathrm{~b}$ provide the best indication for termination of Unit 1a, and suggest that it may have actually continued to aggrade as a relatively stable floodplain until approximately 400 BP. Unit 1a was terminated by a when the channel avulsed and the floodplain was scoured.

Unit $1 \mathrm{~b}$ includes multiple samples dated from Features 41 and 42, two relatively discrete, formal hearth features associated with burned earth and faunal remains. Both features were recovered from relatively dark, massive sediments at the base of the northern end of the block, and were initially interpreted as part of the lower component. Initially, one age was run from each feature. The ages obtained were quite disparate (360 BP and $800 \mathrm{BP}$, respectively), even though the features appeared to represent the same occupation. To clarify the stratigraphic 
picture, five additional ages were run from within and in the vicinity of the two features. Samples were selected from both inside and outside the features and from adjacent units to assure that the rocks were not clustered at the base of intruded (and unnoticed) pits. These ages ranged 300-390 BP (roughly AD 1440-AD 1660), and clearly seemed to indicate that the 800 year old age is anomalous. To further clarify the issue, the five younger dates from Unit $1 \mathrm{~b}$ were combined to yield a single composite age in OxCAL. This yielded a combined age that has a 35 percent probability of falling between AD 1477 and AD 1528 and a 60 percent probability of falling between AD 1554 and AD 1634. All seemed relatively straightforward until a final age run on deer bone from TU 103 yielded yet another age, this time falling between AD 1409 and 1460 .

Considered together, the available radiocarbon ages and the architecture of alluvial deposits in Unit 1 suggest that the deposits of Unit $1 \mathrm{~b}$ represent a southward-thinning wedge of reworked sediment mantling a gently inclined, cut surface. The fact that this gentle slope represents a scour surface and not the original terrace morphology is indicated by the slope of Feature 11, a broad mussel shell lens that clearly defines the attitude of the aggrading Unit 1a surface (see Figure 5-10). The majority of ages from Unit 1b suggest that this scour event occurred sometime between the latter- $15^{\text {th }}$ and mid- $17^{\text {th }}$ centuries AD. Given the ages obtained and the relative integrity of the small hearth features, it is clear that they were constructed on the scoured surface rather than exhumed by the scour event. However, Feature 42 yielded two anomalous (and disparate) ages, suggesting that the lots associated with this feature include material from the underlying Unit 1 a which were either incorporated by small excavations (e.g., the hearth basin) or exhumed during the preceding scour event.

In light of this interpretation, the ages from Unit 2 are quite interesting. As perusal of the data clearly indicates, the Unit $1 \mathrm{~b}$ ages are contemporary with or younger than the relatively robust suite of ages from deposits in Unit 2 overlying them by $50 \mathrm{~cm}$ or more - if the more obvious outliers are eliminated from each group, the two suites of ages are essentially indistinguishable. The character of depositional packets suggests that Unit 2 was deposited by a limited number of floods that carried a high load of fine sand and coarse silt, accumulating a meter or more of sediment on the floodplain in a brief span of time. The presence of Paleosol 1 at the top of Unit 2 indicates that a short period of relative quiescence then occurred, allowing a thin soil to form across the floodplain and in the swale marking the abandoned channel.

Although statistically indistinguishable, the stratigraphic context of the dates from Units $1 \mathrm{~b}$ and 2 suggested that they were very unlikely to represent precisely the same time period, as the samples were stratified in a stratigraphic sequence more than a meter thick. Either the samples from Unit $1 \mathrm{~b}$ were dating slightly too young, or the samples from Unit 2 were dating slightly too old. Given the very strongly-expressed bedding laminations in Unit 2, we were confident that intrusion of old carbon through mixing of Unit 2, or of young carbon through mixing of Unit 1B, was unlikely. The most plausible explanation remaining was that the ages from Unit 2 were slightly too old due to the repeated use of old wood in fueling the burned features in Unit 2. This belief was bolstered by the results of faunal analysis, which suggested that both metal knives and firearms may have been used to take and process some of the faunal remains from Unit 2 (see Chapter 15), which suggests the deposits were laid down no earlier than the latter 
$17^{\text {th }}$ century, when French traders first started bartering firearms with the Caddo in northeast Texas (Schilz and Worcester 1987).

To help resolve the issue, eleven additional radiocarbon samples on bone collagen were selected and run from Units 1 b, 2, and 3. With the exception of an anomalously early age from Unit 3 , the results support this model. Figure 5-21 illustrates the dates obtained from the northernmost $5 \mathrm{~m}$ of the block, arranged according to approximate depth. The samples are color coded by source material, with red plots representing charcoal ages from thermal features and the green representing bone collagen ages from bone scatter features. Although there is still statistical overlap, there is a clear tendency for the bone ages from Unit 2 to date slightly younger than associated charcoal ages. To further explore this difference, the eight bone dates from Unit 2 and the seven available samples from Unit $1 \mathrm{~b}$ were each combined to yield single composite ages in OxCAL. By these measures, Unit 1b aggraded between AD 1466 and 1523 (56.5 percent probability) or AD 1574 and 1626 (38.9 percent probability), while Unit 2 aggraded between AD 1527 and 1544 (12.3 percent probability) or between AD 1633 and 1654 (83.1 percent probability).

Given the weak development of the Unit 2 paleosol (PS1), Unit 3 is believed to have begun accumulating shortly after the cessation of Unit 2 aggradation in the late $17^{\text {th }}$ or early $18^{\text {th }}$ century AD. It is probably still aggrading, albeit very slowly and incrementally, and has currently completely filled the former channel swale, which was still a prominent feature when it began to aggrade. Three radiocarbon samples of $110 \pm 25 \mathrm{BP}, 190 \pm 25 \mathrm{BP}$, and $340+24 \mathrm{BP}$ are available from the upper part of the unit, at depths less than $50 \mathrm{~cm}$ below the surface. Of these, the 340 BP age (which calibrates to AD 1473-1637) is clearly out of place and therefore rejected. The other two ages calibrate to a wide span of ages from the latter $17^{\text {th }}$ to the early $20^{\text {th }}$ century. They are accepted, but provide little additional temporal detail.

Finally, two ages were obtained on mussel shell associated with Features 11 and 42, respectively (Beta-318254 and Beta-318255). These samples, which are not included in Figure 5-19, were not expected to yield accurate ages due to reservoir effects, and were run to check the contemporaneity of the mussel shell in Feature 11 with those surrounding Feature 42 (on the assumption that the magnitude of the hard water error would be consistent). The ages suggest that the mussel shell are not contemporary, while comparison with other ages from the two features suggest the radiocarbon ages are yielding radiocarbon ages between 700-1500 years older than they actually are.

\section{Summary Of Local Landscape History}

Two alternative reconstructions of the sequence of depositional events that formed the area around 41DL436 are illustrated in Figures 5-22 and 5-23. Discussion of these models must begin with a caveat. The deposits making up the higher $\left(\mathrm{T}_{1 \mathrm{~A}}\right)$ floodplain are undated, and are correlated with Ferring's Pilot Point unit based primarily on their stratigraphic position at the surface of the floodplain. However, unlike the trunk system described by Ferring and like other tributaries in the system (e.g., Rowlett Creek [Frederick 2011]; Hunt Creek, Willow Creek, and Chambers Creek [Abbott 2011]), Fish Creek was clearly dominated by lateral channel 


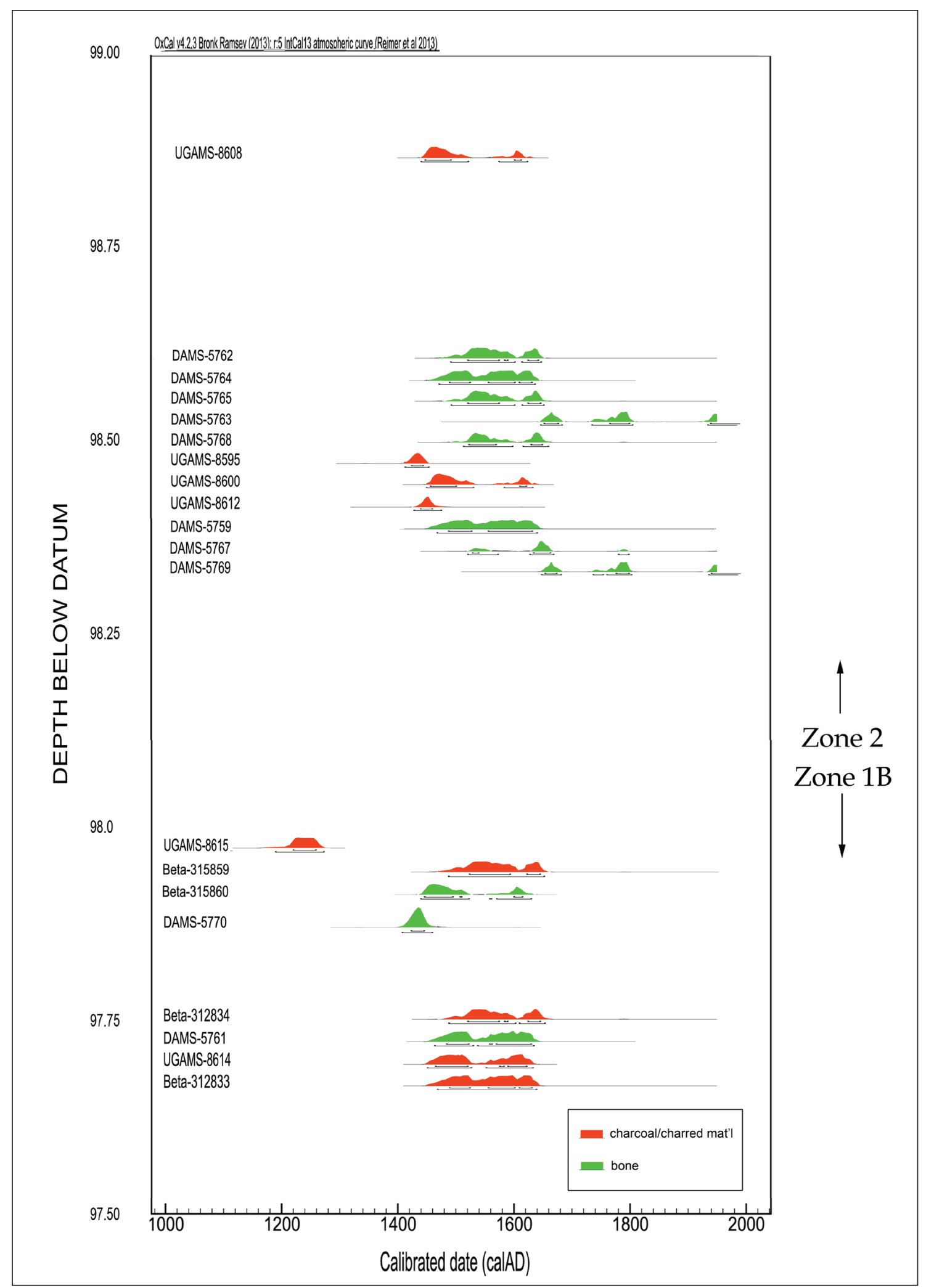

Figure 5-21. Probability plot of samples from the northernmost $5 \mathrm{~m}$ of the block, arranged by approximate depth below datum. Ages on charcoal and charred material are red, while ages on bone collagen are green. 


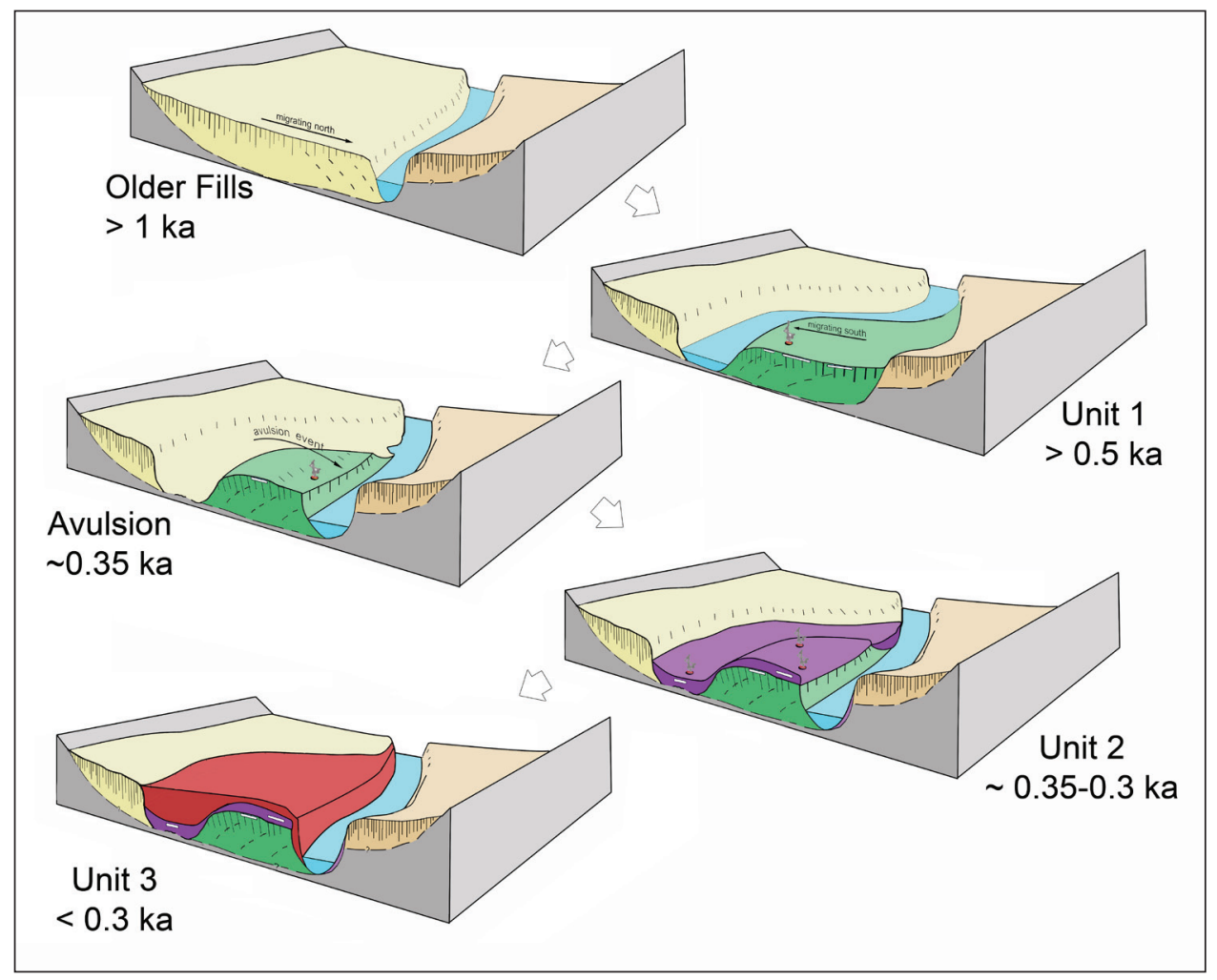

Figure 5-22. Model of local landscape development at the Fish Creek Slough Site.

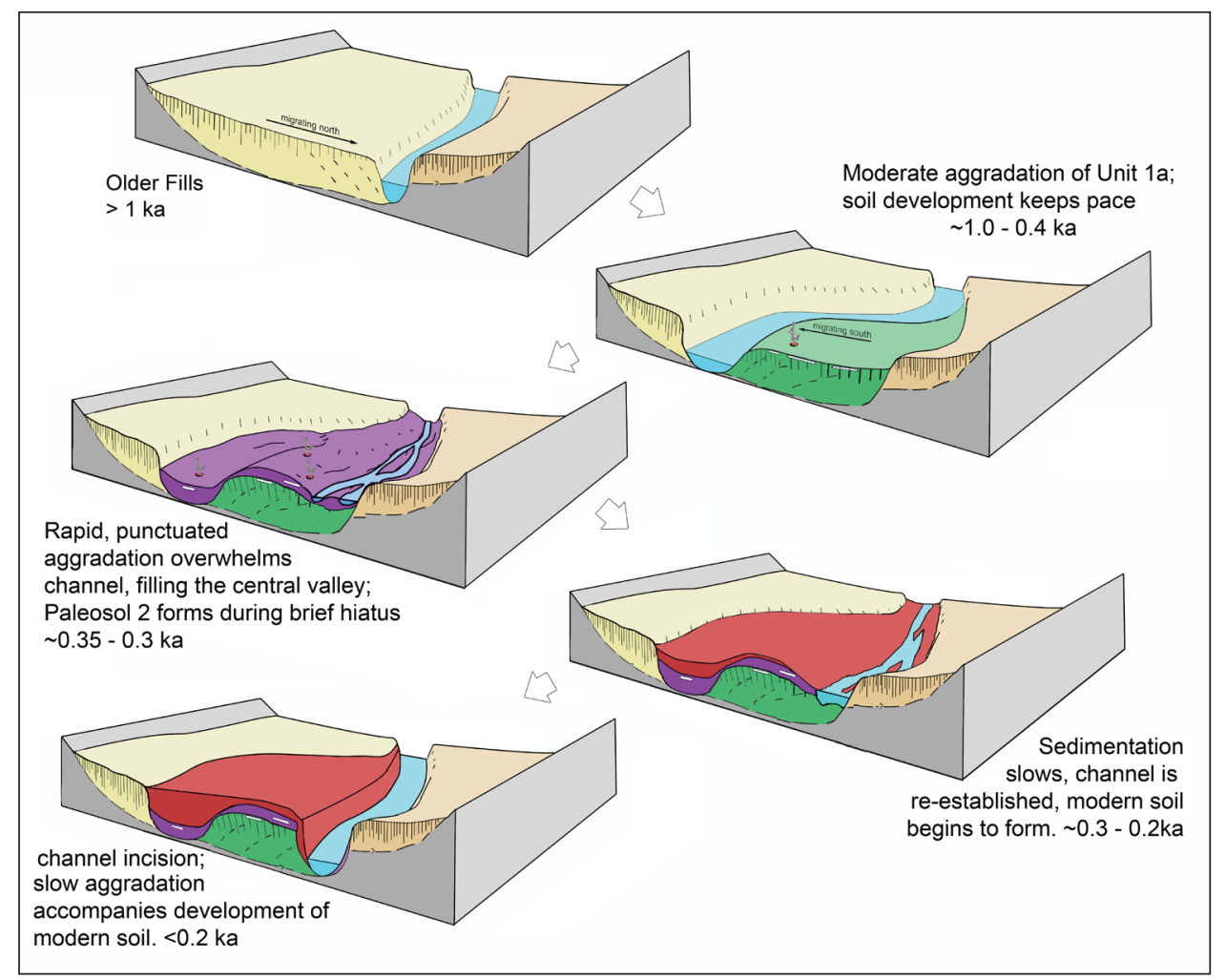

Figure 5-23. Alternative model of local landscape development at the Fish Creek Slough Site 
migration rather than vertical aggradation in the vicinity of the site. As a result, the architecture of the system is inset rather than stacked, and relative elevation is not a good indicator of age because the sequence is not superposed. In other words, it is likely that the older, unnumbered units are far more complex than indicated here. It is also important to keep in mind how the alluvial architecture shown here was created; namely, by a laterally migrating channel operating in a relatively restricted valley. Not only would this cross-section differ markedly even short distances upstream and downstream, but lateral juxtaposition of different age units would reflect both system-wide trends in landscape activity and localized, idiosyncratic systemic behavior (i.e. the specific geometry of channel migration).

Each model illustrates a sequence of specific events that resulted in the formation of 41DL436. The two models each include the same basic events; only the timing differs. Although several earlier phases of channel migration and point bar construction across the valley can be inferred, the earliest depositional event that directly affected the formation of the site was lateral migration and slow aggradation of a steep-banked, vegetated point bar on the north bank of Fish Creek (Unit 1a), which was ongoing by at least 1,000 years ago. The character of sedimentation on the point bar surface was slow and probably sporadic, and an organic floodplain soil (PS2) was forming as the floodplain slowly aggraded. Lateral accretion was the dominant mechanism for most of the deposit, and indeed traces of lateral accretion foresets are visible as subtle color banding in the deep probe trench. However, vertical accretion of overbank loams dominate the upper half meter of the deposit. Plant microfossil data (pollen, phytoliths, diatoms, etc; see Appendix by Scott Cummings et al.) and invertebrate microfauna (see Appendix by Brown) provide a rich fossil record that suggests an open, grassy floodplain habitat with a strong aquatic component, although recovered snail taxa also include some species indicating a more closed deciduous habitat was present in the vicinity. Sporadic occupation by hunter-gatherer groups during this phase of vertical aggradation resulted in the preservation of a few small thermal features and at least one scatter of mussel shell. With the exception of very small artifacts, the stratigraphic integrity of these deposits is probably high, while the spatial integrity could have been compromised to a degree by flooding. Because most conditions that would adversely affect artifact preservation (e.g., shrink-swell processes that could cause physical damage, acidic soil conditions, cyclic wetting and drying) are not present, compositional integrity of the assemblage is probably relatively high, although charcoal and small perishable artifacts (e.g., seeds) was subject to destruction by earthworms and other soil fauna.

The two models diverge at this point, and will be discussed separately. In the first model (see Figure 5-22), a channel shift or avulsion occurs, terminating Unit 1a. Avulsion is the term used when a stream channel jumps suddenly (in a geological sense, anyway) from one location to another without eroding sediments in the intervening space (e.g., Chorley et al. 1984; Schumm 1977). In many cases, the term is reserved for major channel shifts involving miles (sometimes hundreds of miles) of channel, and it is often explicitly distinguished from meander neck cutoffs, which occur as a consequence of meandering and result in the formation of oxbow lakes. Given this distinction and the scale of the system involved, the event affecting 41DL436 in this model was far more similar to a meander neck cutoff than to a classic large system avulsion such as occurs on a stream like the Mississippi River. Nevertheless, classic meander neck cutoff is a byproduct of autocyclic behavior in a stream system, and occurs as 
a meandering channel migrates into itself, shortening its channel. It is unlikely that is the case here, as the scale of the valley and the plan pattern of the stream are not particularly conducive to this type of stream behavior. Moreover, given the very marked change in sediment character and the evidence presented in the snail and pollen/phytolith studies (Chapters 6 and 11), it seems clear that the channel shift accompanied and was probably driven by major changes in the broader environment, including significant soil erosion in the catchment and shifts in the scale and possibly the frequency of flooding. In the first model, the channel shifts abruptly during this transition, scouring the top of Unit 1 and beveling it away from the former channel in the process.

In the alternative model (see Figure 5-23), the avulsion is not an instantaneous event. Rather than shift, the channel simply becomes choked with the Unit 2 sediments entering the system in high volumes, and the stream infills the existing channel and spills out across a hummocky lower floodplain. In this alternative, there is no well-defined channel trench during aggradation of Unit 2.

In either case, the key event is the sudden influx of high volumes of sediment, which represents the shift from deposition of Unit 1a to deposition of Unit $1 \mathrm{~b}$ and 2. Kenneth Brown (this volume) has suggested that climate changes during the transition from the Little Climatic Optimum to the Little Ice Age may have been responsible for systemic changes that drove the activity, and it is true that the timing seems very suspicious. However, while changes in rainfall patterns could provide the energy necessary to mobilize sediments, it is equally likely that this erosion was facilitated by some form of disturbance of the landscape upstream which rendered it vulnerable.

Pinpointing the timing of this shift is hampered by a relatively flat, unsettled part of the radiocarbon calibration curve, but the weight of evidence suggests that it occurred sometime between AD 1477-AD 1634. The shift was accompanied by a surface scour event that eroded more than $50 \mathrm{~cm}$ of the cumulic soil from the floodplain adjacent to the new channel, creating an irregular cut surface that sloped gently north, away from the deep swale formed by the former channel. Almost immediately, a wedge of dark sandy alluvium reworked from the floodplain and containing cultural features aggraded on this surface, forming Unit 1b. However, it is clear that this did not happen in a single storm, as the shallow cut was occupied by people who built several small hearth features (Features 41 and 42) that were preserved largely intact.

Aggradation of packets of fine sand and silt continued episodically through the aggradation of Unit 2, which seems to have occurred episodically immediately after aggradation of Unit 1a. Radiocarbon ages on wood charcoal from Unit 2 are either older than or indistinguishable from Unit $1 \mathrm{~b}$ due to the frequent use of wood that was up to 200 years old, while radiocarbon ages on bone collagen tend to be slightly younger than the charcoal but exhibit poor precision due to a plateau in the radiocarbon calibration curve. However, none of the data suggests that Unit 2 continued to aggrade into the $18^{\text {th }}$ century. It is unclear whether this increased incidence of old wood use is related the catchment erosion noted in the pollen study, but again, the coincidence is intriguing. The character of the sediments probably reflects the rapid erosion happening in the catchment, and document that this stripping was accompanied by flood events that repeatedly 
overtopped the floodplain. In some cases, this flooding was deep and intense enough to deposit beds of graded fine sand up to $10 \mathrm{~cm}$ thick, but most beds consist of alternating thin (mm-scale) beds of fine sands, silts, and loams. These deposits frequently exhibit crossbedding, ripple bedding, and minor reactivation surfaces, suggesting that the depositional energy was probably sufficient to winnow light artifacts. However, the deposits contain a number of preserved flatlying burns and bone scatters, and there is little evidence of appreciable transport damage or preferred orientation in the bone assemblages. Stratigraphic integrity is very high in Zone 2 due to the lack of mixing, while spatial and compositional integrity are probably moderate due to current displacement and decomposition of perishable artifacts, respectively. At some point that is not well-dated, but probably represents no more than a few decades in the latest $17^{\text {th }}$ or earliest $18^{\text {th }}$ century, the system stabilized briefly and a thin cumulic soil (PS1) formed across the floodplain and the infilling swale. If the second model is accurate, this is likely the time that the channel began to re-establish itself in its current location. However, it is worth noting that the infilled paleochannel was still a depression more than a meter deep.

Soon after PS1 began to form, the system began to aggrade again, sealing the soil and terminating pedogenesis. The deposits of this episode were similar in appearance to those of Unit 2, although they were much more sand-poor. This may just represent changes in sediment availability, or it may represent deepening of the new channel. There is little sign that PS1 was scoured appreciably before the aggradation resumed. The timing of this reactivation is not well-established, but based on the minimal degree of development of PS 1 and in the much stronger development of the surface soil, probably occurred no later than the early 18 th century. Unit 3 has aggraded since that time. The initial aggradation was rapid, but the system soon slowed and soil organisms were able to thoroughly homogenize the sediment as it accumulated incrementally on the floodplain. In the second model, it was during this period that the deep Fish Creek channel entrenched in its current location.

A small, crude projectile point was recovered from the uppermost part of the sequence in association with an amorphous burn dated to $190 \pm 25$ and $110 \pm 25 \mathrm{BP}$ (calibrated to AD 1654-1954 and AD 1682-1935, respectively) and an associated bone collagen date of $340 \pm 24$ BP (calibrated to AD 1473-1637). Given the overall stratigraphy and the fact that occupations with stone arrow points are relatively unlikely after the early $19^{\text {th }}$ century, it seems unlikely that this shallowly buried material represents an intact occupation, but if so it indicates that the floodplain continued to aggrade rapidly for a time, then ceased aggrading relatively abruptly. 


\section{SECTION III \\ Paleoenvironment}

AmaTerra Environmental, Inc. 


\section{Chapter 6 \\ Snails, Peaclams, and Freshwater Limpets}

Kenneth M. Brown

\section{INTRODUCTION}

This chapter is a study of 12,769 snail shells, countable shell fragments, peaclams and freshwater limpets collected from 41DL436 during excavations in October, 2010. These have been extracted, sorted, and classified taxonomically as part of the joint multiproxy effort to reconstruct the environmental history of the site. There are three kinds of samples: 1) a discontinuous series of 10 sediment samples (191.2 liters) selected from a column of 20 samples collected in Unit 49, inset into the grid west wall of the Block 3 Gradall trench (Table 6-1;Figure 6-1);2) two smaller sediment samples collected from features (28 and 40) located in the paleochannel area at the grid south end of the Gradall trench; and 3) all the snails collected by the crew from the quarter-inch field screens (161 specimens representing 68 different provenience units). Although the latter two kinds of samples provided supplementary information, the 12,608 specimens recovered from the Unit 49 column provide most of the interpretive data. In addition, 28 slug plates recovered by the lab crew from flotation samples were examined and measured after this study was completed, but are not included in the above totals. At least 26 species of snails along with at least one species each of peaclams

Table 6-1. Synopsis of Snail Samples.

\begin{tabular}{|c|c|c|c|c|c|c|c|}
\hline Level $(\mathrm{cm})$ & $\begin{array}{c}\text { Volume } \\
\text { (liters) }\end{array}$ & Lot no. & $\begin{array}{c}\text { No. of } \\
\text { specimens }\end{array}$ & $\begin{array}{c}\text { Density } \\
\text { (specimens/liter) }\end{array}$ & $\begin{array}{l}\text { Broken snail } \\
\text { shell }(\mathrm{g})\end{array}$ & $\begin{array}{c}\text { Number } \\
\text { of taxa }\end{array}$ & $\begin{array}{c}\text { Depositional } \\
\text { Unit }\end{array}$ \\
\hline \multicolumn{8}{|l|}{ Unit 49 column } \\
\hline $0-10$ & 20.2 & 137 & 2493 & 123.42 & 2.184 & 15 & 3 \\
\hline $10-20$ & 19.75 & 143 & 638 & 32.30 & 0.158 & 14 & 3 \\
\hline $40-50$ & 20.25 & 186 & 299 & 14.77 & 0.201 & 15 & 3 \\
\hline $50-60$ & 22.25 & 191 & 395 & 17.75 & 0.133 & 8 & 3 \\
\hline $60-70$ & 15.8 & 196 & 195 & 12.34 & 0.132 & 13 & 2 \\
\hline $100-110$ & 18.4 & 224 & 168 & 9.13 & 0.201 & 15 & 2 \\
\hline $130-140$ & 19.5 & 234 & 2299 & 117.95 & 1.627 & 22 & 2 \\
\hline $150-160$ & 20.0 & 241 & 1720 & 86.00 & 0.200 & 22 & 1 \\
\hline $160-170$ & 16.25 & 244 & 1744 & 107.32 & 0.195 & 21 & 1 \\
\hline $190-200$ & 18.8 & 255 & 2415 & 128.46 & 0.998 & 19 & 1 \\
\hline \multicolumn{8}{|c|}{ Paleochannel units (absolute elevation) } \\
\hline \multicolumn{8}{|c|}{ Unit 100, Feature 40} \\
\hline $97.21-97.30 \mathrm{~m}$ & 3.85 & 351 & 121 & 34.57 & 0.036 & 9 & 2 \\
\hline \multicolumn{8}{|c|}{ Unit 46A, Feature 28} \\
\hline $97.31-97.41 \mathrm{~m}$ & 3.5 & 170 & 114 & 29.61 & 0.024 & 10 & 2 \\
\hline
\end{tabular}

Note: specimen totals include snails, unidentified spires from snails, peaclams, and limpets. 
and freshwater limpets were recovered (Table 6-2). The quarter-inch screen sample produced one species (Planorbella trivolvis) not recognized in the sediment samples. No introduced Eurasian species were found, not even in the uppermost sample where invasive species might be expected.

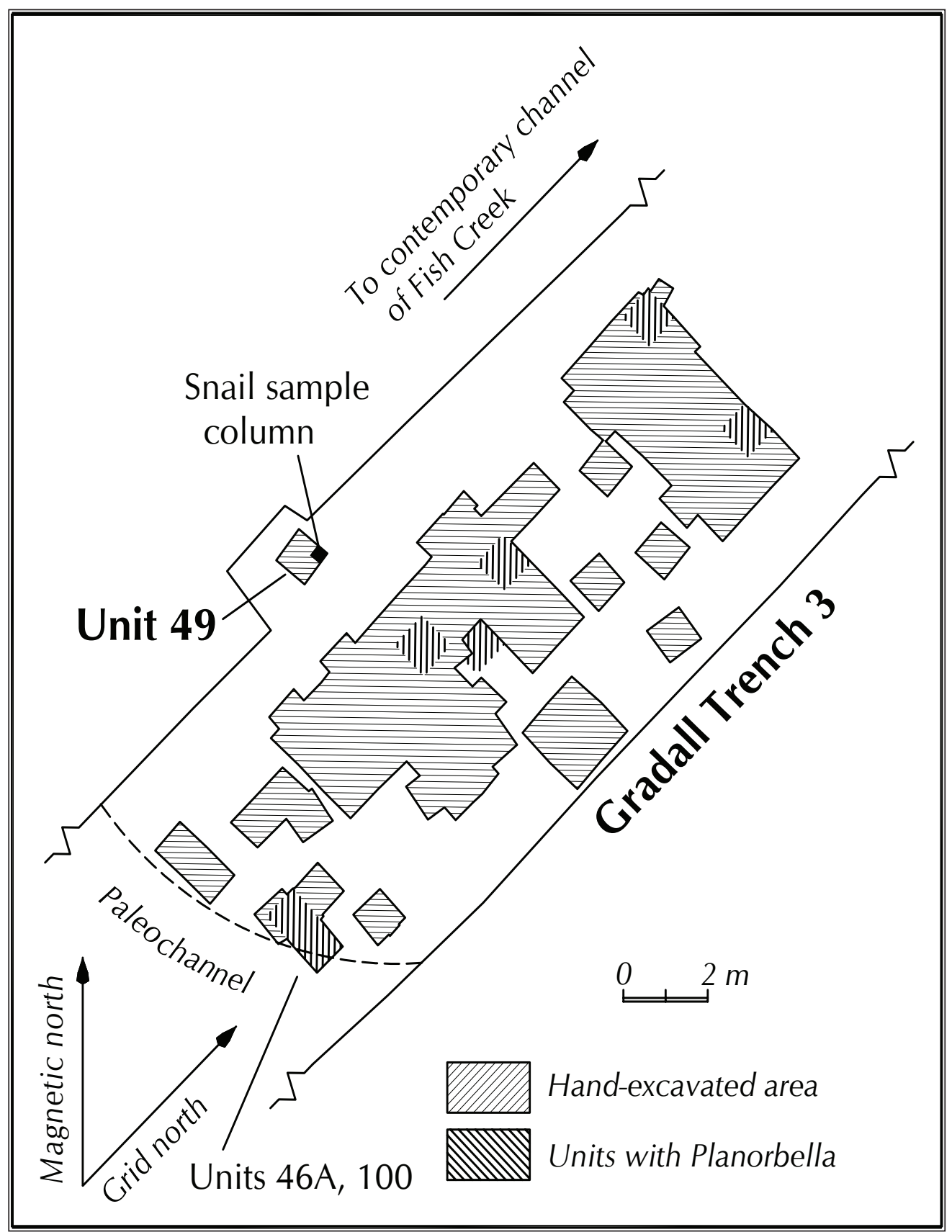

Figure 6-1. Plan of Excavation. Location of sampling units 49, 46A, and 100 is shown, along with field-screened units yielding aquatic snails (Planorbella trivolvis) and edge of Fish Creek paleochannel. Full extent of Block 3 Gradall trench not shown here. 


\section{Sampling and Study Methods}

Twenty sediment samples were collected for microsnail studies in Unit 49, one from each $10 \mathrm{~cm}$ level. Zero depth for this two-meter deep sample column is $99.84 \mathrm{~m}$. Unit 49 was excavated into the grid west wall (or magnetic north) of the Block 3 Gradall trench (see Figure 6-1; the excavation grid is rotated clockwise $45.8^{\circ}$ from magnetic north). It is located about $12 \mathrm{~m}$ from the present south bank of Fish Creek, but was located only about 5-6 m grid northwest of a buried paleochannel of the creek, which was found to cross the Gradall trench from grid southwest to northeast (magnetic west to east). Unit 49 is positioned on the grid northwest (or magnetic north) side of the buried channel, penetrating near-channel floodplain sediments. Five of these sediment samples were selected by the project archaeologist and principal investigator for a pilot study done in 2011. Five additional samples were selected by the present author for further study in 2012. The 10 samples left over were considered somewhat redundant and remain unstudied. The added samples come from the top and base of the column, the top of Paleosol 1, the sediment immediately covering Paleosol 2, and the middle of Depositional Unit 2 (Figure 6-2).

There are two ways to collect columns of sediment samples. The column can be extracted from the standing wall after the excavation is finished, as was done at the Vara Daniel site (Brown 2010:Figure 10-2), or it can be collected from each excavation level as the unit goes down, either by leaving a small block of sediment in the corner until the level is finished, or by digging into the floor before starting the next level. The first method is more difficult and slower, but avoids contamination from things falling into the unit, and tends to have more precise upper and lower bounding surfaces. The second method was used at 41DL436. Each sample consisted of a target volume of roughly four gallons of raw, unscreened sediment collected from the grid northeast corner (magnetic east corner) of each $10 \mathrm{~cm}$ excavation level. The excavator scraped off a couple of centimeters from the surface of the sample, dug into the level floor, and generally stopped a few centimeters above the floor of the next level (Jon Dowling, personal communication, May, 2012). As a result, the sample does not represent the full 10-centimeter vertical span of

AmaTerra Environmental, Inc. 


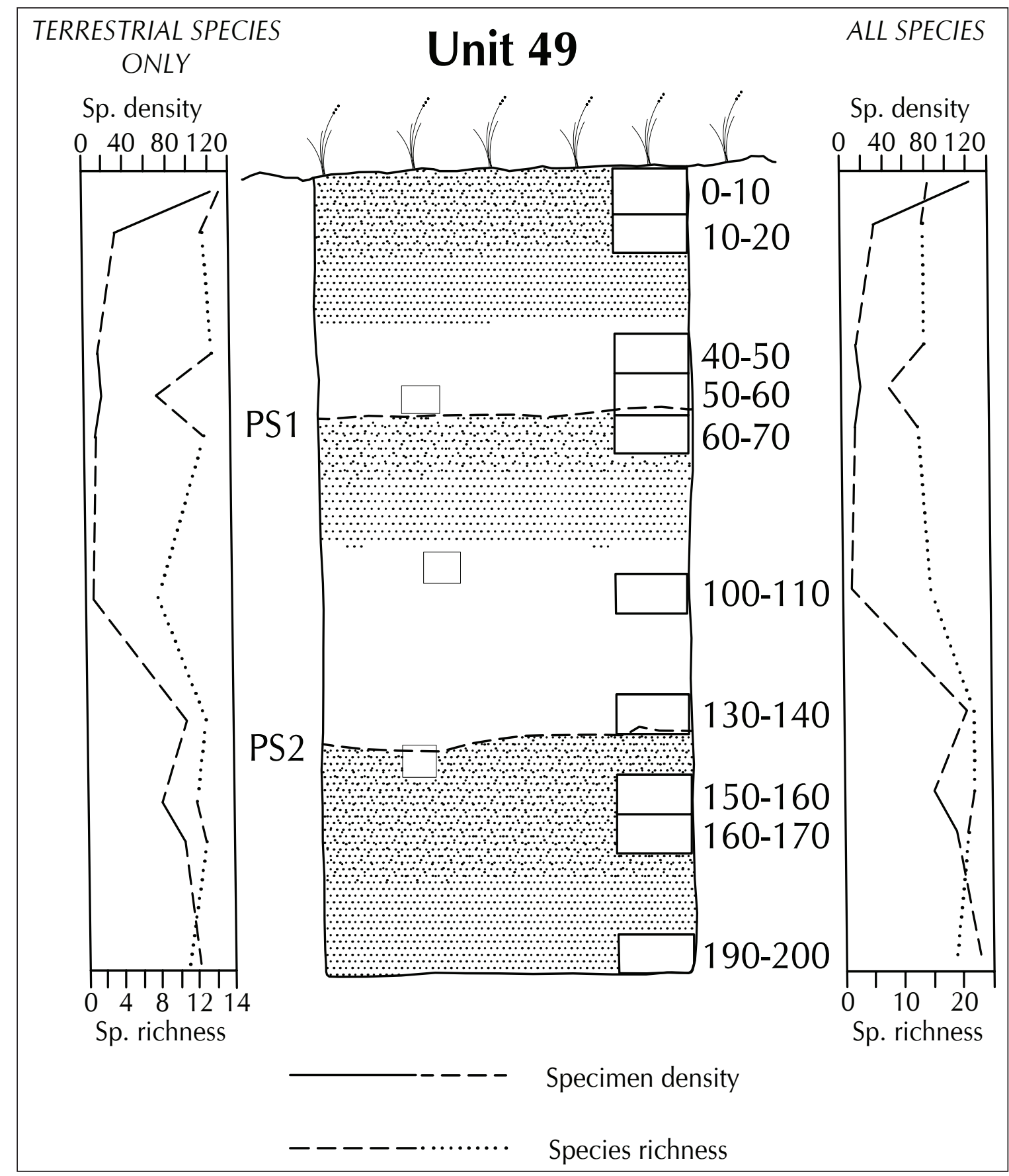

Figure 6-2. Unit 49 Profile. The grid west (magnetic northwest) wall is shown with sample locations in the grid southeast corner projected onto the west wall. Small unlabeled boxes are micromorphology samples. Stippled areas are modern soil and paleosols (PS1 and PS2). The line graph on the left plots specimen density (individuals/liter) and species richness for terrestrial snails only; the righthand graph includes all terrestrial and aquatic snails, peaclams, and freshwater limpets.

the level, but probably on average represents about the middle six centimeters or so. When the samples were picked, they were found to contain modern forb seeds that probably represent part of the seasonal October seed rain occurring on the site during the excavations; these are seeds that fell or blew into the unit during excavation, not indicators of bioturbation. There are 
no indications that any of the other material (snails, bone, charophyte oogonia, etc.) found in the sample represent contamination. When collected, the 10 samples actually averaged about 19.12 \pm 1.9 liters (range, 15.8-22.25 liters) and were processed using the same protocol adopted for an earlier study at the Vara Daniel site (Brown 2010:136). The volume of each sample was measured in liters, then the sediment was dumped into a plastic bucket with a couple of teaspoons of sodium bicarbonate, covered with tapwater, and allowed to soak. Using a stream of tapwater under pressure, each sample was passed through a series of nested, oversize (18inch diameter) geologic sieves: \#10 $(2.0 \mathrm{~mm}), \# 18(1.0 \mathrm{~mm})$, and \#35 (0.5 mm). The residue was bagged and dried by grade and sample, with three grades for each sample. For Unit 49, the \#10 sieve produced a little over two percent of the specimens recovered, the \#18 sieve 33 percent, and the \#35 sieve 65 percent.

The two samples from the paleochannel area are general-purpose sediment samples collected from excavated features and are much smaller in volume (3.5 and 3.85 liters, respectively), producing fewer snails and a truncated list of taxa. In terms of absolute elevation, these lie about $43-63 \mathrm{~cm}$ below the elevation of the Unit 49 column base, but are offset by up to 18 meters, and because they come from Depositional Unit 2, are actually stratigraphically higher than any of the Depositional Unit 1 samples. For these samples, the \#10 sieve produced a little over one percent of the specimens recovered, the \#18 sieve 50 percent, and the \#35 sieve 49 percent.

The sediment samples were found to consist almost entirely of clay and silt. The sieve residue consisted mostly of tree roots, rootlets, a very small amount of sand or pebble-sized clastic or concretionary material, baked clay in some levels, and biological material (snails, peaclams, flakes of freshwater mussel shell, small animal bones, fish scales, small bits of charcoal, hackberry seeds and seed fragments, possible eggshell fragments (?), ostracod valves, and charophyte oogonia; Figures 6-3; 6-6, M). Although at the site, the adjacent stream is incised into Quaternary terrace deposits associated with Mountain Creek, Fish Creek passes only a short distance upstream into bedrock outcrops of calcareous shale, mudstone and limestone of the Eagle Ford Group (the upper members of which are the Arcadia Park Limestone and the South Bosque Formation), and these are the source materials for the sediments at the site. Because so little sand-sized clastic material was present, it was possible to pick and sort the \#35 sieve fraction, something that is often not feasible for many sites. Carychium mexicanum, perhaps the smallest native Texas land snail, was found only in this fraction and would have been missed if the \#35 sieve had not been examined. Likewise, because so few snails were obtained from the quarter-inch field screens, it was possible to examine all of them, again something that is not feasible for most sites.

The ten Unit 49 samples produced variable numbers of specimens, ranging from 166 items at the 100-110 cm level to 2415 at the 190-200 cm level. Overall specimen density for Unit 49 was 64.71 specimens per liter, but density varied widely by level, from a low of 9.13 to a high of 128.51. Snail abundance and species richness can be controlled both by sedimentation rates and by habitat suitability, and I suspect that while both factors probably influenced the snail faunas at 41DL436, sedimentation rates and geologic facies changes probably played a somewhat more important role. Snails recovered from the sieves were well preserved, with fairly low 
rates of breakage, and were mostly quite identifiable. Small fragments with apertural lamellae probably from Linisa texasiana were found in some of the \#35 sieve fractions, suggesting this species may have had something of a tendency to disintegrate. Little evidence of chemical corrosion was seen except for minor surface pitting on some of the aquatic species, presumably a result of algal encrustation while the snails were still living in Fish Creek. Some of the Gastrocopta specimens from the lower levels had perforated shells as a result of some sort of chemical or other postdepositional damage. In clay-rich sites with seasonal rainfall, clays with high shrink-swell capacity can thoroughly digest archaeological snail faunas, leaving nothing but unrecognizable shell hash. This was not the case at 41DL436, where all the biological material seems exceptionally well preserved, especially in the lower component. Very

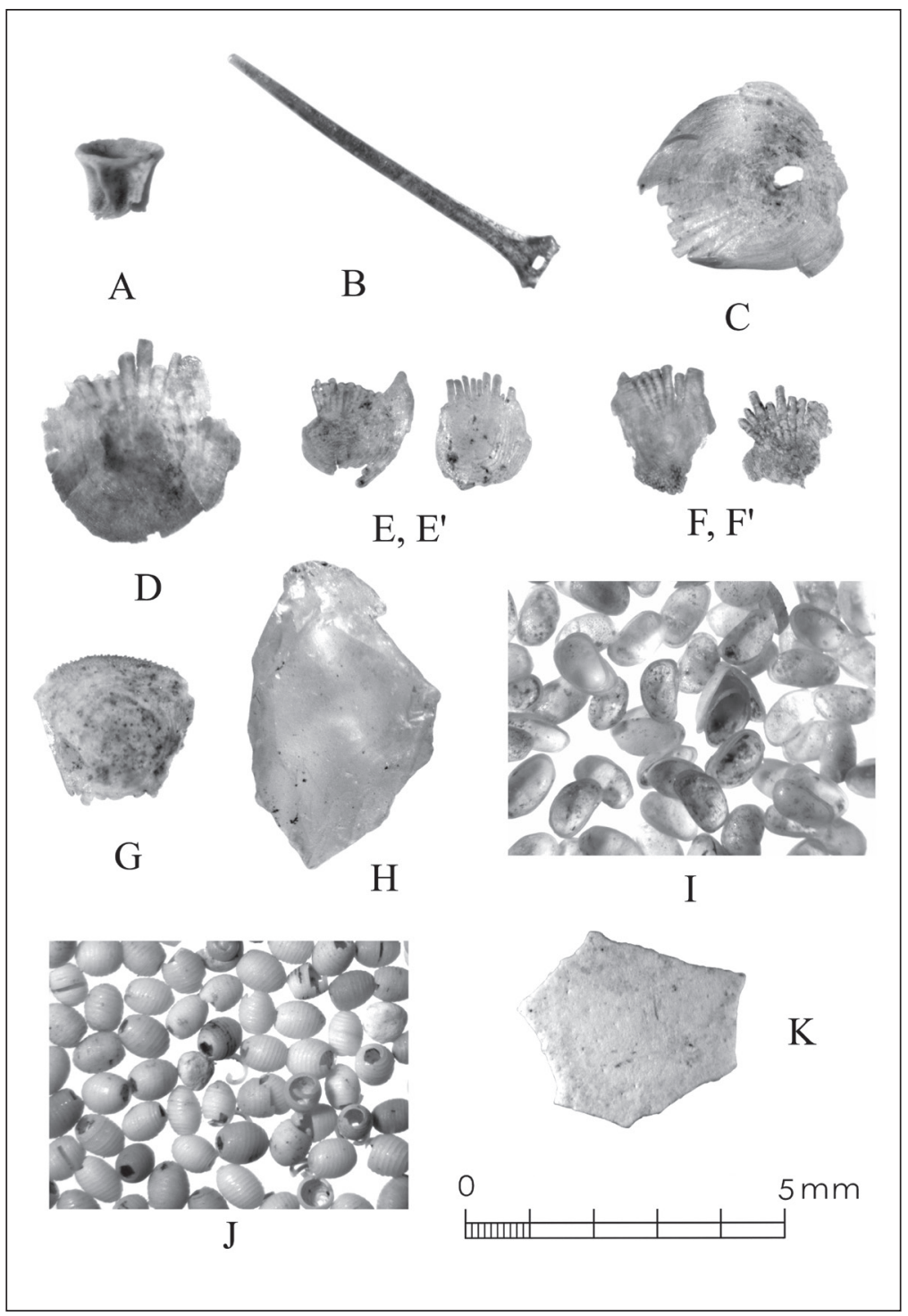

Figure 6-3. Examples of Material Recovered From the Snail Samples. A, B, fish vertebra fragment and fin spine; C-F', fish scales; $\mathrm{G}$, unidentified scale; $\mathrm{H}$, chert or quartz shatter fragment; I, ostracod valves; J, charophyte oogonia; $\mathrm{K}$, eggshell or mineral lining.

\section{fragile items rarely seen}

in unsheltered archaeological sites, such as fish scales, charophyte oogonia, and freshwater limpets, were recovered in good condition from the sediment samples. Many of the fish scales are still flexible. Both cyprinids and perciform fish are represented in the scales, and the smaller perciform scales tend to be more common in the \#35 sieve sample. Many scales come from very young fish or are newly regenerated scales (Dean Hendrickson, personal communication, 2013). In Unit 49, over 88 percent of the snails are terrestrial species (including slugs), over 11 percent are aquatic (including 18 limpets), and less than 1 percent are amphibious. The 260 peaclams recovered are very tiny bivalves, not gastropods, but they often appear in sediment samples collected from alluvial deposits. Many of them have chipped shell margins or are 
snapped altogether. Is this a result of predation, or stream tumbling in some rocky headwater area? In general, the snails change in frequency but not in condition from level to level, indicating few if any were reworked from older deposits upbasin. Microscopic evidence of abrasion was rare and was essentially confined to aquatic taxa (Helisoma, Physa, Amnicola). There is broken snail shell in all samples (see Table 6-1), but breakage does not necessarily imply redeposition. Breakage can occur during soil development, sample collection, or sample processing.

As the dried sieve residue was picked, anything of potential interest (animal bone, charcoal, hackberry seeds, ostracod valves, and so forth) was collected. The three different size grades were kept separate and tabulated separately throughout the analytical process. This has some effect on the accounting process. For example if large fragments of a species are found in the \#10 sieve, and smaller fragments of the same individual occur in the \#18 and \#35 sieves, it could be counted as more than one individual. This slight potential for overcounting when fragments show up in separate sieves is probably more than compensated for by the underrepresentation suffered by fragile species due to breakage. In particular, Glyphyalinia umbilicata is a notably fragile species and is probably underrepresented to some extent.

After picking of the matrix residue, microscopic specimens were identified using a National model 429T-430PHF-10 binocular stereozoom microscope, usually at about 10X magnification, but occasionally up to $40 \mathrm{X}$. Roughly 96 percent of the 12,608 specimens from sediment samples required identification under magnification, which entailed many hours of microscope work. Weights of broken shell were measured with a Veritas S123 precision electronic balance to the nearest $0.001 \mathrm{~g}$.

\section{Snails from the Quarter-Inch Field Screens}

Large and medium-bodied snails recovered from the quarter-inch field screens were sparse, both in number and kind. A minimum number (MNI) of only 161 individuals was recovered, representing four different species. The largest number of specimens from any one unit was 14 , but almost half of the levels with snails had only one specimen. The assemblage of snails from the field screens is so small that it was possible to inventory the entire collection, a practice that is not feasible for many sites in other parts of Texas. Only four specimens came from Unit 49, the unit designated for collection of the stratigraphic snail column; the rest were scattered among units from the floor of the Gradall trench. Because they were found on the field screens, these four specimens are not represented in any of the data tables for the snail sampling column. Linisa texasiana was most abundant (76 specimens, including two juveniles; Figure 6-4, A). A number of fragmentary or collapsed specimens were present; although the similar species Millerelix mooreana has been reported from Dallas County (Pratt 1981:Figure 5), the incomplete specimens are all tabulated here as Linisa because no definite examples of Millerelix have been seen at the site.

Rabdotus was nearly as abundant, with 72 individuals (Figure 6-4, B). As far as can be determined, all examples are probably Rabdotus mooreanus. These are about evenly divided between adults (32 specimens) and juveniles (30 specimens), along with 10 specimens of 


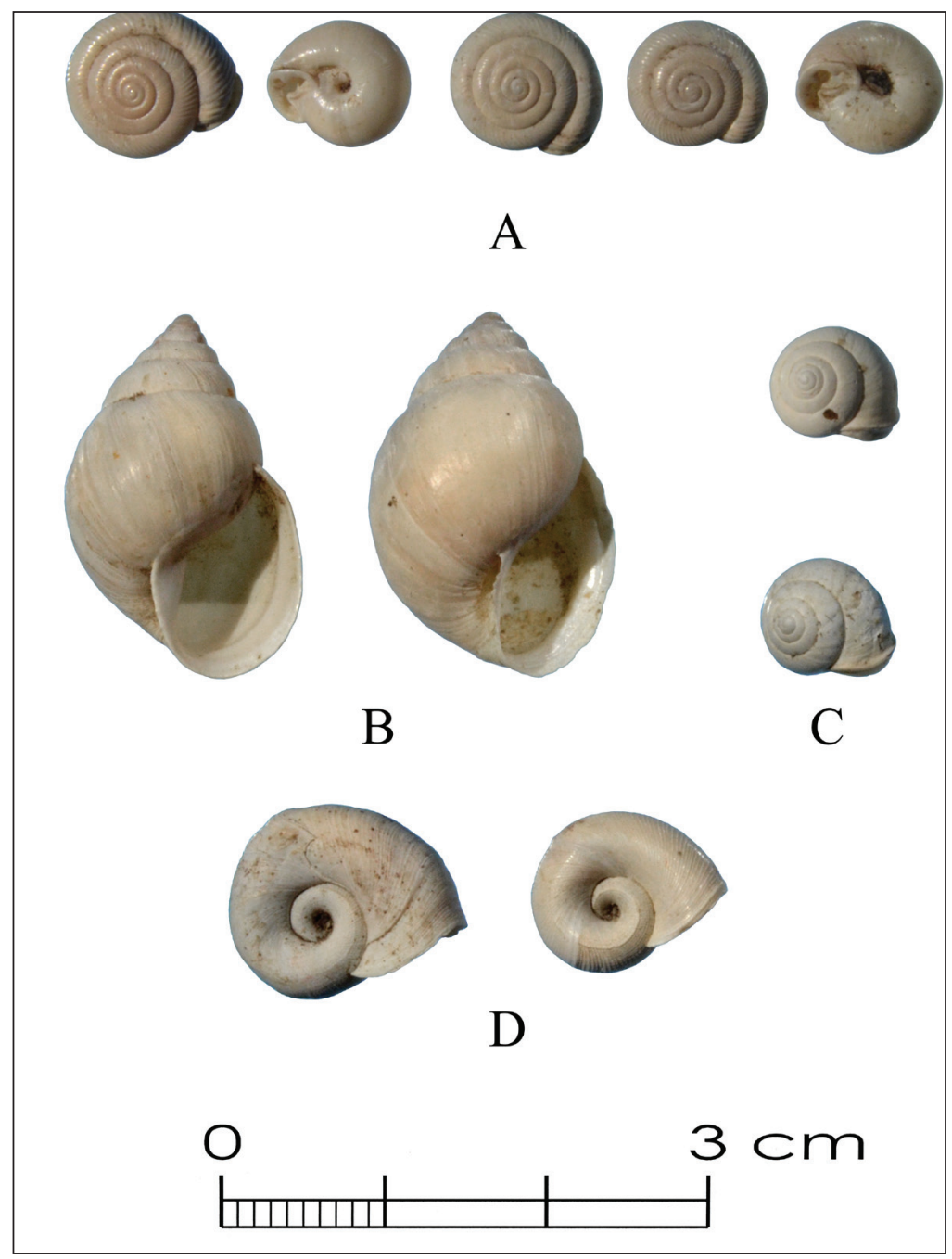

Figure 6-4. Snails From the Quarter-Inch Screen. A, Linisa texasiana adults, apical and umbilical views; B, Rabdotus sp. adults, adaxial view; C, Olygyra orbiculata adults, apical views; D, Planorbella trivolvis juveniles, apical views (note varix on first specimen).

indeterminate age. Other species include Olygyra orbiculata (eight specimens, Figure 6-4, C) and Planorbella trivolvis (five specimens, at least three of which are juvenile; Figure 6-4, D). Although Planorbella is an aquatic snail, the few specimens recovered were not found in units from the paleochannel area, but rather scattered among units toward the northeastern end of the Gradall trench. This species does not appear to be represented in any of the Unit 49 sediment samples, at least in recognizable form.

In general, this sparse and depauperate collection of large and medium-bodied snails suggests an open, perhaps grassy habitat occasionally inundated by Fish Creek. There are no concentrations suggesting the use of snails as a food source. 


\section{Unit 49 Samples}

The Unit 49 samples are described below in terms of their stratigraphic position in relation to the profile recorded by Jim Abbott; however, the profile depicts the west wall of the unit, and the snail samples were actually collected from the grid northeast corner of the unit, so if there are irregularities in the various depositional contacts over the width of the unit, there may be minor discrepancies in the actual stratigraphic position of some of these samples. In the schematic profile (see Figure 6-2), I have projected the sample locations onto the west wall profile.

0-10 cm (99.70-99.80 m; lot 137): This sample comes from the modern surface soil, and has far more pea gravel than any of the underlying samples, but asphalt coatings on some of the gravel indicate it is road metal. An expended shell casing, some very small glass fragments and a few pieces of badly decayed paper were found in the sample, along with some bone, hackberry seed fragments, few mussel shell flakes, little charcoal, abundant undecayed organic particles, and many fine rootlets. At least two specimens of Olygyra orbiculata still have the operculum present in the aperture of the shell. The \#35 sieve fraction required nearly three weeks of picking.

10-20 cm (99.60-99.70 m; lot 143): This sample produced bone from small mammals of various sizes, probably all smaller than rabbit (long bone fragment, ilium fragment, caudal vertebrae, several unfused rodent epiphyses, phalanges), only small amounts of charcoal or hackberry seed fragments, very few mussel shell flakes, and some microdebitage.

40-50 cm (99.30-99.40 m; lot 186): This sample is relatively sterile, containing almost no charcoal, hackberry seed fragments, or bone, and only a few mussel shell fragments. Snail density and abundance are low. It comes from a silty clay zone under the modern A horizon.

50-60 cm (99.20-99.30 m; lot 191): This sample comes from a silty clay zone with disrupted silt lenses about 1-3 cm thick. Micromorphology sample 1 came from this zone, which immediately overlies Paleosol 1 and represents the base of Depositional Unit 3. This sample contains a rodent mandible, some small vertebrate long bones, small snake vertebrae, and no charcoal, hackberry seeds, and very few mussel shell flakes. None of the microvertebrate bone is charred, and the breakage and digestion features resemble that seen on bone from raptor pellets. This sample produced the lowest number of snail taxa in any of the sediment samples. The micromorphology sample has evidence of small-scale bioturbation (Frederick, this volume), but the low snail diversity and abundance are thought to be a result of rapid deposition, not bioturbation.

60-70 cm (99.10-99.2 $0 \mathrm{~m}$; lot 196): This sample lies immediately below the upper contact of Paleosol 1 and marks the top of Depositional Unit 2. This is by far the most sterile sample analyzed from Unit 49. It has rather low snail abundance and diversity. No hackberry seeds and almost no charcoal were recovered. One intact microvertebrate bone and a few very tiny, digested-appearing bone scraps were found. Two charophyte oogonia found in the \#35 sieve (in contrast to the large numbers found in some of the samples below) represent the stratigraphically highest examples found. 
100-110 cm (99.70-99.80 m; lot 224): This sample comes from the middle of Depositional Unit 2, and Feature 37 lies in this level, which consists of crossbedded silty sand. The sample lies just below the level of micromorphology sample 2, which has finely divided charcoal and detritus from soil microfauna. This sample has moderately abundant hackberry seeds and seed fragments (many of which are thin and weathered as if corroded by soil acids). Small amounts of charcoal and some small orange baked clay fragments were recovered. The \#18 sieve has well-preserved bone, but much of it (perhaps half or more) is calcined, charred, or heat-discolored. Calcined epiphyses and phalanges are present. The \#35 sieve also yielded a fairly large multicolored array (white, gray, orange, reddish-brown) of microvertebrate bone (long bones, phalanges, and possibly some tooth enamel), fragmented, and much of it appearing digested as well as heat-discolored, as well as half a dozen tiny chert microflakes. Most of this bone seems to be from terrestrial mammals. A single ostracod valve plus part of another, a moderate number of charophyte oogonia, and a moderate quantity of small charcoal and hackberry seed fragments were recovered from the \#35 sieve. All of this heataltered material is presumably associated with Feature 37. This sample has the lowest snail density and abundance of any in Unit 49. Some peaclams and a few aquatic snails make their appearance in this sample, and these, along with the charophyte oogonia, constitute a minor aquatic influence, but nothing so substantial as in the levels below.

130-140 cm (98.40-98.50 m; lot 234): If this sample location is projected onto the Unit 49 west wall profile, it lies immediately above the upper contact of Paleosol 2 and is the lowest sample in Depositional Unit 2. However, based on the contents (both snail and non-snail), it seems to be aligned with Depositional Unit 1, not Unit 2. It appears to have more silt and less clay, and almost no pebbles. Charcoal and hackberry seed fragments are very scarce, and mussel shell is absent. The \#18 sieve has some charred seeds, very few hackberry seed fragments, a snake vertebra, two fish vertebrae and some other fish bone, some tooth enamel, and eight fish scales. Proceeding downward in the Unit 49 column, this is the first sample in which fish scales and freshwater limpets are encountered, and it has more peaclams than any of the other samples. The \#35 sieve produced many very small bits of broken snail shell, 121 ostracod valves, very abundant charophyte oogonia, some charred seeds, some hackberry seed fragments and very little charcoal, some very small fish and snake vertebrae, fish dorsal fin spines (minnow or darter-sized fish), a possible amphibian bone fragment, and 36 very small fish scales or scale fragments (mostly Perciformes).

150-160 cm (98.20-98.30 m; lot 241): This sample comes from near the top of Paleosol 2, just under micromorphology sample 3 . It has more animal bone than most of the stratigraphically higher samples. The \#10 sieve yielded a charred large mammal bone fragment, several snake vertebrae (large and small), a microtine mandible and molar; small mammal maxillary fragment, long bones and caudal vertebra, a single fish vertebra, and hackberry seeds but no charcoal. The \#18 sieve has many hackberry seed fragments, a moderate amount of charcoal, very few mussel shell flakes, and abundant bone. There are many (about 66) very small snake vertebrae, some lizard dentary fragments, an amphibian long bone fragment, a microtine molar, ribs and rib fragments, and many small mammal long bone and other fragments, some charred. The \#35 sieve has charophyte oogonia, ostracod valves, freshwater limpets, and an array of very small microvertebrate bone fragments. There are about 16 very small snake vertebrae, a rodent 
molar, some fish bone, four very small fish vertebrae, many small mammal bone fragments of various kinds, some amphibian long bones, seven fish scales or scale fragments, and one or two possible reptile scales.

160-170 cm (98.10-98.20 m; lot 244): This sample comes from the lower part of Paleosol 2. The \#10 sieve has abundant hackberry seeds (whole, split, or fragmentary; several are rodentgnawed) but almost no charcoal. There are abundant small mussel shell fragments. Bone consists mostly of small pieces of turtle shell, along with a rodent incisor fragment. The \#18 sieve includes 11 very small snake vertebrae, a very small fish vertebra, possibly some other fish and amphibian bone, a couple of small pieces of turtle shell, and various small mammal bone fragments. Very little is charred, but some of the bone looks more weathered and corroded than in the levels above. There are abundant hackberry seed fragments, a moderate amount of charcoal, and a possible piece of microdebitage. The \#35 sieve has fairly abundant charophyte oogonia, ostracod valves, a mussel shell fragment, and many small microvertebrate bone fragments, some of them charred. A couple of very small snake vertebrae, five very small fish vertebrae, some other fish bone, a couple of amphibian long bones, and some small complete or fragmentary fish scales.

190-200 cm (97.90-97.80 m; lot 255): This is the lowest sample in Unit 49. The \#10 sieve contains some large pieces of freshwater mussel shell, some small pebbles and fragments of firecracked rock, many small nodules of dark brown baked earth or heat-altered sandstone (?), 14 small seeds, both charred and uncharred, a few hackberry seed fragments and a small amount of well-preserved charcoal, two small quartz fragments and two pieces of microdebitage (including a biface edge retouch microflake). Animal bone (much of it charred) includes several pieces of turtle shell, large mammal (?) bone fragments, a piece of tooth enamel, and a fish vertebra. The \#18 sieve yielded a large quantity of small baked earth or heat-discolored sandstone nodules, small carbonate concretions, many small mussel shell flakes, some quartz fragments, a moderate number of hackberry seed and charcoal fragments, three small snake vertebrae, part of a frog ilium, some small fish bones, and many small bits of unidentifiable bone. Much of this material is corroded, and some of it is charred or calcined. The \#35 sieve contains many small hackberry seed fragments and very abundant bits of charcoal, mussel shell flakes, and small gray carbonate concretions. The charcoal and mussel shell flakes were not picked because they were too abundant. Identifiable mussel shells were not found in this level, but the 98.10-97.90 m levels in Unit 49 contained Lampsilis hydiana, Toxolasma spp., and Uniomerus tetralasmus (Howells, Chapter 7). There are also many charophyte oogonia and 64 ostracod valves. There is a very large quantity of very small microvertebrate bone fragments (even more than in the overlying samples), many of them calcined or charred. In contrast to overlying samples, only a couple of very small snake vertebrae were seen. This sample seems to have more bone from small fish (including three small vertebrae) than any of the other samples. There are also 16 very small fish scale fragments and a single freshwater limpet. 


\section{Samples from the Paleochannel Area}

The two samples from the paleochannel area come from features and are general-purpose matrix samples that were not specifically collected for snail sampling, so they are only about 20 percent as large as the Unit 49 samples. Although they are lower in absolute elevation than any of the Unit 49 samples, both features lie in Depositional Unit 2 sediments that dip down into the abandoned creek channel, so they are stratigraphically equivalent to the Depositional Unit 2 sediments in Unit 49, and have similar snail faunas. Neither sample yielded any peaclams or freshwater limpets, and there are very few aquatic snails.

Unit 46A, Level 2, Feature 28, 10-20 cm (97.31-97.41 m; lot 170): This sample is uniform gray-brown sediment with carbonate filaments, 3.5 liters. The \#10 sieve contains some very large pieces of wood charcoal and a few split segments of hackberry seeds. The \#18 sieve has a moderate number of hackberry seed fragments and a single charred seed. The $\# 35$ sieve has many small hackberry seed fragments, a few small pieces of charcoal and some possible charred seeds, and a single charophyte oogonium. Radiocarbon assayed at 1470-1640 cal AD (Beta 312835).

Unit 100, Level 1, Feature 40, 0-10 cm (97.21-97.30 m; lot 351): This sample measures 3.85 liters. The \#10 sieve contains large pieces of baked clay, a few large pieces of charcoal, a single split hackberry seed, and a snake vertebra. The \#18 sieve has small baked clay and carbonate nodules, many small pieces of wood charcoal (fragmentary, but with well-preserved structure), four small spherical carbonized seeds $(1.2-1.5 \mathrm{~mm}$ in diameter), an oblong carbonized seed, a few hackberry seed fragments, and only a single tiny piece of animal bone. There is also a single very small but well-preserved fish scale. The $\# 35$ sieve has a large quantity of very small pieces of wood charcoal, a single ostracod valve, and very little bone except for some very small rib elements (snake?) and a few other pieces (one charred). Calibrated radiocarbon assay with peaks at 1452-1528 cal AD and 1553-1634 cal AD (UGAMS-8613).

\section{Assessing Habitat Preferences}

Evaluating the paleoenvironmental significance of the successive snail faunas at 41DL436 depends on understanding the habitat preferences of the various species. Unfortunately, at least in the older literature, much of the habitat data are quasi-anecdotal in nature, at least for land snails. In some of these older studies, large areas are casually surveyed and frequency is assessed by reporting the number of localities or "stations" (of unspecified area) where a particular species is encountered. In this system, a station occurrence could represent a single individual or a thousand individuals, but the counts are not reported. A better approach is to lay out measured square quadrats $(50 \mathrm{~cm}$ or one meter on a side), collect the surface litter layer plus the top $2 \mathrm{~cm}$ of soil underneath, pass the samples through graded sieves, and count the specimens (Coppolino 2010:98). This is exactly the same procedure as used for archaeological samples, except that 1) the sampling area is wide and shallow rather than narrow and deep, 2) most of the specimens come from the litter layer, and 3) the habitat where the sample is collected is observable and known. The best example of this kind of systematic collection strategy is the Southern Plains Gastropod Survey, run across most of the state of Oklahoma 
by Wyckoff, Theler and Carter (1997). In recent years, similar surveys have been done in Kentucky, Minnesota, New Mexico, Pennsylvania, South Dakota, Tennessee, Wisconsin, and probably other places. Unfortunately, almost no work of this kind with contemporary snails has been done in Texas, although I have participated in some limited sampling in the counties of Comal, Goliad, Hays, Houston, and Val Verde. Other researchers in Texas have done systematic surveys by quadrat, but focused on large-bodied taxa like Rabdotus.

In the following pages, I will refer occasionally to an unpublished systematic survey at the Donnelly yard in San Marcos, Hays County, done in October, 2011, following the severe summer drought and snail die-off that year. The collection area (five one-meter quadrats) is an open, mowed grassy area near a single mesquite tree, and is a good illustration of the kind of arid-tolerant snail faunas that can be expected in open grasslands. Because the terrain is well-drained, almost treeless and closely cropped upland, it is doubtless far more arid than any prairie habitat in the Fish Creek valley.

\section{Species Accounts: Terrestrial Species}

This section provides brief sketches of the different species recovered, listed approximately in order of abundance for the aggregated Unit 49 and feature samples (counts for the quarterinch field screen samples are given separately, and miscellaneous categories like "unidentified juveniles" are listed at the end). I have included the Succineidae in the terrestrial category, though they are often amphibious (Tables 6-3, 6-4).

Helicodiscus singleyanus $(\mathrm{n}=2830$; Figure 6-5, A)

This species has also been listed in some of the recent literature as Lucilla singleyana (Horsák et al. 2009), and the genus Hebetodiscus has also been applied at times. They are also similar to Helicodiscus inermis. This species is ubiquitous in the samples, making up anywhere from about 7-46 percent of the Unit 49 samples; especially large numbers appear in the uppermost and lower samples. On a proportional basis, it is most abundant in Depositional Unit 2 and is best represented at $50-110 \mathrm{~cm}$ and at $190-200 \mathrm{~cm}$. It is the most abundant snail in Feature 40, making up almost 59 percent of the total. It can be easily confused with similar-appearing species such as Hawaiia minuscula or even Vallonia spp. These discoidal snails are typically about $1.5 \mathrm{~mm}$ in diameter (range, about 0.6-2.5 mm). About 78 percent of these (probably almost all juveniles) were recovered from the \#35 sieve, the rest from the \#18 sieve. They are too small to be retained by the \#10 sieve. They have a widespread but scattered occurrence in the eastern US as well as the desert west, including New Mexico, Arizona, and northern Mexico. Habitat preferences for this species are poorly known, but may be similar to $G$. pellucida, occurring often in open, grassy locations. In the Donnelly Yard samples, density was highly variable from quadrat to quadrat, with over 560 specimens appearing in a single one-meter quadrat, suggesting it is well adapted to open grassy habitats. Theler (1997:Tables 4,6 ) found this species in Wisconsin hill prairies, but found it to be one of the least common species in high-stress, arid habitats. Litter sampling in Uvalde County recovered it both in riparian woodland and prairie habitats, but at somewhat greater frequency in the prairie (Neck 1987a:Table 2). They seem to be arid-tolerant, but also capable of tolerating damp habitats. 
Table 6-3. Specimen Counts, Unit 49 and Features.

\begin{tabular}{|c|c|c|c|c|c|c|c|c|c|c|c|c|c|c|c|c|c|c|c|c|c|c|}
\hline \multicolumn{23}{|c|}{ Terrestrial taxa } \\
\hline 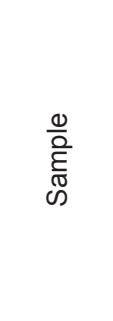 & 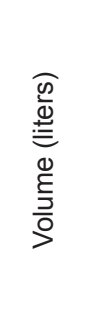 & 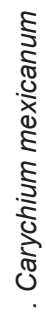 & 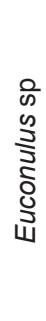 & 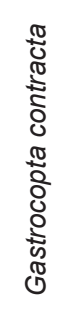 & 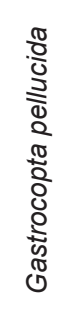 & 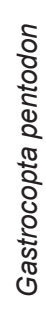 & $\begin{array}{l}\pi \\
0 \\
0 \\
0 \\
0 \\
0 \\
\pi \\
0 \\
0 \\
0 \\
0 \\
0 \\
0 \\
0 \\
0 \\
0 \\
4\end{array}$ & 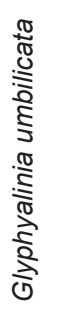 & 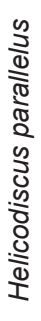 & 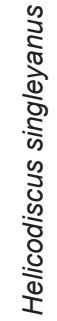 & 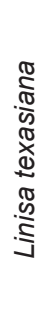 & 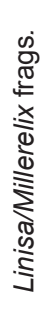 & $\begin{array}{l}\frac{\pi}{\pi} \\
\frac{\pi}{3} \\
\frac{0}{2} \\
\frac{0}{2} \\
\frac{\pi}{0} \\
\frac{0}{2} \\
\frac{7}{0}\end{array}$ & 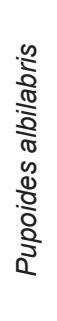 & 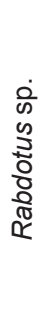 & 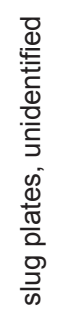 & 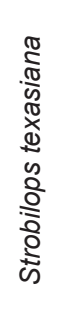 & 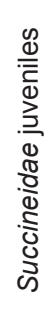 & 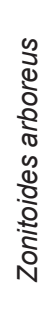 & 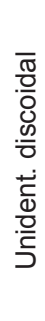 & 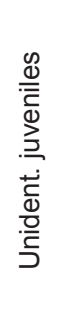 & 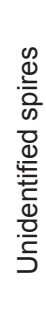 \\
\hline $0-10$ & 20.2 & 9 & 0 & 705 & 215 & 77 & 19 & 19 & 2 & 555 & 0 & 0 & 19 & 42 & 1 & 18 & 718 & 0 & 1 & 16 & 46 & 28 \\
\hline $10-20$ & 19.75 & 1 & 0 & 103 & 42 & 8 & 43 & 14 & 1 & 127 & 0 & 0 & 3 & 101 & 2 & 1 & 123 & 0 & 0 & 0 & 45 & 14 \\
\hline $40-50$ & 20.25 & 22 & 3 & 79 & 2 & 0 & 1 & 80 & 1 & 71 & 1 & 1 & 1 & 3 & 0 & 2 & 4 & 4 & 0 & 0 & 9 & 15 \\
\hline $50-60$ & 22.25 & 15 & 3 & 89 & 0 & 0 & 2 & 64 & 0 & 181 & 0 & 0 & 0 & 0 & 0 & 8 & 4 & 0 & 0 & 0 & 17 & 12 \\
\hline $60-70$ & 15.8 & 5 & 7 & 73 & 1 & 0 & 3 & 14 & 0 & 81 & 1 & 0 & 0 & 1 & 1 & 1 & 2 & 1 & 0 & 0 & 1 & 3 \\
\hline $100-110$ & 18.4 & 0 & 0 & 24 & 0 & 0 & 2 & 41 & 2 & 45 & 0 & 0 & 0 & 28 & 1 & 2 & 0 & 0 & 0 & 0 & 2 & 0 \\
\hline $130-140$ & 19.5 & 0 & 7 & 584 & 633 & 0 & 62 & 99 & 3 & 170 & 3 & 0 & 34 & 41 & 12 & 18 & 0 & 4 & 0 & 0 & 131 & 60 \\
\hline $150-160$ & 20 & 0 & 5 & 200 & 531 & 0 & 101 & 114 & 10 & 192 & 1 & 2 & 0 & 13 & 4 & 15 & 0 & 3 & 0 & 0 & 202 & 55 \\
\hline $160-170$ & 16.25 & 0 & 1 & 508 & 152 & 0 & 32 & 140 & 3 & 328 & 0 & 1 & 1 & 24 & 2 & 52 & 0 & 15 & 0 & 0 & 185 & 65 \\
\hline $190-200$ & 18.8 & 0 & 0 & 121 & 496 & 0 & 60 & 38 & 16 & 982 & 10 & 0 & 0 & 55 & 14 & 6 & 0 & 2 & 0 & 0 & 177 & 33 \\
\hline Fea. 28 & 3.5 & 0 & 0 & 43 & 4 & 0 & 13 & 7 & 0 & 31 & 1 & 0 & 0 & 13 & 0 & 7 & 0 & 0 & 0 & 0 & 2 & 0 \\
\hline Fea. 40 & 3.85 & 0 & 0 & 13 & 3 & 0 & 7 & 3 & 5 & 67 & 0 & 0 & 0 & 5 & 0 & 2 & 0 & 1 & 0 & 0 & 4 & 2 \\
\hline Col. total & 198.55 & 52 & 26 & 2542 & 2079 & 85 & 345 & 633 & 43 & 2830 & 17 & 4 & 58 & 326 & 36 & 132 & 851 & 30 & 1 & 16 & 821 & 287 \\
\hline
\end{tabular}

\begin{tabular}{|c|c|c|c|c|c|c|c|c|c|c|c|}
\hline \multicolumn{12}{|c|}{ Aquatic taxa } \\
\hline $\begin{array}{l}\frac{0}{0} \\
\stackrel{\mathbb{O}}{\mathbb{D}} \\
\stackrel{2}{ }\end{array}$ & 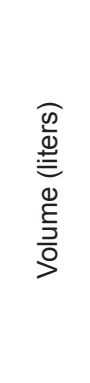 & 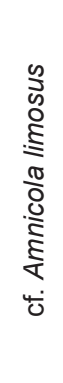 & 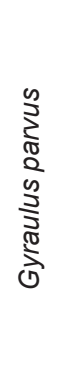 & 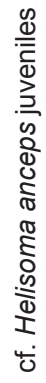 & 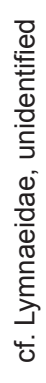 & 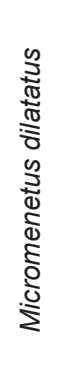 & 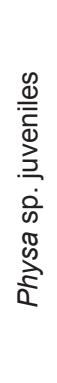 & 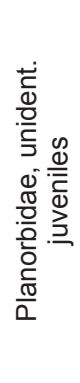 & 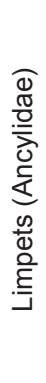 & 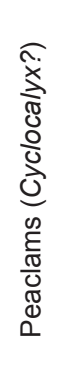 & 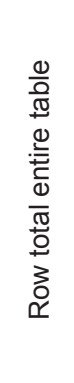 \\
\hline $0-10$ & 20.2 & 0 & 0 & 0 & 0 & 0 & 0 & 0 & 0 & 0 & 2493 \\
\hline $10-20$ & 19.75 & 0 & 1 & 0 & 0 & 0 & 0 & 0 & 0 & 0 & 638 \\
\hline $40-50$ & 20.25 & 0 & 0 & 0 & 0 & 0 & 0 & 0 & 0 & 0 & 299 \\
\hline $50-60$ & 22.25 & 0 & 0 & 0 & 0 & 0 & 0 & 0 & 0 & 0 & 395 \\
\hline $60-70$ & 15.8 & 0 & 0 & 0 & 0 & 0 & 0 & 0 & 0 & 0 & 195 \\
\hline $100-110$ & 18.4 & 8 & 1 & 2 & 1 & 2 & 1 & 0 & 0 & 6 & 168 \\
\hline $130-140$ & 19.5 & 173 & 37 & 28 & 8 & 58 & 22 & 1 & 11 & 102 & 2301 \\
\hline $150-160$ & 20 & 83 & 34 & 6 & 1 & 56 & 21 & 28 & 5 & 41 & 1723 \\
\hline $160-170$ & 16.25 & 108 & 28 & 3 & 4 & 43 & 13 & 0 & 1 & 35 & 1744 \\
\hline $190-200$ & 18.8 & 174 & 52 & 47 & 8 & 35 & 13 & 0 & 1 & 76 & 2416 \\
\hline Fea. 28 & 3.5 & 0 & 0 & 0 & 1 & 0 & 0 & 0 & 0 & 0 & 122 \\
\hline Fea. 40 & 3.85 & 0 & 2 & 0 & 0 & 0 & 0 & 0 & 0 & 0 & 114 \\
\hline Col. total & 198.55 & 546 & 155 & 86 & 23 & 194 & 70 & 29 & 18 & 260 & 12608 \\
\hline
\end{tabular}


Table 6-4. Specimen Density, Unit 49 and Features.

\begin{tabular}{|c|c|c|c|c|c|c|c|c|c|c|c|c|}
\hline \multicolumn{13}{|c|}{ Terrestrial taxa } \\
\hline 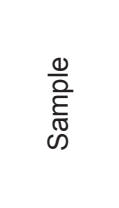 & 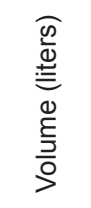 & 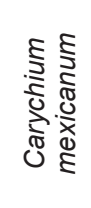 & 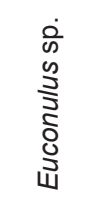 & 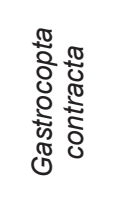 & 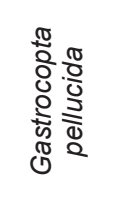 & 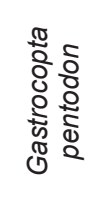 & 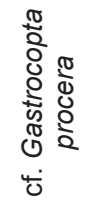 & 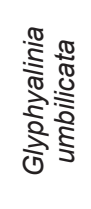 & 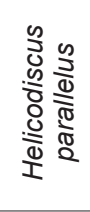 & 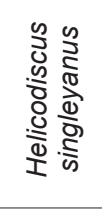 & 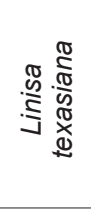 & 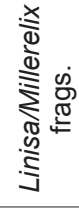 \\
\hline $0-10$ & 20.2 & 0.446 & 0.000 & 34.901 & 10.644 & 3.812 & 0.941 & 0.941 & 0.099 & 27.475 & 0.000 & 0.000 \\
\hline $10-20$ & 19.75 & 0.051 & 0.000 & 5.215 & 2.127 & 0.405 & 2.177 & 0.709 & 0.051 & 6.430 & 0.000 & 0.000 \\
\hline $40-50$ & 20.25 & 1.086 & 0.148 & 3.901 & 0.099 & 0.000 & 0.049 & 3.951 & 0.049 & 3.506 & 0.049 & 0.049 \\
\hline $50-60$ & 22.25 & 0.674 & 0.135 & 4.000 & 0.000 & 0.000 & 0.090 & 2.876 & 0.000 & 8.135 & 0.000 & 0.000 \\
\hline $60-70$ & 15.8 & 0.316 & 0.443 & 4.620 & 0.063 & 0.000 & 0.190 & 0.886 & 0.000 & 5.127 & 0.063 & 0.000 \\
\hline $100-110$ & 18.4 & 0.000 & 0.000 & 1.304 & 0.000 & 0.000 & 0.109 & 2.228 & 0.109 & 2.446 & 0.000 & 0.000 \\
\hline $130-140$ & 19.5 & 0.000 & 0.359 & 29.949 & 32.462 & 0.000 & 3.179 & 5.077 & 0.154 & 8.718 & 0.154 & 0.000 \\
\hline $150-160$ & 20 & 0.000 & 0.250 & 10.000 & 26.550 & 0.000 & 5.050 & 5.700 & 0.500 & 9.600 & 0.050 & 0.100 \\
\hline $160-170$ & 16.25 & 0.000 & 0.062 & 31.262 & 9.354 & 0.000 & 1.969 & 8.615 & 0.185 & 20.185 & 0.000 & 0.062 \\
\hline $190-200$ & 18.8 & 0.000 & 0.000 & 6.436 & 26.383 & 0.000 & 3.191 & 2.021 & 0.851 & 52.234 & 0.532 & 0.000 \\
\hline Fea. 28 & 3.5 & 0.000 & 0.000 & 12.286 & 1.143 & 0.000 & 3.714 & 2.000 & 0.000 & 8.857 & 0.286 & 0.000 \\
\hline Fea. 40 & 3.85 & 0.000 & 0.000 & 3.377 & 0.779 & 0.000 & 1.818 & 0.779 & 1.299 & 17.403 & 0.000 & 0.000 \\
\hline $\begin{array}{l}\frac{0}{0} \\
\frac{0}{E} \\
\infty\end{array}$ & 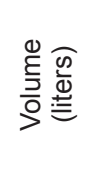 & $\begin{array}{l}\frac{\pi}{0} \\
\frac{\pi}{3} \\
\frac{\pi}{3} \\
\frac{\pi}{0} \\
\frac{0}{0}\end{array}$ & 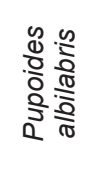 & 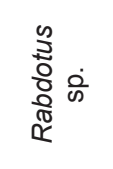 & 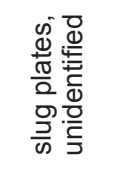 & 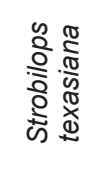 & 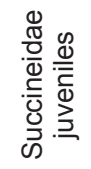 & 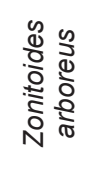 & 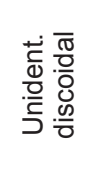 & 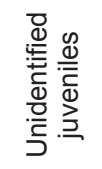 & 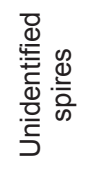 & \\
\hline $0-10$ & 20.2 & 0.941 & 2.079 & 0.050 & 0.891 & 35.545 & 0.000 & 0.050 & 0.792 & 2.277 & 1.386 & \\
\hline $10-20$ & 19.75 & 0.152 & 5.114 & 0.101 & 0.051 & 6.228 & 0.000 & 0.000 & 0.000 & 2.278 & 0.709 & \\
\hline $40-50$ & 20.25 & 0.049 & 0.148 & 0.000 & 0.099 & 0.198 & 0.198 & 0.000 & 0.000 & 0.444 & 0.741 & \\
\hline $50-60$ & 22.25 & 0.000 & 0.000 & 0.000 & 0.360 & 0.180 & 0.000 & 0.000 & 0.000 & 0.764 & 0.539 & \\
\hline $60-70$ & 15.8 & 0.000 & 0.063 & 0.063 & 0.063 & 0.127 & 0.063 & 0.000 & 0.000 & 0.063 & 0.190 & \\
\hline $100-110$ & 18.4 & 0.000 & 1.522 & 0.054 & 0.109 & 0.000 & 0.000 & 0.000 & 0.000 & 0.109 & 0.000 & \\
\hline $130-140$ & 19.5 & 1.744 & 2.103 & 0.615 & 0.923 & 0.000 & 0.205 & 0.000 & 0.000 & 6.718 & 3.077 & \\
\hline $150-160$ & 20 & 0.000 & 0.650 & 0.200 & 0.750 & 0.000 & 0.150 & 0.000 & 0.000 & 10.100 & 2.750 & \\
\hline $160-170$ & 16.25 & 0.062 & 1.477 & 0.123 & 3.200 & 0.000 & 0.923 & 0.000 & 0.000 & 11.385 & 4.000 & \\
\hline $190-200$ & 18.8 & 0.000 & 2.926 & 0.745 & 0.319 & 0.000 & 0.106 & 0.000 & 0.000 & 9.415 & 1.755 & \\
\hline Fea. 28 & 3.5 & 0.000 & 3.714 & 0.000 & 2.000 & 0.000 & 0.000 & 0.000 & 0.000 & 0.571 & 0.000 & \\
\hline Fea. 40 & 3.85 & 0.000 & 1.299 & 0.000 & 0.519 & 0.000 & 0.260 & 0.000 & 0.000 & 1.039 & 0.519 & \\
\hline
\end{tabular}


Table 6-4. Specimen Density, Unit 49 and Features (continued)

\begin{tabular}{|c|c|c|c|c|c|c|c|c|c|c|c|}
\hline \multicolumn{12}{|c|}{ Aquatic taxa } \\
\hline $\begin{array}{l}\frac{0}{0} \\
\frac{E}{\tilde{N}} \\
\infty\end{array}$ & 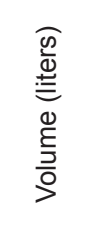 & 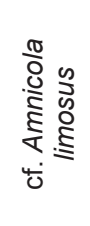 & 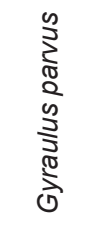 & 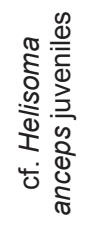 & 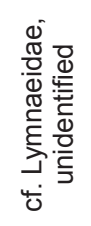 & 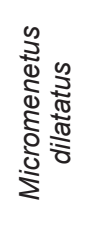 & 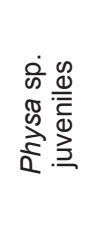 & 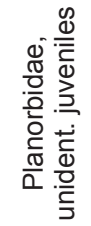 & 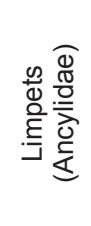 & 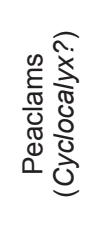 & 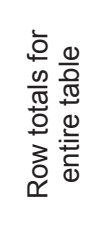 \\
\hline $0-10$ & 20.2 & 0.000 & 0.000 & 0.000 & 0.000 & 0.000 & 0.000 & 0.000 & 0.000 & 0.000 & 123.42 \\
\hline $10-20$ & 19.75 & 0.000 & 0.051 & 0.000 & 0.000 & 0.000 & 0.000 & 0.000 & 0.000 & 0.000 & 32.30 \\
\hline $40-50$ & 20.25 & 0.000 & 0.000 & 0.000 & 0.000 & 0.000 & 0.000 & 0.000 & 0.000 & 0.000 & 14.77 \\
\hline $50-60$ & 22.25 & 0.000 & 0.000 & 0.000 & 0.000 & 0.000 & 0.000 & 0.000 & 0.000 & 0.000 & 17.75 \\
\hline $60-70$ & 15.8 & 0.000 & 0.000 & 0.000 & 0.000 & 0.000 & 0.000 & 0.000 & 0.000 & 0.000 & 12.34 \\
\hline $100-110$ & 18.4 & 0.435 & 0.054 & 0.109 & 0.054 & 0.109 & 0.054 & 0.000 & 0.000 & 0.326 & 9.13 \\
\hline $130-140$ & 19.5 & 8.872 & 1.897 & 1.436 & 0.410 & 2.974 & 1.128 & 0.051 & 0.564 & 5.231 & 118.00 \\
\hline $150-160$ & 20 & 4.150 & 1.700 & 0.300 & 0.050 & 2.800 & 1.050 & 1.400 & 0.250 & 2.050 & 86.15 \\
\hline $160-170$ & 16.25 & 6.646 & 1.723 & 0.185 & 0.246 & 2.646 & 0.800 & 0.000 & 0.062 & 2.154 & 107.32 \\
\hline $190-200$ & 18.8 & 9.255 & 2.766 & 2.500 & 0.426 & 1.862 & 0.691 & 0.000 & 0.053 & 4.043 & 128.51 \\
\hline Fea. 28 & 3.5 & 0.000 & 0.000 & 0.000 & 0.286 & 0.000 & 0.000 & 0.000 & 0.000 & 0.000 & 34.86 \\
\hline Fea. 40 & 3.85 & 0.000 & 0.519 & 0.000 & 0.000 & 0.000 & 0.000 & 0.000 & 0.000 & 0.000 & 29.61 \\
\hline
\end{tabular}

This species ranked sixth in ubiquity in the Southern Plains Gastropod Survey; the highest densities occurred in (respectively) mesa top, rock ledge, riparian woodland, pasture, and toe slope settings (Wyckoff, Theler and Carter 1997:Table 10). These snails seem to occur often in greater densities in archaeological samples than in surface sampling of contemporary live snails. Neck (1994:Table 17) recovered 101 of these from 41 DL 270. Fullington and Fullington (1982) recovered them from $34 \mathrm{Cd} 257$ in Caddo County, Oklahoma, but in lower numbers than are reported here. The shells readily float, and when a separate floated fraction is collected in sieving, most of these usually end up in the floated fraction.

Gastrocopta contracta $(\mathrm{n}=2542 ;$ Figure 6-5, B, C)

This species is easily recognizable for its white color, broad body shape, and distinctive aperture and many of these are represented by small but distinctive basal or aperture fragments. It is the second most abundant species and in Unit 49 occurs in the greatest numbers in the top two levels and in the lowest four, in Depositional Unit 1. However, it has the greatest proportional representation at the $60-70 \mathrm{~cm}$ level, where it accounts for 37 percent of the specimens. Plotted as a percentage of specimens per level, it shows an irregular tendency to increase through time. Identification of juveniles is tentative, but about 85 percent appear to be adults. This species is much more mesic-adapted than G. pellucida and occupies all of the eastern US and the eastern two-thirds of Texas (Brown 2006:Figure 8.6), ranging from Ontario into Mexico. Although it may be found in grassland, it seems to be more common in wooded areas. It often occurs in moist areas under leaf litter and in riparian woodlands (Neck 1987a:Table 2). In Kansas, "it shows a well-defined preference for mesic habitat conditions but occurs also in relatively dry places" (Fitch and Lokke 1956:449-450). In Kaufman County, Logsdon (1967:46-47) says it "was abundant in the wooded floodplains of Forney, the wooded sandy loam at Elmo, and 


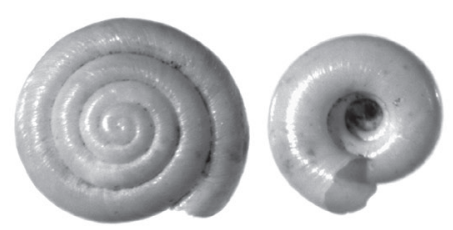

A

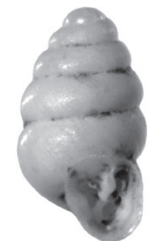

B

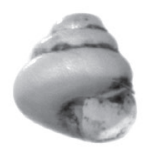

$\mathrm{C}$

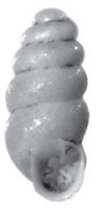

$\mathrm{D}$

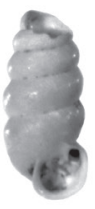

$\mathrm{E}$

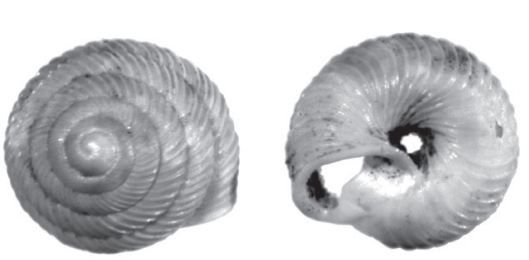

$\mathrm{F}$
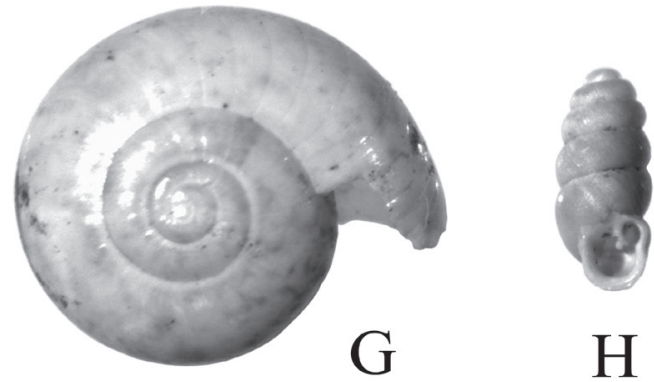

$\mathrm{H}$
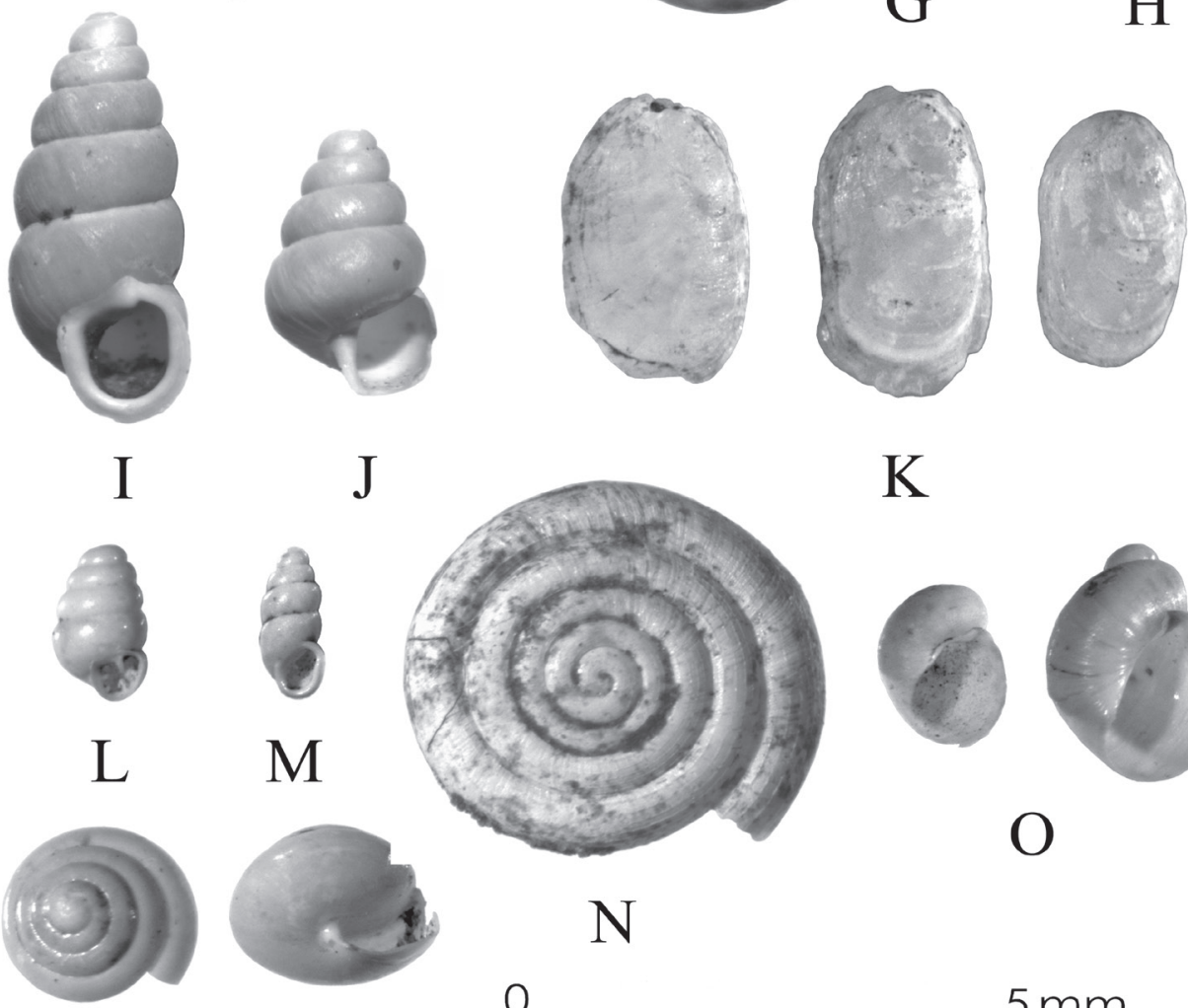

K
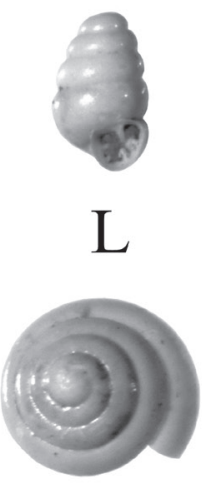

0
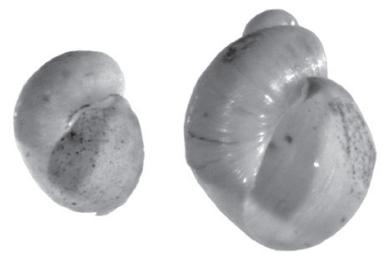

$\mathrm{O}$

$\mathrm{P}$

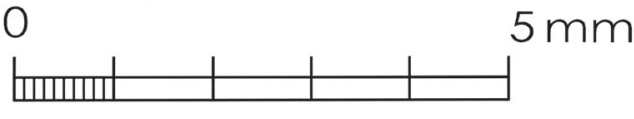

Figure 6-5. Terrestrial Species from Unit 49. A, Helicodiscus singleyanus, apical and umbilical views; B, Gastrocopta contracta adult; C, G. contracta juvenile; D, E, Gastrocopta pellucida; F, Strobilops texasiana, apical view (complete) and umbilical view (basal fragment); G, Glyphyalinia umbilicata; H, Gastrocopta procera; I, Pupoides albilabris adult; J, P. albilabris juvenile; K, slug plates (convex surface); L, Gastrocopta pentodon; M, Carychium mexicanum; N, Helicodiscus parallelus (an unusually large individual); $\mathrm{O}$, Succineidae, two unidentified juveniles; P, Euconulus sp., apical and oblique basal views. 
the grassy woodlands of the Reese Farm.... Specimens were taken from rotten logs, stream debris, under leaves, decaying grass debris, and the rich humus of the Terrell homestead." According to Nekola and Coles (2010:37), it is "found in leaf litter and under logs in a wide range of habitats, ranging from mesic to wet, and forested to open. Although occurring in higher numbers in base-rich sites, it is also frequently present in base-poor locations." In the Southern Plains Gastropod Survey, this species was moderately abundant, but occurred only at the eastern end of the transect, with a density of 505 individuals per square meter in rock ledges, 68 in riparian woodlands, and 52 on toeslopes. It reaches its limit near the 32-35 inch annual rainfall isohyets (Wyckoff, Theler and Carter 1997:37).

\section{Gastrocopta pellucida $(\mathrm{n}=2079 ;$ Figure 6-5, D, E)}

This species is somewhat difficult to separate from Gastrocopta procera, especially when the aperture is clogged with dirt, as is often the case. It is most abundant in the uppermost sample and the lowest four samples in Unit 49. Plotted as a percentage of specimens per level, it shows a very clear stratigraphic pattern of abundance in Depositional Unit 1 (at 130-200 cm depth), scarcity in Depositional Unit 2, and moderate abundance in the contemporary soil; 633 specimens were recovered from the 130-140 cm level. About 93 percent appear to be adults. This species occurs from the eastern US westward into the Southwest, the Chihuahuan Desert, and south into Mexico and Guatemala, and is widespread in Texas (Brown 2006:Figure 8.10; Nekola and Coles 2010:Figure 9). It is common in the Trans-Pecos (Metcalf and Johnson (1971:90) and New Mexico (Metcalf and Smartt (1974:60). Gastrocopta pellucida was the most abundant species in the Southern Plains Gastropod Survey in Oklahoma, where almost 6000 specimens were collected, and was especially common in rock ledge microhabitats (1142 per square meter), occurring also in riparian woodland and wooded dunes (Wyckoff, Theler and Carter 1997:35). Nekola and Coles (2010:37) state "in the southern Plains, populations are most often found in leaf litter accumulations under juniper and among grass tufts on xeric bedrock outcrops and riparian sand deposits. Along the Gulf Coast, individuals occur in open woodlands, parklands, roadsides, and lawns. This is one of the most arid-tolerant snails of the desert southwest, being found throughout southern Arizona and New Mexico in litter accumulations under low juniper, palo verde, or mesquite scrub..."

\section{Strobilops texasiana $(\mathrm{n}=851 ;$ Figure 6-5, F)}

This is the fourth most abundant species, and almost 99 percent of them occur in the upper two samples; a few scattered specimens were recovered at 40-70 cm, but none below that. Except for two specimens, this species is entirely confined to Depositional Unit 3. Only 30 percent are adults, and the remaining 70 percent are juveniles. Identification of juveniles is reliable and can be confirmed by the conspicuous horizontal buttress visible in the aperture. Strobilops texasiana ranges from eastern Pennsylvania (Hubricht 1985:Map 104) through the southeastern states into Texas, where it is widely distributed in the eastern half of the state, extending westward in major river valleys (Fullington and Pratt 1974:Figure 13). It is found near rotten logs, under loose tree bark, and in leaf litter (Fullington and Pratt 1974:26; Coney et al. 1982:93). This species is a good indicator for mature woodland (riparian or otherwise) 
and a stable leaf litter zone. Its concentration at the top of the Unit 49 column is probably an indicator of the relatively recent development of closed-canopy riparian woodland at the site.

Glyphyalinia umbilicata $(\mathrm{n}=633$; Figure 6-5, G)

This species has been previously classed as Retinella indentata paucilirata, and it appears that way in much of the older literature, but Hubricht (1976:105-106) classified Texas examples as Glyphyalinia umbilicata, based on dissection of specimens from Dallas. This species is most abundant in Depositional Unit 3, especially at 160-170 cm, but also has a more modest spike in abundance at the base of Depositional Unit 3 (40-60 cm, just above Paleosol 1). This stratigraphic distribution is somewhat opposite to that of Strobilops, which is curious because both species have similar habitat preferences. This discoidal snail has continuous growth with no morphological marker for adulthood, so it is impossible to tabulate adults and juveniles separately. Nevertheless, it is clear that many small examples are juveniles; diameter ranges from 0.7 to $6.1 \mathrm{~mm}$. Pilsbry (1946:291) says adults are usually $6 \mathrm{~mm}$ or smaller in diameter (maximum recorded, $7.1 \mathrm{~mm}$ ). Baker (1930:210) says "unlike most of the species of Glyphyalus, paucilirata seems to become mature during the summer. None of several hundred individuals, collected near new Braunfels, Comal Co., Texas (June 17-25) is sexually mature, although some of them are very large."

There is almost no information in the literature on habitat preference of this species, but there are much more extensive accounts of Glyphyalinia indentata, and presumably most of those are more or less applicable to G. umbilicata as well. Regarding G. umbilicata, Hubricht (1985:25) says, "usually found under logs and leaf litter in the woods bordering streams." Logsdon (1967:63) collected this species (as $R$. indentata paucilirata) in Kaufman County "from rotten logs, forest debris, and under leaf litter." Diameters ranged from 5.0 to $6.1 \mathrm{~mm}$.

Gastrocopta procera $(\mathrm{n}=345$; Figure 6-5, $\mathrm{H})$

This species closely resembles Gastrocopta pellucida (more so than is generally acknowledged in the literature), and some specimens were originally misclassified as G. pellucida during the pilot study (the sorting was later corrected). They can be difficult to discriminate if the aperture is clogged. Gastrocopta procera has a slightly thicker, less slender body, a more robust reflected peristome, a subcolumellar lamella or tubercle, and a bifurcate angulo-parietal lamella. The color is similar to G. pellucida, but tends to be more gray. Adults in the Unit 49 column ranged up to $2.7 \mathrm{~mm}$ in height (specimens from Archer County average $2.41 \pm 0.16$ mm; Couri 1976:Table 6). Distribution is somewhat similar to G. pellucida: the highest counts occurred at 0-20 cm and in Depositional Unit 3, in the lowest four samples; the highest count was at 150-160 cm. This species has a scattered distribution in the eastern US, and westward as far as the eastern boundary of New Mexico, but ranges much farther north than Gastrocopta pellucida, extending into Wyoming, South Dakota, and Wisconsin. According to Nekola and Coles (2010:38), "This obligate calciphile is found under stones in thatch, and in leaf litter accumulations on scrub-covered and exposed sites such as bedrock glades, dry prairie, and roadside verges. It also occurs in sandy floodplain scrub and forest." In Kaufman County, Logsdon (1967:50) found it in woodland debris under sticks, leaves, and stones, in and around 
rotting logs. According to Neck (1987b:316) it "is found in savannahs and woodlands where it is often associated with G. pellucida and P. albilabris, although G. procera requires more moisture than either of those species." In the Southern Plains Gastropod Survey, this was the second most common species; it was abundant in rock ledges and on toeslopes. Large numbers were found in the dry, brittle grass of the nearly treeless Donnelly Yard sample in Comal County. Final counts are not available yet, but the floated fraction of one 1 x $1 \mathrm{~m}$ surface quadrat is believed to have produced over 2600 specimens.

G. procera is one of relatively few species believed to be somewhat temperature-sensitive. Shell height shows clinal variation, declining northward. Couri (1976) studied museum collections derived from various states in the eastern US, all the way from Maryland to Texas, measured several variables (height, width, number of whorls, etc.) on each snail, and compared them to climatic variables from the collection sites. The highest correlation obtained (- 0.98) was for shell height against average depth of frost penetration; the second highest was for shell height against average annual temperature $(+0.74)$. Shell height was negatively correlated (0.77) with summer precipitation and uncorrelated with spring and fall precipitation, while shell width was just the opposite (Couri 1976:Table 12). The biometric analysis seems to support the notion that Gastrocopta procera is both sensitive to extreme winter temperatures and rather indifferent to dry conditions.

Pupoides albilabris $(\mathrm{n}=326$; Figure 6-5, I, J)

The seventh most common terrestrial species, this is a large microsnail, resistant to breakage and easy to identify. About 60 percent of the specimens are adults, and the rest are juveniles. It occurs throughout the eastern US, westward into Utah, Arizona, and northern Mexico (Nekola and Coles 2010:Figure 14, B). Its distribution in Unit 49 is essentially the same as most of the Gastrocopta species: most common at 0-20 and 130-200 cm, scarce in Depositional Unit 2.

This is an arid-tolerant species with habitat preferences similar to G. pellucida (Metcalf 1984:60). It may be found in grassy woodlands, pastures, and well-drained woodland slopes. Nekola and Coles (2010:43) list it as "a calciphile found under stones, leaf litter under red cedar, in thin grass turf and thatch accumulations on rock outcrops, bedrock glades, xeric prairie, and old fields. It is also occasionally found in riparian forests of the western plains." It was the single most commonly encountered species in the Southern Plains Gastropod Survey in Oklahoma (Wyckoff, Theler and Carter 1997:32), occurring in low number but with high ubiquity. In Kansas, "This was the most common snail in extremely dry conditions on the open prairie, often occurring among the roots of grasses" (Basch, Bainer and Wilhm 1961:194). Although this snail seems to be a good indicator of xeric, open habitats and lack of closed canopy, it is surprisingly abundant in the upper $20 \mathrm{~cm}$ of the column, when riparian woodland was probably more common. 
Slugs, unidentified $(\mathrm{MNI}=132$; measurable $=152$, plus 28 from flotation samples; Figure 6-5, K)

Slugs are snails that lack an external shell, retaining only a very small internal vestigial shell, termed a slug plate (Figure 6-5, K). Slug plates look very much like small chert microflakes, but have a characteristic morphology and faint growth laminations. Slug plates are most abundant in Depositional Units 1-2 at 130-170 cm (a minimum of 52 individuals was found in the 160-170 cm sample) and are scarce above $130 \mathrm{~cm}$ except at $0-10 \mathrm{~cm}$; they are also found in the two features examined.

Because they tend to be thin in the middle, slug plates often snap transversely across the midline; of the 152 measurable specimens, 55 percent were broken, and because it is impractical to refit the broken segments, it is possible only to estimate the minimum number of individuals. In the 160-170 cm level, for example, we can only estimate that the 21 broken halves must represent at least 11 slugs. Over 74 percent of the slug plates were found in the \#35 sieve, many of them snapped. Although the species of slug is unknown, it is doubtless some common native kind like Deroceras laeve, one of the three slug species that are native to Texas. For the aggregated ten Unit 49 and two feature samples, the mean length of the slug plates is $2.12 \pm 0.60 \mathrm{~mm}$ (range, $1.00-3.40 \mathrm{~mm}, 83$ measurable) and mean width is $1.20 \pm 0.29 \mathrm{~mm}$ (range, $0.60-1.90$ $\mathrm{mm}, 152$ measurable). This is somewhat smaller than slug plates from the Pleistocene-Early Holocene deposits at the Vara Daniel site (Brown 2010:Appendix K, page K-18). The smallest examples are undoubtedly from embryonic or juvenile slugs, although it is impossible to sort them by age. In addition to these specimens, 28 slug plates recovered by flotation from cultural features were also made available for examination after this study had been completed. These had a mean length of $3.3 \pm 0.38 \mathrm{~mm}$ (range, $2.20-4.20 \mathrm{~mm}$ ) and mean width of $1.72 \pm 0.27 \mathrm{~mm}$ (range, 1.20-2.50 mm). Included was a very large specimen (length, $4.20 \mathrm{~mm}$, width $2.5 \mathrm{~mm}$ ) from Feature 33. Because slugs lack an external shell, they are even more sensitive to moisture loss than other kinds of snails, and they are good indicators of damp conditions. They usually indicate a damp substrate (often at the margins of wetlands) well protected by heavy vegetation and they often co-occur with aquatic and amphibious snails. They readily enter water (usually in spring and winter when water has more dissolved oxygen and metabolism is lower; Rollo and Shibata 1991:983) and can overwinter in aquatic habitats. The increase in slugs in the 0-10 $\mathrm{cm}$ sample might indicate they were attracted to and feeding on horse manure in the horse pasture area. Deroceras laeve can be found in hardwood swamps, bogs, forested uplands, and sedge marshes (Getz 1959:487). Slugs are often associated with dead wood and may feed on algae, fungi, live plants and litter.

Gastrocopta pentodon (n=85; Figure 6-5, L)

This species has a late arrival, appearing only in the top two levels, with by far most of the specimens found at $0-10 \mathrm{~cm}$. It is difficult to discriminate from the very similar congener Gastrocopta tappaniana, but tends to be smaller, more slender, and to have fewer apertural teeth (Pearce, Fields and Kurita 2007). A sample of 57 specimens from the $0-10 \mathrm{~cm}$ sample has an average shell height of $1.57 \pm 0.09 \mathrm{~mm}$ (range, $1.4-1.8 \mathrm{~mm}$ ), an average diameter of $0.87 \pm 0.05 \mathrm{~mm}$ (range, $0.8-1.0 \mathrm{~mm}$ ) and 5-7 apertural lamellae. 
This cosmopolitan species occurs widely in Canada, the eastern US and into New Mexico and southward as far as Nicaragua; in Texas it is scattered through the eastern half of the state and into the Trans-Pecos. It seems to occur in the Panhandle only as a fossil, suggesting range retraction due to Holocene climatic changes. Cheatum and Fullington (1973:20) report it is "A snail of well-drained woodland areas and of meadows associated with sparse vegetation. Leaf litter and other objects serve as cover." In Kaufman County, Logsdon (1967:48) collected it under leaf debris in a wooded floodplain. In Tennessee, it was found in leaf litter, but inversely correlated with soil moisture (Coney et al. 1982:93); in Kansas, Metcalf (1962:287) found it only in wooded habitats under logs, branches, and leaf litter. It was scarce in the Southern Plains Gastropod Survey, found only in riparian woodland. In an Ohio survey, it was found both in dense woodland and in open fields, but more commonly in the latter (Watters, Menker and O'Dee (2005:Table 1). Theler (1997:Table 3) found it in grassy Wisconsin hill prairies. Compared to Gastrocopta tappaniana, G. pentodon occurs in a wider range of moisture, but tends to be in drier areas (Pearce, Fields and Kurita 2007:71).

\section{Olygyra orbiculata $(\mathrm{n}=58 ; 8$ in field screen sample; Figure 6-4, C)}

This genus is also spelled "Oligyra" in some of the literature. Olygyra orbiculata is curiously uncommon, appearing mostly in the $0-10 \mathrm{~cm}$ and $130-140 \mathrm{~cm}$ samples, mostly as fragments. The opercula from this species were also found and recorded, but have not been tabulated. It is often found in very large numbers in Late Holocene archaeological deposits in Central and South Texas (the shell size is such that about half of the specimens tend to be retained on quarterinch field screens), but only eight specimens were found in the 41DL436 field screen sample. This species was not recovered by the Southern Plains Gastropod Survey (Wyckoff, Theler and Carter 1997) in Oklahoma, but Cheatum (1934:147) says it "is one of the most abundant species of terrestrial gastropods occurring in Dallas County, Texas. After a light shower one can collect hundreds of individuals that are creeping over weeds and grasses in many pasture lands. Since it is a snail that is especially hardy and has a great resistance to drouth, individuals appear to be as abundant in exposed areas as in protected woodland regions. The writer has frequently observed a tendency of this species to ascend trees."

It occurs in gallery woodlands along prairie streams and may be found in open brushy areas; it is a catholic species that can tolerate both very xeric and rather moist habitats (Brown 2006:1073-1077). It is curious that so few specimens were recovered from the sediment samples. In Ellis County, Cheatum and Burt (1931:333) remark, "This interesting species has a general distribution over the county and was found at all of our collecting stations. In favorable habitats the ground is literally covered by its dead shells." Whether this discrepancy between contemporary abundance and archaeological scarcity is due to recovery technique or some other factor is unknown, but large-bodied and medium-bodied species are conspicuously infrequent at this site.

Carychium mexicanum $(\mathrm{n}=52$; Figure 6-5, $\mathrm{M})$

This species is also a relatively late arrival, appearing at $0-70 \mathrm{~cm}$ and confined almost entirely to Depositional Unit 3. These snails are very small and were recovered only in the \#35 mesh 
sieve. The largest specimen has a shell height of $1.7 \mathrm{~mm}$ and diameter of $0.7 \mathrm{~mm}$. Neck (1994) also found these at 41 DL 270. This is a coastal plain species, found from South Carolina through Florida and into the eastern part of Texas (Brown 2006:Figs. 8.4, 8.8) and south as far as Guatemala. Fullington and Pratt $(1974: 9,10)$ remark that "generally, the carychiids are found only in moist or wet places in old logs or under masses of decaying, wet leaves.... Carychium mexicanum in Texas is found in leaf litter, usually on a floodplain. It is often common where it occurs, but is sporadic in its distribution.” According to Brooks and Kutchka (1937:157), “All of the species are terrestrial in habit and may be found living among damp leaves and at the roots of grasses. In some localities they are found near springs and nearly submerged in the water."

\section{Helicodiscus parallelus $(\mathrm{n}=43$; Figure $6-5, \mathrm{~N})$}

This species is uncommon, appearing in significant numbers only in Depositional Unit 1, at $150-160 \mathrm{~cm}$ and $190-200 \mathrm{~cm}$. It is widely distributed in the eastern US, but in Texas is reported only from the eastern border of the state (Hubricht 1985:Map 185). It ranked seventh in occurrence in the Southern Plains Gastropods Survey and was found in rock ledges and riparian woodlands (Wyckoff, Theler and Carter 1997:36). In the Panhandle, Neck (1984:72) found this species in open juniper woodland. According to Pilsbry (1948:627): "It lives on decaying wood in shady or humid places, also on damp leaves. It is generally distributed and may usually be found in leaf siftings and in the drift debris of streams." Logsdon (1967:17) found it in woodland in Kaufman County. In Kansas, Leonard and Goble (1952:1039) report it from limestone ledges and forest debris in oak-hickory-walnut habitat and under decaying vegetation and grass roots. In Minnesota, it was found most often in upland forest and upland grassland (Nekola 2002a:19). Theler (1997:Table 3) found this species in grassy Wisconsin hill prairies, where it was more than twice as abundant as Helicodiscus singleyanus and ranked fourth in abundance among the species recorded. It was infrequent in an Ohio survey, but somewhat more common in open fields than dense woodland (Watters, Menker and O'Dee 2005:Table 1).

Rabdotus sp. ( $\mathrm{n}=36$; plus 72 in field screen sample; Figure 6-4, B)

A minimum of only 36 Rabdotus individuals was recovered from the Unit 49 column (five adults, 30 juveniles, and two of indeterminate age), plus another 72 (32 adults, 30 juveniles, and ten of indeterminate age) from the quarter-inch field screens. None were found in the two features examined. Both Rabdotus dealbatus and $R$. mooreanus occur sympatrically in Dallas County. These are perhaps likely to be Rabdotus mooreanus, but so many of the specimens are either fragmentary or subadult that no specific assignment can be made. The only measurable adult has a height of $18.6 \mathrm{~mm}$ and diameter of $11.3 \mathrm{~mm}$. The largest numbers are found in Depositional Units 1-2, in the 130-140 cm and 190-200 cm samples. There are only five measurable adults in the field screen sample, and the largest of these has a height of $22.8 \mathrm{~mm}$ and diameter of $15.3 \mathrm{~mm}$. In the excavations, these snails were widely and thinly distributed, never concentrated anywhere, and although Rabdotus are known to have been food items elsewhere in Texas, there is no indication they represent subsistence remains at this site. According to Fullington and Pratt (1974:18), "Rabdotus mooreanus is generally found in 
open grassland or savannah, but also occurs in the deciduous woodland along streams flowing through the prairie. It is largely, if not entirely, restricted to limestone substrates." Rabdotus dealbatus is also found in open gallery woodland.

Succineidae, juveniles $(n=30$; Figure 6-5, O)

The amphibious amber snails of the family Succineidae generally are difficult or impossible to identify without soft tissue dissection or DNA studies. Eight different species are recognized in Texas, but one can easily imagine DNA studies greatly collapsing this number. Hubricht (1985) shows Catinella vermeta and Succinea luteola occurring in the Dallas area. Although the shells are thin-walled and fragile, they are often found in archaeological samples. They are surprisingly uncommon in the Unit 49 column, except in the 160-170 cm sample. Most specimens come from Depositional Unit 1. Measurable shell heights range from 0.9-3.1 mm, so even though the species is unknown, these are clearly very small juveniles (for comparison, adult Catinella vermeta may have shell heights as much as 13-14 $\mathrm{mm}$ ); 63 percent were recovered from the \#35 sieve, none from the \#10 sieve. Succineids are rather eurytopic; they are amphibious, often living near water, on damp ground, under rocks, logs, or other cover, or in shallow, periodically flooded swales, but they can also be found in very dry environments, including the Lower Pecos, Trans-Pecos, and into the desert Southwest (Franzen 1982). I have found them on rocky upland cenizo flats in the Lower Pecos. Their ability to estivate for long dry periods, emerging only after rainfall, probably explains their desiccation tolerance. At 41DL436, they may have inhabited the muddy creek bank, along with slugs and lymnaeids.

Euconulus sp. (n=26; Figure 6-5, P)

Two species of Euconulus are currently recognized in Texas: E. fulvus and E. trochulus. Hubricht (1985:Map 331) maps the former only as fossil material, so Euconulus trochulus is perhaps more likely, and this species has been reported from 41DL270 by Neck (1994). This species was recovered sparsely at 40-70 cm (the base of Depositional Unit 3 and in Paleosol 1) and at 130-170 cm (the base of Depositional Unit 2 and well into Paleosol 2). Regardless of species, Euconulus generally inhabits leaf litter and downed wood in woodland habitats.

Linisa texasiana $(\mathrm{n}=17 ; 74$ adults and 2 juveniles in field screen sample; Figure 6-4, A; Figure 6-6, A) and Linisa/Millerelix fragments $(\mathrm{n}=4)$

Inspection seems to show that all the polygyrid specimens from this site are Linisa texasiana (formerly Polygyra texasiana). However, some are too fragmentary for specific identification, and since Millerelix mooreana and M. dorfeuilliana also occur in the area (Pratt 1981:Figs. 5, 9), the general category "Linisa/Millerelix" has been created for ambiguous specimens [but see also Coles and Walsh (2006), who maintain Millerelix is invalid]. Although Linisa is only the sixteenth most abundant taxon in the Unit 49 sediment samples, it is the single most abundant category recovered from the quarter-inch field screens, accounting for 47 percent of all snails collected from the field screens. This illustrates the profound effect that recovery method has on assemblage composition. These snails are medium-sized, but adults are generally large enough to be retained on field screens, while juveniles will usually fall through. In Unit 49, 


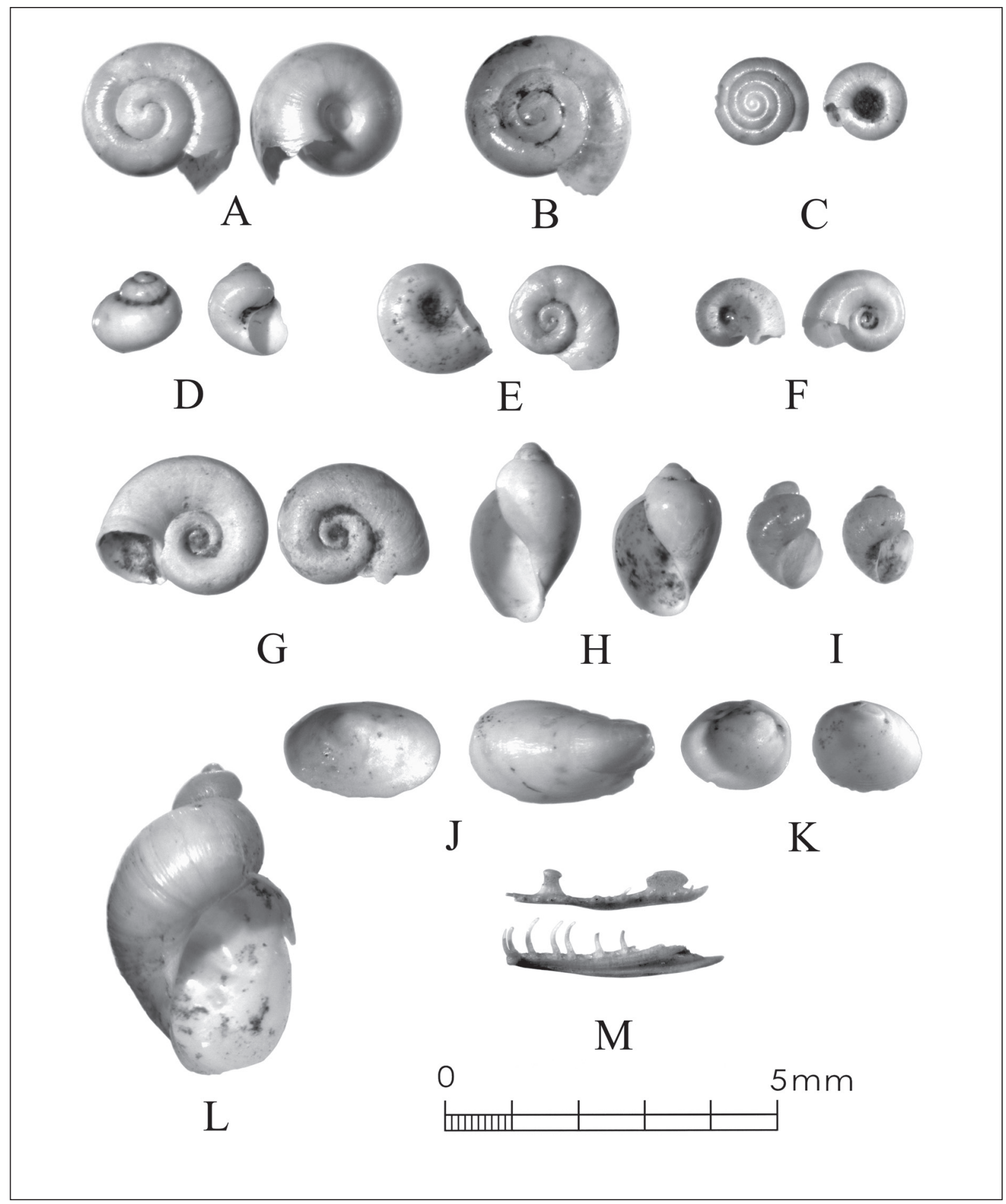

Figure 6-6. Terrestrial and Aquatic Species from Unit 49. A, Linisa texasiana embryos, apical and umbilical views; B, cf. Zonitoides arboreus; C, unidentified discoidal snails (see text); D, cf. Amnicola limosus; E, Micromenetus dilatatus, umbilical and apical views; F, Helisoma anceps embryos, umbilical and apical views; G, Gyraulus parvus, umbilical and apical views; H, Physa sp. juveniles; I, Lymnaeidae, unidentified juveniles; J, freshwater limpets (Ancylidae, unidentified), interior and exterior views of shell; K, peaclams (?Cyclocalyx sp., interior and exterior views of shell); L, cf. Pseudosuccinea columella; M, unidentified vertebrate mandibles. 
most were found in Depositional Unit 1 at 130-200 cm. For the field screen sample, adults have an average diameter of $9.03 \pm 0.58 \mathrm{~mm}$ (range, 7.6-10.6; $\mathrm{n}=32$ measurable); height is $4.58 \pm 0.36 \mathrm{~mm}$ (range, 3.9-5.3; $\mathrm{n}=30$ ). According to Pratt (1981:69), "Over most of its range, Polygyra texasiana is found in the valleys between hills and on the floodplains of small streams, generally in grasslands or open woodlands, on calcareous substrates. It is replaced, on slopes and hilltops, by Millerelix mooreana, M. dorfeulliana [sic], and Polygyra tamaulipasensis, in various parts of its range." In Kaufman County, Logsdon (1967:74) simply says "Polygyra texasiana was widely distributed over the county, being found in every terrestrial site except one, that being an overgrazed semi-arid pasture at Cedarvale."

Unidentified discoidal $(\mathrm{n}=16$; Figure 6-6, C)

Recovered in the \#35 sieve from the $0-10 \mathrm{~cm}$ level were 16 very small discoidal snails (diameter, 0.8-1.3 $\mathrm{mm}$ ) that resemble Helicodiscus singleyanus, but have more domed shells and more prominent radial ridges, and tend to be more beige than the white Helicodiscus. These might simply be aberrant Helicodiscus, but could also be some other species such as juvenile Striatura meridonalis or Hawaiia minuscula.

cf. Zonitoides arboreus $(\mathrm{n}=1$; Figure 6-6, B)

The $0-10 \mathrm{~cm}$ sample produced a single snail in the \#10 sieve that resembles Glyphyalinia umbilicata, but lacks the radial spoke-like impressed lines of that species. It is tentatively identified as Zonitoides arboreus, but with a diameter of only $2.6 \mathrm{~mm}$, is evidently a juvenile. This is a cosmopolitan species usually associated with rotting logs.

Unidentified juveniles $(\mathrm{n}=821)$

This catch-all category represents very small embryonic or juvenile, edentulous terrestrial snails that are simply too young to have taken on the diagnostic characteristics that would allow them to be sorted by species. These are probably mostly embryonic Gastrocopta procera, G. pellucida, or P. albilabris.

Unidentified spires $(\mathrm{n}=287)$

These are spires, mostly from conical terrestrial species like those named above, either adults or juveniles.

\section{Species Accounts: Aquatic Species}

Aquatic taxa are represented by several kinds of aquatic snails (including freshwater limpets) and peaclams. These are most abundant at the base of Depositional Unit 2, in the 130-140 cm sample, and in the Depositional Unit 1 samples (150-170 cm and 190-200 cm). Depositional Unit 3 and the upper part of Depositional Unit 1 have few or no aquatic taxa, as a result of the stream avulsion event. Only a single aquatic snail was found above $100 \mathrm{~cm}$ in the Unit 49 
column. With some exceptions, many of the aquatic snails and peaclams seem to be juveniles. The significance of this will be discussed in the later interpretive parts of this report.

cf. Amnicola limosus juveniles (n = 546; Figure 6-6, D)

These were initially classified as Cincinnatia integra juveniles, until some of the large series in Depositional Unit 1 were examined, when the small size, blunt apex, and very turreted shape became apparent. Except for eight specimens in the 100-110 cm sample, this species is confined to the 130-200 cm zone of Depositional Unit 1 and basal Depositional Unit 2 . These specimens have a shell height of only 0.6-3.6 mm, compared to 3.0-7.0 mm for adult Amnicola limosus (Hershler and Thompson 1988:82). Clarke (1973:257-258) lists shell heights of 2.8$4.6 \mathrm{~mm}$ (mean about 3.5-3.75 $\mathrm{mm}$ ) for Canadian specimens. In the Unit 49 column, 1 percent of this species was recovered from the $2 \mathrm{~mm}$ sieve, 24 percent from the $1 \mathrm{~mm}$ sieve, and 75 percent from the $0.5 \mathrm{~mm}$ sieve.

These are tentatively interpreted as (mostly juvenile) Amnicola limosus (spelled "limosa" in the older literature (Burch and Tottenham 1980:Figs. 286, 288-290, 299; Hershler and Thompson 1988:Figure 1), also known as the "mud amnicola". The taxonomic issues are somewhat convoluted. Cincinnatia and Amnicola have very similar shell shapes. Both were formerly classed as members of the freshwater family Hydrobiidae. However, recent DNA research has now placed Amnicola in a separate family, the Amnicolidae, and shows that the two genera are much more distantly related than their shell shapes might suggest (Wilke et al. 2001:Figure 3 ). In the past, Amnicola limosus has been regarded as an eastern US species, mostly confined east of the Mississippi River. However, more recent research has found it in Kansas, Colorado, North Dakota, Montana, and Utah. Fullington (1978) does not list it for Texas, listing only "Amnicola" peracuta, now regarded as Cincinnatia integra. In an appendix to a report on Joe Pool Lake, Fullington (1988:Appendix 4A) lists reports specimens of Amnicola sp. recovered from 41 DL 189 in the nearby Mountain Creek drainage, but no species is listed. A. limosus has been reported from Spring Lake and the San Marcos River at San Marcos (Diaz 2010:Table A-3) and from Pleistocene sediments in Houston (Aronow, Neck and McClure 1991). In truth, the 41DL436 specimens show a general resemblance to several different hydrobiid or amnicolid species: Cincinnatia "peracuta," C. integra, Marstonia comalensis, and various species of Amnicola. Among these, however, Amnicola limosus seems to correspond best, even though it does not appear on formal lists of Texas aquatic snails. Nearly all seem to be juveniles, although a few of the largest specimens might be borderline adults.

Jokinen(1992:28) says "habitats of $A$. limosa include lakes, permanent ponds, and slowly flowing rivers and streams. The snails prefer decaying aquatic and terrestrial plants, logs, branches, rocks... as substrata. They are frequently associated with aquatic vegetation, such as Chara, Potamogeton, Vallisneria, and Elodea spp., upon which they graze for algae, such as epiphytic diatoms...." A few of the 41DL436 specimens have corroded shells, probably due to algal encrustation. The species is said to be absent from waters that are hot, stagnant, or anaerobic, but has a wide tolerance for $\mathrm{pH}$ and salt levels (among the aquatic snails recovered, this is the only prosobranch, or gill-breathing species except for the pseudobranch limpets). Clarke (1973:259) says it "occurs in all unpolluted, permanent aquatic habitats where macroscopic 
aquatic vegetation grows" (see also Harman 1972:Table 3). This species is concentrated in the same samples where charophyte oogonia were most abundant.

Micromenetus dilatatus $(\mathrm{n}=194$; Figure 6-6, E)

This species (also sometimes listed as Menetus dilatatus) can be distinguished from the very similar-appearing Gyraulus parvus by the slightly carinated apical aspect and slightly more expanded aperture. Diameter of these specimens ranges from 0.9-2.9 mm; 9 percent were recovered from the $1 \mathrm{~mm}$ sieve, 91 percent from the $0.5 \mathrm{~mm}$ sieve, and none from the $2 \mathrm{~mm}$ sieve (the $2.9 \mathrm{~mm}$ specimen came from the \#18 sieve). Based on laboratory studies of live specimens from Georgia, this indicates an age of about two to more than 20 weeks (Fried and Goodchild 1963:Figure 5), with many of them juveniles (however, note that this study dealt with a different subspecies). Jokinen (1992:66) reports that in Connecticut, young first appear in late May, but there is an additional reproductive period in August-September, and the species becomes reproductively viable at a diameter of $1.9 \mathrm{~mm}$.

Micromenetus dilatatus is cosmopolitan, can tolerate a wide range of $\mathrm{pH}$ values, and is widely distributed over the eastern part of the US and into Central America. This species is often found on submerged, decaying plants, wood, and leaf litter or on rocks and gravel, in springs, streams, ponds, and quiet sections of rivers - in other words, exactly the same habitat as A. limosus. This species appears in the lowest sample at 190-200 cm, increases slightly in abundance upsection, and then nearly disappears at $130 \mathrm{~cm}$; only two were found in the $100-110 \mathrm{~cm}$ sample.

Gyraulus parvus $(\mathrm{n}=155$; Figure 6-6, G)

Except for a single specimen in the 10-20 cm sample, this species shows the same distribution as the other aquatic taxa: it is essentially confined to the $130-200 \mathrm{~cm}$ section, with the largest number in the 190-200 cm sample. Except for one specimen found in the $2 \mathrm{~mm}$ sieve, all were found in the $1 \mathrm{~mm}$ sieve. Measured diameters range from 1.5-2.9 $\mathrm{mm}$. A couple of these have corroded shells, but most do not. Clarke (1973:401) lists mean diameters of 2.73-3.57 mm (range, 1.5-4.5 mm) in Canada; Harrold and Guralnick (n.d., 48), up to $7 \mathrm{~mm}$ in Colorado; Jokinen (1992:59), up to $5 \mathrm{~mm}$ in New York. It is characteristic of water bodies with dense aquatic vegetation (Eckblad 1973:215), often with mud bottoms. Clarke (1973:403) collected it in lakes, vernal and permanent ponds, stream backwaters, swamps, creeks and rivers; bottom types were diverse, but mud was present in 60 percent of localities. It is found on or among aquatic plants such as Chara, Typha, Spirogyra, and duckweed, and also occurs in playa lakes. However, Pip (1988:Tables 2-4) found it slightly less common in areas with aquatic vegetation than in areas without.

\section{cf. Helisoma anceps juveniles $(\mathrm{n}=86$; Figure 6-6, F)}

No intact adults of this species were recovered from the Unit 49 column, but broken wall and columella fragments suggest some of the specimens were originally larger. For small columella fragments with chipped apertures, it is difficult to decide if the specimen is really embryonic 
or just the damaged remains of a larger, older specimen. Some, however, are truly embryonic and are about the same size as Gyraulus or Micromenetus. They can be distinguished by their more pronounced and belled apertures. These range in diameter from $0.8-6.1 \mathrm{~mm}$ (adults reach maturity at about 7.5-8.0 $\mathrm{mm}$ and typically have a maximum diameter of about $15-17 \mathrm{~mm}$ ) and are probably less than a year old. These snails have an annual life cycle, but survivors of the previous year's cohort can be found along with the present year's young.

The largest specimen in the 130-140 cm sample has a worn, corroded, delaminated and perforated shell. The next largest appears partially calcined, is corroded and has carbonate deposits on the surface. These look as if they could have been redeposited. Another specimen from 190-200 cm is also heat-discolored. This species was not found in the quarter-inch field screen sample, although a few examples of the related species Planorbella trivolvis were recovered.

Like all the other aquatic taxa, this species is mostly confined to Depositional Unit 1 below $130 \mathrm{~cm}$, though two examples were found in the 100-110 cm sample. The largest number are in the 190-200 $\mathrm{cm}$ and the 130-140 cm sample. In Oklahoma, Branson (1961:61) says "this unmistakable species is widely divergent as to its habitat requirements. It may be found in rapidly flowing creeks and rivers, in back waters, or in ponds. It seems to prefer copious vegetation but there seems to be no substrate specificity." Other sources characterize it as preferring clean running water and gravelly areas. I have seen it in stagnant ponds, however. Harman (1972:Table 3) lists "silt and detritus" as the preferred substrate.

Physa sp. juveniles $(\mathrm{n}=70$; Figure 6-6, H)

The taxonomic history of the Physidae is confusing. The reader is referred to the Vara Daniel report (Brown 2010:141, Appendix K, page K-26) for a detailed discussion. Recent DNA research suggests these snails are likely to be Physa acuta (Wethington and Lydeard 2007), but because of ecophenetic plasticity, identification of adults is very difficult, and specific identification of juveniles like these is essentially impossible. Body size is quite variable and may depend on local environmental variables; the mean shell height for Texas populations is about $7 \mathrm{~mm}$, but for adults can be as much as 13-16 mm. Shell height in the Unit 49 column ranges from $0.9-8.7 \mathrm{~mm}$, and the largest example is probably an adult; the rest are all embryos, with a height of about 1-2 $\mathrm{mm}$, or partly grown juveniles up to $4.5 \mathrm{~mm}$ in height. The embryos are thin-walled and fragile, and have the blunt apices typical of very young snails; 6 percent of the Physa were found in the $2 \mathrm{~mm}$ sieve, 34 percent in the $1 \mathrm{~mm}$ sieve, and 60 percent in the 0.5 $\mathrm{mm}$ sieve. One specimen is corroded, perhaps from algae encrustation; shell texture is matte to glossy. These snails have the same distribution as the other aquatic taxa, but are slightly more abundant immediately above and below Paleosol 2 (at 130-160 cm) than elsewhere.

Physa is a common, cosmopolitan genus with a great deal of ecophenetic plasticity. These snails tolerate extreme conditions, including very warm or very cold water, can estivate during drought, and may be found in almost any kind of aquatic habitat, producing three generations per year. They tend to favor slow to still water, but can be found in flowing springfed streams, and they are preyed upon by sunfish and crawdads. 
Planorbidae, unidentified juveniles $(n=29)$

This miscellaneous category includes 28 specimens in the $0.5 \mathrm{~mm}$ sieve sample at $150-160$ $\mathrm{cm}$ and one in the 130-140 $\mathrm{cm}$ sample. The former are $0.8-1.4 \mathrm{~mm}$ in diameter and may be embryonic Helisoma anceps; the latter is a single body fragment that may be H. anceps. These are all too small or fragmentary for identification.

cf. Lymnaeidae, unidentified juveniles ( $\mathrm{n}=23$; Figure 6-6, I)

These are members of the pulmonate family Lymnaeidae. All are probably juveniles, but there are apparently at least two species represented, and possibly more. Most are embryonic in size, with blunt apices and a height of only one or two millimeters; the full range is 1.0-7.3 mm. Most appear to be some species of Fossaria (or Lymnaea, as it appears in some of the recent literature), and many resemble Fossaria (Lymnaea) cubensis (Burch and Tottenham 1980:Figure 587), but there are several other species that bear a general resemblance (Fossaria parva, F. humilis, F. dalli, F. obrussa). Fossaria cubensis reaches a shell height of nearly $13 \mathrm{~mm}$ in about 22 weeks after birth (Gutiérrez et al. 2000:749). Two specimens resembling Pseudosuccinea columella were recovered from the 190-200 cm sample: a juvenile (height $4.7 \mathrm{~mm}$ ) and a half-grown individual (height $7.3 \mathrm{~mm}$ or more; Figure 6-6, L). Fullington (1978:138) lists a shell height of 12.0-21.5 mm for adult $P$. columella. These snails have the same stratigraphic distribution as the other aquatic taxa, but are uncommon. Recent studies of molecular phylogeny show that Fossaria cubensis is closely related to several morphologically similar lymnaeids, such as Fossaria obrussa and Fossaria humilis, and is more distantly related to Pseudosuccinea columella (Correa et al. 2010:Figure 1).

Regarding habitat preference, Baker (1911:19) wrote: "the small species, like parva and humilis modicella, live on the margins of streams, ponds and creeks, on the mud bordering the shore or on sticks, stones and various kinds of debris. These species are seldom found in the water, unless recently submerged by a rise of the water, their natural habitat seeming to be just above high-water mark." Fullington (1978:130) says "lymnaeids occur in shallow lakes, temporary ponds, sloughs, even on the wet mud adjacent to the water. They seem particularly fond of crenon areas with abundant moss or algae." In drought periods, lymnaeids (especially juveniles) estivate on or under the soil, on downed wood, or under leaf litter.

Freshwater limpets (Ancylidae, unidentified; $\mathrm{n}=18$; Figure 6-6, J)

Although they look somewhat like peaclams or very small mussel valves, the ancylids are actually small pulmonate aquatic snails with uncoiled, caplike ("patelliform") shells, closely related to the Planorbidae. The shells are thin and very fragile, and are rarely recovered in archaeological excavations even when fine-mesh sampling is done, although they have been found at the Hajny Mammoth site and the Burnham site (Oklahoma) and at Rex Rodgers and Lubbock Lake (Texas). According to Harrold and Guralnick (n.d., 13), "Most ancylids are found in the quiet water of lakes and ponds, and in slow moving backwaters of rivers. They are often attached to cattail stems, leaves, rocks, or other objects in the water. Some species prefer clinging to rocks in fast-moving rivers and streams, but those are the exception." 
The distribution of these is similar to other aquatic taxa. Eleven came from the $130-140 \mathrm{~cm}$ sample, five from 150-160 cm, and one each from the two samples below; 78 percent came from the $0.5 \mathrm{~mm}$ sieve, the rest from the $1.0 \mathrm{~mm}$ sieve. The largest specimens have a length of $2.8 \mathrm{~mm}$ and width of $1.5 \mathrm{~mm}$. The others have lengths ranging from 1.0-2.4 $\mathrm{mm}$ and widths ranging from $0.6-1.5 \mathrm{~mm}$.

Most have rounded apices without radial striations, elongated ovate shells, and perhaps resemble Ferrissia rivularis (=Ferrissia fragilis) or Ferrissia walkeri. Blinn, Truitt and Pickart (1989:238) report mean shell lengths of $2.5 \pm 0.15 \mathrm{~mm}$ for $F$. fragilis from Arizona. McMahon and Hopkins (1977:355) report mean aperture lengths of $2.66 \pm 0.17 \mathrm{~mm}$ and aperture width of $1.35 \pm 0.10 \mathrm{~mm}$ for overwintering $F$. walkeri; spring-hatched specimens had aperture lengths of $1.34 \pm 0.11 \mathrm{~mm}$ and widths of $0.75 \pm 0.19 \mathrm{~mm}$ from Tarrant County. According to Dillon and Herman (2009), Ferrissia rivularis and F. fragilis mature at a length of about 2-3 mm. Ferrissia inhabits stems and leaves of aquatic plants like bulrush and arrowhead (Sagittaria) and feeds on diatoms (in an Arizona sample, chiefly species of Epithemia; Blinn, Truitt and Pickart 1989).

Planorbella trivolvis juveniles $(\mathrm{n}=5$, in field screen only; Figure 6-4, D)

This species (formerly Helisoma trivolvis) was recovered only in the quarter-inch field screen (units 18, 27, 31, 55 and 69, all in Depositional Unit 2); no recognizable examples were found in the Unit 49 sediment samples. Diameters range from 6.7-14.3 mm, and height from 4.8-7.5 $\mathrm{mm}$. This is a pulmonate planorbid, closely related to Helisoma anceps and Micromenetus dilatatus. Adults can reach diameters of $30 \mathrm{~mm}$ or more (larger than a quarter). Logsdon (1967:41) lists diameters of 13.4-20.5 mm for Kaufman County specimens. In southern regions, these snails live about a year, and reach reproductive maturity at a diameter of $18 \mathrm{~mm}$ (Boerger 1975; Jokinen 1992:65), so all of these specimens are presumably juveniles. Two of them have varices (shell growth interruption features).

Branson (1961:62) remarks, "In Oklahoma Helisoma trivolvis is seldom, if ever, found in rapidly flowing water. Usually the species is found in stagnant or semi-stagnated waters. The diet consists of living, dead and decaying plant, sometimes animal, materials." Fullington (1978:17) says "It was very common in the shallow backwater areas of streams where green algae was abundant. However, it was also common in the shallow, protected coves of lakes where I found it crawling on mud, old cans, and on stems of emergent vegetation." In northern regions, this species burrows one or two centimeters into the mud to escape winter freezes, but in Texas it probably burrows to escape summer desiccation.

Peaclams (Cyclocalyx sp.? n = 260; Figure 6-6, K)

Like the other aquatic species, these were found mostly below $130 \mathrm{~cm}$. By far, the largest number were found in the $130-140 \mathrm{~cm}$ sample. There are 42 left valves, 59 right, and the rest are indeterminate; 1 percent were found in the $2 \mathrm{~mm}$ sieve, 12 percent in the $1 \mathrm{~mm}$, and 87 percent in the $0.5 \mathrm{~mm}$ sieve. Peaclams are very small bivalves often recovered when finemesh sieving of alluvial sediments is done. For the sample reported here, mean shell length is 
$1.39 \pm 0.38 \mathrm{~mm}$ (range, $0.9-3.6 \mathrm{~mm}, \mathrm{n}=147$ measurable); mean height is $1.13 \pm 0.34 \mathrm{~mm}$ (range, 0.7-3.0 mm, $n=143)$. These appear to be just beyond embryonic size. Shell size at birth for this entire genus is relatively constant at about $1 \mathrm{~mm}$; for $C$. (P.) casertanum, the range of average sizes at birth is about $0.9-1.2 \mathrm{~mm}$, while the maximum adult size is $3.6-5.0 \mathrm{~mm}$; length at maturity is 1.5-2.7 mm (Holopainen and Hanski 1986:Table 1). In Ohio, Cyclocalyx (Pisidium) casertanum reaches reproductive maturity at a shell length of about $3 \mathrm{~mm}$ (Burky, Hornbach and Way 1981:42). There are two forms present in the Unit 49 samples: 1) a strongly ridged or domed shape with prominent concentric growth lines, representing about 44 percent of the specimens, 2) a flatter, more smoothly convex (and sometimes larger) oval with fainter growth lines, representing about 30 percent. The remaining specimens are more or less intermediate in shape, and the large number of intermediate forms perhaps suggests these are different growth habits rather than different species.

There are at least five species of peaclams in Texas (Howells et al. 1996:167), but these specimens cannot be assigned to species. Under conventional taxonomy, peaclams have been represented by the genus Pisidium, but Lee (2001) has recently revised the taxonomy and presumably the peaclams would now be considered Cyclocalyx (see also Lee and Foighil 2003:Figures 1-3).

Without knowing the species, it is difficult to be specific about habitat preferences, and geographic distribution of peaclams is generally widespread and cosmopolitan. In general, peaclams can be found in shallow to deep water, often on muddy or silty bottoms, and often associated with aquatic vegetation. They may live in ponds, lakes, creeks, and rivers. In Pennsylvania springs, $P$. casertanum is mostly confined to silty bottoms; it normally produces one or two generations per year, but may perhaps live as long as five years in cold, poorly oxygenated, unproductive habitats. Pisidium (Cyclocalyx) casertanum can occur in damp sediment in stream banks and in moist leaf litter in vernal ponds (Martin 1998:45).

\section{RESULTS AND INTERPRETATION}

Preservation of microsnails in Unit 49 is very good, and density is high, especially considering the high rates of sedimentation in part of the sample column. The overall density of almost 65 specimens/liter (range, 9.13-128.51) is high for Texas archaeological sites where microsnail sampling has been done, exceeded only by Lubbock Lake with its cienega deposits and abundant aquatic snails. Some Unit 49 samples had at least 22 species, and in terms of species richness, this site is in the top third of Texas sites where archaeomalacological studies have been done. In this analysis section, the basic units used for comparing samples and taxa are densities rather than counts, since the volume of sediment sampled varies somewhat from level to level. It should also be noted that although most of the hand-excavated cultural features lie in Depositional Unit 2, the snail data have less to say about this unit than the other two, because the specimen counts are very low here. 


\section{Is There Evidence of Redeposition?}

Microcharcoal assays produced a series of three inverted radiocarbon ages (Chapter 11; Cummings, Yost and Puseman), suggesting that sometime after 350 RCYBP, Fish Creek began to strip out sediments which had been in storage upstream for at least 5400 years and redeposit them downstream. This raises the question of whether any of the Unit 49 snails had also been redeposited along with this sediment and microcharcoal, and whether any of them might be of mid-Holocene vintage. There seems to be little evidence of this. All broken snail shell as well as partial and complete specimens were picked from the matrix samples, and there is surprisingly little broken shell present, except in the uppermost level. The amounts are also remarkably consistent through most of the column. The microsnails from Unit 49 are often broken, but there is very little evidence of abrasion, except on a very few of the aquatic species. The peaclams are the only specimens to show substantial breakage, but they are rarely abraded, and the breakage may be due to predation, not stream tumbling.

Of course, all of the aquatic items (aquatic snails, peaclams, limpets, fish scales, fish bone, charophyte oogonia, ostracods) are "redeposited" in the sense that they have been dredged up out of the creek during floods and deposited on the surface of the point bar by floodwaters. Some organisms are probably represented by the shells of dead individuals littering the bed of Fish Creek, while others may have been live organisms stranded on top of the point bar by receding floodwaters, left to die by desiccation. But there is no evidence to suggest that any of this bioclastic debris was brought down the creek from any great distance.

What about the terrestrial fauna? Unless clogged with sediment, most microsnails float very well, and the possibility should always be considered that some of the terrestrial snail fauna is bioclastic rather than indigenous, originally living upbasin and brought down by floodwaters, but without clear evidence of this, my assumption is that the terrestrial fauna essentially represents local microhabitats at the site itself (Figure 6-7).

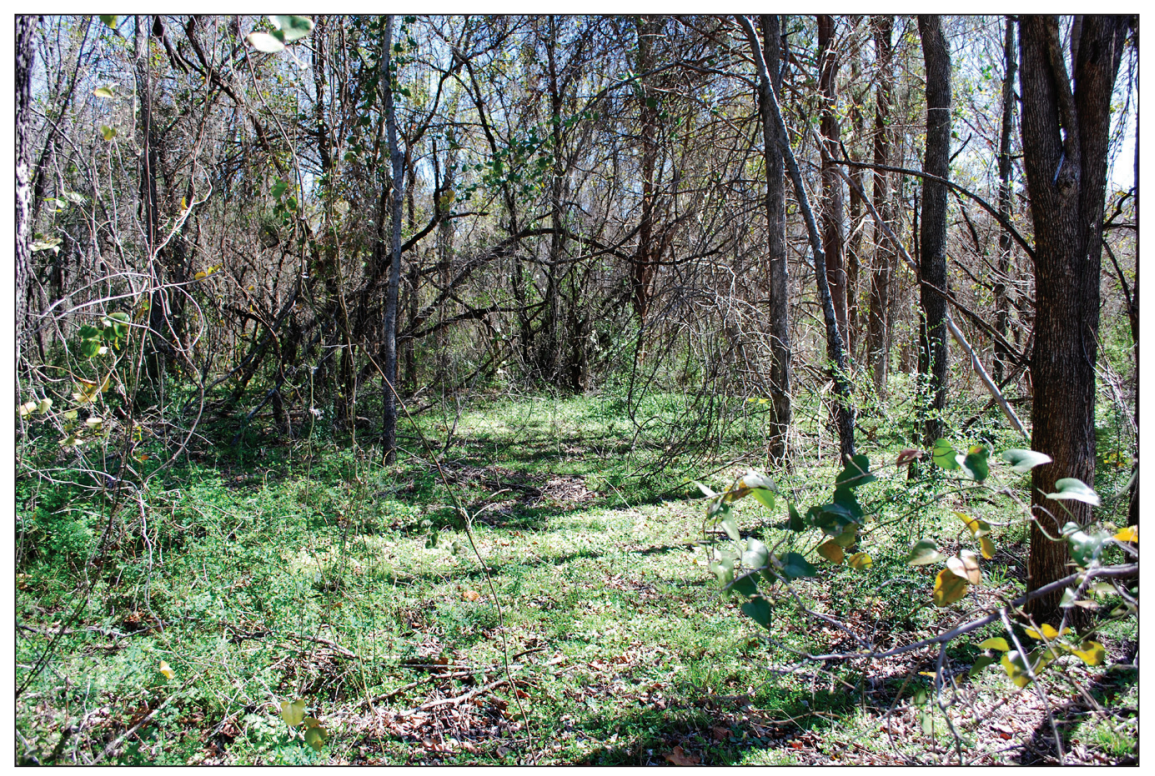

Figure 6-7. Wooded Floodplain West of Fish Creek. View is on the opposite side of the creek from the site, about 275 $\mathrm{m}$ away. Photograph by the author, March 4, 2012. Note heavy ground cover, full deciduous tree canopy, and abundant undergrowth and vines. This is excellent habitat for terrestrial snails. 


\section{History of Depositional Events: Effects on the Snail Assemblages}

The earliest stratum sampled in Unit 49 is Depositional Unit 1, which consists of Late Prehistoric floodplain sediments accumulated both by vertical and lateral accretion (characterized by Abbott as "slow and sporadic"), about 5-6 meters away from a former channel of Fish Creek, on the (magnetic) northwest bank. Because the creek is so close, aquatic taxa (aquatic snails, limpets, and peaclams) deposited by overbank flooding account for about 13-19 percent of specimens, and other kinds of aquatic biota (charophyte oogonia, fish bones and scales, ostracod valves) are common as well. Paleosol 2 documents a stable surface formed on this floodplain. Unit 1a was terminated when Fish Creek abandoned its previous channel and shifted to a location about $12 \mathrm{~m}$ to the (magnetic) northeast. Unit $1 \mathrm{~b}$ then formed during the Protohistoric period, sometime between about 1477-1528 cal AD (Chapter 5, Abbott and Frederick).

Although it is often the case that debris blocks both ends of cutoff channels like this one, forming a floodplain oxbow lake, this evidently did not happen. The paleochannel must have continued to function as an overflow chute, carrying water and sediment, because significant numbers of aquatic taxa continue into the lower part of Depositional Unit 2. The 100-110 cm sample has about 13 percent aquatic taxa. Above that level, except for a single specimen of Gyraulus, aquatic taxa are entirely absent. The evidence suggests that the paleochannel continued to carry floodwaters, but as it filled with sediment, this role became less and less common, until (at some point above $98.80 \mathrm{~m}$ in Unit 49) it no longer contributed aquatic biota to the floodplain.

Filling of the paleochannel by Depositional Unit 2 was clearly rapid, because sediment dilution results in very low snail density at $10-110 \mathrm{~cm}$. This is substantiated by the radiocarbon assays as well, because the assays from Depositional Unit 2 are indistinguishable from those of Unit $1 \mathrm{~b}$ (Chapter 5, Abbott and Frederick). Density plummets from about 118 specimens/liter to about 9 specimens/liter moving upward from the $130-140 \mathrm{~cm}$ to the $100-110 \mathrm{~cm}$ sample. A period of stability represented by Paleosol 1 at a depth of $60 \mathrm{~cm}$ follows, yet is represented by the lowest density of snails in the entire sequence. This is unusual, because buried soils are levels where we expect to find higher densities of snails. Above this buried soil, the sediments of Depositional Unit 3 accumulate (during the historic period, sometime in the last 300 years), draped across the floodplain and down into the swale left by the abandoned channel. During the latter part of Depositional Unit 3 accumulation, the snail data suggest that the floodplain was becoming increasingly forested, with more extensive tree canopy appearing. At the top of the column, the $0-10 \mathrm{~cm}$ sample has the largest number of specimens and the second-highest density in the entire sequence, despite the disturbance implied by recent historic land clearance and occupation. Since much of the site was occupied by horse and cattle pens (documented by the finding of Sporormiella fungal spores in the palynological samples), and since many snails are coprophagous, herbivore dung may have encouraged larger snail populations in the recent $(0-10 \mathrm{~cm})$ history of the site. Recent historic clearing of gallery forest artificially restored the floodplain in the site area to a more savanna-like appearance by removing most of the trees but leaving a few scattered individuals, probably somewhat like the vegetation in Depositional Unit 1 time. This clearing event is too recent to show up in the snail data, however. The time 
resolution of the column is too coarse-grained, and surprisingly, the introduced snail species that are usually the hallmarks of urbanization are absent from this site.

Figure 6-8 illustrates a stratigraphically unconstrained cluster analysis of the density matrix for all specimens (terrestrial and aquatic snails, peaclams, and limpets). The data were logarithmically transformed to reduce the dominance of abundant taxa, and clustered using a Euclidean distance function and unweighted pair group linkage method. The cluster analysis reproduces the stratigraphy very well. The 130-140 cm sample is grouped with the three lower Depositional Unit 1 samples, the two features are correctly grouped with the Depositional Unit 2 samples, and the $0-10 \mathrm{~cm}$ sample appears as a distinct outlier. The two major divisions in the dendrogram are separated somewhere between $110 \mathrm{~cm}$ and $130 \mathrm{~cm}$ in depth, which is precisely where the aquatic taxa drop out due to the avulsion of Fish Creek.

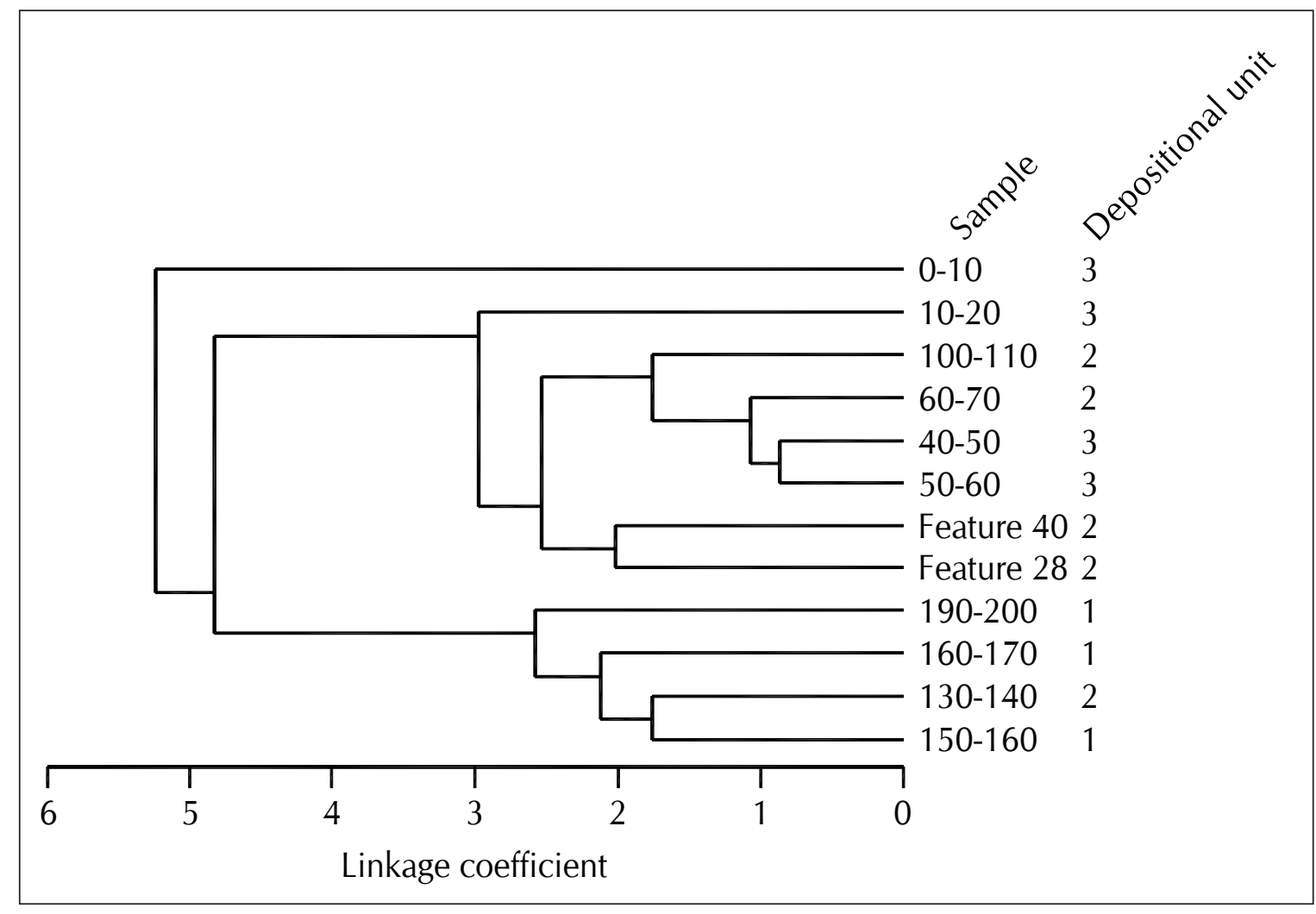

Figure 6-8. Cluster Analysis of Specimen Density. The density matrix (Table 6-4) supplies the data for this cluster analysis. Data were log(e) transformed, then clustered using a Euclidean distance function and unweighted pair group linkage. The cluster analysis shows that the $130-140 \mathrm{~cm}$ sample is grouped with the three lowest samples (in Depositional Unit 1), mainly because large numbers of aquatic species were still present at this level. The two cultural features correctly cluster with Depositional Unit 2; and the $0-10 \mathrm{~cm}$ sample, drawn from the modern soil, appears as an outlier. 


\section{Overview of the Terrestrial Snail Faunas}

Several things are immediately apparent when looking at the kinds and numbers of snails recovered. The collection as a whole is deficient in large-bodied and medium-bodied terrestrial species. Only Rabdotus, Olygyra, unidentified slugs, and Linisa were found (unidentified polygyrid fragments were found, but these are likely Linisa as well). Other large or mediumbodied genera that might be expected in this area (such as Anguispira, Euglandina, Mesodon, Mesomphix, Praticolella, or Euchemotrema, based on either modern or archaeological distribution) were not found, perhaps indicating a lack of tree cover at the site. Only 161 snails were recovered from the quarter-inch field screens across the entire site, so this is not likely simply to be a Unit 49 sampling error. In very general terms, large-bodied terrestrial snails are more characteristic of woodland habitats, and microsnails are apt to dominate in prairie habitats where protective cover such as downed wood or a heavy deciduous leaf mat is lacking. This is well illustrated by the Southern Plains Gastropod Survey across the width of Oklahoma, where Deroceras laeve and Polygyra dorfeuilliana were the only large or medium-bodied species found, and the latter was only found at the eastern end of the transect. The size distribution at 41DL436 is more representative of the eastern US (especially upland grassland habitats) than it is of southern or central Texas (see discussion in Nekola 2005:47).

A less obvious trend is a slight increase in average snail size over time. If the counts for the $2 \mathrm{~mm}$ sieve are converted to percentages and plotted by level, they change relatively little (varying only from 1-4 percent) from the base to the top of the Unit 49 column, but the counts for the $1 \mathrm{~mm}$ sieve increase irregularly (from 19 percent at the base to 42 percent at the top), while the counts for the $0.5 \mathrm{~mm}$ sieve decrease (from 80 percent at the base to 52 percent at the top). If we take each percentage and multiply it by the sieve size, adding together the three products for each level, we can construct a crude level-bylevel size index (Figure 6-9). For example, in the 190-200 cm sample, 3 percent x $2 \mathrm{~mm}$ plus 19 percent $\times 1 \mathrm{~mm}$ plus 80 percent $\times 0.5 \mathrm{~mm}$ yields a size index of 0.62 for that level. Why should snail size increase over time? One explanation might be increased fragmentation in the older samples, but the small and relatively constant amounts of broken snail shell recovered seem to make this unlikely. Decreasing juvenile mortality also seems unlikely. Instead, the cause seems to be an increase toward the

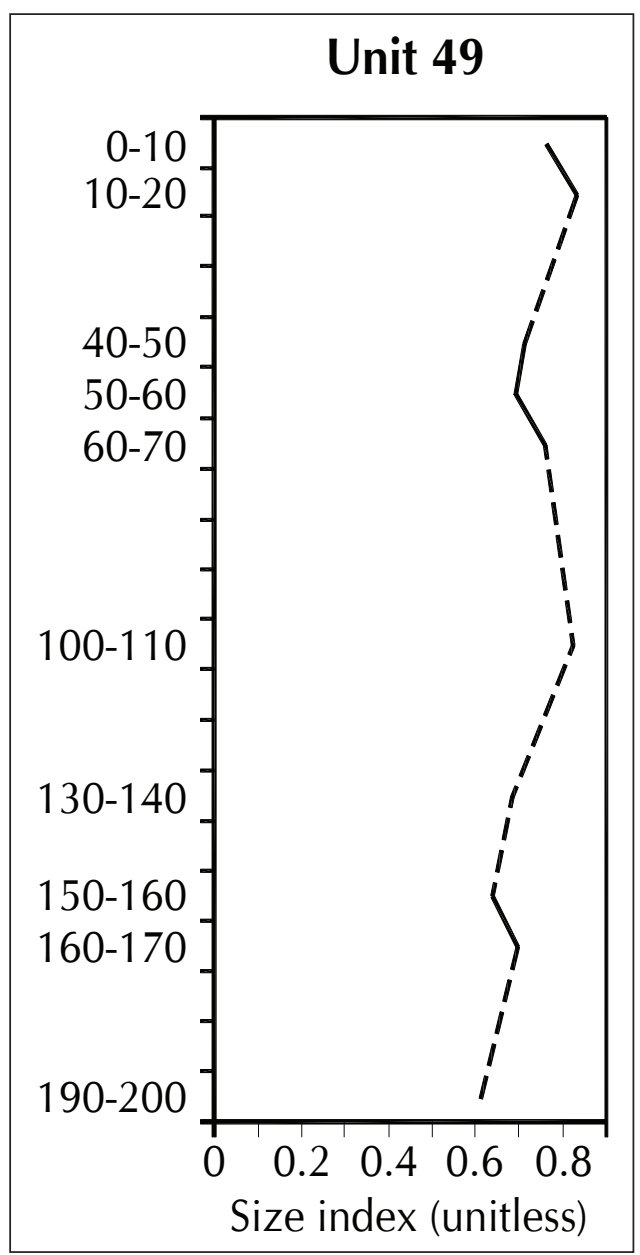

Figure 6-9. Vertical Plot of Size Index. Line graph shows vertical trend of slightly increasing shift toward larger sieve grades through time. See text for explanation. 
top of the column in a few key species (G. contracta, S. texasiana, P. albilabris) that are just large enough to be caught in the mid-sized (\#18) sieve.

There are seven taxa that can fairly reliably be sorted into adults and juveniles: G. contracta, $G$. pellucida, G. procera, O. orbiculata, Rabdotus sp., and S. texasiana. Except for the 50-60 cm level, which has a small sample size, juveniles represent about 8-35 percent of the snails that can be sorted by age; for the Unit 49 column as a whole, there are on average about 4.5 adults per juvenile. However, this does not include the significant number of unidentified juveniles that occur in every level, or the aquatic taxa that occur only as juveniles.

To understand the succession of terrestrial habitats at the site, it is necessary to remove the aquatic taxa from consideration for the moment, so in some of the analyses and diagrams that follow, I have subtracted all the aquatic species. Among the terrestrial species, there are nearly twice as many eurytopic (cosmopolitan, habitat generalist) species as stenotopic (habitatspecific) species. Among the eurytopic species, some seem to have a marked preference for either wooded or open habitats, despite being adaptable to either.

\section{Depositional Unit 1}

At present, even though urbanization is encroaching, the Fish Creek valley near the site is heavily covered by mostly deciduous riparian woodland with substantial understory vegetation. Figure 6-7 shows the floodplain west of the creek, about 275 m northeast of the site. Ground cover consists of deciduous leaf litter and short grasses. Much of the valley looks like this, except where cleared for houses or pastures. However, the snail data suggest that during the Late Prehistoric (here, roughly 900-1400 cal AD), the floodplain was instead rather open and grassy, with scattered trees but no continuous tree canopy. The principal taxa are droughttolerant species often found in open, grassy areas (Helicodiscus singleyanus, Gastrocopta pellucida, G. procera, Pupoides albilabris), along with a significant admixture of species (Gastrocopta contracta, Glyphyalinia umbilicata, Helicodiscus parallelus, Euconulus sp.) that prefer wetter or more protected (often wooded) microhabitats, but can also tolerate fairly dry conditions. Slugs and Succineidae are minor hygrophilous components, probably more common near the creek (Figure 6-10).

When, as is often the case, arid-tolerant and woodland species are found mixed together in the same sample, these disharmonious assemblages probably indicate a mosaic of wooded and open microhabitats - in this case, open prairie with mottes or groves of trees (hackberry, certainly) along the creek bank. This interpretation agrees well with the botanical record for pollen/phytolith Zone 1, which records an open floodplain dominated by tall panicoid grasses and forbs, with pooid grasses and sedges near the creek (Chapter 11; Cummings, Yost and Puseman). Pollen from Asteraceae also points to frequent disturbance by flooding or burning. Indeed, frequent burning by native inhabitants or by natural ignition may have been responsible for maintaining a prairie habitat. The principal difference between the 41DL436 snail and pollen \phytolith data is that the paleobotanists find indicators of moist soils in Unit 1, whereas the only such indicators in the snail data are the slugs, succineids, and lymnaeid snails, which are probably mostly confined to sedge banks along the creek. Algal spores, oogonia, ostracods, 
fish scales, aquatic diatoms, and sponge spicules are evidence of overbank deposition of bioclastic debris next to the creek, not necessarily an indicator of extensive wet floodplain soils. Dering (this volume) had no samples from Depositional Unit 1 to study, but he observed for Depositional Units 2 and 3 that his wood types are from taxa that usually indicate an edge area, "along or adjacent to a creek terrace with a mix of open and closed canopy," and this probably applies to Unit 1 as well. Spatial studies of snail distribution across woodlandgrassland boundaries indicate that substantial woodland populations can extend out into the boundary zone, smaller numbers of grassland populations intrude into the boundary zone, and habitat generalists are most abundant in both the woodland and boundary zones (see Davies 2008:Figure 2.17).

\section{Depositional Unit 2}

Sedimentation rates are high in Depositional Unit 2, and as a result, specimen density is quite

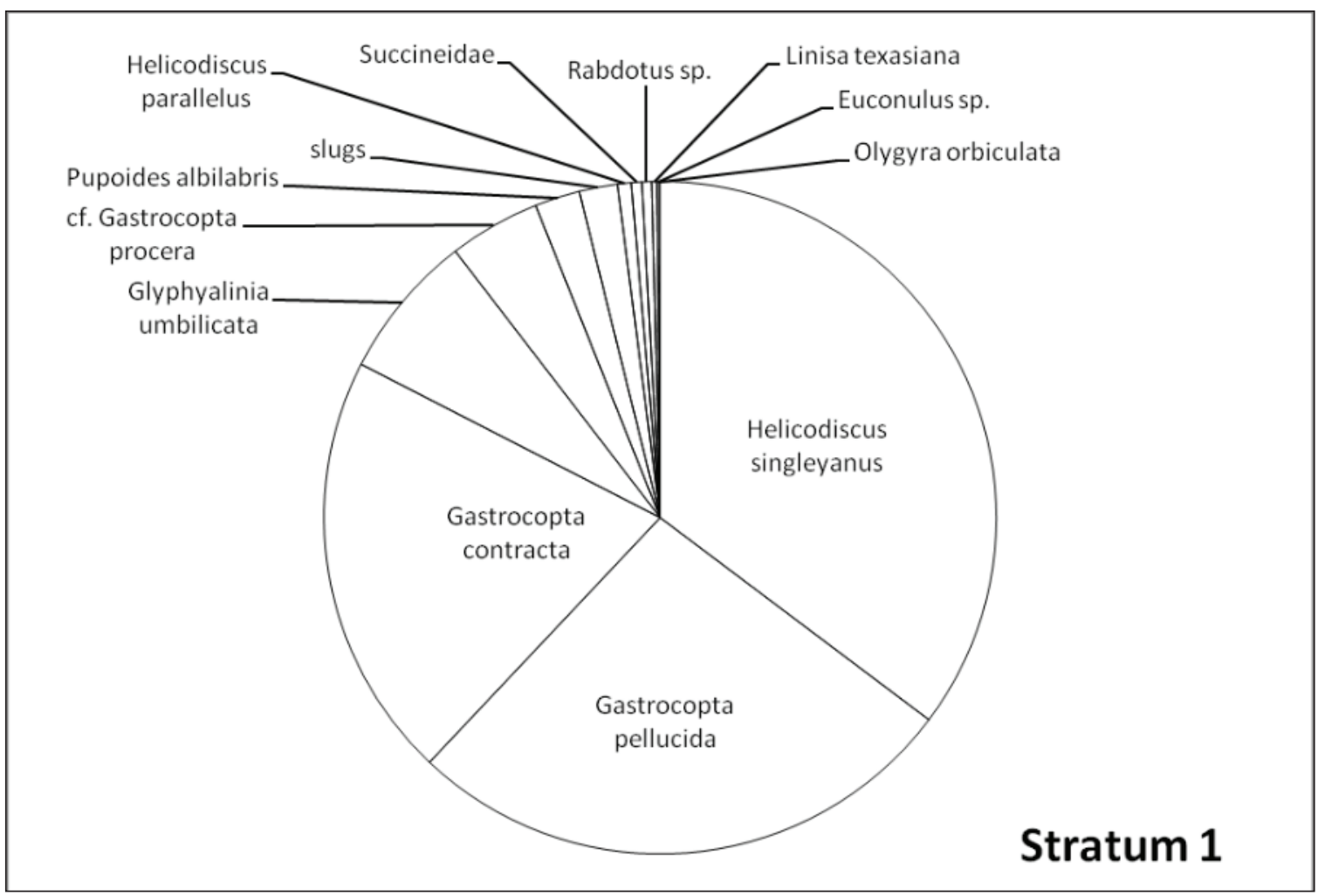

Figure 6-10. Most Common Species in Depositional Unit 1.

low (except in the 130-140 cm sample, immediately overlying Paleosol 2), despite the large matrix samples that were collected in the field. Species richness and diversity are moderateneither exceptionally high nor low. Why sediment dilution should suppress specimen counts more markedly than species diversity is unclear. This stratum also has by far the most excavated cultural features, many of which have evidence of fire. Cummings, Yost and Puseman (Chapter 11) also find evidence at $80-110 \mathrm{~cm}$ that might suggest intentional burning to support cultivation 
of pooid grasses. Has localized or widespread burning during the accumulation of Depositional Unit 2 contributed to diminished snail abundance or diversity? Nekola (2002b) has studied the effects of burning on grassland snail faunas, and found that species richness was reduced by about 30 percent and abundance by 50-90 percent on burned sites, chiefly through destruction of the surface organic layer. Although this might be a reason for the low specimen counts in this stratum, I suspect that sediment dilution is by far the more important factor.

Taxonomic composition in Depositional Unit 2 is similar to Unit 1, except that Gastrocopta contracta trades places with Helicodiscus singleyanus as the most common terrestrial species; Euconulus becomes slightly more abundant; and Carychium mexicanum and Strobilops texasiana make their first appearance (although in very small numbers; Figure 6-11). These are all possible hints that although the terrain is still open and probably grassy, tree canopy is becoming slightly more extensive, and soil moisture levels are perhaps slightly higher. Gastrocopta contracta seems to prefer more protected areas, although it can be found in dry grassland; $H$. singleyanus is drought-resistant but can tolerate damp conditions. Carychium is a wet floodplain indicator and Strobilops is a riparian woodland indicator, but these are more abundant in the overlying stratum. Dering (this volume) finds charcoal from elm, cottonwood/ willow, and Fabaceae (possibly honey locust, often found in east Texas in abandoned pastures) in this stratum. Fabaceae pollen is most common at 130-160 cm. These may have been the types of trees or shrubs that were beginning to encroach on grassy areas at the site.

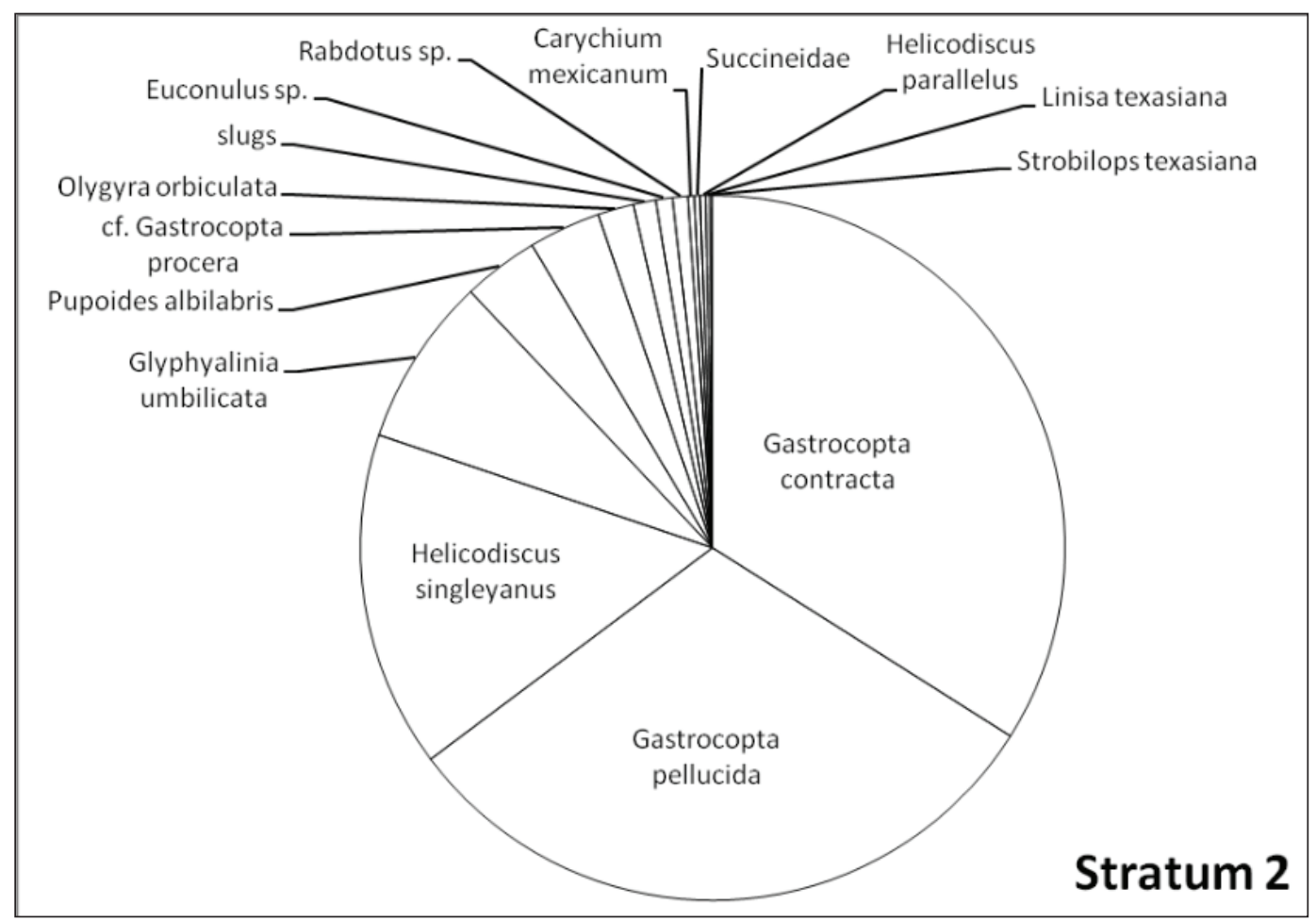

Figure 6-11. Most Common Species in Depositional Unit 2. 


\section{Depositional Unit 3}

The samples in this stratum fall into two distinct groups. The upper two samples at $0-20 \mathrm{~cm}$ encompass the contemporary soil and have increased specimen density, plus four new species that either appear only in the upper $20 \mathrm{~cm}$ ( $G$. pentodon, a single possible Z. arboreus, an unidentified discoidal) or are much more abundant there (Strobilops texasiana). A fifth, the mesic floodplain indicator $C$. mexicanum, is slightly more abundant at 40-70 cm. Three taxa are present in low numbers in the basal part of Depositional Unit 3, but disappear in the upper $20 \mathrm{~cm}$ : Euconulus, Linisa, and Succineidae. There are also six taxa that are not confined to the upper $20 \mathrm{~cm}$ but increase conspicuously in number there compared to the lower part: $G$. contracta, G. pellucida, G. procera, O. orbiculata, P. albilabris, and slugs. Except for a single specimen at $10-20 \mathrm{~cm}$, there are no aquatic taxa in this stratum, and other aquatic indicators (charophyte oogonia, fish scales, etc.) are also absent. The lower two samples in this stratum, at 40-60 cm, have much the same species as the levels above and below, but in greatly reduced numbers. The exception is Carychium mexicanum, which is more abundant at 40-60 cm than anywhere else. The 50-60 cm sample is distinguished by having the largest volume in liters, but the smallest number of taxa (Table 6-1). Cultural features near the base of this stratum produced two radiocarbon assays ranging between about $1650 \mathrm{cal}$ AD and the 1930-1950 era, so it evidently dates entirely from the historic period.

When all of the samples in this stratum are aggregated, the most abundant taxa are, in order, G. contracta, H. singleyanus, Strobilops texasiana, and G. pellucida (Figure 6-12). Pupoides albilabris also becomes more abundant. The most significant changes from Depositional Unit 2 are the reduced number of G. pellucida and G. procera, the appearance of G. pentodon, and the explosion of the Strobilops texasiana population in the contemporary soil. These changes in the faunal assemblage suggest an increase in tree canopy. Soil moisture levels probably also increase in Depositional Unit 3, not necessarily because of regional climatic change, but because heavier deciduous tree cover helps retain soil moisture by providing shade, reducing soil temperature, reducing wind velocity, and by shedding leaf litter and downed wood. Partial clearing of the floodplain by the property owners, creating a grassy opening with scattered standing trees is too recent to leave a recognizable signature in the snail sample column. Cummings, Yost and Puseman note an increase in oak pollen and a decrease in microscopic charcoal in the upper $40 \mathrm{~cm}$, as well as phytolith evidence for an increase in tree and shrub density and a decrease in grass cover. They posit a "long-term trend of decreasing soil moisture," and this is the only real point of disagreement between the botanical evidence and the snail record, which suggests the opposite.

\section{Overview of the Aquatic Fauna}

The aquatic taxa tell a simpler story than the terrestrial snails. There are about half a dozen kinds of pulmonate (lung-breathing) snails (the actual number of species is uncertain because of difficulty in identifying the lymnaeid juveniles) and one very abundant prosobranch (gillbreathing) species, tentatively identified as Amnicola limosus, plus peaclams and a few freshwater limpets, that were deposited on the creek floodplain as bioclastic debris during highwater events. These are all very cosmopolitan species that can tolerate a wide range of water 


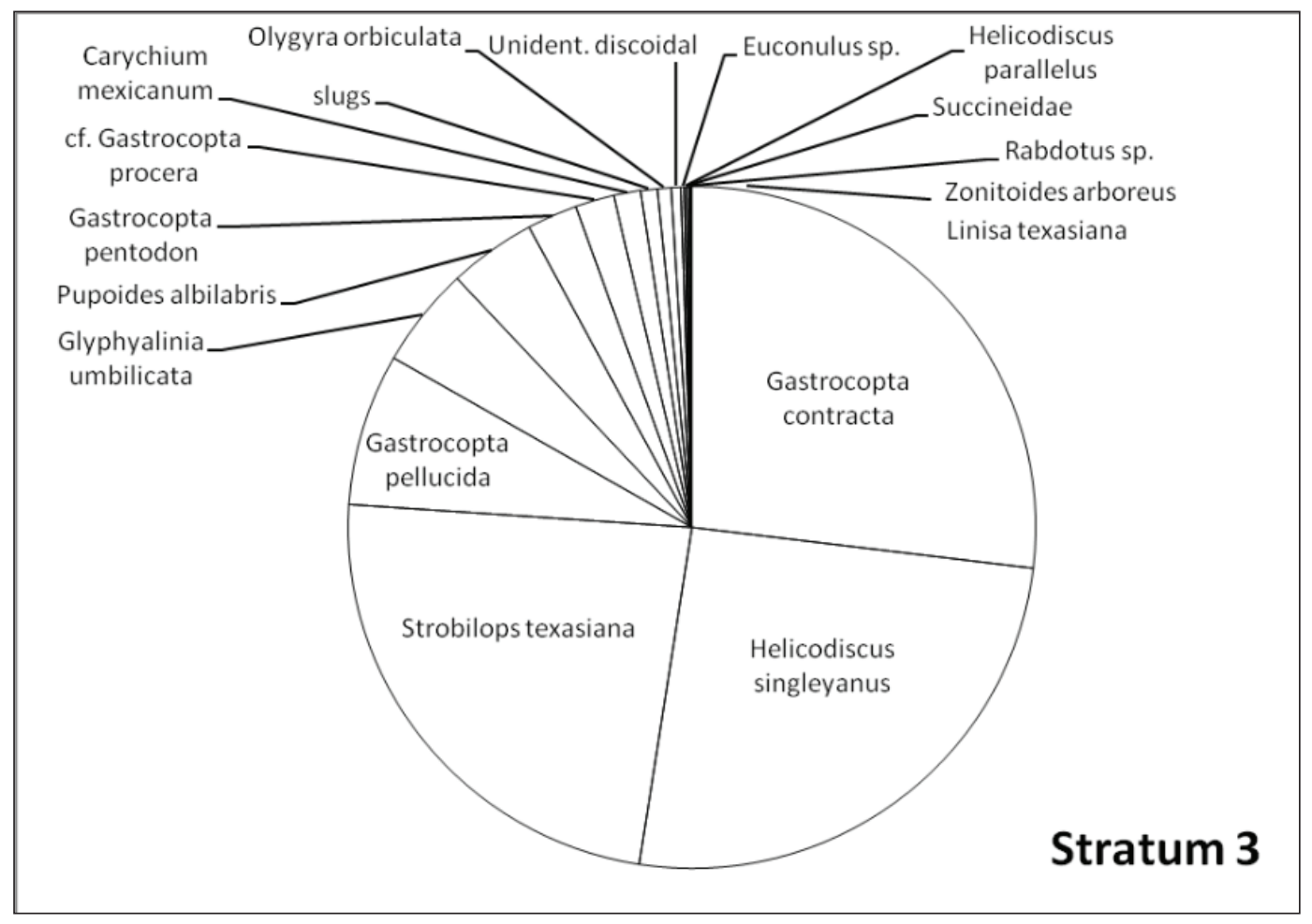

Figure 6-12. Most Common Species in Depositional Unit 3.

temperature, velocity, oxygen and solute levels. They are often found in permanent but slowmoving, muddy water in streams with mud bottoms and very abundant macrophytic vegetation (also documented by the charophyte oogonia found in the samples). This is precisely the kind of aquatic habitat indicated by the freshwater mussels studied by Howells (Chapter 7), and it is essentially the same as the habitat seen in present-day Fish Creek (Figure 6-13). Two of the Planorbella trivolvis have varices, growth interruption features that could indicate periods of desiccation, and the pulmonate species can generally tolerate stagnant water, but the abundant Amnicola are less tolerant of desiccation events. Some of these aquatic snails have pitted shells that suggest algal encrustation, but most do not. The aquatic biota suggest Late Holocene Fish Creek was a groundwater-supported stream, not an intermittent runoff-dominated stream.

Aquatic taxa are abundant in Depositional Unit 1 (indeed, they account for the increased species richness at that level), and continue to appear in the basal part of Depositional Unit 2, even after an avulsion event moved the creek channel some distance away, but they diminish in frequency as Depositional Unit 2 builds up, and have vanished by the time the top of that stratum is reached. Consequently, if there were any changes in hydrology of Fish Creek after the middle of Unit 2 was laid down, they are simply not recorded by the aquatic taxa. Only five Planorbella trivolvis were recovered from hand-dug excavation units in Depositional Unit 2.

Almost all of the aquatic snails recovered are juveniles, many of them embryonic in size. The age structure is most obvious in the larger species, such as Helisoma anceps, Physa sp. and Amnicola limosus. For the small planorbids (Gyraulus parvus and Micromenetus dilatatus), it is much more difficult to assess how many are juveniles, but for Micromenetus at least, it 
also appears most are embryonic, since 91 percent came from the $0.5 \mathrm{~mm}$ sieve. For the aquatic snails as a whole, 67 percent were recovered from the $0.5-\mathrm{mm}$ sieve, 32 percent from the 1-mm sieve, and only two percent came from the $2-\mathrm{mm}$ sieve. There are a few possible examples of adult Amnicola, H. anceps, Physa, or Micromenetus, but otherwise by far most of the aquatic snails are juveniles.

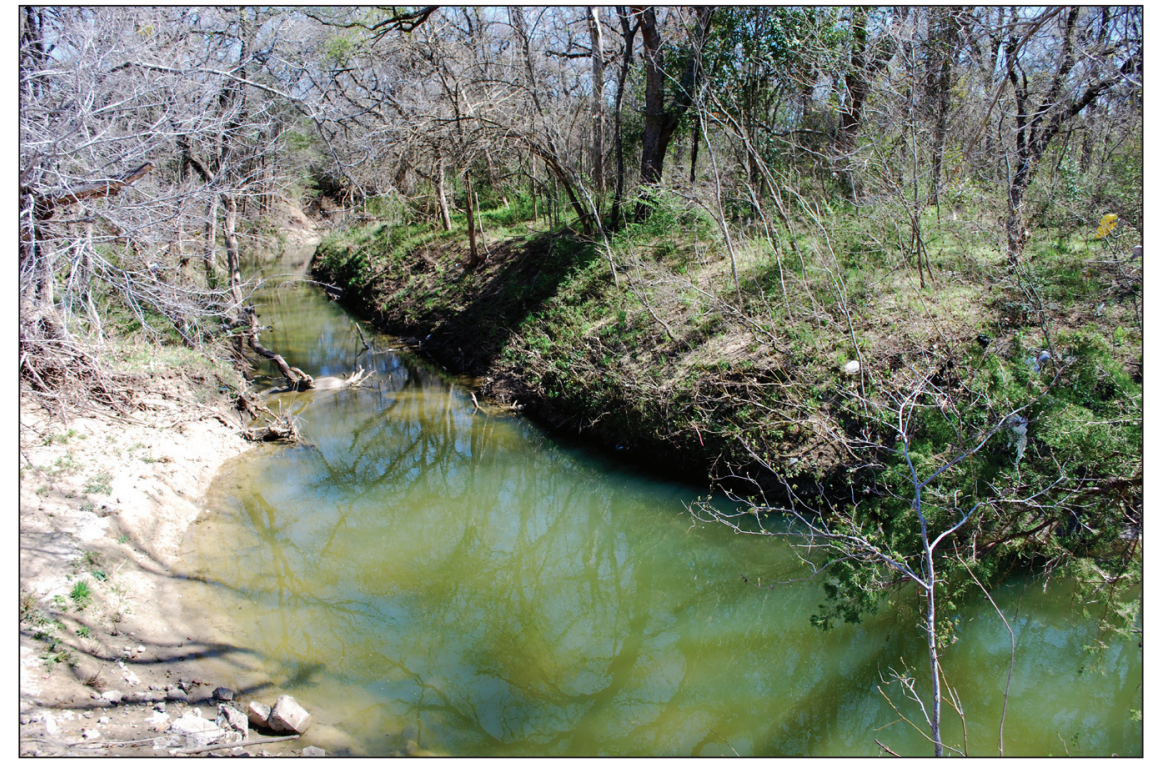

Figure 6-13. Fish Creek, Northeast of Site. Looking downstream (northeast). Note sluggish flow, algal growths, steep clay banks, and contemporary full-canopy deciduous woodland. Photograph by the author, March 4, 2012.

\section{Likewise, most of the}

peaclams appear to be juveniles. It is more difficult to generalize about the small sample of limpets. Some may be adults, but many are probably juveniles.

In an earlier study at the Vara Daniel site, this same kind of assemblage was encountered - aquatic taxa heavily dominated by juvenile and embryonic individuals (Brown 2010:145147). In that study, I suggested the juveniles may have come from overwash derived from vernal pools on the floodplain. That explanation does not seem tenable at 41DL436, because the valley is smaller and the topography is different. Instead, the most likely explanation is probably that most overbank deposition occurred during spring or early summer floods, not long after the spring hatching season for most aquatic snail taxa.

The other possibility is simply that when aquatic snails are deposited on land as bioclastic debris, they are heavily biased toward juvenile individuals, either because juvenile mortality is high, or because the smaller shells are disproportionately transported. A very interesting study conducted in a ditch and a pond in Manitoba by aquatic biologist Eva Pip found the mean size of Planorbella trivolvis shells in bottom sediments to be $8.3 \mathrm{~mm}$; for $H$. anceps, 3.0 and 4.6 mm; for Amnicola limosus, $1.6 \mathrm{~mm}$; and for G. parvus, 2.0, 2.1 and $2.2 \mathrm{~mm}$ (Pip 1988:Tables $2-4)$. For all of these species, with the possible exception of the last, these average sizes are well below the maximum adult size, and they are not very different from the archaeological specimens recovered at 41DL436. If the Canadian data are representative, it suggests juvenile mortality is fairly high and small shell sizes are actually the norm in bottom deposits. 


\section{Discussion and Conclusions}

The Late Holocene is marked by two notable climatic episodes, the Medieval Climatic Anomaly (MCA, or Medieval Warm Period in older literature) and the Little Ice Age (LIA). The MCA is a period of elevated temperature in the Northern Hemisphere, peaking around 1000-1100 AD (Moberg et al. 2005:Figure 2, d) and then declining as the transition to the LIA takes place. The boundary between the MCA and LIA is transitional and poorly defined (perhaps at about 1400-1500 AD), but the lowest temperatures, marked by minor readvances of alpine glaciers in some parts of the world (Reyes et al. 2006), are perhaps around 1600-1750 AD (in the Canadian Rockies, the last major readvance is at about 1825-1850 AD; Luckman 2000:363). In the Plains and Southwest, the MCA was marked by multidecadal droughts, droughts that were similar in geographic extent to modern examples, but much more prolonged (20-40 years) than anything in the historic record (Seager et al. 2007:Figure 2). The origin is generally thought to be persistent La Niña-like conditions caused by a persistently cool tropical Pacific Ocean and a persistently warm subtropical North Atlantic (Seager et al. 2007).

At 41DL436, Depositional Unit 1 accumulated during this waning phase of the Medieval Climatic Anomaly, although Unit 49 is only two meters deep and consequently only extends deep enough to capture the last century or so of this climatic event. In other parts of Gradall Trench 3, sediments dating to earlier phases of the MCA were exposed.

From tree-ring studies, we know the dates of the Medieval Plains megadroughts much more precisely (to the exact calendar year, actually) than we know the ages of the 41DL436 occupational episodes. We even have reconstructed maps of these droughts (Herweijer, Cook and Emile-Geay 2007; Cook et al. 2007), and if we could refine the dating of the site sufficiently, we could estimate their local impact. All of the 41DL436 stratigraphic sequence is covered by tree-ring dated drought maps (based on Cook et al. 2004), which can be downloaded for any particular year (of the last 2000 years) selected from the online North American Drought Atlas hosted by the Lamont-Doherty Earth Observatory at Columbia University. A timeline of the Palmer Drought Severity Index can also be downloaded for the nearest grid point (point $180,97.5^{\circ} \mathrm{W}$ and $32.5^{\circ} \mathrm{N}$ ) to Dallas. Particularly severe droughts affected the Dallas area in $1149,1215-16,1232-33,1236,1292,1346,1374,1544$ AD, and especially in 1240-41 and $1455 \mathrm{AD}$, and the centuries from 1100 to 1300 also had many years with moderate drought. There were also a few fairly wet years, like 1175, 1265, 1540, and 1271 AD, for example. Severe droughts that last for one or two years are probably much less effective than moderate, multidecadal droughts for removing ground cover.

Figure 6-14 shows a plot of the Palmer Drought Severity index for grid point 180. Inspection of this plot clearly shows a shift in the climate system at about $1500 \mathrm{AD}$, a shift that is probably a local chronological marker for the transition from the MCA to the Little Ice Age. Before 1500 $\mathrm{AD}$, the amplitude of wet-dry cycles is markedly greater, and the frequency much lower. After $1500 \mathrm{AD}$, the cycle obviously tightens up - the cycle frequency increases, but the amplitude diminishes significantly, as the climate system becomes much more stable during the LIA. The transition occurs at about $1500 \mathrm{AD}$, about half a century after the last major megadrought in 1455 AD. Dating of the avulsion event that initiated the rapid accumulation of Depositional 
Unit 2 is uncertain (see Chapter 5, Abbott and Frederick), but avulsion might have occurred about a century after this climatic shift. Units 2 and 3 then accumulated during the Little Ice Age. The increased stability of the climate system that shows up in the tree-ring record after $1500 \mathrm{AD}$ is probably a result of diminished El Niño activity originating in the Pacific, documented in the ${ }^{18} \mathrm{O}$ isotope record of corals from Papua New Guinea, where an especially quiescent period has been identified at about 1519-1636 AD (Hereid et al. 2013)

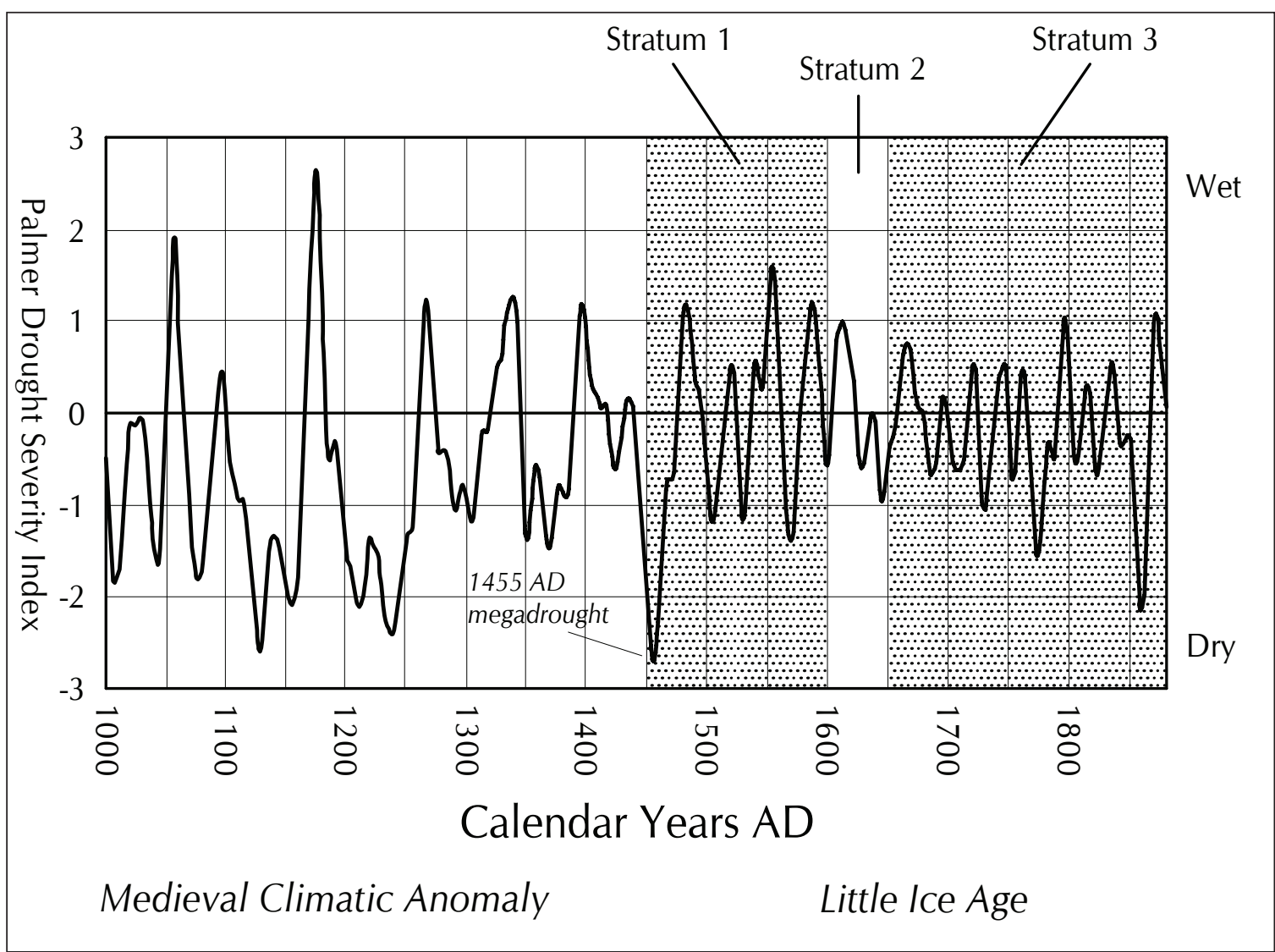

Figure 6-14. Depositional Units Plotted on PDSI Timeline for Data Cell 180. The curve represents the Palmer Drought Severity Index for the Dallas area for the years 1000-1880 AD, based on a gridded network of 835 tree-ring chronologies scattered across the central US. Data from the different tree-ring collection sites are interpolated to form a network of 286 grid points, and the curve shown here represents only data cell 180, the closest grid point to Dallas. Shaded bars are a very rough attempt to define the ages of the three principal strata in Unit 49, based on radiocarbon assays. Although Depositional Unit 1 actually began accumulating before the start of the timeline shown here, the shaded bar labeled "Stratum 1" just represents the part exposed in Unit 49. Note the markedly reduced amplitude and increased frequency of PDSI fluctuations that begins about $1500 \mathrm{AD}$. This is probably a regional marker for the start of the Little Ice Age, and it corresponds to reduced ENSO variability documented in Pacific corals. 
In the geological record, the primary markers of the MCA megadroughts are "extreme" events resulting from depletion of ground cover: eolian deposits burying paleosols that developed in wetter periods, or channel incision in local streams. These events are relatively conspicuous and datable by radiocarbon or OSL assays. In contrast, the Little Ice Age was presumably marked in the Plains by lower temperatures, reduced frequency of La Niña events, reduced evapotranspiration, and increased precipitation and ground cover. These variables enhanced soil development and landform stability, but did not necessarily produce datable events. As a result, the effects of the Little Ice Age are generally less conspicuous in the geological record than the earlier Medieval Climatic Anomaly. In the western hemisphere, the Little Ice Age is also marked by reduced biomass burning (Power et al. 2012) and southward shifting of the Intertropical Convergence Zone (Sachs et al. 2009).

At 41DL436, geologic events are a paramount driver of changes in the snail fauna. Fish Creek was an important conduit for aquatic biota (aquatic snails, freshwater limpets, peaclams, fish, aquatic plants) as well as a source of support for the local water table, but the avulsion event that occurred during the Protohistoric period shifted this conduit to a new location some 12 meters away. Even after the shift, the old channel continued to carry water and aquatic biota during high-water events, but as remobilized sediment from upbasin filled up the old channel, this role soon diminished in importance, and the aquatic biota disappear from the sedimentary column. The aquatic biota suggest that Fish Creek was a sluggish, probably poorly oxygenated, muddy, groundwater-supported stream, heavily choked with aquatic vegetation, but probably not subject to seasonal drying even during the MCA.

The creek floodplain appears to have been open and grassy, unlike its contemporary aspect, with scattered trees or groves of trees, perhaps mostly along the creek bank. In this, the paleobotanical and snail data are in good agreement. The $\delta{ }^{13} \mathrm{C}$ values of the sediments in Depositional Units 1-2 generally fluctuated from about $-18 \%$ o to roughly $-21 \%$ (Chapter 5, Abbott and Frederick). The snail data suggest that there is a slight tendency for an increase in tree canopy over time, but the major increase in woodland extent occurred very late, probably within the last two centuries, and might have been due to fire suppression by Euroamerican settlers. Carychium mexicanum, an important mesic floodplain indicator, and Strobilops texasiana, a woodland indicator, both appear just below the Depositional Unit 2/3 boundary, with the latter becoming very abundant in the modern soil. As tree cover increases on the floodplain, $\delta{ }^{13} \mathrm{C}$ values shift from near -18 or $-19 \%$ to about $-23 \%$ at the modern ground surface (Abbott, this volume), which is closer to the accepted consensus value of $-25 \%$ for trees (which are C3 plants). This same pattern is often seen elsewhere in the Trinity River basin, but may begin much earlier at other sites (Hall et al. 2012:Figure 4). Tree-ring studies show that the extreme and prolonged wet-dry cycles that characterized the Medieval Climatic Anomaly stabilized after about 1500 AD. The last of these MCA megadroughts occurred in 1455 AD. Cessation of the megadroughts and stabilization of the ENSO-driven precipitation regime would have encouraged tree growth and perhaps reduced wildfire frequency. Increased tree canopy helps retain soil moisture by providing shade, reducing soil temperature, reducing wind velocity, and by shedding leaf litter and downed wood, so soil moisture levels probably increased somewhat during the Little Ice Age. 


\title{
Chapter 7 \\ Mussel Shell Species
}

\author{
Robert G. Howells
}

\section{INTRODUCTION}

Freshwater mussels (Family Unionidae) comprise one of several families of bivalve mollusks that occur in fresh waters around North America, with over 50 species reported in Texas (Howells et al. 1996; Howells 2010a). Unionids can be important elements in many aquatic ecosystems where they may be a major component of system biomass (Negus 1966), contribute to nutrient storage and cycling (Nedeau et al., undated), maintain water quality by their waterfiltering activities (Strayer et al. 1999, 2004; Nedeau et al. 2000; Lyons et al. 2007), provide a mechanism to mix and turn-over the substrate (Strayer 2004), support an array of associated commensal and parasitic organisms (Howells 2010a), and provide a forage base for molluskeating predators (Howells et al. 1996).

Native Americans took freshwater mussels for food, used their shells for tools and ornamentation, and collected their pearls as well (Howells 1996; Howells et al. 1996; Parmalee and Bogan 1998; Williams et al. 2008). Unionid shells, valves, and fragments are often found at archaeological sites in Texas and elsewhere (e.g., Murray 1982; Neck 1982; Chandler and Kumpe 1992; Howells 1998, 2002a, 2002b, 2005; Howells et al. 2003) and can contribute to an enhanced understanding of past activities at those sites.

Basic freshwater mussel biology can be both interesting and complex (Howells et al. 1996; Parmalee and Bogan 1998; Williams et al. 2008; and others). Adult unionids dig into the substrate and do not attach to solid objects as do marine mussels (Family Mytilidae) or exotic zebra mussels (Family Dreissenidae) (Howells et al. 1996; Howells 2010a). Some species are generalists and may occupy many different types of habitats (e.g., lakes, streams, rivers, oxbows), others prefer certain types of habitats (e.g., ponds), and still others are restricted to very specific environments and may not occur or survive in others (e.g., flowing-water, gravel riffles with little silt and high oxygen content). Shells are made of calcium carbonate (alternating layers of calcite and aragonite) and those of many species often survive long after their death becoming an important historic record.

Freshwater mussels are extremely sensitive barometers of environmental quality. When ecological changes and environmental degradation occurs, these are often the first organisms to decline and, all too often, vanish. As a result of this sensitivity, significant numbers of freshwater mussels in North America are already extinct, endangered, threatened, of special concern, or will be very soon (Bogan 1996; Strayer et al. 2004; Howells 2010a).

Due to ecological and archaeological importance of this group, unionids have become a focus of the potential impact of many anthropogenic activities. One archaeological site with three 
stratified zones was examined on Fish Creek (a tributary of Mountain Creek and the upper Trinity River) and cultural materials including bone, burnt clay and berry seeds, and charcoal was documented in 2005 (Feit and Campbell 2005). This site was subsequently examined again in 2010 (Abbott 2010).

\section{Materials And Methods}

In October 2010, staff of AmaTerra, Austin, Texas, excavated the Fish Creek Slough site (41DL436) in Dallas County, Texas. Some specimens were recovered from specific levels or depths, while others were found among materials from a Gradall scraped area, and were threepoint provenience using a Total Data Station. Freshwater mussel (Family Unionidae) shell remains recovered were bagged, labeled, and delivered to R.G. Howells, BioStudies, Kerrville, Texas, for examination.

These shell materials were examined and identified based on Howells et al. (1996) and Howells (2010a). Terminology followed those references and Turgeon et al. (1998), but with several more-recent taxonomic updates. Several genera present may include two species, but definitive identifications were not possible with all specimens due to uncertainty associated with natural morphological variation found in unionid mussels, commonly occurring deformities, and erosion and exfoliation associated with dated archaeological and paleontological specimens. These were treated like a unique taxon. Analysis results of each sample are presented in Table 7-1. Fragments of unionid valves were counted by AmaTerra and these original values were used herein because fragments easily break into multiple pieces during handling and transport (artificially inflating the apparent number present). Further, some fragments may come from a single broken specimen, but in other instances, each fragment could have originated from a different individual, so fragment count should be considered qualitatively. Specimens and groups of specimens were also weighed by AmaTerra. Those weights are listed in Appendix Table 7-1 where the total group weight is repeated for each taxon ultimately identified.

The umbo or beak of the unionid shell is often the thickest and most-solid portion of the valve and so often survives when other parts of the valve are lost to breakage or erosion. Similarly, the hinge plate of the valve (including the umbo, interdentum, pseudocardinal teeth, and lateral teeth) often survives intact as well. Both sections of the valve (Figure 7-1) often have diagnostic features. The thinnest portion of the shell is usually along the posterior margin and this area is therefore among that most often damaged or absent (sometimes with the loss of important diagnostic features). Frequently, portions of the disk itself have little value in identification unless unique sculpturing is present. Photographs of mussel valves and valve fragments found at the Fish Creek Slough site are compared to images of recent specimens herein (Figures 7-2 through7-34).

Many unionids have distinctive beak sculpture that, like human fingerprints, can be used to distinguish species. Because most of the species found at the Fish Creek Slough site occur in the same habitat type, many have very similar shell morphology. Beak sculpture was used to assist in making identifications of many of the archaeological specimens from the Fish Creek Slough 


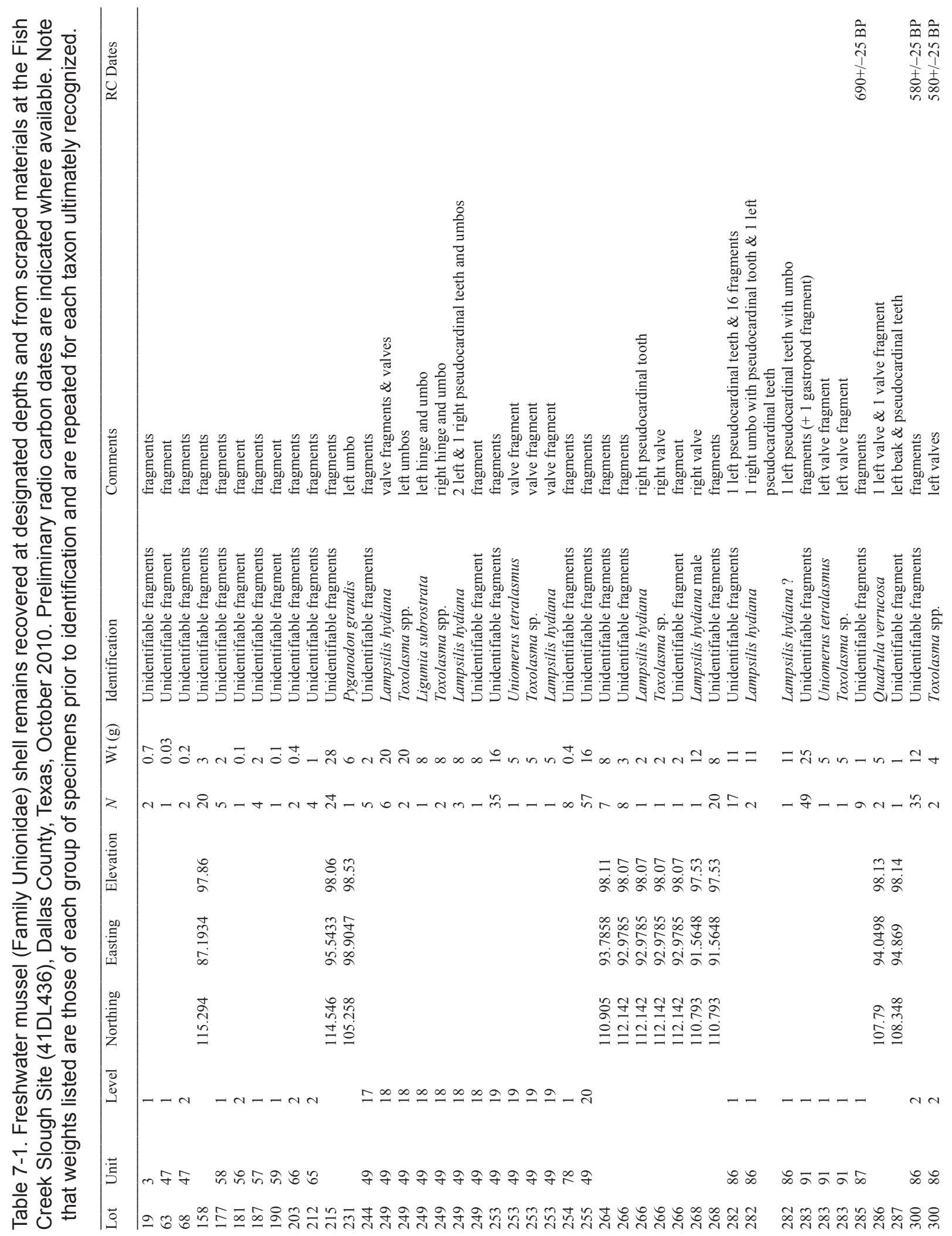




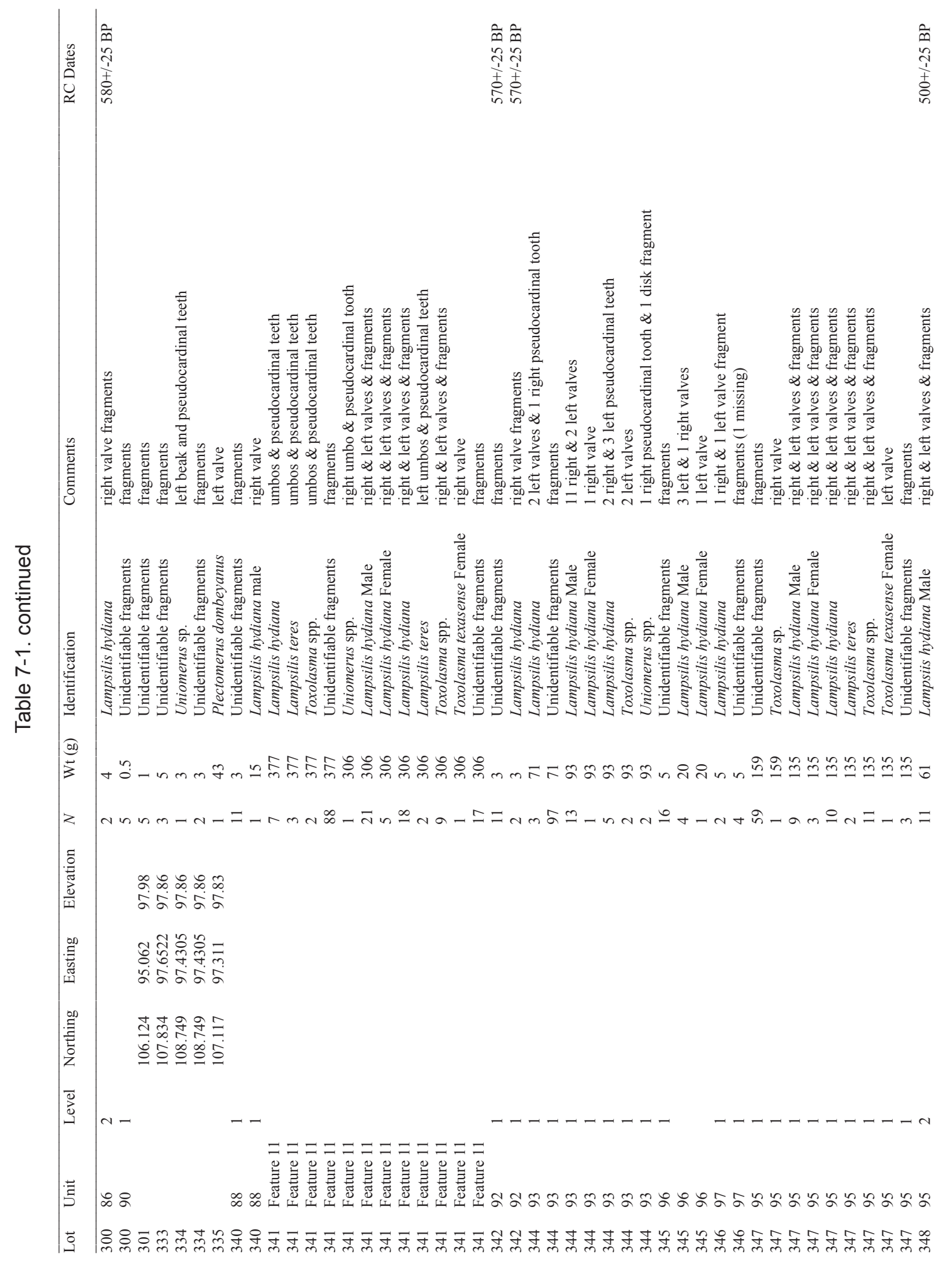




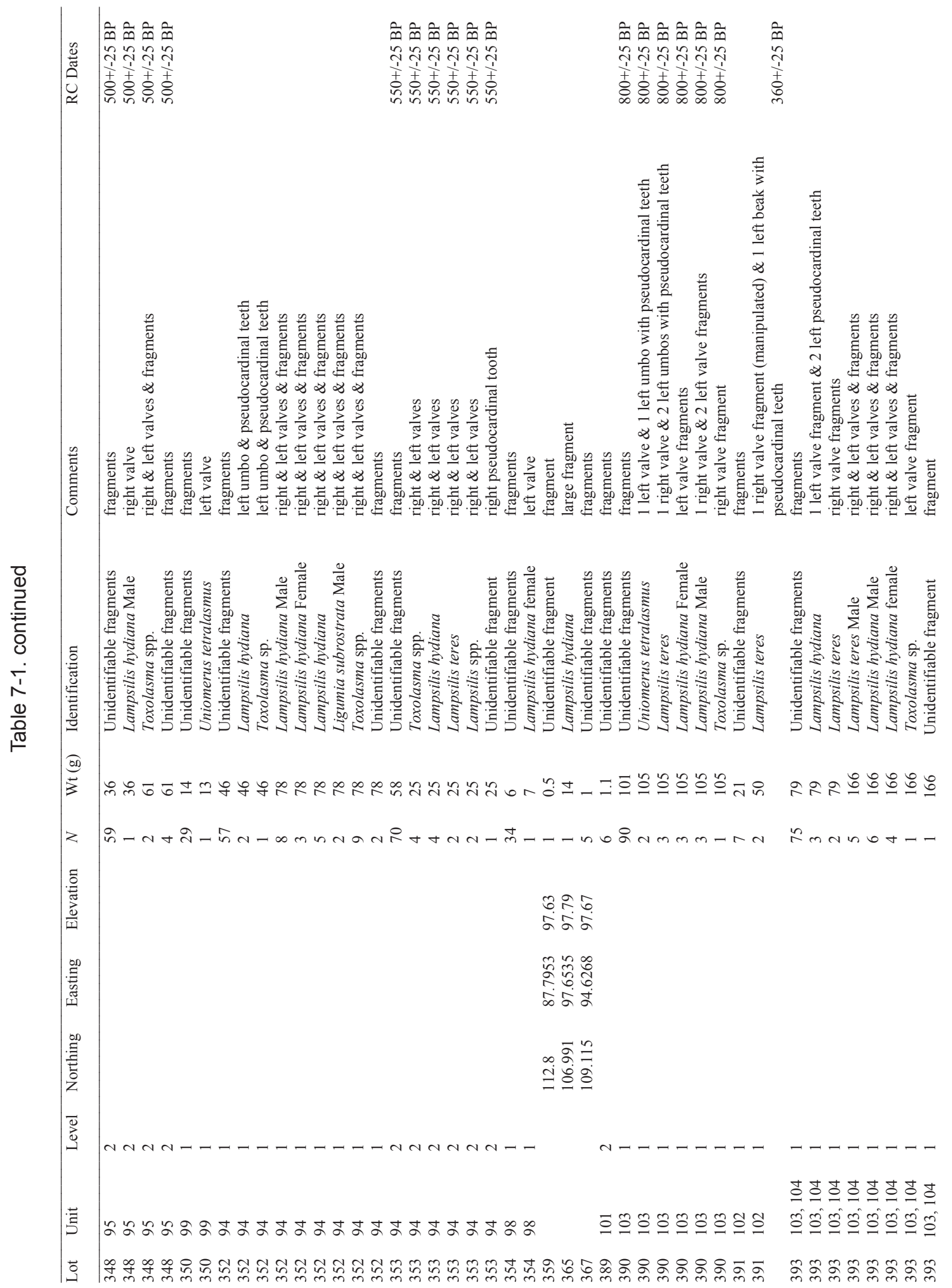




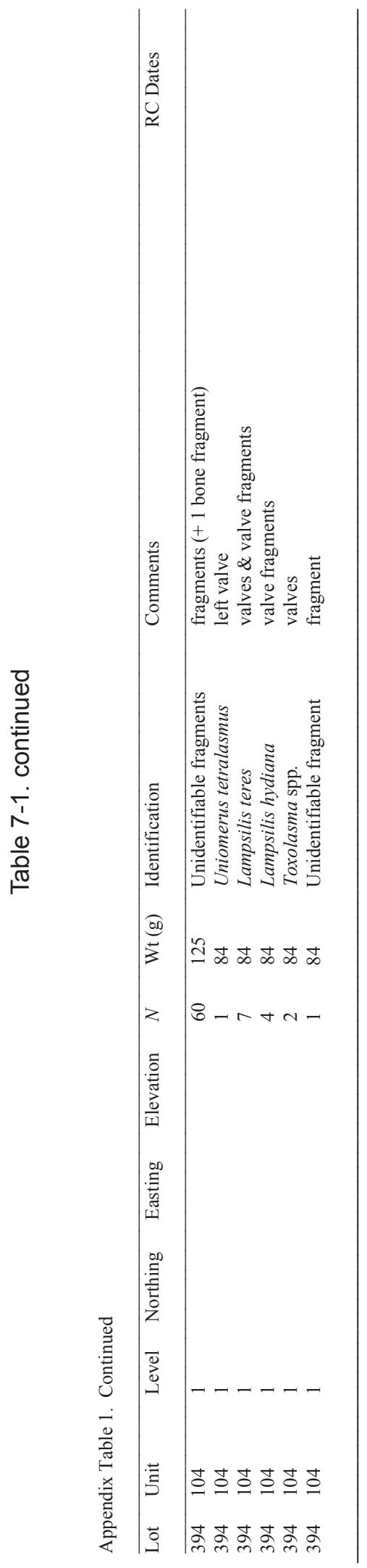




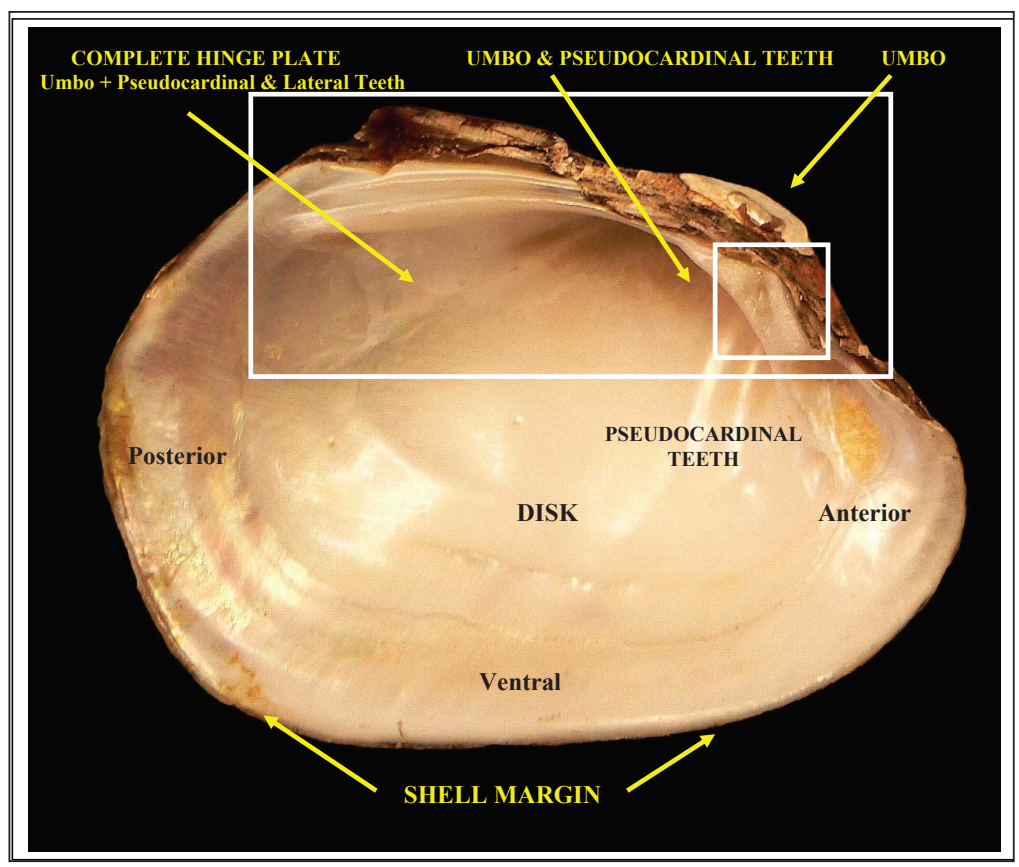

Figure 7-1. Elements and regions of a representative freshwater mussel (Family Unionidae) valve. Note that a shell is composed of a right and left valve. Shown above is a left valve. site. Examples of both archaeological and recent beak sculpture photographs are presented (Figures 7-24 through 7-34).

\section{RESULTS AND DISCUSSION}

At least 27 unionid species have been reported in the upper Trinity River drainage (Table 7-2). Among the 1,426 valves and fragments obtained, shell remains of eight, and possibly as many as 11, unionid taxa were found at the Fish Creek Slough site, in addition to unidentifiable fragments (see Tables 7-2 through 7-4).

Species composition at Fish Creek represented a mussel assemblage typical of ponds, oxbows, and backwater habitats with slow to no flow and soft substrates, with only a small number of specimens otherwise associated with larger water bodies and more firm bottoms.

\section{Species Accounts}

Distribution and ecological aspects are summarized from Howells et al. (1996), Howells (2010a), and the author's unpublished records.

\section{Louisiana fatmucket (Lampsilis hydiana) (Figures 7-2 through 7-4)}

Louisiana fatmucket is a common, sexually dimorphic species found throughout eastern Texas from the San Jacinto and Trinity systems into other drainages to the north and east, with other populations in the central and lower Brazos River, the lower Guadalupe-San Antonio, lower Nueces, and probably the lower Colorado rivers. It may occur in a variety of habitats, including lakes and impoundments, and substrate types. It is not typically a "pond" species, but does occur in slow-flowing, soft-bottom creeks and is sometimes washed into oxbow lakes from adjacent water bodies. Beak sculpture consists of a series of double-looped or V-ridges that do not extend far on to the disk or into the posterior field. Louisiana fatmucket was first in abundance with 181 specimens in the Fish Creek mussel shell remains recovered. It occurred in 22 lots and at depths from 0-98.07 cmbs (Tables 3 and 4). 
Table 7-2. Freshwater Mussels (Family Unionidae) Reported in Historic (less than 1980) and Recent (greater than 1979) Records from the Trinity River Drainage of Dallas, Denton, Collin, and Tarrant Counties, Texas, Based on the R.G. Howells Data Base. Unsuccessful (UI) and Successful (SI) Introductions are Noted.

\begin{tabular}{|c|c|c|c|c|}
\hline Common name & Scientific name & Recent & Historic & Present study \\
\hline Threeridge & Amblema plicata & $x$ & $x$ & - \\
\hline Rock-pocketbook & Arcidens confragosus & - & $x$ & - \\
\hline Tampico pearlymussel & Cyrtonaias tampicoensis & - & UI & - \\
\hline Wabash pigtoe & Fusconaia flava ${ }^{a}$ & - & $x$ & - \\
\hline Louisiana fatmucket & Lampsilis hydiana & $x$ & $x$ & $x$ \\
\hline Yellow sandshell & Lampsilis teres & $x$ & $x$ & $x$ \\
\hline White heelsplitter & Lasmigona complanata & - & UI & - \\
\hline Fragile papershell & Leptodea fragilis & $x$ & $x$ & - \\
\hline Pondmussel & Ligumia subrostrata & $x$ & $x$ & $x$ \\
\hline Washboard & Megalonaias nervosa & - & $x$ & $?$ \\
\hline Threehorn wartyback & Obliquaria reflexa & - & $x$ & - \\
\hline Bankclimber & Plectomerus dombeyanus ${ }^{b}$ & - & - & $x$ \\
\hline Louisiana pigtoe & Pleurobema riddellii & - & $x$ & - \\
\hline Texas heelsplitter & Potamilus amphichaenus & $x$ & $x$ & - \\
\hline Pink papershell & Potamilus ohiensis & SI & - & - \\
\hline Bleufer & Potamilus purpuratus & $x$ & $x$ & - \\
\hline Giant floater & Pyganodon grandis & $x$ & $x$ & $x$ \\
\hline Southern mapleleaf & Quadrula apiculata & $x$ & $x$ & - \\
\hline Western pimpleback & Quadrula mortonic & $x$ & $x$ & - \\
\hline Gulf mapleleaf & Quadrula nobilis & - & $x$ & - \\
\hline Pistolgrip & Quadrula verrucosa & $x$ & $x$ & $x$ \\
\hline Lilliput & Toxolasma parvum & $x$ & $x$ & $?$ \\
\hline Texas lilliput & Toxolasma texasense & - & $x$ & $x$ \\
\hline Deertoe & Truncilla truncata & $x$ & $x$ & - \\
\hline Tapered pondhorn & Uniomerus declivis & $x$ & $x$ & $?$ \\
\hline Pondhorn & Uniomerus tetralasmus & $x$ & $x$ & $x$ \\
\hline Paper pondshell & Utterbackia imbecillis & $x$ & $x$ & - \\
\hline
\end{tabular}

a Wabash pigtoe (Fusconaia flava) has been reported in the Trinity River drainage; however, electrophoretic studies (R.G. Howells, unpublished) and DNA analysis (Hayes 2010) failed to confirm its presence in Texas. This suggests local records may actually be referable to Texas pigtoe $(F$. askewi).

${ }^{\mathrm{b}}$ Bankclimber is present in the Trinity River at downstream locations and occurs at least as far to the northwest (upstream) as Freestone County, but was likely found further upriver in past years.

' Because of confusion in identification of various pimpleback species, both pimpleback (Quadrula pustulosa) and smooth pimpleback (Q. houstonensis) have also been reported in the upper Trinity River drainage; however, DNA analysis (Serb et al. 2003) only identified western pimpleback (Q. mortoni) in the area. Wartyback (Q. nodulata) has been incorrectly reported in the upper Trinity River by amateur shell collectors, but these reports represent misidentified western pimpleback specimens. 

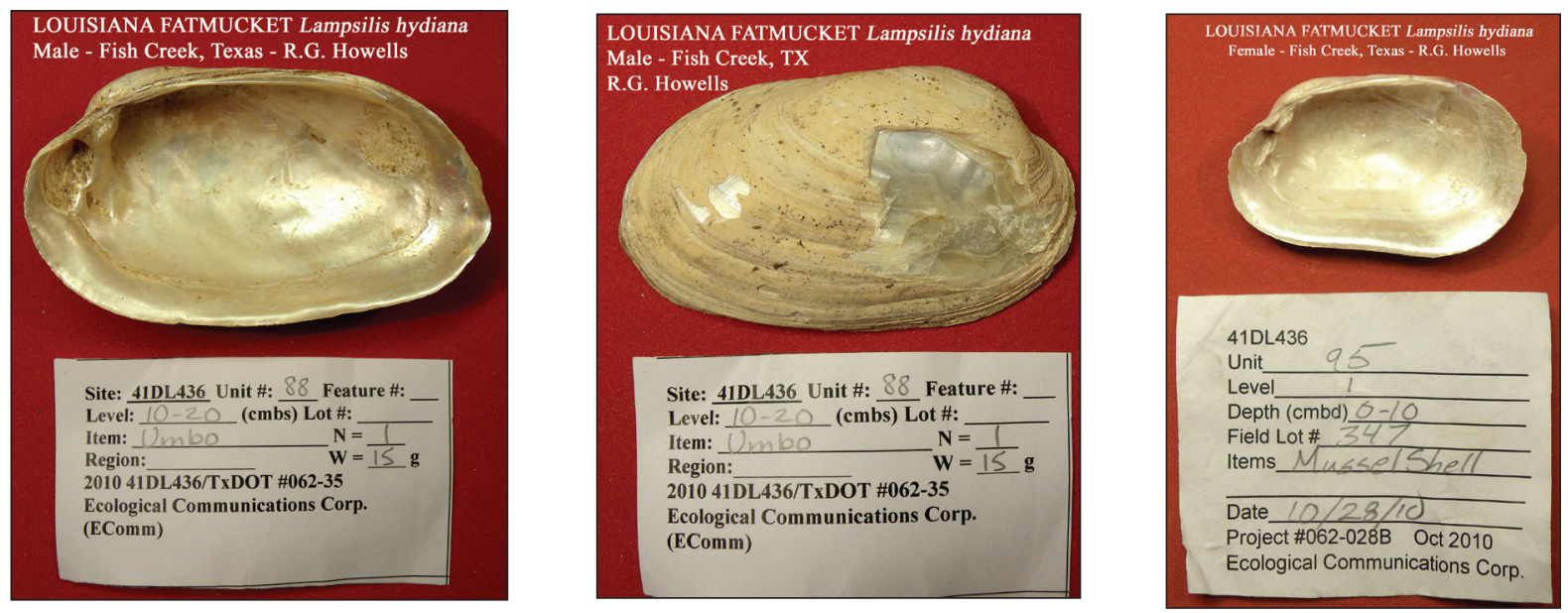

Figure 7-2. Louisiana Fatmucket (Lampsilis hydiana) male (above left and center) and female (above right).

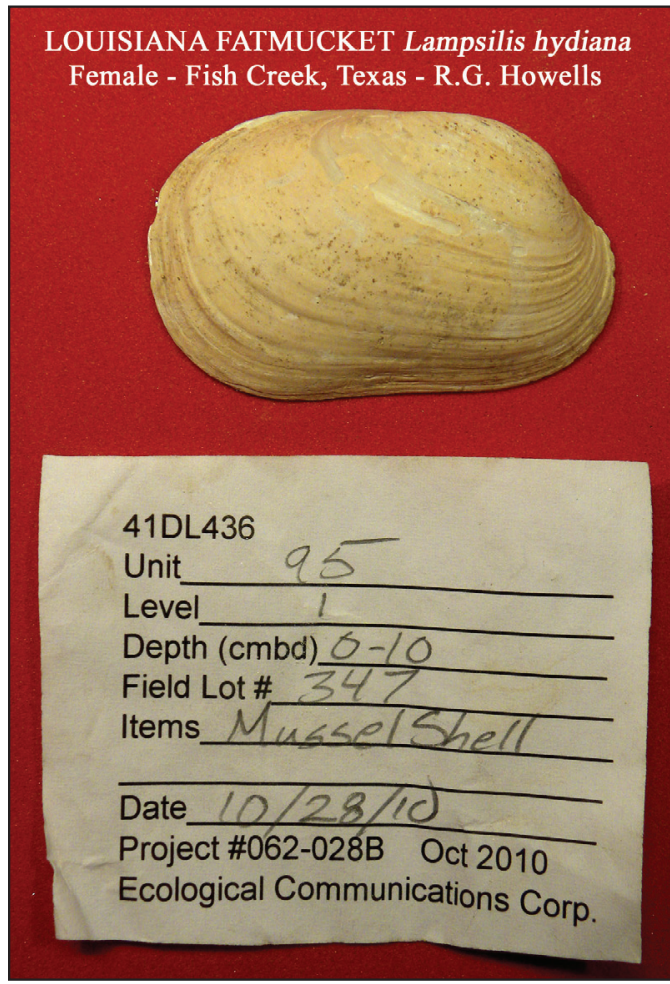

Figure 7-3. Louisiana fatmucket (Lampsilis hydiana) female.

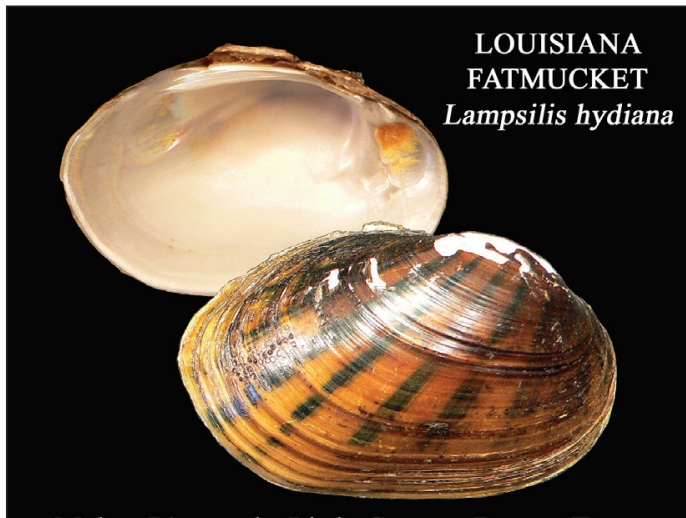

Male - 74 mm sl - Little Cypress Bayou, Texas

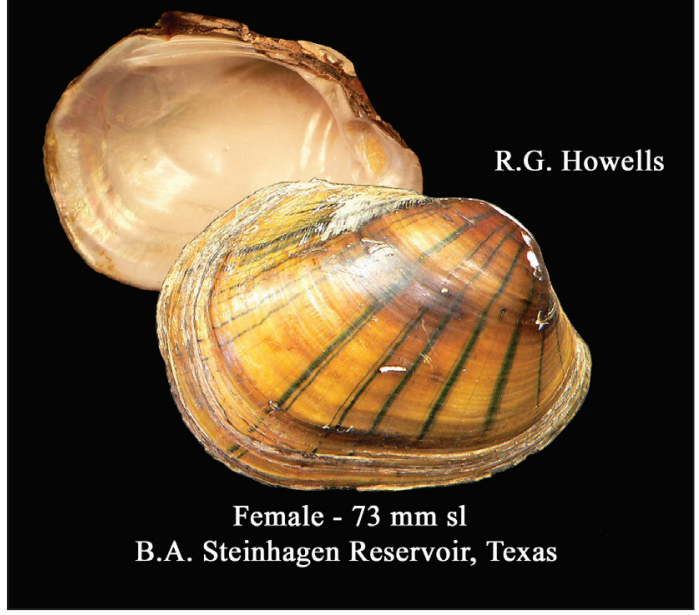

Figure 7-4. Louisiana fatmucket (Lampsilis hydiana) male and female specimens from sites in eastern Texas. 
Table 7-3. Freshwater Mussel (Family Unionidae) Shell Remains Recovered at Designated Levels $(U A=$ Unavailable) at the Fish Creek Slough Site (41DL436), Dallas County, Texas, 2010.

\begin{tabular}{|c|c|c|c|c|c|c|c|c|}
\hline \multirow[b]{2}{*}{ Common name } & \multirow[b]{2}{*}{ Scientific name } & \multicolumn{7}{|c|}{ Level } \\
\hline & & 1 & 2 & 17 & 18 & 19 & 20 & UA \\
\hline Louisiana fatmucket & Lampsilis hydiana & 94 & 18 & 0 & 9 & 1 & 0 & 59 \\
\hline Yellow sandshell & Lampsilis teres & 21 & 2 & 0 & 0 & 0 & 0 & 5 \\
\hline Lampsiliid & Lampsilis spp. & 0 & 2 & 0 & 0 & 0 & 0 & 0 \\
\hline Pondmussel & Ligumia subrostrata & 2 & 0 & 0 & 1 & 0 & 0 & 0 \\
\hline Bankclimber & Plectomerus dombeyanus & 0 & 0 & 0 & 0 & 0 & 0 & 1 \\
\hline Giant floater & Pyganodon grandis & 0 & 0 & 0 & 0 & 0 & 0 & 1 \\
\hline Pistolgrip & Quadrula verrucosa & 0 & 0 & 0 & 0 & 0 & 0 & 2 \\
\hline Lilliput spp. & Toxolasma spp. & 29 & 8 & 0 & 4 & 1 & 0 & 12 \\
\hline Texas lilliput & Toxolasma texasense & 1 & 0 & 0 & 0 & 0 & 0 & 1 \\
\hline Pondhorn & tetralasmus & 5 & 0 & 0 & 0 & 1 & 0 & 0 \\
\hline Pondhorn spp. & Uniomerus spp. & 2 & 0 & 0 & 0 & 0 & 0 & 2 \\
\hline Unidentifiable fragments & & 658 & 184 & 5 & 1 & 35 & 57 & 300 \\
\hline Total taxa (excluding fragments) & & 7 & 4 & - & 3 & 3 & - & 8 \\
\hline Total specimens & & 812 & 214 & 5 & 15 & 38 & 57 & 285 \\
\hline
\end{tabular}

Table 7-4. Freshwater Mussel (Family Unionidae) Shell Remains Listed by Total Number (N) of Specimens, Lots, and Units and Depth Range of Each Species (cm below surface [cmbs]; Unavailable=UA) Recovered at the Fish Creek Slough Site (41DL436), Dallas County, Texas, 2010.

\begin{tabular}{cccccc}
\hline Common name & Scientific name & Total N & N lots & Depth (cmbs) & $\begin{array}{c}\text { N } \\
\text { units+features+UA }\end{array}$ \\
\hline Louisiana fatmucket & Lampsilis hydiana & 181 & 22 & 0 to 98.07 & $5+1+3$ \\
\hline Yellow sandshell & Lampsilis teres & 28 & 7 & UA & $5+2+0$ \\
\hline Lampsiliid & Lampsilis spp. & 2 & 1 & UA & $1+0+0$ \\
\hline Pondmussel & Ligumia subrostrata & 3 & 2 & UA & $2+0+0$ \\
\hline Bankclimber & Plectomerus dombeyanus & 1 & 1 & 97.311 & $1+0+0$ \\
\hline Giant floater & Pyganodon grandis & 1 & 1 & 98.53 & $1+0+0$ \\
\hline Pistolgrip & Quadrula verrucosa & 2 & 1 & 98.13 & $1+0+0$ \\
\hline Lilliput spp. & Toxolasma spp. & 54 & 14 & 0 to 98.07 & $4+1+1$ \\
\hline Texas lilliput & Toxolasma texasense & 2 & 2 & UA & $1+1+0$ \\
\hline Pondhorn & Uniomerus tetralasmus & 6 & 5 & 0 to $10+$ & $5+0+0$ \\
\hline Pondhorn sp. & Uniomerus spp. & 4 & 3 & 0 to 97.86 & $1+1+1$ \\
\hline Unidentifiable fragments & fragments & 1142 & 46 & 0 to 97.6522 & $27+1+12$ \\
\hline
\end{tabular}

Yellow sandshell (Lampsilis teres) (Figures 7-5 through 7-6)

Yellow sandshell is also a sexually dimorphic species that occurs from the Rio Grande north to the Red River. Though dramatically reduced in abundance and distribution in the Rio Grande, it is often locally abundant in many other areas throughout its range in Texas. It may be found in a wide range of habitats and bottom types, but is particularly tolerant of sandy bottoms and can endure some softer substrates. Yellow sandshell is an extremely active species that may even follow flood waters over inundated terrestrial areas. As a result, it is sometimes found 
in oxbows, ponds, and smaller tributary streams adjacent to larger water bodies. Beak sculpture consists of a series of very fine, double-looped or V-ridges that do not extend far on to the disk or into the posterior field (finer than those in Louisiana fatmucket). Yellow sandshell was third in abundance with 28 specimens in the Fish Creek mussel shell remains recovered. It occurred in seven lots (Tables 3-4).

\section{Unidentified Lampsilis spp.}

Some umbos obtained at the Fish Creek Slough site were sufficiently worn and broken, with the remainder of the valve lacking, that it was not possible to determine if they were Louisiana fatmucket or yellow sandshell. In addition to these two species, the only other Lampsilis that could occur in the Trinity River drainage may be sandbank pocketbook (L. satura) (Howells 2010b). However, sandbank pocketbook is a larger species with a globular shell and high, inflated beak that is clearly distinct from Louisiana fatmucket and sandbank pocketbook. Two specimens that could not be assigned to either Louisiana fatmucket or yellow sandshell were found among in the Fish Creek mussel shell remains recovered. They occurred in one lot (Tables 3-4).

\section{Pondmussel (Ligumia subrostrata)}

(Figures 7-7 and 7-8)

Pondmussel occurs from the Frio River drainage of southcentral Texas north to the Red River, but is more frequent in the waters of eastern Texas. It is sexually dimorphic and can sometimes be confused with Louisiana fatmucket populations. Pondmussel, as its name suggests, is typical of farm ponds, oxbows, and backwater habitats and tolerates softer bottom substrates. It rarely occurs in larger or fast-flowing water bodies, but can be locally abundant in protected environments. Pondmussel umbo sculpture is a series of fine double-looped or $\mathrm{V}$-shaped ridges that extend

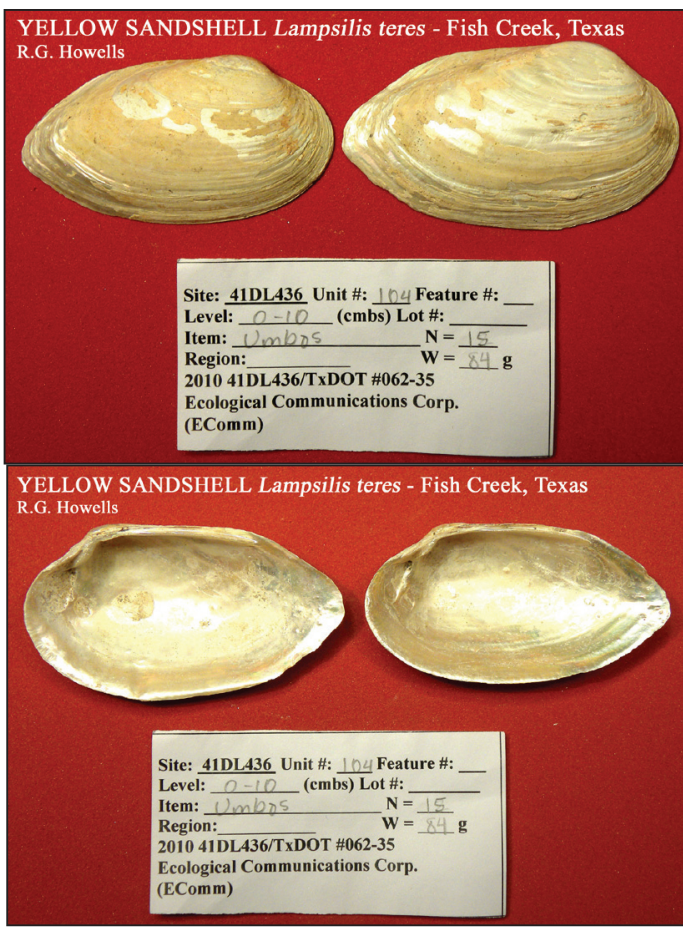

Figure 7-5. Yellow sandshell (Lampsilis teres) males.

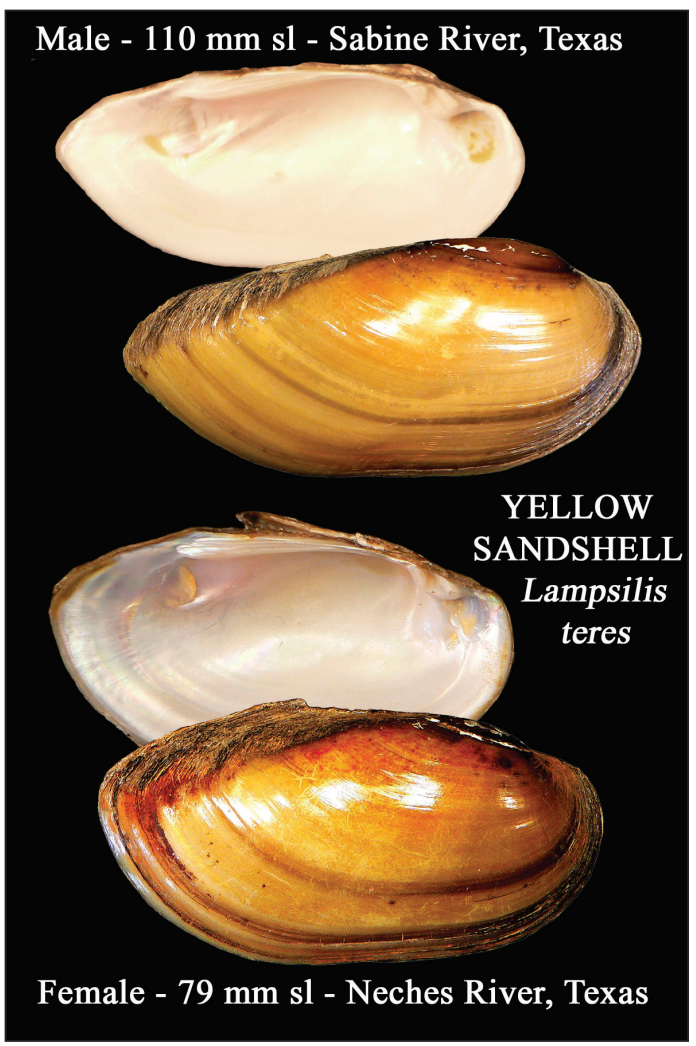

Figure 7-6. Yellow sandshell (Lampsilis teres) male and female from sites in eastern Texas. 


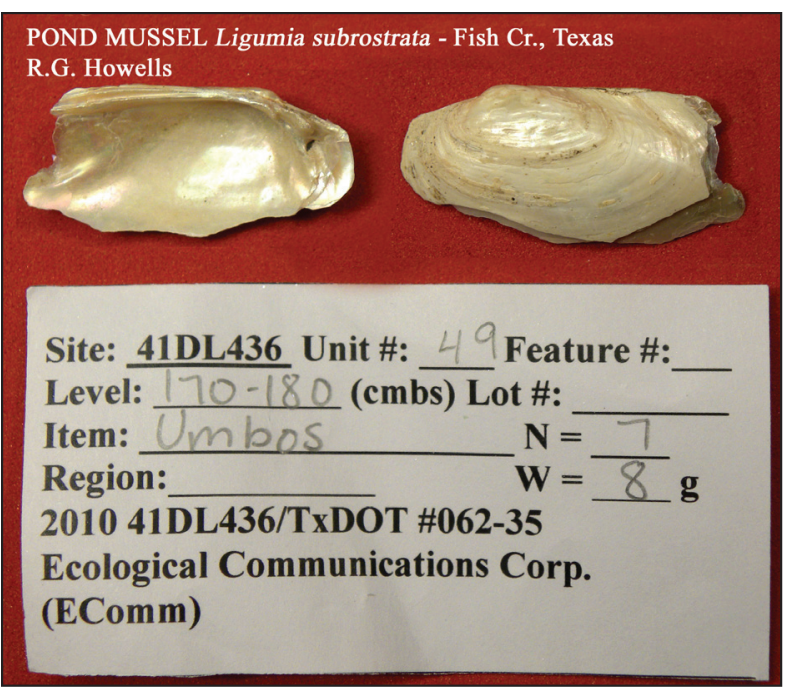

Figure 7-7. Pondmussel (Ligumia subrostrata) .

well posteriorly along the posterior ridge. Three pondmussel specimens in the Fish Creek mussel shell remains recovered. It occurred in two lots (Tables 3-4).

\section{Lilliput spp. (Toxolasma spp.)}

(Figures 7-9 through 7-11)

Two Toxolasma species, Texas lilliput ( $T$. texasense) and lilliput (T. parvum), occur in Texas. Both range from the Rio Grande to the Red River. Both are pond and backwater species often associated with softer substrates and slow- to no-flow waters. Texas lilliput, in particular, can be extremely abundant at some locations. Texas lilliput is strongly sexually dimorphic, but lilliput shows little sexual distinction and may be a hermaphrodite. Differentiation between male and female Texas lilliput specimens and lilliput reflect differences in the posterior margin of the shell. However, this section of shell is usually thinner than other portions and is therefore often damaged or lacking in weathered specimens. Identification to species or sex was often not possible when the rear portions of shells were not present. Texas lilliput often has a greater number of single-looped umbo sculpture ridges than lilliput. Both species have umbo sculpture that angles more sharply over the posterior ridge (not evenly curved throughout). Two specimens were clearly female Texas

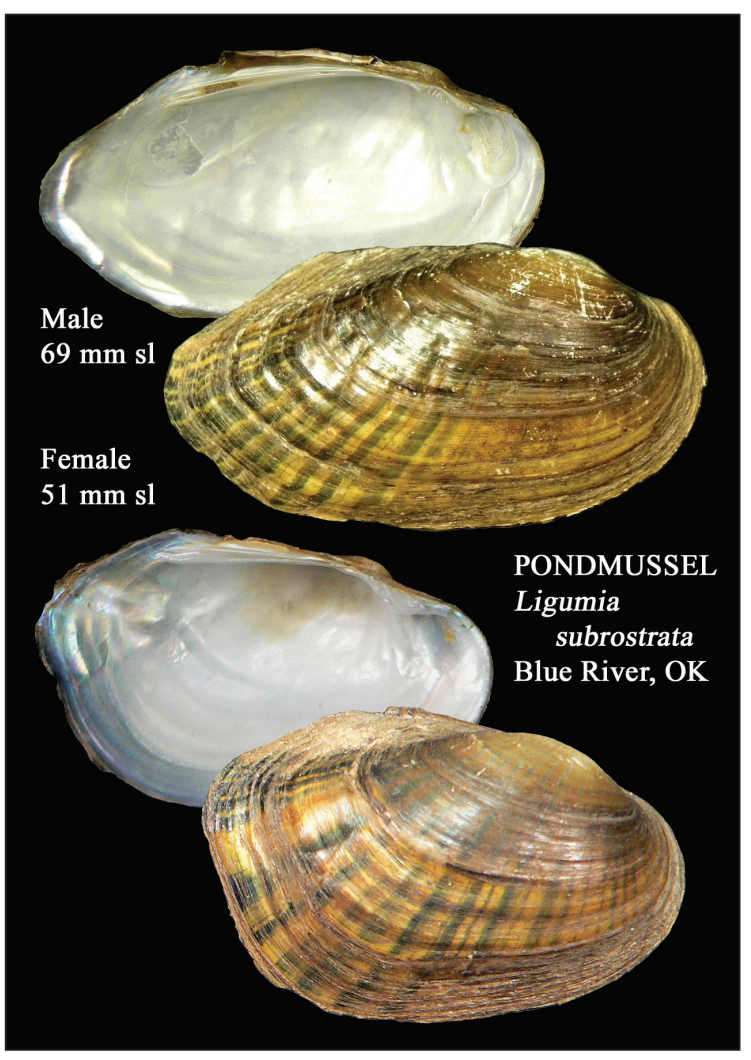

Figure 7-8. Pondmussel (Ligumia subrostrata) male and female from the Blue River, Oklahoma.

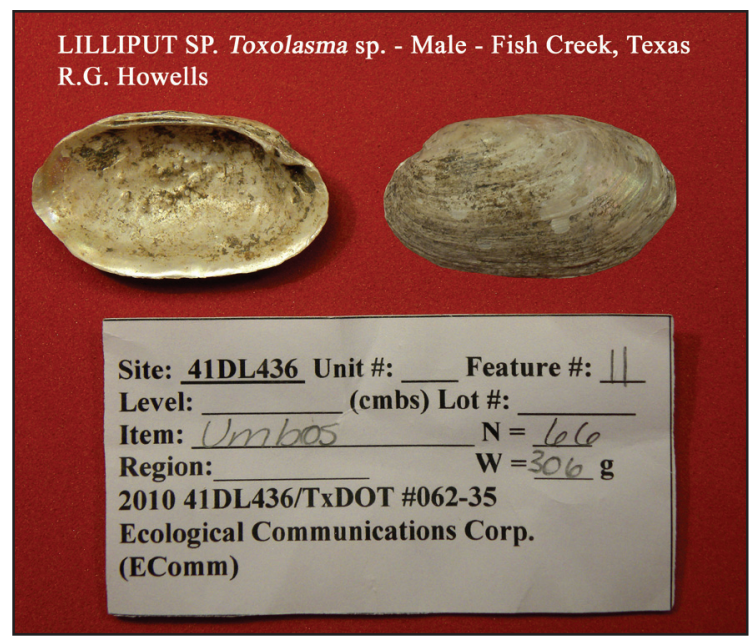

Figure 7-9. Lilliput sp. (Toxolasma sp.). This specimen could be Lilliput (T. parvum) or a male Texas lilliput (T. texasense). 
TEXAS LILLIPUT Toxolasma texasense

Female - Fish Creek, Texas - R.G. Howells

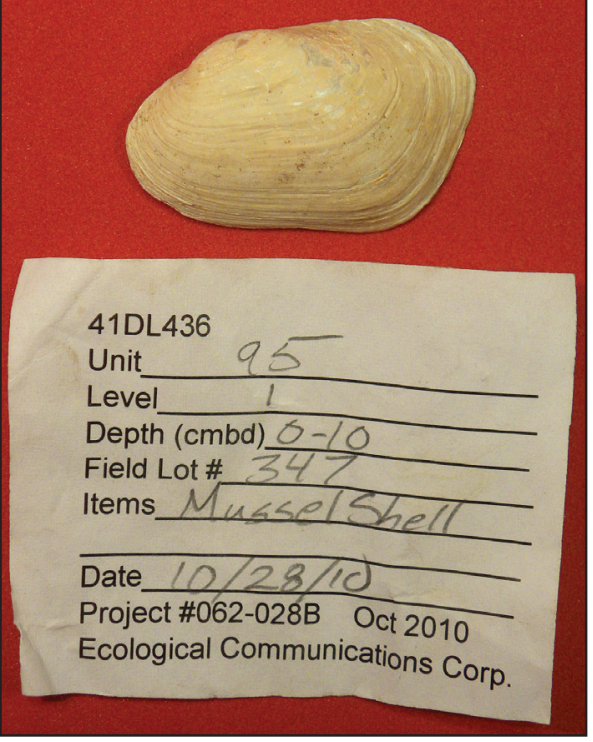

TEXAS LILLIPUT Toxolasma texasense Female - Fish Creek, Texas - R.G. Howells

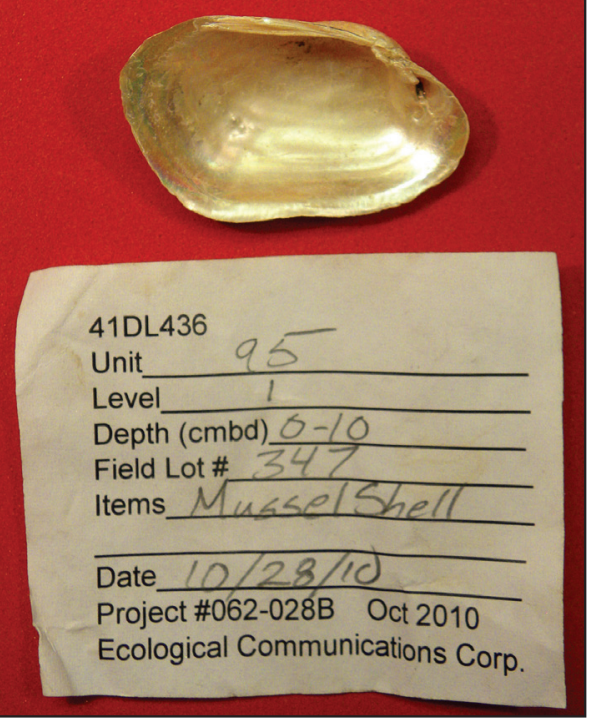

Figure 7-10. Texas lilliput (Toxolasma texasense) female. Most lilliput sp. specimens from this site could not be positively identified to species due to damage to the posterior margin of the shell necessary to determine species and sex. lilliput, but other specimens could not be positively identified. Lilliputs were second in abundance with 56 specimens (54 that could not be identified to species and two Texas lilliput) in the Fish Creek mussel shell remains recovered. They occurred in 14 lots (including Texas lilliput in two lots) and at depths from 0 to 98.0 cmbs (Tables 3-4).

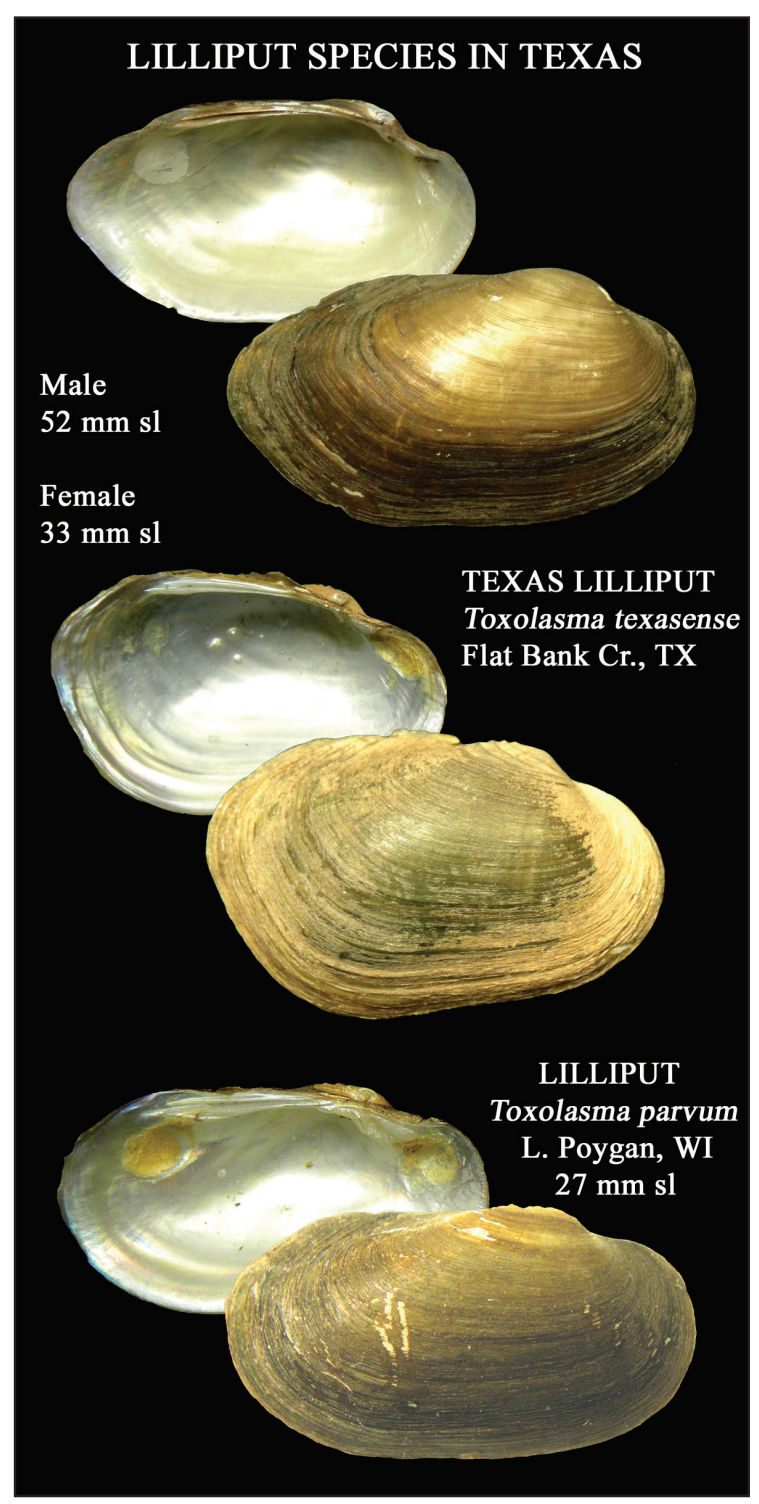

Figure 7-11. Texas lilliput (Toxolasma texasense) male (above top) and female (above center) from southeastern Texas and lilliput (T. parvum) from Wisconsin (above bottom). Both species occur nearly statewide in Texas. Texas lilliput is sexually dimorphic, but lilliput is reported by some to be a hermaphrodite with little apparent sexual dimorphism. 
Pondhorn (Uniomerus tetralasmus and Uniomerus spp.) (Figures 7-12 and 7-13)

Pondhorn and tapered pondhorn ( $U$. declivis) occur from the Rio Grande to the Red River and can be locally abundant in soft-bottom, slow- to no-flow environments. They have a particularly noteworthy tolerance of desiccation, so may even occur in ponds and streams that periodically experience dewatering. Neither species is strongly sexually dimorphic. Pondhorn is subrectangular in shape, with a bluntly truncate posterior margin, a subglossy epidermis, and lateral teeth placed almost horizontally. Tapered pondhorn is far more tapered posteriorly, has a flaky epidermis, and lateral teeth that are angled downward. Unfortunately, most specimens of both species in Texas are morphologically intermediate between the two taxa and positive identification is often not possible. Pondhorn umbo sculpture is a series of moderately course single-looped ridges that are evenly curved along their length, including over the posterior ridge. The beak sculpture of tapered pondhorn is similar (Parmalee and Bogan 1998). Specimens from the Fish Creek Slough site were either pondhorn or too little shell material remained to allow positive distinction between species. Six specimens of pondhorn and four only identified to genus were found in the Fish Creek mussel shell remains recovered. They occurred in five lots and at depths from 0 to $10 \mathrm{cmbs}$ (and the depth of lot 19) (Tables 3 and 4).

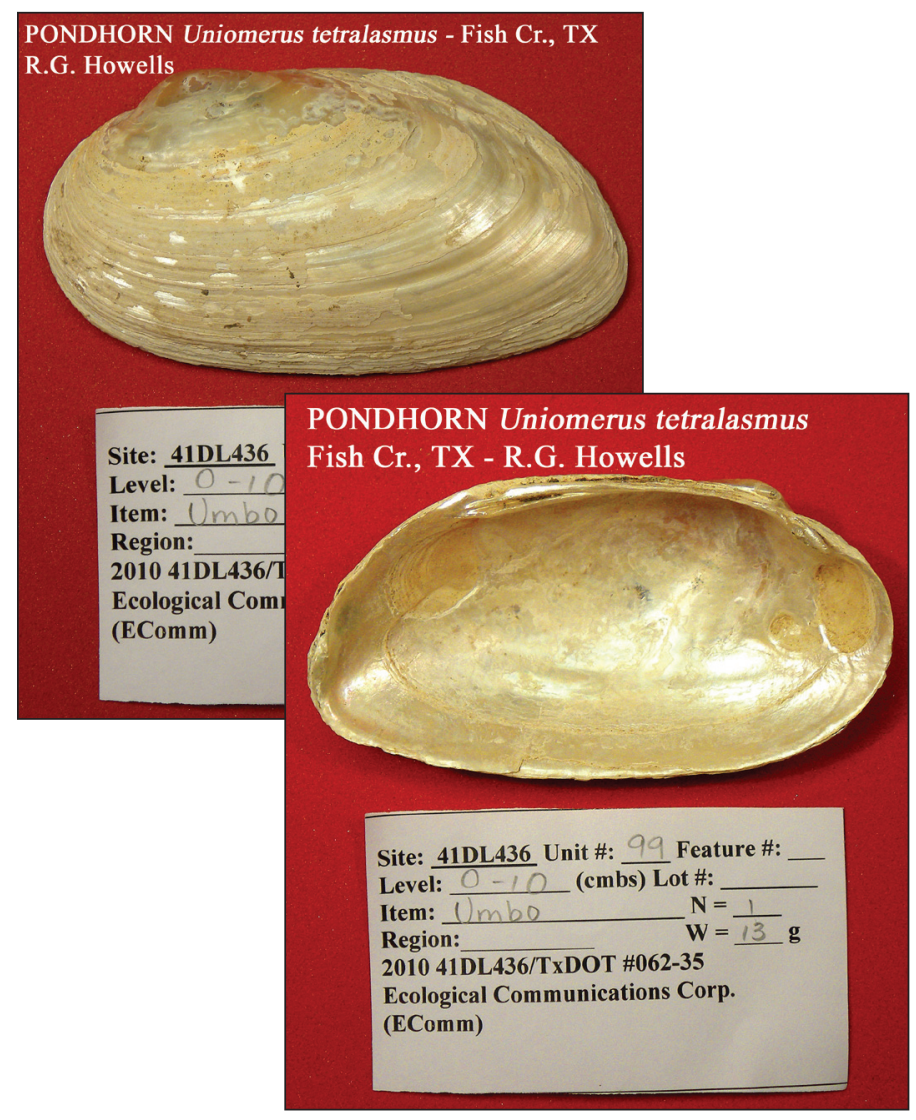

Figure 7-12. Pondhorn (Uniomerus tetralasmus) .

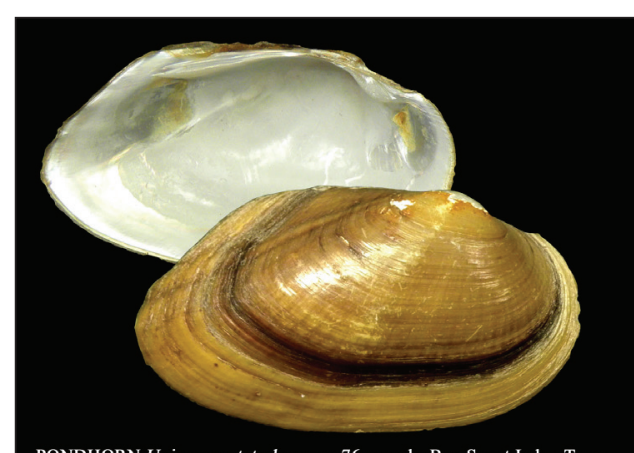

PONDHORN Uniomerus tetralasmus - $76 \mathrm{~mm}$ sl - Boy Scout Lake, Texas

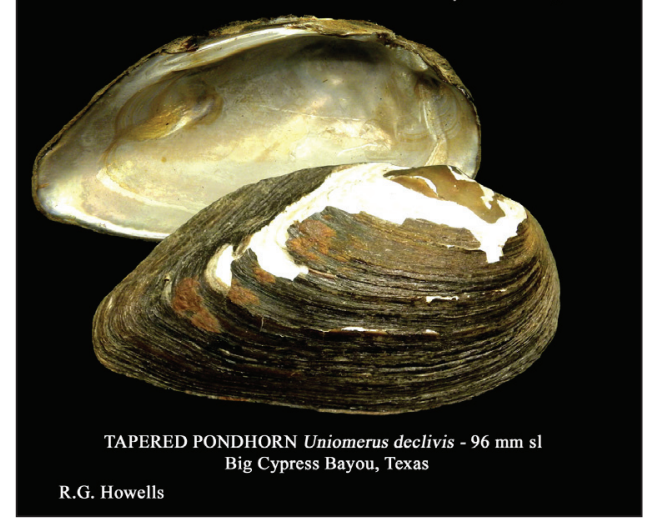

Figure 7-13. Pondhorn (Uniomerus tetralasmus) (above top) from Central Texas and tapered pondhorn (U. declivis) (above bottom) from north-eastern Texas. 
Giant floater (Pyganodon grandis) (Figures 7-14 and 7-15)

Giant floater ranges from the Rio Grande north to the Red and Canadian rivers. It is often common to abundant at numerous locations in Texas, but has not been confirmed in the Rio Grande in several decades. It is often associated with soft bottoms of ponds, lakes, reservoirs, rivers, and streams. Although it attains rather large sizes, it can be abundant in even small pond environments. Giant floater has course, double-looped umbo sculpture. Its shell lacks hinge teeth and is so thin and brittle that it often cracks upon drying. Only a single umbo and part of the hinge was found in the Fish Creek mussel shell remains recovered. It occurred in one lot and at $98.53 \mathrm{cmbs}$ (Tables 7-2 and 7-3). Murray (1982) noted the lack of anodontid remains at another archaeological site he studied and suggested this absence may have reflected the frail nature of their shells that do not survive long after death, unpleasant taste that caused Native Americans to avoid them, or their possible absence from his study area in earlier times. Given that anodontid shells are so frail and disintegrate so easily and frequently, failure to appear in paleonological or archaeological studies is not unexpected. Finding remains even in areas of known abundance is more exceptional than the norm.
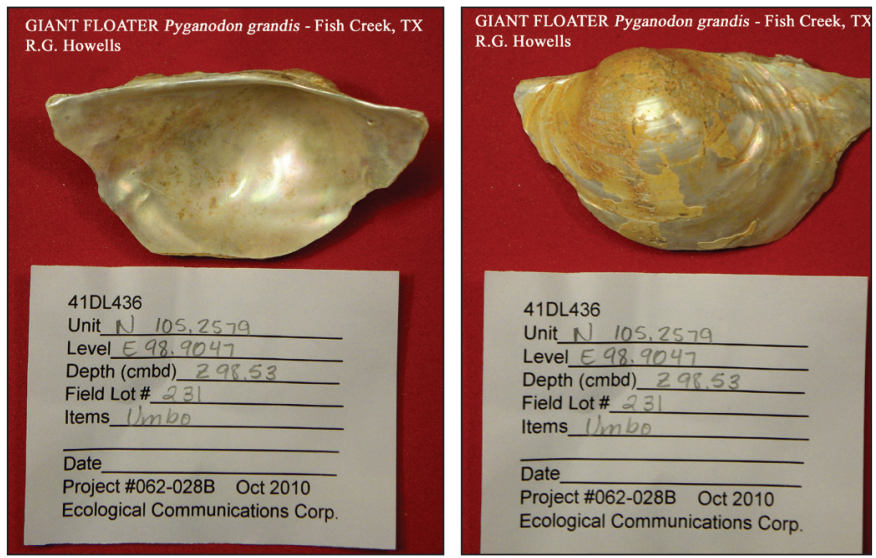

Figure 7-14. Giant floater (Pyganodon grandis). Here the umbo (beak) and part of the hinge is present, but this species has no hinge teeth. Giant floater shells are thin, brittle, and often crack upon drying.

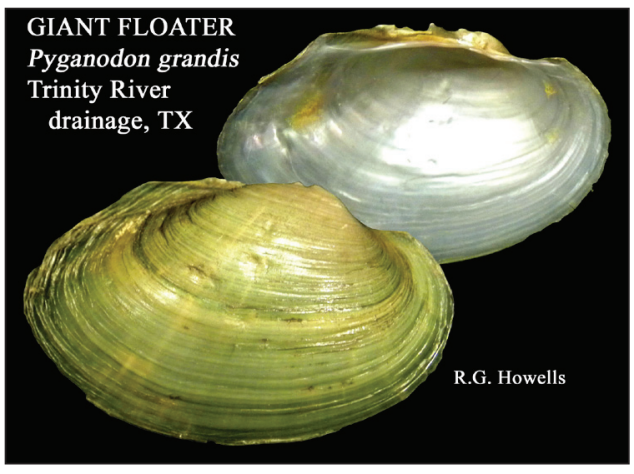

Figure 7-15. Giant floater (Pyganodon grandis) from the Trinity River drainage, Texas. Some specimens have higher and more inflated umbos than in this individual.

\section{Bankclimber (Plectomerus dombeyanus) (Figures 7-16 and 7-17)}

Bankclimber occurs in eastern Texas waters from the San Jacinto River north and east. It occurs in lakes, reservoirs, rivers, and larger streams, but is not a pond or backwater unionid. However, it is an active species and associations with shoreline and bank areas sometimes results in being washed into stream-side oxbows during high-water events. Bankclimber is often relatively abundant at some locations in Texas. Unique morphology, moderately-large size, and sculpturing make this an easily recognized species not often confused with others. Only a single valve was identified in the Fish Creek mussel shell remains recovered. It occurred in one lot and at $97.311 \mathrm{cmbs}$ (Tables 7-3 and 7-4). Bankclimber is not typically associated with pond species like lilliputs, pondhorns, and pondmussel in soft-bottom and no-flow situations. 


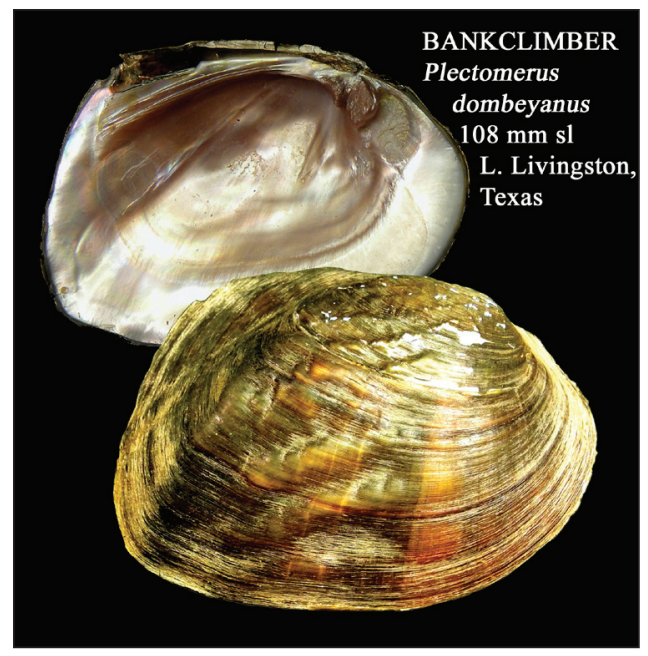

Figure 7-16. Bankclimber (Plectomerus dombeyanus) from Lake Livingston, Texas. Nacre is usually purple in living and recently dead specimens.
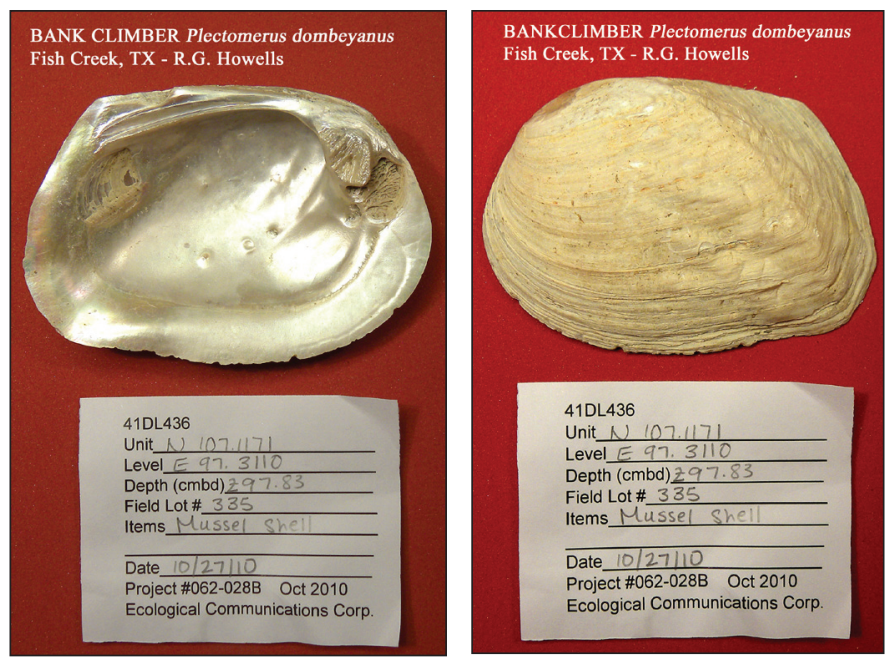

Figure 7-17. Bankclimber (Plectomerus dombeyanus) .

\section{Pistolgrip (Quadrula verrucosa)}

(Figures. 7-18 and 7-19)

In Texas, Pistolgrip ranges from the Guadalupe-San Antonio system north and east. It is strongly sexually dimorphic, especially in populations in eastern Texas (less so in Central Texas), with females being more elongate than males rather than more inflated as in many other unionids. Although the species can be common at some sites, many populations west of the Trinity River appear to have declined dramatically in many waters. Pistolgrip has a unique shape and is heavily sculptured, so identification is almost never problematic. It may occur in lakes, reservoirs, and rivers, but is not a pond or backwater species associated with softer bottoms and no-flow situations. Only two specimens were found among the Fish Creek mussel shell remains recovered. One was the hinge plate from a small juvenile and the other a disk fragment from a larger individual. It occurred in only one lot and at $98.13 \mathrm{cmbs}$ (Tables 7-3 and 7-4). Pistolgrip is not generally associated with pond species like lilliputs, pondhorns, and pondmussel.

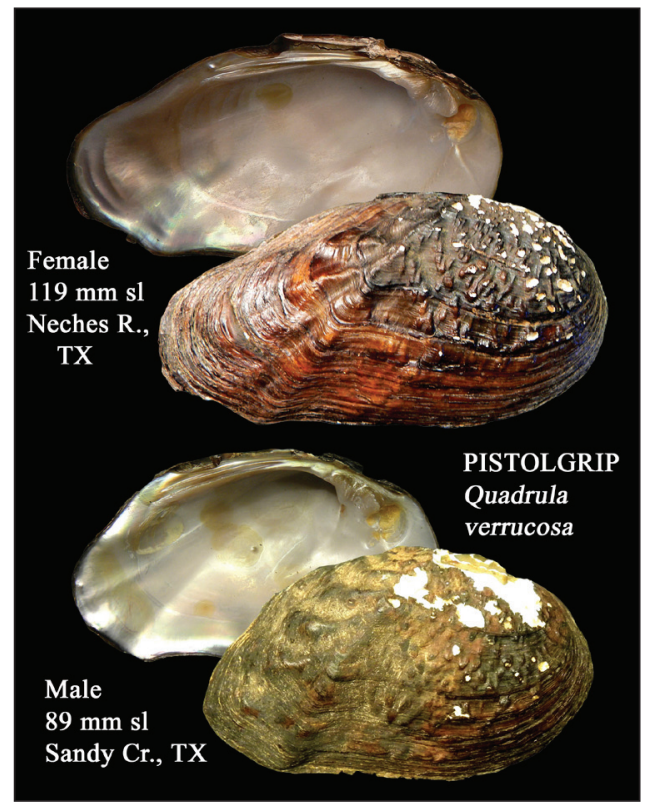

Figure 7-18. Pistolgrip (Quadrula verrucosa) male (above bottom) and female (above top) from eastern Texas. 


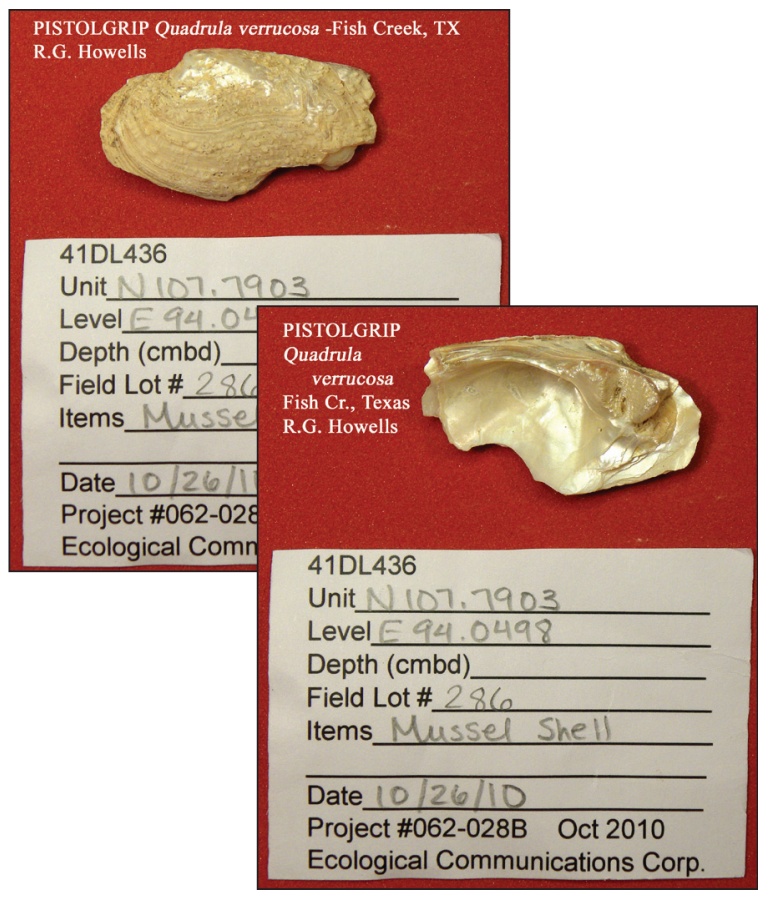

Figure 7-19. Pistolgrip (Quadrula verrucosa). Unique external sculpture is characteristic of this species.

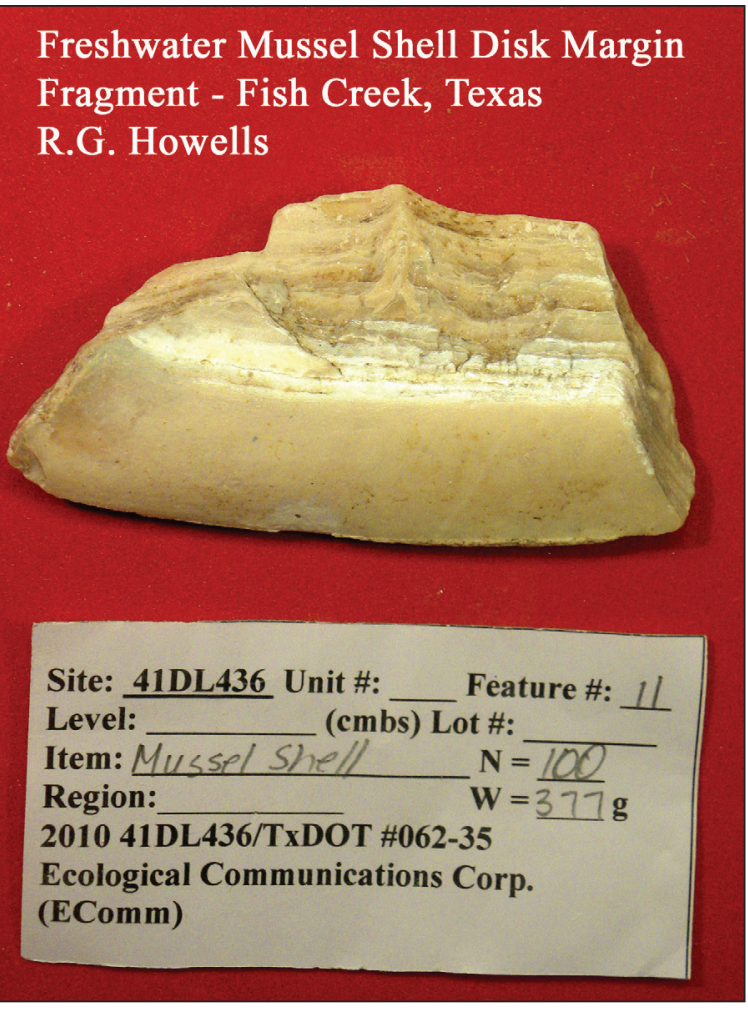

Figure 7-20. This unidentified fragment, may have come from a large washboard

(Megalonaias nervosa) specimen, but diagnostic features are lacking.

\section{Unidentifiable fragments}

A total of 1,132 unidentifiable fragments were counted when these collections were processed. They were taken in 46 lots and at depths from 0 to $200 \mathrm{cmbs}$ (Tables 2 and 3). Most fragments were unidentifiable sections of shell disks or worn hinge plate portions lacking diagnostic features. In addition to giant floater, some fragments may have belonged to fragile papershell (Leptodea fragilis) that is common in many areas in Texas. It too tolerates softer and unstable bottoms and may have occurred in the Fish Creek area. However, like giant floater, its shells and valves often crack upon drying, so they preserve very poorly. Positive identification was not possible.

One particularly large fragment (Figure 7-20) from the ventral margin of a large unionid shell likely came from washboard (Megalonaias nervosa) that is also known from the upper Trinity River drainage. Washboard is typically a "big water" unionid of larger rivers, streams, lakes, and impoundments; however, it can occasionally occur in some smaller streams. It has limited tolerance for soft silt or shifting sand bottoms and prefers firm mud, sand, and gravel. Because this species produces a very large, solid shell (to nearly 12 inches), use as a scoop or plate could easily explain collection elsewhere and relocation to the Fish Creek Slough site by humans.

\section{Habitat Associations of Fish Creek Slough Site Mussels}

Earlier studies described substrate materials at the Fish Creek Slough site as clay, mud, and loam (Feit and Campbell 2005) and sandy-loam and silty-clay (Abbott 2010). Nearly all the mussel species recovered in the present study included unionid species (pondhorns, lilliputs, pondmussel, and giant 
floater) that are typical of ponds, backwaters, and slow-flow streams with those bottom types. Some, like pondhorns, are even tolerant of waters that periodically become dry. The most abundant unionid found, Louisiana fatmucket, can occur in substantial numbers in smaller, but permanent, streams. The presence of Louisiana fatmucket in large numbers suggests a slow-flow, but permanent, stream environment (and not a small pond) and the occurrence of typical "pond" species confirms a limited flow-softer bottom habitat. Other species like yellow sandshell and bankclimber tolerate a moderately wide range of habitat types, but are not typical

of ponds or temporary waters. However, both are active species that sometimes venture into areas adjacent to larger water bodies with other substrates. The pistolgrip specimens found are likewise not associated with ponds or backwater areas. Their presence suggests one or more areas of mud-sand-gravel substrates in a larger water body or pooled area somewhere near the Fish Creek Slough site from which this species may have been introduced.

\section{Comparisons to Recent Unionid Assemblages}

Preliminary radiocarbon dating places the Fish Creek Slough site material at less than about 1000 BP (David Nickels, AmaTerra; pers. comm.), yet the species found are representative of those that still occur in the area. All of the species found in the present study still occur in the upper Trinity River drainage with the exception of bankclimber that appears not to have been recorded upriver of Freestone County. As early as 1931, Strecker (1931) noted mussel losses associated with pollution in the Dallas-Fort Worth area and some unionid species have not been confirmed in this area in many decades. However, construction of reservoirs (there were no natural lakes in the area) has created habitat that has advantaged some unionid species, particularly those tolerant of impoundment or pond conditions.

Among the unionid species typical of pond-oxbow-backwater environments (including lilliputs, pondhorns, pondmussel, and giant floater), only one additional species from the region was not found in the Fish Creek shell remains. Paper pondshell (Utterbackia imbecillis) occurs from the Rio Grande to the Red and Canadian rivers. It is often locally very abundant. However, like giant floater, paper pondshell has a very thin, frail shell that readily cracks upon drying. Therefore, failure to find it in the present study was not unexpected.

\section{Ecological and Human Associations}

With only one definite exception, specimens from the Fish Creek Slough site had no positive indications of human influence. Signs of heating or burning, shape modification, or other indications of human influence were generally lacking. Damage to valves and fragments recovered could easily have been attributed to natural processes. Two additional valve fragments (Figure 7-21) each had a series of parallel lines etched into the mid-disk, one of which also showed point puncture that healed internally long before death. Because of shell disk damage that had healed, it suggests perhaps the parallel marks found could be attributed to scratches from the canine tooth of a predator (e.g., raccoon, Procyon lotor, or other carnivore) that unsuccessfully tried, but failed, to open the specimen. In both cases, the mussel survived the attack, healed the shell damage, and continued to grow. A single yellow sandshell (Figure 7-22) recovered from the Fish Creek Slough site had been etched with a series of parallel lines 
that were a definite indication of deliberate human manipulation. This specimen was found in Lot 391 at Level 1 (0-10 cmbs), with a radio carbon data of 360 \pm 25 BP (David Nickels, AmaTerra; pers. comm.).

\section{$\underline{\text { SUMMARY }}$}

At least eight and possibly as many as 11 unionid taxa, as well as unidentifiable fragments, were found among shell remains recovered at the Fish Creek Slough site (41DL436) in Dallas County, Texas, in 2010. With few exceptions, species present indicated a slow-flow stream environment with a soft bottom substrate and are typical of those that currently occur in the region. Only one specimen demonstrated definite human manipulation.

\section{ACKNOWLEDGMENTS}

Technical information and manuscript review were provided by David Nickels (AmaTerra). Photographs of recent freshwater mussels presented were obtained from BioStudies records and used herein with permission. These images should not be used for other purposes without written permission of BioStudies.

LOUISIANA FATMUCKET Lampsilis hydiana Fish Creek, Dallas County, Texas - R.G. Howells With Predator Damage Before Death

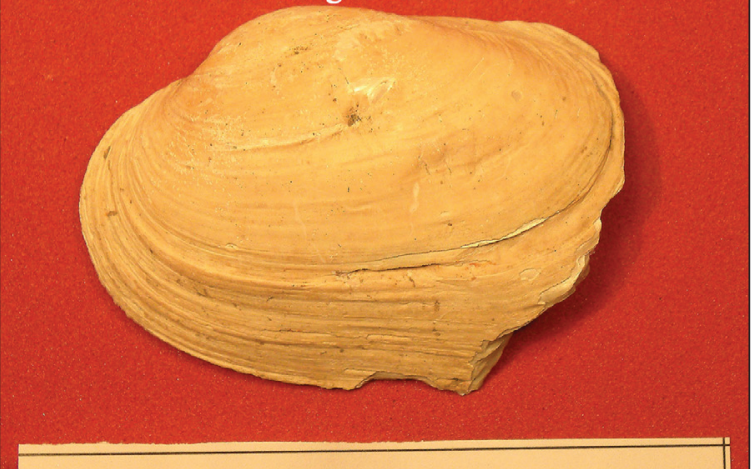

Site: 41 DL436 Unit \#: 10 Z Feature \#: Level: Item: Region: 2010 41DL436/TxDOT \#062-35

Ecological Communications Corp. (EComm)

Figure 7-21. This fragment was attacked by a predator during its life, but survived and continued to grow.

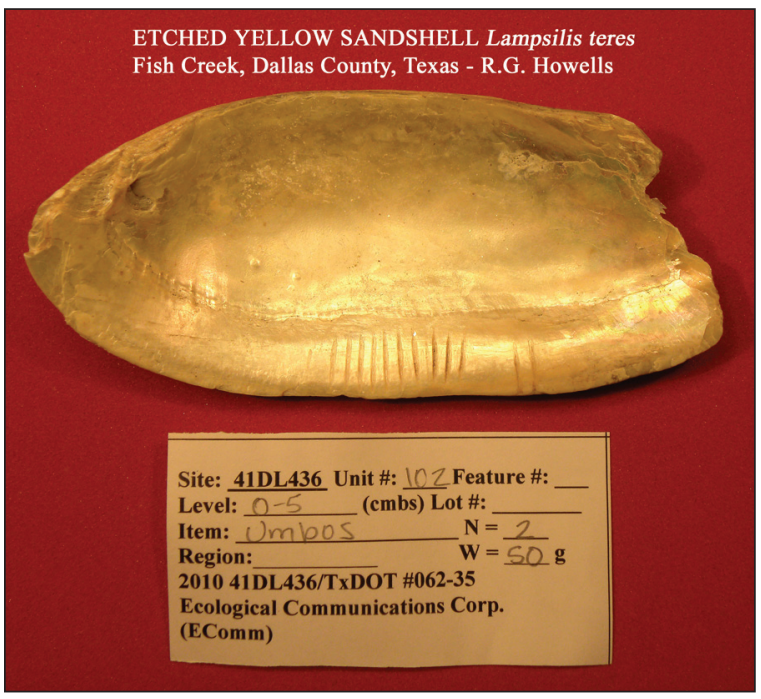

Figure 7-22. This specimen (right) shows clear indication of human manipulation of the valve indicated by a series of parallel grooves etched into the nacre between the pallial line and ventral margin of the valve. It was the only specimen examined during the present study demonstrating anthropogenic modification. 


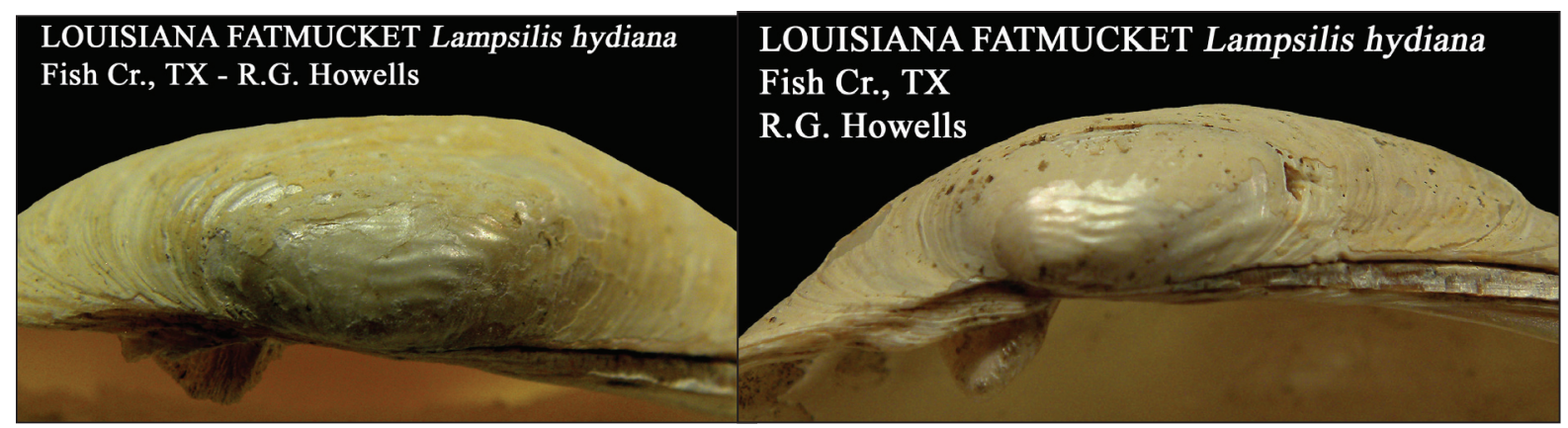

Figure 7-23. Louisiana fatmucket (Lampsilis hydiana) umbos showing typical double-looped or V-shaped beak sculpture.
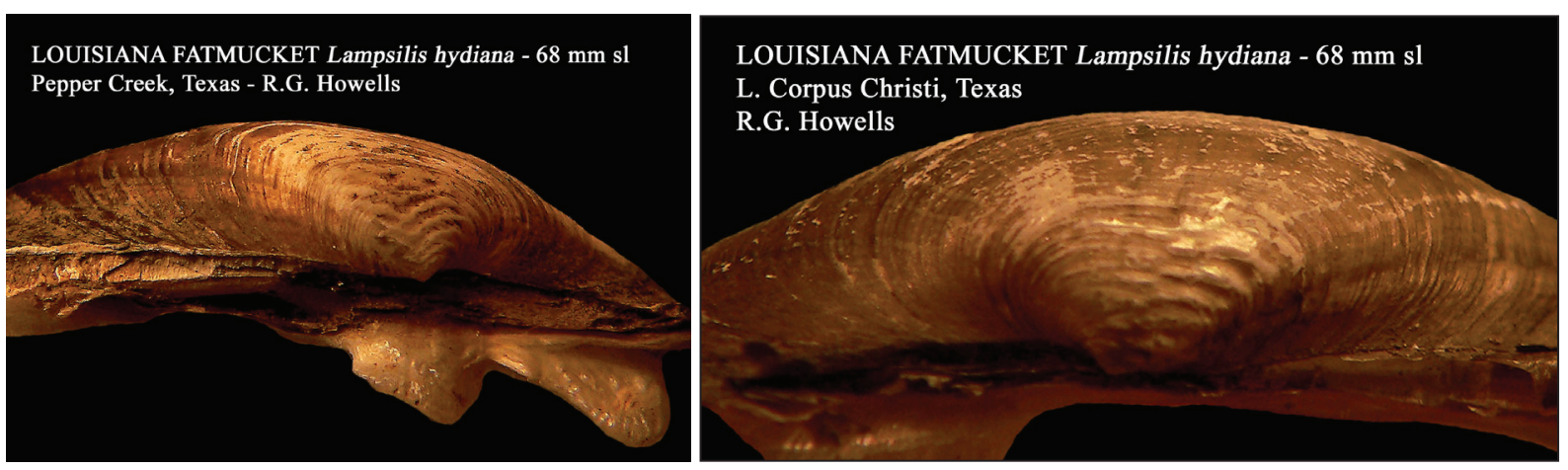

Figure 7-24. Louisiana fatmucket (Lampsilis hydiana) have double-looped or V-shaped beak sculpture (above left), but the tip of the beak may be poorly formed resulting in a sculpture pattern looking more like off-set near-parallel lines (above right).

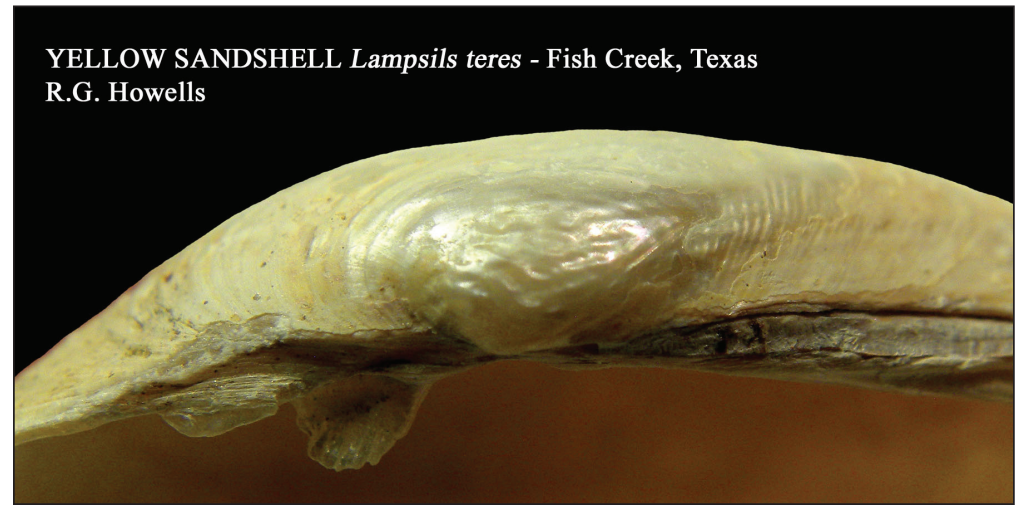

Figure 7-25. Yellow sandshell (Lampsilis teres) umbo showing typical double-looped or V-shaped beak sculpture. 


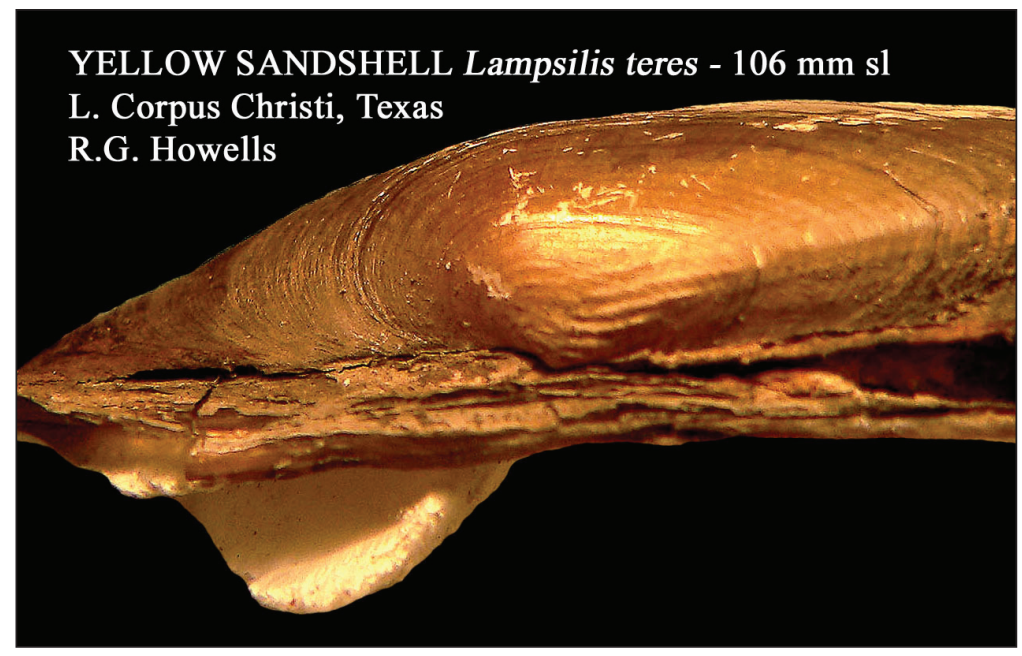

Figure 7-26. Yellow sandshell (Lampsilis teres) umbo with double-looped or V-shaped beak sculpture that is finer than that of Louisiana fatmucket (L. hydiana) but does not extend far into the posterior field.

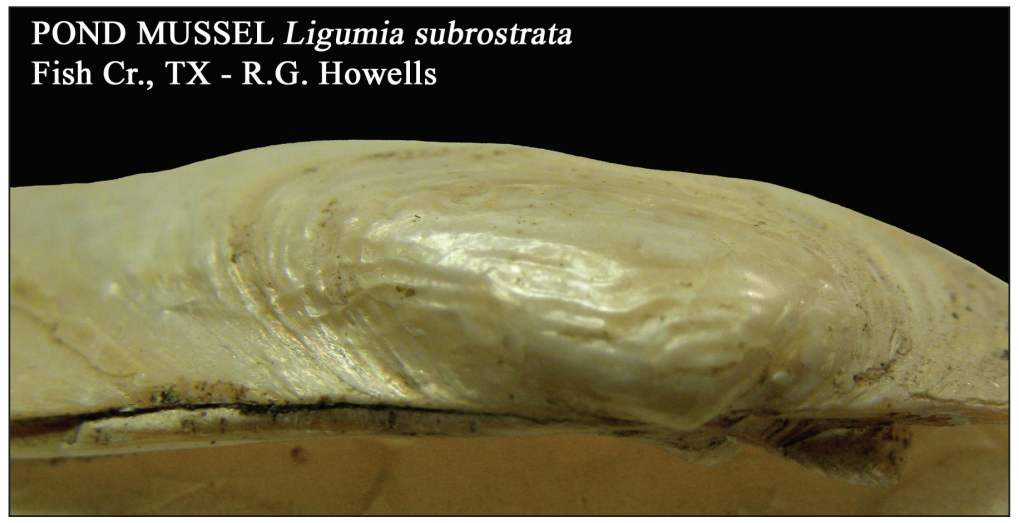

\section{Figure 7-27. Pondmussel (Ligumia subrostrata) umbo showing typical double-looped or V-shaped beak sculpture.}

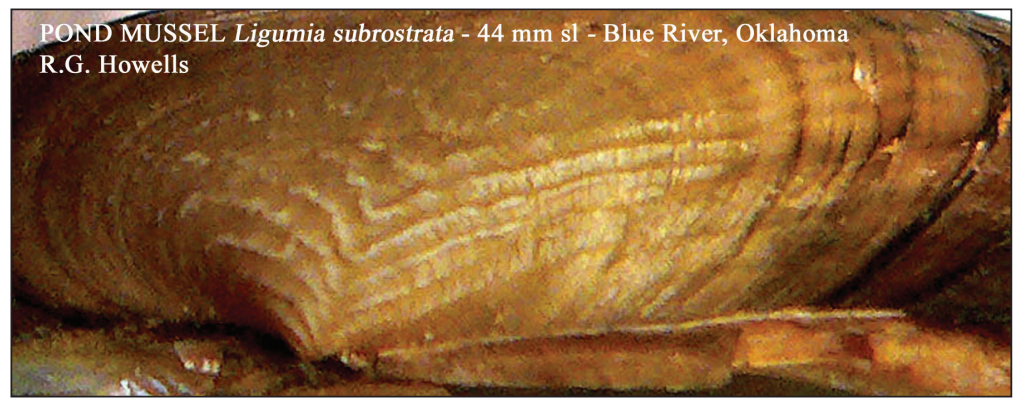

Figure 7-28. Pondmussel (Ligumia subrostrata) umbo that is strongly pointed and with beak sculpture that has a fine double-looped or V-shaped pattern that extends well into the posterior field along the posterior ridge

\section{GIANT FLOATER Pyganodon grandis - Fish Creek, Texas R.G. Howells}

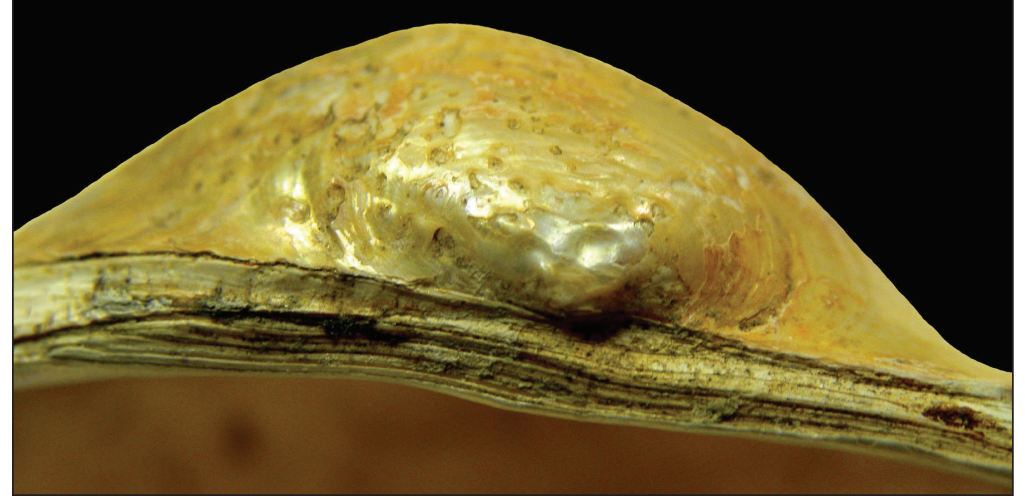

Figure 7-29. Giant floater (Pyganodon grandis) umbo showing typical double-looped pattern. 

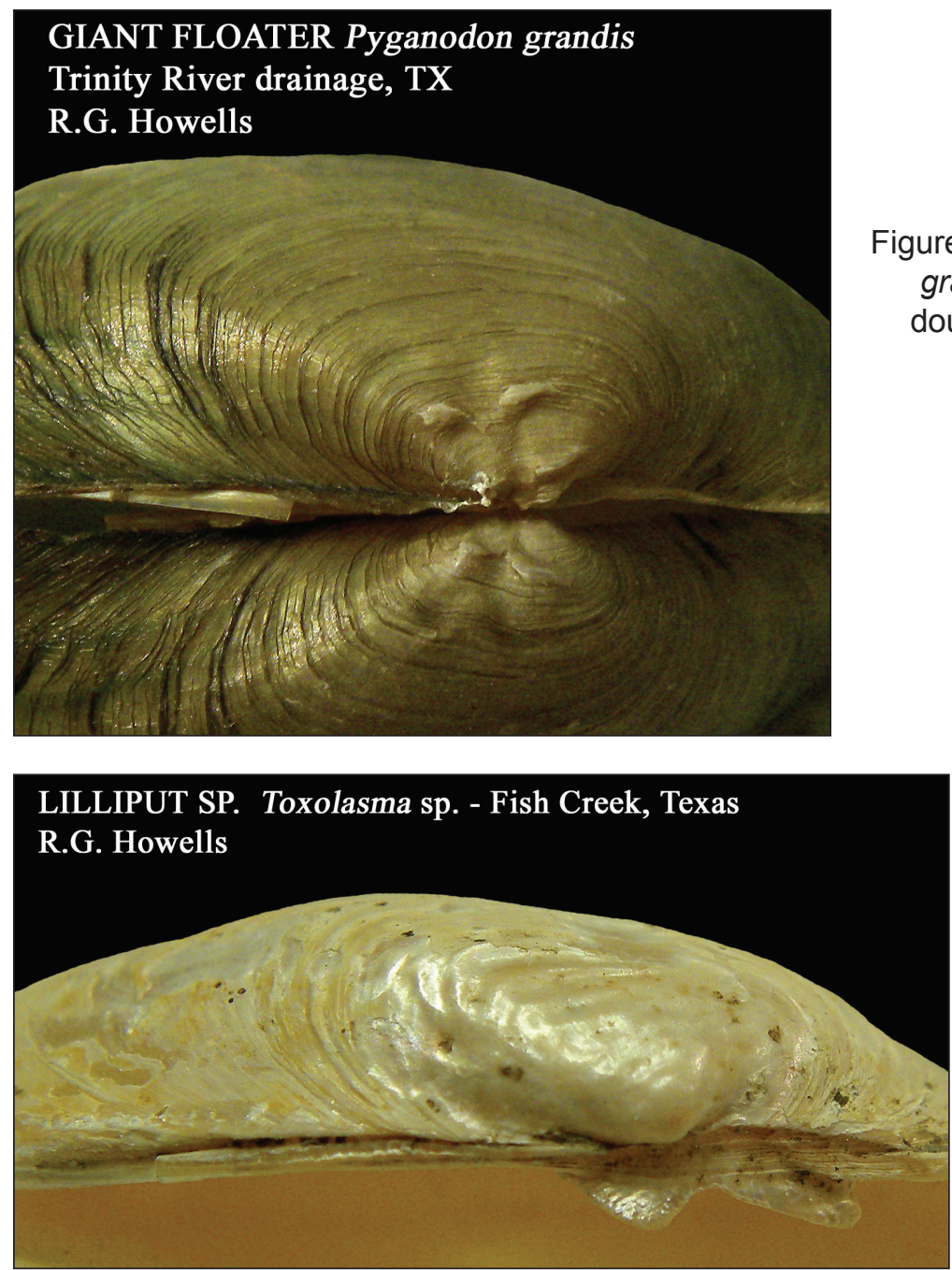

Figure 7-30. Giant floater (Pyganodon grandis) umbos with the typical double-looped sculpture pattern.
Figure 7-31. Lilliput sp. (Toxolasma sp.) umbo. Although the singlelooped sculpture pattern is evident, species cannot be determined.
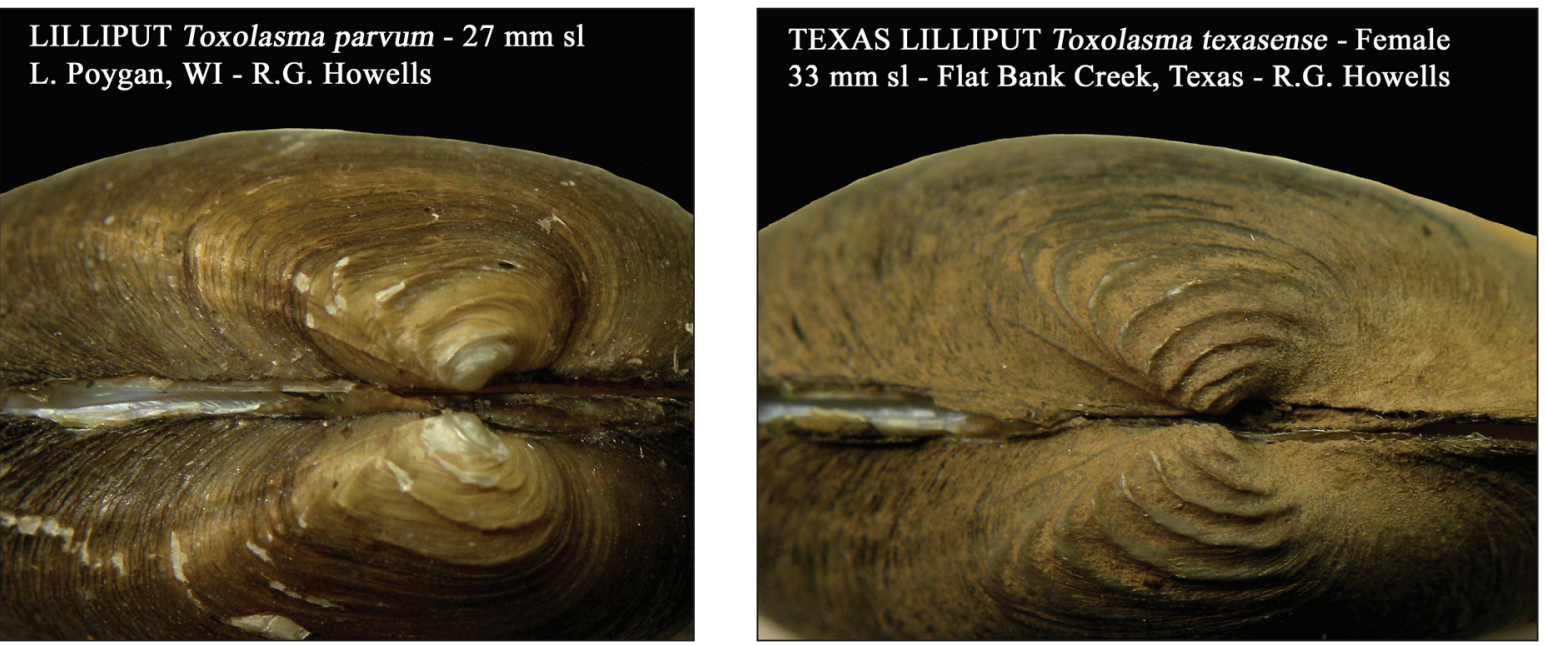

Figure 7-32. Lilliput (Toxolasma parvum) (above left) and Texas lilliput (T. texasense) (above right) umbos showing more numerous single-looped ridges in Texas lilliput, which are angled over the posterior ridge area in both species. 


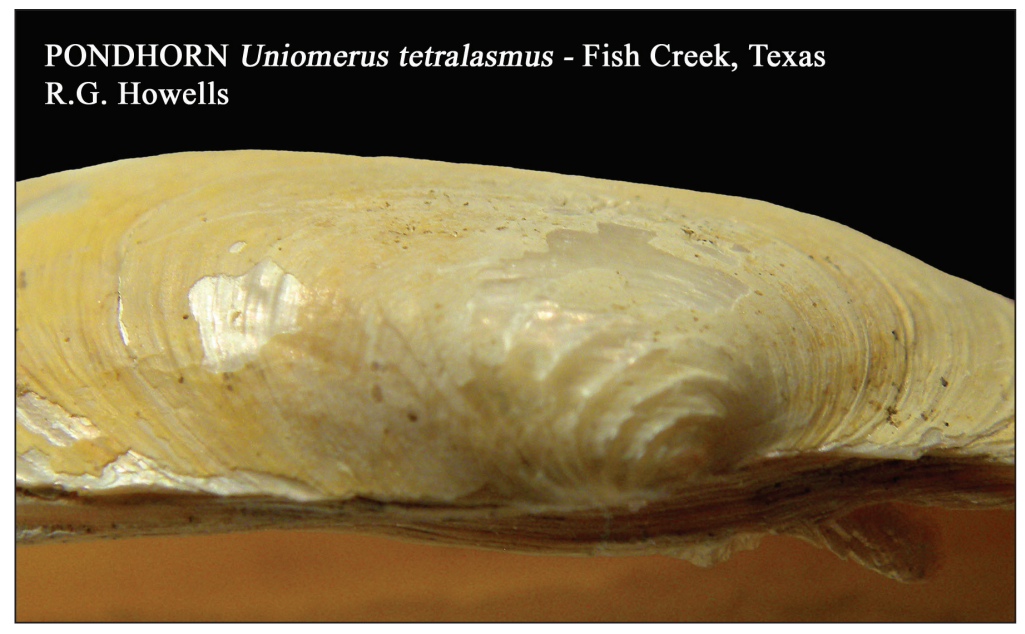

Figure 7-33. Pondhorn (Uniomerus tetralasmus) umbo showing a singlelooped sculpture pattern typical of the species.

\section{PONDHORN Uniomerus tetralasmus} $53 \mathrm{~mm}$ sl - Garrett Lake, Texas

\section{R.G. Howells}

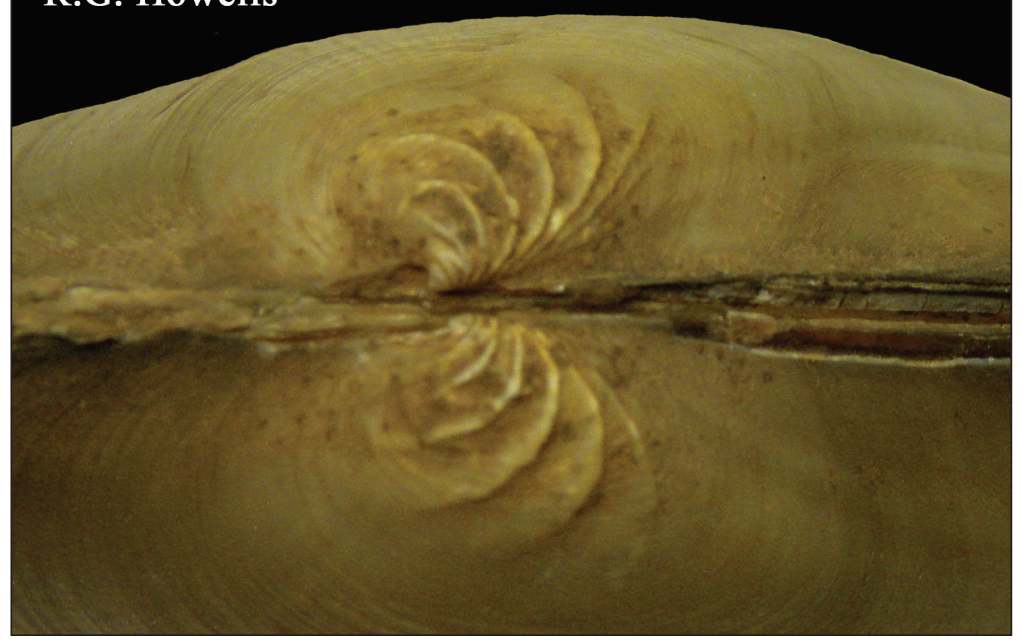

Figure 7-34. Pondhorn (Uniomerus tetralasmus) umbo with a single-looped sculpture pattern that is evenly curved and does not angle back more sharply over the posterior ridges. 


\title{
Chapter 8
}

\section{Analysis and Evaluation of Isotope Data from Mussel Shells}

\author{
David O. Brown
}

\section{INTRODUCTION}

Freshwater mussels recovered from the Fish Creek Slough site were analyzed for oxygen and carbon isotopes to examine their potential for providing proxy information concerning the paleoclimates of the area. Twenty specimens, all Lampsilis hydiana from four different contexts at the site, were selected for analysis. While the analysis does offer information on local paleoclimates during the occupation of the site, the results also indicate relationships between the sampled contexts, a previously little used but potentially powerful aspect of shell isotope analysis.

Since Urey's (1947) pioneering studies it has been known that the ratio of ${ }^{18} \mathrm{O} /{ }^{16} \mathrm{O}$ in shell carbonates offers a proxy for past ocean temperatures. In later studies, Keith et al. (1964), Stuiver (1968, 1970), Fritz and Poplawski (1974), Dettman and Lohman (1993) and a host of others have shown that freshwater molluscs can also provide data on key environmental parameters in non-marine settings. In the Texas area, Brown (1994a, 1994b, 1998, 1999, 2004, 2007, 2010 and Brown et al. 2007) has conducted a series of mussel isotope studies which indicate that freshwater clams from archaeological contexts can provide valuable ancillary data for cultural resource site analysis.

The Fish Creek Slough site (41DL436), whose cultural features include a long, partly discontinuous mussel shell lens in Stratum 1a, presents a unique challenge to the study of mussel isotope data since the mussels are largely present only near the top of the lowermost depositional stratum at the site and rare to absent in the overlying and underlying sediments. Although the relationship between oxygen isotope distribution, biogenic construction of shell carbonates, and water temperatures has been well established in marine environments, and is widely used in paleontology to study ancient oceans, the adaptation of the technique to freshwater invertebrates is still a developing field. Past studies by this author noted above have typically focused on relative differences between vertically separated components since even the approximate reconstruction of paleotemperatures can require data that are not available in many areas, such as a long series of local water temperature readings matched by isotopic analysis of water samples over time. Problems such as variation in isotopic fractionation between mussel species, conversion of calcite to aragonite in some species, and changes in patterns or timing of shell construction during the lifetime of an individual can complicate even the relative analysis of shell isotope composition in archaeological sites. One of the more productive approaches applied to the process in recent decades, micro-sampling, can generate hundreds of samples, adding to the cost and complexities of interpretation, but presents great 
opportunities in future analyses, especially when applied to seasonal shifts in climates. Instead, this analysis follows past procedures designed to elicit broader patterns of climate change, sampling across the lifespan of several presumably contemporary individuals, and comparing those aggregate values to other time periods.

\section{$\underline{\text { SAMPLING }}$}

Working with Jim Abbott of TxDOT and Dave Nickels of AmaTerra, a plan was designed to test the viability of mussel isotope studies as an adjunct analytical method at the site. Begun as an exploratory process to assess the utility of shell carbonate isotopes under the very limited stratigraphic sequence at the site, two samples of five individuals each from two widely separated units (Units 93 [Stratum 1a] and 103/104 [Stratum 1b]) were submitted as a test (Figure 8-1). Analysis of these two groups indicated strong differences between the environments of deposition of mussels from the groups, something not expected in what had initially been suspected as a single, roughly contemporaneous midden of food refuse remains from a single occupation or several, closely timed occupations in the same area. As these data were becoming available, it was discovered that the Unit 103/104 sample may have included shell from Stratum 1a or 2 where it draped over a scour shear face along the drainage at the north end of the site's master profile.

In response to this, TxDOT authorized a second group of ten samples, also chosen from two different contexts to verify the initial findings. Samples were drawn from Unit 95 (Stratum 1a), a meter distant from Unit 93 (Stratum 1a), with both presumably sampling the same shell lens. Additionally, at the request of Nickels, a sample of five shells from Feature 11 (Stratum 1a), a collection of mussel remains made after machine trenching in the area where Unit 95 (Stratum 1a) would later be excavated.

With individuals of Amblema plicata, the primary mussel species analyzed in several previous studies, absent at the site (this large clam typically prefers larger streams), L. hydiana was chosen as an alternate proxy for paleoclimatic data. Though not ideal for analysis, L. hydiana, a relatively small, thin-walled species (especially in smaller streams), nonetheless proved suitable. All twenty samples were right valves collected from the general excavation of these units (species identification was based on the work of Robert Howells). Eleven of the specimens were essentially complete, while the remaining nine showed some breakage that prevented full measurements. Samples varied in size and weight; the smallest complete specimen was about $50 \mathrm{~mm}$ in length, $31 \mathrm{~mm}$ in height, and weighed about $6 \mathrm{gm}$. The largest of the 20 specimens was longer than $85 \mathrm{~mm}$, about $48 \mathrm{~mm}$ in height, and weighed just over $28 \mathrm{gm}$.

The first group of ten shells was delivered to Coastal Science Laboratories in Austin for analysis during the fall of 2011. Kenneth Winters (personal communication, 2003) of Coastal Science Labs provided the following description of their analytical methods.

Shell samples were broken and ground with a glass mortar and pestle. Pieces of each large sample were selected for grinding which approximated the composition of the whole shell. The remaining pieces were saved for other studies. Sample material 


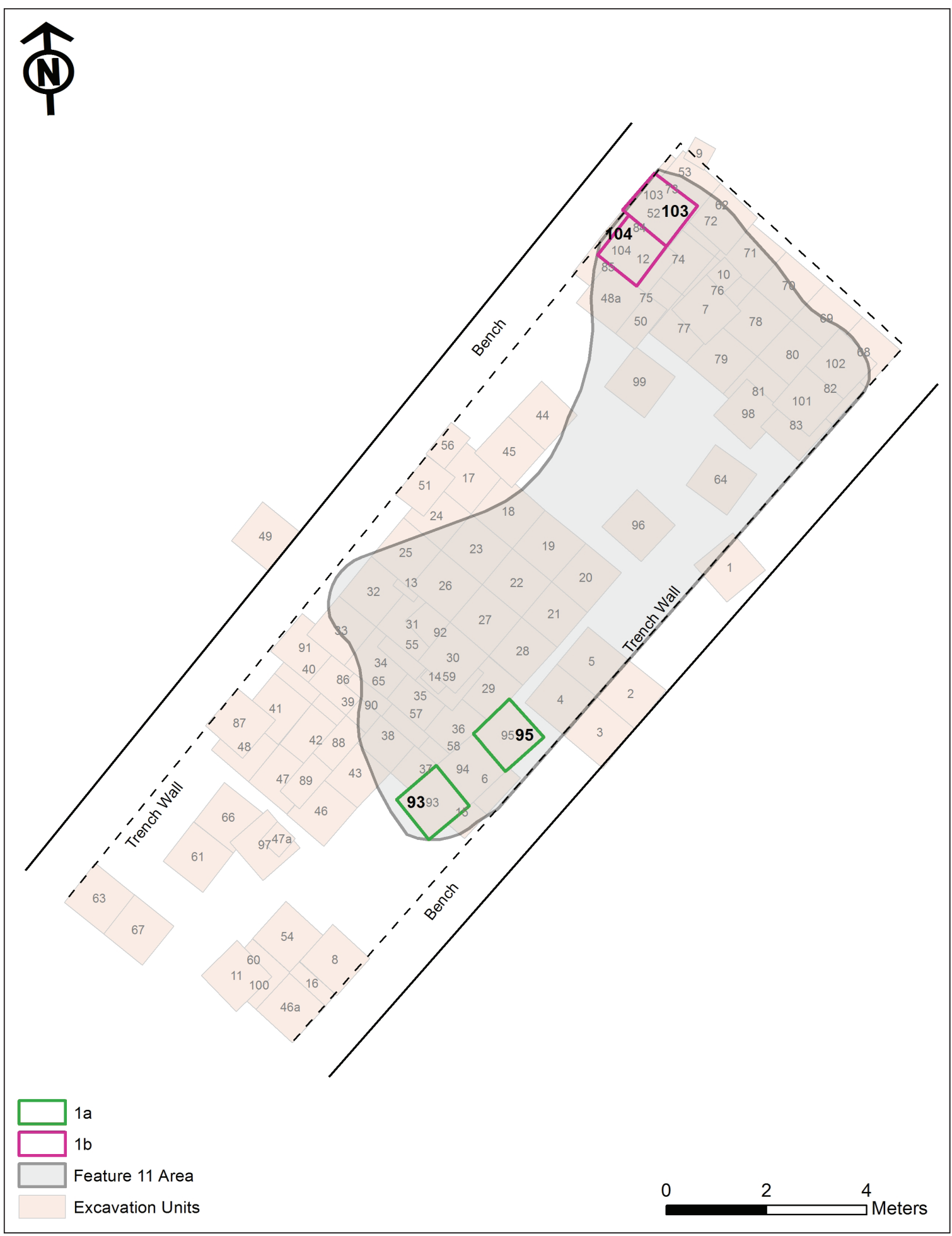

Figure 8-1. Locations of Units 93, 95, 103, 104 and Feature 11. 
which passed a 140 mesh sieve was used for analysis. Samples were acidified with 100 percent phosphoric acid at $30^{\circ} \pm 1$ in a water bath. (McCrea 1950). Appropriate laboratory working standards and NIST standards were acidified and analyzed along with each batch of samples analyzed. Stable isotope values of samples and standards were determined by analysis in a VG Micromass Series II Model 10 triple collector mass spectrometer. Data from each batch of samples was calculated by comparison with data obtained from standards analyzed with each batch.

Two of the ten original samples (Nos. 3 and 9) were run twice for both $\delta^{18} \mathrm{O}$ and $\delta^{13} \mathrm{C}$ to verify accuracy. Three of the four values were identical while the $\delta^{18} \mathrm{O}$ value for Sample No. 9 varied by $0.1 \%$. This level of accuracy is consistent with previous mussel isotope analyses conducted by Coastal Science Labs that rarely ever show analytical differences greater than $0.1 \%$.

Unfortunately, Coastal Science Laboratories closed its doors with the retirement of Kenneth Winters at the end of 2011. The second group of ten samples were submitted to Geochron Laboratories of Cambridge, Massachusetts, a highly respected isotope lab that had run samples for an earlier project in the North-central Texas area (Brown 1994a, 1994b). Two samples previously run by Coastal Science Laboratories were included for comparative purposes. These two samples (Nos. 3 and 9) presented some differences that suggest caution when comparing the results from the two labs. The Geochron values for Sample No. 3 were relatively close for $\delta^{18} \mathrm{O}$, where two runs yielded values of $-2.0 \%$ and $-2.1 \%$, only slightly more positive than the paired $-2.3 \%$ values from Coastal Science Laboratories for this sample. The retest of Sample No. 9 by Geochron, however, yielded a value of 1.0 in two separate analyses, .8\%o and $.9 \%$ greater than the Coastal Science Laboratories values. That difference between laboratory results is roughly equivalent to the total range of two of the sample groups (Units 93 and 95 have total $\delta^{18} \mathrm{O}$ ranges of $1 \%$ and $.7 \%$, respectively).

The often more highly divergent $\delta^{13} \mathrm{C}$ values were indeed somewhat more variable in the retests. The Geochron analysis of Sample No. 3 yielded values of $-6.8 \%$ and $-7.1 \%$, compared to the two identical values of $-5.8 \%$ from Coastal Science Laboratories. Geochron's two retests of Sample No. 9 both yielded $\delta^{13} \mathrm{C}$ values of $-6.6 \%$, notably greater than the Coastal Science Laboratories values of $-7.9 \%$ for both runs on the same sample.

The near equivalence of same sample runs within each of the labs suggests that any error is not in instrumentation or standards. Rather, sample preparation is the likely culprit. Replicability of the process, which involves using a cross-section of the shell to sample the animal's $\delta^{18} \mathrm{O}$ processing history, depends on standardized procedures. In this case, the samples were prepared at each laboratory following this author's instructions, but it is still likely that minor differences in sampling occurred, altering the mix of shell. What is encouraging, however, is that the other test sample was very close. Ultimately, the analysis of results detailed below suggests that whatever sampling error may be present, it does not significantly weaken the basic results though it hinders precise paleotemperature calculations. 


\section{Data Analysis}

Preliminary examination of the first two groups sampled, from Units 93 and 103-104 as presented in Table 8-1, indicated that the two groups represent different environments of shell growth. The mean of $\delta^{18} \mathrm{O}$ results for shell from Unit 93 is -1.98\% while Unit 103/104 yielded an $\delta^{18} \mathrm{O}$ mean of $-.84 \%$. A non-paired Student's T-test of these two means yielded a $p$ value of .0146 for equal variance and .0195 for unequal variance. The mean of $\delta^{13} \mathrm{C}$ results for shell from Unit 93 is $-6.26 \%$ while Unit $103 / 104$ yielded a $\delta^{13} \mathrm{C}$ mean of $-7.5 \%$. A non-paired Student's T-test of these two means yielded a p value of .0182 for equal variance and .0339 for unequal variance. All of these are significant at the $\mathrm{p}$ less than .05 level, supporting the concept that the two groups of samples are not drawn from the same population.

Table 8-1. Fish Creek Mussel Shell Sample and Analysis Data.

\begin{tabular}{|c|c|c|c|c|c|c|c|c|c|c|}
\hline Sample & Unit & Level & Stratum & Depth & Weight & Length & Height & Width & $\delta^{13} \mathrm{C}$ & $\delta^{18} \mathrm{O}$ \\
\hline 1 & 93 & 1 & $1 a$ & 97.85 & 9.33 & ${ }^{*} 68.73$ & 38.64 & 13.53 & -6.3 & -2.0 \\
\hline 2 & 93 & 1 & $1 a$ & 97.85 & 10.20 & 63.94 & 34.43 & 11.25 & -6.5 & -2.0 \\
\hline 3 & 93 & 1 & $1 a$ & 97.85 & 9.62 & *47.63 & *37.79 & 14.94 & -5.8 & -2.3 \\
\hline 4 & 93 & 1 & $1 a$ & 97.85 & 6.99 & 62.47 & 33.41 & 13.12 & -6.3 & -2.3 \\
\hline 5 & 93 & 1 & $1 a$ & 97.85 & 6.59 & 53.59 & 32.12 & 11.74 & -6.4 & -1.3 \\
\hline 6 & $103 / 104$ & 1 & $1 \mathrm{~b}$ & 97.90 & 27.61 & 78.42 & 47.08 & 19.01 & -6.8 & -1.5 \\
\hline 7 & $103 / 104$ & 1 & $1 \mathrm{~b}$ & 97.90 & 7.86 & 58.52 & 34.39 & 13.65 & -7 & -0.5 \\
\hline 8 & $103 / 104$ & 1 & $1 \mathrm{~b}$ & 97.90 & 28.04 & *84.67 & 47.62 & 18.31 & -6.9 & -1.6 \\
\hline 9 & $103 / 104$ & 1 & $1 b$ & 97.90 & 8.56 & 71.07 & 38.68 & 12.56 & -7.9 & 0.1 \\
\hline 10 & $103 / 104$ & 1 & $1 b$ & 97.90 & 10.11 & 61.19 & 37.40 & 12.99 & -8.9 & -0.7 \\
\hline 11 & Feat. 11 & - & $1 a$ & & 8.30 & *57.19 & 34.98 & 13.20 & -6.2 & -2.3 \\
\hline 12 & Feat. 11 & - & $1 a$ & & 9.41 & *56.34 & 36.00 & 13.57 & -6.6 & -1.7 \\
\hline 13 & Feat. 11 & - & $1 a$ & & 6.50 & *55.92 & 34.10 & *12.14 & -7.1 & -3.5 \\
\hline 14 & Feat. 11 & - & $1 a$ & & 6.67 & 50.90 & 31.07 & 11.35 & -4.5 & -2.4 \\
\hline 15 & Feat. 11 & - & $1 a$ & & 6.28 & *44.12 & 74.41 & 11.73 & -5.4 & -2.5 \\
\hline 16 & 95 & 1 & $1 a$ & & 6.12 & 58.23 & 32.33 & 10.86 & -7.1 & -2.6 \\
\hline 17 & 95 & 1 & $1 a$ & & 6.03 & 55.70 & 30.73 & 11.11 & -5.5 & -2.6 \\
\hline 18 & 95 & 1 & $1 \mathrm{a}$ & & 10.57 & ${ }^{*} 63.27$ & *36.79 & 12.29 & -7.2 & -2.9 \\
\hline 19 & 95 & 1 & $1 \mathrm{a}$ & & 8.54 & 60.54 & 35.80 & *12.93 & -6.0 & -2.4 \\
\hline 20 & 95 & 1 & $1 a$ & & 7.43 & 50.36 & 30.30 & 11.77 & -6.1 & -2.2 \\
\hline
\end{tabular}

Weight is in grams; dimensions are in millimeters; starred measurements represent minimum measurements of broken valves; italicized values represent samples that were subjected to additional testing.

The rather marked difference between the two samples begged a follow-up which, as previously noted, was approved by TxDOT, and the second set of samples was submitted. Despite the minor differences in values between laboratories, these latter two sample sets revealed new information about the relationships between the groups that adds not only to data about the site paleoclimate, but about the potential relationships between the unit-levels and strata samples at the site. This relationship is illustrated below in Table 8-2 which features T-test values from various combinations of the groupings. A very low number ( $p$ less than .05 ) suggests that the 
two analytical groups were not drawn from the same populations, while a very high number ( $\mathrm{p}$ greater than .95) would imply the opposite, that there is high likelihood that the two groups could have been drawn from the same population.

Note that most of the relationships are defined by T-test values below $\mathrm{p}=.05$ (Table $8-2$ ). Only the relationships between the Feature 11 shells and those from Units 93 and 95 lie above that, with the F.11-Unit 95 figure so high as to make it seem likely that these two were collected from strata representing the same time period and thus the very same paleoenvironment. At the other end of the spectrum, the shells from Units 103-104 suggest a very low probability (around five chances in a thousand) that they are drawn from the same population as the Feature 11 and Unit 95 samples. Somewhat intermediate are the relationships between Units 93 and 95 , and between Units 103-104 and Unit 93. Given that careful stratigraphic analysis has indicated that the remains from 103-104 may be slightly later than the main midden sampled by other units, this intermediate relationship may be important. In general, it indicates that Feature 11 was drawn from the sample population as the Unit 95 shells but that the relationship to Unit 93 is weaker, and that, in fact, Unit 93 may show some weak similarities to the stratigraphically later Units 103-104. Of course, this latter relationship is tenuous at best and NOT demonstrated by a significant relationship but simply slight trends in the overall numbers.

Our analytical methods have previously used $\delta^{13} \mathrm{C}$, which typically has a modest negative correlation with $\delta^{18} \mathrm{O}$, principally as a check on group relationships. In this case, the $\delta^{13} \mathrm{C}$ values support the relationships observed in $\delta^{18} \mathrm{O}$ values. Table $8-3$ below shows a matrix of T-test significance values for the $\delta^{13} \mathrm{C}$ values from the four 41DL436 sample sets. With the exception of the test between Units 93 and 95, the relationships are much the same as those expressed in Table 8-2, though not as strongly significant. In general, $\delta^{13} \mathrm{C}$ values do not cluster as well as $\delta^{18} \mathrm{O}$, nor do they show the same degree of internal consistency. Nonetheless, the patterning is clear; as $\delta^{18} \mathrm{O}$ increases, implying cooler temperatures, $\delta^{13} \mathrm{C}$ generally decreases. Unfortunately, the causal relationships between $\delta^{13} \mathrm{C}$ and $\delta^{18} \mathrm{O}$ are not well understood, but $\delta^{13} \mathrm{C}$ does respond to changes in hydrology, dissolved inorganic carbon, and $\mathrm{pH}$. Lower $\mathrm{pH}$ values could be related to lesser contribution of springs in limestone aquifer areas such as central Texas; such effects could be correlated, at least in part, with cooler, drier periods that would yield higher shell $\delta^{18} \mathrm{O}$ values and lower $\delta^{13} \mathrm{C}$ values.

While Tables 8-2 and 8-3 show sample group relationships based on the T-test, the range and standard deviation of the sample groups tells a similar story with some interesting twists. Table 8-4 shows that the $\delta^{18} \mathrm{O}$ means of the Feature 11 and Unit 95 groups (Stratum 1a) are essentially 
identical, while the mean of Unit 93 (Stratum 1a) is higher though still close. As expected from the analysis presented above, Units 103/104 have a higher mean (higher $\delta^{18} \mathrm{O}$ values generally imply cooler temperatures). Note, however, that both Units 93 and 95 (Stratum 1a) have a relatively small standard deviation contrasted to the wider standard deviation of Units 103/104 (Stratum 1b) and Feature 11 (Stratum 1a). Despite the near identical means of Feature 11 and Unit 95 (Stratum 1a), the wider range of Feature 11 (Stratum 1a) could indicate that the controlled recovery from the unit sampled a single collecting event or a series of temporally proximate events, while the grab sample collection of Feature 11 may have included a wider variety of events over a slightly longer period of time. Explanation of the wider standard deviation in Units 103/104 (Stratum 1b) is somewhat more problematic but if it is not related to sampling error, it could reflect a more highly variable environment with greater extremes. The lesser difference in the means between Units 95 and 93 (Stratum 1a), separated by only a meter, could reflect slight temporal variation in collection events, or possibly collections from different contexts within the stream.

The $\delta^{13} \mathrm{C}$ values in Table 8-4 present a somewhat different view. The adjacent Feature 11 and Unit 95 (Stratum 1a) have identical means and similar standard deviations, indicating that the hydrology of the stream and the vegetation of the nearby lacustrine environment (one source of which contributes in part to these values) were essentially identical during the collection of these shells. As with the $\delta^{18} \mathrm{O}$ values, $\delta^{13} \mathrm{C}$ values for Unit 93 (Stratum 1a) are slightly more negative implying a similar pattern $\left(\delta^{13} \mathrm{C}\right.$ values are typically negatively correlated with $\delta^{18} \mathrm{O}$ values) and supporting a slight difference between these units, which may indicate that along the horizontal extent of the shell lens at the site, there were a number of collecting events represented. Note that the standard deviation and range of the Unit 93 sample is the lowest of the $\delta^{13} \mathrm{C}$ sample sets. As also seen in the $\delta^{18} \mathrm{O}$ values, Units 103/104 (Stratum 1b) are the most divergent, offering evidence that these specimens built their shell a different environment. The interpretation of $\delta^{13} \mathrm{C}$ in mussel shells is complicated by the relationship between inorganic and organic carbon, the latter of which is significantly lighter (i.e. lower $\delta^{13} \mathrm{C}$ values), and ontological or age-specific effects in the incorporation of metabolic carbon. Given the higher values than would be expected if the shell was constructed totally from organic carbon, the $\delta^{13} \mathrm{C}$ results signal a high influx of inorganic carbon. If this carbon signature were in part a result of more positive values from dissolved limestone bedrock, which often features high $\delta^{13} \mathrm{C}$ values, then decreased $\delta 13 \mathrm{C}$ values in the sampled shells might imply, among other possibilities, lower spring flow and increased contribution of local organic carbon from runoff.

Table 8-4. Means, Standard Deviations, and Ranges of Fish Creek Slough Site Isotope Values.

\begin{tabular}{ccccccccccc}
\hline $\begin{array}{c}\text { Unit/Feat. } \\
\text { (Stratum) }\end{array}$ & $\begin{array}{c}\delta^{13} \mathrm{C} \\
\text { Mean }\end{array}$ & $\begin{array}{c}\delta^{13} \mathrm{C} \\
\text { Std } \\
\text { Dev }\end{array}$ & $\begin{array}{c}\text { Max } \\
\text { value }\end{array}$ & $\begin{array}{c}\text { Min } \\
\text { value }\end{array}$ & $\begin{array}{c}\delta^{13} \mathrm{C} \\
\text { Range }\end{array}$ & $\begin{array}{c}\delta^{18} \mathrm{O} \\
\text { mean }\end{array}$ & $\begin{array}{c}\delta^{18} \mathrm{O} \\
\text { Std } \\
\text { Dev }\end{array}$ & $\begin{array}{c}\text { Max } \\
\text { value }\end{array}$ & $\begin{array}{c}\text { Min } \\
\text { value }\end{array}$ & $\begin{array}{c}\delta^{18} \mathrm{O} \\
\text { Range }\end{array}$ \\
\hline $93(1 \mathrm{a})$ & -6.26 & 0.2702 & -5.8 & -6.5 & 0.7 & -1.98 & 0.4087 & -1.3 & -2.3 & 1 \\
$103,104(1 \mathrm{~b})$ & -7.5 & 0.8972 & -6.8 & -8.9 & 2.1 & -0.84 & 0.7127 & 0.1 & -1.6 & 1.7 \\
F. 11 (1a) & -5.96 & 1.0262 & -4.5 & -7.1 & 2.6 & -2.4679 & 0.6302 & -1.7113 & -3.4574 & 1.7461 \\
95 (1a) & -5.98 & 1.0849 & -5 & -7.2 & 2.2 & -2.5261 & 0.2530 & -2.1963 & -2.8753 & 0.6790 \\
\hline
\end{tabular}


At this stage, with the limited sample, a full analysis of the results is difficult if not impossible. More data are needed on the site and the local environment. But the data do argue that the shells from Units 103/104 (Stratum 1b) were constructed during a slightly cooler period, with annual temperatures as much as ten degrees cooler. In fact, if just the three smaller shells from this group are considered, the temperature differences may have been even more pronounced during the brief lifespan of those individuals. Other factors, such as changes in the hydrology of the creek, dramatic changes in total rainfall or rainfall seasonality, collection of some mussels from another nearby larger stream, or even shell formation fractionation differences in $L$. hydiana, may also account for some of the variability, however. Without more comparative data from the modern environment, it is difficult to actually calculate a mean annual temperature, but the Unit 93 (Stratum 1a) data seem consistent with an annual temperature close to that of the modern Dallas area, while the Unit 103/104 (Stratum 1b) data evidence definite cooler temperatures. Using the Grossman and $\mathrm{Ku}$ (1986) equation, with some extrapolation from values recorded in the San Antonio, Austin, and Waco areas, as well as known historic water and ambient temperatures, and assuming that the Dallas and Grand Prairie area had an annual temperature close to the modern mean annual value (i.e. around 66 degrees), the sample by sample values are shown below in Table 8-5.

Table 8-5. Fish Creek Reconstructed $\delta^{18} \mathrm{O}$ Paleotemperatures.

\begin{tabular}{ccccc}
\hline & \multicolumn{2}{c}{ Coastal Science Labs } & \multicolumn{2}{c}{ Geochron Labs } \\
\hline & Unit 103/104 & Unit 93 & Feat. 11 & Unit 95 \\
\hline Tmean ${ }^{\circ} \mathrm{F}$ estimate & 54.02 & 62.92 & 66.73 & 67.14 \\
Tmean $^{\circ} \mathrm{C}$ estimate & 12.23 & 17.18 & 19.29 & 19.52 \\
Tmean ${ }^{\circ} \mathrm{F}$ estimate corrected* & 58.31 & 67.22 & 66.73 & 67.14 \\
Tmean $^{\circ} \mathrm{C}$ estimate corrected* & 14.62 & 19.57 & 19.29 & 19.52 \\
\hline
\end{tabular}

While there is little to suggest that the differences between Units 103/104 (Stratum 1b) and 93 (Stratum 1a) are due to instrumental or sampling errors, as mentioned earlier, the differences between the analytical labs may be significant. A T-test of the grouped lab $\delta^{18} \mathrm{O}$ values yields a result of $\mathrm{p}=.007$, indicating less than one chance in a hundred that these values were drawn from the same group. No other grouped sets were found to be significant. Of course, the significance may be largely due to the larger difference of Unit 103/104 (Stratum 1b). The bottom two rows of Table 5 show values corrected for the mean differences between the two labs, bringing three of the samples (i.e., Units 93, 95 and Feature 11) into very close alignment near the modern mean annual temperature of the Dallas-Fort Worth area. These differences are well within the range of ordinary lab error and, since this tends to support the established stratigraphy of the site, we propose accepting this calculation. While this brings the temperature estimates of Units 93 and 95 and Feature 11 (Stratum 1a) into close alignment, it still suggests a drop in annual mean temperatures of almost $9^{\circ} \mathrm{F}$ or $5^{\circ} \mathrm{C}$ recorded in the shells from Units 103/104 (Stratum 1b), a marked but not inconceivable value that might reflect the shift to cooler Little Ice Age climates. 


\section{Conclusions}

Staged analysis of $\delta^{18} \mathrm{O}$ and $\delta^{13} \mathrm{C}$ in mussel shell carbonates has indicated strongly divergent values for the shells from Unit 103/104 (Stratum 1b), implying a cooler climate than the shells from other contexts at the site. While the actual reconstructed temperature values suggested above are tentative at best, the magnitude of the difference between the two distinct contexts is probably a reasonable estimate. Even this certainty must be tempered somewhat in assessing its potential impact. With the long-lived A. plicata mussels used in other analyses, the values of the composite samples represent a significant part of the lifespan of the animal, perhaps between 15 and 30 years. Obviously, a $9^{\circ} \mathrm{F}$ difference in a fifteen to thirty-year annual temperature mean could reflect a wider suite of environmental effects than the same variation in a single year's mean. Unfortunately, the smaller, thin-walled L. hydiana may not offer such a longterm perspective. Instead, mature shells may be more likely to represent as little as half the $A$. plicata values, perhaps only 8 to 15 years.

The absence of A. plicata and other larger mussel species, as well as the relatively small size of several of the more common species at the site indicate that the nearby stream was small, but carrying enough water to allow for generations of small to medium-sized mussels to reach maturity (the possibility that the shells could have been carried some distance from a large stream seems remote - most shell food remains are found within a short distance of their collection point). In fact, the large number of mussels apparently represented by the Stratum 1a lens, and the relatively low $\delta^{18} \mathrm{O}$ variability suggests that the stream was stable for some time. The changes seen in the $\delta^{18} \mathrm{O}$ values from Units 103/104 (Stratum 1b) suggests lowered temperatures or shifting hydrologic conditions.

The lack of a well-dated, stratigraphically separated sample from the Fish Creek Slough site has weakened the paleotemperature reconstruction for the selected sample, but the curious nature of the site has revealed a somewhat surprising result: the potential to distinguish the reliability of and relationships between samples from less well-defined contexts such as 41DL436. Overall, the method has proved itself very robust and useful in the analysis of sites contexts from several different perspectives. 


\title{
Chapter 9 \\ OSTRACODES
}

\author{
Mervin Kontrovitz
}

\section{$\underline{\text { INTRODUCTION }}$}

Ostracodes are aquatic crustaceans with mostly microscopic, calcium carbonate shells (calcite) that are commonly preserved in ancient sediments. They are found in deposits from the oceans, estuaries, and from freshwater rivers, streams, ponds, lakes and canals, indeed, in most surface waters.

Different ostracode taxa may inhabit distinct environments and are, therefore, useful in interpreting ecological factors from old sediments. They have proven valuable in reconstructing the environmental history of their containing sediment because they are sensitive to temperature, turbidity, water depth, salinity and other dissolved materials. Many of these factors are known for modern forms and their tolerances allow for an interpretation of environments as recorded in sediment from natural and artificial water bodies (Benson 1963; Kaesler 1983; Kontrovitz and Griffiths 2009; Kontrovitz and Henry 2005).

Wet, or once wet, archaeological sites may have been ideal habitats for ostracodes (Kontrovitz and Henry 2005; Kontrovitz and Snyder 2008). Even if a site was not continuously wet, the ostracode shells still can be preserved in the aquatic portions of the sediment. Furthermore, the ostracodes may be useful to reveal the wet and dry episodes, possibly the case in this study.

\section{Material AND MethodS}

EComm personnel collected material for this study from the Fish Creek Slough Site (41DL436; Unit 49) near Dallas, Texas. Ten sediment samples were supplied by AmaTerra; each represented every-other 10-cm interval beginning with the sample at 190-200 cmbs and ending with the $10-20 \mathrm{cmbs}$ sediment.

Freshwater ostracode shells in most species are known to be thin and fragile, thus preparations techniques are of extreme importance. Each entire sample was soaked in tap-water for 24 hours at the University of Louisiana at Monroe (ULM), and then gently washed with tap-water on a US Standard 120-mesh sieve. ULM tap-water has been shown to be harmless to the calcite shells. No phosphates or other chemicals were used to disperse or otherwise deflocculate the material because such reagents may damage calcium carbonate shells (Kontrovitz et al. 1991). The sediment from each sample was then air dried and sieved with the following US Standard meshes: 20,40,60, 80, and 120. Each size fraction for each sample was scanned for ostracodes. 
Ostracode remains were removed from the dried sediments by the standard micropaleontological technique referred to as picking, a well-established and standard practice (Jones 1956). A portion of each dried sample was sprinkled on a small black-colored tray so there were no overlapping grains. A 00-size artist brush was wetted and touched to a shell; the shell adhered to the brush and was transferred to a paper micropaleontology slide. This was repeated until all of the sediment was examined and all shells were removed from each fraction.

Species were identified using the pertinent literature on modern freshwater forms. From those studies the modern environmental ranges of each taxon were ascertained and then used to interpret the environment represented by each sample from the site that contained ostracodes (see literature citations below).

\section{RESULTS}

Only 28 ostracode valves were recovered from all of the 10 samples. Such a recovery rate is remarkably low. Dozens or even hundreds of shells are commonly seen elsewhere in samples of equal size. Shells of two extant species of ostracodes, representing two genera, were obtained from the sediment samples from the Fish Creek Slough Site (Table 9-1). Additionally, several specimens of Gastropoda, Bivalvia, and Charophyta were recovered.

The maximum number of ostracode species at a single depth was two (Level 16, 150-160 cmbs), while only one species was obtained from the following depths (cmbs): 190-200, 170-180, 130-140. Depths 90-100 cmbs and 50-60 cmbs (Levels 10 and 6) each yielded a single compressed and otherwise poorly preserved carapace from a single species (see Table 9-1).

Table 9-1. Ostracodes Valve Count and Presence or Absence of Other Taxa at Each Depth.

\begin{tabular}{|c|c|c|c|c|c|c|c|}
\hline \multirow[t]{2}{*}{ Level } & \multirow[t]{2}{*}{ cmbs } & \multicolumn{2}{|c|}{ Species } & \multirow[t]{2}{*}{ Gastropoda } & \multirow[t]{2}{*}{ Bivalvia } & \multirow[t]{2}{*}{ Charophyte } & \multirow[t]{2}{*}{ Notes } \\
\hline & & Cs & $\mathrm{Cv}$ & & & & \\
\hline 2 & $10-20$ & & & $x$ & $?$ & & Aquatic? \\
\hline 4 & $30-40$ & Barren & & & & & \\
\hline 6 & $50-60$ & $2 ?$ & & & & & Aquatic? \\
\hline 8 & $70-80$ & & & $x$ & & & $?$ \\
\hline 10 & $90-100$ & $2 ?$ & & $x$ & $?$ & & Aquatic \\
\hline 12 & $110-120$ & Barren & & & & & \\
\hline 14 & $130-140$ & 2 & & $x$ & & $x$ & Aquatic \\
\hline 16 & $150-160$ & 9 & 2 & $x$ & $x$ & $x$ & Aquatic \\
\hline 18 & $170-180$ & 6 & & & $x$ & $x$ & Aquatic \\
\hline 20 & 190-200 & 5 & & $x$ & $x$ & $x$ & Aquatic \\
\hline
\end{tabular}

Cs $=$ Cyprideis salebrosa

$\mathrm{C} v$ = Cypridopsis vidua

$\mathrm{X}=$ Present

$?=$ Probable 
The more commonly occurring species was Cyprideis salebrosa accounting for 26 valves while Cypridopsis vidua, represented by only two valves, was found only in the 150-160 cmbssediments. The following two paragraphs summarize the environmental factors represented by ostracode species recovered at the Fish Creek Slough Site (41DL436).

Cypridopsis vidua (O. F. Müller 1776) has been reported from a wide range of habitats in almost every type of freshwater body, including interstitial waters, ranging in age from Pleistocene to modern. The species is a swimmer, most abundant in permanent and temporary still waters where there are aquatic plants. It can tolerate slow currents if plants and/or algae are present. $C$. vidua has been reported from Holarctic and Neotropical regions where average temperatures are within the range of about $11-32^{\circ} \mathrm{C}$, but Palacios-Fest (1989) indicated it must have at least one month with the average temperatures above $20^{\circ} \mathrm{C}$ to complete its life cycle. Salinity values in waters supporting this species range up to about 8\%oo (Curry 1999; Furtos 1933; Meisch 2000; Palacios-Fest 1989, 2007; Sharpe 1897; Smith 1987; Staplin 1963). In the current study the species was recovered from Level 16 only.

Cyprideis salebrosa (van den Bold, 1963) was described from fossil beds in Trinidad in the Caribbean. It also occurs in modern water bodies including the coastal margins of the Gulf of Mexico, south Louisiana, Lake Whitney in Texas, southern Texas, southeastern New Mexico, and southern Nevada (Forester et al. 2005; Smith and Delorme 2010). Notably, it was also recorded from modern "... moderately saline sodium chloride water and rooted aquatic plants from the margin of Chouteau Springs in central Missouri ..." with salinities in the range of about 7 to $9 \%$ oo (Stout 1981). Thus, modern representatives of C. salebrosa are both euryhaline and eurythermal. In the current study, it was recovered from levels 20, 18, 16, 14, and possibly from levels 10 and 6.

Several of the samples also contained representatives of one or more of the following: Gastropoda; Bivalvia; and calcified oogonia of the algae Charophyta. Each of the gastropods and bivalves were small - that is, only a few millimeters in size. Presumably, the presence of specimens of any of these groups indicates that the containing sediment was deposited in water. Samples 110-120 cmbs and 30-40 cmbs yielded no ostracodes or any of the other taxa mentioned above and, therefore, cannot be described with certainty as aquatic within the context of this study (see Table 9-1).

\section{INTERPRETATION}

Presumably, the material that makes up the sediment represents the original substrate, although the literature indicates a variety of other kinds of substrates are tolerated by the species. Other environmental factors for the taxa are derived from previous studies, and the results for each level are presented in stratigraphic order - that is, oldest to youngest (deepest to least deep).

It should be noted that even in a sample representing a 10-cm interval there is the possibility that the environment changed over the course of that accumulation (i.e. each sample may represent time-averaging). There is no way to speculate further on that possibility without knowing the rate(s) of deposition. 
Sediments from 190 to $200 \mathrm{cmbs}$ (Level 20) yielded a total of five valves, all from the species Cyprideis salebrosa. On this basis, it appears that the paleoenvironment can be characterized as shallow water a few meters in depth. As indicated above, C. salebrosa tolerates, and even prefers, brackish waters; therefore, this sediment probably was deposited under such conditions. Small shells of Gastropoda, Bivalvia, and calcified oogonia of charophytes were also present in this interval.

Level 18 (170-180 cmbs) had six valves of C. salebrosa as well as shells of the two mollusk groups. Recovered gastropod and bivalve remains had no internal soft-parts and the external shell surfaces were barren. Again, the ostracode remains indicate shallow, slightly brackish water; the mollusk remains present no contradiction to this conclusion.

The next higher interval (Level 16; 150-160 cmbs) contained the two species of ostracodes and representatives of Gastropoda, Bivalvia, and Charophyta. It was the only sediment sample in this study with that array of subfossil material. Still, the total of 11 ostracode valves is very low when compared to those in modern water bodies in the Dallas, Texas area. The two species are commonly found in shallow water where each will tolerate moderate salinities up to 8 or $9 \%$ oo.

The material from 130-140 cmbs (Level 14) had only two valves of C. salebrosa along with small gastropod shells and charophyte oogonia. In this case, certainly the ostracodes and charophytes occupied an aquatic environment; it was probably shallow and was at least slightly saline.

Level $12(110-120 \mathrm{cmbs})$ produced no remains attributable to any of the taxa recorded for some of the other samples in this study. There is the possibility that the sediment was not deposited in an aquatic environment. It is an enigma that cannot be resolved in the context of this study.

The next higher sample (Level 10; 90-100 cmbs) presents unclear evidence in regard to its origins. One probable, poorly preserved specimen may be the remnant of an ostracode carapace (two articulated valves). It is collapsed, partially decalcified, and obviously distorted in lateral outline. It is herein speculated that it is from the species Cyprideis salebrosa, but this is uncertain. A few other unrelated shell fragments most closely resemble minute remnants of bivalves, but this too is speculative because of their microscopic size. Two poorly preserved gastropod shells are recognizable, but any interpretation of the depositional environment would be as uncertain as the evidence.

Level 8 (70-80 cmbs) contained no ostracodes, bivalves, or charophytes. Gastropoda were represented by three shells.

The material from Level 6 (50-60 cmbs) contained one poorly preserved specimen, probably a remnant of an ostracode carapace similar to that in Level 10. No gastropods, bivalves, or charophytes were recovered. Again, any interpretation of the depositional environment based on such questionable evidence would be speculative. 
Level 4 (30-40 cmbs) produced no remains attributable to ostracodes, gastropods, bivalves, or charophytes. As with Level 12, no clear explanation can be offered in the context of this study.

Level 2 (10-20 cmbs) contained no ostracodes or charophytes. One gastropod shell and bivalve fragments were present - the latter probably indicating a shallow aquatic environment.

\section{Conclusions}

Even if a site was not continuously wet, ostracode shells may still have been preserved in the aquatic portions of the sediment. Furthermore, ostracodes might be used to reveal the wet and dry episodes, as may be the case in this study.

Shells of two extant species of ostracodes, representing two genera, were recovered from four sediment samples from the Fish Creek Slough Site 41DL436. These species are Cypridopsis vidua and Cyprideis salebrosa, the latter accounting for 26 valves of the 28 valves.

The total ostracode count was unevenly distributed in the 10 samples. Four samples had wellpreserved ostracodes, while two other samples each had a poorly preserved specimen that is interpreted to represent ostracodes. Four samples had no remnants of ostracodes. All levels with ostracode remains represent aquatic environments and are interpreted to have been at least slightly saline and no more than a few meters in depth. A few specimens of Gastropoda, Bivalvia, and Charophyta also were recovered from several samples and lend credence to the interpretation of the depositional environments. Two samples had none of the taxa reported for other levels (see Table 9-1). 


\title{
Chapter 10
}

\section{Diatoms Analysis}

\author{
Barbara Winsborough
}

\section{INTRODUCTION}

Diatoms are unicellular, photosynthetic algae distinguished by the possession of a silica cell wall. They can be found living in a wide variety of aquatic habitats, including seeps, wet walls, dry and damp soil, springs, streams, creeks, sloughs, lakes, rivers, ponds, marshes, lagoons, estuaries, mud flats, bays, and oceans. Most are cosmopolitan-found in many parts of the world under similar environmental conditions, and many species have predictable environmental requirements and pollution tolerances that directly effect diatom species composition.

Diatoms are the most taxonomically diverse and well-studied algal group found in streams. A large and growing body of information exists on the range of ecological tolerance of many common taxa. Large diatom data sets from various parts of the world have shown that living diatom communities provide reliable analogs for estimates of past salinity, conductivity, depth, trophic (nutrient) level, $\mathrm{pH}$, habitat, seasonality, and (indirectly) climate. Published autecological information about individual species form the general basis for interpretation of the diatom assemblage found during this study and these references are included in the bibliography. Since diatoms are sensitive to so many physical and chemical parameters, and are often found in large numbers in sedimentary deposits, they are well-suited for use in paleoenvironmental reconstruction.

This study involves the analysis of diatoms and associated microfossils in ten samples from Unit 49 of Site 41DL436, a Late Prehistoric, Protohistoric, and Historic site located on the floodplain of Fish Creek in southwestern Dallas County, Texas. Fish Creek is a tributary of Mountain Creek in the Trinity River Drainage.

\section{METHODS}

Samples were cleaned of organic material and soluble minerals in preparation for microscopic analysis by boiling first in hydrogen peroxide and then in nitric acid. The oxidized, decalcified material was rinsed repeatedly until a $\mathrm{pH}$ of about seven was reached. A few drops of the cleaned material was air-dried onto $22 \times 22-\mathrm{mm}$ cover glasses and mounted onto glass slides using NAPHRAX $\odot$-a synthetic resin with a high index of refraction-developed to aid in resolving the details of diatom cell wall morphology. Two slides for each sample were scanned at 600x and all diatom cells were counted. Taxonomic determinations were done at 1500x. 


\section{$\underline{\text { RESULTS }}$}

Overall, a total of 90 diatoms comprise the diatom association that was found in the ten samples from Site 41DL436. Ten species were recorded and an additional two fragments could only be identified to the genus Nitzschia (Table 10-1). Many of the diatoms were broken and in poor condition. The diatoms identified to species, in order of abundance are Hantzschia amphioxys (Ehrenberg) Grunow (61 cells), followed by Epithemia turgida (Ehrenberg) Kützing (7 cells), PInnularia borealis Ehrenberg (6 cells), Synedra ulna (5 cells), Navicula radiosa Kützing (2 cells), and one specimen each of Denticula elegans Kützing, Gomphonema parvulum (Kützing) Kützing, Luticola mutica (Kützing) D.G. Mann, Nitzschia sinuata var. delognei (Grunow) Lange-Bertalot and Rhopalodia gibba (Ehrenberg) O. Müller. As many of these species as possible are illustrated in Figure 10-1 (see also Table 10-2).

\section{DisCUSSION}

The assemblage of diatoms occurring together in each sample differed in their diatom content. With one exception, Gomphonema parvulum (Kützing) Kützing found in the level 6, 50-60 cmbs sample, there were no diatoms in the upper seven samples: level 2, 10-20 cmbs; level 4, 30-40 cmbs; level 6, 50-60 cmbs; level 8, 70-80 cmbs; level 10, 90-100 cmbs; level 12, 110-120 cmbs; and level 14, 130-140 cmbs. The Gomphonema parvulum (Figure 10-1.5) found in the level 6 sample is a benthic, attached species that grows on submerged vegetation. Where dominant, it is an indicator of polluted water, but it grows in a wide variety or water quality conditions. In this instance, it was the only diatom in the sample, but it was whole and in better condition than the other diatoms-so it probably came from nearby. Samples from levels 10 and 12 contained a few phytoliths and a few sponge spicules were recorded from sample level 12, but, otherwise, there were no phytoliths, sponge spicules, or statocysts in these seven samples.

In contrast to the upper part of the section, there were 70 diatoms, representing eight taxa, recorded from the next lower sample, level 16, 150-160 cmbs. This was the most diverse sample of the 70 cells: 58 are aerial species, the other 12 are aquatic taxa found in shallow, often seasonally wet streams and ponds. This sample was much more organic-rich and contained abundant plant remains. There were also many chrysophycean statocysts, phytoliths and sponge spicules. Representative forms are illustrated in Figure 10-1.

In the next lower sample, level 18, 170-180 cmbs, 12 diatoms, representing five of the same species as the previous sample, were recorded. Of the 12 cells, seven are represented by two aerial species and five by three aquatic forms. This sample also contained some sponge spicules and bilobate and Poaceae phytoliths. The lowest sample, level 20, 190-200 cmbs, contained six diatoms, from five species. Of these five (all also found in level 16), three are aquatic and two are aerial. There was also a Poaceae phytolith in this sample.

The diatoms found during this investigation are found in habitats that often fluctuate between temporarily submerged to damp or completely dry. They are classified on the basis of where they are most commonly found in abundance. In this case the diatoms are a combination of 
Table 10-1. Diatoms Recorded from Unit 49.

\begin{tabular}{|c|c|c|c|c|c|c|c|c|c|c|c|}
\hline $\begin{array}{l}\text { Sample Level } \\
\text { Depth (cmbs) }\end{array}$ & $\begin{array}{c}2 \\
10-20\end{array}$ & $\begin{array}{c}4 \\
30-40\end{array}$ & $\begin{array}{c}6 \\
50-60\end{array}$ & $\begin{array}{c}8 \\
70-80\end{array}$ & $\begin{array}{c}10 \\
90-100\end{array}$ & $\begin{array}{c}12 \\
110-120\end{array}$ & $\begin{array}{c}14 \\
130-140\end{array}$ & $\begin{array}{c}16 \\
150-160\end{array}$ & $\begin{array}{c}18 \\
170-180\end{array}$ & $\begin{array}{c}20 \\
190-200\end{array}$ & Totals \\
\hline \multicolumn{12}{|l|}{ Diatom Name } \\
\hline $\begin{array}{l}\text { Denticula } \\
\text { elegans } \\
\text { Kützing }\end{array}$ & & & & & & & & & & 1 & 1 \\
\hline $\begin{array}{l}\text { Epithemia } \\
\text { turgida } \\
\text { (Ehrenberg) } \\
\text { Kützing }\end{array}$ & & & & & & & & 4 & 3 & & 7 \\
\hline $\begin{array}{l}\text { Gomphonrma } \\
\text { parvulum } \\
\text { (Kützing) } \\
\text { Kützing }\end{array}$ & & & 2 & & & & & & & & 2 \\
\hline $\begin{array}{l}\text { Hantzschia } \\
\text { amphioxys } \\
\text { (Ehrenberg) } \\
\text { Grunow }\end{array}$ & & & & & & & & 54 & 6 & 1 & 61 \\
\hline $\begin{array}{l}\text { Luticola mutica } \\
\text { (Kützing) } \\
\text { D.G. Mann }\end{array}$ & & & & & & & & 1 & & & 1 \\
\hline $\begin{array}{l}\text { Navicula } \\
\text { radiosa Kützing }\end{array}$ & & & & & & & & 2 & & & 2 \\
\hline $\begin{array}{l}\text { Nitzschia } \\
\text { sinuata var. } \\
\text { delognei } \\
\text { (Grunow) } \\
\text { Lange-Bertalot }\end{array}$ & & & & & & & & 1 & & & 1 \\
\hline Nitzschia sp. & & & & & & & & 1 & & 1 & 2 \\
\hline $\begin{array}{l}\text { Pinnularia } \\
\text { borealis } \\
\text { Ehrenberg }\end{array}$ & & & & & & & & 3 & 1 & 2 & 6 \\
\hline $\begin{array}{l}\text { Rhopalodia } \\
\text { gibba } \\
\text { (Ehrenberg) } \\
\text { O. Müller }\end{array}$ & & & & & & & & 1 & 1 & & 2 \\
\hline $\begin{array}{l}\text { Synedra ulna } \\
\text { (Nitzsch) } \\
\text { Ehrenberg }\end{array}$ & & & & & & & & 3 & 1 & 1 & 5 \\
\hline Total counted & 0 & 0 & 2 & 0 & 0 & 0 & 0 & 70 & 12 & 6 & 90 \\
\hline
\end{tabular}

aquatic species, and aerial diatoms. The aquatic diatoms are all benthic forms associated with sediment, microbial mats, drifting mats of filamentous algae, and rooted vegetation on the floor of a stream, lake or pond. Motile species glide through mud, and others are firmly attached to macrophytes or larger algae, rocks, sand, and shells. Closely related to these particular benthic diatoms, in terms of overlapping habitats, are the aerial diatoms. They are commonly found living exposed to air, are adapted to damp or dry habitats and bloom after wetting. Aerial diatoms are occasionally found in small numbers in aquatic diatom assemblages, such as those found along the margin of streams, and in overbank deposits, when they are transported with the aquatic diatoms during a flood. 
Of the 90 diatom cells found in the assemblage, 68 are aerial diatoms, represented by Hantzschia amphioxys (Figure 10-1.12), Luticola mutica (Figure 10-1.6), Pinnularia borealis. Another 16 diatoms are found primarily in water but are adapted to drying conditions such as mud flats, playa lakes and shallow, seasonal streams. Most of these, including Denticula elegans, Epithemia turgida, Nitzschia sinuata var. delognei (Figure 10-1.1) and Rhopalodia gibba, are species with additional siliceous supports that may assist in tolerating fluctuating osmotic conditions. Of the remaining aquatic taxa, Navicula radiosa is found in both aquatic and wet places, and Synedra ulna is an early colonizer in newly wetted habitats. All of these diatoms prefer a circumneutral to alkaline $\mathrm{pH}$ and shallow, probably hard, temperate to very warm water with elevated salt concentrations. The ecological requirements or preferences of the assemblage indicate moderately enriched water but not seriously polluted.

In addition to diatoms, there were a few phytoliths and chrysophycean statospores in the samples. These were recorded along with the diatoms and photomicrographs of representative examples and are provided on Plate 1 on the chance that they may contain useful paleoecological information or possible evidence of resource procurement. These include a chrysophyte cyst (Figure 10-1.7), phytoliths (Figures 10-1.8, .9, .10), and sponge spicules (Figures 10-1.11 and .12). Phytoliths were recorded because they can provide evidence of plants used as a food source, as well as other purposes such as grass or reeds used for baskets, medical plants, and plant material used for dyes or pigments (Bullock, 2001).

Chrysophyte statospores are resting cysts found most commonly in oligotrophic-eutrophic cool and warm lakes, including alkaline playa lakes that dry out. Statospores are resting stages of members of the algal class Chrysophyceae and the wall of the statospore is siliceous. The cysts allow the algae to survive droughts and other adverse conditions. When abundant, they are used to track changes in paleosalinity; however, there were not enough cysts in these samples to imply anything other than that there was water nearby.

\section{CONClusions}

The diatoms found in these samples indicate that there was probably a water source nearby, but most of the species are found typically in aerial habitats that are frequently to occasionally wetted, such as a mud flat, temporary pond, depression or overbank environment that was sometimes flooded from a stream. One sample, level 16, at 150-160 cmbs, represents wetter conditions than the other samples. Another way that aquatic diatoms can be introduced to an occupation level at a site is by domestic activities such as cooking or washing. Discarded waste water can contain aquatic diatoms collected with the water. 


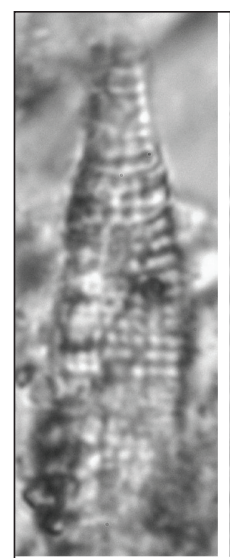

1

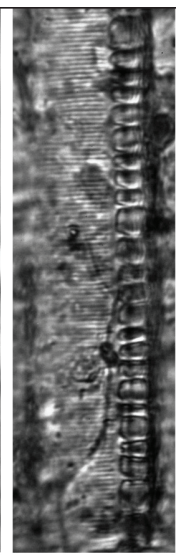

2

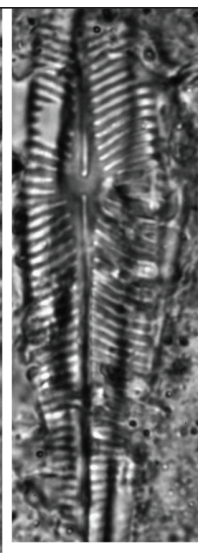

3

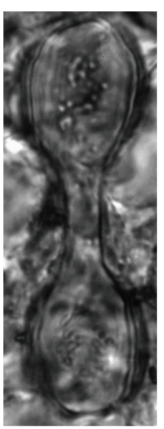

9

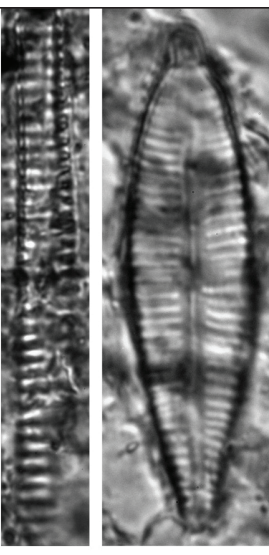

5

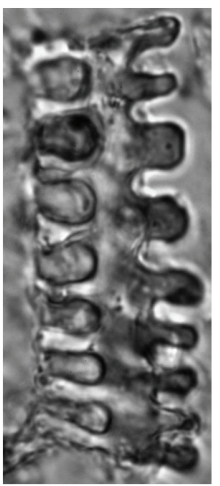

10

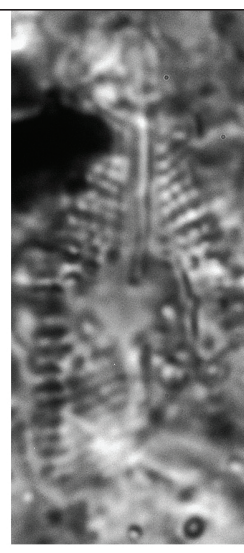

6

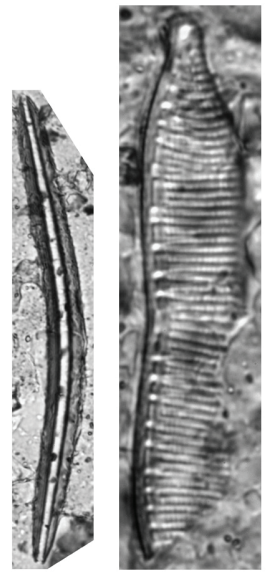

12

PLATE 1

Figure 10-1. Representative Diatom Taxa.

Table 10-2. Photomicrograph Captions for Figure 10-1.

\begin{tabular}{|c|c|c|c|c|}
\hline Fig. & Name & Size & Mag. & Sample \\
\hline 1 & Nitzschia sinuata var. delognei (fragment) & width $7 \mu \mathrm{m}$ & $\mathrm{x} 1000$ & level $16,150-160 \mathrm{cmbs}$ \\
\hline 2 & Nitzschia sp. (fragment) & width $10 \mu \mathrm{m}$ & $x 1000$ & level $16,150-160 \mathrm{cmbs}$ \\
\hline 3 & Navicula radiosa Kützing (fragments of 2 cells) & width $12 \mu \mathrm{m}$ & $x 1000$ & level $16,150-160 \mathrm{cmbs}$ \\
\hline 4 & Synedra ulna (Nitzsch) Ehrenberg (fragment) & width $4 \mu \mathrm{m}$ & x1000 & level $16,150-160 \mathrm{cmbs}$ \\
\hline 5 & $\begin{array}{l}\text { Gomphonrma parvulum (Kützing) } \\
\text { Kützing (complete frustule) }\end{array}$ & width $7 \mu \mathrm{m}$, length $30 \mu \mathrm{m}$ & x1000 & level $6,50-60 \mathrm{cmbs}$ \\
\hline 6 & Luticola mutica (Kützing) D.G. Mann (fragment) & width $7 \mu \mathrm{m}$ & x1000 & level $16,150-160 \mathrm{cmbs}$ \\
\hline 7 & Chrysophycean statospore & diameter $13 \mu \mathrm{m}$ & $x 1000$ & level $16,150-160 \mathrm{cmbs}$ \\
\hline 8 & bilobate phytolith & length $16 \mu \mathrm{m}$ & x1000 & level $16,150-160 \mathrm{cmbs}$ \\
\hline 9 & bilobate phytolith & length $32 \mu \mathrm{m}$ & x1000 & level $16,150-160 \mathrm{cmbs}$ \\
\hline 10 & Poaceae phytolith & width $12 \mu \mathrm{m}$, length $35 \mu \mathrm{m}$ & x1000 & level $16,150-160 \mathrm{cmbs}$ \\
\hline 11 & sponge spicule & width $4 \mu \mathrm{m}$, length $50 \mu \mathrm{m}$ & x1000 & level $16,150-160 \mathrm{cmbs}$ \\
\hline 12 & $\begin{array}{l}\text { Hantzschia amphioxys (Ehrenberg) } \\
\text { Grunow (almost complete) }\end{array}$ & width $7 \mu \mathrm{m}$, length $44 \mu \mathrm{m}$ & x1000 & level $16,150-160 \mathrm{cmbs}$ \\
\hline
\end{tabular}




\title{
Chapter 11
}

\section{Pollen, Phytolith, and Macrofloral Analyses ANd AMS Dating}

\author{
Linda Scott Cummings, Chad Yost, and Kathryn Puseman \\ Assistance from R. A. Varney and Peter Kováčik
}

Site 41DL436 lies in a floodplain of Fish Creek in Dallas County, Texas. Pollen and phytolith samples were collected stratigraphically from a column at this site as a feasibility study to examine preservation of these proxy data records. Four samples were examined by Paleo Research Institute (PRI) for macrofloral remains to recover charred material for AMS radiocarbon dating. Charcoal from features in other areas of the site yielded plausible radiocarbon dates from $110 \mathrm{BP}$ to $1090 \mathrm{BP}$. Four AMS radiocarbon dates were obtained from various levels of the column.

\section{$\underline{\text { METHODS }}$}

\section{Pollen}

A chemical extraction technique based on flotation is the standard preparation technique used in this laboratory for the removal of the pollen from the large volume of sand, silt, and clay with which they were mixed. This particular process was developed for extraction of pollen from soils where preservation has been less than ideal and pollen density is lower than in peat. It is important to recognize that it is not the repetition of specific and individual steps in the laboratory, but rather mastery of the concepts of extraction and how the desired result is best achieved, given different sediment matrices, that results in successful recovery of pollen for analysis.

Hydrochloric acid (ten percent) was used to remove calcium carbonates present in the soil, after which the samples were screened through 250 micron mesh. The samples were rinsed until neutral by adding water, letting the samples stand for two hours, then pouring off the supernatant. A small quantity of sodium hexametaphosphate was added to each sample once it reached neutrality, then the samples were allowed to settle according to Stoke's Law in settling columns. This process was repeated with ethylenediaminetetraacetic acid (EDTA). These steps remove clay prior to heavy liquid separation. The samples then were freeze dried. Sodium polytungstate (SPT), with a density 1.8 , was used for the flotation process. The samples were mixed with SPT and centrifuged at $1500 \mathrm{rpm}$ for 10 minutes to separate organic from inorganic remains. The supernatant containing pollen and organic remains was decanted. Sodium polytungstate again was added to the inorganic fraction to repeat the separation process. The supernatant was decanted into the same tube as the supernatant from the first separation. This supernatant was then centrifuged at $1500 \mathrm{rpm}$ for 10 minutes to allow any silica remaining 
to be separated from the organics. Following this, the supernatant was decanted into a $50 \mathrm{ml}$ conical tube and diluted with distilled water. These samples were centrifuged at $3000 \mathrm{rpm}$ to concentrate the organic fraction in the bottom of the tube. After rinsing the pollen-rich organic fraction obtained by this separation, all samples receive a short (20-30 minute) treatment in hot hydrofluoric acid to remove any remaining inorganic particles. The samples then were acetolated for 3-5 minutes to remove any extraneous organic matter.

A light microscope was used to count pollen at a magnification of 500x. Pollen preservation in these samples varied from good to poor. Comparative reference material collected at the Intermountain Herbarium at Utah State University and the University of Colorado Herbarium was used to identify the pollen to the family, genus, and species level, where possible.

Pollen aggregates were recorded during identification of the pollen. Aggregates are clumps of a single type of pollen and may be interpreted to represent pollen dispersal over short distances or the introduction of portions of the plant represented into an archaeological setting. Aggregates were included in the pollen counts as single grains, as is customary. The presence of aggregates is noted by an " $\mathrm{A}$ " next to the pollen frequency on the pollen diagram. Pollen diagrams are produced using Tilia 2.0 and TGView 2.0.2. Total pollen concentrations are calculated in Tilia using the quantity of sample processed in cubic centimeters (cc), the quantity of exotics (spores) added to the sample, the quantity of exotics counted, and the total pollen counted and expressed as pollen per cc of sediment.

Indeterminate pollen includes pollen grains that are folded, mutilated, and otherwise distorted beyond recognition. These grains are included in the total pollen count since they are part of the pollen record. The microscopic charcoal frequency registers the relationship between pollen and charcoal. The total number of microscopic charcoal fragments was divided by the pollen sum, resulting in a charcoal frequency that reflects the quantity of microscopic charcoal fragments observed, normalized per 100 pollen grains.

\section{Phytoliths}

Extraction of phytoliths from these sediments also was based on heavy liquid floatation. Sodium hypochlorite (bleach) was first used to destroy the organic fraction from $15 \mathrm{ml}$ of sediment. Once this reaction was complete, the samples were rinsed to remove the bleach. Since these sediment samples contained calcium carbonates, they were reacted with 30 percent hydrochloric acid to remove the carbonates, then rinsed until neutral. Next, a five percent solution of sodium hexametaphosphate was added to each sample, then they were allowed to settle according to Stoke's Law in $500 \mathrm{ml}$ beakers. This process was repeated with EDTA. These steps remove clay particles prior to heavy liquid separation. Next, the samples were freeze dried under vacuum. The dried silts and sands were then mixed with sodium polytungstate (density 2.3) and centrifuged to separate the phytoliths, which will float, from the other silica, which will not. The samples were then rinsed with distilled water, then alcohol to remove the water. After several alcohol rinses, the samples were mounted in immersion oil for counting with a light microscope at a magnification of 400x. A phytolith diagram was produced using Tilia and TGView 2.0.2. 


\section{Macrofloral}

The macrofloral samples were floated using a modification of the procedures outlined by Matthews (1979). Each sample was added to approximately three gallons of water, then stirred until a strong vortex formed. The floating material (the light fraction) was poured through a 150-micron mesh sieve. Additional water was added and the process repeated until all floating material was removed from the sample (a minimum of five times). The material that remained in the bottom (the heavy fraction) was poured through a $0.5-\mathrm{mm}$ mesh screen. The floated portions were allowed to dry.

The light fractions were weighed, then passed through a series of graduated screens (US Standard Sieves with 4-mm, 2-mm, 1-mm, 0.5-mm, and $0.25-\mathrm{mm}$ openings) to separate charcoal debris and to initially sort the remains. The contents of each screen then were examined. Charcoal pieces larger than $2 \mathrm{~mm}, 0.5 \mathrm{~mm}$, or $0.25 \mathrm{~mm}$ in diameter were separated from the rest of the light fraction and the total charcoal was weighed. Charcoal pieces in a representative sample were broken to expose fresh cross, radial, and tangential sections, then examined under a binocular microscope at a magnification of 70x and under a Nikon Optiphot 66 microscope at magnifications of 320-800x. The weights of each charcoal type within the representative sample were recorded. The material that remained in the 4-mm, 2-mm, 1-mm, 0.5-mm, and 0.25-mm sieves was scanned under a binocular stereo microscope at a magnification of $10 \mathrm{x}$, with some identifications requiring magnifications of up to $70 \mathrm{x}$. The material that passed through the $0.25-\mathrm{mm}$ screen was not examined. The heavy fractions were scanned at a magnification of $2 \mathrm{x}$ for the presence of botanic remains. The term "seed" is used to represent seeds, achenes, caryopses, and other disseminules. Remains from the light and heavy fractions were recorded as charred and/or uncharred, whole and/or fragments. Macrofloral remains, including charcoal, were identified using manuals (Carlquist 2001; Hoadley 1990; Martin and Barkley 1961; Musil 1963; Schopmeyer 1974) and by comparison with modern and archaeological references. Because charcoal and possibly other botanic remains were to be submitted for radiocarbon dating, clean laboratory conditions were used during flotation and identification to avoid contamination. All instruments were washed between samples, and the samples were protected from contact with modern charcoal.

Samples from archaeological sites commonly contain both charred and uncharred remains. Many ethnobotanists use the basic rule that unless there is a specific reason to believe otherwise, only charred remains will be considered prehistoric (Minnis 1981:147). Minnis (1981:147) states that it is "improbable that many prehistoric seeds survive uncharred through common archaeological time spans." Few seeds survive longer than a century, and most survive for a much shorter period of time (Harrington 1972; Justice and Bass 1978; Quick 1961). It is presumed that once seeds have died, decomposing organisms work to decay the seeds. Sites with unusual levels of preservation, such as caves, water-logged areas, and very arid areas, however, can contain uncharred prehistoric remains. The question of whether an uncharred seed can be interpreted to represent presence in the prehistoric record is considered on a sample-by-sample basis. Extraordinary conditions for preservation are required. 


\section{Microcharcoal Recovery}

It is possible to recover microscopic charcoal (microcharcoal) from sediments for the purpose of obtaining an AMS radiocarbon age. Microscopic charcoal fragments are far superior to humates for this purpose, because they provide dates with the same precision as those obtained from larger pieces of charcoal, with the single exception that the individual pieces of microscopic charcoal are not identified to taxon.

A chemical extraction technique based on that used for pollen, and relying upon heavy liquid extraction, has been modified to recover microcharcoal for the purpose of obtaining an AMS radiocarbon age. After removing calcium carbonates and iron with hydrochloric acid (ten percent), the samples were screened through 150-micron mesh. The material remaining in the screen was added to the floated light fractions and examined for the presence of macroscopic charcoal and other charred remains. Since no macroscopic charcoal was found, the screened samples were rinsed until neutral, and a small quantity of sodium hexametaphosphate was added. The samples then were mixed with reverse osmosis deionized (RODI) water and allowed to settle according to Stoke's Law. After two hours, the supernatant, containing clay, was poured off and the samples were rinsed with RODI water three more times, being allowed to settle according to Stoke's Law after each rinse to remove more clays. This settling process was repeated until the supernatant was clear of clays. Once the clays had been removed, the samples were freeze-dried using a vacuum system, freezing out all moisture at $-107^{\circ} \mathrm{C}$. Sodium polytungstate (SPT), with a density of 1.8, was used for the flotation process. The samples were mixed with SPT and centrifuged at $1500 \mathrm{rpm}$ for 10 minutes to separate organic from inorganic remains. The supernatant containing pollen, organic remains, and microcharcoal was decanted. SPT again was added to the inorganic fraction to repeat the separation process until all visible microcharcoal had been recovered. The microcharcoal was recovered from the SPT and rinsed thoroughly with RODI water. Following this step, the samples were examined using a binocular microscope at a magnification of up to 30x to check the matrix for microscopic charcoal and other debris. Each sample received a treatment with hot hydrofluoric acid (40 percent) to remove all visible silica. RODI water rinses followed, with another examination with the binocular microscope. The hydrofluoric acid treatments were repeated, if necessary, until examination of the samples using the binocular microscope indicated that all that remained was microcharcoal. Once this recovery was complete, the microcharcoal samples received the same pre-treatment as macroscopic charcoal samples.

\section{AMS Radiocarbon Dating}

Charcoal samples submitted for radiocarbon dating were identified and weighed prior to selecting subsamples for pre-treatment. The remainder of each subsample that proceeds to pre-treatment, if any, is permanently curated at PaleoResearch. The subsample selected for pre-treatment first was freeze-dried using a vacuum system, which freezes out all moisture at $-107^{\circ} \mathrm{C}$ and less than 10 millitorr. Charcoal and microcharcoal samples then were subjected to hot (at least $\left.110^{\circ} \mathrm{C}\right), 6 \mathrm{~N}$ hydrochloric acid $(\mathrm{HCl})$, with rinses to neutral between each $\mathrm{HCl}$ treatment, until the supernatant was clear. This step removes iron compounds and calcium carbonates that hamper removal of humate compounds. Next, the samples were subjected to 
five percent potassium hydroxide $(\mathrm{KOH})$ to remove humates. Once again, the samples were rinsed to neutral and re-acidified with $\mathrm{pH} 2 \mathrm{HCl}$ between each $\mathrm{KOH}$ step. This step was repeated until the supernatant was clear, signaling removal of all humates. After humate removal, each sample was made slightly acidic. Charcoal samples (but not wood or other uncharred organic samples) then were subjected to a concentrated, hot nitric acid bath, which removes all modern and recent organics. This treatment is not used on unburned or partially burned samples because it oxidizes unburned material. Each sample again was freeze-dried, then combined with cupric oxide $(\mathrm{CuO})$ and elemental silver $\left(\mathrm{Ag}^{\circ}\right)$ in a quartz tube in a ratio based on the mass of carbon in the sample. The tube was hydrogen flame-sealed under vacuum.

Standards and laboratory background wood samples were treated simultaneously to the same acid and base processing as the charcoal and microcharcoal samples of unknown age, with the exception that they were not subjected to the concentrated, hot nitric acid bath because it oxidizes unburned material. A radiocarbon "dead" EUA wood blank from Alaska that is more than 70,000 years old (currently beyond the detection capabilities of AMS) was used to calibrate the laboratory correction factor. Standards of known age, such as Two Creeks wood that dates to 11,800 RCYBP and others from the Third International Radiocarbon Intercomparison (TIRI) or Fifth International Radiocarbon Inter-comparison (VIRI), also were used to establish the laboratory correction factor. Each wood standard was run in a quantity similar to the submitted samples of unknown age and sealed in a quartz tube after the requisite pretreatment. Once all the wood standards, blanks, and submitted samples of unknown age were prepared and sealed in their individual quartz tubes, they were combusted at $820^{\circ} \mathrm{C}$, soaked for an extended period of time at that temperature, and then slowly allowed to cool to enable the chemical reaction that extracts carbon dioxide $\left(\mathrm{CO}_{2}\right)$ gas.

Following this last step, all samples of unknown age, the wood standards, and the laboratory backgrounds were sent to the Keck Carbon Cycle AMS Facility at the University of California, Irvine, where the $\mathrm{CO}_{2}$ gas was processed into graphite. The graphite in these samples then was placed in the target and run through the accelerator, which produces the numbers that are converted into the radiocarbon date presented in the data section. Dates are presented as conventional radiocarbon ages, as well as calibrated ages using Intcalc04 curves on Oxcal version 3.10 (Ramsey 2005; Reimer et al. 2009). This is a probability-based method for determining conventional ages and is preferred over the intercept-based alternative because it provides a calibrated date that reflects the probability of its occurrence within a given distribution (reflected by the amplitude (height) of the curve), as opposed to individual point estimates. As a result, the probability-based method offers more stability to the calibrated values than those derived from intercept-based methods that are subject to adjustments in the calibration curve (Telford et al. 2004).

\section{RADIOCARbON REVIEW}

When interpreting radiocarbon dates from non-annuals such as trees and shrubs, it is important to understand that a radiocarbon date reflects the age of that portion of the tree/shrub when it stopped exchanging carbon with the atmosphere, not necessarily the date that the tree/shrub died or was burned. Trees and shrubs grow bigger each year from the cambium, where a new layer 
or ring of cells is added each year. During photosynthesis, new cells take in atmospheric carbon dioxide, which includes radiocarbon. The radiocarbon taken in will reflect the radiocarbon present in the atmosphere during that season of growth. Once the sapwood in a tree has been converted into heartwood, the metabolic process stops for that inner wood. Once this happens, no new carbon atoms are acquired, and the radiocarbon that is present starts to decay. Studies have shown that there is little to no movement of carbon-bearing material from one ring to another. As a result, wood from different parts of the tree will yield different radiocarbon dates. The outer rings exhibit an age close to the cutting or death date of the tree, while the inner rings will reflect the age of the tree. Because the younger, outer rings burn off first when a log or branch is burned, it is the older, inner rings that typically are what is left remaining in a charcoal assemblage (Puseman 2009; Taylor 1987).

\section{DisCUSSION}

Site 41DL436 lies within the Fish Creek floodplain and was occupied for nearly 1,000 years. The site is situated in the city of Grand Prairie on the south bank of Fish Creek and lies within the Blackland Prairie natural region. Fish Creek is a moderately-sized tributary in the watershed of the West Fork of the Trinity River. Initial work at 41DL436 suggests that the site is characterized by a series of stratified, burned zones in a relatively recent alluvial terrace of Fish Creek. While these zones of burning might be of natural origin, their frequency in what appears to be a relatively short-term sequence of deposits suggests that humans likely were responsible. One possible explanation is that the repeated burns represent preparation of agricultural fields (Trierweiler and Nickels 2010). A total of 20 stratigraphic samples, collected as $10 \mathrm{~cm}$ blocks, were collected from depths of 0-200 cmbs for pollen and phytolith analyses (Table 11-1). Initially, every other sample, representing ten samples from depths of 10-190 cmbs, was examined for pollen and phytoliths in a feasibility study. The intervening samples not examined during the initial study were submitted later so that the entire column with all 20 samples eventually was examined. Ultimately, pollen and phytoliths were examined from Levels 1-20 (Figure 11-1). Four samples from the column were submitted for macrofloral analysis to obtain charred material for AMS radiocarbon dating. This step was essential because radiocarbon dates were available for this site only from features in the upper three sediment levels. Preliminary information indicated that the oldest date reported for this site was 1090 BP; however, a complete list of radiocarbon dates from the site did not contain a date this old. Instead, the oldest date reported was $830 \pm 25 \mathrm{BP}$ for charcoal recovered from Feature 1 in Level 3. Four AMS radiocarbon dates were obtained on material recovered from stratigraphic macrofloral samples. Two of the stratigraphic macrofloral samples contained charred material in sufficient quantities for dating, while microcharcoal was extracted from the other two samples for dating. Due to patterns observed in the radiocarbon dates, they must be discussed first, before addressing the stratigraphic pollen and phytolith records. From the deepest to the upper levels, the macrofloral samples and resulting AMS radiocarbon dates are discussed immediately below.

Macrofloral sample 241 represents the 150-160 cm level of the column (Level 16). This sample contained a variety of charred remains, including three Chenopodium seed fragments, four 
Galium seed fragments, monocot stem fragments, Poaceae seed awn fragments, a Poaceae B caryopsis fragment from a grass with medium-sized seeds, unidentified fruit and seed fragments, and several fragments of charcoal too small for further identification (Tables 11-2 and 11-3). In addition, fragments of incompletely and partially charred periderm (bark) and several charred parenchymous tissue fragments were present. Parenchyma is the botanical term for relatively undifferentiated tissue composed of many similar cells with thin primary walls. Parenchyma occurs in many different plant tissues in varying amounts, especially large fleshy organs such as roots and stems, but also in fruits, seeds, cones, periderm (bark), leaves, needles, etc. (Hather 2000:1; Mauseth 1988). If charred remains in this sample reflect a burn episode, either natural or cultural, these charred remains suggest that at least goosefoot, bedstraw/stickywilly, grasses, and possibly other monocots grew in the area at the time it burned. The charred Galium seed fragments weighing $0.0018 \mathrm{~g}$ were submitted for AMS radiocarbon dating because they are annuals. These charred seeds returned a date of 535 \pm 50 RCYBP (PRI-11-068-241) and a two-sigma calibrated age range of 650-580 and 570-500 CAL ry. BP or AD 1300-1370 and AD 1380-1450 (Table 11-4, Appendix H). This date is consistent with the archaeological interpretation that the sediments of this terrace accumulated within the past approximately 1000 years. Comments about the date relative to the stratigraphic column will be made later in the report. A variety of uncharred seeds from modern plants were noted in sample 241, as were numerous uncharred Chara oogonia. Chara oogonia represent stonewort, a submerged algae found mostly in hard-water or alkaline lakes and slowly flowing streams with abundant calcium (Prescott 1978:18; Schoch et al. 1988:49). This level of the column appears to have been wet for a long enough time that algae could grow. A few fish scales also were present, and ostracod shells were numerous. Ostracods are small, bivalved crustaceans widely distributed in fresh and saline water, normally under well oxygenated conditions in lakes, ponds, springs, and streams (Palacios-Fest 1994:145). Other non-floral remains in this sample include a moderate amount of uncharred bone fragments, including four small vertebrae and two small mammal teeth, and numerous shell and snail shell fragments. This area of the column appears to have experienced a significant amount of bioturbation, resulting in introduction of modern and more recent material. The macrofloral record is consistent with a relatively recent deposition, as suggested by the AMS radiocarbon date.

Macrofloral sample 234 was taken from Level 14 at a depth of 130-140 cmbs. Charred remains in this sample include several monocot stem fragments, four Poaceae seed awn fragments, four pieces of parenchymous tissue, an unidentified seed fragment, an incompletely charred seed fragment, and several fragments of charcoal too small for identification. The monocot stem fragments, representing annuals, yielded a total weight of $0.0013 \mathrm{~g}$ and were submitted for AMS radiocarbon dating; however, these stem fragments did not survive chemical pretreatment. The small, unidentifiable charcoal fragments weighing $0.0047 \mathrm{~g}$ then were processed for dating. A date of 2105 \pm 20 RCYBP (PRI-11-068-234) was returned for this charcoal, which calibrates to an age range of 2150-2000 CAL yr. BP or 200-50 BC at the two-sigma level (Appendix H). Several uncharred seeds and seed fragments and a few uncharred rootlets reflect modern plants. Recovery of numerous Chara oogonia again suggest that this level experienced standing or slow moving water for a long enough time that algae could grow. Non-floral remains include a few uncharred bone fragments, a few fish bone fragments, several fish scale fragments, a bivalve shell fragment, and numerous snail shells. 
Macrofloral sample 196B was collected from Level 7 at a depth of 60-70 cmbs. The only charred remains noted in this sample were a few fragments of charcoal too small for identification and weighing $0.0007 \mathrm{~g}$. These charcoal fragments were submitted for AMS radiocarbon dating; however, they did not survive chemical pre-treatment. Additional sediment from the sample was processed to recover microscopic charcoal for dating. The microcharcoal in sample 196B yielded a date of 3350 \pm 15 RCYBP (PRI-11-068-196B), with a two-sigma calibrated age range of 3640-3550 and 3530-3480 CAL yr. BP or 1690-1600 BC and 1580-1530 BC (Appendix H). Fewer uncharred remains from modern plants were noted in this sample and consist of a Rudbeckia seed fragment, a few leaf fragments, a few rootlets, and two fragments of unidentified hardwood root wood. The sample also contained an uncharred bone fragment, a moderate amount of insect eggs, and a moderate amount of shell fragments.

Few plant remains were present in macrofloral sample 191, recovered from Level 6 at a depth of 50-60 cmbs. A single small fleck of unidentified charred material weighing $0.0001 \mathrm{~g}$ was noted, which is too small for AMS radiocarbon dating. As a result, microscopic charcoal was extracted from the sample and submitted for dating. A date of 5955 \pm 25 RCYBP (PRI-11-068191) was returned for the microcharcoal, which calibrates to an age range of 6890-6720 CAL yr. BP or 4940-4770 BC at the two-sigma level (Appendix H). Uncharred plant remains in sample 191 consist of a few rootlets, several fragments of Platanus occidentalis root wood, and a few pieces of unidentified hardwood root wood. Since this sample was stratigraphically higher than the other macrofloral samples, recovery of fewer uncharred plant remains suggests the presence of older sediments, as reflected in the radiocarbon date for this sample.

A complete and uniform reversal of radiocarbon dates is unusual, and when it occurs, it usually is interpreted to represent contamination or bioturbation. However, another possibility will be explored here and throughout the discussion below. As a preview, the most probable interpretation of the stratigraphic record, based on the radiocarbon dates and the characteristics of the macrofloral samples, is that the sediments represented in this trench since Level 16, and probably from a lower level, have accumulated during the past approximately 535 radiocarbon years. Sediments that accumulated here were eroded from a landscape, probably upstream. As sediments were removed upstream and transported to this location, probably by relatively slow moving water, they were deposited at 41DL436. This process continued incrementally until it had removed sediments from a discrete area of the landscape back to levels that dated at least 6000 years ago upstream and deposited them in this location. It is likely that radiocarbon dating charcoal recovered in the upper levels would yield even older radiocarbon dates, representing continuation of this pattern of obtaining sediments from an older landscape upstream and depositing them in this location. This stratigraphic inversion of dates, then, is not an expression of bioturbation but rather of the origin of the sediments and their removal from a landscape upstream. Recovery of very few uncharred remains in the upper samples is consistent with this scenario, as there would have been few uncharred remains in the sediments that were eroded. This pattern in the macrofloral record also suggests minimal incorporation of modern vegetal debris into the sediments as they were transported to and deposited in this area. Recovery of a greater abundance of uncharred material in the Level 16 sample, which dated to 535 RCYBP, is consistent with relatively recent deposition of those sediments, as suggested by this date. Further comments will be made as the discussion unfolds, below. 


\section{Stratigraphic Pollen and Phytolith Records}

The stratigraphic pollen and phytolith records yielded four distinct zones that have been labeled sequentially from bottom to top. The pollen record for the lower three zones is significantly different than that for the uppermost zone. Due to this fact, the major elements of the pollen record will be reviewed briefly prior to discussing each of the zones individually. Changes in frequencies of High-spine Asteraceae, Low-spine Asteraceae, Quercus, Cheno-am, Poaceae, and indeterminate pollen, as well as microscopic charcoal, were important in defining the four zones. There is, however, little correspondence between the vegetation record and the stratigraphic profile and its evidence of paleosols and deposition.

\section{Zone 1}

Important observations of the stratigraphic profile include Paleosol 2, with a wavy margin with the overlying sediments in Level 15, indicating that sample $237(140-150 \mathrm{cmbs})$ is a combination of Paleosol 2 and overlying non-organic sediments. Paleosol 2 and the underlying deposits were described as floodplain sediments that accreted slowly. Zone 1 reflects Paleosol 2 and the underlying deposits that represent floodplain sediments and includes samples from Levels 20-16. The radiocarbon date of 535 \pm 50 RCYBP was obtained on Galium seeds in Level 16 near the top of Paleosol 2 (Figure 11-2). Galium (bedstraw/stickywilly) is a facultative upland plant growing in disturbed areas, although a few species also grow in undisturbed wetlands. As such, the possibility must be considered that the Galium seeds that were dated originate in the sediments that were moved to this location, rather than having been burned at this site. These seeds are annuals, so the dates do not need to be adjusted for longevity of woody plants that produced the recovered charcoal. Interpretation of the stratigraphic pollen and phytolith records will proceed assuming that the date of 535 \pm 50 RCYBP is associated with this paleosol. This provides a date that we will stipulate, at this point in the discussion, represents the upper portion of Paleosol 2. Slow accumulation of sediments in and below Paleosol 2 are consistent with relatively large pollen concentrations observed in the middle three samples from this package (approximately 4500 to more than 9000 pollen per cubic centimeter (cc) of sediment). Recovery of a large quantity of algal spores in sample 16 (150$160 \mathrm{cmbs}$ ), representing Level 16, is consistent with recovery of Chara oogonia, ostracods, and fish scales in the macrofloral sample from this level, all of which point to the presence of floodplain sediments, which were recognized in the stratigraphic profile. The pollen record of increased High-spine Asteraceae and Low-spine Asteraceae pollen for this zone indicates that the vegetation along the floodplain included a variety of plants in the sunflower family, many of which respond to disturbance. Plants in the Low-spine Asteraceae group include marshelder, which is one of the common plants colonizing disturbed sediments of floodplains. Increased Cheno-am pollen frequencies are consistent with local growth of goosefoot in wet floodplain sediments. Finally, fluctuating quantities of Poaceae pollen suggest fluctuating response of grasses to the floodplain conditions and competition with plants in the sunflower family. Clarification of the grass record will be made in the phytolith discussion.

The pollen record for Zone 1 indicates a very open habitat, either as part of a floodplain or an upland zone. Small quantities of Pinus, Quercus, and Ulmus pollen suggest occasional pine, 
oak, and elm trees on the upland landscape either in the area around 41DL436 or perhaps upstream (Figure 11-3, Table 11-5). Pollen types that represent plants typical of an open habitat or prairie were numerous in this record and can be divided into those anticipated as part of the floodplain vegetation community and those more typical of upland habitats. First, pollen representing plants that grew as part of the floodplain vegetation community include Apiaceae; some Liguliflorae, Brassicaceae, and Cheno-ams; and Persicaria-type, representing a member of the umbel family, members of the chicory tribe of the sunflower family, members of the mustard family, goosefoot, and one of a group of plants known as knotweeds.

Recovery of small quantities of Artemisia, Cirsium, Ephedra, Eriogonum, Fabaceae, Trifolium pratense-type, Plantago, Rosaceae, Kallstroemia/Tribulus-type, and perhaps some of the Brassicaceae and Cheno-am pollen represent local growth of sagebrush, thistle, ephedra, wild buckwheat, legumes including clover, plantain, a member of the rose family, caltrop/ puncture vine, and perhaps members of the mustard family and Cheno-ams. Caltrop is a native plant, while puncture vine is introduced. Recovery of most of these pollen types in very small quantities and/or only occasionally suggests that these plants were not particularly abundant on the landscape. Exceptions to this include the slightly elevated quantities of Cheno-am pollen in samples from Zone 1 and elevation of legume pollen in the uppermost sample from this zone. Some of the pollen types observed in small quantities represent plants that would have provided edible resources to people living in the area. These include some members of the umbel family, some of the members of the sunflower family, the mustard family, Cheno-ams, legumes, and grass seed. Small quantities of monolete and trilete spores indicate that ferns also grew on the floodplain. Recovery of hystrichospheres and redeposited pollen probably represents liberation of these forms from bedrock and is consistent with transport of sediments. Total pollen concentration in these samples is moderate to moderately high, which is consistent with relatively recent origin and deposition of these sediments. Sample 244 and probably also sample 18 exhibited the highest total pollen concentrations, suggesting the possibility that these samples represent a relatively stable or slowly aggrading and probably recent surface. Quantities of microscopic charcoal varied in these samples, with the largest amount observed in the uppermost sample from this zone. This suggests the possibility of intentional burning of the landscape or of wildfires.

The phytolith record from Zone 1 is characterized by a relatively high percentage of grass subfamily Panicoideae phytoliths and soil moisture indicators such as sedge (Cyperaceae) phytoliths, diatoms, and sponge spicules (Figure 11-4). This evidence suggests that the climate was humid and that soils were moist for extended periods of time, which agrees with the recovery of elevated frequencies of Low-spine Asteraceae pollen and algal forms in the pollen record. Several species of diatoms and freshwater sponges were noted and may provide some specific environmental data if identification to the species level was made through a separate analysis. Although only tentative identifications, the sponges Ephydatia fluviatilis and Ephydatia Muelleri may be present (Figure 11-5D and H). Ephydatia fluviatilis tends to prefer moving water and is tolerant of silty, low light conditions (Harrison 1988). This suggests the presence of moving water close to this location. Pooideae phytoliths (keeled rondels and trapeziform sinuates) peak in the lowest sample from the zone and decline subtly towards the top. In this region, pooid grasses are typically confined to riparian corridors, forest edges, and 
forest understories. Although saddle phytoliths diagnostic of Chloridoideae grasses (short grass prairie taxa) are the dominant phytolith morphotype at around 35 percent relative abundance, they are most likely over-represented in the record. The phytolith work of Fredlund and Tieszen (1994) clearly illustrated that soils from tall grass (Panicoideae) prairie sites near the transition (less than 100 miles) to short grass prairie contained an unusually high percentage of saddle (Chloridoideae) phytoliths, possibly from wind (dust) and ash transport from the west. Thus, a short grass prairie environment might have been typical of the landscape within 100 miles to the west of this site. Wind transport of sediments that contained phytoliths from that short grass prairie would have incorporated them into this record. Other phytoliths observed within this zone include seed phytoliths derived from members of the Asteraceae (Figure 11-5E).

The phytolith record from Zone 1 is also characterized by the presence of seed phytoliths from the herbaceous plants Tradescantia (Figure 11-5A) and Commelina (Figure 11-5C); a member of the Cyperaceae, most likely Cyperus (Figure 11-5B); and phytoliths from the fleshy drupes produced by Celtis trees (Figure 11-4F). There are 14 species of Tradescantia (spiderwort) that grow in Texas. Five species, T. occidentalis, T. ohiensis, T. subacaulis, T. hirsutiflora, and T. gigantea, are found in Dallas County today (B. L. Turner, et al. 2003). Although they are not diagnostic, the Tradescantia seed phytoliths observed in the samples from Levels 20, 19, and 17 most closely resemble those from T. occidentalis and T. ohiensis. Tradescantia plants occur naturally in sandy soils of pine barrens, bottomlands, and along streams. They also have an affinity for disturbed sites with moist soils. The paucity of pine pollen suggests that the Tradescantia growing here are responding to sandy, disturbed soils with elevated levels of moisture, which is typical of floodplain deposits. There are four Commelina (dayflower) species native to Texas. The single Commelina (dayflower) seed phytolith observed here, based on its morphology and geographic range of related taxa, is most likely derived from Commelina erecta (erect dayflower). Commelina erecta occurs naturally in rocky woods, scrub oak woods, and pine barrens, as well as hummocks and sand dunes. It also has an affinity for disturbed places and is a weed of cultivated fields (Faden 2000). Three drupe (fruit) phytoliths from Celtis (hackberry) were observed in samples representing Levels 17 and 16 from the top of Zone 1 (Figure 11-5F). There are five Celtis species native to Texas, with C. laevigata, C. reticulata, and C. tenuifolia found in and near to Dallas County (B. Turner et al. 2003). C. laevigata is found in rich bottomlands along streams, in flood plains, and on rocky slopes. C. reticulata prefers dry hills, ravine banks, and rocky outcrops. C. tenuifolia is found on slopes and along streams in open woods (Serhman-Broyles et al. 1997).

The phytolith record for Level $18(170-180 \mathrm{cmbs})$ from the middle of this zone is somewhat anomalous in that there was a spike in Chloridoideae phytoliths; a drop in Panicoideae phytoliths; a complete absence of Tradescantia, Commelina, and Celtis phytoliths; and a spike in both diatoms and sponge spicules. Asteraceae inflorescence phytoliths also peaked in abundance for the zone. From the pollen record, this sample also exhibited a spike in Highspine Asteraceae pollen. This suggests that some type of disturbance took place during the time period represented by Level 18, possibly a flooding event that provided some pioneer species to thrive briefly, then decline. The spike in Chloridoideae phytoliths suggests that this anomaly might have been accompanied by high winds that blew in some sediments from a drier landscape to the west that mixed with the sediments of more local origin. 
Finally, regarding the phytolith record from this zone, phytolith, diatom and sponge spicule preservation was excellent and resembled that which is typical for modern and fairly young sediments. Thinly silicified grass (Poaceae) epidermal sheet elements and Cyperaceae phytoliths often are under-represented in paleo sediments, but they were most ubiquitous within this zone. Diatoms and sponge spicules often are eroded, pitted, and broken in paleo sediments but were in pristine condition within this zone. Thus, the excellent biogenic silica preservation observed within this zone supports the relatively young date of 535 \pm 50 RCYBP obtained on the Galium seed from Level 16 (150-160 cmbs).

In summary for Zone 1, the pollen and phytolith records suggest that this was a fairly open floodplain habitat dominated by tall $\mathrm{C}_{4}$ panicoid grasses and forbs, with scattered occurrences of hackberry (Celtis) trees within the floodplain zone and probably other species on the uplands. Sedges (Cyperaceae) and $\mathrm{C}_{3}$ pooid grasses probably were confined to moist soils closer to water and shady areas underneath arboreal taxa. The phytolith record does suggest a subtle decrease in $\mathrm{C}_{3}$ Pooideae taxa and a subtle rise in $\mathrm{C} 4$ Panicoideae taxa towards the top of the zone. Overall, the biotic community on the landscape most likely resembled the Bluestem Prairie Vegetation-Type as defined by Kuchler (1964) (see Table 6) and likely represents a natural prairie and riverine ecosystem pre-European settlement of the area. Thus, Paleosol 2 may have developed under a grassland ecosystem, resulting in a buried Mollisol, or it might represent a paleo floodplain soil, or some combination of both of these vegetation communities. The pollen, phytolith, and macrofloral records all exhibit excellent preservation of materials in samples from this zone, which is consistent with the relatively recent radiocarbon date of $535 \pm 50$ RCYBP, suggesting recent deposition of these sediments. All three of the proxy records provide evidence consistent with flooding in this zone.

\section{Zone 2}

Zone 2 is represented by samples from Levels 15-10, acknowledging that Level 15 is a combination of sediments from Paleosol 2 and the overlying level, and spans a depth interval of 140 to $90 \mathrm{cmbs}$. This zone includes the lower portion of sediments below Paleosol 1 and overlying Paleosol 2. This zone is marked by fluctuating quantities of Poaceae and High-spine Asteraceae pollen, suggesting multiple competition sequences in which grasses and members of the sunflower family dominated the local vegetation. An increase in Pinus pollen suggests more input of pollen from uplands either in the vicinity of site 41DL436, to the west of 41DL436, or perhaps upstream. Variations in Quercus pollen frequencies, which mimic variations in Highspine Asteraceae pollen and run in opposition to variations in Poaceae pollen, might represent differences in sediment origin or pulses of sediment transport. Comparison of this pattern with total pollen concentration for these samples does not provide a pattern that suggests changes in floodplain accumulation rates. Instead, relatively low total pollen concentrations (usually below 1000 pollen per cc of sediment) are consistent with rapid floodplain sediment accumulation. Many of the other components of the pollen record are similar to those observed in Zone 1. Differences include occasional recovery of Celtis and Juniperus pollen, which indicate that hackberry and juniper trees grew in the area. Celtis drupe (fruit) phytoliths also were recovered within this zone. In addition, Zone 2 provides the first evidence of Cyperaceae, Erodium, and Vitis pollen, documenting local growth of sedges, filaree, and wild grape. Microscopic charcoal 
continues to be at least moderately abundant, peaking in sample 12, suggesting the possibility of intentional burning of the landscape. This interpretation of burning is echoed in the phytolith record. A radiocarbon date of $2105 \pm 20$ RCYBP, reported on unidentified charcoal fragments recovered from Level 14, suggests erosion of deeper sediments upstream and translocation of those sediments to this location, resulting in an net inversion of sediments (removing from one location and depositing in another). Since this radiocarbon date was older than the one from Level 16, representing a deeper level, it signals the possibility that the pollen recovered from these deposits in the stratigraphic record from this site might represent a mixture of pollen from the sediments that were removed from the landscape upstream and pollen that was incorporated into the sediments as they were deposited at the location sampled at 41DL436. Variations in quantities of Quercus, High-spine Asteraceae, and Poaceae pollen underscores the possibility that as sediments were transported they might contain more or less of the pollen from the original sediments and that the rapid accumulation of floodplain sediments created constantly changing disturbance at 41DL436.

The phytolith record from Zone 2 is characterized by a substantial decrease in phytoliths from tall grass Panicoideae taxa and a steady rise in trapeziform sinuate phytoliths diagnostic of C3 Pooideae grasses. The lowest two samples from the zone representing Levels 15 and 14 appear to be transitory between Zones 1 and 2, as they exhibit some of the characteristics described for Zone 1. Although decreasing, Panicoideae grasses are still abundant, as are diatoms and sponge spicules. Stipa-type bilobates indicative of Stipeae grasses such as Stipa, Achnatherum, and Oryzopsis peak in Level 14, decline, and then start a subtle rise again at Level 10. Stipeae grasses would represent taxa from the hillsides and uplands, not grasses found within floodplains and other high disturbance habitats. A tentative identification of the sponge Ephydatia fluviatilis was made based on the presence of gemmoscleres and megascleres (Figure 11-4H). Ephydatia fluviatilis tends to prefer moving water and is tolerant of silty, low light conditions. This suggests that moving water with a heavy silt load may have been common during this period of time. The upper two samples from this zone are characterized by a continued decrease in Panicoideae phytoliths and a drop in diatoms and sponge spicules. Several opaque perforated plate phytoliths diagnostic of sunflower family (Asteraceae) inflorescence material were also observed in the uppermost samples.

The phytolith record from Level 10 of this zone marks the end of a dramatic increase in trapeziform sinuate phytoliths from $\mathrm{C}_{3}$ Pooideae grasses that started in Level 12. This is an abnormally high percentage of cool season $\mathrm{C}_{3}$ pooid grass phytoliths for this region and suggests that these grasses intentionally were grown for subsistence. It is possible that intentional burning was carried out to increase the frequency of these particular grasses on the landscape. Supporting this notion is the rise in dendriform phytoliths (Figure 11-5J and M) that starts in level 11 and peaks in Level 9 from the overlying Zone 3. Dendriforms originate in the bract material (lemmas, paleas and glumes) that surrounds the seed (caryopsis) of some wild and domesticated grasses such as Hordeum and Elymus. They are very common in the bract material of Pooideae grasses, especially domesticated and cultivated cereal grain taxa. The sample from Level 11 also yielded numerous Poaceae epidermal sheet elements with wavy long-cell walls (Figure 11-5L), one of which has been exposed to fire (Figure 11-5K). These 
types of phytoliths are very common in grass leaf and inflorescence material, and elevated abundances, as exhibited here, can be indicative of grass utilization for subsistence.

Although no diagnostic phytolith or pollen evidence for Zea mays was obtained from Zone 2, a few very intriguing maize-like phytoliths were recovered. The sample from Level 15 yielded a wavy-top rondel that has some maize cob phytolith characteristics (Figure 11-5G). Wavy-top rondels can be produced in large numbers in the glume material for many varieties of maize (Zea mays). A small amount of these phytoliths can accompany the processing, cooking, and consumption of maize and can be recovered from artifacts and features that represent these various activities. The wavy-top phytolith observed in the Level 15 sample almost meets all of the requirements, as outlined by Pearsall et al. (2003), to be considered a maize (Zea mays) cob wavy-top rondel. The main characteristics are that maize wavy-top rondels have a circular to oval base in outline (top view) that is flat, not concave in side view; the base must be longer than the body is high or tall; the top (the side opposite the rondel base) is a single, complete wave that is equal to or less than the length of the rondel base; and the peak or sides of this wave are not horns or spikes. The wavy-top rondel observed here does not have a flat base but rather a concave base in side view, and therefore, is not diagnostic of maize. However, this particular morphotype is well within the range of variation observed from modern Zea mays cob reference material and is very intriguing. A very subtle wavy-top rondel with a razor-thin keel was recovered from Level 11 (Figure 11-5I). This razor-thin keel, although not diagnostic by itself, is another characteristic typical of maize cob phytoliths. Had the wave been more pronounced, this phytolith might have been considered diagnostic of maize.

The sample from Level 10 yielded a cross phytolith that is typical for those found in the leaves of Zea mays (Figure 11-5N) and other panicoid grasses. However intriguing, it should be understood that this cross is not diagnostic for maize and can be produced by other Panicoideae grasses. In the absence of diagnostic phytoliths or pollen for Zea mays, this cross body cannot be interpreted to represent anything but a Panicoideae grass. Despite the inability to recover a single diagnostic maize phytolith, it is still very interesting that of the thousands of phytoliths counted and the tens of thousands of phytoliths observed during the subsequent scans of these samples, the only possible Zea-types observed all were noted in samples between Levels 15 to 10, especially from Levels 11 and 10.

Thus, the phytolith record suggests the possibility that grasses were cultivated or encouraged in this area. Little barley grass (Hordeum pusillum) is the grass most likely to have been cultivated at this time. With Levels 11 though 9 yielding strong evidence for the intentional growing of a cool season grass for subsistence and the intriguing Zea-like phytoliths from Levels 15, 11, and 10, the time period represented by Zone 2, especially the upper portion, might have been a period of agricultural activities, possibly on the upland plateau directly south of the site and within the floodplain along Fish Creek. Microcharcoal particles peak in abundance within Zone 2 , suggesting that burning may have been associated with these possible agricultural activities. 


\section{Zone 3}

Zone 3 is represented by samples from Levels 9-5, spanning the depth interval of 90 to 40 cmbs. The lower three samples of this zone represent the upper portion of Paleosol 1. The upper two samples of this zone represent the sediments that overly Paleosol 1 and underlie the contemporary soil. Differences in the total pollen concentration in the three samples representing the paleosol, which range from almost 3000 pollen per cc of sediment to approximately 1,350 pollen per cc of sediment in the upper samples from the Paleosol, and the much smaller total pollen concentration of the upper two samples (almost 600 to approximately 900 pollen per cc of sediment) are consistent with the sediment descriptions. The pollen samples from this zone were more similar to the basal Zone 1 than they were to those from the immediately underlying Zone 2 for High-spine Asteraceae and Poaceae pollen frequencies. This zone notes the first occurrence of Dalea-type, Fabaceae triangular, Lamiaceae, and Passiflora pollen, representing prairie clover, an unidentified legume, a member of the mint family, and passionflower. Quantities of microscopic charcoal were reduced in these two samples. Overall, the pollen record indicates a continuation of the general vegetation communities noted in the lower sediments. Changes are noted in composition of this community and in fluctuations of the quantities of plants in the sunflower family and grasses. Local vegetation is still typical of an open landscape, and burning appears to have decreased. The upper portion of Paleosol 1 developed on sediments transported from a portion of the landscape upstream that appears to date to approximately 3350 RCYBP. The sediments overlying this paleosol appear to represent sediments stripped from an upstream or upslope landscape that represented a period of accumulation on that surface of nearly 6,000 radiocarbon years ago (5955 RCYBP). Close vertical proximity of these dates might have any one of several different causes. First, it is possible that sediments were eroded from this land surface (down to the 3350 RCYBP sediments) and deposited elsewhere. Another possibility is that sediments between these dates were thin on the original landscape before it was stripped, or that sediments in the upper portion of this landscape originated from a different location than the sediments yielding the date of approximately 3350 RCYBP. Radiocarbon dates do not identify either the location of sediment origin nor the mechanism of sediment transport. Elevation of High-spine Asteraceae pollen in the three samples (196A, 8, and 210, reflecting levels 7, 8, and 9) that represent the upper portion of Paleosol 1 suggests that during stabilization of those deposits, members of the sunflower family grew in abundance on the landscape at 41DL436.

The phytolith record from Zone 3 is bifurcated, with samples from Levels 9 to 7 exhibiting directional change and samples from Levels 5 and 6 exhibiting homogeneity. The pollen record indicates that sediments in Levels 9 to 7 accumulated more slowly than did sediments in Levels 6 and 5. Also, the lowest level of the zone, Level 9, reflects a phytolith assemblage that has an obvious affinity to the possible agricultural Levels 11 and 10 from Zone 2. In fact, Level 9 yielded an irregular starch grain that could be derived from maize kernels or, more likely, from grass seed (Figure 11-5O). Level 9 also yielded the highest level of dendriform (grass seed indicator) phytoliths for the entire project, with 7 tallied during the 300 phytolith count. For cool season grass-dominated landscapes, one or two dendriforms can be a natural occurrence, but 7 out of 300 is considered an unnaturally high abundance, especially in a region where cool season grasses do not dominate the landscape. The combined dendriform and starch grain 
evidence strongly suggests that a cool season grass was intentionally grown for subsistence at this location.

The phytolith record for Levels 9 to 7 are characterized by a dramatic drop in cool season C3 Pooideae phytoliths and a general decrease in all grass silica short cell phytoliths, concomitant with a dramatic rise in large-bodied buliform cell phytoliths. Large spikes in buliform phytoliths can be an indication of phytolith dissolution due to high $\mathrm{pH}$; however, there was no obvious evidence of dissolution. Therefore, it is possible that smaller-sized phytoliths (and soil particles) were lost due to erosion cause by drying soils and/or fire. Numerous charred Asteraceae inflorescence phytoliths do rise slightly in abundance periodically throughout the zone. The upper portion of Zone 3, represented by Levels 6 and 5, yielded a fairly homogenous phytolith assemblage with cool season Pooideae grass phytoliths dramatically increasing in abundance. The presence of Cyperaceae phytoliths and a few sponge spicules in Levels 6 and 5 suggest periodically moist soils for this period of time. Thus, the phytolith record suggests that some type of disturbance or change in land use occurred during the time period represented by Levels 8 and 7, followed by the return and possible introduction of new taxa to the vegetation community in Levels 6 and 5. It is possible that these upper levels of the zone reflect a transition to the Zone 4 plant community discussed next.

\section{Zone 4}

Zone 4 is represented by samples collected from Levels 4 through 1, which are part of the contemporary soil. Quantities of Quercus and High-spine Asteraceae pollen fluctuated in these sediments, probably as a result offluctuating deposition of sediments from upstream. Radiocarbon dates for features recovered from Levels 1 through 3 represent the last approximately 800 radiocarbon years. Notes on the stratigraphy of this area indicate that sediments accumulated rapidly during this interval, but it is likely that they accumulated much more slowly than did sediments associated with the lowest portion of the unit designated as the contemporary soil and the underlying Paleosol 1. The most obvious expression of sediment accumulation rate is total pollen concentration, which varies from approximately 1000 to more than 5000 pollen per cc of sediment in this zone. Elevated quantities of Quercus pollen in samples from this zone might reflect fire suppression policies of the historic era. Fluctuations in pollen frequencies probably are tied to differences in sediment transport or possibly quantities of plants in the sunflower family growing on accumulating floodplain sediments. Local plants, when growing densely, can easily overwhelm quantities of pollen transported longer distances on the wind, which causes erratic change in pollen frequencies that should be more stable or exhibit either increasing or decreasing frequencies, but not wild fluctuations. Such is likely the case here.

A reduction in microscopic charcoal suggests that fire might have been instrumental in maintaining the previous open landscape or that there was a change in fire frequency relatively recently, possibly within the historic era. These two elements of the records suggest the possibility of change in the maintenance of open vegetation through the use of fire, and possibly active modern fire suppression activities, although it is more likely that this pollen record is dominated by pollen growing on the very disturbed accumulating floodplain sediments and reflect changes in deposition conditions and/or frequency. 
In addition to dominance by Quercus pollen, small quantities of Alnus, Carya, Celtis, Fraxinus, Juniperus, Ostrya/Carpinus, Pinus, and Ulmus pollen represent a variety of trees growing either in the floodplain or the adjacent uplands. They include alder, hickory or pecan, hackberry, ash, juniper, hornbeam/hop hornbeam, pine, and elm. Although the quantities of High-spine Asteraceae and Poaceae pollen are moderately low in the samples, they do indicate that members of the sunflower family and grasses were still dominant in the floodplain vegetation community. Recovery of small quantities of Cirsium, Low-spine Asteraceae, Liguliflorae, Cheno-am, Eriogonum, Fabaceae, Malvaceae, Sphaeralcea, and Rosaceae pollen represent local growth of thistle, marsh elder and related plants, members of the chicory tribe probably including dandelion, Cheno-ams, wild buckwheat, legumes, members of the mallow family including globemallow, and at least two members of the rose family, one of which probably was chokecherry. Ferns also were present. Pollen that might represent plants introduced during the historic era includes Erodium and Trifolium pratense-type. These pollen types were, however, noted throughout the pollen record, rather than being confined to the apparently historic Zone 1 samples. The genus Erodium includes both introduced and native species and it is possible that this pollen represents a native species, rather than an introduced one. Likewise, it is possible that the Trifolium pratense-type pollen represents a native clover with pollen that is similar in morphology to that of the introduced red clover.

The uppermost two samples were the only ones to yield Sporormiella dung fungal spores, suggesting use of this area by grazing animals and the probability that these two samples represent sediments that accumulated within the historic era. Sporormiella is an ascomycete fungus found only on the dung of herbivores. The genus is widespread in subboreal and temperate regions of the world. Sporormiella spores are borne in ascomata on the surface of drying dung and are spread passively to nearby vegetation, where they are ingested (Davis and Shafer 2006). Many coprophilous fungi, such as Sporormiella, rely on a cyclic process involving herbivore ingestion of spores with foliage, germination of spores following passage through the gut, mycelial growth within, and eventual sporulation on dung (Wicklow, et al. 1980). While grazing, herbivores can also inadvertently ingest ascomata, the fruiting bodies on dung that contain millions of individual spores, especially in areas where dense herbivore populations exist (Aptroot and Geel 2006). Depending on the context of the sample, recovery of Sporormiella in archaeological samples may be an indicator for the presence and utilization of herbivores. Interpretations can range from presence of dung on the landscape to burning dung for fuel to the utilization of intestinal material for cooking and subsistence.

Sporormiella often becomes more abundant in Historic Period sediments following the historic introduction of grazing animals. Its increasing presence in historic samples has been noted in numerous palynological studies (Davis 1987). Sporormiella fungal spores are not confined to the dung of introduced herbivores, since they also occur in dung from bison, moose, wild sheep, deer, elk, caribou, and rabbits. The increase of Sporormiella spores in historic sediments might relate to changing land use patterns and increase in the length of time that herds of animals occupy any given area.

The phytolith record is characterized by sustained low relative abundances of cool season Pooideae and tall grass Panicoideae phytoliths. Phytoliths derived from warm season short 
grass Chloridoideae phytoliths subtly rise towards the top of the zone. Stipa-type bilobates from Pooideae tribe Stipeae grasses (Stipa, Hesperostipa, Achnatherum, Oryzopsis, etc.) are stable as well throughout the zone. Asteraceae inflorescence phytoliths were relatively numerous as well, especially in the lower levels of the zone. If these samples represent the historic era, then fire suppression likely has created a grass community with a greater component of trees and shrubs and possibly less grass density. The uppermost sample, Level 1 (0-10 cmbs), actually supports this notion, as a few phytoliths from hackberry (Celtis) fruits and pines (Pinus) were observed. Soil moisture indicators were scarce in this zone, as well as in Zone 3, indicating a long-term trend of decreasing soil moisture. Typically, historic era phytolith samples exhibit a decrease in phytolith morphotype diversity as one or a few non-native grasses take over the landscape. This phenomenon was not observed in the phytolith record, but rather grass phytolith morphotype diversity appears to have increased slightly, possibly as a result of microhabitats created by increased tree and shrub growth.

\section{Summary And Conclusions}

Stratigraphic pollen and phytolith analysis, originally conducted as a feasibility study for site 41DL436, yielded an abundance of information about the local vegetation for the stratigraphic sediments. Unfortunately, stratigraphic information and radiocarbon dates from features, including their association with stratigraphic levels, were not available to us earlier. Completion of stratigraphic pollen and phytolith analysis, as well as radiocarbon dating charcoal and charred seeds recovered from these sediments, provides a record of sediment transport from upstream and scouring of an upstream landscape (or possibly sediment movement from upslope) with resulting translocation of sediments to this location. This record suggests the likelihood that sediments comprising an upstream (or upslope) landscape were scoured to at least the 6000 RCYBP level, removing and transporting any archaeological and environmental information contained within that package. This probably resulted from flooding that removed sediments and established a new channel upstream. As that channel continued to erode sediments, they were carried downstream and deposited in this location, which probably also resulted in a change in river channel. Although it is tempting to interpret the stratigraphic pollen and phytolith records as representing mostly local vegetation at the time of sediment deposition, care must be taken to interpret this record literally, since it is possible that pollen and phytoliths moved with the sediments. This explanation results from a combination of the complete and uniform reversal of radiocarbon dates obtained for charcoal and charred seeds recovered from the stratigraphic profile at 41DL436, observations about the contents of the macrofloral samples from which these remains were removed, and variations in preservation in the pollen and phytolith records, including total pollen concentration. Only upon consideration of all of these factors could a cogent narrative be constructed that explains the stratigraphic relationships of the dates and the characteristics of the stratigraphic samples.

Radiocarbon dating charcoal, whether large enough to identify or microscopic, yielded a record of dates likely tied to the origin of the sediments rather than their deposition in this location. Inversion of the four dates obtained suggests stripping sediments from another location, then depositing them in this location. It is likely that this stripping and depositing occurred over the 
past approximately 1500 years and perhaps longer. The date of 535 \pm 50 RCYBP, obtained on charred seeds from Level 16, provides evidence that this is part of a relatively young package of sediment. Preservation in the macrofloral, pollen, and phytolith records is consistent with this radiocarbon date and the interpretation that it represents relatively recent sediments. Dates of $2105 \pm 20,3350 \pm 15$, and $5955 \pm 25$ RCYBP that were returned for Levels 14, 7, and 6 are in agreement with increased degradation of materials (and absence of uncharred materials) in the macrofloral, pollen, and phytolith records. Radiocarbon dates of 3350 and 5955 RCYBP were obtained on Levels 7 and 6, respectively, suggesting the possibility either of very rapid scouring of sediments and their deposition either in this location or elsewhere or a change in origin of the sediments that were deposited in this location.

Specific interpretations from the stratigraphic pollen and phytolith records include the observation of larger quantities of oak that probably grow in the area today and possibly the recent past, that are a relatively recent introduction to this ecosystem, possibly the result of fire suppression, which is further supported by the reduction in the quantities of microscopic charcoal observed in the samples. The pollen and phytolith records suggest that the water table was higher in Zone 1 at the base of this record and that the sediments gradually became drier, with a few exceptions. The higher water table is suggested by an abundance of marsh elder growing in the floodplain, evidence for algae recovered from the pollen and macrofloral samples, as well as numerous diatoms and sponge spicules noted in the phytolith record. The mixture of plants in the sunflower family and grasses changed through time but was not unidirectional, suggesting changing conditions related to floodplain sediment deposition and competition between plants that thrive in disturbed conditions and the possibility that some of the pollen and phytoliths were transported along with the sediments. Phytolith data indicate that the earliest part of the record represents an open habitat dominated by tall panicoid grasses, sedges, and forbs such as spiderwort and erect dayflower. Hackberry trees were also on the landscape. Overall, the biotic community on the landscape for this early period most likely resembled the Bluestem Prairie Vegetation-Type as defined by Kuchler (1964) (see Table 6), and likely represents a natural prairie and riverine ecosystem pre-European settlement of the area. The pollen record also documents local growth of a variety of plants that could have been important in the local subsistence such as some members of the umbel family, some of the members of the sunflower family, the mustard family, Cheno-ams, sedges, legumes, mint family, grass seed, chokecherry, and wild grape.

Phytolith data from the middle portion of the record (Zone 2) yielded some interesting evidence of intentional grass cultivation. No diagnostic evidence for agriculture involving Zea mays was recovered from either the pollen or the phytolith records; however, some intriguing Zea-type phytoliths were recovered within Zone 2. From the pollen record, Zone 2 also exhibited a peak in microscopic charcoal, suggesting that burning may have been part of the agricultural practices employed here. 
Table 11-1. Provenience Data For Samples..

\begin{tabular}{|c|c|c|c|c|c|}
\hline $\begin{array}{c}\text { Sample } \\
\text { No. }\end{array}$ & Zone & Level & $\begin{array}{l}\text { Depth } \\
\text { (cmbs) }\end{array}$ & Provenience/Description & Analysis \\
\hline 137 & 4 & 1 & $0-10$ & Stratigraphic column sample & Pollen Phytolith \\
\hline 2 & & 2 & $10-20$ & Stratigraphic column sample & Pollen Phytolith \\
\hline 167 & & 3 & $20-30$ & Stratigraphic column sample & Pollen Phytolith \\
\hline 4 & & 4 & $30-40$ & Stratigraphic column sample & Pollen Phytolith \\
\hline 186 & 3 & 5 & $40-50$ & Stratigraphic column sample & Pollen Phytolith \\
\hline 6 & & 6 & $50-60$ & Stratigraphic column sample & Pollen Phytolith \\
\hline 191 & & 6 & $50-60$ & Stratigraphic column sample & $\begin{array}{c}\text { Macrofloral Microcharcoa } \\
\text { AMS }{ }^{14} \mathrm{C} \text { Date }\end{array}$ \\
\hline $196 \mathrm{~A}$ & & 7 & $60-70$ & Stratigraphic column sample & Pollen Phytolith \\
\hline 196B & & 7 & $60-70$ & Stratigraphic column sample & $\begin{array}{c}\text { Macrofloral Microcharcoa } \\
\text { AMS }{ }^{14} \mathrm{C} \text { Date }\end{array}$ \\
\hline 8 & & 8 & $70-80$ & Stratigraphic column sample & Pollen Phytolith \\
\hline 210 & & 9 & $80-90$ & Stratigraphic column sample & Pollen Phytolith \\
\hline 10 & 2 & 10 & $90-100$ & Stratigraphic column sample & Pollen Phytolith \\
\hline 224 & & 11 & $100-110$ & Stratigraphic column sample & Pollen Phytolith \\
\hline 12 & & 12 & $110-120$ & Stratigraphic column sample & Pollen Phytolith \\
\hline 225 & & 13 & $120-130$ & Stratigraphic column sample & Pollen Phytolith \\
\hline 14 & 2 & 14 & $130-140$ & Stratigraphic column sample & Pollen Phytolith \\
\hline 234 & & 14 & $130-140$ & Stratigraphic column sample & Macrofloral AMS ${ }^{14} \mathrm{C}$ Date \\
\hline 237 & & 15 & $140-150$ & Stratigraphic column sample & Pollen Phytolith \\
\hline 16 & 1 & 16 & $150-160$ & Stratigraphic column sample & Pollen Phytolith \\
\hline 241 & & 16 & $150-160$ & Stratigraphic column sample & Macrofloral AMS ${ }^{14} \mathrm{C}$ Date \\
\hline 244 & & 17 & $160-170$ & Stratigraphic column sample & Pollen Phytolith \\
\hline 18 & & 18 & $170-180$ & Stratigraphic column sample & Pollen Phytolith \\
\hline 253 & & 19 & $180-190$ & Stratigraphic column sample & Pollen Phytolith \\
\hline 20 & & 20 & 190-200 & Stratigraphic column sample & Pollen Phytolith \\
\hline
\end{tabular}


Table 11-2. Macrofloral Remains.

\begin{tabular}{|c|c|c|c|c|c|c|c|}
\hline \multirow{2}{*}{$\begin{array}{c}\text { Sample } \\
\text { No. }\end{array}$} & \multirow{2}{*}{ Identification } & \multirow{2}{*}{ Part } & \multicolumn{2}{|c|}{ Charred } & \multicolumn{2}{|c|}{ Uncharred } & \multirow{2}{*}{ Weights/Comments } \\
\hline & & & W & $\mathrm{F}$ & W & $\mathrm{F}$ & \\
\hline \multirow[t]{11}{*}{191} & Liters Floated & & & & & & $1.60 \mathrm{~L}$ \\
\hline & Microcharcoal Screen Contents & & & & & & $2.851 \mathrm{~g}$ \\
\hline & Light Fraction Weight & & & & & & $0.936 \mathrm{~g}$ \\
\hline & FLORAL REMAINS: & & & & & & \\
\hline & Unidentified charred material & & & 1 & & & $0.0001 \mathrm{~g}$ \\
\hline & Rootlets & & & & & $x$ & Few \\
\hline & & CHAR & $\mathrm{L} / \mathrm{WC}$ & & & & \\
\hline & Total wood greater than $2 \mathrm{~mm}$ & & & & & & $0.1659 \mathrm{~g}$ \\
\hline & Platanus occidentalis cf. root & Wood & & & & 9 & $0.0665 \mathrm{~g}$ \\
\hline & Unidentified hardwood root & Wood & & & & 5 & $0.0994 \mathrm{~g}$ \\
\hline & NON-FLORAL REMAINS: & & & & & & \\
\hline \multirow{12}{*}{$\begin{array}{c}\text { Level } 6 \\
50-60 \mathrm{cmbs}\end{array}$} & Bone greater than $1 \mathrm{~mm}$ & & & & & 2 & $0.0317 \mathrm{~g}$ \\
\hline & Bone less than $1 \mathrm{~mm}$ & & & & & $x$ & Few \\
\hline & Vertebra & & & & 2 & 1 & $0.0036 \mathrm{~g}$ \\
\hline & Insect & Chitin & & & & $x$ & Few \\
\hline & Insect & Egg & & & $x$ & & Numerous \\
\hline & Rock & & & & & $x$ & Few \\
\hline & Shell greater than $1 \mathrm{~mm}$ & & & & & 7 & $0.0087 \mathrm{~g}$ \\
\hline & Shell less than $1 \mathrm{~mm}$ & & & & & $x$ & Moderate \\
\hline & Snail shell - depressed greater than $1 \mathrm{~mm}$ & & & & 3 & & $0.0021 \mathrm{~g}$ \\
\hline & Snail shell - depressed less than $1 \mathrm{~mm}$ & & & & $x$ & $x$ & Moderate \\
\hline & Snail shell - oblong greater than $1 \mathrm{~mm}$ & & & & 3 & & $0.0024 \mathrm{~g}$ \\
\hline & Snail shell - oblong less than $1 \mathrm{~mm}$ & & & & $x$ & $x$ & Moderate \\
\hline \multirow{10}{*}{$196 \mathrm{~B}$} & Liters Floated & & & & & & $1.60 \mathrm{~L}$ \\
\hline & Microcharcoal Screen Contents & & & & & $0.565 \mathrm{~g}$ & \\
\hline & Light Fraction Weight & & & & & & $1.506 \mathrm{~g}$ \\
\hline & \multicolumn{7}{|c|}{ FLORAL REMAINS: } \\
\hline & Rudbeckia & Seed & & & & 1 & \\
\hline & Unidentified greater than $1 \mathrm{~mm}$ & Leaf & & & & 6 & $0.0018 \mathrm{~g}$ \\
\hline & Rootlets & & & & & $x$ & Few \\
\hline & & CHAR & $\mathrm{LL} / \mathrm{WC}$ & & & & \\
\hline & Total charcoal greater than $2 \mathrm{~mm}$ & & & & & & \\
\hline & Unidentifiable - small & Charcoal & & $x$ & & & $0.0007 \mathrm{~g}$ \\
\hline \multirow{11}{*}{$\begin{array}{c}\text { Level } 7 \\
60-70 \\
\text { cmbs }\end{array}$} & Total wood greater than $2 \mathrm{~mm}$ & & & & & & \\
\hline & Unidentified hardwood root & Wood & & & & 2 & $0.0113 \mathrm{~g}$ \\
\hline & \multicolumn{7}{|c|}{ NON-FLORAL REMAINS: } \\
\hline & Bone greater than $0.5 \mathrm{~mm}$ & & & & & 1 & $0.0001 \mathrm{~g}$ \\
\hline & Insect & Egg & & & $x$ & & Moderate \\
\hline & Shell greater than $1 \mathrm{~mm}$ & & & & & 15 & $0.0487 \mathrm{~g}$ \\
\hline & Shell less than $1 \mathrm{~mm}$ & & & & & $x$ & Moderate \\
\hline & Snail shell - depressed greater than $1 \mathrm{~mm}$ & & & & 4 & 2 & $0.0038 \mathrm{~g}$ \\
\hline & Snail shell - depressed less than $1 \mathrm{~mm}$ & & & & & $x$ & Moderate \\
\hline & Snail shell - oblong greater than $1 \mathrm{~mm}$ & & & & 7 & 1 & $0.0091 \mathrm{~g}$ \\
\hline & Snail shell - oblong less than $1 \mathrm{~mm}$ & & & & & $x$ & Few \\
\hline
\end{tabular}


Table 11-2. Macrofloral Remains.(continued)

\begin{tabular}{|c|c|c|c|c|c|c|c|c|}
\hline \multirow{2}{*}{ Sample No. } & \multirow{2}{*}{ Identification } & \multirow{2}{*}{ Part } & \multicolumn{3}{|c|}{ Charred } & \multicolumn{2}{|c|}{ Uncharred } & \multirow{2}{*}{$\begin{array}{l}\text { Weights/ } \\
\text { Comments }\end{array}$} \\
\hline & & & W & & $\mathrm{F}$ & W & $\mathrm{F}$ & \\
\hline \multirow[t]{14}{*}{234} & Liters Floated & & & & & & & $2.00 \mathrm{~L}$ \\
\hline & Microcharcoal Screen Contents & & & & & & & $17.735 \mathrm{~g}$ \\
\hline & Light Fraction Weight & & & & & & & $0.779 \mathrm{~g}$ \\
\hline & \multicolumn{8}{|c|}{ FLORAL REMAINS: } \\
\hline & Monocot greater than $0.5 \mathrm{~mm}$ & Stem & & 11 & & & & $0.0013 \mathrm{~g}$ \\
\hline & Poaceae greater than $0.25 \mathrm{~mm}$ & Awn & & 4 & & & & $0.0001 \mathrm{~g}$ \\
\hline & Parenchymous tissue greater than $1 \mathrm{~mm}$ & & & 4 & & & & $0.0002 \mathrm{~g}$ \\
\hline & Unidentified vitrified greater than $1 \mathrm{~mm}$ & Seed & 1 ic & 1 & & & & $0.0018 \mathrm{~g}$ \\
\hline & Celtis & Seed coat & & & & 6 & & $0.0103 \mathrm{~g}$ \\
\hline & Chara & Oogonia & & & $x$ & $x$ & & Numerous \\
\hline & Rudbeckia & Seed & & & & 8 & & \\
\hline & Ulmus & Fruit & & & 5 & 3 & & $0.0142 \mathrm{~g}$ \\
\hline & Ulmus & Seed & & & 1 & & & $0.0016 \mathrm{~g}$ \\
\hline & Rootlets & & & & & $x$ & & Few \\
\hline \multirow{16}{*}{$\begin{array}{c}\text { Level } 14 \\
130-140 \\
\text { cmbs }\end{array}$} & \multicolumn{8}{|c|}{ CHARCOAL/WOOD: } \\
\hline & Total charcoal greater than $0.25 \mathrm{~mm}$ & & & & & & & $0.0047 \mathrm{~g}$ \\
\hline & Unidentifiable - small ** & Charcoal & & $x$ & & & & $0.0047 \mathrm{~g}$ \\
\hline & \multicolumn{8}{|c|}{ NON-FLORAL REMAINS: } \\
\hline & Bone greater than $1 \mathrm{~mm}$ & & & & & 2 & & $0.0069 \mathrm{~g}$ \\
\hline & Bone less than $1 \mathrm{~mm}$ & & & & & $x$ & & Few \\
\hline & Fish bone greater than $1 \mathrm{~mm}$ & & & & & 3 & & $0.0037 \mathrm{~g}$ \\
\hline & Fish scale greater than $0.5 \mathrm{~mm}$ & & & & & 10 & & $0.0015 \mathrm{~g}$ \\
\hline & Gravel/Sand & & & & & $x$ & & Few \\
\hline & Shell greater than $1 \mathrm{~mm}$ & & & & & 53 & & $0.0950 \mathrm{~g}$ \\
\hline & Shell less than $1 \mathrm{~mm}$ & & & & & $x$ & & Numerous \\
\hline & Shell - bivalve greater than $1 \mathrm{~mm}$ & & & & & 1 & & $0.0013 \mathrm{~g}$ \\
\hline & Snail shell - depressed greater than $1 \mathrm{~mm}$ & & & & 34 & 14 & & $0.0720 \mathrm{~g}$ \\
\hline & Snail shell - depressed less than $1 \mathrm{~mm}$ & & & & & $x$ & & Numerous \\
\hline & Snail shell - oblong greater than $1 \mathrm{~mm}$ & & & & 84 & 10 & & $0.0731 \mathrm{~g}$ \\
\hline & Snail shell - oblong less than $1 \mathrm{~mm}$ & & & & & $x$ & & Numerous \\
\hline
\end{tabular}




\begin{tabular}{|c|c|c|c|c|c|c|c|c|}
\hline \multirow{2}{*}{ Sample No. } & \multirow{2}{*}{ Identification } & \multirow{2}{*}{ Part } & \multicolumn{3}{|c|}{ Charred } & \multicolumn{2}{|c|}{ Uncharred } & \multirow{2}{*}{$\begin{array}{l}\text { Weights/ } \\
\text { Comments }\end{array}$} \\
\hline & & & W & $\mathrm{F}$ & & W & $\mathrm{F}$ & \\
\hline & Microcharcoal Screen Contents & & & & & $4.051 \mathrm{~g}$ & & \\
\hline & Light Fraction Weight & & & & & & & $1.430 \mathrm{~g}$ \\
\hline \multicolumn{9}{|c|}{ FLORAL REMAINS: } \\
\hline & Bark greater than $1 \mathrm{~mm}$ & & & & & & & $0.0360 \mathrm{~g}$ \\
\hline & Chenopodium & Seed & & & & & & less than $0.0001 \mathrm{~g}$ \\
\hline & Galium ** & Seed & & & & & & $0.0018 \mathrm{~g}$ \\
\hline & Monocot greater than $0.5 \mathrm{~mm}$ & Stem & & & & & & $0.0034 \mathrm{~g}$ \\
\hline & Parenchymous tissue greater than $0.5 \mathrm{~mm}$ & & & & & & & $0.0040 \mathrm{~g}$ \\
\hline & Poaceae greater than $0.25 \mathrm{~mm}$ & Awn & & & & & & less than $0.0001 \mathrm{~g}$ \\
\hline & Poaceae B & Caryopsis & & & & & & $0.0001 \mathrm{~g}$ \\
\hline & Unidentified & Fruit & & & & & & $0.0008 \mathrm{~g}$ \\
\hline & Unidentified & Seed & & & & & & $0.0001 \mathrm{~g}$ \\
\hline & Unidentified & Seed & & & & & & less than $0.0001 \mathrm{~g}$ \\
\hline & Unidentified - vitrified & Seed & 1 & & & & & $0.0008 \mathrm{~g}$ \\
\hline & Celtis greater than $1 \mathrm{~mm}$ & Seed coat & & & & 46 & & $0.0892 \mathrm{~g}$ \\
\hline & Celtis less than $1 \mathrm{~mm}$ & Seed coat & & & & $x$ & & Numerous \\
\hline & Chara & Oogonia & & & $x$ & $x$ & & Numerous \\
\hline & Rudbeckia & Seed & & & 2 & $x$ & & Moderate \\
\hline & Verbesina & Seed & & & 2 & & & \\
\hline & Verbesina & Endosperm & & & 1 & & & \\
\hline & Unidentified greater than $1 \mathrm{~mm}$ & Leaf & & & & 2 & & $0.0008 \mathrm{~g}$ \\
\hline & Unidentified & Seed & & & & 1 & & \\
\hline \multirow{25}{*}{$\begin{array}{c}\text { Level } 16 \\
150-160 \\
\text { cmbs }\end{array}$} & Unidentified & Endosperm & & & 1 & & & \\
\hline & Rootlets & & & & & $x$ & & Few \\
\hline & CHARCOAL/WOOD: & & & & & & & \\
\hline & Total charcoal greater than $0.5 \mathrm{~mm}$ & & & & & & & $0.0089 \mathrm{~g}$ \\
\hline & Unidentifiable - small & Charcoal & & & & & & $0.0089 \mathrm{~g}$ \\
\hline & Total wood greater than $2 \mathrm{~mm}$ & & & & & & & $0.746 \mathrm{~g}$ \\
\hline & Unidentified hardwood root & Wood & & & & 9 & & $0.746 \mathrm{~g}$ \\
\hline & & NON-FLO & REM & & & & & \\
\hline & Bone greater than $1 \mathrm{~mm}$ & & & & 2 & 13 & & $0.0787 \mathrm{~g}$ \\
\hline & Bone less than $1 \mathrm{~mm}$ & & & & & $x$ & & Moderate \\
\hline & Small mammal tooth greater than $0.5 \mathrm{~mm}$ & & & & 2 & & & $0.0042 \mathrm{~g}$ \\
\hline & Vertebra greater than $1 \mathrm{~mm}$ & & & & 4 & & & $0.0057 \mathrm{~g}$ \\
\hline & Fish scale greater than $1 \mathrm{~mm}$ & & & & & 2 & & less than $0.0001 \mathrm{~g}$ \\
\hline & Fish scale less than $1 \mathrm{~mm}$ & & & & & $x$ & & Few \\
\hline & Fish scale - cycloid greater than $1 \mathrm{~mm}$ & & & & 1 & & & less than $0.0001 \mathrm{~g}$ \\
\hline & Insect & Chitin & & & & $x$ & & Few \\
\hline & Ostracod & & & & $x$ & $x$ & & Numerous \\
\hline & Sand & & & & & $x$ & & Few \\
\hline & Shell greater than $1 \mathrm{~mm}$ & & & & & 41 & & $0.0884 \mathrm{~g}$ \\
\hline & Shell less than $1 \mathrm{~mm}$ & & & & & $x$ & & Numerous \\
\hline & Shell - bivalve greater than $1 \mathrm{~mm}$ & & & & 2 & & & $0.0199 \mathrm{~g}$ \\
\hline & Snail shell - depressed greater than $1 \mathrm{~mm}$ & & & & 38 & 16 & & $0.0513 \mathrm{~g}$ \\
\hline & Snail shell - depressed less than $1 \mathrm{~mm}$ & & & & & $x$ & & Moderate \\
\hline & Snail shell - oblong greater than $1 \mathrm{~mm}$ & & & & 48 & 11 & & $0.0487 \mathrm{~g}$ \\
\hline & Snail shell - oblong less than $1 \mathrm{~mm}$ & & & & $x$ & $x$ & & Moderate \\
\hline
\end{tabular}




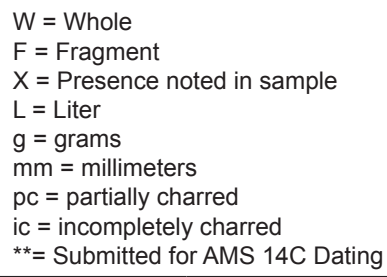

Table 11-3. Index of Macrofloral Remains.

\begin{tabular}{|c|c|}
\hline Scientific Name & Common Name \\
\hline \multicolumn{2}{|r|}{ FLORAL REMAINS: } \\
\hline Celtis & Hackberry \\
\hline Chara & $\begin{array}{l}\text { Stonewort - a submerged algae found mostly in hard-water or alkaline } \\
\text { lakes and slowly flowing streams with abundant calcium }\end{array}$ \\
\hline Chenopodium & Goosefoot, Pigweed \\
\hline Galium & Bedstraw, Cleaver's \\
\hline Monocot & $\begin{array}{l}\text { A member of the Monocotyledonae class of Angiosperms, which include } \\
\text { grasses, sedges, lilies, agave family, spiderwort family, and palms }\end{array}$ \\
\hline Monocot/Herbaceous dicot & $\begin{array}{l}\text { A member of the Monocotyledonae class of Angiosperms, which include } \\
\text { grasses, sedges, agave family, spiderwort family, lilies, and palms/ A non- } \\
\text { woody member of the Dicotyledonae class of Angiosperms }\end{array}$ \\
\hline Periderm & $\begin{array}{l}\text { Technical term for bark; Consists of the cork (phellum) which is } \\
\text { produced by the cork cambium, as well as any epidermis, cortex, and } \\
\text { primary or secondary phloem exterior to the cork cambium }\end{array}$ \\
\hline Poaceae & Grass family \\
\hline Rudbeckia & Coneflower \\
\hline Ulmus & Elm \\
\hline Verbesina & Crownbeard, Cowpen daisy \\
\hline Parenchymous tissue & $\begin{array}{l}\text { Relatively undifferentiated tissue composed of many similar cells with thin primary walls- } \\
\text { occurs in different plant organs in varying amounts, especially large fleshy organs such } \\
\text { as roots and stems, but also fruits, seeds, cones, periderm (bark), leaves, needles, etc. }\end{array}$ \\
\hline \multicolumn{2}{|r|}{ CHARCOAL/WOOD: } \\
\hline Platanus occidentalis & American sycamore \\
\hline Unidentified hardwood & Wood from a broad-leaved flowering tree or shrub \\
\hline \multicolumn{2}{|r|}{ NON-FLORAL REMAINS: } \\
\hline Fish scale - cycloid & $\begin{array}{l}\text { Circular fish scale with smooth edges; found on fish with soft fin } \\
\text { rays such salmon, trout, herring, pike, minnow, etc. }\end{array}$ \\
\hline Ostracod & $\begin{array}{l}\text { Small, bivalved crustaceans widely distributed in fresh and saline water, normally } \\
\text { under well oxygenated conditions in lakes, ponds, springs, and streams }\end{array}$ \\
\hline Snail shell - depressed & Snail shell with a depressed (flat) shape where the width is much bigger than the height \\
\hline Snail shell - oblong & Snail shell with an oblong shape where the height is much bigger than the width \\
\hline
\end{tabular}


Table 11-4. Radiocarbon Results for Samples.

\begin{tabular}{|c|c|c|c|c|}
\hline Sample No. & $\begin{array}{c}\text { Sample } \\
\text { Identification }\end{array}$ & AMS 14C Date* & $\begin{array}{c}\text { 1-sigma Calibrated } \\
\text { Date }(68.2 \%)\end{array}$ & $\begin{array}{c}\text { 2-sigma Calibrated } \\
\text { Date }(95.4 \%)\end{array}$ \\
\hline \multirow[t]{2}{*}{ PRI-11-068-191 } & Microcharcoal & $5955 \pm 25$ RCYBP & $\begin{array}{l}\text { 6835-6815; 6800- } \\
\text { 6740 CAL yr. BP }\end{array}$ & 6890-6720 CAL yr. BP \\
\hline & & & $\begin{array}{l}\text { 4885-4865 BC } \\
4850-4790 \mathrm{BC}\end{array}$ & $4940-4770 \mathrm{BC}$ \\
\hline \multirow[t]{2}{*}{ PRI-11-068-196B } & Microcharcoal & $3350 \pm 15$ RCYBP & 3620-3565 CAL yr. BP & $\begin{array}{l}\text { 3640-3550; 3530- } \\
3480 \text { CAL yr. BP }\end{array}$ \\
\hline & & & $1670-1615$ BC & $\begin{array}{l}1690-1600 \mathrm{BC} \\
1580-1530 \mathrm{BC}\end{array}$ \\
\hline \multirow[t]{2}{*}{ PRI-11-068-234 } & $\begin{array}{l}\text { Unidentifiable } \\
\text { charcoal }\end{array}$ & $2105 \pm 20$ RCYBP & 2120-2040 CAL yr. BP & 2150-2000 CAL yr. BP \\
\hline & & & $170-90 \mathrm{BC}$ & $200-50 \mathrm{BC}$ \\
\hline \multirow[t]{2}{*}{ PRI-11-068-241 } & $\begin{array}{l}\text { Galium seed, } \\
\text { charred }\end{array}$ & $535 \pm 50 \mathrm{RCYBP}$ & $\begin{array}{c}\text { 630-600; } 560-510 \\
\text { CAL yr. BP }\end{array}$ & $\begin{array}{c}650-580 ; 570-500 \\
\text { CAL yr. BP }\end{array}$ \\
\hline & & & $\begin{array}{l}\text { AD } 1320-1350 \\
\text { AD } 1390-1440\end{array}$ & $\begin{array}{l}\text { AD } 1300-1370 \\
\text { AD } 1380-1450\end{array}$ \\
\hline
\end{tabular}

${ }^{*}$ Reported in radiocarbon years at 1 standard deviation measurement precision (68.2\%),

corrected for $\delta 13 \mathrm{C}$

Table 11-5. Pollen Types Observed in Samples.

\begin{tabular}{|c|c|}
\hline Scientific Name & Common Name \\
\hline \multicolumn{2}{|l|}{ ARBOREAL POLLEN: } \\
\hline Betulaceae: & Birch family \\
\hline Alnus & Alder \\
\hline Carpinus/Ostrya & Hornbeam/Hophornbeam \\
\hline Juglandaceae: & Walnut family \\
\hline Carya & Hickory, pecan \\
\hline Juglans & Walnut \\
\hline Celtis & Hackberry \\
\hline Diospyros & Persimmon \\
\hline Fraxinus & Ash \\
\hline Juniperus & Juniper \\
\hline Liquidambar & Sweetgum \\
\hline Pinaceae: & Pine family \\
\hline Abies & Fir \\
\hline Pinus & Pine \\
\hline Quercus & Oak \\
\hline Ulmus & American Elm or, White Elm, Water Elm \\
\hline \multicolumn{2}{|l|}{ NON-ARBOREAL POLLEN: } \\
\hline Apiaceae & Umbel family \\
\hline Asteraceae: & Sunflower family \\
\hline Artemisia & Sagebrush \\
\hline Cirsium & Thistle \\
\hline Low-spine & Includes ragweed, cocklebur, sumpweed \\
\hline High-spine & Includes aster, rabbitbrush, snakeweed, sunflower, etc. \\
\hline
\end{tabular}


Table 11-5. Pollen Types Observed in Samples.(continued)

\begin{tabular}{|c|c|}
\hline Scientific Name & Common Name \\
\hline Liguliflorae & Chicory tribe, includes dandelion and chicory \\
\hline Liguliflorae tricolpate & Chicory tribe, includes dandelion and chicory \\
\hline Brassicaceae & Mustard or cabbage family \\
\hline Turnera & Turnera \\
\hline Cheno-am & Includes the goosefoot family and amaranth \\
\hline Sarcobatus & Greasewood \\
\hline Cyperaceae & Sedge family \\
\hline $\begin{array}{l}\text { Ephedra torreyana-type (includes E. torreyana, } \\
\text { E. trifurca, and E. antisyphilitica) }\end{array}$ & Ephedra, Jointfir, Mormon tea \\
\hline Polygonaceae: & Knotweed/Smartweed family \\
\hline Eriogonum & Wild buckwheat \\
\hline Persicaria-type & Persicaria, Smartweed, Pinkweed \\
\hline Erodium & Storksbill, Heron-bill, Filaree \\
\hline Fabaceae: & Bean or Legume family \\
\hline Dalea-type & Prairie Clover \\
\hline Melilotus & Sweet clover \\
\hline Trifolium & Clover \\
\hline Trifolium pratense-type & Red clover \\
\hline Fabaceae triangular & Bean or Legume family \\
\hline Lamiaceae & Mint family \\
\hline Malvaceae: & Mallow family \\
\hline Sphaeralcea & Globemallow \\
\hline Onagraceae & Evening primrose family \\
\hline Passiflora & Passionflower \\
\hline Polygonaceae: & Knotweed/Smartweed family \\
\hline Eriogonum & Wild buckwheat \\
\hline Persicaria-type & Persicaria, Smartweed, Pinkweed \\
\hline Phlox & Phlox \\
\hline Plantago & Plantain \\
\hline Poaceae & Grass family \\
\hline Rosaceae: & Rose family \\
\hline $\begin{array}{l}\text { Rosaceae - striate (includes Purshia, Prunus, } \\
\text { Coleogyne, Crataegus, Malus, and Pyrus) }\end{array}$ & $\begin{array}{l}\text { Rose family - includes bitterbrush, chokecherry, cherry, plum, peach/ } \\
\text { nectarine, apricot, almond, blackbrush, hawthorn, apple, and pear }\end{array}$ \\
\hline Prunus-type & Chokecherry, cherry, plum, etc. \\
\hline Tribulus-type & Puncture vine \\
\hline Vitis & Grape \\
\hline Indeterminate & Too badly deteriorated to identify \\
\hline \multicolumn{2}{|l|}{ SPORES: } \\
\hline Monolete fern spores & Fern \\
\hline Trilete fern spores & Fern \\
\hline
\end{tabular}


Table 11-5. Pollen Types Observed in Samples.(continued)

\begin{tabular}{ll}
\hline \multicolumn{1}{c}{ Scientific Name } & Common Name \\
\hline ALGAE: & \\
\hline Algae spores & Algal body \\
Zygnema-type & Algal body \\
FUNGAL SPORES: & \\
Sporormiella & Dung fungus \\
OTHER: & \\
Hystrichosphere & Geologic plankton \\
Redeposited Pinus & Redeposited pine pollen \\
Microscopic charcoal & Microscopic charcoal \\
\hline Total pollen concentration & Quantity of pollen per cubic centimeter (cc) of sediment \\
\hline
\end{tabular}

Table 11-6. Bluestem -Grama Prairie Vegetation-Type.

Description: Dense medium tall grassland with many forbs

\section{Dominant Vegetation}

Little bluestem (Andropogon scoparius) $\left(\mathrm{C}_{4}\right.$ - panicoid phytoliths)

Sideoats grama (Bouteloua curtipendula) $\left(\mathrm{C}_{4}\right.$ - saddle phytoliths)

Blue grama (Bouteloua gracilis) $\left(\mathrm{C}_{4}\right.$ - saddle phytoliths)

\section{Associated Vegetation}

Grasses

Pascopyrum smithii $\left(\mathrm{C}_{3}\right.$ - festucoid phytoliths), Andropogon gerardii $\left(\mathrm{C}_{4}\right.$ - panicoid phytoliths), Buchloë dactyloides $\left(\mathrm{C}_{4}\right.$ - saddle phytoliths), Panicum virgatum $\left(\mathrm{C}_{4}\right.$ - panicoid phytoliths), Sorghastrum nutans $\left(\mathrm{C}_{4}\right.$ - panicoid phytoliths $)$, Sporobolus asper $\left(\mathrm{C}_{4}-\right.$ saddle phytoliths)

Forbs

Ambrosia stilostachya (LOW SPINE), Amorpha canescens (FAB), Clematis fremontii (RANUNC), Dalea enneandra (FAB), Echinacea angustifolia (HIGH SPINE), Erysimum asperum (BRASS), Hedeoma hispida (LAMIACEAE), Liatris punctata (HIGH SPINE), Oenothera serrulata (ONAG), Paronychia jamesii (CARYOPH), Psoralea tenuiflora (FAB), Scutellaria resinosa (LAMIACEAE), Stenosiphon linifolius (ONAG) 


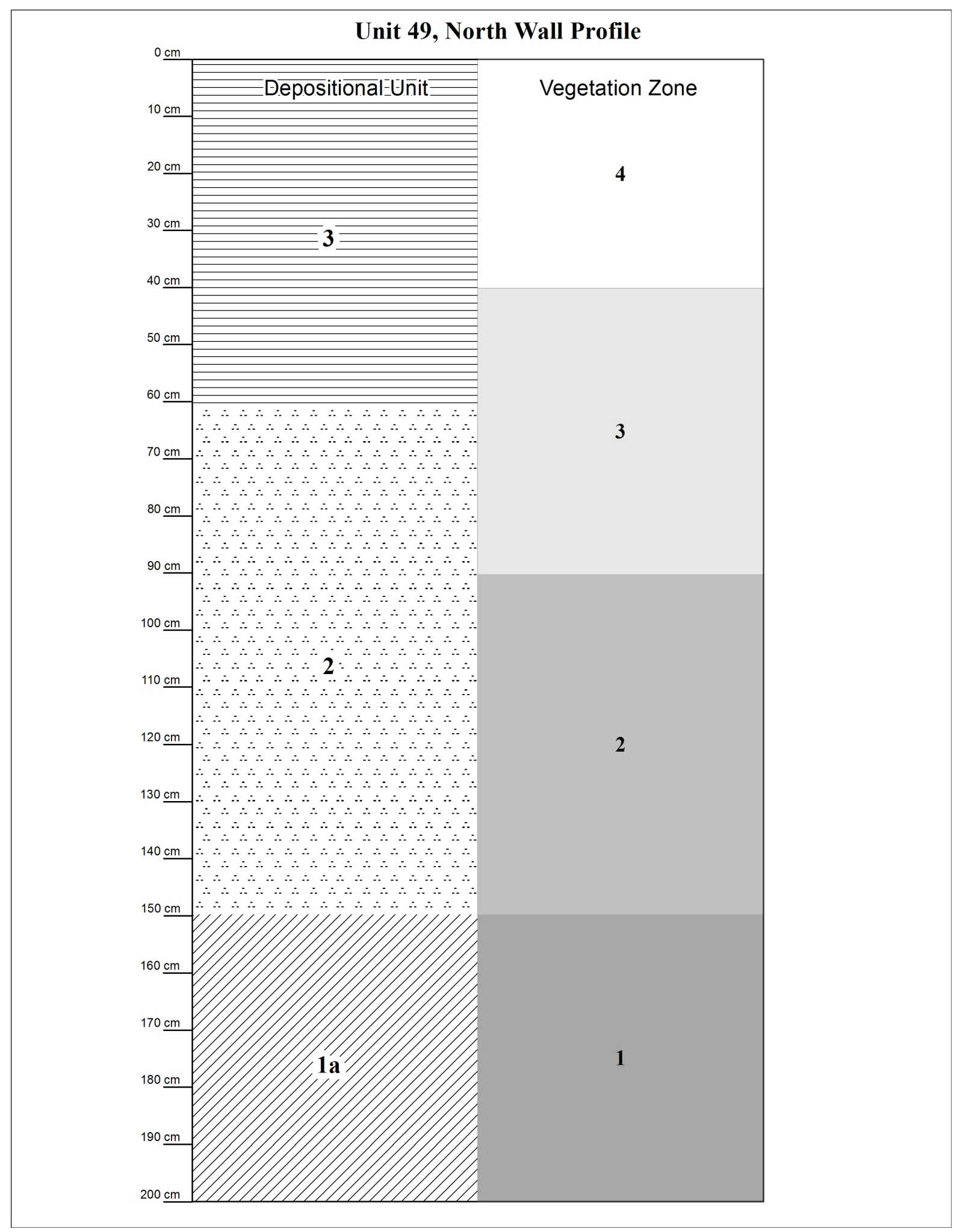

Figure 11-1. Unit 49 depositional units and vegetation zones. 


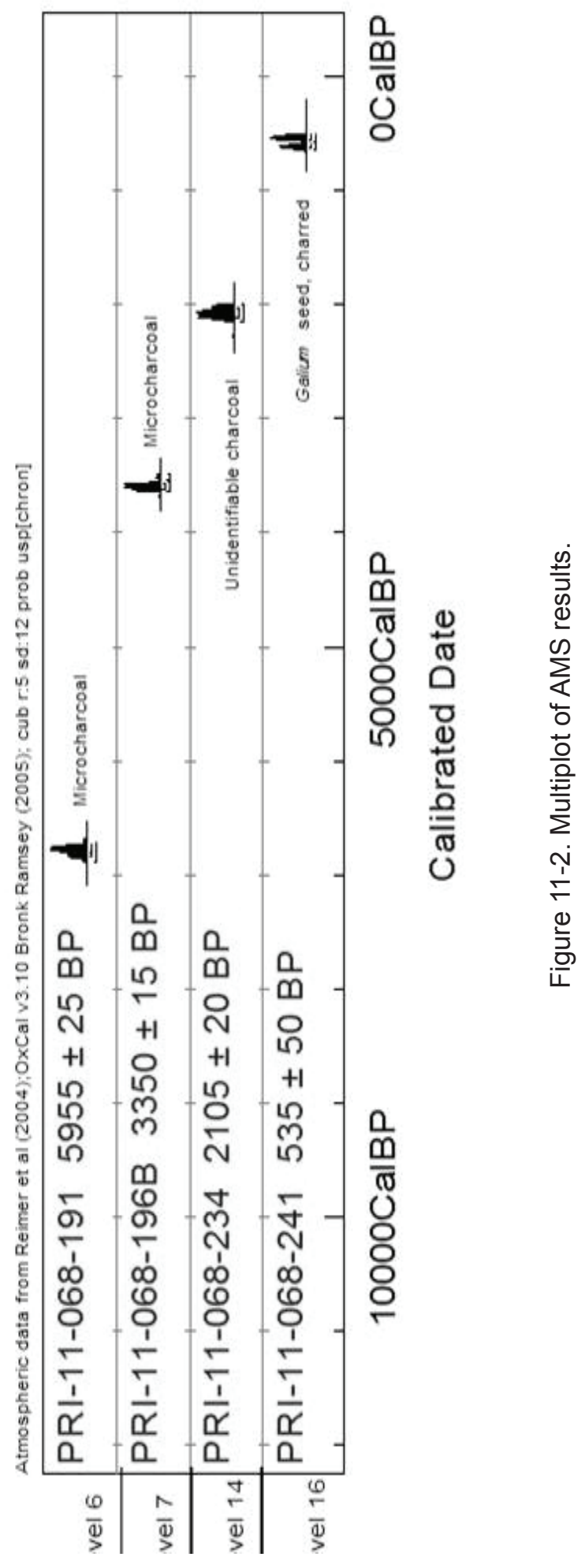




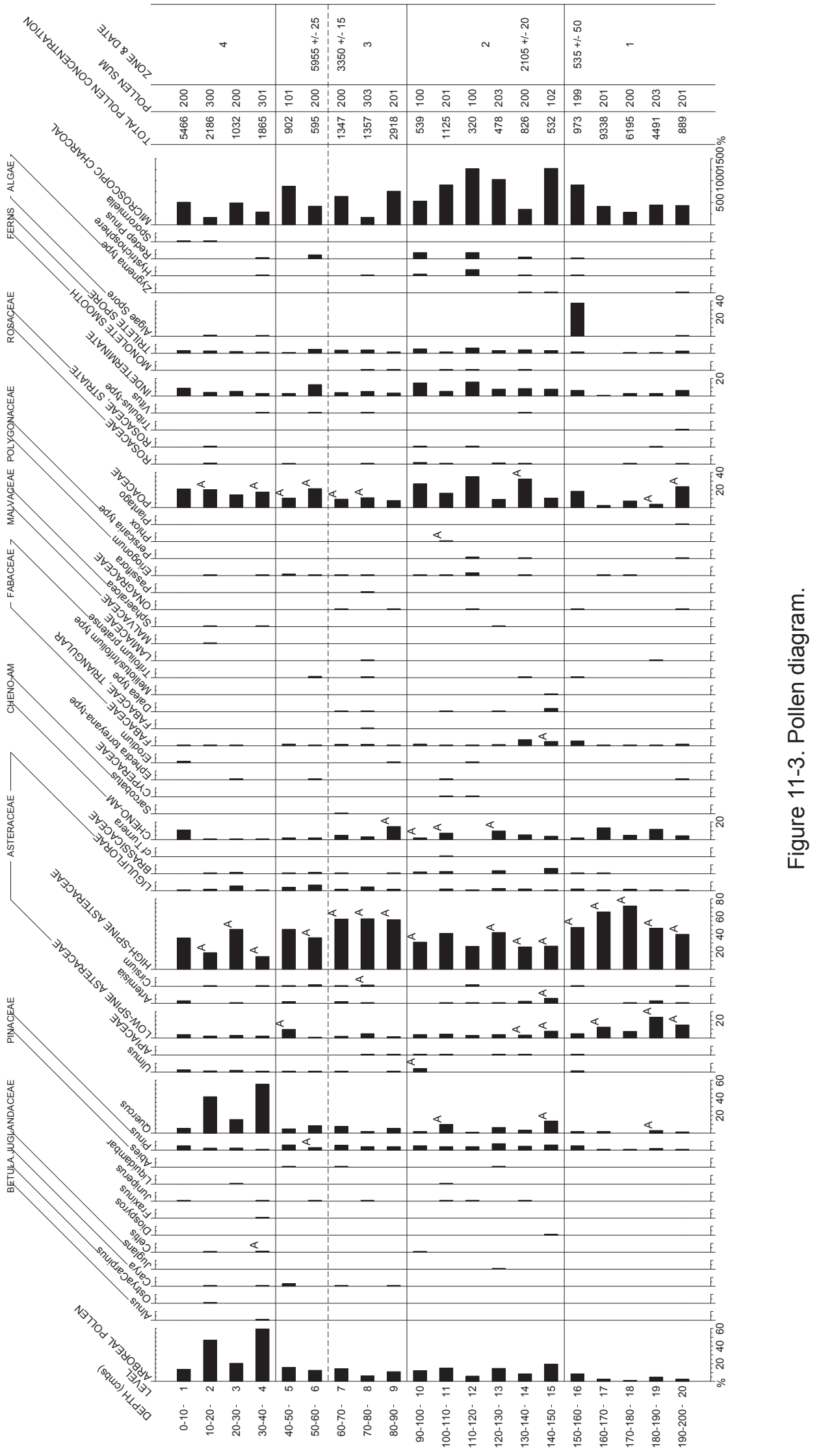




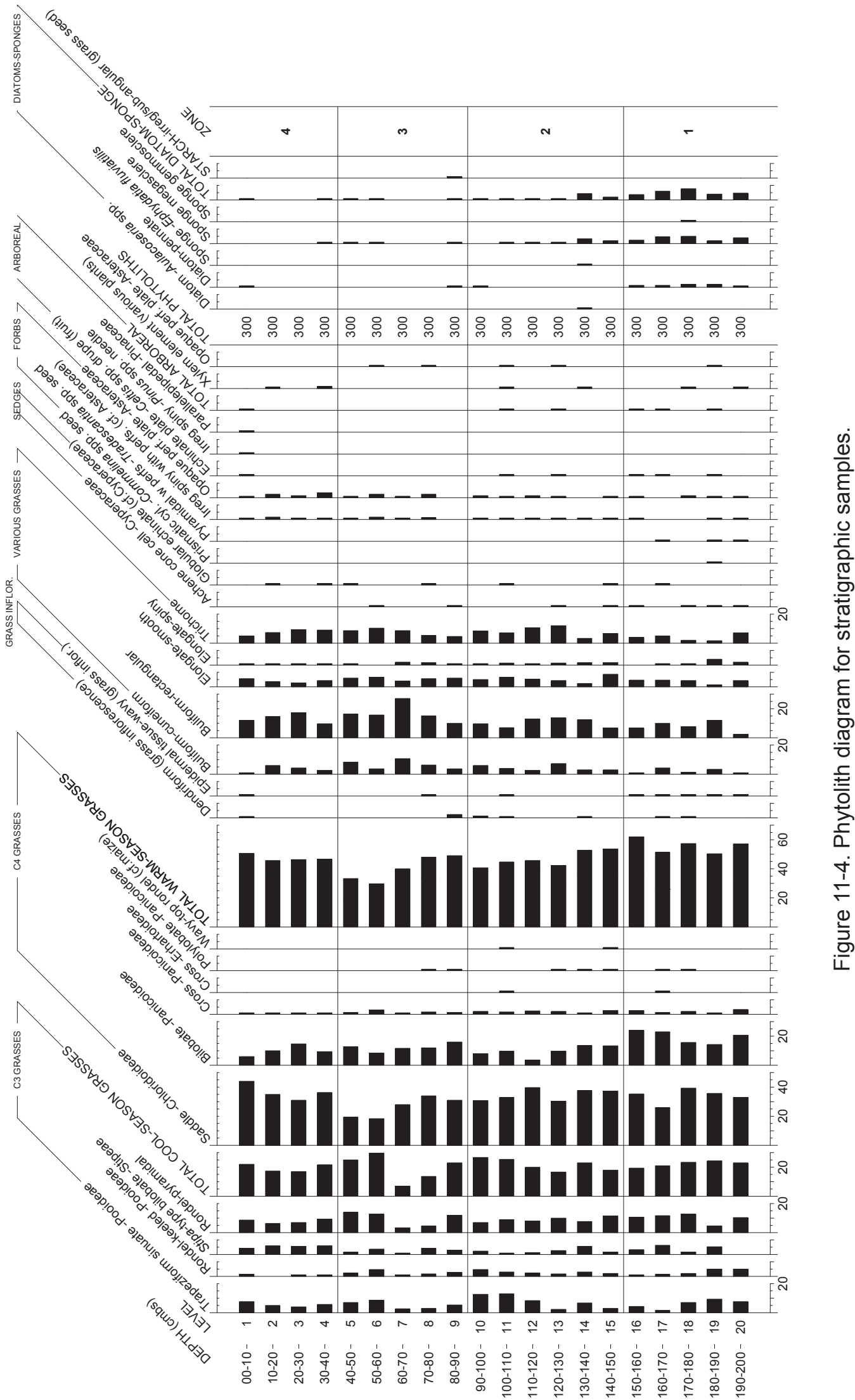




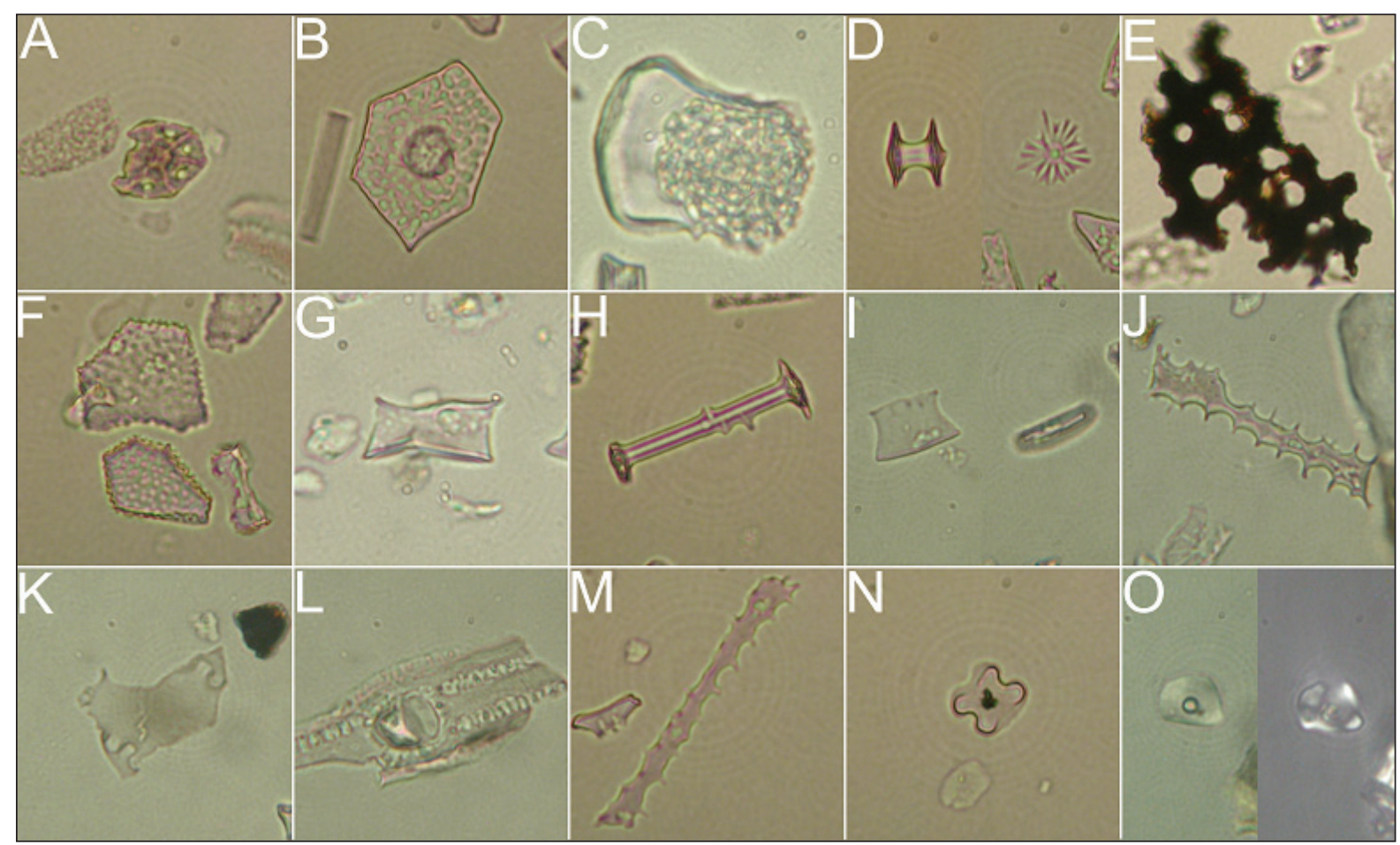

Figure 11-5. Selected phytolith, starch and sponge spicule micrographs from stratigraphic samples.

All micrographs taken at 500x magnification. A) Seed coat phytolith diagnostic of the genus Tradescantia, recovered from Level 20. B) Achene (seed) coat phytolith diagnostic of the sedge family (Cyperaceae), recovered from Level 20. C) Seed coat phytolith diagnostic of the genus Commelina, recovered from Level 19. D) Gemmeosclere from a freshwater sponge, possibly Ephydatia Muelleri, recovered from Level 18. E) Opaque perforated plate phytolith from the inflorescence (seed hull) of a member of the Asteraceae, recovered from Level 18. F) Echinate platelet phytoliths diagnostic of Celtis fruit (drupe). G) Wavy-top rondel phytolith that has some affinity to maize-type rondels produced in cob material, recovered from Level 15. H) Gemmosclere from a freshwater sponge, possibly Ephydatia fluviatilis, recovered from Level 14. I) Wavy-top rondel phytolith that has some affinity to maize-type rondels produced in cob material, recovered from Level 11. J) Dendriform phytolith from the bract material that surrounds grass seed. K) Grass inflorescence epidermal sheet element with wavy-margin longcells that has been exposed to fire, recovered from Level 11. L) Grass inflorescence epidermal sheet element with a rondel phytolith in situ, recovered from Level 11. M) Dendriform phytolith from the bract material that surrounds grass seed, recovered from Level 10. N) A Panicoideae cross body that is similar to those found in maize leaf material, recovered from Level 10 . O) Irregular-shaped starch grain that is most likely derived from grass seed, but within the variation found in maize kernels as well, recovered from Level 9. 


\section{SECTION IV \\ Cultural and Environmental Manifestations}




\title{
Chapter 12
}

\section{Analysis of Lipid Residues Extracted FROM FIRE-CRACKED ROCKS}

\author{
Mary Malainey and Timothy Figol
}

\section{INTRODUCTION}

A total of twelve fragments of fire-cracked rock from site 41DL436 in Dallas County, Texas were submitted for analysis, three in 2011 and another nine in 2012. Exterior surfaces were ground off to remove any contaminants; samples were crushed and absorbed lipid residues were extracted with organic solvents. The lipid extract was analyzed using gas chromatography (GC), high temperature GC (HT-GC) and high temperature gas chromatography with mass spectrometry (HT-GC/MS). Residue identifications were based on fatty acid decomposition patterns of experimental residues, lipid distribution patterns and the presence of biomarkers. Procedures for the identification of archaeological residues are outlined below; following this, analytical procedures and results are presented.

\section{The Identification of Archaeological Residues}

\section{Identification of Fatty Acids}

Fatty acids are the major constituents of fats and oils (lipids) and occur in nature as triglycerides, consisting of three fatty acids attached to a glycerol molecule by ester-linkages. The shorthand convention for designating fatty acids, $\mathrm{Cx}: \mathrm{y} \omega \mathrm{z}$, contains three components. The " $\mathrm{Cx}$ " refers to a fatty acid with a carbon chain length of $x$ number of atoms. The " $y$ " represents the number of double bonds or points of unsaturation, and the " $\omega z$ " indicates the location of the most distal double bond on the carbon chain, i.e. closest to the methyl end. Thus, the fatty acid expressed as C18:1 $\omega 9$, refers to a mono-unsaturated isomer with a chain length of 18 carbon atoms with a single double bond located nine carbons from the methyl end of the chain. Similarly, the shorthand designation, $\mathrm{C} 16: 0$, refers to a saturated fatty acid with a chain length of 16 carbons.

Their insolubility in water and relative abundance compared to other classes of lipids, such as sterols and waxes, make fatty acids suitable for residue analysis. Since employed by Condamin et al. (1976), gas chromatography has been used extensively to analyze the fatty acid component of absorbed archaeological residues. The composition of uncooked plants and animals provides important baseline information, but it is not possible to directly compare modern uncooked plants and animals with highly degraded archaeological residues. Unsaturated fatty acids, which are found widely in fish and plants, decompose more readily than saturated fatty acids, 
sterols or waxes. In the course of decomposition, simple addition reactions might occur at points of unsaturation (Solomons 1980) or peroxidation might lead to the formation of a variety of volatile and non-volatile products which continue to degrade (Frankel 1991). Peroxidation occurs most readily in fatty acids with more than one point of unsaturation.

Attempts have been made to identify archaeological residues using criteria that discriminate uncooked foods (Marchbanks 1989; Skibo 1992; Loy 1994). The major drawback of the distinguishing ratios proposed by Marchbanks (1989), Skibo (1992) and Loy (1994) is they have never been empirically tested. The proposed ratios are based on criteria that discriminate food classes on the basis of their original fatty acid composition. The resistance of these criteria to the effects of decompositional changes has not been demonstrated. Rather, Skibo (1992) found his fatty acid ratio criteria could not be used to identify highly decomposed archaeological samples.

In order to identify a fatty acid ratio unaffected by degradation processes, Patrick et al. (1985) simulated the long-term decomposition of one sample and monitored the resulting changes. An experimental cooking residue of seal was prepared and degraded in order to identify a stable fatty acid ratio. Patrick et al. (1985) found that the ratio of two C18:1 isomers, oleic and vaccenic, did not change with decomposition; this fatty acid ratio was then used to identify an archaeological vessel residue as seal. While the fatty acid composition of uncooked foods must be known, Patrick et al. (1985) showed that the effects of cooking and decomposition over long periods of time on the fatty acids must also be understood.

\section{Development of the Identification Criteria}

As the first stage in developing the identification criteria used herein, the fatty acid compositions of more than 130 uncooked Native food plants and animals from Western Canada were determined using gas chromatography (Malainey 1997; Malainey et al. 1999a). When the fatty acid compositions of modern food plants and animals were subject to cluster and principal component analyses, the resultant groupings generally corresponded to divisions that exist in nature (Table 12-1). Clear differences in the fatty acid composition of large mammal fat, large herbivore meat, fish, plant roots, greens and berries/seeds/nuts were detected, but the fatty acid composition of meat from medium-sized mammals resembles berries/seeds/nuts.

Samples in cluster A, the large mammal and fish cluster had elevated levels of C16:0 and C18:1 (Table 12-1). Divisions within this cluster stemmed from the very high level of C18:1 isomers in fat, high levels of C18:0 in bison and deer meat and high levels of very long chain unsaturated fatty acids (VLCU) in fish. Differences in the fatty acid composition of plant roots, greens and berries/seeds/nuts reflect the amounts of $\mathrm{C} 18: 2$ and $\mathrm{C} 18: 3 \omega 3$ present. The berry, seed, nut and small mammal meat samples appearing in cluster B have very high levels of C18:2, ranging from 35-64 percent (see Table 12-1). Samples in subclusters V, VI and VII have levels of C18:1 isomers from 29-51 percent, as well. Plant roots, plant greens and some berries appear in cluster $\mathrm{C}$. All cluster $\mathrm{C}$ samples have moderately high levels of C18:2; except for the berries in subcluster XII, levels of C16:0 are also elevated. Higher levels of C18:3 33 
Table 12-1. Summary of Average Fatty Acid Compositions of Modern

Food Groups Generated by Hierarchical Cluster Analysis.

\begin{tabular}{|c|c|c|c|c|c|c|c|c|c|c|c|c|c|c|c|}
\hline Cluster & & & $A$ & & & & & & & & & & C & & \\
\hline $\begin{array}{l}\text { Sub- } \\
\text { cluster }\end{array}$ & I & II & III & IV & V & VI & VII & VIII & IX & $x$ & XI & XII & XIII & XIV & $X V$ \\
\hline$\sum_{i}^{\infty}$ & 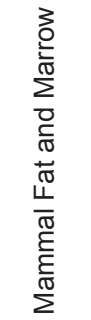 & 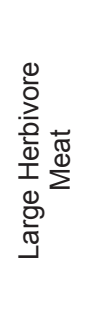 & $\frac{\frac{c}{0}}{i \frac{p}{4}}$ & $\frac{c}{\frac{c}{0}}$ & $\begin{array}{l}\frac{0}{J} \\
\sum \\
0 \\
\frac{0}{0} \\
0 \\
0 \\
\frac{\Phi}{2} \\
\frac{0}{0} \\
\infty\end{array}$ & $\begin{array}{l}\bar{d} \\
\stackrel{x}{\Sigma} \\
\sum\end{array}$ & 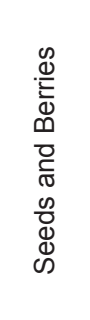 & $\begin{array}{l}\stackrel{n}{0} \\
\stackrel{0}{\square}\end{array}$ & 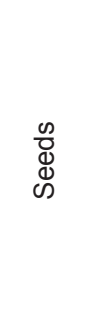 & $\begin{array}{l}\stackrel{0}{\mathbb{d}} \\
\stackrel{x}{\Sigma}\end{array}$ & 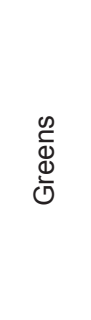 & 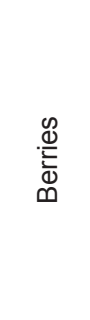 & 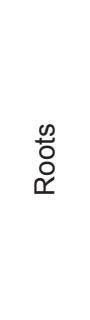 & 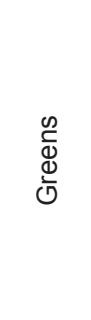 & $\begin{array}{l}\stackrel{\infty}{0} \\
\stackrel{0}{\alpha}\end{array}$ \\
\hline C16:0 & 19.90 & 19.39 & 16.07 & 14.10 & 3.75 & 12.06 & 7.48 & 19.98 & 7.52 & 10.33 & 18.71 & 3.47 & 22.68 & 24.19 & 18.71 \\
\hline C18:0 & 7.06 & 20.35 & 3.87 & 2.78 & 1.47 & 2.36 & 2.58 & 2.59 & 3.55 & 2.43 & 2.48 & 1.34 & 3.15 & 3.66 & 5.94 \\
\hline C18:1 & 56.77 & 35.79 & 18.28 & 31.96 & 51.14 & 35.29 & 29.12 & 6.55 & 10.02 & 15.62 & 5.03 & 14.95 & 12.12 & 4.05 & 3.34 \\
\hline C18:2 & 7.01 & 8.93 & 2.91 & 4.04 & 41.44 & 35.83 & 54.69 & 48.74 & 64.14 & 39.24 & 18.82 & 29.08 & 26.24 & 16.15 & 15.61 \\
\hline C18:3 & 0.68 & 2.61 & 4.39 & 3.83 & 1.05 & 3.66 & 1.51 & 7.24 & 5.49 & 19.77 & 35.08 & 39.75 & 9.64 & 17.88 & 3.42 \\
\hline VLCS & 0.16 & 0.32 & 0.23 & 0.15 & 0.76 & 4.46 & 2.98 & 8.50 & 5.19 & 3.73 & 6.77 & 9.10 & 15.32 & 18.68 & 43.36 \\
\hline VLCU & 0.77 & 4.29 & 39.92 & 24.11 & 0.25 & 2.70 & 1.00 & 2.23 & 0.99 & 2.65 & 1.13 & 0.95 & 2.06 & 0.72 & 1.10 \\
\hline
\end{tabular}

VLCS- Very Long Chain (C20, C22 and C24) Saturated Fatty Acids

VLCU - Very Long Chain (C20, C22 and C24) Unsaturated Fatty Acids

and/or very long chain saturated fatty acids (VLCS) are also common except in the roots which form subcluster XV.

Secondly, the effects of cooking and degradation over time on fatty acid compositions were examined. Originally, 19 modern residues of plants and animals from the plains, parkland and forests of Western Canada were prepared by cooking samples of meats, fish and plants, alone or combined, in replica vessels over an open fire (Malainey 1997; Malainey et al. 1999b). After four days at room temperature, the vessels were broken and a set of sherds analysed to determine changes after a short term of decomposition. A second set of sherds remained at room temperature for 80 days, then placed in an oven at $75^{\circ} \mathrm{C}$ for a period of 30 days in order to simulate the processes of long term decomposition. The relative percentages were calculated on the basis of the ten fatty acids (C12:0, C14:0, C15:0, C16:0, C16:1, C17:0, C18:0, C18:1w9, C18:1w11, C18:2) that regularly appeared in Precontact Period vessel residues from Western Canada. Observed changes in fatty acid composition of the experimental cooking residues enabled the development of a method for identifying the archaeological residues (Table 12-2).

Table 12-2. Criteria for the Identification of Archaeological Residues Based on the Decomposition Patterns of Experimental Cooking Residues Prepared in Pottery Vessels.

\begin{tabular}{cccc}
\hline Identification & Medium Chain & C18:0 & C18:1 isomers \\
\hline Large herbivore & $\leq 15 \%$ & $\geq 27.5 \%$ & $\leq 15 \%$ \\
\hline Large herbivore with plant OR Bone marrow & low & $\geq 25 \%$ & $15 \% \leq \mathrm{X} \leq 25 \%$ \\
\hline Plant with large herbivore & $\geq 15 \%$ & $\geq 25 \%$ & no data \\
\hline Beaver & low & Low & $\geq 25 \%$ \\
\hline Fish or Corn & low & $\leq 25 \%$ & $15 \% \leq X \leq 27.5 \%$ \\
\hline Fish or Corn with Plant & $\geq 15 \%$ & $\leq 25 \%$ & $15 \% \leq X \leq 27.5 \%$ \\
\hline Plant (except corn) & $\geq 10 \%$ & $\leq 27.5 \%$ & $\leq 15 \%$ \\
\hline
\end{tabular}


It was determined that levels of medium chain fatty acids (C12:0, C14:0 and C15:0), C18:0 and C18:1 isomers in the sample could be used to distinguish degraded experimental cooking residues (Malainey 1997; Malainey et al. 1999b). Higher levels of medium chain fatty acids, combined with low levels of C18:0 and C18:1 isomers, were detected in the decomposed experimental residues of plants, such as roots, greens and most berries. High levels of C18:0 indicated the presence of large herbivores. Moderate levels of C18:1 isomers, with low levels of C18:0, indicated the presence of either fish or foods similar in composition to corn. High levels of C18:1 isomers with low levels of C18:0, were found in residues of beaver or foods of similar fatty acid composition. The criteria for identifying six types of residues were established experimentally; the seventh type, plant with large herbivore, was inferred (see Table 12-2). These criteria were applied to residues extracted from more than 200 pottery cooking vessels from 18 Western Canadian sites (Malainey 1997; Malainey et al. 1999c; 2001b). The identifications were found to be consistent with the evidence from faunal and tool assemblages for each site.

Work has continued to understand the decomposition patterns of various foods and food combinations (Malainey et al. 2000a, 2000b, 2000c, 2001a; Quigg et al. 2001). The collection of modern foods has expanded to include plants from the Southern Plains. The fatty acid compositions of mesquite beans (Prosopis glandulosa), Texas ebony seeds (Pithecellobium ebano Berlandier), tasajillo berry (Opuntia leptocaulis), prickly pear fruit and pads (Opuntia engelmannii), Spanish dagger pods (Yucca treculeana), cooked sotol (Dasylirion wheeler), agave (Agave lechuguilla), cholla (Opuntia imbricata), piñon (Pinus edulis) and Texas mountain laurel (or mescal) seed (Sophora secundiflora) have been determined. Experimental residues of many of these plants, alone or in combination with deer meat, have been prepared by boiling foods in clay cylinders or using sandstone for either stone boiling (Quigg et al. 2000) or as a griddle. In order to accelerate the processes of oxidative degradation that naturally occur at a slow rate with the passage of time, the rock or clay tile containing the experimental residue was placed in an oven at $75^{\circ} \mathrm{C}$. After either 30 or 68 days, residues were extracted and analyzed using gas chromatography. The results of these decomposition studies enabled refinement of the identification criteria (Malainey 2007).

\section{Using Lipid Distribution and Biomarkers to Identify Archaeological Residues}

Archaeological scientists working in the United Kingdom have had tremendous success using high temperature-gas chromatography (HT-GC) and gas chromatography with mass spectrometry (HT-GC/MS) to identify biomarkers. High temperature gas chromatography is used to separate and assess a wide range of lipid components, including fatty acids, long chain alcohols and hydrocarbons, sterols, waxes, terpenoids and triacylglycerols (Evershed et al. 2001). The molecular structure of separated components is elucidated by mass spectrometry (Evershed 2000).

Triacylglycerols, diacylglycerols and sterols can be used to distinguish animal-derived residues, which contain cholesterol and significant levels of both triacylglycerols, from plantderived residues, indicated by plant sterols, such as $\beta$-sitosterol, stigmasterol and campesterol, 
and only traces of triacylglycerols (Evershed 1993; Evershed et al. 1997a; Dudd and Evershed 1998). Barnard et al. (2007), however, have recently suggested that microorganisms living off residues can introduce $\beta$-sitosterol into residues resulting from the preparation of animal products. Waxes, which are long-chain fatty acids and long-chain alcohols that form protective coatings on skin, fur, feathers, leaves and fruit, also resist decay. Evershed et al. (1991) found epicuticular leaf waxes from plants of the genus Brassica in vessel residues from a Late Saxon/ Medieval settlement. Cooking experiments later confirmed the utility of nonacosane, nonacosan15-one and nonacosan-15-ol to indicate the preparation of leafy vegetables, such as turnip or cabbage (Charters et al. 1997). Reber et al. (2004) recently suggested $n$-dotriacontanol could serve as an effective biomarker for maize in vessel residues from sites located in Midwestern and Eastern North America. Beeswax can be identified by the presence and distribution of n-alkanes with carbon chains 23 to 33 atoms in length and palmitic acid wax esters with chains between 40 and 52 carbons in length (Heron et al. 1994; Evershed et al. 1997b).

Terpenoid compounds, or terpenes, are long chain alkenes that occur in the tars and pitches of higher plants. The use of GC and GC/MS to detect the diterpenoid, dehydroabietic acid, from conifer products in archaeological residues extends over a span of 25 years (Shackley 1982; Heron and Pollard 1988). Lupeol, $\alpha$ - and $\beta$-amyrin and their derivatives indicate the presence of plant materials (Regert 2007). Eerkens (2002) used the predominance of the diterpenoid, $\Delta-8(9)$-isopimaric acid, in a vessel residue from the western Great Basin to argue it contained piñyon resins. Other analytical techniques have also been used to identify terpenoid compounds. Sauter et al. (1987) detected the triterpenoid, betulin, in Iron Age tar using both ${ }^{1} \mathrm{H}$ and ${ }^{13} \mathrm{C}$ nuclear magnetic resonance spectroscopy (NMR), confirming the tar was produced from birch.

\section{MeTHODOLOGY}

Possible contaminants were removed by grinding off exterior surfaces of each sample with a Dremel® tool fitted with a silicon carbide bit. Immediately thereafter, it was crushed with a hammer mortar and pestle and the powder transferred to an Erlenmeyer flask. Lipids were extracted using a variation of the method developed by Folch et al. (1957). The powdered sample was mixed with a 2:1 mixture, by volume, of chloroform and methanol $(2 \times 25 \mathrm{~mL})$ using ultrasonication $(2 \times 10 \mathrm{~min})$. Solids were removed by filtering the solvent mixture into a separatory funnel. The lipid/solvent filtrate was washed with $13.3 \mathrm{~mL}$ of ultrapure water. Once separation into two phases was complete, the lower chloroform-lipid phase was transferred to a round-bottomed flask and the chloroform removed by rotary evaporation. Any remaining water was removed by evaporation with 2-propanol $(1.5 \mathrm{~mL}) ; 1.5 \mathrm{~mL}$ of chloroform-methanol (2:1, $\mathrm{v} / \mathrm{v}$ ) was used to transfer the dry total lipid extract to a screw-top glass vial with a Teflon $\AA$-lined cap. The resulting total lipid extract was flushed with nitrogen and stored in a $-20^{\circ} \mathrm{C}$ freezer.

\section{Preparation of FAMES}

A $400 \mu \mathrm{L}$ aliquot of the total lipid extract solution was placed in a screw-top test tube and dried in a heating block under nitrogen. Fatty acid methyl esters (FAMES) were prepared by treating the dry lipid with $3 \mathrm{~mL}$ of $0.5 \mathrm{~N}$ anhydrous hydrochloric acid in methanol $\left(68^{\circ} \mathrm{C} ; 60 \mathrm{~min}\right)$. Fatty 
acids that occur in the sample as di- or triglycerides are detached from the glycerol molecule and converted to methyl esters. After cooling to room temperature, $2.0 \mathrm{~mL}$ of ultrapure water was added. FAMES were recovered with petroleum ether $(2 \times 1.5 \mathrm{~mL})$ and transferred to a vial. The solvent was removed by heat under a gentle stream of nitrogen; the FAMES were dissolved in $75 \mu \mathrm{L}$ of iso-octane then transferred to a $\mathrm{GC}$ vial with a conical glass insert.

\section{Preparation of TMS derivatives}

A $200 \mu \mathrm{L}$ aliquot of the total lipid extract solution was placed in a screw-top vial and dried under nitrogen. Trimethylsilyl (TMS) derivatives were prepared by treating the lipid with $70 \mu \mathrm{L}$ of N,O-bis(trimethylsilyl)trifluoroacetamide (BSTFA) containing one percent trimethylchlorosilane, by volume $\left(70^{\circ} \mathrm{C} ; 30 \mathrm{~min}\right)$. The sample was then dried under nitrogen and the TMS derivatives were redissolved in $100 \mu \mathrm{L}$ of hexane.

Solvents and chemicals were checked for purity by running a sample blank. Traces of fatty acid contamination were subtracted from sample chromatograms. The relative percentage composition was calculated by dividing the integrated peak area of each fatty acid by the total area of fatty acids present in the sample.

In order to identify the residue on the basis of fatty acid composition, the relative percentage composition was determined first with respect to all fatty acids present in the sample (including very long chain fatty acids) (see Table 12-5) and second with respect to the ten fatty acids utilized in the development of the identification criteria (C12:0, C14:0, C15:0, C16:0, C16:1, $\mathrm{C} 17: 0, \mathrm{C} 18: 0, \mathrm{C} 18: 1 \mathrm{w} 9, \mathrm{C} 18: 1 \mathrm{w} 11$ and $\mathrm{C} 18: 2)$ (not shown). The second step is necessary for the application of the identification criteria presented in Table 12-2. It must be understood that the identifications given do not necessarily mean that those particular foods were actually prepared because different foods of similar fatty acid composition and lipid content would produce similar residues (Table 12-3). It is possible only to say that the material of origin for the residue was similar in composition to the food(s) indicated. High temperature gas chromatography and high temperature gas chromatography with mass spectrometry is used to further clarify the identifications.

\section{Gas Chromatography Analysis Parameters}

The GC analysis was performed on a Varian 3800 gas chromatograph fitted with a flame ionization detector connected to a personal computer. Samples were separated using a VF-23 fused silica capillary column ( $30 \mathrm{~m} \times 0.25 \mathrm{~mm}$ I.D.; Varian; Palo Alto, CA). An autosampler injected a $3 \mu \mathrm{L}$ sample using a split/splitless injection system. Hydrogen was used as the carrier gas with a column flow of $1.0 \mathrm{~mL} / \mathrm{min}$. Column temperature was increased from $80^{\circ} \mathrm{C}$ to $140^{\circ} \mathrm{C}$ at a rate of $20^{\circ} \mathrm{C}$ per minute then increased to $185^{\circ} \mathrm{C}$ at a rate of $4{ }^{\circ} \mathrm{C}$ per minute. After a 4.0 minute hold, the temperature was further increased to $250^{\circ} \mathrm{C}$ at $10^{\circ} \mathrm{C}$ per minute and held for 2 two minutes. Chromatogram peaks were integrated using Varian MS Workstation ${ }^{\circledR}$ software and identified through comparisons with external qualitative standards (NuCheck Prep; Elysian, MN). 
Table 12-3. Known Food Sources for Different Types of Decomposed Residues.

\begin{tabular}{lll}
\hline Decomposed Residue Identification & \multicolumn{1}{c}{$\begin{array}{c}\text { Plant Foods Known to } \\
\text { Produce Similar Residues }\end{array}$} & $\begin{array}{c}\text { Animal Foods Known To } \\
\text { Produce Similar Residues }\end{array}$ \\
\hline $\begin{array}{l}\text { Large herbivore } \\
\text { OR Bone marrow }\end{array}$ & Tropical seed oils, including sotol seeds & $\begin{array}{l}\text { Bison, deer, moose, fall-early winter } \\
\text { fatty elk meat, Javelina meat }\end{array}$ \\
\hline $\begin{array}{l}\text { Low Fat Content Plant (Plant } \\
\text { greens, roots, berries) }\end{array}$ & $\begin{array}{l}\text { Jicama tuber, buffalo gourd, yopan } \\
\text { leaves, biscuit root, millet }\end{array}$ & Cooked Camel's milk \\
\hline Medium-Low Fat Content Plant & Prickly pear, Spanish dagger & None \\
\hline Medium Fat Content (Fish or Corn) & Corn, mesquite beans, cholla & $\begin{array}{l}\text { Freshwater fish, Rabdotus snail, } \\
\text { terrapin, late winter fat-depleted elk }\end{array}$ \\
\hline Moderate-High Fat Content (Beaver) & Texas ebony & $\begin{array}{l}\text { Beaver and probably raccoon or any } \\
\text { other fat medium-sized mammals }\end{array}$ \\
\hline High Fat Content & $\begin{array}{l}\text { High fat nuts and seeds, } \\
\text { including acorn and pecan }\end{array}$ & $\begin{array}{l}\text { Rendered animal fat (other than } \\
\text { large herbivore), including bear fat }\end{array}$ \\
\hline $\begin{array}{l}\text { Very High Fat Content } \\
\text { including pine nuts }\end{array}$ & $\begin{array}{l}\text { Freshly rendered animal fat } \\
\text { (other than large herbivore) }\end{array}$ \\
\hline
\end{tabular}

\section{High Temperature Gas Chromatography and Gas Chromatography with Mass Spectrometry}

Both HT-GC and HT GC-MS analyses were performed on a Varian 3800 gas chromatograph fitted with a flame ionization detector and a Varian 4000 mass spectrometer connected to a personal computer. For HT-GC analysis, the sample was injected onto a DB-1HT fused silica capillary column $(15 \mathrm{~m} \times 0.32 \mathrm{~mm}$ I.D.; Agilent J\&W; Santa Clara, CA) connected to the flame ionization detector, using hydrogen as the carrier gas. The column temperature was held at $50^{\circ} \mathrm{C}$ for 1 minute then increased to $350^{\circ} \mathrm{C}$ at a rate of $15^{\circ} \mathrm{C}$ per minute and held for 26 minutes. For HT-GC/MS analysis, samples were injected onto a DB-5HT fused silica capillary column (30 m $\times 0.25 \mathrm{~mm}$ I.D.; Agilent J\&W; Santa Clara, CA) connected to the ion trap mass spectrometer in an external ionization configuration using helium as the carrier gas. After a 1 minute hold at $50^{\circ} \mathrm{C}$, the column temperature was increased to $180^{\circ} \mathrm{C}$ at a rate of $40^{\circ} \mathrm{C}$ per minute then ramped up to $230^{\circ} \mathrm{C}$ at a rate of $5^{\circ} \mathrm{C}$ per minute and finally increased to $350^{\circ} \mathrm{C}$ at a rate of $15^{\circ} \mathrm{C}$ per minute and held for 27.75 minutes. The Varian 4000 mass spectrometer was operated in electron-impact ionization mode scanning from $\mathrm{m} / \mathrm{z} 50-700$. Chromatogram peaks and MS spectra were processed using Varian MS Workstation ${ }^{\circledR}$ software and identified through comparisons with external qualitative standards (Sigma Aldrich; St. Louis, MO and NuCheck Prep; Elysian, MN), reference samples and the National Institute of Standards and Technology (NIST) database.

\section{Results of Archaeological Data Analysis}

Descriptions of the samples from which lipids were extracted are presented in Table 12-4. Compositions of the extracted lipid residues are presented in Tables 12-5 and 12-6. In Table 12-5, the term, Area, represents the area under the chromatographic peak of a given fatty acid, as calculated by the Varian MS Workstation ${ }^{\circledR}$ software minus the solvent blank. The term, Rel $\%$, represents the relative percentage of the fatty acid with respect to the total fatty acids in 
Table 12-4. List of Fire-cracked Sandstone Samples.

\begin{tabular}{cccccccc}
\hline Lab No. & $\begin{array}{c}\text { Component } \\
\text { (Stratum) }\end{array}$ & $\begin{array}{c}\text { Field Lot } \\
\text { No. }\end{array}$ & Unit No. & Level No. & Feature No. Sample No. & Mass (g) \\
\hline 11EC 1 & Middle (2) & 235 & 75 & 1 & 2 & 1 & 23.902 \\
\hline 11EC 2 & Lower (1b) & 93 & 103 & 1 & 42 & 1 & 33.761 \\
\hline 11EC 3 & Lower (1a) & 284 & 87 & $1 \& 2$ & 7 & 2 & 34.024 \\
\hline 12EC 1 & Middle (2) & 235 & 75 & 1 & 2 & 4 & 24.352 \\
\hline 12EC 2 & Lower (1a) & 300 & $86 / 90$ & 1 & 5 & 5 & 34.747 \\
\hline 12EC 3 & Lower (1a) & 300 & $86 / 90$ & 1 & 5 & 6 & 32.087 \\
\hline 12EC 4 & Lower (1a) & 300 & $86 / 90$ & 1 & 5 & 7 & 25.249 \\
\hline 12EC 5 & Lower (1a) & 284 & 87 & 1 & 7 & 8 & 29.406 \\
\hline 12EC 6 & Lower (1a) & 284 & 87 & 1 & 7 & 9 & 27.709 \\
\hline 12EC 7 & Lower (1b) & 393 & $103 / 104$ & 1 & 42 & 10 & 34.617 \\
\hline 12EC 8 & Lower (1b) & 390 & 103 & 1 & 42 & 11 & 33.641 \\
\hline 12EC 9 & Lower (1a) & 300 & $86 / 90$ & 1 & 5 & 12 & 35.823 \\
\hline
\end{tabular}

Table 12-5. Lipid Composition of Residue 11EC 1 Extracted from Fire-Cracked Rock.

\begin{tabular}{|c|c|c|}
\hline \multirow{2}{*}{ Fatty acid } & \multicolumn{2}{|c|}{ 11EC 1} \\
\hline & Area & Rel\% \\
\hline C12:0 & 0 & 0.00 \\
\hline C14:0 & 38463 & 1.19 \\
\hline C14:1 & 0 & 0.00 \\
\hline C15:0 & 20126 & 0.62 \\
\hline C16:0 & 748375 & 23.13 \\
\hline C16:1 & 0 & 0.00 \\
\hline C17:0 & 96193 & 2.97 \\
\hline C17:1 & 0 & 0.00 \\
\hline C18:0 & 2070629 & 64.01 \\
\hline C18:1s & 218761 & 6.76 \\
\hline C18:2 & 0 & 0.00 \\
\hline C18:3s & 0 & 0.00 \\
\hline C20:0 & 42523 & 1.31 \\
\hline C20:1 & 0 & 0.00 \\
\hline $\mathrm{C} 24: 0$ & 0 & 0.00 \\
\hline $\mathrm{C} 24: 1$ & 0 & 0.00 \\
\hline Total & 3235070 & 100.00 \\
\hline $\begin{array}{l}\text { Peak Ratios of C48, C50, C52 } \\
\text { and C54 Triacyl-glycerols (TAGs) }\end{array}$ & \multicolumn{2}{|c|}{ 1: 4: 8.3: 6.1 Animal distribution; traces of plant material present } \\
\hline Biomarkers & \multicolumn{2}{|c|}{ Cholesterol confirmed; possibly $\beta$-sitosterol; possibly Azelaic acid } \\
\hline Identification & \multicolumn{2}{|c|}{ Large Herbivore or Javelina Meat with traces of plant material } \\
\hline
\end{tabular}


the sample. Hydroxide or peroxide degradation products can interfere with the integration of the C22:0 and C22:1 peaks; these fatty acids were excluded from the analysis. Only Sample $11 \mathrm{EC} 1$ contained sufficient fatty acids for identification; eleven samples contained insufficient fatty acids to enable identification; most were almost completely devoid of fatty acids.

The presence of lipid biomarkers and distributions of triacylglycerols (TAGs) were determined through HT-GC and HT-GC/MS. The data obtained is useful for distinguishing plant residues, animal residues and plant/animal combinations. The sterol cholesterol is associated with animal products; $\beta$-sitosterol, stigmasterol and campesterol are associated with plant products. The presence and abundance of TAGs varies with the material of origin. When present, amounts of TAGs tend to decrease with increasing numbers of carbon atoms in plant residues. The peak arising from C48 TAGs is largest and peak size (and area) progressively decreases with the C54 TAG peak being the smallest. A line drawn to connect the tops of the C48, C50, C52 and C54 TAG peaks slopes down to the right. In animal residues, amounts of TAGs tend to increase with carbon numbers, with the $\mathrm{C} 52$ or C54 TAG peaks being the largest. A line drawn to connect the tops of the C48, C50, C52 and C54 TAG peaks either resembles a hill or the line slopes up to the right. A parabola-like pattern, such as the shape of a "normal distribution," can also occur in the residues of oil seeds that contain high levels of C18:1 isomers.

With respect to fatty acid composition, the level of C18:0 in residue 11EC 1 is very high, 64 percent, which is a characteristic of the decomposed cooking residues of large herbivores, such as deer, bison and moose (see Table 12-5). Other foods known to produce similar residues include javelina meat and the seed oils of certain tropical plants, such as sotol. The level of C18:1 isomers in this residue is low, less than seven percent, which indicates the meat was quite lean. Small amounts of medium and very long chain saturated fatty acids suggest traces of plant materials are present. This identification is supported by the confirmed presence of the animal sterol cholesterol and possible presence of the plant sterol $\beta$-sitosterol. The biomarker azelaic acid may be present; this short chain dicarboxylic acid is associated with the oxidation of unsaturated fatty acids (Regert et al. 1998). Unsaturated fatty acids are most abundant in seed oils so it is possible that these residues in part reflect the processing of plant seeds. The distribution of TAGs in residue 11EC 1 shows that animal products dominate but small amount of plant products may be present. This lipid residue, extracted from a fire-cracked rock in Feature 2, appears to largely result from the preparation of large herbivore or javelina meat but traces of plant material also occur.

The other eleven residues, 11EC 2 and 3 plus 12EC 1 to 9, contained insufficient lipids for identification; most were virtually devoid of fatty acids (see Table 12-6). Only evidence of plant materials were detected in residues 11EC 2 and 11EC 3 . The presence of the biomarker azelaic acid was confirmed in residue 11EC 2; the plant sterol $\beta$-sitosterol probably occurs in this residue, as well. No biomarkers were detected in residue 11EC 3. While only traces of TAGs appear in these residues, their distribution is most similar to the distribution associated with plants. The lipid residues extracted from fire-cracked rocks from Feature 42 and 7 are both of plant origin. In the case of residue 11EC 2 from Feature 42, plant seeds are the most probable source. 
Table 12-6. Biomarker and TAG Distributions in Lipid Residues with Insufficient Fatty Acids.

\begin{tabular}{|c|c|c|c|}
\hline Lab No. & Biomarkers Detected & Occurrence of Triacylglycerols (TAGs) & Identification \\
\hline 11EC 1 & $\begin{array}{l}\text { Azelaic acid; probably } \\
\beta \text {-sitosterol }\end{array}$ & $\begin{array}{l}\text { Traces of TAGs present Distribution } \\
\text { more similar to a plant pattern }\end{array}$ & Traces of Plant seeds oils \\
\hline 11EC 2 & None detected & $\begin{array}{l}\text { Traces of TAGs present Distribution } \\
\text { more similar to a plant pattern }\end{array}$ & Traces of plant material \\
\hline 12EC 1 & $\begin{array}{l}\text { Cholesterol; } \beta \text {-sitosterol; } \\
\text { Dehydroabietic acid }\end{array}$ & $\begin{array}{l}\text { Traces of C48 TAGs present Distribution } \\
\text { more similar to a plant pattern }\end{array}$ & $\begin{array}{l}\text { Plant and animal products present, } \\
\text { plant products may dominate; } \\
\text { conifer products present }\end{array}$ \\
\hline 12EC 2 & Cholesterol; $\beta$-sitosterol; & $\begin{array}{l}\text { Traces of C50 TAGs present Distribution } \\
\text { more similar to an animal pattern }\end{array}$ & $\begin{array}{l}\text { Animal and plant products present } \\
\text { but animal products may dominate }\end{array}$ \\
\hline 12EC 3 & Cholesterol; $\beta$-sitosterol; & $\begin{array}{l}\text { Traces of C48 TAGs present Distribution } \\
\text { more similar to a plant pattern }\end{array}$ & $\begin{array}{l}\text { Plant and animal products present, } \\
\text { plant products may dominate }\end{array}$ \\
\hline $12 \mathrm{EC} 4$ & $\begin{array}{l}\text { Cholesterol; } \beta \text {-sitosterol; } \\
\text { Dehydroabietic acid }\end{array}$ & $\begin{array}{l}\text { Traces of C48 TAGs present Distribution } \\
\text { more similar to a plant pattern }\end{array}$ & $\begin{array}{l}\text { Plant and animal products present, } \\
\text { plant products may dominate; } \\
\text { conifer products present }\end{array}$ \\
\hline 12EC 5 & $\begin{array}{l}\text { Cholesterol; } \beta \text {-sitosterol; } \\
\text { Dehydroabietic acid }\end{array}$ & $\begin{array}{l}\text { Traces of C48 TAGs present Distribution } \\
\text { more similar to a plant pattern }\end{array}$ & $\begin{array}{l}\text { Plant and animal products present, } \\
\text { plant products may dominate; } \\
\text { conifer products present }\end{array}$ \\
\hline 12EC 6 & $\begin{array}{l}\text { Cholesterol; } \beta \text {-sitosterol; } \\
\text { Dehydroabietic acid }\end{array}$ & No pattern detectable & $\begin{array}{l}\text { Plant and animal products present; } \\
\text { conifer products present }\end{array}$ \\
\hline 12EC 7 & $\begin{array}{l}\text { Cholesterol; } \\
\text { } \text {-sitosterol; possibly } \\
\text { Dehydroabietic acid }\end{array}$ & $\begin{array}{l}\text { Traces of C48 TAGs present Distribution } \\
\text { more similar to a plant pattern }\end{array}$ & $\begin{array}{l}\text { Plant and animal products present, } \\
\text { plant products may dominate; } \\
\text { conifer products may be present }\end{array}$ \\
\hline 12EC 8 & $\begin{array}{l}\text { Cholesterol; } \beta \text {-sitosterol; } \\
\text { possibly Stigmasterol }\end{array}$ & $\begin{array}{l}\text { Traces of TAGs present Possible } \\
\text { plant and animal combination }\end{array}$ & $\begin{array}{l}\text { Plant and animal products present, } \\
\text { plant products may dominate }\end{array}$ \\
\hline 12EC 9 & $\begin{array}{l}\text { Cholesterol; } \beta \text {-sitosterol; } \\
\text { Dehydroabietic acid }\end{array}$ & $\begin{array}{l}\text { Traces of TAGs present Distribution } \\
\text { more similar to a plant pattern }\end{array}$ & $\begin{array}{l}\text { Plant and animal products present; } \\
\text { conifer products present }\end{array}$ \\
\hline
\end{tabular}

Evidence of both plant and animal products were detected in all residues analyzed in 2012, 12EC 1-9. The presence of the animal sterol cholesterol and the plant sterol $\beta$-sitosterol was verified in all nine residues; the plant sterol stigmasterol may occur in residue 12EC 8. Dehydroabietic acid, which is the biomarker for conifer products, was confirmed in residues 12EC 1, 12EC 4, 12EC 5, 12EC 6, and 12EC 9; it may be present in residue 12EC 7, as well. Because the only C48 TAG peak was detectable or it was the largest peak, plant products

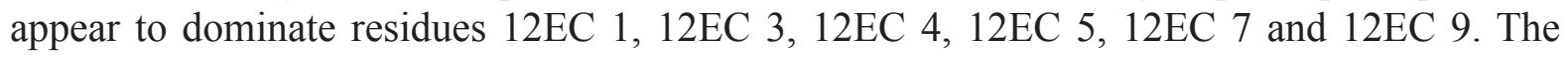
distribution of TAGs indicates that animal products dominate residue 12EC 2; residue 12EC 8 seems to represent a plant and animal combination. The presence of TAGs could not be confirmed in residue 12EC 6. 


\title{
Chapter 13 \\ Microfossil Analysis of Fire-Cracked Rock SAMples
}

\author{
Timothy E. Riley
}

\section{INTRODUCTION}

Two groups of fire-cracked rocks were analyzed for microfossils. An analysis of the first group of six was conducted as part of a pilot study to determine the potential for extracting significant information regarding subsistence items at 41DL436. Based upon the positive results obtained from the pilot study, an additional 18 pieces of fire-cracked rocks were analyzed.

Thus, this chapter is divided into three main sections. Section I provides background information regarding the study of microfossils in general. Section II presents a report of findings from an analysis of the first set of six rocks, and Section III presents a report of findings on the second set of 18 rocks.

\section{Section I - The Study of Microfossils}

\section{Starch in Archaeology}

Starch granules have been observed in archaeological contexts since the late 1970s (Anderson 1980; Ugent et al. 1982, 1984; Ugent et al. 1981) but this line of evidence has only recently become a major component of microbotanical research (Torrence and Barton 2006; Fullager et al. 2006; Loy et al. 1992). Starch analysis can provide evidence of the use of plants as food resources where macrobotanical remains are rare or uninformative. In some cases, starch granules have been found that predate other evidence of domestication (Perry et al. 2007). Piperno and Holst (1998) examined ground stones and found maize (Zea mays), Manihot esculenta, Dioscorea sp., and Maranta arundinacea starch grains from Central Panama, providing evidence for the use of tuber crops since $8000 \mathrm{ybp}$. Loy et al. (1992) studied lithic flakes from 28,000 year old cave sediments on the Solomon Islands and recovered starch grains from them. Some of the granules were identified as Colocasia sp.

To date, most starch research has focused on tools and soils recovered from the Tropics, with very little focus on the potential of this line of research in temperate climates (Fullagar and Field 1997; Fullagar et al. 2006; Fullagar et al. 1996; Fullagar et al. 1998; Horrocks et al. 2004; Horrocks et al. 2002; Horrocks and Lawlor 2006; Horrocks and Nunn 2007; Horrocks and Weisler 2006; Irwin et al. 2004; Lentfer et al. 2002; Pearsall et al. 2004; Perry 2004a, b, 
2005; Perry et al. 2007; Piperno 1998; Piperno and Holst 1998; Piperno et al. 2004; Smith et al. 2001). A handful of temperate Old World sites have been investigated. Shibutani (2008) studied anvil stones, grinding slab, and grinding stones from four archaeological sites in southern part of Japan, dating from Japanese Paleolithic to incipient Jomon period. She recovered intact and damaged starch grains from grinding surfaces of the tools. The recovered starch grains are not identified to taxa conclusively. Piperno et al. (2004) reported the earliest evidence of grass seed processing. They identified starch grains of barley and possibly wheat from an Upper Paleolithic ground stone found in Israel.

While Loy had some early publications on starch recovered from North American artifacts, only two recently published studies examines starch recovered from North America (Boyd et al. 2006; Zarrillo and Kooyman 2006). The Zarrillo and Kooyman (2006) article focuses on the recovery of maize and berry starch on late prehistoric groundstone from the northern Great Plains. In addition, there have been a handful of studies done for contract projects, mostly from the Southwest and Great Basin (Cummings $1992 \mathrm{a}-\mathrm{c}, 1993 \mathrm{a}-\mathrm{b}, 1997 \mathrm{a}-\mathrm{b}$ ). Only two studies evaluating starch recovered in Texas has been encountered in the current literature review (Cummings 1993c; Perry 2008). The paucity of publications on the recovery of starch from North American archaeological sites highlights some of the potential for this line of research as well as a dearth of qualified researchers currently investigating starch with a regional focus on North America. This is surprising in light of the fact that much of the continent has copious artifacts associated with both incipient horticulture and hunter-gatherer sites. As Piperno et al. (2004) state, the association of macroscopic remains from economically important plants with potential plant processing tools such as grinding slabs, mortars and pestles is rarely evident. Starch analysis of groundstone and cooking features provides direct evidence of past human food processing.

To date, there has been very little research on the recovery of starch from known cooking features in the archaeological record. Recent experimental studies have shown that earth oven cookery results in the dispersal of starch granules and other microfossils throughout the oven feature, depositing residue related to the cooked foodstuffs and packing material used in the oven on many of the rocks used as heating elements (Messner and Schindler 2010).

\section{Ecological Background}

Dallas County is located in the Blackland Prairie Omernik Ecoregion (Griffith et al. 2004). The Blackland Prairie is a tall grass prairie characterized by high plant community diversity, due in part to the variety in soil texture and $\mathrm{pH}$ associated with the different soil orders represented within this ecoregion (Diamond et al. 1987; Diamond and Smeins 1985). This diversity is further enhanced by microtopographic features such as gilgai and mima mounds, which create microhabitats due to differences in drainage (Diamond and Smeins 1993). Despite the diversity within this prairie, the region can be characterized by a general pattern of tallgrass prairie on the uplands with riverine woodlands and forest across much of the bottomland (Diamond and Smeins 1993). This ecoregion has a great number of potential food resources including grass seeds (Sorghastrum nutans, Sporobolus silveanus, Panicum virgatum) and other small seeds (Carex sp., Chenopodium sp., Amaranthus sp.) and geophytes from the uplands as well as 
nuts from the the bottomlands. This ecoregion is maintained by grazing and fire disturbance, which suggests that the ecotonal boundary between the Blackland Prairie and surrounding ecoregions would have been highly mutable and dependent on the history of disturbance. This characterization of the modern vegetation provides a known set of wild food resources that would have been accessible to the site's prehistoric inhabitants.

\section{Materials and Methods}

All FCR samples in this study were processed in the Palynology Research Laboratory, Department of Anthropology, Texas A\&M University. Each sample was subjected to a two-part brushing procedure to minimize the potential for modern starch contamination. After initial examination of a sample, an area of $3 \mathrm{~cm}$ by $3 \mathrm{~cm}$ was selected for sampling. This sub-sampling method was designed to reserve as much of the artifact as possible for future corroborative studies while yielding enough microfossil residue for the current study. This area was sprayed with a dilute (10 percent) solution of $\mathrm{HCl}$ to dissolve any calcium carbonate buildup. Following this, the sampling area was brushed and washed into a collection beaker until the water was visibly clear. The same area was then brushed again with a sonicating brush (Phillips Sonicare E Series) and the resultant residue was washed into a second collection beaker. While this method undoubtedly removes some potential microfossil residue that is directly associated with the use of the earth oven feature, it is an important step in limiting the mis-interpretation of the feature based on microfossil evidence that post-dates the use of the feature. This removal of potential contaminants allows for a much more secure interpretation of the second residue sample, which contains only those microfossils that required sonication to remove.

The resultant residue samples were transferred to $15 \mathrm{ml}$ centrifuge tubes and placed in a five percent Calgon solution for six hours. Following this treatment, each sample was washed in water several times. The samples were then placed in a heavy density solution of $\mathrm{ZnBr}$ at a specific gravity of 2.38. After thorough mixing, the sample were centrifuged for five minutes at low speed, followed by five minutes at high speed. The light fraction resulting from this was pipetted off and the procedure repeated. Following this step, the light fraction was washed several times in water and transferred to a dram vial for storage. The heavy fraction was examined microscopically to determine that all starch granules and phytoliths had been recovered in the light fraction. The heavy fractions consisted primarily of weathered minerals, primarily quartz, and no microfossils were observed in any of the heavy fractions. Following this extraction procedure, a slide was made of the light fraction residue from each sample. This slide was examined under brightfield and cross-polarized light for starch granules and phytoliths. As no phytoliths were encountered in this study, the remainder of this section focuses solely on starch recovery and identification.

\section{Starch Reference Collection}

Archaeological starch research has seen little application to hunter-gatherer sites in North America (Messner 2008; Zarrillo and Kooyman 2006). This is partly due to the need for a reference collection of major potential food resources for each region. The development of this 
collection is hindered by the rare recovery of geophytes and small seeds from the archaeological record, as well as the imprecision of the observations available in the ethnohistoric record (Thoms 2008). This section presents an overview of the starch reference collection developed over the course of this research following a brief review of the microscopic methods useful in starch grain analysis.

The identification of starch granules recovered from archaeological contexts has become one of the more important components of recent paleoethnobotanical studies over the last decade (see Torrence and Barton [2006 ] for a recent overview). While this is a relatively new subfield in archaeology, starch microscopy has long had a place in food science (Flint 1994) and botany (Cortella and Pochettino 1994). Starch was first observed and identified microscopically in 1719 by Antonie van Leeuwenhoek (Thomas and Atwell 1999). Since then, many researchers have shown that starch granules can be microscopically associated with botanical source material based on distinguishing morphological characteristics, the most important being shape and size (Badenhuizen 1965; Cortella and Pochettino 1994; Czaja 1978; Evers 1979; Moss 1976; Reichert 1913). This section provides an overview of some of the techniques used in the light microscopy of starch. Many of the diagnostic features of starch used by paleoethnobotanists, such as differences in the lamellae and hilum location, have been observed and described under brightfield light. Transmitted brightfield light can be used to observe starch granules but it can be very difficult to observe the features necessary to distinguish individual differences between starch grains (Barton and Fullagar 2006). Additionally, because starch grains generally exhibit very low contrast in most mounting media, it can be very difficult to observe granules from an unknown specimen with other microscopic components. For these reasons, much of the initial microscopy used to identify the presence of starch in an archaeological sample relies on polarized light microscopy.

All undamaged starch grains have a high degree of molecular orientation (Evers 1979). This structured organization of the granule results in a characteristic birefringence pattern when starch is viewed in cross-polarized light (Thomas and Atwell 1999). This uniaxial birefringent pattern is known variously as an extinction cross or a maltese cross (Barton and Fullagar 2006; Weaver 2003). Birefringence is a complex optical property of many ordered compounds. Light entering the specimen is split into two components which are plane polarized perpendicular to each other. The refractive index of a birefringent specimen varies with the direction of passage, causing one of the components to be retarded relative to the other component. This optical path difference creates either constructive or destructive interference when the two component waves recombine after leaving the specimen. When the resultant recombined light passes through a second polarizing filter (the analyzer) set at a right angle to the original polarizing filter, any light that has not passed through a birefringent compound will be prevented from passing the analyzer. This microscopic method is very useful for the initial investigation of unknown samples since starch grains are readily visible and relatively distinct from other birefringent biological compounds (Canti 1997; Canti 1998; Canti 1999; Haslam 2006; Loy 2006).

While the extinction cross does provide some distinguishing features and is useful for the initial indication of starch ubiquity, many of the attributes used to differentiate between starch types are obscured in polarized light microscopy. This method may also not detect damaged 
or gelatinized starch grains, which lose birefringence as the molecular order of native starch is disrupted (Evers 1979). Starch grains with very high amylopectin content may also not exhibit birefringent optical properties (Evers 1979).

Under traditional food preparation methods, starch grain structure can be modified by mechanical damage from grinding and milling techniques or gelatinized through wet cooking methods (Babot 2003). Freezing, dehydration, roasting, and charring can also cause damage to starch granules that alters diagnostic features necessary for the identification of native starch granules (Babot 2003). Starch grains recovered in coprolites or latrines may also exhibit enzymatic damage from partial digestion (Autio 2001; Evers 1979). Mechanical damage can result in four different types of modification; 1) radial cracking associated with the hilum, 2) chipping and splitting along the margins of the granule, 3) abrasions and 4) a partial loss of granule structure resulting in a "ghost" granule (Williams 1968).

The current study utilized cross-polarized light microscopy for the initial identification of starch granules in the FCR specimens. Granules identified as starch were further examined under brightfield light to detect features important for botanical source identification.

Reference starch granules were examined for a total of 18 plant taxa known or suspected to be food resources for Texas hunter-gatherer populations. These resources include grass seeds and geophytes, both common resources encountered in the Blackland Prairie ecoregion. Table 13-1 presents summary data for the starch granules for these resources. Figures 13-1 through 13-3 provide micrographs of the starch granules encountered in each taxa examined.

\section{Section II - Pilot Study}

This section presents the results of a microfossil analysis performed on six pieces of firecracked rock (FCR) recovered from earth oven features during excavation of a prehistoric archaeological site (41DL436), Dallas County, Texas. Starch was recovered from all six of the FCR samples submitted for analysis. While each sample was examined for the presence of diagnostic phytoliths as well as starch granules, none of the samples contained phytoliths. This may be due to the preservational context of the site. While most of the starch recovered from the FCR samples could not be conclusively identified to a known botanical source, the results from the study still add to our understanding of hot rock cookery in Texas.

\section{Results}

Starch granules were encountered in the discrete sonicated sub-sample from all six of the FCR samples submitted for analysis. The metric data for these granules is presented in Table 13-2. Due to the limited processing of each sample necessary to ensure starch recovery, the slides of these samples contained a great deal of organic and mineral detritus that was not identifiable. This did not limit the identification of starch granules in the samples. The remainder of this section will present the starch data by feature. 
Table 13-1. Measurements of Starch Granules from Modern Botanical References.

\begin{tabular}{|c|c|c|c|c|c|c|c|c|}
\hline Taxa & Part & Shape & Length (wm) & $\begin{array}{l}\text { Cross } \\
\text { angle }\end{array}$ & Hilum & $\begin{array}{l}\text { Fissures/ } \\
\text { Striations }\end{array}$ & Lamellae & $\begin{array}{l}\text { Vacuole/ } \\
\text { Visible } \\
\text { Hilum }\end{array}$ \\
\hline Achnatherum hymenoides & seed & spherical & $3.5-4.0$ & 90 & centric & Absent & Absent & Absent \\
\hline Amaranthus sp. & small fruit & spherical & $2.0-2.5$ & 90 & centric & Absent & Absent & Absent \\
\hline Andropogon gerardii & seed & spherical & $15.0-18.0$ & 100 & centric & Absent & Absent & Absent \\
\hline Callirhoe involucrata & USO & spherical/oval & $5.0-25.0$ & 110 & eccentric & Some & Present & Absent \\
\hline Carex comosa & seed & spherical & $3.0-5.0$ & 90 & centric & Absent & Absent & Absent \\
\hline Claytonia virginica & USO & bell shaped & $5.0-25.0$ & 90 & eccentric & Some & Present & Absent \\
\hline Cooperia drummondi & USO & variable & $15.0-50.0$ & 110 & eccentric & Present & Present & Present \\
\hline Erythronium sp. & USO & bell shaped & $45.0-55.0$ & 130 & eccentric & Absent & Present & Absent \\
\hline Liatrus mucronata & USO & bell shaped & $15.0-25.0$ & 130 & eccentric & Absent & Absent & Present \\
\hline Nothoscordum bivalve & USO & lenticular/spherical & $5.0-30.0$ & 110 & eccentric & Present & Present & Present \\
\hline Opuntiasp. & seed & spherical & $4.0-6.5$ & 90 & centric & Absent & Absent & Absent \\
\hline Opuntiasp. & cladode & None & $\mathrm{N} / \mathrm{A}$ & N/A & $\mathrm{N} / \mathrm{A}$ & N/A & $\mathrm{N} / \mathrm{A}$ & $\mathrm{N} / \mathrm{A}$ \\
\hline Opuntiasp. & tuna & None & $\mathrm{N} / \mathrm{A}$ & $\mathrm{N} / \mathrm{A}$ & $\mathrm{N} / \mathrm{A}$ & $\mathrm{N} / \mathrm{A}$ & $\mathrm{N} / \mathrm{A}$ & $\mathrm{N} / \mathrm{A}$ \\
\hline Panicum sp. & seed & spherical & $4.5-6.0$ & 90 & centric & Absent & Absent & Absent \\
\hline Prosopis glandulosa & seedpod & variable & $6.0-30.0$ & variable & eccentric & Absent & Some & Present \\
\hline Quercussp. & nut & ovoid & $8.0-15.0$ & $90-120$ & centric & Absent & Absent & Absent \\
\hline Setaria lutescens & seed & spherical & $6.0-8.0$ & 90 & centric & Absent & Absent & Absent \\
\hline Smilax sp. & USO & bell shaped & $7.0-12.0$ & 90 & centric & Absent & Absent & Present \\
\hline Sporobolus sp. & seed & spherical & $6.0-8.0$ & 90 & centric & Absent & Absent & Absent \\
\hline Tucca bacata & Leaf & Spherical & $13.0-19.0$ & 90 & centric & Absent & Absent & Present \\
\hline Tucca bacata & Caudex & Spherical & $10.0-15.0$ & 90 & centric & Absent & Absent & Present \\
\hline
\end{tabular}

Feature 42. This feature has two directly associated radiocarbon dates of $390 \pm 25$ and $390 \pm 30$ YBP. This is the oldest feature submitted for analysis and one of the oldest dates for the site. This sandstone FCR fragment had a single starch granule encountered during analysis. The starch granule, designated as Type A, was a relatively large (20 um) polyhedral with clear birefringence (Figure 13-4).

Feature 7. Two FCR samples were submitted from this feature, which has an associated radiocarbon date of $690 \pm 25$ YBP. Three starch types were encountered across both samples, in both gelatinized and native states. The first type encountered, type B, is a 15 um spherical granule (See Figure 13-4). This type was found in a native $(n=1)$ and gelatinized/damaged $(n=2)$ state on the same sample (Field Lot 284, Sample 1). Type C was encountered on both samples from this feature (See Figure 13-4). This granule is a small (10-12 um) angular type. All three type $\mathrm{C}$ granules encountered in this study exhibited a loss of internal birefringence consistent with partial gelatinization. The size and shape of this type is similar to that observed in grass seeds, although the author has not encountered known grass seed starch granules with such an extreme angular shape. The final type encountered from this feature, type D, was recovered only from one sample (Field Lot 284, Sample 2). Overall, this type exhibits strong similarities with type A, although the shape of D is much more spherical than the granule designated type A (See Figure 13-4). The single granule designated as type D has clear mechanical damage.

Feature 2. One FCR sample was submitted from this feature (radiocarbon date of $500 \pm 25$ YBP). Two distinctive starch granule types were encountered in the sonicated residue analyzed for microfossils. Four starch granules consistent with type A (defined for feature 42) were encountered on this sample, along with a single granule defined as type E. Type E is a rectangular 


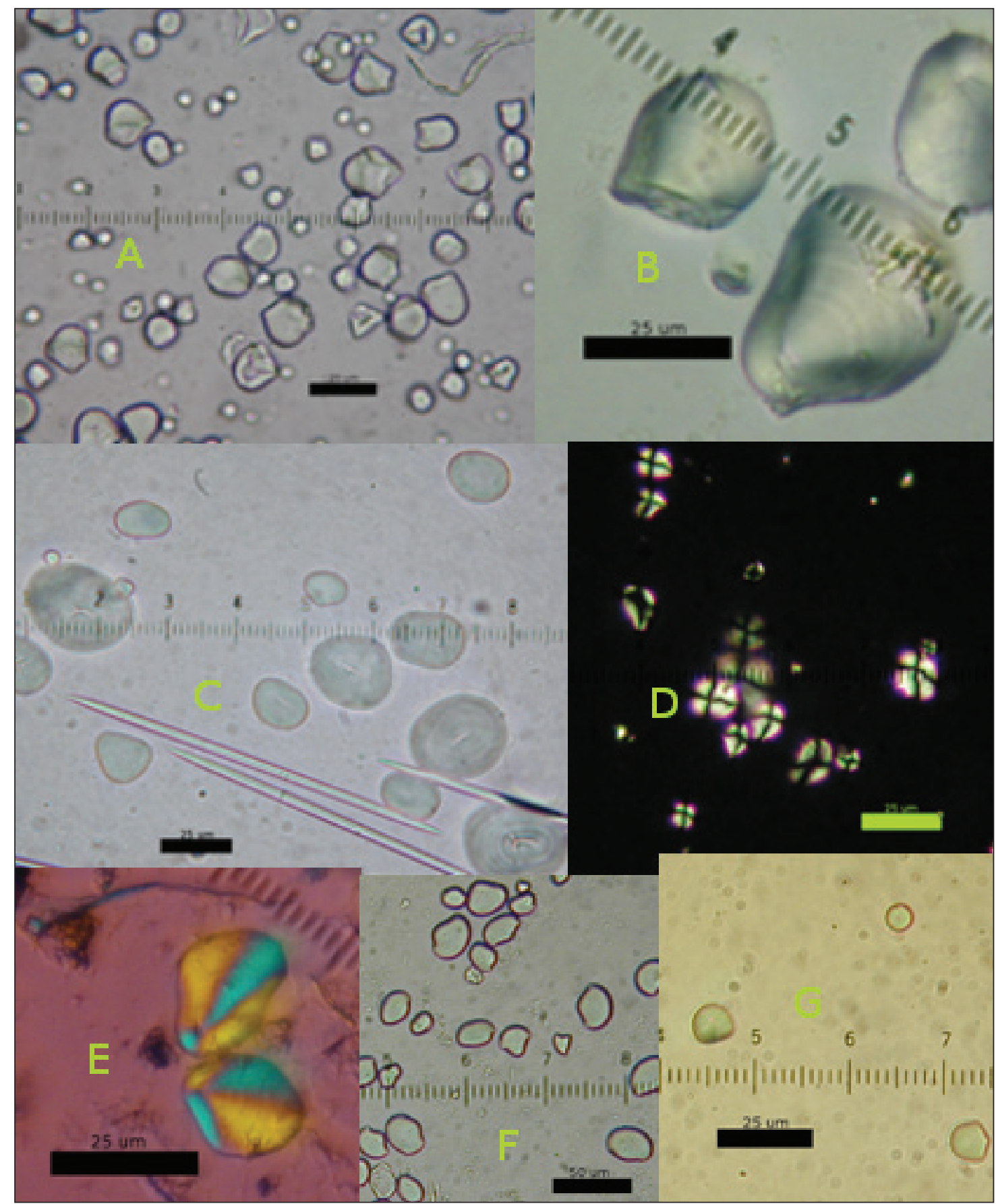

Figure 13-1. Micrographs of Starch Granules from Geophytes (A- Brightfield Micrograph of Callirhoe involucrata, B- Brightfield Micrograph of Cooperia drummondi, C- Brightfield Micrograph of Claytonia virginica, D- Cross-Polarized Light Micrograph of Erythronium sp.,

E- $1 / 4 \lambda$ Retarded Cross-Polarized Light Micrograph of Liatrus mucronata, F- Brightfield Micrograph of Nothoscordum bivalve, G- Brightfield Micrograph of Smilax sp.) 


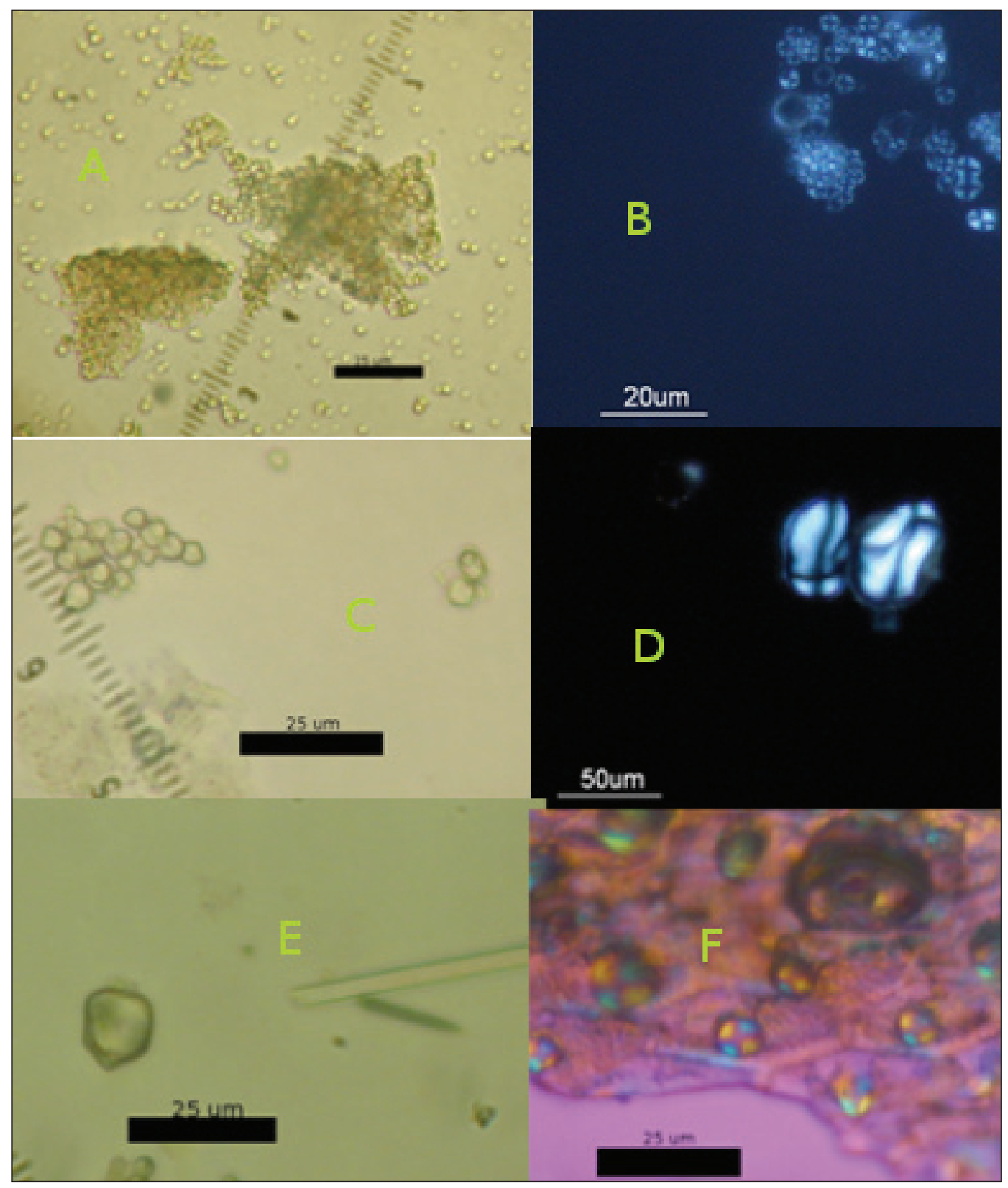

Figure 13-2. Micrographs of Starch from seeds and meristem (A- Brightfield Micrograph of Amaranthus sp., B- Cross-Polarized Light Micrograph of Carex Comosa, C- Brightfield Micrograph of Opuntia sp., D- Cross-Polarized Light Micrograph of Prosopis glandulosa, E- Brightfield Micrograph of Yucca bacata caudex, F- $1 / 4 \lambda$ Retarded Cross-Polarized Light Micrograph of Yucca bacata leaf meristem) 


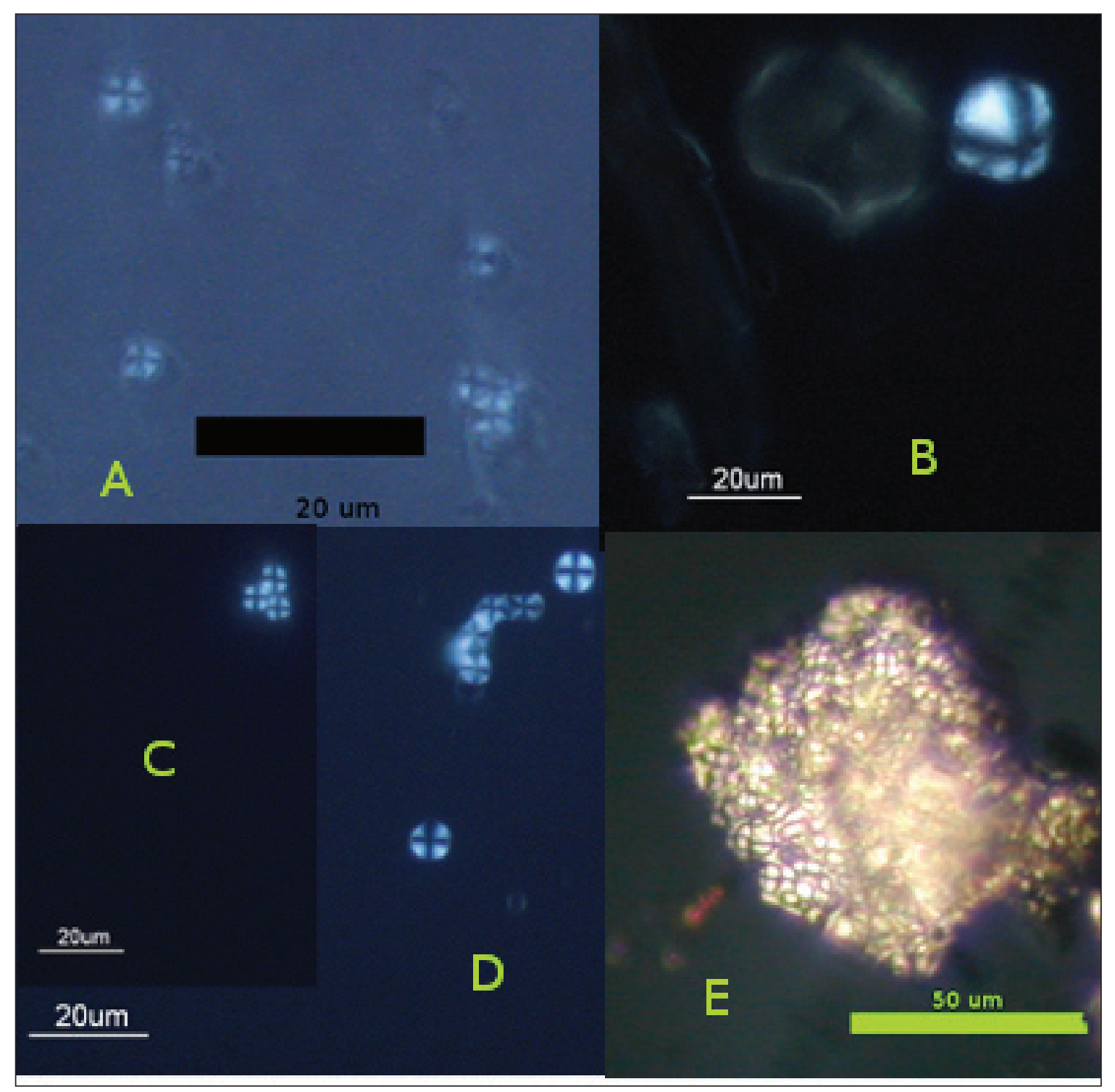

Figure 13-3. Cross-Polarized Light Micrographs of Starch Granules from Grass Seeds (A-Achnatherum hymenoides, B-Andropogon gerardii, C-Setaria lutescens, D-Panicum sonorum, E-Sporobolus asper).

Table 13-2. Measurements of Starch Granules from FCR Samples.

\begin{tabular}{|c|c|c|c|c|c|c|c|c|c|c|}
\hline Sample & Granule ID & Count & Shape & Length (um) & Cross Angle $\left(^{\circ}\right)$ & Hilum & Fissures & Lamallae & Vacuole & Notes \\
\hline Field Lot 93 , Sample 1 & A & 1 & Polyhedral & 20 & 90 & Centric & Absent & Absent & Absent & \\
\hline Field Lot 284 , Sample 1 & $B$ & 2 & Spherical & 15 & N/A & Centric & N/A & Absent & N/A & Gelatanized/Damaged with minimal birefringence \\
\hline Field Lot 284 , Sample 1 & c & 1 & Angular & 10 & 90 & Centric & N/A & Absent & Present & Gelatanized/Damaged with minimal birefringence \\
\hline Field Lot 284 , Sample 1 & $B$ & 1 & Spherical & 15 & 110 & Centric & Absent & Absent & Absent & \\
\hline Field Lot 284 , Sample 1 & D & 1 & Spherical & 20 & 90 & Centric & Radial & Absent & Present & mechanically damaged \\
\hline Field Lot 284 , Sample 2 & c & 2 & Angular & 12.5 & 90 & Centric & N/A & Absent & Present & Gelatanized/Damaged with minimal birefringence \\
\hline Field Lot 235 , Sample 1 & A & 4 & Polyhedral & 20 & 100 & Centric & Absent & Absent & Present & \\
\hline Field Lot 235 , Sample 1 & E & 1 & Polyhedral & 25 & 90 & Centric & Absent & Absent & Present & Rectangular \\
\hline Field Lot 87 , Sample 1 & $\mathrm{~F}$ & 1 & Irregular & 27.5 & 110 & Centric & Present & Absent & Absent & \\
\hline Field Lot 87 , Sample 1 & G & $\sim_{30}$ & Ovoid & 25 & 120 & Eccentric & Absent & Present & Absent & Most still embedded in cellular structure \\
\hline Field Lot 278 & B & & Spherical & 12.5 & 90 & Centric & Absent & Absent & Absent & \\
\hline
\end{tabular}




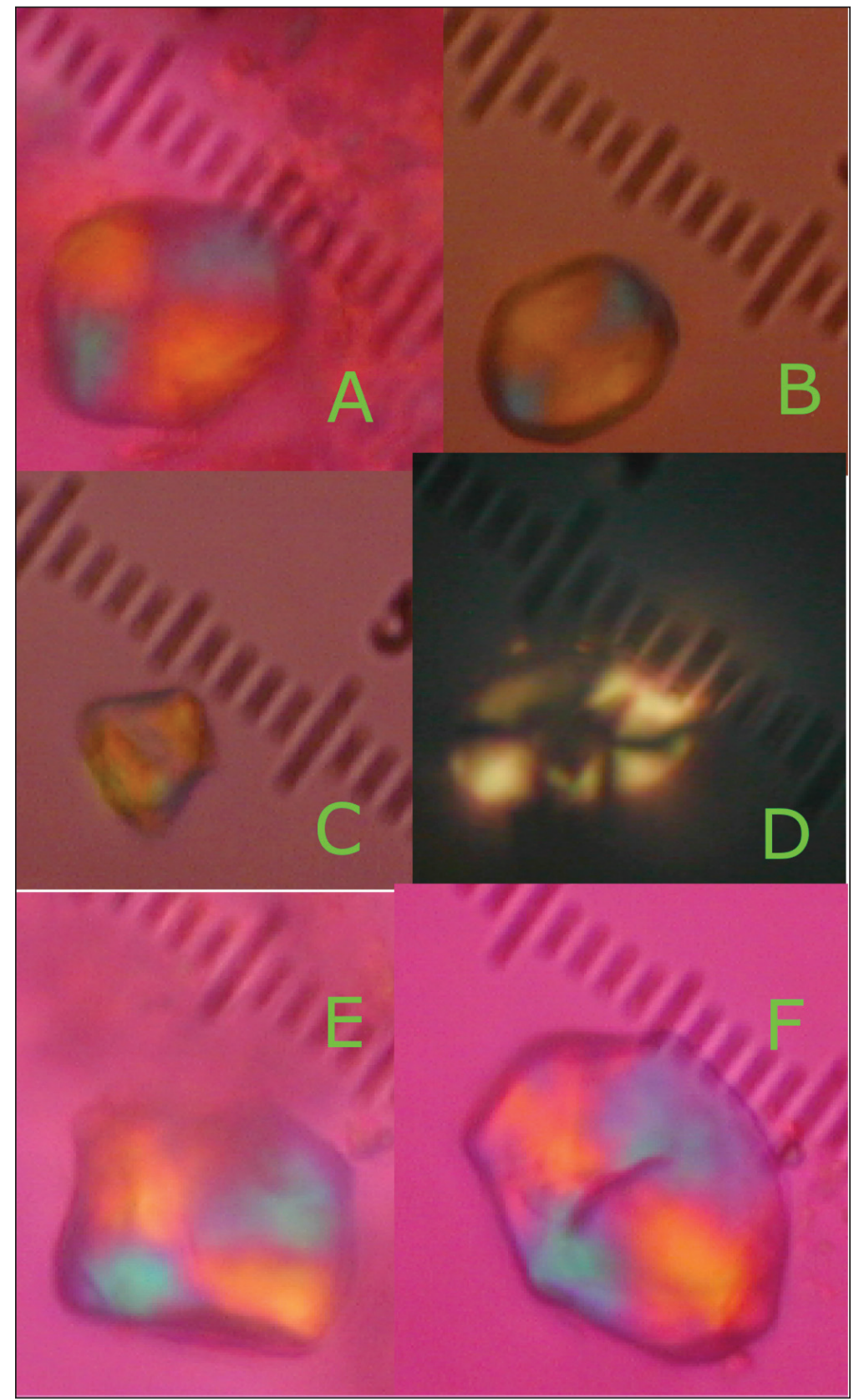

Figure 13-4. Micrographs of unknown Starch Granules from FCR (A- $1 / 4 \lambda$ Retarded Cross-Polarized Light Micrograph of unknown type $A, B-1 / 4 \lambda$ Retarded Cross-Polarized Light Micrograph of unknown type B, C- $1 / 4 \lambda$ Retarded Cross-

Polarized Light Micrograph of unknown type C, D- CrossPolarized Light Micrograph of unknown type D, E- $1 / 4 \lambda$ Retarded Cross-Polarized Light Micrograph of unknown type E, F- $1 / 4 \lambda$ Retarded Cross-Polarized Light Micrograph of unknown type F). All micrographs taken at 400x. polyhedral shape with a maximum length of 25 um (See Figure 13-4).

Feature 24. One FCR sample was submitted from this feature, the youngest considered in the current study (radiocarbon date of $400 \pm 25$ YBP). This sample yielded the most starch of any FCR considered in this study. Two different starch granule types were observed in the sonicated residue from this sample. The first, type $F$, is a large (27.5 um), irregular granule with a large fissure across the hilum (See Figure 13-4). The other starch granule, type G, was encountered in some abundance. Over 30 of these granules were observed within amyloplast structures (Figure 13-5). These specialized organelles are commonly encountered in geophytes and some fruits. The granules associated with the amyloplasts are ovoid in shape and about 25 um along the longest dimension. Type $G$ exhibits visible lamellae or growth rings and also has an eccentric hilum (see Figure 13-5). The combination of these features is suggestive of a geophytic origin for these granules.

Feature 9. This feature, with associated radiocarbon dates of $500 \pm 25$ between $450 \pm 25$ and $208 \pm 22$ YBP, yielded 
a single starch granule. This granule was consistent with type $\mathrm{B}$, initially encountered in Feature 7.

\section{Discussion}

While starch granules were recovered from all six FCR samples analyzed in this study, the exact botanical sources of these starches remain unclear. None of the unknown starch granule types appear to be associated with the botanical references presented earlier in this report. Nevertheless, these unknown starch granules provide some important information on the use of the cooking features at site 41DL436. Type A, encountered in two different features, is a fairly indistinctive granule. Based on the size of this granule, it is unlikely to be from a grass seed and is much more likely to be from a geophyte or other anatomical structure with amyloplasts. Type B appears similar to the starch granules in a number of wild grasses (Messner 2008), though it is slightly bigger than most starch from wild grass seeds. The large angle of the extinction cross is uncommon in many grasses, but it is observed in some economically important grasses such as Hordeum pusillum (Little Barley) (Messner 2008).

Type $\mathrm{C}$ is more angular than the starch granules encountered in most grasses, but seems likely to be from a seed or small hard fruit. Its possible that the angular nature of this granule is due to intercellular packing during the development of the granule. Type D has had its structure mechanically damaged. This has altered the size and shape of the granule, limiting the possibility of identifying the botanical source of this granule.

Types E, F, and $\mathrm{G}$ are all consistent with starch granules associated with geophytes or aquatic storage organs.

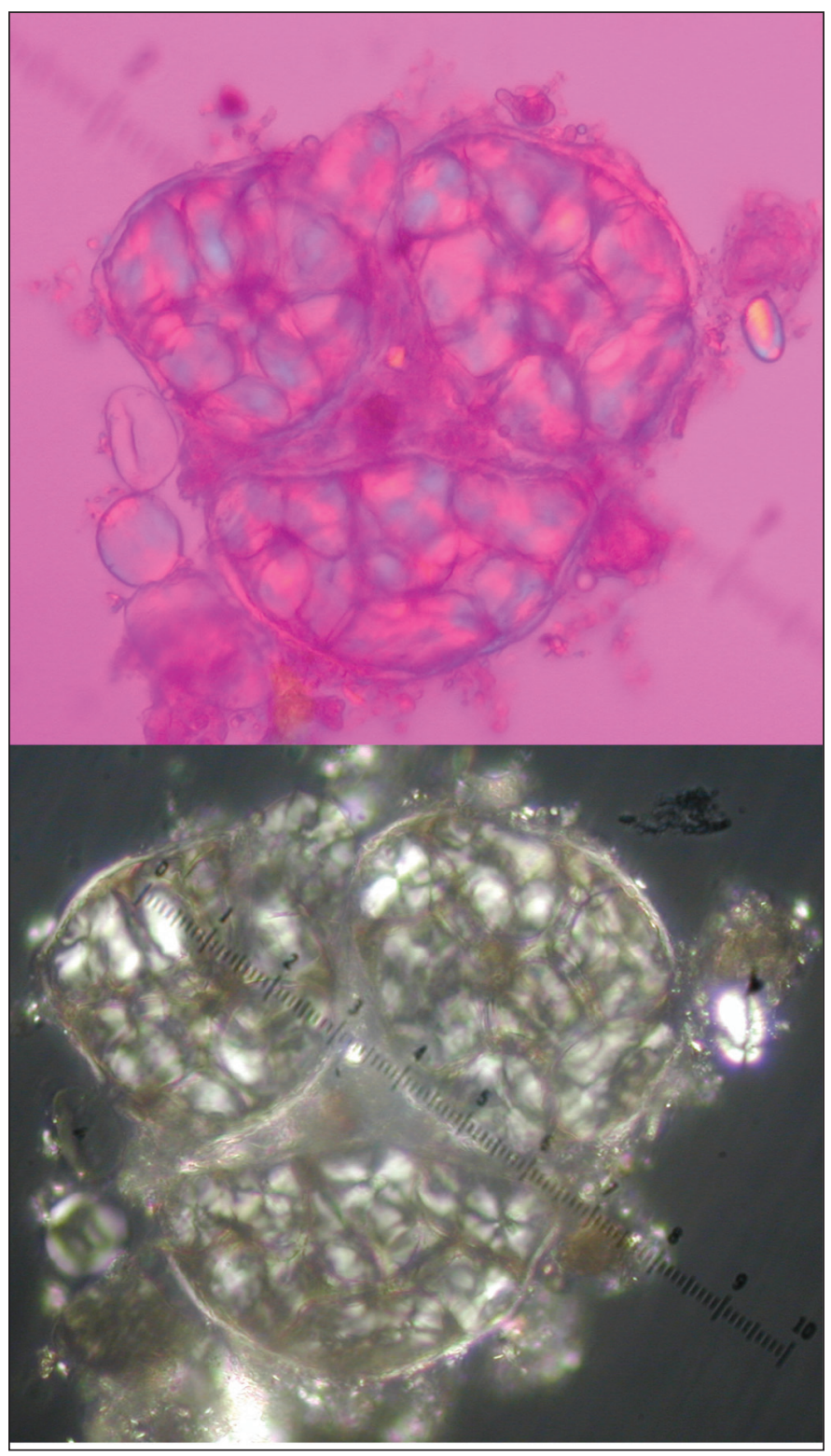

Figure 13-5. Micrographs of unknown starch granule type $\mathrm{G}$ and amyloplasts recovered from FCR sample from Feature 24. Micrographs taken at 400x. 
Type $\mathrm{G}$, in particular, is very reminiscent of several of the aquatic resources identified by Messner (2008), although it doesn't directly match with any of the botanical sources in his reference collection for the Delaware River watershed. The eccentric hilum and visible lamellae, along with the direct evidence of associated amyloplasts, are encountered in geophytes and aquatic storage organs but are unknown in fruits or small seeds. Types E and F are less secure, but are still likely to come from geophyte sources based on size, shape, and extinction cross angles.

\section{Future Directions}

Clearly there are still large gaps in the current understanding of prehistoric subsistence strategies in the Blacklands Prairie and surrounding ecoregions. While this study shows the utility and promise of FCR starch residues, the limited ethnohistoric and archaeological understanding of the comprehensive subsistence resource universe exploited by the human populations in this region severely limits the interpretation of this data. A more rigorous examination of ethnographically known subsistence resources across the region would further develop the known starch references and allow for more secure interpretation of unknown starch granules recovered from archaeological contexts.

Very few starch granules were encountered on most of the FCR samples examined in this study. This is primarily due to the minimal sampling technique employed, which leaves a bulk of the sample's microscopic residue intact for further studies. In addition to limiting the overall quantity of starch granules recovered from each sample, this technique may also limit the number of types of starch recovered on any one sample. This could be avoided by a more complete sampling strategy on each artifact, but this in turn would limit the replicability of this study as well as any attempts at future biochemical residue studies.

\section{SECTION III - Follow-ON STUdY}

This section presents the results of a microfossil analysis performed on eighteen pieces of fire-cracked rock (FCR) recovered from earth oven features during excavation of a prehistoric archaeological site (41DL436), Dallas County, Texas. This is a follow up to a pilot study on six pieces of FCR from the same site. Starch was recovered from all six of the FCR samples submitted for the initial analysis. Unfortunately, none of the samples from this follow-up study yielded starch granules. However, several of the samples in the follow-up study did yield small numbers of phytoliths. It is unclear why the samples from the pilot study had some starch preservation while the other eighteen samples did not.

No starch granules were encountered in the discrete sonicated sub-samples of the FCR submitted for analysis. Five of the samples contained phytoliths. All of the encountered phytoliths are identifiable as coming from the grass (POACEAE) family. These were encountered in such a limited a quantity that very little can be interpreted from their presence. It is possible that the phytoliths are evidence of the use of grass in the earth ovens, most likely as packing material. The phytoliths may also be indicators of a grassland environment during the use of the oven 
features. Microscopic charcoal fragments associated with the use of these rocks as thermal elements were encountered in all eighteen samples submitted for analysis.

Two different phytolith forms were found in the study. Type A is a bilobate form associated with grasses in the subfamily Panicoideae, such a bluestem grasses (Andropogon sp.) and switchgrass (Panicum virgatum) (Figure 13-6). Type B is a saddle-shape associated with grasses in the subfamily Chloridoideae, which includes dropseeds (Sporobolus sp.) and gramas (Bouteloua sp.) (Figure 13-1.B). Sample 4 had two phytoliths of type A and one of type B. Sample 8 had two type B phytoliths. Sample 10 had four type B phytoliths. Sample 12 had two type A bilobate phytoliths and one type B phytolith. Sample 13 had three phytoliths of type A and one of type B. While these phytoliths all indicate the presence of grasses, the limited quantity preclude any meaningful assessment.

Table 13-3. Fire-cracked Rock samples Analyzed in the Follow-on Study.

\begin{tabular}{ccccccc}
\hline Component & Date & Unit \# & Level \# & Feature \# & Material Type & Sample \# \\
\hline Middle & $500 \pm 25$ & 75 & 1 & 2 & Sandstone & 7 \\
\hline Middle & $580 \pm 25$ & $86 / 90$ & 1 & 5 & Sandstone & 8 \\
\hline Middle & $580 \pm 25$ & $86 / 90$ & 1 & 5 & Sandstone & 9 \\
\hline Middle & $580 \pm 25$ & $86 / 90$ & 1 & 5 & Sandstone & 10 \\
\hline Middle & $580 \pm 25$ & $86 / 90$ & 1 & 5 & Sandstone & 11 \\
\hline Middle & $580 \pm 25$ & $86 / 90$ & 1 & 5 & Sandstone & 12 \\
\hline Middle & $580 \pm 25$ & $86 / 90$ & 1 & 5 & Sandstone & 13 \\
\hline Lower & $690 \pm 25$ & 87 & 1 & 7 & Sandstone & 14 \\
\hline Lower & $690 \pm 25$ & 87 & 1 & 7 & Sandstone & 15 \\
\hline Lower & $690 \pm 25$ & 87 & 1 & 7 & Sandstone & 16 \\
\hline Lower & $690 \pm 25$ & 87 & 1 & 7 & Sandstone & 17 \\
\hline Lower & $800 \pm 25$ & $103 / 104$ & 1 & 42 & Sandstone & 18 \\
\hline Lower & $800 \pm 25$ & $103 / 104$ & 1 & 42 & Sandstone & 19 \\
\hline Lower & $800 \pm 25$ & 103 & 1 & 42 & Limestone Conglomerate & 20 \\
\hline Middle & $580 \pm 25$ & $86 / 90$ & 1 & 5 & Sandstone & 21 \\
\hline Middle & $580 \pm 25$ & $86 / 90$ & 1 & 5 & Sandstone & 22 \\
\hline Lower & $690 \pm 25$ & 87 & 1 & 7 & Sandstone & 23 \\
\hline Lower & $690 \pm 25$ & 87 & 1 & 7 & Sandstone & 23 \\
\hline
\end{tabular}




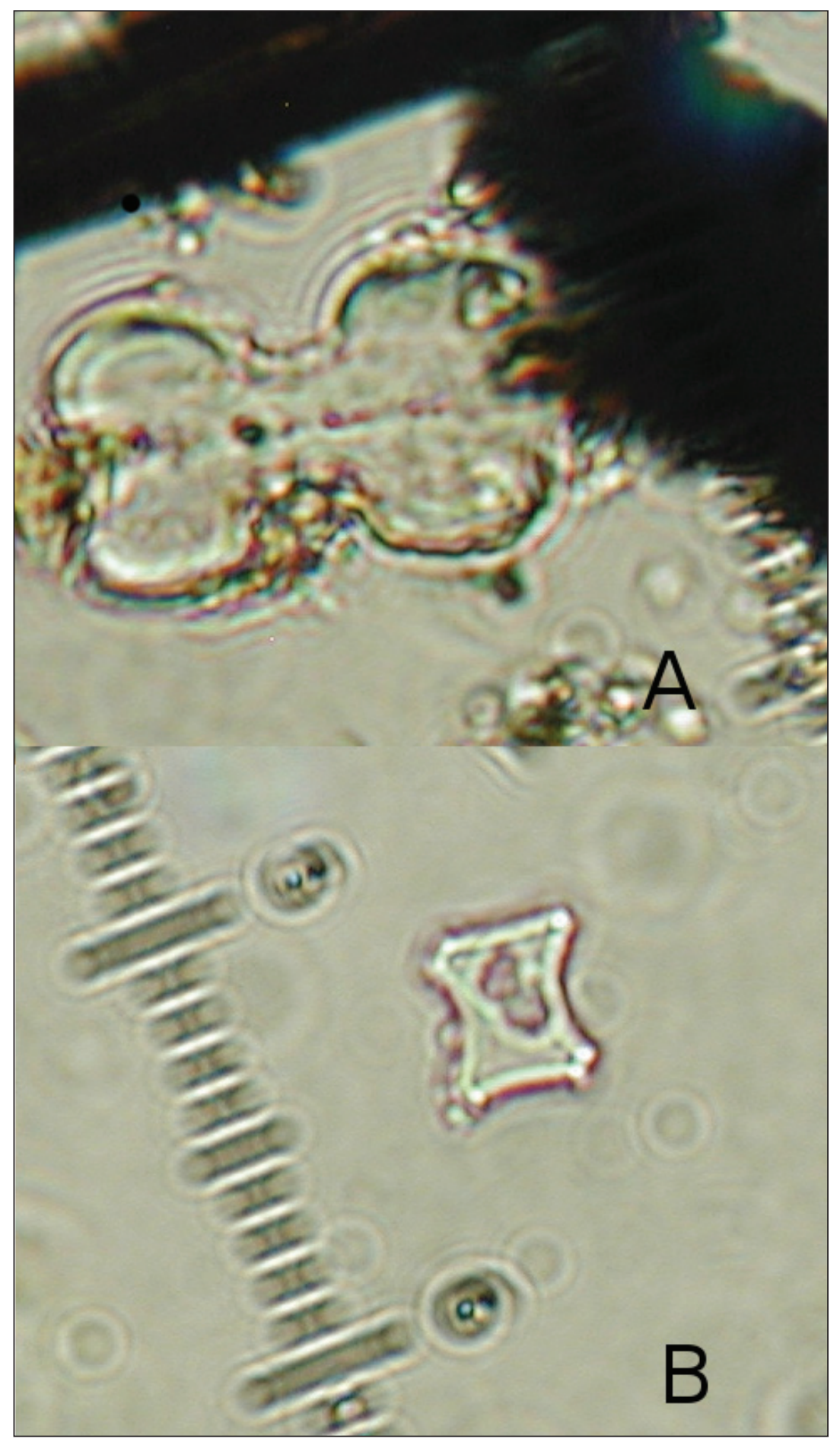

Figure 13-6. Micrographs of poaceae phytoliths recovered from fire cracked rock. A-Bilobate form associated with Panicoideae; B-Saddle-shape phyotlith associated with Chloridoideae. 


\section{Chapter 14 \\ ETHNOBOTANICAL}

\section{Phil Dering}

The purpose of this analysis is to provide an assessment of the botanical assemblages from 41DL436. Ten flotation samples, totaling 79.5 liters, were submitted for analysis. Sample sizes ranged from 1.0 to 31 liters. The data will be utilized to assess the nature and condition of the plant remains from these sites and provide some evidence for plant utilization and local environmental conditions.

\section{METHODS}

Flotation is a method of recovering organic remains from archaeological sediments by using water to separate heavy or soluble inorganic particles from plant parts and small animal bone. The material floating to the surface is called the light fraction, and this is caught on a fine mesh screen or strainer. The material that sinks to the bottom is the heavy fraction and it is also caught on a fine mesh screen. Most of the soil including clay and silt is suspended in water and passes through the screens and is either recycled or discarded. In this study, both the light and heavy fractions were submitted for analysis.

The analysis followed standard archaeobotanical laboratory procedures. The volume of the light fraction is first measured. In most cases up to $100 \mathrm{ml}$ of light fraction from each sample is set aside for analysis. Then the portion to be analyzed is passed through a nested set of screens of 4-mm, 2-mm, 1-mm, and 0.450-mm mesh and examined for charred material, which is separated for identification. The heavy fraction is also scanned for charcoal, which is set aside for identification. The results are combined with identifications from each corresponding light fraction. In the current study, charred plant material was so scarce that I sorted through the entire volume of each light fraction that was submitted for analysis.

Plant material is sorted into two categories - woody fragments, and seed/fruit fragments, including maize or agave parts when present. Identification of carbonized wood was accomplished by using the snap technique, examining the fragments at 8-45 magnifications with a hand lens or a binocular dissecting microscope, and comparing the material to samples in the archaeobotanical herbarium. All seed identifications were made using seed manuals and reference collections at Shumla Archaeobotanical Services. Only charred plant material is included in the analysis, because uncarbonized material is consumed by insects, fungi and bacteria and does not survive more than a few years in the deposits of open sites.

Up to 25 wood charcoal fragments large enough to be manipulated are examined and identified from each flotation sample. Fragments smaller than two or three mm cannot be manipulated. They are usually placed in the indeterminate category. When a sample contains more than 25 
fragments, the rest of the material is scanned to make sure that no other taxa are present. Then the volume of the charcoal is measured and included along with its weight in the report. The results for each sample are presented in tabular format showing count and weight totals for the taxa (Diehl 2003:213; Huckell 2002:645; Miksicek 1994:243).

Disturbance Indicators. Sample content may be affected by various biological disturbance factors, including insect or small mammal activity, plant root growth, gastropods, and shrinking/ swelling of soils due to changes in moisture content. In an effort to assess this impact, the amounts of insect parts, termite pellets, gastropods, leaves, mammal remains (including fecal pellets), and modern uncharred seeds are estimated for each flotation sample. These amounts are reported on a scale of $1-5(+), 6-25(++), 26-50(+++)$, and over $50(++++)$.

\section{Results AND Discussion}

Results of the analysis are presented in Tables 14-1 and 14-2. Table 14-1 presents an overview of each sample, including proveniences pre-flotation volume, light fraction volume and weight, disturbance indicators, uncharred seeds, number of seed or bulb taxa (if any), and total number of carbonized seeds and other edible plant resource fragments and total charcoal, along with seed taxa counts and seed counts from each sample. Identifications, counts, and weights of the plant taxa recovered from each sample appear in Table 14-2.

Table 14-1. Sample Summaries.

\begin{tabular}{|c|c|c|c|c|c|c|c|c|c|}
\hline$\frac{\frac{\pi}{0}}{\frac{0}{\tilde{D}}}$ & 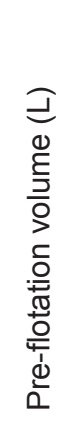 & 蒙 & 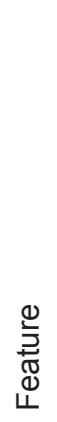 & 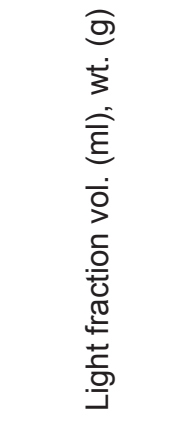 & 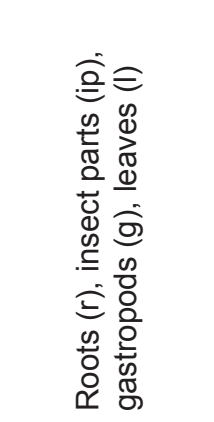 & 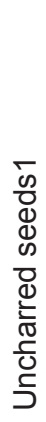 & 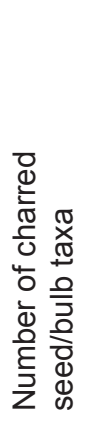 & 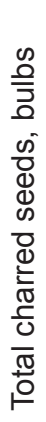 & 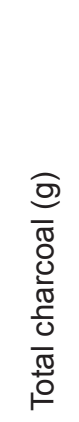 \\
\hline 235 & 8.0 & 75 & 2 & $40 \mathrm{~mL}, 14.2 \mathrm{~g}$ & silt and roots & - & 0 & 0 & 0.0 \\
\hline $7,15-19$ & 12.0 & $2-5$ & 3 & $82 \mathrm{~mL}, 22.2 \mathrm{~g}$ & $\mathrm{r}+++, \mathrm{g}+, \mathrm{l}+$ & - & 0 & 0 & 1.5 \\
\hline 300 & 31.0 & $86,88,90$ & 5 & $445 \mathrm{~mL}, 192 \mathrm{~g}$ & mostly charcoal & 7 & 1 & 1 & 147.4 \\
\hline 285 & 5.0 & 87 & 7 & $14 \mathrm{~mL}, 7.9 \mathrm{~g}$ & $\mathrm{r}+++, \mathrm{g}+, \mathrm{I}+$ & - & 0 & 0 & 0.3 \\
\hline 25 & 4.0 & 5 & 8 & $10 \mathrm{~mL}, 0.3 \mathrm{~g}$ & $\mathrm{r+++}$ & - & 0 & 0 & $<0.1$ \\
\hline 87 & 5.0 & 32 & 24 & $12 \mathrm{~mL}, 1.1 \mathrm{~g}$ & $\mathrm{r+++}, \mathrm{g}+, \mathrm{l}+$ & - & 0 & 0 & $<0.1$ \\
\hline 192 & 1.0 & 53 & 31 & $22 \mathrm{~mL}, 3.7 \mathrm{~g}$ & $\mathrm{r+++}, \mathrm{g}++$ & - & 0 & 0 & $<0.1$ \\
\hline 195,197 & 7.5 & 55,65 & 35 & $22 \mathrm{~mL}, 5.2 \mathrm{~g}$ & $\mathrm{r+++}, \mathrm{g}+$ & - & 0 & 0 & 0.8 \\
\hline 392 & 4.5 & 102 & 41 & $72 \mathrm{~mL}, 18.6 \mathrm{~g}$ & $\mathrm{r+++}, \mathrm{g}++$ & - & 0 & 0 & 1.3 \\
\hline 390 & 1.5 & 103 & 42 & $8 \mathrm{~mL}, 1.2 \mathrm{~g}$ & $\mathrm{r++}, \mathrm{g}++$ & - & 0 & 0 & $<0.1$ \\
\hline
\end{tabular}

${ }^{1}$ Seven hackberry nutlets were recovered from this sample. Although there is a possibility that hackberry is part of the archaeological record, none of these nutlets were discolored by fire or weathering, and it is likely they constitute modern contamination. 
Disturbance indicators were abundant. Roots and small gastropods constituted the majority of the disturbance indicators, and some samples contained insect parts and uncharred seeds. Recovery of charred plant material in the flotation samples was quite variable. The total charcoal in each sample varied from no charred plant material in Field Lot 235 to $147.4 \mathrm{~g}$ in Field Lot 300 from Feature 5. The sample from Feature 5 was almost completely composed of charred plant material. No bulb-type fragments were identified in the samples, but a single charred grape seed was recovered from Field Lot 300. All but one of the samples contained carbonized wood fragments.

Four wood types comprised most of the carbonized plant material in the samples, woody legume-type, cottonwood/willow-type, elm-type, and rose family-type. The charcoal identified as woody legume-type is probably Gleditsia tricanthos, honey locust, a common member of the legume family. The elm-type could be one of many elm species, including American elm, cedar elm, or slippery elm. The rose family type is a wood type that spans a couple of prominent genera, including Mexican plum (Prunus mexicana), and various hawthorns (Crataegus spp.). Indeterminate wood is a label for carbonized wood (hardwood, not pine or juniper), that lacks diagnostic anatomical features due to its small size, weathering, fungal attack, root or insect damage, or distortion caused by heat. Often charred roots, which may be difficult to identify, are found in heating features, and some of the material in the current study is root material.

Table 14-2. Results of the Flotation Samples.

\begin{tabular}{|c|c|c|c|c|c|c|c|c|}
\hline Feature & Stratum & Unit & Taxon & Common & Part & Count & Vol (mL) & Wt. (g) \\
\hline 2 & 2 & 75 & $\begin{array}{l}\text { No carbonized } \\
\text { plant remains }\end{array}$ & & & & & \\
\hline 3 & 3 & $2-5$ & Fabaceae & Woody legume & Wood & 20 & & 0.8 \\
\hline 3 & 3 & $2-5$ & Indeterminate & NA & Wood & 25 & & 0.7 \\
\hline 3 & 3 & $2-5$ & Indeterminate & NA & Seed & 4 & & - \\
\hline 3 & 3 & $2-5$ & Vitis sp. & Grape & Seed & 1 & & - \\
\hline 3 & 3 & $2-5$ & $\begin{array}{l}\text { Celtis sp. (probably } \\
\text { modern) }\end{array}$ & Hackberry & Nutlet & 7 & & - \\
\hline 5 & $1 a$ & $86,88,90$ & Salicaceae & $\begin{array}{l}\text { Cottonwood/ } \\
\text { willow }\end{array}$ & Wood & $25+$ & 78 & 68.3 \\
\hline 5 & $1 a$ & $86,88,90$ & Indeterminate & NA & Wood & $25+$ & 27 & 18.3 \\
\hline 5 & $1 a$ & $86,88,90$ & Fabaceae & Woody legume & Wood & $25+$ & 62 & 43.7 \\
\hline 5 & $1 a$ & $86,88,90$ & Ulmus sp. & Elm & Wood & $25+$ & 31 & 15.8 \\
\hline 5 & $1 a$ & $86,88,90$ & Rosaceae & Rose family wood & Wood & 24 & & 1.3 \\
\hline 7 & $1 a$ & 87 & Salicaceae & $\begin{array}{l}\text { Cottonwood/ } \\
\text { willow }\end{array}$ & Wood & 19 & & 0.3 \\
\hline 8 & 3 & 5 & Indeterminate & NA & Wood & 2 & & $<0.1$ \\
\hline 24 & 2 & 32 & Fabaceae & Woody legume & Wood & 4 & & $<0.1$ \\
\hline 31 & 2 & 53 & Ulmus sp. & Elm & Wood & 4 & & $<0.1$ \\
\hline 35 & 2 & 55,65 & Ulmus sp. & Elm & Wood & 28 & & 0.8 \\
\hline 41 & $1 a$ & 102 & Ulmus sp. & Elm & Wood & 11 & & 0.4 \\
\hline 41 & $1 a$ & 102 & Indeterminate & NA & Wood & 10 & & 0.5 \\
\hline 41 & $1 a$ & 102 & Salicaceae & $\begin{array}{l}\text { Cottonwood/ } \\
\text { willow }\end{array}$ & Wood & 9 & & 0.4 \\
\hline 42 & $1 a$ & 103 & Indeterminate & NA & Wood & 10 & & $<0.1$ \\
\hline
\end{tabular}




\section{CONCLUSION}

The ten flotation samples contain woody legume-type, cottonwood/willow-type, elm-type, and rose family-type wood. Disturbance indicators were abundant, and most of the samples had very little carbonized material. The botanical assemblage is very reduced; five of the samples contained less than $1.0 \mathrm{~g}$ of charred plant material. Only one grape seed (most likely consumed without processing) and no other edible plant fragments, including bulb fragments, were recovered from the samples. Thus, direct evidence for bulb baking or other plant preparation is not forthcoming from this site. As a result the botanical assemblage provides little useful evidence for local or regional land use beyond the selection of wood types for fuel.

However, the wood types in the samples are unusual, and do provide some evidence for the nature of the local environment during the time the site was occupied. With the exception of the elm and cottonwood/willow types, I find this to be an unusual group of taxa for a prehistoric site. One would expect at least some oak in the assemblage, if for no other reason that oak is a preferred fuel, the charcoal is resistant to weathering, and even small pieces have easy to recognize diagnostic characters. Other than the elm wood, the wood types come from smaller trees. In fact, the wood types are from taxa that usually indicate an edge area, possibly along or adjacent to a creek terrace with a mix of closed and open canopy. Honey locust is usually found in open areas of disturbed ground, and Mexican plum is usually (but not always) found growing as understory in moister areas (Cox and Leslie 1988). The single grape seed also suggests an edge environment, as grapevines often drape smaller trees located along the edge of clearings. 


\title{
Chapter 15
}

\section{Faunal Analysis}

\author{
Jodi A. Jacobson
}

\section{SECTiON I: Site Overview}

\section{Introduction}

Data recovery of 41DL436 was undertaken by AmaTerra under the auspices of TxDOT. Zooarchaeological studies conducted by TRC during the data recovery phase were designed to determine species variability, human subsistence strategies, taphonomic processes, and cultural use of bone. Research design questions related to fauna are presented in Chapters 3 and 18 . All data are presented as a site overview and then individually by strata allowing for intra-site comparison within a temporal framework. Discussion does not address individual features, any feature material is contained only within it's greater stratigraphic context.

Vertebrate remains recovered during 1/4-inch screening of excavated deposits and heavy fraction flotation by Amaterra were analyzed and results are presented. Material floated by Ken Brown and included in his discussion of snails, peaclams and freshwater limpets (Chapter 6) were not included in this analysis. All bones analyzed were identified through use of the analyst's private faunal collection, use of loan specimens from the University of Tennessee's Department of Anthropology's Vertebrate Comparative Skeletal Collection, a visit to the University of Texas's Vertebrate Paleontology Lab, and assorted identification manuals and articles (Olsen 1964; Olsen 1968; Balkwill and Cumbaa 1992; Jacobson 2004; Ford 1990). Taxonomic classification for mammals follows Schmidly (1994) and classification for reptiles and amphibians follows Stebbins (2003). Taxonomic classification for birds follows Peterson (1988) and follows Page and Burr (1991) for fish. All bone was identified to the most specific taxonomic level possible. When diagnostic characteristics were not as variable, for example presence of a character which had been noted as defining only 65 percent of the time in bison, identifications to species were listed as "compares favorably" or "c.f." For example, in the case above a species determination would have been listed as c.f. Bison bison.

As not all of the animal bone was identifiable beyond class, size categories were used to differentiate the various bones for analytical purposes. Size categories by class or other taxonomic level are useful for understanding human subsistence strategies and prey choice preference (high biomass versus low biomass) within an environment. Size categories may also give an indication of an environment's overall species richness (Lawton 1990). The size categories for mammals included large (bison, cattle, horse, etc.), medium-large (deer, antelope, pig, etc.), medium (dog, raccoon, bobcat etc.), small-medium (opossum, beaver, skunk), small (rabbit, prairie dog, squirrel, etc.), very small mammal (wood rat, hispid cotton rat, vole, etc.), 
and microtine mammal (mouse, shrew, etc.). Size categories for birds included large (swan, bald eagle, etc.), medium-large (goose, turkey, great-blue heron, etc.), medium (mallard duck, caracara, red-tailed hawk, etc. ), and small (dove, American golden plover, screech owl, etc.). Size categories for reptiles included very small reptile (gecko, earth snake etc.). Identified Artiodactyla bones not identifiable to species were sub-divided into large artiodactyl (bison, cow, elk, etc.), medium-large artiodactyl (white-tailed deer, mule deer, pronghorn antelope, etc.) and medium or larger artiodactyl (any artiodactyl such as bison, deer, sheep, etc. of a size larger than a sheep or goat). Enough specimens were classifiable to the family Muridae (rats, mice, and voles), but not to species that sub categories of very small muridae (cotton rats, wood rats, prairie vole, etc.) and microtine muridae (plains harvest mouse, Texas mouse, northern pygmy mouse, etc.) were included. Additionally, turtle was prevalent enough that broader classification of medium testudines (river cooter, slider, box turtle, etc.) and small testudines (mud turtle, immature box turtle, etc.) were utilized when identification beyond order was not possible.

Summaries of material recovered from the site as a whole and discussions regarding environment and subsistence strategies, taphonomy, cultural bone modifications, and interpretations are discussed in the following sections, along with a discussion of the same topics divided by strata. Furthermore, discussion of shifts in human subsistence strategies, changes associated with movement from prehistoric to protohistoric to historic and the introduction of European technology, along with general trends are presented.

\section{Site Overview}

The total vertebrate number of identified specimens (NISP) recovered from the site was 8,701 of which 4,620 (53.1 percent) were identifiable to class. The dominate class of vertebrate represented in the assemblages was mammal accounting for 68.6 percent $(n=3,170)$ of the bones identifiable to class. Reptiles, with 1,343 bones (29.1 percent) identifiable to class, accounted for the second most prevalent class of remains present. There were also 75 bird bones ( 1.6 percent), 8 amphibian bones ( 0.2 percent), 23 fish bones ( 0.5 percent), and 1 nondeterminable herpetile bone (less than 0.1 percent) identified from the assemblage. A detailed account of taxa identified and the NISP and minimum number of individuals (MNI) for each taxa are listed in Table 15-1.

While over 50 percent of the bones from a Texas assemblage are rarely identifiable to class, the preservation of material is further emphasized when taking into consideration that over 2,726 (31.3 percent) of the 8,701 bones were recovered during flotation (heavy fraction). Typically, highly fragmented and unidentifiable bone fragments dominate heavy fraction samples. In fact, only 442 of the 2,726 bones (17 percent) recovered from the heavy fraction were identifiable to class. By contrast, of the 5,939 bones recovered during screening through $1 / 4$-inch mesh 74 percent $(n=4,379)$ were identifiable to class (Figure 15-1).

For comparison, Wilson-Leonard is considered one of the more well-preserved archaeological faunal assemblages in Texas and is located in a similar open (non-rockshelter) alluvial setting in Williamson County (Baker 1998). Of the total 15,309 vertebrate remains recovered from 
Table 15-1. Vertebrate Remains .

\begin{tabular}{|c|c|c|c|}
\hline CLASS & TAXA (COMMON NAME) & NISP & $\mathrm{MNI}$ \\
\hline \multirow[t]{44}{*}{ Mammal } & Didelphis virginiana (opossum) & 1 & 1 \\
\hline & Cryptotis/Notiosorex (least/desert shrew) & 1 & 1 \\
\hline & Canis sp. (dog/coyote) & 22 & 1 \\
\hline & Procyon lotor (raccoon) & 1 & 1 \\
\hline & Medium Carnivore & 3 & 1 \\
\hline & Bison bison (bison) & 147 & 4 \\
\hline & c.f. Bison bison (bison) & 8 & \\
\hline & Bos taurus (cow) & 1 & 1 \\
\hline & c.f. Bos taurus (cow) & 1 & \\
\hline & Bovidae (bison/cow) & 100 & 2 \\
\hline & c.f. Bovidae (bison/cow) & 3 & \\
\hline & Antilocapra americana (pronghorn antelope) & 14 & 1 \\
\hline & Odocoileus virginianus (white-tailed deer) & 22 & 2 \\
\hline & c.f. Odocoileus virginianus (white-tailed deer) & 2 & \\
\hline & Odocoileus hemionus (mule deer) & 6 & 2 \\
\hline & c.f. Odocoileus hemionus (mule deer) & 5 & \\
\hline & Odocoileus sp. (deer) & 89 & 3 \\
\hline & c.f. Odocoileus sp. (deer) & 6 & \\
\hline & Antilocapra/Odocoileus (pronghorn/deer) & 82 & \\
\hline & Large Artiodactyla & 145 & \\
\hline & Medium-large Artiodactyla & 18 & \\
\hline & Medium or larger Artiodactyl & 64 & \\
\hline & Artiodactyl & 10 & \\
\hline & Spermophilius sp. (ground squirrel) & 2 & 1 \\
\hline & Very small Sciuridae (squirrel) & 1 & 1 \\
\hline & Geomys sp. (pocket gopher) & 7 & 2 \\
\hline & Geomidae (pocket gopher) & 1 & 1 \\
\hline & Dipodomys sp. (kangaroo rat) & 5 & 2 \\
\hline & Castor canadensis (beaver) & 1 & 1 \\
\hline & Oryzomys palustris (marsh rice rat) & 11 & 2 \\
\hline & Sigmodon hispidis (hispid cotton rat) & 5 & 3 \\
\hline & Sigmodon sp. (cotton rat) & 38 & 5 \\
\hline & Sigmodontinae (rice/cotton rat) & 7 & 2 \\
\hline & Neotoma sp. (wood rat) & 3 & 1 \\
\hline & Reithrodontomys sp. (harvest mouse) & 2 & 1 \\
\hline & Peromyscus sp. (mouse) & 2 & 1 \\
\hline & Microtus pinetorum (woodland vole) & 3 & 1 \\
\hline & Microtus sp. (vole) & 4 & 1 \\
\hline & Very small Muridae (rat/vole) & 10 & \\
\hline & Microtine Muridae (mouse/vole) & 23 & \\
\hline & Muridae & 2 & \\
\hline & Small Rodent & 4 & \\
\hline & Very Small Rodent & 62 & \\
\hline & Microtine Rodent & 12 & \\
\hline
\end{tabular}




\begin{tabular}{|c|c|c|c|}
\hline CLASS & TAXA (COMMON NAME) & NISP & MNI \\
\hline & Sylvilagus sp. (cottontail rabbit) & 17 & 2 \\
\hline & Leporidae (rabbit) & 3 & \\
\hline & Large Mammal & 384 & \\
\hline & Medium-large Mammal & 474 & \\
\hline & Medium Mammal & 30 & \\
\hline & Medium or larger Mammal & 316 & \\
\hline & Small-Medium Mammal & 4 & \\
\hline & Small Mammal & 4 & \\
\hline & Very small Mammal & 18 & \\
\hline & Microtine Mammal & 5 & \\
\hline & Miscellaneous Mammal & 960 & \\
\hline & Subtotal & 3170 & \\
\hline \multirow[t]{15}{*}{ Aves } & c.f. Anserinae (goose) & 1 & 1 \\
\hline & Medium Anatidae (duck) & 2 & 1 \\
\hline & Anseriformes (waterfowl) & 1 & 1 \\
\hline & Buteo jamaicensis (red-tailed hawk) & 1 & 1 \\
\hline & Falconiformes (hawks, eagles, falcons) & 3 & 1 \\
\hline & Falconiformes/Strigiformes (birds of prey) & 4 & 1 \\
\hline & Charadriidae/Scolopacidae. (plover/sandpiper) & 1 & 1 \\
\hline & Charadriiformes (shore bird) & 2 & 1 \\
\hline & Small Passeriformes (perching bird) & 1 & 1 \\
\hline & Large Aves & 2 & \\
\hline & Medium-large Aves & 2 & \\
\hline & Medium Aves & 42 & \\
\hline & Small Aves & 7 & \\
\hline & Miscellaneous Aves & 6 & \\
\hline & Subtotal & 75 & \\
\hline \multirow[t]{18}{*}{ Reptile } & Terrapene ornata (western/ornate box turtle) & 147 & 4 \\
\hline & c.f. Terrapene ornata (western/ornate box turtle) & 9 & \\
\hline & Terrapene carolina (eastern box turtle) & 18 & 1 \\
\hline & Terrapene sp. (box turtle) & 233 & 5 \\
\hline & c.f. Kinostern flavescens (yellow mud turtle) & 6 & 1 \\
\hline & Kinosternidae (mud/musk turtle) & 4 & 1 \\
\hline & Trachemys scripta (red-eared slider) & 77 & 2 \\
\hline & Trachemys/Pseudomys (slider/cooter turtle) & 9 & 1 \\
\hline & Emydidae (pond turtle) & 142 & \\
\hline & Trionyx spiniferous (spiny softshell) & 1 & 1 \\
\hline & Trionyx sp. (softshell turtle) & 1 & 1 \\
\hline & Medium Testudines (turtle) & 475 & \\
\hline & Small Testudines (turtle) & 2 & \\
\hline & Testudines (turtle) & 166 & \\
\hline & Phrynosoma cornutum (Texas horned lizard) & 1 & 1 \\
\hline & Medium Lacertilia (lizard) & 6 & \\
\hline & Small Lacertilia (lizard) & 3 & \\
\hline & Very Small/Microtine Lacertilia (lizard) & 6 & \\
\hline
\end{tabular}




\begin{tabular}{|c|c|c|c|}
\hline CLASS & TAXA (COMMON NAME) & NISP & MNI \\
\hline & Agkistrodon sp. (copperhead/cottonmouth snake) & 6 & 1 \\
\hline & Crotalus sp. (rattlesnake) & 1 & 1 \\
\hline & Nerodia sp. (water snake) & 3 & 1 \\
\hline & Natricinae (garter/water snake) & 1 & 1 \\
\hline & Elaphe sp. (rat snake) & 1 & 1 \\
\hline & Small Colubridae (non-venomous snake) & 14 & \\
\hline & Very small Colubridae (non-venomous snake) & 2 & \\
\hline & Serpentes (snake) & 1 & \\
\hline & Medium Squamata (lizard/snake) & 1 & \\
\hline & Small Squamata (lizard/snake) & 2 & \\
\hline & Very small Reptile & 1 & \\
\hline & Miscellaneous Reptile & 4 & \\
\hline & Subtotal & 1343 & \\
\hline \multirow[t]{5}{*}{ Amphibian } & Bufo sp. (toad) & 1 & 1 \\
\hline & Medium Anura (frog/toad) & 2 & 1 \\
\hline & Very small Anura (frog/toad) & 3 & 1 \\
\hline & Small Amphibian & 2 & \\
\hline & Subtotal & 8 & \\
\hline Herpetiles & Small Reptile/Amphibian & 1 & \\
\hline \multirow[t]{6}{*}{ Osteichtheyes } & Ictalurus sp. (catfish) & 2 & 1 \\
\hline & Ictaluridae (catfish) & 1 & 1 \\
\hline & Small-medium Osteichtheyes & 1 & \\
\hline & Small Osteichtheyes & 3 & \\
\hline & Very small Osteichtheyes & 16 & \\
\hline & Subtotal & 23 & \\
\hline Vertebrate & Miscellaneous Vertebrate & 4081 & \\
\hline TOTAL & & 8701 & \\
\hline
\end{tabular}

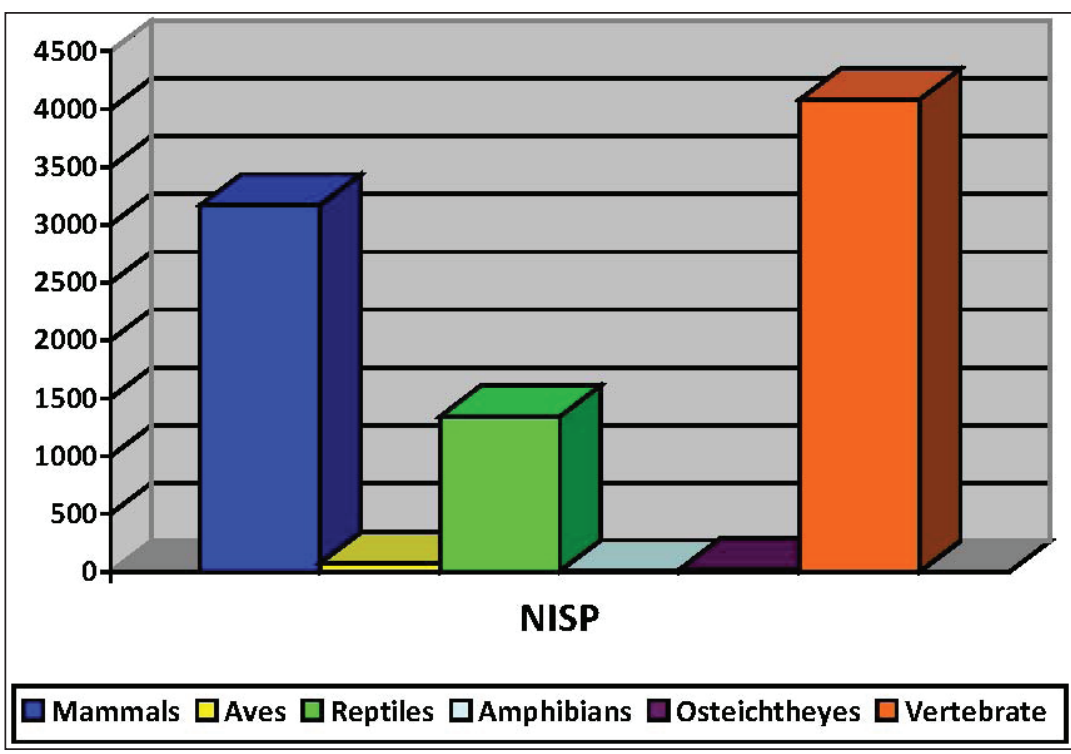

Figure 15-1. Distribution by Class of bone recovered during Data Recovery. 
1/4-inch screens at Wilson-Leonard, only 30 percent were identifiable to class or more specific taxon. Of the total 38,618 specimens recovered from the $1 / 8$-inch screens, only 32 percent were identifiable to class or more specific taxon.

Overall, the assemblage was not as fragmented as most regional faunal assemblages were. Of the total 8,701 bones recovered from the site, 435 bones (five percent) were complete, unbroken elements. For comparison, at Wilson Leonard only 0.7 percent of the $1 / 4$-inch screened and 0.6 percent of the 1/8-inch screened bone was complete and unbroken. There are both contributing cultural and taphonomic reasons for the excellent preservation which are discussed within this report.

Given the remarkable preservation, good stratigraphic context, and plethora of bone recovered the faunal assemblage data are highly informative with regards to environment, subsistence strategies, butchering and processing, cultural bone modification, introduction of European technology, and taphonomic conditions.

\section{Species Frequencies by Class}

\section{Mammal}

There were a total of 3,170 mammal bones recovered from 41DL436. Overall, large mammals (bison, cow, large bovid, and large artiodactyl) accounted for 789 bones (24.9 percent of the mammal assemblage). Medium-large mammals (deer, antelope, medium-large artiodactyls, etc.) accounted for 718 bones (22.6 percent of the mammal assemblage. Medium mammals (dog, coyote, raccoon, medium carnivore, etc.) only accounted for 56 bones (1.8 percent of the mammal assemblage), but a general grouping of medium or larger mammals accounted for 380 bones (12.0 percent of mammal assemblage). All told, all mammals included above of medium-size or larger accounted for 1,943 bones, or 61.3 percent of the total mammal assemblage. Therefore, there was a much higher percentage of small, very small, and microtine mammals present than would be expected at a site where bison was one of the primary prey species. Small-medium (opossum and beaver) and small mammals (cottontail rabbit, squirrel etc.) accounted for 6 bones ( 0.2 percent of the mammal assemblage) and 24 bones ( 0.8 percent of mammal assemblage), respectively. Very small mammals and microtines (cotton rats, wood rats, mice, voles, etc.) made up 7.1 percent $(n=224)$ of the assemblage. For a detailed species list refer to Table 15-1.

Given the groupings above, subsistence would have been focused on medium or larger mammals. Small mammals were not widely selected. While the very small mammals and microtines within the assemblage could be predominantly intrusive or naturally occurring, there is evidence for human subsistence due to cultural modification on some of the very small and microtine mammals. Coprolite studies from the Lower Pecos indicate that cotton rats, voles, and other rodents were commonly consumed by Native Americans (Bryant 1974; Reinhard and Bryant 1992). 
An analysis of MNI indicates similar reliance as NISP. For the most part, only one bone, or no more of any one element was present for most species. In those cases, the minimum number of individuals (MNI) was determined to be one. The mammal species with the greatest MNI was bison. Bison MNI was based on four right distal radii. In addition to bison, bovid MNI was 2 based on two left humerus diaphysis segments (one adult and one foetal). Other artiodactyls such as white-tailed deer had an MNI of 2 based on multiple elements including one complete and one distal right metacarpal, two left scapular glenoid cavities, and two right distal unfused tibias. Mule Deer MNI was determined as 2 based on one left distal mule deer tibia and one left distal cf mule deer tibia. Indeterminate deer (Odocoileus sp.) had an MNI of 3 based on one right almost complete and two right proximal radius. Small mammal presence was limited with an MNI for cottontail rabbits at 2 based on two complete right calcanei.

MNI for very small rodents indicated a not unsubstantial presence at the site. Pocket gopher (Geomys sp.) MNI was 2 based on two upper left 1st incisors and two upper left 4th premolars. Kangaroo rat MNI was 2, two based on two left tibias (one complete and one $4 / 5$ complete) and two right tibias (one complete and $1 / 2$ proximal). Due to the presence of two right mandibles (i1, $\mathrm{m} 1$, and $\mathrm{m} 2$ ), MNI for marsh rice rat was also 2. Sigmodon hispidis MNI was 3 based on three left mandibles, but as Sigmodon sp. MNI = 5 based on 5 left mandibles the MNI for all cotton rats would be eight.

Though cow (Bos taurus) and c.f. cow were identified in the assemblage, the presence was minimal and debatable. Identification of cow $(n=1)$ were based on one left complete 2nd-3rd fused carpal. The defining characteristics (Balkwill and Cumbaa) were only 57 percent accurate for bison for character 1, 46 percent accurate for cow for character 2, and only 59 percent accurate for bison and 72 percent accurate for cow for character 3 . There is some room for error. C.f. cow was identified based on characteristics of one complete right intermediate carpal. The carpal exhibited three cow characteristics and one bison characteristic. There were similar sized c.f. bison carpals within the same field lot and it is possible that all of the carpals were from the same animal. Again, the identification of cow within the assemblage is weak.

\section{Aves}

There were a total of 75 avian bones recovered from 41DL436. Overall, medium aves (duck, red-tailed hawk, etc.) dominated the avian assemblage with 53 bones ( 70.7 percent of avian assemblage) recovered. Medium to large aves (goose, etc.) was only represented by 3 bones (4.0 percent of avian assemblage) while small aves (plover, sandpiper, etc.) accounted for 11 bones (14.7 percent of avian assemblage). There was also a very minor presence of large aves (swan, bald eagle, etc.) in the assemblage $(n=2,2.7$ percent of avian). The MNI for each bird present in the assemblage was one.

\section{Reptile}

There were a total of 1,342 reptile bones recovered from 41DL435. Medium-sized reptiles, specifically turtle but some snake as well, dominated the reptile assemblage accounting for 1,124 bones or 83.7 percent or the reptiles recovered from the site. There were no large reptiles 
(alligators, etc.) recovered from the site. Small reptiles (mud/musk turtles, Texas horned lizard, small snakes, etc.) accounted for 38 bones ( 2.8 percent of the reptile assemblage). Very small reptiles (very small snakes and lizards) made up only 0.7 percent $(n=9)$ of the reptile assemblage. Similar to mammals, while some researchers may assume that only the mediumsized reptiles were consumed, there is coprolitic evidence from southwest Texas and elsewhere (Bryant 1974; Reinhard and Bryant 1992) that Native Americans consumed small lizards as well as rodents. Given other evidence for cultural modification of the bone (cuts and thermal alteration), all reptile species are considered potential subsistence resources.

Many turtle bones were individually counted (NISP) but were unfused and could be re-pieced into larger segments of shell. For turtle, MNI may actually be a better indicator of overall species presence at the site than NISP. Artiodactyl species presence was probably more underrated based on MNI than turtle. Ornate box turtle MNI was 4 based on 4 complete or nearly complete nuchals, yet MNI for eastern box turtle could only be established as 1. Terrapene sp. MNI was 5 based on five complete or $2 / 3$ or greater complete nuchals. When combined with identified ornate box turtles, overall box turtle MNI recovered from the site would be nine. Red-eared slider MNI was 2 based on two nearly complete or complete nuchals.

\section{Amphibian Remains}

There were only eight amphibian bones recovered from the site. Species present included toads and other Anura (frog/toads) with both medium toads the size of a large woodhouse toad and very small (tree frog size) Anura present. There was also one bone classified as herpetile that was indeterminate between reptile and amphibian. Similar to the arguments with rodents and reptiles, the amphibians present are considered potential subsistence resources. MNI for all amphibian taxon were 1 .

\section{Osteichtheyes}

There were a total of 23 bony fish remains recovered from 41DL436. Very small fish ( $\mathrm{n}=16)$ dominated the assemblage accounting for 69.6 percent of the fish assemblage. Small $(n=3)$ and small to medium $(n=4)$ accounted for 13.0 percent and 17.4 percent of the fish assemblage respectively. Fish can drastically alter size within their lifetime. Channel catfish (Ictalurus punctatus) can range from 4 inches long to up to 50 inches. For this reason a channel catfish could be classified anywhere from a small to a large fish. Species associations with general size classifications are not possible for fish.

There was enough cultural evidence (see below and Section III) for the use of most species present at the site, even rodent and lizards, as a subsistence resource. It is possible that some of the species present were intrusive (rodents) or naturally occurring, but evidence is scant.

\section{ENVIRONMENT}

The species present indicate that a wide range of habitats were utilized by the human occupants of 41DL436. Opossum, raccoon, woodland vole, and white-tailed deer are indicative of forest 
or forest-edge (Schmidly 1994). Mule deer, cottontail rabbits, kangaroo rats, and some plovers (upland sandpiper, mountain plover) prefer shrub brush/chaparral habitats (Schmidly 1994, NRCS 1999). Bison, pronghorn antelope, hispid cotton rat, pocket gopher, and ornate box turtle are indicative of open prairie and grassland. Beaver, marsh rice rat, goose, duck, other waterfowl, water snake, box turtles, mud/musk turtles, red-eared sliders, spiny softshell turtles, and catfish all inhabit aquatic/wetland habitats. Texas horned lizards prefer arid open spaces relatively devoid of vegetation (Schmiddly 1994, Stebbins 2003, Peterson 1988).

Some of the terrestrial species present in the assemblage can inhabit multiple ecotones within the above such as prairie or brush (ground squirrel or hispid cotton rat) or from desert to riparian and everything in-between (Peromyscus sp., wood rat, toad, copperhead/cottonmouth, and rattlesnake).

Overall, the species present are incredibly diverse and representative of multiple habitats.

\section{Data on Seasonality}

There were numerous indicators for seasonal use of the site. The abundance of reptiles $(\mathrm{n}=$ 1343, 15.4 percent of assemblage) which are cold-blooded, especially turtle, indicate the site was used during warmer seasons with temperatures above 38-45 degrees Fahrenheit (temperature at which most species of turtles hibernate), likely between spring to late fall (March - November) (Roots 2006; NOAA 2013 ). Furthermore, as many amphibians and reptiles, especially land based reptiles such as western box turtles, will estivate during times of drought, it is probable that the site was not occupied during mid-summer for the cultural component levels associated with drier species presence of ornate box turtle.

While antler was recovered from the site, typically antler is not necessarily indicative of human subsistence and hunting as deer antlers are shed annually and were a highly sought after resource for tool manufacture. There were 16 antler fragments consistent with being in velvet at time of death. Most of these fragments $(n=15)$ were in one unit and likely fragments of the same antler. The antler fragments would suggest a summer/early fall (July to September) occupation of the site based on typical antler development of modern Texas deer (Schmiddly 1994; Jacobson 1994; Marchinton and Miller 1994).

Other indicators for seasonality using deer were available due to the presence of young fawn (Odocoileus sp.) bones including a complete but unfused right radius, the distal $3 / 4$ of a right humerus, and a right mandible including the diastema and tooth row. Both the radius and humerus belonged to an individual that was two to four months of age at time of death. Deer reproductive cycles are based on annual photoperiodic cues set based on the location of their birth. Given modern and historic reproductive cycles for white-tailed deer in the Dallas area (Jacobson 1994), this would suggest seasonal occupation sometime between August to October. Though species of the immature bone was not able to be established and mule deer reproductive dates can differ slightly from white-tailed deer, in general, parturition of the two species is typically synchronic or only slightly offset in areas where the two species overlap (Whittaker and Lindzey 1999). The mandible, based on eruption of the 3rd premolar, was 
associated with an individual approximately six months of age following (Cain and Wallace 2003). This would place seasonal occupation sometime around December.

There was a presence of bovid foetal/neonate bones ([n=5] [2 percent of bovid bone]). Given that the majority of bovid bones identifiable beyond family were bison ( 98 percent), it is more than likely that the bovid foetal bones are that of bison. Regardless, bison and cows have similar reproductive cycles so any seasonality assessments based on bison would be within similar range for cattle. Bison conception generally occurs between July and September with calving occurring between April and June (Schmiddly 1994; Haugen 1974; Borgreen 2010). The general size of the bison foetal long bones (Figures 15-2 and 15-3) were indicative of a later term, but not at term birth. As one bovid foetal femur was present in the assemblage, it was compared with Mckee's (1985) research on determining seasonality on foetal bone (scapula and femurs) from the River Bend Site (48NA202) near Casper, Wyoming. The smallest anterior-posterior measurement of the femur diaphysis at mid-shaft was taken on the one identified foetal bison femur from 41DL436 assemblage. The measurement of $15 \mathrm{~mm}$, is slightly larger than the comparative seven-month old female bison fetus included in McKee's (1985) study and smaller than the eight-month male and eight-month female fetus, as well as, smaller than a premature calf. Given the above it is likely season of maternal death occurred sometime between February and April. Other foetal bison bone is of a relatively similar size.

There was additional foetal bone recovered of a size/development which could be bison $(n=13)$, but which were not identifiable beyond large artiodactyl so seasonal occupations of the site were not possible based on those bones.

Other bison bones were indicators of seasonality based on ageing and known development (Duffield 1970, 1974; Fuller 1959; Johnson et al. 2005). Of the bones recovered for which age profiles based on growth and development were available (epiphyseal fusion, dental eruptions, etc.) a few were specific enough (months rather than years) to aid in determining season of death. One bone, a metacarpal, was identified as belonging to a $0-2$ month old bovid based on development and comparison with known-age-at-death bison in the comparative collection at the Vertebrate Paleontology Lab at the University of Texas. The calf must have died sometime between April and August. Similarly, a bovid metatarsal was aged as 0-6 months at time of death based on proximal fusion and calcification (Duffield 1970). The calf would have died sometime between April and December. Using dental eruption patterns (Fuller 1951, Johnson et al. 2005), 3 bovid teeth were aged to approximately 30 months at time of death (Figure 15-4) and a bison mandible with a deciduous premolar and two erupting permanent premolars were aged to between 30-36 months at time of death. In general, a bison aged 30 months would have died late fall/early winter (October to December). A bison which died between 30 to 36 months could have died anytime between October to June.

While most indicators above effectively suggest occupation of the site during moderate temperature months (spring or late summer/early fall), there is also evidence for mid-summer and winter use of the site, though more minimal. 


\section{TAPHONOMY}

The bones were examined for signs of breakage (spiral and green breaks versus dry breaks) and weathering. As stated previously, 435 bones were complete and unbroken. The degree of weathering to which a bone had been subjected was recorded for each bone. Degree of weathering was recorded following Lyman's (1994) synthesis of Behrensmeyer (1978), Andrews (1990), and Johnson (1985). The weathering scale consisted of rankings from 0 to 5 where 0 equals a bone with some flesh still attached and 5 would be a bone with large splinters which is disintegrating. Typically, all archaeological material would be minimally assigned a 2 or 3 ranking. Typically, bone assigned a ranking of 5 were exposed to sun and the elements for a prolonged time prior to burial, whereas bones with a ranking of 2 or 3 would have been buried shortly after or at discard. Most ( $\mathrm{n}=6,870,79$ percent) of the bone recovered from 41DL436 was assigned a ranking of 3 . Two bones were assigned a ranking of 1 (plover/ sandpiper humerus and bison humerus) and are assumed to be associated with a modern deposit or intrusive. Of the remaining, 534 bones were assigned a ranking of 2; 747 bones a ranking of 4 ; and 475 bones a ranking of 5. Seventythree bones were not assigned a ranking due to burning which obscured degree

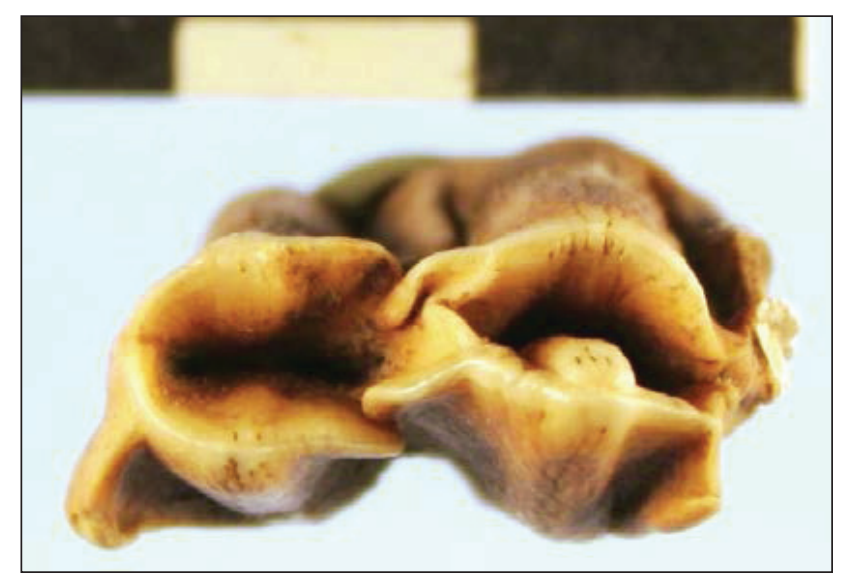

Figure 15-4. Stratum 2 (Field Lot \# 256) Bison mandibular 3rd molar . 
of weathering, oversight, and indeterminate classifications. Additionally, while all but 435 of the bones exhibited a break of some kind, the fragments were in general larger and more identifiable as is evidenced by the low ratio of bones assigned as indeterminate vertebrate.

\section{Skeletal Part Frequencies}

Skeletal part frequencies can be used to infer butchering, transport, food preparation, disposal habits, nutritional analysis, activity areas, site function, economic institutions, and social organization (Reitz and Wing 1999). Researchers (Read 1971; Styles 1981) have proposed that bones of large animals may not be transported from the kill site to the habitation site and the likelihood of differential conveyance increases with the animals' distance from the habitation site. White (1952) posited that not all parts of a large animal, such as bison, whould have been brought back to camp. He stated that "Since the lower limb does not carry any useable meat it is conceivable that is was chopped off and left at the place of kill to reduce the load" (White 1953:162).

Skeletal part frequency analysis is useful in not only determining potential site function (kill site versus habitation site), but can provide additional insight. Skeletal part frequencies can help researchers infer taphonomic conditions, for instance when less dense bones such as vertebrae may be present in lower frequency than dense bone such as long bone fragments. They provide information about the archaeological site's ecological surroundings. If there are different frequencies of high versus low utility bones for similar sized species but which inhabit different habitats, the case may be made that one of those species is being locally obtained while the other may be coming from a greater distance, Skeletal part frequencies can also aid in understanding the relationship between human subsistence strategies and dietary stress, for instance, if only high utility "gourmet" parts were present of select species versus highly processed lower utility parts

As bovids (cow and bison) and cervids (white-tailed deer and mule deer) were the most prevalent typical prey species an examination of skeletal part frequencies was conducted. Pronghorn antelope, while similar sized to deer, were only minimally represented $(n=22)$ in the assemblage and were represented by no more than one animal ( $\mathrm{MNI}=1)$. Given the absence of a robust sample, pronghorn were not included in the analysis as any discussion would be lacking in relevance.

Figure 15-5 depicts similar trends in skeletal part frequencies for both bovids and cervids with the exceptions of cranial, vertebral, ribs, and scapular elements. Cervids have relatively fewer thoracic and lumbar vertebrae, ribs, and scapula present than bovids. This skewing is most likely due to the fact that pronghorn antelope were also present at the site and these elements would be more difficult to distinguish between deer and pronghorn when fragmented. Also, given the protohistoric and potential historic overlap with upper strata, other artiodactyls such as pigs and sheep/goat could not be excluded as possibilities, so more frequently classifications were left broad for these difficult to assign to species elements. In addition to the above 4 cervid rib fragments, 11 rib bones were assigned a classification of deer/pronghorn and 34 rib bones were left at a broader classification of medium-large artiodactyl. In addition there were 1 
cervical vertebra, 1 thoracic vertebra and 9 indeterminate vertebrae not distinguishable beyond medium-large artiodactyl also identified. Given the high percentage of deer bone at the site, it is likely that these bones do belong to deer, but due to similar-sized potential other artiodactyls presence, just can not be positively identified. Therefore, the minimal nature of vertebra and ribs present for deer can be at least partially attributed to the inability to positively identify those elements to species.

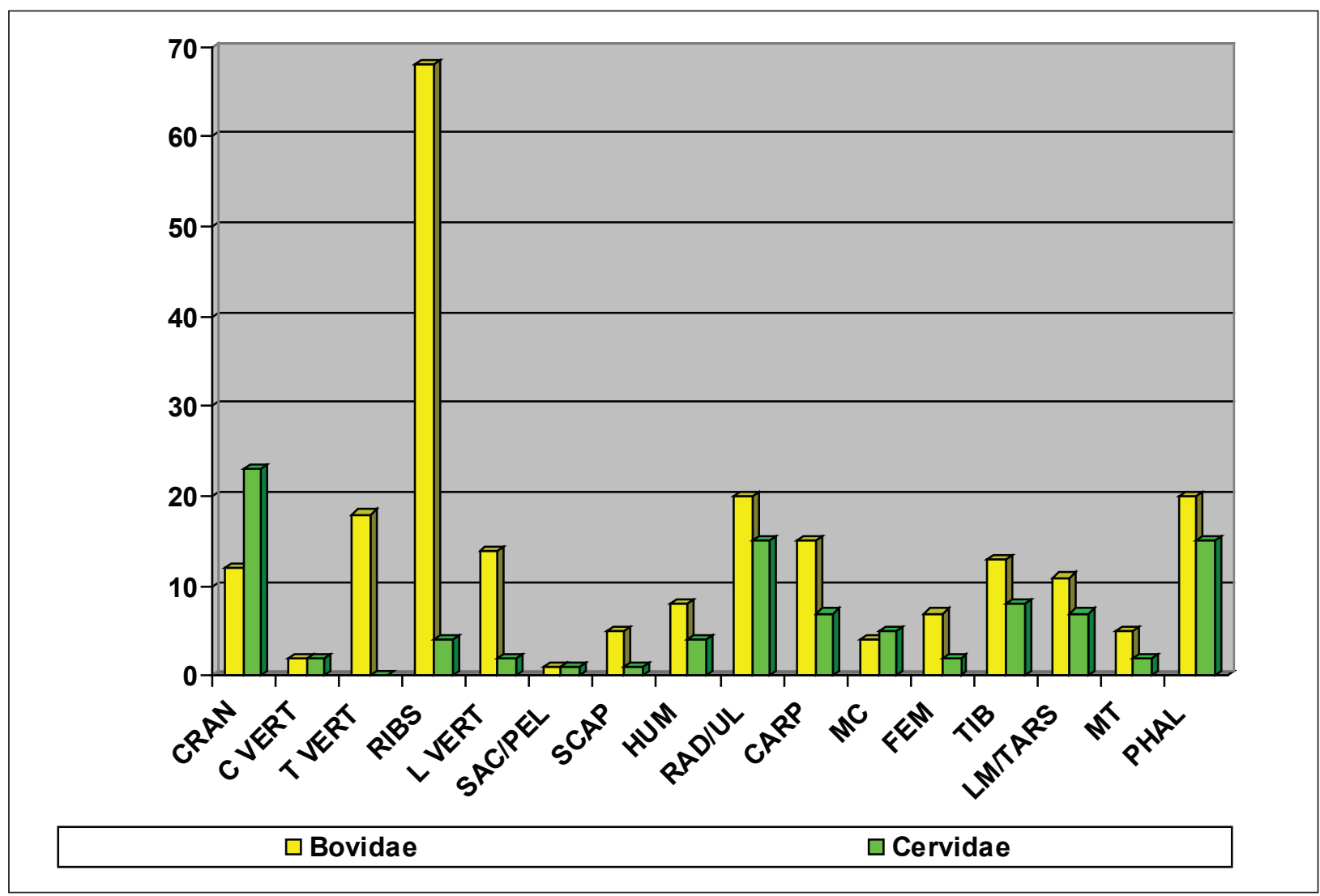

Figure 15-5. Distribution of skeletal fragments for bovids and cervids.

Of note, though, is that cervid cranial elements occurred at a much higher frequency relative to other elements than with bovids. Bovid cranial bones recovered consisted of predominantly teeth and 2 mandibular fragments. Cervid cranial elements recovered included teeth, mandibular fragments, petrous portions, along with premaxilla, temporal, occipital, frontal, and maxillary fragments. Given;

a) the lack of other bovid cranial bones;

b) the greater density of large bovid skeletal material relative to medium-large cervid (read not due to taphonomic processes); and

c) the fact that there are more cervid cranial bones than bovids though there are more large bovid bones in the assemblage than cervids, the difference in relative frequency of cranial bones is significant and due to cultural, rather than taphonomic, variables. 


\section{Cervids}

Variations within cervid species were also examined to determine if there were differences between mule deer and white-tailed deer. While the two species have been known to ecologically overlap and even hybridize, their preferred habitats are different. Differences in skeletal part frequencies could indicate differences in hunting strategies or local availability of the two species. Figure 15-6 contains a break down of skeletal elements recorded for both species from the site. The primary means of differentiating between skeletal remains are related to limb bone morphology and were developed by Jacobson (2003, 2004). Additional work differentiating between carpal and tarsal bones of many artiodactyls, including mule deer and white-tailed deer, were developed by Ford (1990). Discussion of differences in skeletal part frequencies is focused on limb elements which are discernible to species.

To better interpret the data, utility rankings for white-tailed deer (Jacobson 2000) were used to determine the number of Odocoileus elements identifiable to species of high, middle, and low utility ranking (Figure 15-7). Deer species (mule deer, white-tailed deer, and indeterminate deer) from 41DL436 were broken down by utility ranking and plotted to compare their skeletal part frequencies to the frequencies of elements with the same utility rankings in one animal (Figure 15-8).

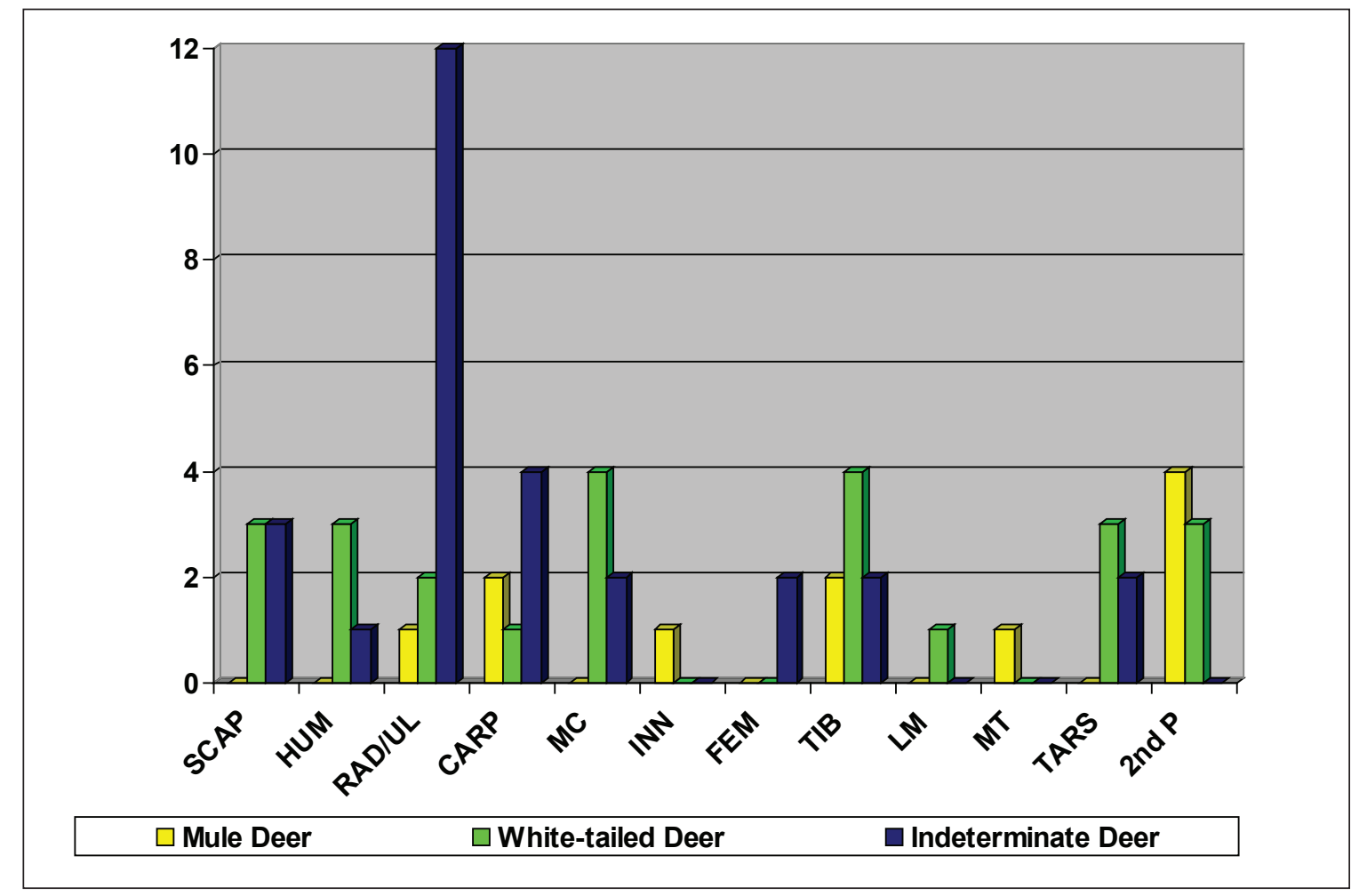

Figure 15-6. Distribution of forelimb and hindlimb skeletal fragments for mule deer, white-tailed deer, and indeterminate deer. 


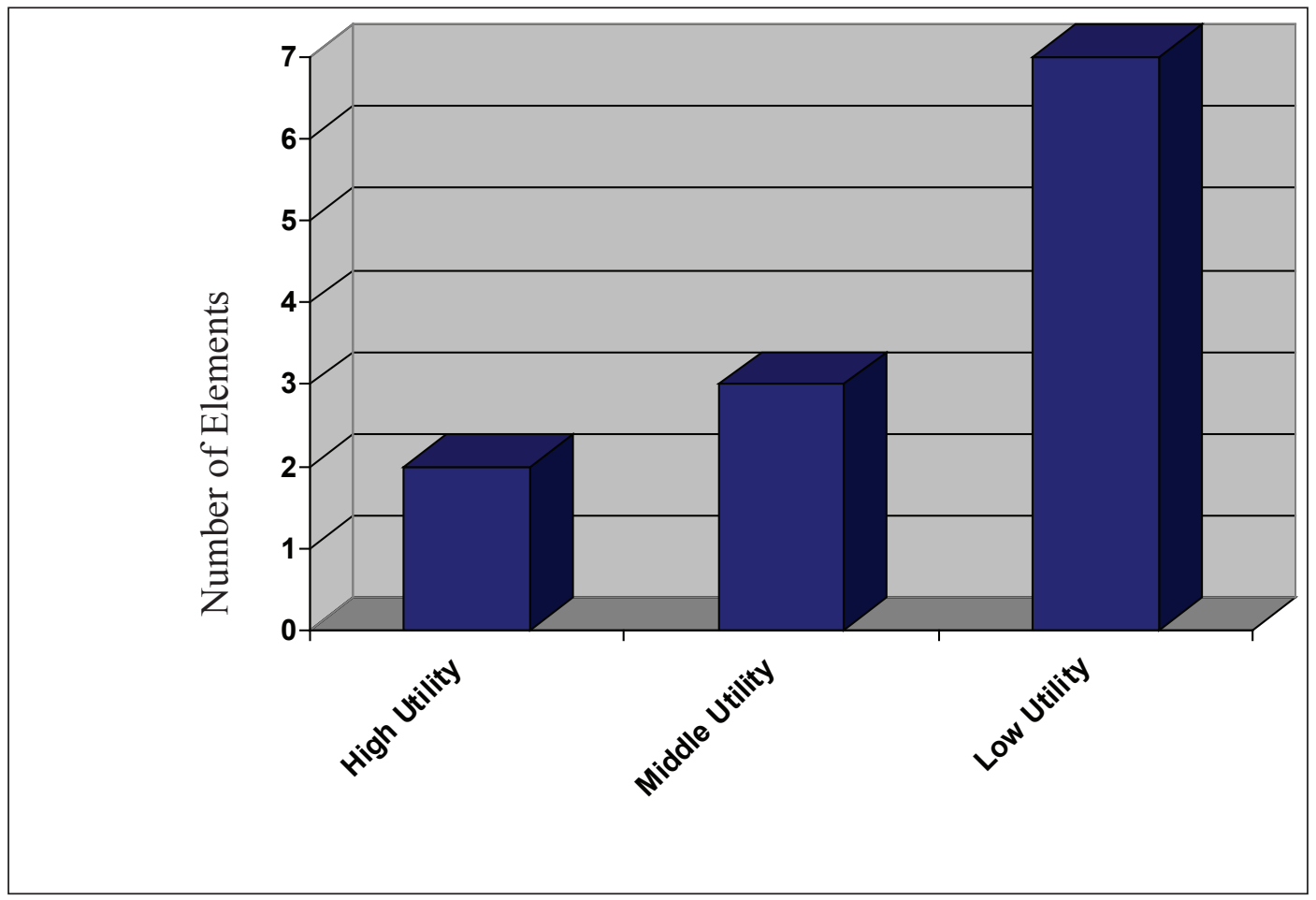

Figure 15-7. Average Utility (from Jacobson 2000) Distribution for Deer Elements.

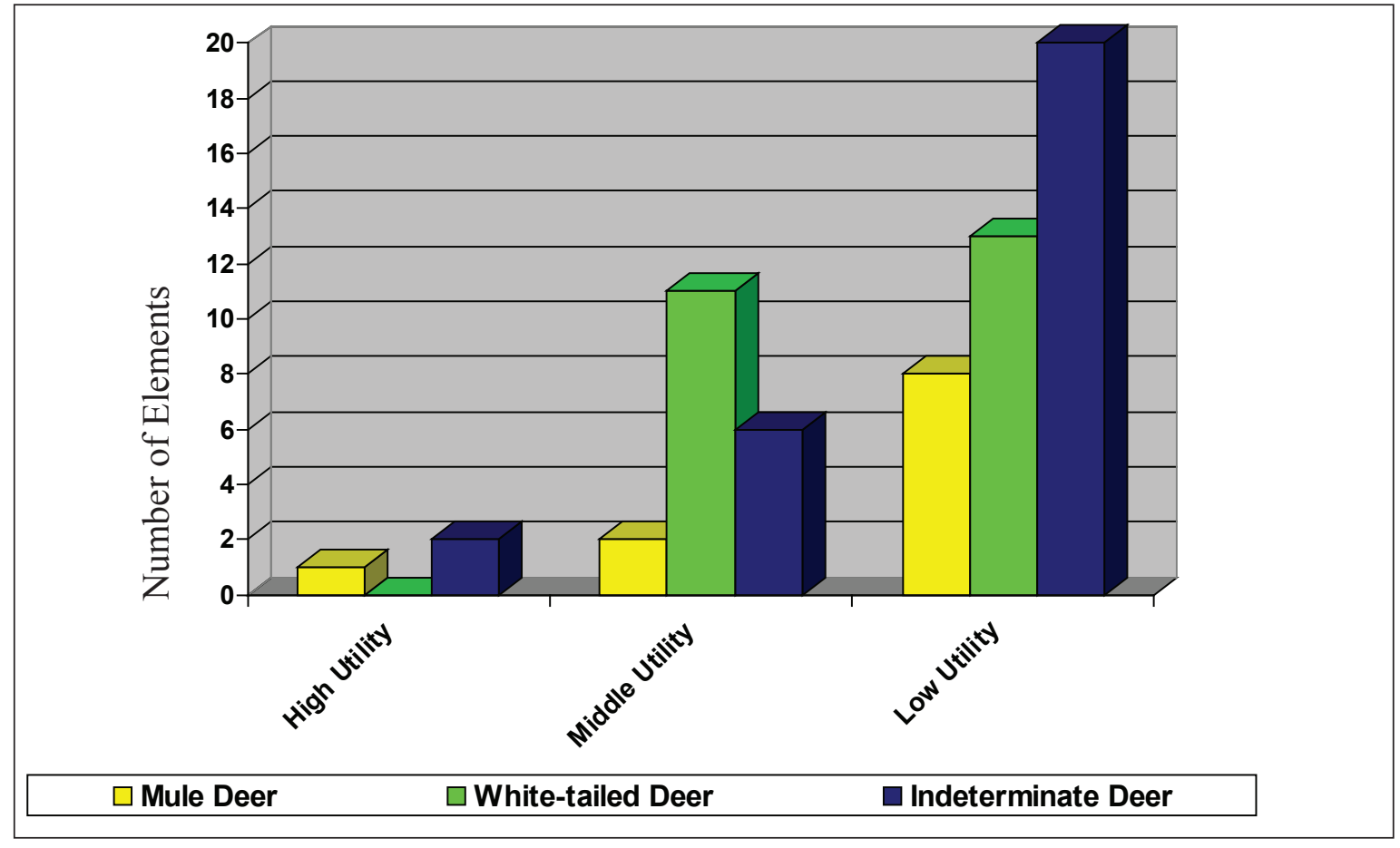

Figure 15-8. Distribution of elements by utility ranking and species for deer bone recovered. 
Upon examination, mule deer and indeterminate deer reflect a utility curve similar to that of the distribution of average utility for the elements in question relative to one whole animal. White-tailed deer, however, are completely unrepresented by any high utility parts and are over represented by middle utility parts relative to the average distribution.

\section{Bison}

Skeletal part frequencies and standardized gross utility rankings for bison were also examined. Emerson's (1990) averaged total products model was used to separate bison elements into high, middle, and low utility categories. Any elements with a unit value greater than 70 (ribs, thoracic vertebrae, and lumbar vertebrae) were considered high utility. Any elements with a unit value between 30 and 70 (cervical vertebrae, sternum, sacrum/pelvis, femur, and scapula) were considered middle utility. Any elements with a unit value less than 30 (humerus, cranial tibia, radius/ulna, metacarpal, metatarsal, caudal vertebrae, tarsals, phalanges, and carpals) were considered low utility. While low, humeri and tibia are right on the cusp between low and middle. The general distribution of elements within these rankings is depicted in Figure 15-9 and their occurrence at the site in Figure 15-10.

As can be noted in Figure 15-10, there were more high utility parts relative to low than are standard within the typical distribution. In addition, there were much fewer middle utility parts present relative to both high and low utility parts as there are in the standard elemental distribution. While most of the middle utility elements (cervical vertebrae, sternum, pelvis, scapula) are less dense (Lyman 1994) and, therefore, more subject to taphonomic processes, one of the middle utility elements (femur) is much more dense and likely to be preserved. It should be noted, however, that there was an even NISP for both bovid and cervid bones with respect to cervical vertebrae and sacral/pelvic bones. It is possible other taphonomic factors beyond soil acidity, erosion, etc. could be the cause. Canid bones and evidence of carnivore gnawing and breakage of bone at the site were present. Canid gnawing of spongy bone could be destructive. In general though, given the preservation of other fragile bone, such as artiodactyl neonate bone, other factors beyond taphonomy are likely responsible.

As noted in Figure 15-5, there were only two bovid cervical vertebral fragments recovered at the site, neither of which could be identified as bison. Given the paucity of cranial fragments, it is possible that the cervical vertebrae, which articulate with the skull, were removed along with the skull. Meat could be removed in strips from the cervical vertebrae. The cranium of a bison is very heavy with low utility, excepting the tongue which could be removed. Based on personal experience disarticulating animals for research and processing down to bone, disarticulation is easier near the junction of the cervical vertebrae with the thoracic vertebrae rather than between cervical vertebrae or at the base of the skull. Either the skull was not transported back to the site to minimize labor, or was removed from the site post-butchery as a trophy.

Also lacking from the assemblage were any pelvic fragments. Again, as with the cervical vertebrae it is possible canid scavenging was responsible for the loss of some of the bones, but it is unusual that when less dense foetal artiodactyl bones are so well preserved, especially given that some of those pelvic bones were originally directly associated with the foetal bones. 


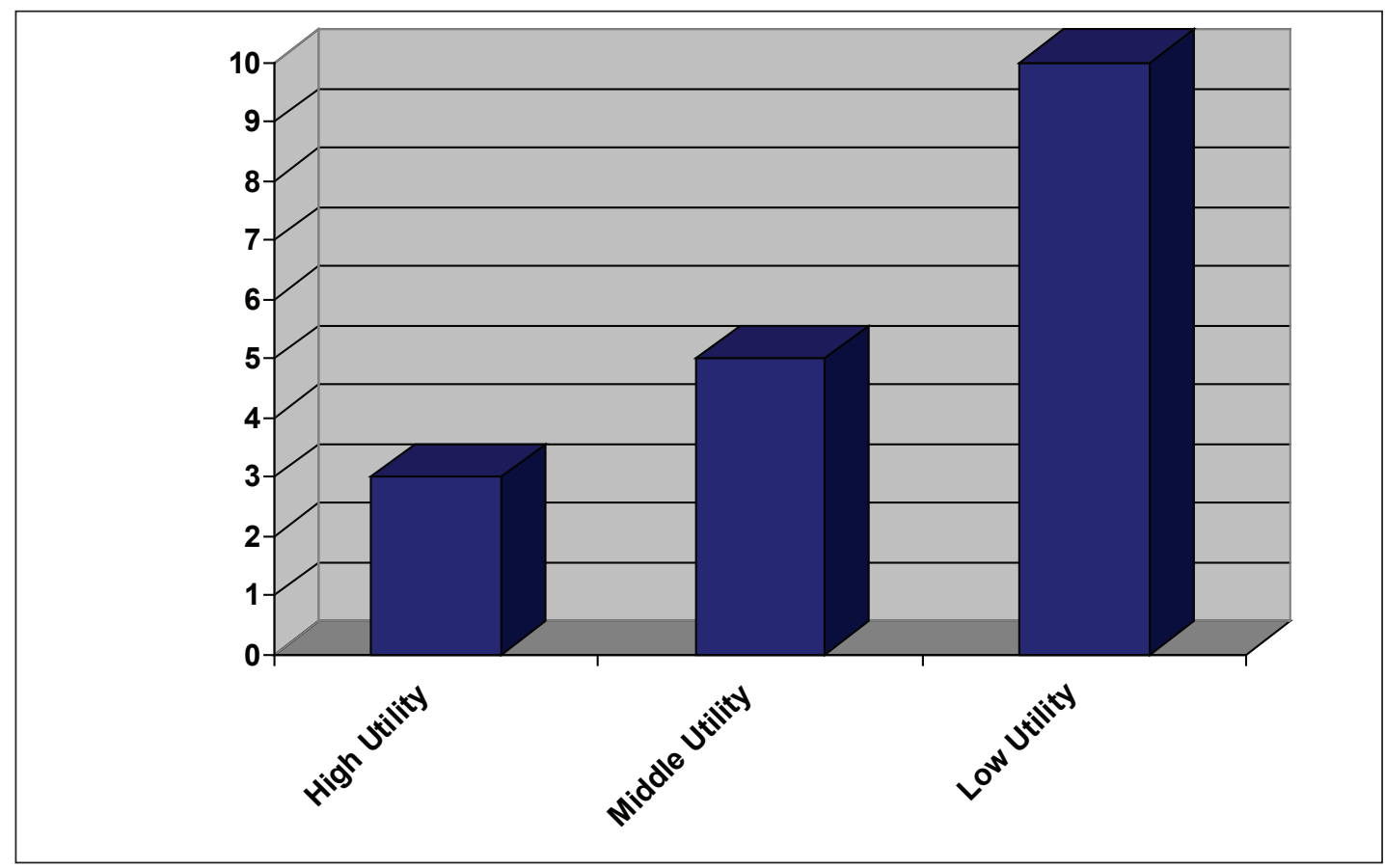

Figure 15-9. Average Utility (from Emerson 1990) Distribution for Bison Elements.

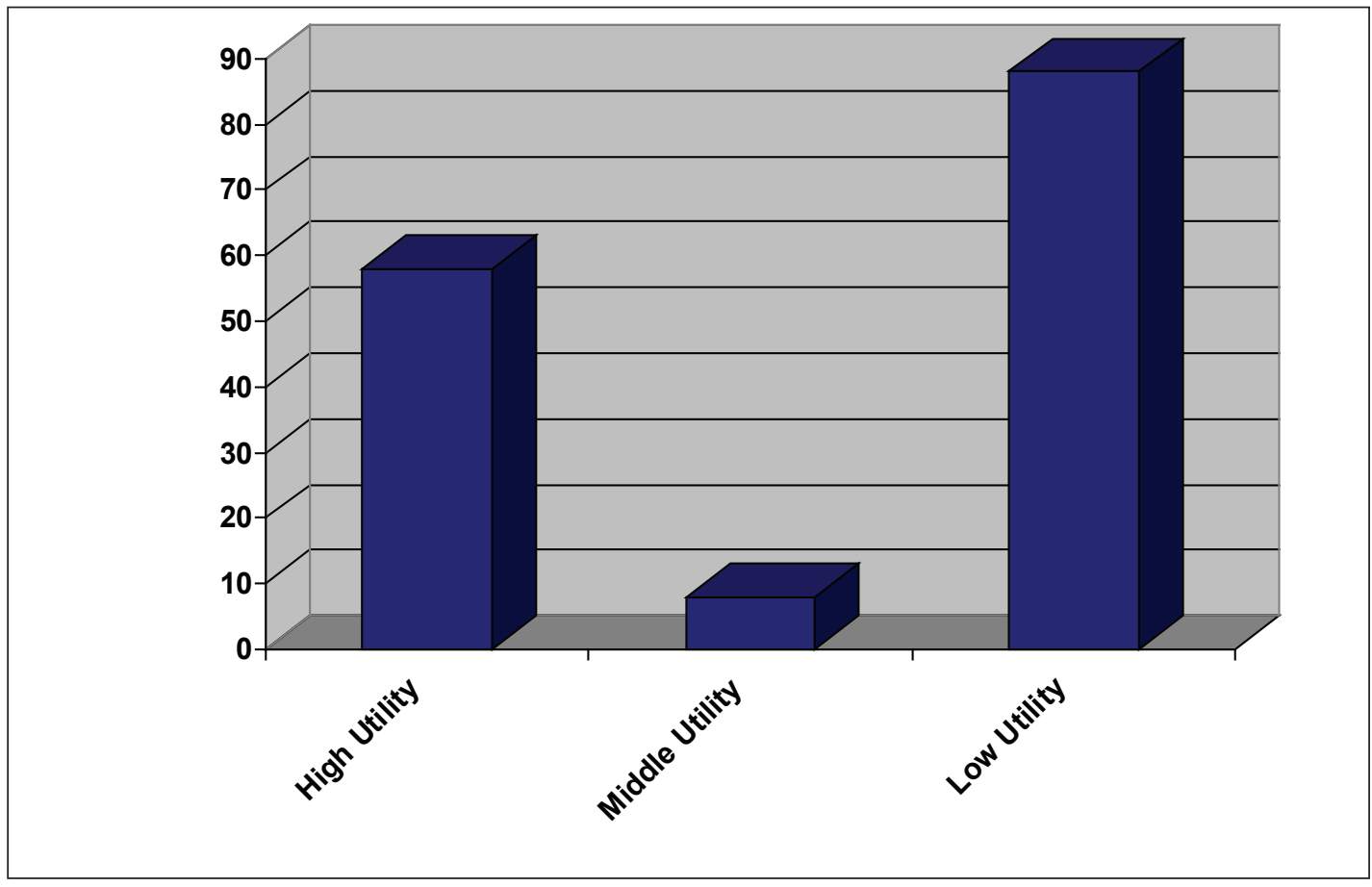

Figure 15-10. Distribution of bison elements by utility ranking. 
The pelvic girdle (pelvis and scapula) is heavy. It is possible that despite its utility, meat was stripped and the bone discarded at the kill site. Other slower to process elements, such as long bones, or easier to divide elements, such as thoracic and lumbar vertebrae, may have been transported to a secondary processing site or base camp.

While overall middle utility elements were minimal, bison scapulae $(n=3)$ and bison femurs $(\mathrm{n}=5)$ were still present in relatively similar frequencies as most other bison long bones such as humeri $(n=4)$, metacarpals $(n=3)$, and metatarsals $(n=5)$. Only bison tibias $(n=8)$ and radii $(n=7)$ occurred at a higher frequency.

\section{Fragmentation}

The types and amount of fragmentation of bones were examined and recorded (Table 15-2). Extensive fragmentation of larger bones is typically indicative of heavy processing for marrow and bone grease. Smashing of long bones of medium mammals and larger was common amongst most Great Plains groups for the extraction of marrow and bone grease (White 1953, 1954, 1955; Kehoe and Kehoe 1960). General observations during analysis were that some long bones, those with higher utility based on marrow content had been

Table 15-2. Bone Breakage.

\begin{tabular}{cc}
\hline TYPE OF BREAK & NISP \\
\hline Spiral & 151 \\
Green & 80 \\
Dry & 6387 \\
Indeterminate & 1576 \\
Unbroken & 435 \\
\hline TOTAL & 8701 \\
\hline
\end{tabular}
fractured, but the bone had not been smashed for bone grease extraction. In addition, while femurs, humerii, tibias, and radii had been broken for marrow, metapodials and phalanges had not been intentionally broken.

Only three percent of the bones from the assemblage exhibited spiral and green breaks. Of the 151 bones with spiral fractures, 148 bones belonged to medium or larger mammals including indeterminate mammal, artidactyls, pronghorn, deer, and bovids. The other three bones with spiral fractures were a bird bone, rabbit bone, and indeterminate vertebrate bone. The majority of the bone ( $\mathrm{n}=142,94$ percent) exhibiting spiral fractures were long bones. The low frequency of intentional breakage and percentage of unbroken bones indicate that dietary stress was not too severe as the bones had not been as highly processed.

\section{Carnivore and Rodent Modification}

Of the 8,701 bones recovered from the site, only 73 (0.8 percent) demonstrated signs of carnivore or rodent modification. Fifty-six bones had evidence for carnivore modification. Of the carnivore modified bones 39 had been gnawed. Two of the bones had been punctured by a canine or carnassial. Eight bones exhibited etching typical of bones which had been through a carnivore's digestive tract. Five bones had gnaw marks and scatological signs, 1 bone with gnaw and puncture marks, and 1 bone with gnaw, puncture, and scatological marks. 
Rodents had gnawed on 19 of the bones recovered from the site. Nine bones had been gnawed by mice, rats, or voles. Ten bones had been gnawed by squirrels. Research (Klippel and Synstelien 2007) has shown that brown rats only gnaw bone which is fresh and still laden with fats, while squirrels only gnaw on thicker bone cortices after fats had leached away. Rats will gnaw on bones recently deposited. Squirrels would be more likely to gnaw on bone left exposed for a prolonged time.

\section{Taphonomy Summary}

Despite the fact that most of the bone ( $\mathrm{n}=7,962 ; 91.5$ percent) exhibited dry (post-depositional) or indeterminate (unknown whether just post-mortem or post-depositional) breaks, the bone from 41DL436 was more identifiable and better preserved than most assemblages in Texas. Given the minor degree of green/spiral breaks, it is assumed that the identifiability of the assemblage is directly relational to the absence for any evidence of substantial bone grease processing at the site. The minor presence of advanced weathering of the bone combined with the overall preservation of the bone also is indicative of relatively fast burying of the material. Despite some evidence for carnivore and rodent gnawing, there was only a minor degree of scavenging on remains after human butchering. This would also indicate fairly rapid burying of the material during or just post-deposition. Last, taphonomy alone cannot be responsible for skeletal part frequency differential distributions of the major prey species at the site. There is some evidence for transport and selective choice of elements.

\section{Cultural Modification}

The bone was examined for evidence of cultural modification, including cut, chop, and saw marks, other signs of processing such as a striking platform for bone breakage and marrow extraction, or any form of thermal alteration. Bone was also examined for modification into or use as a bone tool. Early on, evidence for European technology with butchering (cut marks made by metal knives) or hunting (buck/bird shot impacts) was also noted on the bone. Of the 8,701 bones recovered from the site, 1,298 (15 percent) had evidence for cultural modification. Of the 5,939 bones recovered from the $1 / 4$-inch mesh screening, 11.1 percent $(n=657)$ had been modified. Of the 2,726 heavy fraction bone, 641 (23.5 percent) had been culturally modified. But, of the 641 heavy fraction bones which had been culturally modified, thermal alteration $(\mathrm{n}=638,99.5$ percent) was by far the most common form of modification. Given the general degree of fragmentation and size difference, the ability to observe cut and chop marks would have been easiest with the $1 / 4$-inch mesh material rather than the heavy fraction bone.

Table 15-3 presents a breakdown of cultural modification by taxon. Data in Table 15-3 are not necessarily cumulative with respect to "Total NISP Modified." In some cases, only one bone had evidence for multiple types of modification. A bone exhibiting thermal alteration may have also had cut marks on the bone. While noted in both the "NISP Burned" and "NISP Cut" columns, the numbers were not added as they were representative of the same fragment (NISP $=1)$. 
Table 15-3. Frequency of Cultural Modification to the Bone.

\begin{tabular}{|c|c|c|c|c|c|c|}
\hline Taxon & $\begin{array}{c}\text { NISP } \\
\text { Thermal } \\
\text { Alteration }\end{array}$ & $\begin{array}{l}\text { NISP } \\
\text { Cut }\end{array}$ & $\begin{array}{l}\text { NISP } \\
\text { Chop }\end{array}$ & $\begin{array}{l}\text { NISP Strike } \\
\text { Platform }\end{array}$ & $\begin{array}{l}\text { NISP Tool } \\
\text { / Other } \\
\text { Cultural }\end{array}$ & $\begin{array}{l}\text { Total NISP } \\
\text { Modified }\end{array}$ \\
\hline Canis sp. (dog/coyote) & 0 & 1 & 0 & 0 & 0 & 1 \\
\hline Procyon lotor (raccoon) & 0 & 1 & 0 & 0 & 0 & 1 \\
\hline Bison bison (bison) & 23 & 51 & 8 & 4 & 5 & 68 \\
\hline c.f. Bison bison (bison) & 0 & 1 & 2 & 1 & 1 & 3 \\
\hline Bovidae (bison/cow) & 6 & 19 & 3 & 3 & 3 & 20 \\
\hline c.f. Bovidae (bison/cow) & 0 & 1 & 0 & 0 & 0 & 1 \\
\hline Antilocapra americana (pronghorn antelope) & 1 & 6 & 2 & 0 & 1 & 7 \\
\hline Odocoileus virginianus (white-tailed deer) & 1 & 4 & 0 & 0 & 1 & 6 \\
\hline c.f. Odocoileus hemionus (mule deer) & 1 & 1 & 0 & 0 & 0 & 2 \\
\hline Odocoileus sp. (deer) & 1 & 7 & 0 & 0 & 3 & 10 \\
\hline c.f. Odocoileus sp. (deer) & 4 & 0 & 0 & 0 & 0 & 4 \\
\hline Antilocapra/Odocoileus (pronghorn/deer) & 0 & 1 & 0 & 0 & 0 & 1 \\
\hline Large Artiodactyla & 6 & 7 & 1 & 2 & 1 & 14 \\
\hline Medium-large Artiodactyla & 2 & 2 & 0 & 0 & 1 & 4 \\
\hline Geomys sp. (pocket gopher) & 0 & 1 & 0 & 0 & 0 & 1 \\
\hline Oryzomys palustris (marsh rice rat) & 1 & 0 & 0 & 0 & 0 & 1 \\
\hline Sigmodon sp. (cotton rat) & 10 & 0 & 0 & 0 & 0 & 10 \\
\hline Very small Muridae (rat/vole) & 4 & 0 & 0 & 0 & 0 & 4 \\
\hline Microtine Muridae (mouse/vole) & 1 & 0 & 0 & 0 & 0 & 1 \\
\hline Very Small Rodent & 22 & 0 & 0 & 0 & 0 & 22 \\
\hline Leporidae (rabbit) & 1 & 0 & 0 & 0 & 0 & 1 \\
\hline Large Mammal & 18 & 9 & 2 & 2 & 6 & 34 \\
\hline Medium-large Mammal & 27 & 4 & 0 & 1 & 1 & 31 \\
\hline Medium or larger Mammal & 46 & 4 & 2 & 0 & 4 & 53 \\
\hline Small-Medium Mammal & 2 & 0 & 0 & 0 & 0 & 2 \\
\hline Very small Mammal & 11 & 0 & 0 & 0 & 0 & 11 \\
\hline Miscellaneous Mammal & 36 & 0 & 0 & 0 & 0 & 36 \\
\hline Subtotal & 224 & 120 & 20 & 13 & 27 & 349 \\
\hline Large Aves & 0 & 1 & 0 & 0 & 0 & 1 \\
\hline Medium-large Aves & 0 & 0 & 0 & 0 & 1 & 1 \\
\hline Medium Aves & 1 & 2 & 0 & 0 & 3 & 6 \\
\hline Small Aves & 1 & 0 & 0 & 0 & 0 & 1 \\
\hline Subtotal & 2 & 3 & 0 & 0 & 4 & 9 \\
\hline Terrapene ornata (western/ornate box turtle) & 3 & 0 & 0 & 0 & 0 & 3 \\
\hline Terrapene sp. (box turtle) & 36 & 0 & 0 & 0 & 0 & 36 \\
\hline c.f. Kinostern flavescens (yellow mud turtle) & 2 & 0 & 0 & 0 & 0 & 2 \\
\hline Trachemys scripta (red-eared slider) & 14 & 3 & 0 & 0 & 0 & 17 \\
\hline Emydidae (pond turtle) & 31 & 0 & 0 & 0 & 0 & 31 \\
\hline Medium Testudines (turtle) & 109 & 0 & 0 & 0 & 0 & 109 \\
\hline Testudines (turtle) & 49 & 0 & 0 & 0 & 0 & 49 \\
\hline
\end{tabular}




\begin{tabular}{lcccccc}
\hline \multicolumn{1}{c}{ Taxon } & $\begin{array}{c}\text { NISP } \\
\text { Thermal } \\
\text { Alteration }\end{array}$ & $\begin{array}{c}\text { NISP } \\
\text { Cut }\end{array}$ & $\begin{array}{c}\text { NISP } \\
\text { Chop }\end{array}$ & $\begin{array}{c}\text { NISP Strike } \\
\text { Platform }\end{array}$ & $\begin{array}{c}\text { NISP Tool } \\
\text { / Other } \\
\text { Cultural }\end{array}$ & $\begin{array}{c}\text { Total NISP } \\
\text { Modified }\end{array}$ \\
\hline Small Lacertilia (lizard) & 0 & 1 & 0 & 0 & 0 & 1 \\
Very small Colubridae (non-venomous snake) & 1 & 0 & 0 & 0 & 0 & 1 \\
\hline Subtotal & 242 & 4 & 0 & 0 & 0 & 246 \\
\hline Vertebrate & 682 & 0 & 1 & 0 & 0 & 683 \\
\hline TOTAL & 1155 & 127 & 21 & 13 & 31 & 1287 \\
\hline
\end{tabular}

\section{Thermal Alteration}

The color of the burned bones was recorded as an indicator of the degree of thermal alteration. Brown discoloration is indicative of short-term and lower heat burning, such as exposure to a grass fire or camp fire for less than 6 minutes (Lyman 1994). Blackened bone has been carbonized and would indicate prolonged exposure to a grass fire or camp fire. Grey and white bone has been fully calcined which means that it has lost all organic matter and become plastically deformed. Thermal alteration was by far the most prevalent modification on the bone $(\mathrm{n}=1,155 ; 89$ percent of culturally modified bone, 13 percent of all bone in the assemblage). Of the 1,155 bones with thermal alteration, 314 exhibited brown discoloration, 670 had been blackened, and 171 had been fully calcined.

Thermal alteration included both direct burning of the bone which was exposed to fire and indirect modification of the bone from another heat source. It was noted during analysis that numerous long bones, a mandible, and a rib had a localized brown spot on the bone varying in size but approximately $2-3 \mathrm{~cm}$ long by about $2-3 \mathrm{~cm}$ wide. Within the browning were microfractures on the bone radiating out indicating quick contact with extreme heat (rather than being held over a flame and slowly increasing in heat to the bone). The localized browning was almost exclusively at or directly adjacent to a spiral/green break, typically at the breakage point along a long bone for marrow extraction. In at least one incident, the browning and break were associated with a striking platform. While similar brown marks have been described elsewhere in the literature, they have been assumed to be associated with traditional fire weakening the bone for marrow extraction. Given the intense quick heat needed to cause the microfractures on the bone from 41DL436, however, it is posited here that these marks are instead the result of application of a heated rock to the bone, in essence searing the bone and weakening it, such that striking it would cause it to break with less effort. There is evidence from 41DL436 for burned rock features. The rock could have been heated while/for conducting other processing of the meat removed from bison and deer, and the rocks placed on the bone temporarily then replaced in the fire. As heating of poor lithic raw material was well-known to make breakage more predictable and less labor-intensive (Domanski 1992), it is possible similar techniques were applied to bone for marrow extraction.

Given that even fragments of small lizard (cut), very small colubrid (thermal alteration), small aves (thermal alteration), pocket gopher (cut), marsh rice rat (thermal alteration), cotton rat (thermal alteration), and a microtine mouse/vole (thermal alterations) had evidence for cultural modification, it is suggestive that all species present at the site were subject to human consumption. 


\section{SECTiOn II: EnVironment And Subsistence}

The majority of the bone recovered were from well-stratified deposits with numerous C14 dates (see Chapter 5). Of the 8,701 total bones recovered from the site, 8,422 (97 percent) were from well-defined stratigraphic levels. The remaining 279 bones were either located between levels or could only be assigned to rough approximations of levels. [Note: In this section, we use the term "Stratum," which correlates to Abbott's geological "Units"].

While there were a couple of outlier dates per strata, most radiocarbon dates clustered into solid calibrated calendrical ranges of AD 1270-1445 (Stratum 1a), AD 1440-1650 (Stratum 1b), AD 1405-1660 (Stratum 2), and AD 1654-1954 (Stratum 3). Though the date ranges of Stratum $1 \mathrm{~b}$ and Stratum 2 were similar suggesting overlapping components, stratigraphically Stratum $1 \mathrm{~b}$ was completely overlain by Stratum 2 indicating that material within that level pre-dated material in Stratum 2. Given the good stratigraphic control and good preservation of bone, it was possible to examine shifts in species presence at the site over time and determine changes in both subsistence strategies and environment. As the strata divide into pre-European contact (Stratum 1 a: AD 1270-1445), protohistoric (Stratum 1b: AD 1440-1650 and Stratum 2: AD 1405-1660), and historic (Stratum 3: AD 1654-1954) periods, any shifts could also give insight to impacts of European contact.

\section{Stratum 1a}

Stratum 1a was the lowest stratigraphic level associated with cultural material. When on the surface, Stratum 1a appears to have been the floodplain and bank for Fish Creek, a small rise situated between a later incised Fish Creek channel and a small slough (possibly an earlier channel in the process of being back-filled). Based on the profile mapping (Figure 15-11) the habitat associated with 1a would have been expected to be wetland with an association of either flood plain grasses or hardwood trees when ground surface. Table 15-4 documents the NISP for each species recovered from the site.

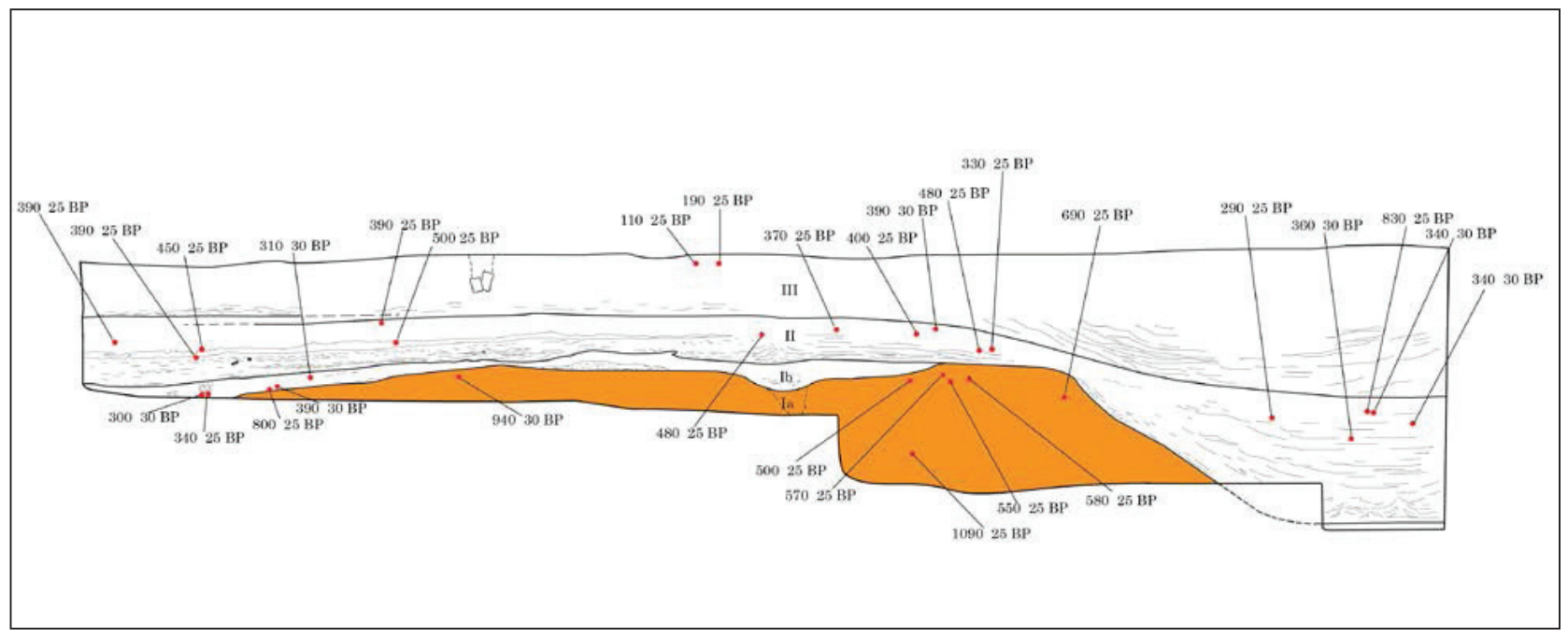

Figure 15-11. Stratigraphic profile with Stratum 1a highlighted. 
Table 15-4. Fauna Associated with Stratum 1a. Calibrated Date Range for Stratum 1a Based on Radiocarbon Dates is AD 1270-1445.

\begin{tabular}{|c|c|c|}
\hline CLASS & TAXA & NISP \\
\hline \multirow[t]{21}{*}{ Mammal } & Cryptotis/Notiosorex (least/desert shrew) & 1 \\
\hline & Bison bison (bison) & 2 \\
\hline & Bovidae (bison/cow) & 1 \\
\hline & Antilocapra americana (pronghorn antelope) & 1 \\
\hline & c.f. Odocoileus hemionus (mule deer) & 1 \\
\hline & Odocoileus sp. (deer) & 9 \\
\hline & Antilocapra/Odocoileus (pronghorn/deer) & 8 \\
\hline & Medium-large Artiodactyl & 7 \\
\hline & Geomyidae (pocket gopher) & 1 \\
\hline & Oryzomys palustris (marsh rice rat) & 3 \\
\hline & Sigmodon sp. (cotton rat) & 2 \\
\hline & Microtus sp. (vole) & 1 \\
\hline & Very Small Rodent & 11 \\
\hline & Large Mammal & 45 \\
\hline & Medium-large Mammal & 15 \\
\hline & Medium Mammal & 2 \\
\hline & Medium or larger Mammal & 16 \\
\hline & Small Mammal & 1 \\
\hline & Microtine Mammal & 1 \\
\hline & Miscellaneous Mammal & 44 \\
\hline & Subtotal & 172 \\
\hline \multirow[t]{6}{*}{ Aves } & Charadrius sp. (plover) & 1 \\
\hline & Charadriiformes (shore bird) & 2 \\
\hline & Medium Aves & 4 \\
\hline & Small Aves & 2 \\
\hline & Miscellaneous Aves & 2 \\
\hline & Subtotal & 11 \\
\hline \multirow[t]{14}{*}{ Reptile } & Terrapene ornata (western/ornate box turtle) & 39 \\
\hline & c.f. Terrapene ornata (western/ornate box turtle) & 3 \\
\hline & c.f. Terrapene carolina (eastern box turtle) & 6 \\
\hline & Terrapene sp. (box turtle) & 58 \\
\hline & Trachemys scripta (red-eared slider) & 9 \\
\hline & Emydidae (pond turtle) & 5 \\
\hline & Medium Testudines (turtle) & 146 \\
\hline & Testudines (turtle) & 21 \\
\hline & Medium Lacertilia (lizard) & 6 \\
\hline & Very Small/Microtine Lacertilia (lizard) & 1 \\
\hline & Nerodia sp. (water snake) & 3 \\
\hline & Elaphe sp. (rat snake) & 1 \\
\hline & Small Colubridae (non-venomous snake) & 1 \\
\hline & Miscellaneous Reptile & 4 \\
\hline
\end{tabular}




\begin{tabular}{|c|c|c|}
\hline CLASS & TAXA & NISP \\
\hline & Subtotal & 303 \\
\hline \multirow[t]{2}{*}{ Amphibian } & Small Amphibian & 2 \\
\hline & Subtotal & 2 \\
\hline \multirow[t]{4}{*}{ Osteichtheyes } & Ictalurus sp. (catfish) & 2 \\
\hline & Ictaluridae (catfish) & 1 \\
\hline & Small Osteichtheyes & 1 \\
\hline & Subtotal & 4 \\
\hline Vertebrate & Miscellaneous Vertebrate & 445 \\
\hline TOTAL & & 937 \\
\hline
\end{tabular}

While there is a presence of grassland species such as bison $(n=2)$, pronghorn $(n=1)$, pocket gopher $(n=1)$, and ornate box turtle $(n=42)$ in Stratum 1a, their numbers are minimal $(n=46)$ and account for a small percent (five percent) of the assemblage associated with Stratum 1a. Bovid $(n=1)$ bone in this assemblage is most likely bison as all dates indicate the strata was formed prior to European contact and any possible introduction of a cow. Dominating the strata are aquatic/wetland species such as marsh rice rat $(n=3)$, water snake $(n=3)$, eastern box turtles $(n=6)$, red-eared sliders $(n=9)$, pond turtles $(n=5)$, other turtles $(n=167)$ and catfish $(n=3)$ and small fish $(n=1)$. While sandpipers, plovers $(n=1)$ and other charadriiformes $(n=2)$ are shore birds and do prefer open areas near water, upland sandpipers, mountain plovers, long-billed curlew and other interior charadriiformes prefer grassland. Some species require large scale (greater than 40 acres) of short to mid grass prairie for survival (NRCS 1999). Here charadriiformes are classified as prairie species. As well, cotton rats $(n=2)$ can inhabit scrub brush or grassland. Mule deer $(\mathrm{n}=1)$ prefer scrub brush and chaparral habitats. Odocoileus sp. $(n=9)$ could represent either mule deer or white-tailed deer. While white-tailed deer are more diverse in habitats which they can utilize, they must have forest edge/riparian nearby for foraging. As the indeterminate Odocoileus bone cannot be assigned to species, and mule deer and white-tailed deer tend to utilize different habitats in areas where they overlap, their presence is considered uninformative. Microtus $\mathrm{sp} .(\mathrm{n}=1)$ depending on the species can also occur in either grasslands or woodlands. Therefore, their presence is non-informative as well. Similarly, as box turtles can be either more aquatic or terrestrial depending on species, Terrapene sp. were not included.

Therefore, based on the species presence, it is likely that the area in association with 41DL436 during the timeframe associated with Stratum 1a was predominantly wetland/aquatic with adjacent grassland floodplains based on both the species present and the mapped profile. Most of the aquatic species present (goose, ducks, waterfowl, plovers and shorebirds, as well as catfish, sliders, eastern box turtles, and mud/musk turtles) prefer slow moving or shallow ponds of water with muddy bottoms. Figure 15-12 depicts the frequencies of grassland/prairie, chaparral, and woodland species. Figure 15-13 depicts the frequencies of aquatic versus terrestrial resources. 


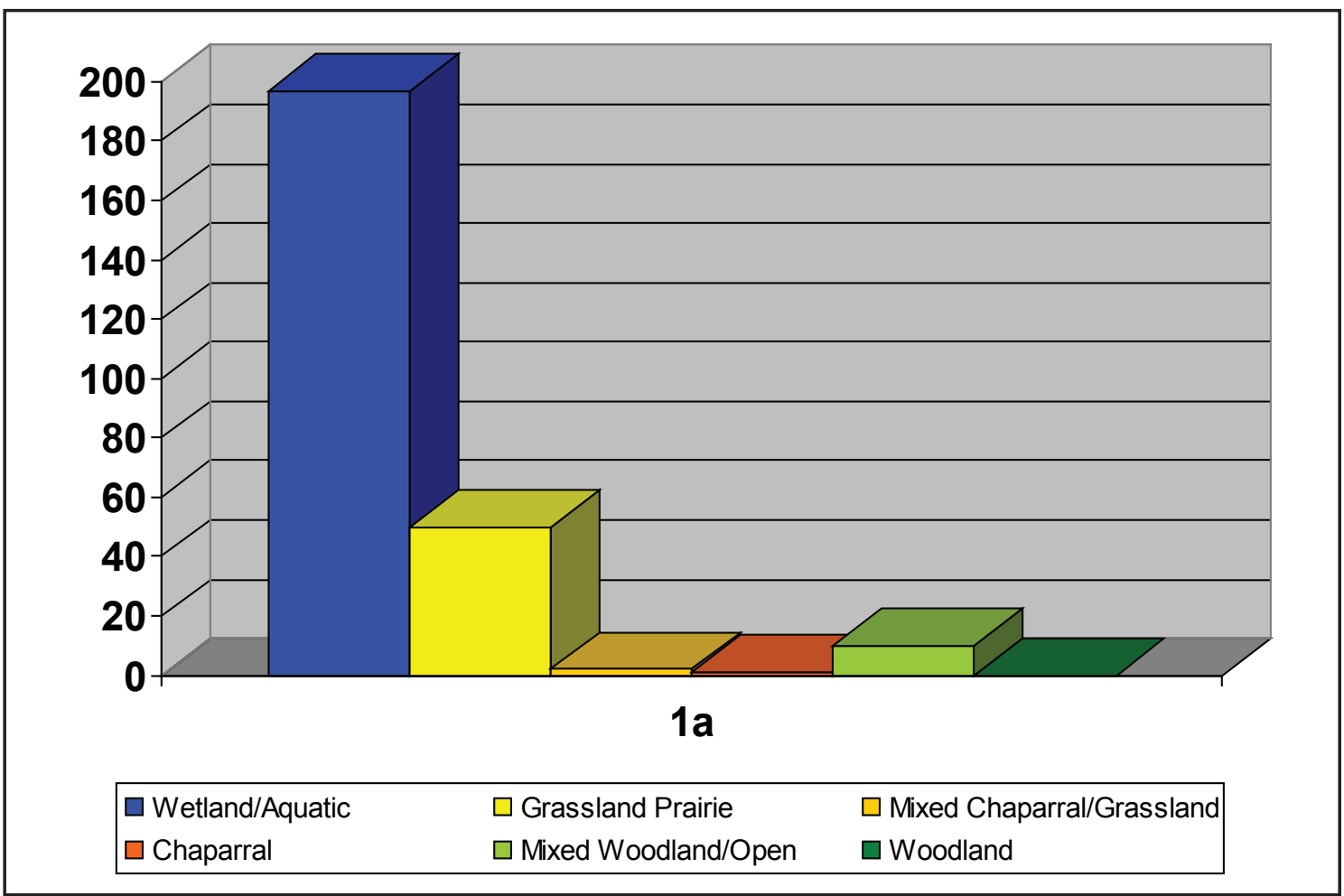

Figure 15-12. Distribution of species NISP in Stratum 1a by habitat niche.

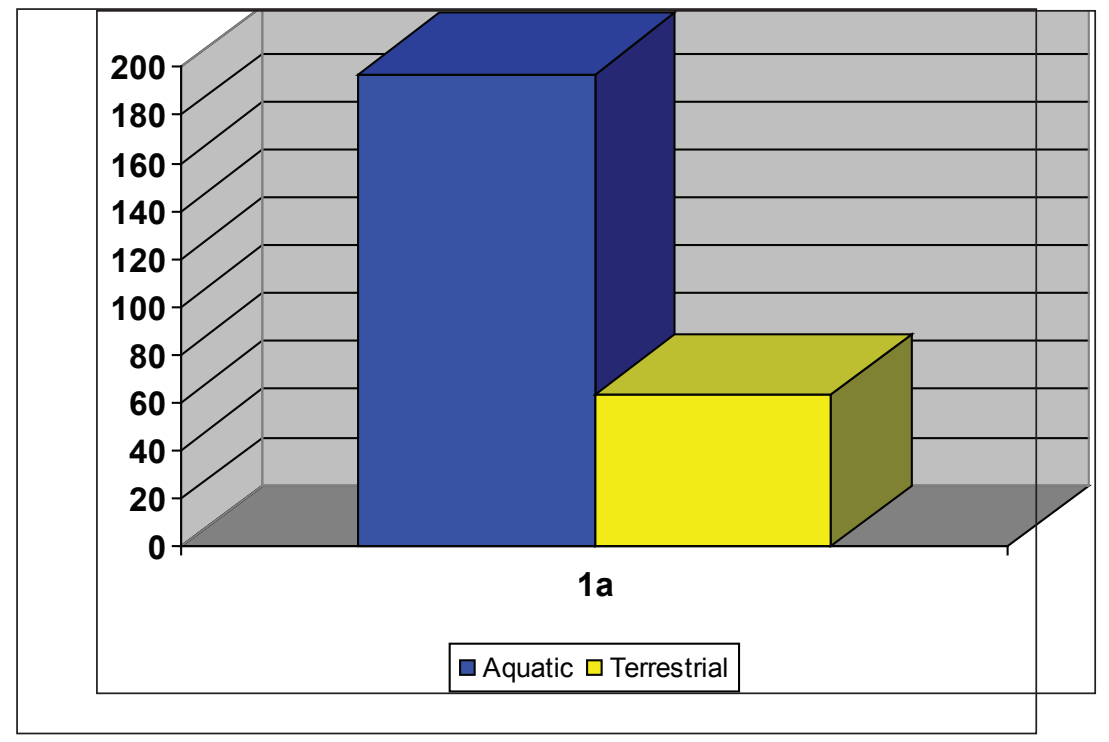

Figure 15-13.

Frequency of aquatic species to terrestrial species in Stratum 1a.

\section{Seasonality Data}

Given the high percentage of reptiles (especially turtles) in the assemblage, there is evidence for warmer weather occupation of the site, as turtles typically hibernate when temperatures drop below 45 degrees Fahrenheit. Based on historic and modern daily averages, the average daily temperatures in the Dallas area are above 45 degrees from March through November. 
The two deer bones described in Section I's discussion of overall seasonality at the site which belonged to a 2-4 month old fawn (radius and humerus) were associated within Stratum 1a. Given birth date ranges for modern North Texas white-tailed deer (Jacobson 1994), the fawn(s) would have been killed between August and October suggesting a late summer-early fall occupation at the site.

\section{Skeletal Part Frequencies}

As there were only three bovid bones (one bovid, two bison) and ten cervid bones (one mule deer, nine Odocoileus sp.) recovered from Stratum 1a, any statements on skeletal part frequencies are weak at best. There were one bison thoracic vertebra, one bison femur element, and one bovid calcaneous recovered. Thoracic vertebrae are high utility, femura are middle utility, and calcanei are low utility.

There was one mule deer accessory carpal. General deer bone in this strata included two lumbar vertebrae, one scapula, one humerus, two radii, one ulna, and one molar. In general lumbar vertebrae, scapulae, and humerii are middle utility while radii/ulnae, carpals, and cranial (tooth) are low utility. The humerii and one radius, however, belonged to a $2-4$ month old fawn. It would be simple to transport an entire fawn that age so utility is irrelevant for those bones. There were no high utility portions present.

Again, sample size is so low it is difficult to make solid statements regarding the frequencies, though it appears at least some processing occurred onsite and if not killed onsite, then given the presence of low utility bones in even or greater numbers it is likely the kill location was at least nearby and elements were not transported far.

\section{Weathering}

Bone from Stratum 1a were assessed for their degree of weathering. One bone had a ranking of 1 and it is possible was intrusive to the assemblage via rodent burrowing. Bone with a ranking of $3(n=673)$ was most prevalent, though there were 40 fragments with a ranking of 2 as well. In general, weathering would indicate that the majority of the bone was buried just after use, but there were 5 bones with a ranking of 4 and 43 bones with a ranking of 5 , indicating that at least some bone was left exposed for a prolonged period before burial.

\section{Stratum 1b}

Stratum 1b was a smaller level which overlaid part of stratum 1a and appeared to be associated with backfilling associated with a flood event and continued fill/sedimentation of the relict Fish Creek channel or slough (Figure 15-14). When surface, Strata $1 \mathrm{~b}$ appears to have been part of a similar landscape as Strata 1a, but with filling of some previous dips essentially slightly reducing specific wetland environment. Table 15-5 documents the NISP for each species recovered from the site. 
Bison presence is still minimal $(\mathrm{n}=1)$, but there is a higher presence of another grassland artiodactyl-pronghorn antelope $(\mathrm{n}=11)$. Other grassland species presence such as pocket gopher $(n=2)$ and ornate box turtle is minimal $(n=1)$. Bovid bone $(n=3)$ in the assemblage is still likely bison. Though dates overlap European contact and the strata represents a protohistoric context, cow presence was minimal to non-existent in Texas until late 17th century (Richardson and Hinton 2013). There is a moderate presence of species preferring brushy/chaparral or edge open environments including mule deer $(n=1)$ and cottontail $(n=7)$ and other leporid rabbit $(n=1)$. Unlike Stratum 1a where there was no direct evidence for woodland or forest edge species, Stratum $1 \mathrm{~b}$ included raccoon $(\mathrm{n}=1)$, white-tailed deer $(\mathrm{n}=5)$, and woodland vole $(\mathrm{n}=3)$. Despite an increase in terrestrial species presence, wetland and aquatic species including goose $(n=1)$, eastern box turtle $(n=6)$, yellow mud turtle $(n=6)$, red-eared slider $(n=52)$, slider/cooter $(n=7)$, other pond turtles $(n=90)$, spiny softshell turtle $(n=1)$, and indeterminate turtle $(n=135)$ still dominate the assemblage (Figures 15-15 through 15-17).

\section{Seasonality Data}

Given the presence of reptiles (especially turtles) in the assemblage, there is evidence for warmer weather occupation of the site, as turtles typically hibernate when temperatures drop below 45 degrees Fahrenheit (Roots 2006). Based on historic and modern daily averages (NOAA 2013), the average daily temperatures in the Dallas area are above 45 degrees from March through November. Goose could also indicate warmer temperatures, but some geese winter in the Dallas area so their presence is not definitive.

There was one bison immature metatarsal aged 0-6 months in the Stratum 1b material. The calf would have died sometime between April and December based on calving dates for bison (Schmiddley 1994; Haugen 1974; Borgreen 2010). There was also on deer mandible aged about six months based on tooth eruption and wear patterns (Cain and Wallace 2003) which would place occupation of the site around December based on birth date ranges for modern North Texas white-tailed deer (Jacobson 1994).

Given the above, it is probable that Stratum $1 \mathrm{~b}$ was occupied on a more temporary basis multiple times at least within two different seasons.

\section{Skeletal Part Frequencies}

When skeletal part frequencies from bovids and deer are examined from Stratum 1b, interesting trends are noted. Deer bone recovered from Stratum $1 \mathrm{~b}$ included 10 cranial fragments and fragments from phalanges $(n=3)$, tarsals $(n=3)$, carpals $(n=1)$, metacarpals $(n=2)$, and ulna $(n=1)$, which are all low utility bones. There were also fragments from three tibias and one humerus (middle utility), and two femurs (high utility) recovered. The skewing (Figure 15-18) towards low utility less dense fragile fragments, such as cranial elements) would indicate the possibility that higher utility parts were transported away from the site. It is likely that the deer bone present is representative of a local kill. 


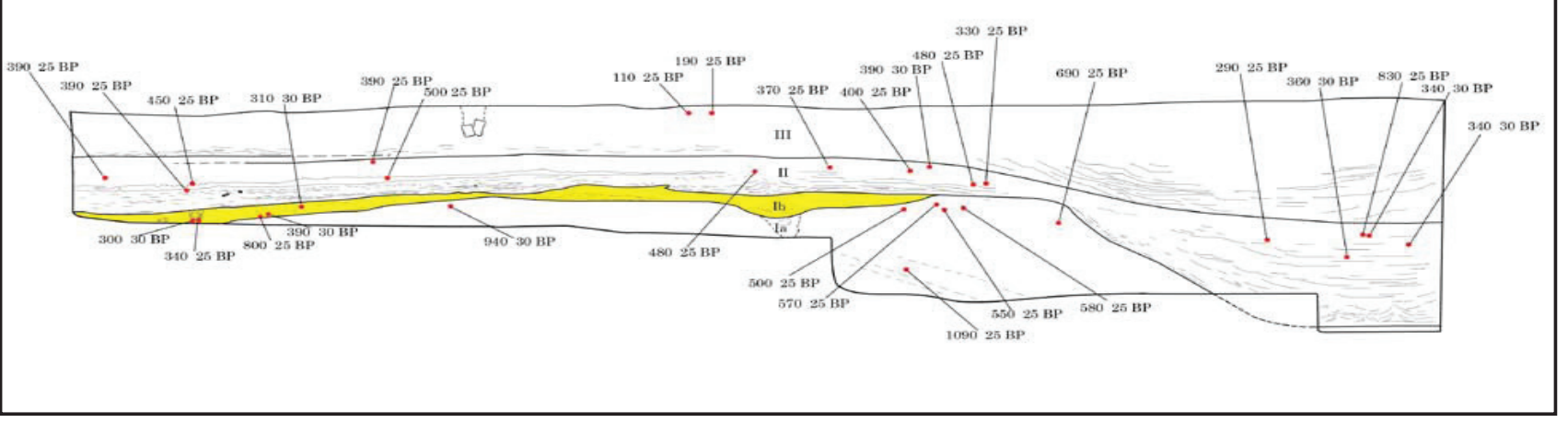

Figure 15-14. Stratigraphic profile with Stratum 1b highlighted.

Table 15-5. Fauna Associated with Stratum 1b. Calibrated Date Range for Stratum 1b Based on Radiocarbon Dates is AD 1440-1650.

\begin{tabular}{|c|c|c|}
\hline CLASS & TAXA & NISP \\
\hline \multirow[t]{27}{*}{ Mammal } & Procyon lotor (raccoon) & 1 \\
\hline & Bison bison (bison) & 1 \\
\hline & Bovidae (bison/cow) & 3 \\
\hline & $\begin{array}{c}\text { Antilocapra americana } \\
\text { (pronghorn antelope) }\end{array}$ & 11 \\
\hline & $\begin{array}{l}\text { Odooileus virginianus } \\
\text { (white-tailed deer) }\end{array}$ & 4 \\
\hline & $\begin{array}{l}\text { c.f. Odooileus virginianus } \\
\text { (white-tailed deer) }\end{array}$ & 1 \\
\hline & $\begin{array}{l}\text { c.f. Odocoileus hemionus } \\
\text { (mule deer) }\end{array}$ & 1 \\
\hline & Odocoileus sp. (deer) & 25 \\
\hline & c.f. Odocoileus sp. (deer) & 2 \\
\hline & $\begin{array}{l}\text { Antilocapra/Odocoileus } \\
\text { (pronghorn/deer) }\end{array}$ & 42 \\
\hline & Large Artiodactyla & 8 \\
\hline & Medium-large Artiodactyla & 1 \\
\hline & Medium or larger Artiodactyl & 1 \\
\hline & Artiodactyl & 2 \\
\hline & Geomys sp. (pocket gopher) & 2 \\
\hline & Sigmodontinae (rice/cotton rat) & 3 \\
\hline & Microtus pinetorum (woodland vole) & 3 \\
\hline & Very small Muridae (rat/vole) & 2 \\
\hline & Very Small Rodent & 1 \\
\hline & Sylvilagus sp. (cottontail rabbit) & 7 \\
\hline & Leporidae (rabbit) & 1 \\
\hline & Large Mammal & 6 \\
\hline & Medium-large Mammal & 87 \\
\hline & Medium Mammal & 3 \\
\hline & Medium or larger Mammal & 97 \\
\hline & Miscellaneous Mammal & 60 \\
\hline & Subtotal & 375 \\
\hline
\end{tabular}

\begin{tabular}{|c|c|c|}
\hline CLASS & TAXA & NISP \\
\hline \multirow[t]{6}{*}{ Aves } & c.f. Anserinae (goose) & 1 \\
\hline & Large Aves & 1 \\
\hline & Medium-large Aves & 1 \\
\hline & Medium Aves & 15 \\
\hline & Miscellaneous Aves & 2 \\
\hline & Subtotal & 75 \\
\hline \multirow[t]{14}{*}{ Reptile } & $\begin{array}{c}\text { Terrapene ornata (western/ } \\
\text { ornate box turtle) }\end{array}$ & 1 \\
\hline & $\begin{array}{l}\text { Terrapene carolina } \\
\text { (eastern box turtle) }\end{array}$ & 6 \\
\hline & Terrapene sp. (box turtle) & 56 \\
\hline & $\begin{array}{l}\text { c.f. Kinostern flavescens } \\
\text { (yellow mud turtle) }\end{array}$ & 6 \\
\hline & Kinosternidae (mud/musk turtle) & 4 \\
\hline & $\begin{array}{c}\text { Trachemys scripta (red- } \\
\text { eared slider) }\end{array}$ & 52 \\
\hline & $\begin{array}{l}\text { Trachemys/Pseudomys } \\
\text { (slider/cooter turtle) }\end{array}$ & 7 \\
\hline & Emydidae (pond turtle) & 90 \\
\hline & $\begin{array}{l}\text { Trionyx spiniferus (spiny } \\
\text { softshell turtle) }\end{array}$ & 1 \\
\hline & Medium Testudines (turtle) & 133 \\
\hline & Small Testudines (turtle) & 2 \\
\hline & Medium Lacertilia (lizard) & 6 \\
\hline & Small Squamata (lizard/snake) & 1 \\
\hline & Subtotal & 365 \\
\hline Vertebrate & Miscellaneous Vertebrate & 663 \\
\hline TOTAL & & 1478 \\
\hline
\end{tabular}




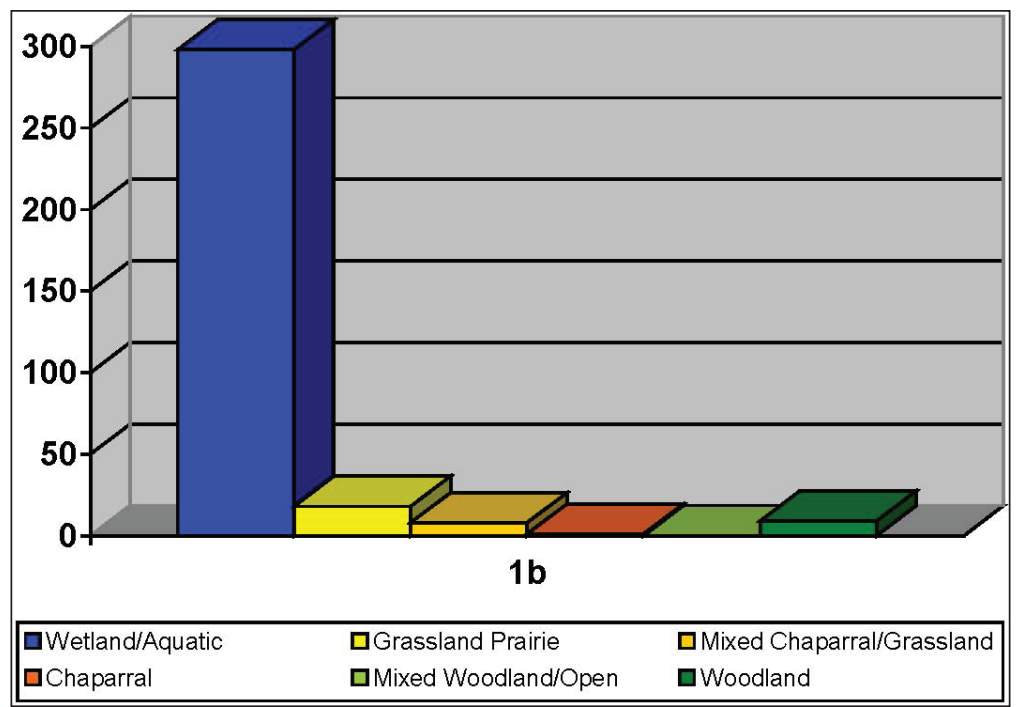

Figure 15-15. Distribution of species NISP in Stratum

$1 \mathrm{~b}$ by habitat niche.

Figure 15-16. Frequency of aquatic species to terrestrial species in Stratum 1b.
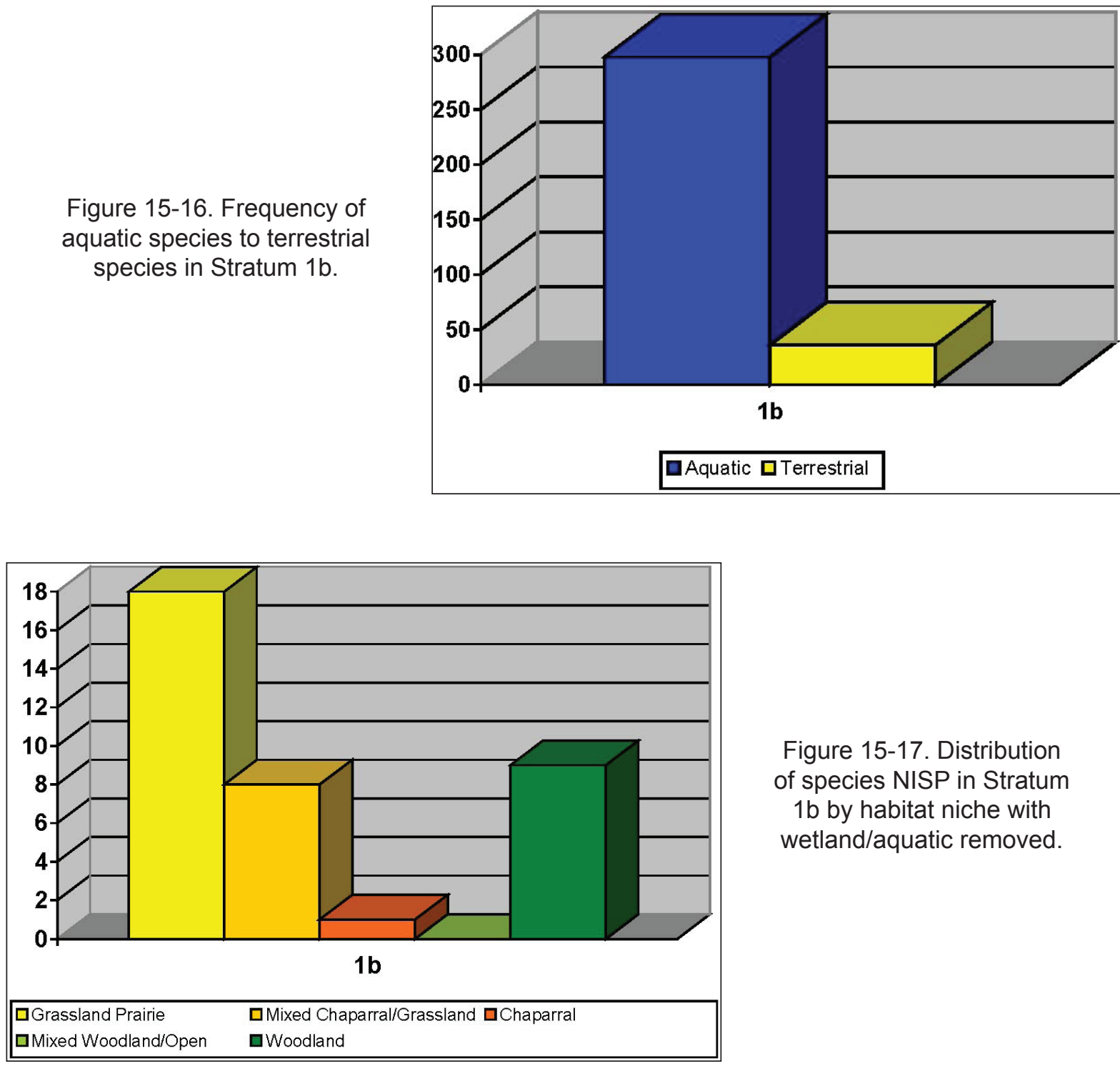

Figure 15-17. Distribution of species NISP in Stratum $1 \mathrm{~b}$ by habitat niche with wetland/aquatic removed. 


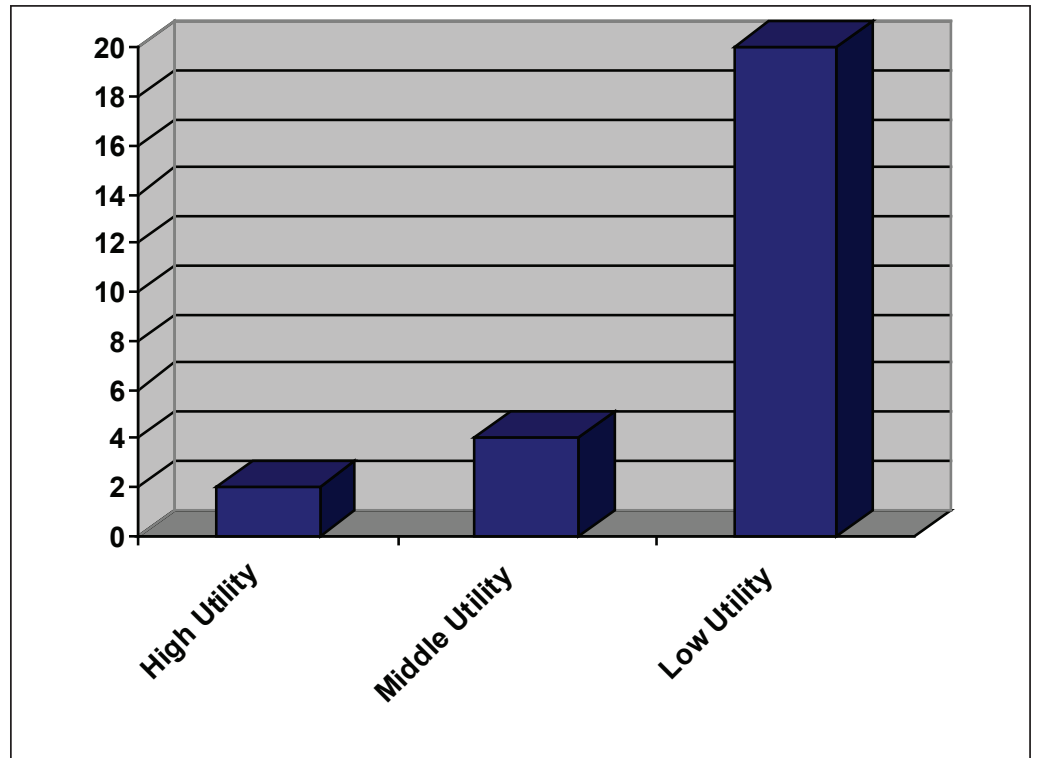

Figure 15-18. Distribution of deer bone elements by utility ranking in Stratum $1 \mathrm{~b}$.

Bison and bovid bone present, however, indicated a presence of all parts. Fragments of a horn core $(n=1)$, thoracic vertebra $(\mathrm{n}=1)$, pelvis $(\mathrm{n}=1)$, humerus $(\mathrm{n}=1)$, and metatarsal $(\mathrm{n}=1)$ are representative of varying utility. Again, given the minimal number of bovid bone present, any statement made concerning transport is not definitive. Given the presence, however, of high, middle, and low utility parts the bison was likely killed onsite or nearby.

\section{Weathering}

Bone from Stratum $1 \mathrm{~b}$ were assessed for their degree of weathering. Bone with a ranking of 3 $(\mathrm{n}=956)$ was most prevalent. There were 37 fragments with a ranking of 2, 208 bones with a ranking of 4, and 16 bones with a ranking of 5. Given the high degree of 3 and 4 rankings it is likely that bone was left exposed for a small, but not prolonged, period prior to burial. As the site seems to have been used temporarily during different seasons it is likely it was associated with temporary camp sites where material was discarded surficially. A flooding event could have covered any remaining exposed material. This is further supported as $1 \mathrm{~b}$ appears to be associated with potential flood deposition and build up between the creek and slough.

\section{Stratum 2}

Stratum 2 was associated with partial back filling of the Fish Creek channel, deposition verlaying Stratum 1b, and complete backfilling of the small slough/relief. When surface, Stratum 2 would have had an absence of the relief/slough noted in Strata 1a and 1b and a slower ponded more slough like channel than creek bed in association with the relict Fish Creek channel. Based on the profile mapping (Figure 15-19) here should still be minimal wetland species associated with the slough (relict Fish Creek channel), but overall there should have been a decrease in wetland/aquatic habitat. There was also a leveling of the terrain adjacent to the former channel. Table 15-6 documents the NISP for each species recovered from the site.

The material from Stratum 2 accounts for half of the total assemblage $(n=4376,50.3$ percent of total bone). While still some presence of aquatic species such as marsh rice rat $(\mathrm{n}=8)$, duck $(n=2)$, eastern box turtle $(n=12)$, red-eared slider $(n=16)$, slider/scooter $(n=2)$, pond turtles $(n=45)$, turtles $(n=392)$ garter/water snakes $(n=1)$, toad $(n=1)$ and frog/toad $(n=2)$, and fish 


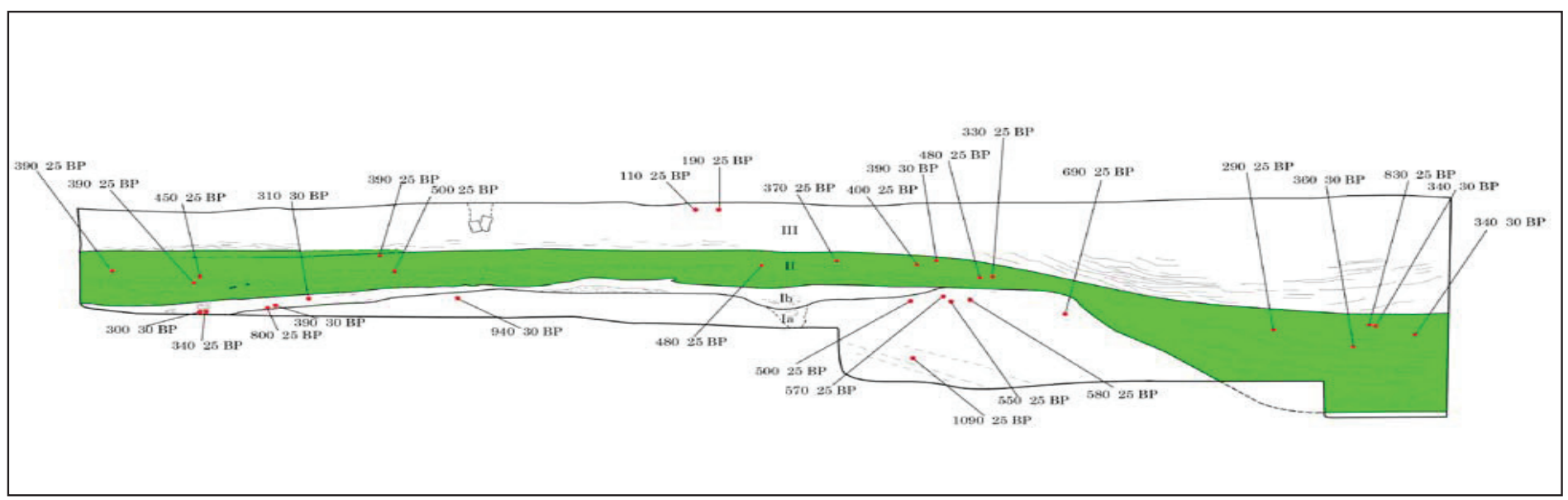

Figure 15-19. Stratigraphic profile with Stratum 2 highlighted.

Table 15-6. Fauna Associated with Stratum 2. Calibrated Date Range for Stratum 2 Based on Radiocarbon Dates is AD 1405- AD 1660.

\begin{tabular}{ccc}
\hline CLASS & TAXA & NISP \\
\hline Mammal & $\begin{array}{c}\text { Didelphis virginiana (opossum) } \\
\text { Canis sp. (dog/coyote) }\end{array}$ & 1 \\
Medium Carnivore & 2 \\
Bison bison (bison) & 1 \\
c.f. Bison bison (bison) & 126 \\
$\quad$ Bos taurus (cow) & 7 \\
c.f. Bos taurus (cow) & 1 \\
Bovidae (bison/cow) & 1 \\
c.f. Bovidae (bison/cow) & 78 \\
Antilocapra americana \\
(pronghorn antelope) \\
Odocoileus virginianus \\
(white-tailed deer)
\end{tabular}

\begin{tabular}{|c|c|c|}
\hline CLASS & TAXA & NISP \\
\hline & Geomys sp. (pocket gopher) & 1 \\
\hline & Dipodomys sp. (kangaroo rat) & 4 \\
\hline & $\begin{array}{l}\text { Oryzomys palustris } \\
\text { (marsh rice rat) }\end{array}$ & 8 \\
\hline & $\begin{array}{l}\text { Sigmodon hispidis } \\
\text { (hispid cotton rat) }\end{array}$ & 5 \\
\hline & Sigmodon sp. (cotton rat) & 31 \\
\hline & Sigmodontinae (rice/cotton rat) & 3 \\
\hline & Neotoma sp. (wood rat) & 3 \\
\hline & Peromyscus sp. (mouse) & 2 \\
\hline & Very small Muridae (rat/vole) & 23 \\
\hline & $\begin{array}{l}\text { Microtine Muridae } \\
\text { (mouse/vole) }\end{array}$ & 4 \\
\hline & Small Rodent & 3 \\
\hline & Very Small Rodent & 35 \\
\hline & $\begin{array}{l}\text { Sylvilagus sp. } \\
\text { (cottontail rabbit) }\end{array}$ & 9 \\
\hline & Leporidae (rabbit) & 2 \\
\hline & Large Mammal & 231 \\
\hline & Medium-large Mammal & 96 \\
\hline & Medium Mammal & 2 \\
\hline & Medium or larger Mammal & 228 \\
\hline & Small-Medium Mammal & 2 \\
\hline & Small Mammal & 3 \\
\hline & Very small Mammal & 15 \\
\hline & Microtine Mammal & 1 \\
\hline & Miscellaneous Mammal & 641 \\
\hline & Subtotal & 1814 \\
\hline
\end{tabular}


Table 15-6. Fauna Associated with Stratum 2. Calibrated Date Range for Stratum 2 Based on Radiocarbon Dates is AD 1405- AD 1660 (continued).

\begin{tabular}{|c|c|c|}
\hline CLASS & TAXA & NISP \\
\hline \multirow[t]{10}{*}{ Aves } & Medium Anatidae (duck) & 2 \\
\hline & $\begin{array}{l}\text { Buteo jamaicensis } \\
\text { (red-tailed hawk) }\end{array}$ & 1 \\
\hline & $\begin{array}{l}\text { Falconiformes (hawks, } \\
\text { eagles, falcons) }\end{array}$ & 3 \\
\hline & $\begin{array}{l}\text { Falconiformes/Strigiformes } \\
\text { (birds of prey) }\end{array}$ & 4 \\
\hline & $\begin{array}{l}\text { Small Passeriformes } \\
\text { (perching bird) }\end{array}$ & 1 \\
\hline & Large Aves & 1 \\
\hline & Medium Aves & 21 \\
\hline & Small Aves & 3 \\
\hline & Miscellaneous Aves & 2 \\
\hline & Subtotal & 38 \\
\hline \multirow[t]{9}{*}{ Reptile } & $\begin{array}{l}\text { Terrapene ornata (western/ } \\
\text { ornate box turtle) }\end{array}$ & 107 \\
\hline & $\begin{array}{c}\text { c.f. Terrapene ornata } \\
\text { (western/ornate box turtle) }\end{array}$ & 6 \\
\hline & $\begin{array}{l}\text { Terrapene Carolina } \\
\text { (eastern box turtle) }\end{array}$ & 12 \\
\hline & Terrapene sp. (box turtle) & 132 \\
\hline & $\begin{array}{l}\text { Trachemys scripta } \\
\text { (red-eared slider) }\end{array}$ & 16 \\
\hline & $\begin{array}{l}\text { Trachemys/Pseudomys } \\
\text { (slider/cooter turtle) }\end{array}$ & 2 \\
\hline & Emydidae (pond turtle) & 45 \\
\hline & Medium Testudines (turtle) & 247 \\
\hline & Testudines (turtle) & 145 \\
\hline
\end{tabular}

\begin{tabular}{|c|c|c|}
\hline CLASS & TAXA & NISP \\
\hline & Small Lacertilia (lizard) & 2 \\
\hline & $\begin{array}{l}\text { Very Small/Microtine } \\
\text { Lacertilia (lizard) }\end{array}$ & 5 \\
\hline & $\begin{array}{l}\text { Agkistrodon sp. (copperhead/ } \\
\text { cottonmouth snake) }\end{array}$ & 6 \\
\hline & Crotalus sp. (rattlesnake) & 1 \\
\hline & $\begin{array}{l}\text { Natricinae (garter/ } \\
\text { water snake) }\end{array}$ & 1 \\
\hline & $\begin{array}{l}\text { Small Colubridae (non- } \\
\text { venomous snake) }\end{array}$ & 13 \\
\hline & $\begin{array}{l}\text { Very small Colubridae } \\
\text { (non-venomous snake) }\end{array}$ & 2 \\
\hline & Serpentes (snake) & 1 \\
\hline & $\begin{array}{l}\text { Medium Squamata } \\
\quad \text { (lizard/snake) }\end{array}$ & 1 \\
\hline & Very small Reptile & 1 \\
\hline & Subtotal & 745 \\
\hline \multirow[t]{3}{*}{ Amphibian } & Bufo sp. (toad) & 1 \\
\hline & Medium Anura (frog/toad) & 2 \\
\hline & Subtotal & 3 \\
\hline Herpetiles & Small Reptile/Amphibian & 1 \\
\hline \multirow[t]{3}{*}{ Osteichtheyes } & Small-medium Osteichtheyes & 1 \\
\hline & Very small Osteichtheyes & 2 \\
\hline & Subtotal & 3 \\
\hline Vertebrate & Miscellaneous Vertebrate & 1772 \\
\hline TOTAL & & 4376 \\
\hline
\end{tabular}

$(\mathrm{n}=3)$, terrestrial species dominate the assemblage. There was a high frequency of grassland species such as bison $(n=173)$, pronghorn $(n=1)$, pocket gopher $(n=1)$ and ornate box turtles $(n=113)$. Bison was the most prevalent mammal bone in the assemblage. Scrub brush/chaparral species present in Stratum 2 included mule deer $(n=6)$ and kangaroo rats $(n=4)$. Some species such as ground squirrels $(n=2)$, cottontail $(n=9)$ and other rabbits $(n=2)$, and hispid and other cotton rats $(n=36)$ use both grassland and brush habitats. Red-tailed hawks $(n=1)$, falconiformes $(n=3)$, and other birds of prey $(n=4)$ can be found in both forested and open prairies, though more likely to nest in trees. Perching birds $(n=1)$ would require wooded or scrub brush habitat. Opossum $(n=1)$ and white-tailed deer $(n=14)$ prefer forest-edge environments.

Stratum 2 is also the only strata to have definite association of canids (Canis sp. dog or coyote, $\mathrm{n}=2$ ). Temporally, it is during a timeframe when domesticated dogs were utilized by Native Americans both as hunting assistants and transport animals. Stratum 2, however, also had multiple bone scatters which may have indicated some carnivore scavenging. The two elements present were not identifiable to species. 
There was one cow bone present in the assemblage, but as discussed in Section I, all identifications of cow were tenuous at best and based on weak characteristics. Also, regardless of whether cow or bison, all bovids $(n=81)$ have been included as grassland animals (Figures 15-20 and 15-21).

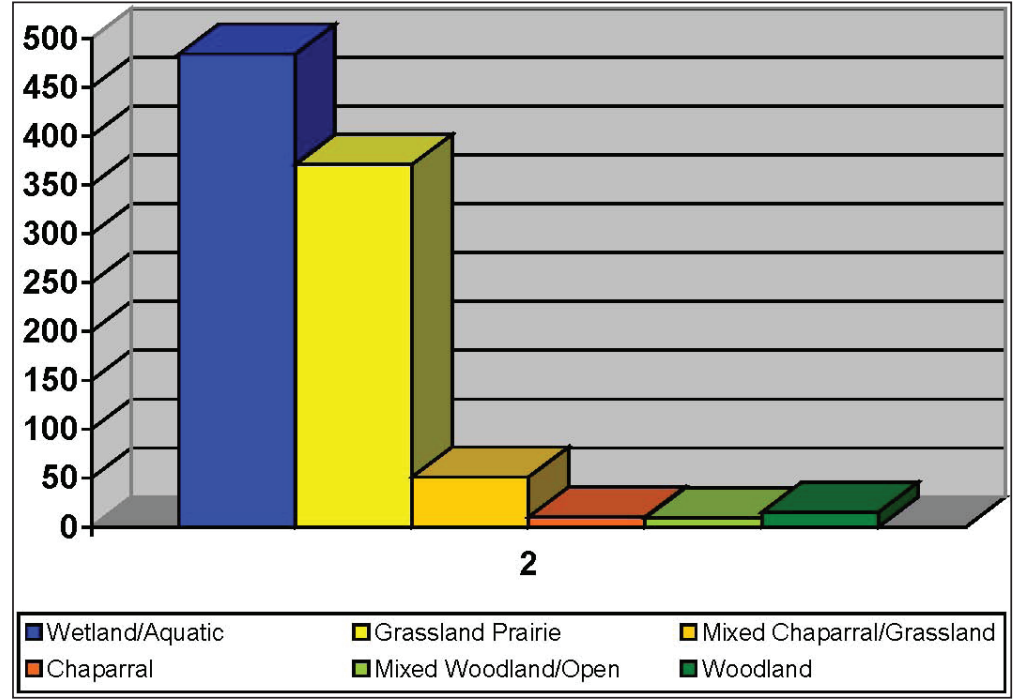

Figure 15-20. Distribution of species NISP in Stratum 2 by habitat niche.

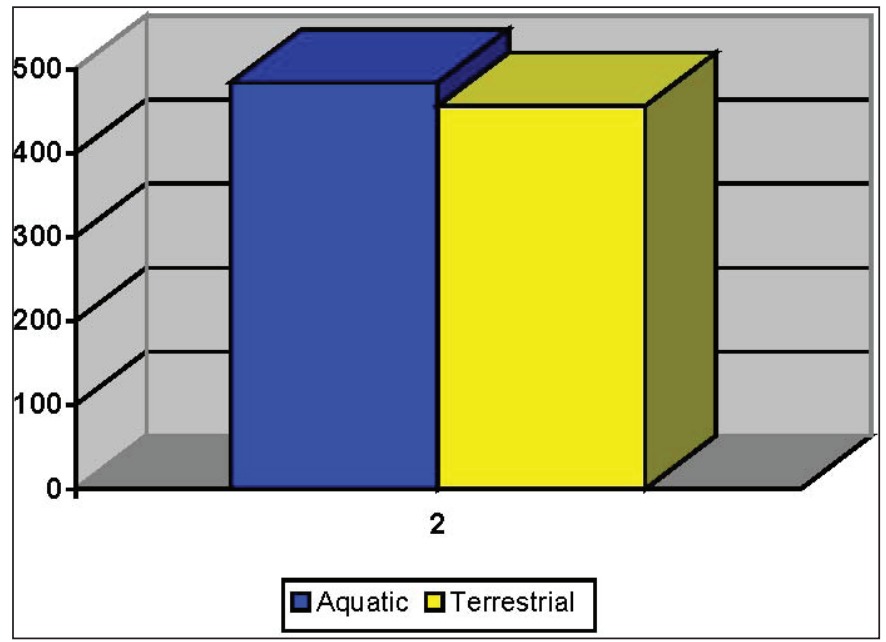

Figure 15-21. Frequency of aquatic species to terrestrial species in Stratum 2.

\section{Seasonality Data}

Given the presence of reptiles (especially turtles) in the assemblage, there is evidence for warmer weather occupation of the site, as turtles typically hibernate when temperatures drop below 45 degrees Fahrenheit. Based on historic and modern daily averages, the average daily temperatures in the Dallas area are above 45 degrees from March through November.

There were multiple bison bones indicative of season of occupation. The majority of the bovid foetal neonate bone from the complete assemblage was recovered from Stratum 2. As 
most of the foetal bone was aged around 7-8 months, maternal death would have occurred between February and April based on calving dates for bison (Schmiddley 1994, Haugen 1974, Borgreen 2010). In addition, there was one metacarpal from a neonate aged at 0-2 months of age, which would have died sometime between April and August. There was also one bison tooth belonging to an individual about 30 months old. In general a bison aged 30 months would have died during the late fall/early winter (October to December).

Based on the above, the site seems to have predominant indications for spring and summer use, but at least one piece of evidence for a late fall/early winter occupation as well.

\section{Skeletal Part Frequencies}

Skeletal part frequencies from bovids and deer were examined from Stratum 2. The distribution of elements for bovids and cervids are presented in Figure 21. There was only a minimal presence of deer axial elements (vertebrae, ribs, etc.), but these bones also consist predominantly of trabecular bone and are less likely to survive than long bone diaphyses which are predominantly cortical bone. The elements which are absent, however, or only minimally present such as ribs, thoracic vertebrae, pelvis/ sacrum, femur, cervical vertebrae, and lumbar vertebrae are all the high utility bones and the highest ranking middle utility bones (Figure 15-22 and 15-23). Given this, it is likely deer were killed at or near the site and the high utility parts transported away.

Not surprising since the majority of bison and bovid present at the site was recovered from Stratum 2, skeletal part frequencies in Stratum 2 almost exactly mirror that of the

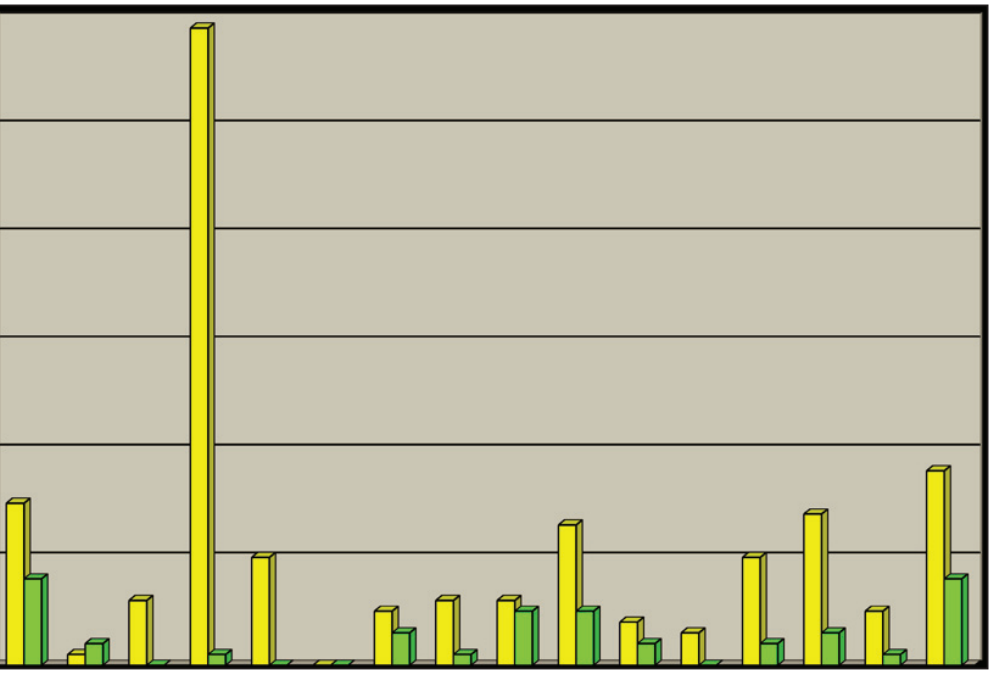

Figure 15-22. Distribution of skeletal fragments for bovids and cervids recovered from Stratum 2.

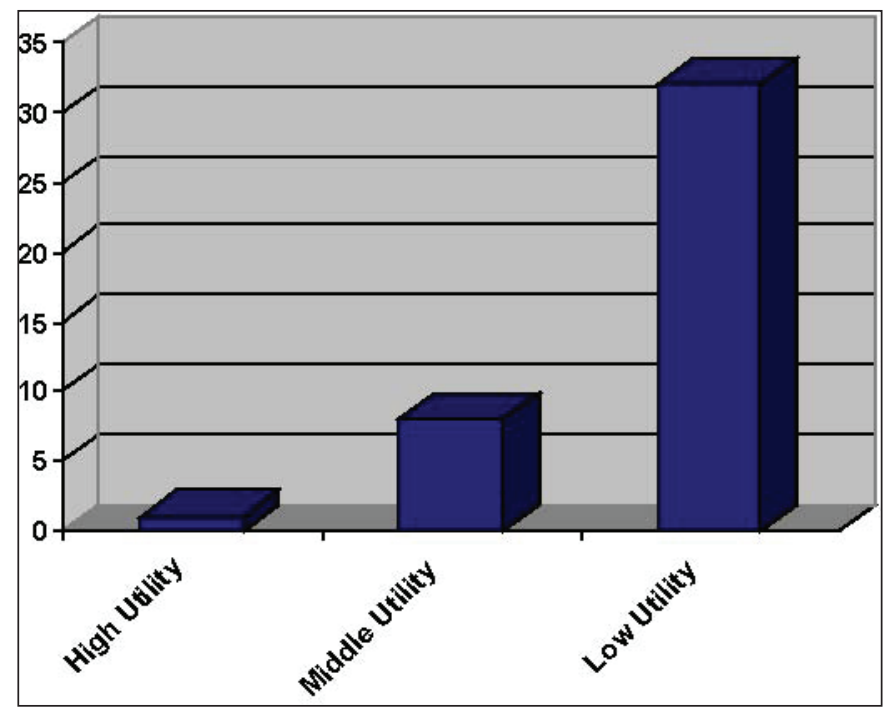

Figure 15-23. Distribution of deer bone elements by utility ranking in Stratum 2 . 
site-wide distribution discussed in Section I (see Figure 5). While there was an overabundance of high utility and low utility parts with only minimal middle utility presence, the long bones with a middle utility ranking were still present in similar quantities as high and low utility long bones. Of greatest note was the absence of non-tooth cranial fragments and complete lack of any pelvic girdle (sacrum and pelvis) bones. As these elements are heavy and can have what useful meat they are associated with easily stripped or removed, discard of these bones would be a reasonable choice to minimize labor if the bison was killed even a minimal (1/2 mile) distance from a site.

\section{Weathering}

Bone from Stratum 2 were assessed for their degree of weathering. Bone with a ranking of 3 $(n=3571)$ was most prevalent. There were 425 fragments with a ranking of 2; 358 bones with a ranking of 4; and 23 bones with a ranking of 5. Given the gentle curve with strong peak over Stratum 3, bone is typical of weathering associated with any occupation site where material was buried relatively quickly after use.

\section{Stratum 3}

Stratum 3 was associated with the post-contact historic time frame with calibrated radiocarbon dates from AD 1654 to AD 1954. During this time the Fish Creek channel/slough was completely filled in and landscaped relatively leveled (Figure 15-24). Due to the absence of slough or channel, wetland habitat would have disappeared or become extremely reduced. Table 15-7 documents the NISP for each species recovered from the site.

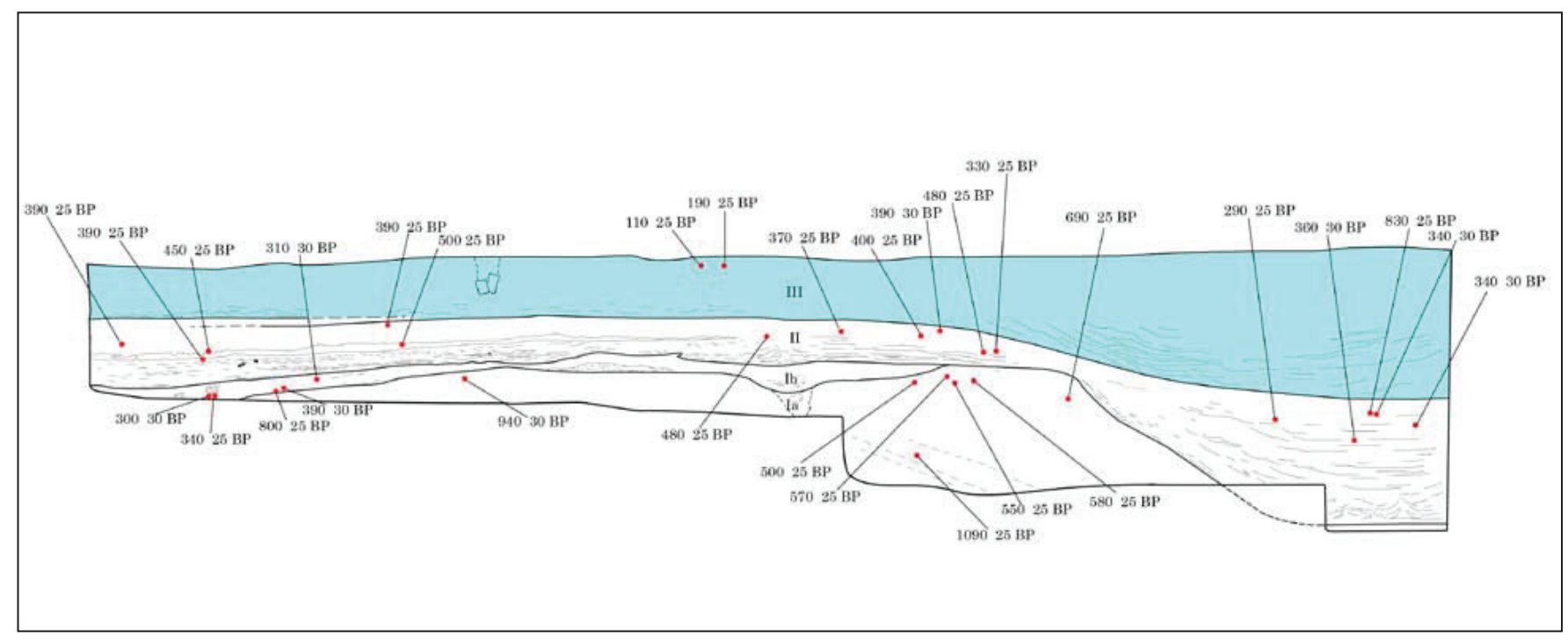

Figure 15-24. Stratigraphic profile with Stratum 3 highlighted. 
Table 15-7. Fauna Associated with Stratum 3. Calibrated Date Range for Stratum 3 Based on Radiocarbon Dates is AD 1654-1954 (modern).

\begin{tabular}{|c|c|c|}
\hline CLASS & TAXA & NISP \\
\hline \multirow[t]{28}{*}{ Mammal } & Medium Carnivore & 1 \\
\hline & Bison bison (bison) & 3 \\
\hline & c.f. Bison bison (bison) & 1 \\
\hline & Bovidae (bison/cow) & 11 \\
\hline & Odocoileus virginianus (white-tailed deer) & 2 \\
\hline & Odocoileus hemionus (mule deer) & 1 \\
\hline & Odocoileus sp. (deer) & 23 \\
\hline & Antilocapra/Odocoileus (pronghorn/deer) & 1 \\
\hline & Large Artiodactyla & 3 \\
\hline & Very small Sciuridae (squirrel) & 1 \\
\hline & Sigmodon sp. (cotton rat) & 5 \\
\hline & Sigmodontinae (rice/cotton rat) & 1 \\
\hline & Reithrodontomys sp. (harvest mouse) & 2 \\
\hline & Microtus sp. (vole) & 3 \\
\hline & Very small Muridae (rat/vole) & 3 \\
\hline & Microtine Muridae (mouse/vole) & 4 \\
\hline & Small Rodent & 1 \\
\hline & Very Small Rodent & 14 \\
\hline & Microtine Rodent & 12 \\
\hline & Sylvilagus sp. (cottontail rabbit) & 1 \\
\hline & Large Mammal & 21 \\
\hline & Medium-large Mammal & 214 \\
\hline & Medium or larger Mammal & 17 \\
\hline & Small-Medium Mammal & 2 \\
\hline & Very small Mammal & 3 \\
\hline & Microtine Mammal & 3 \\
\hline & Miscellaneous Mammal & 88 \\
\hline & Subtotal & 441 \\
\hline \multirow[t]{5}{*}{ Aves } & Anseriformes (waterfowl) & 1 \\
\hline & Medium-large Aves & 1 \\
\hline & Medium Aves & 2 \\
\hline & Small Aves & 2 \\
\hline & Subtotal & 6 \\
\hline \multirow[t]{3}{*}{ Reptile } & Emydidae (pond turtle) & 1 \\
\hline & Medium Testudines (turtle) & 3 \\
\hline & Subtotal & 4 \\
\hline Amphibian & Very small Anura (frog/toad) & 3 \\
\hline \multirow[t]{3}{*}{ Osteichtheyes } & Small Osteichtheyes & 2 \\
\hline & Very small Osteichtheyes & 14 \\
\hline & Subtotal & 16 \\
\hline Vertebrate & Miscellaneous Vertebrate & 1164 \\
\hline TOTAL & & 1631 \\
\hline
\end{tabular}


Species present are predominantly terrestrial with minimal wetland/aquatic species including waterfowl $(n=1)$, pond turtle $(n=1)$, turtle $(n=3)$ and some fish $(n=16)$. The most noted change from earlier strata to Stratum 3 is the drastic decrease in the presence of turtles. Of the terrestrial species, only two white-tailed deer fragments are indicative of any nearby woodland or forestedge habitats, like that lining the nearby new alignment of Fish Creek channel. The remaining terrestrial species all indicate either grassland (bison $n=4$, harvest mouse $n=2$ ) or chaparral (mule deer $n=1$ ) habitat, or are species which utilize multiple habitats (cotton rat $n=5$ and cottontail rabbit $n=1)$. Bovidae $(n=11)$ could easily be cow or bison within the historic context of this strata, but would still require grassland for grazing and are included in the grassland species.

Of all the strata, Stratum 3 contained the lowest frequency of bone identifiable to class, with 1,164 of the 1,631 bones ( 71 percent) recovered from this strata identified only as indeterminate vertebrate. Of the 441 bones identified as mammal, only 348 (79 percent) were identifiable to order or more specific taxon. Therefore, statements regarding environment are somewhat limited. The fact that turtle bone is easy to identify to order and the density of turtle bone, however, still indicates that the drop in presence of turtle bone in comparison to the other 3 strata is significant. The seeming significance of aquatic resources in the diet has shifted from predominantly turtle to fish (Figures 15-25 and 15-26).

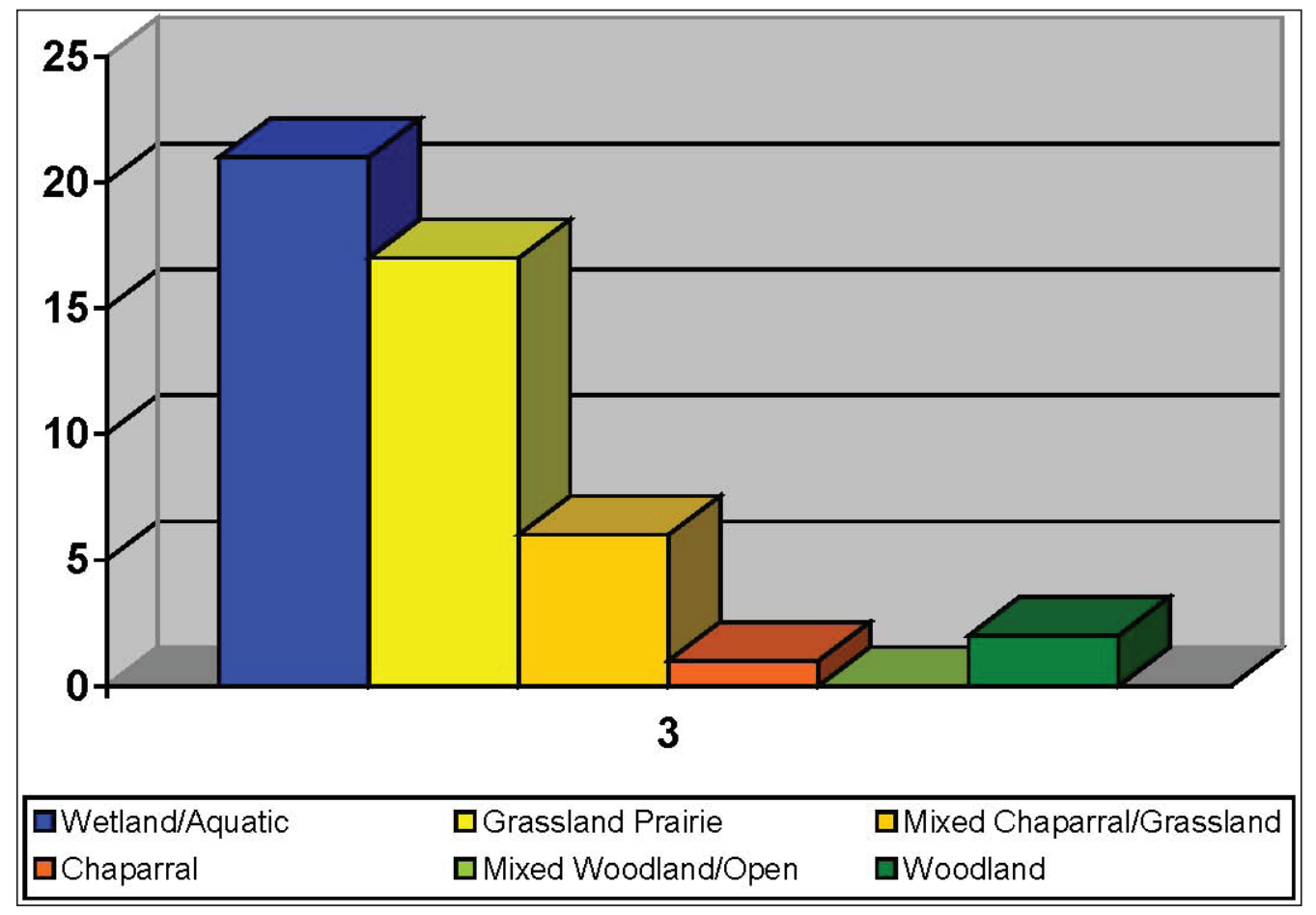

Figure 15-25. Distribution of species NISP in Stratum 3 by habitat niche. 


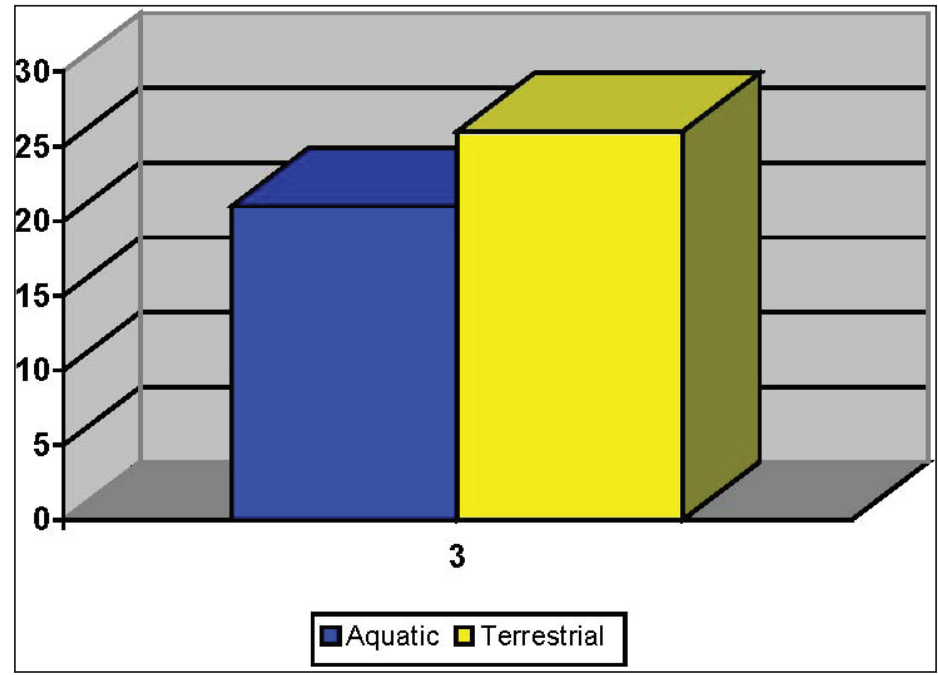

Figure 15-26. Frequency of aquatic species to terrestrial species in Stratum 3.

\section{Seasonality Data}

There were no seasonal indicators from the material recovered from Stratum 3. All bovids and cervids identifiable to age were adult. Frog and reptile present were very minimal given the previous strata $(n=7)$.

\section{Skeletal Part Frequencies}

When skeletal part frequencies from bovids and deer are examined from Stratum 3, some differences are noted. Bovid bone recovered from this strata included fragments of rib $(n=6)$, sternum $(n=1)$, cervical vertebrae $(n=1)$, thoracic vertebrae $(n=1)$ lumbar vertebra $(n=2)$ all of which are high or middle utility parts. There were low utility parts including fragments of humeri $(n=1)$ and tibia $(n=1)$ recovered. In general, the high and middle utility parts by far exceed low utility. It is likely bovids were killed elsewhere and only higher utility parts transported to the location. Given the drastic reduction in presence of bison at the site from Stratum 2, it is assumed that bison were no longer available in large numbers near the site due to either environmental or human impacts.

Deer bone was also scarce and the majority of the assemblage dominated by antler fragments $(n=22)$. There were also fragments from one each of a scapula, humerus, radius, and 3rd phalanx. Utility rankings are insufficient for interpretation due to the small sample size.

\section{Weathering}

Bone from Stratum 3 were assessed for their degree of weathering. Bone with a ranking of 3 $(n=1212)$ was most prevalent. There were only four fragments with a ranking of 1 or 2 . Of the remainder, 28 bones had a ranking of 4 , and 393 bones had a ranking of 5. This stratum had the highest frequency of weathered bone with a ranking of 5. This is indicative that more of the bone was left exposed for a prolonged period prior to burial. This exposure and higher degree of weathering may also be partially responsible for the lower percentage of bone identifiable to class as weathering typically leads to more fragile and easily fragmented bone.

\section{Summary}

In general, there is a decrease in frequency of wetland/aquatic resources from Strata $1 \mathrm{a}$ and $1 \mathrm{~b}$ to Strata 2 and 3 (Figure 15-27). This is at least partially correlated to the rapid sedimentation within the Fish Creek channel. There is an associated increase in the frequency of grassland/ 
prairie species as well as other mixed open chaparral/grassland and chaparral species as well. The change in frequency can be better seen in Figure 15-28.

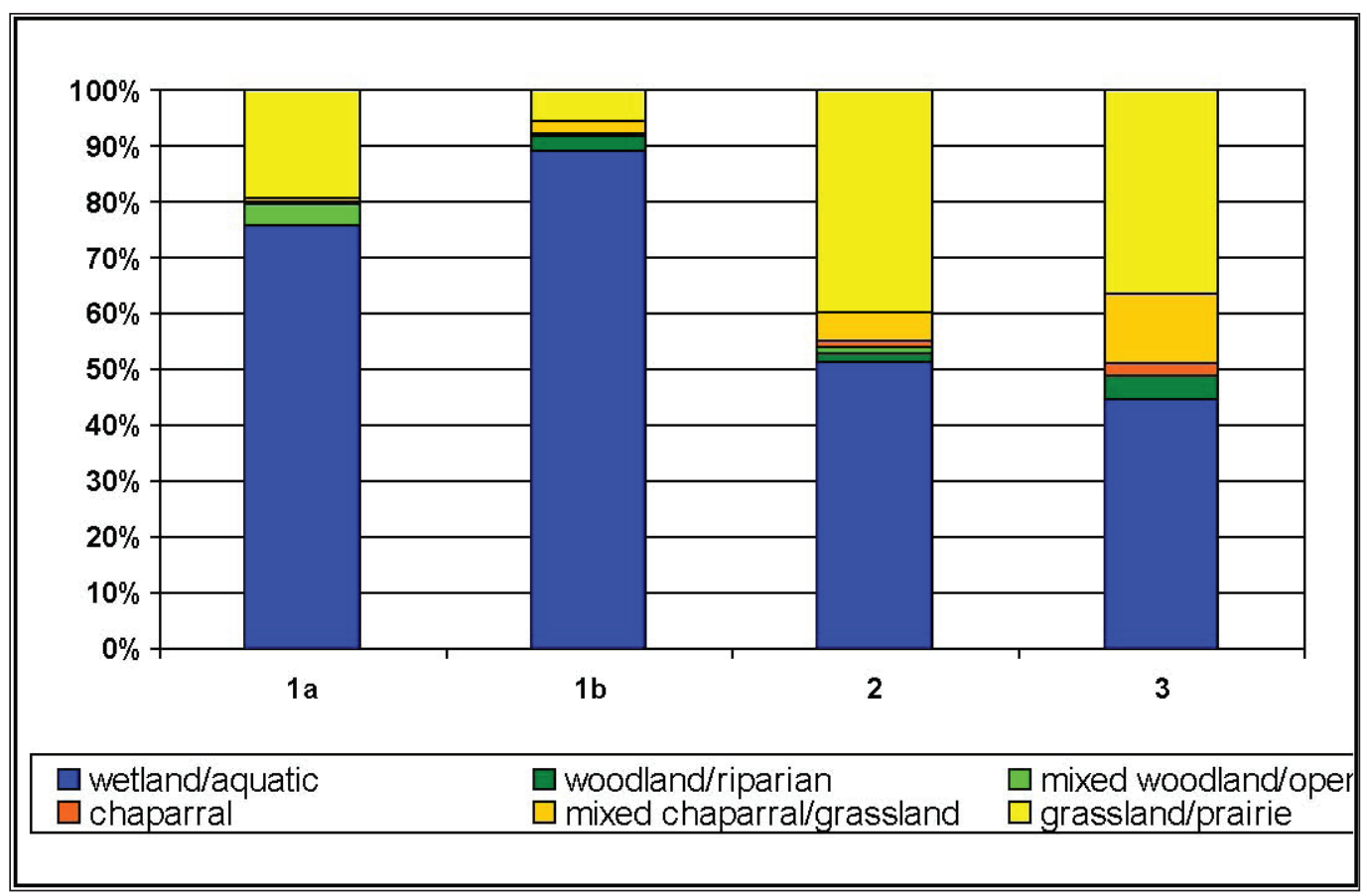

Figure 15-27. Summary of Species Habitat Distributions by Strata.

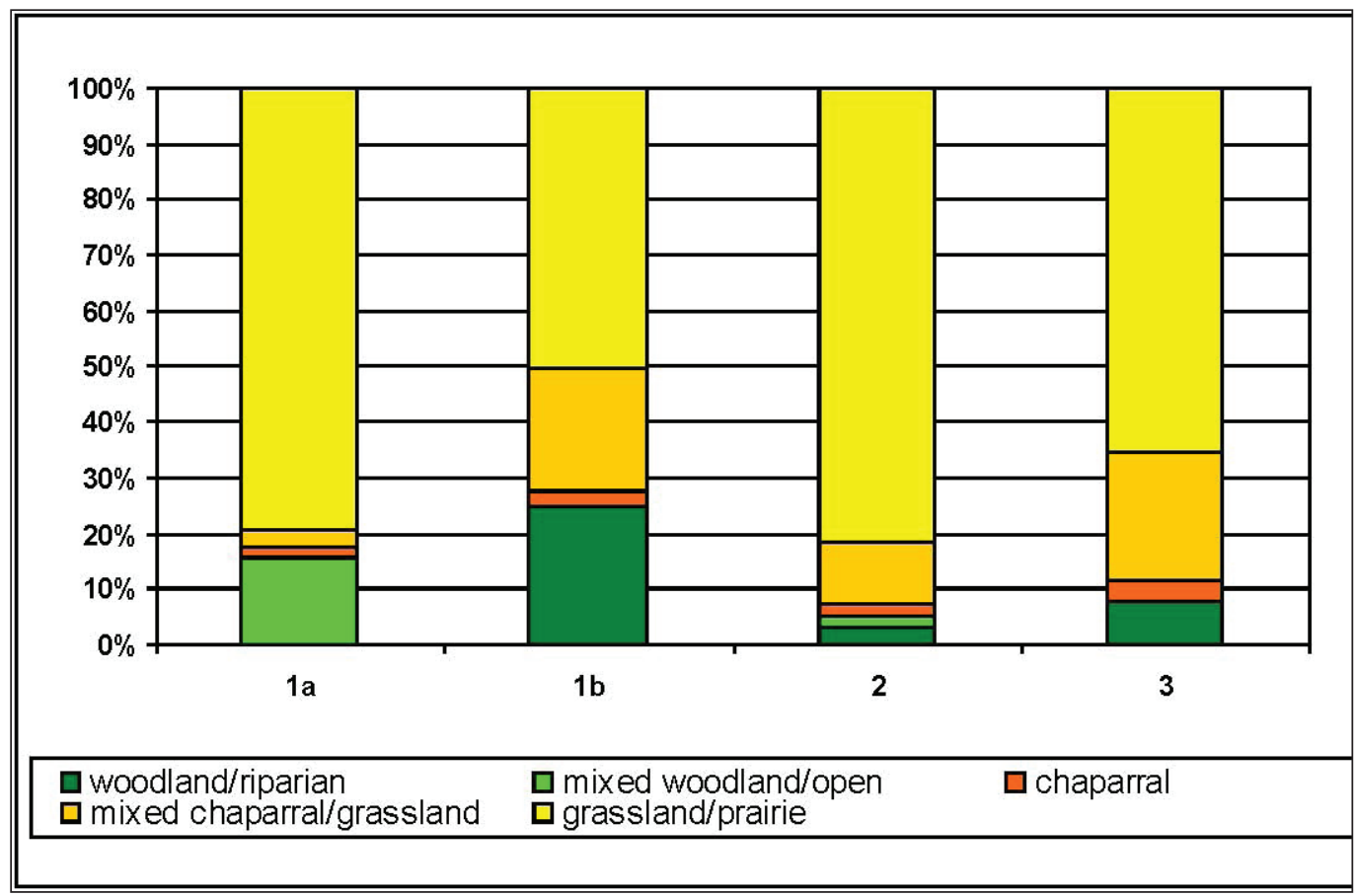

Figure 15-28. Summary of Species Habitat Distributions by Strata with Aquatic Resources Removed. 
When aquatic species are removed (Figure 26) and only terrestrial species are examined, it is noted that Stratum $1 \mathrm{~b}$ had the highest frequency of woodland/riparian presence. Given the location and the drastic decrease in woodland species and increase in prairie species, notably bison, from Stratum 1a to Stratum 2, the change is more than a mere change in prey preference. It is likely that the reduction in woodland environments resulted in habitat (mixed or tall prairie) more suitable to and preferred by bison. A broader scale discussion of the changes is continued in Section IV.

\section{Section III: Cultural Indicators}

Similar to environment and subsistence, the well-stratified nature of the site also allowed for identifying shifts in other cultural indicators beyond just subsistence strategies at the site through time. These cultural shifts can be combined with the above discussion of environment and subsistence to get at a very real understanding of protohistoric lifeways in Dallas County, Texas.

\section{Butchering}

In general, most of the butchering evidence is consistent with meat removal and marrow extraction. While butchering techniques (locations of cuts, methods of marrow extraction, etc.) were consistent across strata, variations in type of tools and frequencies were noted.

\section{Cut Marks}

There was little variation in general positioning of cut marks. Cut marks were located, as previously mentioned in Section I, along areas of muscle and tendon attachment. Along the long bones there were typically series of cuts on the diaphysis directly adjacent to the epiphyses with additional discrete or series of cuts along the shaft. Thoracic and lumbar vertebrae typically exhibited a series of cuts where the transverse processes intersected with the arch, cuts typically made during removal of backstrap or loin sections.

Of the 127 bones in the assemblage with cut marks, $108 \quad(85$ percent) were able to be clearly assigned to one of the 4 well-defined strata (Table 15-8). In general, bone in Strata $1 \mathrm{a}$ and 3 , have between Table 15-8. NISP of Cuts by Strata. a quarter to one-ninth of the amount of cut marks as Strata $1 \mathrm{~b}$ and 2. It should be noted, however, that while over half of the bone from Stratum 1a was identifiable to at least Class, there were very few artiodactyl bones $(n=29)$ in the assemblage. Pre-consumption meat removal is of greater necessity with 
larger animals than with smaller animals, and of all the strata, Stratum 3 had the least percent of bones ( $n=467,29$ percent) identifiable to class. This was likely due to smaller, more fragmented bone, which would have less likelihood to have discernible cuts.

Given the protohistoric and historic components of the site, each cut mark was examined to determine whether it was made with a stone or metal knife following Greenfield(1999) and Jones (2011). In general, cut marks with an acute angle "V" shape or narrow straight lined "U" shape with smooth boundaries are more consistent with metal knife cuts. Cut marks which have a more open right-to oblique-angled "V" with uneven ridges along the cut lines and a tendency for one side of the cut to be more vertical and the other more horizontal are more consistent with stone knife cuts.

Most of the marks on the 41DL436 bone were difficult to positively differentiate, but of the 108 bones from the well-defined strata with cut marks, marks on 16 bones were clearly definable as being made with metal knives and marks on 13 bones were clearly definable as being made with stone tools. Table 15-9 presents the break down of stone, metal, and indeterminate cuts per strata.

Table 15-9. NISP of Knife and Stone Tool Cuts by Strata.

\begin{tabular}{cccccc}
\hline $\begin{array}{l}\text { Stratum (Calibrated } \\
\text { Callendrical Dates) }\end{array}$ & $\begin{array}{c}\text { NISP Metal } \\
\text { Knife Cuts }\end{array}$ & $\begin{array}{c}\text { NISP Stone } \\
\text { Tool Cuts }\end{array}$ & $\begin{array}{c}\text { NISP } \\
\text { Indeterminate } \\
\text { Cuts }\end{array}$ & Total NISP Cuts \\
\hline 1a & (A.D. 1270-A.D. 1445) & 0 & 2 & 2 & 4 \\
1 b & (A.D. 1440-A.D. 1650) & 1 & 6 & 17 & 24 \\
2 & (A.D. 1405-A.D. 1660) & 14 & 5 & 60 & 79 \\
3 & (A.D. 1654-A.D. 1954) & 1 & 0 & 3 & 82 \\
\hline
\end{tabular}

As can be noted in Table 15-9, Stratum 1a only had direct evidence of cut marks made with stone tools. As this level pre-dates European contact, it is consistent with what was available during occupation. While there was minimal evidence for a metal knife cut, Stratum $1 \mathrm{~b}$ had a higher frequency of stone cuts than metal. By Stratum 2, however, metal knife cuts dominated based on identifiable cuts. Stone tool cut marks were still present, but in a smaller frequency than metal. While few cut marks were identified on bone in Stratum 3 , only metal knife marks and those which were indeterminate were recorded, not stone. The cuts clearly demonstrate an increasing reliance on European-introduced technology over time. Figures 15-29 through 15-45 depict a representative sample of cut marks noted on the bones.

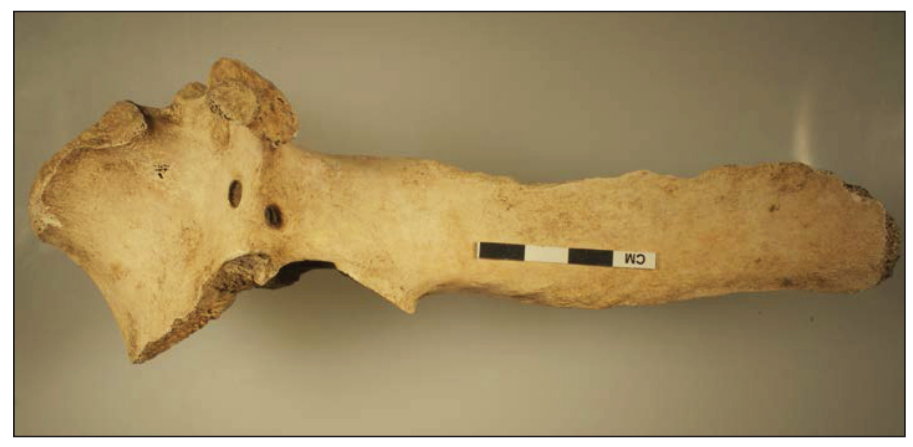

Figure 15-29. Stratum 1a (Field Lot \#255) bison thoracic vertebra with cuts. 


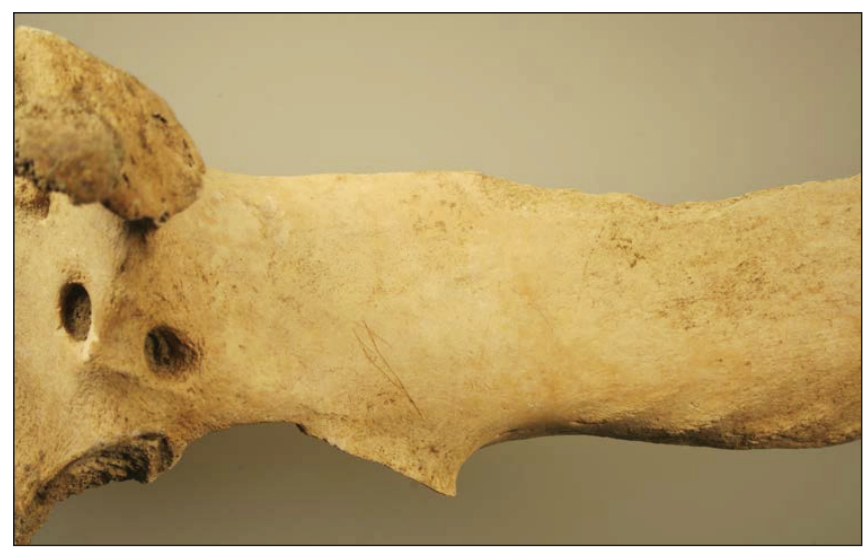

Figure 15-30. Stratum 1a (Field Lot \#255) bison thoracic vertebra with cuts.

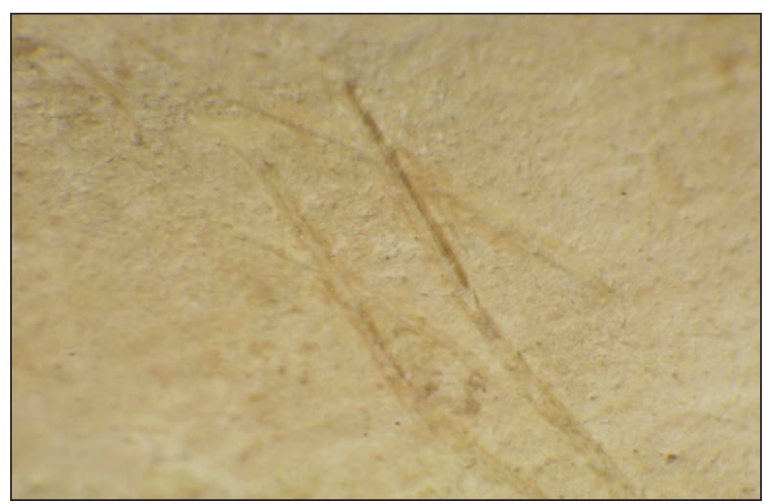

Figure 15-31. Stratum 1a (Field Lot \#255) bison thoracic vertebra with cuts.

Figure 15-32. Stratum 1a (Field Lot \#285) juvenile deer bone with stone tool cuts.

Figure 15-33. Stratum 1b (Field Lot \# 354) deer radius. Note stone tool cut marks at top.
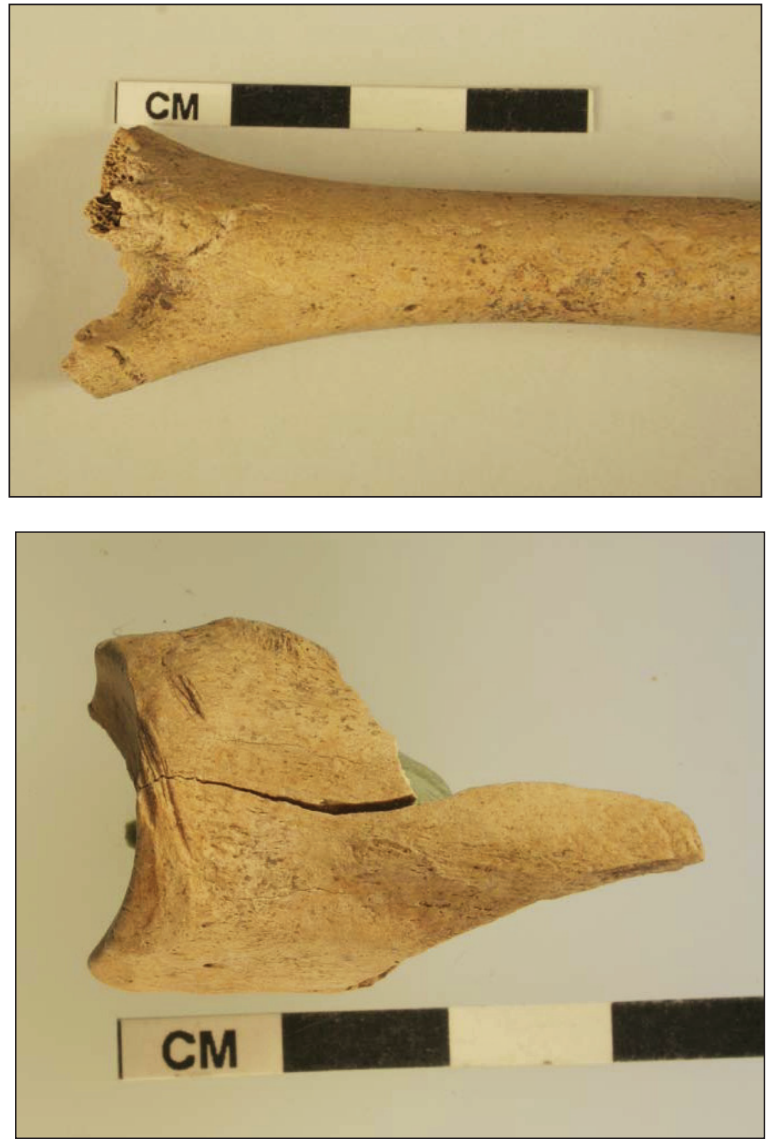


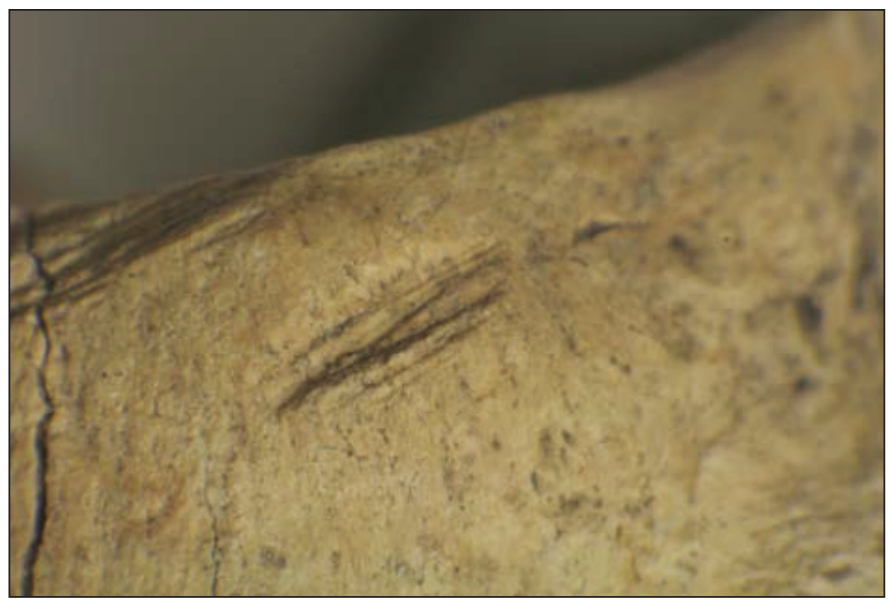

Figure 15-34. Stratum 1b (Field Lot \# 354) deer radius. Microscopic view of cuts on bone in Figure 15-33.

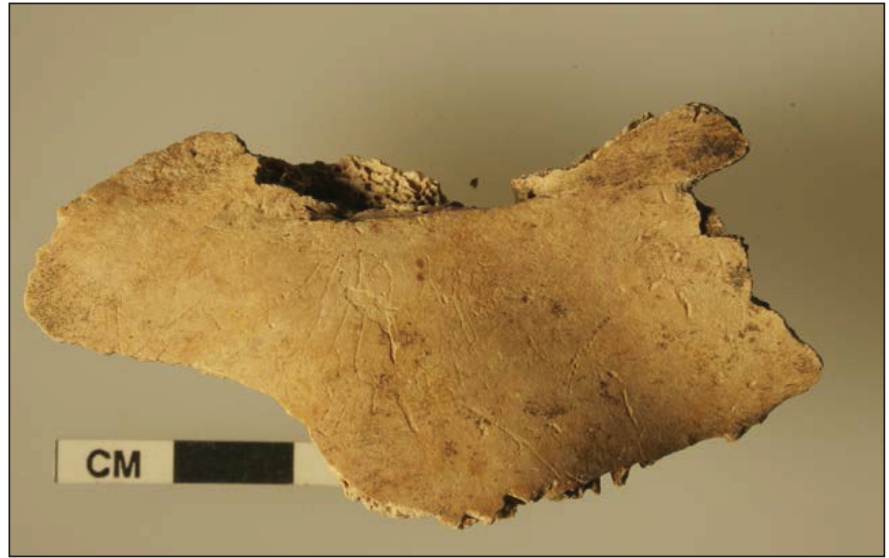

Figure 15-35. Stratum 1b (Field Lot \#394) deer frontal bone with cuts.

Figure 15-36. Stratum 1b (Field Lot \#394) deer frontal bone with cuts - microscopic view of one of the cuts from Figure 15-35.

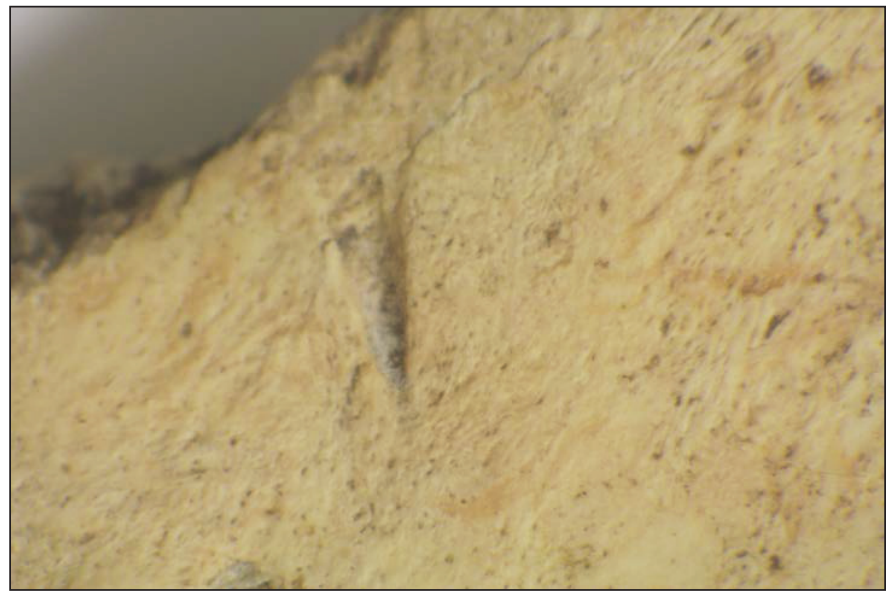

Figure 15-37. Stratum 1b (Field Lot \# 391) medium-large mammal longbone with series of cuts.

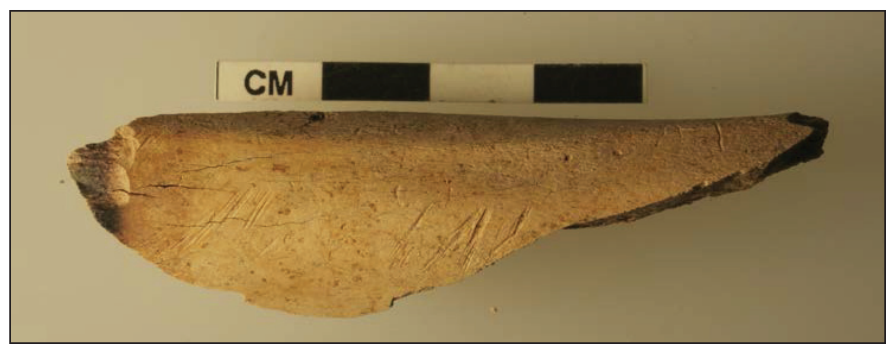




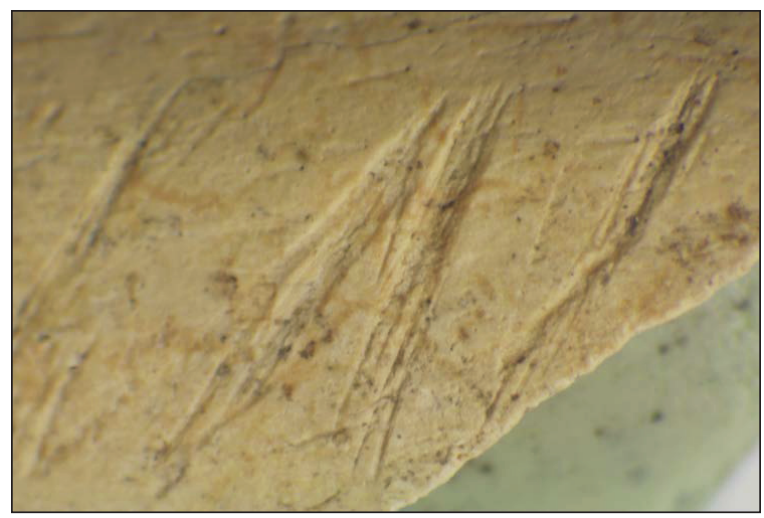

Figure 15-38. Stratum 1b (Field Lot \#391) medium - large mammal longbone stone tool cuts under microscope.

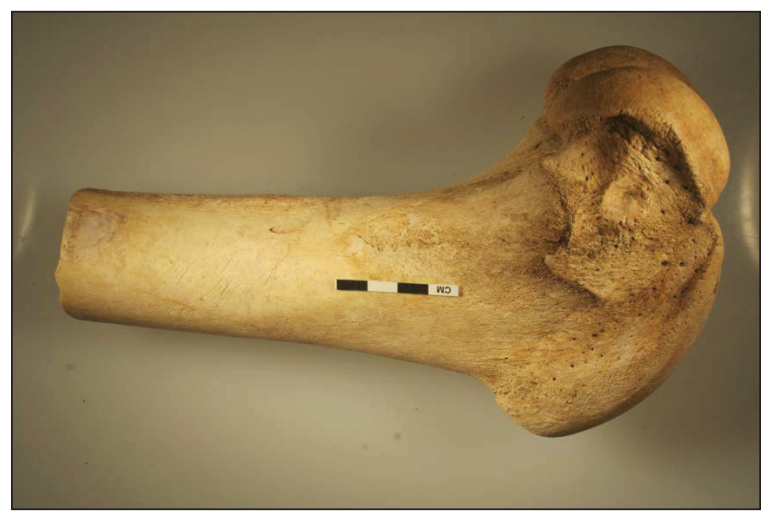

Figure 15-39. Stratum 2 (Field Lot \# 280 ) bison femur with series of cut marks and striking platform.

Figure 15-40. Stratum 2 (Field Lot \# 280) bison femur with series of cut marks and striking platform close-up of Figure 15-39.

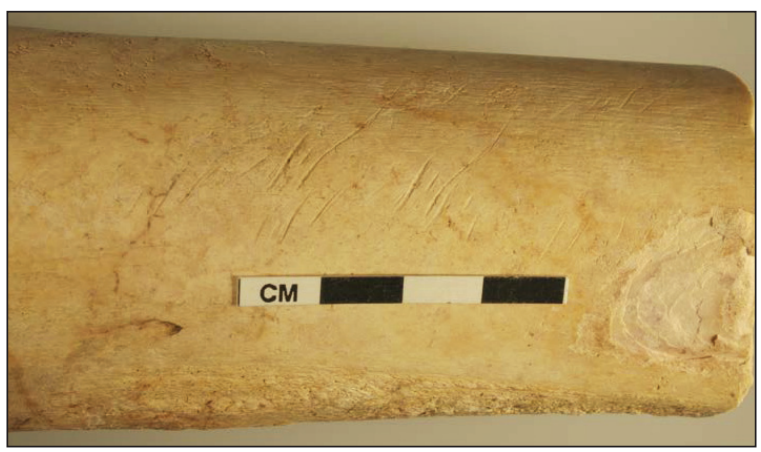

Figure 15-41. Stratum 2 (Field Lot \# 280) bison femur with series of cut marks microscopic view of Figure 39 - note metal knife cut marks.

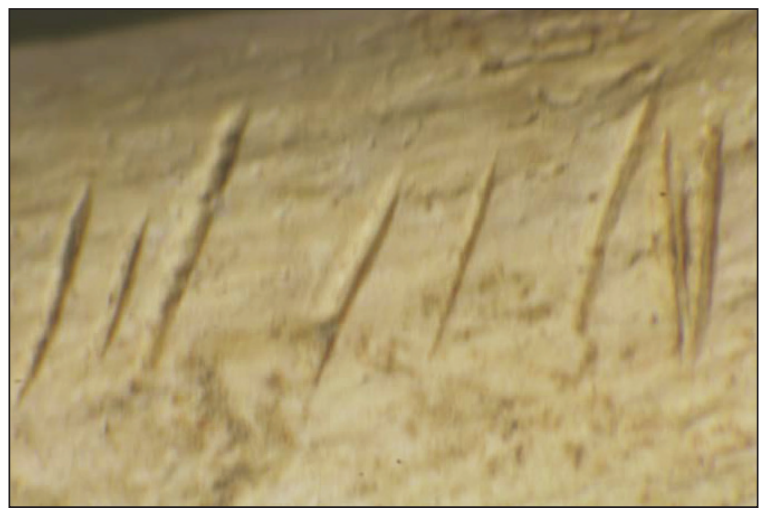



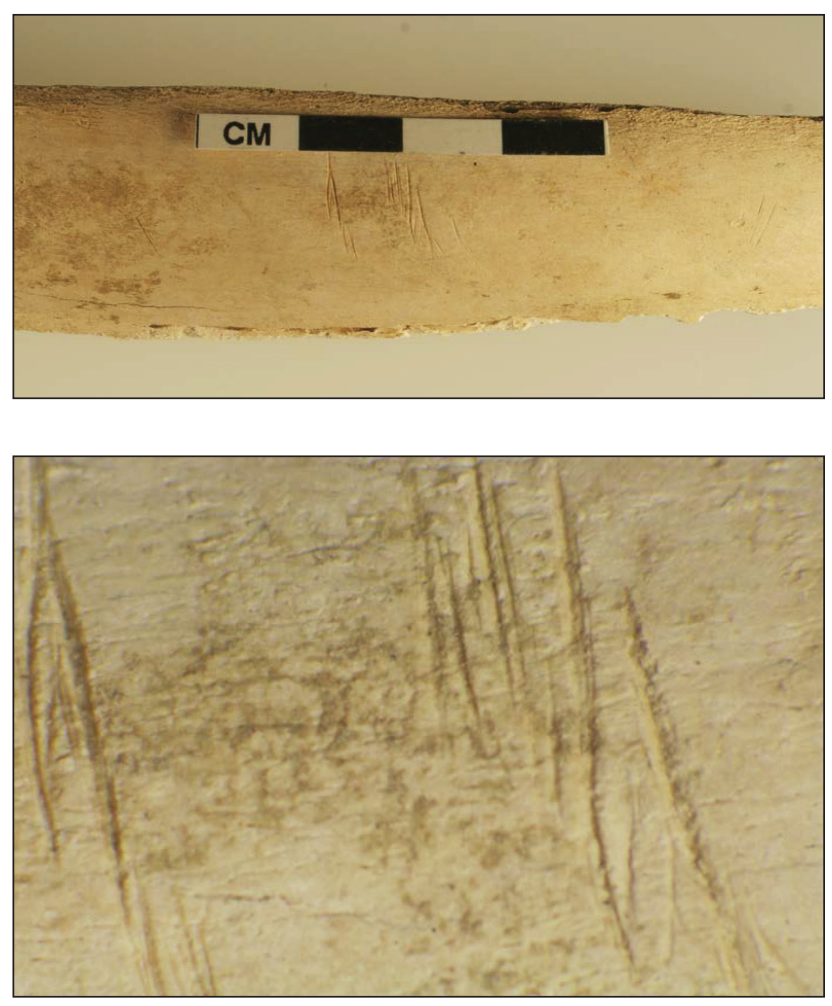

Figure 15-42. Stratum 2 (Field Lot \#282) Bovid Rib.
Figure 15-43. Stratum 2 (Field Lot \#282) Bovid Rib microscopic view of Figure 15-42.
Figure 15-44. Stratum 2 (Field Lot \#282) Bovid Rib microscopic view.

Figure 15-45. Stratum 3 (Field Lot \# 8) large mammal fragment microscopic view - metal knife cuts.
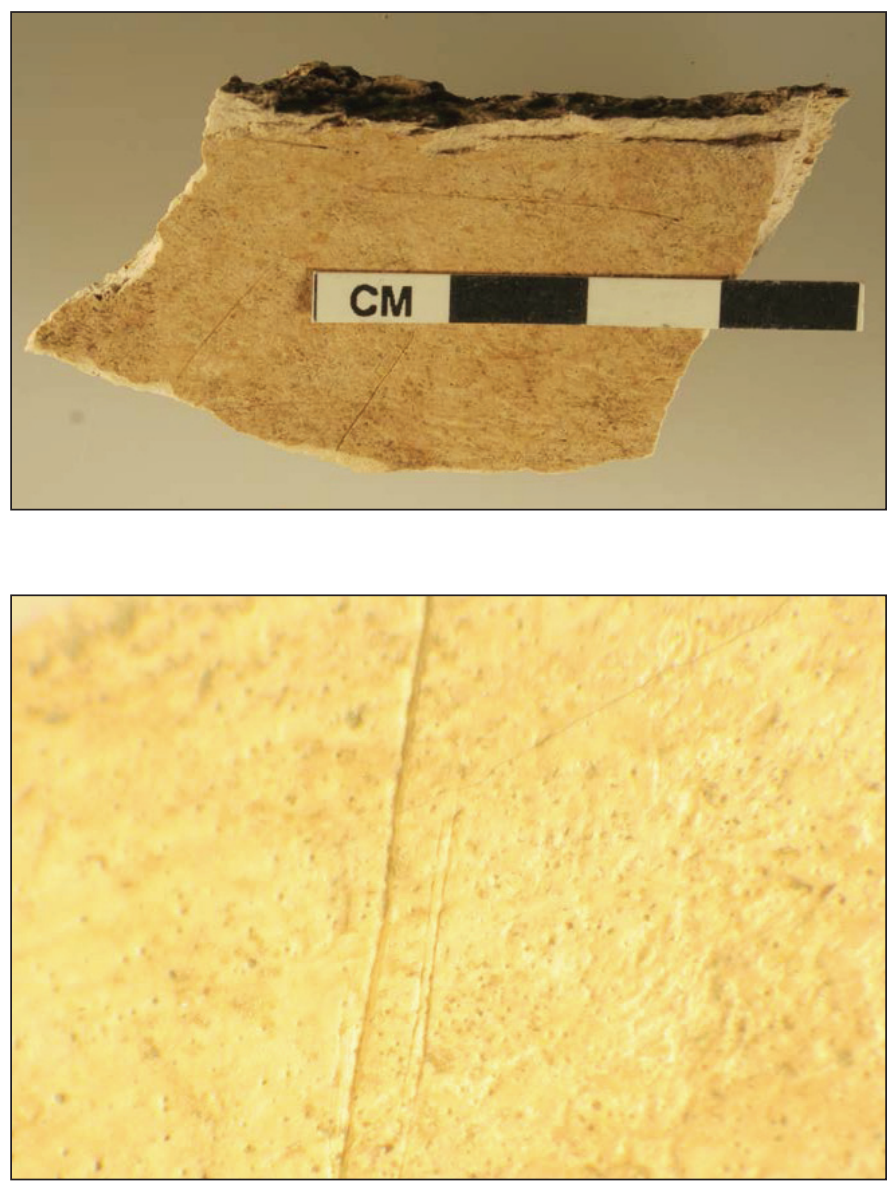


\section{Marrow Processing}

An analysis of bone breakage, platform strikes, and browning associated with localized heating for bone breakage was conducted to determine potential differences between strata. Table 15-10 documents the percent of unbroken bone associated with each strata. Table 15-11 documents the number of each type of break by strata. Bone breakage occurred at a higher frequency with $1 \mathrm{~b}$ and 3 than site average ( 5 percent) while the bone breakage is at a lower frequency than site average with 2 .

Table 15-10. NISP of Unbroken Bone by Strata.

\begin{tabular}{ccc}
\hline Stratum & NISP Unbroken & Percent of bone in Strata \\
\hline 1a & 40 & $4 \%$ \\
1b & 29 & $2 \%$ \\
2 & 298 & $7 \%$ \\
3 & 32 & $3 \%$ \\
\hline Total & 399 & $5 \%$ \\
\hline
\end{tabular}

Spiral breaks are typical with human impact fracturing of bone. While carnivores frequently gnaw on trabecular ends or create bone chips or spalls on cortical bone, they can occasionally fracture a cone causing a spiral. More often, this infrequent

Table 15-11. NISP of Breaks by Type for each Strata.

\begin{tabular}{cccccc}
\hline & $\begin{array}{l}\text { Stratum (Calibrated } \\
\text { Callendrical Dates) }\end{array}$ & NISP Spiral & $\begin{array}{c}\text { NISP } \\
\text { Green }\end{array}$ & NISP Dry & $\begin{array}{c}\text { NISP } \\
\text { Indeterminate }\end{array}$ \\
\hline 1 a & (A.D. 1270-A.D. 1445) & 7 & 4 & 678 & 34 \\
1 1b & (A.D. 1440-A.D. 1650) & 42 & 25 & 1031 & 141 \\
2 & (A.D. 1405-A.D. 1660) & 93 & 34 & 3240 & 724 \\
3 & (A.D. 1654-A.D. 1954) & 1 & 2 & 949 & 719 \\
\hline & TOTAL & 143 & 65 & 5898 & 1618 \\
\hline
\end{tabular}

spiraling is overlain by splintering, jagged edges or gnaw marks and is distinguishable from human modification (Haynes 1983). Green breaks can be associated with carnivores or perimortem injury, but most of the green breaks noted in this assemblage were the result of bone peels, twists, or breaks associated with human processing.

An equalized graph (Figure 15-46) was generated to depict the differences in bone breakage between strata. Stratum 3 had a much higher frequency of indeterminate breaks. This is likely related to the higher degree of heavily fragmented (not identifiable to class), weathered, and burned bone when compared with other strata. Indeterminate bone was removed from Figure 46 to better compare identifiable breaks (Figure 15-47).

In general, bone at this site was not heavily processed by people. While there is some evidence for intentional human breakage with each strata, the least evidence occurred during strata 3. The greatest frequency of spiral and green breaks associated with intentional human processing occurred with Strata 1b. When isolated to only longbone breakage patterns (those most likely to be processed for marrow), the below was seen.

Based on Figure 15-48, Stratum $1 \mathrm{~b}$ had not only the smallest percent of unbroken bone, but also the highest percent of intentional breakage associated with cultural activities. Indeterminate bone was removed from the table for a better direct comparison of the bone with which type of 


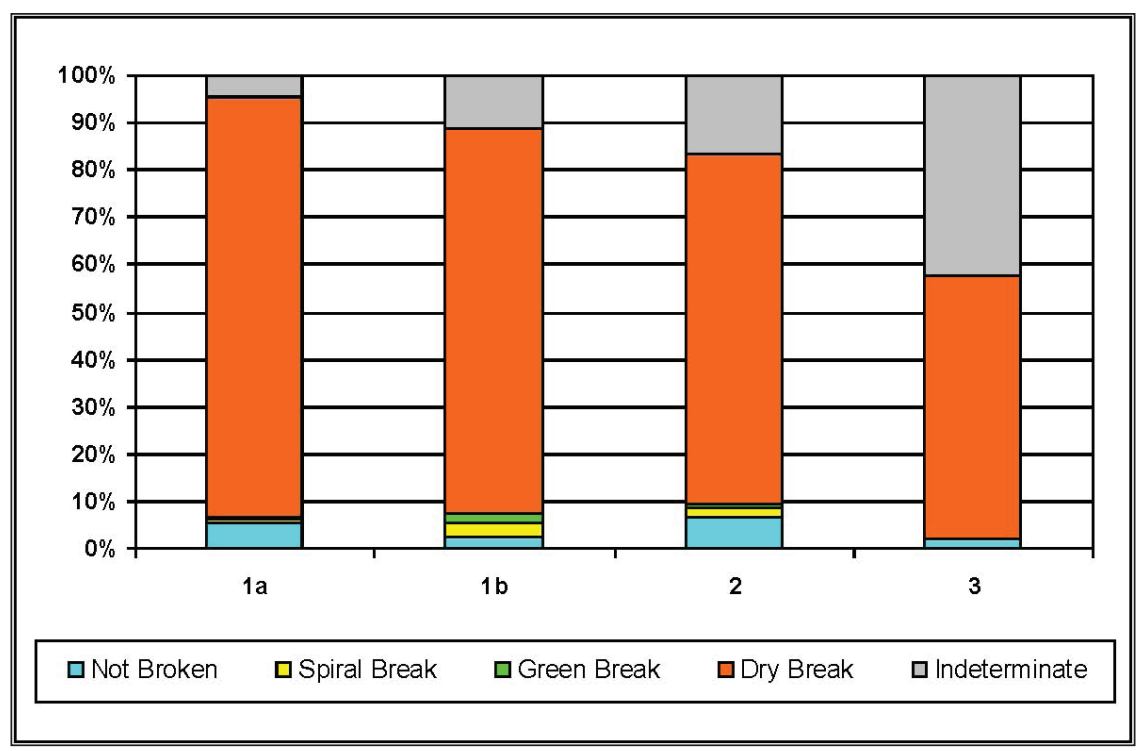

Figure 15-46. Distribution of Bone Fragmentation across Strata.

Figure 15-47.

Distribution of Bone

Fragmentation across Strata with indeterminate bone removed.
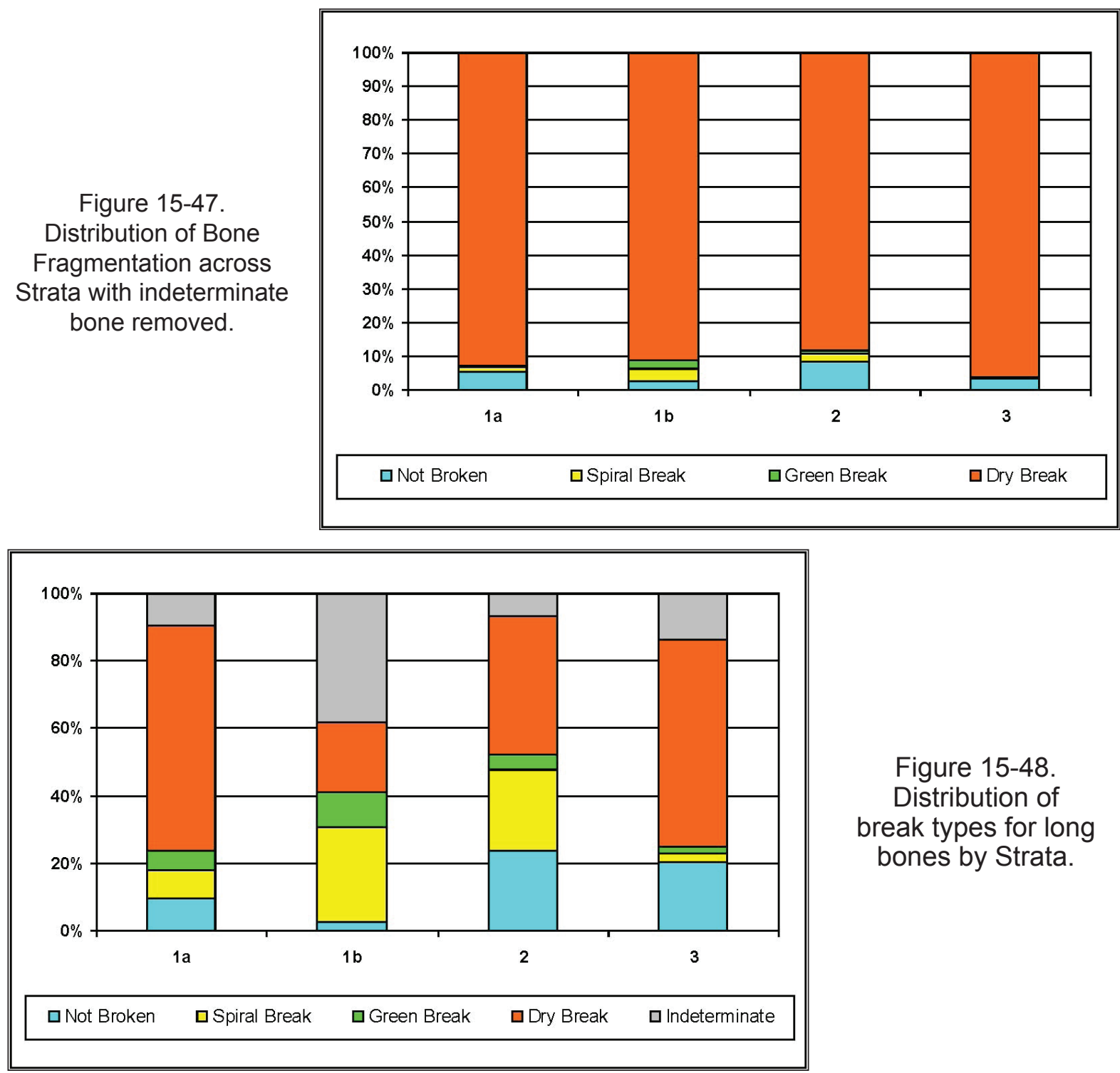

Figure 15-48.

Distribution of break types for long bones by Strata. 
breakage could be determined. There was a lower degree of unbroken bone, higher degree of intentional breakage, and general species diversity associated with Stratum 1b, including high use of easy to capture yet low biomass resources such as turtle. There were fewer large game species available and, therefore, more reliance on the resources provided by the whole animal, including marrow which would have had higher processing labor demands than simple meat removal.

Overall, Stratum 2 had the highest relative percent of unbroken long bones, yet also the second highest percent of intentional breakage (Figures 15-47 and 15-48). Artiodactyl long bones which were unbroken in Stratum 2 included phalanges and a metacarpal. Smaller mammal longbones including humeri, femurs, tibias, and an ulna were also unbroken.

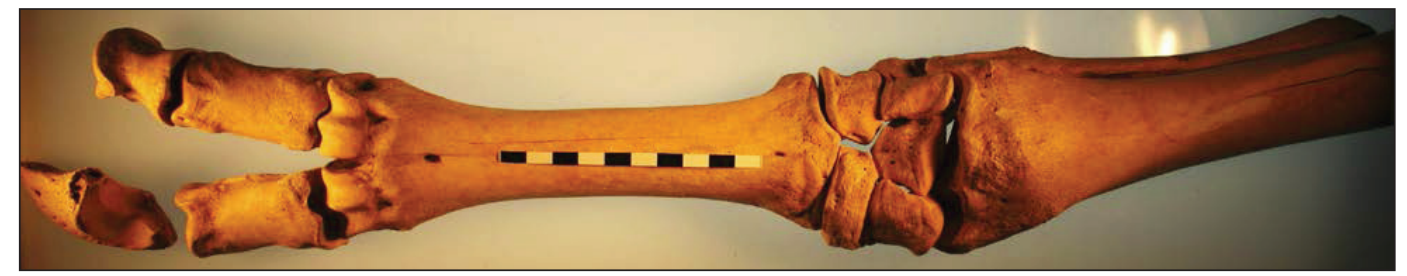

Figure 15-49. Stratum 2 (Field Lot \# 84) articulated bison radius, carpals, and phalanges. Note radius exhibits spiral fracture at end at far right of photograph (See Figure 48).

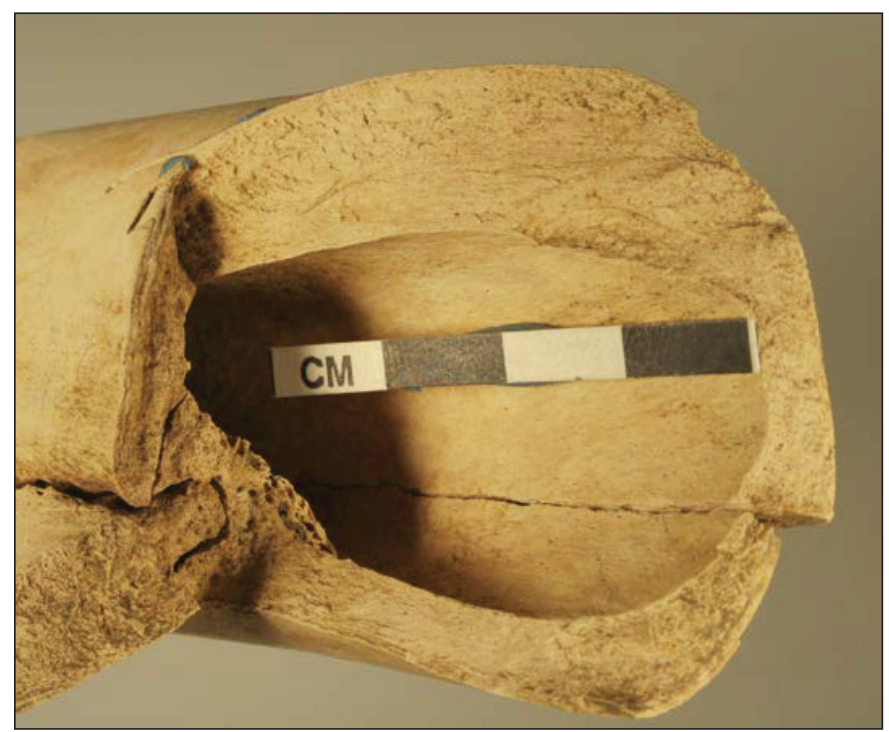

Figure 15-50. Stratum 2 (Field Lot \#84) bison radius from Figure 47 . Note spiral fracture.
Stratum 3 had the least evidence for intentional breakage. The majority of the bone was either unbroken or broken post-depositionally. Given the minimal nature of cut marks and low frequency of intentionally broken bone, it would appear that there was little onsite processing associated with Stratum 3. However, Stratum 3 also had the highest percentage of burned bone (see below), so it is possible the burning obscured cut marks and created additional fragmentation of the bone obscuring original spiral and green breaks.

Striking Platforms were noted on 11 bones. Of those nine, bones could be positively associated with specific strata. Stratum 1a had only one bone, a large mammal long bone diaphysis fragment with an evident striking platform. The bone also exhibited a spiral break. Stratum $1 \mathrm{~b}$ contained two bones, a medium-large mammal long bone diaphysis and a bovid left proximal anterior metatarsal, with striking platforms and both with spiral or green fractures indicating intentional breakage for marrow extraction. Stratum 2 consisted of six bones with evidence of striking platforms or radiating breaks indicative of striking impact for 
marrow processing. The five of the six bones included a large mammal long bone diaphysis fragment, two large artiodactyl long bone diaphysis fragments, a large bovid posterior diaphysis radius fragment, and a bison left distal metatarsal. The sixth bone was a large bison rib segment with circular impact. The impact could have either been from an exterior strike or projectile. Stratum 3 was the only strata without evidence for a striking platform on the bones.

Additional indications of butchery were identified in Stratum 2. Three proximal bison rib segments had green twist breaks at their end near the articulation with thoracic vertebrae. The breaks were consistent with a dorsal lift and twist in an attempt to either pull/push open a rib cage or to disarticulate the ribs from vertebrae. None of these twist breaks were observed on ribs from other strata.

As noted in Section I, brown discoloration was noted on numerous bones, typically in association with spiral fractures and striking platforms. It has been posited here that the browning represents localized heat, such as the placement of a pre-heated rock, on the bare bone to weaken the bone structure. Breakage of the long bones would take less labor and time. A review of the presence of the browning by strata was conducted to determine if there was any difference in the frequency over time. In some cases, it may have been difficult to differentiate between the brown mild charring from exposure to a campfire and the brown stains associated with the localized heating on smaller fragments of bone. The browning associated with breakage was mostly noted on larger segments of bones (Figure 15-51). Table 15-12 documents the frequency of the browning by strata.

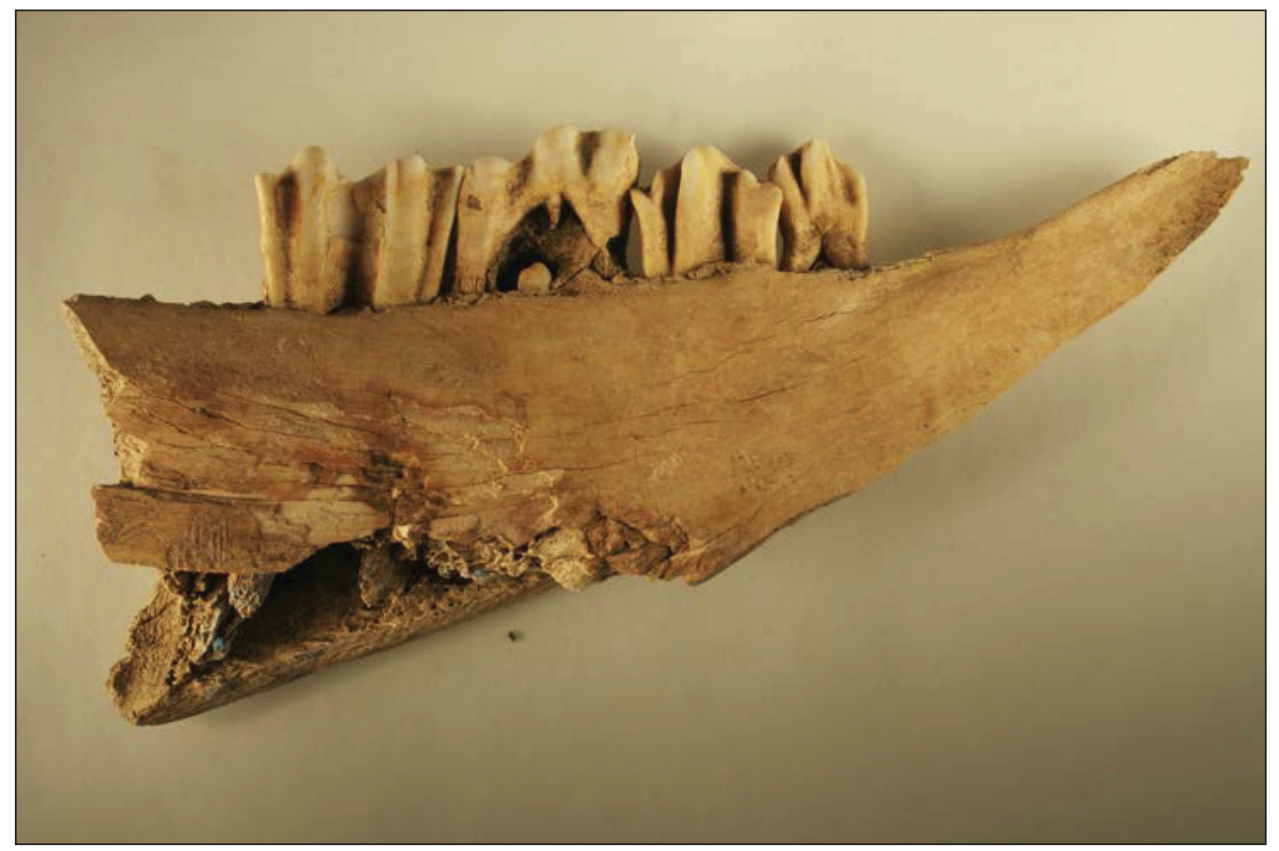

Figure 15-51. Stratum 2 (Field Lot \# 303) Bison mandible with browning and micro fractures. Also note eruption of permanent premolar replacing deciduous tooth. 
Table 15-12. Frequency of Occurrence of Localized Browning by NISP per Strata.

\begin{tabular}{ccccc}
\hline $\begin{array}{c}\text { Stratum (Calibrated } \\
\text { Callendrical Dates) }\end{array}$ & $\begin{array}{c}\text { NISP } \\
\text { Browning }\end{array}$ & $\begin{array}{c}\text { Percent of Total } \\
\text { NISP from Strata }\end{array}$ & $\begin{array}{c}\text { Percent of NISP of Spiral/ } \\
\text { Green Break Bone in } \\
\text { Strata from Table 11 }\end{array}$ \\
\hline 1 1a & (A.D. 1270-A.D. 1445) & 2 & $0.2 \%$ & $18.2 \%$ \\
1 1b & (A.D. 1440-A.D. 1650) & 6 & $0.4 \%$ & $9.0 \%$ \\
2 & (A.D. 1405-A.D. 1660) & 30 & $0.6 \%$ & $23.6 \%$ \\
3 & (A.D. 1654-A.D. 1954) & 1 & $<0.01 \%$ & $33.3 \%$ \\
\hline \multicolumn{2}{c}{ TOTAL } & 39 & $0.5 \%$ & $18.9 \%$ \\
\hline
\end{tabular}

There was $\mathrm{m}$ i $\mathrm{n}$ i $\mathrm{m}$ a 1 presence of the browning in Strata $1 \mathrm{a}$ and 3, but both strata also exhibited $\mathrm{m}$ i $\mathrm{n} \mathrm{i} \mathrm{m}$ a 1 evidence for in te n t i on a 1 b r e a k a g e.

Strata $1 \mathrm{~b}$ and 2 had the greatest evidence for intentional breakage of bone, yet there was a comparatively higher frequency of browning on bone in Stratum 2. The increase is likely related to the higher presence of artiodactyls within the assemblage. All browning associated with local heat for breakage was noted on pronghorn, deer, bison or bovid, large artiodactyl, and medium-large or large mammal bone. Given the increase in these taxon's presence in Stratum 2 it is not surprising that the frequency of browning is increased as well.

\section{Thermal Alteration}

Thermally altered bone was sorted by strata. "Brown" bone in Table 15-13 also includes the numbers for bone that was locally heated as it is still representative of thermal alteration. In general, Strata 2 and 3 had higher frequencies of burned bone that either Stratum 1a or 1b. As Stratum 3 has other minimal evidence for cultural modification, the high frequency of thermally altered bone solidifies association of much of the assemblage with cultural deposits.

Table 15-13. Distribution of Burned Bone by Level of Thermal Alteration and Strata.

\begin{tabular}{cccccc}
\hline Stratum & Brown & Black & Gray/Calcined & Total & $\begin{array}{c}\text { Percent of } \\
\text { Bone in Strata }\end{array}$ \\
\hline 1a & 32 & 49 & 14 & 95 & $11 \%$ \\
1b & 118 & 30 & 0 & 148 & $10 \%$ \\
2 & 121 & 402 & 135 & 658 & $16 \%$ \\
3 & 19 & 184 & 15 & 218 & $18 \%$ \\
\hline Total & & & 1119 & $14 \%$ \\
\hline
\end{tabular}

Strata 1a and 2 depict fairly standard curves for thermal alteration with the majority of the bone blackened/charred with additional presence of brown and gray or calcined bone. In general, brown discoloration is indicative of short-term and lower heat such as exposure to a campfire or grass fire for 6 minutes, whereas blackened or carbonized bone suggests prolonged exposure (around 30 minutes) to heat approximately 400-500 degrees Celsius. This would be consistent with cooking activities around a campfire or hearth. The calcined gray or white bone has been exposed to temperatures above 600 degrees Celsius or for an extensive amount of time (Lyman 1994). The presence of all three levels of thermal alteration and the greater frequency 
of blackened/charred bone in Strata 1a and 2 would indicate that the thermal alteration was associated with cooking or food processing activities.

Stratum $1 \mathrm{~b}$, however, has a predominance of browned bone, minor amounts of charred bone, and a complete lack of calcined bone. While the majority of burned bone was turtle $(n=67)$, there was also a presence of pronghorn antelope $(n=1)$, bison $(n=1)$, white-tailed deer $(n=1)$, indeterminate mammal $(n=1)$, medium or larger mammal $(n=9)$, medium-large mammal $(n=9)$, rabbit $(n=1)$, duck $(n=1)$, and indeterminate vertebrate $(n=59)$. All taxa in Stratum 1 b with burn marks were widely consumed by prehistoric Native Americans. Despite the low frequency of blackened and calcined bone, given the species distribution of burned bone it is still likely that the thermal alteration was cultural (brief exposure to campfire) rather than exposure to a fast moving grass fire. Culturally though, cooking would have exposed the bone to direct heat for a lower amount of time than was used during later strata.

Stratum 3, which has little evidence for cultural use beyond burning, demonstrates a much higher frequency of blackened bone. The majority of burned bone recovered from Stratum 3 is highly fragmented indeterminate vertebrate $(n=207)$. The remaining bone includes bison $(n=1)$, mouse/rat/vole $(n=2)$, large mammal $(n=1)$, and indeterminate mammal $(n=7)$.

\section{Bone Tools and other Cultural Evidence}

There was evidence within the recovered assemblage for bone with modifications beyond standard subsistence. Many of the bones displayed evidence of polishing or smoothing that was not attributable to scatological or alluvial processes. Quite a few bones had abraded edges indicating expedient use as bone tools. Essentially, as a sharp edge had been created when bone was broken, the edge was used as a tool, likely as a scraper or to aid in marrow removal, until the tool was either too worn or no longer needed and was then discarded. Formal tools, including an awl/punch and a potential bone billet/hammer were also present. There was also a presence of asphaltum, in one case at least intentionally used decoratively, on some of the bone. Last, one distal bison humerus displayed evidence of having been shot. Multiple small impacts ranged from $2.0 \mathrm{~mm}$ to $2.4 \mathrm{~mm}$ with an average size of $2.2 \mathrm{~mm}$, approximately the size of \#8 birdshot typically used to hunt dove and quail (Wikipedia 2013). While not a tool, it is direct evidence for the presence of other European technology within a predominantly Native American prehistoric to protohistoric to historic period site. Cultural evidence on bone are presented in Table 15-14 by strata. Images and discussion of select artifacts follow by strata. No non-subsistence based (butchery marks, thermal alteration, etc.) cultural modifications were noted on bone recovered from Stratum 1a.

There were no tools or other bones associated with non-subsistence modification in Stratum 1a. There were 7 bones with evidence for non-subsistence based cultural modification associated with Stratum 1b. There was one slightly polished bird bone with a circular (non-carnivore associated) hole punched in the bone. There were a few fragments on polished bone absent the striations associated with carnivore digestive system and with a sheen typical of repeated use or handling. One large artiodactyl metacarpal appeared slightly polished from repeated handling which may have been used as a billet or hammer. A deer metacarpal (Figure 15-52) had been 
Table 15-14. Tool and other Cultural Modifications by Strata.

\begin{tabular}{|c|c|c|}
\hline $\begin{array}{l}\text { Stratum (Calibrated } \\
\text { Callendrical Dates) }\end{array}$ & Type of Cultural Modification & NISP \\
\hline $1 b \quad(A D$ 1440-1650) & Polished bone & 3 \\
\hline & Slightly polished bird bone with non-animal puncture/punch & 1 \\
\hline & Deer metacarpal awl/punch & 1 \\
\hline & Large artidactyl metacarpal billet/hammer & 1 \\
\hline & $\begin{array}{l}\text { Deer metacarpal with mid-shaft impact from } \\
\text { possible projectile point or other weapon }\end{array}$ & 1 \\
\hline & Subtotal & 7 \\
\hline \multirow[t]{10}{*}{ (AD 1405-1660) } & Polished bone & 7 \\
\hline & Bone with abraded edges from use-wear & 4 \\
\hline & Bison ulna expedient bone tool & 1 \\
\hline & Large mammal long bone expedient bone tool with abraded edge & 1 \\
\hline & Large mammal bone tool smoothed/polished trabecular surface & 1 \\
\hline & Bison tibia worn and chipped with black line (possible asphaltam) & 1 \\
\hline & Medium or larger mammal long bone gouged by tool & 1 \\
\hline & Bison humerus with birdshot impacts & 1 \\
\hline & Possible asphaltum drip on bone & 3 \\
\hline & Subtotal & 20 \\
\hline \multirow[t]{3}{*}{$3 \quad(A D$ 1654-1954) } & Bone polished with smooth edge, potential bead blank & 1 \\
\hline & Bison femur with multiple intentional asphaltum splatters & 1 \\
\hline & Subtotal & 2 \\
\hline TOTAL & & 28 \\
\hline
\end{tabular}

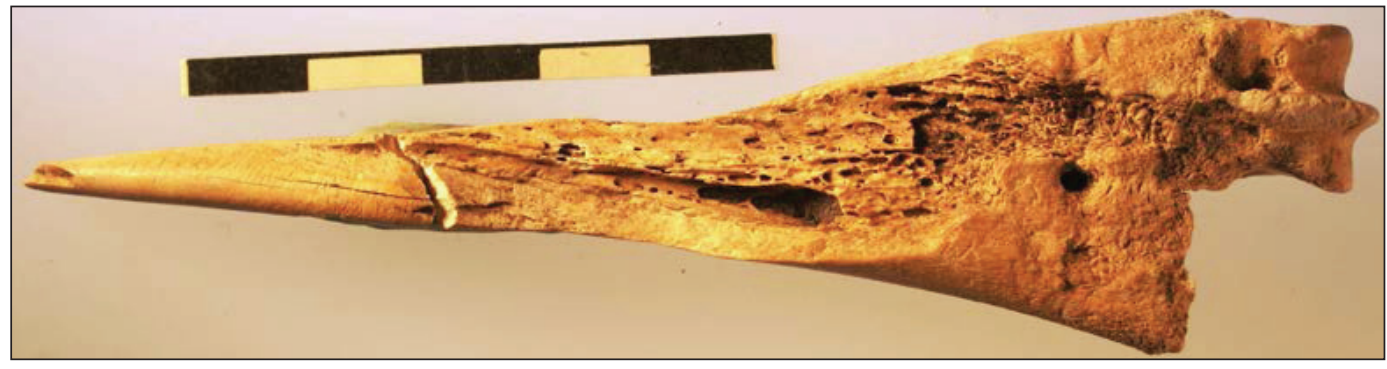

Figure 15-52. Stratum 1b (Field Lot \#390) Deer metacarpal awl/ punch. Note striations on tip and twist break.

modified substantially into an awl or punch. There were numerous striations along the bone near the tools point indicative of repetitive twisting or scraping. The tip of the tool had small pre-depositional chips absent as if broken during use. Another deer metacarpal had not been modified as a tool, but had a

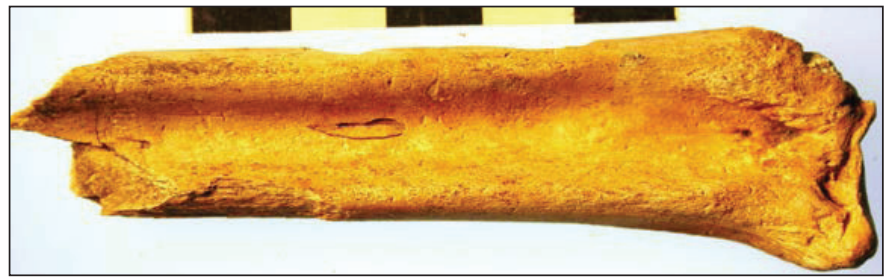

Figure 15-53. Stratum 1b (Field Lot \# 391) Deer metacarpal with impact break on posterior surface. perimortem impact fracture on its posterior surface consistent with impact from a projectile point (Figure 15-53). 


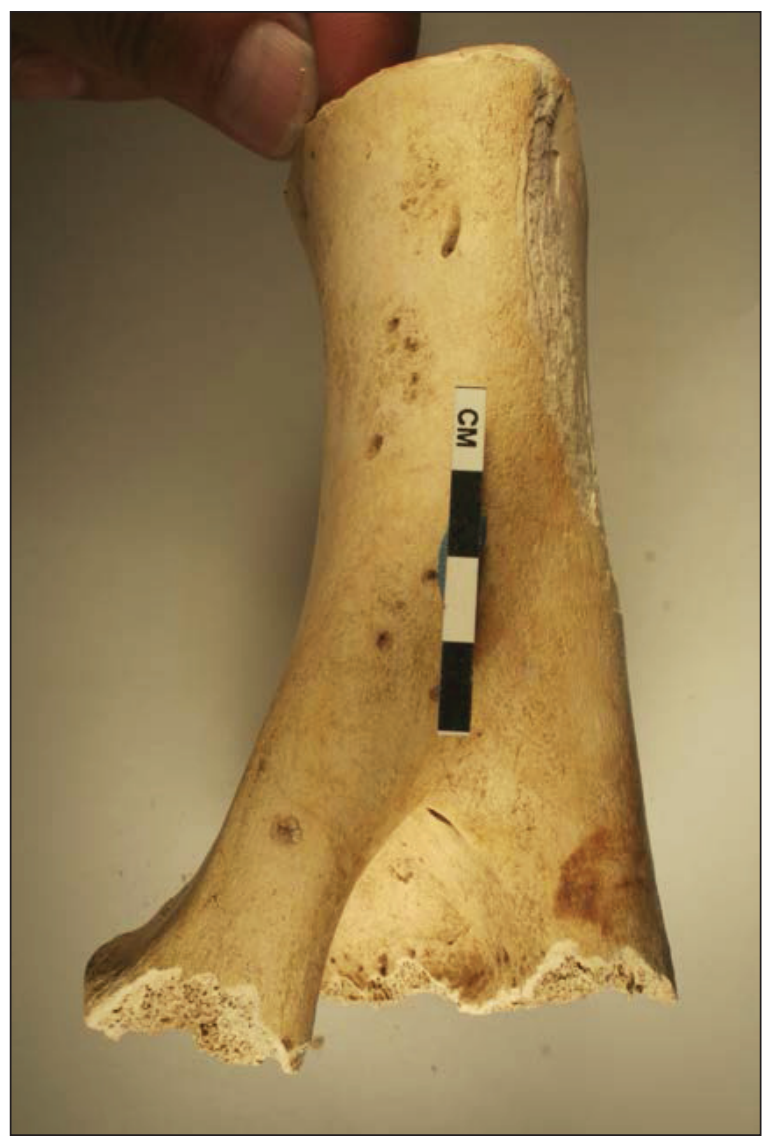

Figure 15-54. Stratum 2 (Field Lot \#303) Bison humerus with birdshot.

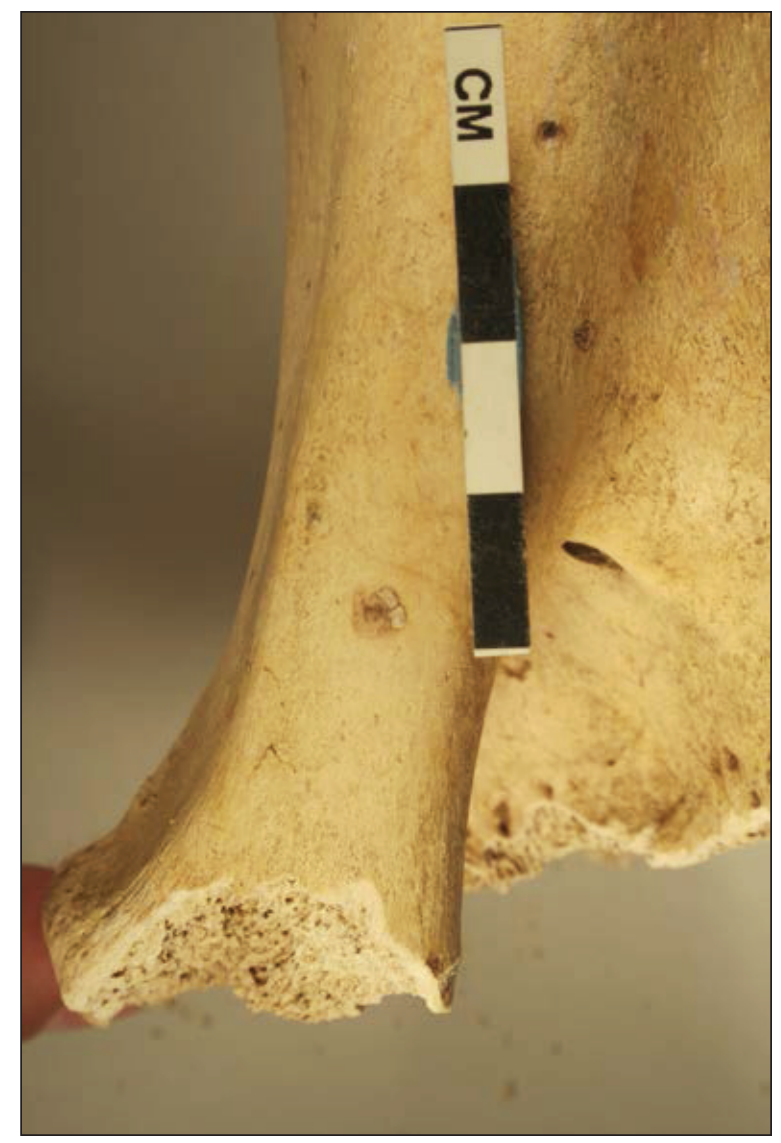

Figure 15-55. Stratum 2 (Field Lot \#303) bison humerus with birdshot, note impact.

Stratum 2 had the largest number of culturally modified bone not associated with butchering or food processing. The artifact of most note, however, is the previously mentioned bison humerus with evidence for birdshot (Figures 15-54 and 15-55). While early guns such as arquebuses and muskets (available and in use during the 16th century) were predominantly used with larger shot, they were designed such that they were frequently also used with smaller shot for hunting. Furthermore blunderbusses have been identified as early as the 1670s in Plymouth Colony and were typically used with bird shot and goose shot (PARP 2013).

Also noted in Stratum 2 were a variety of abraded expedient bone tools. Some of the bone tools seem more intentional and are similar in shape to stone tools such as the scraper in Figure 54. The edge to the right in the photograph is noticeably worn, but the edge along the top of the photograph has been worn as well. In general, the area around 41DL436 is a lithic poor area so bone would have been an easy and available resource during butchering or hide preparation. Figures 15-56 and 15-57 depict an expedient tool that was likely secondary to its original purpose. As noted in Figure 15-58, the ulna refits with a radius recovered from the same field lot. The break on the ulna lines up on the break with the radius which has been intentionally broken to remove the marrow. It is likely that the ulna fragment was used to aid in the removal, or digging out, of marrow from the radius. Once its sharp edge was worn and the tool no longer useful it was discarded along with radius. 
Figure 15-56. Stratum 2 (Field Lot\# 280) abraded long bone expedient tool.
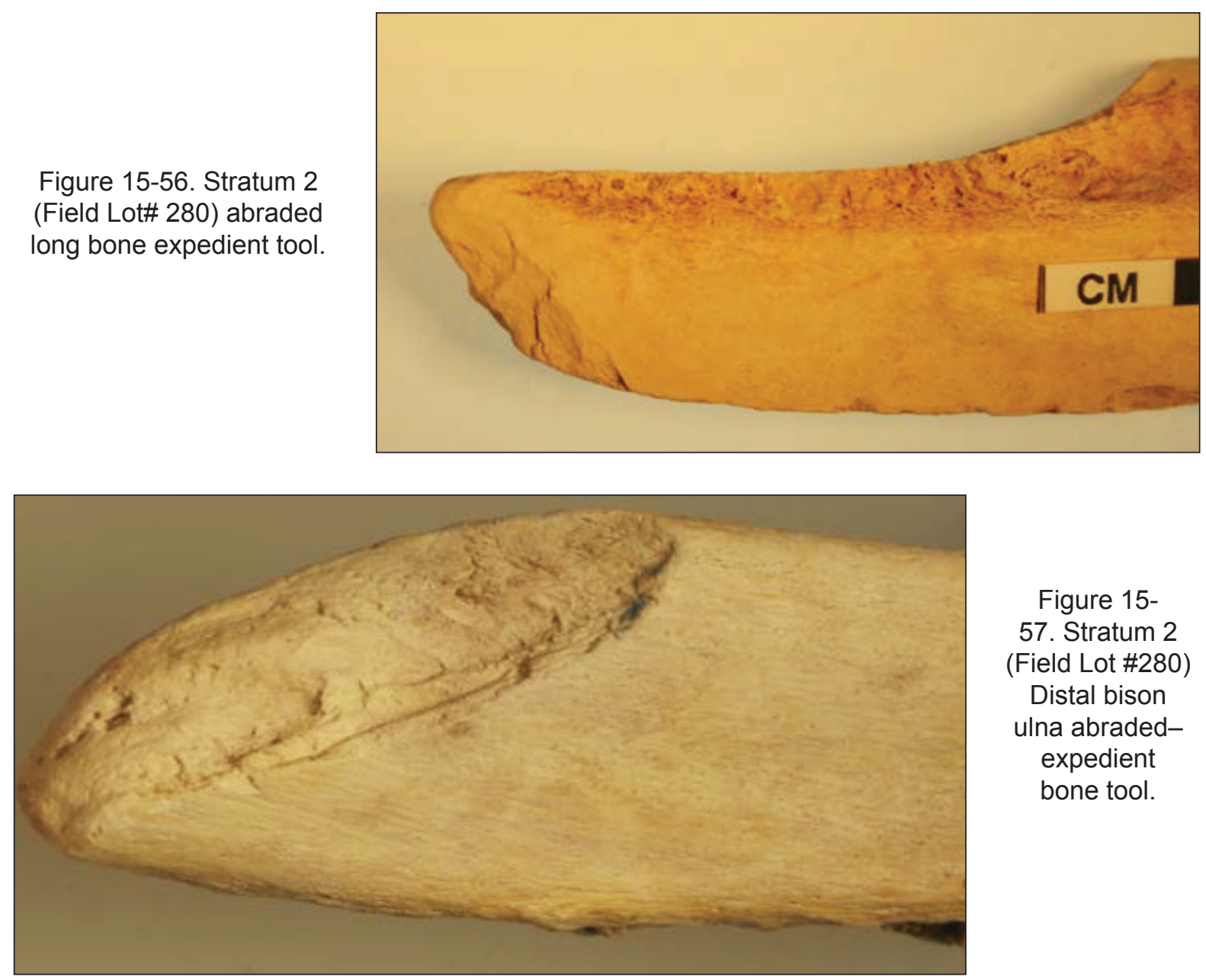

Figure 15-

57. Stratum 2

(Field Lot \#280)

Distal bison

ulna abraded-

expedient

bone tool.

Figure 15-58. Stratum 2 (Field Lot \# 280)

Distal bison ulna abraded-expedient bone tool from

Figure 57 articulated with bison radius recovered with same Field Lot.

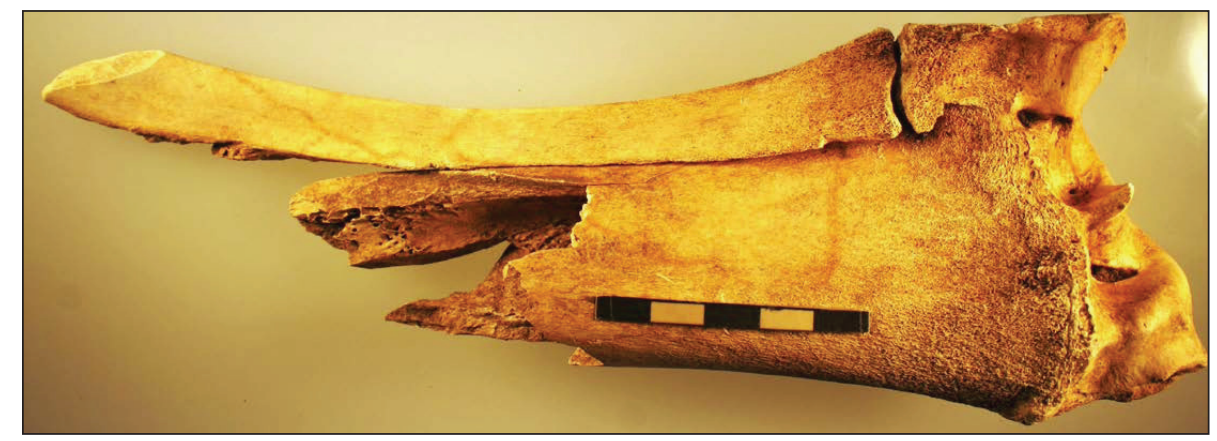

Stratum 3 only had a minimal presence of culturally modified bone not associated with butchery or food processing. There was one bird bone which had been slightly polished, smoothed and chopped and could have been intended as a bead. The second bone, a bison femur, had the only evidence for intentional decoration or art within the assemblage. There were numerous asphaltam splatters on the bone spidering out from a central point (Figures 15-59 and 15-60). The bone was decorated after it was processed for marrow as some of the asphaltum occurs over breaks and on the internal cortical surface of the bone. Asphaltum has been known to be used by Native Americans as a paint on pottery and as a glue on bone for hafting (TBH 2013b). 


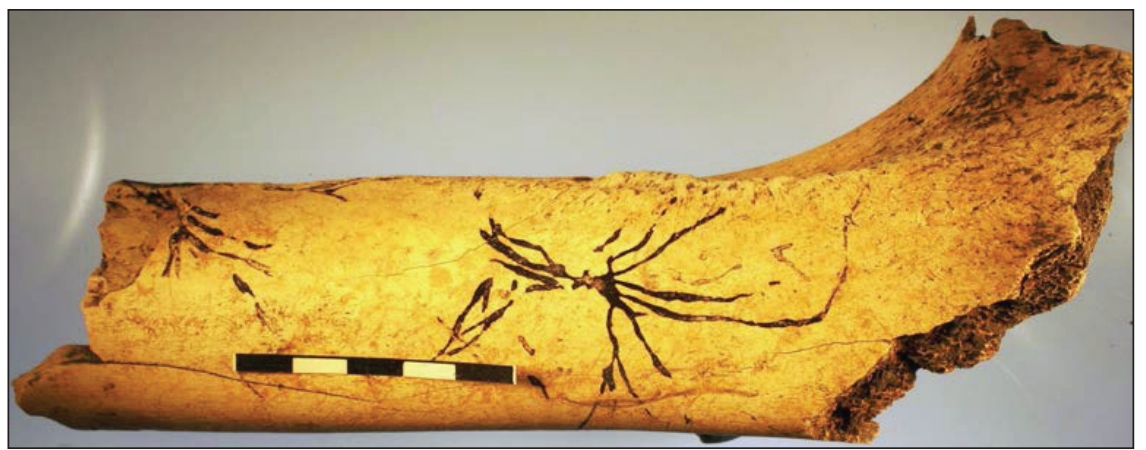

Figure 15-59. Stratum 3 (Field Lot \#1) Bison femur with intentional asphaltum splatter. Note splatter on far left overlaps on broken surface.

Figure 15-60. Stratum 3 (Field Lot \#1) close-up of Bison femur with intentional asphaltum splatter.

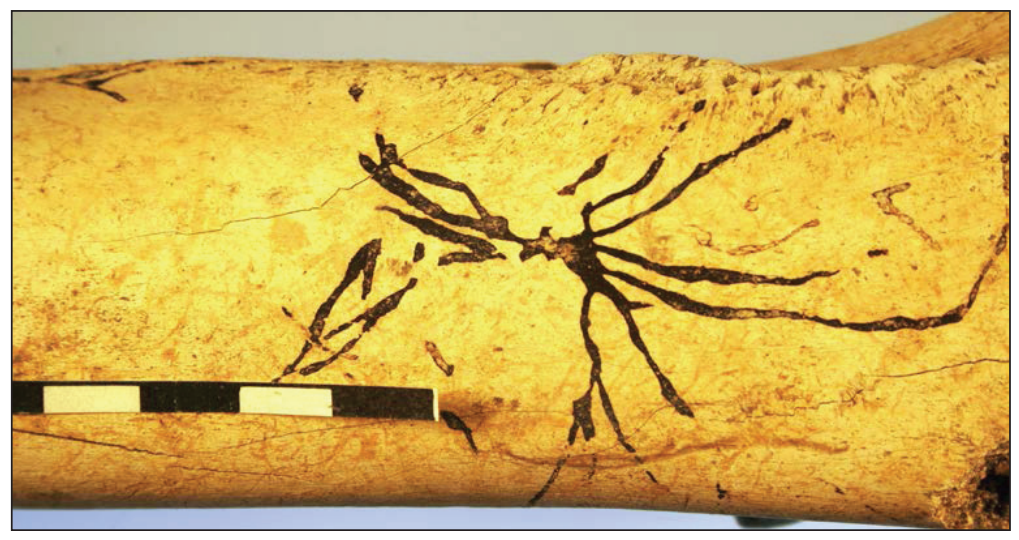

\section{Summary}

Overall, there was substantive evidence for culturally-associated modification of bone throughout all the strata (Table 15-15). There is enough cultural modification associated with each strata to determine that most, if not all, of the bone recovered from 41DL436 was culturally, rather than naturally deposited. During excavation the cultural versus natural association was in question given some large scale bone scatters. Much of the bone associated with those scatters had been intentionally broken for marrow processing or exhibited cut or chop marks from butchering.

Table 15-15. Direct Evidence (cut/chop/striking platform/tool/birdshot/etc.) and Indirect Evidence (Burning/Spiral Fractures) for Human Modification of Bone by Strata.

\begin{tabular}{ccccc}
\hline Stratum & Direct Cultural & Indirect Cultural & Total Cultural & Percent of Bone in Strata \\
\hline 1a & 5 & 98 & 103 & $11 \%$ \\
$1 \mathrm{~b}$ & 37 & 149 & 186 & $13 \%$ \\
2 & 149 & 654 & 803 & $19 \%$ \\
3 & 15 & 218 & 233 & $19 \%$ \\
\hline Total & 255 & 1119 & 1325 & $17 \%$ \\
\hline
\end{tabular}

\section{SECTION IV: SUMMARY}

Research questions posed prior to analysis included species presence, subsistence strategies, taphonomy, and cultural use of bone. The breadth of information presented thus far will be summarized with respect to these issues. 


\section{Species Presence}

Environmental conditions and species availability within the catchment area of the site altered over time. While predominantly aquatic environments with the presence of some grassland species, bison and bovid-presumed-bison presence was minimal in three of the four welldefined strata indicating a general lack within the area for those associated timeframes. Given the dominance of bison in the diet when available, this minimal presence is assumed to be an indication for limited availability and general small species presence within the region and site location specifically.

Creel, Scott and Collins (1990), Huebner (1991) and Lynott (1979) have documented the fluctuating presence and absence from sites in Texas. All three studies noted an increase in bison in Texas and the Southern Plains in general after AD 1300. Creel et al. (1990) noted shifts in bison presence at 41TG91 in Tom Green County within a similar setting as 41DL436. Site 41TG91 was located along the South Concho River in deep alluvial flood deposits with dates from circa $600 \mathrm{BC}$ to present. Stratum I at their site correlated to AD 1650 to present (equitable with Stratum 3 from 41DL436). Stratum II at 41TG91 dated from AD 1300-1650, (contemporaneous with Strata $1 \mathrm{~b}$ and 2 at 41DL436). Stratum III at 41TG91 dated from 100 BC to AD 1300, overlapping with Stratum 1a at 41DL436. Creel et al. noted an absence or minimal presence of bison in the pre AD1300 deposits. But there was a substantial presence of bison in both Stratum I and II dated between AD 1300 to approximately AD 1800.

At 41DL436 there is a very minor presence of bison in Late Prehistoric deposits associated with Stratum 1a (AD 1270-1445) and Stratum 1b (AD 1440-1650). These strata would overlap the AD 1300 date proposed by Lynott (1979), Creel et al., (1990) and Dillehay (1974) for an increased presence of bison and spread into Texas and the rest of the southern Plains, yet bison presence in proximity to 41DL436 would still have been minimal. Huebner (1991) proposes that it is the channels incision around 1000 B.P. associated with more xeric conditions, which allows for an increase in bison. Incising of stream banks can undercut tree roots and other forest vegetation leading to a collapse of banks. The incision of the creeks along with the xeric nature can lead to expanding grasslands. Eventually, incised creeks begin to degrade and banks collapse, leading to slow aggradation. It is interesting to note that the profile associated with the bank filling of Fish Creek occurred during Stratum 2 (AD 1405-1660). The channel modification may be a result of increasing xeric conditions. The decrease in woodland species presence from Stratum $1 \mathrm{~b}$ to their most negligible presence in Stratum 2 would be supportive of these environmental shifts.

Of additional note, is the higher NISP of pronghorn antelope bone associated with Stratum $1 \mathrm{~b}(\mathrm{n}=11)$ than Stratum $2(\mathrm{n}=1)$. While grassland species, pronghorn prefer shortgrass. Other shortgrass species such as the plover/sandpiper was noted in Stratum 1a and kangaroo rats in Stratum 1b. According to Knapp et al. (1999), while bison can survive in short grass, they really need mixed grass or tall grass prairies to thrive and proliferate. The decrease in short grass species between Strata $1 \mathrm{~b}$ and 2 along with the drastic increase in bison could be linked as well to a greater presence of mixed or tall grass prairie. 


\section{Subsistence Strategies}

All stratigraphic levels of the site had a significant inclusion of aquatic resources. White (1953) indicated that a box turtle would typically provide $0.7 \mathrm{lbs}$ of meat while an average mature female bison would provide $400 \mathrm{lbs}$. of meat. Given this, it would take 571 box turtles to equal the meat provided by one bison. Despite the high frequency of aquatic resources, the primary food resource based on available meat would be the artiodactyls present in the assemblage. Butchery patterns were well-defined and clear and have been presented in Section III. While there was a shift in need/actual marrow processing through time and variability with bone breakage, and more intentional breakage during the protohistoric (Strata $1 \mathrm{~b}$ and 2) than during the historic (Stratum 3) component, overall strategies for butchering remained the same except for the introduction of a metal knife. Overall bone at site is not indicative of a high degree of marrow processing (metapodials and phalanges had not been intentionally broken) and there is minimal to almost no direct evidence for bone grease. It is possible, however, that there was some grease processing associated with the historic context (Stratum 3). It would be difficult to identify because bone is so highly fragmented (smashed) during grease processing and discarded bone may be ladled out of the pots into the fire. Stratum 3 had a higher degree of unidentifiable highly fragmented bone and a much higher degree of burned, especially blackened bone, consistent with approximately 30 minutes of direct exposure to a campfire. If this is indicative of a higher level of processing, combined with the minimal presence of any bison bone, there may have been greater dietary stresses and less access to resources during the historic component than with the earlier protohistoric and Late Prehistoric associations.

Throughout Strata 1a, 1b, and 2 , there is enough of a presence of turtles and fish, to indicate that were other members of society gathering resources, instead of an all able-bodied stereotypical male hunting party. Furthermore, even Stratum 3 has a higher presence of fish with identified catfish in the assemblage. Fish, especially catfish is another easy resource for kids or the less physically able to help gather.

\section{Cultural vs. Non-Cultural Species Use}

Many species usually listed as commensal or intrusive due to Euro-centric views of acceptable food resources such as pocket gopher, rice rats, cotton rats, and lizards, small snakes, etc. were obviously used for subsistence based on direct (cut/chop) and indirect (burned) cultural modification of the bone. Therefore, most of the species documented are considered as potential subsistence resources. While it is likely that some of the smaller rodents such as marsh rice rats, cotton rats, harvest mouse, woodland voles, etc. were intrusive, there is direct evidence via coprolitic studies from other sites in Texas (Bryant 1974; Reinhard and Bryant 1992) along with direct cultural modification evidence on the bone from 41DL436 to indicate at least some of these species were consumed. 


\section{Chapter 16 \\ Cultural Components and \\ Features Analysis}

David L. Nickels

\section{$\underline{\text { INTRODUCTION }}$}

\section{Cultural Components}

For this discussion we use the term "stratum", which correlates to Abbott's allostratigraphic depositional "unit". For example, Stratum 1a is equivalent to Abbott's allostratigraphic depositional Unit 1a, and so on. The radiocarbon ages obtained from the excavations suggest a Late Prehistoric occupation within Stratum 1a, Protohistoric occupations within Strata 1b and 2, and an Historic occupation within the upper Stratum 3. In addition, the absence of metal cutmarks on Strata 1a faunal remains imply a pre-contact period, while metal cutmarks on fauna in the above three strata provided evidence for European contact. These are in addition to apparent birdshot-sized pellet markings from a firearm observed on a bison humerus in Stratum 2. A broken Gurrero-like arrow point recovered from the upper Stratum 3 component further argues for occupation of the site during the early Historic period. Notably, the NISP of metal tool cutmarks increases relative to a decrease in NISP of stone stool cutmarks through time. As Jodi Jacobson (Chapter 15) has stated "The cuts clearly demonstrate an increasing reliance on European-introduced technology over time." Jim Abbott (personal communication) opines that it is possible that metal knives became the primary tools and lithics were used as backup only.

Unlike most very late Late Prehistoric/Protohistoric components, no Native American ceramics, no Perdiz points, and only a scant few pieces of chipped stone were found in Stratum 1a at 41DL436. As discussed in Chapter 2, Europeans were known to have occasionally passed through the area in the late 1500s, and by about AD 1700 had begun settlements. Although it is not known for sure what Native American groups were in the area of 41DL436 in the 1500s through 1700s, it is possible that members of the Wichita Confederacy occupied the site in the earlier part of the Protohistoric period.

Subsequent occupants may have been either the Kichai, Ionis,, Tonkawa, Wichita, Taovayas, Tawakoni, Yscani, Waco, and Kichai. Later early Historic groups who may have temporarily occupied the site are the more mobile Comanche, Kiowa, and Lipan Apache (see further discussion in Chapter 2). It is unlikely that any of the more sedentary Plains Village groups occupied the site because they characteristically leave behind not only arrow points, but gun flints, bison hoes, native pottery items, metal knives, horse tack, shot, kettle fragments, trade beads, and various European ceramics. Conspicuously absent from the Protohistoric/Historic components in Strata 1b, 2, and 3 were ceramics, both ferrous and nonferrous metal objects, flaked glass, and other European produced items such as glass beads. 
We resume this chapter with a description of the 42 features and two unique items documented during the October 2010 excavations. They are separated by cultural components and strata, with six features and a unique item in the lower component (Stratum 1), 27 features in the middle component (Stratum 2), and nine features and one unique item in the upper component (Stratum 3). Next we present information regarding natural forest and range fires, as well as replication studies designed to distinguish between naturally occurring burns versus cultural hearths. Following that, in an attempt to sort out cultural hearths from natural burns, we rely on replication studies and Magnetic Soil Susceptibility values to analyze selected features at 41DL436.

Human activity patterning at 41DL436 is then addressed, followed by an attempt at modeling subsistence and mobility lifeways employing Optimal Foraging Theory's Diet-Breadth model. Our research of Late Prehistoric and Protohistoric/Historic components in Texas has yielded no clear evidence allowing for a distinct separation between the very late end of the Late Prehistoric Toyah manifestations and the early Protohistoric/Historic cultural assemblages. And, although we explore a few subtle differences at 41DL436, like all sites where a continuum of very late occupations occur, the specific time periods of occupations at 41DL436 become blurred. In that regard, we have elected to compare 41DL436 with nine high integrity components across the state, with ages comparable to those at 41DL436.

Finally, we interject here our recognition that the burning of old wood can indeed account for radiocarbon dates that are older than the actual use of hearths or the natural surface burns that have occurred. That said, we are presenting the following based upon the actual ages received from the charcoal present. For a detailed discussion on the "old wood" problem, see Abbott's Chapter 5.

\section{Lower Component - Stratum 1a}

\section{Introduction}

As shown in Figure 16-1, Stratum 1a generally lies between 170 and $200 \mathrm{~cm}$ below the modern ground surface, which equates to the lower cultural component at the site; but its depth varies considerably and dips sharply on the southern portion of the trench, where the natural stratigraphy follows the paleo channel of Fish Creek. A total of 27 levels within 18 excavation units were dug within Stratum 1a (Figure 16-2), resulting in the recovery of 46 pieces of firecracked rocks (FCR) greater than 1-inch in size, one piece of chipped stone, 88 identifiable mussel shells, 32 snails, an abundant amount of charcoal, and 872 pieces of animal bone. In addition, four features and a unique item were recorded; they are listed in Table 16-1, and are described below.

\section{Feature 5-Lower Component-Fire-cracked Rock Hearth}

Feature 5 is a basin-shaped, circular hearth with 69 pieces of fire-cracked rocks greater than 1-inch $(2.54 \mathrm{~cm})$ in length, mussel shells, burned clay, fauna, and heavy charcoal and 


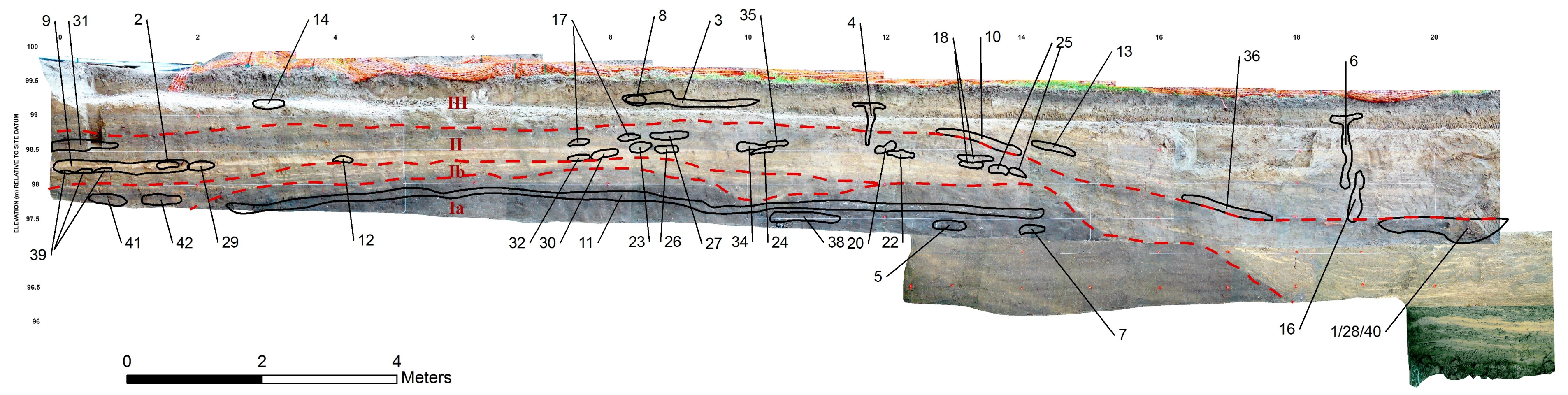

Figure 16-1. Photo mosaic of east wall profile showing strata and features. 
This page is intentionally left blank. 


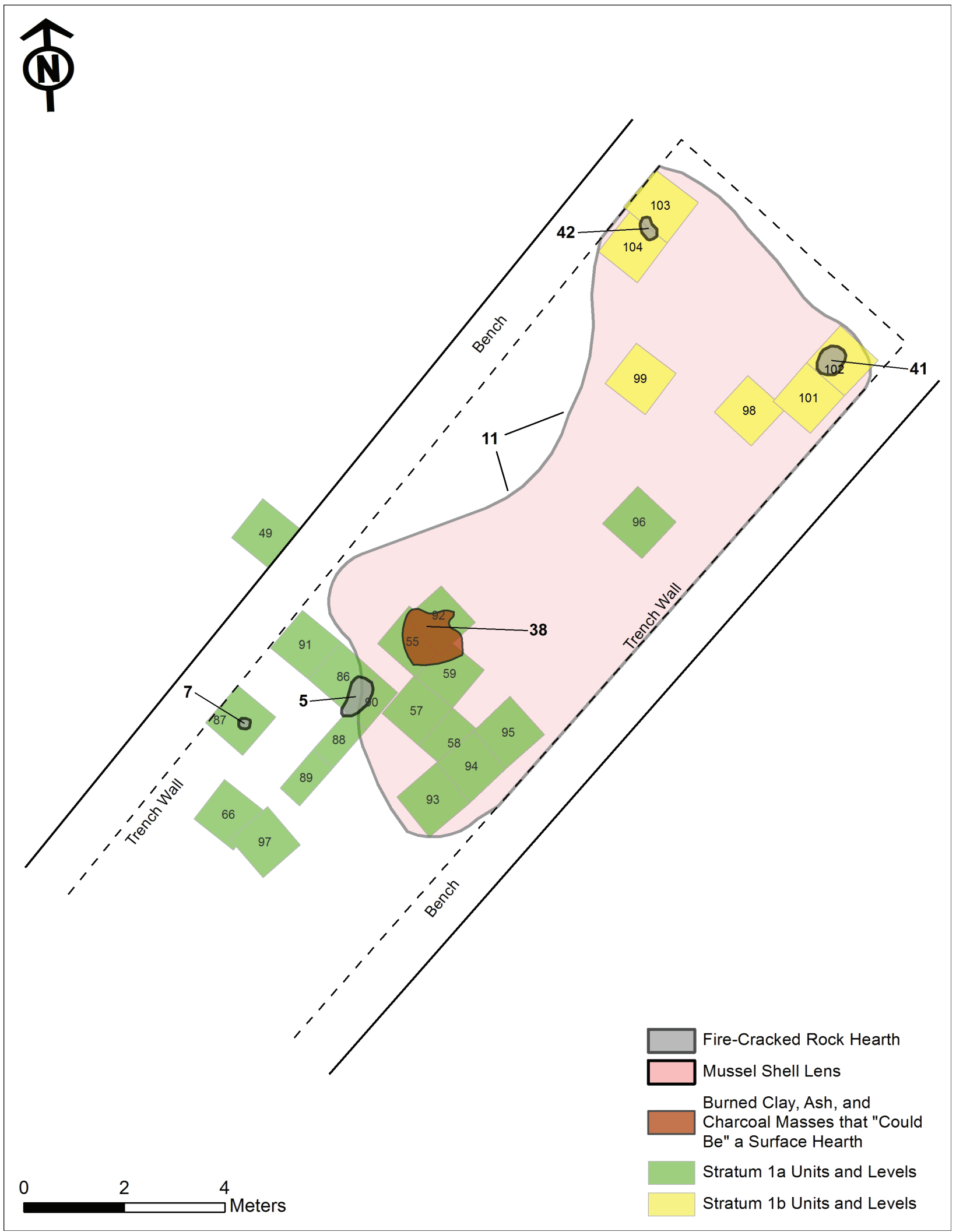

Figure 16-2. Planview of lower cultural component (Stratum 1) units and features. 
Table 16-1. List of Features and Radiocarbon Dates for the Lower Cultural Component (Strata 1a and 1b).

\begin{tabular}{lll}
\hline Feature \# & Description & Valid RC Dates (BP) \\
\hline $5(1 \mathrm{a})$ & Fire-cracked Rock Hearth & $580 \pm 25$ \\
\hline $7(1 \mathrm{a})$ & Fire-cracked Rock Hearth & $690 \pm 25$ \\
\hline $11(1 \mathrm{a})$ & Mussel Shell Lens & $550 \pm 25$ and $500 \pm 25$ \\
\hline $38(1 \mathrm{a})$ & Burned Clay, Ash, and Charcoal Mass & $570 \pm 25$ \\
\hline $41(1 \mathrm{~b})$ & Fire-cracked Rock Hearth & $360 \pm 25$ and $300 \pm 30$ \\
\hline $42(1 \mathrm{~b})$ & Fire-cracked Rock Hearth & $390 \pm 30$ \\
\hline$(1 \mathrm{a} / \mathrm{b})$ & Calcite Chunk & \\
\hline
\end{tabular}

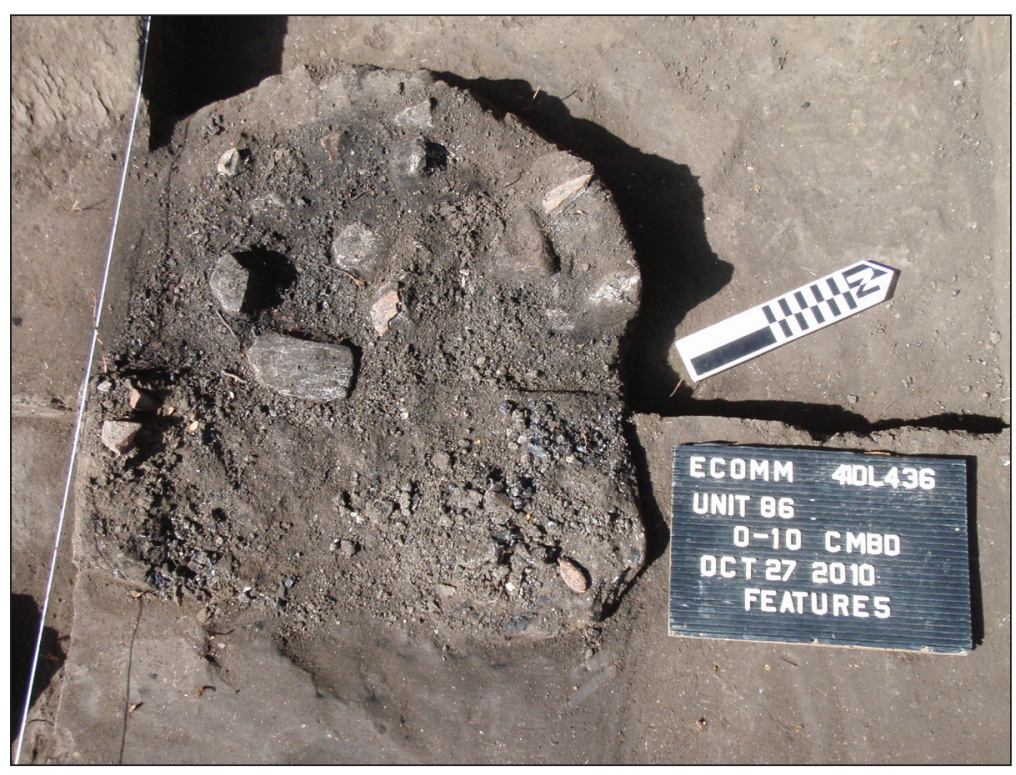

Figure 16-3. Feature 5.

carbon staining (Figures 16-3). All of the FCR was sandstone, except four were macrocrystalline calcite. Other material in close association included two smoothed stone fragments and a small piece of raw, unworked quartzite. The hearth was situated within a strata of dark brown (10YR $4 / 2$ ) clay loam between 160-170 cmbs, and was excavated in Units 86, 88, and 90 in Block 3.

A conventional radiocarbon age obtained from in situ charcoal suggests that this hearth was likely used sometime between AD 1304 and 1364, or perhaps between AD 1384 and 1414 (2 Sigma Calibrated Measured Radiocarbon Age $580 \pm 25$ BP-UGAMS \#8597).

Although four of the 69 FCR (Samples 12EC2-4 and 9) were submitted to Mary Malainey for analysis, insufficient evidence of fatty acids was found on any of the four to make positive identification. However, she was able to determine that plant and animal products were present, with plant products the apparent predominate, to include conifer.

Nine of the 69 pieces of FCR were submitted to Timothy Riley for starch and phytolith analysis. None of the samples contained starch granules. However, a total of 13 grass phytoliths were identified on four of the nine samples. Nine (Type A) were most likely bluestem (Andropogon sp.) and switchgrass (Panicum virgatum). The remaining four phytoliths (Type B) were most likely from dropseeds (Sporobolus sp.) and gramas (Bouteloua sp.). 


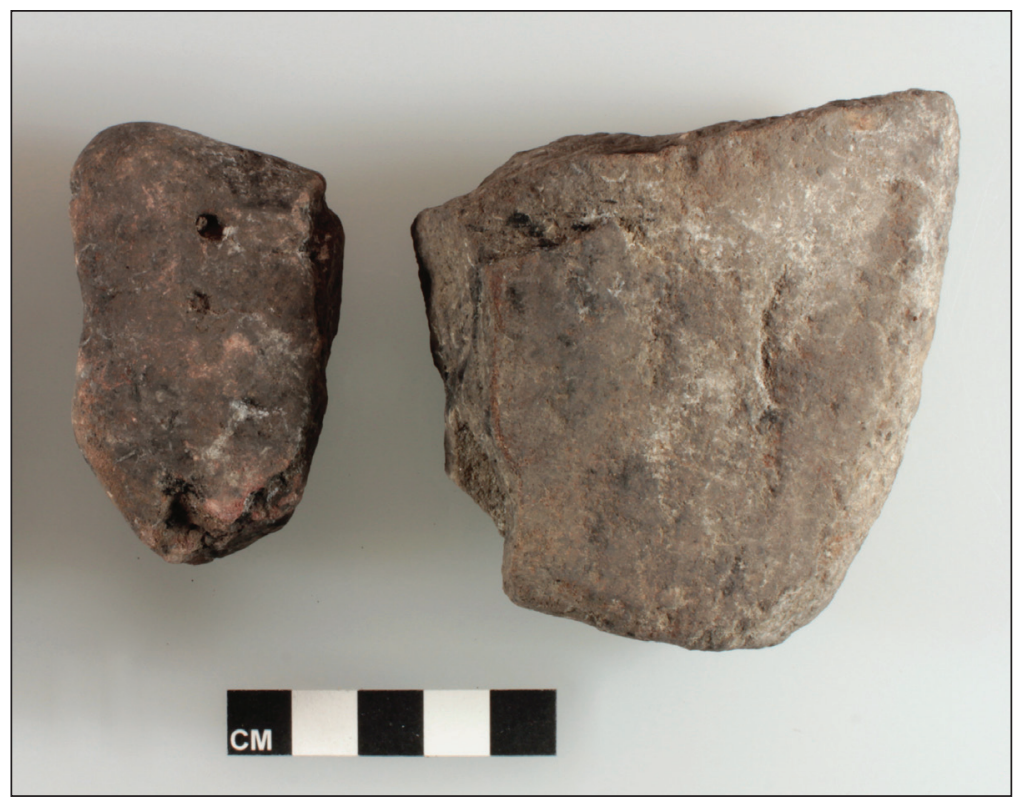

Figure 16-4. Smoothed sandstone within Feature 5.
The processing of seeds may be indicated by the discovery of two pieces of smoothed sandstone shown in Figure 16-4. Both are recycled smoothed stones used as heating elements in the hearth. Sample A has a smoothed dorsal surface only. Charcoal and calcium carbonates are evident on all faces. This second specimen measures $6.35 \mathrm{~cm}$ long $\mathrm{x}$ $4.10 \mathrm{~cm}$ wide $\mathrm{x} 3.09 \mathrm{~cm}$ thick. Sample B also exhibits smoothing on its dorsal surface. Charcoal stains are very visible on both its dorsal and ventral surfaces, as well as on its cracked facing. It measures $7.84 \mathrm{~cm}$ long x $7.18 \mathrm{~cm}$ wide $\mathrm{x} 4.25 \mathrm{~cm}$ thick.

A floatation sample comprising 31 liters of soil submitted to Phil Dering for analysis yielded pieces of charred hardwood, along with uncharred Hackberry nutlets $(n=7)$, cottonwood/willow $(n=25+)$, woody legume $(n=25+)$, elm $(n=25+)$, and rose family of wood $(n=24$; possibly Mexican plum, a variety of hawthorn).

Out of the 32 pieces of bone recovered in association with Feature 5, one vertebra is identified as from a pronghorn antelope, one scapula is from a deer/pronghorn, and one long bone is likely from a hare or rabbit. Otherwise, six fragments could be identified as parts of mediumlarge sized mammals, four fragments from mammals of an indeterminate size, one phalax from a microtene mammal, and 18 fragments from an unidentifiable vertebrate. Notably, the only evidence of burning or heating on any of these specimens was blackening on three of the vertebrate pieces.

Identifiable mussel remains associated with Feature 5 include Louisiana fatmucket (Lampsilis hydiana) and Lilliput (Toxolasma spp.). The Louisiana fatmucket is found throughout the Trinity River system, occurs in slow-flowing, soft-bottom creeks, and is sometimes washed into oxbow lakes. It was the most abundant species found during excavations at the site. The Lilliputs are pond and backwater species often associated with softer substrates and slow-tono-flow waters. These species were the second-most identified at the site.

In sum, this small hearth feature made up of predominantly sandstone slabs and chunks as heating elements, was used approximately 580 years BP and served as a foci for cooking a variety of wild game such as pronghorn and deer, and other medium-large sized mammal and vertebrates. The absence of clear burning on the larger bones suggest that perhaps the meat 
was de-boned and either boiled or jerked instead of being placed over the fire attached to the bone. In addition, the diet was likely supplemented with plant seeds ground on the smoothed, recycled sandstone fragments found within the hearth. As dietary supplements, mussels were likely gathered from the creek at a time when the flow was sluggish.

\section{Feature 7-Lower Component-Fire-cracked Rock Hearth}

Feature 7 is a small, oblong-shaped fire-cracked hearth located between 160-170 cmbs in dark brown (10YR 4/2) clay loam (Figure 16-5). Cultural material in association included mussel shells, faunal remains, and charcoal. It was uncovered in Unit 87, Block 3. All 14 pieces of FCR were tabular sandstone with heavy calcium carbonates on both dorsal and ventral surfaces.

Cultural material found in association included mussel shells, faunal material, and abundant charcoal. A conventional radiocarbon age obtained from in situ charcoal indicates that this hearth was likely used sometime between AD 1269 and 1307, or perhaps between AD 1362 and 1385 (2 Sigma Calibrated Measured Radiocarbon Age $690 \pm 25$ BP- UGAMS \#8598).

Three of the 14 FCR (Samples 11EC3, 12EC5, 12EC6) were submitted to Mary Malainey for lipid analysis. However, insufficient evidence of fatty acids was found on any of the three to make positive identification. Nevertheless in one of the three samples (11EC3), she was able to determine that plant products were present in one, while both plant and animal products were present in the other two, with plant products the apparent predominate, to include conifer.

Eight of the 14 pieces of FCR were submitted to Timothy Riley for starch and phytolith analysis. Two of the eight samples contained Type B starch granules similar to Little Barley (Hordeum pusillum), Type $\mathrm{C}$ granules likely from a seed or small hard fruit, and Type $\mathrm{D}$ granules that in this case could not be more clearly defined. None of the samples yielded evidence of phytoliths. A floatation sample comprising five liters of soil submitted to Phil Dering for analysis yielded only 19 pieces of uncharred cottonwood/willow.

Although eight mussel shell fragments were submitted to Bob Howells, they were so highly fragmented that none could be identified to the species level. Otherwise, a total of 89 pieces of bone were recovered in association with Feature 7. They include a radius of a deer age 2-4 months old, a humerus of a 2-4 month old deer that exhibited culturally induced cut marks, a scapula of a juvenile deer, what appears to be a pelvis from an immature deer or other

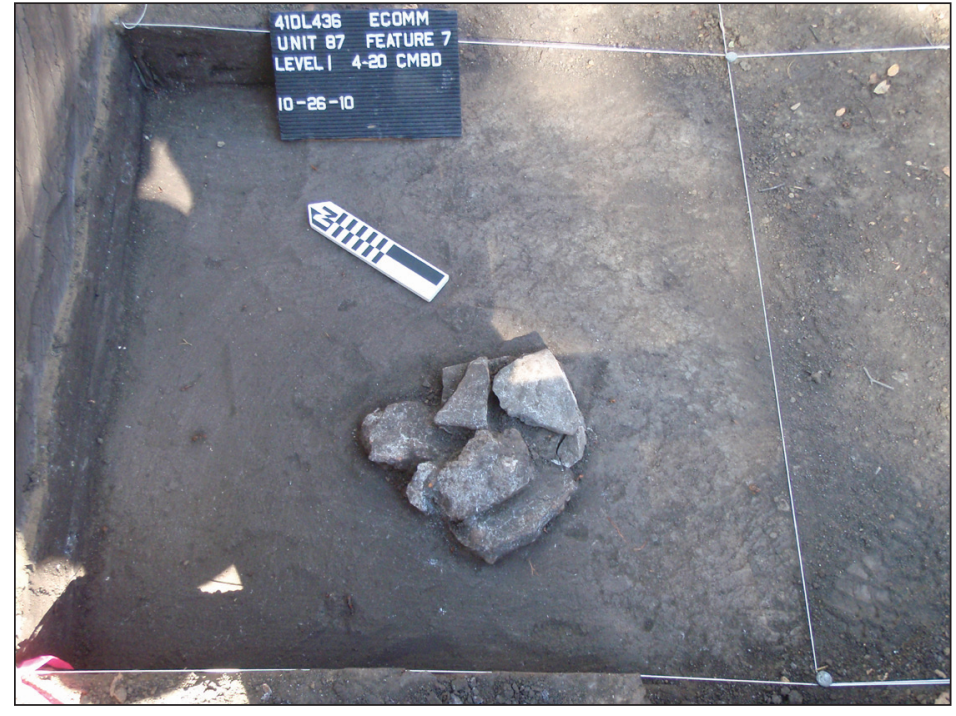

Figure 16-5. Photograph of Feature 7. 
small mammal, five unidentifiable mammal fragments, five pieces of a pond slider turtle, seven unidentifiable turtle fragments, one vertebra of a rat snake, and 67 other fragments of unidentifiable vertebrates. Notably, the only evidence of burning or heating on any of these specimens was blackening on 16 of the vertebrate pieces, and one of the pond slider pieces was browned.

In sum, this small hearth feature made up of relatively large sandstone slabs as heating elements, was used approximately 690 years BP, and served as a foci for cooking a variety of wild game such as deer, other medium-large sized mammals, turtles, and other vertebrates. The absence of clear burning on the bones suggest that perhaps the meat was de-boned and either boiled or jerked instead of being placed over the fire attached to the bone. In addition, the diet was likely supplemented with plants gathered in the immediate area. Other dietary supplements likely included mussels gathered from the creek.

\section{Feature 11-Lower Component-Mussel Shell Lens}

A thick and extensive mussel shell lens between 170-180 cmbs, slightly undulating and sloping toward the Fish Creek paleo-channel to the south, was designated as Feature 11. It covers an area roughly $6 \times 12 \mathrm{~m}$ within an occupation zone encapsuled by dark brown (10YR 3/3) clay loam (see east wall mosaic), and is stratigraphically co-eval with Features 5 and 6, two small fire-cracked rock hearth features, and Feature 38, an orange/blackened burn area in Unit 92. The entire zone is laced with charcoal, with the densest being in the area of Units 93-95. (Note: While much of this discussion of Feature 11 focuses on Units 94 and 95, the reader is encouraged to consider the likecontexts of Features 5 and 6).

Although the occupation zone appears to be only $5-7 \mathrm{~cm}$ thick, some mussel shells are sparsely scattered deeper within the clay loam strata. A sample of mussel shells was collected following each 2-4-cm Gradall scrape. Block 3 excavations were conducted to investigate this entire occupation zone, to include the mussel shell lens (see Figure 16-1). In addition, individual units were opened where concentrations of charcoal or bone were uncovered with the Gradall. Such was the case with Units 94 and 95 (Figures 16-6 and 16-7).

The first of two charcoal samples to be submitted for assay from Feature 11 contexts was collected in situ from Unit 95,

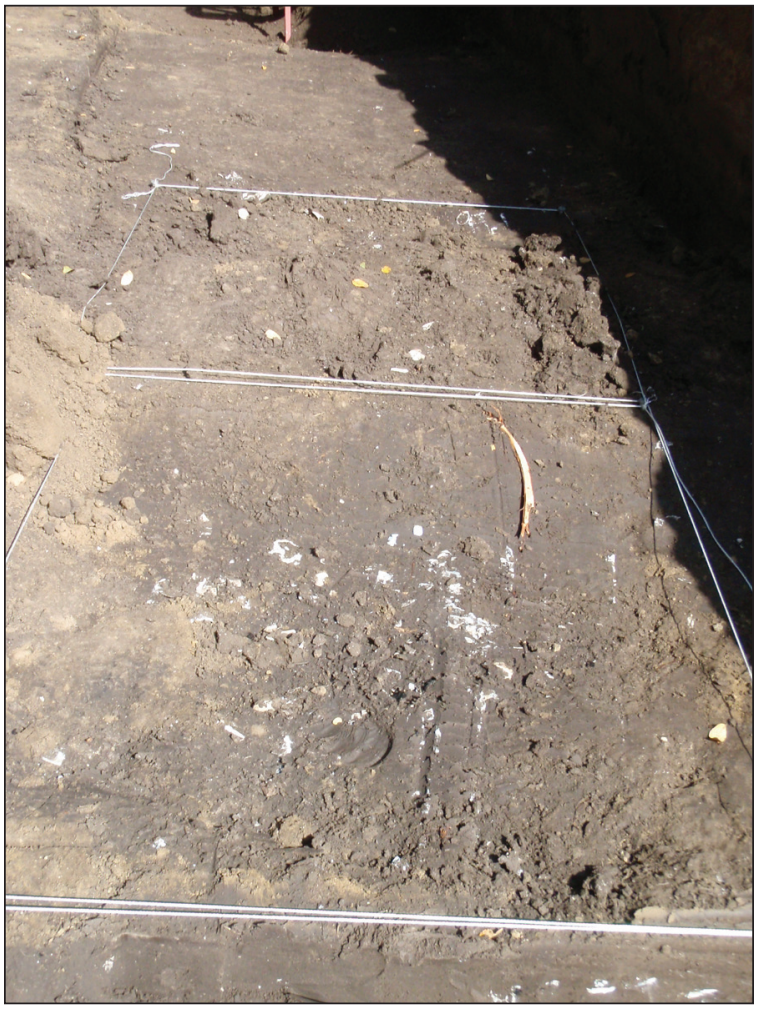

Figure 16-6. Feature 11 in Unit 95, Level 2; Unit 94 in foreground, Unit 95 in background, prior to beginning excavations; facing north. 
Level 2. It yielded a conventional radiocarbon age between $\mathrm{AD} 1416$ and 1435-as well as between AD 1406 and 1444 (2 Sigma Calibrated Measured Radiocarbon Age $500 \pm 25$ BP-UGAMS \#8601).

The second in situ charcoal sample was collected from Unit 94, Level 1, yielding a conventional radiocarbon age between AD 1317 and 1354, as well as between AD 1389 and 1430 (2 Sigma Calibrated Measured Radiocarbon Age $550 \pm 25$ BPUGAMS \#8602).

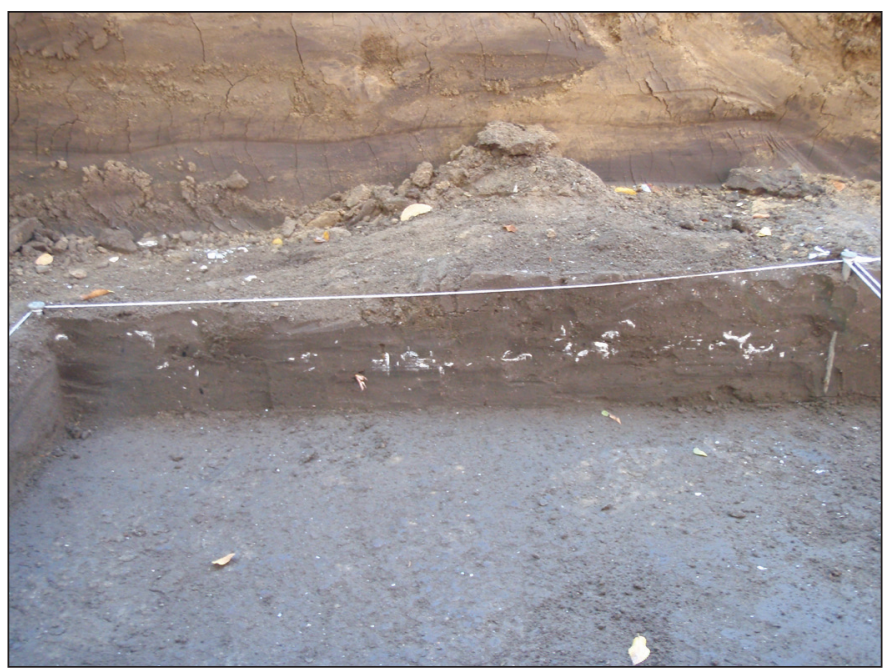

Figure 16-7. Feature 11 - Mussel shell lens in east wall of Units 94 and 95.

While relatively few Rabdotus shells were found and collected, mussel shells were collected in abundance. While the Gradall scraped the roughly $6 \times 12-\mathrm{m}$ surface, archaeologists collected a representative sample; these, as well as those collected from excavation units were submitted to Bob Howells for analysis. For a detailed discussion of the mussel shell remains and their implication as subsistence items and paleonvironmental indicators, the reader is referred to Chapters 7 and 8 . Suffice it to say here that although none of the specimens from Feature 11 revealed evidence of heating, burning, shape modification, or other human influence, that is not to say that mussels were not exploited for human consumption. The sheer abundance in concentrations across a constrained area in association with hearth features and faunal remains argues that they were indeed very much a part of the human diet at the time.

As mentioned above, fire-cracked rock Features 5 and 6 are stratigraphically co-eval with the mussel shell lens designated as Feature 11. However, only three other isolated sandstone FCR pieces were found; these being within Units 94 and 95. Faunal remains recovered from Units 94 and 95 include one metapodial from a deer, two fragments from a medium-large mammal, and 20 fragments from unidentifiable vertebrata (four of which were blackened).

In sum, the attributes and contexts of this mussel shell lens argue that mussels were being exploited from a slow-moving Fish Creek roughly 500-550 B.P. They were likely a supplementary part of the diet that also included game animals as well as grass seeds (see discussion of Features 5 and 7).

\section{Feature 38-Lower Component-Ash, Charcoal, and Burned Clay Mass}

Feature 38 is an irregularly shaped mass of burned clay, charcoal, and ash covering an area roughly $1 \mathrm{~m}$ in size (Figures 16-8 and 16-9). It was discovered in Unit 92, Level 1, approximately 175-185 cmbs in a dark brown clay loam strata. Dense calcium carbonates were present throughout the surrounding soil, and mussel shells were observed at the base of the feature. It was 


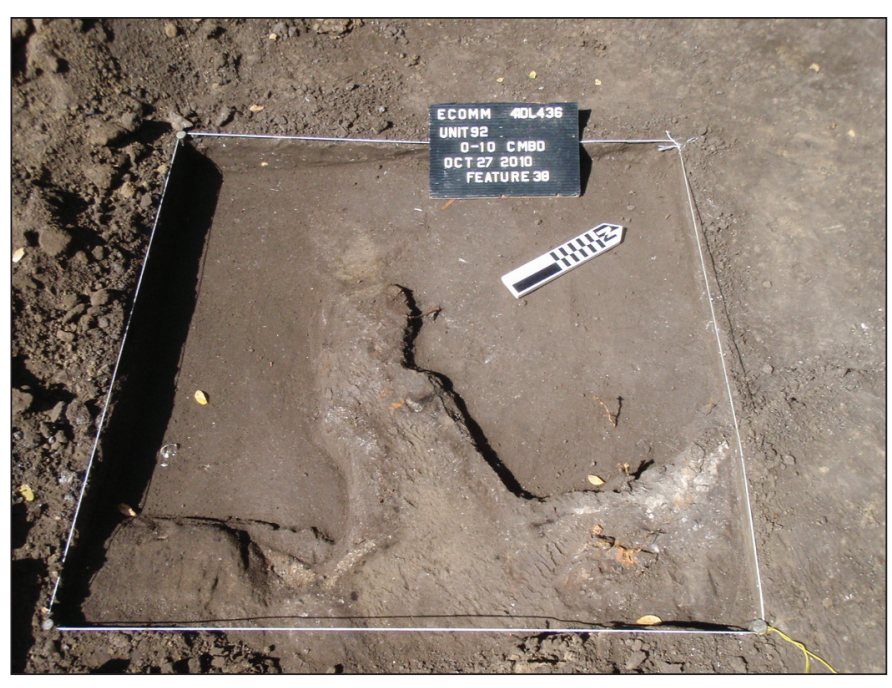

Figure 16-8. Photograph of Feature 38. discovered on the last day of allotted field time for the excavations, and thus was only documented in Unit 92. Our observations at the time were that the burned area undoubtedly extended to the south and southeast outside of Unit 92, but also along the same dark brown clay loam surface. In any case, we believe that sufficient data was obtained within Unit 92 so to properly place the feature within the lower cultural component, and depositional strata 1a.

A conventional radiocarbon age obtained from in situ charcoal indicates that the burn likely occurred sometime between AD

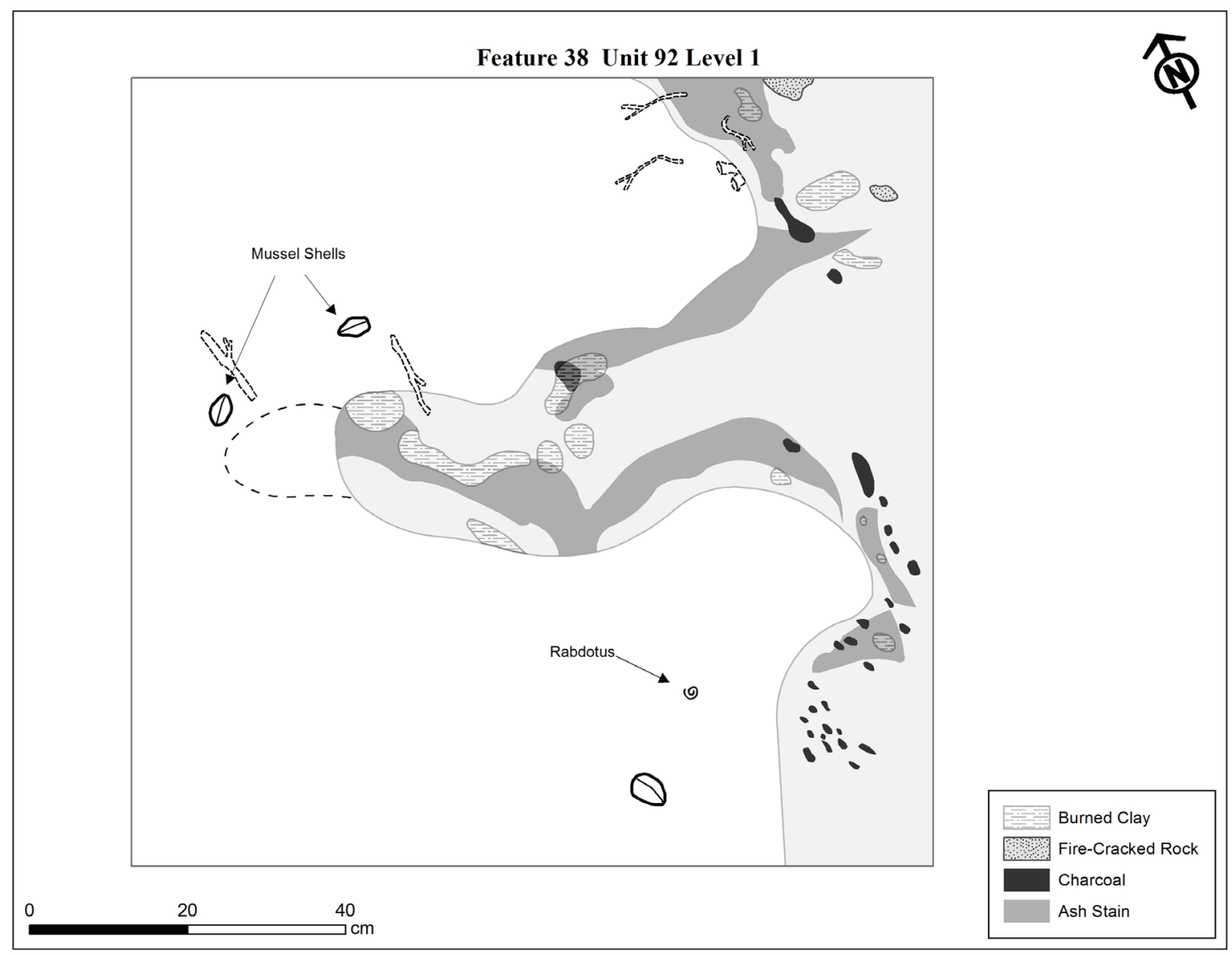

Figure 16-9. Planview of Feature 38, Unit 92, Level 1. 
1308 and 1361 or between AD 1386 and 1419 (2 Sigma Calibrated Measured Radiocarbon Age $570 \pm 25$ BP-UGAMS 8611).

A floatation sample from the feature yielded a handful of Rabdotus shell fragments and charcoal flecks. Materials recovered from the $1 / 4$-inch screen excavations included five fragments from one or more Louisiana fatmuckets (Lampsilis hydiana), a mussel that thrives in slow flowing, soft bottom creeks and oxbow lakes. In addition, Jodi Jacobsen analyzed the 52 pieces of faunal remains recovered from Level 1 (Table 6-2).

Table 16-2. Faunal Remains from Feature 38.

\begin{tabular}{llll}
\hline Class & Common Name & Specimens & Description \\
\hline Mammal, Very Small & Vole & 1 & Tooth \\
\hline Mammal, Very Small & Rodent & 4 & $\begin{array}{l}\text { Rib, Tibia, Phalanx, } \\
\text { Vertebra }\end{array}$ \\
\hline Mammal, Medium-Large & Unidentifiable & 1 & Long Bone Fragment \\
\hline Reptile, Small & Non-Venomous Snake & 1 & Vertebra \\
\hline Reptile, Microtine & Lizard & 1 & Vertebra \\
\hline Reptile, Medium & Turtle & 2 & Fragments \\
\hline Vertebrate & Unidentifiable & 42 & Fragments(a) \\
\hline
\end{tabular}

(a) 18 are either browned, blackened, or calcined from burning

Without conclusive evidence that suggests that this burn was induced by humans, our initial assessment is that Feature 38 was likely a natural and potentially extensive surface burn that occurred sometime between AD 1308 and 1419. However, without further evidence, we cannot rule this feature out as a 'possible' surface hearth.

\section{Lower Component - Stratum 1B}

\section{Introduction}

As shown in Figure 16-1, Stratum 1b generally lies between 170 and 200 $\mathrm{cm}$ below the modern ground surface, which equates to the lower cultural component at the site; but its depth varies considerably and dips sharply on the southern portion of the trench, where the natural stratigraphy follows the paleo channel of Fish Creek. A total of seven levels within six excavation units were dug within Stratum 1b (Figure 16-2), resulting in the recovery of 40 pieces of fire-cracked rocks (FCR) greater than 1-inch in size, one piece of chipped stone, 44 identifiable mussel shells, nine whole snails, an abundant amount of charcoal, and 1,238 pieces of animal bone. In addition, two features and a unique item were recorded; they are listed in Table 16-3. 


\section{Feature 41 - Lower \\ Component - Fire-cracked Rock Hearth}

This slightly basin-shaped firecracked sandstone hearth was uncovered in Unit 102, Level 1, between 175-190 cmbs, within a dark brown clay loam strata (Figures 16-10 and 16-11). Faunal remains and abundant charcoal were found in direct association, as were fragmented pieces of quartzite. Additional pieces of fire-cracked rocks were observed extending into

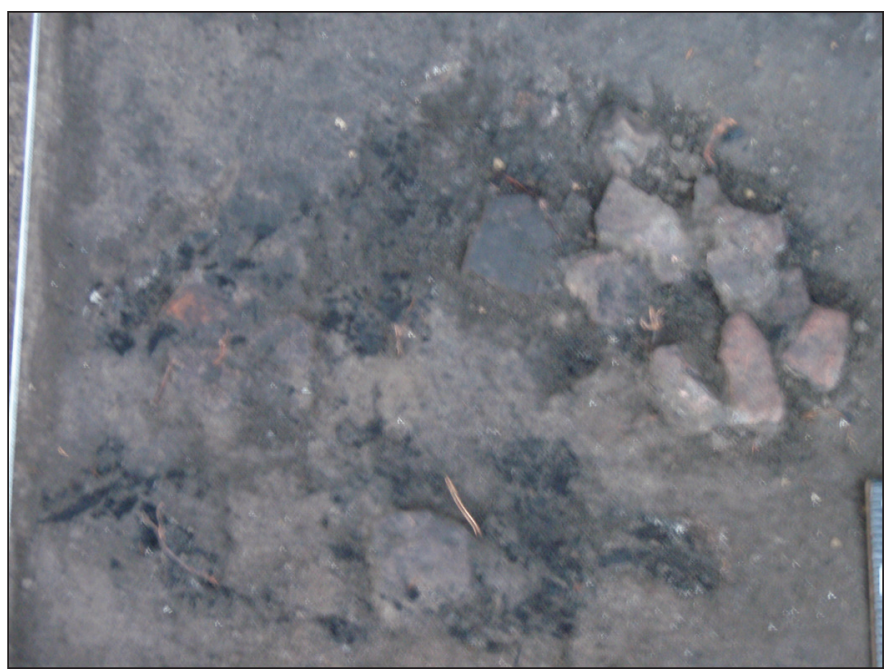

Figure 16-10. Photograph of Feature 41. the north wall and northwest corner of the unit. Numerous mussel shell fragments were also observed extending into the east wall at this same level. Charcoal that was recovered came predominately from either inside the hearth or immediately around it.

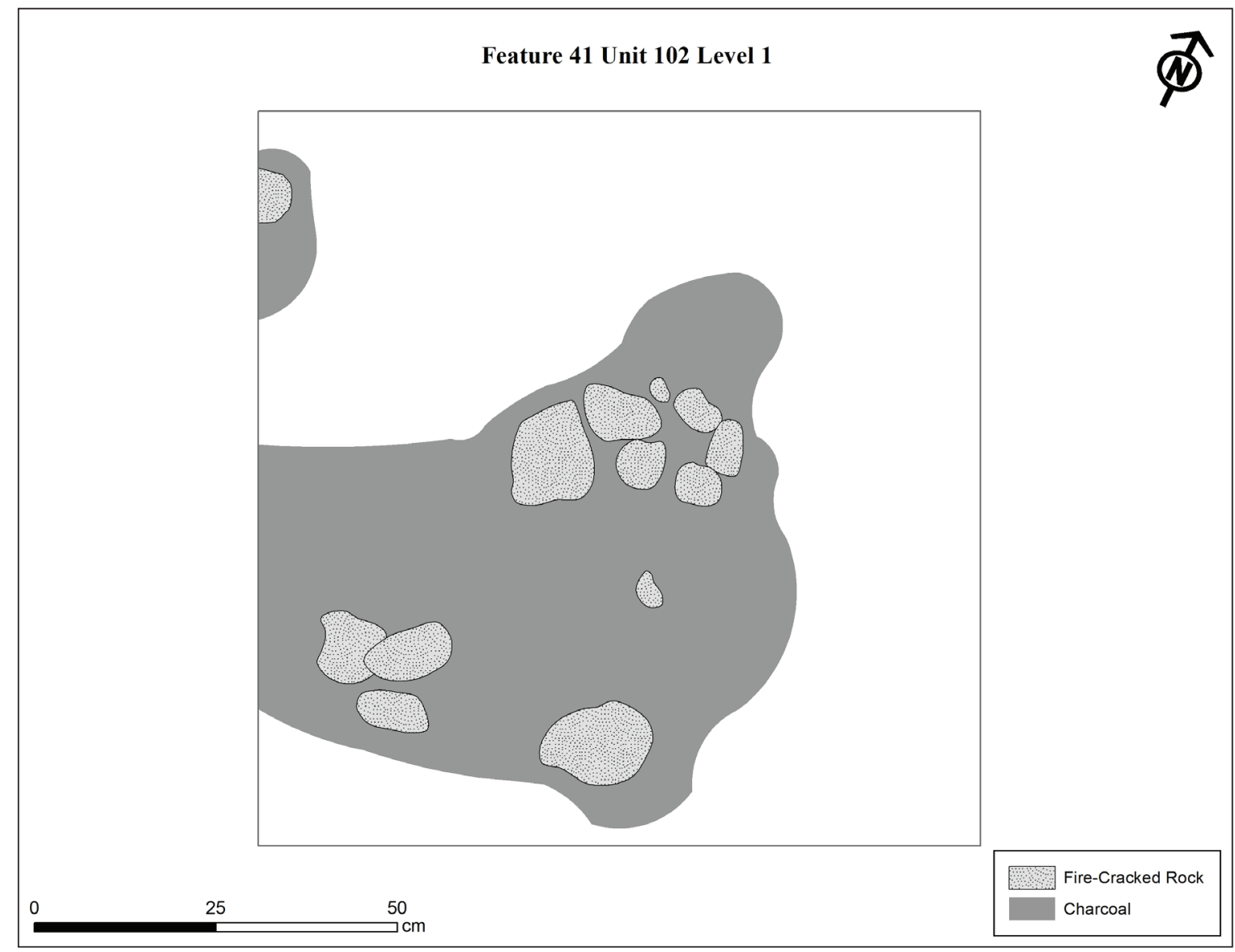

Figure 16-11. Planview of Feature 41. 
A few snails (not analyzed, but curated) and charcoal chunks and flecks were recovered from the floatation sample. From the 1/4-inch screen archaeologists recovered seven unidentifiable mussel shell fragments and shells from two yellow sandshell mussels (Lampsilis teres) that follow flood waters over inundated terrestial areas and thrive in sandy bottoms and soft substrates. A total of 28 pieces of heated sandstone comprised the heating elements in the hearth; none were selected for starches or lipid analysis. Faunal remains are listed in Table $16-4$.

Table 16-4. Faunal Remains from Feature 41.

\begin{tabular}{llll}
\hline \multicolumn{1}{c}{ Class } & \multicolumn{1}{c}{ Common Name } & Specimens & \multicolumn{1}{c}{ Description } \\
\hline Aves, Medium & Bird & 2 & Synacrum fragments \\
\hline Aves, Medium & Possibly Red-Tailed Hawk & 2 & Vertebral segment (a) \\
\hline Aves & Unidentifiable & 2 & Fragments \\
\hline Mammal, Large & Cow/Bison & 1 & Metatarsal (b) \\
\hline Mammal, Large & Probable Bison & 1 & Horn core fragment \\
\hline Mammal, Medium or Larger & Unidentifiable & 1 & Long bone (c) \\
\hline Mammal, Medium-Large & Probably Mule Deer & 1 & Tibia (d) \\
\hline Mammal, Medium-Large & Deer & 1 & Phalanx (e) \\
\hline Mammal, Medium-Large & Deer & 2 & Cranial \\
\hline Mammal, Medium-Large & White-tailed Deer & 1 & Metacarpal (f) \\
\hline Mammal, Medium-Large & Unidentifiable & 1 & Long Bone \\
\hline Mammal, Medium-Large & Unidentifiable & 1 & Velveted antler \\
\hline Mammal, Medium-Large & Unidentifiable & 1 & Long bone (g) \\
\hline Mammal, Medium-Large & Hooved animal & 1 & Phalanx (h) \\
\hline Mammal, Medium-Large & Unidentifiable & 15 & Fragments \\
\hline Reptile, Medium & Pond/Water Turtle & 8 & Carapace (i) \\
\hline Vertebrate & Unidentifiable & 41 & Fragments \\
\hline
\end{tabular}

(a) Cut marks

(b) Neonate, six months old; exhibits striking point for marrow extraction

(c) Juvenile

(d) Approximately two years old

(e) Juvenile, <two years old

(f) Possible impact from spear or arrow

(g) Burning (blackening) on tip overlays spiral fracture; five possible defleshing cutmarks

(h) Juvenile

(i) One browned from burning

A floatation sample comprising 4.5 liters of soil submitted to Phil Dering for analysis yielded 11 pieces of uncharred elm wood, 10 pieces of charred hardwoods, and 9 pieces of uncharred cottonwood/willow.

Two charcoal samples were submitted for assay from this feature. The first conventional radiocarbon date came from in situ charcoal indicating that the hearth was probably used sometime between AD 1489 and 1604 or between AD 1650 (2 Sigma Calibrated Radiocarbon age $300 \pm 30$ BP-Beta 312834).

The second conventional radiocarbon date was obtained from charcoal retrieved in a floatation sample from Unit 100 indicates that the hearth was likely fired sometime between AD 1452 
and 1527 or between AD 1553 and 1633 (2 Sigma Calibrated Measured Radiocarbon Age $360 \pm 25$ BP-UGAMS 8614). Notably, these are the exact same dates as those obtained from Feature 40, described below as a naturally burned toppled tree and root. 1) A third set of dates was obtained from deer bone collagen (Table 5-2 and Appendix I). The radiocarbon age was $347 \pm 25 \mathrm{BP}$, with calibrated ages of AD 1465-1831 and 1539-1635 (DAMS-5761).

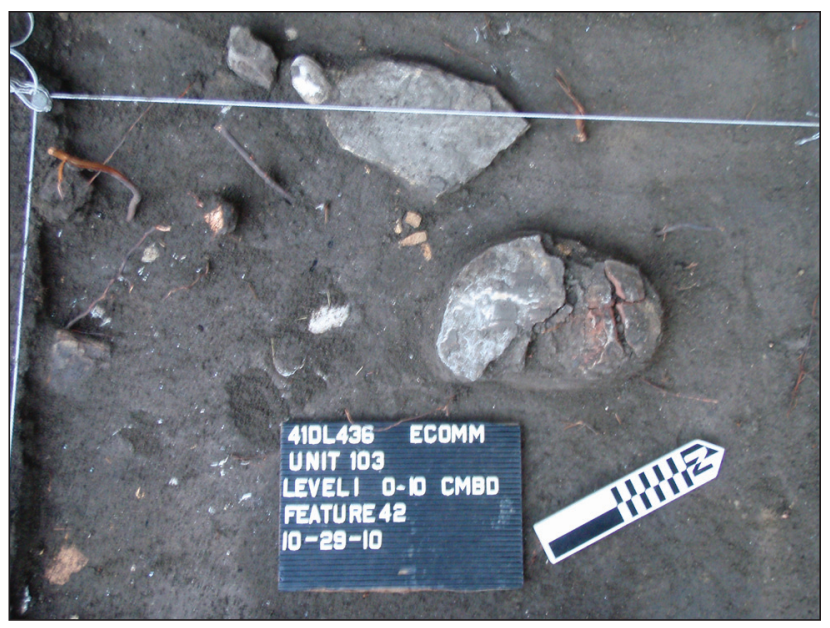

Figure 16-12. Photograph Feature 42, Unit 103.

\section{Feature 42-Lower Component- Fire-cracked Rock Hearth}

Feature 42 is a fire-cracked sandstone hearth uncovered between 180-190 cmbs in Level 1, Unit 103, in homogeneous dark grayish brown (10YR 4/2) clay loam (Figures 16-12 and 16-13). Presumably cultural material found in direct association with the hearth included burned clay, faunal remains, charcoal, and several whole and mussel shells fragments.

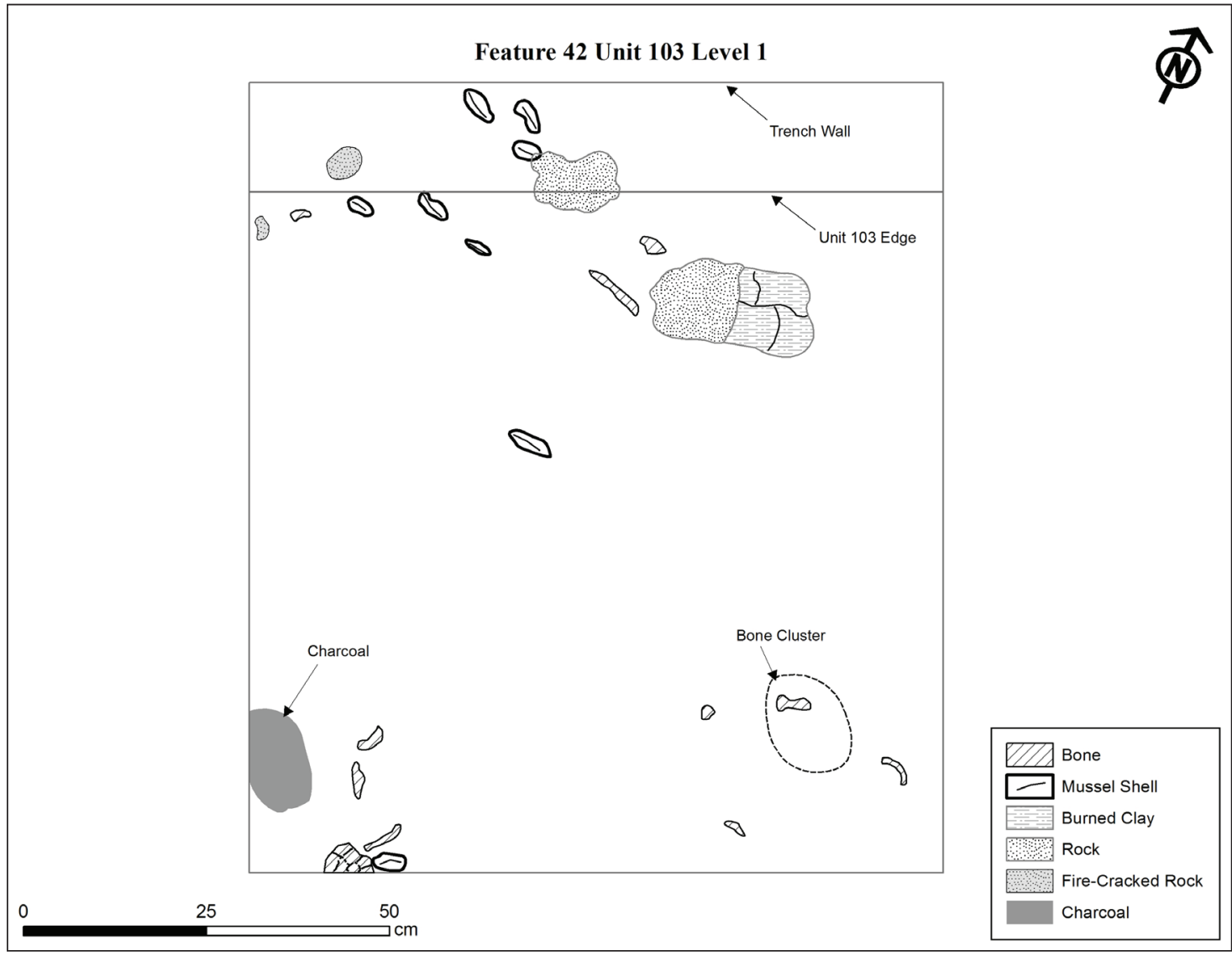

Figure 16-13. Planview of Feature 42 in Unit 103, Level 1. 
Although a conventional radiocarbon date of $800 \pm 25$ BP (2 Sigma Calibrated Measured Radiocarbon Age-UGAMS 8615) was obtained from charcoal retrieved in situ from the hearth, the date is rejected based upon stratigraphy. A subsequent bone date of $390 \pm 30$ was obtained (Beta 315860), 2) and another radiocarbon date was obtained on deer bone collagen (Table 5-2 and Appendix I), that being $469 \pm 31$ BP, with a calibrated age of AD1409-1460 (DAMS-5770). Charcoal flecks, very small mussel shell fragments, and a few snails (not

Table 16-5. Faunal Remains from Feature 42.

\begin{tabular}{|c|c|c|c|}
\hline Class & Common Name & \# Pieces & Description \\
\hline Aves, Large & Goose & 1 & Diaphysis (a) \\
\hline Aves, Large & Bird & 1 & Long Bone (b) \\
\hline Aves, Medium & Possibly Red-Tailed Hawk & 1 & Humerus \\
\hline Aves, Medium/Large & Unidentifiable & 1 & Long Bone (c) \\
\hline Mammal, Large & Bison/Cow & 1 & Pelvis (d) \\
\hline Mammal, Large & Hooved Animal & 2 & Rib, Long Bone (e) \\
\hline Mammal, Medium-Large & Deer & 1 & Mandible (f) \\
\hline Mammal, Medium-Large & Deer & 1 & Tibia (g) \\
\hline Mammal, Medium-Large & Deer & 1 & Phalanx \\
\hline Mammal, Medium-Large & Deer & 1 & Metacarpal (h) \\
\hline Mammal, Medium-Large & Deer/Antelope & 22 & Ribs, Vertebrae, Metatarsals, Calcaneus, Scapula (i) \\
\hline Mammal, Medium-Large & Pronghorn Antelope & 8 & Cranial, Radius, Ulna, metacarpal, metatarsal, tarsal, tooth (j) \\
\hline Mammal, Medium-Large & Unidentifiable & 16 & Long bones, Rib Cartilage, Cartilage (k) \\
\hline Mammal, Small-Medium & Raccoon & 1 & Radius (I) \\
\hline Mammal, Very Small & Mouse/Vole & 2 & Calcaneus, Mandible \\
\hline Mammal, Very Small & Pocket Gopher & 1 & Ulna \\
\hline Mammal & Unidentifiable & 9 & Unidentifiable \\
\hline Reptile, Medium & Box Turtle & 10 & Carapace, Plastron (m) \\
\hline Reptile, Medium & Pond Slider & 5 & Carapace, Plastron (n) \\
\hline Reptile, Medium & Pond Water Turtle & 25 & Caracoid, Plastron (o) \\
\hline Reptile, Small \& Medium & Turtle & 48 & Carapace, Shell, Unidentifiable (p) \\
\hline Reptile, Small & Lizard/Snake & 1 & Vertebra \\
\hline Reptile, Small & Musk/Mud Turtle & 1 & Carapace \\
\hline Reptile, Small & Yellow Mud Turtle & 6 & Carapice (q) \\
\hline \multirow[t]{2}{*}{ Vertebate } & Unidentifiable & 296 & Fragments $(r)$ \\
\hline & TOTAL & 462 & \\
\hline
\end{tabular}

(a) Heated but not burned

(b) Two discrete cuts near spiral break

(c) Awl-like impression

(d) Chop marks

(e) Two crosswise cuts on long bone

(f) Deer about six months old

(g) Deer less than 20 months old

(h) Awl-like tool with usewear patina, usewear striations, and distal break indicative of use

(i) Ribs and vertebrae exhibit numerous cuts typical of meat removal; Scapula is from a juvenile; none of the 22 bones are burned

(j) None clearly burned or heated; cut on metatarsal is consistent with meat removal; cut on

tarsal consistent with disarticularation; tooth suggests a deer 3-6 years in age

(k) Two of the long bones exhibit evidence a brown stain, suggesting that they that they were likely heated for easy breakage;

one of the long bones has four cuts consistent with meat removal; one other bone has been clearly blackened from heat

(I) Possible cutmark

(m) Two carapace pieces browned from burning

(n) All are browned from heating

(o) 24 are browned from heating

(p) 15 are browned or blackened from heating

(q) Two pieces only burned on fringe

(r) 53 were either browned or blackened from heating 
analyzed, but curated) were recovered from the floatation sample. In addition, a phenomenal 462 pieces of faunal material were found in the $1 / 4$-inch screen (Table 16-5).

All of the mussel shell pieces were submitted to Bob Howells for analysis. Although 90 of those were unidentifiable fragments, he was able to identify the following:

- Pondhorn $(n=2)$ - favor soft bottoms, slow to no-flow water; can occur in streams that periodically dry up.

- Yellow Sandshell $(n=3)$ - favor sandy bottoms, soft substrates; they follow flood waters over inundated terrestial areas.

- Louisiana Fatmucket $(n=6)$ - favor slow moving, soft bottom creeks and oxbow lakes.

- Lilliput $(\mathrm{n}=1)$ - favor soft substrates in slow to no-flow waters and backwaters.

Seven tabular sandstone pieces comprised the heating elements in the hearth. Although three of the seven were submitted to Mary Malainey for lipid analysis, none of the three contained sufficient lipids for identification (see Chapter 12 for a full discussion). The first sample (11EC2) yielded only traces of plant material, with plant seeds the most probable source. Evidence of both plant and animal products were detected in the other two samples (12EC7 and 12EC8). Analysis of the second sample (12EC7) suggests that plant products dominated, with conifer likely. Analysis of the third sample (12EC8) indicated that plant products appeared to dominate over animal products.

Four of the seven burned sandstone pieces were submitted to Tim Riley for starches and phytolith analysis (see Chapter 13 for a full discussion). The first of four yielded evidence of a starch granule designated as Type A, likely from a geophyte (perrenial plant propogated by underground bulbs). The third and fourth samples yielded no evidence of starches. A small floatation sample comprising 1.5 liters of soil submitted to Phil Dering for analysis yielded only ten pieces of charred hardwood.

\section{Unique Item-Lower Component-Calcite Chunk}

By far, the most massive piece of lithic material found at the site is a macrocrystalline calcite chunk with crystals (Figure 16-14). It was uncovered by a Gradall scrape roughly $6 \mathrm{~m}$ from the north wall and $3 \mathrm{~m}$ from the east wall at elevation 97.52 , or roughly $180 \mathrm{cmbs}$. Its provenience suggests it was located in the lower cultural component, at the Strata $1 \mathrm{a} / 1 \mathrm{~b}$ divide. It measures $13 \mathrm{~cm}$ long $\mathrm{x} 10$ $\mathrm{cm}$ wide x $6.5 \mathrm{~cm}$ thick, and weighs $1.24 \mathrm{~kg}$. Given its mass, we surmise that it had to have been a manuport, as all indications are that for the past millennia Fish Creek has generally been a slow moving stream incapable of transporting a specimen of this size to the site locale.

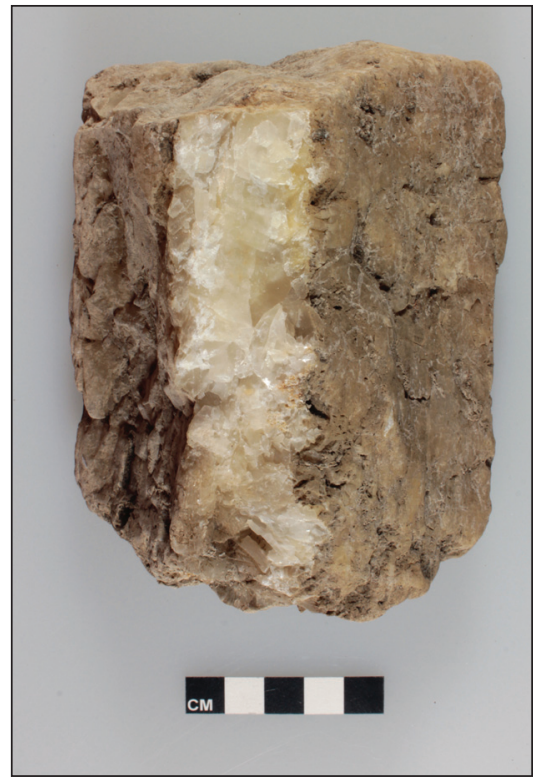

Figure 16-14. Calicite chunk with crystals found in the lower component, Stratum 1a/b divide. 
Notably, much smaller macrocrystalline calcite pieces were recovered from Unit 102 (Stratum 1b), Units 94 and 96 (Stratum 1a), and Units 25 and 74 (Stratum 2).

\section{Middle Cultural Component - Stratum 2}

As shown in Figure 16-1, Stratum 2 generally lies roughly between 70 and $170 \mathrm{~cm}$ below the modern ground surface, which equates to the middle cultural component at the site; but its depth varies considerably and dips sharply on the southern portion of the trench, where the natural stratigraphy follows the paleo channel of Fish Creek. A total of 157 levels within 72 excavation units were dug within the middle cultural component (Figure 16-15), resulting in the

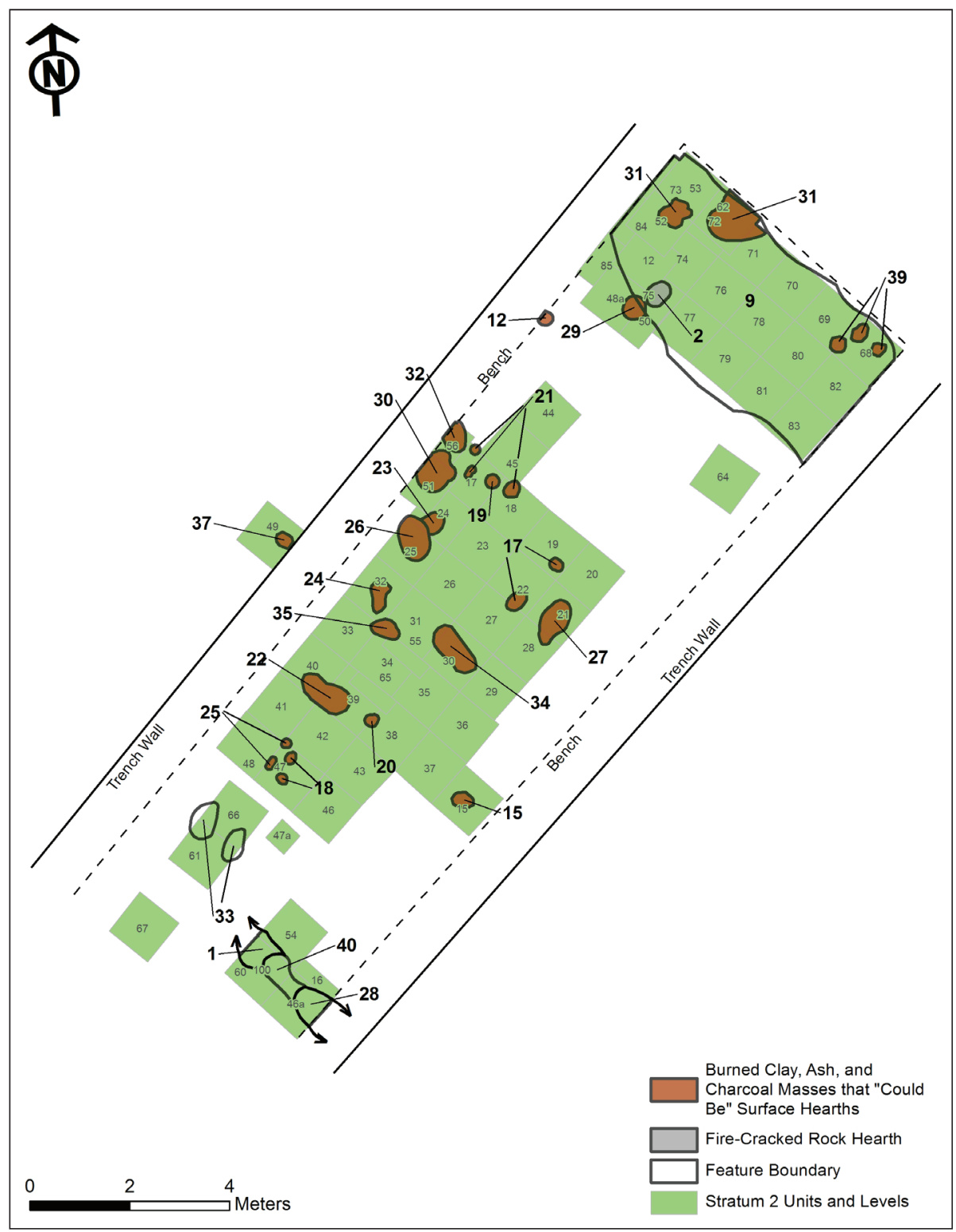

Figure 16-15. Middle Component (Stratum 2) excavation units and features inclusive to Stratum 2 and the middle cultural component. 
recovery of 26 pieces of fire-cracked rocks (FCR) greater than 1-inch in size, 37 pieces of chipped stone, few mussel shell fragments, several snails, an abundant amount of charcoal, and 2,315 pieces of animal bone. In addition, 27 features were recorded (Table 16-6).

\section{Feature 1-Middle Component-Natural Tree and Root Burn}

Feature 1 is a discolored, red, grey, orange, and blackened burn area that appears to be a downed tree with a large limb extending to the north, and a smaller limb or root emanating from the base (east end) of the feature toward the northeast. It was uncovered in Units 54 and 60 , sloping from $180 \mathrm{cmbs}$ to greater than $200 \mathrm{cmbs}$, following what appears to be the natural sloping cutbank of the Fish Creek paleo-channel (Figures 16-16 and 16-17). The discolored area lay on a gray clay loam strata, with yellow silt mottling. Further excavations in Unit 60 revealed that this same feature connected with Feature 28 in Unit 46A, suggesting a roughly 2-m surface burn in this area that simply followed the naturally sloping terrain. As illustrated in

Table 16-6. List of Features and Radiocarbon Dates for the Middle Cultural Component (Stratum 2).

\begin{tabular}{|c|c|c|}
\hline Feature \# & Description & Valid RC Dates (BP) \\
\hline 1 & Tree and Root Burn & $340 \pm 30$ \\
\hline 2 & Fire-cracked Rock Hearth & $500 \pm 25,289 \pm 23$, and $212 \pm 26$ \\
\hline 9 & Bone Scatter & $390 \pm 25$ through $208 \pm 22$ \\
\hline 12 & Ash and Charcoal Lens & \\
\hline 15 & Ash and Charcoal Lens & \\
\hline 17 & Burned Earth and Charcoal Mass & $480 \pm 25$ \\
\hline 18 & Burned Clay, Ash, and Charcoal Masses & \\
\hline 19 & Charcoal and Ash Lens & \\
\hline 20 & Charcoal and Ash Matrix & \\
\hline 21 & Burned Clay, Ash, and Charcoal masses & \\
\hline 22 & Burned Clay, Ash, and Charcoal Lens & $330 \pm 25$ \\
\hline 23 & Burned Clay, Ash, and Charcoal Mass & \\
\hline 24 & Probable Surface Hearth Area & $400 \pm 25$ \\
\hline 25 & Ash and Charcoal Lens & \\
\hline 26 & Burned Clay, Ash, and Charcoal lens & $370 \pm 25$ \\
\hline 27 & Ash and Charcoal Stain & \\
\hline 28 & $\begin{array}{l}\text { Basin Shaped Pit with Burned Clay, Ash, } \\
\text { and Charcoal }\end{array}$ & $340 \pm 30$ \\
\hline 29 & Burned Clay and Charcoal Lens & $370 \pm 25$ \\
\hline 30 & Surface Hearth & \\
\hline 31 & Burned Clay, Ash, and Charcoal Lens & $390 \pm 25$ \\
\hline 32 & Burned Clay, Ash, and Charcoal Lens & \\
\hline 33 & Burned Clay and Ash Smear & $290 \pm 25$ \\
\hline 34 & Burned Clay, Ash, and Charcoal Mass & \\
\hline 35 & Burned Clay, Ash, and Charcoal Mass & $480 \pm 25$ \\
\hline 37 & Probable Surface Hearth & \\
\hline 39 & Burned Clay, Ash, and Charcoal Masses & $450 \pm 25$ \\
\hline 40 & Burned Tree and Root & $360 \pm 25$ \\
\hline
\end{tabular}




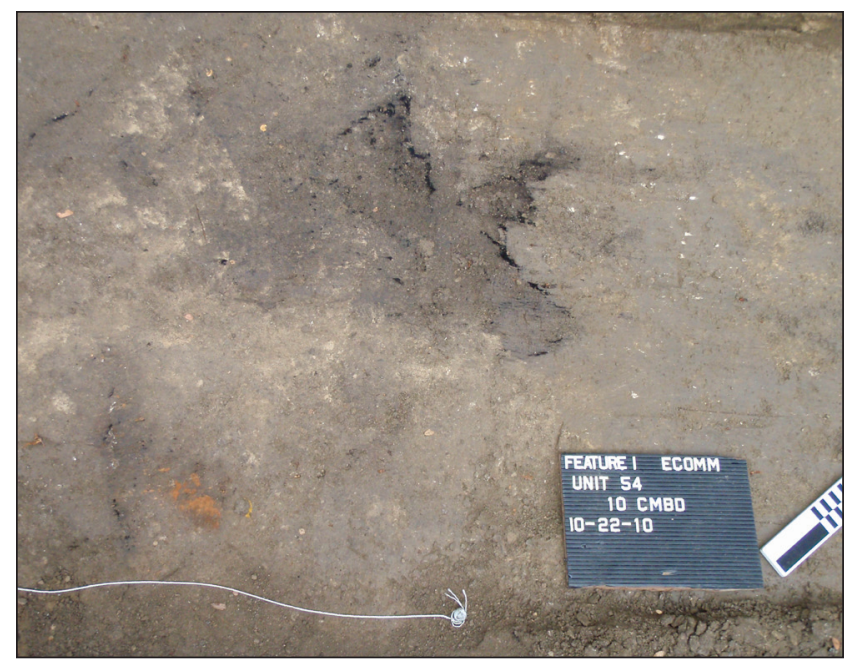

Figure 16-16. Feature 1 in Unit 54, as it was initially uncovered with a Gradall scrape.

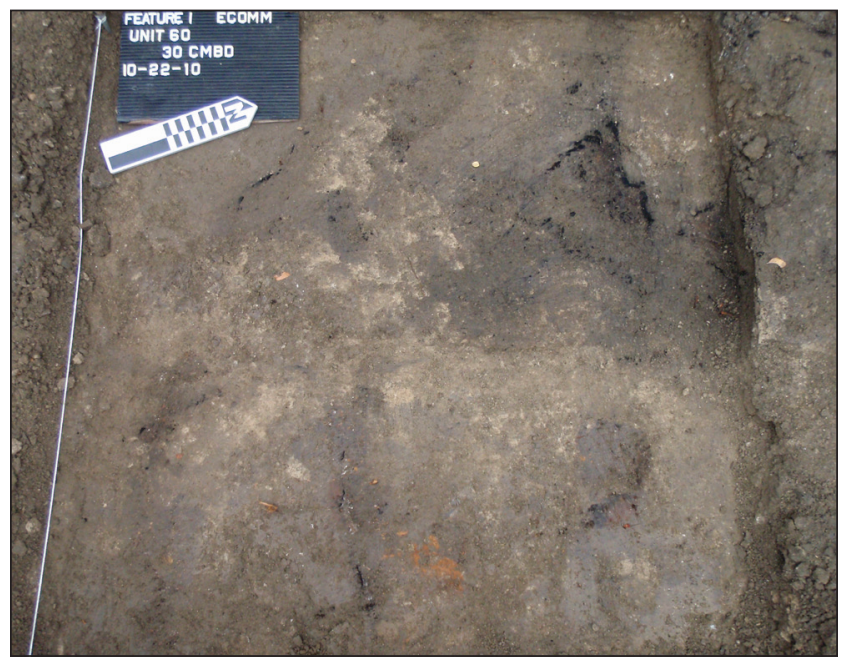

Figure 16-17. Feature 1 in Unit 60, Level 2.
Figures 16-18 and 16-19 (Planviews), the outline of the burned area shifted considerably as excavations progressed. Whether or not the burned tree and root resulted from human intervention or occurred naturally is indeterminate.

A conventional radiocarbon age obtained from in situ charcoal in Unit 60 indicates that the burning most probably occurred between A.D. 1450 and 1640 (2 Sigma Calibrated Measured Radiocarbon Age 500-310 BP-Beta 312837). Besides an abundant amount of charcoal, 35 unmodified vertebrate fragments that could not be identified to a species or genus were discovered in association with the burning event.

\section{Feature 2-Middle Component- Fire-Cracked Rock Hearth}

Feature 2 is a fire-cracked rock (FCR) hearth feature constructed with mostly tabular sandstone, but with one chert and one macrocrystalline calcite rock, and measures roughly $60 \mathrm{x} 90-\mathrm{cm}$ in size (Figure 16-20). It was discovered in Unit 75 in Block 2, 145 cmbs. The hearth remains lay on the surface of a dark sandy loam, and were encapsulated by yellow coarse sand.

A conventional radiocarbon age obtained from in situ charcoal indicates that this hearth was most likely used sometime between A.D. 1406 and 1444 (2 Sigma Calibrated Measured Radiocarbon Age $500 \pm 25$ BP-UGAMS \#8595). 1) Surmising that this was probably an old wood sample, two bone collagen samples were subsequently submitted for dating (Table 5-2 and Appendix I). Collagen from a bovidae bone found in association with Feature 2 yielded a radiocarbon age of $208 \pm 26$ BP (DAMS-5763), with calibrated ages of AD 1647-1684 (29.1 percent), AD1736-1805 (49.2 percent), and post-AD 1935 (17.1 percent). A second collagen sample from a bison bone yielded a radiocarbon age of $289 \pm 24$ BP (DAMS-5758), with calibrated ages of AD 1514-1599 (62.3 percent) and AD1617-1660 (33.1 percent). Nine tabular sandstone fire-cracked rocks were used as heating elements. Two of the nine FCR were submitted to Mary Malainey for evidence of lipids. The first sample (11EC1) yielded a very high fatty acid content, characteristic of decomposed cooking residue from large herbivores, such as deer, 


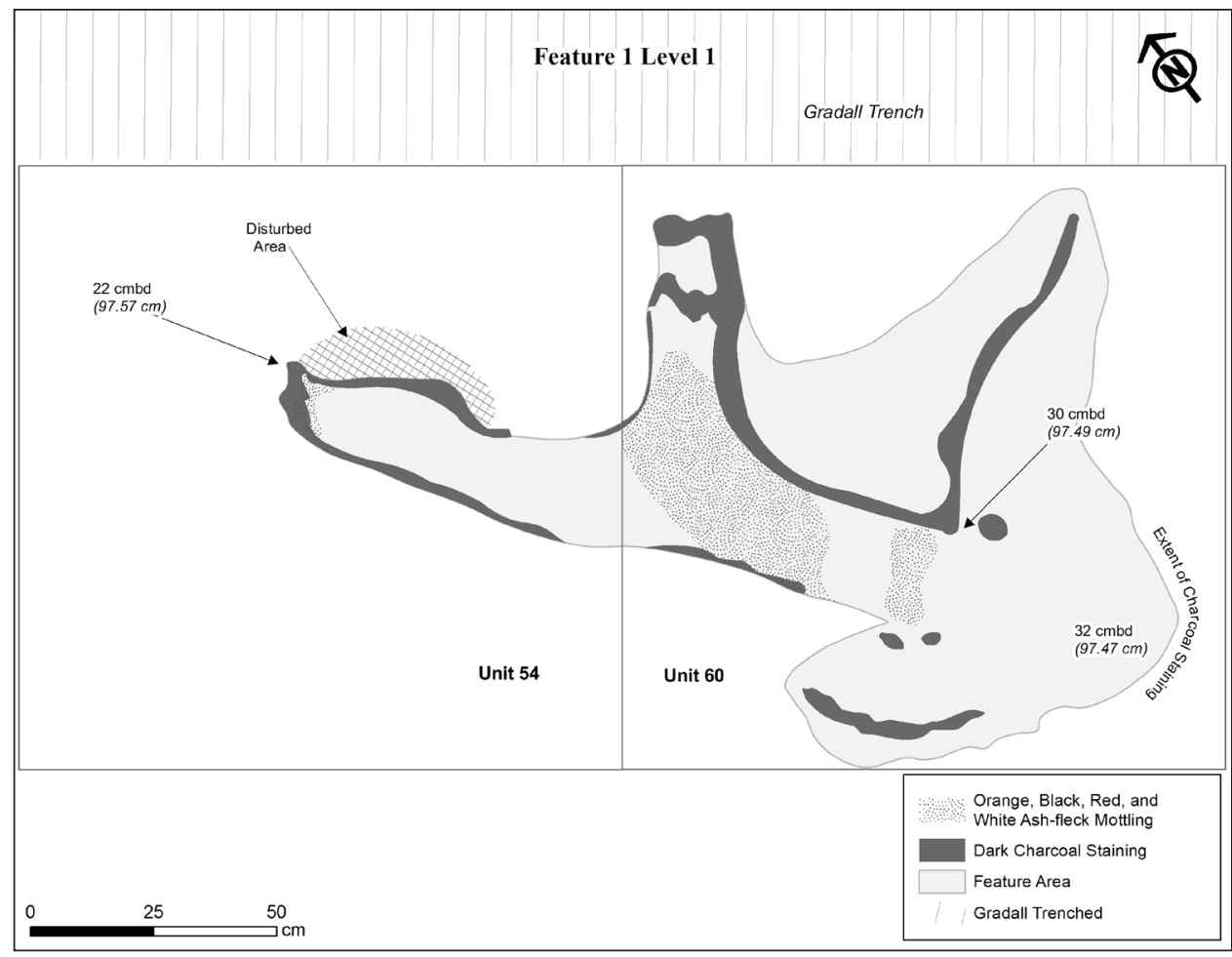

Figure 16-18. Feature 1 planview in Units 54 and 60 in Level 1.

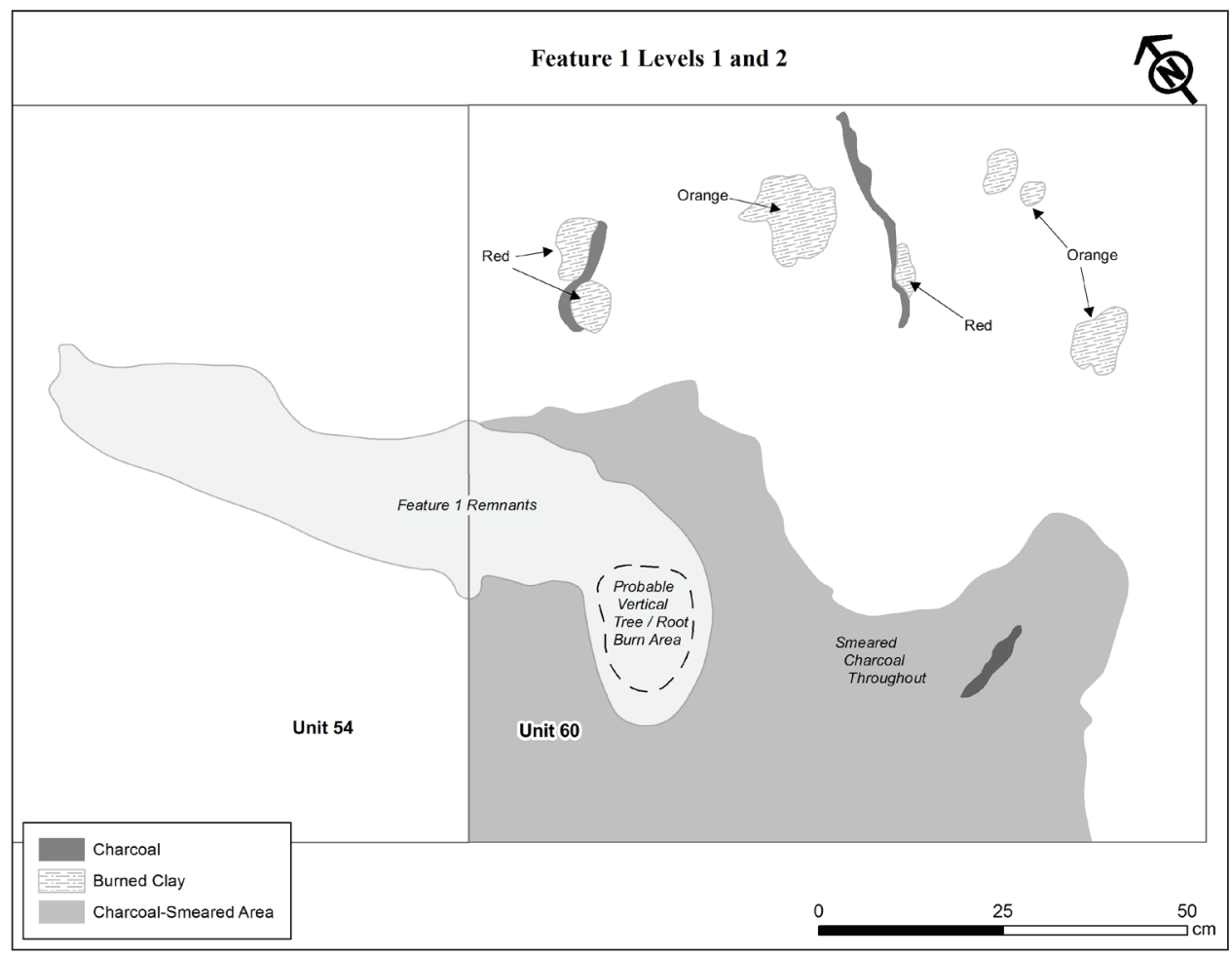

Figure 16-19. Evolving shape of Feature 1 as excavations progressed in Unit 60 to Level 2. 


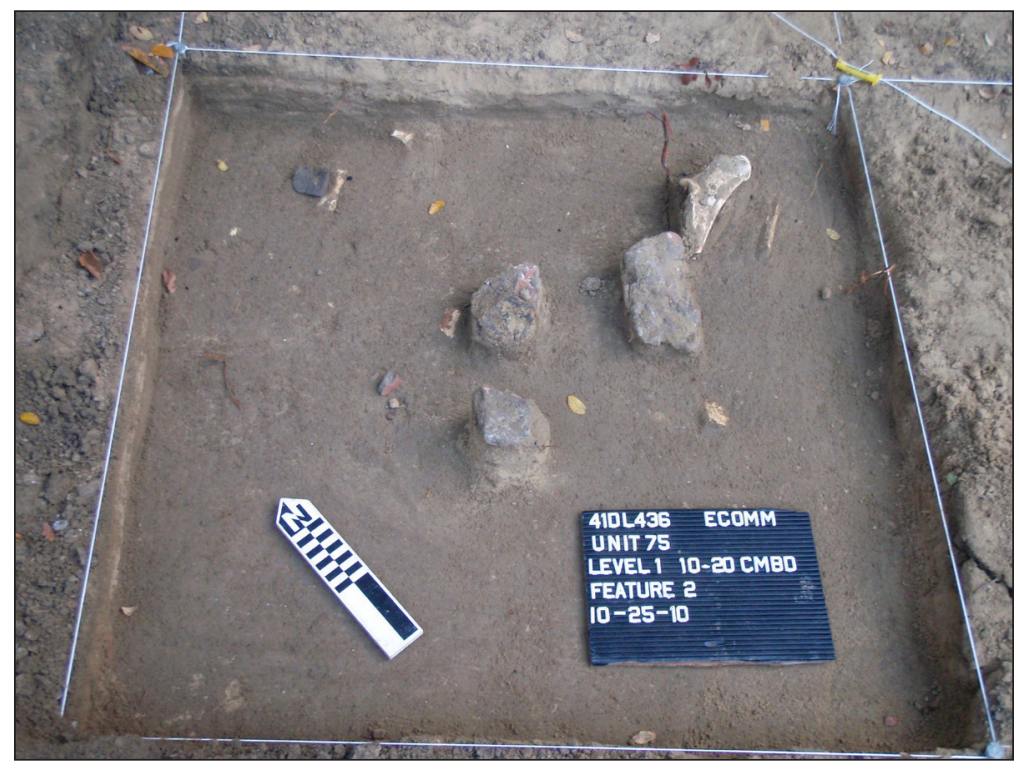

Figure 16-20. Photograph of Feature 2 in Unit 75, Level 1. bison, and moose, but could also be from javelina as well. In any case the meat was very lean, with little animal fat. Traces of unsaturated fats detected in the first sample imply that plant seeds were also being cooked in the hearth (perhaps sotol), but to a lesser degree than large herbivores or javelina. Both plant and animal residues were found in the second sample (12EC1), with plants likely the predominant residue; conifers was also detected.

Two of the nine pieces of FCR were submitted to Timothy Riley for starch and phytolith analysis. One of the two samples contained four starch granules (Type A) that are unlikely from a grass seed, but more likely from a geophyte (perennial plant propogated by underground bulbs, tubers, or corms). This same sample contained an additional single starch granule (Type E) that is also tentatively identified as from a geophyte.

Out of the 110 pieces of bone recovered in association with Feature 2, at least four are bovidae (cow/bison), with one ulna from a five-year old animal exhibiting a series of cut marks, and four pieces that are described as fetus or neonatal in age. Four pieces of bone are likely from a red-tailed hawk, one is from a garter/water snake, one tooth is from a medium-large deer, eight are from medium-large mammals, one is from a medium-sized bird, and the remainder could only be identified as mammal or vertebrate. Within the collection, Jodi Jacobsen identified one bone that had been culturally altered. It is a broken long bone from a medium-large mammal that had been polished.

A floatation sample comprising 8 liters of soil submitted to Phil Dering for analysis yielded no evidence of charred plant remains.

Although no chipped stone was recovered from the 1/4-inch screen, eight small pieces were found in a floatation sample. Six of the eight are uniface thinning or re-sharpening flakes, while the remaining two are biface thinning flakes. All are made from fine-grained chert ranging in color from pale brown, to gray, to dark grayish brown. One of the larger specimens is a biface manufacturing flake that has been heavily burned, and broken post-depositionally. Otherwise the remaining seven are whole, and only two of those appear to have been heat-treated.

In sum, this small hearth feature made up of predominantly sandstone slabs and chunks as heating elements, was used approximately 500 years BP and served as a foci for cooking a 
variety of wild game such as bison, deer, possibly javelina and red-tailed hawk, perhaps a garter snake, and other medium-large sized mammal and vertebrates. In addition, the diet was likely supplemented with plant bulbs. Based upon the chipped stone recovered, it appears that these subsistence items were processed using primarily unifacial scrapers and cutting tools that were manufactured and re-sharpened in the immediate area.

\section{Feature 9-Middle Component-Bone Scatter}

This feature is a bone scatter with a small scattered hearth (Feature 2) in the southwest quadrant of a 3 x 6-m block of units (Block 2), between 145-160 cmbs (Figures 16-21 and 16-22). The bones were first discovered in a Gradall scrape. Other bone was exposed in the Gradall slightly downslope and to the south end of the excavation block; these were shot in with the TDS and collected. The excavation block was taken down in 10-cm levels, but generally corresponded with natural strata. The bone scatter and FCR were concentrated within a layer of pale brown (10YR 6/3) fine sand,

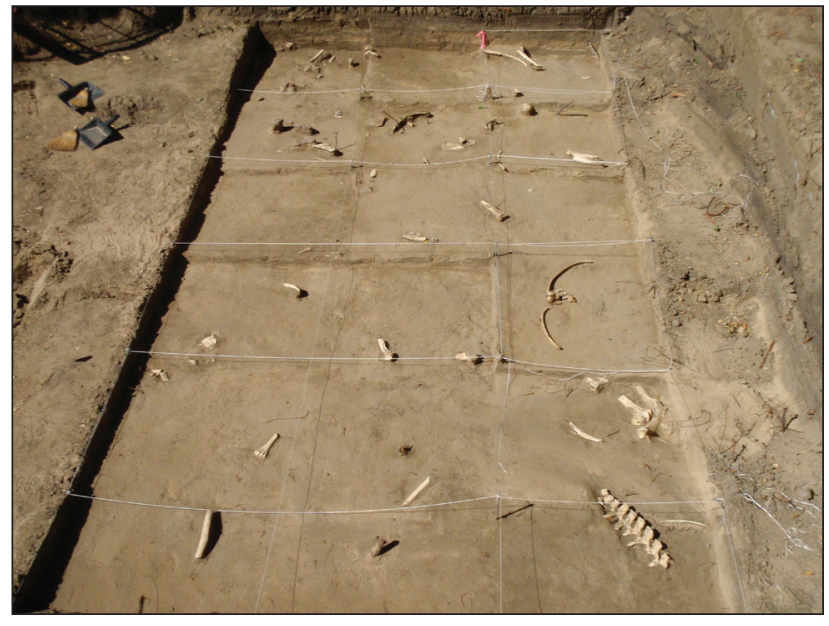

Figure 16-21. Photograph of Feature 9; facing northwest.

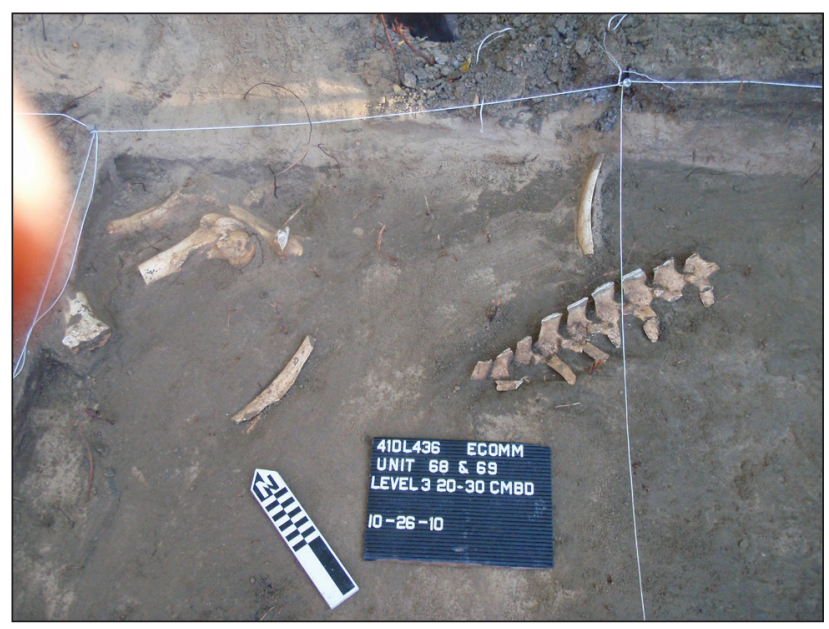

Figure 16-22. Units 68 and 69 in Feature 9. and generally lay upon a strata of dark grayish brown (10YR 4/2) loam with occasional scattered charcoal. The pale brown sand layer begins at elevation 98.41 in the northeast corner (Unit 68) of the excavation block and is $8 \mathrm{~cm}$ thick there. Otherwise, this sand lens varies in thickness from 8-12 cm across the block. It slopes to the south so that the top of the sand strata is at elevation 98.38 in the northeast corner of Unit 83. The top of the sand strata in the northwest corner of the block is 98.57 ; there the sand strata is 9-10 $\mathrm{cm}$ thick. These data indicate a 17 $\mathrm{cm}$ slope in the sand strata across $6 \mathrm{~m}$, from west to east.

A conventional radiocarbon age obtained from in situ charcoal indicates that the butchering event (or events) likely occurred sometime between AD 1441 and 1522, or between AD 1574 and 1584, or between AD 1589 and 1625 (2 Sigma Calibrated Measured Radiocarbon Age $390 \pm 25$ BP-UGAMS \#8600). Specifically, the charcoal sample that was used to date the eastern end of Feature 9 was collected from the northwest corner of Unit 69 (see Figure 16-15). 
Although an additional radiocarbon date of $450 \pm 25$ BP (AD 1419-1468) was received from another charcoal sample (UGAMS-8612), although Abbott (Chapter 5) surmised this was an old wood sample. To corroborate that assumption, a total of eight bone collagen samples were submitted for dating (Table 5-2 and Appendix I). They yielded radiocarbon dates and calibrated ages as follows:

\begin{tabular}{|c|c|c|}
\hline DAMS-5759 & $342 \pm 34 \mathrm{BP}$ & AD $1466-1641(95.4 \%)$ \\
\hline DAMS-5762 & $309 \pm 25 \mathrm{BP}$ & AD 1492-1603 (73.2\%) and AD 1615-1648 (22.2\%) \\
\hline DAMS-5763 & $212 \pm 26 \mathrm{BP}$ & $\begin{array}{l}\text { AD 1647-1684 (29.1\%), AD 1736-1805 (49.2\%), and post AD } 1935 \\
17.1 \%)\end{array}$ \\
\hline AMS-5764 & $340 \pm 25 \mathrm{BP}$ & AD $1472-1637(95.4 \%)$ \\
\hline DAMS-5765 & $300 \pm 26 \mathrm{BP}$ & AD 1493-1602 (70.0\%) and AD1615-1652 (25.4\%) \\
\hline DAMS-5767 & $264 \pm 24 \mathrm{BP}$ & $\begin{array}{l}\text { AD } 1522-1574(25.1 \%), \text { AD 1629-1669 (62.4\%), and AD 1781- } \\
1799(7.8 \%)\end{array}$ \\
\hline DAMS-5768 & $289 \pm 24 \mathrm{BP}$ & AD 1514-1599 (62.3\%) and AD 1617-1660 (33.1\%) \\
\hline DAMS-5769 & $208 \pm 22 \mathrm{BP}$ & $\begin{array}{l}\text { AD1649-1682 (29.3\%), AD 1738-1765 (5\%), AD1761-1804 } \\
(43.3 \%), \text { and post-AD } 1937(17.9 \%)\end{array}$ \\
\hline
\end{tabular}

Cultural material found in association with Feature 9 obviously included an abundance and wide variety of faunal remains, fire-cracked rocks (within Feature 2), mussel shells, Rabtotus snails, and abundant charcoal. For a discussion of the lipid and starches analyses of the firecracked rocks from Feature 2, see the description of Feature 2, above.

A total of 838 whole and fragmented pieces of faunal material was collected from Feature 9. For an indepth description of the faunal remains, the reader is referred to Chapter 15 and Appendix G. Among the wide variety of identifiable remains are

1) bison and cow/bison-vertebra, rib, humerus, tibia, tooth; some blackened from burning, some with visible cut marks; 2) dog/coyote-cut marks consistent with skinning; 3) hispid cotton rat, marsh rice rat, cotton rat; 4) opossum; 5) ornate box turtle and other turtle-some with browning from heating; 6) pronghorn/deer; 7) rabbit-possible humanly polished; and 8) rattlesnake.

Other than the fire-cracked rocks recovered from Feature 2 in Unit 75, three other pieces were found within the contexts of Feature 9: one in Unit 74, Level 2; one in Unit 76, Level 1; one in Unit 80, Level 2. Upon examination in the lab, the specimen from Unit 76 exhibited evidence of smoothing on both its dorsal and ventral surfaces. Charcoal stains were apparent on its ventral surface, suggesting that it was used for processing foodstuffs, and subsequently recycled as a heating element. It is made from tabular sandstone and measures $8.7 \mathrm{~cm}$ long x $6.7 \mathrm{~cm}$ wide x $2.31 \mathrm{~cm}$ thick (Figure 16-23).

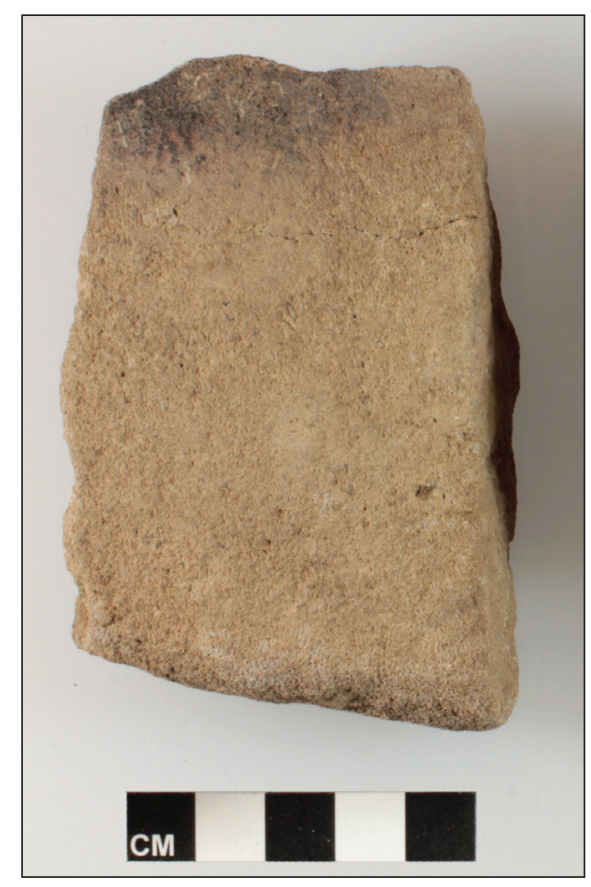

Figure 16-23. Smoothed sandstone recovered from Feature 9, Unit 76, Level 1. 
One FCR from Unit 74, Level 1was submitted to Timothy Riley for starch and phytolith analysis. He identified one Type B starch granule on this sample which is indicative of wild grasses such as Little Barley (Hordeum pusillum).

Although mussel shell fragments were submitted to Bob Howells, they were so highly fragmented that none could be identified to the species level. Scant few and scattered Rabdotus snails were found only in Units 69, 70, and 82.

Seven small pieces of chipped stone were recovered from the $1 / 4$-inch screens in association with Feature 9 (none from floatation samples). Two are biface manufacturing flakes. Two are biface thinning flakes, one of which can be categorized as a micro-tool with evidence of being unifacially re-sharpened. One is a core reduction flake with smoothed, stream-rolled cortex. One is a uniface re-sharpening flake, and one is simply angular debris. All were manufactured from gray to grayish brown fine-grained chert.

In sum, most of this large scatter of faunal remains was most probably discarded by Native Americans from about AD 1466-1641 with some remains most likely in later years. Although the wide variety of fauna suggests a long-term occupation the fact that the bone was simply left distributed across the surface suggests a short term occupation. A review of hearth distributions in the Middle Component indicates most hearths were located near the center of the trench, so it is possible that Feature 9 accumulated over a 'relatively long term' occupation (i.e. a few seasons or years) as a garbage area. Nevertheless, the absence of clear burning on most bones suggest that perhaps most of the meat was de-boned and either boiled or jerked instead of being placed over the fire attached to the bone. In addition, the diet was likely supplemented with plants gathered in the immediate area. Another dietary supplement likely included an occasional mussel gathered from the creek.

\section{Feature 12-Middle Component-Ash and Charcoal Lens}

Feature 12 is a small, basin-shaped lens of charcoal and ash documented $140-147$ cmbs in the west wall of the Gradall trench on the last day of excavations. It was not excavated, but the wall profile was troweled smoothed and brushed before the feature was described, sketched, photographed, and shot in with the TDS. As shown in Figure 16-24, it was situated within a thin layer of yellow sand setting on grayish brown loam, in the same strata as Feature 9.

It was manifested as a thin burned layer of gray ash and black charcoal

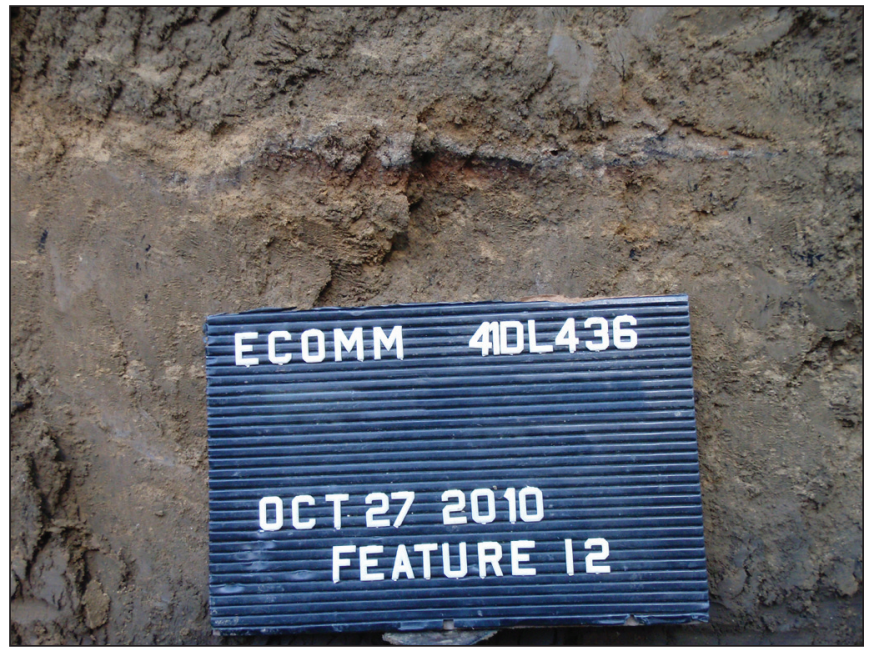

Figure 16-24. Photograph of Feature 12; west wall of Gradall trench. 
approximately $7 \mathrm{~cm}$ thick and $50 \mathrm{~cm}$ in length as it was exposed. No cultural material nor organic material other than the ash and charcoal was observed. This feature is typical of multiple burned areas throughout this strata, and without conclusive evidence, whether or not this burning event was natural or induced by human activity remains an unknown.

\section{Feature 15-Middle Component-Ash and Charcoal Lens}

This feature is comprised of a thin layer $(1-3 \mathrm{~cm})$ of charcoal and ash that is spotty across an apparent once stable surface of brown (10YR 4/3) silty loam with common calcium carbonate threads throughout. The soil is also mottled with yellow silt, suggesting at least some degree of turbation has occurred. The charcoal and ash layer was explored via excavations in Units 6 and 15, and it was determined that it was $1-3 \mathrm{~cm}$ thick, extending across an area of about $35 \mathrm{x}$ $55 \mathrm{~cm}$, at a depth of 120-123 cmbs (Figure 16-25).

In addition to numerous and scattered minute charcoal particles, two unmodified vertebrate fragments were found. Without conclusive evidence of cultural material or human intervention, we must surmise that Feature 15 was probably a naturally occurring surface burn, but an expediently constructed surface hearth cannot be ruled out.

\section{Feature 17-Middle Component-Burned Earth and Charcoal Mass}

This feature consists of compacted burned earth with charcoal and dense calcium carbonate fines and strings, in addition to a concentration of turtle shell, and small rodent and mammal bones found in association in Units 19 and 22 (Figure 16-26). It was setting within an 8 to $10-\mathrm{cm}$ dark loam strata that also contains dense calcium carbonates. Directly below is a yellow sand strata. A few pieces of bone exhibited evidence of burning, but most did not. Stratigraphically, the two components of this feature-burned area and turtle shell area - appear to be equivalent from 130-140 cmbs.



Figure 16-25. Features 4 and 15.

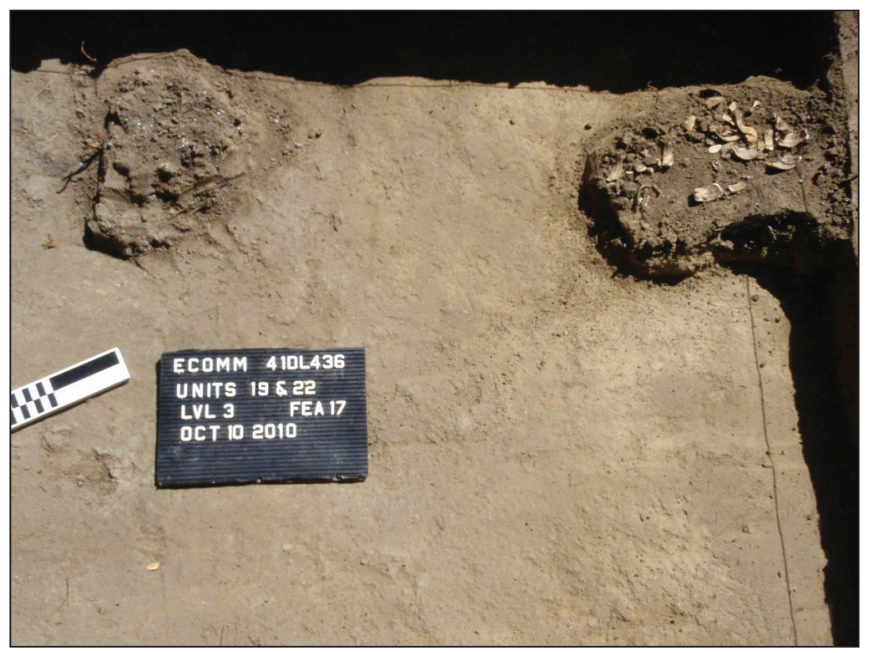

Figure 16-26. Photograph of Feature 17 - Level 1. 
A noted disturbance included possible rodent burrowing manifested by a 1-inch vertical hole just south of the burned area, infilled with black loam with no calcium carbonates. Also, whole and cracked hackberry seed hulls were common throughout, and widely dispersed charcoal and stains were evident throughout the 2nd and 3rd levels of Units 19 and 22.

A conventional radiocarbon age obtained from in situ charcoal indicates that the burn likely occurred sometime between AD 1423 and 1441 or between AD 1413 and 1447 (2 Sigma Calibrated Measured Radiocarbon Age $480 \pm 25$ BP-UGAMS \#8603). However, Abbott (Chapter 5) surmise this was an old wood sample. In addition to the mass of charcoal and ash, presumably cultural material found in association include multiple pieces of faunal remains, and one charred seed. Thirteen Rabdotus snail shells were also found. No chipped stone, firecracked rocks, or mussel shells were observed in association with the feature.

A total of 426 pieces of bone and turtle shell were recovered in association with Feature 17. They include 1) Terrestrial Box turtle/Turtle ( $\mathrm{n}=204)$ - 14 are blackened from heating; 2) Pond Turtle ( $\mathrm{n}=12)$ : 3) Vertebrates ( $\mathrm{n}=207)$ _one calcined; 4) Wood Rat ( $\mathrm{n}=1)$-Juvenile; 5) Marsh Rice Rat ( $\mathrm{n}=1)$; 6) Hispid Cotton Rat ( $\mathrm{n}=1)$; and 7) Unidentifiable fragment ( $\mathrm{n}=1)$-Blackened.

In sum, this relatively small mass of charcoal and ash was possibly a small hearth constructed on a once stable surface sometime between AD 1413-1447. The faunal remains recovered suggest that a variety of game animals may have been processed for subsistence, predominantly vertebrates and terrestrial turtles. The general absence of evidence of heating on the faunal remains imply that the meat may have been stripped from the bones and shells before being possibly boiled and consumed.

\section{Feature 18-Middle}

\section{Component-Burned Clay, Charcoal, and Ash Masses}

Feature 18 (Figure 16-27) consists of two burned clay, charcoal, and ash masses with associated charcoal, mussel shells, bone, and burned clay lying between 140-150 cmbs in sandy loam. Excavated within Unit 47, their approximate sizes were 35 x $50 \mathrm{~cm}$ and 30 x $40 \mathrm{~cm}$. Although charcoal samples were collected, none were submitted for assay. No pieces of chipped stone, fire-cracked rocks, or other cultural materials were found in association.

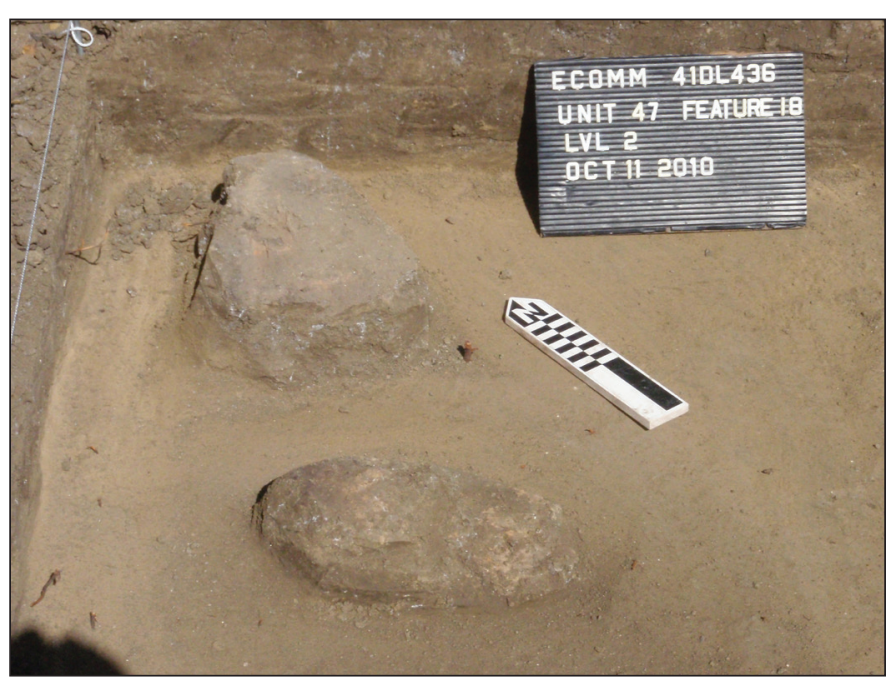

Figure 16-27. Photograph of Feature 18, Unit 47, Level 2. 
Of the 20 pieces of faunal remains found in association with Feature 18, three were deer vertebra, six were from unidentifiable mammals (three calcined), ten were from unidentifiable vertebrates (one blackened), and one was a molar tooth from a rodent mammal. The mussel shell remains submitted to Bob Howells were so highly fragmented that no possible identification could be obtained.

In sum, these isolated and concentrated masses of burned clay, charcoal, and ash anomalies argue against a natural tree fall or root burn, but with associated bone and mussel shells instead suggest that they are likely isolated hearths fired with wood, but without stone heating elements. They appear to have been constructed on a stable occupation surface stratigraphically co-eval with Feature 17, approximately 480 BP (but a possible old wood sample dated [see Chapter 5]).

\section{Feature 19-Middle Component-Charcoal and Ash Lens}

Feature 19 (Figure 16-28) is a blackened matrix of charcoal and an ashy soil lens $2 \mathrm{~cm}$ thick, with snail shells and hackberry seeds as inclusions. It was uncovered by a Gradall scrape and subsequent excavations in the southeast quadrant of Unit 17, Level 1, 135-140 cmbs, just above the yellow sand zone that contains the Middle Component at this site. Although charcoal samples were collected in situ, none were selected for assay from this feature. The only piece of faunal material found in Level 1 was a molar from a rodent. Because no clearly cultural material was associated with this feature, its classification as a cultural feature is questionable.

\section{Feature 20-Middle}

\section{Component-Charcoal and} Ash Matrix

Feature 20 is a round and slightly bowl-shaped charcoal and ash matrix $5-7 \mathrm{~cm}$ deep, approximately $20 \mathrm{~cm}$ in diameter, and excavated in Unit 39 (Figures 16-29 and 16-30). It is

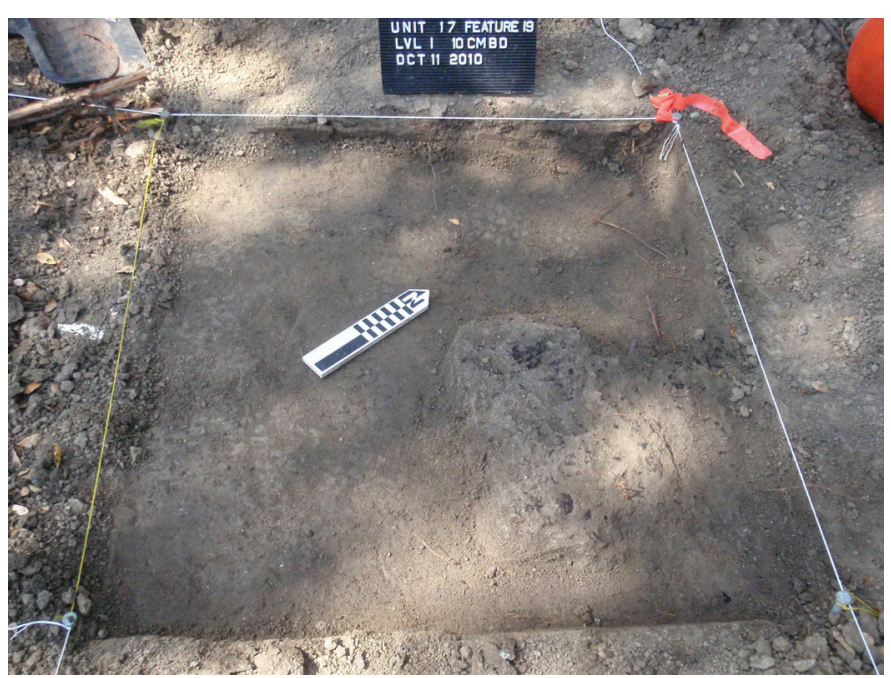

Figure 16-28. Photograph of Feature 19.

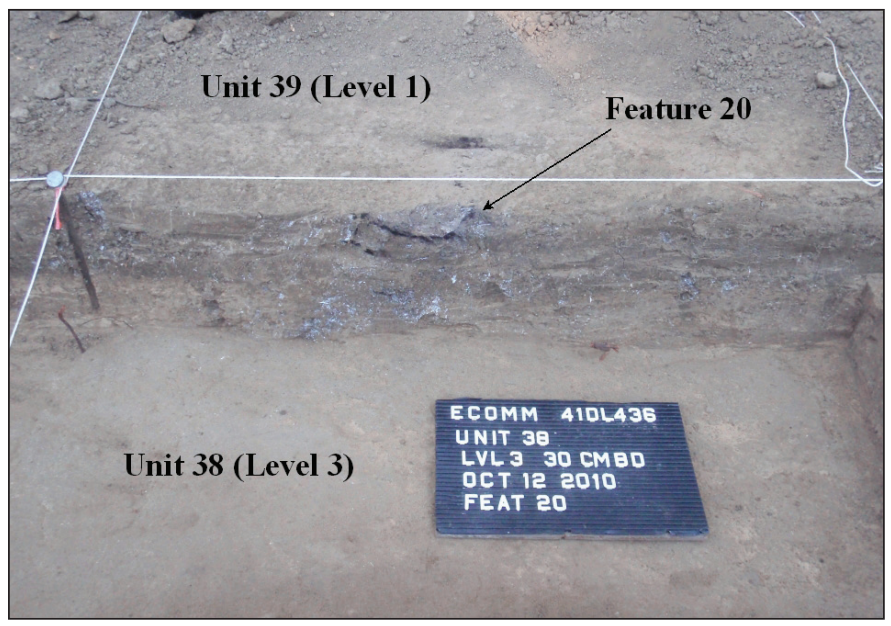

Figure 16-29. Photograph of Feature 20 in profile. 


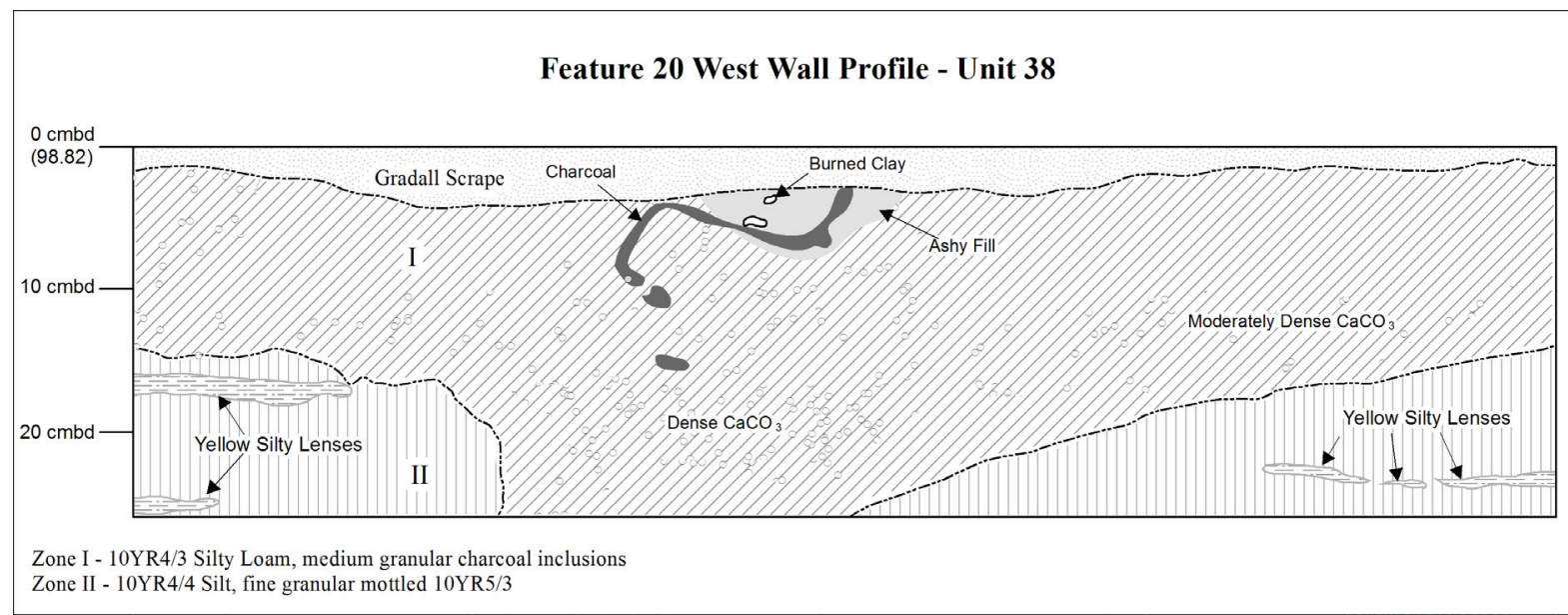

Figure 16-30. Feature 20 in north wall profile of Unit 38.

lying within a brown (10YR 4/3) zone of silty loam with calcium carbonate fines and strings, 140-147 cmbs. Although charcoal samples were collected in situ from Feature 20, none were submitted for assay. No faunal remains were recovered from Level 1 in the unit, which equates to the uppermost 1-2 centimeters of the feature. A total of 21 pieces of fauna were recovered from Level 2. They consist of one sternum that compares favorably with falcon, five box turtle and turtle shell fragments, three vertebra from a medium-large size mammal, five fragments from an unidentifiable mammal, five fragments from an unidentifiable vertebrate (all blackened or calcined), one tibia from a very small lizard, and one complete bison phalanx.

We caution here that the very small 20 -cm diameter burned area that we designated Feature 20 may not necessarily be directly associated with the faunal remains. In fact, the excavator at the time noted that he could detect no cultural material that could be directly associated with the feature. Without conclusive evidence, we surmise that Feature 20 'could' represent the remains of a very small surface hearth, but otherwise could also have simply been a natural burn on an undulating surface.

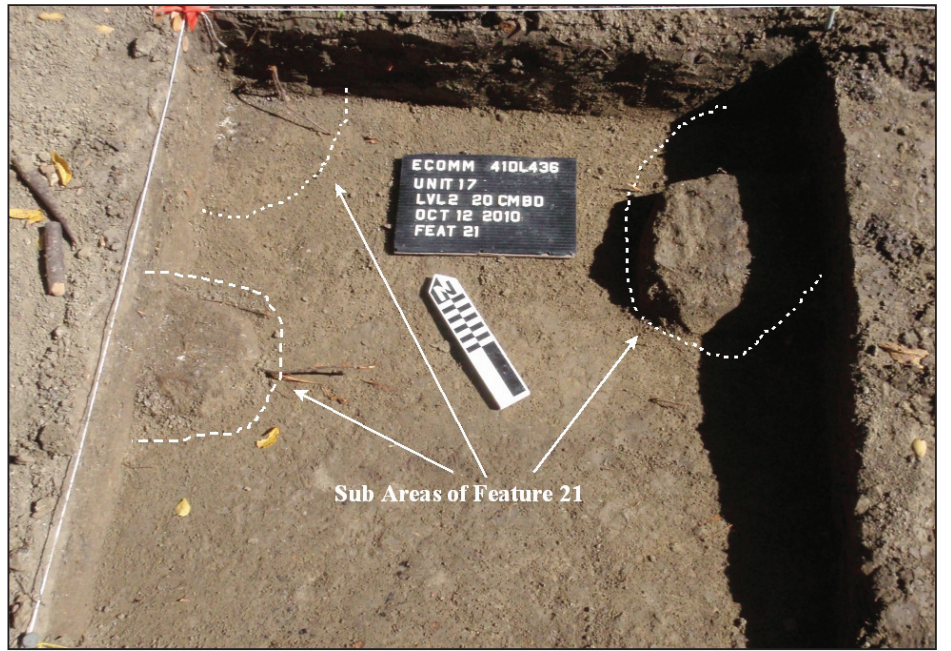

Figure 16-31. Photograph of Feature 21 in Unit 17.

\section{Feature 21-Middle} Component-Burned Clay, Ash, and Charcoal Masses

The attributes of Feature 21 were manifested in three separate areas when investigated by excavations in Units 17 and 18, Level 2, between 140-150 cmbs. Overall, the burned area consisted of burned clay, ash, and charcoal encompassing an area roughly $170 \mathrm{~cm}$, but in three apparent isolated subareas (Figures 16-31 


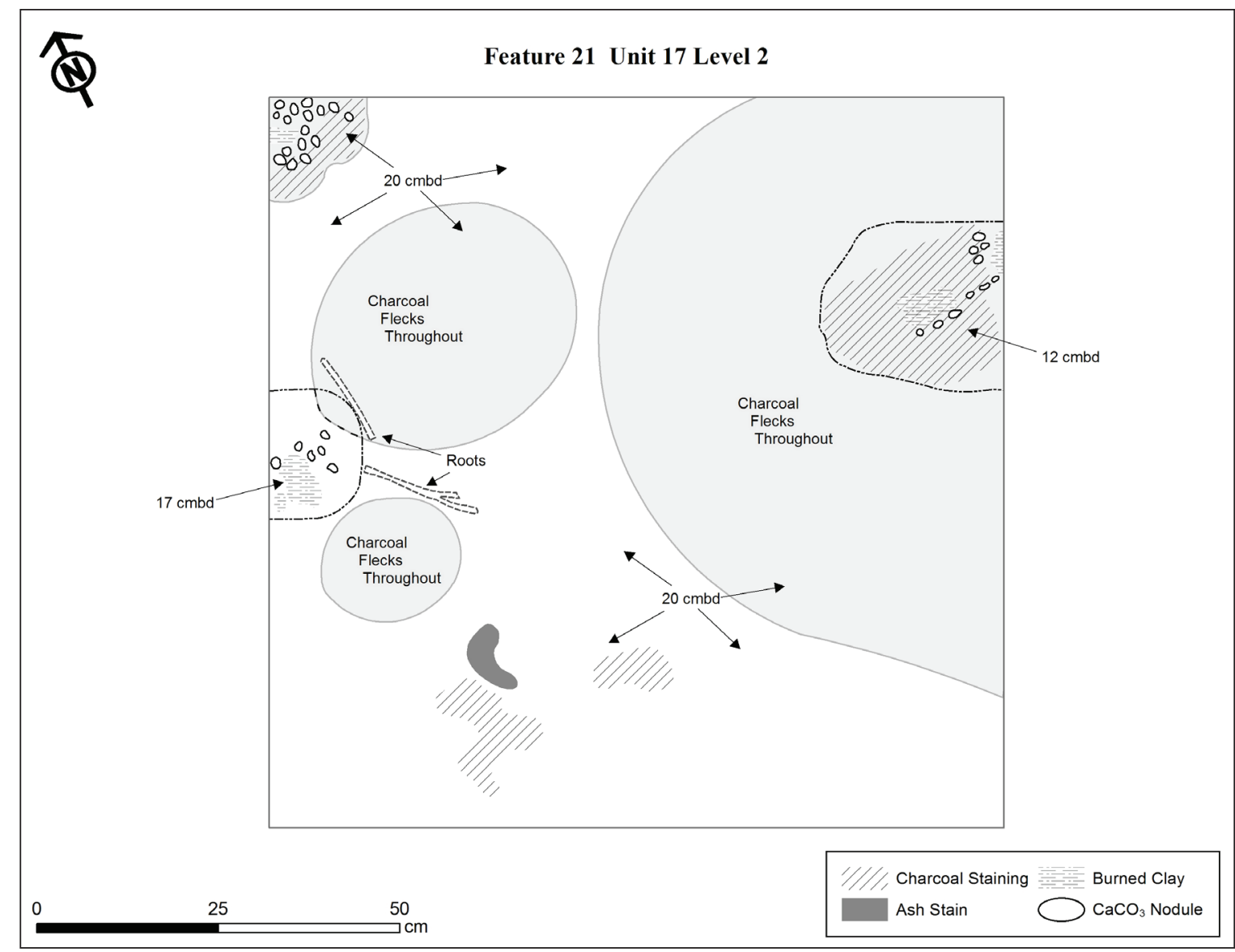

Figure 16-32. Plan view of the three components designated Feature 21.

and 16-32). It is undetermined whether these three areas represent cultural isolated hearths or simply isolated areas of a natural surface burn. Although charcoal samples were collected in situ from the feature, none were submitted for assay.

Obvious disturbances noted by excavators included horizontal roots that had penetrated the feature and its exterior, suggesting a stable surface possibly once occupied by humans. Otherwise, the soils which encompassed the feature were soft, silty sand with flecks of charcoal, and tan sand mottling throughout.

Sixteen pieces of fauna recovered from Level 2 in Units 17 and 18 include one blackened long bone fragment from a small-medium size mammal, three blackened and browned turtle shells, eight vertebrate fragments, a pelvis and femur from a rat/vole mammal, and two unidentifiable vertebrate fragments.

\section{Feature 22-Middle Component-Ash, Charcoal, and Burned Clay Lens}

Feature 22 is a burned and blackened stain laced with ash, bits of charcoal and small bits of burned red clay (Figure 16-33). The stain was oval shaped, measuring approximately $50 \mathrm{x}$ $70 \mathrm{~cm}$, and ranged in thickness from 1-3 cm. It was first exposed by a Gradall scrape, and 
then further exposed with the excavation of Unit 39, Level 3, and Unit 40, Level 1, between 140-150 cmbs. Stratigraphically, it was located just above a silty, yellowish loam. The base of Feature 22 was lying in very silty loam with calcium carbonate strings and fines observed only in association with the feature. In sum, the size of the feature, with associated faunal remains suggest that it is likely a cultural hearth.

A conventional radiocarbon age obtained from in situ charcoal from Unit 40, Level 1 indicates that the burn likely occurred sometime between AD 1483 and 1641 (2 Sigma Calibrated Measured Radiocarbon Age $330 \pm 25$ BP-UGAMS \#8604).

Twenty-one pieces of faunal remains recovered from Unit 39 Level 3 and Unit 40 Level 1 include eight bison bones, six cow/bison bones, and seven complete and fragmented large mammal bones. The only bone fragment that exhibited evidence of cultural alteration was a long bone from a large mammal, with browning from heating near a chop break.

\section{Feature 23-Middle}

\section{Component-Ash, Charcoal, and Burned Clay Mass}

Feature 23 is an area of burned clay, charcoal, and ash, with some bone within compacted brown sandy clay loam, and $3 \mathrm{~cm}$ above a yellow sand strata, 140-150 cmbs (Figure 16-34). It was exposed during the excavation of Units 23 and 24, Levels 2 and 3. It is unclear whether or not this is a cultural feature. Stratigraphically, it lies within the same sandy clay loam as that of adjacent Feature 26, where a conventional radiocarbon age obtained from in situ charcoal indicates that the burn likely occurred sometime between AD 1449 and 1524 or between AD 1558 and 1631 (2 Sigma Calibrated Measured Radiocarbon Age $370 \pm 25$ BP-UGAMS \#8606).

In association with Feature 23, archaeologists collected an abundance of charcoal, two cotton rat mandibles, four fragments of an unidentifiable vertebrate (all fauna

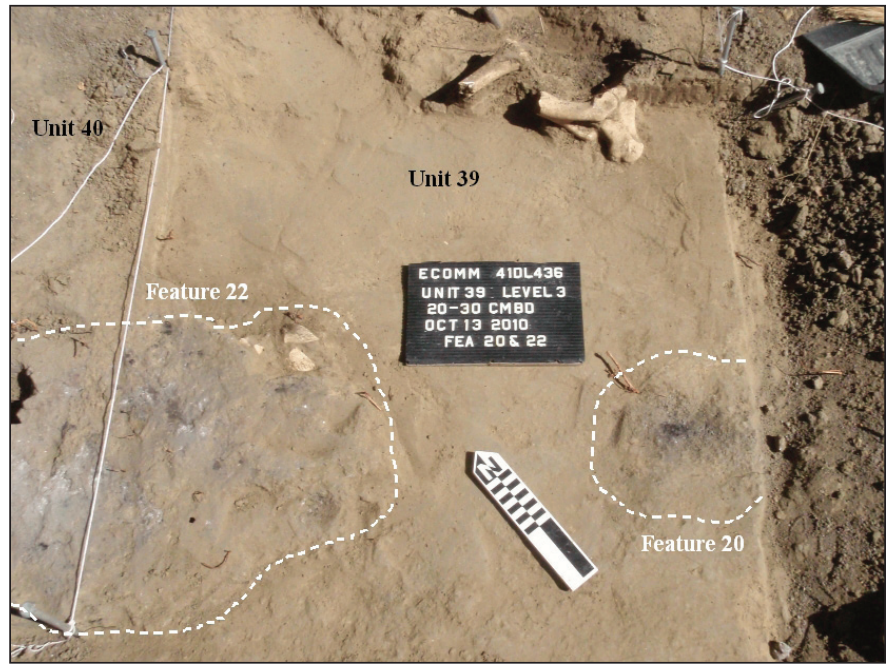

Figure 16-33. Photograph of Features 20 and 22 in Unit 39.

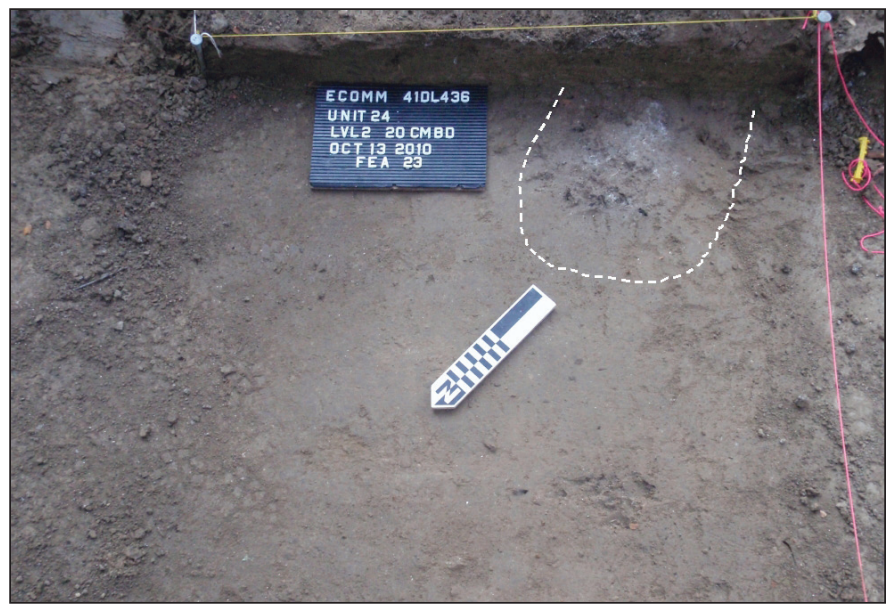

Figure 16-34. Photograph of the upper portion of Feature 23 in Unit 24. 
unmodified) from excavations, and one gray chert, non-heated uniface thinning flake from a floatation sample.

\section{Feature 24-Middle Component-Probable Hearth Area}

Feature 24 consists of a concentration of multiple elements that include a small bifacial tool, a refit core reduction flake, a tabular sandstone rock, charred bone and turtle shell, and charcoal (Figure 16-35). It was discovered between 140-150 cmbs in Unit 32, Level 2, within a pale brown (10YR 6/3) sand strata.

Abundant charcoal both in flecks and small chunks was present throughout the feature. A conventional radiocarbon age obtained from in situ charcoal indicates that the hearth area was likely used sometime between AD 1439 and 1518 or between AD 1594 and 1618 (2 Sigma Calibrated Measured Radiocarbon Age $400 \pm 25$ BP-UGAMS \#8605).

One of the two chipped stone pieces is a biface manufacturing flake made from gray, finegrained chert that appears to have been heat treated. Its right lateral edge exhibits finely pressure flake sharpening scars, presumably for use as a small cutting tool. The second piece is a core reduction flake that has been broken post-depositionally, but the two conjoining pieces of this specimen refit. It was manufactured from an apparent small fine-grained, light gray chert cobble. Its dorsal cortex is brown and stream-smoothed. One edge exhibits small step fractures typical of usewear.

The single burned tabular sandstone rock measured $17.5 \mathrm{~cm}$ long x $12 \mathrm{~cm}$ wide $\mathrm{x} 2 \mathrm{~cm}$ thick. It was submitted to Tim Riley for starches analysis, resulting in the detected presence of Type $\mathrm{F}$ and $\mathrm{G}$ starch granules. Both types are associated with geophytes (perrennial plants propogated by underground buds) or some fruits; other than that, the study by Riley on this specimen yielded little useful results.

A floatation sample comprising five liters of soil submitted to Phil Dering for analysis yielded only four pieces of uncharred woody legume. A total of 195 pieces of faunal material were recovered in association with Feature 24 (Table 16-7).

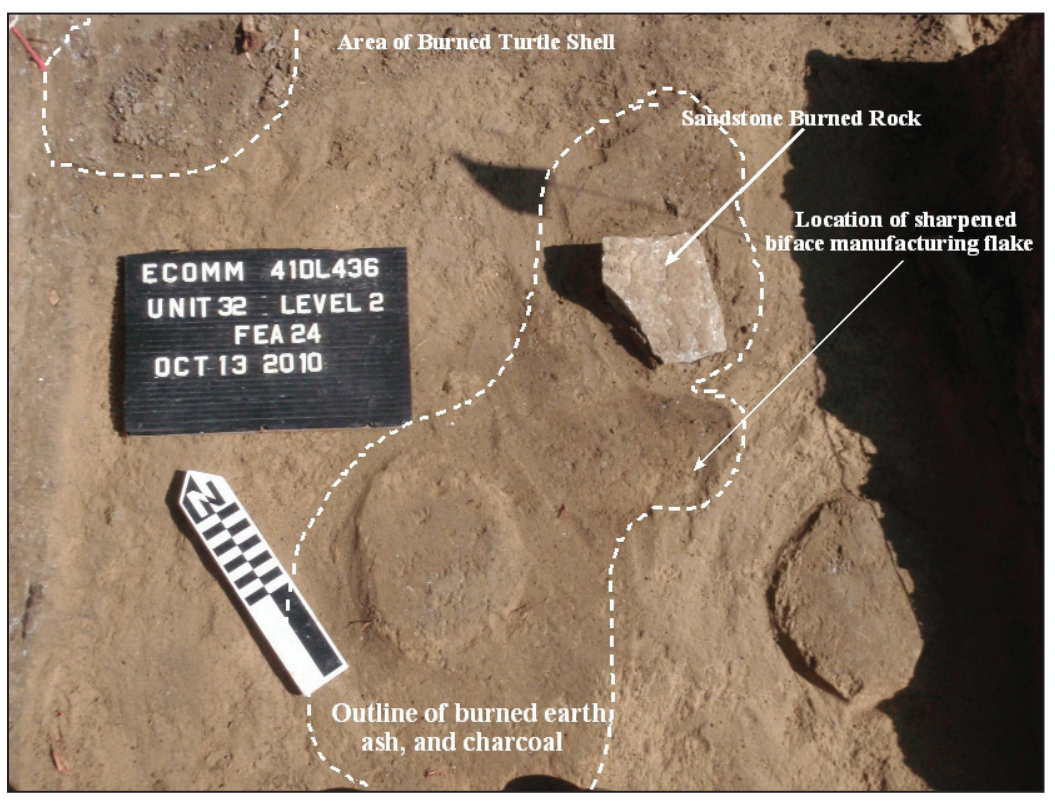

Figure 16-35. Feature 24; photograph taken after bone and bifacial tool removed. 
Table 16-7. Faunal Remains from Feature 24.

\begin{tabular}{llll}
\hline Class & Common Name & Specimens & Description \\
\hline Aves & Birds & 3 & Humerus, fragments \\
\hline Mammal, Small & Small rodent & 1 & Tooth \\
\hline Mammal, Very Small & Cotton Rat & 2 & Femurs \\
\hline Mammal, Large & Unidentifiable & 5 & Axial fragments \\
\hline Mammal, Large & Cow/Bison & 1 & Rib fragment (a) \\
\hline Mammal & Unidentifiable & 1 & Axial fragment \\
\hline Mammal, Very Small & Rice Rat & 2 & Mandible, Tibia \\
\hline Mammal, Very Small & Unidentifiable & 1 & Femur \\
\hline Mammal, Small & Unidentifiable & 3 & Tooth fragments \\
\hline Mammal, Very Small & Mouse/Vole & 2 & Metapodial \\
\hline Mammal, Very Small & Rice/Cotton Rat & 2 & Femur \\
\hline Mammal, Very Small & Rat & 4 & Femur, Tibia \\
\hline Reptile & Turtle & 13 & Shell fragments (b) \\
\hline Reptile & Box Turtle & 1 & Humerus \\
\hline Vertebrate & Non-Venomous Snake & 14 & Vertebra and Ribs (c) \\
\hline Vertebrate & Unidentifiable & 140 & Fragments \\
\hline
\end{tabular}

(a) broken edges are slightly abraded, suggesting use by humans

(b) eight are browned from heating

(c) matches best with racer, garter snake, and water snake

\section{Feature 25-Middle}

\section{Component-Ash and} Charcoal Lens

Feature 25 consists of very thin (less than $2 \mathrm{~cm}$ ) lenses of two dark and ashy basinshaped stains with dense calcium carbonate fines and strings in an area roughly $8 \mathrm{~cm} \times 25 \mathrm{~cm}$ horizontally (Figures 16-36 and 16-37). They were exposed in the west wall of Unit 47, Level $1, \quad 140-142$ cmbs, within a brown clay loam strata sandwiched between two

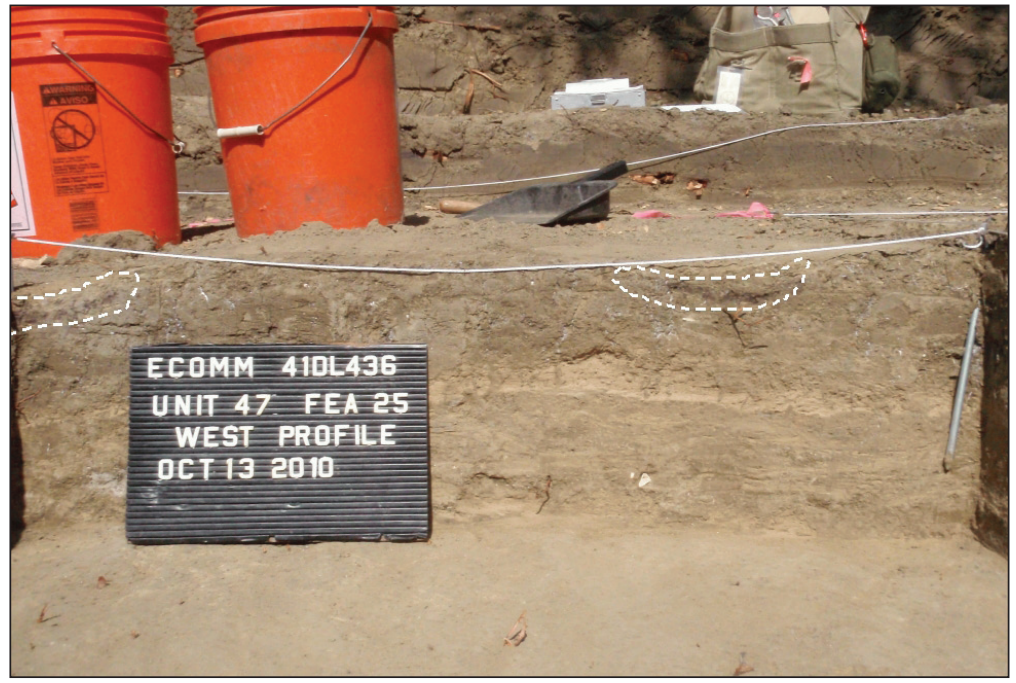

Figure 16-36. Photograph of Feature 25 in profile. yellow sand strata.

In addition to charcoal samples collected in association with the ash and charcoal lenses, a single Rabdotus shell, and four pieces of faunal remains were collected from this level. Faunal remains included one phalanx from a very small rodent, one long bone from a small reptile/amphibian, 


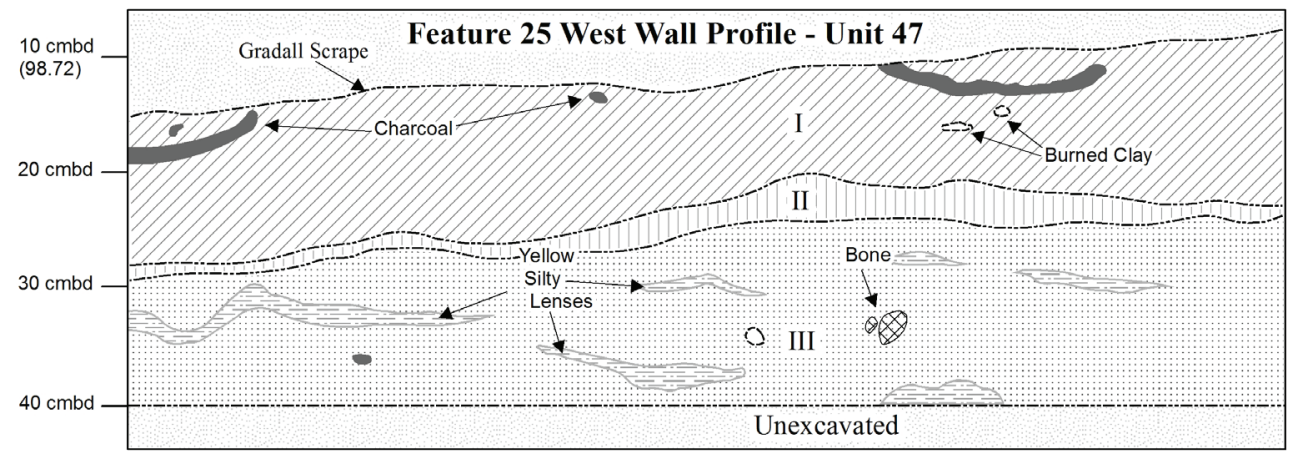

Zone I - 10YR4/3 Silty Loam, $\mathrm{CaCO}_{3}$ threads throughout, mottled with medium granular 10YR5/4 silt Zone III - 10YR4/4 Silt, fine granular with 10YR5/4 silt

Zone II - 10YR5/4 Silt, fine granular

Figure 16-37. Two ash and charcoal lenses comprising Feature 25 in Unit 48; shown here in the west wall profile of adjacent Unit 47.

and ten vertebrate fragments (one of which was blackened).

The inconclusive evidence that the material found in association with these two ash and charcoal lenses implies that their classification as cultural features is questionable. Instead, they may simply represent a natural burning event across an undulating surface.

\section{Feature 26-Middle}

\section{Component-Ash, Charcoal,} and Burned Clay Lens

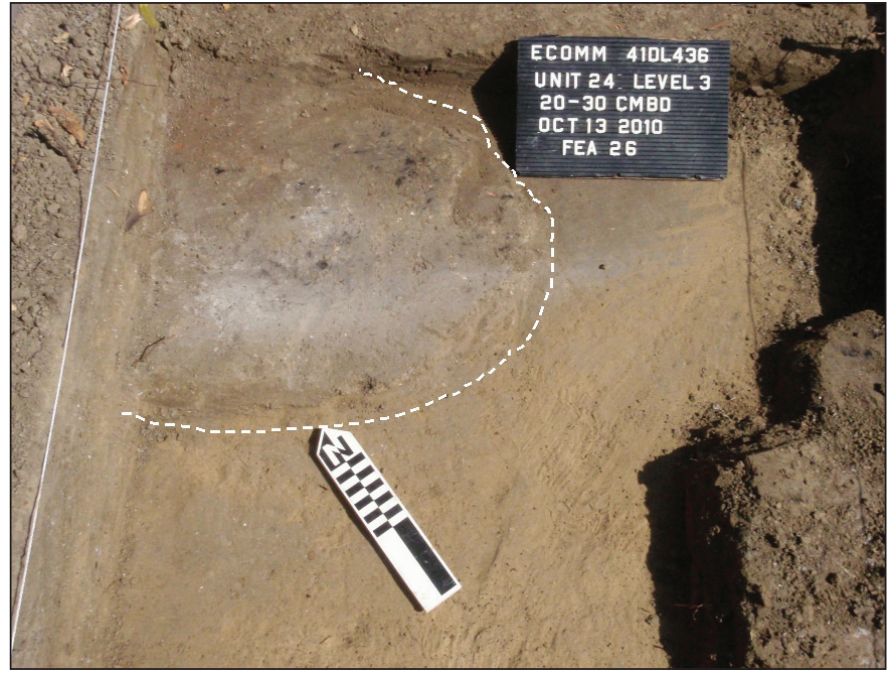

Figure 16-38. Feature 26 in Unit 24.

This feature is an oblong-shaped thin (ca. 2m) lens of charcoal, ash, and orange burned clay measuring roughly $50 \times 50 \mathrm{~cm}$, and embedded within a soil strata comprised of dark yellowish brown (10YR 3 /4) silty, sandy clay loam immediately setting on a yellow, soft sand strata (Figures 16-38 and 16-39). It was excavated in Unit 24, level 3, approximately 145-147 cmbs. Although burned and unburned bones were recovered from the lens that comprises Feature 26, it is unclear whether the feature is a cultural or natural surface burn.

Abundant charcoal both in flecks and small chunks was present throughout the feature. A conventional radiocarbon age obtained from in situ charcoal indicates that the hearth area was likely used sometime between AD 1449-1524 or, between AD 1558-1631 (2 Sigma Calibrated Measured Radiocarbon Age $370 \pm 25$ BP-UGAMS \#8606). However, Abbott (Chapter 5) surmises that this was possibly an old wood sample. A total of 133 pieces of faunal remains were recovered (Table 16-8). 


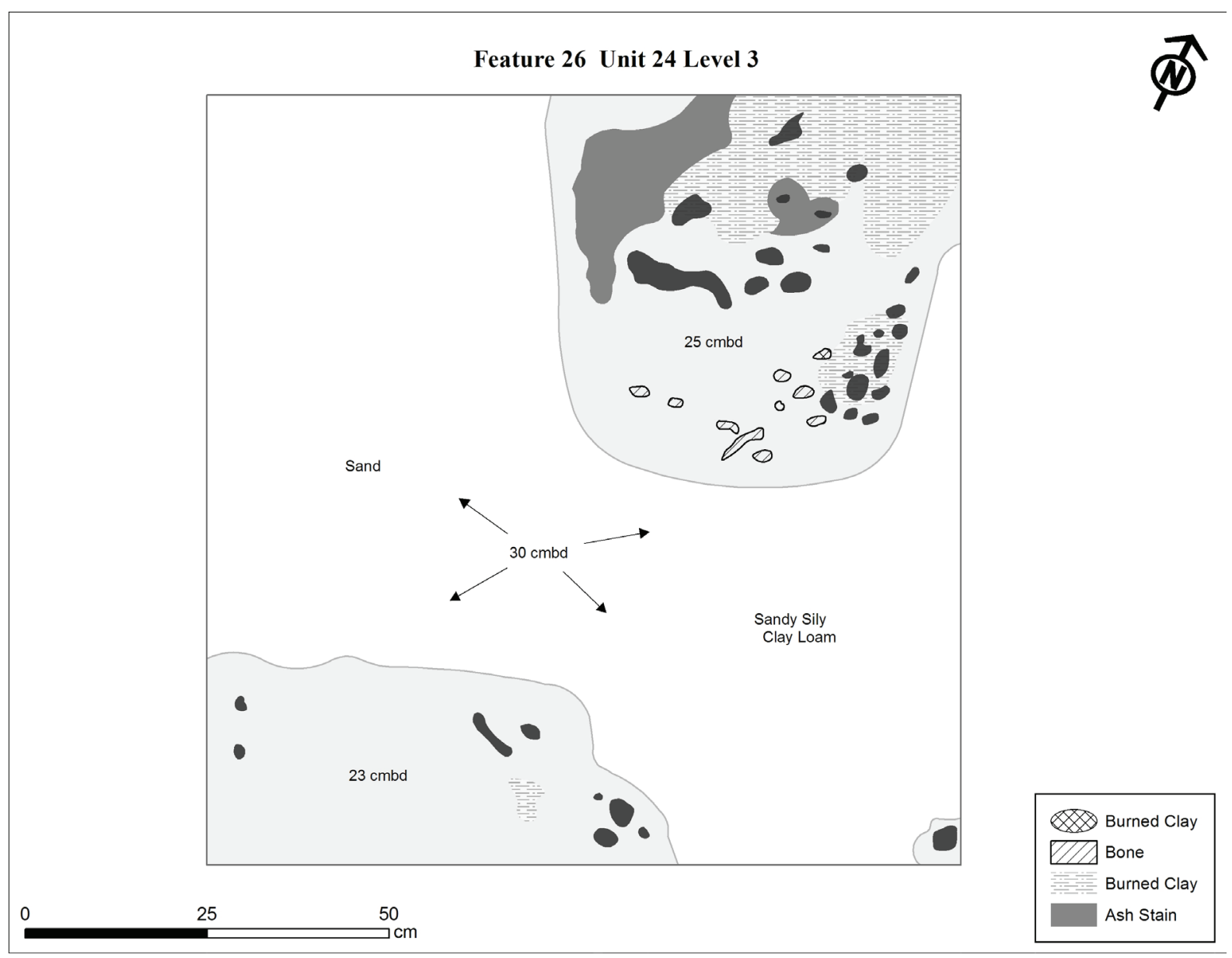

Figure 16-39. Planview of Feature 26.

Table 16-8. Faunal Remains from Feature 26.

\begin{tabular}{llcl}
\hline \multicolumn{1}{c}{ Class } & \multicolumn{1}{c}{ Common Name } & Specimens & \multicolumn{1}{c}{ Description } \\
\hline Mammal, Very Small & Cotton Rat & 9 & 4 Mandibles, Femur, Tibia, Pelvis \\
\hline Mammal, Very Small & Wood Rat & 1 & Femur \\
\hline Mammal, Very Small & Unidentifiable Rat & 3 & Cranial, Pelvis, Tibia \\
\hline Mammal, Medium-Large & Deer & 1 & Carpal \\
\hline Mammal & Artiodactyl & 1 & Long Bone (a) \\
\hline Mammal, Very Small & Unidentifiable & 5 & Vertebra, Phalanx \\
\hline Reptile & Turtle & 10 & Shell fragments (b) \\
\hline Vertebrate & Non-Venomous Snake & 1 & Vertebra \\
\hline Vertebrate & Unidentifiable & 102 & Fragments (c) \\
\hline
\end{tabular}

(a) Compression break from biting; broad bite, could be human

(b) Blackened and charred

(c) Grayed, blackened, and calcined 


\section{Feature 27-Middle Component-Ash and Charcoal Stain}

Feature 27 is a $2-\mathrm{cm}$ lens of charcoal and ash surrounded by darkened and stained soil (Figure 16-40). It was found at a depth of 140-142 cmbs in Unit 21, in the lowest portion of Level 1 and the extreme upper portion of Level 2, and covering an area roughly $50 \mathrm{x} 75 \mathrm{~cm}$. It was situated within brown sandy loam, approximately $10 \mathrm{~cm}$ above yellow sand. With no clearly cultural material associated with this feature, it cannot be certain as to whether or not it is cultural; but, it may represent an expedient surface hearth.

Although an abundance of charcoal flecks was observed, and larger samples were collected from in situ, none were submitted for assay. Three Rabdotus snail shells were recovered from Level 1, along with a single medium-large deer phalanx blackened from burning. The only fauna pieces recovered from Level 2 were eight unidentifiable mammal fragments and one unidentifiable vertebrate fragment (none modified).

\section{Feature 28-Middle}

\section{Component-Basin Shaped} Pit with Ash, Charcoal, and Burned Clay

The foci of Feature 28 is a $10-\mathrm{cm}$ deep basin shape pit, infilled with charcoal and ash, with a 1-2-cm lens of darkened soiled stained with charcoal and ash surrounding it at the top. It had an orange burned clay layer laden with charcoal chunks and flecks, and dark ash in a thin (ca. $1 \mathrm{~cm}$ ) layer, irregular in shape, lying on a dark brown clay loam strata roughly $180 \mathrm{cmbs}$. This burned orange clay lens thickened toward the east and extended into the Gradall Trench wall as shown in Figure 16-41. The orange splotches of burned clay were generally surrounded with black charcoal. Some areas had white and gray ash remnants.

The feature was first exposed in the bottom of the Gradall trench. Excavation was then begun in Unit $46 \mathrm{~A}$ by scraping with a flat shovel in

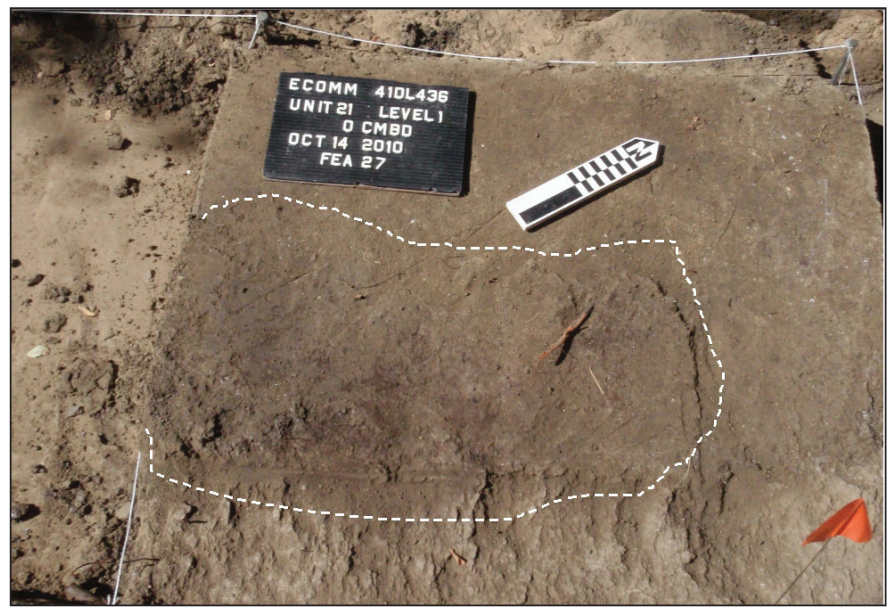

Figure 16-40. Feature 27 in Unit 21.

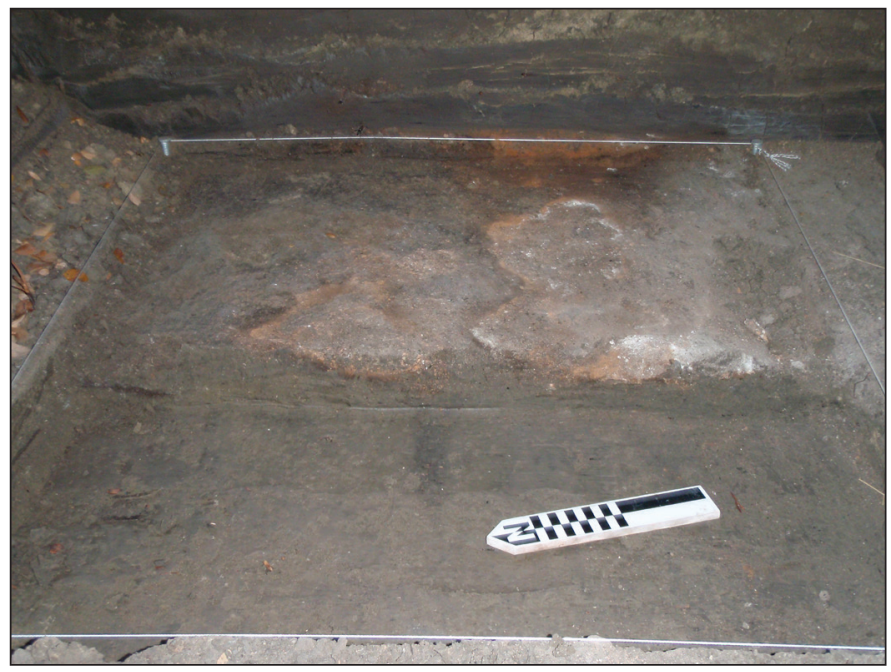

Figure 16-41. Photograph of Feature 28 halved; 0-10 cmbd, with top of feature pedestaled. 
1-cm increments to $3 \mathrm{cmbd}$. The pattern of burned versus unburned areas shifted slightly with depth in Level 1.

The western $30 \mathrm{~cm}$ of Unit 46A was then excavated in order to expose it in profile. Notably, as shown in Figure 16-41, the orange burned clay clearly extended to the east, into the Gradall trench wall.

Following that, the western half of the unit was excavated, leaving the eastern half of the unit intact in order to provide another exposure of the feature in profile. As shown in Figure 16-42, there was a bowl shape to the center of the feature.

Finally, following the termination of excavations in Unit 46A, Figure 16-43 shows the profile of the burned orange clay layer part of Feature 28 as it extended into the east wall of the Gradall trench.

When collecting charcoal samples, the excavator noted a root or branch that appeared to be only charred, suggesting a recent burn. However, a conventional radiocarbon age obtained from in situ heavily burned charcoal indicates that the burned

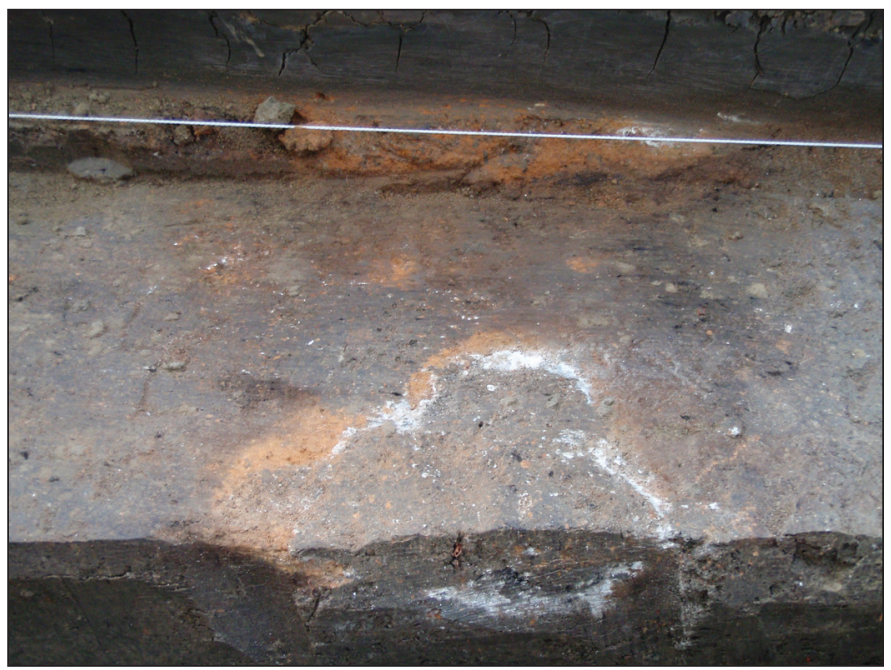

Figure 16-42. Photograph of Feature 28 east wall profile (50 $\mathrm{cm}$ from west wall).

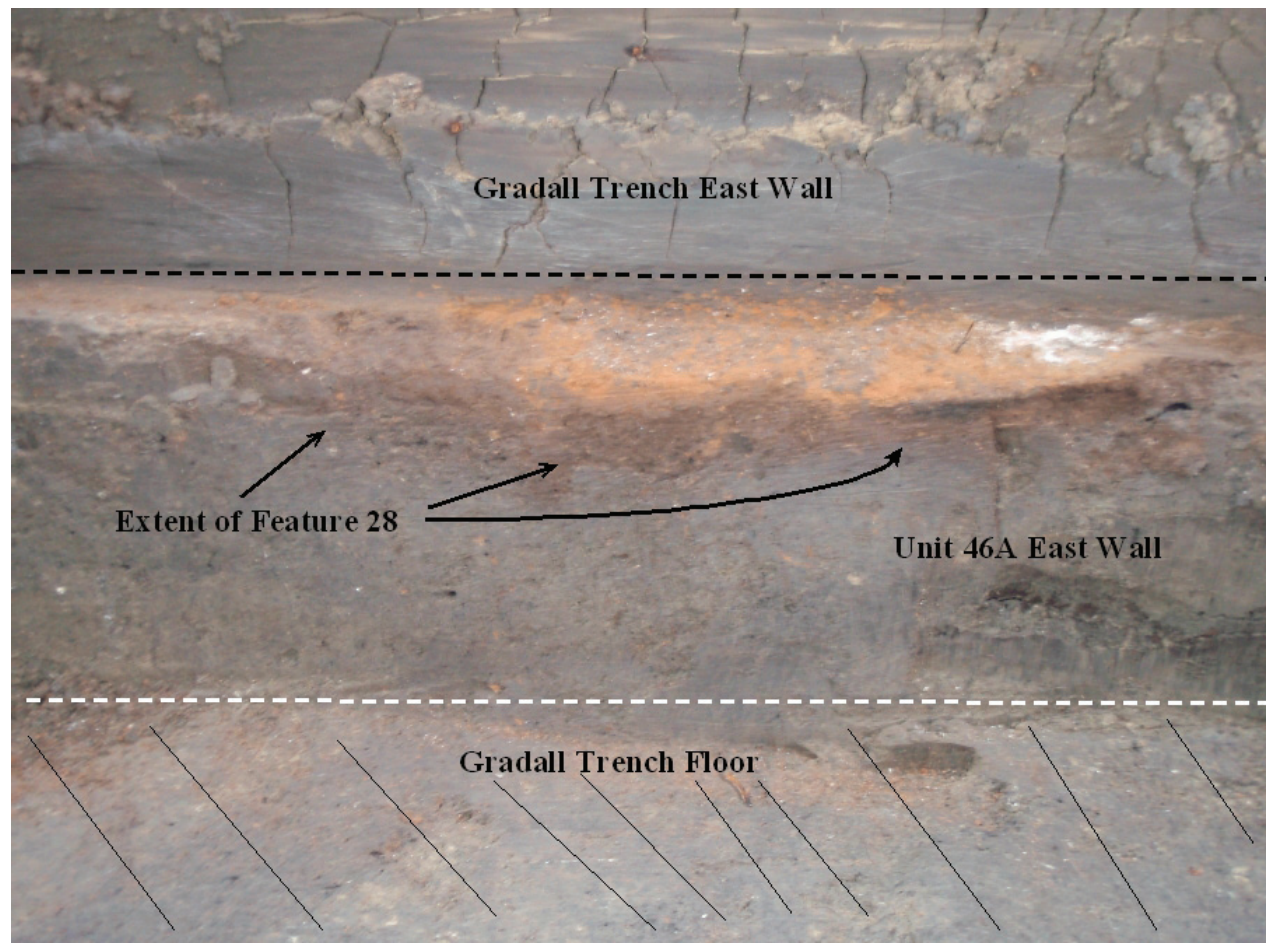

Figure 16-43.

Photograph

of Feature 28

extension into

Gradall trench

wall following

excavation of

Unit 46A. 
area was likely ignited sometime between AD 1470 and 1840 (2 Sigma Calibrated Measured Radiocarbon Age $340 \pm 30$ BP-Beta 312835). The 47 pieces of faunal remains recovered from Level 1 in Unit 46A include 45 unidentifiable vertebrate fragments, 28 of which were calcined from burning, and three were blackened. The remaining two pieces were a pelvis from a very small mammal, and an unidentifiable fragment from a mammal (neither of which exhibited evidence of burning or other modification).

In sum, without conclusive associated evidence that this feature is a result of cultural actions, it is quite possibly a natural and an intensively burned surface, with charcoal chunks and ash trending along the natural slope of the Fish Creek paleochannel.

\section{Feature 29-Middle Component-Burned Clay and Charcoal Lens}

Feature 29 (Figure 16-44) is a burned clay and charcoal stained lens that is setting on a 10YR 6/3 silt layer and is below a $10 \mathrm{YR} 3 / 2$ silty clay loam. The shape of it is amorphous, measuring $60 \mathrm{x}$ $85 \mathrm{~cm}$, and it was uncovered $120 \mathrm{cmbs}$ in Level 2 of Units 12 and 48A, and Level 1 in Unit 50.

A conventional radiocarbon age obtained from in situ heavily burned charcoal indicates that the burned area was likely ignited sometime between AD 1447 and 1527,

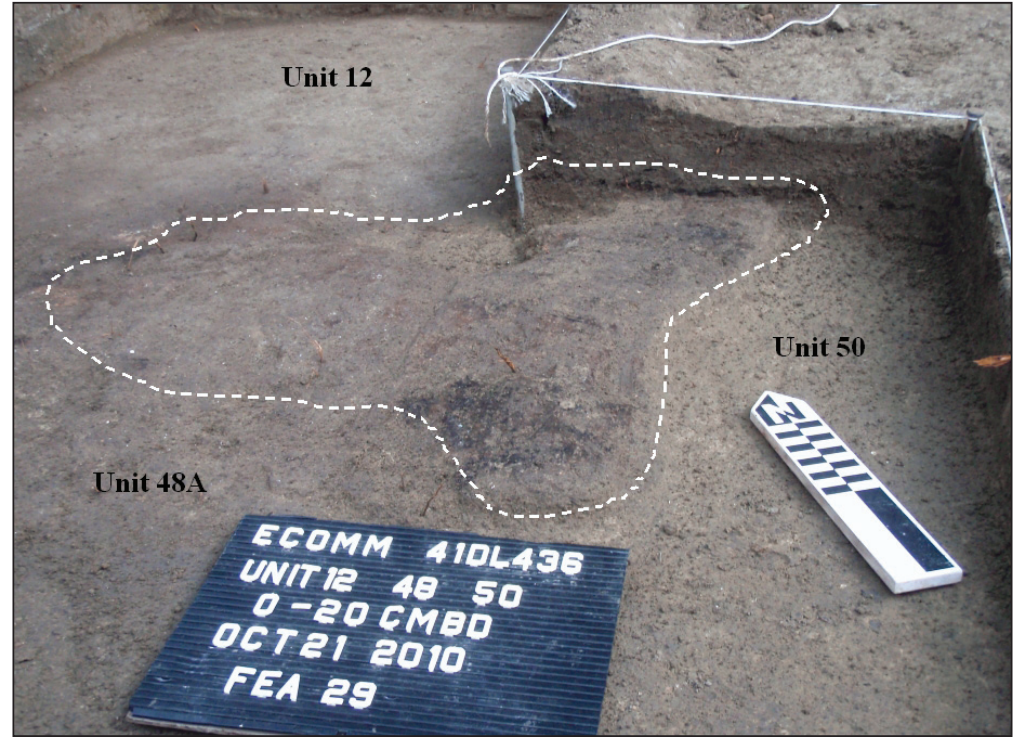

Figure 16-44. Photograph of Feature 29. or between AD 1553 and 1633 (2 Sigma Calibrated Measured Radiocarbon Age $370 \pm 30$ BP-UGAMS 8607). Although charcoal was abundant, no faunal remains, or any other artifacts were observed in any of the three units and levels associated with Feature 29. This appears to corroborate the excavator's observation in the field when he noted that there were no artifacts associated with this feature, and that it was most likely a naturally occurring surface burn. However, a cultural surface hearth cannot be ruled out.

\section{Feature 30-Middle Component-Open Surface Hearth}

This feature is a burned clay/charcoal/ash concentration approximately $1-3 \mathrm{~cm}$ thick, roughly $60 \times 120 \mathrm{~cm}$ in size, and discovered $120 \mathrm{cmbs}$ in a Gradall scrape. It was a thin layer that sat within a 10YR 4/3 silty loam, and on top of a 10YR 5/4 layer of silt (Figures 16-45 and 
16-46). Level 1 in Units 51 and 56 were opened in order to investigate the feature. Excavators noted that some burned bone was found on top of the feature in both units, and there seemed to have been a greater amount of charcoal in Unit 56. The feature extended slightly into the west wall of the Gradall trench, and was not further exposed, but only flecks of charcoal could be seen in the trench wall, and the excavators opined that the feature likely did not

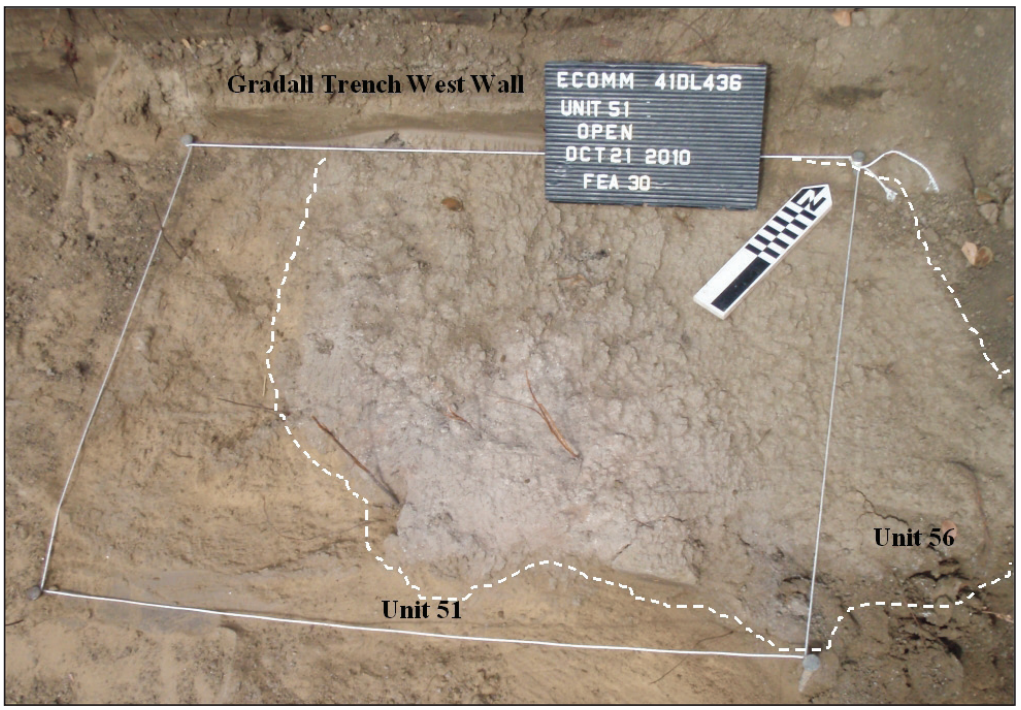

Figure 16-45. Photograph of Feature 30. extend much further in that direction.

Although charcoal samples were collected in situ from the feature, none were submitted for assay. A handful of small snail shells were recovered from a floatation sample (not analyzed, but curated), as was additional charcoal. A total of 232 faunal remains were recovered from Unit 51, Level 1 (Table 16-9).

In sum, the wide variety of animal remains found in association with this feature, and the various degrees of burning that has occurred on virtually all classes of animals strongly argue that this feature was indeed used as a cooking element for roasting meat over an open hearth. The absence of rocks as heating elements further implies that the hearth was constructed with wood only. This open hearth feature without fire-cracked rocks may be typical of the many smaller and constricted burned areas uncovered during these excavations.

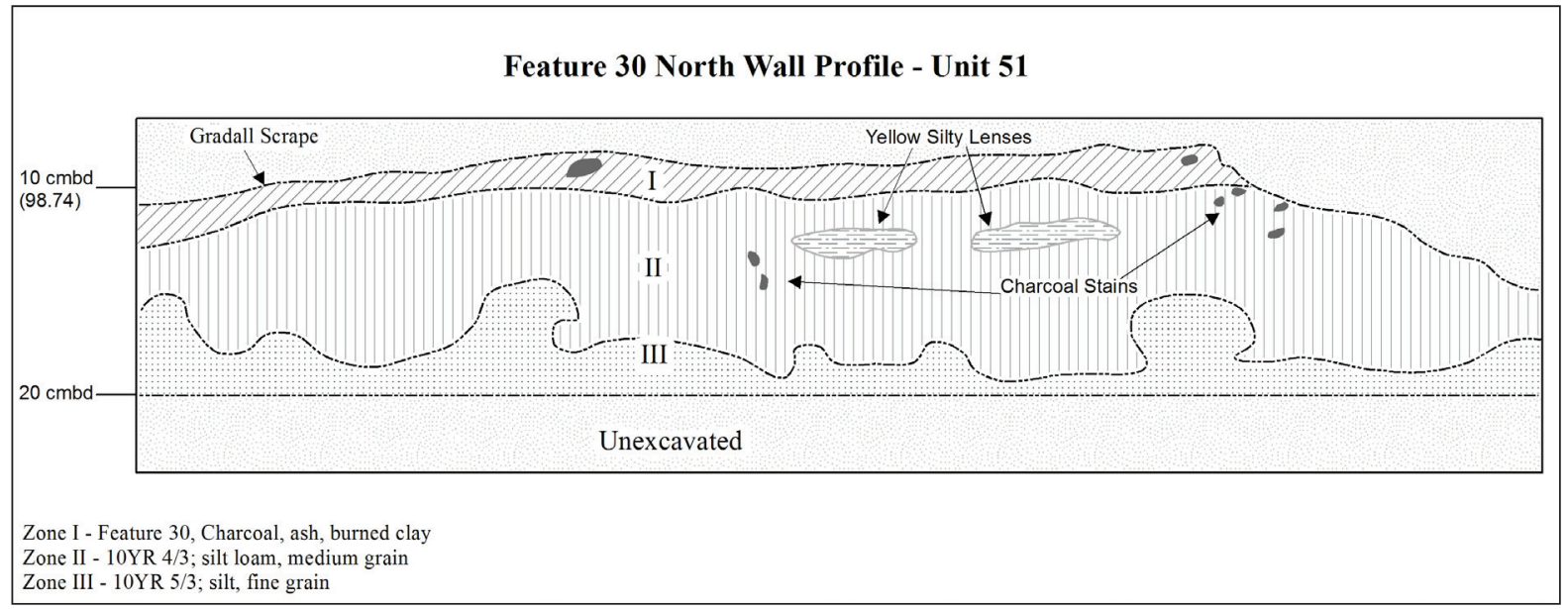

Figure 16-46. Profile of Feature 30 in north wall of Unit 51. 
Table 16-9. Faunal Remains from Feature 30.

\begin{tabular}{llcl}
\hline Class & Common Name & Specimens & Description \\
\hline Aves, Small \& Medium & Birds & 2 & Phalanx - (a) \\
\hline Mammal, Very Small & Cotton Rat & 11 & Vertebra, Calcaneous - (b) \\
\hline Mammal, Very Small & Rodent & 19 & Phalanx, Tooth - (c) \\
\hline Mammal, Medium-Large & Artiodactyl & 1 & Rib \\
\hline Mammal, Very Small & Unidentifiable & 4 & Vertebra - (d) \\
\hline Mammal, Very Small & Unidentifiable & 4 & Fragments - (e) \\
\hline Mammal, Very Small & Rodent & 1 & Tooth \\
\hline Reptile, Medium & Box Turtle & 2 & Plastron, Carapace - (f) \\
\hline Reptile, Small & Lizard & 2 & Tibia, Rib \\
\hline Reptile, Medium & Turtle & 31 & Plastron, Shell - (g) \\
\hline Vertebrate & Unidentifiable & 245 & Fragments - (h) \\
\hline
\end{tabular}

\footnotetext{
(a) Grayed and blackened from burning

(b) Grayed, blackened, calcined

(c) Grayed, blackened

(d) Grayed, calcined

(e) Grayed

(f) Plastron (breastplate) blackened

(g) Grayed, blackened

(h) Browned, blackened, calcined
}

\section{Feature 31-Middle Component-Ash, Charcoal, and Burned Clay Lens}

Feature 31 is a charcoal and burned clay stain with small splotches of dark red and orange burned clay among the ash and charcoal. Although generally 2-3 cm thick, some areas contained the same matrix as much as $6 \mathrm{~cm}$ thick. The outline of the stain was irregular in shape, and was discovered $120 \mathrm{cmbs}$ during a Gradall scrape. Upon broom sweeping the entire surface across the north end of the trench surface scraped by the Gradall, it became apparent that the ash, charcoal, and burned clay lens extended alternately and sporadically across the entire six-meter width of the trench (Figures 16-47 and 16-48).

The extensive lens lay on top of yellowish, silty and sandy loam. Mussel shell fragments and unburned seeds (probably hackberry) were observed in small areas around the stain. A charcoal concentration in the shape of a burned branch was observed running across the

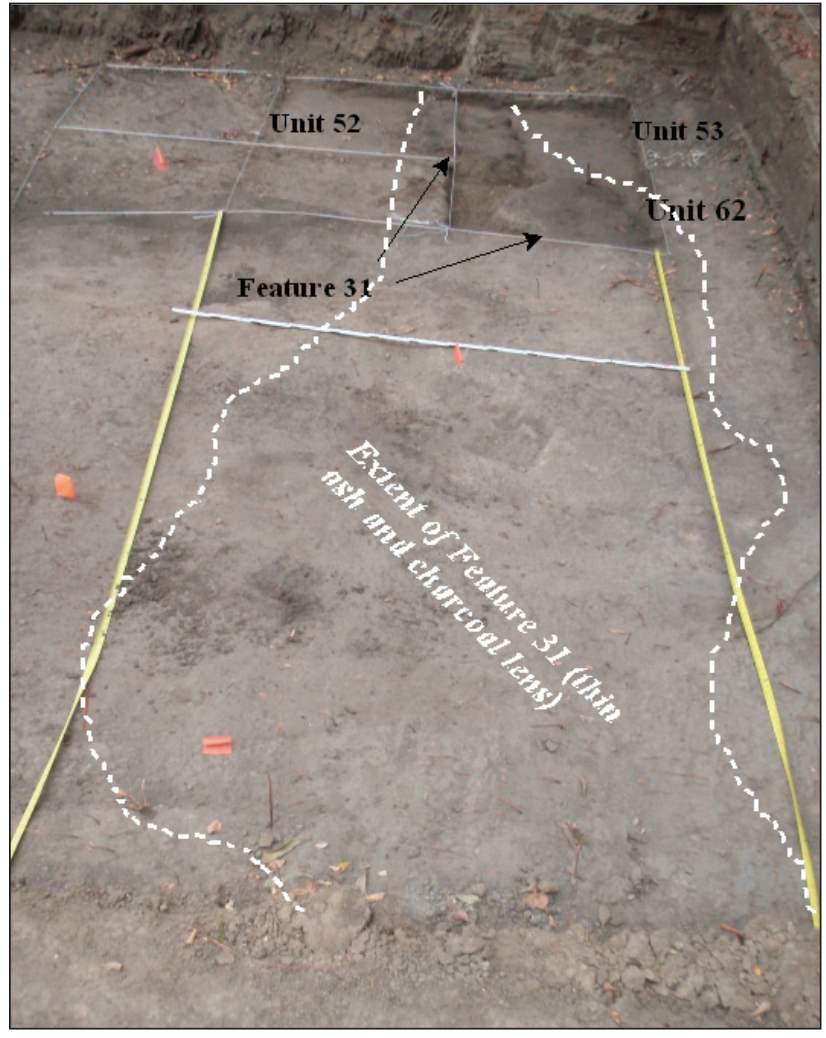

Figure 16-47. Photograph showing locations of Units 52, 53, and 62 relative to the entire extent of Feature 31; facing west. 
stained area from the northwest to the southeast. After the Gradall exposed the upper surface of the stained area, excavation units 52, 53, and 62 were opened to further investigate the feature.

A conventional radiocarbon age obtained from in situ charcoal in Unit 53 indicates that the burn likely occurred sometime between AD 1442 and 1522, or between AD 1574 and 1584, or between AD 1590 and 1624 (2 Sigma Calibrated Measured Radiocarbon Age $390 \pm 30$ BPUGAMS 8608). However, as discussed in Chapter 5 (Table 5-2), Abbott surmises this may have been an old wood sample. Besides abundant charcoal observed in Units 52, 53, and 62, one Rabdotus snail was recovered from Unit 62. Other than that, the only piece of faunal material recovered was a fragment from an unidentifiable vertebrate. A small floatation sample comprising merely one liter of soil submitted to Phil Dering for analysis yielded only four pieces of charred elm wood.

In sum, the absence of clearly cultural materials or other conclusive evidence suggests that the extensive but thin ash and charcoal lens represents a natural burn occurring on an undulating surface sometime between $\mathrm{AD}$ 1442 and 1624.

\section{Feature 32 - Middle Component - Ash, Charcoal, and Burned Clay Lens}

Feature 32 is a small (ca. 30 $\mathrm{cm}$ x $40 \mathrm{~cm}$ ) burned clay and charcoal concentration located a few centimeters above Feature 30 in Unit 56. This very thin (ca. 2-3 cm) layer sets on top of a silty loam 116-118 cmbs. It was exposed while trying to expose the boundary of Feature 30, although they appear to not be associated with each other. The west edge of Feature 32 extended slightly into the west wall of the Gradall trench (Figures 16-49 and 16-50 [Photo

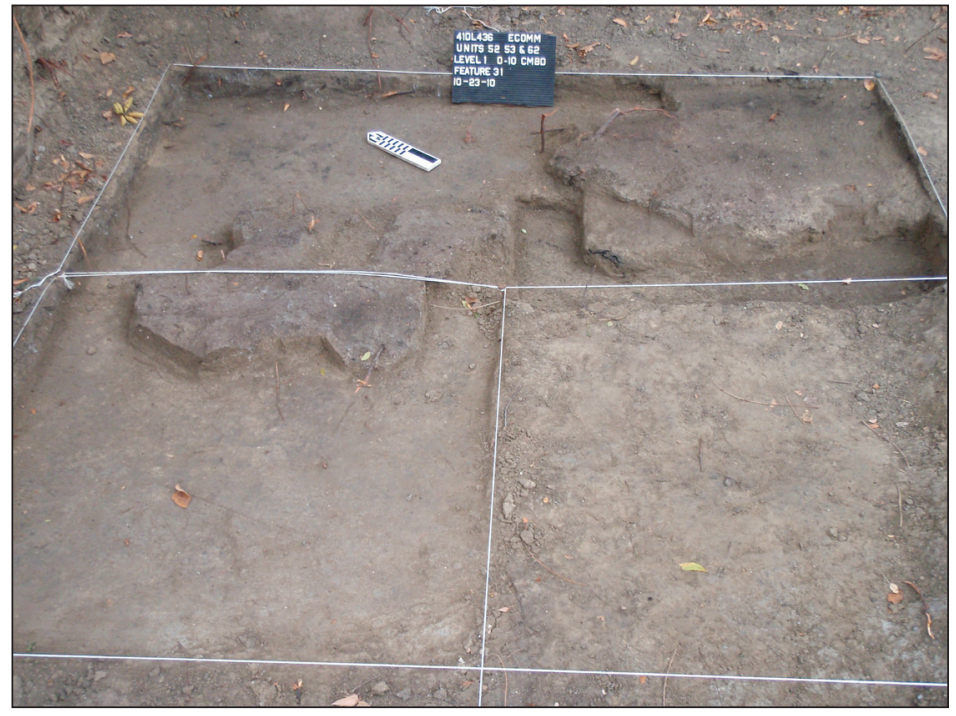

Figure 16-48. Photograph of Feature 31 in Units 52,53 , and 62 ; facing east.

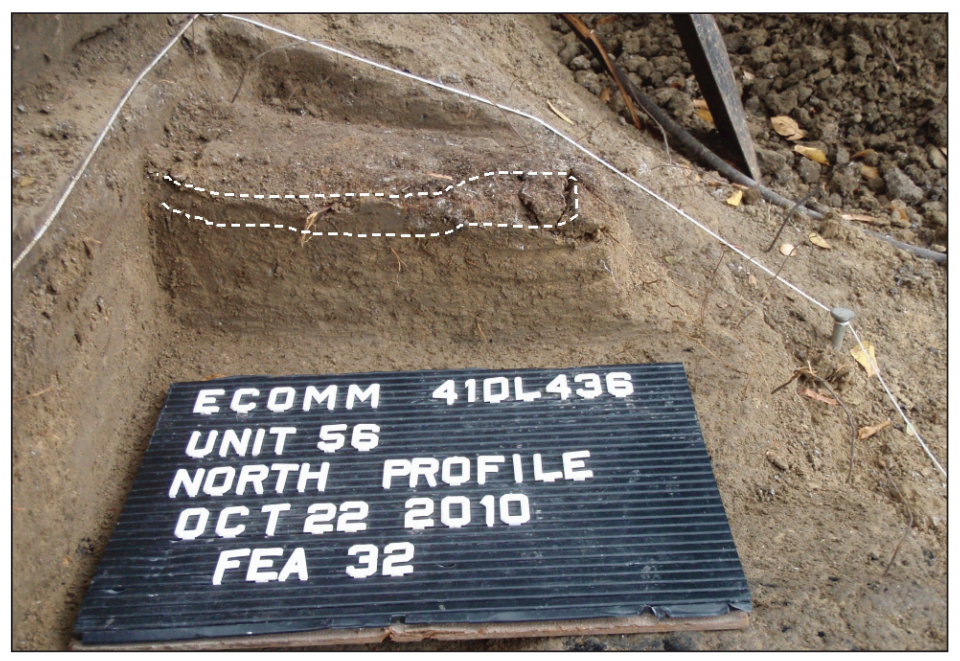

Figure 16-49. Photograph of Feature 32; facing north. 


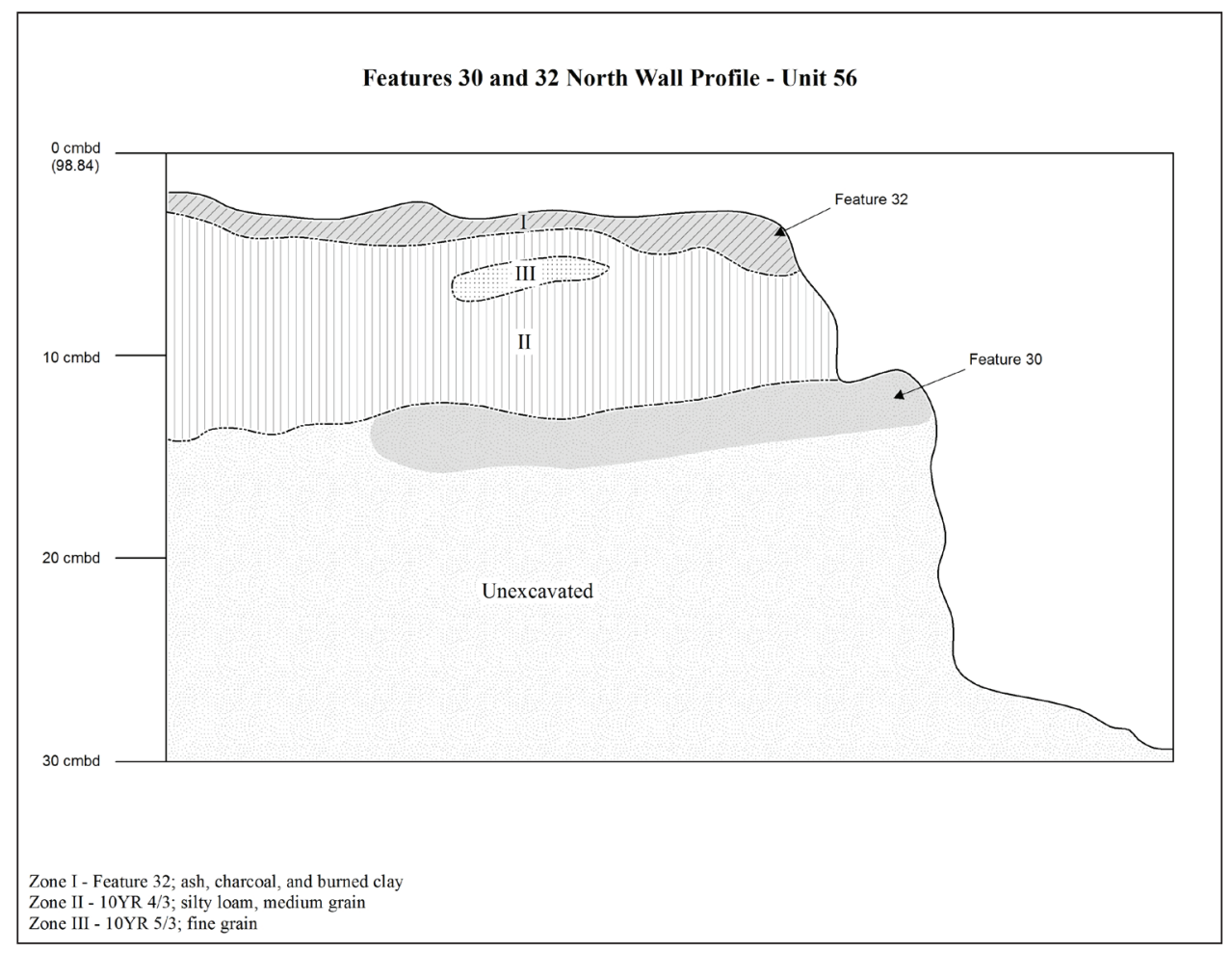

Figure 16-50. North wall profile of Features 30 and 32 in Unit 56.

Organic material observed in association with Feature 32 (Unit 56, Levels 1 and 2) included an abundance of fine charcoal and ash, one unidentifiable fragment of a mussel shell, and 36 pieces of bone. The bone pieces included: two mandibles and a maxilla from a cotton rat; a rib from a cow or bison; a femur from a ground squirrel; two tibia and a femur from a kangaroo rat; three calcined vertebra from an unidentified rat; eight phalanxes from an unidentified rodent (or rodents) that exhibited evidence of graying, blackening, and calcining from burning; two fragments from a medium-large but unidentifiable mammal; one fragment from a very small but unidentifiable mammal; seven plastron (breastplate) fragments from a box turtle, six of which were either browned, blackened, or calcined; three plastron fragments from an unidentifiable turtle, two of which were browned and blackened; and, four vertebrate fragments.

In sum, as with Feature 30 described above, the wide variety of animal remains found in association with Feature 32, and the various degrees of burning that have occurred on virtually all classes of animals strongly argue that this feature was indeed used as a cooking element for roasting meat over an open hearth. The absence of rocks as heating elements further implies that the hearth was constructed with wood only. This open hearth feature without fire-cracked rocks seems to be typical of many smaller and constricted burned areas uncovered during these excavations.

\section{Feature 33-Middle Component-Burned Clay and Ash Smear}

This feature consists of a burned clay and ash smear crossing and sloping along what is the Fish Creek paleochannel. The amorphous stain started at elevation $98.2 \mathrm{~m}$ and headed downslope 
toward the south and east, and elevation $98.1 \mathrm{~m}$. It consisted of three main smears; two in Unit 61 in the northeast and northwest corners, and one in Unit 66 in the southwest corner. All three smears were outlined by a very dark, nearly black burned area, with lighter burnt orange and pale brown hues in the centers. The same example of this outer burned and blackened area showed up in the west wall profile of Unit 61 (Figures 16-51 and 16-52).

The feature's surrounding matrix included mostly clay loam on its southern boundary, with lighter mottling of sandy clay loam on its northern boundary. The burnt orange stain may have been caused by more intensive clay burning, with the darker colors representing either less clay content or less intensive heat. Whether or not this feature is cultural is unknown.

A conventional radiocarbon date obtained from charcoal collected from a floatation sample in Unit 61 , Level 2 indicates that the burn most probably occurred sometime between AD 1499 and 1501, or between $\mathrm{AD} 1513$ and 1600, or between AD 1617 and 1660 (2 Sigma Calibrated Measured Radiocarbon Age $290 \pm 30$ BP-UGAMS 8609).

Besides abundant charcoal, ash, and burned clay observed in Units 61 and 66, small snail shells were recovered from a Unit 61 floatation sample (not analyzed, but curated). The only faunal remains recovered that could be associated with the sloping feature were 18 fragments from an unidentifiable vertebrate, one of which was blackened from

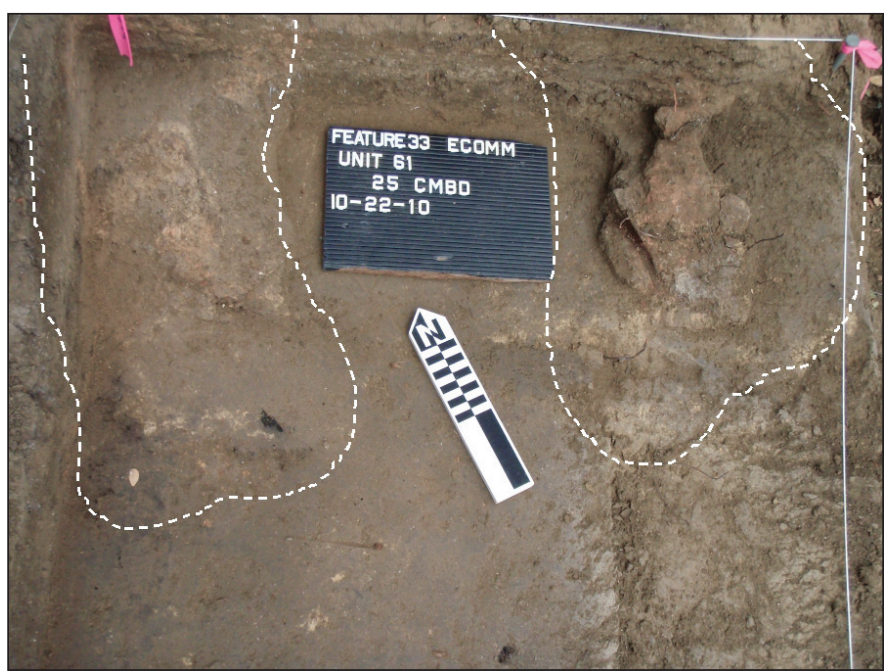

Figure 16-51. Photograph of Feature 33, Unit 61.

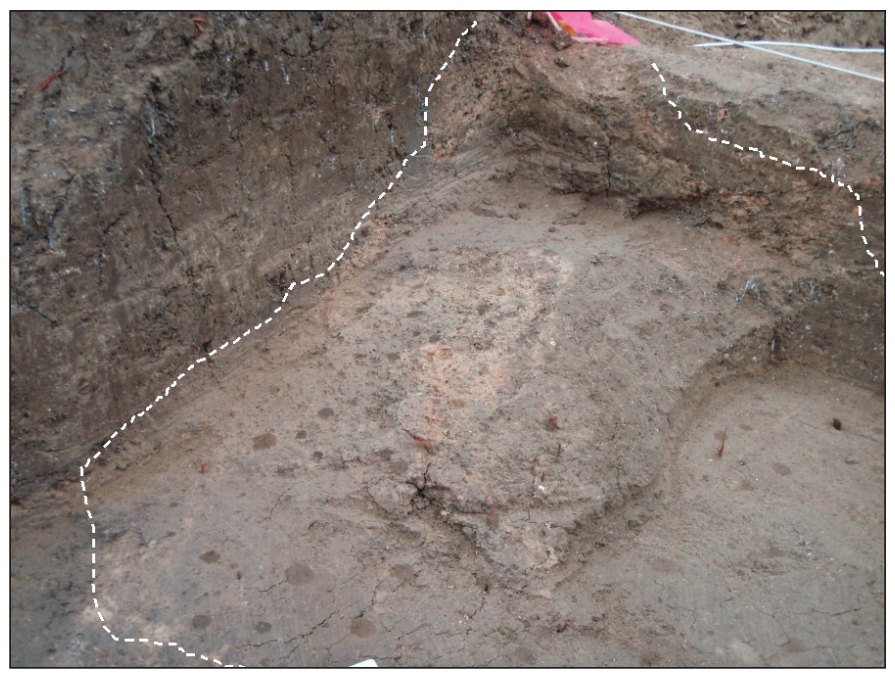

Figure 16-52. Feature 33 outline in Unit 61; facing northwest. burning.

In sum, without conclusive evidence that suggests that this burn was induced by humans, we must presume that it was a natural surface burn that followed the sloping bank of Fish Creek sometime between AD 1499 and 1660. 


\section{Feature 34 - Middle Component - Ash, Charcoal, and Burned Clay Mass}

Feature 34 (Figure 16-53) is an amorphous conglomerate of burned clay, ash, and charcoal discovered between 120-127 cmbs in Level 1 of Units 55 and 59. Slightly oval in shape, it measured approximately 60 $\mathrm{cm} \times 100 \mathrm{~cm}$. As shown in Figure 16-53, the feature appears to have been interrupted by a rodent burrow. Stratigraphically, it appears to be co-eval with Feature 35 in Units 55 and 65, where a conventional radiocarbon date indicates that the hearth was probably used sometime between AD 1413 and 1447 (2 Sigma Calibrated Measured Radiocarbon

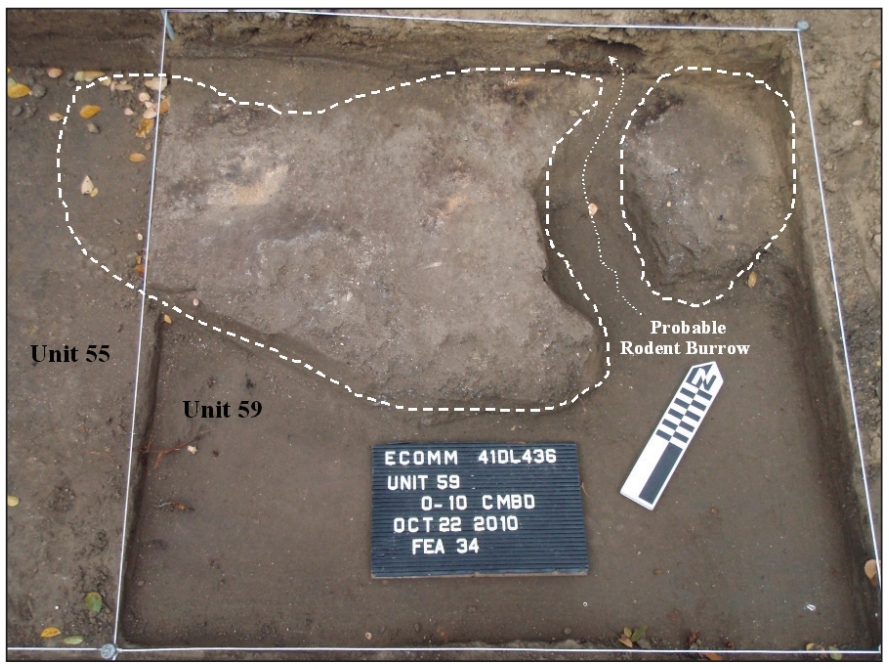

Figure 16-53. Photograph of Feature 34 in Unit 59. Age $480 \pm 25$ BP-UGAMS 8610).

However, as Abbott argues in Chapter 5, this was probably an old wood sample (see Table 5-2).

Although abundant charcoal was observed and samples collected, none were submitted for assay. The single mussel shell fragment recovered and submitted to Bob Howells was unidentifiable as to species. In addition, three Rabdotus snails were found in association with the feature, as were 140 pieces of faunal remains (Table 16-10).

Table 16-10. Faunal Remains from Feature 34.

\begin{tabular}{llcl}
\hline \multicolumn{1}{c}{ Class } & \multicolumn{1}{c}{ Common Name } & Specimens & \multicolumn{1}{c}{ Description } \\
\hline Amphibian, Small & Unidentifiable & 2 & Long Bone \\
\hline Aves, Medium & Bird & 1 & Vertebral Segment \\
\hline Mammal, large & Unidentifiable & 43 & Long Bone Fragments \\
\hline Mammal, Very Small & Pocket Gopher & 1 & Mandible \\
\hline Mammal & Unidentifiable & 8 & Fragments (a) \\
\hline Mammal, Medium-Large & Deer/Pronghorn & 1 & Sesmoid \\
\hline Mammal, Microtene & Least Desert Shrew & 1 & Mandible \\
\hline Mammal, Medium-Large & Hooved Animal & 1 & Cranial \\
\hline Mammal, Very Small & Rice Rat & 3 & Femurs, Pelvis (b) \\
\hline Mammal, Very Small & Rodent & 6 & Teeth, Metapodial, Phalanx \\
\hline Reptile, Medium & Turtle & 3 & Carapace (dorsal plates) (c) \\
\hline Reptile, Medium & Box Turtle & 1 & Carapace (dorsal plate) \\
\hline Vertebrate & Unidentifiable & 69 & Fragments (d) \\
\hline
\end{tabular}

(a) 2 calcined; 3 blackened

(b) 1 Femur browned

(c) 2 blackened

(d) 7 blackened 
In sum, the wide variety of faunal remains associated with this feature suggest that it was relatively large surficial hearth used for roasting meat. The absence of rocks as heating elements further implies that the hearth was constructed with wood only. As with Features 30 and 32, this open hearth feature without fire-cracked rocks appear to be typical of many smaller and constricted burned areas uncovered during these excavations.

\section{Feature 35-Middle Component-Ash, Charcoal and Burned Clay Mass}

Feature 35 is an amorphous conglomerate of burned clay, ash, and charcoal discovered between $115-120 \mathrm{cmbs}$ in Level 1 of Units 55 and 65 (Figure 16-54). Slightly oval in shape, with only a very slight basin shape, it measured approximately 35 $\mathrm{x} 40 \mathrm{~cm}$. It was located $5 \mathrm{~cm}$ above, and $1 \mathrm{~m}$ north of Feature 34.

A conventional radiocarbon age from in situ charcoal indicates that the hearth was likely used sometime between $\mathrm{AD} 1423$ and 1441, or between AD 1413 and 1447 (2 Sigma

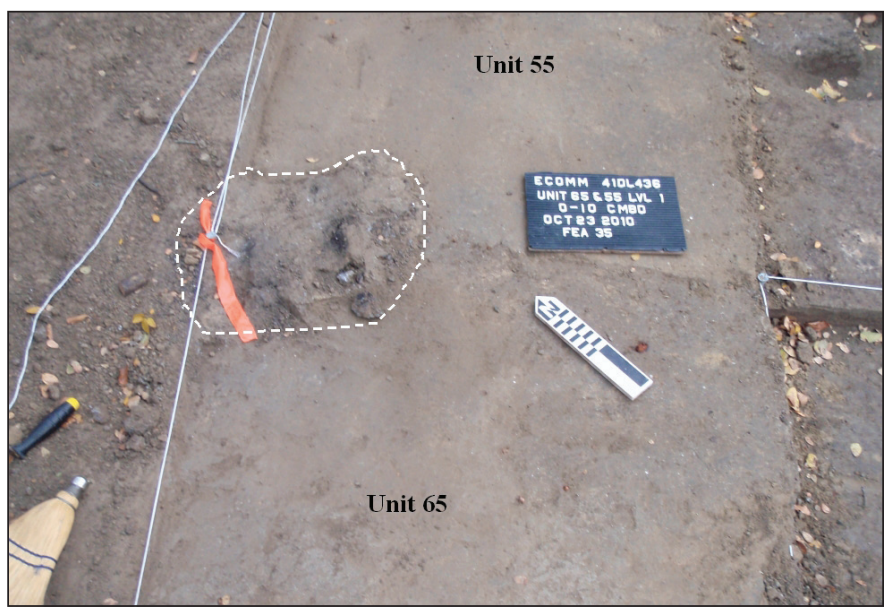

Figure 16-54. Photograph of Feature 35. Calibrated Measured Radiocarbon Age $480 \pm 25$ BP-UGAMS 8610). However, as Abbott posits in Chapter 5, this was probably an old wood sample (see also, Table 5-2). A few small snail shells (not analyzed, but curated) and charcoal was recovered from a floatation sample. A floatation sample comprising 7.5 liters of soil submitted to Phil Dering for analysis yielded only 28 pieces of uncharred elm wood. From the 1/4-inch screen, excavators recovered two Rabdotus shells, charcoal, and 14 faunal specimens (Table 16-11).

Table 16-11. Faunal Remains from Feature 35.

\begin{tabular}{cccc}
\hline Class & Common Name & \# Pieces & Description \\
\hline Mammal, Medium-Large & White-Tailed Deer & 2 & Ulna, Radius (a) \\
\hline Mammal, Large & Hooved Animal & 2 & Ulna \\
\hline Mammal, Very Small & Rodent & 2 & Teeth \\
\hline Osteichtheyes, Very Small & Bony Fish & 2 & Cleithrum, Pectoral Spine \\
\hline Vertebrate & Unidentifiable & 6 & Fragments (b) \\
\hline
\end{tabular}

(a) Animal is greater than 4 years old; cut marks on ulna possibly by humans, then

gnawed by carnivore; both ulna and radius show signs of disease

(b) Two blackened from burning 
In sum, the variety of faunal remains associated with this feature suggest that it is a small surficial hearth used for roasting meat. The absence of rocks as heating elements further implies that the hearth was constructed with wood only. As with Features 30, 32, and 34, this open hearth feature without fire-cracked rocks is typical of the many smaller and constricted burned areas uncovered during these excavations.

\section{Feature 37-Middle Component-Probable Open Surface Hearth}

Feature 37 is a ca. $30 \times 40-\mathrm{cm}$ concentration of burned clay, charcoal, and ashy matrix with calcium carbonate fines throughout. It was uncovered in Unit 49, Level 11, approximately between 116-121 cmbs (Figure 16-55). A soil sample collected for floatation from the surrounding soil yielded a few small snails (not analyzed, but curated), as well as abundant fine charcoal. Material recovered from the $1 / 4$-inch screen in Level 11 included charcoal samples, along with 12 unidentifiable vertebrate fragments (two of which were grayed from burning). None of the charcoal samples from this particular feature were submitted for assay.

Malacology samples collected from Level 11 were subsequently fine-screened and analyzed by Ken Brown. According to Brown, this level had the lowest snail density and abundance of any of the 20 levels in Unit 49; eight identifiable terrestial taxa, and seven identifiable aquatic taxa.

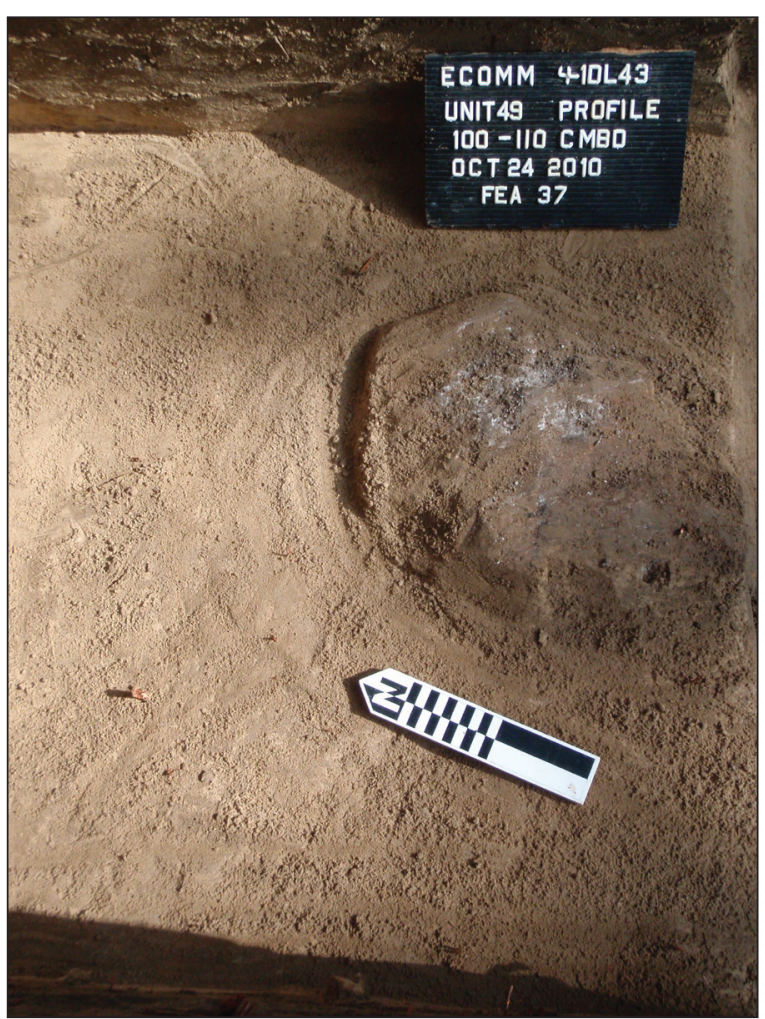

Figure 16-55. Photograph of Feature 37. Nevertheless, the few aquatic snails present, along with a green algae plant (charaophyte oogonia), suggest an aquatic influence, but not as significant as in lower levels 12 through 20 (see Chapter 6 for a full discussion).

A soil sample from Feature 37-submitted to Linda Scott Cummings for an analysis of potential phytoliths - yielded some interesting results. She and her colleagues identified an abnormally high percentage of $\mathrm{C}_{3}$ Pooideae grasses, a cool season grass, and opines that it is possible that intentional burning was carried out to increase the frequency of these particular grasses on the landscape. Supporting her opinion are the presence of numerous epidermal elements of phytoliths that can be indicative of grass utilization for subsistence. In sum, she opines that there is a possibility that Little barley grass (Hordeum pusillum) is a grass that was most likely to have been cultivated, with intentional burning of the fields. In addition, although not purely diagnostic, a maize-like (Zea mays) phytolith was recovered from the soil sample. 
In sum, there is admittedly no conclusive evidence to validate this relatively small burned feature as a surface hearth. Contradictorily however, the small feature is constricted to a very small area, with no apparent extended, burned or discolored area across the surrounding buried surface. That said, the preponderance of a lack of evidence for a large area natural surface burn implies that this was likely a small surficial hearth fired without the benefit of stone heating elements, akin to those hearths designated as Features 30, 32, 34, and 35 in this same Middle Cultural Component. Phytolith data as discussed above suggests that the hearth feature was used for processing subsistence grasses, and even perhaps Zea mays.

\section{Feature 39-Middle Component-Ash, Charcoal, and Burned Clay Masses}

Although possibly three distinct hearths, Feature 39 consists of three thin masses of burned clay, smeared charcoal, and ash, each roughly $30 \mathrm{x} 30 \mathrm{~cm}$ in size (Figure 16-56). They were discovered 145-148 cmbs in Level 1 of Units 68 and 69, within 10YR 4/4 silty loam that overlies 10YR 6/3 sand. A conventional radiocarbon date obtained from in situ charcoal in Unit 69 indicates that the burn probably occurred sometime between AD 1432 and 1450, or between AD 1420 and 1467 (2 Sigma Calibrated Measured Radiocarbon Age 450 \pm 25 BP-UGAMS 8612). However, Abbott (Table 5-2) posits that this was probably an old wood sample.

The only materials recovered from a floatation sample were a handful of snails (not analyzed, but curated), and charcoal. Materials from the $1 / 4$-inch screen were a few snails, charcoal, and an unburned fragment from an unidentifiable vertebrate.

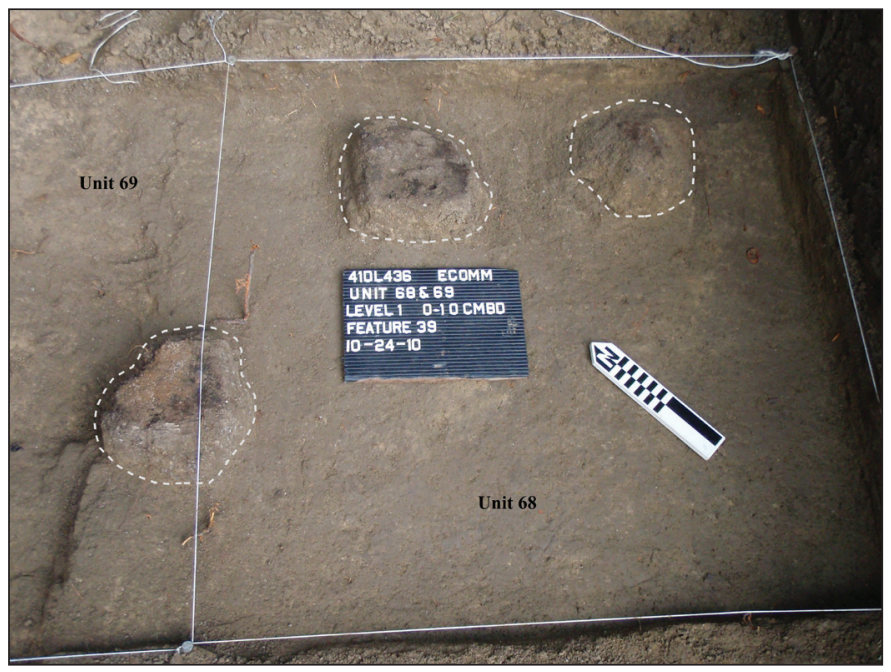

Figure 16-56. Photograph of Feature 39.

In sum, these three sub-features were first identified as isolated portions of an extensive very thin $(1-\mathrm{cm})$ lens of darkened soil extending across roughly $6 \times 3$ meters in the northern portion of the trench. Upon sweeping this surface with a push broom, these three anomalies were identified and pedestaled in Units 68 and 69 (see Figure 16-56). Notably, the extensive stain and these three ash and charcoal masses that are designated as Feature 39 were within the brown silty loam that overlies the yellowish sand which encompasses Feature 9, a bone scatter (see discussion of Feature 9, above). In addition, although at 2 sigma the calibrated radiocarbon ages from both Feature 9 and Feature 39 do overlap, the ages from the lower, Feature 9 are generally younger, suggesting possibly a stratigraphic uncomformity in the northeast portion of the trench, or as Abbott argues an "old wood" problem with the Feature 39 sample assayed.

In any case, given the observation that these three ash and charcoal sub-features are inclusive of a relatively large apparent surface burn, and there was no conclusive evidence to indicate 


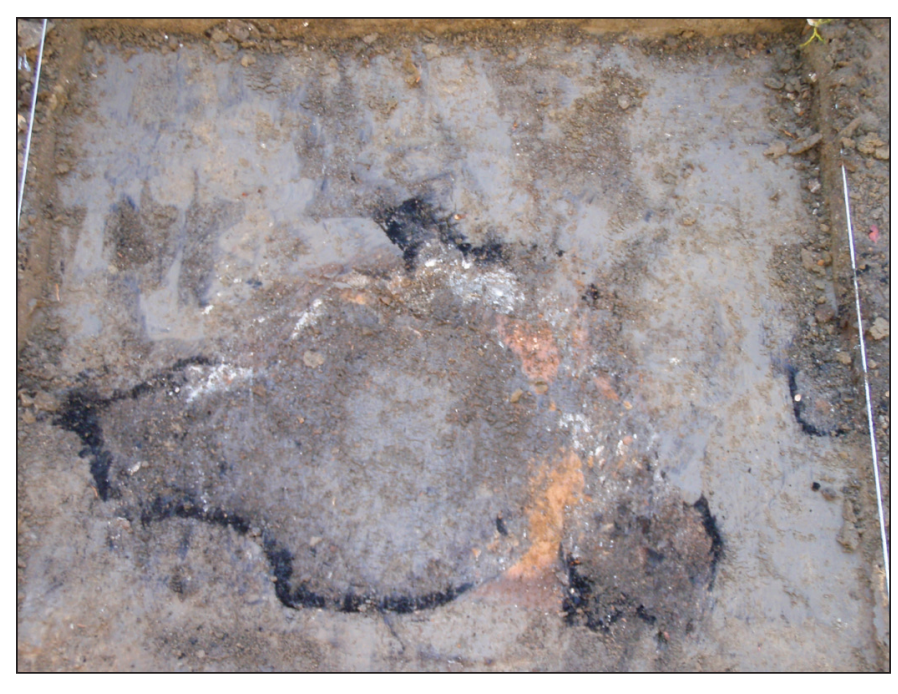

Figure 16-57. Photograph of Feature 40 in Unit 100, Level 1; facing east. cultural influence, we must conclude that they could represent discrete areas of a natural surface burn on a gently undulating surface.

\section{Feature 40-Middle Component-Burned Tree and Root}

Feature 40 is an intensive burn area with red, orange, and black clay, white ash, abundant charcoal, and baked clay (Figure 16-57). It was located on the southern-most end of the Gradall trench in what may have been the bottom of the Fish Creek paleochannel. Following excavation of the feature to greater

than $210 \mathrm{cmbs}$, it appeared to be the remains of a burned tree and root that toppled and the root continued to burn. [Note to the Reader: see the discussion of Feature 41 below, a fire-cracked rock hearth].

A conventional radiocarbon date obtained from in situ charcoal in Unit 100 indicates that the burn likely occurred sometime between AD 1452 and 1527, or between AD 1553 and 1633 (2 Sigma Calibrated Measured Radiocarbon Age $360 \pm 25$ BP-UGAMS 8613). The only associated materials recovered were charcoal flecks and a few snails (not analyzed, but curated) from a floatation sample, along with charcoal chunks from the $1 / 4$-inch screen. Although six fragments from an unidentifiable vertebrate were also recovered from Level 1 in the $1 / 4$-inch screen, none of the six were burned.

\section{UPPER Component - Stratum 3}

As shown in Figure 16-1, Stratum 3 generally lies roughly from the modern ground surface to $70 \mathrm{~cm}$ below, which equates to the upper cultural component at the site; but its depth varies considerably and dips sharply on the southern portion of the trench, where the natural stratigraphy follows the infilled paleo channel of Fish Creek. A total of 37 levels within 18 excavation units were dug within the upper cultural component (Figure 16-58), resulting in the recovery of no fire-cracked rocks (FCR), three pieces of chipped stone, few mussel shells, a handful of snails, an abundant amount of charcoal, and 1,219 pieces of animal bone. In addition, nine features and a unique item were recorded; they are listed in Table 16-12, and are described below. 


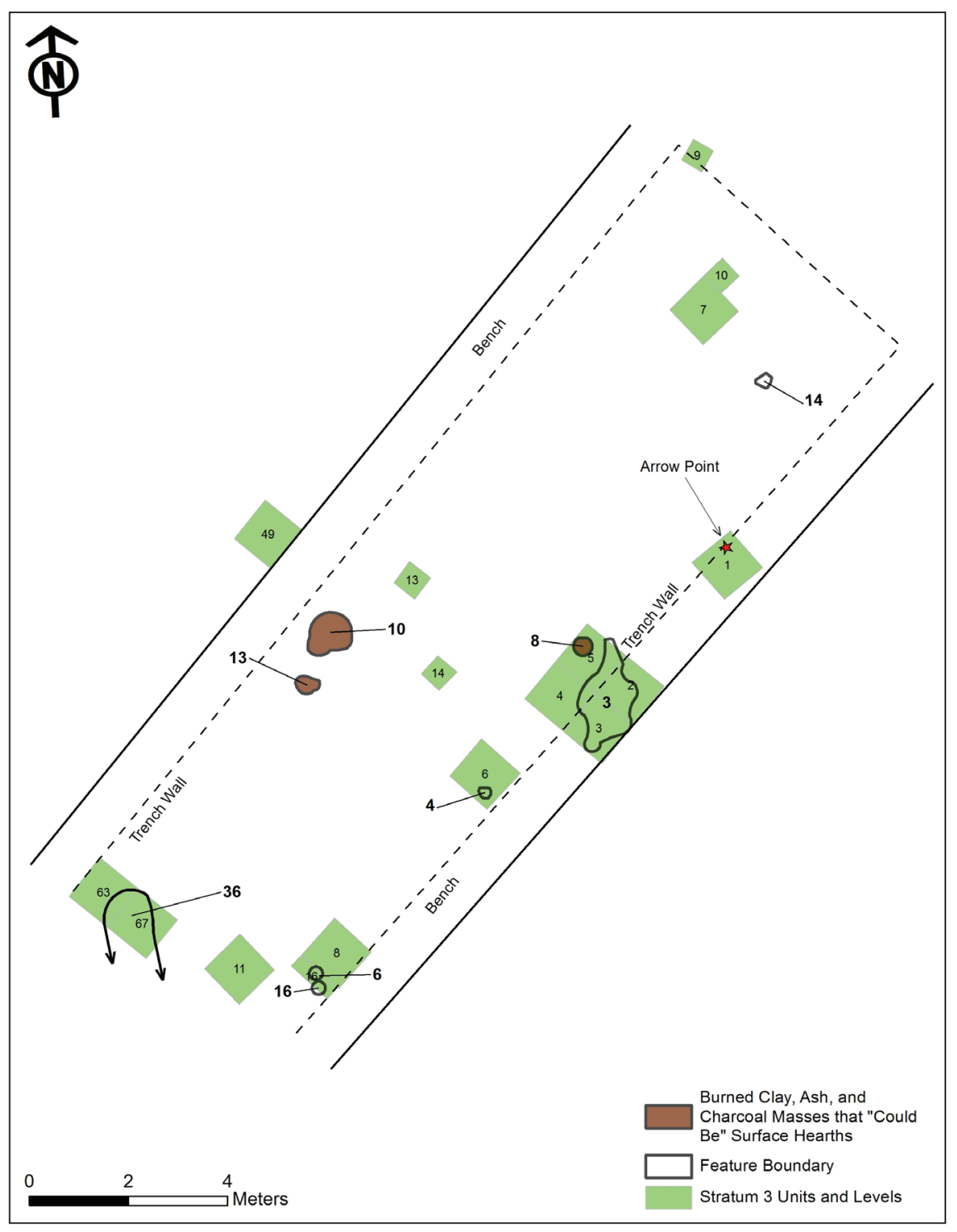

Figure 16-58. Excavation units and features within the upper cultural component (Stratum 3).

Table 16-12. List of Features, Unique Item, and Radiocarbon Dates for the Upper Cultural Component (Stratum 3).

\begin{tabular}{ccc}
\hline Feature \# & Description & Valid RC Dates (BP) \\
\hline 3 & Ash and Charcoal Mass & $110 \pm 25$ \\
\hline 4 & Root Burn & \\
\hline 6 & Tree and Root Burn & $190 \pm 25$ \\
\hline 8 & Ash and Charcoal Mass \\
\hline 10 & Ash and Charcoal Smear \\
\hline 13 & Ash and Charcoal Layer \\
\hline 14 & Ash and Charcoal Lens \\
\hline 36 & Root Burn \\
\hline \multicolumn{4}{c}{ Burned Clay, Ash, and Charcoal Layer } \\
\hline
\end{tabular}




\section{Feature 3-Upper Component-Ash and Charcoal Mass}

As shown in Figure 16-59, Features 3 and 8 are very close together, and rest on the same surface. As such, it could be that these two features represent the same burning event. Nevertheless, we choose to describe them as separate entities, and let the reader decide.

Feature 3 is a large, irregularly shaped ash and charcoal mass $6-10 \mathrm{~cm}$ thick. It was uncovered in Units 2-5, between 40 and $50 \mathrm{cmbs}$. The bottom of the feature

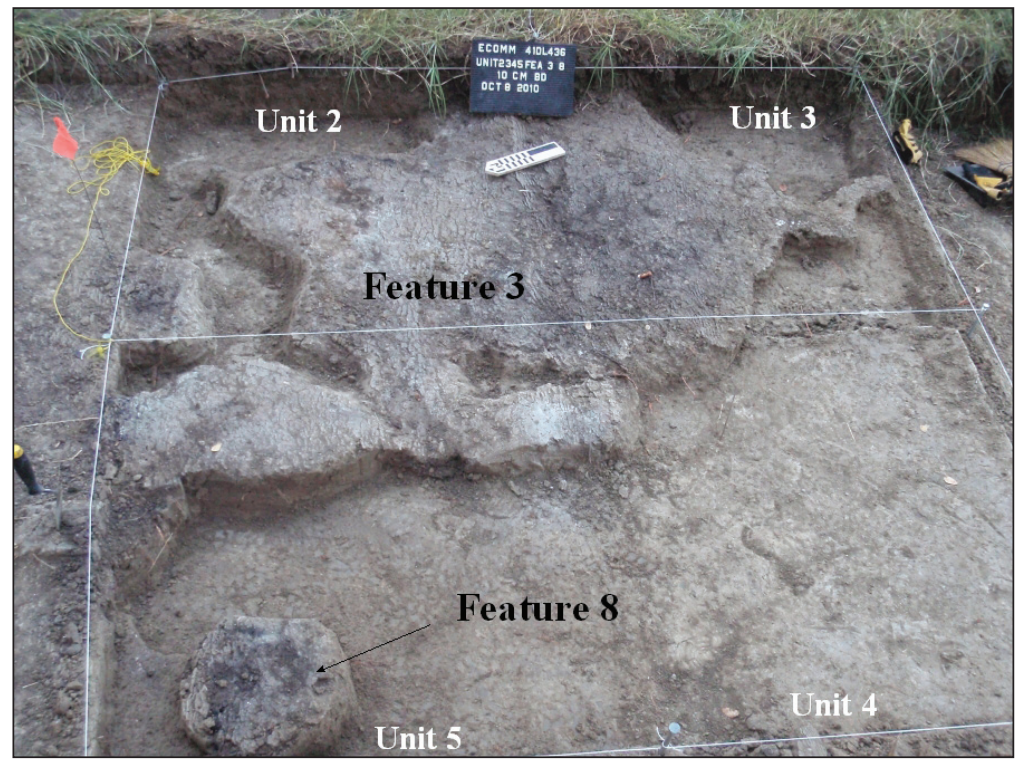

Figure 16-59. Photograph of Features $3 \& 8$. was setting on the surface of a pale brown (10YR 6/3) sandy loam strata. The feature is further described as containing bits of burned clay and mussel shell fragments, with unburned bone and snails directly underlying it. However, its validity as a cultural feature is questionable, and without conclusive evidence, we surmise that it could be a naturally occurring burn feature.

A conventional radiocarbon age obtained from in situ charcoal indicates that the burn likely occurred sometime between AD 1682 and 1736, or between AD 1804 and 1935 (2 Sigma Calibrated Measured Radiocarbon Age $110 \pm 25$ BP-UGAMS \#8596). In addition to the mass of charcoal and ash, presumably cultural material found in association include one piece of chipped stone, mussel shells, and multiple pieces of faunal remains.

Out of the 664 pieces of bone recovered in association with Feature 3, the predominance of identifiable species are either cotton rat, rat, or harvest mouse. Other than that, one specimen is from a cottontail rabbit, and one is from a turtle. Notably, only 187 of the 664 pieces (28 percent) exhibit evidence of burning, suggesting that they were likely intrusive following the burning event (in addition, 122 of the 187 burned specimens [65 percent] were from a single unidentifiable vertebrate). Finally, none of the 664 specimens exhibit evidence of human alteration.

A floatation sample comprising 12 liters of soil submitted to Phil Dering for analysis yielded wood pieces from a woody legume $(n=20)$, charred pieces from an unidentified hardwood $(n=25)$, pieces from an unidentified seed $(n=4)$, a grape seed, and seven Hackberry nutlet fragments. Notably, other than the charred hardwoods, no others were charred, suggesting that they most likely represent relatively modern contamination. 
Only two fragmented pieces of mussel shells were recovered from in and around Feature 3. According to Bob Howells, these were unidentifiable as to species. As such they are of little significance, and likely represent one of a frequent series of flooding events along the periphery of Fish Creek.

The only piece of chipped stone recovered in association with Feature 3 is a biface thinning flake found in a floatation sample. As with the rest of most chipped stone artifacts found at this site, it is made from brown, fine-grained chert, and typically small, measuring a maximum of only $83 \mathrm{~mm}$. Notably, this specimen appears to have been heat-treated.

Magnetic Soils Susceptibility values recorded within and around this feature are consistent with an intense burn with a dense fuel load over a relatively long period. These data are consistent with burning logs and limbs in a forest regime (see Magnetic Susceptibility discussion, above). This rather extensive mass of charcoal and ash appears to have been a surface burn of downed timber that likely occurred between AD 1805 and 1935 (see also, Table 5-2). In sum, our assessment is that the preponderance of the data from Feature 3 implies that it represents a surface burn rather than an intentionally constructed hearth. What remains intriguing is whether the or not the surface burn was intentionally ignited by human intervention, or whether it was naturally occurring.

\section{Feature 4-Upper Component-Root Burn}

Feature 4 is interpreted as a root burn extending from $80-125$ cmbs. It was discovered as an oval-shaped, dark brown stain when scraped over with the Gradall. The upper $10 \mathrm{~cm}$ was pedestaled and photographed in Unit 6 (Figures 16-60-16-63).

Following the hand excavations, the Gradall was used to further expose the south edge of Feature 4. When skimming the south face of Unit 6 , an undulating charcoal and ash layer at the base of Feature 4 suggested that Feature 4 continued vertically. Therefore Unit 15 was then opened adjacent to Unit 6. The lower extremity of Feature 4 was then further excavated in Unit 15. Throughout subsequent levels were darker soils with calcium carbonated ped faces. The dense calcium carbonates and sometimes weakly cemented soils immediately surrounding the vertical feature were isolated in layers differentiated by both layered yellowish brown and light brown sands and sandy loams, but with no calcium carbonates.

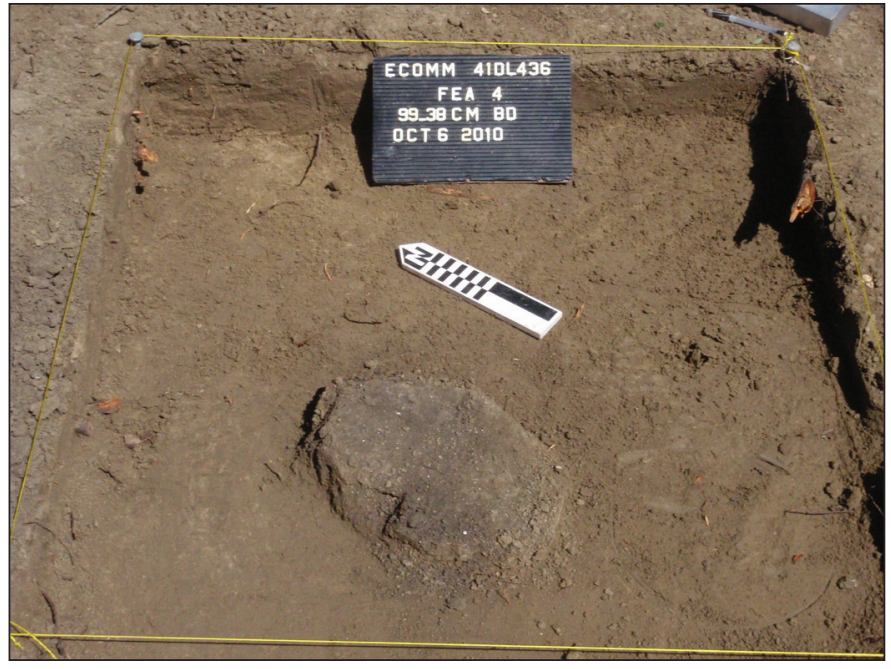

Figure 16-60. Upper $10 \mathrm{~cm}$ of Feature 4 pedestaled in Unit 6 before it was further excavated an additional $35 \mathrm{~cm}$ deeper. 




Figure 16-61. Photograph of Feature 4.

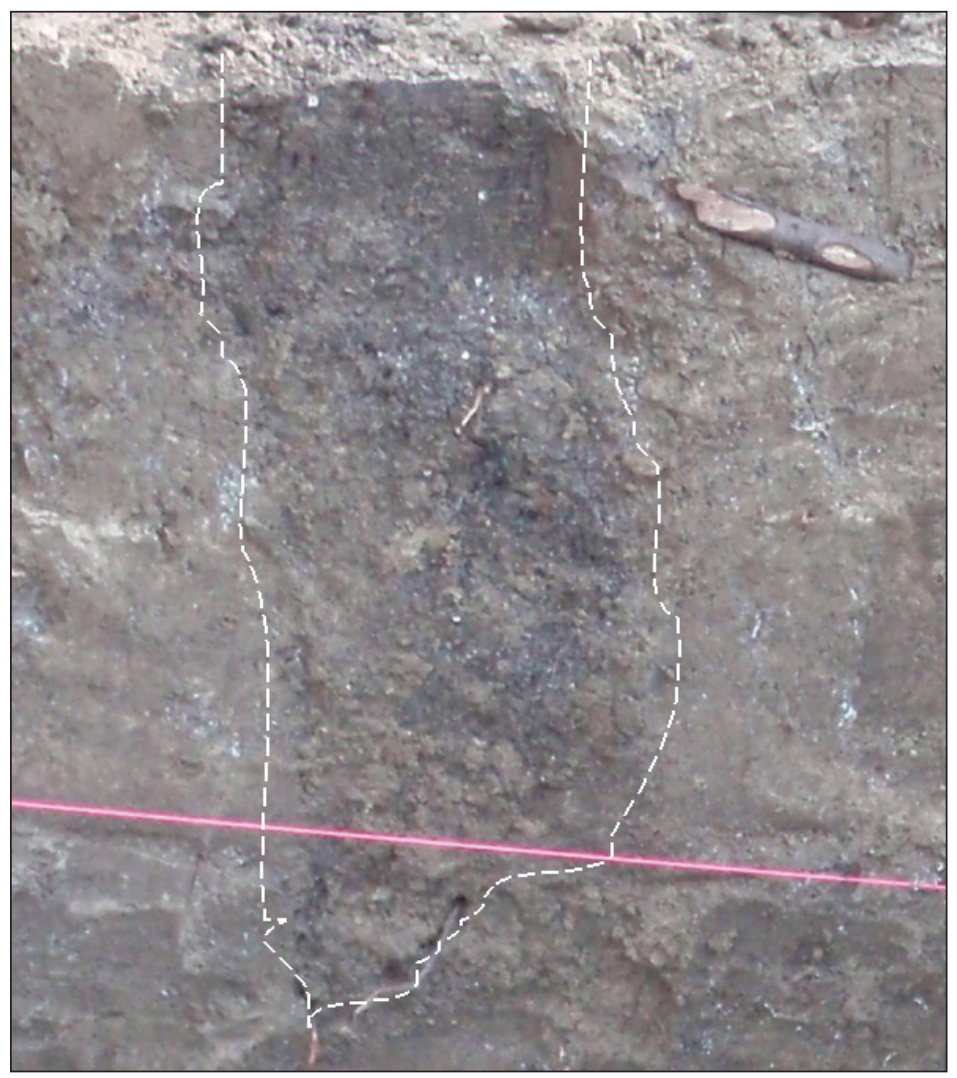

Figure 16-62. Close-up of Feature 4 in profile.
An occasional micro-snail shell fragment was also observed within the feature. The feature matrix seemed slightly ashy, and the matrix texture was slightly more compact than the surrounding soils. The middle $10 \mathrm{~cm}$ of the feature was also pedestaled in Level 2 before being removed. The middle of the feature was within a 9-10$\mathrm{cm}$ layer of silty loam, while the top of the feature was on a light brown silty loam, and penetrated $12-15 \mathrm{~cm}$ of very narrowly banded light brown silty loam with banded yellowish brown silt loams (see Figures 16-61 and 16-62). Root disturbances appeared to be minimal, but numerous roots were observed running horizontally at the base of the feature, suggesting a stable surface. The base of the feature was reached at 120 $\mathrm{cmbs}$, and a 2-cm ash lens (see Figures 16-61-16-63). This lens is stratigraphically co-eval with that seen in Units 11 and 12 to the west. In sum, Feature 4 appears to be a tree root burn that began on a once stable surface roughly $80 \mathrm{~cm}$ below the modern surface, and extended vertically for approximately $55 \mathrm{~cm}$.

\section{Feature 6-Upper Component-Burned Tree and Root}

Feature 6 is interpreted as a tree and root burn extending from approximately $\quad 80-180$ cmbs (Figures 16-64 and 16-65). The 


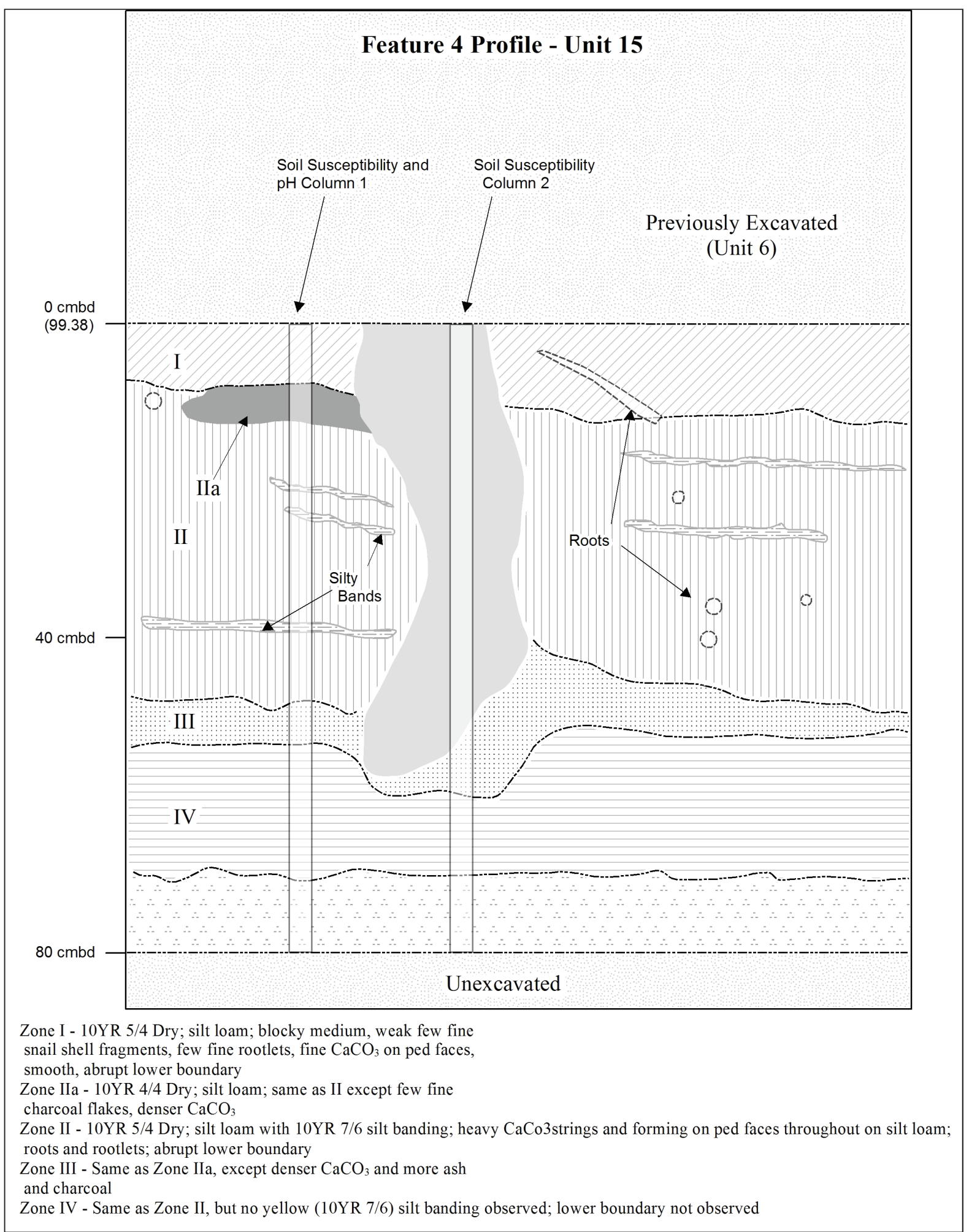

Figure 16-63. Schematic of Feature 4 in profile. 
top of it was exposed by a Gradall scrape, and then further in profile and planview in Units 8 and 16 excavations. The top of Feature 6 appears to be stratigraphically co-eval with the top of Feature 4, suggesting that the bases of both trees were in the same surface strata when they were consumed by fire. In addition, this same strata appears to be co-eval with that of Features 3 and 8 .

Although faunal material and snails were recovered while exposing the feature in Unit 16 , none can clearly be associated with the feature. As shown in Figure 6-65,

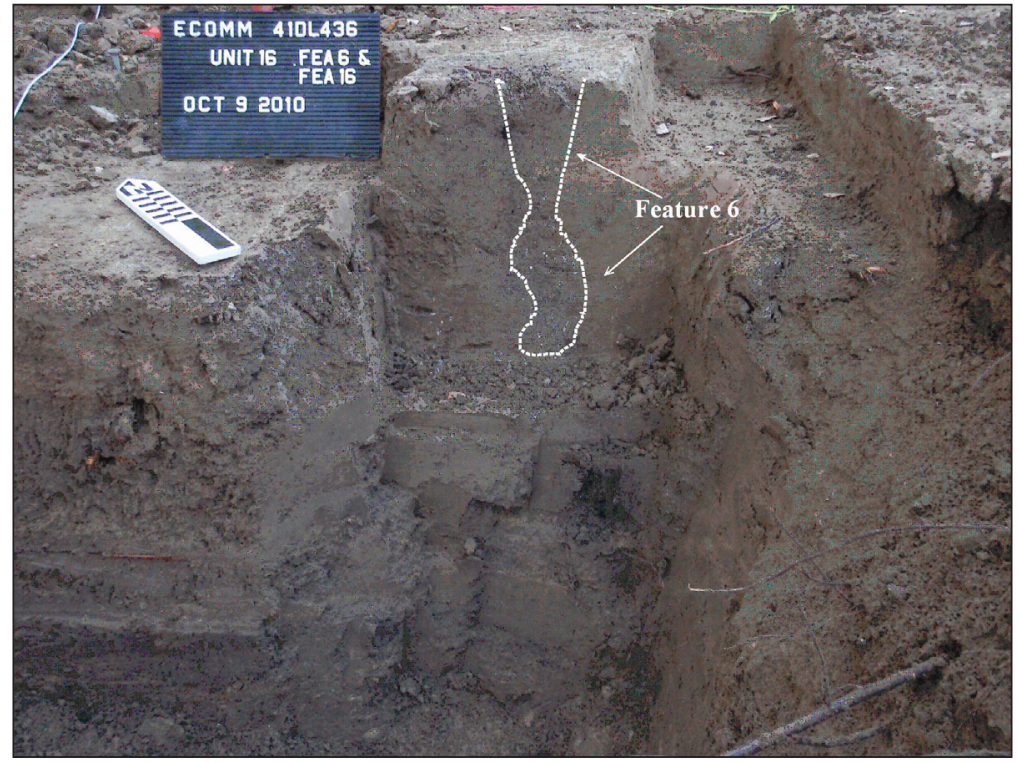

Figure 16-64. Photograph of Feature 6 in profile. magnetic soil susceptibility samples were taken in vertical columns both within, and to one side of the feature. They revealed values which suggest that Feature 6 represents a natural smoldering root burn (see discussion further in this chapter).

\section{Feature 8-Upper Component-Ash and Charcoal Mass}

Feature 8 is a small and compact conglomeration of ash and charcoal, approximately $5 \mathrm{~cm}$ thick, and with a slight bowl shape (Figure 16-66; also see Figure 16-59). It is situated approximately $30 \mathrm{~cm}$ west of Feature 3, and in the same soil strata, between 40-50 cmbs. Whether or not this feature is cultural is unknown; when it was uncovered, the excavator in the field surmised that it may be a natural tree burn. In addition, it is stratigraphically co-eval with the upper portion of Features 4 and 6 (tree and root burns), and therefore its validity as a cultural feature is questionable. As with Feature 3, the bottom of the feature was setting on the surface of a pale brown (10YR 6/3) sandy loam strata.

A conventional radiocarbon age obtained from in situ charcoal indicates that the burn likely occurred sometime between AD 1654 and 1687 or between AD 1731 and 1809 (2 Sigma Calibrated Measured Radiocarbon Age $190 \pm 25$ BP-UGAMS \#8599). In addition to the mass of charcoal and ash, presumably cultural material found in association include one piece of chipped stone, a few mussel shells, and multiple pieces of faunal remains.

Thirteen pieces of bone were recovered in association with Feature 8; three are probably from one or more tree frog-like amphibians, and the remaining ten are small vertebrate fragments. Only two of the 13 showed evidence of heating. A floatation sample comprising four liters of soil submitted to Phil Dering for analysis yielded only two pieces of charred hardwood. 


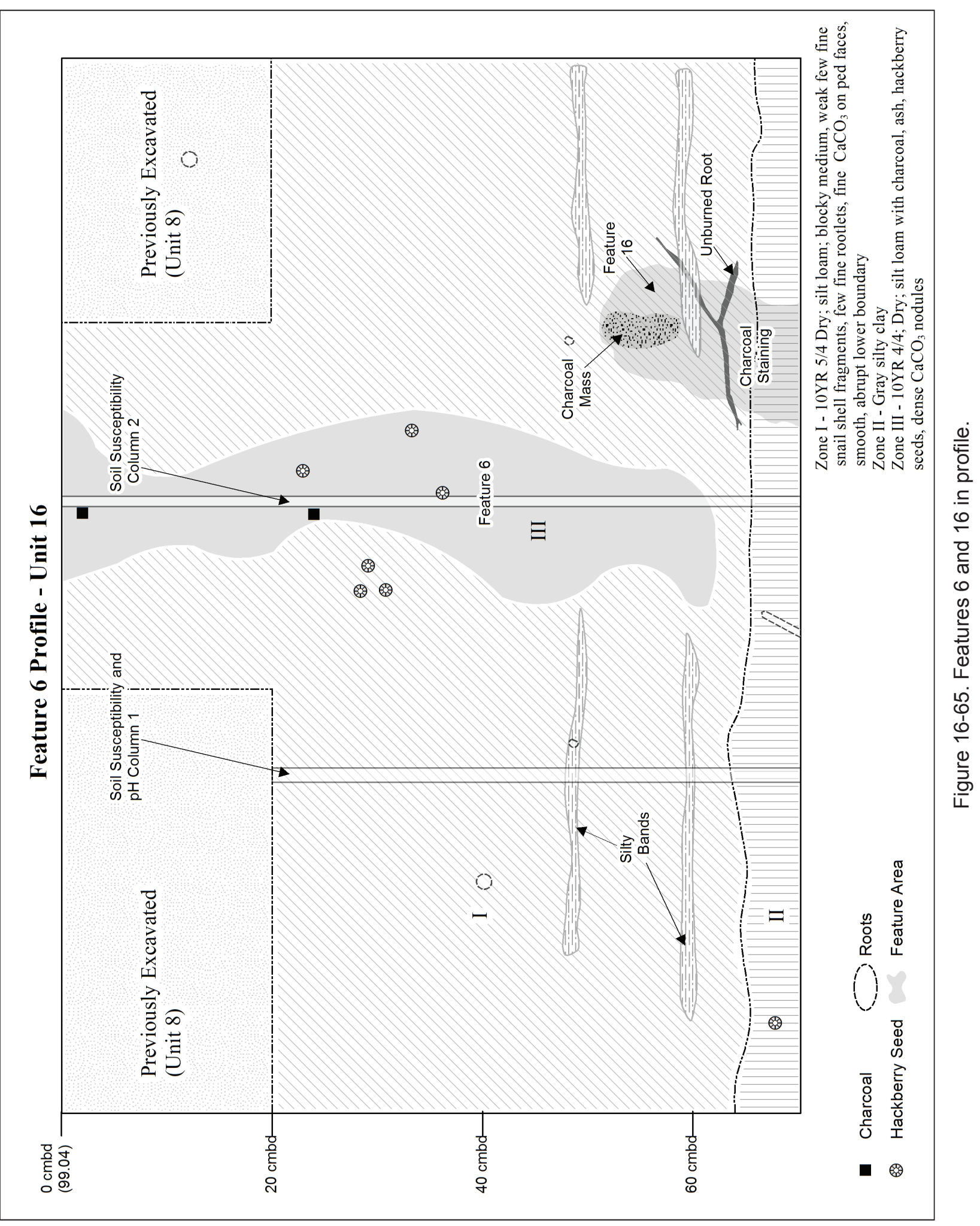




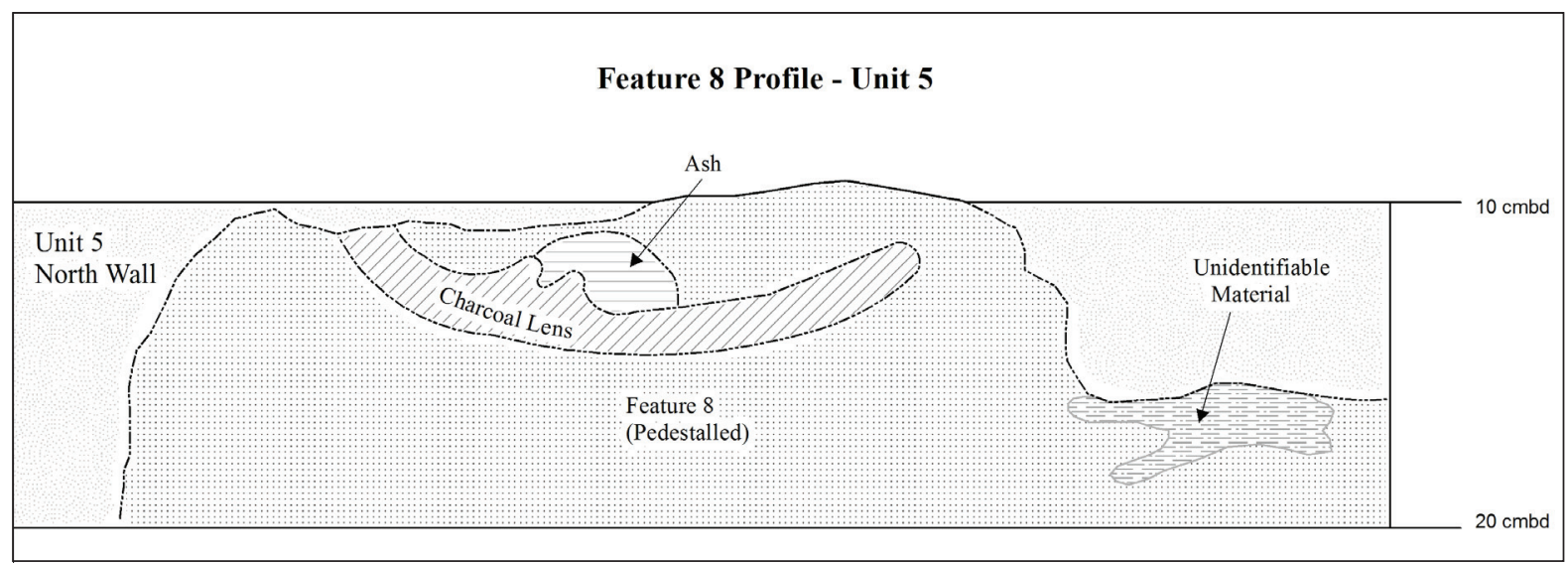

Figure 16-66. East wall profile of Feature 8 in Unit 5.

In this case, magnetic soil susceptibility values were recorded in a systematic grid. The data suggests that this burned area manifests MSS values consistent with cultural hearths (see discussion further in this chapter).

In sum, this relatively small mass of charcoal and ash appears to have been a surface hearth that was likely constructed possibly as early as AD 1654, and possibly much later, perhaps as late as 1809. This period is on the cusp of the "Protohistoric" period in this area of north Texas. However, as with nearby Feature 3, other than corroborating MSS data, we have no conclusive evidence to determine whether this surface burn was intentionally ignited by human intervention, or whether it was naturally occurring.

\section{Feature 10-Upper \\ Component-Ash and Charcoal Smear}

Feature 10 (Figure 16-67) consists of a spotty ash and blackened charcoal smear area $1-3 \mathrm{~cm}$ thick, across an area roughly $65 \times 130 \mathrm{~cm}$, and $75-80$ cmbs, and uncovered with a Gradall scrape roughly $80 \mathrm{cmbs}$. The spots of charcoal are most likely of the same burning event, but were not now physically connected. Most of the charcoal was setting in a brown (10YR 4/3) silty loam strata. The thin

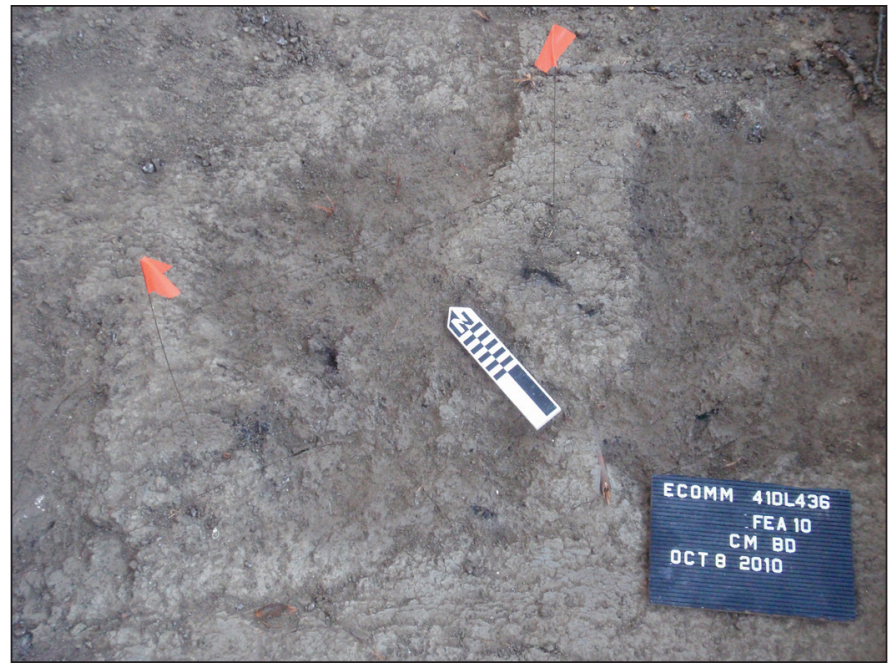

Figure 16-67. Photograph of Feature 10.

lens was recorded with the TDS and photographs, but given its relative ephemeral nature no excavation units were warranted. No cultural material was observed on or within this thin layer, suggesting that this is a naturally occurring surface burn with no evidence of human intervention. However, it is similar in structure and morphology to cultural surface hearths documented at Dust Cave (see discussion later in this chapter). 


\section{Feature 13-Upper Component-Ash and Charcoal Layer}

Feature 13 (Figure 16-68) is made up of a thin $(1-3 \mathrm{~cm})$ and spotty charcoal and black ashy layer covering an area approximately $80 \times 180 \mathrm{~cm}$, and lying roughly $75 \mathrm{cmbs}$. It lies within the upper portion of brown (10YR 4/3) silty loam, approximately $75-78 \mathrm{cmbs}$. Because of its ephemeral nature and no cultural or other organic materials observed in association, an excavation unit to further explore it was not warranted. Instead, its extent was explored with a trowel, photographs were taken, and its provenience was shot in with the TDS. It is stratigraphically co-eval with Feature 10, another ash and charcoal smear about 1 meter to the north. This burned area is another of a number of similar features where no clear evidence of cultural influence is apparent. Therefore, whether or not this thin ash and charcoal layer represents a natural surface burn, or if it was an expedient surface hearth induced by human intervention is unknown.

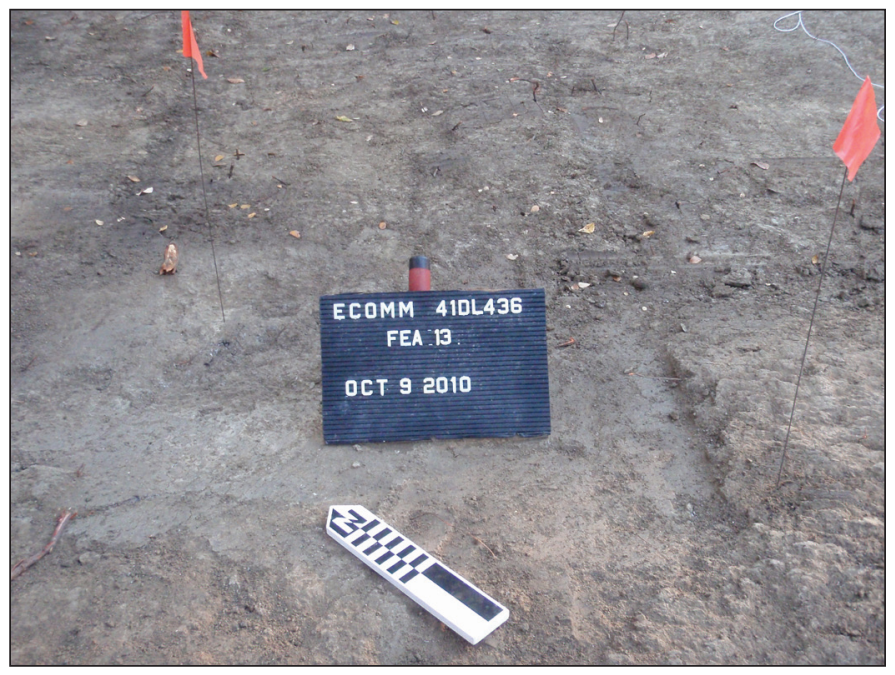

Figure 16-68. Photograph of Feature 13.

\section{Feature 14-Upper \\ Component-Ash and Charcoal Lens}

Feature 14 was manifested as a small, but distinct and darker discoloration in the soil caused by ash and charcoal that was uncovered after a shallow Gradall scrape (Figure 16-69). It was not formally excavated, but was probed; it measured roughly 10 $\mathrm{x} 12 \mathrm{~cm}$, was $5 \mathrm{~cm}$ thick at it most thickest and center area, and was situated within the upper portion of a brown (10YR 4/3) silty loam strata, 45-50 cmbs. It was shot in with the TDS, and photographed.

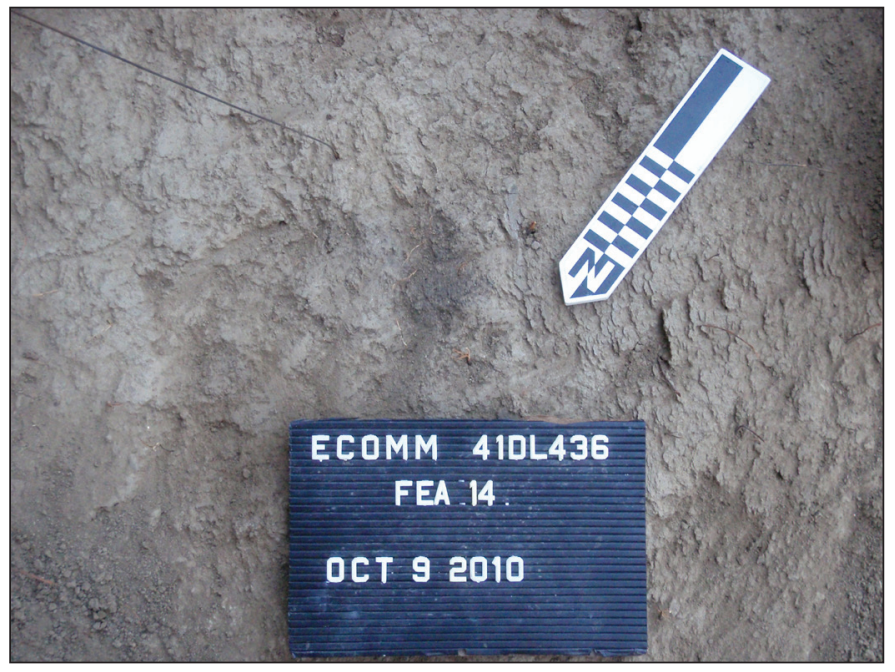

Figure 16-69. Feature 14.

As with Feature 13 and others alike, it is among of a number of similar features where no clear evidence of cultural influence is apparent. Therefore, whether or not this very small thin ash and charcoal layer represents a natural surface burn, or if it was induced by human intervention is unknown. Given its small size, we opine that it is likely a natural burn on an undulating surface, but we cannot be sure. 


\section{Feature 16-Upper Component-Ash and Charcoal Mass}

Feature 16 is a small cone-shaped mass matrix of ash, charcoal, and darkened silty clay loam near the base of Feature 6 (Figure 16-70; see also Figure 6-65), herein interpreted as a burned tree root. Stratigraphically, this burned mass matrix lay within brown (10YR 4/3) silty clay loam. Although indiscernible in profile, the presence of small caches of cracked hackberry seeds suggest at least some degree of rodent disturbance. The absence of any cultural material in association implies that it is not likely a cultural feature, unless it can be later somehow be proven that the burn was intentionally set with human intervention.

\section{Feature 36-Upper Component-Ash, Charcoal, and Burned Clay Layer}

This feature was discovered on a sloping surface from $180-210 \mathrm{cmbs}$ that represents the infilled sloping Fish Creek paleochannel. It was first manifested as an orange burned stain in a Gradall scrape on the south end of the trench (Figures 16-71 and

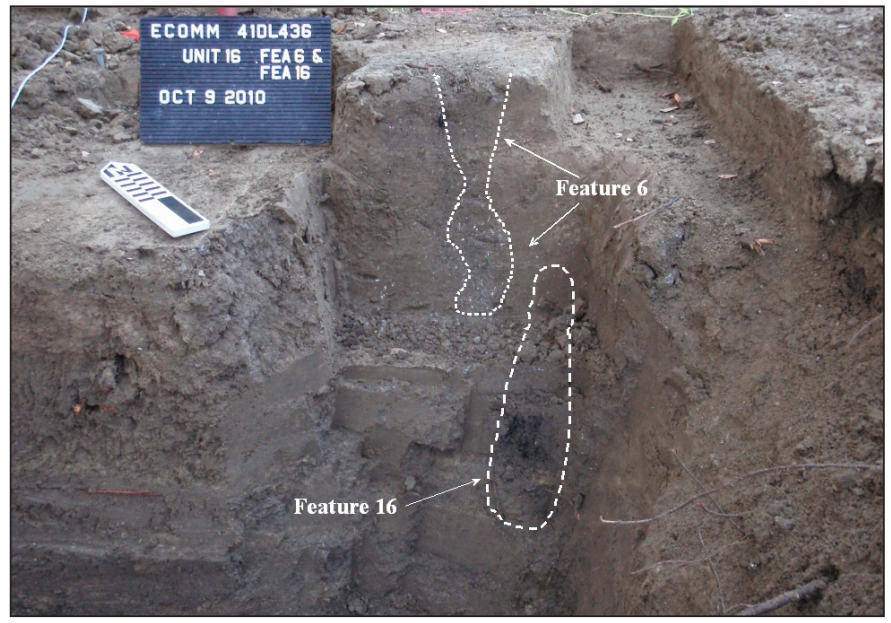

Figure 16-70. Photograph of Feature 16 in relation to Feature 6.

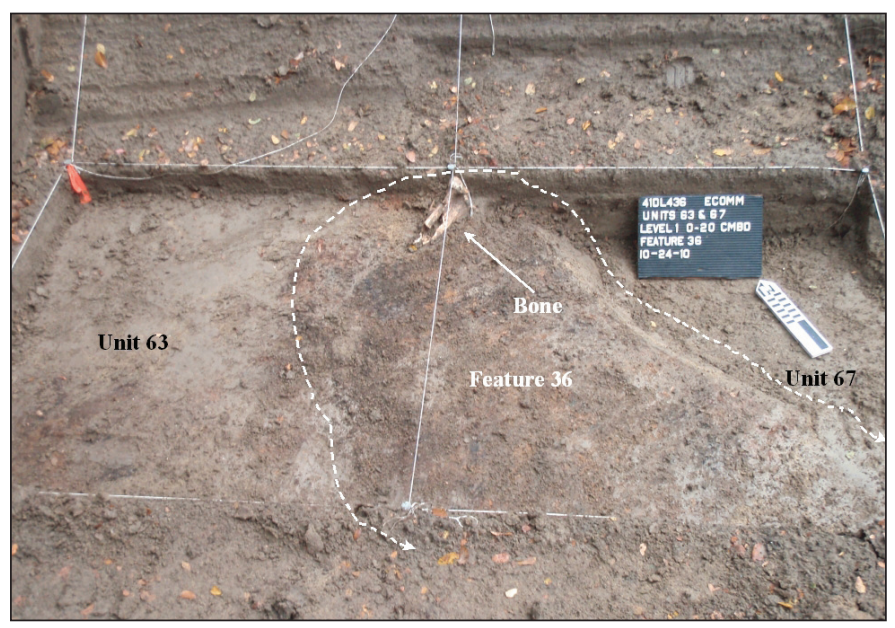

Figure 16-71. Photograph of Feature 36. 16-72). Units 63 and 67 were opened to investigate its depth and horizontal extent. At the lower, eastern extent of this feature, it was stratigraphically associated with the burn that is Feature 28, again demonstrating its continuity across a fairly steep slope in the lower portion of the Fish Creek paleochannel cutbank. The excavator at the time remarked that it was his opinion that any discontiguous burn areas that were observed had either been removed by the Gradall scrape, or are merely less intensely burned areas with ephemeral charcoal smears.

From the surface of Units 63 and 67, the thickness of the stain appeared to be only 1-3 cm thick. However after excavating deeper in Unit 67 in order to expose the feature in profile, as shown in Figure 16-72, the actual burned earth extended to roughly 7-10 cm in depth, and the feature developed on a possibly stable surface of light brown sandy loam. 
Although an abundance of charcoal flecks were observed throughout the feature and larger pieces were collected in situ, none were submitted for assay. Although no charcoal was collected, nor faunal remains observed in the floatation sample, one Rabdotus snail shell and 21 pieces of fauna were collected from the $1 / 4$-inch screen. Faunal remains included a charred and blackened tibia from a bison, five fragments from an unidentifiable mammal, and 15 fragments from an unidentifiable vertebrate (or vertebrates), three of which were blackened or grayed from burning.

In sum, although bison, other unidentifiable mammals, and vertebrates were among the faunal assemblage that could be associated with this burning event, the sloping terrain upon which it lay suggests that it is not a cultural open hearth feature, but more possibly a natural surface burn along the Fish Creek paleochannel.

\section{Unique Item-Upper Component-Arrow Point}

Unit 1was opened to investigate a rib bone uncovered during a Gradall scrape. The bone was pedestaled (Figure 16-73), and upon its removal, the proximal portion of an arrow point was discovered directly beneath the rib bone near the bottom of Level 1, approximately $18 \mathrm{~cm}$ below the modern ground surface. The arrow point was made from fine-grained, dark gray chert that appears to have been heat treated, and was broken during use (Figure 16-74). Morphologically, it is very much historic (e.g., resembles Guerrero).

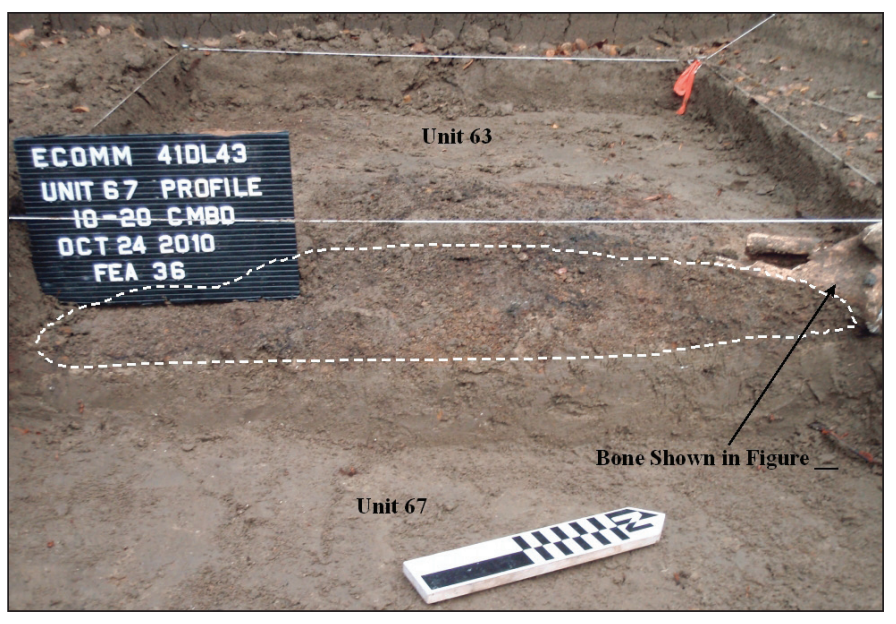

Figure 16-72. Photograph of Feature 36 in profile.

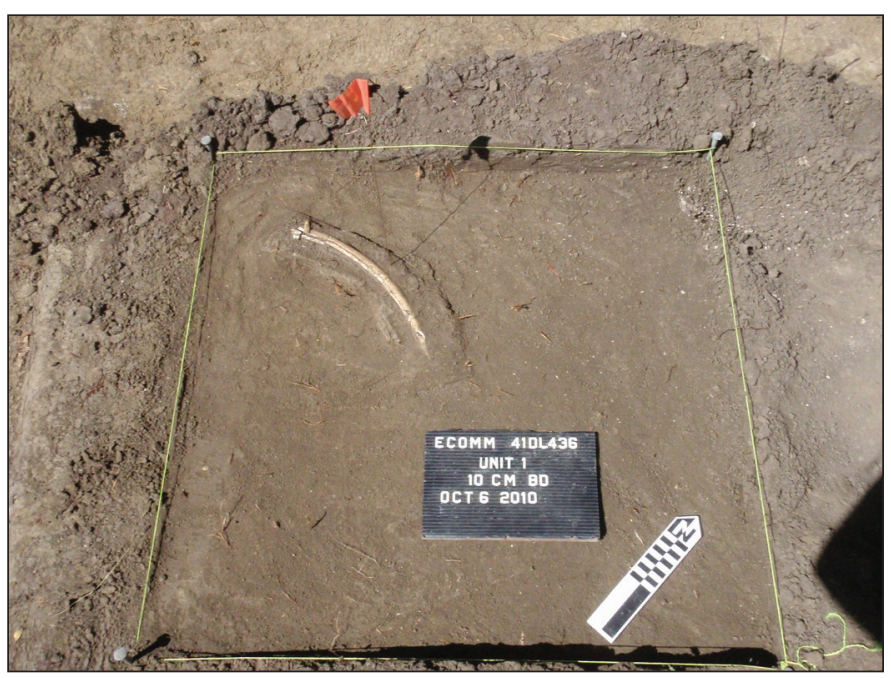

Figure 16-73. Rib bone in Unit 1; arrow point was recovered directly beneath the bone.

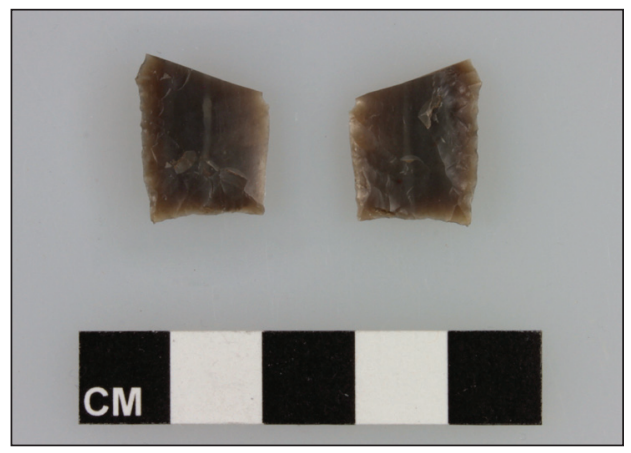

Figure 16-74. Photograph showing both faces of an arrow point found in Unit 1. 
No charcoal was found in Unit 1 , and a floatation sample yielded only a few whole and fragmented snails. However, a total of 48 pieces of bone were recovered. One exhibited numerous cutmarks consistent with meat removal, and one was polished and smoothed for possible bone bead manufacture. The fauna material recovered is identified in Table 16-13.

Table 16-13. Faunal Material from Unit 1.

\begin{tabular}{cccc}
\hline Class & Common Name & Specimens & Description \\
\hline Bovidae & Bison/Cow & 10 & Sternum, Humerus, Ribs (a) \\
\hline Mammal & Unidentifiable & 15 & Fragments \\
\hline Vetebrate & Unidentifiable & 15 & Fragments \\
\hline Reptile & Pond Turtle & 1 & Carapace \\
\hline Reptile & Turtle, Medium-size & 2 & Carapace \\
\hline Mammal & Rodent, Small & 1 & Femur \\
\hline Aves & Bird, Medium-Large & 1 & Long Bone \\
\hline Aves & Bird, Medium-size & 3 & Ulna, Long Bones (b) \\
\hline \multicolumn{5}{c}{ TOTAL } & 48 &
\end{tabular}

(a) One rib exhibits 21 cutmarks consistent with meat removal; one rib "could be" elk;

sternum exhibits slight browning; humerus indicates age of less than 6 years

(b) One long bone exhibits polishing and smoothing on one end for possible bone bead manufacture.

\section{Natural Fires and Cultural Hearths}

Humans have used fire in many ways for hundreds and thousands of years, and the occurrences of both natural and culturally induced fires have maintained a close relationship throughout the Holocene. On a broad scale, large fires have been used to herd prey animals, clear dense vegetation, or prepare the area for slash and burn agriculture. For example, fire has been used by prehistoric Native Americans in California and the Southern Appalachians to cut down on the brush and shrubs, and to hence allow for subsistence beneficial plants to thrive (Keeley 2002:311; Delacourt et al. 1998:276). On a relative microscale, fire has been used for warmth, light, and cooking (Sauer 1950).

Although much of the following discussion emphasizes a dichotomy between formal hearths and natural burns that have at occurred on 41DL436, it should not be construed that we are disregarding other possibilities, such as culturally set, uncontrolled fires for clearing, landscape management, or driving game, and controlled but amorphous fires on a short term for warmth and/or insect management. In fact, these possibilities are further addressed at the conclusion of this chapter, as well as in Chapter 18 (see also, Historic Section in Chapter 2).

Deeper into this chapter we examine features from comparable sites in various regions within the state, and note that charcoal and ash lenses, oxidized earth patches, and charcoal filled pits are commonly documented. Although recent research in an effort to sort out the origins of burned charcoal, ash, and clay lenses and masses on archaeological sites has been enlightening, these features remain an enigma in North Texas as well. This view was recently expressed following excavations at 41TR170 when archaeologists stated that "As yet, no satisfactory explanation exists for the cause of the thick ashy deposits..." (Lintz et al. 2008:145). Elsewhere in Dallas County, burned clay, ash, and charcoal masses and lenses where no fire-cracked 
rocks were observed in association have been identified as features at 41DL203 (Tinsley and Dayton 2011), 41DL270 (Anthony and Brown 1994), 41DL406 (Todd and Skinner 2006), and 41DL441 (Trask et al. 2008); these are synthesized below.

\section{DL203}

Feature 5 at site 41DL203 is described as an area of dark stained soil with charcoal flecking roughly $4 \mathrm{~cm}$ thick and over $60 \times 60 \mathrm{~cm}$ in size; although in this case, four small burned rocks were in association. Archaeologists opined that it was either a shallow heating basin that did not oxidize the underlying sediments and soils, or it represented remnants of a cleaned-out nearby hearth.

\section{DL270}

Feature 2 at site 41DL270 was a burned clay concentration $(75 \times 75 \mathrm{~cm})$ that was not fully excavated, but investigators decided that Feature 2 was likely a burned tree root.

Feature 4 (no size given) is described as a burned clay and charcoal feature that tapered and branched out with depth, and was thought to be a burned tree root.

Feature 19 consisted of a $1.0-\mathrm{m} \times 65-\mathrm{cm}$ feature with burned yellow to orange to dark red and brown clay. Archaeologists noted its irregular shape, and submitted that this could indicate a tree root burn, but were not absolute in that regard.

Feature 22 is a circular concentration of charcoal with brownish black clay infilled into what archaeologists believed was most likely not a post hole, but they would not rule out that the feature could have been cultural in origin.

Feature 23 was an $80 \times 45-\mathrm{cm}$ circular orange-colored burned clay mass about $15 \mathrm{~cm}$ at its thickest. However, archaeologists surmised that the depth of the feature was not due to pit excavation, but rather due to thermally altered soil below the feature. They tentatively interpreted Feature 23 as a cultural fire feature or hearth.

Feature 30 was an ovid-shaped (no size given) charcoal concentration with charcoal flecks, burned clay, and apparently tiny burned sandstone. Investigators opined that Feature 30 was probably a burned tree root rather than a cultural feature.

Feature 33 is described as a dense lens concentration of charcoal and burned orange clay with turtle and mussel shell fragments, but no burned rocks. Investigators opined that the 1.4-m x $50-\mathrm{cm}$ feature represented part of an intensively used occupation area. 


\section{DL406}

At site 41DL406, a concentration of burned clay and sediments discovered in a backhoe trench was first thought to have been part of a culturally dug pit, but following excavations investigators determined that it was an infilled natural tree fall depression.

\section{DL441}

An approximately 5-cm thick layer of burned clay, charcoal, and ash was uncovered $60 \mathrm{cmbs}$ during backhoe trenching operations at site 41DL441. Investigators initially surmised that it was either a single campfire constructed for a single day or night, or perhaps it was a log that had burned in place and thermally altered the underlying and surrounding clay. Upon later investigation it was determined that it was the remains of a campfire constructed sometime around either 1838 or 1928.

Numerous burned surfaces have been encountered during all three archaeological projects at 41DL436, but whether or not they were culturally induced or natural range/woodland fires has been an ongoing subject of debate. One school of thought when the initial research design was put together for the October 2010 data recovery effort was that they could possibly represent intentionally burned horticultural fields, or areas burned for early agriculture. However, upon excavation of the site, it became apparent that the burned areas were discrete, both large and small. Some areas were very heavily burned, with red oxidized sediments and soils, surrounded by charcoal and ash, while other areas appeared as charcoal smears. Notably, the site was occupied within a time frame when megadroughts in the western hemisphere were frequent

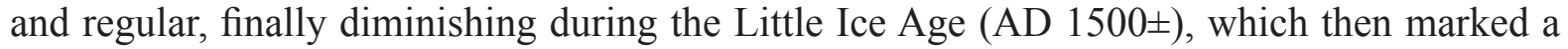
period of reduced biomass burning (Power et al. 2012).

The recovery of cultural materials within and around some of these burned areas indicates that some of them could represent prepared surface hearths. However, several of the features were discovered mantling sloping paleosurfaces, making such a use unlikely in these cases. In this section we will examine these burned areas in an attempt to determine which of those are likely naturally burned surfaces with varying degrees of fuel, and which of the burned areas are likely surface hearths. In doing so, we rely heavily on the use of magnetic soil susceptibility as an indicator of sediment and soil temperatures.

\section{Effects of Natural Fire}

Depending upon the ecosystem and fuel sources, surface fires are typically low intensity fires in high frequency (Swetman 1993). However, high severity, intense and isolated fire regimes can occur within surface fires when the fuel load is differentially high in discrete areas. When this occurs, following the fire there is a patchwork of areas that have been intensively burned; for instance, when trees have fallen, burned, and smoldered for days (see for example, Figure 16-75). In order for this to take place, a surface fire spreads rapidly across a surface with sufficient ground cover tinder, but then where ground cover is scarce, fire works its way into the tree canopy (Todd 2006; Thompson 2012). We surmise that this was the case at 41DL436, 


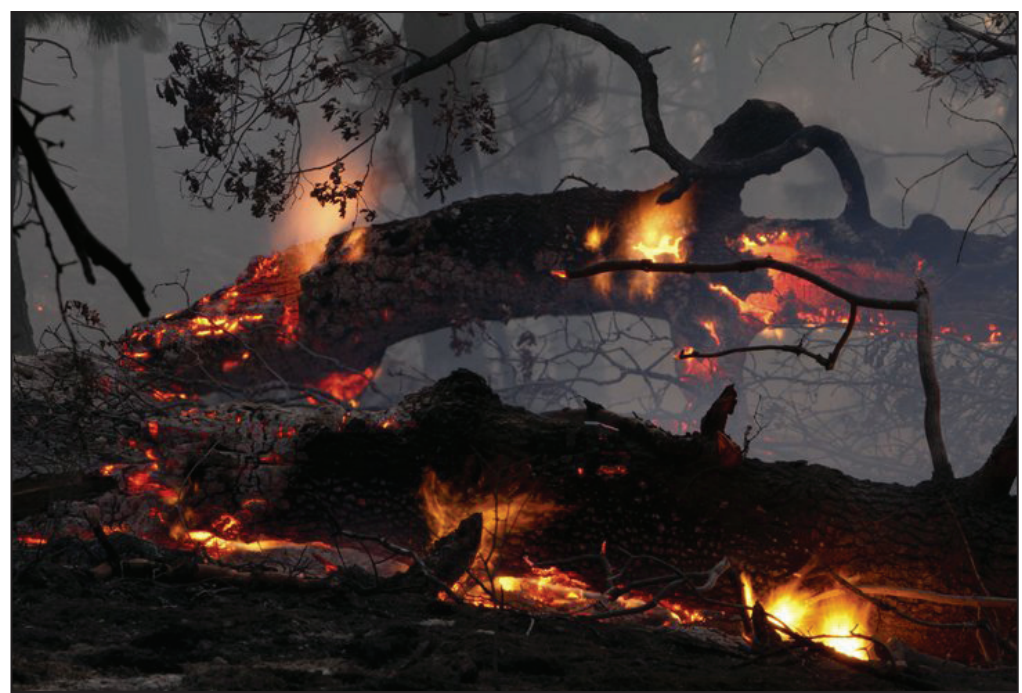

Figure 16-75. Burning trees downed in the 2006 Mount Laguna Fire near San Diego, California. where a mosaic patchwork of both burned and unburned surfaces are apparent.

Conner et al. (1989) refer to these oxidized patches of earth caused by a surface fire on archaeological sites as 'faux features,' and Alperson-Afil et al. (2013) refer to them as 'phantom hearths.' As Johnson (2004) points out, it is likely that most archaeologists rarely consider the effects of ancient wildfires when investigating archaeological sites. However, Johnson has

documented multiple 'phantom hearths' that appeared following the 2002 Mustang Fire in northeastern Utah. That fire was patchy, ranging in intensity from high to low, depending on for one factor, ground cover. "Dense stands of trees or tall brush, or more open tree stands with ample dead wood and ladder materials, support intense, long-duration burns. Fire severity and related changes are less frequent or less severe in grasslands, and in riparian or other areas with damp soils, although isolated hotspots occur even in these areas" (Johnson 2004:4). The ecological environment and vegetation described in the previous quote sounds very similar to the descriptions drawn from the 41DL436 studies in Chapters 6-11 and 15 in this publication.

A recent study examining the effects of a large surface fire on archaeological sites occurred following the high intensity Little Venus Fire in northwestern Wyoming. Specifically, two archaeological sites (48PA2772 and 48PA2776) were documented before and after the fire. Both sites exhibited large quantities of artifacts spread across the surface. Following the fire, discrete patches of oxidized earth which had not been apparent pre-fire, were observed on both sites after the fire, very similar to those documented at 41DL436 (see photograph in Thompson 2012:33). According to Thompson (2012:33), "These patches were produced as a piece of fuel (such as a stump or fallen log) smoldered for a sufficient amount of time to reach a temperature hot enough to rust (or oxidize) the surrounding sediments." Had the burn occurred across 41DL436, these same patches could have been found during the 2010 excavations. Following the Little Venus Fire, six such discrete patches were found on the surface at 48PA2776 and 21 patches on 48PA2772. Typical oxidized sediment patches from 48PA2772 are pictured in Figure 16-76a-d.

In 2012, Dr. Todd returned to the 2006 Little Venus Fire area and excavated one of the burned patches. Shown in Figure 16-77 are a planview and profile of the burned patch following excavation. Note the similarity between this 'phantom hearth' feature and Feature 28 at 41DL436 (see Figures 16-41 and 16-42, Feature 28, Middle Component discussion above). 


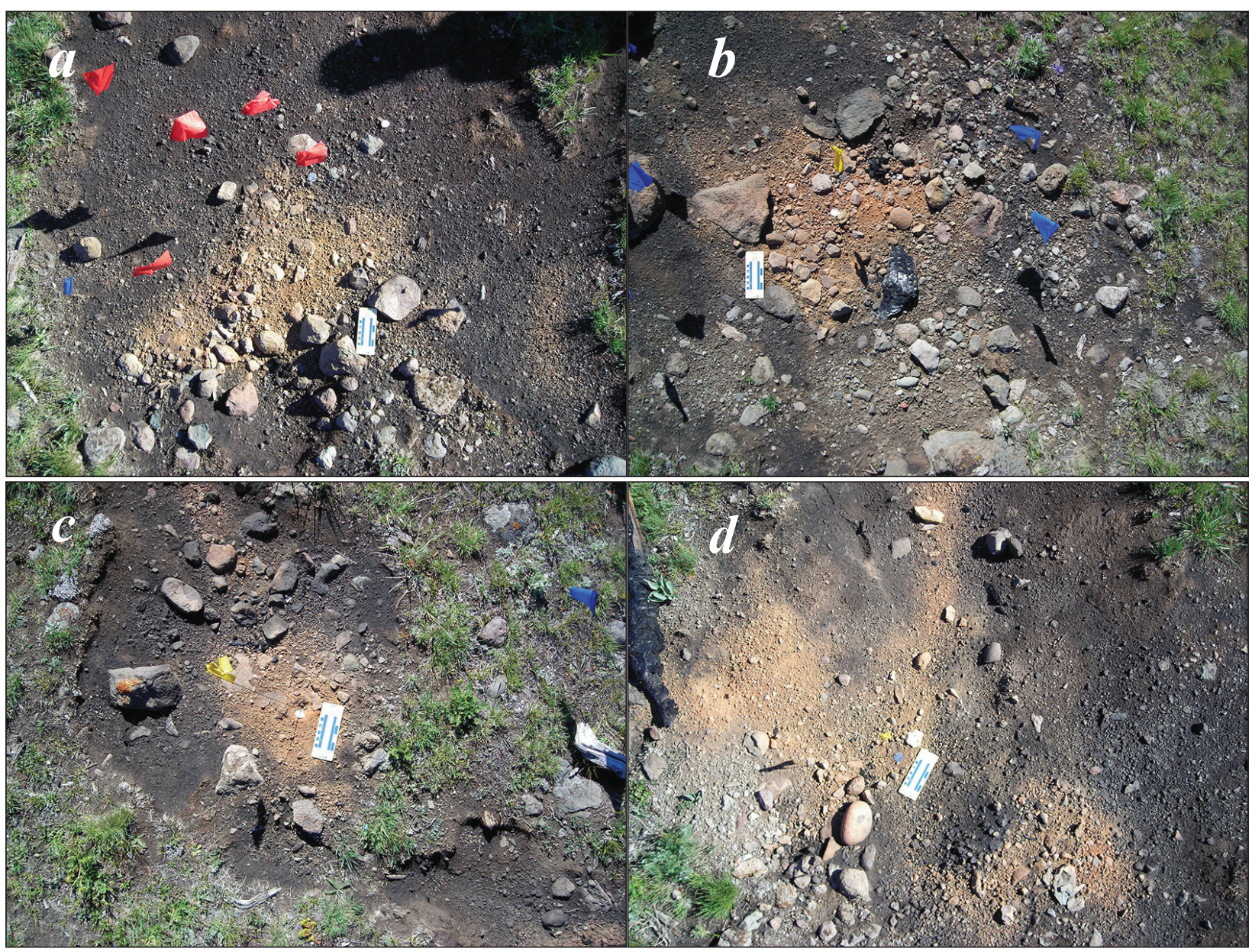

Figure 16-76a-d. Four oxidized earth patches following Little Venus Fire in 2006 (Photographs by Dr. Larry Todd, Colorado State University; used with his permission, August 21, 2013).

As with all range and forest fires, the resulting ash from the Mustang Fire was transported across the landscape by aeolian, alluvial, and colluvial processes. Such is likely the case that accounts for the older microcharcoal dates obtained at 41DL436 by Linda Scott-Cummings et al. (see Chapter 11). Following the Mustang Fire, Johnson noted that the entire surface was stained, so that any attempt by archaeologists to identify cultural features by surface staining was futile, and not at all practical. In fact, any discrete surface stains that may have been of cultural origin were obliterated following the fire. Other observations were that natural depressions were filled in with ash and fine stained sediments, and some cultural features that on the surface originally, were deflated below the surface following the fire. As for other physical changes that would have occurred in past surface fires of any age, wooden structures such as brush huts would have been consumed by fire. Most apropos to the burned features documented at 41DL436 is a burned area in the Mustang Fire area that could mistakenly be interpreted as a cultural feature, but is instead a "faux feature," an oxidized area of burned earth, ash, and charcoal with an associated burnt limb and rocks (Figure 16-78). It is a classic example similar to what we believe Feature 1 looked like (sans rocks) immediately following a surface burn at 41DL436 (see Figure 16-16 and 16-17, Feature 1, Middle Component discussion above). 

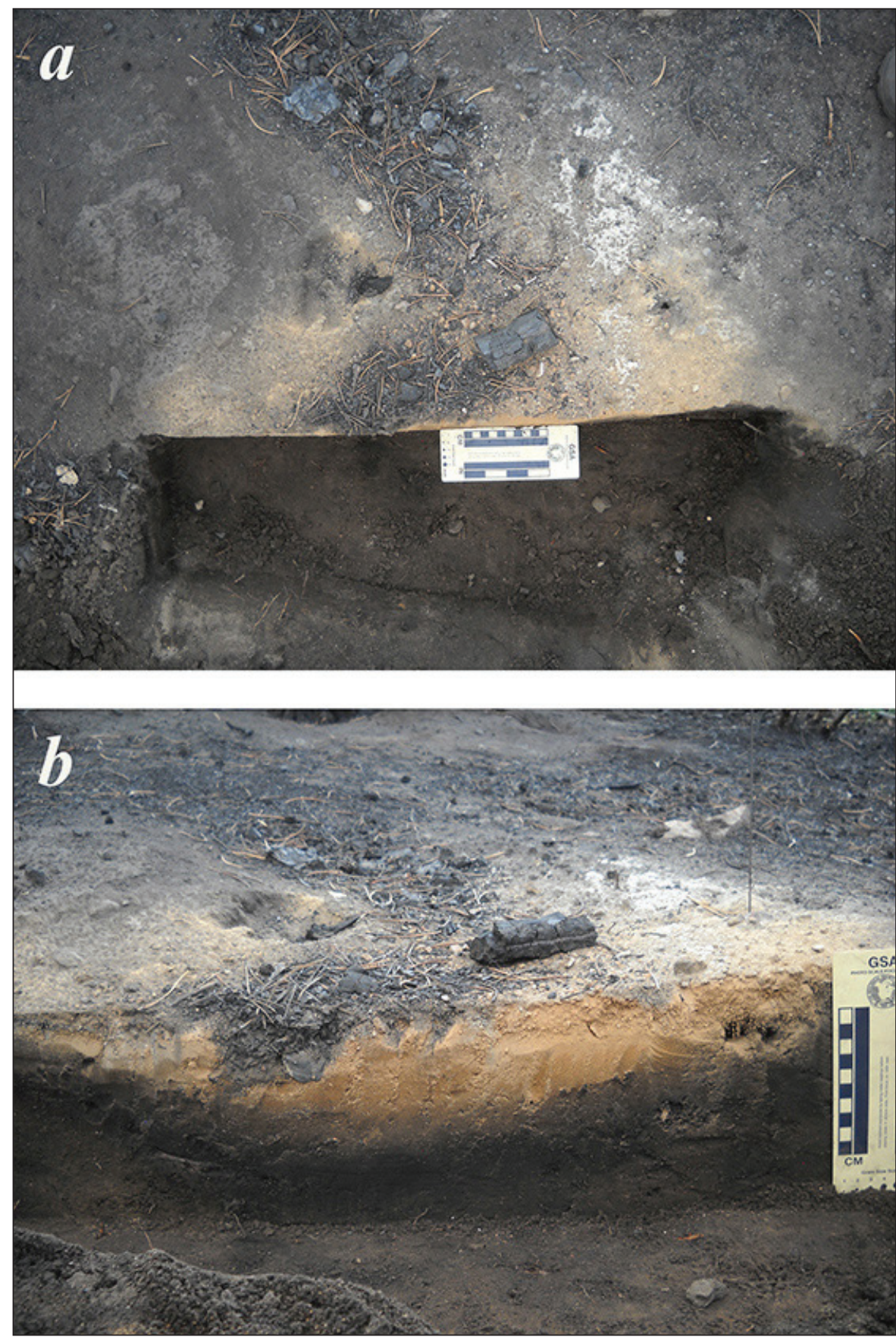

Figure 16-77. Planview and cross section of a 'phantom heath' created by the Little Venus Fire in 2006, and subsequently excavated by Larry Todd in 2012 (Photograph by Dr. Larry Todd, Colorado State University; used with his permission, August 21, 2013). 
Although Abbott (Chapter 6, this volume) surmises that a tree throw pit filled in with charcoal, ash, and burned earth may have been a culturally related by-product (presumable intentional surface burn), it appears to be a classic example of what a 'faux feature' looks like. If not recognizable for what it truly is, archaeologists could mistakenly categorize it as a cultural pit hearth.

In 2003, Clay Johnson of the Ashley National Forest in Vernal, Utah presented what a hypothetical excavation profile of the 'phantom' hearth' shown

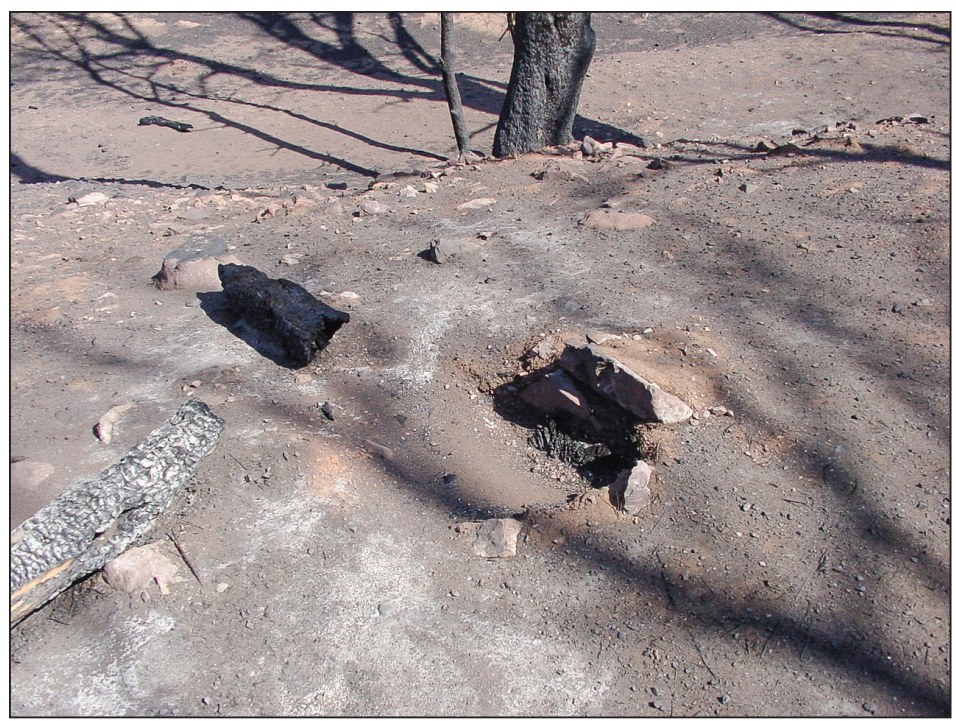

Figure 16-78. Mustang Fire tree burn in northeastern Utah with ash layer, burnt limb, outer rock "ring" at approximate extent of roots, and central burnt trunk charcoal (photograph used with permission of Clay Johnson, 21 August 2013). in Figure 16-78 would look like after decades to centuries of elapsed time (Figure 16-79). Based upon our 2010 excavations at 41DL436, it appears that his depiction is quite accurate.

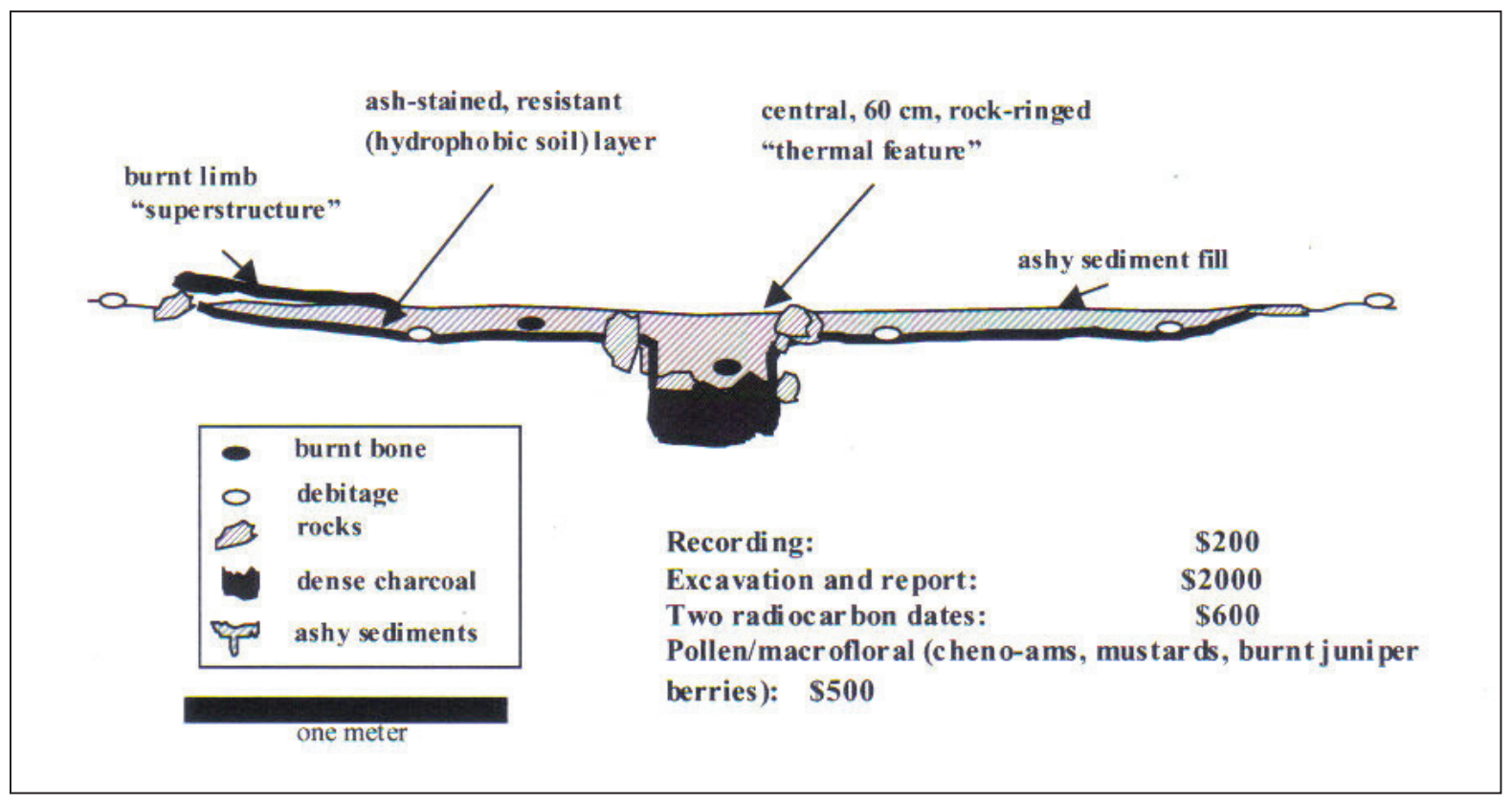

Figure 16-79. Hypothetical excavation profile of the 'phantom hearth' shown in Figure 16-78 above, as surmised by Clay Johnson in 2003 (Drawing used with permission of Clay Johnson, 21 August 2013). 


\section{Fire Temperatures}

As discussed in Chapters 6-11, 15, and 17, the ecological environment in the immediate area of 41DL436 was with little variability over the past roughly 900 years, generally a mosaic of grasses, brush, and large canopy trees within an often moist and damp environment. It is within those contexts that we consider the potential temperatures of natural surface fires that have occurred across the site. Quite simply, the temperatures of grass fires are less than those of the more dense fuel loads of forest fires. A grassfire spreads across the surface rapidly, but because of its fine fuels, burns with high intensity.

The dense fuel loads in woodlands versus grasslands naturally allows for higher temperature gradients both on the surface and in sub-surface soils and sediments. The flash point for wood to begin burning is $300^{\circ} \mathrm{C}$ (Gabbert 2013). However, because grass fuel is fine, it combusts thoroughly and at a faster rate and at lower temperatures than denser, wooded species (Pyne 1984). Temperatures of natural surface burns in shrub and forested regimes can reach those within cultural hearth features, with deadfall trees, and thick organic zones up to $750^{\circ} \mathrm{C}$. At $750^{\circ} \mathrm{C}$, soil oxidation and pockets of ash are created (Conner et al. 1989:298, 303-305).

Other studies of natural burns in shrub and forest regimes have produced maximum temperatures between $350-450^{\circ} \mathrm{C}$ and lasting usually less than six minutes (Bailey and Anderson 1980:37; Hemry 1996:6; Patten and Cave 1984:277), while dense forest fuel loads burn at temperatures in excess of $650^{\circ} \mathrm{C}$, from one to three hours, and can reach $800^{\circ} \mathrm{C}$ or higher (Bellomo 1993:533, 536; Bierman and Gillespie 1991:642-643; How Wildfires Work 2013). Hemry (1996:4) found that tree stumps and roots burn at significantly higher temperatures, approaching $1500^{\circ} \mathrm{C}$, and may last for a week.

Heat from range or forests fires is transferred to the ground by conduction. Thus, the greater the burning mass of fuel load on or very near the surface, the greater the temperature of the soil (Albini 1980; Peter 1992), and the duration of burning is relative to the increased soil temperature (Hungerford et al. 1990). In other words, the conduction or transfer of heat to the soil is greater under downed and burning trees, as well as adjacent to smoldering tree roots. Such appears to have been the case at 41DL436.

During a surface fire, the temperature gradient works its way downward from the fuel load to the soil (Hungerford 1990). Even after the surface flames have passed over, subsurface temperatures often continue to rise (Steward et al. 1989). According to Busse et al. (2005), masticated residues roughly $7.5 \mathrm{~cm}$ thick that continue to burn (such as duff) will cause lethal effects on plants at about $60^{\circ} \mathrm{C}$ to as deep as $10 \mathrm{~cm}$ below the surface. In cases where moist duff covers the surface, the duff insulates the soil and inhibits heat penetration. However, the smoldering duff also increases the duration of soils and sediment heating (Hungerford 1990; Peter 1992). As discussed elsewhere, the ecological environment of 41DL436 was likely damp and moist for most if not all of its occupation periods. As shown in Table 16-14, studies on grassland prairie fires have provided various temperature data. Provided also are the depths at which these temperatures penetrate the surface. 
Table 16-14. Surface Temperature Data on Grassland Prairie Fires.

\begin{tabular}{lll}
\hline \multicolumn{1}{c}{ Surface Temperatures } & \multicolumn{1}{c}{ Heat Penetration Below the Surface } & \multicolumn{1}{c}{ References } \\
\hline Average $-102^{\circ} \mathrm{C}-388^{\circ} \mathrm{C}$ & $175^{\circ} \mathrm{C}$ to $1.5 \mathrm{~cm}$ & Wright and Bailey 1982:9-11 \\
\hline Maximum $-682^{\circ} \mathrm{C} \mathrm{(a)}$ & Not Available & Gibson et al. 1990 \\
\hline Average $-93^{\circ} \mathrm{C}-545^{\circ} \mathrm{C}$ & $\begin{array}{l}\text { Lethal to most plants to } 1 \mathrm{~cm} \text { in the lower range of } \\
\text { temperatures }\end{array}$ & Hungerford et al. 1990 \\
\hline $\begin{array}{l}\text { Average }-502^{\circ} \mathrm{C} \\
\text { Maximum }-874^{\circ} \mathrm{C}\end{array}$ & $64^{\circ} \mathrm{C}$ to $2 \mathrm{~cm} \mathrm{(b)}$ & Lata and Weirich 2013:102-104 \\
\hline Average $-140^{\circ} \mathrm{C}-400^{\circ} \mathrm{C}$ (c) & Not Available & Cf. Jackson 1998:31 \\
\hline
\end{tabular}

(a) Includes grasslands mixed with small trees and shrubs

(b) High sand content; moisture $21.5 \%$ by weight

(c) Temperatures sustained for $2-3$ minutes

As previously stated, the focus of this section is our ability to discern cultural hearth features from naturally occurring surface burns. Somewhat problematic in distinguishing between the two is that natural fires in shrub and forested regimes such as what appeared to be the case at 41DL436 is that temperatures in these ecological environments are akin to those of most cultural hearths. Besides the obvious, usually circular of oval-shaped morphology of a cultural hearth, is the extent of the burn. That is, cultural hearths, either with or without fire-cracked rocks are normally constrained to a discrete area, whereas studies following naturally occurring fires revealed burned surfaces patches irregular in size, mosaic patterns, and defined by distinct boundaries (Bierman and Gillespie 1991:642; Conner et al. 1989:298). Both of these patterns are those uncovered at 41DL436 during the October 2010 excavations.

Bellomo's (1990) comprehensive replication studies of natural range/grassland fires and burned tree stumps determined that there are significant differences in surface temperatures elevated by campfires versus tree stumps or grass fires (Table 16-15). Subsurface temperatures decreased with depth, except around the tree stumps. In addition, he found that both tree stump burns and multi-use campfires exhibit sub-surface forms, but in different shapes. That is, the experimental hearths formed a basin shape to as deep as $15 \mathrm{~cm}$ below the surface. Burned tree stumps, on the other hand, exhibited oxidation in the top 1-2 cm around the stump, and left a hole in the substratum. Grassfires were not of sufficient intensity and duration to oxidize the surface soils, but did leave a thin layer of ash. Similar to Bellomo's observations, Thoms' (1996) studies of natural forest burns in Montana recorded one instance of fire-cracked rocks dropping $40 \mathrm{cmbs}$ into a burned tree stump cavity. Without the knowledge that this occurred following a recent forest fire, the slumped burned rocks could be misconstrued by future archaeologists as a cultural, basin shaped-hearth.

\section{Cultural Hearths}

Four fire-cracked rock hearths (Features 5, 7, 41, 42) were uncovered at 41DL436, and appear to represent what archaeologists have come to know as 'classic' small, circular, rock-lined 
hearths. Otherwise, burned features at 41DL436 include amorphous masses of clay, ash, and charcoal. Perhaps one of the better studies of similar features was most recently undertaken at Dust Cave in Alabama, with follow-up replication studies conducted by students from Skidmore College and Middle Tennessee State University (Homsey 2003; Homsey and Chapman 2005; Homsey and Capo 2006; Homsey et al. 2010; Sherwood and Chapman 2005; Walker et al. 2002).

Burned features at Dust Cave included not only fire-cracked rock hearths, but also charcoal and ash pits, and amorphous surface masses of charcoal and ash with burned clay. Researchers selected 60 features from Dust Cave, hardened the fill samples in the lab, and then crosssectioned them to examine their chemistry and micromorphological makeup. The chemical analysis was conducted in detail, yielding stark contrasts between feature types.

Surface hearths at Dust Cave are generally charcoal-rich, with some ash. Under the surface hearths are burned red clay. High firing temperatures have blackened and calcined microartifacts within the fill. The wide variety in the chemical makeup of the fill suggests that a wide variety of foodstuffs and possibly other materials were burned. Based upon the chemical makeup and microartifacts recovered from the fill, researchers opined that the hearths represented 1) roasting food on a spit or rack over a fire using dry heat (Hudson 1976), 2) parching selected foodstuffs in coals overlying hot, flat clay (Stafford 1991).

The latter category they defined as expedient hearths, morphologically distinct as roughly 40 $\mathrm{cm}$ in diameter, fired on a flat, prepared clay surface, not purposely dug into the substrate, but subsequently collapsing into the burned substrate as much as $10 \mathrm{~cm}$. Characteristically, these features exhibit well-stratified ash microlenses sometimes underlain with a thin lens of charcoal, suggesting that the coals smoldered for extended periods, tuning into ash. In addition, many of these types of expedient features contained microartifacts with evidence of burning to a lesser degree than those found in specially prepared surface hearths. In addition, plant remains were generally only partially charred, likewise indicating lower temperature burns. Micro burned and unburned fish bones in the Dust Cave expedient hearths suggested that fish may have been roasted in the coals, while the presence of charred nutshells suggested their use as perhaps both a subsistence item as well as a fuel source.

Two studies of expedient hearths replicated those hearths found in Dust cave. In 2002, Students from Skidmore College packed $3 \mathrm{~cm}$ of clay roughly 1-m in diameter on a flat surface. They then built a fire on the clay surface and measured its temperature at a maximum $300^{\circ} \mathrm{C}$, let it burn down to coals to $100^{\circ} \mathrm{C}$, placed a two-pound catfish wrapped in sassafras leaves directly on the coals, and covered the fish with clay and additional coals. Following a 45-minute cooking period in the smoldering coals, the fish was removed. The students observed that the fish was well done, cooked thoroughly, and moist, with no evidence of bone discoloration.

For their second experiment they cooked a largemouth bass, using the same cooking techniques as with the catfish, but without placing a thin clay cap over the fish. In less than one hour the bass was thoroughly cooked. None of the bones were either burned or calcined, with only a few bones showing evidence of charring. Thus, their experiment revealed two things 1) using 
a prepared clay surface with smoldering charcoal was an effective technique for cooking, and 2) bones cooked in this manner showed little if any, evidence of heating. "Moreover, when a fire is made and cleared, the resulting feature resembles the expedient hearths seen at Dust cave in several physical properties, including a friable and fire-hardened surface, large quantities of strontium-rich ash deposits overlying the prepared clay surface, and thin lens of ash adhering to the clay where the coals were swept away" (Homsey et al. 2010:188; Homsey 2004).

Recent experimental studies at Site 41DL203 in Texas examining the compositional makeup of burned clay balls in both archaeological contexts and replicated experimental clay balls from off-site has proven useful. Charles Frederick (2011:105-117) found a distinct petrographic difference in clay balls manufactured from off-site clays versus trampled clay on-site when viewed in thin section. Citing Henderson (2000) and Whitbread (1995), Frederick was able to discern from the degree of rubification and partial sintering of the clay matrix that the clay was heated to roughly between $800^{\circ}$ and $990^{\circ} \mathrm{C}$.

As for the burned features at 41DL436, sediment thin sections analyzed by Charles Frederick (Appendix A) revealed a 1 to 3 -cm oxidation rind capped with small zones of ash and charcoal. Underlying the cap is generally rubified and blackened earth from charcoal staining. Charles opines that these features represent an oxygen restricted heating event.

Additionally, Leslie Cecil (2012) analyzed prehistoric burned clay samples from Site 41BX256 and using an Isotope Programmable Muffle Surface, was able to estimate prehistoric firing temperatures based upon color changes realized when the samples were re-heated. We submit that the same protocols applied to burned clay at Dust Cave, 41BX256, 41DL203, and by Charles Frederick during this project should be applied to future studies of burned features at sites in North Central Texas similar in makeup to 41DL436.

\section{Fires Resulting from Human Activities Versus Naturally Occurring Surface Fires}

Among other methods, Bellomo (1993) used relative magnetic soil susceptibility values to differentiate between burning caused by grass fires, isolated tree stump fires, and forest fire sites - versus archaeological hearths and ovens. Specifically, "The magnetic susceptibility results indicate that this parameter of investigation has the potential to identify archaeological evidence of humanly-controlled fire, because multiple-burn campfire samples exhibited greater differences in magnetic susceptibility (i.e. between campfire samples and adjacent unfired control samples) than the susceptibility differences displayed by tree stump fire or grass fire samples and their respective control samples. Multi-burn campfire samples produce greater differences in magnetic susceptibility because campfires generate higher temperatures than either tree stump fires or grass fires" (Bellomo 1992:547).

Thompson and Oldfield (1986) summarize magnetic susceptibility as a measure of the degree of intensity through which soils are magnetically enhanced. Bellomo (1993) based his premises of using magnetic susceptibility values in the above described studies on the findings of previous researchers who determined that temperatures from fires effects magnetic enhancement (e.g., 
Le Borgne 1964; Tite and Mullins 1971; Mullins 1977; Thompson et al. 1980; Ozdemir and Banerjee 1982; Thompson and Oldfield 1986).

\section{Magnetic Soil Susceptibility}

Soils acquire a magnetic susceptibility from the Earth's ambient magnetic field. The proportion of this constant magnetic force is called the magnetic susceptibility. This low-field susceptibility is also proportional to the concentration of ferro- and ferromagnetic constituents of the material. The magnetic susceptibility of soils can be altered by both pedogenic and cultural processes. In both cases, the organically induced pedogenic and cultural processes enhance (increase) the susceptibility values. In pedogenic studies, a significant increase in soil susceptibility values has been observed in the A horizon of soil profiles, probably as a result of organic activities, which creates maghemite (see for example, Singer and Fine 1989). Other research (e.g., Heller and Evans 1995) indicates that the susceptibility values can also be altered by changes in climate.

Although the pedogenic and climatic processes that may alter the magnetic susceptibility (MS) of soils is important, and begs further research on and around archaeological sites, thus far the most significant variability in susceptibility noted by archaeologists and Dr. Wulf Gose, Director of the Paleomagnetism Laboratory at The University of Texas at Austin (now retired), has been derived from the presence of wood ash and charcoal. Granted, wood ash can also be present due to past range and forest fires. However, horizontal studies within distinct strata indicate that the increase in values around prehistoric hearths is remarkably distinct, as is the vertical separation of clearly distinguishable cultural strata from natural strata (see for example, Gose and Nickels 1998). This is particularly true if multiple heating events are distinguishable in the archaeological record (e.g., Heller and Evans 1995). In Central Texas, where many of the soils are particularly carbonaceous, the increase in magnetic susceptibility values on archaeological sites is remarkably significant compared to the culturally unaltered surrounding soils (Collins et al. 1994).

Magnetic soil susceptibility (MSS) has also proven useful in identifying the horizontal extent of burned areas as well as identifying temperatures to which sediments and soils have been heated. In heating experiments of sediments, Bellomo (1993) identified modifications in magnetic susceptibility values as a function of heating, which changes the mineralogy of the sediments.

In Texas, experiments conducted by Mauldin and Figueroa (2006) demonstrated that measuring magnetic susceptibility values of sediments may have the potential to identify cultural versus natural features. Theoretically, changes in mass-specific susceptibility values should be relative to heating temperatures of a given sample. Mauldin (1998:128-130) has demonstrated that post-firing temperatures in caliche hearths average between $300^{\circ} \mathrm{C}$ and $600^{\circ} \mathrm{C}$ for as much as six hours after firing. In addition, mineralogical changes that occur most commonly when sediments are heated between $300^{\circ} \mathrm{C}$ and $600^{\circ} \mathrm{C}$ may be reflected in magnetic susceptibility values when these same sediments are reheated (Crowther 2003; Dearing 1999). 
Assuming subsistence cooking practices were consistent across 41DL436, and the site was repeatedly used as a short-term logistical activity site, then presumably hearth temperatures should have been relatively consistent. How these temperatures compare to natural surface burns of downed vegetation is explored in a comparative study of surmised temperature ranges in some of the burned clay patches based upon magnetic soil susceptibility values.

The purpose for measuring soil susceptibility at 41DL436 was to evaluate the peaks in MSS of sediment samples collected at regular intervals from in and around features that were clearly identifiable as cultural, as well as those that could possibly be natural range and forest fires. Ideally, information produced from the analysis of MSS values should coincide with zones in which high frequencies of cultural materials are found. All soil susceptibility measurements were recorded in the field using a ZH Instruments Model SM-30 Magnetic Susceptibility Meter, the values recorded on standardized forms, and the data then entered into a spreadsheet.

Our premises of Magnetic Soil Susceptibility values of the burned features rely heavily on both replication studies and data obtained from a fire-cracked rock hearth feature at 41PR44 in Parker County, Texas (Mauldin and Figueroa 2006). Although the following discussion of 41PR44 is admittedly lengthy, we believe that it is necessary in order to understand how the 41PR44 data is relatively co-eval with the data obtained from the 2010 excavations at 41DL436. In addition, to our knowledge, there is no other study on sediment MSS in northern Texas from which to use as a control datum in order to evaluate the data from 41DL436.

In their experiment, Mauldin and Figueroa first collected four sediment samples not in any apparent heated or burned contexts from the San Antonio area in Bexar County, Central Texas. They first measured their Natural Remnant Magnetization (NRM). They then heated all four samples in increments of $400^{\circ} \mathrm{C}, 500^{\circ} \mathrm{C}$, and $600^{\circ} \mathrm{C}$. Following each heating event, they allowed the samples to cool for two hours and then measured their susceptibilities. The temperature increments were selected based upon Mauldin's (1998:128-130) experiments where he found that small hearths retain temperatures between $500^{\circ} \mathrm{C}$ and $300^{\circ} \mathrm{C}$ for as long as six hours after firing. And, according to Dearing (1999) and Crowder (2003), depending upon the mineral composition of the sediments, changes in magnetism should be most commonly observed within those temperature ranges. The resulting average increases in magnetic susceptibility were as follows:

$$
\begin{aligned}
& \text { NRM to } 400^{\circ} \mathrm{C}=24.25 \% \text { increase } \\
& \text { NRM to } 500^{\circ} \mathrm{C}=33.09 \% \text { increase } \\
& \text { NRM to } 600^{\circ} \mathrm{C}=31.77 \% \text { increase }
\end{aligned}
$$

However, a second experiment on a previously unheated sediment sample from a slightly different area of Bexar County, Texas produced similar end results, but with very different incremental percentage increases. The resulting average increases in magnetic susceptibility from that study were as follows, and clearly demonstrate the variability that can occur in MSS of heated sediments, dependent upon the parent mineralogy of the soils. These data appear to represent an anomally: 
NRM to $400^{\circ} \mathrm{C}=16.3 \%$ increase

$\mathrm{NRM}$ to $500^{\circ} \mathrm{C}=100.0 \%$ increase

$\mathrm{NRM}$ to $600^{\circ} \mathrm{C}=300.0 \%$ increase

Next, Mauldin and Figueroa collected a presumably previously unheated sediment sample from archaeological site 41PR44 in Parker County, in the northern Panhandle of Texas. The sample's provenience was roughly 2.5 meters remote from a fire-cracked rock hearth feature (Feature 12), but within the same strata. This sample was also heated and subsequently cooled in the lab in 100-degree increments, and MSS values recorded following each event. The resulting averages in magnetic susceptibility from that independent sample appear to be more within the norm, and were as follows:

$\mathrm{NRM}$ to $400^{\circ} \mathrm{C}=15.6 \%$ increase to an MSS value of 41.5

$\mathrm{NRM}$ to $500^{\circ} \mathrm{C}=27.7 \%$ increase to an MSS value of 45.8

Mauldin and Figueroa then measured 21 sediment samples that crosscut Feature 4, at 41PR144, and the MSS values of each of these 21 samples were compared to the independent sample remote from the feature (see discussion directly above). Excluding three readings that are considered anomalies, the resulting average magnetic susceptibility values from that study were as follows:

\section{MSS Outside Feature 12}

36.8 (equivalent to non-heated sediment)
MSS Inside Feature 12

42.91 (roughly equivalent to $400^{\circ} \mathrm{C}$ )

49.72 (roughly equivalent to $500^{\circ} \mathrm{C}$ )

In sum, the percentages of MSS variances among the samples in each of the studies clearly illustrate differences in soil mineralogy. But, regardless of the mineral makeup, the important and distinguishing factors are the relative (our emphasis) variances between heating episodes within each of the samples, and that the shifts in MSS values demonstrate a direct correlation to heating events and temperatures in sediments. Thus, it is plausible that the results of these studies can be reliably used as a model for predicting heating temperatures of the burned features discovered at 41DL436.

\section{DL436 BurNed Features}

As discussed above, magnetic susceptibility increases significantly in value with the presence of ash. It then stands to reason that magnetic susceptibility values will be higher in discrete areas where dense fuel loads with intense and sustained burning has occurred. This could include both downed trees and limbs, as well as repeated use of cultural hearths. Notably, Mauldin and Figueroa collected soil samples and used an in-lab M55 meter, while we used a portable handheld device in the field. While the handheld instrument may be less accurate, what is important here is the relative differentiation in the readings-not the actual numbers. 


\section{Stratum 3 - Upper Component Burned Features}

\section{Unit 11 (Non-Feature)}

Unit 11 was excavated to recover a single bone. Although charcoal flecks were noted occasionally across the $1-\mathrm{m}^{2}$ unit, no burned sediment areas were apparent. The soil consisted of very dark grayish brown (10YR3/2) silty clay, mottled with brown (10YR4/3) silt. Six evenly spaced MSS readings were taken across the unburned surface, resulting in an average value of 9.93 . These soils are generally what could be expected within Stratum 3, and the MSS values are not out of the norm for the unburned sediments and soils discussed around Features 3, 4, 6, and 11.

\section{Features 3 and 8}

We first examine the MSS values from Features 3 and 8, described as ash and charcoal masses in Stratum 3, the upper cultural component (see Upper Component discussion, above). Charcoal from this feature yielded dates of $190 \pm 25 \mathrm{BP}$ and $110 \pm 25 \mathrm{BP}$. A total of $31 \mathrm{MSS}$ readings were recorded from within and around the two features (Figure 16-80).

Shown in Figure 16-81 are the moving averages of MSS values within Features 3 and 8, along with the MSS moving averages outside of both of these features. The average MSS value outside both features is 13.23; within Feature 3 is 21.18; within Feature 8 is 17.80. Using

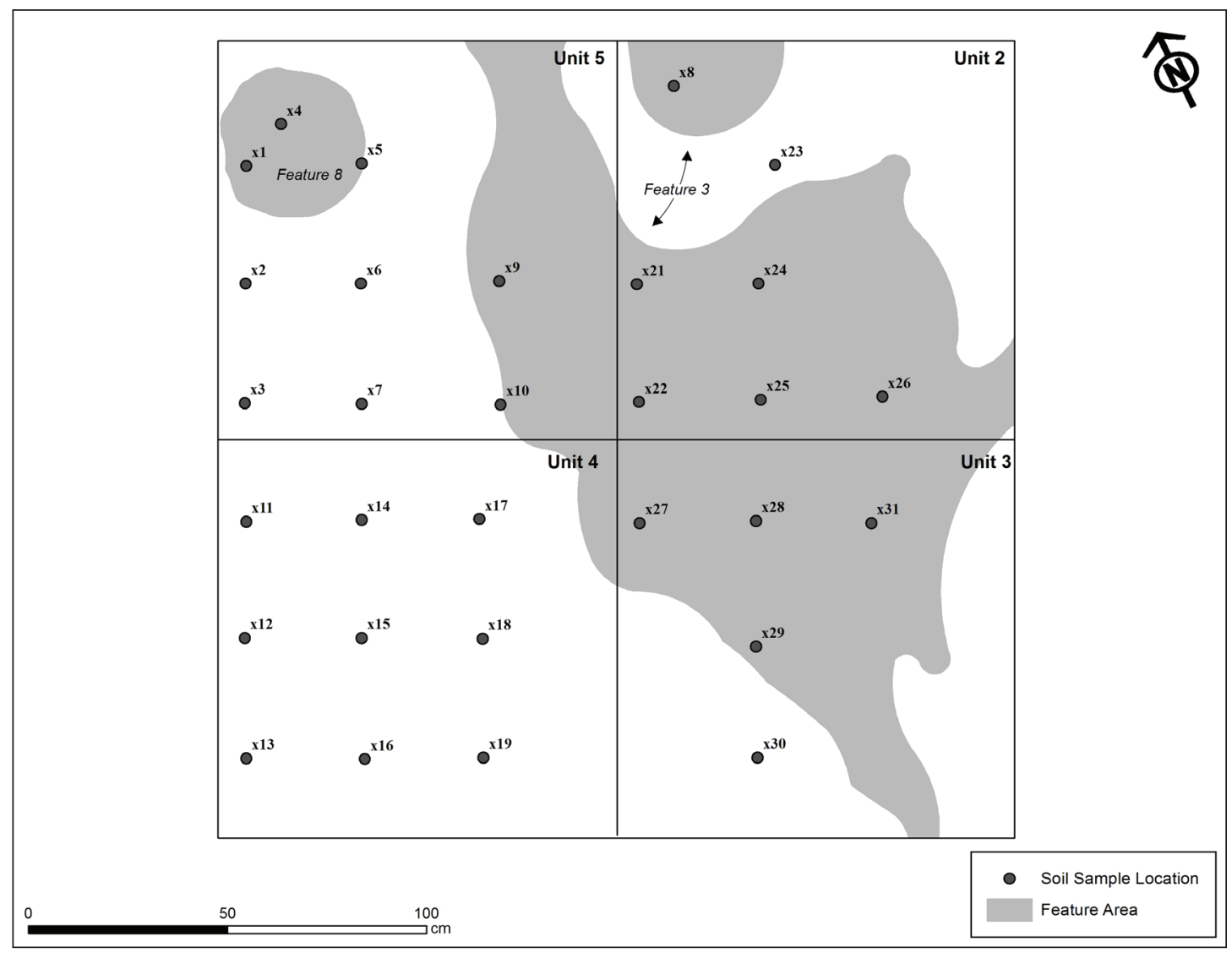

Figure 16-80. Locations of MSS readings within and around Features 3 and 8. 
the baseline mean value of 13.23 for the presumably unburned sediments, these data indicate a 62.46 percent increase in MSS in Feature 3, and a 34.54 percent increase in Feature 8. By implication then, Feature 3 was a burning event that was oxygen-rich, of longer duration, greater intensity, relatively hotter temperature, and with a more dense fuel load than Feature 8.

\section{Feature 4}

Feature 4 is interpreted as a tree root burn that began on a once stable

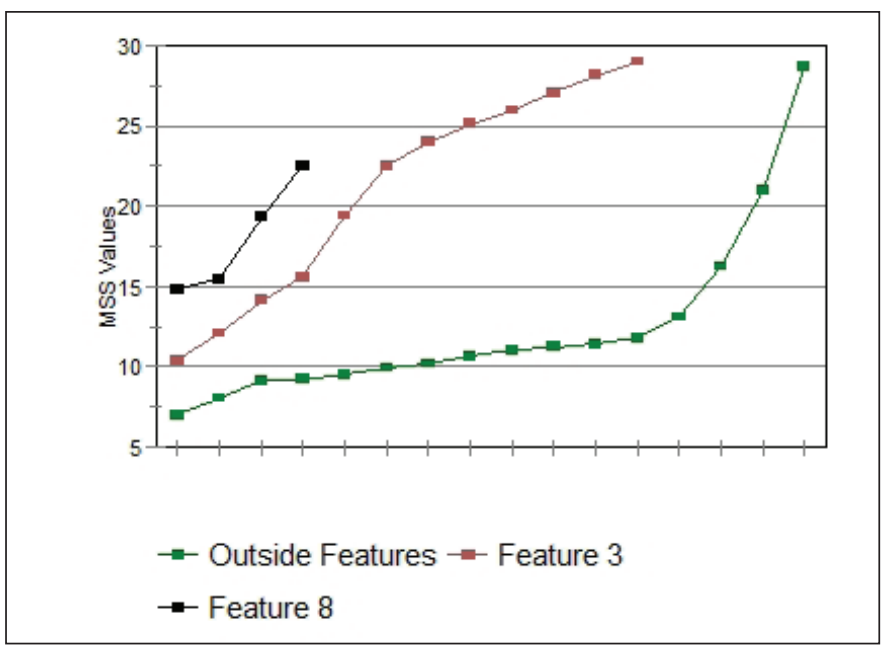

Figure 16-81. Moving averages of Magnetic Soil Susceptibility values in and around Features 3 and 8 . surface roughly $80 \mathrm{~cm}$ below the modern surface, and extended vertically for approximately $55 \mathrm{~cm}$. The feature matrix seemed slightly ashy, and the matrix texture was slightly more compact than the surrounding soils. The upper $20 \mathrm{~cm}$ of the feature was pedestaled in Unit 6, photographed, and removed (no MSS readings were recorded).

A total of 53 MSS readings were taken $20 \mathrm{~cm}$ below the top of Feature 4, across the surface of Unit 6 (Figure 16-82a). Four readings (Points 1, 38, 43, 53) were skewed because of their close proximity to metal nails driven for excavation control, and thus were discarded for this analysis.

Shown in Figure 16-82b are the moving averages of MSS values inside and outside of Feature 4, 20 below its top. The average MSS value across the presumably unburned surface sediments outside Feature 4 is 9.66 ; within Feature 4 it is 12.20 . Using the baseline mean value of 9.66 for the unburned sediments, these data indicate a 26.29 percent increase in MSS. This moderate increase in MSS suggests that the upper portion of Feature 4,

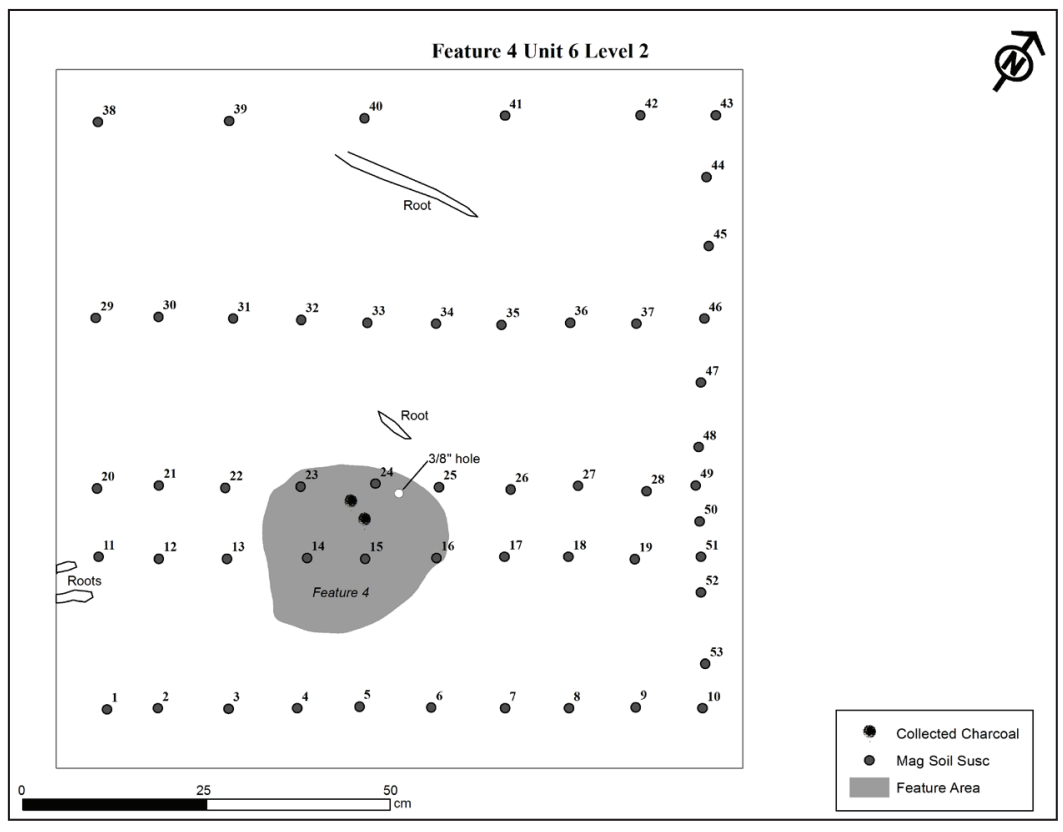

Figure 16-82a. Locations of MSS readings $20 \mathrm{~cm}$ below the top of Feature $4(20 \mathrm{cmbd})$ in Unit 6. 
$20 \mathrm{~cm}$ below the surface on which the burning in Feature 4 began suggests an oxygenstarved, relatively low intensity, relatively low temperature burn, much like should be expected in a smoldering root burn. And, as discussed below and illustrated in Figure 16-83, these fire temperatures appear to have decreased only slightly with depth.

Next we examined the MSS values along the vertical, lower extremity extent of Feature 4 from 20-70 cmbd. Shown in Figure 16-63 (see Upper Component discussion above) are the locations of MSS columns 1 and 2; column 1 being located outside of the feature, and column 2 located within the feature. Shown below in Figure 16-83 is a chart depicting the MSS values from $20-70 \mathrm{cmbd}$. Note that a line has been added at $70 \mathrm{cmbd}$, showing where the bottom few centimeters veered away from column 2, so that readings below the line were presumably within unheated sediments. The MSS values within Feature 4 are consistently greater than those outside the feature; however,

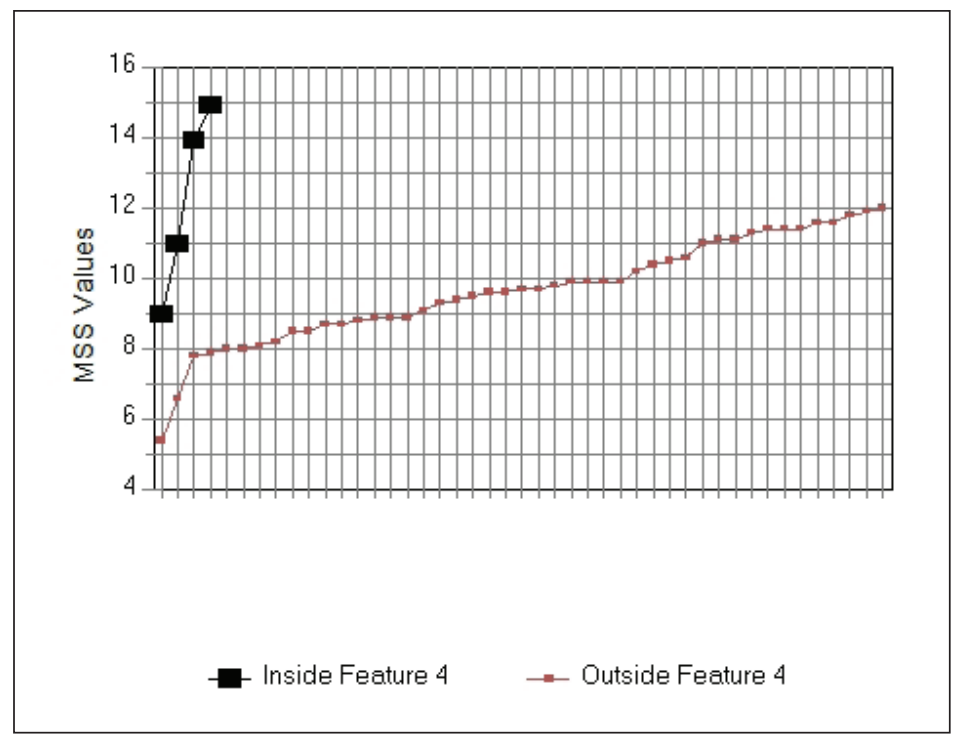

Figure 16-82b. Chart showing MSS values inside and outside the upper $20 \mathrm{~cm}$ of Feature 4; sorted by MSS value ( $\mathrm{Y}$ value).

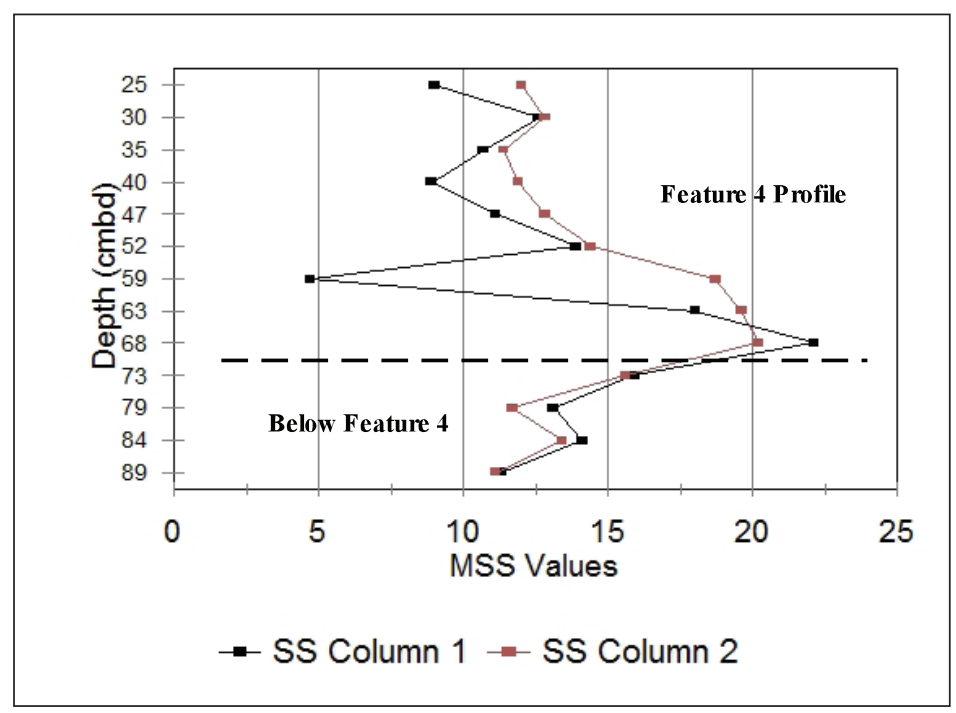

Figure 16-83. Chart showing MSS values outside and inside of Feature 4. below the $70-\mathrm{cm}$ line depicted in Figure 16-83, the data trends mirror each other.

The average MSS value outside Feature 4 between $20-70 \mathrm{cmbd}$ is 12.33 , while the MSS value within Feature 4 is 14.87, an increase of 20.60 percent. This moderate percentage increase also suggests an oxygen-starved, low intensity, relatively low temperature burn, much like should be expected in a smoldering root burn. However, the percentage of increase in MSS values within the lower levels is slightly less compared to the percentage increase in MSS values from the upper $20 \mathrm{~cm}$ of this feature (26.29 to 20.60 percent), suggesting that temperatures were likely decreasing the lower the root burned. 


\section{Feature 6}

Feature 6 is interpreted as a tree and root burn extending from approximately $80-180 \mathrm{cmbs}$ (see Figures 16-64 and 16-65). The top of Feature 6 appears to be stratigraphically co-eval with the top of Feature 4, suggesting that the bases of both trees were in the same surface stratum when they were consumed by fire. In addition, this same stratum appears to be co-eval with that of Features 3 and 8 .

After the top of Feature 6 was exposed during a Gradall scrape, Unit 8 was opened, the feature was pedestaled, and the surrounding matrix excavated to $10 \mathrm{cmbd}$, and $10 \mathrm{~cm}$ below the top of Feature 6. Nine MSS measurements were recorded across the surface of Unit 8 as shown in Figure 16-84, $10 \mathrm{cmbd}$. A tenth measurement (Point \#4) was recorded on the very top of Feature 6.

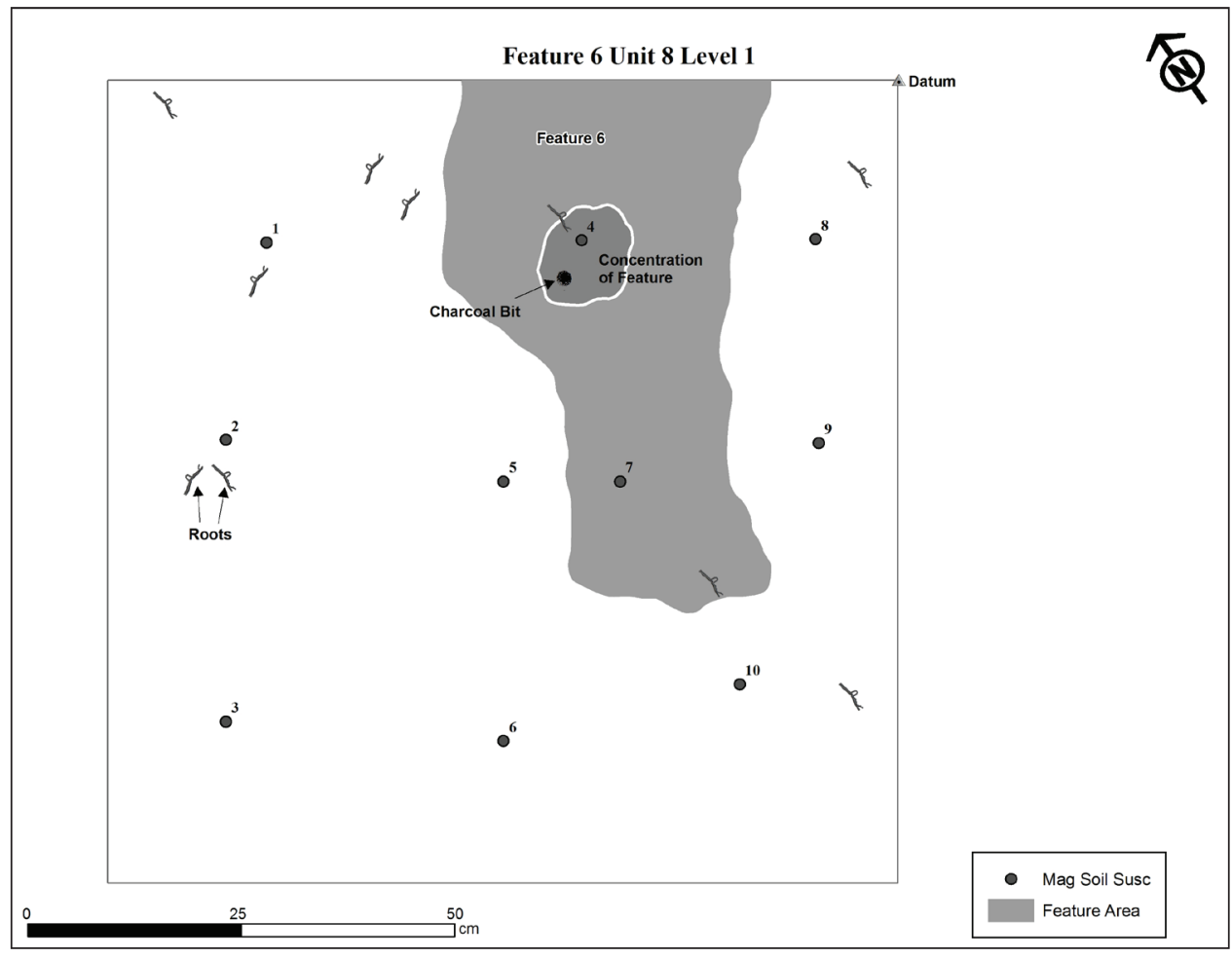

Figure 16-84. Locations of MSS readings on top of Feature 6, and $10 \mathrm{cmbd}$ around the feature in Unit 8, Level 1.

Shown in Figure 16-85 is a chart illustrating the MSS value on the top of Feature 6 (Point \#4), as well as those values recorded $10 \mathrm{~cm}$ below the top of Feature 6 . The only MSS point clearly within Feature 6 is Point \#4, with a significant peak in value of 15.70 . The surrounding values in the unburned sediments $10 \mathrm{~cm}$ below average 8.04 . These data represent an increase in sediment MSS values of 87.44 percent at the top of the burn. A significant increase of this magnitude suggests that when the top of Feature 4 burned it was exposed to an oxygen-rich environment, and was made up of a dense fuel load that burned at a high temperature for a relatively extended period of time. 
However, we now recognize that our field methods were somewhat flawed in that we failed to measure the MSS values of the surrounding unburned sediments in co-eval strata around the very top of the feature, before they were removed during excavation. Nevertheless, by comparison, we present MSS values on sediments within and adjacent to the lower portion of Feature 6. Shown in Figure 16-86 is a drawing of Feature 6 in profile, showing the two columns where MSS readings were taken; Column 1 being outside the feature, and Column 2

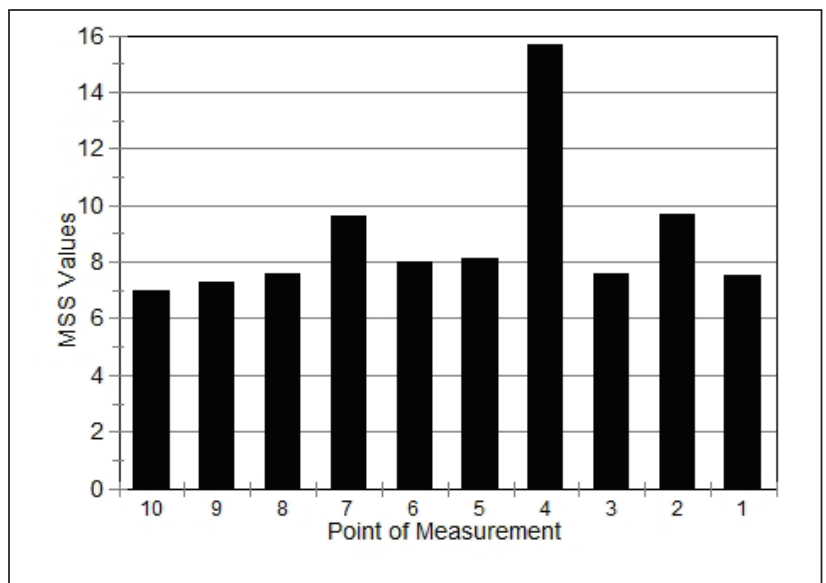

Figure 16-85. Chart showing the MSS values on top of Feature 6 , as well as $10 \mathrm{~cm}$ below the top. being inside the feature.

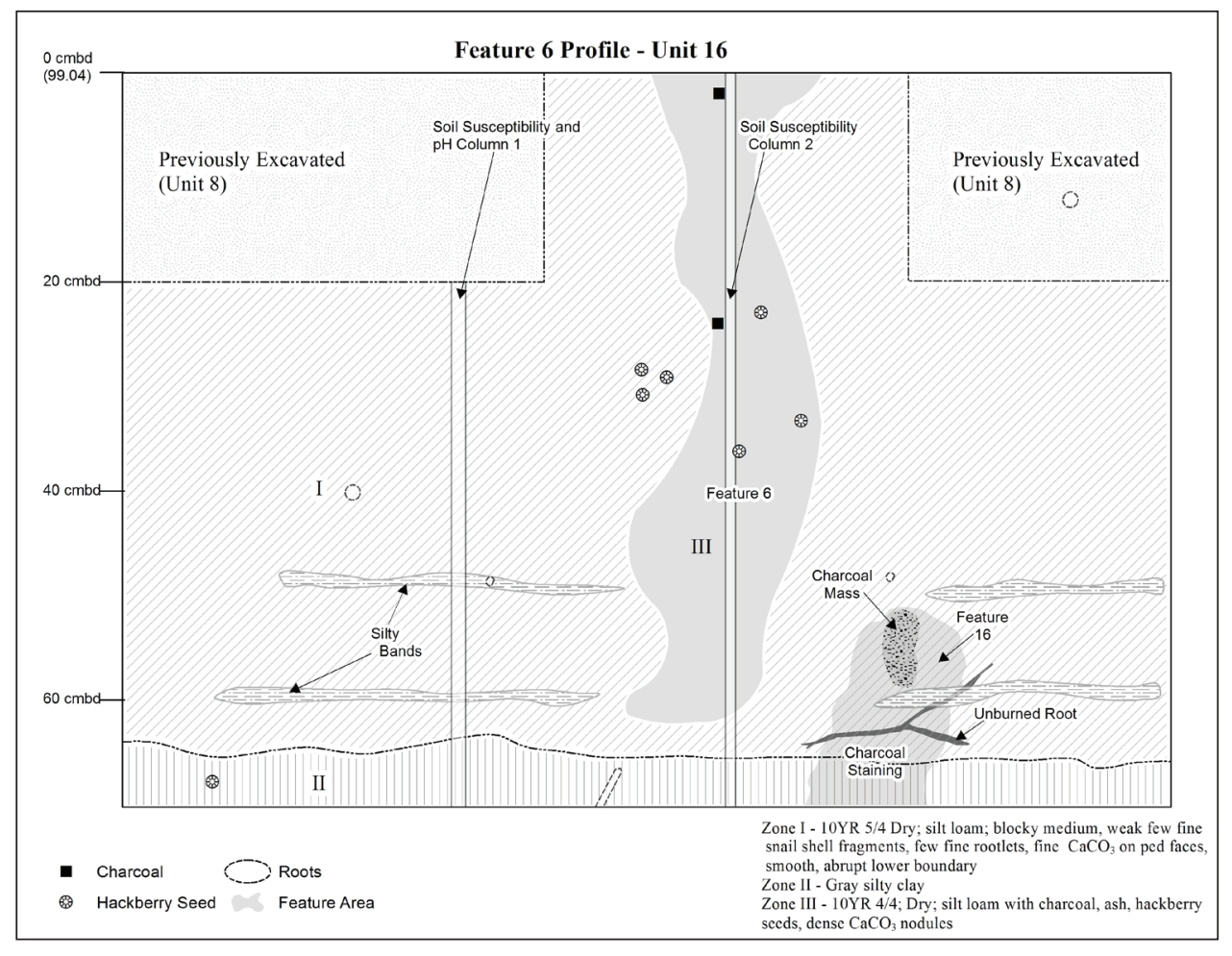

Figure 16-86. Profile of Feature 6 showing locations of MSS columns.

As shown in Figure 16-86 above, the bottom of Feature 6 appeared to end just over $60 \mathrm{cmbd}$. However, the MSS values as illustrated in Figure 16-87 indicate that burning likely terminated closer to $50 \mathrm{cmbd}$, where the two MSS value trend lines converge. The average MSS value outside the feature between $20-50 \mathrm{cmbd}$ is 12.38 , while the average MSS value inside the feature at those same depths is 15.26, a 23.26 percent increase. This relative percentage increase is very close to the 20.60 percent increase in MSS values from the lower portion of 
Feature 4. As with our evaluation of the data from Feature 4, Feature 6 data also suggests an oxygen-starved, low intensity, relatively low temperature burn, much like should be expected in a smoldering root burn.

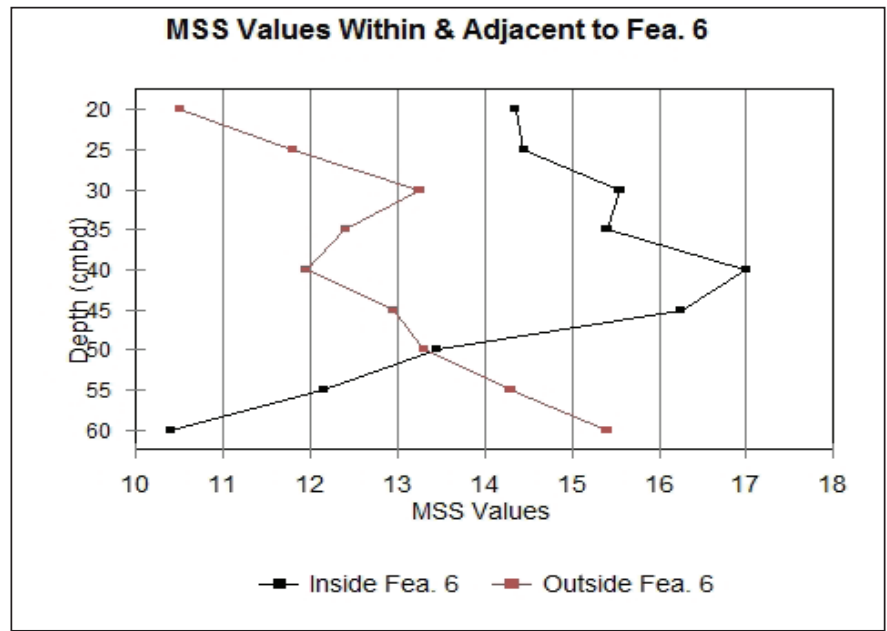

Figure 16-87. Moving average of MSS values inside and outside of Feature 6.

\section{Stratum 2 - Middle Component Burned Features and Areas}

In this section, we first assess the unburned sediments and soils from selected excavation units in order to provide a relevant baseline for MSS values in unburned sediments and soils versus clearly burned sediments and soils. In that regard, we first discuss the MSS values from silty clay, silty clay loam, and fine sands within Stratum 2. Next, we use these values as a relevant baseline for the burned features 28 and 31 uncovered.

\section{Unit 19 (Non-Feature)}

Unit 19 was opened as part of a block excavation in Stratum 2. Six MSS values were recorded in an even grid pattern across the surface of Unit 19 in Level 2, $20 \mathrm{cmbd}$, within dark grayish brown (10YR 3/2) silty clay that contained tiny charcoal flecks throughout. The bottom of Level 2 lies roughly $2 \mathrm{~cm}$ above Feature 17, a burned earth and charcoal mass dating to $480 \pm \mathrm{BP}$.

The MSS values of the unburned sediments and soils on the surface of Level 2 ranged from 13.6 to 24.4 , with an average MSS value of 20.27. This average value of 20.27 appears to be within the norm for unburned silty clay sediments and soils with charcoal flecks throughout within Stratum 2.

\section{Unit 22 (Non-Feature)}

Unit 22 is adjacent to Unit 19, and was also part of a block excavation in Stratum 2. Six MSS values were recorded in an even grid pattern across the surface of Unit 22 in Level 1, 10 cmbd, within dark grayish brown (10YR 3/2) silty clay loam that contained tiny charcoal flecks widely dispersed throughout. Feature 17, a burned earth and charcoal mass dating to $480 \pm \mathrm{BP}$ lies roughly $10 \mathrm{~cm}$ below Level 1; note that Abbot (Chapter 5, Table 5-2) surmises that this was an old wood sample.

The MSS values of the unburned sediments and soils on the surface of Level 1 ranged from 12.6 to 17.0 , with an average MSS value of 14.13. Although lower MSS values than recorded 
in Unit 19, Level 2, this average value of 14.13 also appears to be an acceptable norm for unburned silty clay loam sediments and soils with occasional tiny charcoal chunks within Stratum 2.

\section{Unit 27 (Non-Feature)}

Unit 27 was excavated adjacent to Unit 22, and was also part of a block excavation in Stratum 2. Six MSS values were recorded in an even grid pattern across the surface of Unit 27 in Level 2, $20 \mathrm{cmbd}$, within light yellowish brown (10YR6/4) loose fine sand. No apparent evidence of heated or burned sediments or soils was observed across the surface of Level 2.

The MSS values of the unburned loose fine sand on the surface of Level 2 ranged from 3.7 to 7.7 , with an average MSS value of 6.25. In this case, the low values compared to unburned, but comparatively organically enriched silty clays and silty clay loams most probably represent the mineralogical makeup of the unburned sand source, which likely contains only minute traces of organic material. Nevertheless, the MSS values provide what are likely the baseline for unheated fine sands in Stratum 2 at this site.

\section{Unit 35 (Non-Feature)}

Unit 35 was opened as part of a block excavation near the center of the trench. No burned sediments or soils were observed, but six MMS readings were taken in a grid fashion across the surface of Level 3. Soils consisted of yellowish brown (10YR5/6) fine silt. The MSS values ranged from 5.3 to 11.1 , with an average value of 8.0. These values are only slightly higher than the unburned loose fine sand measured in Unit 27, and provide a baseline for unburned silt in this area of the trench.

\section{Feature 28}

Feature 28 is fully described and illustrated with photographs in the "Middle Cultural Component" section. Succinctly, it is described as a roughly 10-cm deep basin shape pit, infilled with charcoal and ash, with a 1-2-cm lens of darkened soiled stained with charcoal and ash surrounding it at the top. It has an orange burned clay layer laden with charcoal chunks and flecks, and dark ash in a thin (ca. $1 \mathrm{~cm}$ ) layer, irregular in shape, lying on a dark brown clay loam strata roughly $180 \mathrm{cmbs}$. The orange splotches of burned clay are generally surrounded with black charcoal. Some areas have white and gray ash remnants. A conventional radiocarbon date obtained from in situ heavily burned charcoal indicates that the burned area was likely ignited sometime between AD 1470 and 1840 (2 Sigma Calibrated Measured Radiocarbon Age $340 \pm 30 \mathrm{BP})$.

Shown in Figure 16-88 are the locations of MSS value recordings, and Figure 16-89 illustrates the MSS values inside and outside of the feature. First we noted the extremely high values in MSS both outside and inside the feature compared to values observed in other features throughout the site. The sediments and soils outside of the main portion of the feature exhibited a matrix of ash and charcoal staining. In these areas, the average values outside the feature is 32.99 , 


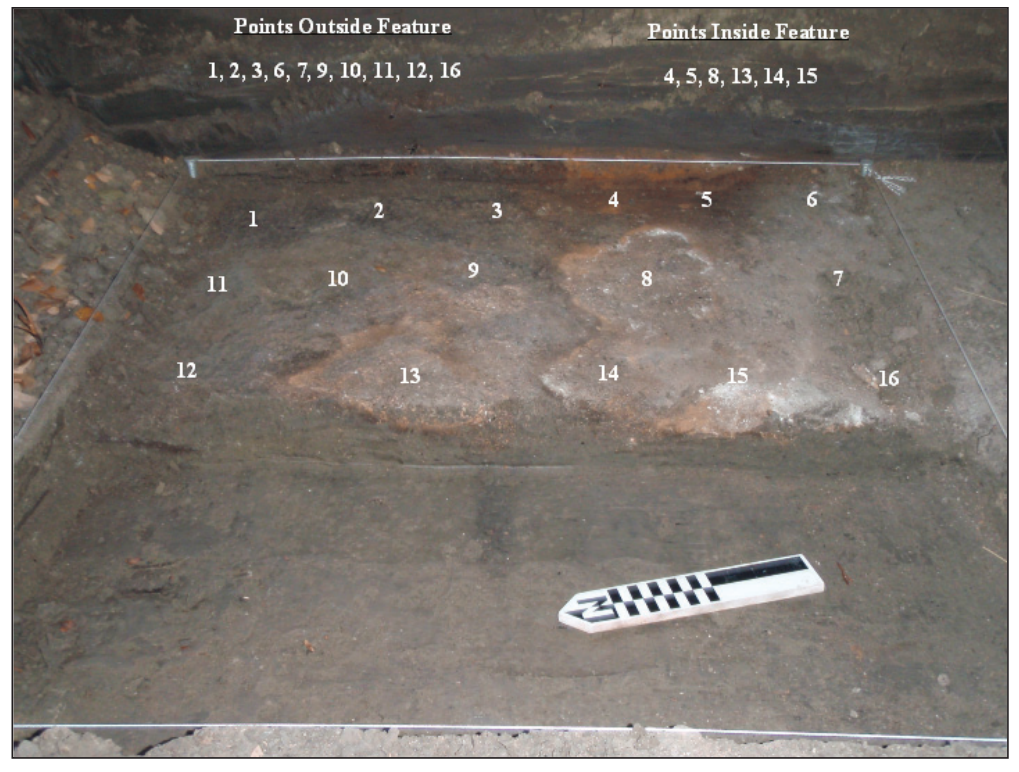

Figure 16-88. Photograph of Feature 28 in Unit 46A showing locations and values of MSS readings.

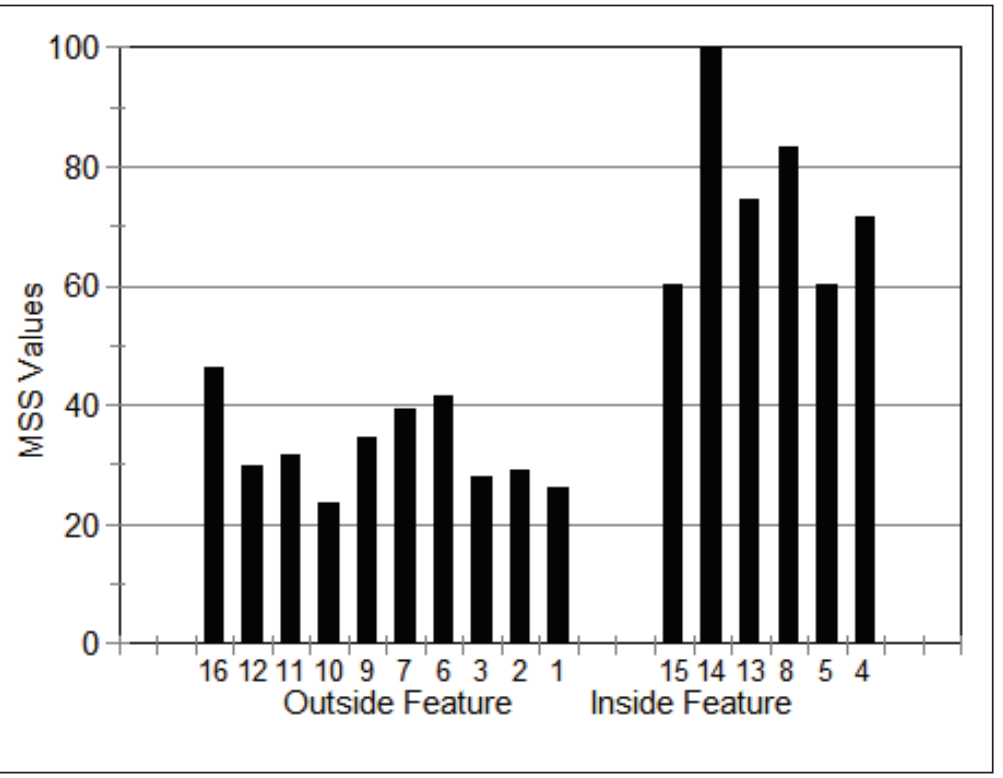

Figure 16-89. MSS values in and around Feature 28. significantly higher than any other areas of either burned or unburned sediments recorded elsewhere. This high value in and of itself suggests a probable sustained surface burn of moderate to high intensity and temperatures. However, standing in stark contrast to all other MSS values are those extremely high values recorded within the heart of the feature; an average of 74.92. The values represent an increase of 127.10 percent from around the feature to within its heart.

These data suggest that this burn was of the greatest intensity, duration, and temperatures that occurred at the site. We are of the opinion that it represents a tree fall that continued to burn for an unknown period, much like that shown in Figure 16-78 during the modern Mustang Fire in Utah.

\section{Feature 31}

Feature 31 is a charcoal and burned clay stain with small splotches of dark red and orange burned clay among the ash and charcoal laying on top of yellowish, silty and sandy loam (see Figures

16-47 and 16-48, Feature 31, Middle Component discussion, above). Although generally 2-3 $\mathrm{cm}$ thick, four areas contained the same matrix as much as $6 \mathrm{~cm}$ thick. Upon sweeping the entire surface with a push broom, it became apparent that the ash, charcoal, and burned clay lens extended alternately and sporadically across the entire six-meter width of the trench. A charcoal concentration in the shape of a burned branch was observed running across the stained area from the northwest to the southeast. 
In sum, the absence of clearly cultural materials or other conclusive evidence suggested that the extensive but thin ash and charcoal lens represented a natural burn occurring on an undulating surface sometime between AD 1442 and 1624 (2 Sigma Calibrated Measured Radiocarbon Age $390 \pm 30$ BP-UGAMS 8608).

Once again, we use MSS values in an attempt to determine whether or not this large burned area is a manifestation of cultural or natural occurrences. A total of 35 MSS readings were recorded across the surface (Figure 16-90). Note that in Figure 16-91, there are four high-node trending areas where the MSS values are above 20. These are interpreted as 'hot spots' within the overall ash and charcoal-stained lens. These consist of 13 points with an average MSS value of 28.12; by comparison, the average MSS value of 22 points outside of these four 'hot spots' is 13.27. These data represent a 111.91 percent increase in MSS within the four 'hot spots' compared to the burned sediments and soils surrounding them.

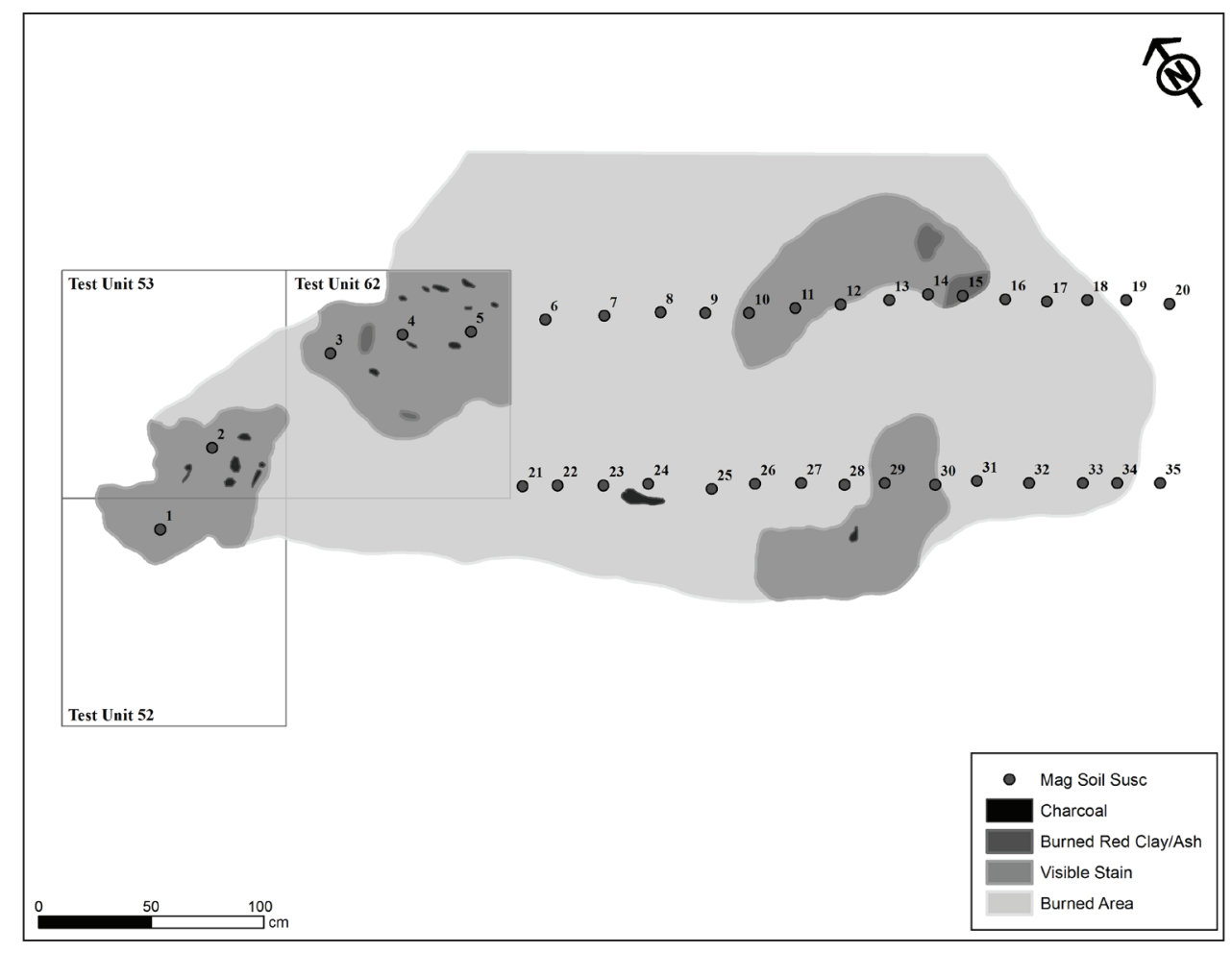

Figure 16-90. Planview of Feature 31 showing locations of MSS readings taken.

It is clear that this entire ca. 6-m surface area of Feature 31 had been burned. The areas outside of the four 'hot spots' yielded an average MSS value of 13.27. This value is well within the norm, and correlates to other readings taken from unburned sediments around surface Features 3 and 8, as well as sediments within tree root burned Features 4 and 6 . By relative comparison then, the MSS value of 13.27 within Feature 31 suggests a low intensity, sparse fuel load, short-term burn with relative low temperatures. 


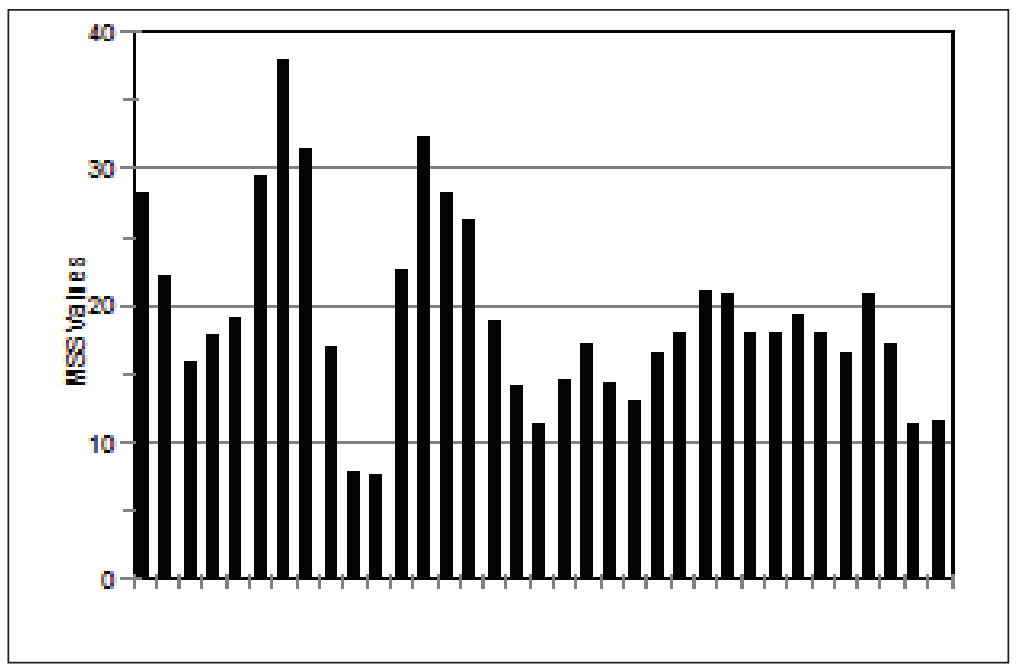

Figure 16-91. MSS values within Feature 31.
The significant increase in MSS values within the four 'hot spots' suggests that there were four areas across the surface where dense brush or fallen timber remained burned in isolated pockets for a period of time following the diffusion of the surrounding surface burn. Notably, this 111.91 percent increase compares favorably with the 127.10 percent increase demonstrated in our discussion of a burned tree fall in Stratum 2 (Feature 28)

above. Otherwise, although both were surface burns occurring statistically within the same time period(s), the MSS values in the Feature 31 'hot spots' are significantly lower than those recorded in Feature 28, implying that the overall intensity, fuel load density, duration of burn, and temperatures were relatively lower in Feature 31 'hot spots' than in the high intensity burn of Feature 28.

In sum, the data seem to suggest that Feature 31 occurred as a natural burn across the surface, with the high nodes in MSS values representing thick brush and/or downed small timber or limbs burning in 'hot spots.'

\section{Summary of Burn Zones Evaluated with Magnetic Soil Susceptibility}

We caveat this discussion by admitting that MSS values can be problematic, primarily due to the mineralogical makeup of the soils and sediments, and most assuredly can be significantly enhanced with the introduction of ash and charcoal. That said, based upon the discussion at the beginning of this section, and our findings at 41DL436, we believe that the magnitude of percentage increases (enhancement) in MSS values can certainly be used as corroborating evidence for either validating features as cultural, or for discounting selected features that could be misconstrued as cultural in origin.

Table 16-15 presents a synthesis of replication studies conducted by Mauldin and Figueroa, as well as MSS values from a fire-cracked rock hearth (Mauldin and Figueroa 2006). The table presents for comparison, the MSS values of multiple areas of unburned sediments as well as burned features at 41DL436. Using the replication studies data and the Feature 12 firecracked rock hearth at 41PR44, we can surmise the temperatures that occurred in the features at 41 DL436.

For example, the percentages of MSS enhancement at Feature 12 at 41PR44 are 16.5 percent at what is likely the equivalent of about $400^{\circ} \mathrm{C}$. When the percentage of enhancement approaches 
34.7 percent, the implied temperature is roughly $500^{\circ} \mathrm{C}$. Studies by Bellomo $(1990 ; 1992)$ indicate surface temperatures of campfires average $400^{\circ} \mathrm{C}$. Other surface hearth replications indicate temperatures between $578-775^{\circ} \mathrm{C}$ (Gillespie et al. 1989:277), $615-805^{\circ} \mathrm{C}$ (stone boiling experiment by Witkind 1977:205), and 400-600 ${ }^{\circ} \mathrm{C}$ (Brink et al. 1986:205). Thus, by implication the percentages of enhancement can potentially be interpolative to campfires.

A review of Table 16-16 indicates that of the eight burned areas studied, Features 4, 6 (lower portion below surface), and 8 are the only three that fall within the 16.5 percent to 34.7 percent MSS enhancement range offered by Mauldin and Figueroa for a cultural hearth. Features 4 and 6 are clearly burned tree roots and can be discounted as cultural hearths. However, Feature 8 is described as an ash and charcoal mass surface burn. Its enhancement percentage of 34.54 suggests that it is well within the range expected of a surface hearth with a heat temperature reaching approximately $500^{\circ} \mathrm{C}$.

Table 16-16. Summary of MSS Values.

\begin{tabular}{|c|c|c|c|}
\hline $\begin{array}{l}\text { Bexar County Soils } \\
\text { Experiment }\end{array}$ & $\begin{array}{l}\text { Unburned Sediments } \\
\text { (Mean MSS Value) }\end{array}$ & $\begin{array}{l}\text { Burned Sediments (Mean } \\
\text { MSS Value) }\end{array}$ & $\%$ Enhancement \\
\hline Non Feature & 35.9 & $41.5\left(400^{\circ} \mathrm{C}\right)$ & $15.6 \%$ \\
\hline Non Feature & 35.9 & $45.8\left(500^{\circ} \mathrm{C}\right)$ & $27.7 \%$ \\
\hline 41PR44 & $\begin{array}{l}\text { Unburned Sediments } \\
\text { (Mean MSS Value) }\end{array}$ & $\begin{array}{l}\text { Burned Sediments (Mean } \\
\text { MSS Value) }\end{array}$ & $\%$ Enhancement \\
\hline $\begin{array}{c}\text { Feature } 12 \text { (Fire-cracked } \\
\text { Rock Hearth) }\end{array}$ & 36.9 & $\begin{array}{l}42.91 \text { (Roughly equivalent to } \\
\pm 400^{\circ} \mathrm{C} \text { ) }\end{array}$ & $\begin{array}{c}16.5 \% \text { (Roughly equivalent to } \\
\pm 400^{\circ} \mathrm{C} \text { ) }\end{array}$ \\
\hline $\begin{array}{c}\text { Feature } 12 \text { (Fire-cracked } \\
\text { Rock Hearth) }\end{array}$ & 36.9 & $\begin{array}{l}49.72 \text { (Roughly equivalent to } \\
\pm 500^{\circ} \mathrm{C} \text { ) }\end{array}$ & $\begin{array}{l}34.7 \% \text { (Roughly equivalent to } \\
\pm 500^{\circ} \mathrm{C} \text { ) }\end{array}$ \\
\hline 41DL436 -Stratum 3 & $\begin{array}{l}\text { Unburned Sediments } \\
\text { (Mean MSS Value) }\end{array}$ & $\begin{array}{l}\text { Burned Sediments (Mean } \\
\text { MSS Value) }\end{array}$ & $\%$ Enhancement \\
\hline Unit 11-Non Feature & 9.93 (Sandy clay) & & \\
\hline $\begin{array}{c}\text { Feature 3-Ash and Charcoal } \\
\text { Mass Surface Burn }\end{array}$ & 13.23 & 23.13 & $74.83 \%$ \\
\hline Feature 4-Root Burn & 9.66 & 12.29 & $26.29 \%$ \\
\hline Feature 4-Root Burn & 12.33 & 14.87 & $20.60 \%$ \\
\hline $\begin{array}{c}\text { Feature 6-Tree and Root } \\
\text { Burn (Surface) }\end{array}$ & 8.04 & 15.07 & $87.44 \%$ \\
\hline $\begin{array}{l}\text { Feature 6-Tree and Root } \\
\text { Burn (Below Surface) }\end{array}$ & 12.38 & 15.26 & $23.26 \%$ \\
\hline $\begin{array}{c}\text { Feature 8-Ash and Charcoal } \\
\text { Mass (Surface Burn) }\end{array}$ & 13.23 & 17.80 & $34.54 \%$ \\
\hline 41DL436-Stratum 2 & $\begin{array}{l}\text { Unburned Sediments } \\
\text { (Mean MSS Value) }\end{array}$ & $\begin{array}{l}\text { Burned Sediments (Mean } \\
\text { MSS Value) }\end{array}$ & $\%$ Enhancement \\
\hline Unit 19-Non Feature & 20.27 (Silty clay) & & \\
\hline Unit 22-Non Feature & 14.13 (Silty clay Loam) & & \\
\hline Unit 27-Non Feature & 6.25 (Fine sand) & & \\
\hline Unit 35-Non Feature & 8.00 (Silt) & & \\
\hline $\begin{array}{l}\text { Feature 28-Basin Shaped Pit } \\
\text { with Burned Clay, Ash, and } \\
\text { Charcoal (Surface Burn) }\end{array}$ & $\begin{array}{c}32.99 \text { (Heavily charcoal } \\
\text { Stained) }\end{array}$ & 74.92 & $127.10 \%$ \\
\hline $\begin{array}{l}\text { Feature 31-Burned Clay, } \\
\text { Ash, and Charcoal Lens } \\
\text { (Surface Burn) }\end{array}$ & 13.27 (Charcoal Stained) & 28.12 & $111.91 \%$ \\
\hline
\end{tabular}


Next, a review of Table 16-16 indicates that the MSS enhancement percentages for Features 3, 6 (surface area burn), 28, and 31 are exorbitantly higher than the prescribed range of a normal surface campfire. These significantly higher percentages suggest fires of a magnitude well in excess of cultural hearths, and imply that a dense fuel load burned for longer durations at significantly higher temperatures in these select areas.

Finally, we submit three observations. First, in hindsight we must acknowledge our shortcomings in field methods in that we did not record any MSS values in Stratum 1, the lower cultural component, and most notably in and around Features 5, 7, 41, and 42. Data recorded in and around these four fire-cracked rock lined hearths may have added considerably to this study.

Second, we opine that the MSS data gathered from the 41DL436 excavations can be substantially credited or discredited by multiple replication studies of cultural hearths in various parts of the region. That is, we envision defined microcosms where sediments and soils are first measured for MSS values, and hearths both rock-lined and unlined are fired. Thermocouples both within, around, and below these hearths should be implanted in order to measure time/temperature variables, and MSS values recorded upon excavation of these hearth areas.

Although current and future replication studies are useful, it depends highly on the mineralogical makeup of the soil as to how MSS values will fluctuate at various temperatures. In that regard, we recommend that each and every burn feature should be carefully troweled and brushed to determine the extent of the burned areas by strata, and MSS readings be taken across an entire block surface, but within the same strata, because of the variations in mineralogical enhancement by strata.

\section{Human ACTIVITY}

There are clearly five fire-cracked rock hearths, four in the lower cultural component (Strata $1 \mathrm{a}$ and $1 \mathrm{~b}$ ), and one in the middle component (Stratum 2). Based upon our observations, many of the burned charcoal and ash masses appear to be the result of natural surface burns in amorphous shapes and mosaic patterns. However, there are also multiple areas with burned clay, ash, and charcoal masses and lenses that 'could be' surface hearths with no fire-cracked rocks similar to those at Dust Cave (see discussion above). With no definitive evidence to the contrary, for purposes of this discussion, we very optimistically, but with skepticism, treat them as cultural hearths. That said, the reader's attention is invited to Figures 16-2, 16-15, and 16-58 (planviews showing feature locations).

Throughout this discussion, we are aware that the burning of old wood can indeed account for radiocarbon dates that are older than the use of hearths or the natural surface burns that have occurred. We also acknowledge that gaps in radiocarbon ages may simply be a matter of sampling. That said, we are presenting the following based upon the actual ages received from the charcoal present, as well as from bone collagen samples.

As illustrated in Figure 16-92, the radiocarbon ages from features suggest an initial occupation period on the southern end of the trench near the paleochannel of approximately 725-565 BP 


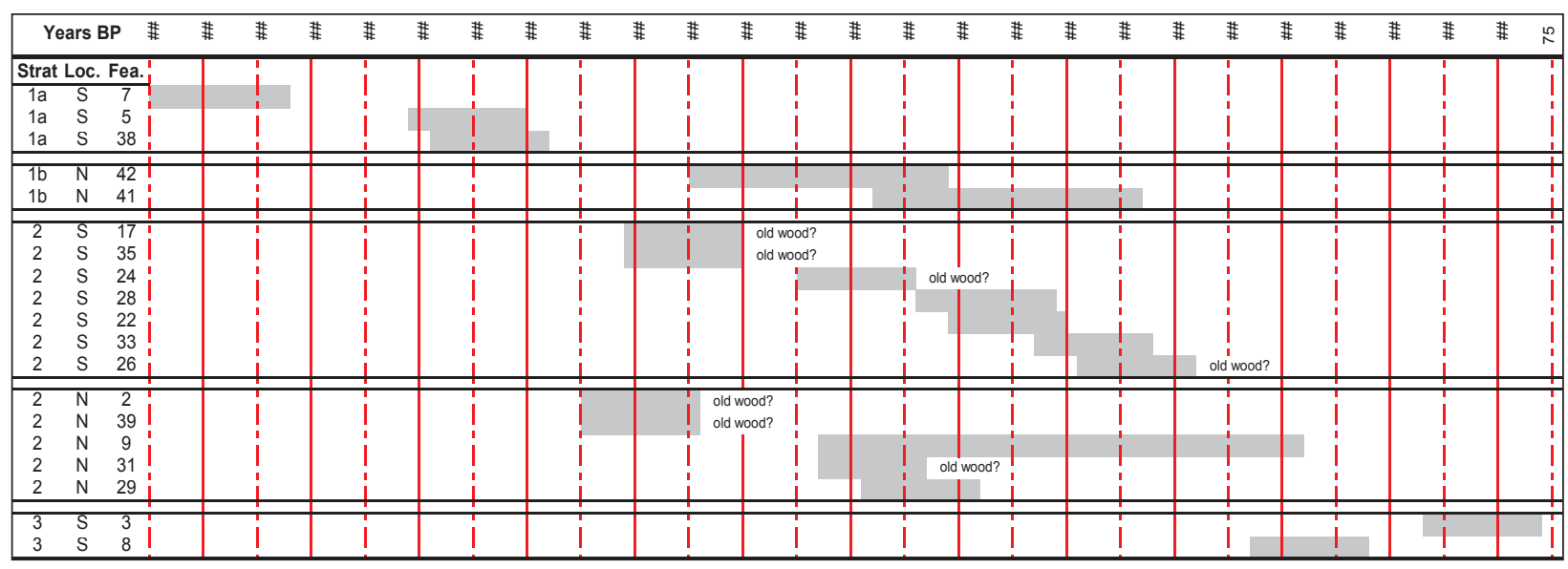

Figure 16-92. Radiocarbon dates from burned features.

( 2 sigma), followed by a supposed hiatus in occupation until about $605-545$ BP. The ages that we have would imply that the site was then not occupied again until around $525 \mathrm{BP}$ and lasting at least periodically through perhaps $455 \mathrm{BP}$.

Although the date ranges as illustrated in Figure 16-92 suggest two spans of roughly 20 years when the site was not occupied, we view this information with skepticism in that there are several 'possible' surface hearths that in the middle component (Stratum 2) that were not radiocarbon dated. Finally, are the two late dates received for Features 3 and 8 in the upper component (Stratum 3). In sum, the data suggests that 41DL436 was likely occupied at least periodically in a continuum over about a 640-year span.

Normally, spatial patterning of activity areas would be addressed using the locations of chipped stone tools and debitage, hearths, faunal remains, charred plant remains, ground stone, etc. However, due the paucity of lithics recovered, as well as other cultural materials and organic remains, in the following discussions we are able to address activity areas based only upon the hearth locations and distribution of faunal remains.

\section{Lower Cultural Component-Stratum 1}

Shown in Figure 16-93 are the units within the lower cultural component. The units are colored depending upon the presence/absence of bison \& cow/bison, white tailed deer, and turtles. These three were selected for comparison based upon their ubiquity throughout all three components. Figure 16-93 illustrates that the presence of turtle is evenly distributed across the lower component, both in the southern cluster of units which make up Stratum 1a, and the northern cluster of units which comprise Stratum 1b. Although both white-tailed deer and bison are present in both clusters, deer remains are more predominant, suggesting a slightly higher reliance on deer for subsistence. In addition, the figure illustrates a greater presence of both deer and bison in the northern cluster, suggesting 1) a less intense occupation in the southern cluster roughly between 725-545 BP higher, and 2) perhaps a more intense occupation with a greater reliance on larger game animals roughly 420-270 BP. 


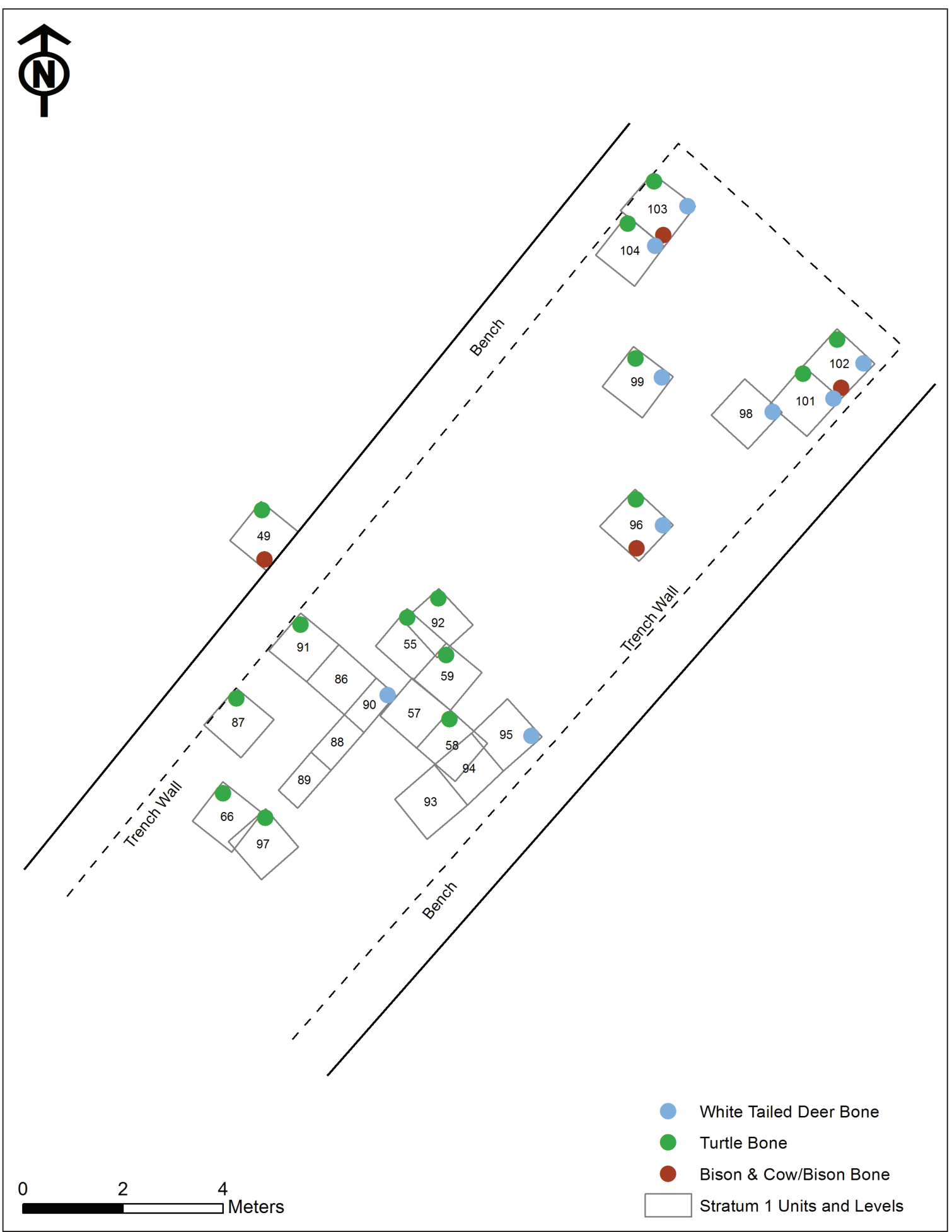

Figure 16-93. Turtle, bison \& cow/bison, and white tailed deer presence/absence in the lower cultural component (Stratum 1) units; Stratum 1a units in southern cluster, Stratum 1b units in northern cluster. 
The patterning of hearth features in the lower cultural component (Figure 16-94) indicates that there were apparently two separate activity areas. Two fire-cracked rock hearths (Features 5 and 7) were constructed adjacent to the Fish Creek Slough paleochannel, roughly $2 \mathrm{~m}$ apart. In addition, a burned clay, ash, and charcoal mass resulting from a possible surface hearth (Feature 38) was located only slightly upslope and approximately $1 \mathrm{~m}$ to the east.

\section{Lower Component-Stratum 1a (Southern Cluster)}

Based upon radiocarbon data, Feature 7 appears to be the oldest, with a date of $690 \pm 25$ BP. As discussed in a previous description of Feature 7, this hearth served as a foci for cooking a variety of wild game such as deer, other medium-large sized mammals, turtles, and other vertebrates. The absence of clear burning on the bones suggests that perhaps the meat was de-boned and either boiled or jerked instead of being placed over the fire attached to the bone. In addition, the diet was likely supplemented with plants gathered in the immediate area. Other dietary supplements likely included mussels gathered from the creek. Remains of a young deer 2-4 months old suggests an occupation between August and October. No smoothed stones were found, and although two deer bones exhibited cut marks, no stone tools were found in association, and only one small piece of lithic debitage was found in Stratum 1a.

Dated charcoal from Features 5 and 38 suggest that these two hearths are younger by over 100 years, with dates of $580 \pm 25 \mathrm{BP}$ and $570 \pm 25 \mathrm{BP}$, respectively. The small hearth that is Feature 5 served as a focus for cooking a variety of wild game such as pronghorn and deer, and other medium-large sized mammal and vertebrates. The absence of clear burning on the larger bones suggest that perhaps the meat was de-boned and either boiled or jerked instead of being placed over the fire attached to the bone. In addition, the diet was likely supplemented with plant seeds ground on the smoothed, recycled sandstone fragments found within the hearth. As dietary supplements, mussels were likely gathered from the creek at a time when the flow was sluggish, and snails could have been gathered for consumption.

Thirty-four of the 52 pieces of bone found within Feature 38 were apparent unburned remains from small reptiles and mammals, a turtle, and a medium-sized mammal. This would once again suggest that the meat was de-boned before being cooked; however, as discussed above, experiments in cooking meat on clay surface hearths normally did not reveal evidence of heating. The remaining 18 pieces were unidentifiable vertebra, and were either browned, blackened, or calcined, suggesting they were directly exposed to intense heat. These small vertebra likely represent de-fleshed bone tossed into the fire. As with Feature 5, mussel shell fragments were also found within Feature 38.

\section{Lower Component-Stratum 1b (Northern Cluster)}

Features 41 and 42 are two fire-cracked rock hearths uncovered near the eastern end of the trench. These two are the youngest within the lower component, and are closest to the modern Fish creek channel, suggesting that sometime between 570 and 500 BP, Fish Creek shifted from its paleochannel where Features 5, 7, and 38 were located to it present channel. Notably, no burned features, and relative few artifacts were discovered between the two hearth clusters. 


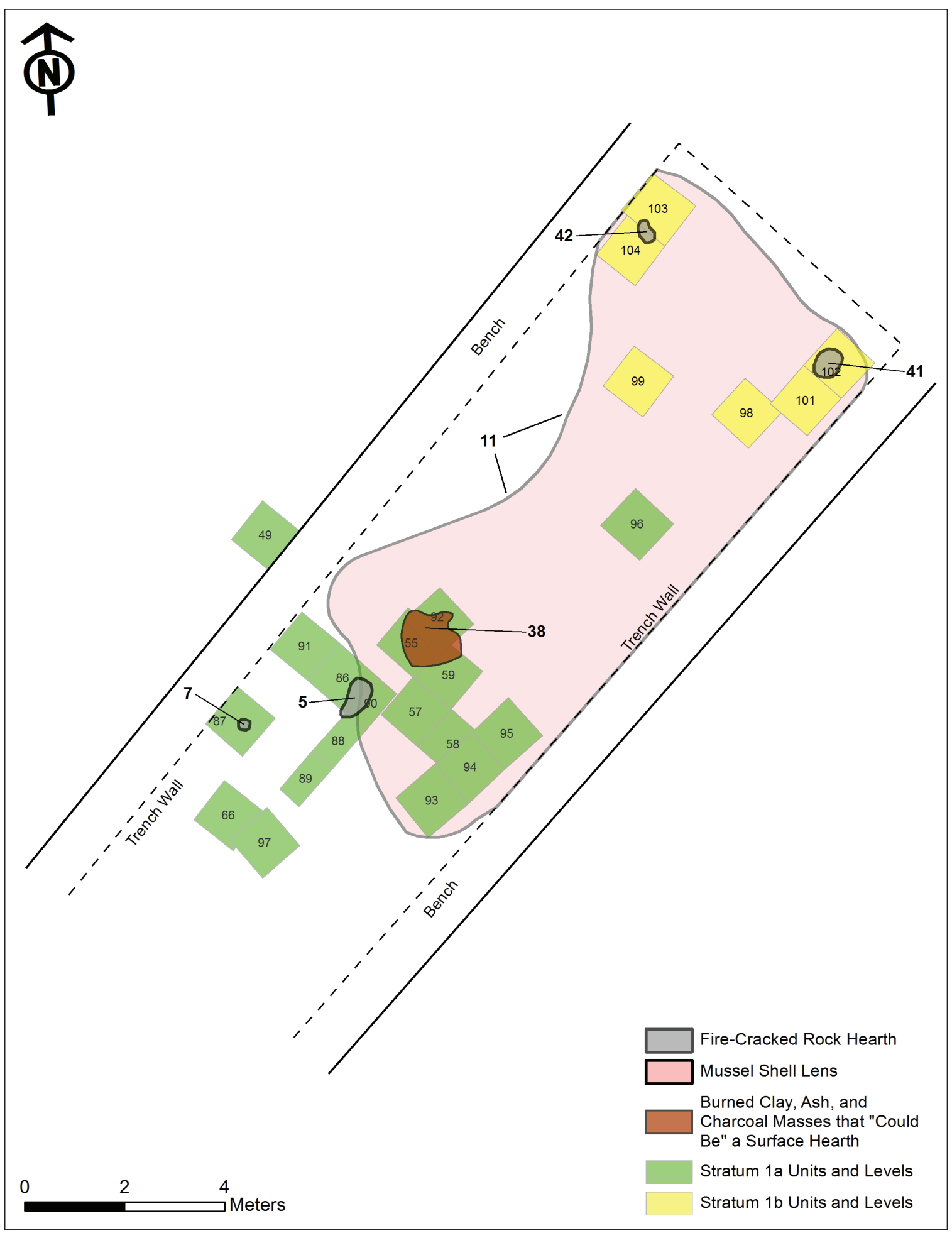

Figure 16-94. Locations of hearth features and possible hearth features within the lower cultural component.

The reader is reminded that the absence of features between the two clusters is not a phenomena 
of the absence of excavation units within that void, as excavation units were opened based upon the discovery of burned areas uncovered by the Gradall scrapes (see Methods - Chapter 4). The continuum across this time period appears to be the extended mussel shell lens (Feature 11), with dates of 550 and 500 BP. Nor were any charcoal, ash, and burned clay masses or lenses found in the area of Features 41 and 42.

Feature 41 is possibly the younger of the two hearths, dating to $360 \pm 25 \mathrm{BP}$ and $300 \pm 30 \mathrm{BP}$, however, statistically the two hearths are contemporaneous. Although no stone tools or lithic debitage were found nearby, faunal remains found in association exhibited possible de-fleshing cut marks, and a possible spear or arrow impact. Together, the obvious de-fleshing cut marks and the near absence of evidence of burning on the cow/bison bones once again suggest that the large pieces of meat were de-boned before being cooked. One cow/bison bone was broken for marrow extraction. However, in addition to cow/bison, the inhabitants who gathered around Feature 7 exploited a wide variety of game animals, such as mule deer, white-tailed deer, birds, turtles, and mussels.

Radiocarbon dating from charcoal within Feature 42 indicates that this hearth was fired around $390 \pm 30 \mathrm{BP}$, most probably at the same time as Feature 41 . The two hearths are about $4 \mathrm{~m}$ apart, parallel to and equally distant from the modern Fish creek channel. The faunal remains associated with Feature 42 are more robust, representing a wider species variety than found around Feature 41, including bison/cow, deer, antelope, raccoon, birds, turtles, snakes, lizards, very small mammals, and mussels. Cut marks indicating de-fleshing and disarticulation were found on some bones; the only stone tool found in association was a unifacially serrated piece of red sandstone. Otherwise, a utilized biface manufacturing flake found in Unit 99 was the only other piece of worked stone found in Stratum $1 \mathrm{~b}$.

\section{Middle Component-Stratum 2}

In the middle component, we emphasize that the patterns noted are precisely that - patterns apparent in a series of discrete occupations that occurred sequentially as the floodplain aggraded. In treating them as a component for analytical purposes, we are lumping substrata that are stratigraphically separated by as much as a meter. It is important to remember that they are not behaviorally linked, except as evidence of a repeating pattern of behavior over a span of, minimally, decades, and the spatial relationships 'between' most features therefore have little meaning.

Shown in Figure 16-95 are the units within the middle cultural component. Figure 16-95 illustrates a high presence of turtle in the southern cluster of units, implying a high activity area where turtles were either processed for cooking, or their shells were used as cooking vessels. Other observations to be made are 1) overall, there appears to have been a heavy reliance on bison during the middle component occupation, roughly 525-185 BP, 2) there are no white tailed deer remains in the northern cluster of units, while bison remains were present in nearly every unit, suggesting a bison processing area nearest to the modern Fish Creek channel, 3) deer and bison remains were found in abundance in the southern cluster of units, 


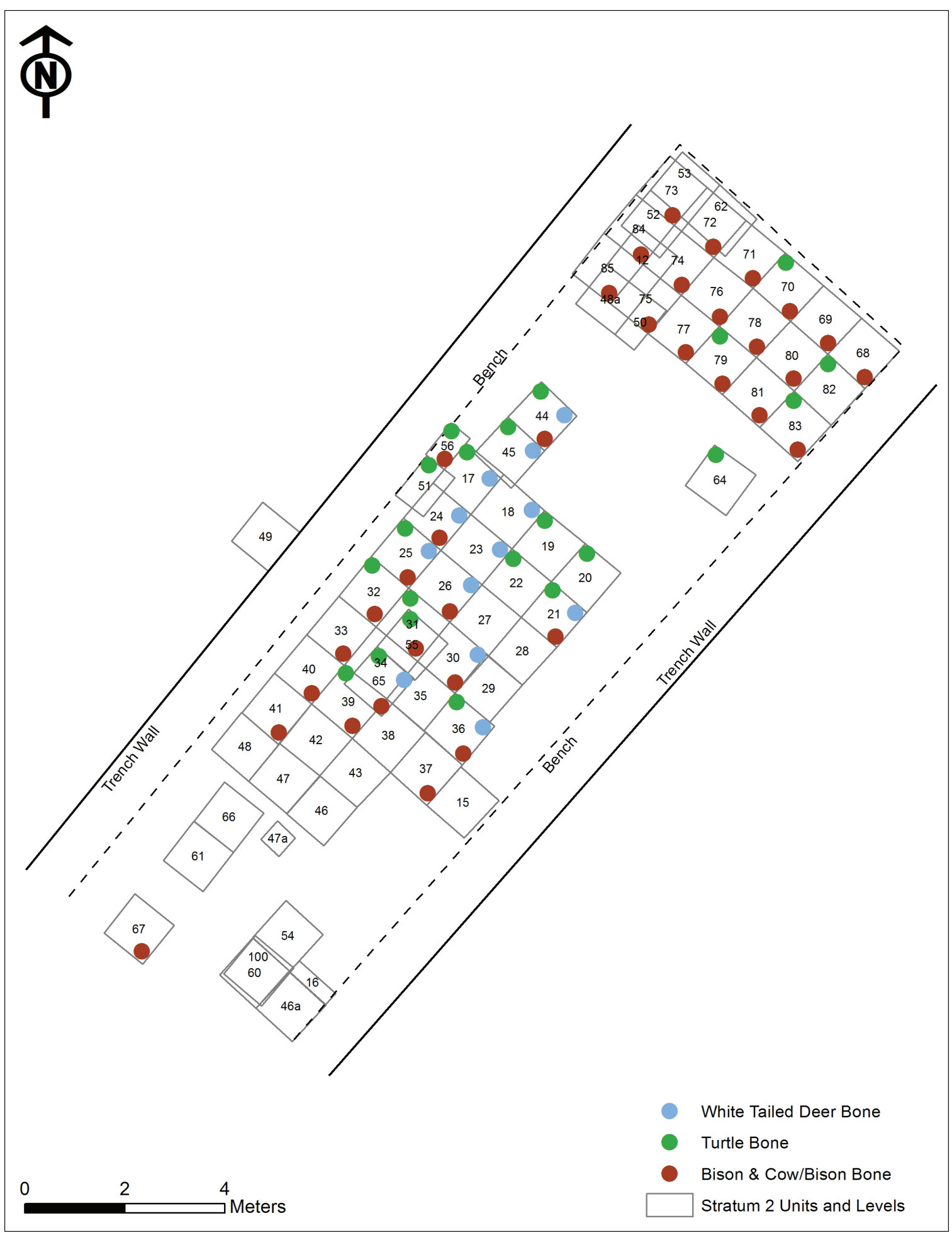

Figure 16-95. Turtle, bison \& cow/bison, and white tailed deer presence/ absence in the middle cultural component (Stratum 2) units. 
and frequently both deer and bison bones were found in the same units, indicating deer and bison were both processed in that locale.

\section{Middle Component-Stratum 2 (Northern Cluster)}

We caveat this discussion by stating that defining burned clay, charcoal, and ash lenses and masses found in the middle cultural component is admittedly problematic. Some of these types of features could fit the descriptions of 'phantom' hearths as discussed above, or they could fit into the category of surface hearths found at Dust Cave. That said, with guarded optimism, in this section we have categorized them as cultural features.

Notably, only one fire-cracked rock hearth was discovered in the middle component, and with the exception of two burned features that we can confidently opine were tree and root burns, and one large bone scatter, the remaining 24 features consisted of burned clay, ash, and charcoal in varying degrees of texture, mass, depth, and extent.

Presuming that the 24 burned matrices are cultural, as shown in Figure 16-96, there is one large cluster located generally in the center of the trench and a second smaller cluster with a firecracked rock hearth (Feature 2) located near the modern Fish Creek channel. Noting the void in artifacts and features between the two clusters, we attribute that either 1) a clear separation representing site formation over different time periods, or 2) an area void of a sufficient natural fuel load to create either burned masses or significant soil discoloration or staining. As we will discuss below, the many documented burned clusters in the middle component have yielded dates spanning approximately 230 years (255 calibrated years). It is highly unlikely that the same area would be void of a high fuel load for that extended period; thus, one argument in favor of cultural hearths instead of natural burns.

The fire-cracked rock hearth (Feature 2) appears to be the oldest feature in the area closest to Fish Creek, dating to $500 \pm 25 \mathrm{BP}$, temporally co-eval with the large mussel shell lens (Feature 11). However, as discussed elsewhere, the charcoal was possibly from old wood because collagen dates of bone in association-212 $\pm 26 \mathrm{BP}$ and $289 \pm 24 \mathrm{BP}$-were obtained. Charcoal from Feature 39 was dated to $450 \pm 25$ BP. Identifiable faunal and lipid remains directly associated with Feature 2 include cow/bison, deer, possibly javelina, red-tailed hawk, and snake. A series of cut marks on one bone are likely from stone tools brought to the site, as six uniface thinning or re-sharpening flakes, and two biface thinning flakes were found. Starches found on the firecracked rocks suggest that the diet was likely supplemented with plant bulbs. In addition, a broken long bone from a medium-large mammal had been polished.

Feature 39 actually consists of three small burned clay, charcoal, and ash masses. It was described as within brown silty loam lying on top of yellow fine sand that encapsulated Feature 9, an extensive bone scatter. However, with a paucity of faunal remains and no other remains of significance, it appears that Feature 39 may have been fired on the surface of a slight stratigraphic nonconformity. 


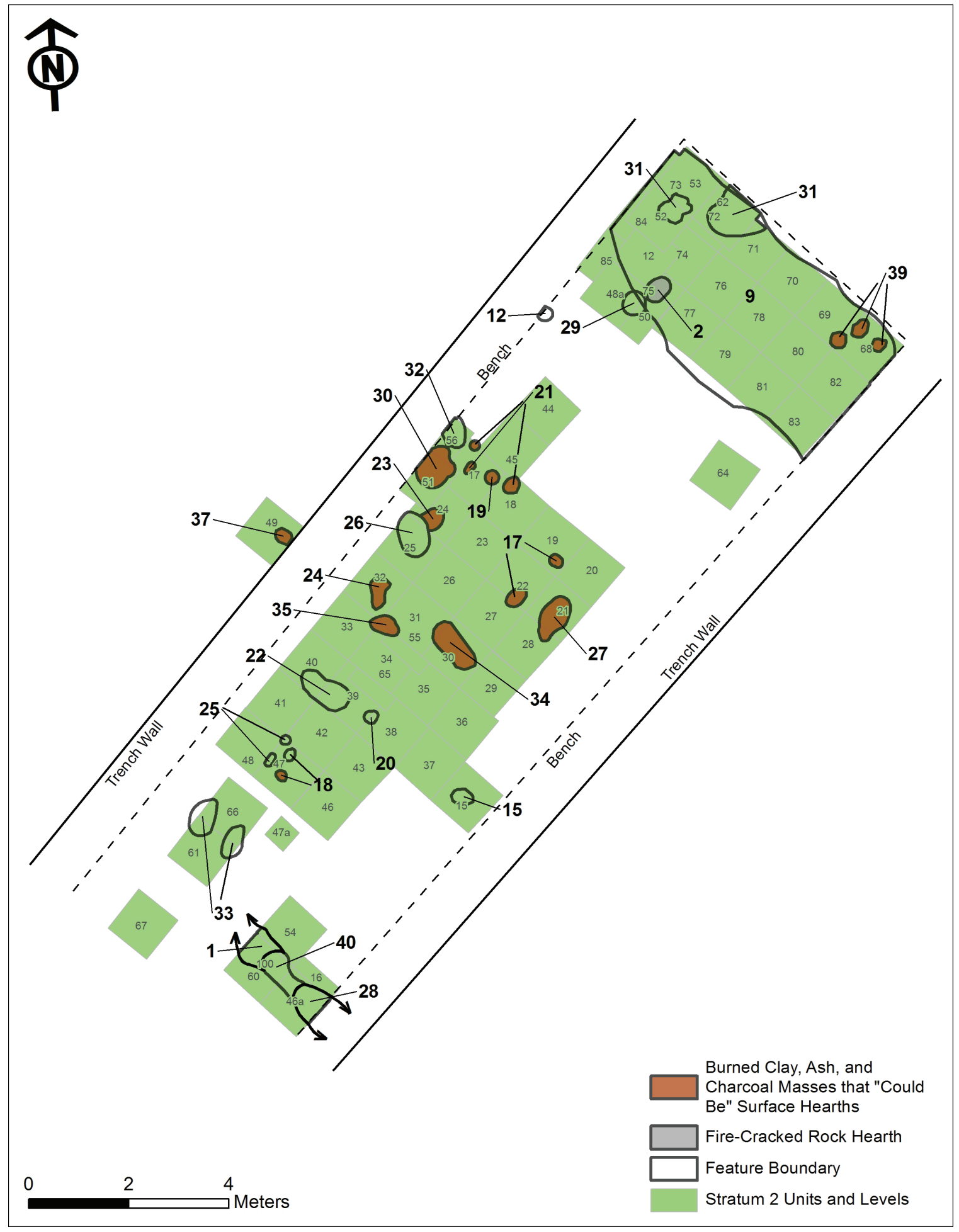

Figure 16-96. Locations of hearth features and possible hearth features within the middle cultural component. 
The two remaining burned features in the cluster closest to the modern Fish Creek channel are 29 and 31 . The radiocarbon dates on charcoal within these two are clearly younger by 110-130 years compared to Feature 2, and by 60-80 years compared to Feature 39. The two dates on these are $370 \pm 25$ for Feature 29, and $390 \pm 25$ for Feature 31. Whether or not these two features were fired during the same year or within a few years of each other will remain an unknown, but the dates indicate a defined temporal divide between Features 29 and 31 when compared to Features 2 and 29.

No faunal remains or any other artifacts were observed in association with Feature 29. Without corroborating evidence, it appears to have been a natural surface burn, but a cultural surface hearth cannot be ruled out. Only one unidentifiable and fragmented piece of bone was found in direct association with Feature 31. A charcoal concentration in the shape of a burned branch running across the surrounding stained area suggested to excavators that the burn was natural in nature, but as with Feature 29, without corroborating evidence, a cultural surface hearth cannot be ruled out.

Encompassing a 3x6-meter area across the northern end of the trench is Feature 9, an extensive bone bed, and the reason for a block of units excavated in that area. A radiocarbon date obtained from charcoal in Unit 9 indicates that at least one of the butchering events most probably occurred around $390 \pm 25 \mathrm{BP}$, contemporaneous with the firing of Features 29 and 31 . However, a series of collagen dates obtained from Feature 9 fauna range between $340 \pm 25 \mathrm{BP}$ and $212 \pm 25$ BP (see Tables 5-2 and 16-92). Among the wide variety of identifiable remains are bison and cow/bison (some blackened from burning, some with visible cut marks), dog/coyote (cut marks consistent with skinning), hispid cotton rat, marsh rice rat, cotton rat, opossum, ornate box turtle and other turtle (some with browning from heating), pronghorn/deer, rabbit (possibly humanly polished), and rattlesnake.

Under the diet-breadth model, the wide variety of fauna that is Feature 9 suggests a longterm occupation. However, it could also represent repeated occupations. The absence of clear burning on most bones suggest that perhaps the meat was de-boned and either boiled or jerked instead of being placed over the fire attached to the bone. Otherwise, it may have been cooked in Features 29 and 31 as described in hearth replication studies at Dust cave (described above), leaving little or no evidence of burned bones. In addition to meat, the diet was likely supplemented with plants gathered in the immediate area. Another dietary supplement likely included an occasional mussel gathered from the creek. Biface manufacturing and thinning flakes, as well as a uniface and re-sharpening flake suggests that stone tools were being manufactured and re-sharpened during the butchering process. In addition, the diet was likely supplemented with plants gathered in the immediate area. Another dietary supplement likely included an occasional mussel gathered from the creek. The use of turtle shell as vessels could account for lack of ceramics. They may have been a quick food source for a bison/deer hunting camp and evidence of a collector task group.

Twenty-nine of the 37 pieces of chipped stone in the middle component were recovered from the northern area. Six were biface manufacturing flakes, 14 were biface thinning flakes, 7 were uniface thinning or re-sharpening flakes, 1 was a core reduction flake, and 1 was a chunk of 
angular debris. In addition, metal cutmarks were observed on some bones. Combined with the robust assemblage of faunal remains with cut marks and few burn marks, these data suggest that this was an activity area where both bifacial and unifacial tools were manufactured, utilized, and re-sharpened during the disarticulation and de-fleshing of bones before the meat was cooked or jerked.

\section{Middle Component-Stratum 2 (Southern Cluster)}

The southern cluster is comprised of 17 features, with some sub-features; all are categorized as burned masses of charcoal, ash, and in some cases clay. Although not predominate in terms of numbers relative to the overall faunal count, notably 13 of the 17 features had faunal remains in association that exhibited at least some degree of heat intensity. Six of the burned features had turtle shells and breastplates that had been either browned, blackened, grayed, or calcined from heat, while vertebrate remains from eight features exhibited the same stages of heating. Otherwise evidence of heating was found on a variety of remains with no obvious species preference (see Middle Component discussion on features, as well as Chapter 15). The frequency of turtle and vertebra remains exhibiting high heat suggests that they were either commonly tossed into the fire following meat extraction, or a cooking technique that exposed these selected reptiles and vertebrates to direct heat. However, just cooking the meat should not account for the extreme heat that causes blackening and calcining. One possibility is that turtle shells were being used as cooking vessels over an open fire Other modifications to bone of note included browning of a long bone near a chop break (Feature 22), a cow/bison rib that appeared to have been used as a tool (Feature 24), one long bone from an artiodactyl that exhibited teeth marks that are possibly from a human (Feature 26), and cut marks on a white-tailed deer ulna likely caused by humans (Feature 35). Only eight chipped stone flakes were recovered from the southern cluster of features, two were biface manufacturing flakes, four were biface thinning flakes, one was a uniface thinning/re-sharpening flake, and one was a core preparation flake. Although certainly few in numbers by normal standards, their variety suggests that a continuum of lithic reduction technology occurred in this portion of the site, from early stage core reduction activities through late stage bifacial and unifacial tool completion and utilization. The only evidence of possible horticulture was manifested by the presence of possibly Little barley grass and a Zea-maize-like phytolith recovered from Feature 37 (see Chapter 11).

\section{Upper Component - Stratum 3}

Shown in Figure 16-97 are the units within the upper cultural component. Although a few deer remains were found scattered within Strata 3, none were within excavated units. However, bison remains were found in five units. This implies a self-sufficient reliance on primarily bison as the big game animal of choice for subsistence. The distribution of bison remains is relatively widespread across the northern half of the site area excavated, suggesting that bison processing was not focused in any specific activity area. 


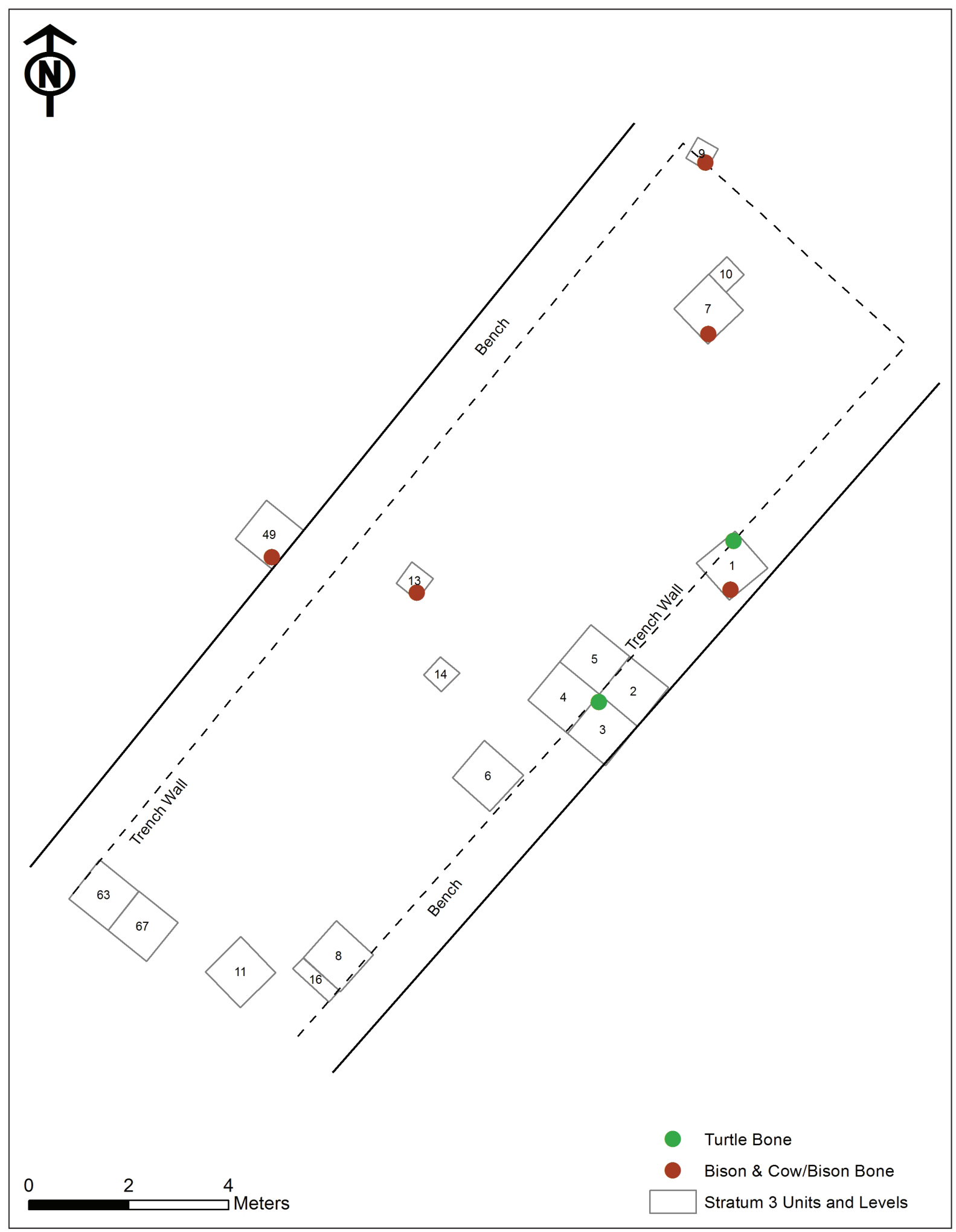

Figure 16-97. Turtle, bison \& cow/bison presence/absence in the upper cultural component (Stratum 3 ) units (no deer present). 
Unlike the lower components, there are no distinct clusters of features in the upper component (Figure 16-98), and notably, only five were discovered that could be construed as possible surface hearths, hinting at either less intense occupation(s), or fewer occupations over the past roughly $275 \pm$ years. Radiocarbon dates on charcoal from Features 3 and 8 range from 215-165 BP and 135-85 BP, respectively. By this time the paleochannel had been filled, so that any occupations would likely have been tethered to the modern Fish Creek channel. However, as shown in Figure 16-98, the three burned clay, ash, and charcoal features that are possibly surface hearths are located near the center of the trench, some 25-30 m from today's channel.

No cultural materials were observed either within or in direct association with Features 10 and 13, and of the 13 pieces of bone in association with Feature 8, two exhibited signs of heating. Whether these three features are culturally fired expedient hearths or they represent natural surface burns is unclear, although Feature 8 manifested MSS values consistent with cultural hearths.

Overall, 1,231 pieces of bone were recovered from the upper component, representing a broad species diversity. Degrees of exposure to heat in the form of browning, blackening, graying, and calcining were evident on only a few specimens, predominately vertebrates.

Bison bones and large mammal bones exhibiting cut marks consistent with meat removal were found in Units 1, 7 and 9. The only stone tool found during the excavations in all three cultural components was found in Unit 7; an arrow point that was broken during use. Otherwise, a biface thinning flake was discovered in Unit 3, and a uniface thinning flake in Unit 7. Metal cutmarks on some bones suggest that metal knives were being substituted for stone tools, and as discussed in Chapters 18 and 19, there appears to be a heavier reliance on metal knives through time. One bird bone recovered in Unit 1 exhibited evidence of polishing in what may have been the first stages of bone bead manufacture. Bone beads are commonly found in many Late Prehistoric components, as well as protohistoric components in Texas (e.g., Nickels 2000).

Finally, we carefully re-examined the structure and contexts of Features 4, 6, and 16. These have been interpreted as tree root burns, but without certainty, we entertained the possibility that perhaps Features 4 and 6 could be burned structural posts. The feasibility of Feature 16 being a burned structural post was discounted because although Feature 16 is within Stratum 3 , as shown in Figure 16-1, it is imbedded within the paleo channel fill well below Features 4 and 6.

Conversely, the upper portions of Features 4 and 6 are stratigraphically co-eval with Features 3 and 8, and all appear at nearly the same level below the modern surface. Two additional subtle factors argue in favor of burned posts 1) they are approximately $5.5 \mathrm{~m}$ from each other, a distance similar to medium-sized protohistoric houses found in Native American villages (Caddo Ancestors 2013), and 2) their configuration in relation to Features; that is, no burned features that could be construed as cultural hearths were discovered either between the two, or to the west. In sum, we cannot rule out the 'possibility' that some sort of structure existed, although during the excavations we discerned no differentiation in the texture and sediments 


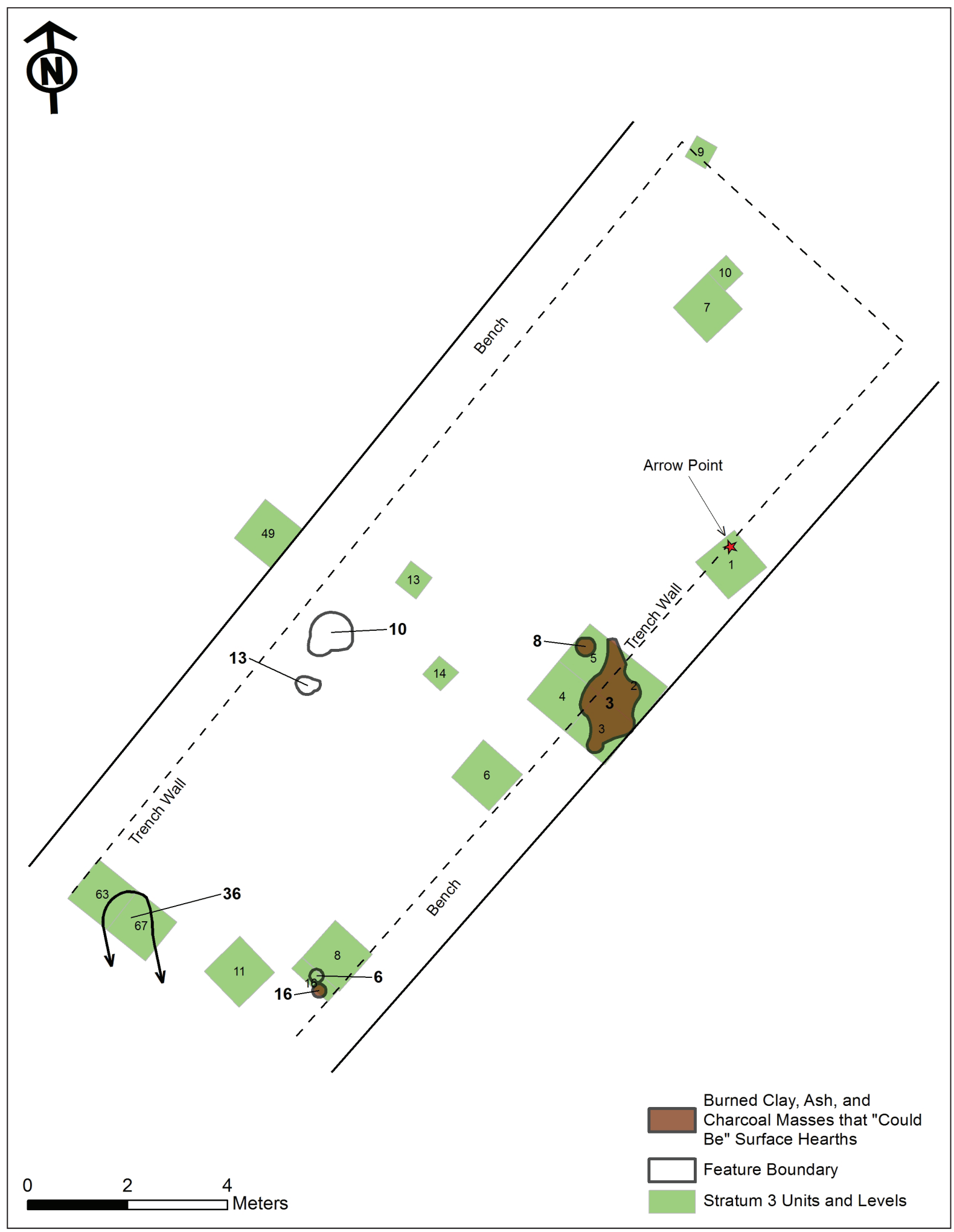

Figure 16-98. Locations of features in the upper cultural component. 
in these areas, and the faunal record indicates no anomalies in either species or numbers in association with these two features.

\section{$\underline{\text { Subsistence AND Mobility }}$}

\section{Theoretical Framework}

At its most fundamental level, data recovery analysis and research for 41DL436 focused on describing, quantifying, classifying, and typing the material remains in order to draw conclusions or generate a theory about aspects of prehistoric lifeways. The research orientation for this project has drawn from several common models used to frame human behavior of the prehistoric past. First, interpretation and analysis of the excavated remains draw on the ideas encompassed by human ecology (Binford 1962, 1965; Steward 1955), which posits that human behavior and cultural expression are conditioned by environmental factors, and that human behavior is systematic and structured.

The theoretical framework for operationalizing the methodological portion of the analysis of the cultural remains is the optimal foraging theory's diet-breadth model (e.g., Kelly 1983, 1995; Winterhalder and Smith 1992). Optimal foraging theory and its constructs of behavioral ecology as a foundation, and ultimately the diet-breadth model, are synthesized in the following discussion. The theoretical considerations in conjunction with the cultural context previously presented serve as a basis for evaluating site function, subsistence, and mobility through time.

\section{Optimal Foraging Theory}

Optimal foraging theory is grounded in the behavioral ecology paradigm that assumes individuals are responsible for their behavior, that through a natural selection process they subconsciously make decisions about the cost and benefits of their actions, and as a result they will always seek to optimize return benefits over the costs involved. Optimal foraging theory is based on the four basic concepts involved in foraging: goals, calories, constraints, and options. The goal of hunter-gatherers is to maximize foraging efficiency, considering the efforts involved in searching for and handling (processing) resources; calories represent the energy that can be derived from the available resources; constraints represent the availability of resources, or the ability to digest them; and options represent the decisions on whether or not to take the resources that are encountered. In optimal foraging theory the cost-versus-benefits applies particularly to foraging and collecting behavior. Optimal foraging models developed by behavioral ecologists rely on a material means with which to measure productivity; most frequently benefits are measured in terms of caloric return per hour of work (Kelly 1995:39-64). The stage is then set to discuss three models of optimal foraging theory: linear programming, diet-breadth, and patch-choice. 


\section{Diet-Breadth}

The diet-breadth model (MacArthur and Pianka 1966) assumes that hunter-gathers will increase the breadth of their diet to meet caloric requirements. It assumes that they will maximize their efficiency by pursuing and taking the higher-ranked resources first, and then progressively lower-ranked resources as needed. Ranking is based upon the number of kilocalories per hour produced relative to the mean dietary return rates, in return for the cost of obtaining them. The opposite is true also; when higher- or equal-ranked resources become available they will be taken, and lower-ranked resources will be dropped from the diet. Thus, the increase or decrease in the diet of the variety or breadth of plants and animals implies the name diet-breadth model. This model assumes that the availability of resources is homogeneous, and that all resources will be encountered at random. The model is preferred over the linear programming model because it allows one to separate search from handling costs, and it allows for the ranking of resources.

Although theoretical models should be designed so that they can be tested empirically, identifying residential mobility and subsistence patterns using the diet-breadth and patch-choice models are limited in their application by the archaeological remains left at hunter-gatherer campsites and our abilities to extract meaningful information from the record. Repeated use of a campsite creates a palimpsest of occupations that confuses the interpretations of when the site was used, for how long, and by how many people. As Kelly relates, modern and highly mobile groups leave behind an extreme paucity of archaeological material when they vacate a camp. However, as will be demonstrated for the 41DL436 excavations during this project, there are ways to tease out discrete evidence.

\section{The Forager/Collector Continuum}

Binford (1980) equates residential mobility with a continuum of hunting and gathering; on one extreme end of the continuum are what he terms foragers, while on the other extreme are collectors (Figure 16-99). Characteristically, foragers will move their entire residence frequently, encountering resources randomly in a fine-grained environment; that is, they will encounter them in relation to their abundance in the environment (Figure 16-100). This concept infers then, that residential moves are dependent upon the density and distribution of resources. They will process and consume what is available before moving on. They normally do not store food. Presumably, foragers would be prevalent in an area of seasonal abundance, probably in areas with temperate ETs. On the other extreme, collectors will map onto a resource patch and send out task groups on long distance forays to collect food, conduct limited processing, and then return it in bulk to camp (Figure 16-101). They would probably cull the parts of animals or plants that are of little or no nutritional value before transporting the rest back to camp.

The question arises as to how long a group, either forager or collector, could be expected to stay at a patch. One construct based on the patch-choice model, called diminishing return, is ascribed for foragers, and suggests that a group will stay at a particular patch until the return that they receive from the resources in the patch falls below the mean of surrounding patches (Charnov 1976; Kelly 1995:91-92). A second, called central foraging, is attributed to collector 
models and suggests that a group will stay because there are sufficient resources around it to enable long forays to bring back the additional necessary resources. This may occur most commonly when groups are tethered to a specific resource, such as a waterhole. A common criticism of identifying modern hunter-gatherers with tethered resources is that they are often tethered to modern farms or gardens.

\section{FORAGERS}

Residential mobility - entire camp moves frequently

Group moves to food source

High residential mobility - little logistical mobility

Assumes food is available most of the year round - gathered daily

Bulk storage is minimal

Sites are commonly reused

Tool assemblages with little diversity and small variety

\section{COLLECTORS}

Logistical mobility - individuals or small task-specific gropus return to base camp

Groups move to wood or water sources and bring food back to camp

Infrequent residential moves - more logistical mobility

Assumes food is seasonally available - group moves with the seasons

Bulk storage is necessary

Sites display evidence of long term use or reuse

Tool assemblages are more diverse and larger in variety

Figure 16-99. Hunter-Gatherer subsistence and settlement pattern model (from Binford 1980; Kelly 1983 adapted from Nickels 2000).

\section{Technological Variability}

Binford $(1973,1979)$ proposed classifying assemblages as expedient or curated. Expedient tools are those that can be produced quickly for short term use. Expensive tools are generally thought of as curated tools that take more time and effort to manufacture, but are designed for re-use, are resharpened, and are generally more easily transportable.

Although as will be discussed further in this chapter, there would have been no shortage of Ogallala gravels along the Trinity River basin, the availability of raw materials within close proximity to 41DL436 is minimal at best. To accurately infer subsistence and mobility from such a limited chipped stone assemblage that exists at 41DL436 is at best problematic. And, the increasing use of metal knives would skew the results, as metal tools could complete several tasks and could in some uses be more durable than stone. Metal tools may therefore represent a new degree or category of curation.

Schiffer posits that we should be able to determine the occupation span of sites by the variety of tools found at the site, assuming curate and donor behavior is the same at all sites. Schiffer (1975) states that items of short use-life (debitage, utilized flakes, waste products) best represent 


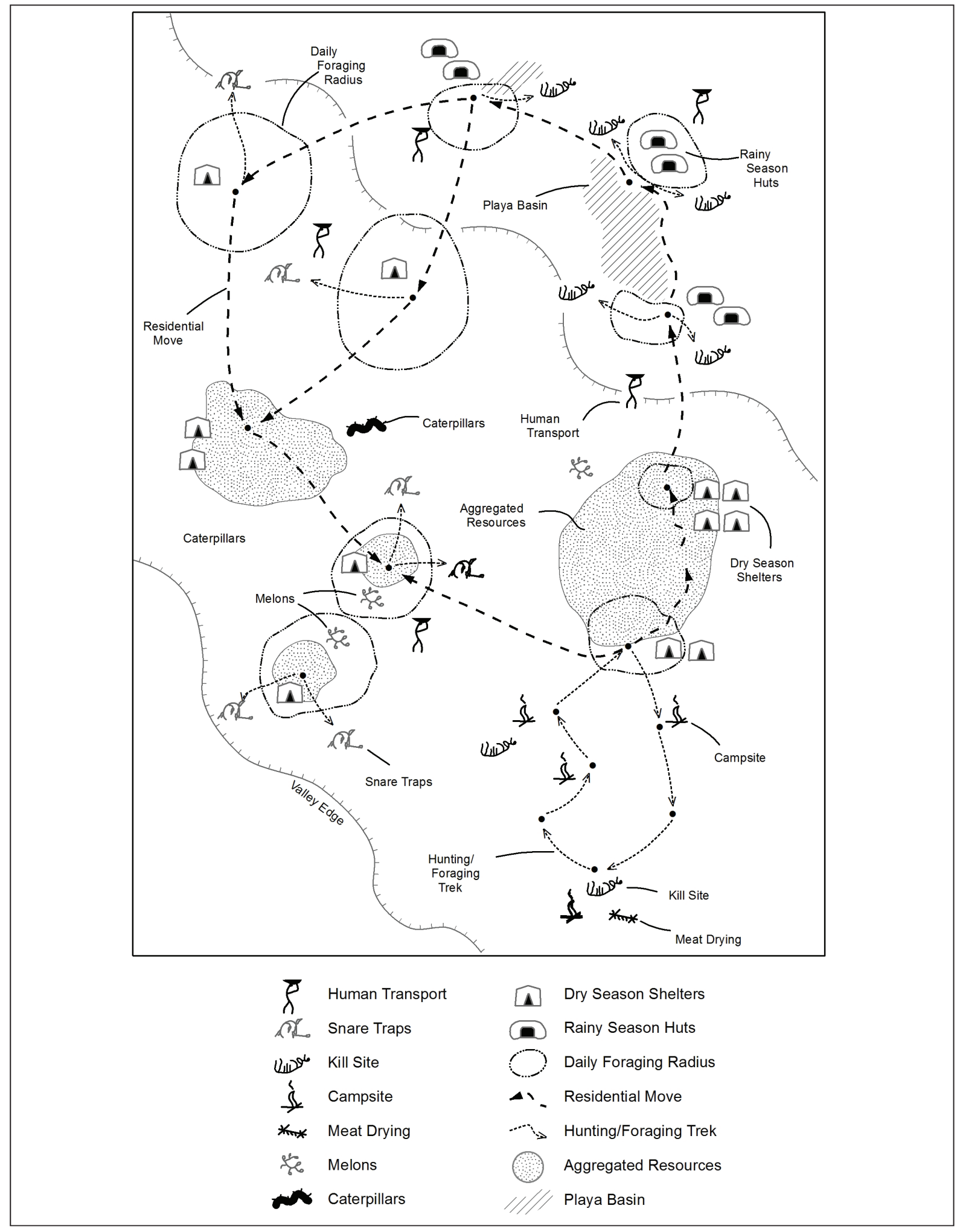

Figure 16-100. Characterization of a foraging subsistence-settlement system (after Binford 1980:6; redrawn by Joel Butler). 


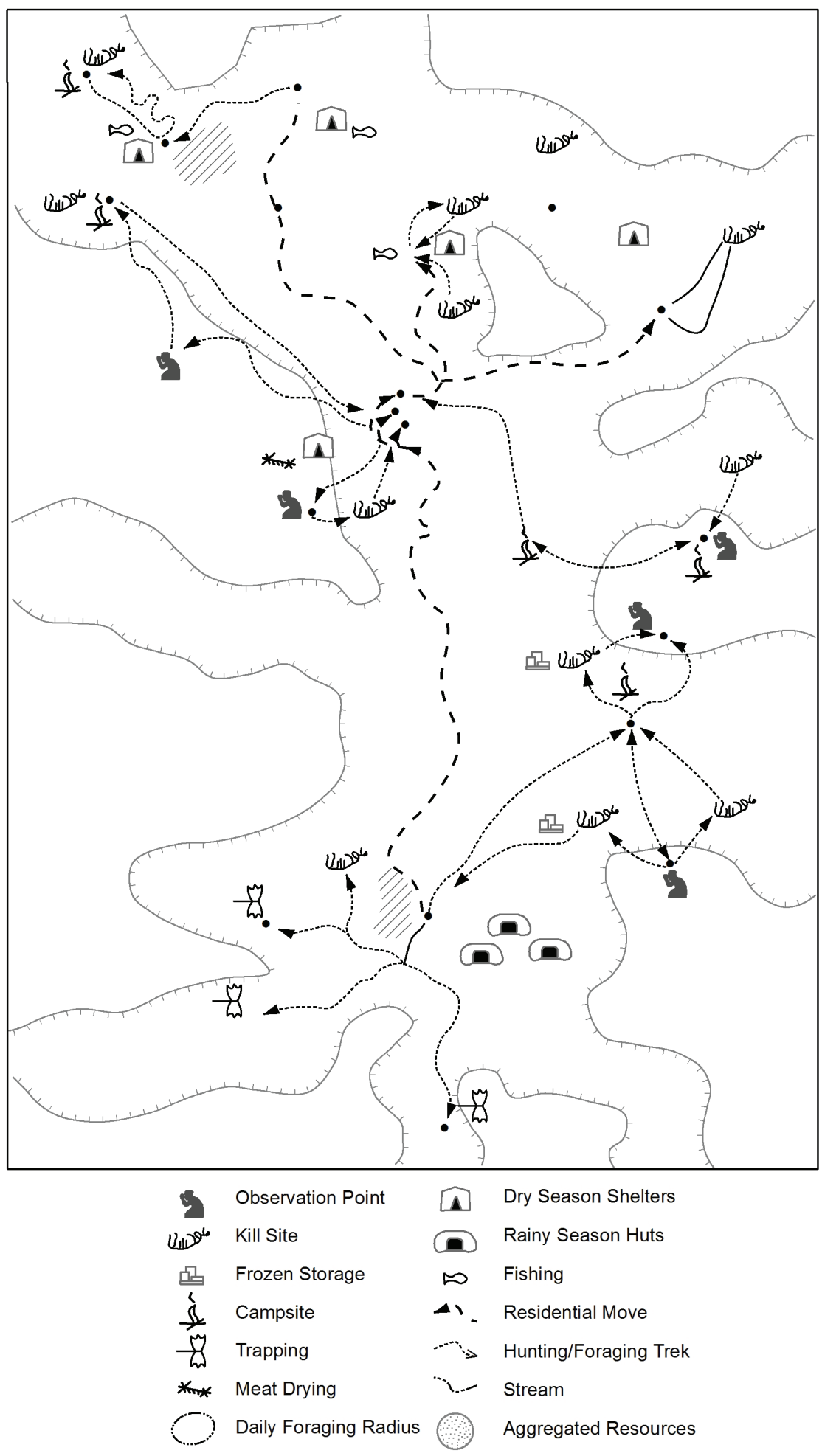

Figure 16-101. Characterization of a collector subsistence-settlement system (after Binford 1980:11; redrawn by by Joel Butler). 
the function of the site, but they do not necessarily represent the occupation span and curate behavior at the site. Simply comparing the quantity in the assemblage will not do, because the same quantities could result from repeated occupations, or from one continuous long-span occupation. Finally, if raw material is readily available either en route to, or at the next site, then there should be no need to produce bifaces for transport.

In sum, it makes sense that the curated artifacts brought to a site (the founding curate set) are brought because they are portable; the occupants have weighed the replacement versus transport costs. In areas with good raw material sources, one would expect to see a greater variety of tools, along with less evidence of curated tools. Further, the tools that are transported from a site and therefore no longer visible in the systemic population (the site assemblage) can be assumed to have a longer use-life than those we see in the de facto refuse (the normal outputs population).

We posit that the longer a site is occupied, not only will greater quantities of tools become part of the assemblage, but a greater variety of tools will also be present. Our argument lies within the collector/forager continuum in which Binford (1980) argues that groups who move residences infrequently but have greater logistical mobility will have tool assemblages that are more diverse and larger in variety. Problematic with this site however, is the relatively very small numbers of chipped stone artifacts. In addition, the appearance of metal cut marks on bone in Stratum 2 substantially alters the interpretation of the lithic assemblage with regard to organization of technology and mobility.

\section{$\underline{\text { SUMmarY }}$}

Table 16-17 provides a general synthesis/summation of the main points of this discussion. The following are logical arguments of the main points.

Table 16-17. Key Points That Have Been Made in this Discussion.

Curated, Reliable, and Maintainable Tools
A-Tools are reliable and maintainable
B-Binford's curated tools are essentially Bleed's maintainable and reliable tools ${ }^{2}$
C-Curated tools are reliable and easily transported
D-If good raw material is available at the site, there will be fewer curated tools ${ }^{4}$
E-Curated technology = high mobility
F-Curated technology (both reliable and maintainable) is predominantly bifacial technology
Bifacial, Expensive Technology
G-Curated technology is predominantly bifacial technology ${ }^{2}$
H-Bifacial technology is expensive technology
I-Standardized cores are expensive technology
J-Bifacial technology suggests uncertainty of raw materials
K-Bifacial technology suggests food resources were eratic, yet predictable ${ }^{2}$
L-A decrease in bifacial (formal) tools = decreased mobility
M-Increased bifacial technology = increased mobility


Technology and Mobility

$\mathrm{N}-$ Increased bifacial technology $=$ increased mobility ${ }^{1,2}$

$\mathrm{O}-\mathrm{A}$ decrease in bifacial (formal) tools $=$ decreased mobility $^{6}$

$\mathrm{P}-$ An increase in expedient tools $=$ decreased mobility $^{6}$

$\mathrm{Q}-$ An increase in expedient core technology $=$ increased sedentism ${ }^{6}$

$\mathrm{R}-$ Collectors move with the seasons ${ }^{5}$

$\mathrm{S}-$ Collectors move less frequently ${ }^{5}$

T-Foragers have frequent residential moves ${ }^{5}$

$\mathrm{U}$-Temperate climate foragers reacting to scarce and unpredictable resources will be highly nomadic ${ }^{7}$

Assemblage Formation

$\mathrm{V}-$ Good raw material at a site $=$ a greater variety of tools ${ }^{4}$

$\mathrm{W}$-Foragers have little diversity or variety in tool assemblage ${ }^{5}$

$X$-Collectors have more diversity and variety in tool assemblage ${ }^{5}$

$\mathrm{Y}$-The longer a group occupies a site, the greater the quantity and variety of tools will be found ${ }^{4}$

Diet Breadth

Z-An abundant availability of hlgh-ranked resources $=$ a narrow diet breadth ${ }^{8}$

AA-Temperate climate foragers reacting to scarce and unpredictable resources will have a broad $\operatorname{diet}^{7}$

BB-Bifacial technology suggests food resources were eratic, yet predictable ${ }^{2}$

Foragers/ Collectors (other)

CC-Foragers thrive in mild effective temperatures ${ }^{5}$

DD-A long-term campsite assemblage represents a forager/collector continuum ${ }^{9}$

${ }^{1}$ Bleed 1986

${ }^{4}$ Schiffer 1975; Shott 1989

${ }^{7}$ Hayden 1986
Bousman 1993

${ }^{5}$ Binford 1980, 1983

${ }^{8}$ Kelly 1983 33inford 1973, 1979

${ }^{6}$ Parry and Kelly 1987

${ }^{9}$ Nickels 2000

1) In a predominantly foraging group, expensive technology $(\mathrm{F}, \mathrm{H})$ involves a smaller variety of tools (W), and implies greater mobility (E) in search of a broader diet (AA), because high ranked resources are either not available or are erratic $(Z, B B)$.

2) In a predominantly collecting group, less expensive technology $(\mathrm{H}, \mathrm{P}, \mathrm{Q})$ involves a greater variety of tools $(\mathrm{X})$, and implies less mobility $(\mathrm{S})$, because highly ranked resources are seasonally available (Z); thus a narrower diet breadth $(Z)$.

3) In a forager/collector continuum (mixed strategies), the forager strategy becoming predominant will be evidenced when the variety of stone tools, both bifacial and expedient (W, X), decreases as the variety of animals and plants processed increases (AA).

4) When campsite assemblages are compared, the predominantly foraging strategies will be manifested by the relatively wider varieties of plant and animal remains found at those sites implying which sites were occupied for relatively longer periods of time (AA, S, T, Y). This relative ranking should correlate to the increases/decreases in the variety of stone tools at each site (W, $\mathrm{X}, \mathrm{AA}$ ). Foragers, who move more frequently, should have a broader diet, with fewer tools (T, W, AA). Collectors, who move less frequently, should have a narrower diet, with more tools $(\mathrm{S}, \mathrm{X})$. 
By their very nature, and because of the diverse paradigms, and simple understanding of terminology, the issues and related models discussed in this chapter are indeed complex. The issues can be, and will be, we suspect debated for decades to come.

\section{Technology, Subsistence and Mobility Patterns at 41DL436}

The previous sections discuss how inferences about past human behavior can be made by inserting the results of a functional lithic analysis into these models. However, at more than a few archaeological sites in North-central Texas there is generally a paucity of lithic materials. Such is the case at 41DL436. Therefore, we emphasize that when available, an analysis of dietbreadth should include ceramics, faunal, and plant remains.

\section{Lithic Raw Material Availability}

The type of lithic materials for either fashioning stone tools, or to be used as heating elements for personal warmth or cooking foodstuffs, are dependent upon their availability, either on-site or within the area. The availability of lithic raw material must have been an important factor in planning the next move. If good material was always available at each site, then there was no need to intensively repair or "retool' at these sites. However, if good raw material was not readily available, as is the case at 41DL436, then it must have been transported onto the site from elsewhere. The availability, or lack thereof, of raw material as it affects mobility and technology will be discussed further in this chapter. Suffice it to say here, that raw material sourcing is very important in understanding both the movement of people across the landscape, as well as the extent and type of manufacturing technology that occurred at 41D436.

Forty-two of the 43 pieces of chipped stone recovered were made from high quality light gray and pale brown chert. The remaining one was manufactured from red sandstone (see Appendix C-3). Fire-cracked rocks used in constructing hearths were comprised of sandstone $(n=80)$, macrocrystalline calcite $(n=3)$, and limestone $(n=2)$. Although archaeologists collected 100 percent of all lithic material, only 26 limestone and sandstone pebbles and gravels were observed and collected. Twenty-four were less than $2 \mathrm{~cm}$ long, while the remaining two were 3 and $6 \mathrm{~cm}$ long, respectively. All except one are well rounded and were likely stream transported to the site. The largest one appears to have been burned, is sandstone, and may have been manually transported onto the site for hearth construction. The absence of larger gravels suggests that stream flooding velocity over the site through time was likely slow, and corroborates the paleoenvironmental information obtained from various studies contained herein (see Chapters 6-11). The small, isolated limestone pebbles with a thin carbonate crust and a yellow weathering rind suggest that they have been reworked from older gravels upstream.

Citing paleoenvironmental information from Linda Scott-Cummings et al. and Ken Brown (Chapters 6 and 11), the Fish Creek channel migration at the site as described by Jim Abbott (Chapter 5) occurs first with a lateral migration and slow aggradation of a steep-banked, vegetated point bar, forming Stratum 1a. Sometime between AD 1477 and AD 1634 the channel shifted to its current position along the north edge of the site, coinciding with what 
Ken Brown opines is a transition period from the Little Climatic Optimum and the Little Ice Age (see Chapter 6). However, this shift did not occur suddenly and with substantial fluviatile energy necessary to expose any underlying gravels, nor transport gravels of any useful size from geological deposits upstream. In sum, although rapid stream runoff may have occurred in the upper reaches of the Fish Creek valley, that energy was generally dissipated by the time the flooding in the site area occurred. The paleoenvironmental data indicates that Fish Creek in the immediate area of the site has not possessed the energy of exposing raw material at any time during the recorded occupations at the site. Thus, any raw material used for the stone debitage and the single point found on the site had to have been procured from off-site. This presumption is supported by the fact that (1) 39 of the 42 (93 percent) pieces of the chipped stone have no cortex, one has roughly 5 percent cortex, one has roughly 10 percent cortex, and only one piece has all of its cortex remaining, and (2) as will be discussed in the Lithic Technology section of this chapter, the data suggests that stone tools were initially brought to the site either already in late stages of reduction, or as finished tools.

As shown in Figure 2-3, 41DL436 is situated in Fluvatile terrace deposits (Qt), which contain gravels within contiguous terraces of different ages. Approximately 1.4 miles upstream to the west of the site lies the Eagle Ford formation (or Eagle Ford Group undivided). In addition, easterly protudences of the Eagle Ford come within .75 mile of 41DL436. The Eagle Ford Group is comprised of sandstone, shale, and limestone. The shale is characteristically selentic, with calcareous concretions and large septaria; that is, there are large macrocrystalline calcitefilled cracks in the Eagle Ford Group, a most likely source for the macrocrystalline calcite chunks, as are the sandstones and limestones found at the site (Barnes 1988).

The Eagle Ford Group underlies Austin Chalk, which also contains microangular macrocrystalline calcite. Notably, some areas of both Eagle Ford and Austin Chalk are covered with Uvalde and Trinity River gravels. Uvalde gravels are relict deposits carried in Tertiary and Pleistocene riverbeds from the High Plains, while Trinity gravels lie within Quaternaryages terrace deposits along the Trinity River basin (Ferring 1990; Brillinger 1985; Allen and Flanigan 1986).

The site lies within Frio silty clay (see Figure 2-4). During trenching to as deep as $4 \mathrm{~m}$ (13+ $\mathrm{ft}$ ) below the surface no gravel concentrations were observed, and small rounded pebbles were extremely rare. However, according to a local soils publication, gravels and limestone can be found at 6 feet below the surface within Frio series clays. To the south and upslope of the site lies Crockett fine sandy loam which is capable of bearing siliceous pebbles. Otherwise, there are 17 different soils types upstream from 41DL436, and many of these could contain chert gravels.

All 42 chert artifaces were made from high quality, fine-grained chert. These data suggest a common source of procurement, and without further examination does not rule out the possibility that the raw materials used are Ogallala gravels. That is, Ogallala gravels are comprised of various quartzites, chalcedony, basalt, petrified wood, as well as chert. But, to the naked eye the dark-gray chert from Ogallala gravels (Holliday 1997:250) can be mistaken for Edwards Formation chert (Hood 1978; Holliday and Welty 1981; banks 1990; Shelley 1993). 
However, in comparing Ogallala cherts to Edwards cherts "Testing of Edwards lookalikes under short- and long-wave ultraviolet light has revealed that none fluoresce the orange to tan colors typical of Edwards Formation chert" (Hurst et al. 2010:100; see also, Hofman et al. 1991; Hilsman 1992). In a study of Ogallala gravel characteristics "Twenty chert nodules that resembled Edwards Formation chert ... were cracked open for examination under UV light. Confirming Hillsman's (1992) study, none of the chert fluoresced orange to tan colors typical of Edwards Formation chert. Four of the chert nodules fluoresced green under shortwave UV reaction, which also is not typical for Edwards Formation chert. This result further corroborated the UV light is successful in distinguishing cherts in the Ogallala gravels from Edwards Formation chert" (Hurst et al. 2010:104).

Without exception, all 42 pieces of chert debitage and the arrow point fluoresced a hue range from yellow, to yellowish orange, to orange when subjected to ultraviolet light. Based upon the reaction to ultraviolet light of the 42 chert specimens from 41DL436, we must presume that the source of the raw material is the Edwards Formation. As shown in Figure 16-102, the main Edwards Formation as mapped, lies some 110 miles west-southwest and south-southwest of 41DL436. However, the northernmost recorded Edwards is at Fort Worth, roughly 22 miles west of 41DL436, where a there are a few feet of crystalline, thin- to medium-bedded limestone beds, and at Benbrook where the Edwards appears to be about four feet thick (Sellards et al. 1932:339). The narrow, thin-lined Edwards Formation in these two areas overlie the eastern edge of Goodland Formation. Figure 16-103 shows the possible ephemeral Edwards exposures along the Goodland's eastern edge. Theoretically, raw material used for the chipped stone found at 41DL436 could have been transported overland from any of the streambeds that drain the main Edwards Formation or the ephemeral formation west of the site.

In an effort to determine whether or not the chipped stone found at 41DL436 was manufactured from nearby gravels in Fish Creek, Joel Butler presents a more detailed summary of this effort in Appendix F. In short, two grab samples were collected from the locales shown in Figure F-1 (Appendix F). The samples were numbered before being measured to the nearest maximum length in centimeters, then broken open with a hammer. The material type, grain size, and color were recorded. Next they were exposed to both short and long-wave ultraviolet light. In summary, no chert or other raw material suitable for knapping was observed in either of the two samples.

\section{Chipped Stone Technology}

All chipped stone collected from the excavations was cataloged and further separated into the following distinctive classes: complete flake, incomplete flake, shatter, uniface, point. Once the lithics were separated into each class, their additional attributes were further analyzed in order to provide a technological and morphological characterization of the lithic assemblage at the site. During the lithic analysis we identified a single biface (an arrow point proximal portion), an edge-serrated piece of sandstone, and 41 pieces of chipped stone debitage. 


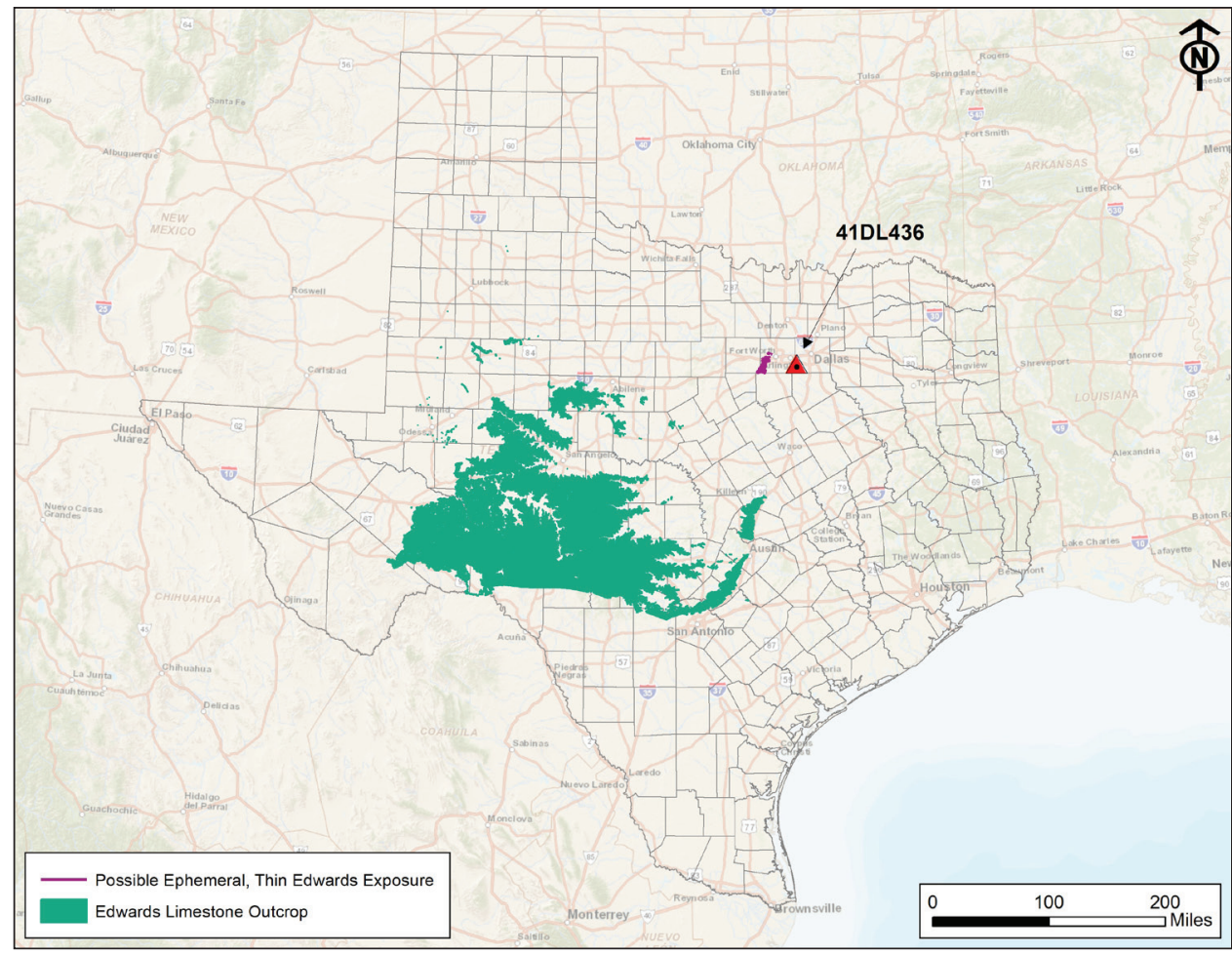

Figure 16-102. Main Edwards Formation relative to 41DL436.

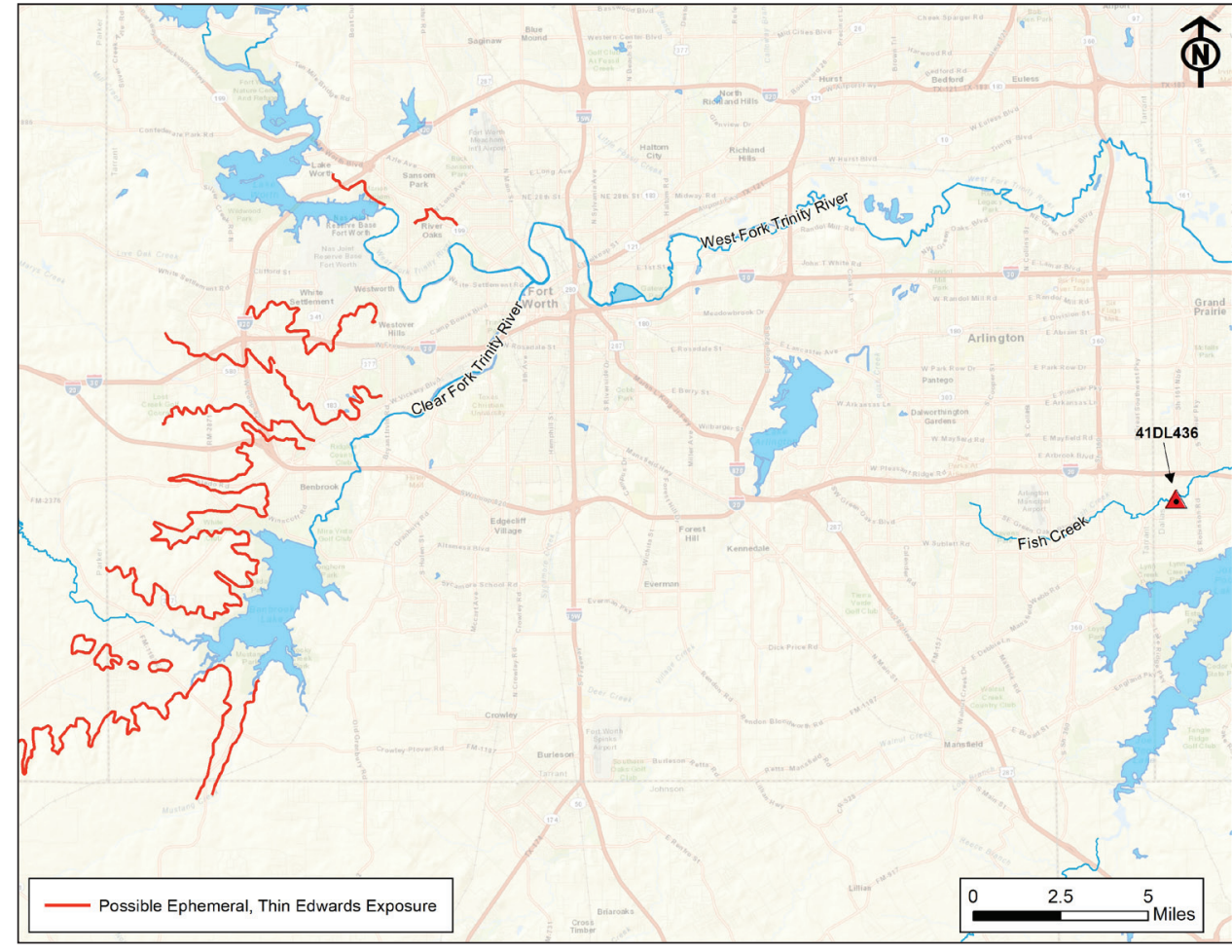

Figure 16-103. Ephemeral line of Edwards Formation exposures west of 41DL436. 


\section{Projectile Points}

Projectile points are one of the more important artifact categories because they can provide information on cultural affiliations and chronology. For the single projectile point recovered, the following attributes as applicable were recorded: raw material type, raw material quality, burning, projectile point subgroup, projectile point type, serration, beveling, completeness, break type, maximum length, blade length, blade width, haft length, neck width, base width, and maximum thickness. Finally, the specimen was exposed to ultraviolet light to evaluate its possible raw material source.

\section{Unifaces}

Artifacts that have been flaked on one surface are classified as unifaces. With the exception of one unifacially piece of red sandstone, all unifaces were made from chert flakes. The attributes of flakes was recorded as discussed below, and notes made regarding edge modification such as utilization and intentional flaking.

The degree of retouch for unifaces is a subjective category. The possible classifications are expedient, minimal, formal, and indeterminate. Expedient unifaces are flakes that have been modified through use, but not by intentional flaking or shaping. Minimally retouched unifaces have not been drastically altered from their original form, but some flaking has been used to alter the shape of one or more of its edges. Formal unifaces include artifacts functionally classified as scrapers, gouges, or unifacial knives. One or more its edges have been significantly shaped through the deliberate patterning of flake removals. For purposes of this discussion, we use the term "late stage" to imply the reduction process of formal unifaces.

\section{Flakes}

All flakes were separated as complete, incomplete, or shatter, based on two specific attributes: (1) presence of an intact platform and (2) a measurable termination (feathered or hinged). Attributes recorded for all flakes consisted of: raw material type, grain size, length, width, thickness, percentage of cortex, flake type, and heat treatment. Flake types were noted as biface manufacture, biface thinning/resharpening, uniface manufacture/resharpening, blade, platform preparation and/or core preparation, notching, sequence, channel, or indeterminate (see Appendix C-3). Definitions of these flake types are presented below.

\section{Biface Manufacture Flakes}

These flakes are defined as primary and secondary flakes having moderate to large dorsal flake scar ridges and with minimal to considerable longitudinal curvature. The striking platforms on this type range from single to multi-faceted, although single and double faceting is most common. These flakes are usually removed with a hard hammerstone or large billet, and the dorsal flake scarring is indicative of sequential flake removals and flake removals from opposite edges (Mehalchick et al. 1996). In the system employed during this analysis, overshot flakes are classified as biface manufacture flakes. 


\section{Biface Thinning/Resharpening Flakes}

In other studies, biface thinning flakes have been separated from biface resharpening flakes (cf. Mehalchick et al. 1996), but because much of the distinction between the two is based on the presence of use-wear, this study did not attempt any such separation. These types of flakes are generally tertiary flakes that were removed by pressure or by a soft hammerstone or billet. They have a moderate to large number of dorsal flake scars, but unlike biface manufacture flakes, this type has shallow flake scar ridges. Longitudinal curvature ranges from moderate to slight depending on the type of parent artifact. The striking platform is generally multifaceted and may be ground (although this was not coded), with some lipping on the ventral edge (Mehalchick et al. 1996).

\section{Uniface Manufacture/Resharpening}

As with biface thinning and resharpening flakes, the primary distinction between uniface manufacture and uniface resharpening flakes is that uniface resharpening flakes show evidence of use-wear on the platforms. For the purposes of this study, the two flake types are treated as one category. These flakes are generally small to medium in size no bigger than two centimeters, with single-faceted platforms. Often, there is a slight longitudinal curvature at the distal end of the flake, usually accompanied by a discernable ridge oriented perpendicular to the longitudinal axis of the flake. This ridge is formed by the intersection of the original dorsal surface of the blank and the subsequent flakes scars originating from the lateral edges of the blank. Other characteristics of uniface manufacture/resharpening flakes are that the dorsal surface generally is marked by a series of parallel flake scars and small step fractures, the result of use or previous manufacturing at the proximal end (Mehalchick et al. 1996).

\section{Blades}

Generally, a blade is defined as a flake that is twice as long as it is wide (Mehalchick et al. 1996), although in this study, the definition is restricted to flakes removed from a blade core. These flakes are characterized by single or multiple dorsal ridges that are roughly parallel to the longitudinal axis of the flake. These ridges are indicative of earlier blade removals. The longitudinal curvature of blades is slight to moderate. Striking platforms are generally single or corticate faceted, although double- and multiple-faceted platforms occur as well (Mehalchick et al. 1996).

\section{Platform Preparation and/or Core Preparation Flakes}

Platform and core preparation flakes are highly variable in size, shape, amount of dorsal cortex, and platform faceting, but they all represent an attempt to prepare a platform or core for subsequent flake removals. Size and platform faceting are dependent upon the stage of reduction during which they were removed and the size of the parent material, which may be a core or artifact. Likewise, shape is dependent on the type of core from which they were removed. The amount of dorsal cortex is also highly variable, ranging from 0 to 100 percent, depending on the stage of reduction (Mehalchick et al. 1996). 


\section{Notching Flakes}

These small flakes are usually 5-15 $\mathrm{mm}$ long, and are removed by pressure flaking during the creation of notches on projectile points or other notched tools. The flakes have distinctive U-shaped platforms and scalloped dorsal surfaces indicative of prior notching flake removals (Mehalchick et al. 1996).

\section{Sequence Flakes}

Sequence flakes are indicative of a particular core reduction strategy in which a cobble is first split lengthwise and then flakes are removed in sequence beginning at one end of the core. These flakes can be recognized by a double-negative bulb centered above or on the platform with a tabular surface. Sequence flakes are unique to a particular type of core technology, but without a series of them, they are most likely accidental in nature (Jelinek et al. 1971). This method of flake removal may have been useful in an environment where raw material was commonly available as tubular cobbles rather than as tabular or spherical cobbles.

\section{Channel Flakes}

Channel flakes are produced as a result of fluting projectile points. They are most commonly found on Paleoindian sites, but may also be found where later point types such as Pedernales have been fluted. "They are generally parallel-sided, flat in longitudinal section, slightly planoconvex in lateral cross section, and have well prepared, isolated, ground platforms" (Frison and Bradley 1980:26).

\section{Indeterminate Flakes}

If a flake could not be assigned with certainty to one of the types described above, it was coded as indeterminate. Generally, flakes displaying attributes associated with two or more different types were included in the indeterminate category.

\section{Vertical Distribution of Chipped Stone}

Although in this section we discuss stratigraphic cautions and mechanisms that can disrupt the correct interpretations of data, we do not think these processes are appreciable at 41DL436. As is emphasized in Chapter 5, this site is remarkable for the high degree of strata preservation. Nevertheless, always of concern is the possibility that flakes of various sizes have been transported vertically either upward or downward in the profile. Villa (1982:277) points out that both Old World and New World archaeologists routinely observe clear breaks in sedimentary stratigraphy with associated cultural material, and accept these separations as isoluable components. As such, these discrete assemblages are suitable for constructing relative cultural chronologies. However, she argues that stratigraphic disturbances and the resulting movement of artifacts are not always obvious and detectable by even the most trained eye in the field. She cites "living floor" studies which presume that layers that appear to be undisturbed "would yield discrete assemblages." but were sometimes criticized as being too coarse-grained (Villa 1982:277). Even thin floors may represent a palimpsests of occupations, and "considerable 
vertical displacement of artifacts (both upward and downward) may occur even when the matrix itself has not been disturbed or displaced." (Villa 1982:278).

It has been pointed out that sediments and soils are not static mediums (Wood and Johnson 1978). Natural post-depositional processes affecting the vertical distribution of artifacts include frost heave, dry soil creep, solifluction (saturated soil creep), and subsidence (sinking) in cave deposits. Although in some cases these processes are easily identifiable in the field, in many other cases they are not. Another post-depositional disturbance often overlooked is biogenic perturbation, e.g., termites, earthworms, and other animal burrowing. Human post-depositional influences on artifacts may include trampling, tool reuse, the digging of postholes, storage pits, baking pits, or burial graves, and the borrowing of sediments for sealing cooking ovens or ceramic manufacture. Yellen (1977:103), Gifford and Behrensmeyer (1977), and Stockton (1973) argue that trampling will cause the smaller artifacts to move downward, while generally leaving the larger artifacts on or very near their original surface. Periodic wetting and drying of soils due to percolating rainwater, and an oscillating water table will also cause artifacts to move downward (Cahen and Moeyersons 1977). In sum, Villa (1982:286-287) cautions against "overinterpreting stratified sequences" without analyzing conjoinable pieces of stone, bone and pottery relative to the total assemblage.

Soil types and textures certainly are a variable in the extent that vertical movement of artifacts can occur. But Stockton (1973) argues that the phenomena can occur in all types of deposits, whether mostly sand, or a mixture of sand, silt, and clay. Gifford-Gonzalez and others (1985:808) have demonstrated in experimental studies that 94 percent of artifacts recovered in loamy soils were vertically within $1 \mathrm{~cm}$ of their original placement after trampling, and the looser matrix caused by trampling "caught and held small- to medium-sized flakes." Conversely, in sandy soils the majority of artifacts easily worked their way downward, at least until they encountered a moist layer of sand.

Although we agree with Villa (1982) that the best method to evaluate the vertical movement of artifacts is by refitting or conjoining artifacts, using flake weights and lengths have also been demonstrated as effective alternative means of evaluating vertical displacement. Yellen (1977:103), Gifford and Behrensmeyer (1977), and Stockton (1973) argue that trampling will cause the smaller artifacts to move downward, while generally leaving the larger artifacts on or very near their original surface. Gifford-Gonzalez and others (1985) concluded from their experiments and those of Villa and Courtin (1983) that length, weight and volume are interrelated variables that affect the downward displacement of flakes caused by trampling, and thus statistically can be used interchangeably to evaluate their stratigraphic integrity.

Unlike trampling which causes artifacts to move downward, argilliturbation causes artifacts to move upward. The wetting and drying of surficial layers of clays, called vertisols (Soil Survey Staff 1975) push artifacts toward the surface. "When expansion occurs, an artifact is lifted slightly from its original position, leaving a small void or cavity under the artifact. As the soil dries, the matrix around the artifact shrinks. Because the cavity under the artifact also shrinks, the artifact cannot fall back into its original position, and fine-grained particles fill the void." (Waters 1992:299-300). 
In sum, these and other studies implicate that the integrity of occupation zones can be methodically tested by examining the vertical distribution of artifacts; on occupation surfaces that have been heavily trampled, particularly in sandy soils, we should see a "champagne glass" distribution, with greater quantities of larger flakes on or near the surface, underlain by progressively smaller flake quantities and sizes. Conversely, on occupation surfaces that are covered by vertisols we should see size sorting in the form of smaller artifacts moving upward. There will be exceptions: animal burrowing, subsequent cracking in clayey soils, and some human intervention (e.g., borrowing and digging) may displace larger artifacts to lower levels and conversely, smaller artifacts upward; however, an overall mean size (or weight) should exhibit the champagne glass shape. At other sites in south and central Texas, Vierra (1997) and others (e.g., Nickels et al. 1998:91-92) have examined the vertical movement of artifacts through soil horizons, and have successfully correlated the data with occupation levels. The following section demonstrates this phenomena at the Fish Creek Slough site.

As stated in Chapter 5, four isolable strata with cultural materials were identified at the site. Normally, we would plot the sizes and mean weights of all flakes in a vertical distribution and compare those data with sediment and soil strata throughout the site. However, in this case there is simply an insufficient quantity of pieces of chipped stone to make any valid assumptions regarding artifact displacement based upon either flake lengths or weights. Suffice it to say here, that the sediment and soils depositional context on the Fish Creek Slough site is such that vertical movement of artifacts through the multi-layered packages due to size sorting should not be as problematic as it is in sandy soils (e.g., Stevenson 1991; Vierra 1998).

Corroborating this assumption, a review of flake data presented in Appendix C-3, reveals that in all cases the flakes recovered were all within one level only of individual units; in no case were flakes found in levels above or below. That data alone strongly argues for in situ cultural materials, that are not being vertically displaced with any significant degree. As for conjoinable pieces, a refitted core reduction flake was found in Stratum 2, in the same unit and same level (Unit 2, level 1).

\section{Results of the Analysis}

Forty-three pieces of chipped stone were recovered during the 2010 excavations at 41DL436; 31 from the $1 / 4$-inch screens, 11 from floatation samples, and 1 from the surface of a Gradall scrape (Appendix C-1). Forty-two of the pieces are made from fine-grained chert, while the remaining specimen is a serrated piece of red sandstone. The only formal tool found was the proximal piece of an arrow point in the upper portion of the upper cultural component, Stratum 3, Unit 1, Level 1 (see Upper Component discussion above).

Shown in Table 16-18 is flake ubiquity within each stratum. There are noticeable differences in the average number of flakes per cubic meters excavated, but statistically the flakes per cubic meter excavated in Strata 3 and 1a/1b lie within one standard deviation $(0.5265-2.4643)$ from the mean, while flakes per cubic meter excavated in Stratum 2 lie just beyond one standard deviation, but well within two standard deviations. Although admittedly problematic because of the low numbers, statistically it appears then that chipped stone manufacturing was 
Table 16-18. Flake Ubiquity by Stratum.

\begin{tabular}{cccc}
\hline Stratum & \# Flakes & $\mathbf{M}^{\mathbf{3}}$ Excavated & Flakes per $\mathbf{~}^{\mathbf{3}}$ \\
\hline 3 & 2 & 2.1917 & 0.9125 \\
\hline 2 & 37 & 12.9333 & 2.8608 \\
\hline $1 \mathrm{a}$ & 1 & 2.2050 & 0.4535 \\
\hline $1 \mathrm{~b}$ & 1 & .6000 & 1.6667 \\
\hline
\end{tabular}

occurring at about the same intensity comparable to the supposed intensity of occupation in all four strata. Statistically then, we presume that flake data can reasonably be used to further evaluate chipped stone technology at the site. Table 16-19 summarizes the flake types, both whole and broken.

Table 16-19. Flake Types (Both Complete and Incomplete).

\begin{tabular}{cccccccc}
\hline $\begin{array}{c}\text { Flake } \\
\text { Type } \rightarrow\end{array}$ & $\begin{array}{c}\text { Core } \\
\text { Preparation } \\
(\mathrm{n}=3)\end{array}$ & $\begin{array}{c}\text { Biface } \\
\text { Manufacturing } \\
(\mathrm{n}=9)\end{array}$ & $\begin{array}{c}\text { Biface } \\
\text { Thinning } \\
(\mathrm{n}=19)\end{array}$ & $\begin{array}{c}\text { Uniface } \\
\text { Thinning } \\
(\mathrm{n}=5)\end{array}$ & $\begin{array}{c}\text { Uniface Re- } \\
\text { sharpening } \\
(\mathrm{n}=5)\end{array}$ & $\begin{array}{c}\text { Indeterminate } \\
(\mathrm{n}=1)\end{array}$ & $\begin{array}{c}\text { Totals } \\
(\mathrm{n}=41)\end{array}$ \\
\hline Stratum & & & 1 & 1 & & 2 \\
\hline 3 & 2 & 8 & 18 & 8 & 1 & 37 \\
\hline 2 & 1 & & & & & 1 \\
\hline $1 \mathrm{a}$ & 1 & & & & 1 \\
\hline $1 \mathrm{~b}$ & & & & & & & \\
\hline
\end{tabular}

As discussed above, with the exception of a piece of sandstone, all 41 flakes were made from fine-grained chert ranging in colors from light gray to pale brown to the naked eye, and all fluoresced hues ranging from yellow to orange. However, differences in the assemblage are apparent upon closer examination of the overall dataset. As shown in Table 16-20, over 51 percent of the flakes in Stratum 2 were broken, all 19 exhibiting evidence of post-depositional breakage. Post-depositional breaks are typically the result of force applied to the lateral surface of the specimen. This results in a bulb of percussion originating not from the edge of the artifact, but from its face (Tomka 1986:96). Post-depositional breaks can result from numerous activities including natural and artificial activities. From a cultural perspective, broken pieces of chipped stone are a manifestation of trampling while the chipped stone is exposed to the surface. The percentages of broken chipped stone increases with intensity of occupation (or occupations) relative to the length of time the pieces are exposed on stable surfaces.

In this case, with over 51 percent of the flakes in Stratum 2 having been broken postdepositionally, the implication is that the site was intensively occupied on stable surfaces during the period between 500 and $270 \mathrm{BP}$. This finding tends to be in disagreement with the faunal analysis from Stratum 2, where the predominance in degree of weathered bone is typical of weathering associated with any occupation site where material was buried relatively quickly after use (see Chapter 15). Studies of the effects of trampling on chipped stone indicate that damage done to chipped stone is more a matter of substrate, where artifacts are more likely to exhibit damage if trampled on an impenetrable substrate (McBreaty et al. 1998). The multi-layering of fine sands, fine
Table 16-20. Total Number of Flakes Versus Broken Flakes.

\begin{tabular}{ccc}
\hline Stratum & Total \# Flakes & \# Broken Flakes \\
\hline 3 & 2 & 0 \\
\hline 2 & 37 & $19(51.4 \%)$ \\
\hline $1 \mathrm{a} / 1 \mathrm{~b}$ & 2 & 0 \\
\hline
\end{tabular}


sandy loam, and loam within Stratum 2 implies multiple flooding episodes, in a scenario where debitage lying on more compact substrate was successively covered fairly quickly.

The remaining 22 flakes are unbroken (complete), and will be used as a dataset for further analysis (Table 16-21).

Table 16-21. Complete Flakes.

\begin{tabular}{|c|c|c|c|c|c|}
\hline & Stratum 3 & Stratum 2 & Stratum 1a & Stratum $1 \mathrm{~b}$ & Totals \\
\hline \multicolumn{6}{|l|}{ Flake Type } \\
\hline Core Reduction & & 1 & 1 & & 2 \\
\hline Biface Manufacturing & 1 & 2 & & 1 & 4 \\
\hline Biface Thinning & & 9 & & & 9 \\
\hline Uniface Thinning/Re-sharpening & & 6 & & & 6 \\
\hline Indeterminate (Shatter) & & 1 & & & 1 \\
\hline Totals & 1 & 19 & 1 & 1 & 22 \\
\hline
\end{tabular}

In terms of raw numbers, most evident in the analysis of complete flakes is that bifacial manufacturing was the predominate activity occurring at the site; 13 of the 21 identifiable flake types (59.1 percent) were biface manufacturing or biface thinning flakes, while unifacial technology accounts for 6 of the 21 ( 28.6 percent), with the remaining 2 ( 9.5 percent) being core reduction flakes.

In the chipped stone tool assemblage at 41DL436 we see both (1) expensive/formal/curated, and (2) less expensive/informal/expedient technologies: expensive/formal/curated in the form of biface flakes, re-sharpening flakes, and the only formal tool, an arrow point; less expensive/ informal/expedient technology in the form of uniface manufacturing flakes, utilized flakes, and slightly re-touched flakes.

What we are not seeing in the assemblage are those tools that were brought to the site (Founder Curate Set), and those that were carried away from the site (Donor Curate Set) upon abandonment. Based upon the few flake types recovered, it is clear that they brought bifaces and unifaces with them. With the exception of the one arrow point, the fact that there we found no other formal tools either complete or broken, indicates that whatever stone tools they used at the site were carried away, likely expecting to move to a new campsite where raw material was likewise either non-existent or scarce.

There are no clear indications in the limited assemblage that will confidently allow for a heavy reliance on one lithic technology versus the other. In fact, the two technologies appear to be of equal importance. Thus, applying the chipped stone tool assemblage to the diet-breadth model as discussed above, there are arguments both for both foragers and collectors occupying the site. They were both foragers and collectors, with a limited variety of stone tools, and with a degree of mobility and diet breadth within the medium of the forager/collector continuum. 
However, having been unable to see any real contrast in the mobility and subsistence habits of the site occupants based upon the limited chipped stone tool assemblage, we examined with more detail, the makeup of the robust faunal assemblage at 41DL436.

\section{DL436 Faunal Diversity}

One of the principal goals of faunal analysis is to evaluate consumption patterns. In most cases the analyst will attempt to identify the Minimum Number of Individuals (MNI) or the Number of Identified specimens (NISP). However, there are problems with both of them that one must be aware of before using either one in evaluating a faunal assemblage. We must note here, that Jodi Jacobson has aptly addressed these issues in Chapter 15.

NISP is most frequently used in faunal analysis, however the numbers can be distorted based on recovery. It can also be misconstrued if a simple count is interpreted directly as relative importance; i.e., just because there are more rabbit than bison bones does not mean rabbits are more sought after, or are preferred in the diet. Additionally, among other problems with using NISP is the same as with MNI; one can't be sure whether the whole animal was brought back to the site, or whether only the choice cuts were returned (Binford 1978). Additionally, rabbits may have been returned to the site whole, while the bison was butchered elsewhere and only the bones with the most meat were returned to the site.

MNI is the method least commonly used because among other problems (see for example, Grayson 1984; Reitz and Scarry 1985), it can substantially underestimate the number of individuals. Most analysts identify the faunal specimens to the genus or species level and the quantity of each is the NISP (Lyman 1994a; Meissner 1998). In sum, neither MNI or NISP are completely reliable predictors of relative importance or biomass.

Problematic with any attempt to compare faunal assemblages from archaeological sites is the sophistication of faunal analysis that varies with each report, dependent upon the degree of bone preservation, the quantity of sediments excavated, and the goals of the faunal analysis. That is, some analysts report MNI, some report NISP, some report only to genus, some report to species, some report bone conditions and taphonomy in great detail while others do not, some report assemblages in terms of cubic meters excavated while others do not, etc. The literature pertaining to optimal foraging theory most often focuses on such issues as return rates, calorie counts, cost-benefit analysis, etc. However, the focus of this discussion is diversity in the archaeological record. Therefore, the presence/absence of remains is considered appropriate for our analysis of faunal assemblages.

When comparing assemblages between cultural components at 41DL436, we are not particularly concerned at the disparity in the number of cubic meters excavated within each component because as we stated in our Methods, excavation units were generally opened following exposure of fauna by a Gradall scrape. There were exceptions, where isolated bones were recorded with a TDS, and no hand excavations were conducted, but that percentage is considered non-significant in relation to the overall assemblage. 
Table 16-22 provides the presence/absence of animals identified by common names at 41DL436. The overall assemblage consists of a high "species richness", as reflected by the 24 named animals. This "species richness" in faunal remains may be considered a proxy measure of diet breadth, and this issue will be further addressed below.

Under the diet-breadth model of optimal foraging theory, when campsite assemblages are compared, the predominantly foraging strategies will be manifested by the relatively wider varieties of plant and animal remains found at those sites, implying which sites were occupied for relatively longer periods of time. Although this relative ranking should correlate to the increases/decreases in the variety of stone tools at each site, this assumes that raw material for fashioning stone tools was immediately available. However, as discussed above, that was simply not the case at 41DL436. But, as we previously discussed the use of metal knives apparently began replacing stone tools.

Table 16-22. Presence/Absence of Common Named Fauna.

\begin{tabular}{|c|c|c|c|c|}
\hline Common Name & $\begin{array}{c}\text { Lower Component } \\
\text { Stratum 1a }\end{array}$ & $\begin{array}{c}\text { Lower Component } \\
\text { Stratum 1b }\end{array}$ & $\begin{array}{c}\text { Middle Component } \\
\text { Stratum } 2\end{array}$ & $\begin{array}{l}\text { Upper Component } \\
\text { Stratum } 3\end{array}$ \\
\hline Bird & $\mathrm{X}$ & & $\mathrm{X}$ & \\
\hline Bison & $x$ & $x$ & $x$ & $x$ \\
\hline Cottontail rabbit & & $x$ & $x$ & $x$ \\
\hline Cow & & & $x$ & \\
\hline Cow/Bison & & $x$ & $x$ & $x$ \\
\hline Dog/Coyote & & & $x$ & \\
\hline Duck & & $x$ & $x$ & \\
\hline Fish & $x$ & $x$ & $x$ & \\
\hline Frog/Toad & $x$ & & $x$ & $x$ \\
\hline Ground Squirrel & & & $x$ & $x$ \\
\hline Lizard & & $x$ & $x$ & \\
\hline Mouse & & & $x$ & $x$ \\
\hline Mule Deer & $x$ & $x$ & $x$ & \\
\hline Opossum & & & $x$ & \\
\hline Pocket Gopher & $x$ & $x$ & $x$ & \\
\hline Pronghorn & $x$ & $x$ & $x$ & \\
\hline Raccoon & & $x$ & & \\
\hline Rat & $x$ & $x$ & $x$ & $x$ \\
\hline Rodent & & $x$ & $x$ & $x$ \\
\hline Shrew & $x$ & & & \\
\hline Snake & $x$ & $x$ & $x$ & \\
\hline Turtle & $x$ & $x$ & $x$ & $x$ \\
\hline Vole & & $x$ & $x$ & $x$ \\
\hline White-tailed Deer & & $x$ & $x$ & \\
\hline
\end{tabular}




\section{Mobility and Subsistence of Comparable Toyah Assemblages}

The radiocarbon ages obtained from cultural features at 41DL436 range from 715-85 BP. These dates are within acceptable ranges offered for the late Late Prehistoric, Protohistoric, and early Historic periods in Texas. Therefore, we considered for comparison various comparable age components throughout the state.

In doing so, we offer some implications about comparable age mobility and subsistence based on the environment and cultural remains. We first synthesize published reports of comparable age assemblages in the South and Central Texas regions, and the southern end of the Southern Great Plains in West-central Texas. Next, we compare Effective Temperature and Primary Productivity values for ten high integrity components. Finally, we compare these values with available subsistence data.

\section{Comparable Age Assemblages Considered}

Schiffer (1975) suggests that the best way to test his model to predict the effects of occupation span on site content is to use large data sets from excavated sites with like components. In this case we compare assemblages from like temporal components recovered from excavated gizemént contexts (Collins 2004). We reviewed the published literature from like components that Collins (2004:113, Figure 3-9a) cites as high and moderate integrity sites, as well as those mentioned by Hester (2004) as significant. The locations of sites mentioned are shown in Figure 16-104, and our review by site follows.

\section{The Sites}

\section{The Mustang Branch Terrace Site (41HY209-T)}

The Mustang Branch Site (41HY209) is located on the Mustang Branch tributary of Onion Creek, just below the Balcones Escarpment in east-central Hays County, Texas. The site was excavated in 1989 by the Texas Archeological Research Laboratory (TARL), The University of Texas at Austin. Block excavations to investigate the comparable age component consisted of $1231 \times 1-\mathrm{m}$ squares. The materials of an age comparable to 41DL436 were located under a Holocene terrace (T1) along Mustang Branch, 30-40 cm below the surface in a 5-cm lens. Eleven features were encountered: an oval, basin-shaped bone-filled pit; four hearths; a bone bed, three clusters of fire-cracked rocks, and a chert debitage concentration (Ricklis 1994:326316). "Various lines of evidence indicate a short-term, spring occupation sometime between the late fifteenth and early seventeenth centuries" (Ricklis 1994:9).

The faunal assemblage included bison, deer, antelope, small birds, reptiles, and mammals, and 14,423 unidentified fragments (Masson and Holderby 1994). Thus the subsistence breadth by taxa was extensive. Faunal material includes evidence of 19 adult and six late-term or newborn deer, eight antelope, and two bison. The deer were quartered, and selected portions of the bison were removed before being brought to the campsite. Evidence of cut marks suggesting defleshing was present on 6.9 percent of the bison bones. Practically 100 percent of the bone 
assemblage had been cracked or crushed, suggesting a very high dependency on grease extraction (Masson and Holderby 1994:421-422). A single freshwater mussel shell found in Block B, and none in Block B North, indicates they were not part of the subsistence base at this site (Treece et al. 1993b:86-97), and no mention of mussel shells being part of the subsistence base could be found.

Excavations produced 41 arrow points and arrow point fragments; 23 of the 41 were complete enough to be typed, 7 were complete (Ricklis 1994:243). Other lithic materials recovered include 1 biface, not alternately beveled (Ricklis 1994:245), 36 unifacial end scrapers, 12 bifacial knives and large tin bifaces (only two beveled), 11 flake drills, five choppers, seven cores exhibiting unidirectional blade-like removal, 13 hammerstones, 57 utilized and nonutilized blades, 6,106 pieces of debitage, and one piece of ground stone made of shale which

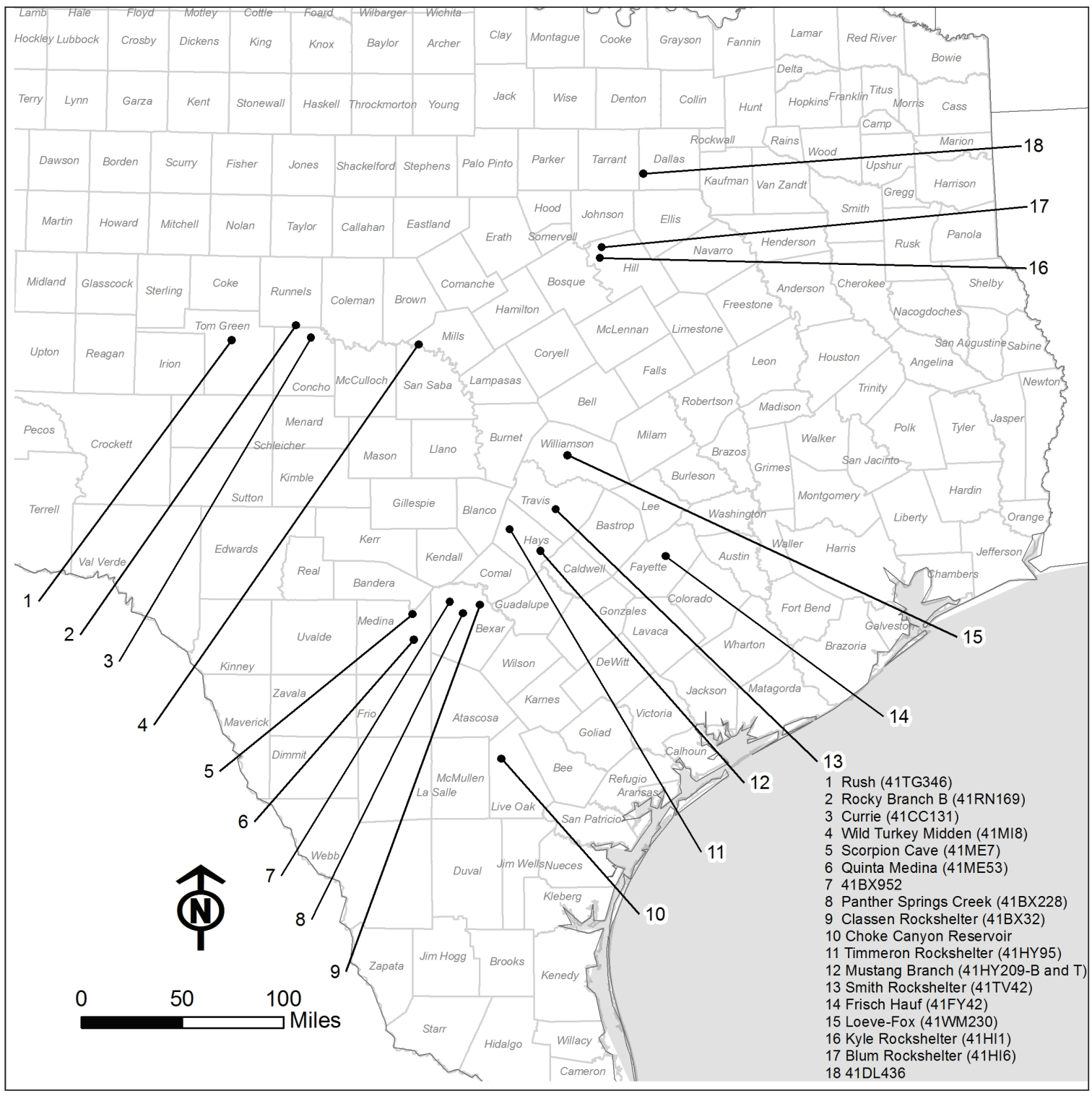

Figure 16-104. Comparable age components discussed in the text. 
Ricklis suggests may have been used as a burnishing tool. Two bone awls were also found, along with 480 pottery sherds representing five vessels and a smoking pipe. Despite the classic Late Prehistoric lithic assemblage present in the lens at 41HY209-T, problems are presented with the presence of six Archaic dart points, which Ricklis (1994:244) posits were curated. Notably, the site also has a burned rock midden dating to AD 550-700.

\section{The Mustang Branch Bluff Site (41HY209-B)}

Although Perdiz points, thin bifacial knife fragments, prismatic blades, a few bone-tempered potsherds, and bison bone were found in the upper $30 \mathrm{~cm}$, there are problems with the Bluff Site. Toyah materials were mixed with Scallorn points, primarily in the upper $20 \mathrm{~cm}$. "Due to the mixed nature of the deposits, inferences concerning the Toyah occupation are limited," and ...the weighted averages of the radiocarbon dates from the terrace and bluff areas suggest the "possibility of simultaneous occupation of the two loci within a dispersed settlement layout" (Ricklis 1994:9).

\section{The Rush Site (41TG346)}

Site 41 TG346 was discovered during clearing and trenching operations for a pipeline across the North Concho River in northeastern Tom Green County. This site is located within a Late Holocene terrace of the North Concho, and was mitigated in 1993 by Mariah and Associates with a block of $451 \times 1-\mathrm{m}$ square units. Thirteen features identified as hearths, ash piles, ash lenses, and burned rock concentrations were encountered during the excavations. These in situ features and the associated Toyah complex materials found in an approximately $30-\mathrm{cm}$ thick lens circa 110-140 cm below the surface were designated Occupation 4 (Quigg and Peck 1995).

The faunal assemblage included 12 bison, deer, rabbit, wood rat, turtle, fish, and a bird. Thus the faunal richness was somewhat diverse. The deer were quartered, and selected portions of the bison were removed before being brought to the campsite, and then the bones were defleshed. Most of the large mammal bone assemblage had been smashed or crushed, suggesting a very high dependency on grease extraction. The 12 freshwater mussel shells found indicates they were probably not part of the subsistence base at this site, but may have been used as scoops or ladles (Quigg and Peck 1995:106-124).

\section{The Rocky Branch B Site (41RN169)}

The Rocky Branch B Site (41RN169) is located in an alluvial terrace at the confluence of Rocky Branch Creek and the Colorado River in southeastern Runnels County, west-central Texas. Blocks B and B-North were excavated in 1988 and 1989 by Mariah and Associates (Treece et al. 1993b). The two blocks consisted of 1351 x 1-m square excavation units. An intact Toyah component (named Cultural Unit 1) was located approximately $4 \mathrm{~m}$ below the modern surface. Forty-two Toyah-associated features were documented within the block excavations and backhoe trenches, including 26 ash lenses, five basin-hearths, four organic stains, three bison rib peg alignments, one trench wall of a possible structure, a dense accumulation of burned 
rock, an end scraper cache, and a natural depression filled with Toyah complex materials. The Toyah living surface dated to circa AD 1450 (Treece et al. 1993b:38).

The faunal assemblage from Block B included four bison, one deer, one ground squirrel, one turtle, and 1,293 unidentified fragments divided into sized specimens. Treece et al. (1993b:86) suggest that the ground squirrel and turtle were not consumed and should not be included as part of the subsistence base at the site. Thus the diet breadth was very limited. The deer were quartered, and selected portions of the bison were removed before being brought to the campsite. Evidence of cut marks suggesting defleshing was present on 19.2 percent of the bison bones. Selected bones were then crushed more frequently than others. In this case, 74.99 percent of the axial bones were crushed, presumably for bone grease extraction. Block B-North included two bison, one rabbit, and 36 unidentified fragments divided into sized specimens. Treece et al. (1993b:86) suggest that the rabbit may have not been consumed and therefore perhaps should not be included as part of the subsistence base at the site. Unlike the bison found in Block B, the ones found in Block B-north appear to have been brought back to camp in whole and then butchered. A high percentage of smashed bone in Block B-North also suggests a high dependency on grease extraction. A single freshwater mussel shell found in Block B and none in Block B-North indicates they were not part of the subsistence base at this site (Treece et al. 1993b:86-97).

\section{The Currie Site (41CC131)}

The Currie Site is located in the second terrace of the Colorado River above its confluence with the Concho River in northeast Concho County (Treece et al. 1993b:119). Work at the site was accomplished in 1989 by Mariah and Associates, and consisted of opening two large block excavations, revealing a Late Prehistoric (Neo-Archaic, after Prewitt 1981) cultural level 25-35 cm thick, and lying approximately $84-130 \mathrm{~cm}$ below the surface. Sixty-two features, including hearths, oxidized earth areas, ash and charcoal lenses, unlined pits, post holes, hematite caches, lithic or bone concentrations, a daub concentration, wall trench, natural disturbance, and a limestone boulder were documented (Treece et al. 1993b:154-297).

Only 34 unmodified mussel shells were recovered suggesting that they were an insignificant portion of the subsistence base. The faunal analysis indicates a winter and spring occupation period. The five to seven bison remains found at the site suggest that whole carcasses (probably quartered) were brought to the campsite where they were skinned and butchered. Most of the long bones were smashed, suggesting a high dependency on bone grease (Treece et al. 1993b:210-222).

\section{Kyle Rockshelter (41HII)}

Fifteen years after Kelley first proposed the Comparable age Foci, the recovery of a distinct complex of cultural material exclusively associated with Perdiz points at the Kyle Rockshelter in northwestern Hill County tentatively defined the Toyah foci for Central Texas (Jelks 1962). The site was excavated by members of the Texas Archeological Salvage Project and the Dallas Archeological Society in the late '50s and early '60s. Exclusively Toyah age complex materials 
came from Stratum 5 in association with eleven hearths, an ash-filled pit, a small cedar limb structure, twisted cordage, and a smashed-in bison skull. Preservation within the confines of the rockshelter was excellent, and normally perishable tools such as digging sticks and arrow shafts were found. Such perishables are noticeably absent from the archaeological record of open campsites. Although a detailed faunal analysis apparently was not conducted, Jelks (1962) inferred that mussels and bison were consumed in the shelter.

\section{The Loeve-Fox Site (41WM230)}

The Loeve-Fox Site is located in an alluvial terrace of the San Gabriel River in eastern Williamson County, Texas. The site was excavated in 1972 and 1973 by Mr. Clarence Loeve, members of the Texas Archeological Survey, and students and volunteers from the University of Texas at Austin. Although the site is included in Collins' recognized gizemént sites (2004:113, Figure 3-9), potential problems with the data from the site are: 1) the latest radiocarbon date (Sample No. Tx-1765) is fifty years earlier than Johnson and Goode's (1994:39-40) and Collins' (1995:385) suggested an approximate beginning date of A.D. 1150 for the later interval of the Late Prehistoric, and 2) the later occuaption is "Identified on the bases of eight Perdiz and one Cliffton arrow point recovered by Mr. Loeve in his uncontrolled excavations, and one small potsherd recovered from the cemetery fill" (Prewitt 1974:8, 14, 23).

\section{Smith Rockshelter (41TV42)}

The Smith Rockshelter is located on Onion Creek in west-central Travis County. The site was excavated in 1954 and 1955 by volunteer students from the University of Texas at Austin, who dug 45 squares. A discrete Toyah component was found in the uppermost, Cultural Zone III, Layer XI, overlying Austin and Edwards Plateau components. Although charcoal and snail samples were collected, no record of radiocarbon dates for the site was available. Although specific counts of animal bones and MNI are not available, Suhm (1957) relates that deer were by far the most plentiful species in the faunal assemblage, with bison also of importance in the diet, particularly in the Toyah component. Other remains inferred to have been found in Layer XI include those of antelope, turtle, fish, skunk, raccoon, coyote, wolf, cotton rat, pack or wood rat, and rabbit. Because of their abundance and association with hearths, Suhm (1957:51) suggests that Buimulus dealbatus mooreanus land snails may have been used as food. Mussel shells, particularly Lampsilis were abundant in the Toyah component.

\section{The Hinojosa Site (41JW8)}

The Hinojosa Site (41JW8) is located in an alluvial deposit along Chiltipin Creek in northwest Jim Wells County. The site was tested by the Center for Archaeological Research, The University of Texas at San Antonio (CAR-UTSA) in 1975 with twelve 2 x 2-m square excavation units and a vertical cut on the creek bank (Hester 1977). CAR returned to the site in 1981 and '82, and excavated an additional 82 units (Black 1986). We choose to exclude the Hinojosa site from our regional analysis because of problematic radiocarbon dates (Black 1986:146-155; Hester 1977:27). 


\section{$41 M E 19$}

Site 41ME19 is located on the bank of an unnamed tributary of Fort Ewell Creek in southeastern Medina County. The site was tested in 1976 by the Center for Archaeological Research, The University of Texas at San Antonio with four 1 x 1-m squares and 11 shovel tests. Although no radiocarbon dates were obtained, Toyah complex materials were recovered to $25 \mathrm{~cm}$ below the surface (Hester and Kelly 1976).

An analysis of the limited faunal assemblage indicates the presence of cow or bison, and deer. The generally few quantities of mussel shell lead Hester and Kelly (1976:8) to posit that they were probably not a human dietary staple at the site. No floatation samples for macrobotanical remains were conducted.

\section{The Finis Frost Site (41SS20)}

The Finis Frost Site (41SS20) is an open occupation site located in an alluvial terrace adjacent to Richland Springs Creek in western San Saba County. It has not been excavated, but an extensive, obviously Toyah complex of artifacts from the site were documented by Green and Hester (1973). Casual observations were also made on the fauna at the site. Because all of the artifacts reported are from surface context, most in the possession of collectors, radiocarbon dates from the complex do not exist, and data is not available on faunal or macrobotanical remains, we have chosen to not include the site as part of a regional analysis.

\section{$41 T G 91$}

Site 41TG91 is located in a levee deposit of the South Concho River nearly in the center of Tom Green County. The site was excavated in 1978 by the Texas State Department of Highways and Transportation covering a horizontal block excavation of 180 square meters (Luke 1978; Creel 1990). Although undoubtedly a late Late Prehistoric complex consisting of at least five slablined hearths, two mussel shell concentrations, and one chert debitage concentration exists at the site, the provenience from which radiocarbon dates and cultural samples were obtained are in many cases unclear (Creel 1990). Because of these problems (detailed by Creel 1990), we have chosen to exclude the 41TG91 data from a regional analysis.

Other cryptic notes on the site are: Zone A-3 is the least biased. All artifacts are either late Late Prehistoric or Historic. Features 5H, 8, 9, 10, 12, 5M, 26, 32, and 33 are Late Prehistoric Features in Zone A-3. The Toyah component is least biased in Units 1, and 13 thru 17. The Toyah zone is ca. 40-50 cm thick and varies generally from between 15 and $70 \mathrm{cmbd}$. Most Toyah artifacts are above $55 \mathrm{~cm}$. They include 10 Perdiz, 2 Cliffton, 1 Harrell, 3 preforms, 2 arrow points, numerous scrapers, etc. Many mussel shells were lost. Human remains of perhaps 2 individuals were found, but in disarray; some were probably lost. Probably most significant were the 447 sherds representing at least 18 vessels. 
The Clark Site (41ML39)

The Clark Site (41ML39) is located in an alluvial terrace remnant of the Brazos River in northcentral McLennan County. Excavation conducted on a single day in 1955 by members of the Central Texas Archaeological Society consisted of two large trenches, and "a few small test pits" (Watt 1965:103). The only feature encountered was a single basin-shaped hearth, which yielded a radiocarbon date of AD $1277 \pm 150$. Faunal remains were those of deer, rodents, and turtle.

Watt (1965) inferred that deer were the primary source of subsistence, with mussels and snails playing only a very minor role. Most notable were the recovery of 63 ceramic sherds, three of which were incised and/or punctated. The stone tool assemblage recovered very much resembles that of the Toyah complex. Problematic with the assemblage documented by Watt is that it is not complete; all excavated sediments were not screened, and "other specimens are known to have been collected, but none of these could be traced down and hence, they are not included in this report" (Watt 1965:104). Because of these problems and generally incomplete data provided in the report, we have chosen to exclude the Clark Site from our regional analysis.

\section{Buzzard Shelter (41-26D7-12)}

Buzzard Rockshelter is located in limestone bluffs along the Brazos River in east-central Bosque County. The shelter was excavated in 1947, 1950 and 1957-58 by members of the Smithsonian Institution and the Dallas and Fort Worth Archaeological Societies (Long 1961; Stephenson 1970). Stephenson (1970:184-185) posits that Stratums II and III represent Toyah occupations at the site. Although no radiocarbon dates were obtained, the integrity of the stratums appear to be good. A lithic concentration was the only feature recorded in either stratum. While mussels and snails may have been included sparingly in the diet, Stephenson makes no mention of any faunal remains recovered.

\section{$41 L K 201$}

Site 41LK201 is located in a natural levee of the Frio River in northwestern Live Oak County. Phase II Block excavations Areas A, B, and C were conducted by archaeologists from the Center for Archaeological Research-University of Texas at San Antonio (CAR-UTSA), and students with a UTSA field school in 1980 and 1981 respectively. The most concentrated, intact Late Prehistoric component was documented in the upper $30 \mathrm{~cm}$ (Levels 1-6) of Area C; features included articulated bison remains and a mussel shell concentration. Cultural material recovered included ceramics, Perdiz points, bifaces, mussel shells, numerous faunal remains, and other chipped stone. Although an analysis of faunal material related strictly to Area $\mathrm{C}$ is not available, the faunal data from Levels 1 through 6 across the site is considered valid for comparison to Area $\mathrm{C}$ artifact counts. A single radiocarbon date from the Late Prehistoric component places the dates of potential occupation between AD 1510-1590 (Highley 1986). 


\section{Comparable High Integrity Components}

In our assessment of the published literature on comparable age assemblages we considered three criteria crucial to validating the credibility of the component's integrity. In order of importance they are: 1) an isolable stratigraphic context of the whole assemblage, 2) absolute dating of the assemblage, and 3) potential mixing of cultural material due to non-systematic collection. As with all attempts to compare archaeological assemblages, not every site is excavated with the same methods, and goals, thus the reported data is either absent or insufficient. In sum, based purely on reported data, we have chosen to compare the data available from nine components that we believe contain high integrity comparable age components, and have rejected seven others (Table 16-23). Radiocarbon dates for the sites to be compared are at Appendix E.

Table 16-23. Comparable Age Components Considered for Comparison.

\begin{tabular}{|c|c|c|}
\hline Site; Component & Selected / Rejected & Reason for Rejection \\
\hline $\begin{array}{l}\text { 41HY209-T: Mustang Branch Terrace Site, } \\
\text { Levels } 3 \text { and } 4^{*}\end{array}$ & Selected & NA \\
\hline $\begin{array}{l}\text { 41RN169: Rocky Branch B Bluff Site, } \\
\text { Blocks B and B North }\end{array}$ & Selected & NA \\
\hline $\begin{array}{l}\text { 41CC131: Currie Site, Cultural Unit 2-Block A, } \\
\text { and Cultural Unit 3-Block B }\end{array}$ & Selected & NA \\
\hline 41HI1: Kyle Rockshelter, Strata 5 & Selected & NA \\
\hline 41LK201, Areas A, B, and C-Levels 1-6 & Selected & NA \\
\hline 41TG346: Rush Site, Occupation 4 & Selected & NA \\
\hline 41TV42: Smith Rockshelter, Layer XI & Selected & NA \\
\hline 41ME19 & Selected & NA \\
\hline 41-26D7-12: Buzzard Shelter, Stratums II and III & Rejected & No faunal or macrobotanical data \\
\hline 41WM230: Loeve Fox & Rejected & Unprovenienced Toyah interval points \\
\hline 41HY209-B: Mustang Branch Bluff Site & Rejected & $\begin{array}{l}\text { Mixed deposits; Problematic weighted averages } \\
\text { of radiocarbon dates }\end{array}$ \\
\hline 41JW8: Hinojosa Site & Rejected & Problematic radiocarbon dates \\
\hline 41SS20: Finis Frost & Rejected & $\begin{array}{l}\text { No radiocarbon dates; Surface collected data; } \\
\text { Limited other usable data }\end{array}$ \\
\hline 41TG91 & Rejected & $\begin{array}{l}\text { Radiocarbon dates and associated cultural } \\
\text { material is unclear }\end{array}$ \\
\hline 41ML39: Clark Site & Rejected & Non-systematic collection \\
\hline
\end{tabular}

\section{Analysis}

\section{Effective Temperature and Primary Productivity}

Micro-scale optimal foraging theory and macro-scale global comparisons using effective temperature (ET) and primary productivity (PP) can complement one another. Effective temperature is a measure of the precipitation and solar energy available at certain latitudes. Primary productivity is the amount of plant food that is edible by herbivores, as well as humans. Binford (1980) has demonstrated that ET is related to hunter-gatherer mobility patterns and 
storage. Using the ethnographic data from hunter-gatherer groups around the world, he argues that hunter-gatherers living in areas of high ET and high primary biomass (i.e. jungle, tropical, equatorial), as well as those living in areas of low ET and low primary biomass (i.e. Arctic) are more mobile than those groups living in temperate or semi-arid zones (ca. 15 to $19 \mathrm{ET}$ ).

The exceptions occur where groups are highly dependent on aquatic resources; the best example of this would be on the northwest coast of North America where groups are highly dependent upon salmon. They are sedentary, yet live in an area of high primary biomass forests. They are dependent upon fish, and the animals in the forest are small or if large, few in number. Thus their nutrient needs are met, and it is not cost effective to pursue resources in any quantity other than fish. Binford also argues that ET is related to storage; groups store more in temperate climates or areas with low ET when winters are long. As ET increases, groups become more mobile, and storage occurs less frequently, if at all.

Binford equates residential mobility with a continuum of hunting and gathering; on one extreme end of the continuum are what he terms foragers, on the other extreme are collectors. Characteristically, foragers will move their entire residence frequently, encountering resources randomly in a fine-grained environment; that is, they will encounter them in the abundance of the mean as they occur in the environment (see Figure 16-100). This concept infers then, that residential moves are dependent upon the randomness of resources. They will process and consume what is available before moving on. They normally do not store food. Presumably, foragers would be prevalent in an area of seasonal abundance, probably in temperate ETs. On the other extreme, collectors will map onto a resource patch and send out foragers on long distance forays to collect food, conduct limited processing, and then return the bulk of it to camp (see Figure 16-101). They would probably cull the parts of animals or plants that are of little or no nutritional value before transporting the rest back to camp.

As has been discussed in previous chapters and is synthesized in Chapter 17, the climate appears to have changed little from the Late Prehistoric interval to today. Thus, we reviewed the average recorded rainfall and temperature data during modern times from the six counties in which the sites we have chosen for comparison.

Kelly (1995:66) provides the formula for computing ET: $18 W-10 C \div(W-C)+8$, where $C$ is the mean annual temperature in ${ }^{\circ} C$, and $W$ and $C$ are the warmest and coldest months of the year. The mean annual temperature data and ET values for the pertinent counties in Texas are shown in Table 16-24.

The amounts of precipitation and sunlight available in differing areas produce varying quantities of potentially edible plant resources available to herbivores, referred to as Primary Production (PP), stated in terms of grams of production within a square meter per year. Owen and Schmidly (1986) have provided current, simplified, and relevant data for Texas and computed primary productivity (PP) values for Texas. We extracted their values for the comparable age components we have chosen to compare (Table 16-25). 
Table 16-24. Effective Temperatures for the Counties with Comparable Age Components.

\begin{tabular}{llccc}
\hline \multicolumn{1}{c}{ County } & \multicolumn{1}{c}{ Reference } & $\begin{array}{c}\text { Warmest Month } \\
\text { Temp. }\left({ }^{\circ} \mathrm{C}\right)\end{array}$ & $\begin{array}{c}\text { Coldest Month } \\
\text { Temp. }\left({ }^{\circ} \mathrm{C}\right)\end{array}$ & $\begin{array}{c}\text { Effective } \\
\text { Temperature }\left({ }^{\circ} \mathrm{C}\right)\end{array}$ \\
\hline Concho & Clower and Dowell 1988:78 & 36.1 & 0.6 & 14.7977 \\
\hline Dallas & Coffee et al. 1990: & 35.4 & 1.9 & 14.8964 \\
\hline Hays & Batte 1984:96 & 35.9 & 3.2 & 15.0860 \\
\hline Hill & Brooks 1978:88 & 35.8 & 0.9 & 14.8019 \\
\hline Live Oak & Dittmar and Stevens 1980:88* & 36.1 & 4.7 & 15.3071 \\
\hline Medina & Dittmar 1977:88 & 36.9 & 3.7 & 15.2331 \\
\hline Runnels & Wiedenfeld et al. 1970:59 & 36.5 & 1.1 & 14.8825 \\
\hline Tom Green & Wiedenfeld and Flores 1976:56 & 36.9 & 1.3 & 14.9427 \\
\hline Travis & Werchen et al. 1974:118 & 35.3 & 4.7 & 15.2383 \\
\hline Wilson & Taylor 1977:94 & 36.3 & 4.2 & 15.2544 \\
\hline
\end{tabular}

*Data for Live Oak County is not available in compatible format; data from adjoining Atascosa County used.

Table 16-25. Mean Annual precipitation, Effective Temperature, and Primary Production Values in the Areas of Comparable Age Components.

\begin{tabular}{|c|c|c|c|c|c|}
\hline Site \# & Name & County & $\begin{array}{c}\text { Annual Precipitation } \\
\text { (inches) }\end{array}$ & $\mathrm{ET}\left({ }^{\circ} \mathrm{C}\right)$ & $\underline{\mathrm{PP}}(\mathrm{g} / \mathrm{M} 2 / \mathrm{yr})$ \\
\hline 41DL436 & Fish Creek Slough & Dallas & 35.06 & 14.8964 & 1,431 \\
\hline $41 \mathrm{WN} 88$ & Biesenbach & Wilson & 28.96 & 15.2544 & 1,255 \\
\hline 41HY209 & Mustang Branch & Hays & 33.46 & 15.0860 & 1,519 \\
\hline $41 \mathrm{CC} 131$ & Currie & Concho & 23.87 & 14.7977 & 836 \\
\hline 41RN169 & Rocky Branch B & Runnels & 22.27 & 14.8825 & 836 \\
\hline $41 \mathrm{HI}$ & Kyle Rockshelter & Hill & 34.13 & 14.8019 & 1,775 \\
\hline 41LK201 & - & Live Oak & 27.85 & 15.3071 & 861 \\
\hline 41ME19 & -- & Medina & 28.46 & 15.2331 & 1,359 \\
\hline 41TV_ & Smith Rockshelter & Travis & 32.58 & 15.2383 & 1,519 \\
\hline 41TG346 & Rush & Tom Green & 18.63 & 14.9427 & 810 \\
\hline
\end{tabular}

\section{Comparing Subsistence Assemblages}

Having determined ET and PP for the sites to be compared, we then extracted tool assemblage and subsistence data from the published reports. The inventoried assemblages include not only flaked stone tools, but also ground stone and ceramic vessels. The degree of lithic analysis detail varied with each published report. Therefore, Table 16-26 provides a presence/absence synthesis of the chipped stone tools identified at each site, along with ground stone and ceramics at each site. Notably, evidence of metal tools and firearms appears only at 41DL436.

The literature pertaining to optimal foraging theory most often focuses on such issues as return rates, calorie counts, cost-benefit analysis, etc. As should be discerned by now, the focus of this discussion is diversity in the archaeological assemblage. Therefore, the presence/absence of remains is appropriate for our analysis of the faunal assemblages. In addition, the sophistication of faunal analysis varies with each report, dependent upon the degree of bone preservation, the quantity of sediments excavated, and the goals of the faunal analysis. For example, in most 
cases MNI or NISP is not presented. Much of the current literature provides greater detail, and in that regard is more useful.

Therefore, based on the available information in published reports, and giving consideration to size and similarities in specific habitat in which they would be found, we were able to either consolidate and group, or list specifically, the taxa of the identifiable remains as shown in Table 16-27. Note that the group numbers are for reference only; they are not rankings. Common names are as defined by the various analysts. Armadillo is not included, as it is recently intrusive. Unknown or unidentified animal bones were not included as a group. Also included at the end of the table are mussels and snails.

Table 16-28 lists the number of animal subsistence groups identified (see Table 7-8) within the assemblages of the ten comparable cultural components. Mussel and snail groups are included if there were large quantities found at the site, suggesting they were being eaten.

\section{Comparing Plant Consumption}

The final component of subsistence we examined included plant consumption as identified by charred remains in floatation samples. We note here that pollen, phytolith, lipid, and starch analyses from 41DL436 yielded traces of additional edible plant remains. However, these detailed analyses were not conducted at the other sites; therefore, we can only use floatation results for comparison. We note here, that the results and analyses could be considered problematic due to the small sample sizes and varying degrees of taphonomic effects among sites. However, thy represent the best samples available. Only five site reports provided data on edible plants recovered from floatation samples; their results are shown in Table 16-29. 
Table 16-27. Consolidated Listing of Fauna, Mussel Shell, and Snail Groups from Comparable Cultural Components.

\begin{tabular}{|c|c|}
\hline Common Names & Group \\
\hline American bison; bison/Bos/cf. bison; cattle, bison, horse-sized; deer to bison-sized (70-greater than 300 lbs.) & 1 \\
\hline Black bear & 2 \\
\hline $\begin{array}{l}\text { Deer, sheep, goats; mule deer; white-tailed deer; pronghorn; antelope; dog to deer-sized (30-300 lbs.); deer- } \\
\text { sized ( } 70-300 \text { lbs.) }\end{array}$ & 3 \\
\hline Medium mammal (canis sp.); wolf; carnivore; dog-like; dog-sized (30-70 lbs.) & 4 \\
\hline Collared peccary & 5 \\
\hline Turtle; water turtle; pond slider; box turtle; mud turtle; Texas tortoise; spiny shell turtle & 6 \\
\hline Snake; western diamondback rattlesnake; rat snake; garter snake & 7 \\
\hline Frog/toad & 8 \\
\hline Alligator & 9 \\
\hline Spiny lizards & 10 \\
\hline Small mammal (rabbit or hare, jackrabbit, blacktailed jackrabbit, cottontail rabbit, rabbit-sized) & 11 \\
\hline Small mammal (skunk, prairie dog, gopher) & 12 \\
\hline Small mammal (squirrel, packrat, woodrat, cotton rat, ground squirrel, tree squirrel, rat-sized) & 13 \\
\hline Small mammal (pine vole, pygmy mouse, pocket mouse, harvest mouse, white-footed mouse) & 14 \\
\hline Small mammal (opossum) & 15 \\
\hline Small mammal (muskrat) & 16 \\
\hline Medium mammal (bobcat) & 17 \\
\hline Medium mammal (beaver) & 18 \\
\hline Medium mammal (badger) & 19 \\
\hline Medium mammal (raccoon) & 20 \\
\hline Large birds (chicken-sized); hawks or eagles; turkeys; turkey or hawk-sized & 21 \\
\hline Medium birds (robin-sized); bobwhite quail & 22 \\
\hline Ducks & 23 \\
\hline Small birds (sparrow-sized) & 24 \\
\hline Fish; catfish; garfish & 25 \\
\hline Mussels & 26 \\
\hline Snails & 27 \\
\hline
\end{tabular}

Table 16-28. Animal Groups Found at Comparable Cultural Components.

\begin{tabular}{ccc}
\hline \multicolumn{1}{c}{ Site } & Animal Groups Identified & $\begin{array}{c}\text { Total Number } \\
\text { of Groups }\end{array}$ \\
\hline Fish Creek Slough & $1,3,4,6,7,8,10,11,12,13,14,15,20,21,22,23,24,25,26$ & 19 \\
\hline Biesenbach & $1,3,4,5,6,7,11,13,15,20,21,22,23,24,25,26,27$ & 17 \\
\hline Rocky Branch & $1,3,4,7,8,11$ & 6 \\
\hline Currie & $1,3,4,6,11,12,13,17,18,21,25$ & 11 \\
\hline Kyle & $1,3,6,7,8,11,12,13,26$ & 9 \\
\hline Mustang Branch & $1,3,4,6,7,8,11,13,14,15,21,22,24,25$ & 14 \\
\hline Rush & $1,3,4,6,12,13,20,25,26,27$ & 8 \\
\hline Smith & 1,3 & 10 \\
\hline 41ME19 & $3,4,5,6,8,9,10,11,13,14,15,16,17,19,20,21,25,26,27$ & 2 \\
\hline 41LK201 & 19 & 19 \\
\hline
\end{tabular}


Table 16-29. Presence/absence of Charred, Edible Plant Remains from Comparable Cultural Components.

\begin{tabular}{|c|c|c|c|c|c|c|}
\hline Common Name & Scientific Name & $\begin{array}{l}\text { Fish Creek } \\
\text { Slough }\end{array}$ & Biesenbach & Kyle & Rush & $\begin{array}{l}\text { Rocky } \\
\text { Branch }\end{array}$ \\
\hline Acorns & Quercus sp. & & & $x$ & & $x$ \\
\hline Cane & $\begin{array}{l}\text { Phragmites sp., or } \\
\text { Arundinaria sp. }\end{array}$ & & & $x$ & & $\mathrm{x}$ \\
\hline Dropseed & Sporobolus sp. & & $x$ & & & \\
\hline Goosefoot or Pigweed & $\begin{array}{l}\text { Chenopodium/ } \\
\text { Amaranthus }\end{array}$ & & $x$ & & & \\
\hline Hickory, Pecan, or Walnuts & $\begin{array}{c}\text { Carya sp., Carya } \\
\text { Illinoensis, Juglans nigra }\end{array}$ & & $\mathrm{x}$ & $x$ & $\mathrm{X}$ & \\
\hline Mesquite Seeds & Prosopis glandulosa & & & & $x$ & \\
\hline Prickly Pear Leaf & Opuntia sp. & & & $x$ & & \\
\hline Purslane & Portulaca oleracea & & $x$ & & & \\
\hline Sunflower Seeds & Helianthus sp. & & & $x$ & & \\
\hline Wild Onion Sheaths & Allium sp. & & & $x$ & & \\
\hline Wild Grape seeds & Vitis sp. & $x$ & & & & \\
\hline \multirow[t]{2}{*}{ Wild Plum Seeds } & Prunus sp. & $x$ & $\mathrm{x}$ & $x$ & & \\
\hline & Total & 2 & 5 & 7 & 2 & 2 \\
\hline
\end{tabular}

Probably of no real surprise is the greater variety of charred seeds found at the Kyle Rockshelter, an environment where the degree of macrobotanical preservation should be greater than in the Fish Creek Slough, Biesenbach, Rush, and Rocky Branch open campsites.

\section{Comparing Site Occupation Spans}

In order to evaluate the relationships between presumed site occupation span, variety of stone tools, plants and animals, and climate, we compared the data from Tables 16-18 through 16-23. To begin, we ran a Spearman's correlation coefficient for five of the six pertinent variables; plants were not included as only five of the ten components examined provided macrobotanical data.

We first examined the relationship between animals and primary productivity (biomass). As the biomass increases in temperate climates without large forests, one would expect to see a corresponding increase in animal variety. As shown in Figure 16-105, there are no significant outliers, but some interesting observations can be made. One is that the area around Fish Creek Slough yields a moderate primary productivity but produces a wider variety of animals when compared for instance to Kyle, Smith, Mustang Branch, and 41ME19 with higher primary productivity, but fewer animal resources. Thus it would appear that the occupants at Fish Creek Slough were drawn to the area because of its relative abundance of game animals compared to other sites.

Second, although in temperate climates without high biomass forests one would expect to see an increase in animal variety commensurate with primary productivity, it appears that is not necessarily the case for instance at 41ME19, Kyle, and Smith. It could be that the occupants of 


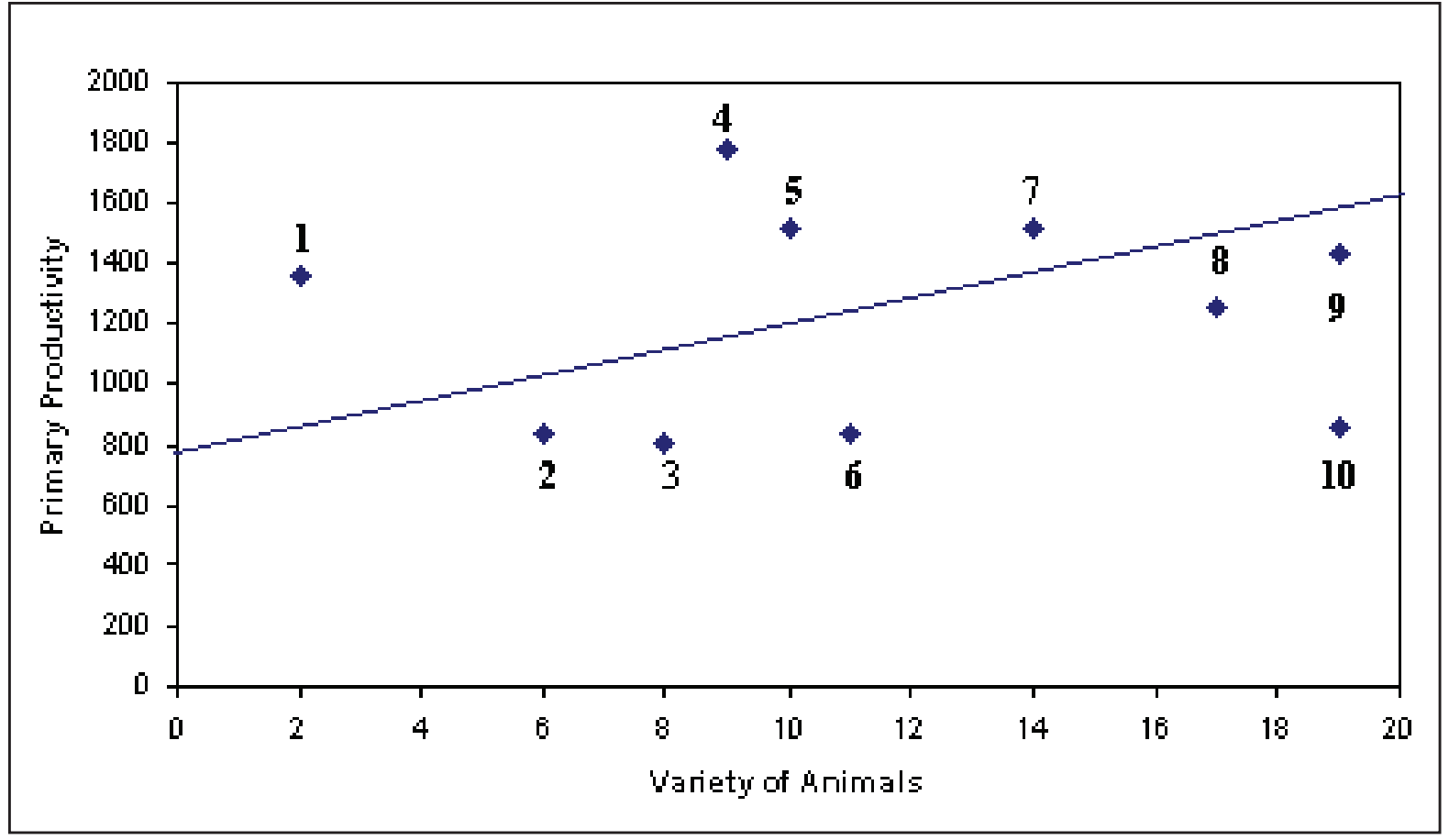

Figure 16-105. Scattergram of animals and primary productivity (1) 41ME19 (2) Rocky Branch (3) Rush (5) Kyle (6) Smith (7) Currie (8) Biesenbach (9) Fish Creek Slough (10) 41LK201).

these sites relied more on collecting and gathering plants, nuts, and seeds for subsistence and less on animals; we examine that issue below.

Third, if there is an outlier in these data, it is 41LK201. Although the occupants were exploiting a wide variety of animals, the primary productivity and inferred biomass in that region is relatively low. Upon further review of the faunal assemblages, we observed that a significant common denominator among all the sites except 41LK201 was bison. Folks at 41LK201 pursued a wider variety of medium-sized mammals, while folks at Fish Creek Slough enjoyed high-yield bison.

The Spearman's calculations revealed an obviously significant correlation occurring between rainfall and primary productivity, presumably because of the weight given rainfall in the formula for computing primary productivity. However, statistically there were no other significant correlations or for that matter, outliers. However, when we plotted the data on various scattergrams, we observed two obvious outliers when animals and tools were compared; these being Fish Creek Slough and 41LK201 (Figure 16-106).

Our previous discussion of optimal foraging theory says that the foraging strategy becomes predominant when the variety of stone tools decreases as the variety of animals processed increases, and foragers who move more frequently should have a broader diet, with fewer tools. Following that argument, we further posit that when campsite assemblages are compared, the predominantly foraging strategy will be manifested by the relative wider variety of plants and animal remains found, and by comparing campsite assemblages we should be able to imply which sites were occupied for relatively longer periods of time (see also, Hayden 1986). 


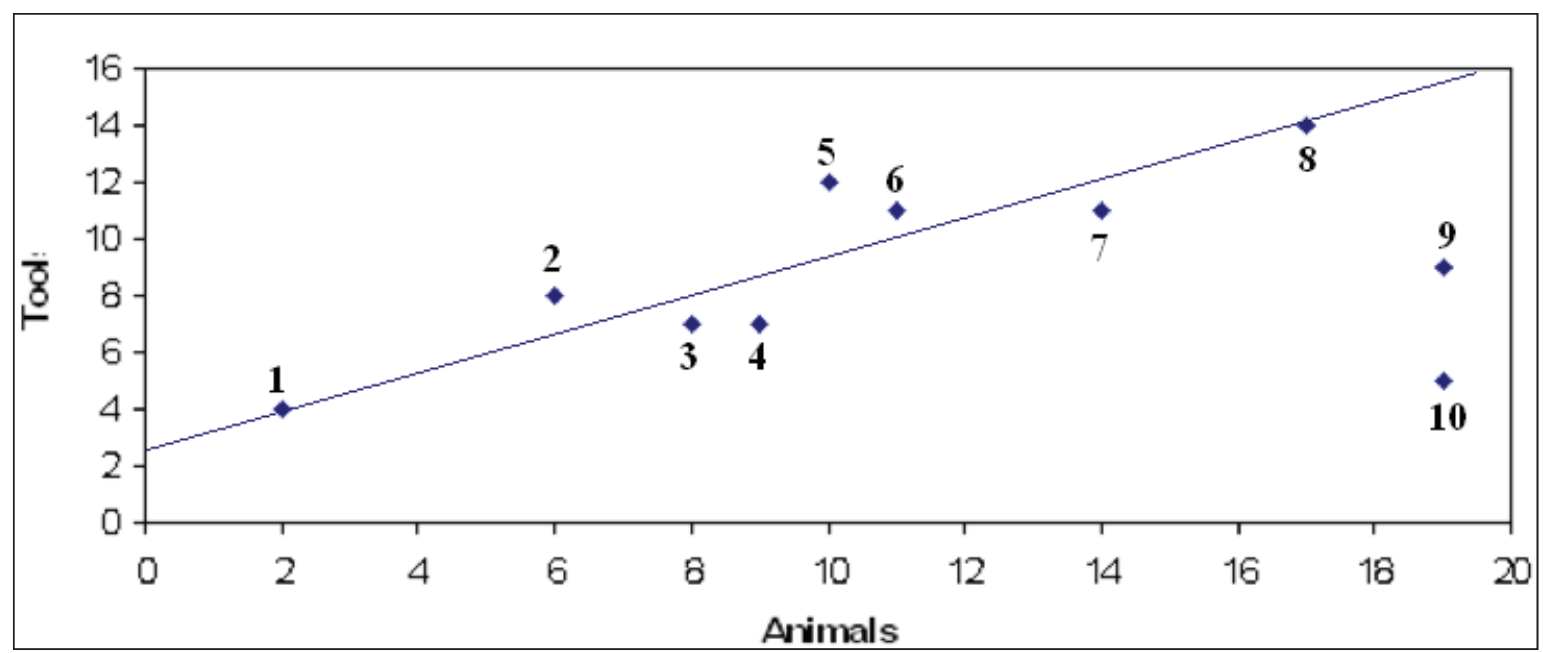

Figure 16-106. Scattergram of animals and tools (1) 41ME19 (2) Rocky Branch (3) Rush (4) Kyle

(5) Smith (6) Currie (7) Mustang Branch (8) Biesenbach (9) 41LK201 (10) Fish Creek Slough.

Using these two arguments, as shown in Figure 16-106, the correlation between tools and animals in Groups 1 through 8 generally fit the norm of what one would expect to see in a forager/collector continuum. That is, they likely practiced both foraging and collecting. An examination of Figure 16-106 also indicates that the Fish Creek Slough site (\#10) has a relatively smaller variety of tools with a relatively wider variety of animals than eight of the ten sites compared, suggesting the occupants of Fish Creek Slough were predominantly foragers with a broad diet, reacting to scarce and unpredictable resources in the lowest temperate climate $(E T=14.9)$. Normally, low variety of tools coupled with a high dependence upon a very broad variety of animals would imply that they were highly mobile, occupying the site for relatively shorter periods of time than those groups at the nine other sites compared.

However, notably two tool categories identified only at 41DL436 are metal knives and firearms. We submit that the presence of these two represent an unknown multiplier effect in terms of tool variety over chipped stone. That said, it suggests A wider variety of animals were perhaps more easily exploitable at 41DL436 than at all other sites.

Very similar, but with subtle differences, the group who occupied 41LK201 (\#9) processed a similar variety of animals, but with a slightly higher variety of tools, in the highest temperate climate $(\mathrm{ET}=15.3)$. The implication is that the occupants of 41LK201 were also highly mobile foragers. In sum, it would appear that both the Fish Creek Slough and 41LK201 groups practiced a predominantly foraging strategy in the forager/collector continuum, but in terms of mobility, they occupied their campsites for shorter periods of time than did the other eight groups.

On the other end of the scale, the group at 41ME19 (\#1) processed the least variety of animals with the least variety of tools, in a high temperate climate $(E T=15.2)$. The combination of a small variety of tools, and animals although processed in a relatively high temperate climate, suggests they were likely a small group both foraging and collecting, but were more nomadic, occupying the site for a relatively short period of time. 


\section{Introduction of Plants}

In an effort to see how the introduction of plants, seeds, and nuts into the subsistence base may have influenced mobility and lengths of site occupations, we next examined the macrobotanical data from the five sites that processed floatation samples. As shown in Figure 16-107, in four of five cases the number of identifiable charred plant remains increases commensurate with increases in primary productivity; the exception is Fish Creek Slough.

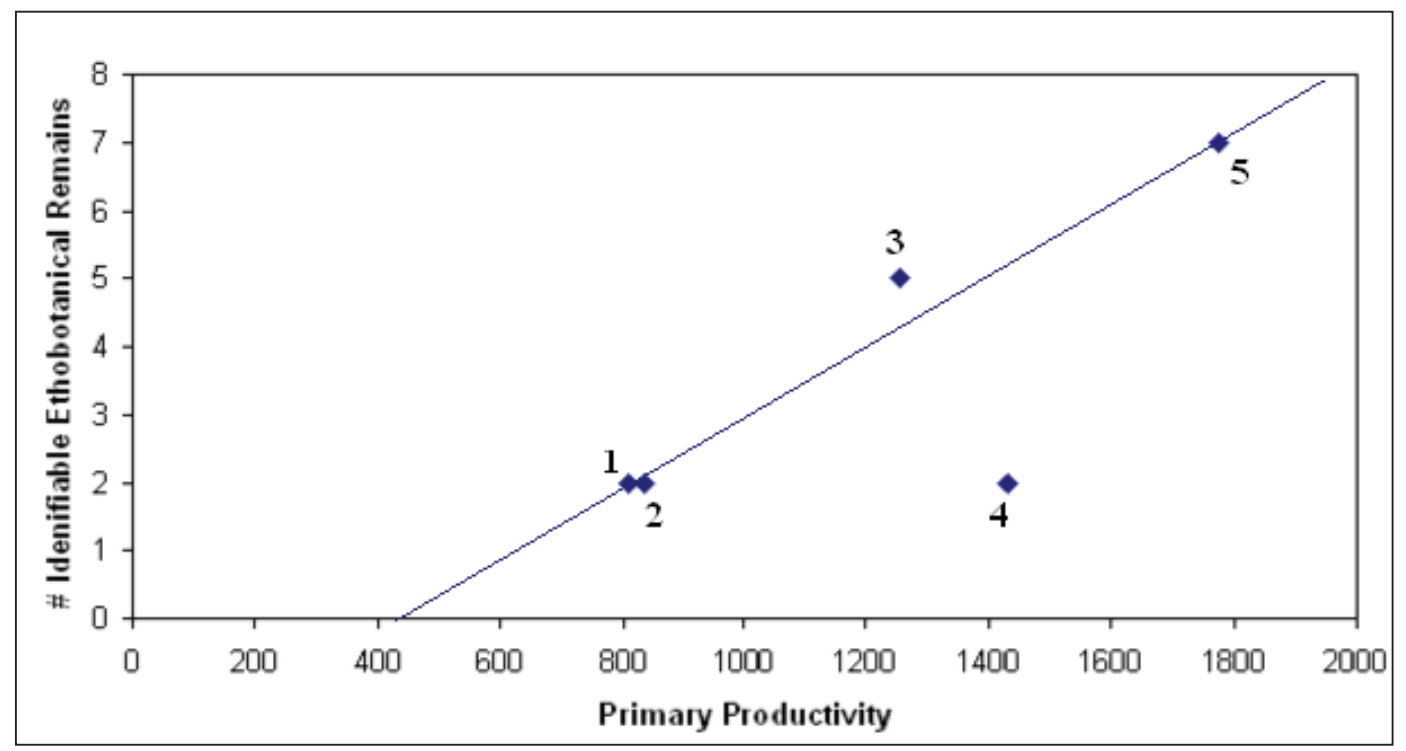

Figure 16-107. Scattergram of primary productivity and ethobotanical remains (1) Rush (2) Rocky Branch (3) Biesenbach (4) Fish Creek Slough (5) Kyle.

Thus, the data imply that occupants of four of the sites collected plants, seeds, and nuts across the immediate landscape in correlation to their availability. However, such was not the case at Fish Creek Slough. Instead, they relied heavily on foraging for animals, while gathering/ collecting plant resources was secondary for survival.

Next, we looked at the variety of tools compared to plant remains. Figure 16-108 illustrates the close correlation between tool types and charred and identifiable plant remains at four of the five sites, including Fish Creek Slough. Kyle Shelter stands alone as having a greater variety of plant remains relative to tools; this is not surprising given the normally high degree of preservation in rockshelters compared to open campsites.

Although the data we have discussed from the Fish Creek Slough assemblage suggests that the occupants were predominantly foragers, the correlation between plants and tools would seem to imply that they were possibly equally foragers and gatherers/collectors. Fish Creek Slough has 3.5:1 ratio of tools:plants compared to Biesenbach (2.8:1), Rush (ratio 3.5:1), and Rocky Branch (ratio 4:1).

Although the data and logic previously presented implies collectors tend to remain at campsites for relatively longer periods of time than foragers, that is not necessarily always the case. A 


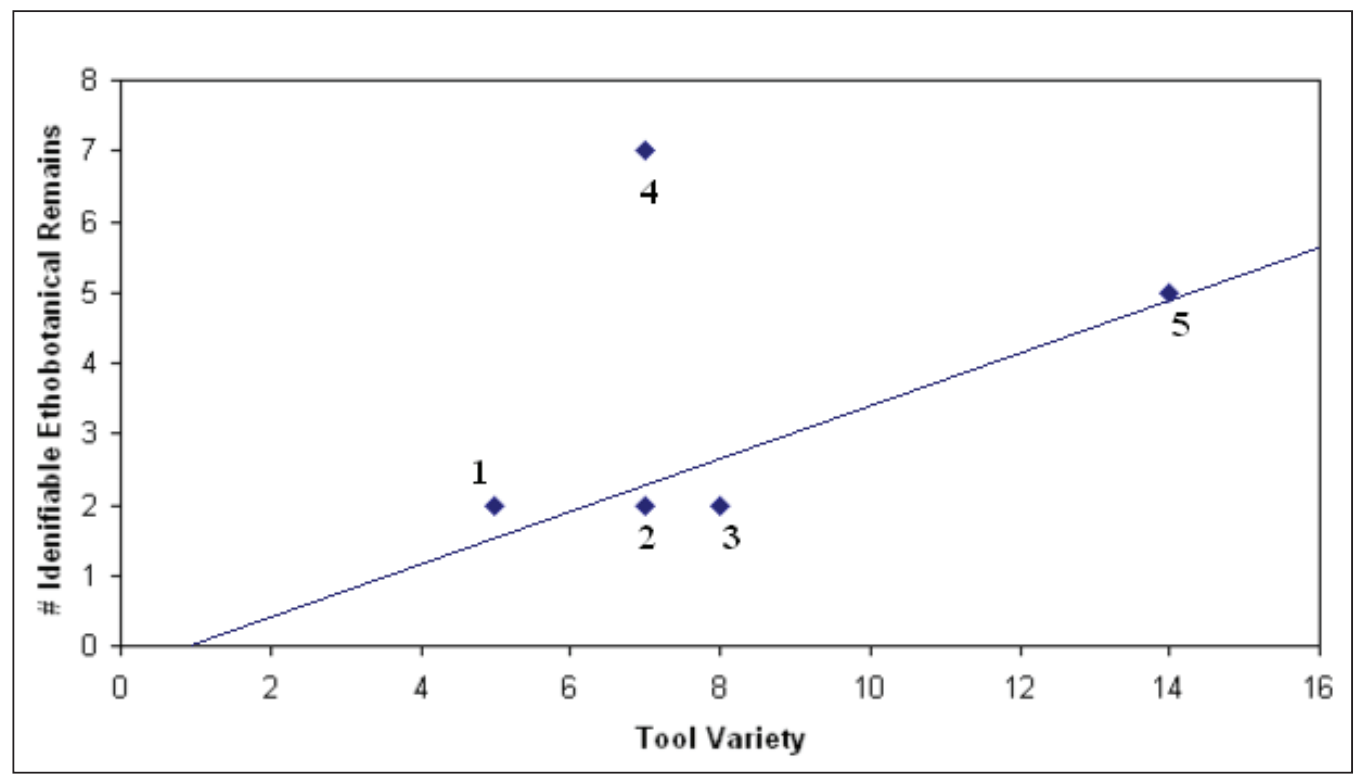

Figure 16-108. Scattergram of tools and charred ethnobotanical remains (1) Fish Creek Slough (2) Rush (3) Rocky Branch (4) Kyle (5) Biesenbach.

dependence on plants is not necessarily contradictory to the idea that gathering and processing plants requires a long stayover. Thus, the remains at Fish Creek Slough imply a short-term, seasonal occupation as is characteristic of mobile foragers.

\section{Introduction of Pottery}

Interestingly, the only two sites where no pottery sherds were found are Rocky Branch and Fish Creek Slough. We found no direct correlation in artifact assemblage data between these two sites, although 26 ash lenses were reported within the comparable age component at Rocky Branch. The absence of pottery at Fish Creek Slough is an anomally among comparable age components state-wide, and within the surrounding archaeological regions.

However, ceramic vessels are fragile and generally will not transport. Even at short-term campsites one would expect to find at least a few sherds if pottery was a part of the toolkit. Yet, not a single sherd was found during any of the three investigations at Fish creek Slough. The absence of pottery argues strongly in favor that the site was occupied by highly mobile groups who neither manufactured ceramic vessels at the site, nor traded for them to be used while at the site. Another consideration is that by the time Stratum 3 was occupied, Indian and Europeans would probably had metal pots or metal spits. Native ceramics are quickly replaced by European metal in the $1700 \mathrm{~s}$.

As for the question of how foodstuffs may have been cooked without the use of ceramic vessels, we have stated above that meat was likely hung from spits above the surface hearths, and various foodstuffs may have been prepared in the large numbers of burned turtle shells recovered in direct association with the surface hearths. 


\section{Absence of Raw Material}

It makes sense that without an abundance of raw material, site occupants will tend to curate and exhaust all the tools they have brought with them, leaving few if any behind. Conversely, occupants of sites where good raw material is abundant will tend to fashion stone tools on site, expediently use sharp-edge flakes, and otherwise create substantial amounts of broken tools and debitage on the site.

Much of the preceding discussion on applying cultural materials to the theoretical optimal foraging theory and diet-breadth model, we note that although the availability or nonavailability of raw material influences the founder curate set, normal outputs, and donor curate set of stone tools present and absent in an assemblage, we posit that raw material is a resource that is often only cursorily considered. In fact, from our discussion of raw material availability and lithic analysis at the beginning of this chapter it is clear that good quality raw material in the vicinity of Fish Creek Slough was simply not available, and the chipped stone found on the site apparently derived from Edwards chert sources.

In sum, we must caveat any interpretations of site occupation spans based solely upon tool variety as debatable. The importance of raw material is a variable that is probably not practically quantifiable, and its availability effected by sedimentation and exposure through time. Nevertheless, we recommend that future archaeological projects integrate a raw material study into the research design, and that any discussion or analysis of lithics include a consideration of raw material availability. Finally, the all-important introduction of metal knives and firearms to the toolkit at 41DL436 most certainly diminishes the need for certain stone tool types and should be a major factor when assessing the lithic assemblage at any similar sites.

\section{Summary and Conclusions of Later Prehistoric and Protohistoric OCCupants}

Employing the logical arguments, general discussions throughout this chapter and others, and the preponderance of evidence from all datasets presented above, we thus attempt to place the ten groups in terms of where they most probably fall within the forager/collector continuum of subsistence, along with their implied relative ranking of lengths of occupation (Table 16-30).

It appears that the group who occupied the Biesenbach Site stayed there longer than those at the other nine sites, while the 41ME19 encampment appears to have been relatively very short term. The robust faunal assemblage at Fish Creek Slough, the paucity of stone tools and plant remains, and the absence of ceramics most strongly argue in favor of the site as being an area of multiple short-term and seasonal encampments. The occupants were obviously attracted to the immediate area because of the fresh water in Fish Creek and the wide variety of animals that could be preyed upon. Although plants were an apparent mix in the subsistence base, their role was minor and seasonal.

We have iterated more than once in this chapter and others, the apparent increasing reliance on metal knives and firearms. When these two are added to the toolkit, the multiplier effect in 
terms of subsistence is unknown. However, without raw materials for fashioning both unifacial and bifacial stone tools, they were forced to bring tools and preforms to the site, use every bit of chipped stone available, and then carry off any remaining upon abandoning the site. The occupants were without ceramic vessels for cooking or storing, and may have used turtle shells to prepare food. Early occupants of the lower cultural component apparently had access to exposed sandstone with which to construct hearths, but later occupants constructed surface hearths without stone.

The most intense period of occupations occurred roughly between $525-245 \mathrm{BP}$, as manifested by multiple probable surface hearths and a very robust and well-preserved faunal assemblage. It can be presumed that the majority of the burned ash, clay, and charcoal masses and lenses uncovered during the excavations represent cultural surface hearths. However, there are also clearly irregular patches of oxidized earth that have been created by natural burning of downed timber.

As discussed in Chapter 11 and summarized in Chapter 17, Linda Scott Cummings and others have identified pollen and phytoliths in the lower cultural component (Stratum 1a) that suggest the possibility of intentional burning of the landscape or of wildfires. In the middle component (Stratum 2) Zea-mays types pollen and phytolith were found, along with those which strongly suggests that a cool season grass was intentionally grown for subsistence, and burning may have been associated with possible agricultural activities. In sum, although no conclusive evidence was found that any surface burns were intentionally set as part of early forms of horticulture or agriculture, based upon the pollen and phytolith data, the possibility that some degree of horticulture/agriculture took place cannot be ruled out.

Table 16-30. Relative Lengths of Occupations by Groups at Ten Toyah Components.

\begin{tabular}{ccccccc}
\hline Site & $\begin{array}{c}\text { Animal } \\
\text { Variety }\end{array}$ & $\begin{array}{c}\text { Tool } \\
\text { Variety }\end{array}$ & $\begin{array}{c}\text { Ceramics } \\
\text { Present }\end{array}$ & $\begin{array}{c}\text { Plant } \\
\text { Remains }\end{array}$ & $\begin{array}{c}\text { Predominant Form } \\
\text { of Subsistence }\end{array}$ & $\begin{array}{c}\text { Relative Lengths of Occupation } \\
\text { Ranking (Longest to Shortest) }\end{array}$ \\
\hline Biesenbach & 17 & 14 & $\mathrm{X}$ & 2 & Foragers & 10 \\
\hline 41LK201 & 19 & 9 & $\mathrm{X}$ & & Foragers & 9 \\
\hline Smith & 10 & 12 & $\mathrm{X}$ & & Foragers & 7 \\
\hline Mustang Br. & 14 & 11 & $\mathrm{X}$ & & Foragers & 6 \\
\hline Currie & 11 & 11 & $\mathrm{X}$ & & Foragers & 5 \\
\hline Rocky Branch & 6 & 8 & & 2 & Foragers & 4 \\
\hline Rush & 8 & 7 & $\mathrm{X}$ & 2 & Collectors & 3 \\
\hline Kyle & 9 & 7 & $\mathrm{X}$ & 7 & Collectors & 2 \\
\hline $\begin{array}{c}\text { Fish Creek } \\
\text { Slough }\end{array}$ & 19 & 5 & & 2 & Foragers & 1 \\
\hline 41ME19 & 2 & 4 & $\mathrm{X}$ & & Foragers & \\
\hline
\end{tabular}




\section{Historical Sites Comparisons}

\section{Lower Walnut Settlement Sites}

The faunal assemblage, calendar ages, and feature patterning at 41DL436 are very similar to those documented at the Lower Walnut Settlement, Wichita sites along the Walnut and Arkansas River drainage in Kansas with median probability calendar dates ranging from AD 1347-AD 1751. That is, bison and turtles (especially box turtles) comprised by far the largest proportion of the identifiable fauna. Although deer were a lesser part of the assemblage, they were nevertheless consistently present. As at 41DL436, the Wichitas encamped along the Walnut and Arkansas rivers also exploited a wide variety of medium and small mammals such as canids, rabbits, beavers, raccoons, ground squirrels, cotton rats, gophers, moles, mice, and voles. In addition, a very wide variety of birds were consumed, along with fish. Notably, storage pits with faunal remains were discovered at the Wichita sites in Kansas. And, despite the apparent abundance of game, the Wichitas apparently continued to emphasize some degree of horticulture. As with 41DL436, the Wichita sites were occupied for a long period of time, probably seasonally, such that clear patterning in the dispersal of features could not be determined. Unlike 41DL436, ceramics were found at the Lower Walnut Settlement (Haury 2008; Hawley and Stein 2008).

\section{The Stone Site (41ML38)}

The Waco split from the Tawakonis, a Wichita language subgroup. A Waco/Wichita Village site that was occupied during a same period as was 41DL436 is the Stone Site (41ML38) on the Brazos River, northwest of the present-day city of Waco. This site has been documented in historical records as being occupied in the 1770s, but abandoned by 1786 . Both sites were occupied in the 1770s, and though somewhat different, the artifact assemblages do reflect similarities. One obvious difference is the large size of the Stone Site, probably covering about 18.5 acres, with possibly 30 families, perhaps 75 structures, and between 150 and 250 warriors (Bolton 1914; Cook and Dunbar 2008; Turner-Pearson 2008). Aside from that, it is interesting to note that by the 1770 s, the Wacos were "...quickly switching to European tools but had not yet given up use of some of their own handmade objects" (Turner-Pearon 2008:567). They had for some period of time been using firearms, bullets, musket balls, steel hatchets, and knives (Smith, F. T. 2000). Other artifacts obtained through European trade were glass beads, jewelry, metal for arrow points and handmade nails. The Wacos/Wichitas also continued to fashion stone tools such as scrapers and arrow points, and bone fishhooks were found along with metal fish hooks. One stark contrast is that ceramics were very much a part of the Waco/Wichita assemblage, while as discussed in Chapter 16, no ceramics were found at 41DL436. Finally, it is estimated that about 500 acres was under cultivation at the Stone Site (Cook and Dunbar 2008; Turner-Pearson 2008).

\section{The Spanish Fort Sites}

Recent analysis by previously unreported artifacts collected from the Spanish Fort areas in Montague County, Texas and the Longest Site (41JF1) in Oklahoma revealed east Texas Caddoan and European-made type ceramics, as well as a wide variety of chipped stone tools, 
iron arrow points, a metal knife blade fragment, and a breech plug from an eighteenth century flintlock gun. Perttula (2012) surmises that these may represent either a prehistoric Henrietta complex (e.g., Boyd 1995), and/or the eighteenth-century Wichita occupation of Spanish Fort. However, once again, as discussed in Chapter 2, unlike the probable occupations at 41DL436, the Spanish Fort sites were generally occupied by long-term, relatively sedentary Native Americans.

\section{The Vinson Site}

The Vinson Site (41LT1) is a typical Norteño, Wichita-speaking Indian Village in Limestone County, Texas was documented over a twenty-year period with multiple archaeological investigations. Cultural remains argue for a late eighteenth-century occupation, with houses, storage pits, and both English and French trade goods. Based upon the evidence, it appears that only commonalities with 41DL436 is that evidence of firearms and metal tools were found, and that the Vinson site was occupied seasonally, during the late Fall to Spring (Blaine 1993: Smith et al. 1993: Yates 1993). 


\section{SECTION V}

SYNTHESIS 


\section{Chapter 17 \\ Paleoenvironmental Climate and Biota}

\section{David L. Nickels}

This section summarizes and synthesizes the detailed paleoenvironmental information contained in Chapters 5-11, 14, and 15. Multiple lines of evidence derived from numerous professionals are brought together to tease out how they see the environment changing (or not changing) over the past millennia in North-central Texas. We begin with a discussion of the depositional and erosional episodes that have occurred across the site. Following that, we draw on Ken Brown's snail study, Bob Howell's mussel species identification, David Brown's isotope analysis of mussel shells, Phil Dering's identification of ethnobotanical remains, Barbara Winsborough's study of diatoms, Mervin Kontrovitz' identification of ostracodes, and finally, Jodi Jacobson's analysis of a very robust faunal assemblage. Following these discussions, we present a figure that briefly illustrates these climatic episodes and trends in terms of cultural components and soil stratums as shown in Table 17-1.

Table 17-1. Cultural Components and Soil Stratums.

\begin{tabular}{cccc}
\hline Cultural Component & Stratum & Years BP $(2$ Sigma $)$ & AD Calendar Years \\
\hline Lower & 1a & $725-545$ & AD 1225-1405 \\
Lower & 1b & $420-270$ & AD 1530-1680 \\
Middle & 2 & $525-345$ & AD 1425-1605 \\
Upper & 3 & $215-85$ & AD 1735-1865 \\
\hline
\end{tabular}

\section{Depositional Episodes and Landscape Stability}

Jim Abbott and Charles Frederick laid the groundwork in Chapter 5 by using multiple lines of evidence to reconstruct the depositional episodes and landscape stability resulting from periodic inundation of the site by Fish Creek over the past roughly 1,100 years. As discussed extensively in Chapter 16, periods of landscape stability pretty much coincided with peaks in evidence of human occupation. The results of their findings are incorporated into our "Summary and Synthesis," below.

\section{Snail Species}

In his study of 12,769 snail shells, countable shell fragments, peaclams and freshwater limpets, Ken Brown (Chapter 6) found that preservation in the ten malacology samples examined was excellent. Although the creek obviously flooded the site periodically following heavy rainfall upstream, the aquatic biota suggest Late Holocene Fish Creek was predominantly a groundwater-supported stream, not an intermittent runoff-dominated stream. 
At 41DL436, Depositional Unit 1 accumulated during the waning phase of the Medieval Climatic Anomaly (MCA), a period of elevated temperatures peaking roughly 1000-1100 AD. In the Plains and Southwest, the MCA was marked by multidecadal droughts that were similar in geographic extent to modern examples, but much more prolonged (20-40 years) than anything in the historic record. More precisely, Ken defines the years that droughts occurred in the Dallas area based upon the Palmer Drought Severity Index. Following a cooling trend, it appears that the Little Ice Age comes about, with the lowest temperatures occurring perhaps around 1600-1750 AD.

The aquatic biota suggest that Fish Creek was a sluggish, probably poorly oxygenated, muddy, groundwater-supported stream, heavily choked with aquatic vegetation, but probably not subject to seasonal drying even during the MCA. The snail data suggest that there is a slight tendency for an increase in tree canopy over time, but the major increase in woodland extent occurred very late, probably within the last two centuries, and might have been due to fire suppression by Euroamerican settlers. In general, the interpretations from the snail data corroborate the interpretations from the mussel shell, phytolith, and pollen studies. The results of Ken's findings are incorporated below into our "Summary and Synthesis."

\section{Mussel Shell Species}

In the 1,426 valves and fragments that Bob Howells examined, he found shell remains of eight, and possibly as many as 11 unionid taxa. In general, the specimens present suggest that the immediate area was periodically inundated with slow flowing water, and at times became a ponded or backwater area with a soft mud or sandy bottom. One species present suggests a high-water event creating a stream-side oxbow. The results of Bob's findings are incorporated below into our "Summary and Synthesis."

\section{Mussel Shell Isotopes}

David Brown analyzed isotope data from 20 selected mussel shells and discovered discrete differences in Lower Component samples from Stratum 1a versus 1b. Specifically, it appears that the mussels within Stratum 1b were developed acquiring an isotopic signature indicating the temperatures were as much as ten degrees cooler when compared to those in Stratum 1b. He surmises that this could possibly be a Little Ice Age indicator. The results of David's findings are incorporated below into our "Summary and Synthesis."

\section{Ethnobotanical Remains}

Phil Dering identified carbonized plant remains in nine out of ten floatation samples submitted for analysis. The only charred item that can be construed as a prehistoric consumable was a grape seed. Otherwise, Dering submits that the wood charcoal taxa found were unusual, and therefore provide useful evidence of environmental change. That is, the site appears to have been covered predominately with smaller trees that are most commonly found in an edge area along or adjacent to creek terraces. The presence of honey locust suggests disturbed ground, 
Mexican plum and/or Hawthorne wood suggests an understory in a moist environment, and a grape seed suggests vines on smaller trees near a clearing. Overall, Dering's findings infer a mixture of closed and open canopy along Fish Creek. The results of Phil's findings in a pilot study are brevetted in Table 17-2, and further incorporated below into our "Summary and Synthesis."

Table 17-2. Synthesized Results of Charred Plant Remains in Pilot Study Floatation Samples.

\begin{tabular}{lll}
\hline \multicolumn{1}{c}{ Feature } & Depositional Unit & \multicolumn{1}{c}{ Charred Remains } \\
\hline Feature 5-Fire-cracked rock hearth & 1a & $\begin{array}{l}\text { Woody legume-type (probably honey locust); } \\
\text { rose wood (Mexican plum/Hawthornes) }\end{array}$ \\
\hline Feature 7-Fire-cracked rock hearth & 1a & Cottonwood/willow \\
\hline Feature 41-Fire-cracked rock hearth & $1 \mathrm{a}$ & Cottonwood/willow; Elm; Indeterminate wood \\
\hline Feature 42-Fire-cracked rock hearth & $1 \mathrm{a}$ & Indeterminate wood \\
\hline Feature 2-Fire-cracked rock hearth & 2 & None \\
\hline $\begin{array}{l}\text { Feature 24-Fire-cracked rock, } \\
\text { bone, turtle shell, biface }\end{array}$ & 2 & Woody legume-type (probably honey locust) \\
\hline Feature 31-Charcoal, burned clay, ash & 2 & Elm \\
\hline Feature 35-Charcoal, burned clay, ash & 2 & Elm \\
\hline Feature 3-Burned charcoal mass & 3 & $\begin{array}{l}\text { Woody legume-type (probably honey locust); } \\
\text { hackberry nutlet (probably modern); Grape seed }\end{array}$ \\
\hline Feature 8-Burned charcoal mass & 3 & Indeterminate wood \\
\hline
\end{tabular}

\section{Ostracode Remains}

Although the number of ostracode shells recovered was relatively low compared to samples of like size from other sites, Mervin Kontrovitz was able to identify a sufficient number so as to interpret possible cyclical changes in the paleoenvironment. The ostracode species recovered from the samples, as well as the absence of ostracode remains, suggest varying and cyclical periods of possible flooding periods or events. As well, they suggest possible periods where the site was not flooded, but was dry enough to create a stable surface appropriate for human occupation. The results of Mervin's findings are brevetted in Table 17-3, and further incorporated below into our "Summary and Synthesis."

\section{Diatoms}

Paleoenvironmental interpretations based on the diatom species recovered, as well as the absence of diatom remains in certain levels, suggest varying and cyclical flooding events and drying periods. In the ten samples submitted from Unit 49, Barbara Winsborough found a total of 90 diatoms representing ten species, and two fragments that could be identified to the genus level. Most notably however, is that 88 of the 90 diatoms were found in the lower three levels sampled, all within Stratum 1a. With the exception of 150-160 cmbs in Unit 49 (Strata 1a) that indicates wetter conditions, most of the species are found typically in aerial habitats that are frequently to occasionally wetted, such as a mud flat, temporary pond, depression or overbank environment that was sometimes flooded from a stream. The results of Barbara's findings are brevetted in Table 17-4, and further incorporated below into our "Summary and Synthesis." 
Table 17-3. Synthesized Results of Ostracode Analysis of Pilot Study Samples from Unit 49.

\begin{tabular}{ccccl}
\hline Level & Depth (cmbs) & $\begin{array}{c}\text { Depositional } \\
\text { Unit }\end{array}$ & $\begin{array}{c}\text { Ostracode } \\
\text { Valves }(\mathrm{n})\end{array}$ & \multicolumn{1}{c}{ Interpretation } \\
\hline 20 & $190-200$ & 1 & 5 & Shallow water \\
\hline 18 & $170-180$ & 1 & 6 & Shallow water \\
\hline 16 & $150-160$ & 1 & 11 & $\begin{array}{l}\text { Still, perhaps slightly flowing, slightly saline waters; } \\
\text { temperatures between } 11-32^{\circ} \mathrm{C}\left(51.8-89.6^{\circ} \mathrm{F}\right), \text { with one } \\
\text { month of continuous temperatures above } 20^{\circ} \mathrm{C}\left(68^{\circ} \mathrm{F}\right) .\end{array}$ \\
\hline 14 & $130-140$ & 2 & 2 & Shallow water \\
\hline 12 & $110-120$ & 2 & 0 & Unexplained absence; possible non-flood period \\
\hline 10 & $90-100$ & 2 & 2 & $\begin{array}{l}\text { Fragmented specimens make } \\
\text { interpretation speculative at best }\end{array}$ \\
\hline 8 & $70-80$ & 2 & 0 & $\begin{array}{l}\text { Unexplained absence; possible non-flood period } \\
\text { (10) }\end{array}$ \\
\hline 5 & $50-60$ & 3 & 2 & $\begin{array}{l}\text { Fragmented specimens make } \\
\text { interpretation speculative at best }\end{array}$ \\
\hline 2 & $30-40$ & 3 & 0 & $\begin{array}{l}\text { Unexplained absence; possible non-flood period } \\
\text { Unexplained absence; but possible shallow, aquatic event }\end{array}$ \\
\hline
\end{tabular}

Table 17-4. Synthesized Results of Diatom Analysis of Samples from Unit 49.

\begin{tabular}{ccccl}
\hline Level & $\begin{array}{c}\text { Depth } \\
(\mathrm{cmbs})\end{array}$ & $\begin{array}{c}\text { Depositional } \\
\text { Unit }\end{array}$ & Diatoms $(\mathrm{n})$ & \multicolumn{1}{c}{ Interpretation } \\
\hline 20 & $190-200$ & $1 \mathrm{a}$ & 6 & $\begin{array}{l}\text { Covered with muds and sands deposited under } \\
\text { slightly saline, fresh brackish waters, perhaps } \\
\text { swampy; area was a newly wetted habitat }\end{array}$ \\
\hline 18 & $170-180$ & $1 \mathrm{a}$ & 12 & $\begin{array}{l}\text { Covered with fresh, only slightly brackish, and slightly } \\
\text { saline water over a swampy mud and sand substrate; } \\
\text { likely a newly wetted habitat, shallowly covered, } \\
\text { and one that likely dried out relatively quickly }\end{array}$ \\
\hline 16 & $150-160$ & $1 \mathrm{a}$ & 70 & $\begin{array}{l}\text { Covered with fresh, only slightly brackish, and slightly saline } \\
\text { water over a swampy mud and sand substrate; high probability } \\
\text { that the site was covered with water after a prolonged drought }\end{array}$ \\
\hline 14 & $130-140$ & 2 & 0 & - \\
\hline 12 & $110-120$ & 2 & 0 & - \\
\hline 8 & $90-100$ & 2 & 0 & - \\
\hline 6 & $70-80$ & 2 & 0 & - \\
\hline 4 & $50-60$ & 3 & 2 & Aquatic and aerial vegetation submerged in likely polluted water. \\
\hline 2 & $10-40$ & 3 & 0 & - \\
\hline
\end{tabular}

\section{Pollen and Phytoliths}

Linda Scott-Cummings, Chad Yost, and R. A. Varney found remarkable pollen and phytolith preservation in the 20 samples submitted from Unit 49. Based upon the large quantities and wide variety of species found, they observed marked changes in the environment through time, and were able to separate these changes into four separate zones. As shown in Table 17-5, the paleoenvironmental interpretations based on the pollen and phytolith taxa observed in the samples suggest varying and cyclical periods of flooding periods or events. As well, they offer the possibility that the growth of Zea-maize and some grasses may have been encouraged for human consumption. 
Table 17-5. Synthesized Results of Pollen and Phytolith Analysis of Samples from Unit 49.

\begin{tabular}{|c|c|c|c|c|}
\hline Level & $\begin{array}{l}\text { Depth } \\
\text { (Cmbs) }\end{array}$ & $\begin{array}{l}\text { Depositional } \\
\text { Unit }\end{array}$ & $\begin{array}{l}\text { Vegetational } \\
\text { Zone }\end{array}$ & Interpretation \\
\hline 20 & 190-200 & $1 \mathrm{a}$ & 1 & $\begin{array}{l}\text { Open habitat with pine, oak, elm trees; sedges and } \mathrm{C}_{3} \text { grasses } \\
\text { on edge of creek; declining water table, but with intervals of } \\
\text { high water and flooding; moist soils for extended periods; humid } \\
\text { climate; subtle decline in dense vegetation; sandy, disturbed soils } \\
\text { with elevated levels of moisture typical of floodplain deposits }\end{array}$ \\
\hline 19 & $180-190$ & $1 \mathrm{a}$ & 1 & $\begin{array}{l}\text { Sandy, disturbed soils with elevated levels of } \\
\text { moisture typical of floodplain deposits }\end{array}$ \\
\hline 18 & $170-180$ & $1 \mathrm{a}$ & 1 & $\begin{array}{l}\text { Open habitat with pine, oak, elm trees; sedges and } \mathrm{C}_{3} \\
\text { grasses on edge of creek; declining water table, but with } \\
\text { moist soils for extended periods; relatively larger flood } \\
\text { event; relatively more stable landscape period; humid } \\
\text { climate; subtle decline in dense vegetation; possibility of } \\
\text { intentional burning of the landscape or of wildfires }\end{array}$ \\
\hline 17 & $160-170$ & $1 \mathrm{a}$ & 1 & $\begin{array}{l}\text { Relatively stable or slowly aggrading, and probably } \\
\text { recent surface; sandy, disturbed soils with elevated levels } \\
\text { of moisture typical of floodplain deposits; possibility of } \\
\text { intentional burning of the landscape or of wildfires }\end{array}$ \\
\hline 16 & $150-160$ & $1 \mathrm{a}$ & 1 & $\begin{array}{l}\text { Open habitat with pine, oak, elm trees; sedges and } \mathrm{C}_{3} \\
\text { grasses on edge of creek; declining water table, but } \\
\text { with intervals of high water and flooding; moist soils for } \\
\text { extended periods; increased intentional burning or wildfires; } \\
\text { humid climate; subtle decline in dense vegetation }\end{array}$ \\
\hline 15 & $140-150$ & 2 & 2 & $\begin{array}{l}\text { Floodplain sediments; sunflower family, possible } \\
\text { marshelder and goosefoot; fluctuating response of } \\
\text { grasses to the floodplain conditions; occasional pine, oak, } \\
\text { and elm trees in the area; possible Zea-mays type }\end{array}$ \\
\hline 14 & $130-140$ & 2 & 2 & $\begin{array}{l}\text { Less open habitat with pine, oak, elm, hackberry, and juniper } \\
\text { trees; sedges and } \mathrm{C}_{3} \text { grasses on edge of creek; added } \\
\text { local sedges, filaree, and wild grapes; general decrease in } \\
\mathrm{C}_{4} \text { grasses, increase in } \mathrm{C}_{3} \text { grasses; climate changing from } \\
\text { drier and warmer to cooler and more moist; relatively faster } \\
\text { sediment aggregation; silty, moving water covered the site; } \\
\text { biological transitional to Zone 2; possible Zea-mays type }\end{array}$ \\
\hline 13 & $120-130$ & 2 & 2 & Same as Level 13, also with possible Zea-mays type \\
\hline 12 & $110-120$ & 2 & 2 & $\begin{array}{l}\text { Less open habitat with pine, oak, elm, hackberry, and juniper } \\
\text { trees; sedges and } C_{3} \text { grasses on edge of creek; added local } \\
\text { sedges, filaree, and wild grapes; general decrease in } \mathrm{C}_{4} \text { grasses, } \\
\text { increase in } \mathrm{C}_{3} \text { grasses; climate changing from drier and warmer } \\
\text { to cooler and more moist; relatively faster sediment aggregation; } \\
\text { increased intentional burning or wildfires; possible Zea-mays type }\end{array}$ \\
\hline 11 & $100-110$ & 2 & 2 & $\begin{array}{l}\text { Elevated abundance of grass leaf phytoliths can be } \\
\text { indicative of grass utilization for subsistence; phytolith } \\
\text { characteristic of Zea-maize cob; burning may have } \\
\text { been associated possible agricultural activities }\end{array}$ \\
\hline 10 & $90-100$ & 2 & 2 & $\begin{array}{l}\text { Less open habitat with pine, oak, elm, hackberry, and juniper } \\
\text { trees; sedges and } \mathrm{C}_{3} \text { grasses on edge of creek; added local } \\
\text { sedges, filaree, and wild grapes; general decrease in } \mathrm{C}_{4} \\
\text { grasses, increase in } \mathrm{C}_{3} \text { grasses; climate changing from drier } \\
\text { and warmer to cooler and more moist; relatively faster sediment } \\
\text { aggregation; increased intentional burning or wildfires; possibly } \\
\text { intentionally grown grasses for human consumption; burning } \\
\text { may have been associated with possible agricultural activities }\end{array}$ \\
\hline 9 & $80-90$ & 2 & 3 & $\begin{array}{l}\text { Starch grain that could be derived from maize kernels } \\
\text { or, more likely, from grass seed; highest level of grass } \\
\text { seed; strongly suggests that a cool season grass was } \\
\text { intentionally grown for subsistence; burning may have } \\
\text { been associated with possible agricultural activities }\end{array}$ \\
\hline
\end{tabular}




\begin{tabular}{|c|c|c|c|c|}
\hline Level & $\begin{array}{c}\text { Depth } \\
\text { (Cmbs) }\end{array}$ & $\begin{array}{c}\text { Depositional } \\
\text { Unit }\end{array}$ & $\begin{array}{c}\text { Vegetational } \\
\text { Zone }\end{array}$ & Interpretation \\
\hline 8 & $70-80$ & 2 & 3 & $\begin{array}{l}\text { Gradual return to more open habitat with scattered pine, } \\
\text { oak, and elm trees; } \mathrm{C}_{4} \text { tall grasses, forbs; sedges and } \\
\mathrm{C}_{3} \text { grasses along creek; prairie clover, legume, mint; } \\
\text { decreased burning of the area; long-term trend of decreasing } \\
\text { moisture; land disturbed, or change in land use }\end{array}$ \\
\hline 7 & $60-70$ & 2 & 3 & $\begin{array}{l}\text { Gradual return to more open habitat with scattered pine, } \\
\text { oak, and elm trees; } \mathrm{C}_{4} \text { tall grasses, forbs; sedges and } \\
\mathrm{C}_{3} \text { grasses along creek; prairie clover, legume, mint; } \\
\text { decreased burning of the area; long-term trend of decreasing } \\
\text { moisture; land disturbed, or change in land use }\end{array}$ \\
\hline 6 & $50-60$ & 3 & 3 & $\begin{array}{l}\text { Gradual return to more open habitat with scattered pine, oak, and } \\
\text { elm trees; } \mathrm{C}_{4} \text { tall grasses, forbs; sedges and } \mathrm{C}_{3} \text { grasses along } \\
\text { creek; prairie clover, legume, mint; decreased burning of the area; } \\
\text { cool season grasses dramatically increase in abundance; long- } \\
\text { term trend of decreasing moisture; biological transition to Zone } 4\end{array}$ \\
\hline 5 & $40-50$ & 3 & 3 & $\begin{array}{l}\text { Cool season grasses dramatically increase in } \\
\text { abundance; periodically moist soils; }\end{array}$ \\
\hline 4 & $30-40$ & 3 & 4 & $\begin{array}{l}\text { Historic era; lesser open habitat; more and wider variety } \\
\text { of trees and shrubs, with less grass likely due to fire } \\
\text { suppression; wider diversity of taxa in microhabitats; } \\
\text { long-term trend of decreasing moisture }\end{array}$ \\
\hline 3 & $20-30$ & 3 & 4 & $\begin{array}{l}\text { Historic era; lesser open habitat; more and wider variety } \\
\text { of trees and shrubs, with less grass likely due to fire } \\
\text { suppression; wider diversity of taxa in microhabitats; } \\
\text { long-term trend of decreasing moisture }\end{array}$ \\
\hline 2 & $10-20$ & 3 & 4 & $\begin{array}{l}\text { Historic era; lesser open habitat; more and wider variety } \\
\text { of trees and shrubs, with less grass likely due to fire } \\
\text { suppression; wider diversity of taxa in microhabitats; } \\
\text { long-term trend of decreasing moisture }\end{array}$ \\
\hline 1 & $0-10$ & 3 & 4 & $\begin{array}{l}\text { Long-term trend of decreasing soil moisture; fire suppression } \\
\text { likely has created a grass community with a greater } \\
\text { component of trees and shrubs and possibly less grass } \\
\text { density; non-native grasses take over the landscape }\end{array}$ \\
\hline
\end{tabular}

Note: The specific detailed interpretation of the pollen is partly a creation of the samples and taphonomy, These are averaged by collected levels.

\section{Faunal Assemblage}

Jodi Jacobson's analysis of 8,701 identified specimens indicated they were incredibly diverse, and representative of multiple habitats. Some animals present were typically those found in forest or on forest edges, some preferred shrub brush/chaparral habitats, others open prairie and grasslands, or arid spaces relatively devoid of vegetation. Finally, a large and diverse number would have preferred an aquatic/wetlands habitat. Such a robust and diverse faunal assemblage is indeed unique and very informative (see Chapter 15). A brief summary of Jodi's assessment of the paleoenvironment and setting at 41DL436 based upon NISP is presented below. Otherwise, the gist of her findings are further incorporated below into our "Summary and Synthesis."

\section{Stratum 19}

- Predominantly aquatic/wetland with adjacent grassland floodplains

- Slow moving or shallow ponds with muddy bottoms 
- Some short to mid grassland prairie

- Scrub brush

- Forest edge/riparian

Stratum $1 b$

- Predominantly aquatic/wetland

- Increase in grassland species

- Brushy/chaparral and edge open areas

- Woodland/forest edge

\section{Stratum 2}

- Predominantly aquatic/wetland

- Significant increase in grassland species

- Scrub brush/chaparral

- Grassland/brush habitat

- Forest and open prairies

- Forest-edge habitat

\section{Stratum 3}

- Predominantly grasslands

- Significant decrease in aquatic/wetland species

- Aquatic - significant decrease in turtle; increase in fish

\section{Paleoenvironmental Summary and Synthesis}

The dates and strategraphic sequences presented below are derived

from Abbott's and Fredericks'(Chapter 5) interpretations of

landscape evolution and accepted radiocarbon dates.

\section{Lower Component-Stratum 1a (AD 893-1450)}

Examination of the sediments and soils that make up Stratum 1a reveals alluvium that was deposited on a vegetated point bar, but terminated with a transition to a Stratum $1 \mathrm{~b}$ sometime after about AD 1450. Stratum 1a may have actually continued to aggrade as a relatively stable floodplain until perhaps as late as AD 1550, when the termination of Stratum 1a deposition represents the beginning of a significant hydraulic shift in the Fish Creek system.

The pollen and phytoliths identified in Stratum 1a (and 1b inclusive) samples argue for a declining water table, with particular intervals of high water and flooding, with soils that were moist for extended periods of time, but also with periodic stable landscape stability. The humid climate supported a very open habitat, with pine, oak, and elm trees. The data also suggests possible intentional burning or wildfires. There was a subtle decline in denser vegetation that is more commonly found in riparian corridors, forest edges, and forest understory; in other words, the immediate area was slowly becoming more open. In sum, the pollen and phytolith information from Stratum 1a suggests a generally open habitat dominated by dense, medium $\mathrm{C}_{4}$ tall grasses and forbs, with scattered large pine, oak, and elm trees, but where sedges and $\mathrm{C}_{3}$ grasses were probably prevalent closer to Fish Creek. 
The faunal remains in Stratum 1a of the lower cultural component imply that the area was predominantly an aquatic/wetland consisting of slow moving water or shallow ponds with muddy bottoms, adjacent forest edge/riparian vegetation, and grass floodplains. Nearby was likely a short to mid grassland prairie, as were areas of scrub brush.

The snail species recovered from Stratum 1a infer years of cyclical wetting and drying. The Palmer Drought Severity Index indicates severe droughts during the years AD 1232-33, 1236, $1292,1346,1374,1544$, and especially in 1240-41 AD. There were also a few fairly wet years, AD 1265, 1540, and 1271 for example. These alternating extreme wet periods caused flooding that resulted from the depletion of ground cover, followed by eolian deposits burying paleosols that developed in the wetter periods. Channel incision in local streams likely occurred during the wet periods.

The mussel species in Stratum 1a thrived in slow to-no flow water, with a soft sandy substrate. These would have been inundated terrestrial areas, backwaters, and possibly an intermittent Fish Creek. The relatively low $\delta^{18} \mathrm{O}$ variability in mussel shell isotopes corroborates that the stream was likely stable for some time, and the data seem consistent with an annual temperature close to that of the modern Dallas area.

Overall, the ethnobotanical remains infer a mixed, closed and open canopy along Fish Creek. Woody legume types (probably honey locusts) which grow well in disturbed soils were detectable in the ethnobotanical record, along with cottonwood/willow trees which also do well in a moist environment. The presence of Mexican plum and/or Hawthorne wood suggests an understory, again in a moist environment.

The ostracode found in the lowest levels of Stratum 1a (190-200 cmbs) characterize the area as being covered with sediment deposited under brackish, shallow waters probably less than a few meters in depth. In the lowest sampled in Strata 1a (190-200 cmbs), Collectively, five different diatom species identified at this level suggest that the area was covered with muds and sands deposited under slightly saline, fresh brackish waters. One species suggests that the immediate area was likely covered with alkaline muds and was perhaps swampy. The presence of a second species implies that the area was a newly wetted habitat.

Ostracode remains from 170-180 cmbs indicate that the site was likely still (or again) covered with brackish, slightly saline, and shallow water. Temperatures and water salinity at the time these sediments were deposited cannot be accurately interpreted because the specimens recovered from this level can thrive in a wide variation of both temperature and salinity. Between 170-180 cmbs, shallow, slightly brackish water was present. An analysis of the diatom samples from 170-180 cmbs suggest that the site was covered with fresh, only slightly brackish, and slightly saline water over a swampy mud and sand substrate. The presence of two species suggest a newly wetted habitat, shallowly covered, and one that likely dried out relatively quickly. A phytolith sample from 170-180 cmbs suggests a probably flooding event occurred that allowed for some pioneer species to thrive briefly, then decline. 
One specimen of ostracode found from 150-160 cmbs suggests that the site was covered with either permanent or still, perhaps slightly flowing waters,. The temperature could have ranged from $11-32^{\circ} \mathrm{C}$, but with at least one month of continuous temperatures above $20^{\circ} \mathrm{C}$. The diatoms from 150-160 cmbs all together suggest that the site was covered with fresh, only slightly brackish, and slightly saline water over a swampy mud and sand substrate. However, the pronounced high abundance of one particular diatom in these sediments strongly suggests that the site was covered with water after a prolonged drought.

\section{Lower Component-Stratum 1b (AD 1440-1650)}

An examination of the sediments and soils that encapsulate Stratum $1 \mathrm{~b}$ in the lower cultural component reveals a wedge of very dark loam and sandy loam with interbedded sands, loamy sands, and rippled laminae that formed in the northern part of the excavation block. While Abbott and Frederick submit that the weight of evidence suggests that a channel avulsion occurred sometime between AD 1477 and AD 1634, accompanied by a surface scour event, K. Brown points out that it may have taken place in conjunction with the peak in the Little Ice Age that occurred around AD 1500.

The faunal remains are indicative of animals that do most well in a predominantly aquatic/ wetland environment along a woodland/forest edge, with brushy/chaparral and edge open areas. It also appears that there was an overall increase in grassland species during this period. The snail species data suggests that the aquatic taxa was heavily dominated by juvenile and embryonic individuals; the most likely explanation is probably that most overbank deposition occurred during spring or early summer floods, not long after the spring hatching season for most aquatic snail taxa. If there were any changes in hydrology of Fish Creek after the middle of Unit 2 was laid down, they are simply not recorded by the aquatic taxa. During the lower component occupation(s), the snail species suggest a mosaic of wooded and open microhabitats, with both tree groves along the Fish Creek channel, as well as open prairies on the slightly higher elevated slopes. The ethnobotanical record indicates the presence of cottonwood/willows and elm trees, with both open and closed canopy along the creek.

The mussel shell species found in Stratum 1b indicate a possibly intermittent Fish Creek, with slow to no-flow waters and a soft, sandy bottom. Also likely on the site was an inundated backwater terrestrial area. The changes seen in the mussel shell $\delta^{18} \mathrm{O}$ values from stratum $1 \mathrm{~b}$ suggest lowered temperatures or shifting hydrologic conditions. Shells from Units 103/104 (stratum 1b) were constructed during a slightly cooler period, with annual temperatures as much as ten degrees cooler than that of the modern Dallas area. They further suggest a drop in annual mean temperatures of almost $9^{\circ} \mathrm{F}$ or $5^{\circ} \mathrm{C}$ recorded in the shells from stratum 1a, a marked but not inconceivable value that might reflect the shift to cooler Little Ice Age climates.

\section{Middle Component-Stratum 2 (AD 1405-1660)}

Stratum 2 is made up of a sequence of silts and sands aggraded rapidly in a sediment-rich environment. Rapid erosion occurred in the Fish Creek catchment, accompanied by flood 
events that repeatedly overtopped the floodplain; some flood events were occasionally deep and intense. Fauna at the time favored a predominantly aquatic/wetland with forest and forest-edge habitat. Also in the area were open prairies with a significant increase in grassland species, grassland/brush habitat, and scrub brush/chaparral areas. The ethnobotanical remains recovered from Stratum 2 are of the woody legume-type (probably honey locusts) that grow well in disturbed soils; elms. The data further suggests that there were areas of both open and closed canopy along the creek.

According to Ken Brown's research, the Palmer Drought Severity index for the Dallas area clearly shows a shift in the climate system at about $1500 \mathrm{AD}$, a shift that is probably a local chronological marker for the transition from the Midieval Climatic Anomaly (MCA) to the Little Ice Age (LIA). Before $1500 \mathrm{AD}$, the amplitude of wet-dry cycles is markedly greater, and the frequency much lower. After $1500 \mathrm{AD}$, the cycle obviously tightens up - the cycle frequency increases, but the amplitude diminishes significantly, as the climate system becomes much more stable during the LIA. The transition occurs at about $1500 \mathrm{AD}$, about half a century after the last major megadrought in 1455 AD. Dating of the avulsion event that initiated the rapid accumulation of Stratum 2 sediments and soils is uncertain (see Chapter 5, Abbott and Frederick), but avulsion might have occurred about a century after this climatic shift. Stratums 2 and 3 then accumulated during the Little Ice Age, with an increase in ground moisture. The Little Ice Age was presumably marked in the Plains by lower temperatures, reduced frequency of La Niña events, reduced evapotranspiration, and increased precipitation and ground cover. These variables enhanced soil development and landform stability, but did not necessarily produce datable events.

The pollen record for Stratum 2 is similar to that of Stratum 1, but with a decrease in sunflower family plants, and with a concurrent increase in grasses. There appears to have been a more rapid aggregation of sediments when compared to Stratum 1, and moderately abundant microcharcoal suggests the possibility of intentional burning or wildfires. Interestingly, increased tree canopy during the Little Ice Age likely helped retain soil moisture by providing shade, reducing soil temperature, reducing wind velocity, and by shedding leaf litter and downed wood, so soil moisture levels probably increased somewhat during the Little Ice Age, contributing to a reduction in biomass wildfires.

There is also an added presence of hackberry and juniper tree pollen, as well as local sedges, filaree, and wild grapes. Overall, there appears to have been a general decrease in $\mathrm{C}_{4}$ tall grasses, with a concurrent increase in shorter $\mathrm{C}_{3}$ grasses, suggesting a gradual change from a relatively drier and warmer climate regime to one that becomes cooler and more moist.

Roughly 130-40 cmbs appears to have been an environmental transitionary zone, when silty, slow moving water likely covered the site. Ostracode recovered in a sample from 130-140 cmbs imply that the site was an aquatic environment; probably covered with shallow and slightly brackish water. An absence of ostracode between 110-130 cmbs indicates a possibility that these sediments were deposited by other than alluvial and fluvial events. 
The pollen and phytoliths found between 90-100 cmbs could represent intentionally grown grasses for human consumption with possible intentional burning being carried out to increase the frequency of these particular grasses on the landscape. Between 90-100 cmbs, grasses were possibly cultivated or encouraged for human consumption, with Little barley grass being the most likely candidate for cultivation at the time. The pollen/phytolith record further suggests that when sediments aggregated between $70-80 \mathrm{cmbs}$, the land was either disturbed, or a change in land use occurred, followed by the return of older taxa, as well as the possible introduction of new taxa by the time sediments in Stratum 3 accumulated. An absence of ostracode between 70-80 cmbs suggests a possible non-flood period, as does the absence between $30-40 \mathrm{cmbs}$. Fragmented bivalves and gastropods between 10-20 cmbs possibly indicate a shallow, flood event.

\section{Upper Component-Stratum 3 (AD 1654-1954)}

When Stratum 3 was occupied, the terrace continued to build, with relict silty loam, and disrupted lenses of coarse silt and fine sand. The faunal species at the time fed on predominant grasslands in the area. A significant decrease is noted in aquatic/wetland species, with a notably significant decrease in turtle and an increase in fish being exploited. The pollen and phytolith record for Stratum 3 is very similar to Stratum 1, suggesting a shift back to a generally open habitat dominated by dense, medium $\mathrm{C}_{4}$ tall grasses and forbs, with scattered large pine, oak, and elm trees, and with sedges and $\mathrm{C}_{3}$ grasses along Fish Creek. The overall phytolith record for the Stratum 3 indicates a long-term trend of decreasing moisture. It further indicates a sustained, relatively lower abundance of cool season and tall grasses. The greater abundance of trees and shrubs versus less grass density is likely due to fire suppression in historic times. The diversity in phytoliths is expected to decrease in an historic era environment as native grasses tend to take over. In the ethnobotanical record are elms, and woody legume-types (probably honey locusts) which thrive in disturbed soils, and there appears to have been areas of both open and closed canopy along the creek. A grape seed found suggests there were vines clinging to smaller trees in a moist environment near a clearing. Significant changes in the snail assemblage suggest an increase in tree canopy. Soil moisture levels probably also increase in Stratum 3, not necessarily because of regional climatic change, but because heavier deciduous tree cover helps retain soil moisture by providing shade, reducing soil temperature, reducing wind velocity, and by shedding leaf litter and downed wood.

Two diatom species found between $50-60 \mathrm{cmbs}$ infer that the sediments from $50-60 \mathrm{cmbs}$ were covered with polluted water and snails indicative of mesic floodplain areas are slightly more abundant between 40-70 $\mathrm{cm}$ (60 $\mathrm{cm}$ being the lower boundary of Stratum 3). However, pollen and phytolith specimens recovered from 50-60 cmbs may represent a transitional period to the modern biological community representing historic era changes in use of the landscape, with less reliance on maintaining an open landscape through open burning. Although oak trees now dominate, there are also alder, hickory or pecan, hackberry, ash, juniper, hornbeam/hop hornbeam, pine, and elm. Grasses and sunflower family members were dominant understory vegetative types. Among others, pollen was observed from many plants that are of the historic era, including, thistle, marsh elders, dandelions, Cheno-ams, wild buckwheat, legumes, chokecherry, and ferns. For the first time, prairie clover, an unidentified legume, a member 
of the mint family, and passionflower are present on the landscape. The far less quantities of microcharcoal in the samples imply that burning of the immediate area has decreased. 


\title{
Chapter 18 \\ Research IsSues AdDressed
}

\author{
David L. Nickels, James T. Abbott, Jodi A. \\ Jacobson, and W. Nicholas Trierweiler
}

Chapter 3 discusses in detail the research questions that we had both before and after the field work at the Fish Creek Slough Site, and the strategies designed to obtain the best information possible in order to answer some of those questions. This chapter serves only to summarize our findings, as all of them have been discussed in one manner or another in the preceding Chapters 5 through 17. In most cases we were successful in our approach and recovery efforts; in a few cases we were not.

Jim Abbott and Charles Frederick laid the groundwork in Chapter 5 by using multiple lines of evidence to reconstruct the depositional episodes resulting from periodic inundation of the site by Fish Creek over the past approximately 1,250 years. In addition, Jim synthesizes multiple soil layers along with multiple radiocarbon dates to identify four soil units which he equates to stratums and is then able to place archaeological excavations within those separate stratums.

Ken Brown, Robert Howells, David Brown, Mervin Kontrovitz, Barbara Winsborough, and Linda Scott-Cummings and others conducted an in-depth analysis of paleoenvironmental indicators as discussed in Chapters 6 through 11. Evidence of plant and animal remains as potential subsistence items were explored by Mary Malainey, Timothy Riley, and Philip Dering in Chapters 12 through 14. By far, the most evidence for subsistence activities at the site is derived from Jodi Jacobson's analysis of the very abundant quantity of faunal remains in Chapter 15.

Finally, David Nickels discussed the cultural components to include both cultural and noncultural features in Chapter 16, and summarized the paleoenvironmental record in Chapter 17.

\section{Geoarchaeology}

The following discussion addresses geoarchaeological questions posed in two iterations of the research design, produced prior to the excavation to justify and guide the fieldwork (the initial research design) and to guide analysis (the final research design). Each geoarchaeological question framed in the research designs is repeated and addressed, including subsidiary questions. However, many of the questions have already been addressed at length in Chapter 5, and will be merely recapped below.

Question 1: Cultural and Geoarchaeological Chronologies, and Site Integrity. Can the site be more confidently dated both archaeologically and geologically? 
A: The answer to this question this was "yes". In sum, a total of 48 radiocarbon dates were obtained which further helped define the site both archaeologically and geologically.

Subsidiary Questions

1.1 Are two radiocarbon dates received thus far out of sequence as they appear relative to soil strata?

A: Yes; collagen dating on bone samples clarified that part of the problem with radiocarbon sequences is due to the burning of old wood.

1.2 What are the implications for fine-grained microcharcoal dates in a sequential, vertical column in correlation with subsamples that can provide significant paleoenvironmental information?

A: Dating of microcharcoal proved to be problematic, with the results yielding a stratigraphically-reversed sequence.

1.3 Can fine-grained dating be used to correlate environmental changes and soil deposition rates with possible cultural changes through time?

A: Although useful paleoenvironmetal information was obtained (see Chapter 11), its proper temporal association is also problematic due to the upside down dates for the stratigraphic sequence.

1.4 Can fine-grained dating be used to correlate environmental changes and soil deposition to the availability of raw material through time?

A: $\quad$ Because of the reversed dating sequence obtained from microcharcoal, it failed to adequately address any correlation between environmental changes and availability of raw material.

1.5 Can fine-grained dating be used to correlate environmental changes with subsistence practices through time?

A: $\quad$ Because of the reversed dating sequence obtained from microcharcoal, it failed to adequately address any correlation between environmental changes and subsistence practices.

Question 2: Depositional Context and Chronostratigraphy. What is the depositional context of the site matrix at 41DL436? What is the timing of these depositional events?

A: $\quad$ The deposits at 41DL436 consist of stratified alluvial deposits of Fish Creek, deposited by flooding on the proximal floodplain and within an abandoned channel swale between approximately AD 900 and the present.

Subsidiary Questions: 
2.1 What is the sequence of depositional and erosional events and periods of stability that are represented by the deposits? How can these events be characterized?

A: The deposits preserved at 41DL436 can be divided into three primary depositional units on the basis of appearance. Unit 1 consists of loamy, very dark gray to very dark brown alluvium that aggraded through point bar migration and subsequent vertical floodplain aggradation in proximity to a former channel of Fish Creek. It is subdivided into two subunits, Units 1a and Unit 1b. Unit 1a forms the majority of the deposit, and is dominated by a thick, dark cumulic paleosol (PS2). It contains scattered zones of subhorizontal burns, bone scatters, and at least one extensive mussel shell scatter. Unit $1 \mathrm{~b}$ consists of a wedge of similarly-colored alluvium that thickens away from the paleochannel, and interpreted as reworked floodplain (Unit 1a) sediments that were eroded and transported a short distance during an initial scour sequence (short transitional period) that occurred in conjunction with a channel avulsion. Therefore, although the unit is more similar to Unit 1a in appearance, it is geomorphically related to the channel avulsion and its aftermath that formed Unit 2 . There are also several small burned rock hearths contained in the initial fill following the scour event.

Unit 2 consists of highly stratified fine sands, silts, and loams deposited on the floodplain and in the recently abandoned channel of Fish Creek. As in Unit 1, a number of discrete interstratified burns and bone scatters of possible and probable cultural origin throughout the sequence. Unlike Unit 1, which was largely homogenized by soil processes at a microscopic level, Unit 2 is only lightly turbated. Unit 2 was subdivided into two subunits in profile based on a prominent interstratified sandy bed, but these subunits could not be correlated across the hand unit excavations. Unit 2 is capped by a thin cumulic paleosol (PS1) that is developed across the floodplain and in the swale marking the former channel. Like Unit 1, it is characterized by a number of interstratified horizontal burns, bone scatters, and mussel shell scatters representing a succession of activity loci. The number and placement of these loci imply that people were returning to the site over and over again, while the paucity of material remains suggests that these visits were only for short periods.

Unit 3 consists of highly stratified silts and loams that grade up into a massive A-Bw soil profile. Obvious stratification is only preserved in the lower $20-30 \mathrm{~cm}$ of the unit, except in the channel swale, where it is almost a meter thick. There is comparatively little cultural material in Unit 3, and what is present (particularly in the small block defined by test units 2-5) must be considered of questionable origin.

2.2 How consistent is the corpus of chronometric data? What processes or other explanations are possible to explain apparent discrepancies in the sequence of ages?

A: With the exception of three ages on microscopic charcoal assayed from the pollen column, all ages from 41DL436 post-date 1090 BP. This includes two ages from Unit 3 (cal. AD 1654 to 1954); 16 ages from Unit 2 (including 15 provisionally accepted ages ranging from cal AD 1405 to 1660 and one older age rejected as intrusive); 6 ages from Unit 1b (including 5 accepted ages ranging from cal AD 1440 to 1650 and one older age rejected as intrusive); and 7 ages from Unit 1a (cal AD 893 to 1445). 
In addition, four vertically stacked ages on microcharcoal and seeds from the pollen column in Test Unit 49 yielded a stratigraphically-reversed sequence dating from $530 \pm 25 \mathrm{BP}$ at the base to $5955 \pm 25 \mathrm{BP}$ at the top. Scott Cummings et al. (Chapter 11) interpret this sequence as a record of pronounced soil erosion in the catchment, which is in keeping with distinct shift in stream behavior apparent between Unit 1a and Unit 2.

Although all but the two ages cited above are accepted as legitimate dates on organic matter burned in situ, there are a number of minor reversals present through Units $1 \mathrm{~b}$ and 2 that are interpreted as old wood errors. These errors are far more common in Unit 2 than in Unit1B, suggesting that old wood may have become more available in the system as Unit $1 \mathrm{~B}$ and 2 accumulated, possibly as a consequence of tree mortality resulting from pronounced erosion in the Fish Creek watershed. In all cases, the old wood ages are no more than a few hundred years too old.

\subsection{What is the scale of the avulsion event represented in the site sediments?}

A: Although this is not possible to determine with certainty given current information, the scale of the Fish Creek valley makes it unlikely that the avulsion represented by the channel abandonment at 41DL436 is anything larger than a meander neck cutoff. However, given the current low sinuosity of the stream, and the lack of floodplain available for sinuosity to develop, it is also unlikely that the meander cutoff occurred as a result of a breach caused as the channel meandered back into itself. Rather, the marked change in the character of sedimentation and the rapid accumulation of stratified sediments on the floodplain surface (Unit 2) strongly suggest that this breach was caused by one or more significant flood events, which were able to cut a new channel across the loamy floodplain. Whether the channel avulsion was achieved in one flood or not, the sequence of deposits represented by Unit 2 document repeated significant flooding during the fifty years or so following the avulsion, with intermittent reoccupation of the floodplain for short periods.

\subsection{How does this sequence compare with other sites of similar age that have been} investigated in the region?

A: $\quad$ There are few sequences of this age that have been explored in the region, and none that have been worked up in detail. The most similar site in terms of stratigraphy and depositional process is the Gemma Site, 41COL150, described by Ferring and Yates (1997) in Collin County, where two distinct, highly stratified channel fill sequences are present. However, the deposits at the Gemma Site are older (Late Archaic), and correlable with Ferring's regional Pilot Point Alluvium, while the deposits at the Fish Creek Slough site probably represent the transition from the Pilot Point to the subsequent "Recent" deposits (see below).

\subsection{How does the sequence compare with the regional model proposed by Ferring (1994)?}

A: In addition to elevated terraces dating as far back as the middle Pleistocene (which will not be discussed here), Ferring's model describes a series of three named allostratigraphic units stacked beneath the floodplain of streams in the upper Trinity drainage. The oldest of 
these, the Aubrey alluvium, dates to the Latest Pleistocene (i.e. 14.2-11.5 ka). It is followed by the Sanger Alluvium, which dates from approximately 11.5 to $6 \mathrm{ka}$, and the Pilot Point Alluvium which dates from approximately 4.5 to $0.5 \mathrm{ka}$. In many settings, the Pilot Point Alluvium immediately underlies the floodplain surface, but elsewhere (particularly in channel proximity) it can be buried by up to $2 \mathrm{~m}$ of alluvium Ferring terms "recent". In terms of timing and architecture, Unit 1A is a good correlate for the Pilot Point alluvium, while Units 1B, 2 and 3 are equivalent to Ferring's post-Pilot Point ("recent") fill.

\section{Question 3: Soil Development. What is the character of soil development at Site 41DL436?}

A: Each of the three major depositional units (Units 1-3) is associated with a soil. The soil making up the exposed part of Unit 1A (PS2) consists of a very dark brown to very dark gray cumulic soil a meter or more thick. It is developed in silty and loamy sediments, and characterized primarily by a lack of depositional features, pedogenic structure that is subdued to absent, and common threads and films of secondary calcium carbonate. Despite its very dark coloration, organic matter content is generally less than one percent. Scour and reworking of the upper part of this soil resulted in the formation of Unit 1B, which resembles Unit 1A in color, but includes clear depositional structures, including lenses and flasers of lighter colored fine loamy sand.

The soil capping Unit 2 is very different, consisting of a thin zone of massive to weakly stratified, grayish brown loam. It represents a brief depositional hiatus - perhaps no longer than a few years - before Unit 3 began to accumulate. It represents cumulic accumulation of slightly finer and more organic rich material on the floodplain during a period of relatively restrained flooding, and can be traced from the floodplain surface into the channel swale. As in Paleosol 2, secondary films and filaments of calcium carbonate are common, and measured organic concentration does not exceed one percent.

Unit 3 is capped by the modern surface soil, which is similar in color to PS1 but far thicker $(60-80 \mathrm{~cm})$, representing a much longer period of pedogenesis. It exhibits a very dark gray to very dark grayish brown A horizon and a dark grayish brown B horizon. Although the upper horizon exhibits approximately three times the amount of organic matter in the two paleosols, it is visually similar to PS1. The net result of pedogenesis has been to thoroughly turbate the A and $\mathrm{B}$ horizon, obliterating primary stratification in the upper $60-80 \mathrm{~cm}$ of the section.

\section{Subsidiary Questions:}

3.1 How does soil development differ between the two paleosols? What are the implications for the manner of their formation? What are the implications for the local climate and environments?

A: The older paleosol (PS2) is the product of slow overbank deposition in a relatively stable, channel-proximate environment. Units $1 \mathrm{~b}$ and 2 represent a dramatic shift in the character of the environment, almost certainly reflecting significant distruption of the contributing watershed, increased sediment yield, and flashier discharge. The younger paleosol (PS1) represents a 
brief episode when this new phase of activity paused, allowing a thin cumulic soil to form/ accumulate, while the lower part of Unit 3 represents a return to this unstable pattern. Only as the floodplain approached its current elevation did this activity slow, allowing soil fauna and flora to blur the upper profile of Unit 3 and form the extant soil.

It is difficult to state with confidence what all the broader factors driving these changes in stream behavior were, but it is likely that they were linked to broader changes in landscape stability, and that climatic changes were contributing factors. As Ken Brown (this volume) notes, the time period in question is noted for a significant global climatic shift, from the relatively mesic Little Climatic Optimum to the much colder Little Ice Age (Bradley 1985). This shift would probably have led to local changes in the amount, timing, and intensity of precipitation that could profoundly influence stream behavior. Prolonged drought and/or human activity (particularly fire behavior) could have also conditioned the landscape response to such changes, but it seems clear that the upper Fish Creek watershed experienced significant erosion, and that changes in the sediment load and probably in the intensity and duration of stream flow led to marked changes in depositional behavior and the character of the local environment.

3.2 What was the character of drainage during each period of pedogenesis? What are the implications of pedogenic iron compounds and carbonates?

A: $\quad$ Based on the sediment character and the character of associated fauna and flora, Unit 1a represents a very wet environment, and Units 2 and 3 are only slightly drier. Secondary carbonate in the form of filaments and soft crystalline concentrations (incipient nodules) are common throughout the sequence, as are iron and manganese staining and small manganese nodules. Because the sediments accumulated so quickly, the accumulation of iron and manganese and the accumulation of calcium carbonate in the soil can be assumed to have occurred penecontemporaneously. Such features are often interpreted as indicative of differing soil conditions reflecting climatic shifts (e.g., Birkeland 1999), but this seems unlikely in the Fish Creek Slough sequence given the time involved.

Question 4: Site Integrity. What implications does the depositional sequence have for the integrity of archaeological and paleoecological data recovered from 41DL436?

A: The stratigraphic sequence at the Fish Creek Slough site accumulated extremely rapidly and has demonstrated excellent potential to preserve archaeological materials in good context.

\section{Subsidiary Questions:}

\subsection{What are the expectations for vertical integrity and mixing?}

A: Sedimentary structures in Unit 2 and the lower part of Unit 3 are remarkably wellpreserved, and evidence of stratigraphic mixing is minimal except in the modern soil zone and, to a lesser extent, in Unit 1. Even where significant homogenization of the profile is evident, the persistence of features indicates it was dominated by very small-scale (e.g., insect/ 
annelid) disturbances that probably did not substantially displace larger artifacts. Given the well-preserved primary strata and the paucity of evident stratigraphic disturbance, the overall potential for high vertical (stratigraphic) integrity is excellent. The only issue is that the method of excavation was not particularly conducive to tracing strata across the block. Because the strata are not flat-lying, correlation between features and artifact clusters within the block is problematic unless they are vertically superposed.

\subsection{What are the implications for horizontal integrity?}

A: Based on the patterning of materials and the co-occurrence of artifacts and features, horizontal integrity of most strata at 41DL436 also appears to be reasonably high. Although the character of flooding was such that spatial reorganization of site materials was certainly possible, the distribution of faunal material and the co-occurrence of hearth features and presumably associated turtle shells suggest that burial occurred rapidly and horizontal integrity is generally good.

4.3 What is the implication of the physical and chemical environment for the compositional integrity of the assemblage?

A: The accumulation of iron-manganese compounds and carbonate compounds during the short life of these deposits suggest that the hydrochemistry of the site is complex, and that over the long term biotic remains would probably suffer degradation. However, the results of various studies (e.g., malacological, vertebrate faunal) clearly indicate that biotic remains are remarkably well-preserved.

Question 5: Burn Zones. What can be deduced about the numerous zones of burned and reddened sediment observed during testing and data recovery?

A: $\quad$ One of the aspects of the site that was used to justify data recovery in the first place was the presence of multiple large burned zones in the sedimentary sequence. This phenomenon was approached with multiple working hypotheses: 1) that the burns represent evidence of agricultural/horticultural activity by Plains Village groups; 2) that the burns represent informal hearths or controlled localized burns by prehistoric people; and 3) that the burns represent regional wildfires of natural or cultural origin. The purpose of this research topic was to explore the data potential of these features and their relationship to other aspects of the site.

\section{Subsidiary Questions:}

5.1 Does the sequence of burned surfaces represent agricultural/horticultural use of the site?

A: To address this question, the following discussion first develops a context for the question, then derives expectations that follow from this context, and finally explores those expectations. 
Initial work at 41DL436 suggested that the site included a series of stratified, burned zones. While these zones of burning may be of natural origin, their frequency in what appears to be a relatively short-term sequence of deposits suggested that humans were likely responsible. One possible explanation considered was that the repeated burns represented preparation of agricultural fields. While hunter-gatherer groups were common in the Dallas area during the Late Prehistoric, and are generally assumed to represent the majority of the record (Prikryl 1990), there is also artifactual evidence (e.g., examples of bison scapula hoes) that agriculture was practiced in the region surrounding Dallas. However, villages associated with agriculturalists are rare in comparison to areas to the north and east. To our knowledge, no prehistoric agricultural features of any type have yet been documented anywhere in northern Texas.

Although occupational sites are most commonly investigated, humans conduct a variety of activities on the landscape, and localities where non-residential activities were conducted (e.g., obtaining raw material, plant foods, or other specific types of resources; processing foodstuffs; trapping, killing and/or butchering game; conducting warfare, etc.) are also by definition archaeological sites. By the Late Prehistoric (latter Woodland and Plains Village periods), one of the generally recognized aspects of cultural systems to the north and east (e.g., Caddoan groups, Henrietta Focus) is the adoption of agriculture. Although mobile hunter-gatherers were in the Dallas area, it appears likely that some Plains Village-like adaptations were also present in area during the Late Prehistoric (Prikryl 1990:80).

The historic record of Caddoan (Hasinai) tribes is based primarily on descriptions provided by Spanish missionaries (Franciscans) and military, and French explorers and traders (Griffith 1954). These accounts make it clear that historic tribes in northeast Texas raised at least two varieties of maize. A number of other crops, including a variety of beans, squash (calabash), pumpkin, sunflower, melons, and tobacco are identified in historic accounts, and other crops grown by Mississippian groups (e.g., marsh elder [sumpweed] and goosefoot) may have also been represented, as could managed arboreal crops (e.g., plum, pecan). Although little is known about native agricultural patterns, the descriptions suggest that fields were relatively small and communally worked. What is known specifically about agricultural practices comes from very few historic sources, such as Joutel's account of the ill-fated La Salle expedition (1906), reports of Spanish missionaries like Fray Casañas, Fray Hidalgo, and Fray Espinosa (Hatcher 1927a; 1927b;1927c;1927d) and the "Téran map" from the expedition of 1691-92 led by Téran del Rio. To our knowledge, no agricultural fields have been identified and characterized archaeologically from the Caddo region to this point, and few attempts (e.g., Frederick n.d.) have been made to do so.

The term 'swidden,' or slash-and-burn, refers to a mode of agriculture practiced widely in tropical regions, where soil fertility is generally quite low. Swidden agriculturists operate by clear-cutting native forest and burning the cut vegetation. Planting is done in and around these burned zones to take advantage of the nutrients in the ash, and the field is typically abandoned after one or two crops as these nutrients are depleted (Johnson 1974). Because forest regeneration after clear-cutting is slow, it is often viewed as an inefficient and destructive system (particularly by governments in the tropics), although it has many defenders who argue 
that it is often an efficient, sustainable system (e.g., Dove, 1983; Ziegler et al. 2009). In his seminal treatment of North American agriculture, Doolittle (2000:186-187) argues that there is little evidence of true swidden agriculture - involving by definition slashing, burning, and frequent field rotation - anywhere north of Latin America, but that evidence of burning (for a variety of agricultural and non-agricultural reasons, including field/range maintenance, field preparation, understory control in arboreal husbandry, driving game, increasing visibility, and as a war tactic) is common. Burning is advantageous not only because it can clear fields of brush and weedy vegetation, but because it converts organics and minerals bound up in those plants into readily available nutrients.

If the burned zones represent clearing and preparation of fields for agriculture, then a number of expectations can be identified. These expectations are explored below:

Appropriate age. If the burns represent agriculture, then they should date to the post-Archaic. Although Woodland ages are possible, it is more likely that latter part of the Late Prehistoric, when evidence from surrounding areas suggests that agriculture became important for subsistence and Plains Village adaptations were established. Radiocarbon dates should be in stratigraphic order and date from no earlier than approximately AD 1.

Results: Radiocarbon dating of the site indicates that most of the sequence, and all the cultural manifestations noted, are of Late Prehistoric or Protohistoric Age and in reasonable stratigraphic order (with allowances for old wood errors).

Appropriate scale. Burned zones should be extensive and laterally continuous. The apparent intensity of burning, spacing of burned zones, and volumes of combustion products should reflect the character of burned vegetation.

Results: The results of block excavations indicate that the features are locally bounded and not consistent with a wildfire burn-over.

Disrupted bedding/patterned burning/patterned disturbance. Although it seems a trivial statement, agriculture involves disturbance of the soil. Because the burning is hypothesized to be part of the process of field preparation and would precede planting, it follows that at least some intentional disturbance of the burned zone would occur during planting of the seed bed. The degree to which this would be recognizable in plan or profile is questionable, but because primary bedding is so well preserved and thin zones of burning were noted, recognizable disturbance may be localized around crop locations. Alternatively, weeding and hoeing around maturing crops might obscure such patterning, or it might result in localized preservation of burned lenses beneath individual "corn hills" (Doolittle 2001) as the burned surface was scraped with hoes to form planting mounds or ridges. Another possibility is that the pattern of planting might be preserved as fresh overbank sediment was draped over a patterned series of planting ridges or corn hills. Inferences may also follow from the patterning (or lack thereof) of zones of higher and lower intensity burning, the scale and pattern of burned vegetation (e.g., mature forest vs. scrub vs. grasses and weeds). 
Results: Exposure of burned zones in plan and in profile did not reveal any systematic disruption of traceable beds and burned strata.

Microfossils and macrofossils. Most researchers agree that maize was the most important single crop for Plains Villagers, but beans, squash, pumpkin, sunflower, and tobacco were also described in historic sources. Other plants that may have been cultivated include goosefoot (Chenopodium berlandieri) marshelder (Iva annua) sunflower (Helianthus anuus) and little barley (Hordeum pusillum) (Adair 1996). While the recovery of maize remains (a tropical import) would be an extremely strong argument for cultivation, most other potential crops (e.g., Cucurbita spp.; Chenopidium spp.) may occur naturally and the strength of the argument would hinge of the relative concentration of evidence (e.g., seeds and macrofragments, pollen, and/or phytoliths) against the background.

Results: The results are equivocal. Although relatively weak, the analysts (Scott Cummings, Yost and Puseman, this volume) see evidence indicative of possible intentional propagation of wild cool-season grasses, possibly through intentional burning, during their pollen zone 2 (equivalent to the lower part of Unit 2). They also note the presence of "a few very intriguing maize-like phytoliths" from the same level, and other potentially used (but naturally common) plants like goosefoot and sunflower are also present in the assemblage.

Discussion: When constraints and limitations imposed by differences in production and preservation of these proxies are considered, potential crop remains should be common all but the lowest strata in burned zones if the site area was used repeatedly as an agricultural field. This does not seem to be the case. Neither were physical manifestations indicative of prehistoric agriculture, such as patterned disruptions of bedded sediments due to planting with a digging stick or use of a scapula hoe around crops, noted in plan or in section during excavation. Although the timing of deposition includes the latest Prehistoric and Protohistoric time range, burning for horticultural purposes is rejected as an explanation of the fired features. However, it is still considered possible that horticulture was practiced in the broader watershed, and may have contributed to the environmental shifts between Units 1 and 2.

\subsection{What is the distribution of these burns in the site matrix?}

A: $\quad$ Burned zones were noted in all three depositional units, but they were concentrated in Unit 2 (Stratum 2). They were present on the floodplain surface and in the channel swale. Patterning in Unit 2 indicates a separation between clusters on the northern end of the excavation trench versus the middle portion. However, it should be noted that Unit 2 is over $1 \mathrm{~m}$ thick, and the burn features likely did not occur simultaneously, but alternately over several decades. Nevertheless, there does appear to be a general separation between clusters (see Chapter 16).

\subsection{What is the morphology of the burned zones? How big are they?}

A: $\quad$ Most burned zones mantled a level or dipping paleosurface. There was no evidence that a basin or pit was prepared, although some appeared to occupy a shallow natural concavity. 
Plan shape was variable, and size varied from less than a meter in diameter to three or four meters in maximum diameter. Larger features tended to be elongate, and several were oriented with the slope. Margins were not regular, but there were clear (albeit transitional) boundaries to most of the burned zones. None of the features appeared to be unconfined areal burns, and no microstratigraphic associations (co-occurrences on the same buried paleosurface) were documented among different burns. However, such associations between features cannot be ruled out.

In section, the burns typically consisted of an oxidation rind $1-3 \mathrm{~cm}$ thick capped with small zones of ash and infrequent charcoal. In thin section, identifiable facies include, from top to bottom, a zone of mixed thermal refuse (charcoal, ash, rubified earth, and charcoal-stained earth), an ash zone; a distinct zone of rubified earth, and a darkened zone (termed by Frederick the "carbon core"; see Appendix A, this volume) that probably represents heating in a more restricted oxygen environment.

As discussed in Chapter 16, there are indeed burned features that exhibit characteristics of smoldering burns in oxygen starved environments. In some cases we have determined that they are likely tree and root burns. However, there are also features that suggest they very well could have been surface hearths. Morphologically, these potential surface hearths are generally smaller in size (less than $1 \mathrm{~m}$ ) and unlike tree and root burns are regularly circular or oblong, and restricted to a defined paleosurface.

\subsection{Are there cultural features (hearths)?}

A: Given the relatively high heat indicated, the restricted area, and the frequency of features in the sequence, these burn features appear to represent intentionally set and managed localized fires. It is likely that surface hearths sans rocks as heating elements served as hearths for cooking and warmth. It is equally likely that the features were used to provide warmth or smoke for insect control in conjunction with butchering activity at a special purpose kill/ butchering locality.

\subsection{Are they features resulting from regional burns?}

A: Given the restricted distribution, the features do not appear to represent the result of wildfires.

\subsection{What is the potential that they represent intentionally-set fires?}

A: $\quad$ It is considered likely that the fires were intentionally set and managed.

\subsection{What types of temperatures and durations are necessary to form such features?}

A: Although there are technical approaches to address this issue (e.g., Linford and Platzman 2004) and to conclusively distinguish between cultural and natural burns (Bellomo 1993), they involve samples and instruments that were not employed during the current study. All that can be said is that the features display significant thermal modification, including a distinct zone 
of oxidation overlying a more subtle zone of anoxic alteration, and that this is consistent with the type of focused and sustained heat characteristic of cultural features (Bellomo 1993). In addition, we compared Magnetic Soils Susceptibility values of 41DL436 features with burned features at other sites and in replication studies in an attempt to sort out the differences in cultural hearths versus downed timber and root burns.

5.8 Is there evidence that the thermal features were used for cooking or disposal of waste products from butchering activities?

A: No evidence suggests that they were used for disposal of waste products. However, lipid analysis of fire-cracked rock samples suggest that at least some hearths were used for cooking.

\section{Faunal Analysis}

Site 41DL436 is a well-stratified site with known contexts dating from modern/historic period to approximately 700 years ago. Previous investigations at the site revealed excellent preservation of organic remains and evidence of butchery. Lithic artifact presence during earlier investigations was negligible, and even data recovery resulted in a paucity of nonorganic artifacts. Bone, shell, and botanical material, however, were numerous and remarkably preserved. Zooarchaeological studies conducted during the data recovery phase were designed to determine species variability, human subsistence strategies, taphonomic processes, and cultural use of bone.

Due to the well-dated stratified nature of the site, there is the potential to analyze faunal material from multiple components allowing for intra-site comparison within a temporal framework. The majority of archaeological sites within Texas either have poor bone content due to extensive breakage for marrow and bone grease extraction, highly acidic soils, or other cultural and/or taphonomic factors. The rare exception for preservation at 41DL436 could provide useful data to answer not only relevant site specific questions, but which could also be extrapolated to inform regional questions concerning mobility, subsistence strategies, environmental change, division of labor, and non-subsistence use of bone.

Question 6: Species Presence. What do the species present at the site relay about the availability of resources within the area of $41 D L 436$ ?

A: Environmental conditions and species availability within the catchment area of the site altered over time. While predominantly aquatic environments with the presence of some grassland species, bison and bovid presumed bison presence was minimal in three of the four well-defined strata, indicating a general lack within the area for those associated timeframes. Given the dominance of bison in the diet when available, this minimal presence is assumed to be an indication for limited availability and general small species presence within the region and site location specifically.

\section{Subsidiary Questions}


6.1 Does the presence or absence of certain species at the site, notably bison, indicate shifts in environmental conditions affecting the availability of certain prey?

A: Oppossum, raccoon, woodland vole, and white-tailed deer remains recovered at the site are indicative of a forest or forest-edge environment. Mule deer, cottontail rabbits, kangaroo rats, and plover remains suggest that the habitat was brush/chaparral. The bison, pronghorn antelope, hispid cotton rat, pocket gopher, and ornate box turtle remains are indicative of an open prairie and grassland. The bones of beaver, marsh rice rat, goose, duck, other waterfowl, water snake, box turtles, mud/musk turtles, red-eared sliders, spiny softshell turtles, and catfish suggest an aquatic/wetland habitat. Overall, the variety of species present at the site are incredibly diverse and represent multiple habitats.

The species recovered from Stratum la suggest that the environment was predominantly wetland/aquatic with adjacent grass floodplains and prairies. The aquatic species imply slow moving water, or shallow ponded water with muddy bottoms. Stratum $1 \mathrm{~b}$ species suggest a slight increase in the wetland/aquatic environment, with a concurrent slight decrease in grassland prairie. There is a very minor presence of bison associated with Stratums 1a and 1b, but there is higher presence of pronghorn antelope in Stratum 1b. Minor environmental thoughout Stratua $1 \mathrm{a}$ and $1 \mathrm{~b}$ include mixed chaparral/grassland, chaparral, mixed open woodland, and woodland.

There is a marked decrease in woodland species presence from Stratum $1 \mathrm{~b}$ to their most negligible presence in Stratum 2, suggesting increasing xeric conditions, and possibly accounting for the slow aggradation profile seen in Stratum 2.

There is greater NISP of species that prefer shortgrass (e.g., antelope) in Stratums 1a and 1b when compared to Stratum 2. While bison can survive in short grass, they really need mixed grasses or tall prairie grasses. The decrease in short grass species between Stratum $1 \mathrm{~b}$ and Stratum 2, along with the drastic increase in bison could be linked as well to a greater presence of mixed or tall prairie grass. In general, there is a decrease in frequency of wetland/aquatic resources in Stratum 3. This partially correlated to the the rapid sedimentation within the Fish Creek channel. There is an associated increase in the frequency of grassland/prairie species as well as other mixed open chaparral/grassland, and chaparral species.

\subsection{Does the availability of certain prey species change over time?}

A: Environmental conditions and species availability within the catchment area of the site altered over time. While predominantly aquatic environments with the presence of some grassland species, bison and bovid presumed bison presence was minimal in three of the four well-defined strata, indicating a general lack within the area for those associated timeframes. Given the dominance of bison in the diet when available, this minimal presence is assumed to be an indication for limited availability and general small species presence within the region and site location specifically.

While there is still some presence of aquatic species in Stratum 2, terrestrial species dominate the assemblage, and bison was the most prevalent mammal bone. Given the drastic reduction 
in presence of bison at the site in Stratum 3, it is assumed that bison were no longer available in large numbers near the site due to either environmental or human impacts. The biggest change in aquatic skeletal remains from Stratum 3 suggests a marked shift from a reliance on turtles to a reliance on fish.

6.3 Are there indicators for seasonal variability of resources at the site? Or do the species present indicate that the site was utilized only at certain times of the year while exploiting particular resources?

A: There were numerous indicators for seasonal use of the site. Cold-blooded reptiles, especially turtles, indicate the site was used during warmer seasons with temperatures above 38-45 degrees Fahrenheit, likely March to November. Deer antler fragments with velvet suggest a July to September occupation. The remains of a young fawn suggest an occupation between August and October, while a tooth suggests a December occupation. Fetal bison remains suggest a February to April occupation. In sum, the wide variety of species suggests that the resources were exploited seasonally as they were available and imply a continuum of occupations from spring through early winter (March through December).

The reptile species associated with Stratum 1a suggest a warmer weather occupation, typically above 45 degrees Fahrenheit; March through November. Stratum 1a also yielded the young fawn remains, suggesting a late summer - early fall occupation; August through October.

The presence of reptiles (especially turtles) in Stratum 1b suggest that the site was occupied during periods when temperatures were above 45 degrees, from March through November. The remains from an immature bison calf suggest an April through December occupation, and a deer mandible further implies a December occupation.

As with Stratum 1a, the reptile species associated with Stratum 2 suggest a warmer weather occupation, typically above 45 degrees Fahrenheit; March through November. Skeletal remains from multiple bison remains in Stratum 2 imply predominant indications for spring and summer use, but with at least one piece of evidence for a late fall/early winter occupation as well.

There were no seasonal indicators from the material recovered from Stratum 3.

6.3 Is there enough variability in species present to indicate possible divisions of labor whereby larger animals (bison, deer) were "hunted" by able-bodied members of a group and smaller or slower prey species (turtle, fish) were "gathered?"

A: Throughout Strata 1a, 1b, and 2 there is enough of a presence of turtles especially, and maybe fish, to indicate that there were other members of the party gathering resources, instead of an all able-bodied stereotypical male hunting party. Furthermore, Stratum 3 has a higher presence of fish with identified catfish in the assemblage. Fish, especially catfish is another easy resource for kids or less physically able adults to help gather. 
6.4 How do the presence of certain species, specifically bison, fit in with regional models (Creel 1990, 1991; Lynott 1979)?

A: $\quad$ The minor presence of bison in Stratums $1 \mathrm{a}$ and $1 \mathrm{~b}$ at 41DL436 with dates of AD 12701650 overlap with the AD 1300-1800 dates proposed by Lynott (1979), Creel et al. (1990), and Dillehay (1974) for an increased presence of bison in Texas and the southern Plains, yet bison presence in proximity to 41DL436 would have been minimal.

Question 7: Subsistence Strategies. What are the implications for prey choice versus prey availability at 41DL436? What degree of bone present is due to natural versus cultural circumstances?

A: The prey of choice would have been bison because of the high yield. However, bison was apparently not in abundance at any time while the site was occupied. Instead the primary high-yield prey available was artiodactyls. Beyond that, a very wide variety of animals both terrestrial and aquatic were hunted and gathered.

Based upon direct chop/cut marks and indirect (burned) cultural modification of the bones, many species usually listed as commensal or intrusive due to Euro-centric views of acceptable food resources were obviously used for subsistence at 41DL436. Therefore, most of the species documented, including gophers, rats, harvest mice, woodland voles, lizards, and small snakes are considered as potential subsistence resources.

Overall, there was substantive evidence for culturally-associated modification of bone throughout all the strata. There is enough cultural modification associated with each strata to determine that most, if not all, of the bone recovered from 41DL436 was culturally, rather than naturally deposited.

\section{Subsidiary Questions}

7.1 As the location of the site is along a river, what degree of fauna present indicates aquatic versus terrestrial resource procurement?

A: All stratigraphic levels at the site had a significant inclusion of aquatic resources. Despite the high frequency of aquatic resources, the primary food resource based on available meat would be the artiodactyls present in the assemblage.

\subsection{Are there indicators for cultural breakage or butchering on the bone?}

A: In general, most of the butchering evidence is consistent with meat removal and marrow extraction. While butchering techniques were consistent across strata, variations in tool types and frequencies were noted. Direct evidence for cultural breakage or butchering included cut and chop marks, striking platforms, tool marks, and tool marks. Indirect evidence included burning and spiral fractures. Cut marks were apparent on a total NISP of 111, including 16 metal knife cuts and 13 stone tool cuts, and 82 indeterminate tool cuts. 
Although green bone breaks can be associated with carnivores or perimortum injury, most of the green breaks in the 41DL436 assemblage were the result of bone peels, twists, or breaks associated with cultural breakage. Only three percent of the total bone assemblage exhibit spiral and green breaks. The low frequency of intentional breakage and high percentage of unbroken bone indicate that dietary stress was not too severe, as the bones had not been highly processed.

7.3 Do skeletal part frequencies indicate on-site killing and butchering of species, transport of higher utility elements to the site from a separate kill location, or killing on-site with removal of higher utility body parts for consumption elsewhere?

A: In Stratum 1a, sample size is low, although it appears that at least some processing occurred onsite. If not killed onsite, then given the presence of low utility bones in even or greater numbers, it is likely that the kill location was at least nearby, and the elements were not transported far.

In Stratum 1b, skeletal part frequencies from bovids and deer indicate the possibility that higher utility parts were transported away from the site. It is likely that the deer bone present is representative of a local kill.

In Stratum 2, skeletal part frequencies of deer suggest that it is likely the deer were killed at or near the site, and the high utility parts transported away. Bison remains suggest the bison were killed a minimal distance (1/2 mile) from the site, and the choice meats stripped or removed from the bone before returning to the site.

In Stratum 3, skeletal part frequencies from bovids indicate that it is likely bovids were killed elsewhere and only higher utility parts were transported to the site.

7.4 Does the degree and type of bone fragmentation indicate processing of bone for marrow and/or grease?

A: Overall, bone at the site is not indicative of a high degree of marrow processing, and there is minimal to almost no direct evidence for bone grease. While there was a shift in marrow processing through time and variability with bone breakage, more intentional bone breakage occurred during the prehistoric and protohistoric (Strata 1b and 2) than during the historic (Stratum 3) component.

7.5 In the levels where high biomass species are present, i.e. bison, are there indicators for low species diversity indicating a specialized hunting strategy?

A: $\quad$ Presenting the data in statistical format allows us to easily identify and further evaluate the differences and similarities in assemblages. Presented in Table 18-1 are adjusted residuals for faunal remains. Adjusted residuals measure the difference between observed and expected values in contingency table cells, and converts this difference to a z-score (Haberman 1978). For purposes of this analysis, a five percent level of significance will be used, which equates to 
an adjusted residual of greater than 1.96 or less than 1.96 (see Chapter 15 for a more detailed discussion of adjusted residuals).

We recognize that a possible issue with using a contingency table is that there is a bais toward certain elements more readily identified, and taphonomic wasting, and high bison counts could skew the results. Nevertheless, we must use the data that is available.

For purposes of simplicity we elected to count bison/cow by NISP, versus the number of identified species in all other fauna classes or categories. As shown in Table 18-1, in Stratum 1a there are significantly fewer bison/cow remains that would be expected if the makeup of the entire fauna assemblages were comparably equal in all four strata. Conversely, there appears to be a significantly greater reliance on aquatic reptiles and fish than would be expected.

In Stratum 1b, the data indicates that the site occupants still relied significantly less on bison/ cow, but relied heavily on deer/pronghorn and other mammals, as well as a continued heavy dependency on reptiles.

Table 18-1. Actual and Expected Frequencies of Faunal Remains.

\begin{tabular}{|c|c|c|c|c|c|}
\hline & Stratum 1a & Stratum 1b & Stratum 2 & Stratum 3 & Total \\
\hline \multicolumn{6}{|l|}{ Observed } \\
\hline Bison/Cow (NISP) & 3 & 4 & 216 & 15 & 238 \\
\hline Deer/Pronghorn & 5 & 7 & 8 & 4 & 24 \\
\hline Other Mammals & 13 & 17 & 32 & 20 & 82 \\
\hline Birds & 5 & 5 & 9 & 4 & 23 \\
\hline Reptiles & 14 & 13 & 20 & 2 & 49 \\
\hline Amphibians & 1 & 0 & 2 & 1 & 4 \\
\hline Fish & 4 & 0 & 2 & 2 & 8 \\
\hline \multicolumn{6}{|l|}{ Expected } \\
\hline Bison/Cow (NISP) & 25.0 & 25.6 & 160.0 & 26.7 & \\
\hline Deer/Pronghorn & 2.5 & 2.6 & 16.2 & 2.7 & \\
\hline Other Mammals & 8.6 & 8.8 & 55.4 & 9.2 & \\
\hline Birds & 2.4 & 2.5 & 15.5 & 2.6 & \\
\hline Reptiles & 5.2 & 5.3 & 33.1 & 5.5 & \\
\hline Amphibians & 0.4 & 0.4 & 2.7 & 0.5 & \\
\hline Fish & 0.8 & 0.9 & 5.4 & 0.9 & \\
\hline \multicolumn{6}{|l|}{ Adjusted Residual } \\
\hline Bison/Cow (NISP) & -6.99 & -6.78 & 11.49 & -3.60 & \\
\hline Deer/Pronghorn & 1.70 & 3.00 & -3.68 & 0.87 & \\
\hline Other Mammals & 1.75 & 3.25 & -6.13 & 4.21 & \\
\hline Birds & 1.80 & 1.75 & -2.99 & 0.96 & \\
\hline Reptiles & 4.38 & 3.79 & -4.24 & -1.68 & \\
\hline Amphibians & 0.95 & -0.70 & -0.75 & 0.88 & \\
\hline Fish & 3.68 & -0.99 & -2.59 & 1.25 & \\
\hline
\end{tabular}


Most glaring and robust in the contingency table is the very significant and heavy dependency on bison/cow as a food source in Stratum 2. Conversely, the data indicates dependency on all other categories of animals (other than amphibians) is significantly less.

In Stratum 3, there is once again a significantly less reliance on bison/cow, the dependency on all other categories except 'other mammals' is pretty much as would be expected.

In sum, these data clearly demonstrate that when bison were present in abundance, there is a low species diversity in the faunal assemblage, and conversely, when bison are low in abundance the occupants broadened their diet breadth.

Question 8: Taphonomy. Given the preservation at the site, what indications are there for pre and post-depositional alteration to the bone? Is it possible to differentiate between cultural and natural associations of the bone?

A: Pre-depositional alteration to the bone includes cuts marks, rodent and canid gnawing, stages of burning, types of etching, decorative art forms, and degrees of weathering. Postdepositional alteration includes stages of burning, squirrel gnawing, types of etching, and degrees of weathering. Cultural and natural associations are differentiated using a combination of all of the preceding.

\section{Subsidiary Questions}

8.1 As there are indications of burn zones at the site, does the burned bone recovered at the site inform as to whether the burns were associated with cultural events (prolonged exposure or evidence of high temperature) or with natural events (low temperature and fast burning fires associated with wildfires)?

A: Within identifiable strata, a total of 290 pieces of bone exhibited brown discoloration. Brown discoloration is indicative of short-term and lower heat burning, such as fast burning range fires or exposure to a camp fire for less than six minutes. A total of 665 pieces had been blackened. Blackened bone has been carbonized and would indicate prolonged exposure to a grass or camp fire. A total of 164 pieces were calcined to a grey and white. Grey and white bone has been fully calcined, indicative of extreme heat over a relatively more prolonged period. These data suggest that 829 of the 1,119 pieces (74.1 percent) were subjected to a cultural camp fire.

8.2 Does the degree of bone weathering indicate bones were exposed for some time prior to deposition by a natural flooding event, or is the degree of weathering consistent with quick burial potentially indicating more prolonged use of the site?

A: $\quad$ Over 88 percent of the bone (673 of 761) from Stratum 1a exhibited minor degrees of weathering indicating that it was quickly buried just after use. Given the predominance of the degree of weathering on bone in Stratum 1b, it is likely that the bone was left exposed for a small, but not prolonged period prior to burial. As the site seems to have been used temporarily 
during different seasons, it is likely that it was associated with temporary camp sites where material was discarded surficially. A flooding event could have covered any remaining exposed material. This is further supported as Stratum $1 \mathrm{~b}$ appears to be associated with potential flood deposition and build up between the creek and slough.

A similar pattern is seen in Stratum 2 species where the predominance in degree of weathered bone is typical of weathering associated with any occupation site where material was buried relatively quickly after use. However, a marked difference is seen in the degree of weathering on bone in Stratum 3. The weathered bone in Stratum 3 is indicative that more of the bones were left exposed for a prolonged period prior to burial.

8.3 While well-preserved, bone at the site is broken. What is the degree of fresh versus dry breaks on the bone? Do the breaks represent a natural death and post-depositional breakage or are the breaks indications of marrow processing?

A: A total of 65 bones exhibit evidence of fresh, green breakage. Spiral breakage representing marrow processing is evident on 143 specimens, and 5,989 were broken after drying.

8.4 What degree of the bone has been scavenged by carnivores or rodents? Does rodent scavenging indicate use of the bone while still fresh (rat or mouse gnawing) or scavenging of the bone long after death after bone has dried out (squirrel gnawing)?

A: Of the 8,701 bones recovered from the site, only 73 ( 0.8 percent $)$ demonstrated signs of carnivore or rodent modification. Rodents had gnawed 19 of the bones recovered from the site. Nine bones had been gnawed by mice, rats, or voles. Ten bones had been gnawed by squirrels. Research has shown that brown rats only gnaw bone which is fresh and still laden with fats, while squirrels only gnaw on thicker bone cortices after fats had leached away. Rats will gnaw on bones recently deposits. Squirrels would be more likely to gnaw on bone left exposed for a prolonged period (Klippel and Synstelien 2007). Stratum 2 is the only stratum to have definite association of canids. Temporally, it is during a timeframe when domesticated dogs were utilized by Native Americans both as hunting assistants and transport animals. Stratum 2 also had multiple bone scatters which may have indicated some carnivore scattering.

Question 9: Cultural Use of Bone. What implications are there for use of animal bone beyond a representation of subsistence and consumption of a food resource?

A: A total of 28 bones exhibited evidence of cultural modification for use as tools or art decoration. Due to the paucity of lithic material in the area, it is evident that occupants were utilizing bone for at least some tools instead of stone. This is evident especially with the use of expedient bone tools at the site used for extracting marrow and/or as scrapers. 


\section{Subsidiary Questions}

9.1 Given the paucity of lithic and other organic artifacts recovered from the site, are there indications for use of and/or on-site manufacturing of bone tools? What function did the bone tools serve and what percentage of the assemblage do they represent?

Bone tools represent less than one percent of the assemblage. Tool types include an awl/punch, a billet/hammer, bones with abraded edges from useware, and expedient choppers.

9.2 Were bones modified for use not just as tools but as decorative and/or ritualistic items (e.g., bone beads, pendants, etc.)?

A: In Stratum 3, one polished, smoothed, and chopped bird bone was likely intended as a bead. Also in Stratum 3, a bison femur exhibited spattered asphaltum for intentional decoration or art. A wide variety of abraded expedient bone tools were found in Stratum 2. There were seven bones in Stratum 1b modified for use as tools, including polished bone, a probable billet, and an awl or punch. No culturally modified tools or decorative items were found in Stratum 1a.

9.3 Are markings (e.g., asphaltam, red staining) on bone from the site intentional decoration, functional (localized heating for breakage), or an incident of natural phenomena?

A: One bison femur from Stratum 3 exhibits multiple asphaltum splatters, and three specimens from Stratum 2 exhibit possible asphaltum drips. Multiple bones exhibited localized browning at or directly adjacent to a spiral/green break, suggesting that it was subjected to intense quick heat needed to weaken the bone in a specific area that is typically at the breakage point for marrow extraction from long bones. Staining was the result of localized heating. Asphaltum is intentional decoration.

\section{Burning Replication}

Experiments conducted by Mauldin and Figueroa (2006) demonstrated that measuring magnetic susceptibility values of sediments may have the potential to identify cultural versus natural features. Theoretically, changes in mass-specific susceptibility values should be relative to heating temperatures of a given sample. Mauldin (1998:128-130) has demonstrated that post-firing temperatures in caliche hearths average between $300^{\circ} \mathrm{C}$ and $600^{\circ} \mathrm{C}$ for as much as six hours after firing. In addition, mineralogical changes that occur most commonly when sediments are heated between $300^{\circ} \mathrm{C}$ and $600^{\circ} \mathrm{C}$ may be reflected in magnetic susceptibility values when these same sediments are reheated (Crowther 2003; Dearing 1999).

Assuming subsistence cooking subsistence practices were consistent across 41DL436, and the site was repeatedly used as a short-term logistical activity site, then presumably hearth temperatures should have been relatively consistent. How these temperatures would compare to natural surface burns of downed vegetation is unclear, and a comparative study of temperature ranges in burned clay patches could lend itself to distinguishing groupings. 
Question 10: Magnetic Soil Susceptibility (MSS) Values as Indicators of Subsistence Practices. How do temperatures in cultural hearth features compare to natural surface burns of downed vegetation?

A: Temperatures are dependent upon fuel load, length of burn, and oxygen supply. Studies by Bellomo $(1990 ; 1992)$ indicate surface temperatures of campfires average $400^{\circ} \mathrm{C}$. Other surface hearth replications indicate temperatures between $578-775^{\circ} \mathrm{C}$ (Gillespie et al. 1989:277), $615-805^{\circ} \mathrm{C}$ (stone boiling experiment by Witkind 1977:205), and 400-600 ${ }^{\circ} \mathrm{C}$ (Brink et al. 1986:205). In sum, Bellomo submits that the average campfire temperature is $400^{\circ} \mathrm{C}$, the average tree stump burn is $600^{\circ} \mathrm{C}$, and the average grassfire temperature is $225^{\circ} \mathrm{C}$.

\section{Subsidiary Questions}

10.1 How do magnetic susceptibility values taken at $41 D L 436$ compare to replicated, experimental surface burns and hearth features?

The percentages of MSS enhancement at Feature 12 at 41PR44 are 16.5 percent at what is likely the equivalent of about $400^{\circ} \mathrm{C}$. When the percentage of enhancement approaches 34.7 percent, the implied temperature is roughly $500^{\circ} \mathrm{C}$. Enhancement percentages on a replicated hearth in Bexar County were 15.6 percent at $400^{\circ} \mathrm{C}$, and 27.7 percent at $500^{\circ} \mathrm{C}$.

Thus, by implication the percentages of enhancement can potentially be interpolative to campfires. However, our study of MSS value enhancement at 41DL436 indicate that some features that clearly appear to be tree and root burns fall with the enhancement percentages prescribed for hearths.

However, at least one feature described as an ash and charcoal mass surface burn exhibited an enhancement of 34.54 percent, within the range expected of a surface hearth with a heat temperature reaching approximately $500^{\circ} \mathrm{C}$. On the other hand, the MSS enhancement percentages for some features are exorbitantly higher than the prescribed range of a normal surface campfire. These significantly higher percentages suggest fires of a magnitude well in excess of cultural hearths, and imply that a dense fuel load burned for longer durations at significantly higher temperatures in these select areas.

10.2 Can magnetic susceptibility values reliably be used to differentiate between cultural hearth features and natural burns that have occurred on previously exposed surfaces at $41 D L 436 ?$

A: $\quad$ MSS values can be problematic, primarily due to the mineralogical makeup of the soils and sediments, and most assuredly can be significantly enhanced with the introduction of ash and charcoal. That said, based upon our findings at 41DL436, we believe that the magnitude of percentage increases (enhancement) in MSS values can certainly be used as corroborating evidence for either validating features as cultural, or for discounting selected features that could be misconstrued as cultural in origin. 
10.3 Can magnetic susceptibility values be reliably correlated with hearth stone and clay cooking temperatures, and thus infer subsistence items that were heated, cooked, boiled?

A: Magnetic susceptibility enhancement percentages imply heating temperatures. The values recorded in selected probable cultural hearth features at 41DL436 generally suggest open surface hearths in oxygen-rich environments. These temperatures would have been sufficient for heating foods, cooking foodstuffs over an open fire with a stick or spit, and sufficient to heat boiling stones. As is discussed in Chapters 15 and 16, it is likely that meat was cooked or jerked over an open fire on a stick or spit or possibly in metal pots. In addition, turtle shells may have been used as cooking vessels placed directly into an open fire onto a retained hot bed of coals. It is interesting to note that the turtle shell numbers drop during the historic period, as it could imply turtle shell being replaced by metal pots; but this could also reflect a change in diet. The paucity of raw material in the area would have made the use of boiling stones impractical, and no boiling stones were recovered any of the three projects.

10.4 If magnetic susceptibility values correlate with temperatures in replicated, experimental, firings, do they provide the results that either corroborate, or conflict with the results of lipid and starches analyses?

A: Magnetic susceptibility value enhancement percentages indicate that the surface hearths without fire-cracked rocks reached sufficient temperatures for cooking both meats and plants. However, no susceptibility values were obtained from the fire-cracked rock features which were analyzed for lipids and starches. Therefore, we cannot directly answer this question. However, based upon the enhancement variations observed in selected hearths without firecracked rocks, we see no discrete markers that would suggest their use specifically for cooking plants versus meats.

\section{Human Activity}

Cultural remains at the site include features as well as faunal remains and chipped stone. An initial assessment indicates that cultural materials are horizontally and vertically discrete within well-stratified sediments and soils. Depositional stratification at this site is fine-grained to the extent that individual occupation events can possibly be bracketed to isolate discrete behavioral episodes. Elsewhere, sharply defined stratification has enabled clear demarcation and tracing of individual occupation events (e.g., 41RN169 [Treece et al. 1993]). The burned zones and well-preserved bedding at 41DL436 provide a similar opportunity to define and trace late prehistoric and protohistoric occupations.

Question 11: Occupation Periods and Activities. Can discrete occupations be teased out of the archaeological record? Can human activity within those discrete occupations be well defined?

A: It appears that Stratum 1a and Stratum 2 represent a number of discrete occupations spanning decades to a century or more, thus the analytical units (components) are possibly short term palimpsests (admixed in Stratum 1a and discrete in Stratum 2), so that spatial distribution 
is somewhat blurred. However, four discrete general occupational components (1a, 1b, 2, and 3) appear to be confined to well stratified gizeménts (Collins 1995).

In addition, the overall distribution of probable hearth features with associated fauna suggest that activity was tethered to the paleochannel during the earliest occupation. When the channel shifted, later occupations created hearths adjacent to the modern Fish Creek channel. Based upon the distribution of burn features, lithic debitage, and faunal remains during the $1 \mathrm{~b}$ and 2 occupations, there appears to have been an area in the middle of the site that was not as intensively utilized.

\section{Subsidiary Questions}

\subsection{Are occupation surfaces discrete and well-defined?}

A: Generally, occupation surfaces are discrete and well-defined throughout all periods of occupation except in the upper, historic component when stratigraphy is interrupted, and land clearing began.

\subsection{Are activities occurring at the site spatially isolated?}

A: Hearth features during the earliest occupation were located adjacent to the paleochannel. Hearths moved to the north, next to the modern channel following an avulsion event. During the later part of the early occupation (lower component, Stratum 1b), hearths were constructed on the northern portion of the site, paralleling the modern Fish Creek channel. In later occupations (Middle Component, Stratum 2) hearths were constructed on both the northern and southern portions. Probable surface hearths on the southern portion are more in number, while a bone scatter along the modern channel with a few hearth features suggests and apparent animal processing area. One and possibly two surface hearths were constructed during the historic period (Upper Component-Stratum 3) approximately in the middle of the site.

The distribution of faunal remains across the site also manifested certain patterns. For examples, a greater presence of both deer and bison in the northern portion of the site during the lower component (Stratum 1) occupation, and a probable bison processing area nearest to the modern Fish Creek channel during the middle component occupation (Stratum 2).

\subsection{What do these activities imply in terms of subsistence and mobility through time?}

A: The concentrated, yet sometimes erratic patterning of small hearth features (particularly during the middle component occupations) combined with the faunal remains suggest very temporary encampments by highly mobile groups (possibly task groups) who occupied the site seasonally to exploit the game and plant materials available at various times during the year, from early spring through late fall. 


\section{Subsistence And Mobility}

\section{Theoretical Considerations}

Data obtained from the study of plant remains, starches, lipids, and faunal remains can be applied to optimal foraging theoretical models to infer both subsistence diet breadth and mobility patterns through time (e.g., Kelly 1983, 1988, 1995). Research into the relationships between hunters and gatherers and their environment is seeded in two paradigms; that of Cultural Ecology and Behavioral Ecology. Cultural ecology is based on the premise that cultural and social organizations will adapt to their environment. Steward $(1968,1969)$ believed that technological adaptation to the environment shaped social organizations, and that "The social environment, as contrasted with the natural environment, is also a factor in shaping the nature of any society but its role is minimal in most of these cases." (1969:188). Thus to Steward, subsistence technology was the core of culture (Kelly 1995:42).

Behavioral ecology is based on the premise that cultural and social organization will evolve through Darwinian natural selection. In essence, behavioral ecologists posit that specific activities or actions have developed because through an unintentional evolutionary process whereby humans subconsciously evaluate their ability to survive in certain environments. Furthering their position, behavioral ecologists believe that hunter-gatherer behavior, and thus cultural change is dependent upon the food resources available in the environment (Kelly 1995:52-53). Behavioral ecologists agree that human behavior is based on rational choices, but go beyond and state that natural selection fixes, alters, or maintains the rational choices. Evolutionary theory argues that individuals will methodically forage to optimize their rate of return. Some evolutionists argue that hunter-gatherers will maximize their rate of foraging efficiency, or food intake when: (1) starving (2) specific nutrients are in short supply (3) time is limited (4) foraging is risky or dangerous (5) more food equals more production (Kelly 1995:39-64).

Optimal Foraging Theory is grounded in the behavioral ecology paradigm which assumes that individuals are responsible for their behavior, that through a natural selection process they subconsciously make decisions about the cost and benefits of their actions, and as a result they will always seek to optimize return benefits over the costs involved. Optimal foraging theory is based on the four basic concepts involved in foraging: goals, calories, constraints, and options. The goal of hunter-gatherers is to maximize foraging efficiency, considering the efforts involved in searching for, and handling (processing) resources; calories represent the energy that can be derived from the available resources; constraints represent the availability of resources, or the ability to digest them; and options represent the decisions on whether or not to take the resources that are encountered. In Optimal Foraging Theory the cost-versus-benefits applies particularly to foraging and collecting behavior. Optimal foraging models developed by behavioral ecologists rely on a material means with which to measure productivity; most frequently benefits are measured in terms of caloric return per hour of work (Kelly 1995:3964). In Chapter 15, we extensively discuss the cultural remains and how they are applicable to the diet-breadth model of optimal foraging theory. 
Question 12: Subsistence Practices. What information can be obtained regarding subsistence?

A: Data obtained from the study of plant remains, starches, lipids, and faunal remains can be applied to optimal foraging theoretical models to infer both subsistence diet breadth and mobility patterns through time (e.g., Kelly 1983, 1988, 1995).

\section{Subsidiary Question}

12.1 What are the results studies on faunal remains, plant remains, lipid analysis, and starches analysis?

A: Faunal - An analysis of the faunal remains revealed a very robust and wide variety of fauna in all stratums, and bone preservation was good to excellent. Some appeared to have cut marks caused by humans, a few exhibited use as tools or art, and several exhibited evidence of burning.

Ethnobotanical-With only a single charred grape seed and a probable Mexican plum wood found in 79.5 liters of sediments sampled, the results of floatation analysis regarding evidence of plant foods being cooked and consumed at the site were at best minimal, and less than expected. In addition, samples were submitted from all six features that were clearly identified as apparently intact fire-cracked rock hearths, or fire-cracked rock scatters, and where one would expect the highest return rate for charred plant remains.

Lipids - For the pilot study, Mary Malainey and Timothy Figol conducted an analysis of lipid residues extracted from 12 sandstone fire-cracked rocks from stratums 1 and 2. One specimen contained residue indicating that meat from either a large herbivore (bison or deer) or a javelina was cooked in a sandstone hearth (Feature 2). The level of C18:1 isomers indicated that the meat was lean, suggesting a season (or seasons) when abundant forage was not available. The same FCR specimen contained residue from the seed oil of a tropical plant, such as sotol, a xeric type of plant.

Fire-cracked rocks from Features 7 and 42 yielded evidence of plant residues. Residue extracted from the Feature 7 specimen was derived from the cooking of plants. Residue extracted from the Feature 42 specimen was derived from the cooking of tropical plant seeds, such as sotol.

Starches-Research of this nature in archaeological contexts had thus far been extremely limited in North America, and had not been heretofore attempted at all in the Blackland Prairie region of northern Texas. Timothy Riley analyzed 24 fire-cracked rocks (FCR) for evidence of starches. Although hampered by the paucity of information available regarding subsistence resources in north central Texas, Timothy's analysis nevertheless produced some very interesting results. While none of the starch granules could be clearly matched with the known botanical references, seven different starch types were identified. However, we acknowledge that the presence of starches in archaeological contexts are problematic. That is, it may be that the starches are a by-product of starch rain (Laurence et al. 2011). 


\section{LiThIC TECHNOLOGY}

We approach this research issue by acknowledging the fact that a few cut marks on faunal remains were apparently caused by a metal knife or knives. Thus, at least some degree of meat processing was accomplished with other than stone tools. However, no metal objects in any form were found during any of the three archaeological projects on the site.

Question 13: Lithic Analysis. What information can be obtained from a study of the lithic assemblage?

A: $\quad$ Forty-three pieces of chipped stone were recovered during excavations at 41DL436. Although relatively sparse in numbers, when applied to theoretical models, the tool and debitage types can be used to infer subsistence and mobility practices through time.

\section{Subsidiary Questions}

\subsection{Can chipped stone assemblages be assigned to discrete occupations?}

A: Thirty-seven of the 43 pieces of chipped stone were recovered from the middle cultural component (Stratum 2), two in the lower component (Stratum 1), and two in the upper component (Stratum 3).

\subsection{What types of stone tools are in the assemblage?}

A: One broken arrow point, expediently utilized and sharpened chert flakes, and a re-touched piece of sandstone make up the tool assemblage.

\subsection{What types of lithic debitage are in the assemblage?}

A: Biface manufacturing flakes, uniface and biface thinning and re-sharpening flakes, core reduction flakes, and a piece of angular debris were recovered. Some of the flakes exhibit evidence of re-sharpening and/or utilization.

\subsection{What types of lithic technological variability can be derived from the assemblage?}

A: There are no clear indications in the limited assemblage that will confidently allow for a heavy reliance on one lithic technology versus the other. In fact, bifacial and unifacial technologies appear to be of equal importance.

13.5 What types of stone tools does the debitage assemblage imply were being manufactured or re-sharpened at the site?

A: Late stage bifaces and unifaces in the form of performs or finished tools were being manufactured on the site. Both biface and uniface flakes were then re-sharpened for use. 
Question 14: Availability of Lithic Raw Material. Was stone not available during certain occupation periods?

A: Lithic raw material for manufacturing stone tools was not available in the immediate area, but was likely available within less than one mile, possibly up to three miles upstream.

\section{Subsidiary Questions}

\subsection{Why were more pieces of chipped stone not recovered during the excavations?}

A: The paucity of chipped stone recovered from the site is possibly a direct reflection of the absence of lithic raw material in the general area. All chipped stone pieces had to have been transported in from off-site, either as late stage reduced pieces or as finished tools. Two other possible reasons may account for the lack of the chipped stone (1) non-lithic tools such as bone or wood were being used (2) metal tools replaced the need for stone tools in later period.

\subsection{What type of raw material was used to make stone tools?}

A: Forty-two of the 43 pieces of chipped stone recovered were made from high quality, light gray and pale brown chert. The remaining one was manufactured from red sandstone.

\subsection{What type of raw material was used in hearths as heating elements?}

A: A total of 206 pieces of burned rocks 1-inch or greater in size were found in association with hearth features. Of those, 191 were red predominantly tabular sandstone, five were sandstone/calcite chunks, four were calcite chunks, three were limestone chunks, one was a limestone comglomerate piece, one was purely calcite, and one was a small chert chunk (1-inch in size).

14.4 What geologic formations that could contribute as a raw material source are either in the immediate area of the site, or lie upstream?

A: $\quad$ Site 41DL436 is situated in Fluvatile terrace deposits (Qt), which contain gravels within contiguous terraces of different ages. Approximately 1.4 miles upstream to the west of the site lies the Eagle Ford formation (or Eagle Ford Group undivided). In addition, easterly protudences of the Eagle Ford come within .75 mile of 41DL436. The Eagle Ford Group is comprised of sandstone, shale, and limestone. The shale is characteristically selentic, with calcareous concretions and large septaria; that is, there are large calcite-filled cracks in the Eagle Ford Group, a most likely source for the calcite chunks, as are the sandstones and limestones found at the site (Barnes 1988).

The Eagle Ford Group underlies Austin Chalk, which also contains microangular calcite. Notably, some areas of both Eagle Ford and Austin Chalk are covered with Uvalde and Trinity River gravels. Uvalde gravels are relict deposits carried in Tertiary and Pleistocene riverbeds 
from the High Plains, while Trinity gravels lie within Quaternary-age terrace deposits along the Trinity River basin (Ferring 1990; Brillinger 1985; Allen and Flanigan 1986).

The site lies within Frio silty clay. During trenching to as deep as $4 \mathrm{~m}(13+\mathrm{ft})$ below the surface no gravel concentrations were observed, and small rounded pebbles were extremely rare. However, gravels and limestone can be found at 6 feet below the surface within Frio series clays. To the south and upslope of the site lies Crockett fine sandy loam which is capable of bearing siliceous pebbles. Otherwise, there are 17 different soils types upstream from 41DL436, and many of these could contain chert gravels.

\subsection{How does the potential for raw material exposure compare to the paleoenvironment} and the rates of aggradation at the site through time?

A: Citing paleoenvironmental information from Linda Scott-Cummings et al. and Ken Brown (Chapters 6 and 11), the Fish Creek channel migration at the site as described by Jim Abbott (Chapter 5) occurs first with a lateral migration and slow aggradation of a steepbanked, vegetated point bar, forming Stratum 1a. Sometime between AD 1477 and AD 1634 the channel shifted to its current position along the north edge of the site, coinciding with what Ken Brown opines is a transition period from the Little Climatic Optimum and the Little Ice Age (see Chapter 6). However, this shift was not occur suddenly and with substantial fluviatile energy necessary to expose any underlying gravels, nor transport gravels of any useful size from geological deposits upstream. In sum, although rapid stream runoff may have occurred in the upper reaches of the Fish Creek valley, that energy was generally dissipated by the time the flooding in the site area. The paleoenvironmental data indicates that Fish Creek in the immediate area of the site has not possessed the energy of exposing raw material at any time during the recorded occupations at the site. Thus, any raw material used for the stone debitage and the single point found on the site had to have been procured from off-site. This presumption is supported by the fact that (1) 39 of the 42 (93 percent) pieces of the chipped stone have no cortex, one has roughly 5 percent cortex, one has roughly 10 percent cortex, and only one flake has all of its dorsal cortex remaining, and (2) as discussed in the Lithic Technology section of Chapter 16, the data suggests that stone tools were initially brought to the site either already in late stages of reduction, or as finished tools.

\section{PaleoenVironment}

At present, the paleoenvironmental record in north-central Texas is very poorly understood. However, the results obtained from studies on phytoliths, pollen, ostracods, mussel shells, snails, and other fauna were very productive and encouraging.

\section{Snail Species}

The preservation of snails in the five malacology samples examined during the pilot study was excellent. Interpretation of the snail data is that the site area was covered with a "...mosaic of scattered trees or small groves interspersed with more open, grassy areas". The water in 
Fish Creek was sluggish, slow-moving, and turbid. It had a muddy bottom, and supported an abundance of aquatic vegetation. In general, the interpretations from the snail data corroborate the interpretations from the mussel shell, phytolith, and pollen studies.

\section{Mussel Shell Species}

Overall, the mussel shells were very well preserved. Among the 1,426 valves and fragments examined, remains of eight, and possibly as many as 11 unionid taxa were discovered. In general, the specimens present suggest that the immediate area was periodically inundated with slowly flowing water, and at times became a ponded or backwater area with a soft mud or sandy bottom. One species present suggests a high-water event creating a stream-side oxbow. One shell (Yellow sandshell) identified as clearly incised by humans was recovered from stratum 2 , and is associated with a radiocarbon date of $360+/-25$ B.P. A second shell (Washboard) that may have been transported for use at the site as a scoop or plate was also found.

\section{Ostracods}

Paleoenvironmental interpretations based on pilot study ostracode species recovered from the samples, as well as the absence of ostracode remains, suggest varying and cyclical periods of possible flooding periods or events. As well, they suggest possible periods where the site was not flooded, but was dry enough to create a stable surface appropriate for human occupation. In sum the pilot study of ostracode remains demonstrated that 1) there are ostracodes present, and 2) their preservation is sufficient to yield significant paleoenvironmental information.

\section{Pollen and Phytoliths}

Overall, there was remarkable pollen and phytolith preservation in the 20 samples submitted for study. Based upon the large quantities and wide variety of species found, marked changes in the environment were observed through time, and could be separated into four separate zones. The paleoenvironmental interpretations based on the pollen and phytolith taxa observed in the samples suggest varying and cyclical periods of flooding periods or events. As well, they offer the possibility that the growth of some grasses may have been encouraged for human consumption.

\section{Mussel Shell Isotopes}

Isotope data obtained from 20 samples analyzed yielded a relatively strong separation between two groups from different areas of the site, suggesting that important proxy information might be gleaned from a broader analysis. In addition, the results provided proxy information regarding changes in temperature through time. 


\section{Other Fauna}

Jodi Jacobson's analysis of 8,701 identified specimens indicated they were incredibly diverse, and representative of multiple habitats. Some animals present were typically those found in forest or on forest edges, some preferred shrub brush/chaparral habitats, others open prairie and grasslands, or arid spaces relatively devoid of vegetation. Finally, a large and diverse number would have preferred an aquatic/wetlands habitat. Such a robust and diverse faunal assemblage is indeed unique and very informative (see Chapter 15).

Question 15: Paleoenvironmental Information. What paleoenvironmental information was obtained?

\section{A: Depositional Episodes and Landscape Stability}

Jim Abbott and Charles Frederick laid the groundwork in Chapter 5 by using multiple lines of evidence to reconstruct the depositional episodes and landscape stability resulting from periodic inundation of the site by Fish Creek over the past roughly 1,100 years. As discussed extensively in Chapter 16, periods of landscape stability pretty much coincided with peaks in evidence of human occupation.

\section{Snail Species}

In his study of 12,769 snail shells, countable shell fragments, peaclams and freshwater limpets, Ken Brown (Chapter 6) found that preservation in the ten malacology samples examined was excellent. Although the creek obviously flooded the site periodically following heavy rainfall upstream, the aquatic biota suggest Late Holocene Fish Creek was predominantly a groundwater-supported stream, not an intermittent runoff-dominated stream.

At 41DL436, Depositional Unit 1 accumulated during the waning phase of the Medieval Climatic Anomaly (MCA), a period of elevated temperature temperatures peaking roughly 1000-1100 AD. In the Plains and Southwest, the MCA was marked by multidecadal droughts that were similar in geographic extent to modern examples, but much more prolonged (20-40 years) than anything in the historic record. More precisely, Ken defines the years that droughts occurred in the Dallas area based upon the Palmer Drought Severity Index. Following a cooling trend, it appears that the Little Ice Age comes about, with the lowest temperatures occurring perhaps around 1600-1750 AD.

The aquatic biota suggest that Fish Creek was a sluggish, probably poorly oxygenated, muddy, groundwater-supported stream, heavily choked with aquatic vegetation, but probably not subject to seasonal drying even during the MCA. The snail data suggest that there is a slight tendency for an increase in tree canopy over time, but the major increase in woodland extent occurred very late, probably within the last two centuries, and might have been due to fire suppression by Euroamerican settlers. In general, the interpretations from the snail data corroborate the interpretations from the mussel shell, phytolith, and pollen studies. 


\section{Mussel Shell Species}

In the 1,426 valves and fragments that Bob Howells examined, he found shell remains of eight, and possibly as many as 11 unionid taxa. In general, the specimens present suggest that the immediate area was periodically inundated with slow flowing water, and at times became a ponded or backwater area with a soft mud or sandy bottom. One species present suggests a high-water event creating a stream-side oxbow.

\section{Mussel Shell Isotopes}

David Brown analyzed isotope data from 20 selected mussel shells and discovered discrete differences in Lower Component samples from Strata 1a versus 1b. Specifically, it appears that the mussels within Strata $1 \mathrm{~b}$ were developed acquiring an isotopic signature indicating the temperatures were as much as ten degrees cooler when compared to those in Strata $1 \mathrm{~b}$. He surmises that this could possibly be a Little Ice Age indicator.

\section{Ethnobotanical Remains}

Phil Dering identified carbonized plant remains in nine out of ten floatation samples submitted for analysis. The only charred item that can be construed as a prehistoric consumable was a grape seed. Otherwise, Dering submits that the wood charcoal taxa found were unusual, and therefore provide useful evidence of environmental change. That is, the site appears to have been covered predominately with smaller trees that are most commonly found in an edge area along or adjacent to creek terraces. The presence of honey locust suggests disturbed ground, Mexican plum and/or Hawthorne wood suggests an understory in a moist environment, and a grape seed suggests vines on smaller trees near a clearing. Overall, Dering's findings infer a mixed of closed and open canopy along Fish Creek.

\section{Ostracode Remains}

Although the number of ostracode shells recovered was relatively low compared to samples of like size from other sites, Mervin Kontrovitz was able to identify a sufficient number so as to interpret possible cyclical changes in the paleoenvironment. Based on the ostracode species recovered from the samples, as well as the absence of ostracode remains, suggest varying and cyclical periods of possible flooding periods or events. As well, they suggest possible periods where the site was not flooded, but was dry enough to create a stable surface appropriate for human occupation.

\section{Diatoms}

Paleoenvironmental interpretations based on the diatom species recovered, as well as the absence of diatom remains in certain levels, suggest varying and cyclical flooding events and drying periods. In the ten samples submitted from Unit 49, Barbara Winsborough found a total of 90 diatoms representing ten species, and two fragments that could be identified to the genus 
level. Most notably however, is that 88 of the 90 diatoms were found in the lower three levels sampled, all within Stratum 1a. With the exception of 150-160 cmbs in Unit 49 (Strata 1a) that indicates wetter conditions, most of the species are found typically in aerial habitats that are frequently to occasionally wetted, such as a mud flat, temporary pond, depression or overbank environment that was sometimes flooded from a stream.

\section{Pollen and Phytoliths}

Linda Scott-Cummings, Chad Yost, and R. A. Varney found remarkable pollen and phytolith preservation in the 20 samples submitted from Unit 49. Based upon the large quantities and wide variety of species found, they observed marked changes in the environment through time, and were able to separate these changes into four separate zones. As shown in Table 17-5, the paleoenvironmental interpretations based on the pollen and phytolith taxa observed in the samples suggest varying and cyclical periods of flooding periods or events. As well, they offer the possibility that the growth of Zea-maize and some grasses may have been encouraged for human consumption.

\section{Faunal Remains}

Jodi Jacobson's analysis of 8,701 identified specimens indicated they were incredibly diverse, and representative of multiple habitats. Some animals present were typically those found in forest or on forest edges, some preferred shrub brush/chaparral habitats, others open prairie and grasslands, or arid spaces relatively devoid of vegetation. Finally, a large and diverse number would have preferred an aquatic/wetlands habitat. Such a robust and diverse faunal assemblage is indeed unique and very informative.

\section{Subsidiary Questions}

15.1 Based upon the results of the studies, what sample analyses provided the least amount of information?

A: In our opinion, the least amount of useful information was derived from the starches study, followed in order of least importance by diatoms, ostracods, and ethnobotanical.

\subsection{How can depositional trends be attributed to the relative robustness or decline in} sample ubiquities through time?

A: As stated previously, the site appears to exhibit several gizemonts, or well-defined cultural strata enveloped by gently laid-down alluvium sediments from Fish Creek. The stratigraphic integrity at the site is high, while the spatial integrity could have been compromised to a degree by flooding. Because most conditions that would adversely affect artifact preservation (e.g., shrink-swell processes that could cause physical damage, acidic soil conditions, cyclic wetting and drying) are not present, compositional integrity of the assemblage is probably relatively high. 
However, depositional and erosional sequences were detected in our studies. For example, an avulsion, or channel shift, was probably driven by changes in the broader environment, including significant soil erosion in the catchment and shifts in the scale and possibly the frequency of flooding. A series of megadroughts were detected during the lower component occupations (Stratum 1a), events resulting from the depletion of ground cover, when eolian deposits buried paleosols that developed in wetter periods, and channel incision occurred in local streams. In Stratum 1b (lower component), it appears that most overbank deposition occurred during spring or early summer floods. Increased precipitation and ground cover during the middle component occupations enhanced soil development and landform stability. During the upper component occupation(s), the landform was relatively stable, allowing for more dense vegetation, and hence a thicker cover of duff and downed timber.

Other indications of deposition and exposure were examined in the faunal record. Among other causes, taphonomic wasting of fauna occurs due to weathering. The degree of weathering on bones can be used to compare the temporally-relative depositional processes; i.e. how long they were on the surface, or how quickly they were covered by sediments. Understandably, different bones weather or age under varying exposures to sun and moisture, temperature, and soil conditions. However, again with caution, the degree of weathering on a collection of bones as a whole can infer depositional processes (Lyman 1994:405). In discussing the biostratinomic and taphonomic processes of bone burial, Weigelt (1989:18) states that "The more the bones are exposed to the air, the more quickly they disintegrate," and Lyman (1994:405) opines that "...subsequent to the initial deposition of a bone (upon an animal's death), the sooner that a bone is buried beneath the sediment-air interface for good, the better preserved (more like it was in life) it will often be." And Meissner (1998:48) summarizes "If most of the bone shows little weathering, then the implication is that the bone was buried immediately after deposition. If all the bone has roughly the same degree of weathering it will suggest that it was deposited at roughly the same time and spent roughly the same amount of time on the surface before being buried. A great deal of differentiation in weathering will suggest different depositional scenarios."

At the Fish Creek Slough site, Jodi Jacobson found that in the lower component (Stratum 1a) the majority of the bone was buried just after use, but a lesser quantity was left exposed for a longer time before burial. Also in the lower component (Stratum 1b), she found that the majority of the bones were left exposed on the surface for a small period of time before being buried. The majority of the faunal remains in the middle component (Stratum 2) exhibited weathering that is indicative of an archaeological site where cultural materials are buried relatively quickly after the site is abandoned. In sum, the predominance of the faunal assemblage indicates frequent flooding across the site.

\section{$\underline{\text { SUMMARY }}$}

All of the research issues discussed in Chapter 3 were addressed during this project. Employing multiple lines of evidence, the overall goals of the project to establish the site formation processes and its integrity, identify cultural zones or components, identify and document burned features in an effort to determine their association with either cultural events, obtain 
paleoenvironmental information, and examine the probable subsistence and mobility patterns through time were met for the most part with high success. A research issue that could not be answered with a high degree of confidence is the ability to clearly distinguish between cultural hearths and natural surface burns. 


\title{
Chapter 19 \\ Summary, Conclusions And \\ RECOMMENDATIONS
}

\author{
David L. Nickels, James T. Abbott, W. NicholasTrierweiler
}

\section{Summary ANd Conclusions}

During all three archaeological investigations at this site (2005, June 2010, October 2010), excavators documented amorphous burned clay, ash, and charcoal lenses and masses, and an abundance of faunal remains. The October 2010 geoarchaeological study revealed a very well stratified depositional sequence encapsulating cultural materials in discrete, high integrity zones. Data recovery excavations in October 2010 documented the presence of 42 cultural and non-cultural features, including five fire-cracked rock hearths, open surface hearths without rocks, as well apparent natural burns of toppled trees and roots. The data recovery efforts effectively mitigated any adverse effect to the portion of the site that will be impacted by construction of the Lake Ridge Parkway extension, and bridge over Fish Creek.

\section{Climate and Biota}

Although multiple datasets indicate that for the most part the climate has not changed significantly over the past perhaps 1,000 years, there are distinct and discrete markers within that time. To wit, the snails examined corroborate the influence of the Medieval Climatic Anomaly with elevated temperatures peaking around 1000-1100 AD, and a subsequent cooling trend culminating in a peak in the Little Ice Age around $1500 \mathrm{AD}$. Isotope analysis on mussel shells from the site also belies the presence of the Little Ice Age, with temperatures as much as 10 degrees $(\mathrm{F})$ cooler than today.

Geoarchaeological investigations of the terrace deposits suggests that the Fish Creek channel underwent an avulsion event sometime around AD 1550, accompanied by a surface scour event, most probably in conjunction with the peak in the Little Ice Age. This resulted in a shift from a Fish Creek paleochannel along the southwest edge of the site to its present position along the northeast edge of the site. Overall, the terrace sediments and soils revealed cyclical episodes of flood inundations followed by landscape stability, allowing for new vegetation to flourish, and inviting periodic human habitation.

Although the aquatic snail species suggest that Fish Creek was predominately a groundwatersupported stream in the past, today it only flows during heavy rainfalls. Otherwise, the biological remains analyzed indicate that before historic development and intervention, the creek was probably a sluggish, slow flowing, oxygen poor body of water with a muddy bottom, 
and choked with aquatic vegetation. The periodic spring and early summer overbank flooding left behind ponded backwater areas with soft mud and sands.

The subtle changes in climate and alluvial deposits caused adaptable changes in vegetation. Before roughly AD 1500-1550, vegetation influenced by the Medieval Climatic's relatively drier and warmer climate thrived on a point bar, but with a declining water table and sporadic intervals of high water and flooding, the humid climate allowed for diminishing riparian vegetation, forests, and forest edges in the immediate area. With the advent of the Little Ice Age, the cooler and more moist conditions enabled a mosaic of both wooded and open microhabitats, with groves of cottonwoods, willows and elms trees along the creek, as well as open prairies along its slopes.

With a warming trend following the Little Ice Age, perhaps around AD 1700 the habitat gradually became more open, with $\mathrm{C}_{4}$ tall grasses and forbs, cottonwoods, willows, pines, oaks, hackberries, juniper, and elms in open areas, but with sedges, $\mathrm{C}_{3}$ grasses and a more closed tree canopy with at least some grape vines along the creek. Pollen data from the upper portion of the site indicate that by the 1800s historic era changes are apparent. Oak trees are now predominant, with alder, hickory, pecan, hackberry, ash, pine, elm, and others. The introduction of thistle, marsh elders, dandelions, and an assortment of others further attest to an historic presence in the area.

\section{Human ACTIVITy}

Recognizing the possibility that old wood was burned, radiocarbon ages obtained from wood charcoal suggest that site is a well-stratified multi-component Late Prehistoric, Protohistoric, and Historic open campsite. Four discrete occupational components were defined, with the earliest occupation occurring possibly as early as AD 980, and the last (pre-modern) occupation possibly as late as AD 1865. The cultural materials within these four components represent relatively short term occupations confined within four separable depositional units, but separated temporally by perhaps a season, a year, a decade, or several decades. For example, charcoal ages from Cultural Component 2 range from about AD 1425-1705, but the cultural features and materials lie vertically within Depositional Unit 2 (Stratum 2), which is as much as a meter thick.

During the earliest period of occupations spanning roughly AD 1000-1500, hearths and faunal remains appeared to be tethered to the Fish Creek paleochannel. Following an avulsion event sometime around AD 1500, later occupations (ca. AD 1500-1700) tended to construct hearths approximately $20 \mathrm{~m}$ away from the modern Fish Creek channel, while processing most fauna, including a bison processing area, nearer the channel, leaving an apparent gap between the cooking/living areas and the discarded bones. The later occupancy (ca. AD 1700-1870) appears to have been less intense and perhaps of relatively shorter duration, camping nearer the middle of the site, and leaving little in the way of faunal remains. Ethnographic accounts from roughly 1700 through 1870 generally agree with this observation, as tribes would have had horses to remove their equipment, plus metal would have replaced lithics. Also, the area was generally in 
turmoil, as it was being used by multiple Plains tribes competing for dwindling territories and food sources; thus, stays of short duration would have been presumably safer.

Possible divisions of labor were implied by the faunal species being exploited. That is, throughout the earlier occupations the abundance of turtles and some fish suggest that these smaller and slower species were being gathered and caught by perhaps young persons, or less physically able adults. It is apparent that more fish were being caught during the latest occupation (ca. AD 1700-1870). In terms of prey choice versus prey availability, bison would have been preferred because of the high yield. However, bison did not appear to have been available in abundance at any time during site occupations. Instead, a high reliance was placed on artiodactyls, supplemented by a wide variety of terrestrial and aquatic animals. In sum, when bison is present there is an overall low species diversity in the diet, and conversely, when bison are low in abundance, the occupants broadened their diet.

During the earliest occupations (ca. AD 1000-1500) there appears to have been a relatively lesser dependence on bovids, but with a greater reliance on deer/pronghorn and other mammals, as well as reptiles and fish. From about AD 1500-1700 there is a very heavy dependency on bovids as a food source, with significantly less dependency on all other animals except amphibians. During the roughly AD 1700-1870 period, the site occupants once again relied significantly less on bovids, and instead diversified their prey choices. Overall, bone elements and butchering marks on the faunal remains are consistent with meat removal and marrow extraction. However, based upon the low frequency of intentional breakage and high percentage of unbroken bone, dietary stress must not have been remarkable. The bone does not indicate a high degree of marrow processing, and there is little if any evidence for bone grease.

It appears that during the early occupation (ca. AD 1000-1500) kill locations for animals were likely nearby, and selected elements transported to the site for further processing. In addition, the higher utility portions of bovids and deer were then transported away from the site upon abandonment. During the roughly AD 1500-1700 timeframe, the faunal remains suggest that it is likely deer were killed at or near the site, and high utility portions were transported away from the site. The bison remains found at the site imply that the animals were killed maybe a half mile from the site, and the choice cuts were removed from the bone before returning to the site. The same is basically true for the later period (ca. AD 1700-1870) when guns and horses likely caused an increase in hunting distance.

While no evidence was found that could construe snails being harvested for consumption during any time period, an abundance of mussel shells found in Stratum 1a (Feature 11) indicates that around AD 1375-1425 mussels were being heavily relied upon as a supplemental food source. Other than during that time period, mussels may have been only a very minor part of the diet.

A single charred grape seed and a fragment of Mexican plum wood suggest a possibility that grapes and plums were available seasonally. Otherwise, pollen and phytoliths recovered hint at the possibility of some degree of horticulture. Intentional burning of the landscape is hinted at during in the Lower Cultural Component, sometime between about AD 1000-1500. An abnormally high percentage of $\mathrm{C}_{3}$ Pooideae grasses recovered from a probable surface hearth 
(Feature 37) fired between about AD 1500-1700 suggests that intentional burning may been conducted to increase the frequency of these type of grasses on the site. Numerous epidermal elements of phytoliths that can be indicative of grass utilization for subsistence were also found, and the cultivation of Little barley grass (Hordeum pusillum) in conjunction with intentional burning of the fields is feasible. In addition, although not purely diagnostic, a maize-like (Zea mays) phytolith was recovered from the same probable surface hearth. In sum, although no conclusive evidence was found that any surface burns were intentionally set as part of early forms of horticulture or agriculture, based upon the pollen and phytolith data, the possibility that some degree of horticulture/agriculture occurred cannot be ruled out.

Given the Late Prehistoric temporal association during the earlier occupations of the site, one would normally expect a robust stone tool assemblage. However, that is not the case at 41DL436. A total of 43 pieces of chipped stone were recovered and analyzed. One of those was a broken Guerrero-like arrow point that was found in the ca. AD 1700-1870 occupation zone, along with a single flake. Thirty-seven flakes were found in the ca. AD 1500-1700 occupation zone, and two flakes in the ca. AD 1000-1500 zone. The artifacts exhibited evidence of both bifacial and unifacial technology, with no preference for either. All were made from Edwards chert except for an additional piece of serrated sandstone. It is apparent that stone tools were transported to the site and re-sharpened. The very small flakes, many of which were utilized strongly suggest that the occupants were curating, utilizing, and exhausting any stone tools available. A raw material study conducted on stone collected from Fish Creek reinforces the presumption that quality raw material in any for was not available in the area.

In lieu of stone tools, the site occupants in some cases used metal knives and bone. Metal cut marks were observed on bone recovered from both the ca. AD 1500-1700 and ca. AD 1700-1870 occupation zones. The metal cutmarks increase in frequency and demonstrate an increasing reliance on European-introduced technology over time. It could be that metal knives became the primary butchering tools and lithics were used as backup only. Another "tool" employed during the ca. AD 1500-1700 period was a firearm, evidenced by apparent birdshotsized pellet markings observed on a bison humerus.

Other stone tools recovered include pieces of ground stone from Feature 5, a fire-cracked rock hearth with charcoal dating to AD 1345-1395 and Feature 9, a bone bed area with charcoal assayed at between AD 1535 and 1585. Bone modified for use as tools include polished bone, a probable billet, and an awl or punch recovered from the ca. AD 1000-1500 occupation zone, and a number of expediently utilized bone pieces found in the ca. AD 1500-1700 occupation zone. Not often thought of as "tools" are turtle shells. However, given the absence of ceramics at this site and a high ubiquity of burned turtle shells it is surmised that turtle shells may have been used as cooking vessels, especially during the ca, AD 1500-1700 period. Finally, a Washboard mussel shell that may have been transported for use at the site as a scoop or plate was found in association with a radiocarbon age of AD 1375-1475. 


\section{DECORATIVE ITEMS}

The occupants were not without creative artistic designs. For example, one Yellow sandshell identified as clearly incised by humans was recovered from Stratum 2 (Unit 102), and is associated with a radiocarbon date of between AD 1565-1615. In addition, a possible bone bead blank and a bison femur with intentional asphaltum splatters were found in the later occupation zone (Stratum 3).

\section{Cultural Affiliations and Named Native American Groups}

Unlike most very late Late Prehistoric Toyah components, no Native American ceramics, no Perdiz points, no beveled knives, and only a scant few pieces of chipped stone were found in Stratum 1a at 41DL436. As discussed in Chapter 2, Europeans were known to have occasionally passed through the area in the late $1500 \mathrm{~s}$, and by the 1840s had begun settlements. Although it is not known what Native American groups were in the area of 41DL436 from 1500 through 1700 , it is possible that members of the Wichita Confederacy occupied the site in the earlier part of the Protohistoric period.

Subsequent occupants may have been either the Kichai, Ionis, Tonkawa, Wichita, Taovayas, Tawakoni, Yscani, Waco, and Kichai. Later early Historic groups who may have temporarily occupied the site are the more mobile Comanche, Kiowa, and Lipan Apache. By 1837 there was a Kickapoo encampment in the area that is modern-day Dallas, and whites reported that the Waco on Village Creek Indian tribe occupied much of present-day Tarrant County, and the Shawnee occupied the Grayson and Cook County region. In addition, scattered bands roamed the upper tributaries of the Trinity in the 1840s. In 1822, the Delaware were reported as peaceful hunters in what is today Fannin County, while in 1845 the Creeks, Cherokees, Caddoes, and Wichitas continued to either occupy or raid within the region. 


\section{REFERENCES}

Abbott, J. T.

2010 Geoarcheological Observations at 41DL436, Dallas County, Texas. Texas Department of Transportation, Environmental Affairs Division, Austin.

2011 Geoarcheology of North-Central Texas: A Framework for Archeological Investigation, Interpretation, and Cultural Resource Management in the Fort Worth Highway District. Report 130, Archeological Studies Program, Environmental Affairs Division, Texas Department of Transportation.

Adavasio, J. M., and J. Page

2002 The First Americans. In Pursuit of Archaeology's Greatest Mystery. Random House Publishing, New York.

Aitken, M. J.

1974 Physics and Archaeology, 2nd Ed. Oxford: Clarendon Press.

Albert, L. E., and D. G. Wyckoff

1984 Oklahoma Environments: Past and Present. In Oklahoma Archaeology, edited by Robert E. Bell, pp. 1-44, Academic Press, Inc. Orlando.

Alperson-Afil, N., D. Richter, and N. Goren-Inbar

2013 Phantom Hearths and the Use of Fire at Gesher Benot Ya'agov, Israel. PaleoAnthropology 1-15. http://ww.eva.mpg.de/evolution/staff/richter/pdf/07-Richter Paleoanthropology.pdf [Accessed August 20, 2013].

Anderson, P. C.

1980 A Testimony of Prehistoric Tasks: Diagnostic Residues on Stone Tool Working Edges. World Archaeology 12(2):181-194.

Anderson, F.

2005 The War that Made America: A Short History of the French and Indian War. Viking Press, New York.

Andrews, P.

1990 Owls, Caves, and Fossils. University of Chicago Press, Chicago, Illinois. 
Anthony, D., and D. O. Brown

1994 Archaeological Investigations in the Denton Creek Floodplain. Data Recovery Excavations at 41DL270, Denton and Dallas Counties. Hicks and Company Archaeology Series 37, Austin, Texas.

Aptroot, A., and B. van Geel

2006 Fungi of the Colon of the Yukagir Mammoth and from Stratigraphically Related Permafrost Samples. Review of Palaeobotany ad Palynology 141:225-230.

Autio, K.

2001 Light Microscopic Techniques to Understand Starch Digestibility. Manipulating Pig Production VIII:235-239.

Babot, M. del P.

2003 Starch Grain Damage as an Indicator of Food Processing. In Phytolith and Starch Research in the Australian-Pacific-Asian Regions: The State of the Art. D. M. Hart and L. A. Wallis, eds., pp. 69-82. Terra Australis, Vol. 19. Canberra: Pandanus Books.

Badenhuizen, N. P.

1965 Occurence and Development of Starch in Plants In Starch: Chemistry and Technology. R. L. Whistler and E. F. Paschall, eds., pp. 65-104. Academic Press, London.

Bailey, A. W., and M. L. Anderson

1980 Fire Temperatures in Grass, Shrub and Aspen Forest Communities of Central Alberta. Journal of Range Management 33(1):37040.

Baker, B. W.

1998 Vertebrate Faunal Remains from the 1/4-inch and 1/8-inch screens. In Wilson Leonard: An 11,000-year Archeological Record of Hunter-Gatherers in Central Texas, Vol V: Special Studies. Edited by M. W. Collins. Studies in Archeology 31, Texas Archeological Research Laboratory, The University of Texas at Austin; Archeology Studies Program, Report 10, Texas Department of Transportation, Environmental Affairs Division, Austin.

Balkwill, D. M., and S. L. Cumbaa

1992 A Guide to the Identification of Postcranial Bones of Bos Taurus and Bison bison. Syllogeus 71, Canadian Museum of Nature, Ottawa, Ontario, Canada.

Barnard, H., A. N. Dooley, and K. F. Faull

2007 Chapter 5: An Introduction to Archaeological Lipid Analysis by GC/MS. In Theory and Practice of Archaeological Residue Analysis, edited by H. Barnard and J. W. Eerkens, pp.4260. British Archaeological Reports International Series 1650. Oxford, UK. 
Barnes, V. E. (Ed)

1983 Geologic Atlas of Texas: San Antonio Sheet. Bureau of Economic Geology, The University of Texas at Austin.

1987 Geologic Atlas of Texas, Dallas Sheet, 1972 Revised 1987. Gayle Scott Memorial Edition. Bureau of Economic Geology, University of Texas at Austin.

Barton, H., and R. Fullagar

2006 Microscopy. In Ancient Starch Research. R. Torrence and H. Barton, eds. pp. 47-52. Left Hand Press. Walnut Creek, California.

Baugh, S.

1986 Late Prehistoric Bison Distributions in Oklahoma. In Current Trends in Southern Plains Archeology, edited by T. Baugh, pp. 83-96. Memoir No. 21. Plains Anthropologist, Lincoln.

Behrensmeyer, A. K.

1978 Taphonomic and Ecologic Information from Bone Weathering. Paleobiology. 4:150-162.

Bellomo, R. V.

1990 Methods for Documenting Unequivocal Evidence of Humanly-Controlled Fire at Early Pleistocene Archaeological Sites in East Africa: The Role of Actualistic Studies. Unpublished Ph.D. Dissertation. University of Wisconsin-Milwaukee.

1993 A Methodological Approach to Identifying Archaeological Evidence of Fire Resulting from Human Activities. Journal of Archaeological Sciences 20:523-553.

1994 Methods of Determining Early Hominid Behavioral Activities Associated with the Controlled Use of Fire at FxJj 20 Main, Koobi Fora. Journal of Human Evolution 27:173-194.

Belovsky, G.

1987 Hunter-Gatherer Foraging: A Linear Programming Approach. Journal of Anthropological Archaeology 6:29-76.

Benson, R. H.

1961 Ecology of Ostracode Assemblages. In R. C. Moore (Ed.), Treatise on Invertebrate Paleontology, Volume Q56 - Q63. University of Kansas Press, Lawrence.

Binford, L. R.

1962 Archaeology as Anthropology. American Antiquity 28(2):217-225.

1965 Archaeological Systematics and the Study of Culture Process. American Antiquity 31:203-10.

1973 Interassemblage Variability - the Mousterian and the "Functional" Argument. In The Explanation of Culture Change, pp. 227-254, edited by C. Renfrew. London Press.

1978 Nunamiut Ethnoarchaeology. Academic Press, New York. 
1979 Organization and Formation Processes: Looking at Curated Techniques. Journal of Anthropological Research 35(3):255-273.

1980 Willow Smoke and Dog's Tails: Hunter-Gatherer Settlement Systems and Archaeological Site Formation. American Antiquity 45:4-20.

1983 In Pursuit of the Past: Decoding the Archaeological Record. Thames and Hudson, New York.

1991 When the Going Gets Tough, the Tough Get Going: Nunamiut Local Groups, Camping Patterns and Economic Organization. Ethnoarchaeological Approaches to Mobile Campsites: Hunter-Gatherer and Pastoralist Case Studies, edited by C. S. Gamble and W. A. Bolsmier, pp. 25-137. International Monographs in Prehistory, Ann Arbor.

Birkeland, P. W.

1974 Pedology, Weathering, and Geomorphological Research. Oxford University Press, London.

Black, S. L.

1989 Central Texas Plateau Prairie. In From the Gulf to the Rio Grande: Human Adaptation in Central, South, and Lower Pecos Texas, by T. R. Hester, S. L. Black, D. G. Steele, B. W. Olive, A. A. Fox, K. J. Reinhard, and L. C. Bement, pp. 17-36. Research Series No. 33. Arkansas Archeological Survey, Fayetville.

Blaine, J. C.

1993 Firearms and Related Artifacts from the Vinson Site. Bulletin of the Texas Archeological Society (57):221:163-186.

Bleed, $\mathrm{P}$.

1986 The Optimal Design of Hunting Weapons: Maintainability or Reliability. In American Antiquity 51:737-747.

Blum, M. D., and S. Valastro, Jr.

1989 Response of the Pedernales River of central Texas to Late Holocene climatic change. Annals of the Association of American Geographers 79:435-456.

Bogan, A. E.

1996 Decline and Decimation: The Extirpation of Unionid Freshwater Bivalves in North America. Journal of Shellfish Research 15:484.

Bolton, H. E. (editor and translator)

1914 Athanase de Mézières and the Louisiana-Texas Frontier, 1768-1780 (2 Volumes). Arthur H. Clarke Co, Cleveland, Ohio.

Borgreen, M. J.

2010 The Reproductive Performance of Bison at the National Bison Range. Unpublished M. A. thesis, Montana State University, Bozeman, Montana 
Bousman, B. C.

1998 Paleoenvironmental Change in Central Texas: The Palynological Evidence. Plains Anthropologist. 43(164):201-219.

Bousman, C. B.

1993 Hunter-Gatherer Adaptations, Economic Risk and Tool Design. In Lithic Technology 18(1\&2):59-86.

Bowman, S.

1990 Interpreting the Past: Radiocarbon Dating. Berkeley: University of California Press.

Boyd, M., C. Surette, and B. A. Nicholson

2006 Archaeobotanical Evidence of Prehistoric Maize (Zea mays) Consumption at the Northern Edge of the Great Plains. Journal of Archaeological Science 33(8):1129-1140.

Bradley, R. S.

1984 Quaternary Paleoclimatology: Methods of Paleoclimatic Reconstruction. Allen \& Unwin, London.

Brink, J. M., M. Wright, B. Dawe, and D. Glaum

1986 Final Report of the 1984 Season at Head-Smashed-In Buffalo Jump, Alberta. Manuscript Series No. 9, Archaeological Survey of Alberta, Edmonton.

Bronk R. C.

2005 OxCal. 3.1 ed. www.rlaha.ox.ac.uk/oxcal/oxcal.htm.

2008 Depositional Models for Chronological Records. Quaternary Science Reviews 27 (1-2):42-60.

2009 Bayesian Analysis of Radiocarbon Dates. Radiocarbon 51(1):337-360.

Brown, D. O.

1987a Aquilla Lake Food Resource Exploitation: Catchment Analysis Evaluation. In Archeology at Aquilla Lake: 1978-1982 Investigations. Volume III, compiled by David O. Brown. Texas Archeological Survey, Research Report 81, The University of Texas at Austin.

1987b Floodplain Sites Summary. In Archeology at Aquilla Lake: 1978-1982 Investigations. Volume II, compiled by David O. Brown. Texas Archeological Survey, Research Report 81, The University of Texas at Austin.

1994a Freshwater Shell Isotope Studies. In Archeological Investigations in the Denton Creek Floodplain: Data Recovery Excavations at 41DL270, Denton and Dallas Counties, Texas. Edited by Dana Anthony and David O. Brown. Hicks \& Company, Archeology Series 37. Austin, Texas.

1994b Past Climates of North Central Texas. Paper presented at the annual meeting of the Plains Anthropological Conference, Lubbock, Texas. 
1998 Late Holocene Climates of North-Central Texas. Plains Anthropologist 43(164):168-157.

1999 Tracking Texas Paleoclimates-Oxygen Isotopes as Proxy Climatic Indicators. Paper presented at the annual meeting of the Texas Archeological Society. Fort Worth, Texas.

2004 Freshwater Shell Isotopes and Holocene Paleoclimatic Reconstruction in South-Central Texas. Paper presented at the annual meeting of the Texas Academy of Science, Kerrville.

2007 Freshwater Shell Isotope Studies at Applewhite Reservoir. In Archaeological and Paleoecological Investigations at the Richard Beene Site, 41BX831, South-Central Texas. Volume I: Paleoecological Studies, Cultural Contexts, and Excavation Strategies. Edited by Alston V. Thoms and Rolfe D. Mandel, pp 101-112. Reports of Investigation No. 8, Center for Ecological Archaeology, Texas A\&M University, College Station.

2010 Paleoclimatic Implications of Isotopic Compositions of Freshwater Mussel Shell. In Archaeological Excavation of a Deeply Buried Paleoindian Component at the Vara Daniel Site (41TV1364), Travis County, Texas. By David L. Nickels, Mason Miller, and Nicholas Trierweiler. Ecological Communications Corporation, Austin.

Brown, D. O., G. Fredlund, and R. Neck

2007 Molluscan Fauna and Holocene Paleoclimatic Reconstruction in South-Central Texas. Paper presented at the annual meeting of the Society for American Archaeology, Austin, Texas.

Brownlow, R. K.

2001 The Testing of Four Sites at the Texas Army National Guard's Fort Wolters Facility, parker County, Texas. Studies in Archeology 37, Texas Archeological Research Laboratory, The University of Texas at Austin. Environmental Report 2, Texas Army National Guard, Austin.

Brownlow, R. K., D. J. Prikryl, T. Gustavson, J. Garner, and M. B. Collins

1999 An Intensive Cultural Resources Survey of the Texas Army National Guard's Fort Wolters Facility, Parker and Palo Pinto Counties, Texas. Studies in Archeology 32, Texas Archeological Research Laboratory, The University of Texas at Austin. Environmental Report 1, Texas Army National Guard, Austin.

Bryant, V. M., Jr.

1974 Prehistoric Diet in Southwest Texas: The Coprolite Evidence. American Antiquity. 39:407-420.

Buechner, H. K.

1950 Life History, Ecology, and Range Use of the Pronghorn Antelope in Trans-Pecos Texas. American Midland Naturalist 43(2):257-354.

Bull, W. B.

1991 Geomorphic Responses to Climatic Change. Oxford University Press, Oxford, England. 
Bullock, P. Y.

2001 Laguna Gatuna: Excavations at LA 120945, Lea County, New Mexico. Museum of New Mexico Office of Archaeological Studies, Archaeological Notes 282, Santa Fe, New Mexico.

Bureau Veritas North America, Inc.

2008 Geotechnical Data Report, Proposed Lake Ridge Parkway Extension, Grand Prairie, Texas. BNVA Project No. DE08-008, Richardson, Texas.

Burt, R. (ed.)

2004 Soil Survey Laboratory Methods Manual. Soil Survey Investigations Report No. 42, Version 4.0. USDA-NRCS, Lincoln, Nebraska.

Burning Trees

2013 http://www.utsandiego.com/news/2013/Jul/08/fire-julian-mount-laguna-evacuation;http:// media.utsandiego.com/img/photos/2013/07/09. [Accessed August 21, 2013].

Caddo Ancestors

2013 Texas Beyond History. http://www.texasbeyondhistory.net/tejas/ancestors/late.html. [Accessed September 11, 2013].

Cahen, D., and J. Moeyersons

1977 Subsurface Movement of Stone Artifacts and Their Implications for the Prehistory of Central Africa. Nature 266:812-825.

Cain, A., and M. Wallace

2003 A Guide to Age Determination of White-tailed Deer. Texas Parks and Wildlife Department, Austin, Texas.

Cannon, M. D., and D. J. Meltzer

2004 Early Paleoindian Foraging: Examining the Faunal Evidence for Large Mammal Specialization and Regional Variability in Prey Choice. Quaternary Science Reviews 23(2004):1955-1987.

Canti, M. G.

1997 An Investigation of Microscopic Calcerous Spherulites from Herbivore Dungs. Journal of Archaeological Science 24:219-231.

1998 The Production and Preservation of Faecal Spherulites: Animals, Environment, and Taphonomy. Journal of Archaeological Science 26:251-258.

1999 The Micromorphological Identification of Faecal Spherulites from Archaeological and Modern Materials. Journal of Archaeological Science 25:435-444. 
Carlquist, S.

2001 Comparative Wood Anatomy: Systematic, Ecological, and Evolutionary Aspects of Dicotyledon Wood. Springer Series in Wood Science. Springer, Berlin.

Cecil, L.

2012 Estimated Firing Temperature for Clay Samples from 41BX256. In Archaeological Data Recovery on Three Sites along the San Antonio River, Bexar County, Texas - Volume II: Further Excavations at 41BX256, Appendix D.Ama Terra Project report No. 011-041 prepared for the U.S. Army Corps of Engineers, Fort Worth District.

Charnov, E. L.

1976 Optimal Foraging, the Marginal Value Theorem. Theoretical Population Biology 9:129-136.

Charters, S., R. P. Evershed, A. Quye, P. W. Blinkhorn, and V. Denham

1997 Simulation Experiments for Determining the Use of Ancient Pottery Vessels: Te Behaviour of Epicuticular Leaf Wax during Boiling of a Leafy Vegetable. Journal of Archaeological Science 24:1-7.

Chorley, R. J., S. A. Schumm, and D. E. Sugden

1984 Geomorphology. Methuen, London.

Climate

2013 Climate for Dallas-Fort Worth, Texas. http://www.rssweather.com/climate/Texas/DallasFort\%20Worth. [Accessed August 21, 2013].

Coffee, D. R., R. H. Hill, and D. D. Ressel

1980 Soil Survey of Dallas County, Texas. United States Department of Agriculture, Soil Conservation Service, Washington, D.C. In cooperation with Texas Agricultural Experiment Station, College Station.

Collins, M. B.

1995 Forty Years of Archeology in Central Texas. Bulletin of the Texas Archeological Society 66:361-400.

2004 Archeology in Central Texas. In The Prehistory of Texas, edited by T. K. Perttula, pp. 101126. Texas A\&M University Press, College Station.

Collins, M. B., and K. M. Brown

2000 The Gault Gisment: Some Preliminary Observations. Current Archeology in Texas 2(1):8-11. 
Collins M. B., B. Ellis, and C. Dodt-Ellis

1990 Excavations at the Camp Pearl Wheat Site (41KR243): An Early Archaic Campsite on Town Creek, Kerr County, Texas. Studies in Archaeology 6. Texas Archaeological Research Laboratory, The University of Texas at Austin.

Collins, M. B., W. A. Gose, and S. Shaw

1994 Preliminary Geomorphological Findings at Dust and Nearby Caves. Journal of Alabama Archaeology 40:35-56.

Collinson, J. D., and D. B. Thompson

1982 Sedimentary Structures. London: George Allen \& Unwin.

Condamin, J., F. Formenti, M. O. Metais, M. Michel, and P. Blond

1976 The Application of Gas Chromatography to the Tracing of Oil in Ancient Amphorae. Archaeometry 18(2):195-201.

Conner, M. A., K. P. Cannon, and D. C. Carvelato

1989 The Mountains Burnt: Forest Fires and Site Formation Processes. North American Archaeologist 10(4):293-310.

Connor, S. V.

1959 The Peters Colony of Texas: A History and Biographical Sketches of the Early Settlers. The Texas State Historical Association, Austin.

Cook, G., and J. Dunbar

2008 Mapping an Eighteenth Century. In Land of Our Ancestors: Studies in Protohistoric and Historic Wichita Cultures. Plains Anthropologist Vol. 53, No. 208, Memoir No. 40, pp. 487-502.

Cortella, A. R., and M. L. Pochettino

1994 Starch Grain Analysis as a Microscopic Daignostic Feature in the Identification of Plant Material. Economic Botany 48:171-181.

Cortés, J.

1799 Views from the Apache Frontier: Report on the Northern Provinces of New Spain. Edited by E. A. H. John and J. Wheat. Published in 1994 by University of Oklahoma Press, Norman.

Cox, M.

2008 The Texas Rangers: Wearing the Cinco Peso, 1821-1900. Tom Doherty Associates, LLC., New York, NY. 
Cox, P., and P. Leslie

1988 Texas Trees: A Friendly Guide. Corona Publishing Company. San Antonio.

Creel, D.

1991 Bison Hides in Late Prehistoric exchange in the Southern Plains. American Antiquity 56(1):40-49.

Creel, D., R. F. Scott IV, and M. B. Collins

1990 A Faunal Record from West-central Texas and Its Bearing on Late Holocene Bison Population Changes in the Southern Plains. Plains Anthropologist 35(127):55-69.

Crook, W. W. Jr., and R. K. Harris

1957 Hearths and Artifacts of Early Man near Lewisville, Texas, and Associated Faunal Material. Bulletin of the Texas Archeological Society 28:7-97.

1958 A Pleistocene Campsite near Lewisville, Texas. American Antiquity 23(3):233-246.

Crowther, J.

2003 Potential Geomorphological Findings at Dust and Nearby Caves. Journal of Alabama Archaeology 40:35-56.

2003 Potential Magnetic Susceptibility and Fractional Conversion Studies of Archaeological Soils and Sediments. Archaeometry 45:685-701.

Cummings, L. S.

1992a Pollen and Starch Analysis of Stratigraphic and Housepit Samples from 48SU595, Wyoming. Ms. on file with Archaeological Services, Western Wyoming College, Rock Springs.

1992b Preliminary Examination of Five Pieces of Groundstone from Lander County, Central Nevada, for Pollen, Phytoliths, Starch Granules, and Blood Residue. Ms. on file with Dames and Moore, Las Vegas, Nevada.

1992c Pollen, Phytolith, Starch, Parasite, and Macrofloral Analyses on a Coprolite from Luster Cave, Utah. Ms. on file with Kae McDonald, Glenwood Springs, Colorado.

1993a Pollen and Starch Analysis of Features in a Pithouse at the Paquet Gulch Bridge Site (35WS125), Oregon. Ms. on file with State Museum of Anthropology, University of Oregon, Eugene.

1993b Exploratory Pollen and Starch Analysis of Three Samples from the Big M Site, Fort Rock Basin, Oregon. Ms. on file with the Department of Anthropology/State Museum of Anthropology, University of Oregon, Eugene.

1993c Phytolith, Starch, and Blood Residue Analysis of Artifacts from Site 41MU55, Texas. Ms. on file with Department of Anthropology, Texas A\&M University, College Station.

1997a Pollen, Phytolith, and Starch Granule Analysis of a Piece of Ground Stone, 35JE355, Oregon. Ms. on file with Sisters Ranger District, U.S. Forest Service, Sisters, Oregon. PRI Technical Report 97-59. 
1997b Stratigraphic Pollen Analysis at 48CK1409 and 48CK1416, and Pollen/Starch Analysis of Groundstone at 48CK1417, Wyoming. Ms. on file with TRC Mariah Associates, Inc., Laramie, Wyoming. PRI Technical Report 97-18.

Curry, B.

1999 An Environmental Tolerance Index for Ostracodes as Indicators of Physical and Chemical Factors in Aquatic Habitats. Palaeogeography, Palaeoclimatology, Palaeoecology 148(1-3):51-63.

Czaja, A.

1978 Structure of Starch Grains and the Classification of Vascular Plant Families. Taxon $27: 463-470$.

Dalan, R. A.

2008 A Review of the Role of Magnetic Susceptibility in Archaeogeophysical Studies In The USA: Recent Developments and Prospects. Archaeological Prospection 15:1-31.

Dalan, R. A., and S. K. Bannerjee

1998 Solving Archaeological Problems Using Soil Magnetism. Geoarchaeology 13(1):3-36.

Davis, O. K.

1987 Spores of the Dung Fungus Sporormiella: Increased Abundance in Historic Sediments and Before Pleistocene Megafaunal Extinction. Quaternary Research 28:290-294.

Davis, O. K., and D. S. Shafer

2006 Sporormiella Fungal Spores, a Palynological Means of Detecting Herbivore Density. Palaeogeography, Palaeoclimatology, Palaeoecology 237:40-50.

Dearing, J.

1999 Environmental Magnetic Susceptibility. Chi Publishing, Kenilworth, England.

1999 Environmental Magnetic Susceptibility using the Bartington MS2 System, 2nd ed. Bartington Instruments.

Dearing, J. A., R. J. L. Dann, K. Hay, J. A. Lees, P. J. Loveland, B.A. Maher, and K. O’Grady

1996 Frequency-dependent Susceptibility Measurements of Environmental Materials. International Journal of Geophysics 124:228-240.

Delcourt, H. R., P. A. Hazel, R. Delcourt, C. R. Ison, W. E. Sharp, and K. J. Gremillion

1998 Prehistoric Human Use of Fire, the Eastern Agricultural Complex, and Appalachian Oak Chestnut Forests: Paleocology of Cliff Palace Pond, Kentucky. American Antiquity 63(2):263-278. 
Dettman, D. L., and K. C. Lohman

1993 Seasonal Change in Paleogene Surface Water 180: Fresh-Water Bivalves of Western North America. In Climate Change in Continental Isotope Records. Edited by P. K. Swart, K. C. Lohmann, J, McKenzie, and S. Savin. pp. 153-163. Geophysical Monograph 78. American Geophysical Union. Washington, DC.

Diamond, D. D., and F. E. Smeins.

1985 Composition, Classification, and Species Response Patterns of Remnant Tallgrass Prairie in Texas. American Midland Naturalist 113:294-309.

1993 The Native Plant Communities of the Blackland Prairie. In The Texas Blackland Prairie: Land, History, and Culture, M. R. Sharpless and J. C. Yelderman, eds, pp. 66-81. Baylor Univ. Program for Regional Studies, Waco, Texas.

Diamond, D. D., D. H. Riskind, and S. L. Orzell.

1987 A Framework for Plant Community Classification and Conservation in Texas. Texas Journal of Science. 39:203-221.

Diehl, M.

2003 Prehistoric Subsistence Strategies and the Macrobotanical Assemblage. In Hohokam Farming on the Salt River Floodplain, edited by T. Kathleen Henderson, pp. 211-230. Anthropological Papers No. 42, Center for Desert Archaeology. Tucson, Arizona. Anthropological Papers No. 9. Pueblo Grande Museum. Phoenix, Arizona.

Dillehay, T. D.

1974 Late Quaternary Bison Population Changes on the Southern Plains. Plains Anthropologist 19(65):180-196.

Domanski, M., and J. A. Webb

1992 Effect of Heat Treatment on Siliceous Rocks Used in Prehistoric Lithic Technology. Journal of Archaeological Science 19:601-614.

Dreimanis, A.

1962 Quantitative Gasometric Determination of Calcite and Dolomite Using a Chittick Apparatus. Journal of Sedimentary Petrology 32(3):520-529.

Dudd, S. N., and R. P. Evershed

1998 Direct Demonstration of Milk as an Element of Archaeological Economies. Science 282:1478-1481.

Duffield, L. F.

1965 The Taovayas Village of 1759: In Texas or Oklahoma? Great Plains Journal 4:39-48. 
1970 Some Panhandle Aspect Sites in Texas: Their Vertebrates and Paleoecology. Ph.D. Dissertation, University of Wisconsin.

1973 Ageing and Sexing the Post-cranial Skeleton of Bison. Plains Anthropologist 18:132-39.

Dunn, W. E.

1911 Apache Relations in Texas, 1718-1750. Texas Historical Association Quarterly 14:198-274.

Eerkens, J. W.

2002 The Preservation and Identification of Pinon Resins by GC-MS in Pottery from the Western Great Basin. Archaeometry 44(1):95-105.

Emerson, A. M.

1990 Archaeological Implications of Variability in the Economic Anatomy of Bison bison. Ph.D. Dissertation. Washington State University. Ann Arbor, University Microfilms.

Evers, A. D.

1979 Cereal Starches and Proteins. In Food Microscopy. J. G. Vaughan, ed., pp. 139-191. London: Academic Press.

Evershed, R. P.

1993 Biomolecular Archaeology and Lipids. World Archaeology 25(1):74-93.

2000 Biomolecular Analysis by Organic Mass Spectrometry. In Modern Analytical Methods in Art and Archaeology, edited by E. Ciliberto and G. Spoto, pp. 177-239. Volume 155, Chemical Analysis. John Wiley \& Sons, New York.

Evershed, R. P., C. Heron, and L. J. Goad

1990 Analysis of Organic Residues of Archaeological Origin by High Temperature Gas Chromatography and Gas Chromatography-Mass Spectroscopy. Analyst 115:1339-1342.

1991 Epicuticular Wax Components Preserved in Potsherds as Chemical Indicators of Leafy Vegetables in Ancient Diets. Antiquity 65:540-544.

Evershed, R. P., H. R. Mottram, S. N. Dudd, S. Charters, A. W. Stott, G. J. Lawrence, A. M. Gibson, A. Conner, P. W. Blinkhorn, and V. Reeves

1997a New Criteria for the Identification of Animal Fats in Archaeological Pottery. Naturwissenschaften 84:402-406.

Evershed, R. P., S. J. Vaugh, S. N. Dudd, and J. S. Soles

1997b Fuel for Thought? Beeswax in Lamps and Conical Cups from Late Minoan Crete. Antiquity 71:979-985. 
Evershed, R. P., S. N. Dudd, M. J. Lockheart, and S. Jim

2001 Lipids in Archaeology. In Handbook of Archaeological Sciences, edited by D. R. Brothwell and A. M. Pollard, pp. 331-349. John Wiley \& Sons, New York.

Ewers, J. C. (editor)

1969 The Indians of Texas in 1830 by Jean Louis Berlandier. Smithsonian Institution Press, Washington, D.C.

Faden, R. B.

2000 Commelinaceae R. Brown. In Flora of North America North of Mexico, edited by Flora of North America Editorial Committee. vol. 22. 16+ vols. Oxford University Press, New York.

Farwig, V. J., W. K. Lauenroth, I. C. Burke, and R. A. Shakesby

2004 The Effects of Heating on Mineral Magnetic Enhancement of Soils: A Case Study Using Australian Soils. Geophysical Research Abstracts Vol. 6, No. 04912. European Geosciences Union, Strausbourg, France.

Fehrenbach, T. R.

1974 Comanches: The Destruction of a People. De Capo Press, Inc., New York, NY.

Feit, R., and J. Campbell

2005 Archeological Survey Along Fish Creek Within the Proposed Extension to Lake Ridge Parkway, Dallas and Tarrant Counties, Texas. Archeology Series No. 151, Hicks \& Company, Austin.

Ferring, C. R.

1986 Late Quaternary Geology and Environments of the Upper Trinity Basin. In An Assessment of the Cultural Resources in the Trinity Basin, Dallas, Tarrant, and Denton Counties, Texas, edited by B.C. Yates and C. Reid Ferring, pp.32-112. Institute of Applied Sciences, North Texas State University, Denton.

1990 Late Quaternary Geology and Geoarcheology of the Upper Trinity River Basin, Texas. Guidebook, Field Trip 11, Geological Society of America.

1994 Late Quaternary Geology of the Upper Trinity River Basin, Texas. Unpublished Ph.D. Dissertation, University of Texas at Dallas.

2000 The Late Quaternary Geology and Prehistoric Archaeology of the Grand Prairie and Cross Timbers Portions of North Central Texas. Guidebook to the 13th Annual Field Trip of the South-Central Cell of the Friends of the Pleistocene. Department of Geography and Center for Environmental Archaeology at the University of North Texas, Denton.

2001 The Archeology and Paleoecology of the Aubrey Clovis Site (41DN479), Denton County, Texas. University of North Texas Denton Center for Environmental Archeology, Department of Geography. 
Ferring, C. R., and B. C. Yates

1997 Holocene Geoarcheology and Prehistory of the Ray Roberts Lake Area, North Central Texas. Institute of Applied Sciences, University of North Texas, Denton.

1998 Archeological Investigations at Five Prehistoric Sites at Lewisville Lake, Denton County, Texas. Center of Environmental Archeology, Department of Geography, University of North Texas, Denton.

Flint, O.

1994 Food Microscopy: A Manual of Practical Methods, Using Optical Microscopy. Volume 30. Oxford: BIOS Scientific Publishers.

Flint, R., and S. C. Flint (editors)

1997 The Coronado Expedition to Tierras Nueva: The 1540-1542 Route Across the Southwest. University Press of Colorado, Niwot, Colorado.

Folch, J., M. Lees, and G. H. Sloane-Stanley

1957 A Simple Method for the Isolation and Purification of Lipid Extracts from Brain Tissue. Journal of Biological Chemistry 191:833.

Ford, P. J.

1990 Antelope, Deer, Bighorn Sheep and Mountain Goats: A Guide to the Carpals. Journal of Ethnobiology 10(2):169-181.

Forester, R. M., A. J. Smith, D. F. Palmer, and B. B. Curry

2005 North American Non-Marine Ostracode Database (NANODe) Version 1. http://www.kent. edu/NANODe (accessed July 15 to October 9, 2009). Kent State University, Kent, Ohio.

Fox, F. W., C. B. Smith, and D. O. Lintz

1992 Herd Bunching at the Waco Mammoth Site, Preliminary Investigations 1978-1987. In Proboscidean and Paleoindian Interactions. Edited by J. W. Fox, C. B. Smith, and K. T. Wilkins, pp. 51-68. Baylor University Press, Waco, Texas.

Frankel, E. N.

1991 Recent Advances in Lipid Oxidation. Journal of the Science of Food and Agriculture 54:465-511.

Frederick, C. D.

2011 Chapter 7: Geoarchaeological Field and Experimental Investigations, Part 1: Field Investigations. In Archaeological Testing and Data Recovery Excavations at Site 41DL203, President George Bush Turnpike-Eastern Extension from SH 78 to IH 30, Dallas County, Texas, C. Tinsley and C. Dayton (eds), pp. 83-102. Geo-Marine, Inc., Miscellaneous Reports of Investigations No. 484. 
Fredlund, G. G., and L. T. Tieszen

1994 Modern Phytolith Assemblages from the North American Great Plains. Journal of Biogeography 21:321-335.

Fritz, P., and S. Poplawski

$1974{ }^{18} \mathrm{O}$ and ${ }^{13} \mathrm{C}$ in the Shells of Freshwater Mollusks and Their Environments. Earth and Planetary Science Letters 24:91-98.

Fullagar, R., and J. Field

1997 Pleistocene Seed Grinding Implements from the Australian Arid Zone. Antiquity 71:300-307.

Fullagar, R., J. Field, T. Denham, and C. Lentfer

2006 Early and Mid Holocene Tool-use and Processing of Taro (Colocasia esculenta), Yam (Dioscorea sp.) and Other Plants at Kuk Swamp in the Highlands of Papua New Guinea. Journal of Archaeological Science 33(5):595-614.

Fullagar, R., J. Furby, and B. Hardy

1996 Residues on Stone Artefacts: State of a Scientific Art. Antiquity 70:740-745.

Fullagar, R., T. Loy and S. Cox

1998 Starch Grains, Sediments and Stone Tool Function: Evidence from Bitokara, Papua New Guinea. In A Closer Look: Recent Australian Studies of Stone Tools, edited by R. Fullagar, pp. 49-60. vol. Series 6. Sydney University Archaeological Methods, Sydney.

Fuller, W. A.

1959 The Horns and Teeth as Indicators of Age in Bison. Journal of Wildlife Management 23(3):342-344.

Furtos, N. C.

1933 The Ostracoda of Ohio. Bulletin of the Ohio Biological Survey 37:414-524.

Gale, S. J., and P. G. Hoare

1991 Quaternary Sediments: Petrographic Methods for the Study of Unlithified Rocks. Belhaven Press, London.

Gibson, D. J., D. C. Hartnett, and G. L. S. Merrill

1990 Fire Temperature Heterogeneity in Contrasting Fire-prone Habitat: Kansas Tallgrass Prairie and Florida Sandhills. Bulletin of the Torrey Botanical Club 117:349-356.

Gifford, D. P., and A. K. Behrensmeyer

1977 Observed Formation and Burial of a Recent Human Occupation Site in Kenya. Quaternary Research 8:245-266. 
Gifford-Gonzalez, D. P., D. B. Damrosch, J. Pryor, and R. L. Thunen

1985 The Third Dimension in Site Structure: An Experiment in Trampling and Vertical Dispersal. American Antiquity 50(4):803-818.

Gillespie, A. R., F. E. Budinger, and E. A. Abbottt

1989 Verification of Prehistroic Campfires: Analysis of Fire-Baked Stones. Journal of Archaeological Science 16:271-291.

Gose, W. A., and D. L. Nickels

1998 Archaeomagnetic and Magnetic Susceptibility Analyses. In Test Excavations at the Culebra Creek Site, 41BX126, Bexar County, Texas, by D. L. Nickels, C. Britt Bousman, J. D. Leach, and D. A. Cargill (reprinted in 2001), pp. 204-214. Archaeological Survey Report, No. 265, Center for Archaeological Research, the University of Texas at San Antonio; Archeological Studies Program, Report 3, Environmental Affairs Division, Texas Department of Transportation, Austin.

Gould, F. W.

1975 Texas Plants, A Checklist and Ecological Summary. Texas A\&M University Press, College Station, Texas.

Gould, F. W., G. O. Hoffman, and C. A. Rechentain

1960 Vegetational Areas of Texas. Leaflet No. 492, Texas.

Grayson, D. K. and D. J. Meltzer

2002 Clovis Hunting and Large Mammal Extinction: A Critical Review of the Evidence. Journal of World Prehistory 16(4):313-359.

Greaves, R. D.

2003 Camp Maxey 5: Archaeological Testing of Seven Sites on the Camp Maxey Training Facility, Lamar County, Texas. Archaeological Survey Report No. 330. Center for Archaeological Research, The University of Texas at San Antonio.

Greenfield, H. J.

1999 The Origins of Metallurgy: Distinguishing Stone from Metal Cut Marks on Bones from Archaeological Sites. Journal of Archaeological Science 26 (7):797-808.

Griffith, G. E., S. A. Bryce, J. M. Omernik, J. A. Comstock, A. C. Rogers, B. Harrison, S. L. Hatch, and D. Bezanson

2004 Ecoregions of Texas. U.S. Environmental Protection Agency, Corvallis, Oregon. 
Grossman, E. L., and T. Ku

1986 Oxygen and Carbon Isotope Fractionation in Biogenic Aragonite: Temperature Effects. Chemical Geology (Isotope Geoscience Section) 59:59-74.

Haberman, S. J.

1977 Analysis of Qualitative Data. Academic Press, New York.

Hackett, C. W. (editor)

1941 Picardo's Treatise on the Limits of Louisiana and Texas, Vol. 3. University of Texas Press, Austin.

Hall, G. D.

2014 Mission San Sabá. < http://www.texasbeyondhistory.net/sansaba/credits.html>. Accessed October 1, 2014.

Hamilton, A. L.

1988 Sentinal of the Southern Plains: Fort Richardson and the Northwest Texas Frontier, 1866 1878. Texas Christian University Press, Fort Worth.

Harrington, H. D.

1972 Western Edible Wild Plants. The University of New Mexico Press, Albuquerque.

Harrison, F. W.

1988 Utilization of Freshwater Sponges in Paleolimnological Studies. Palaeogeography,

Palaeoclimatology, Palaeoecology 62(1-4):387-397.

Haslam, M.

2006 Potential Misidentification of in situ Archaeological Tool-residues: Starch and Conidia. Journal of Archaeological Science 33(1):114-121.

Hather, J. G.

2000 Archaeological Parenchyma. Archetype Publications Ltd., London.

Haugen, A. O.

1974 Reproduction in the Plains Bison. Iowa State Journal of Research 49(1).

Haury, C. E.

2008 Bison and Box Turtles: Faunal Remains from the Lower Walnut Settlement. In Land of Our Ancestors: Studies in Protohistoric and Historic Wichita Cultures. Plains Anthropologist Vol. 53, No. 208, Memoir No. 40, pp. 503-550. 
Hayden, B.

1986 Resource Models of Inter-Assemblage Variability. Lithic Technology 15(3):82-89.

Hayes, D. M.

2010 Genetic Diversity and Distribution of Selected Freshwater Mollusks (Gastropoda and Bivalvia) from West of the Mississippi River with an Emphasis on Arkansas Taxa. Doctoral dissertation, Arkansas State University, Jonesboro.

Haynes, G.

1983 Frequencies of Spiral and Green-bone Fractures on Ungulate Limb Bones in Modern Surface Assemblages. American Antiquity. 48(1):102-114.

Hegmon, M.

2003 Setting Theoretical Egos Aside: Issues and Theory in North American Archaeology. American Antiquity 68(2):213-243.

Heller, F., and M. E. Evans

1995 Loess Magnetization. Reviews of Geophysics 33:211-240.

Hemry, L.

1996 Green basin: Studying Effects of Springtime Burns on Cultural Materials. In A Management Strategy and Study of Prescribed Burning Impacts on Heritage Resources in Ponderosa Pinel Douglas-Fir Composition Types on the Kootenai National Forest, Northwestern Montana, edited by R. Timmons, pp. 1-10. United States Department of Agriculture, Forest Service, Northern region, Missoula, Montana.

Heron, C., and A. M. Pollard

1988 The Analysis of Natural Resinous Materials from Roman Amphoras. In Science and Archaeology Glasgow 1987. Proceedings of a Conference on the Application of Scientific Techniques to Archaeology, Glasgow, 1987, edited by E. A. Slater and J. O. Tate, pp. 429447. BAR British Series 196 (ii), Oxford.

Heron, C., N. Nemcek, K. M. Bonfield, J. Dixon, and B. S. Ottaway

1994 The Chemistry of Neolithic Beeswax. Naturwissenschaften 81:266-269.

Hester, T. R.

1995 The Prehistory of South Texas. Bulletin of the Texas Archeological Society 66:427-459.

Hickerson, N. P.

1994 The Jumanos: Hunters and Traders of the South Plains. University of Texas Press, Austin.

1996 Jumano Indians. The New Handbook of Texas, Vol. 3, pp. 1016-1018. The Texas State Historical Association, Austin. 
Hindes, V. K, M. R. Wolf, G. D. Hall, and K. K. Gilmore

1995 The Rediscovery of Santa Cruz de San Sabá, A Mission for the Apache in Spanish Texas. Texas State Historical Association and Texas Tech University.

Hoadley, R. B.

1990 Identifying Wood: Accurate Results with Simple Tools. The Taunton Press, Inc., Newtown, Connecticut.

Hodder, I.

1991 Postprocessual Archaeology and the Current Debate. In Processual and Postprocessual Archaeology, edited by Robert Pruecel, pp. 30-41. Occasional Paper No. 10. Center for Archaeological Investigations, Southern Illinois University, Carbondale.

Hofman, J. L.

1989 Protohistoric Culture History on the Southern Great Plains. In From Clovis to Comanchero: Archeological Overview of the Southern Great Plains, by J. L. Hofman, R. L. Brooks, J. S. Hays, D. W. Owsley, R. L. Jantz, M. K. Marks, and M. H. Manheim, pp. 91-100. Research Series No. 35. Arkansas Archeological Survey, Fayetteville.

Hollen, W. E. (Editor)

1956 William Bollaert's Texas. The Newberry Library, Chicago in cooperation with The University of Oklahoma Press, Norman, Oklahoma.

Holliday, V. T.

1997 Paleoindian Geoarchaeology of the Southern High Plains. University of Texas Press, Austin.

How Wildfires Work

2013 http://science.howstuffworks.com/nature/natural-disasters/wildfire.htm. [Accessed August 22, 2013].

Holmgren, G. G. S.

1967 A Rapid Citrate-dithionite Extractable Iron Procedure: Soil Science Society of America Journal 31:210-211.

Horrocks, M., and I. Lawlor

2006 Plant Microfossil Analysis of Soils from Polynesian Stonefields in South Auckland, New Zealand. Journal of Archaeological Science 33(2):200-217.

Horrocks, M., and M. I. Weisler

2006 A Short Note on Starch and Xylem of Colocasia Esculenta (Taro) in Archaeological Deposits from Pitcairn Island, Southeast Polynesia. Journal of Archaeological Science 33(9):1189-1193. 
Horrocks, M., and P. D. Nunn

2007 Evidence for Introduced Taro (Colocasia esculenta) and Lesser Yam (Dioscorea esculenta) in Lapita-era (c. 3050-2500 cal. yr BP) Deposits from Bourewa, Southwest Viti Levu Island, Fiji. Journal of Archaeological Science 34(5):739-748.

Horrocks, M., G. Irwin, M. Jones, and D. Sutton

2004 Starch Grains and Xylem Cells of Sweet Potato (Ipomoea batatas) and Bracken (Pteridium esculentum) in Archaeological Deposits from Northern New Zealand. Journal of Archaeological Science 31(3):251-258.

Horrocks, M., M. D. Jones, R. E. Beever, and D. G. Sutton

2002 Analysis of Plant Microfossils in Prehistoric Coprolites from Harataonga Bay, Great Barrier Island, New Zealand. Journal of the Royal Society of New Zealand 32(4):617-628.

Howells, R. G.

1996 Tampico pearlymussel (Cyrtonaias tampicoensis): Shades of the Old West. American Conchologist 24(2):24-26.

1998 Chapter 12. Freshwater Mussel Shell Remains, pp. 164-175 and Appendix G. Mussel Shell Data, pp. 324-338 in 41MV120: a stratified Late Archaic site in Maverick County, Texas by B. Vierra. Archaeological Survey Report 251. Center for Archaeologial Research, The University of Texas at San Antonio.

2002a Freshwater Mussel (Bivalvia: Unionidae) Shell Remains Associated with Site 41CW54. Appendix G, pp. 277-290 in Data Recovery at the Armstrong Site (41CW54) Caldwell County, Texas. Volume I. Background, Methods, and Site Context, by E. A. Schroeder and E. R. Oksanen. Texas Antiquities Permit 2250. Paul Price Associates, Inc., Austin, Texas.

2002b Freshwater Mussel Shell Remains. Appendix E, pp. 195-209 in The Smith Creek Bridge Site (41DW270): a Terrace Site in DeWitt County, Texas by D. Hudler, K. Prilliman, and T. Gustavson. Studies in Archeology 35. Texas Archeological Research Lab, The University of Texas at Austin.

2005 Freshwater Mussel Shell Remains Recovered from 41BP627, McKinney Roughs, Bastrop County, Texas. BioStudies, Kerrville, Texas. Prepared for SWCA Environmental Consultants, Austin, Texas.

2010a Guide to Texas Freshwater Mussels. BioStudies, Kerrville, Texas.

2010b. Sandbank pocketbook (Lampsilis satura): Summary of Biological and Ecological Data for Texas. Prepared for Save Our Springs Alliance, Austin by BioStudies, Kerrville, Texas.

Howells, R. G., J. Neel-Hartman, and S. A. Wagner

2003 Freshwater Mussel Shell from 41MM340. Data Recovery Excavations at 41MM340: A Late Archaic Site along Little River in Milam County, Texas by R. B. Mahoney and six coauthors, Appendix G, pp. 245-270. Archaeological Survey Report 340. Center for Archaeological Research, The University of Texas at San Antonio. 
Howells, R. G., R. W. Neck, and H. D. Murray

1996 Freshwater Mussels of Texas. Texas Parks and Wildlife Press, Austin.

Huckell, L.

2002 Paleoethnobotany. In Tonto Creek Archaeological Project: Artifact and Environmental Analyses Volume 2: Stone Tool and Subsistence Studies, ed. by Jeffery J. Clark, pp. 643-709. Anthropological Papers No. 23. Center for Desert Archaeology. Tucson, Arizona.

Huebner, Jeffery A.

1990 Late Prehistoric Bison Populations in Central and Southern Texas. Plains Anthropologist $36: 343-358$

Hungerford, R. D., J. K. Brown, and R. G. Krebill

1990 Describing Downward Heat Flow for Predicting Fire Effects. USDA Forest Service Research Paper INT-4403.

Inman, B. J., and D. B. Hudler

1998 Preliminary Results from a Use-wear Analysis of Clovis Blades from the Gault Site. Tarl Research Notes 6(1):18-20.

Irwin, G. J., L. J. Williams, M. Horrocks, H. J. Hall, M. S. McGlone, and S. L. Nichol

2004 Evidence for Diet, Parasites, Pollen, Phytoliths and Diatoms in Prehistoric Coprolites from Kohika. In Te Kohika: A Prehistoric Maori Lake Village, edited by G. Irwin, pp. 217-239, Auckland University Press, Auckland, New Zealand.

Jackson, M. A.

1998 The Nature of Fire-Cracked Rock: New Insights from Ethnoarchaeological and Laboratory Experiments. Unpublished Master's Thesis. Texas A\&M University, College Station.

Jacobson, H.

1994 Reproduction. In Deer, edited by D. Gerlach, S. Atwater, and J. Schnell. Stackpole, pp. 98-108. Wildlife Series, Harrisburg, Pennsylvania.

Jacobson, J.

2000 White-tailed Deer Utility Indices: Development and Application of an Analytical Method. Unpublished M. A. thesis, University of Tennessee, Knoxville.

2003 Identification of Mule Deer (Odocoileus hemionus) and White-tailed Deer (Odocoileus virginianus) Postcranial Remains as a Means of Determining Human Subsistence Strategies. Plains Anthropologist 48(187):287-297.

2004 Determining Human Ecology on the Plains Through the Identification of Mule Deer (Odocoileus hemionus) and White-tailed Deer (Odocoileus virginianus) Postcranial Material. Ph.D. dissertation. University of Tennessee, University Microfilms, Ann Arbor, Michigan. 
Jelks, E. B.

1996a Taovaya Indians. The New Handbook of Texas, Vol. 6, p. 203. The Texas State Historical Association, Austin.

1996b Spanish Fort Sites. The New Handbook of Texas, Vol. 6, p. 4. The Texas State Historical Association, Austin.

Johansen, J. R.

1999 Diatoms in Aerial Habitats. In The Diatoms: Applications for the Environmental and Earth Sciences edited by E. F. Stoermer \& J. P. Smol, pp. 264-273. Cambridge University Press, Cambridge, UK.

John, E. A. H.

1975 Storms Brewed in Other Men's Worlds. Texas A\&M University Press. College Station.

1982 Portrait of a Wichita Village, 1808. The Chronicle of Oklahoma 60:412-437.

Johnson, C.

2004 Archaeological Sites and Fire-Induced Changes. In Ancient and Historic Lifeways in North America's Rocky Mountains: Proceedings of the Rocky Mountain Anthropological Conference, Estes Park, Colorado. Edited by R. H. Brunswig and W. B. Butler. Sixth Bienneal Rocky Mountain Anthropological Conference, Estes Park, Colorado.

Johnson, E.

1985 Current Developments in Bone Technology. In Advances in Archaeological Method and Theory Volume 8. edited by M. B. Schiffer, pp. 157-235. Academic Press, New York, New York.

Jones, D. J.

1956 Introduction to Microfossils. Harper Brothers Publishers, New York.

Jones, J. K., Jr., and R. M. Manning

1992 Illustrated Key to Skulls of Genera of North American Land Mammals. Texas Tech University Press, Lubbock, Texas.

Jordan, J. A.

1965 Ethnobotany of the Kiowa-Apache. Unpublished Master's Thesis, University of Oklahoma, Norman.

Justice, O. L., and L. N. Bass

1978 Principles and Practices of Seed Storage. Agriculture Handbook No. 219 506. United States Department of Agriculture, Agricultural Marketing Service, Washington, D.C. 
Kaesler, R. L.

1983 Usefulness of Ostracoda: Questioning the Rule of Thumb. In Applications of Ostracoda, Proceedings of the Eighth International Symposium on Ostracoda, edited by R. F. Maddocks, pp. 8-18. University of Houston.

Keeley, J.

2002 Native American Impacts on Fire Regimes of the California Coastal ranges. Journal of Biogeography 29:303-320.

Keene, A.

1978 Economic Optimalization Models and the Study of Hunter-Gatherer Subsistence Settlement Systems. In Transformations: Mathematical Approaches to Culture Change, edited by C. Renfrew and K. Cooke, pp. 369-404. Academic Press, New York.

Keith, M. L., G. M. Anderson, and R. Eichler

1964 Carbon and Oxygen Isotopic Composition of Mollusk Shells from Marine and Fresh-water Environments. Geochímica et Cosmochímica Acta 28:1757-1786.

Kelly, R. L.

1983 Hunter-Gatherer Mobility Strategies. Journal of Anthropological Research 39:277-306.

1988 The Three Sides of a Biface. American Antiquity 53(4):717-734.

1995 The Foraging Spectrum: Diversity in Hunter-Gatherer Lifeways. Smithsonian Institution Press, Washington D.C.

Kenmotsu, N., and T. Perttula

1993 Archeology in the Eastern Planning Region, Texas: A Planning Document. Cultural Resource Management Report 3. Department of Antiquities Protection, Texas Historical Commission, Austin.

Klippel, W., and J. A. Synstelien

2007 Rodents as Taphonomic Agents: Bone Gnawing by Brown Rats and Gray Squirrels. Journal of Forensic Sciences 52(4).

Knapp, A. K., J. M. Blair, J. M. Briggs, S. L. Collins, D. C. Hartnett, L. C. Johnson, and E. G. Towne

1999 The Keystone Role of Bison in North American Tallgrass Prairie. Bioscience 49(1):39-50.

Kontrovitz, M., and H. I. Griffiths

2009 Ostracods from the Wet Moat at Caerlaverock Castle. Transactions, Dumfriesshire and Galloway Natural History and Antiquarian Society, 83:1-4. Dumfries, Scotland. 
Kontrovitz, M., and M. J. Henry

2005 Ostracods from Moat Sediments at Beaumaris Castle, Anglesey, Wales. Archaeology in Wales 44:200-205.

Kontrovitz, M., and S. W. Snyder

2008 Ostracods and Foraminifera from Two Viking Sites in Dublin. Irish Naturalists'Journal 29(1):58-59.

Kontrovitz, M., J. M. Slack, and Y. Z. Yuhong

1991 On the Use of Some Phosphates in the Preparation of Ostracod Shells. Journal of Micropalaeontology 10(2):143-147.

Krieger, A. D.

1947 Certain Projectile Points of the Early American Hunters. Bulletin of the Texas Archeological and Paleontological Society 18:7-27.

Kuchler, A. W.

1964 Potential Natural Vegetation of the Conterminous United States. American Geographical Society, 36:152, Special Publication 36.

Lata, M., and F. Weirich

2013 Fire Temperature Dynamics in Grasslands of the Eastern Great Plains. http://images. library.wisc.edu/EcoNatRes/EFacs/NAPC/NAPC16/reference/econatres.napc16.mlata.pdf. [Accessed August 22, 2013].

Laurence, A. R., A. V. Thoms, V. M. Bryant, and C. McDonough

2011 Airborne Starch Granules as a Potential Contamination Source at Archaeological Sites. Journal of Ethnobiology 31(2):213-232.

Lawton, J. H.

1990 Species Richness and Population Dynamics of Animal Assemblages: Patterns in Body Size: Abundance space. Philosophical Transactions of the Royal Society. 330(1257):283-291.

LeBorgne, E.

1964 The Relationship Between the Magnetic Susceptibility and the History of Soils. In Problems in Paleoclimatology, edited by A. E. M. Nairn, pp. 666-669. Interscience Publishers, London.

Lentfer, C., M. Therin, and R. Torrence

2002 Starch Grains and Environmental Reconstruction: a Modern Test Case from West New Britain, Papua New Guinea. Journal of Archaeological Science 29(7):687-698. 
Lewis, D. R.

1978 Use of Phosphate Analysis for Determining Land Use Patterns. In Bulletin of the Texas Archeological Society 49:309-317.

Libby, W. F.

1955 Radiocarbon Dating. Chicago: University of Chicago Press.

Lintz, C, S. A. Hall, T. G. Baugh, and T. Osburn

2008 Archeological testing at 41TR170, Along the Clear Fork of the Trinity River, Tarrant County, Texas. Miscellaneous Reports of Investigations, Number 348. Geo-Marine, Inc., Plano, Texas.

Loomis, N. M., and A. P. Nasatir

1967 Pedro Vial and the Roads to Santa Fe. University of Oklahoma Press, Norman.

Loy, T. H.

1994 Residue Analysis of Artifacts and Burned Rock from the Mustang Branch and Barton Sites (41HY209 and 41HY202). In Archaic and Late Prehistoric Human Ecology in the Middle Onion Creek Valley, Hays County, Texas. Volume 2: Topical Studies, by R. A. Ricklis and M. B. Collins, pp. 607-627. Studies in Archeology 19, Texas Archaeological Research Laboratory, The University of Texas at Austin.

2006 Optical Properties of Potential Look-Alikes. In Ancient Starch Research, edited by R. Torrence and H. Barton, pp. 123-124. Left Coast Press, Walnut Creek, California.

Loy, T. H., M. Spriggs, S. Wickler

1992 Direct Evidence for Human Use of Plants 28,000 Years Ago: Starch Residues on Stone Artefacts from the Northern Solomon Islands. Antiquity 66:898-912.

Lyman, R. L.

1994 Vertebrate Taphonomy. Cambridge University Press, Cambridge, Great Britain.

Lynott, M. J.

1975 Archaeological Excavations at Lake Lavon 1974. Contributions in Anthropology No. 16. Archaeology Research Program, Southern Methodist University, Dallas, Texas.

1977 A Regional Model for Archaeological Research in North-Central Texas. Unpublished Ph.D. Dissertation, Southern Methodist University, Dallas.

1979 Prehistoric Bison Populations of North-central Texas. Bulletin of the Texas Archeological Society 50:89-101.

Lyons, M. S., R. A. Krebs, J. P. Holt, L. J. Rundo, and W. Zawisik

2007 Assessing Causes of change in the Freshwater Mussels (Bivalvia: Unionidae) in the Black River, Ohio. American Midland Naturalist 158(1):1-15. 
MacArthur, R. H., and E. R. Pianka

1966 On the Optimal Use of a Patchy Environment. American Naturalist, 100.

Malainey, M. E.

1997 The Reconstruction and Testing of Subsistence and Settlement Strategies for the Plains, Parkland and Southern boreal forest. Unpublished Ph.D. thesis, University of Manitoba.

2007 Chapter 7: Fatty Acid Analysis of Archaeological Residues: Procedures and Possibilities. In Theory and Practice of Archaeological Residue Analysis, edited by H. Barnard and J. W. Eerkens, pp.77-89. British Archaeological Reports International Series 1650. Oxford, UK.

Malainey, M. E., K. L. Malisza, R. Przybylski, and G. Monks

2001a The Key to Identifying Archaeological Fatty Acid Residues. Paper presented at the 34th Annual Meeting of the Canadian Archaeological Association, Banff, Alberta, May 2001.

Malainey, M. E., R. Przybylski, and B. L. Sherriff

1999a The Fatty Acid Composition of Native Food Plants and Animals of Western Canada. Journal of Archaeological Science 26:83-94.

1999b The Effects of Thermal and Oxidative Decomposition on the Fatty Acid Composition of Food Plants and Animals of Western Canada: Implications for the Identification of archaeological vessel residues. Journal of Archaeological Science 26:95-103.

1999c Identifying the former contents of Late Precontact Period pottery vessels from Western Canada using gas chromatography. Journal of Archaeological Science 26(4):425-438.

$2001 \mathrm{~b}$ One Person's Food: How and Why Fish Avoidance May Affect the Settlement and Subsistence Patterns of Hunter-Gatherers. American Antiquity 66(1):141-161.

Malainey, M. E., R. Przybylski, and G. Monks

2000a The Identification of Archaeological Residues Using Gas Chromatography and Applications to Archaeological Problems in Canada, United States and Africa. Paper presented at The 11th Annual Workshops in Archaeometry, State University of New York at Buffalo, February 2000.

2000b Refining and Testing the Criteria for Identifying Archaeological Lipid Residues Using Gas Chromatography. Paper presented at the 33rd Annual Meeting of the Canadian Archaeological Association, Ottawa, May 2000.

2000c Developing a General Method for Identifying Archaeological Lipid Residues on the Basis of Fatty Acid Composition. Paper presented at the Joint Midwest Archaeological \& Plains Anthropological Conference, Minneapolis, Minnesota, November 2000.

Marchbanks, M. L.

1989 Lipid Analysis in Archaeology: An Initial Study of Ceramics and Subsistence at the George C. Davis Site. Unpublished M.A. thesis, The University of Texas at Austin. 
Marchbanks, M. L., and J. M. Quigg

1990 Appendix G: Organic Residue and Phytolith Analysis. In Phase II Investigations at Prehistoric and Rock Art Sites, Justiceburg Reservoir, Garza and Kent Counties, Texas, Volume II, by D. K. Boyd, J. T. Abbott, W. A.Bryan, C. M. Garvey, S. A. Tomka and R. C. Fields. pp. 496-519. Reports of Investigations No. 71. Prewitt and Associates, Inc, Austin.

Marchinton, L. R., and K. V. Miller

1994 The Rut. In Deer, edited by D. Gerlach, and J. Schnell, pp. 109-121. Stackpole, Mechanicsburg, Pennsylvania.

Marcy, R. B.

1852 Exploration of the Red River of Louisiana in the Year 1852. Senate Document 54, 33 ${ }^{\text {rd }}$ Congress, $1^{\text {st }}$ Session.

Martin, A. C., and W. D. Barkley

1961 Seed Identification Manual. University of California, Berkeley.

Martin, J. F.

1983 Optimal Foraging Theory: A Review of Some Models and Their Applications. American Anthropologist 85:612-629.

Matthews, M. H.

1979 Soil Sample Analysis of 5MT2148: Dominguez Ruin, Dolores, Colorado. Appendix B. In The Dominguez Ruin: A McElmo Phase Pueblo in Southwestern Colorado, edited by Alan D. Reed. Bureau of Land Management Cultural Resource Series. Vol. 7. Bureau of Land Management, Denver, Colorado.

Maxwell, L. C.

1996 Grand Prairie, Texas. The New Handbook of Texas, Vol. 3, pp. 277-278. The Texas State Historical Association, Austin.

Mauldin, R. P., and A. L. Figueroa

2006 Data Recovery Excavations at 41PR144, Fort Wolters, Texas. Archaeological Report, No. 369. Center for Archaeological research, The University of Texas at San Antonio.

Mauldin, R. P., and D. L. Nickels

2001 An Archeological Survey of Twin Buttes Reservoir, Tom Green County, Texas. Archaeological Survey Report, No. 300. Center for Archaeological Research, The University of Texas at San Antonio. 
Mauldin, R. P., C. J. Broehm, and D. L. Nickels

2003 Archaeological Testing to Determine the National Register Eligibility Status of 18 Prehistoric Sites on Camp Bowie, Brown County, Texas. Center for Archaeological Research, The University of Texas at San Antonio Archaeological Survey Report No. 334. Prepared for the Adjutant General's Department of Texas, Directorate of Facilities and Engineering, Environmental Branch.

Mauldin, R. P., T. Graves, and M. Bentley

1998 Small Sites in the Central Hueco Bolson: A Final Report on Project 90-11. Conservation Division, Directorate of Environment, United States Army Air Defense Artillery Center, Fort Bliss, Texas.

Mauseth, J. D.

1988 Parenchyma. Chapter 3. In Plant Anatomy, pp. 43-51. The Benjamin/Cummings Publishing Company, Inc., Menlo Park, California.

Maxwell, L. C.

2011 Dallas County. Handbook of Texas Online. http://www.tshaonline.org/handbook/online/ articlae/hcd02. [Accessed August 5, 2011].

McBreaty, S., L. Bishop, T. Plummer, R. DeWar, and N. Conard

1998 Tools Underfoot: Human Trampling as an Agent of Lithic Artifact Edge Modification. American Antiquity 63(1):108-129.

McCrea, J. M.

1950 On the Isotope Chemistry of Carbonates and a Paleotemperature Scale. Journal of Chemical Physics 18:849-857.

McGuire, R.

1992 Marxist Archaeology. Academic Press, San Diego.

McKay, D., Kahl, K., and R. Proctor

2003 Cultural Resources Inventory of 3,942 Acres at Five Lakes in Eastern Oklahoma and Northeastern Texas: Tenkiller, Eufaula, Fort Gibson, Pat Mayse, and Texoma. Report of Investigations Number 3. Lopez Garcia Group, Dallas.

Mckee, D. F.

1985 The Utilization of Bison Fetal Bones and Mandibles in a Study of Seasonality at the River Bend Site (48NA202). Wyoming Archaeologist 28:29-38. 
McMahan, C. A., R. G. Frye, and K. L. Brown

1984 The Vegetation Types of Texas, Including Cropland, Map and Accompanying Illustrated Synopsis. Texas Parks and Wildlife Department.

Meisch, C.

2000 Freshwater Ostracoda of Western and Central Europe. Spektrum Akademischer Verlag, Heidelberg, Berlin.

Meissner, B. A.

1998 Analysis of Vertebrate Faunal Remains from a Spanish Colonial Mission, San Antonio de Valero (The Alamo). Unpublished Master's Thesis, The University of Texas at San Antonio.

Meltzer, D. J.

1987 The Clovis Paleoindian Occupation of Texas: Results of the Texas Fluted Point Survey. Bulletin of the Texas Archeological Society 57:27-68.

Meltzer, D. J., and M. R. Bever

1994 Paleoindians of Texas: An Update on the Texas Clovis Fluted Point Survey. Bulletin of the Texas Archeological Society 66:47-81.

Messner, T.

2008 Woodland Period People and Plant Interactions: New Insights from Starch Grain Analysis. Unpublished PhD dissertation, Temple University.

Messner, T., and B. Schindler

2010 Plant Processing Strategies and Their Affect Upon Starch Grain Survival When Rendering Peltandra virginica (L.) Kunth, Araceae editor. Journal of Archaeological Science 37(2):328-336.

Miksicek, C.

1994 Deceptive Barrenness: Archaeobotanical Material From the Schuk Toak Project Area. In Archaeological Studies of the Avra Valley, Arizona: Excavations in the Schuk Toak District. Vol 2. Scientific Studies and Interpretations, edited by Allen Dart, pp. 243-266. Anthropological Papers No. 16. Center for Desert Archaeology. Tucson.

Minnis, P. E.

1981 Seeds in Archaeological Sites: Sources and Some Interpretive Problems. American Antiquity 46(1):143-152.

Morrell, L. A.

1996 Spanish Fort, Texas. The New Handbook of Texas, Vol. 6, pp. 3-4. The Texas State Historical Association, Austin. 
Morse, J.

1822 Appendix I: Indian Phrases, by W. A. Trimble. In A Report to the Secretary of War of the United States on Indian Affairs, pp. 256-260. Reproduced by Ulan Press, Lexington, Kentucky (2014).

Moss, G. E.

1976 The Microscopy of Starch. In Examination and Analysis of Starch and Starch Products. edited by J. A. Radley, pp. 1-31. Applied Science Publishers, London.

Muller, O. F.

1776 Zoologiae Danicae prodromus, seu animalium Daniae et Norvegiae indigenarium characteres, nomina, et synonyma imprimis populatium, Hallager, Copenhagen, Denmark, I-XXXII, 1-282.

Murray, H. D.

1982 Unionids from Indian Sites in McMullen and Live Oak counties, Texas. Bulletin of the American Malacologial Union 1981:10-11.

Muscio, C.

2002 The Diatom Pollution Tolerance Index. City of Austin Watershed Protection and Development Review Department, Environmental Resource Management Division. SR-0202:1-17. Published online at City of Austin website http://www:ci.austin.tx.us/watershed/ downloads/

Musil, A. F.

1963 Identification of Crop and Weed Seeds. Agricultural Handbook no. 219. U.S. Department of Agriculture, Washington D.C.

Neck, R. W.

1982 A Review of Interactions Between Humans and Freshwater Mussels in Texas. In Proceedings of the Symposium on Recent Benthologial Investigations in Texas and Adjacent States, pp. 169-182, edited by J. R. Davis. The Texas Academy of Science, Austin.

Nedeau, E. J., M. A. McCollough, and B. I. Schwartz

2000 The Freshwater Mussels of Maine. Maine Department of Inland Fisheries and Wildlife, Augusta.

Nedeau, E., A. K. Smith, and J. Stone

Undated Freshwater Mussels of the Pacific Northwest. U.S. Fish and Wildlife Service. 
Negus, C.

1966 A Quantitative Study of Growth and Reproduction of Unionid Mussels in the River Thames at Reading. Journal of Animal Ecology 35:513-532.

Newcomb, W. W., Jr.

1993 The Indians of Texas from Prehistoric to Modern Times. University of Texas Press, Austin.

Nickels, D. L.

2000 The Biesenbach Site (41WN88): A Case Study in Diet Breadth. Unpublished Master's Thesis, The University of Texas at San Antonio.

Nickels, D. L., C. B. Bousman, J. D. Leach, and D. A. Cargill

1998 Test Excavations at the Culebra Creek Site, 41BX126, Bexar County, Texas. Archaeological Survey Report No. 265, Center for Archaeological Research, The University of Texas at San Antonio; Archeology Studies Program, Report 3, Environmental Affairs Division, Texas Department of Transportation, Austin.

Nickels, D. L., M. D. Miller, and W. N. Trierweiler

2010 Archaeological Excavation of a Deeply Buried Paleoindian Component at the Vara Daniel Site (41TV1364), Travis County, Texas. Texas Antiquites Permit 5177. Ecological Communications Corporation, Austin, Texas.

NOAA

2013 Dallas/Fort Worth-Monthly and Annual Average Temperatures. Retrieved from http://www. srh.noaa.gov/fwd/?n=dmotemp.

Nordt, L. C.

1992 Archaeological Geology of the Fort Hood Military Reservation, Fort Hood, Texas. Research Report No. 25, Archaeological Resource Management Series. U.S. Army Fort Hood, Texas.

NRCS (Natural Resources Conservation Service)

1999 Grassland Birds. Fish and Wildlife Habitat Management Leaflet. 8:1-12.

Oksanen, E., J. T. Abbott, and J. Jacobson

n.d. Interim Report of Intensive Archeological Survey, Lake Ridge Parkway Extension, Dallas and Tarrant Counties, Texas. CSJ: 0918-45-747 and 0918-45-608. Report on file, Environmental Affairs Division, Texas Department of Transportation.

Olsen, S. J.

1964 Mammal Remains from Archaeological Sites. Papers of the Peabody Museum of Archaeology and Ethnology 56(1). Peabody Museum, Cambridge, Massachussetts. 
1968 Fish, Amphibian, and Reptile Remains from Archaeological Sites. Papers of the Peabody Museum of Archaeology and Ethnology 56(2). Peabody Museum, Cambridge, Massachussetts.

Olson, G. W. (compiler)

1976 Criteria for Making and Interpreting a Soil Profile Description: A Compilation of the Official USDA Procedure and Nomenclature for Describing Soils. Lawrence: University of Kansas Publications, Lawrence, Kansas.

Ozdemir, O, and S. K. Banerjee

1982 A Preliminary Magnetic Study of Soil Samples from West-Central Minnesota. Earth and Planetary Science Letters 59:393-403.

Page, L. M., and B. M. Barr

1991 Freshwater Fishes. Peterson Field Guide Series. Houghton Mifflin Company, Boston.

Palacios-Fest, M. R.

1989 Early Irrigation Systems in Southeastern Arizona: the Ostracode Perspective. In Prehistoric Agricultural Activities of the Lehi-Mesa Terrace: Perspectives in Hohokam Irrigation Cycles, edited by N. W. Ackerly and T. K. Henderson, pp. 263-278. Prepared for Arizona Department of Transportation, Contract 86-102, by Northland Research, Inc., Flagstaff, Arizona.

1994 Nonmarine Ostracode Shell Chemistry from Ancient Hohokam Irrigation Canals in Central Arizona: A Paleohydrochemical Tool for the Interpretation of Prehistoric Human Occupation in the North American Southwest. Geoarchaeology: An International Journal 9(1):1-29.

2007 Superfamily Cypridoidea: an Assisting Tool for Identifying Ostracode Species and Their Basic Ecological Requirements. Terra Nostra Earth Sciences Research, LLC, and California State University. Poster available online, www.tnesr.com (accessed August 6, 2009).

Parmalee, P. W., and A. E. Bogan

1998 The Freshwater Mussels of Tennessee. The University of Tennessee Press, Knoxville.

PARP (Plymouth Archaeological Rediscovery Project)

2013 Firearms in Plymouth Colony. Retrieved from http://plymoutharch.tripod.com/id71.html.

Parry, W., and R. Kelly

1987 Expedient Core Technology and Sedentism. In The Organization of Core Technology, edited by J. Johnson and C. Morrow, pp. 285-309. Westview Press, Boulder, Colorado.

Patrick, M., A. J. de Konig, and A. B. Smith

1985 Gas Liquid Chromatographic Analysis of Fatty Acids in Food Residues from Ceramics Found in the Southwestern Cape, South Africa. Archaeometry 27(2):231-236. 
Patrick, W. H., Jr. and R. A. Khalid

1974 Phosphate Release and Sorption by Soils and Sediments: Effect of Aerobic and Anaerobic Conditions. In Science 186:53-55.

Pearsall, D. M., K. Chandler-Ezell, and A. Chandler-Ezell

2003 Identifying Maize in Neotropical Sediments and Soils Using Cob Phytoliths. Journal of Archaeological Science 30:611-627.

Pearsall, D. M., K. Chandler-Ezell, and J. A. Zeidler

2004 Maize in Ancient Ecuador: Results of Residue Analysis of Stone Tools from the Real Alto Site. Journal of Archaeological Science 31(4):423-442.

Perkins, S. M., and T. Baugh

2008 Prehistory and the Wichita. In Land of Our Ancestors: Studies in Protohistoric and Historic Wichita Cultures. Plains Anthropologist Vol. 53, No. 208, Memoir No. 40, pp. 381-394.

Perry, L.

2004 Starch Analyses Reveal the Relationship Between Tool Type and Function: An Example from the Orinoco valley of Venezuela. Journal of Archaeological Science 31(8):1069-1081.

2005 Reassessing the Traditional Interpretation of "Manioc" Artifacts in the Orinoco Valley of Venezuela. Latin American Antiquity : A Journal of the Society for American Archaeology 16(4):409-426.

2008 Appendix F, Starch Analyses from the BLM Landis Site: A Pilot Study. In Final Interim Report: Phase I of the Data Recovery at Three Prehistoric Sites (41PT185, 41PT186, and 41PT245) Located within the Landis Property in Potter County, Texas, by J. M. Quigg, C. D.Frederick and K. G. Luedecke, pp.174-192. TRC Environment Report 1508323, Austin.

Perry, L., R. Dickau, S. Zarrillo, I. Hotst, D. M. Pearsall, D. R. Piperno, M. J. Berman, R. G. Cooke, K. Rademaker, A. J. Ranere, J. S. Raymond, D. H. Sandweiss, F. Scaramelli, K. Tarble, and J. A. Zeidler

2007 Starch Fossils and the Domestication and Dispersal of Chili Peppers (Capsicum spp. 1.) in the Americas. Science 315(5814):986.

Perttula, T. K.

1995 The Archeology of the Pineywoods and Post Oak Savanna of Northeast Texas. Bulletin of the Texas Archeological Society 66:331-359.

2004 An Introduction to Texas Prehistoric Archaeology. In The Prehistory of Texas, edited by T. K. Perttula, pp. 5-13. Texas A\&M Press, College Station.

2012 Long Unreported Artifact Collections from Spanish Fort Bend Wichita Indian Sites in Oklahoma and Texas. Bulletin of the Texas Archeological Society (57) 221:63-69. 
Perttula, T. K. (Editor)

1999 The Hurricane Hill Site (41HP106): The Archaeology of a Late Archaic/Early Ceramic and Early Middle Caddoan Settlement in Northeast Texas, Volume 1. Special Publication \#4. Friends of Northeast Texas Archaeology. Pittsburg, TX.

Peter, D. E., and D. E. McGregor (editors)

1988 Late Holocene Prehistoric of the Mountain Creek Drainage. Joe Pool Lake Archaeological Project Vol. 1. Archaeology Research Program of North Texas, Denton.

Peter, D. E., and J. Harrison

2011 Archaeological Data Recovery (41TR198) and Survey within the Riverside Oxbow Project, Tarrant County, Texas. Geo-Marine, Inc., Miscellaneous Reports of Investigations No. 467.

Peter, S. J.

1992 Heat Transfer in Soils Beneath a Spreading Fire. Unpublished PhD Dissertation, University of New Brunswick. New Brunswick, Canada.

Peterson, R. T.

1988 A Field Guide to the Birds of Texas and Adjacent States. Peterson Field Guide Series. Houghton Mifflin Company, Boston.

Piperno, D. R., and I. Holst

1998 The Presence of Starch Grains on Prehistoric Stone Tools from the Humid Neotropics: Indications of Early Tuber Use and Agriculture in Panama. Journal of Archaeological Science 25(8):765-776.

Piperno, D. R., E. Weiss, I. Holst, and D. Nadel

2004 Processing of Wild Cereal Grains in the Upper Palaeolithic Revealed by Starch Grain Analysis. Nature 430(7000):670.

Porter, S. D.

2008 Algal Attributes: An Autecological Classification of Algal Taxa Collected by the National Water-Quality Assessment Program. U.S. Geological Survey Data Series 329, (http://pubs. usgs.gov/ds/ds329/).

Potapova, M. G., and D. F. Charles

2002 Benthic Diatoms in USA Rivers: Distributions Along Spatial and Environmental Gradients. Journal of Biogeography 29, 167-187.

2007 Diatom Metrics for Monitoring Eutrophication in Rivers of the United States. Ecological Indicators 7, 48-70. 
Potapova, M. G., D. F. Charles, K. C. Ponader, and D. M. Winter

2004 Quantifying Species Indicator Values for Trophic Diatom Indices: A Comparison of Approaches. Hydrobiologia 517, 24-41.

Prescott, G. W.

1978 How to Know the Freshwater Algae. 3rd ed. Wm. C. Brown Company Publishers, Dubuque.

Prewitt, E. R.

1981 Cultural Chronology in Central Texas. Bulletin of the Texas Archeological Society 52:65-89.

1983 From Circleview to Toyah, Comments of Central Texas Chronology. Bulletin of the Texas Archeological Society 54:201:238.

Prikryl, D. J.

1990 Lower Elm Fork Prehistory: A Redefinition of Cultural Concepts and Chronologies along the Trinity, North Central Texas. Report No. 37. Office of the State Archeologist, Texas Historical Commission, Austin.

Prikryl, D. J., and B. C. Yates (editors)

1987 Test Excavations at 41CO141, Ray Roberts Reservoir, Cooke County, Texas. Institute of Applied Sciences, North Texas State University, Denton.

Pyne, S. J.

1982 Fire in America: A Cultural History of Wildland and Rural Fire. Princeton University Press. Princeton, New Jersey.

Puseman, K.

2009 Choose Your Wood Wisely: Bigger Isn't Always Better. Paper presented at the Ninth Biennial Rocky Mountain Anthropological Conference, Western State College of Colorado, Gunnison.

Quick, C. R.

1961 How Long Can a Seed Remain Alive? In Seeds, the Yearbook of Agriculture, edited by A. Stefferud, pp. 94-99. United States Department of Agriculture, Washington D.C.

Quigg, J. M., C. Lintz, S. Smith, and S. Wilcox

2000 The Lino Site: A Stratified Late Archaic Campsite in a Terrace of the San Idelfonzo Creek, Webb County, Southern Texas. Technical Report No. 23765, TRC Mariah Associates Inc., Austin. Texas Department of Transportation, Environmental Affairs Division, Archaeological Studies Program Report 20, Austin. 
Quigg, J. M., M. E. Malainey, R. Przybylski, and G. Monks

2001 No Bones About It: Using Lipid Analysis of Burned Rock and Groundstone Residues to Examine Late Archaic Subsistence Practices in South Texas. Plains Anthropologist 46(177):283-303.

Quigg, J. M., P. M. Matchen, C. D. Frederick, R. A. Ricklis, B. Gregory, D. Maki, and M. Bateman

2013 Long View (41RB112): Data Recovery of Two Plains Village Components in Roberts County, Texas. Volume 1. Report prepared for the Texas Department of Transportation. Archeological Studies Program Report No. 147.

Read, C. E.

1971 Animal Bones and Human Behavior: Approaches to Faunal Analysis in Archaeology. Ph.D. dissertation, University of California, Los Angeles.

Reber, E. A., S. N. Dudd, N. J. van der Merwe, and R. P. Evershed

2004 Direct Detection of Maize in Pottery Residue via Compound Specific Stable Carbon Isotope Analysis. Antiquity 78:682-691.

Regert, M.

2007 Chapter 6: Elucidating Pottery Function Using a Multi-step Analytical Methodology Combining Infrared Spectroscopy, Chromatographic Procedures and Mass Spectrometry. In Theory and Practice of Archaeological Residue Analysis, edited by H. Barnard and J. W. Eerkens, pp.61-76. British Archaeological Reports International Series 1650. Oxford, UK.

Regert, M., H. A. Bland, S. N. Dudd, P. F. van Bergen, and R. P. Evershed

1998 Free and Bound Fatty Acid Oxidation Products in Archaeological Ceramic Vessels. Philosophical Transactions of the Royal Society of London, B 265 (1409):2027-2032.

Reichert, E. T.

1913 The Differentiation and Specificity of Starches in Relation to Genera, Species, Etc. Washington: Carnegie Institute.

Reimer, P. J., M. G. L. Baillie, E. Bard, A. Bayliss, J. W. Beck, P. G. Blackwell, C. Bronk Ramsey, C. E. Buck, G. S. Burr, R. L. Edwards, M. Friedrich, P. M. Grootes, T. P. Guilderson, I. Hajdas, T. J. Heaton, A. G. Hogg, K. A. Hughen, K. F. Kaiser, B. Kromer, F. G. McCormac, S. W. Manning, R. W. Reimer, D. A. Richards, J. R. Southon, S. Talamo, C. S. M. Turney, J. van der Plicht, and C. E. Weyhenmeyer

2009 IntCa109 and Marine09 Radiocarbon Age Calibration Curves, 0-50,000 Years Cal BP. Radiocarbon 51(4):1111-1150.

Reineck, H. E., and I. B. Singh

1980 Depositional Sedimentary Environments: With Reference to Terrigenous Clastics (2nd Edition). New York: Springer-Verlag. 
Reinhard, K. J. and V. M. Bryant, Jr.

1992 Coprolite Analysis: A Biological Perspective on Archaeology. Papers in Natural Resources, Paper 46. University of Nebraska-Lincoln, Lincoln, Nebraska.

Reitz, E. J. and E. S. Wing

1999 Zooarchaeology. Cambridge: Cambridge University Press.

Richardson, R. N.

1996 The Comanche Barrier to South Plains Settlement. Eakin Press, Austin, Texas.

Richardson, T. C., and H.P. Hinton,

2013 Ranching. Handbook of Texas Online (http://www.tshaonline.org/handbook/online/articles/ azr02), accessed July 06, 2013. Published by the Texas State Historical Association.

Roe, F. G.

1955 The Indian and the Horse. University of Oklahoma Press, Norman.

Roemer, F.

1935 Texas. Translated from German by Oswald Mueller. Naylor Publishing, San Antonio, Texas.

Roots, C.

2006 Hibernation. Greenwood Press. Westport, Connecticut.

Round, F. E.

1981 The Ecology of the Algae. Cambridge University Press.

Sauer, C. O.

1950 Grassland Climax, Fire, and Man. Journal of range Management 3(1):16-21.

Sauter, F., E. W. H. Hayek, W. Moche, and U. Jordis

1987 Betulin aus archäologischem Schwelteer. Z. für Naturforsch 42c (11-12):1151-1152.

Schiffer, M. B.

1975 The Effects of Occupation Span on Site Content. The Cache River Project, edited by M. B. Schiffer and J. House, pp. 265-269. Arkansas Archaeological Survey, Fayettville.

1996 Relationships Between Behavioral and Evolutionary Archaeologists. American Antiquity 61(4):643-662.

1999 Behavioral Archaeology: Some Clarifications. American Antiquity 64(1):166-168. 
Schmidly, D. J.

1994 The Mammals of Texas. University of Texas Press, Austin, Texas.

Schoch, W. H., B. Pawlick, and F. H. Schweingruber

1988 Botanical Macro-Remains. Paul Haupt Publishers, Berne and Stuttgart.

Schoeneberger, P. J., D. A. Wysocki, E. C. Benham, and W. D. Broderson,( eds)

2002 Field Book for Describing and Sampling Soils, Version 2.0. Natural Resources Conservation Service, National Soil Survey Center, Lincoln, Nebraska.

Schopmeyer, C. S.

1974 Seeds of Woody Plants in the United States. Agricultural Handbook No. 450. United States Department of Agriculture, Washington, D.C.

Schumm, S. A.

1977 The Fluvial System. John Wiley and Sons, New York.

Sellards, E. H., and G. L. Evans

1960 The Paleo-Indian Culture Succession in the Central High Plains of Texas and New Mexico. In Men and Cultures: Selected Papers of the 5th International Congress of Anthropological and Ethnographical Science, 1956.

Sellards, E. H., G. L. Evans, and G. E. Meade

1947 Fossil Bison and Associated Artifacts from Plainview, Texas. Bulletin of the Geological Society of America 58:927-954.

Sellards, E. H., W. S. Adkins, and F. B. Plummer

1932 The Geology of Texas, Volume 1: Stratigraphy. The University of Texas Bulletin \#3232, Austin.

Serb, J. M., J. W. Buhay, and C. Lydeard

2003 Molecular Systematics of the North American Bivalve Genus Quadrula (Unionidae: Ambleminae) based on mitochondrial ND1 sequences. Molecular Phylogenetics and Evolution 28(2003):1-11.

Serhman-Broyles, S. L., W. T. Barker, and L. M. Schultz

1997 Ulmaceae Mirbel. In Flora of North America North of Mexico, edited by Flora of North America Editorial Committee. vol. 3. 16+ vols. Oxford University Press, New York.

Shackley, M.

1982 Gas Chromatographic Identification of a Resinous Deposit from a 6th Century Storage Jar and Its Possible Identification. Journal of Archaeological Science 9:305-306. 
Sharpe, R. W.

1897 Contribution to the Knowledge of North American Fresh-Water Ostracoda Included in the Families Cytheridae and Cyprididae. Bulletin of the Illinois Laboratory of Natural History 4: 414-482.

Shibutani, A.

2008 Starch Residues on Stone Tools from the Tachikiri, Kakuriyama, Soujiyama and Okunonita Sites. Cultura Antiqua (Japanese). 60(1):130-140.

Shott, M. J.

1989 On Tool-Class Use Lives and the Formation of Archaeological Assemblages. American Antiquity 54(1):9-30.

Singer, M. J., and P. Fine

1989 Pedogenic Factors Affecting Magnetic Susceptibility of Northern California Soils. Soil Science of America Journal 53:1119-1127.

Skibo, J. M.

1992 Pottery Function: A Use-Alteration Perspective. Plenum Press, New York.

Skinner, S. A.

1981 Aboriginal Demographic Changes in Central Texas. Plains Anthropologist. 26(92):111-118.

Smith, A. J.

1987 The Taxonomy and Paleoecology of the Holocene Freshwater Ostracoda of Pickerel Lake, South Dakota. Unpublished PhD dissertation, Department of Geology, University of Delaware, Newark.

Smith, A. J. and L. D. Delorme

2010 Ostracoda. In Ecology and Classification of North American Freshwater Invertebrates, edited by J. Thorp and A. Covich, pp. 725-772. Elsevier Inc., Amsterdam.

Smith, C. L.

1995 The Boy Captives (7th edition). Anchor Publishing Company, San Angelo, Texas.

Smith, C. S., W. Martin, and K. A. Johansen

2001 Sego Lilies and Prehistoric Foragers: Return Rates, Pit Ovens, and Carbohydrates. Journal of Archaeological Science 28(2):169-183. 
Smith, E. A., and B. Winterhalder

1992 Natural Selection and Decision Making: Some Fundamental Principles. In Evolutionary Ecology and Human Behavior, edited by E. Smith and B. Winterhalder, pp. 25-60. Aldine de Gruyter, Hawthorne, New York.

Smith, F. T.

1996 The Caddos, the Wichitas, and the United States, 1846-1901. Texas A\&M University, College Station.

2000 The Wichita Indians: Traders of Texas and the Southern Plains, 1540-1845. Texas A\&M University, College Station.

2008 Wichita Locations and Population, 1719-1901. In Land of Our Ancestors: Studies in Protohistoric and Historic Wichita Cultures. Plains Anthropologist Vol. 53, No. 208, Memoir No. 40, pp. 407-414.

Smith, J. E. II, J. C. Blaine, K. Gilmore, R. K. Harris, and I. M. Harris

1993 The Vinson Site (41LT1): A Norteno Focus Indian Village in Limestone County, Texas. Bulletin of the Texas Archeological Society (57):221:65-162.

Soil Survey Staff, Natural Resources Conservation Service, United States Department of Agriculture.

n.d. Soil Survey Geographic (SSURGO) Database for Dallas County, Texas. Available online at http://soildatamart.nrcs.usda.gov. [Accessed November 2011].

1993 Soil Survey Manual. U.S. Department of Agriculture Handbook Number 18. U. S. Government Printing Press, Washington D.C.

Soiltest, Inc.

1976 Soil Testing Equipment Catalog. Soiltest, Inc., Evanston. IL.

Solomons, T. W. G.

1980 Organic Chemistry. John Wiley \& Sons, Toronto.

Staplin, F. L.

1963 Part II. Subfamilies Cyclocyprinae, Cypridopinae, Ilyocyprinae; Families Darwinulidae and Cytheridae, Stratigraphic Ranges and Assemblage Patterns. Journal of Paleontology 37:1164-1203.

Stebbins, R. C.

2003 Western Reptiles and Amphibians. Peterson Field Guide Series. Houghton Mifflin Company, New York, New York. 
Steel, D.

2000 Bayesian Statistics in Radiocarbon Calibration. Philosophy of Science 68(3), Supplement: Proceedings of the 2000 Biennial Meeting of the Philosophy of Science Association. Part 1: Contributed Papers (Sep. 2001), S153-S164.

Stevenson, M. G.

1991 Beyond the Formation of Hearth-Associated Artifact Assemblages. In The Interpretation of Archaeological Spatial Patterning, edited by E. M. Kroll and T. D. Price, pp. 269-299. Plenum Press, New York.

Stevenson, R. J., and Y. Pan

1999 Assessing environmental conditions in rivers and streams with diatoms. In E. F. Stoermer and J. P. Smol: The Diatoms, Applications for the Environmental and Earth Sciences. pp. 11-40.Cambridge University Press.

Steward, F. R., S. Peter, and J. B. Richon

1989 A Method for Predicting the Depth of Lethal Heat Penetration into Mineral Soils Exposed to Fires of Various Intensities. Canadian Journal of Forest Research 20:919-926.

1973 Shaw's Creek Shelter: Human Displacement of Artifacts and Its Significance. Mankind 9:112-117.

Steward, J. H.

1955 Theory of Culture Change. University of Illinois Press, Urbana.

1968 Casual Factors and Processes in the Evolution of Pre-Farming Societies. Man the Hunter, pp. 321-334. R. B. Lee and I. DeVore (editors). Aldine Press, Chicago.

1969 Observations on Bands. In Contributions to Anthropology: Band Societies, D. Damas (editor), pp. 187-190. National Museum of Canada Bulletin 228, National Museum of Canada, Ottawa.

Stopka, C., and T. Black

2014 Partial List of Texas Ranger Company and Unit Commanders. List compiled by C. Stopka (Director, Texas Ranger Research Center) and T. Black (Texas State Library and Archives, Austin). http://www.texasranger.org/ReCenter/captains.pdf. $<$ Accessed October 1, 2014>.

Story, D. A.

1990 Culture History of the Native Americans. In Archeology and Bioarcheology of the Gulf Coastal Plain, Vol. I, by D. A. Story, J. A. Guy, B. A. Burnett, M. D. Freeman, J. C. Rose, D. G. Steele, B. W. Olive, and K. J. Reinhard, pp. 163-366. Arkansas Archeological Survey Research Series Number 38. Arkansas Archeological Survey, Fayetteville.

Stout, L. N.

1981 An Unusual Occurrence of the Brackish-water Ostracode Cyprideis salebrosa in central Missouri. Journal of Paleontology 55:898-900. 
Strayer, D. L., J. A. Downing, W. R. Haag, T. L. King, J. B. Layzer, T. J. Newton, and S. J. Nichols

2004 Changing Perspectives on Pearlymussels: North America's Most Imperiled Animals. BioScience 54(5):429-439.

Strayer, D. L., N. F. Caraco, J. J. Cole, S. Findlay, and M. L. Pace

1999 Transformation of Freshwater Ecosystems by Bivalves. BioScience 49(1):19-27.

Strecker, J. K., Jr.

1931 The Distribution of the Naiads or Pearly Fresh-water Mussels of Texas. Baylor University Museum Special Bulletin 2, Waco, Texas.

Strickland, R. W.

1942 Moscoso’s Journey through Texas. Southwestern Historical Quarterly XLVI:109-137.

Stuiver, M.

1968 Oxygen 18 Content of Atmospheric Precipitation During the Last 11,000 Years in the Great Lakes Region. Science 162:994-995.

1970 Oxygen and Carbon Isotope Ratios of Fresh-Water Carbonates as Climatic Indicators. Journal of Geophysical Research 75(27):5247-525.

Styles, B. W.

1981 Faunal Exploitation and Resource Selection: Early Late Woodland Subistence in the Lower Illinois Valley. Northwestern University Archaeological Program, Evanston.

Suhm, D. A.

1954 An Introductory Handbook of Texas Archaeology. Bulletin of the Texas Archeological Society 25 .

1957 Excavations at the Smith Shelter, Travis County, Texas. Texas Journal of Science 9:26-58.

Swetman, T. W.

1993 Fire History and Climate Change in Giant Sequoia Groves. Science 262(5135):885-889.

Taylor, R. E.

1987 Radiocarbon Dating: An Archaeological Perspective. Academic Press, Inc., Orlando.

Telford, R. J., E. Heegaard, and H. J. B. Birks

2004 The Intercept Is a Poor Estimate of a Calibrated Radiocarbon Age. The Holocene 14(2):296-298. 
Texas Beyond History

2013a Rodents. Retrieved from http://www.texasbeyondhistory.net/st- plains/nature/images/rodents. html.

2013b Asphaltum. Retrieved from http://www.texasbeyondhistory.net/coast/nature/images/ asphaltum.html.

Thomas, D. J., and W. A. Atwell

1999 Starches. Eagan Press, St. Paul, Minnesota.

Thompson, A. K.

2012 Dead Trees Do Tell Tales: Investigations into the Role of Fires on Archaeological Site Location and Recognition in the Piney Creek Drainage of the Greater Yellowstone Ecosystem. Unpublished Master's Thesis. Colorado State University, Fort Collins, Colorado.

Thompson, R., and F. Oldfield

1986 Environmental Magnetism. Allen and Unwin, London.

Thoms, A. V.

1996 A Management Strategy and Study of Prescribed Burning Impacts on Hertiage Resources in Ponderosa Pine/Douglas-Fir Composition Types on the Kootenai National forest, Northwestern Montana, edited by R. Timmons, pp. 37-43. Study by Texas A\&M University, College Station, TX for U.S. Department of Agriculture, Forest Service, Northern Region, Missoula, Montana.

2008 The Fire Stones Carry: Ethnographic Records and Archaeological Expectations for Hot-rock Cookery in Western North America. Journal of Anthropological Archaeology 27(4):443-460.

Tinsley, C. M., and C. Dayton, eds.

2011 Archaeological Testing and Data Recovery Excavations at Site 41DL203, President George Bush Turnpike-Eastern Extension from SH 78 to IH 30, Dallas County, Texas. Geo-Marine, Inc., Miscellaneous Reports of Investigations No. 484, Plano, Texas.

Tite, M. S., and C. Mullins

1971 Enhancement of the Magnetic Susceptibility of Soils on Archaeological Sites. Archaeomoetry 13:209-219.

Todd, J., and S. A. Skinner

2006 Archaeological Testing of the Gilkey Hill Site (41DL406), Dallas County, Texas. Cultural Resources Report 2006-04, AR Consultants, Inc., Dallas, Texas. 
Todd, L. C.

2006 Reconnaissance and Preliminary Archaeological impacts Assessment $f$ the Little Venus Fire (Park County, Wyoming). Unpublished report on file, Shoshone National Forest, FS Agreement No. 05-CS-11021400-08. Colorado State University, Fort Collins, Colorado.

Tomka, S. A.

1999 The Effect of Processing Requirements on Reduction Strategies and Tool Form: A New Perspective. Paper presented at the 64th Annual Meeting of the Society for American Archaeology in the symposium entitled Morphology, Myth, and Meaning: New Directions in Lithic Debitage Analysis.

1986 Biface Manufacture Failures at 41BP19. Manuscript on File, Center for Archaeological Research, The University of Texas at San Antonio.

Toomey, R. S. III, M. D. Blum and S. Valastro, Jr.

1993 Late Quaternary Climate and Environments of the Edwards Plateau, Texas. Global and Planetary Change 7:299-320.

Toomey, R. S., and T. W. Stafford, Jr.

1995 Paleoenvironmental and Radiocarbon Study of the Deposits from Hall's Cave, Kerr County, Texas. Program and Abstracts, 52nd Plains Conference, 65th Annual Meeting of the Texas Archeological Society, Lubbock.

Torrence, R., and H. Barton

2006 Ancient Starch Research. Left Coast Press, Walnut Creek, California.

TPWD

2011a Ecoregions of Texas. Http://www.tpwd.state.tx.us [Accessed August 7, 2011]

2011b Cross Timbers and Prairie Ecological Region. Http:/www.state.tx.us/landwater/land/habitats/ cross_timbers/ecoregions \{Accessed August 7, 2011]

2011c Biotic Provinces of Texas. Http://www.tpwd.state.tx.us/publivations/pwdpubs/media/ [Accessed August 7, 2011]

Trask, L. K., J. Todd, and S. A. Skinner

2008 Archaeological Testing of Site 41DL441 for the Trinity Parkway in Dallas County, Texas. Cultural Resources Report 2008-83, AR Consultants, Inc., Dallas, Texas.

Trierweiler, W. N., and D. Nickels

2010 Initial Research Design and Fieldwork Plan: Data Recovery Investigations, 41DL436. Lake Ridge Parkway Extension at Fish Creek, Texas Department of Transportation, Dallas District, Dallas County. CSJ: 0918-45-608. Ecological Communications Corporation. 
Turgeon, D. D., and nine co-authors.

1998 Common and Scientific Names of Aquatic Invertebrates of the United States and Canada: Mollusks. American Fisheries Society Special Bulletin 16, Bethesda, Maryland.

Turner, B., H. Nichols, G. C. Denny, and O. Doron

2003 Atlas of the Vascular Plants of Texas 2. 2 vols. Botanical Research Institute of Texas.

Turner-Pearson, K.

2008 The Stone Site: A Waco Indian Village Frozen in Time. In Land of Our Ancestors: Studies in Protohistoric and Historic Wichita Cultures. Plains Anthropologist Vol. 53, No. 208, Memoir No. 40, pp. 565-593.

Ugent, D., S. Pozorsky, and T. Pozorsky

1981 Prehistoric Remains of the Sweet Potato from the Casma Valley of Peru. Phytologia 49:401-415.

1982 Archaeological Potato Tuber Remains from the Casma Valley of Peru. Economic Botany 36(2):182-192.

1984 New Evidence for Ancient Cultivation of Canna edulis in Peru. Economic Botany $38: 417-432$.

Urey, H. C.

1947 The Thermodynamic Properties of Isotopic Substances. Journal of the Chemical Society of London 108:562-581.

USDA

n.d.a. Web Soil Survey. (http://websoilsurvey.nrcs.usda.gov/app/). [Accessed July 2010].

n.d.b. Official Soil Series Descriptions. (http://soils.usda.gov/technical/classification/osd/index. html) [Accessed July 2010].

n.d.c Online soil texture calculator. (http://soils.usda.gov/technical/aids/investigations/texture/) [Accessed February 2012].

Van Dam, H., A. Mertens, and J. Sinkeldam

1994 A Coded Checklist and Ecological Indicator Values of Freshwater Diatoms from the Netherlands. Netherlands Journal of Aquatic Ecology 28 (1), 117-133.

Van den Bold, W A.

1963 Upper Miocene and Pliocene Ostracoda of Trinidad. Micropaleontology 9(4):361-424.

Vierra, B.

1998 Archaeological Investigations at 41MV120, Maverick County, Texas. Archaeological Survey Report No. 251. Center for Archaeological Research, The University of Texas at San Antonio. 
Villa, P.

1982 Conjoinable Pieces and Site Formation Processes. American Antiquity 47(2):276-290.

Villa, P., and J. Courtin

1983 The Interpretation of Stratified Sites: A View from Underground. Journal of Archaeological Science 10:267-281.

Wallace, E.

1993 Ranald S. Mackenzie on the Texas Frontier. Texas A\&M University Press, College Station.

Wang, Yi-K., R. J. Stevenson, and L. Metzmeier

2005 Development and Evaluation of a Diatom-based Index of Biotic Integrity for the Interior Plateau Ecoregion, USA. J. N. American Benthological Soc. 24(4), 990-1008.

Waters, M. R.

1991 Principles of Geoarchaeology: A North American Perspective. University of Arizona Press, Tuscon.

Weaver, R.

2003 Rediscovering Polarized Light Microscopy. American Laboratory:55-61.

Webb, W. P. (editor)

1952 The Handbook of Texas. 2 Vols. Texas State Historical Association, Austin, Texas.

Websoil

2011 Dallas County. http://websoilsurvey.nrcs.usda.gov/app/WebSoilSurvey.aspx. [Accessed August 5, 2011].

Weddle, R. S.

1964 The San Sabá Mission: Spanish Pivot in Texas. Texas. A\&M University Press, College Station.

1968 San Juan Bautista: Gateway to Spanish Texas. University of Texas Press, Austin.

Weigelt, J.

1989 Recent Vertebrate Carcasses and Their Paleobiological Implications (English translation by J. Schaefer). University of Chicago Press.

Weissner, P.

1982a Beyond Willow Smoke and Dogs' Tails: a Comment on Binford's Analysis of HunterGatherer Settlement Systems. American Antiquity 47:171-178. 
1982b Risk, Reciprocity and Social Influences on !Kung San Economics. In Politics and History in Band Societies, edited by E. R. Leacock and R. B. Lee. Cambridge University Press, London.

1982c Reconsidering the Behavioral Basis of Style: A Case Study Among the Kalahari San. Journal of Anthropological Archaeology 3:190-234.

White, T. E.

1952 Animal bone and Plains archaeology. Plains Archaeological Conference Newsletter 4:46-78.

1953 A Method of Calculating the Dietary Percentage of Various Food Animals Utilized by Aboriginal Peoples. American Antiquity. 18:396-397.

Whittaker, D. G., and F. G. Lindzey

1999 Effects of Coyote Predation on Early Fawn Survival in Sympatric Deer Species. Wildlife Society Bulletin 27(2):256-262.

Wicklow, D. T., Sr., K. Angel, C. D. P., and J. Lussenhop

1980 Fungal Community Expression in Lagomorph Versus Ruminant Feces. Mycologia 72(5):1015-1021.

Wikipedia

2013 Shot (Pellet). Retrieved from http://en.wikipedia.org/wiki/Shot_(pellet).

Wilbarger, J. W.

1889 Indian Depredations in Texas. Hutchings Printing House. Austin, Texas. Reprinted by Eakin Press, Austin, Texas (1985).

Williams, J. D., A. E. Bogan, and J. T. Garner

2008 Freshwater Mussels of Alabama \& the Mobile Basin in Georgia, Mississippi \& Tennessee. The University of Alabama Press, Tuscaloosa.

Williams, J. W.

1942 Southwestern Historical Quarterly XLVI:138-157.

Wilmsen, E. N.

1968 Lithic Analysis in Paleoanthropology. Science 161:982-987.

Winsborough, B. M.

1995 Diatoms. In Late Quaternary Valley Fills and Paleoenvironments of the Southern High Plains. Memoir 186, edited by V. Holliday, pp. 67-83. Geological Society of America.

2010 Appendix B: Algal Community Interpretation for Nutrient Effects on Small Brazos River Basin Streams. In P. L. Radloff, C. Contreras, A. Whisenant, \& J. M. Bronson. Nutrient Effects in Small Brazos Basin Streams, Final Report, pp. 1-77, by P. L. Radloff, C.

Contreras, A. Whisenant, \& J. M. Bronson. Water Quality Technical Series WQTS-2010-02. 
Water Resources Branch, Texas Parks and Wildlife Department, 4200 Smith School Road, Austin, Texas.

Winter, J. G., and H. C. Duthie

2000 Epilithic Diatoms as Indicators of Stream Total N and Total P Concentration. Journal of North American Benthological Society 19 (1), 32-49.

Winterhalder, B., and E. A. Smith

1992 Evolutionary Ecology and Social Sciences. In Evolutionary Ecology and Human Behavior, edited by E. Smith and B. Winterhalder, pp. 3-24. Aldine de Gruyter, Hawthorne, New York.

Witkind, W.

1977 An Experiment in Stone Boiling. In Hop Hill: Culture and Climatic Change in Central Texas, edited by J. Gunn and R. Mahula, pp. 205-208. Special Report No. 5, Center for Archaeological Research, The University of Texas at San Antonio.

Wobst, H. M.

1978 The Archaeo-ethnology of Hunter-gatherers, or the Tyranny of the Ethnographic Record in Archaeology. American Antiquity 43:303-309.

Wood, W. R., and D. L. Johnson

1976 A Survey of Disturbance Processes in Archaeological Site Formation. Advances in Archaeological Method and Theory, vol. 1, edited by M. B. Schiffer, pp. 315-381. Academic, New York.

Wormington, H. M.

1957 Ancient Men in North America. 4th ed. The Denver Museum of Natural History, Colorado.

Wright, H. A., and A. W. Bailey

1982 Fire Ecology. John Wiley \& Sons, New York.

Yates, B. C.

1982 Vertebrate Faunal Remains. In Archeological Investigations at the San Gabriel Reservoir Districts, Central Texas, edited by T.R. Hays, pp. 15-57-15-227. Institute of Applied Sciences, North Texas State University, Denton.

1993 Faunas from House 5 at the Vinson Site. Bulletin of the Texas Archeological Society (57):221:187-225.

Yates, B. C., and C. R. Ferring (editors)

1986 An Assessment of the Cultural Resources in the Trinity River Basin, Dallas, Tarrant, and Denton Counties, Texas. Institute of Applied Sciences, North Texas State University, Denton. Submitted to the U.S. Army Corps of Engineers, Fort Worth District. 
Yellen, J. E.

1977 Archaeological Approaches to the Present: Models for Predicting the Past. Academic Press, New York.

Zarrillo, S., and B. Kooyman

2006 Evidence for Berry and Maize Processing on the Canadian Plains from Starch Grain Analysis. American Antiquity 71(3):473-499. 


\section{Appendix A Soil Micromorphological ObServations}


Appendix $A$ 


\title{
Report on Soil Micromorphological Observations from 41DL436
}

\author{
Charles D. Frederick
}

\section{Introduction}

Five blocks of sediment collected by Abbott were provided from different contexts at the site. The samples, which were wrapped in toilet paper and tape, were first dried, and then embedded in a mixture of polyester resin and styrene under a vacuum (a styrene cured unsaturated polyester resin (316 NP) catalyzed with methyl ethyl ketone peroxide, obtained from Advance Coatings Company, Westminster, Massachusetts). The embedded blocks were then peeled using a rock saw whereby the outer $1 \mathrm{~cm}$ of the embedded block was sawed off so the internal structure of the block could be better assessed. This process yielded between four and six cut faces, which were then examined for features of interest. From the peeled block one or more $\sim 1$ $\mathrm{cm}$ thick slab(s) were cut and examined. The locations of thin sections blanks were then chosen, drawn onto the slab with a sharpie, and the block was scanned on a flatbed scanner. A tile trim saw was next used to cut the thin section blanks to size and these were then labeled and sent to Spectrum Petrographics in Vancouver, Washington, to be made into thin sections. Upon return, the 2"x3" slides were scanned at 1000 dpi with transmitted light on a flatbed scanner prior to microscopic analysis. Full page color prints of the high resolution scans were used to perform the first pass assessment of each slide and locate features of interest for description. Description of the thin sections was facilitated by viewing the slides at low magnification with a Leica S8 APO binocular microscope fitted with transmitted light base and polarizing filters and at higher magnification using a Leica DMEP polarizing light microscope. Descriptive terminology follows, in general, the nomenclature of Stoops (2003) and Bullock et al (1985).

\section{Sample 1 (Test Unit 49 Profile, Base of Stratigraphic Unit 3, C horizon, depth $=5260 \mathrm{cmbs}$ )}

This deposit is a prominently bedded alluvial overbank sediment that consists of alternating coarse and fine textured beds. All of these beds appear to originally have been laminated, but the finer textured beds have experienced disproportionate post-depositional alteration by soil fauna, particularly worms. The embedded large hand specimen exhibited a moderate prismatic to subangular blocky structure that was most clear in the finer textured beds. For descriptive purposes, the sample can be divided into two major parts: coarse beds and fine beds, each of which exhibit typical thicknesses of a few mm or less (Figure A1). 
Coarse Beds

The coarse beds are primarily composed of very well to well sorted fine sand and coarse silt that exhibits a granular microstructure. These deposits are prominently laminated (in soil micromorphological terms they are layered, as they are composed of juxtaposed alternating textured sections) and exhibit thin fining upward laminae that are sand at the base and medium to coarse silt at the top. These deposits have a $\mathrm{c} / \mathrm{f} 63 \mu \mathrm{ratio}$ of 90:10, exhibit a monic $\mathrm{c} / \mathrm{f}$ related distribution, and have no significant micomass. The finer textured portions

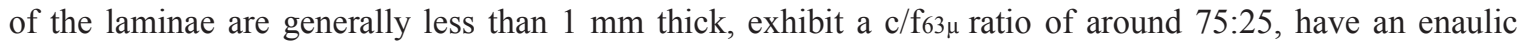
related distribution, and the micromass exhibits a speckled b-fabric. The sands in the deposit overall are primarily subrounded to subangular quartz $(70 \%$ to $80 \%)$ and limestone $(<20 \%)$.

\section{Fine Beds}

The fine textured beds appear to have been laminated (or layered) at one time, but this portion of the deposit exhibits many worm passage features/excrement pedofeatures and only small fragments of the original bedding are present. This portion of the deposit exhibits a crumb to granular microstructure with weak to moderate pedality and a c/f63 $\mu$ ratio of around 60:40 and a porphyric related distribution. The micromass exhibits a speckled b-fabric, and is light to moderate brown colored in plane light.

\section{Pedofeatures}

The dominant pedofeatures observed in this sample were layering (previously discussed), excrements, and calcium carbonate pore coats. The excrements, when discrete, are generally large, 1-2 mm, ellipsoidal to mammilated, and exhibit internal packing structures ranging from very porus to dense. Almost one half of the slide consisted of relatively dense excrement. The coarse beds, as noted previously, exhibit few excrement pedofeatures (10-20\%) when compared to the fine beds, which range from $60-90 \%$ excrement pedofeatures.

Although present in both textural groups, calcium carbonate coats and hypocoats lining pores were most common in the fine beds. These features are difficult to discern in plane light, but quite apparent in cross-polarized light. They range from 1-2 mm thick.

\section{Sample 2 (Test Unit 49 Profile, Stratigraphic Unit 2b, depth 95-102 cmbs)}

A single thin section was prepared from sample 2, and the thin section obtained was somewhat deficient, having been ground too thin on either end and only well done in the middle section, which was left too thick resulting in anomalous interference colors for most minerals. 
The sample exhibits several large linear channels, one of which retains vestiges of root material, the other of which contains a loose assemblage of relatively coarse excrement pedofeatures. The microstructure ranges from channel to vughy, and the sample is, in general terms, quite porous. Some of the tonal variation on the slide is reminiscent of alternating coarse and fine textured beds, but with considerably more post-depositional disturbance by soil microfauna. The sample has a c/f63 $\mu$ ratio of around 50:50 to 60/40, and a close to open porphyric related distribution. The groundmass exhibits a speckled b-fabric. The dominant coarse mineral present is subangular to subrounded quartz which comprises about $80 \%$ of the slide, followed by limestone rock fragments. There are about 1-2\% finely dispersed $0.01-0.03 \mathrm{~mm}$ charcoal fragments and a few larger fragments that approach 1-2 $\mathrm{mm}$ in diameter. Small snails $(<5 \mathrm{~mm})$ were also noted.

The dominant pedofeature present are the many excrement pedofeatures that range from loose, discrete roughly spherical particles 0.05 to $2 \mathrm{~mm}$ in diameter, to densely coalesced excrements that can be discerned with difficulty. There are also a few 0.5 to $2 \mathrm{~mm}$ calcium carbonate hypocoats lining pores.

\section{Sample 3 (Test Unit 49 Profile, top of Stratigraphic Unit 3, depth 142-150 cmbs)}

A single thin section was prepared from this oriented sample. The specimen exhibited a massive structure that was vughy in a few places, but exhibits a distinct lack of obvious pedality. The texture of this sample

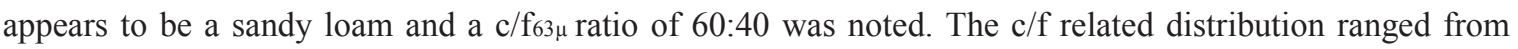
close porphyric to chitonic. The mineralogy of the coarse fraction is dominated by subangular to subrounded quartz, which comprises about $80 \%$ of the visible grains. Sedimentary rock fragments, of which limestone is the most common, appear to make up the second most frequently occurring framework grain. Quite a few small charcoal fragments were noted in the thin section (Figure A2), and some of these had clearly been disarticulated by faunal activity. The micromass is dark brown in color (plane light) and exhibits a speckled b-fabric.

The most common pedofeatures present are excrement pedofeatures created by soil microfauna. Although the thin section appears massive at first glance, close examination reveals many small $0.5-1.5 \mathrm{~mm}$ rounded excrement peds that for the most part are densely coalesced and difficult to discern. There are several young, much less coalesced passage features as well. The slab from which the thin section was prepared clearly showed numerous worm passage features, which are linear, $\sim 0.5 \mathrm{~cm}$ wide tracks of excrement peds, which were visible owing to subtle color variations of the fine matrix; however, these were much more difficult to observe in the thin sections on the basis of color. 
The other major pedofeature present are rare to few $(<<1 \%)$ small $(<2 \mathrm{~mm})$ calcium carbonate nodules that are of similar size to the calcium carbonate hypocoatings in samples 1 and 2 , but lack the obvious pore at their centers.

The darker color, absence of obvious bedding, and dominance of aged excrement pedofeatures is reminiscent of a buried soil, but the absence of more obvious pedality is somewhat surprising.

Sample 4 (Eastern Block Profile, thermal feature in upper Unit $2 \mathrm{~b}$ in swale, $18.5 \mathrm{~m}$ south, depth = $97.40 \mathrm{~m}$ relative to arbitrary datum, approx. $2.3 \mathrm{~m}$ bgs)

This sample was collected from an in situ burnt feature and one of the primary questions is whether there is evidence of multiple uses of the feature and whether it is a hearth. Four thin sections were made from this specimen, examining different aspects of the feature and one of these is shown on Figure A3. In general terms this featue appears to be consistent with a hearth, and the microstratigraphy of this feature can be divided into four micro-facies from top to bottom: 1. Mixed thermal refuse, 2. Ash interface, 3. Rubified earth, and 4. Carbon core.

\section{Mixed Thermal Refuse}

The upper most part of the feature is a zone of mixed thermal refuse that rests upon the ash. This microfacies consists of a mixture of charcoal and fine dispersed charcoal enriched sediment, rounded fragments of rubified earth, and fragments of ash jumbled together. A few thin hypocoats of calcium carbonate are present around pores but these are generally rare. The fragments of rubified earth are most likely attributable to either rake out of the feature and/or post-depositional relocation of this sediment by soil fauna.

\section{Ash Interface}

This microfacies is situated at the interface between the ash and the earthen base of the thermal feature. The ash interface is generally $<0.5$ to $1 \mathrm{~cm}$ thick and consists of laminated ash (calcitic material) that ranges from massive micrite to idiomorphic ash that retains plant structures. The ash is generally white to gray in color and contains very small charred plant fragments, and occasional fragments of reddened earth.

\section{Rubified Earth}

Immediately beneath the ash interface is the zone of reddened or rubified earth that often has been heavily reworked by soil fauna. Directly below the interface, ash can be seen capping rounded aggregates of the rubified earth and filtering down into interstial spaces. In several of the thin sections, a thin $(<0.5 \mathrm{~mm})$ crust-like graded laminae that ranges in texture from fine loamy sand at the base to silt loam at the top was present at the interface between the ash and rubified earth, and at least one other feature like this was noted at depth within the rubified earth (see the arrows on expanded view 1 on Figure A3). At least one of these exhibited periodic vertical cracks similar to desiccation cracks. It is not clear if this is a product of use/firing or was a preexisting structure, but the manner in which this feature articulates to the topographic irregularities of the ash interface lead me to think this is a thermal feature. The rubified earth also contains 
many $(\sim 15 \%)$ thick $(0.3$ to $1 \mathrm{~mm})$ hypocoats of calcium carbonate that are most likely redeposited or reprecipitated ash.

\section{Carbon Core}

Both thin sections that examined the lower portion of feature exhibited a slightly darker band at the base of the rubified earth that is here termed a "carbon core." This microfacies shares many attributes with the rubified earth (including its general color and presence of many calcitic hypocoats lining pores), but also contains more charcoal. This charcoal includes large fragments that may be roots) as well as finely disseminated fragments.

Collectively, there is no concrete evidence of multiple uses of this hearth, but the close association between the thin graded bed-like crusts deep within the rubified earth and in proximity to the carbon core does look suspicious. The degree of thermal alteration (substantially rubified substrate, and significant white to gray ash) is consistent with cooking fires described by Mallol et al (2007).

\section{Sample 5 (Eastern Block Profile, mussel shell feature in upper Unit 1a, $11.6 \mathrm{~m}$ south, depth $=$} $97.80 \mathrm{~m}$ relative to arbitrary datum, approx. $1.9 \mathrm{~m}$ bgs)

This block was collected from a mussel shell discard feature within a paleosol. Two slides were prepared from this block (Figure A4). The basic micromorphological attributes of the deposit are similar to sample 3 , with the exception of the occupation zone, which exhibits several distinct differences that are primarily attributable to less extensive post-depositional disturbance owing to the presence of the shells.

The occupation zone is quite discrete, measuring between 2 and $3 \mathrm{~cm}$ between the two slides. The defining elements are the large freshwater mussel shells. These shells are well preserved, still retaining the "bark" on the exterior surface. None of the larger shells are burnt, but both slides contained small fragments of mussel shell that had been burnt (as evidenced by a brown to dark yellow discoloration). Other thermal refuse is also present, specifically large charcoal fragments. Together with the mussel shell fragments are also several small bone fragments and snails. The sediment in direct proximity to the mussel shells appears to have been less-reworked by soil fauna, resulting in significantly better charcoal preservation. There have been some worm passages through this section of the deposit, but most of these appear to hug close to the large shells. A few isolated smaller fragments of probably cultural debris are present away from the occupation zone, and most of these are small enough to have been ingested by soil fauna. 


\section{References Cited}

Bullock, P. N. Federoff, A. Jongerius, G. Stoops, and T. Tursina 1985 Handbook for Soil Thin Section Description. Waine Research Publications, Wolverhampton, UK

Mallol, C., F. W. Marlowe, B. M. Wood, and C. C. Porter 2007 Earth, wind and fire: ethnoarchaeological signals of Hadza fires. Journal of Archaeological Science 34:2035-2052.

Stoops, Georges 2003 Guidelines for Analysis and Description of Soil and Regolith Thin Sections. Soil Science Society of America, Madison Wisconsin. 

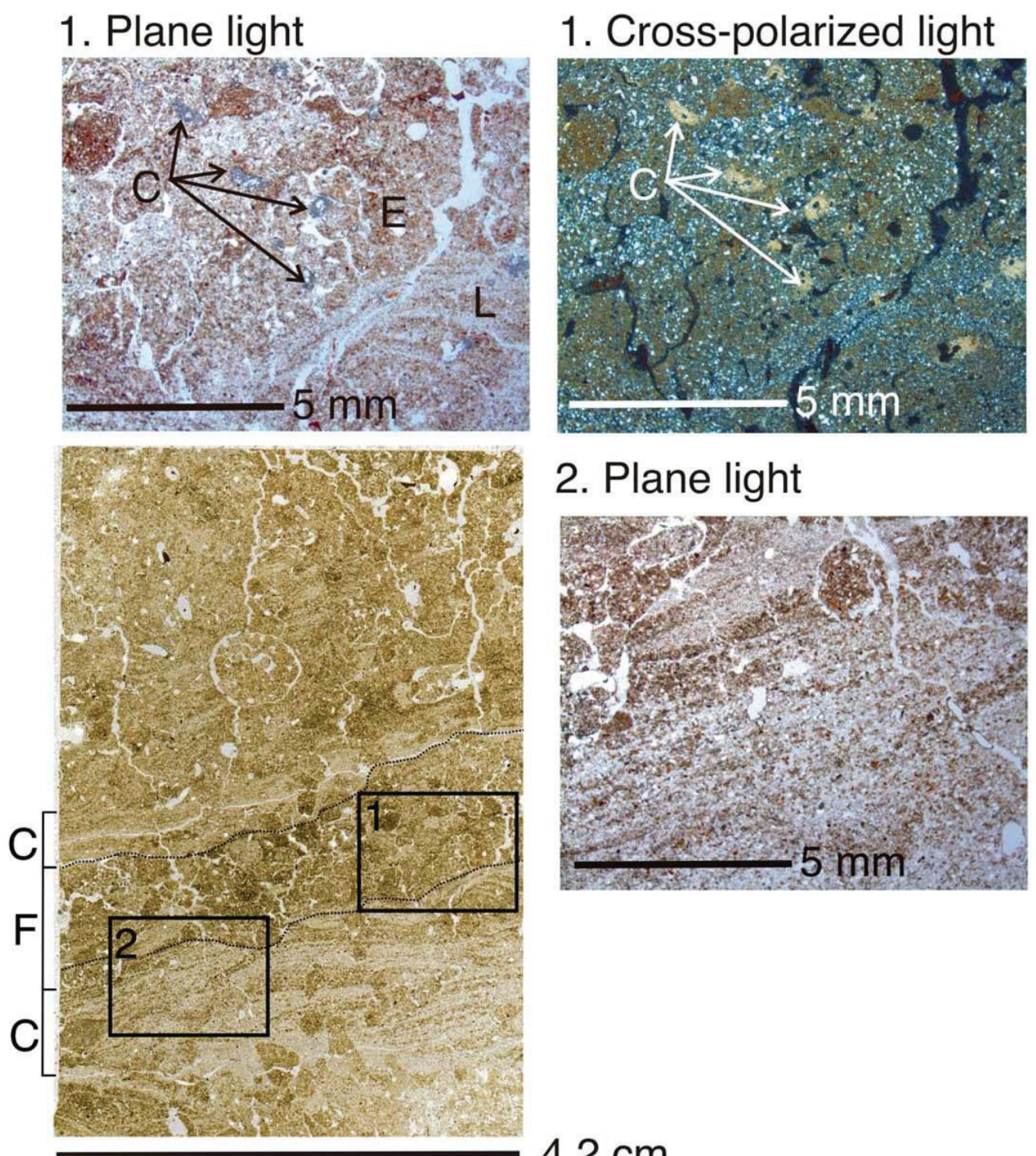

\section{Plane light}

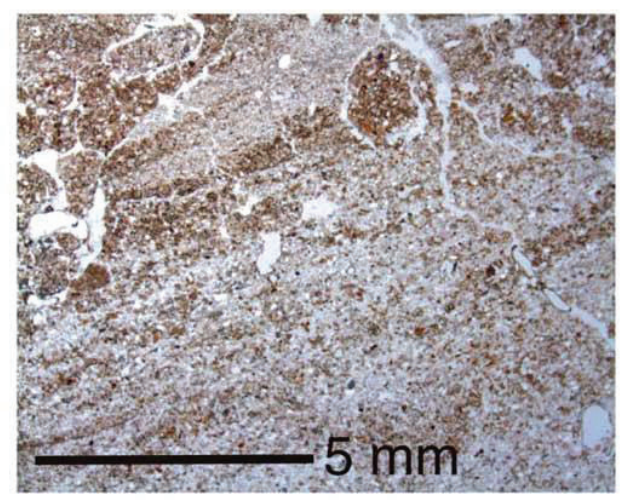

\section{$4.2 \mathrm{~cm}$}

Figure A1. Bottom left: Transmitted light scan of sample 1. The letters on left side denote some of the fine (F) and coarse (C) beds described in the text, and a dotted line highlights the approximate borders of the heavily bioturbated fine bed. The two boxes denote the location of the enlarged areas (1, above, and 2, to the right).

1. Enlarged photomicrograph of a porion of a finer textured bed showing excrement pedofeatures (only one labeled with "E") and small calcium carbonate hypocoats ("C") which are much more visible in cross-polarized light.

2. Enlarged photmicrograph of layered sediment associated with a coarse bed. The finer textured layers are dark brown whereas the sands are lighter colored. 


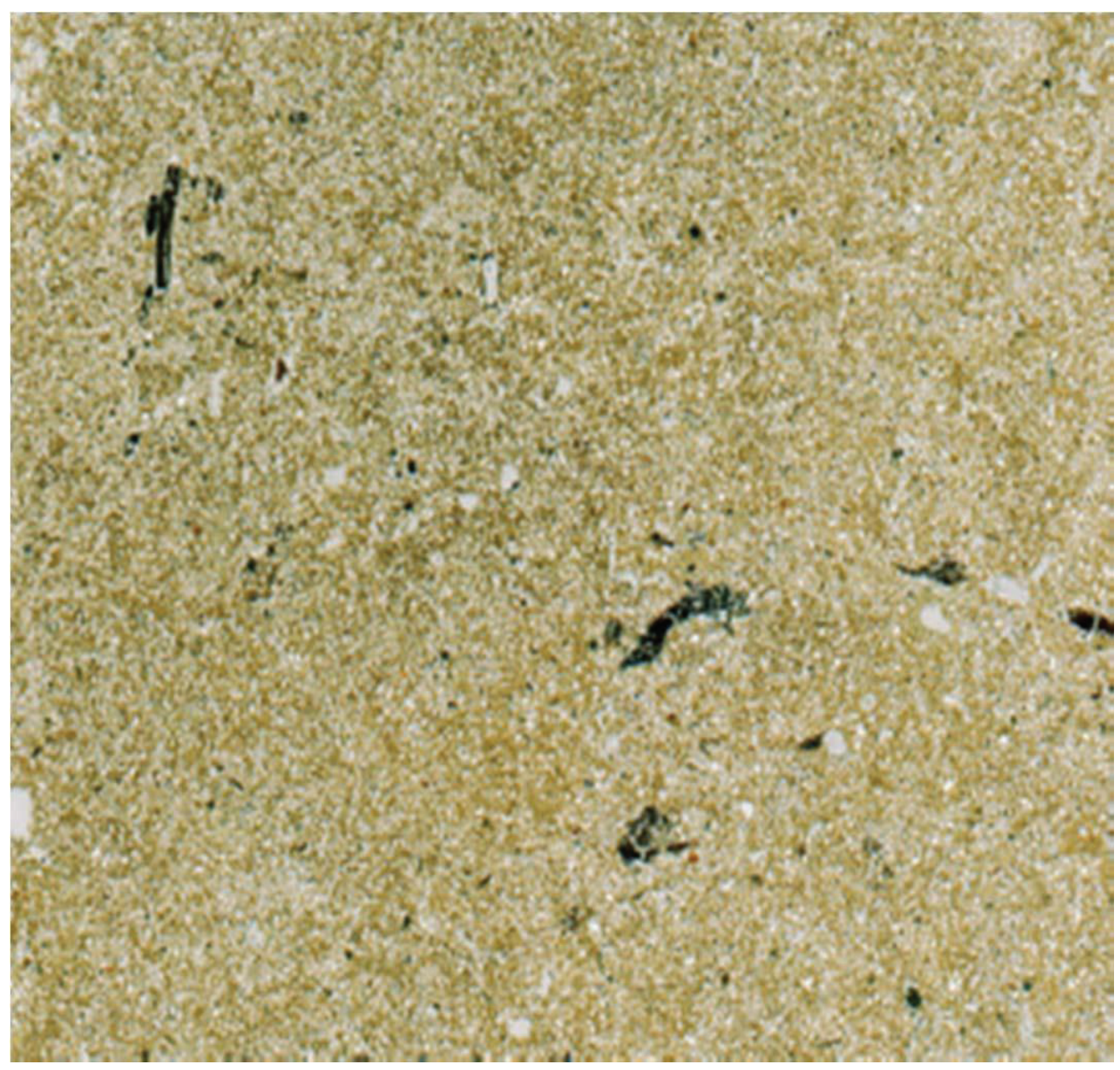

Figure A2: Low power scan of sample 3, illustrating the lack of structure and the presence of dispersed charcoal. 
1. Plane light
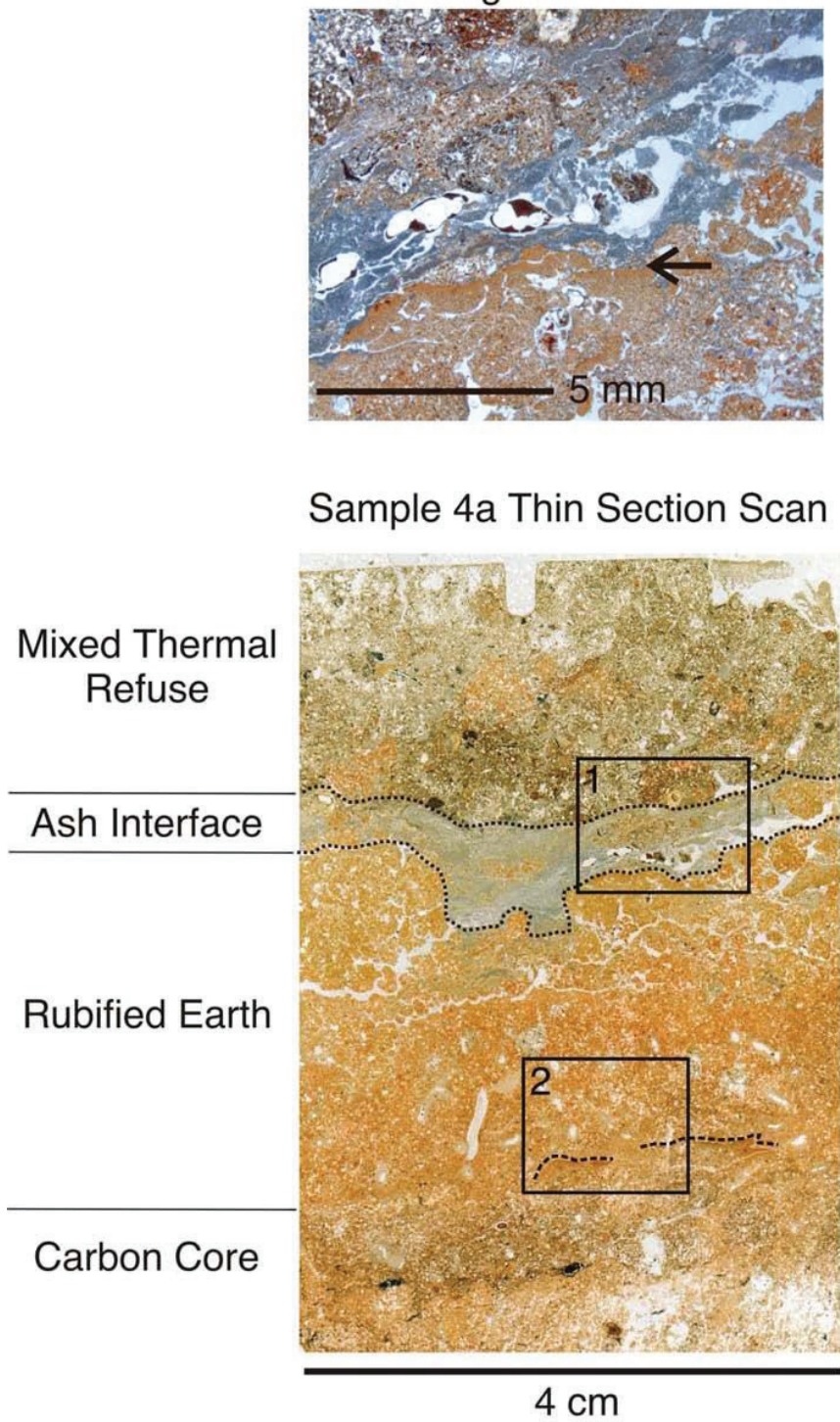

1. Cross-polarized light

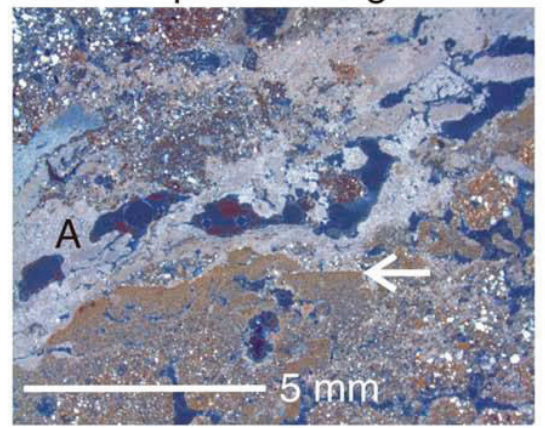

2. Plane light

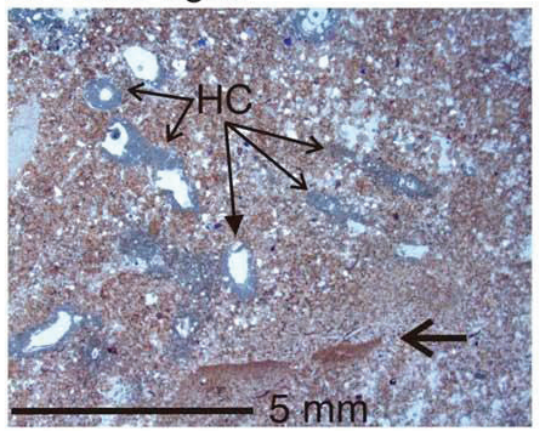

2. Cross-polarized light

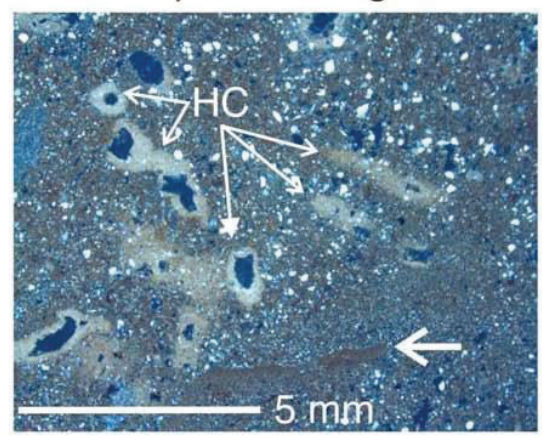

Figure A3 Bottom left: Transmitted light scan of the thin section 4b, with the microfacies discussed in the text labeled on the left. The Ash interface is delineated with a dotted line on the scan. The two rectangles denote the location of the enlarged views shown above (number 1) and at right (number 2). Number 1 (top two photos) shows the ash interface resting on rubified earth, the top of the latter is denoted by a thin laminae that appears to fine upward (shown by arrow). Number 2 (at right) shows a portion of the rubified earth that contains many small hypocoatings of calcium carbonate lining pores. Such features are common in all of the deposits examined from the site but occur in much higher frequency immediately below the hearth most likely owing to short distance translocation of ash, which is largely calcium carbonate. 

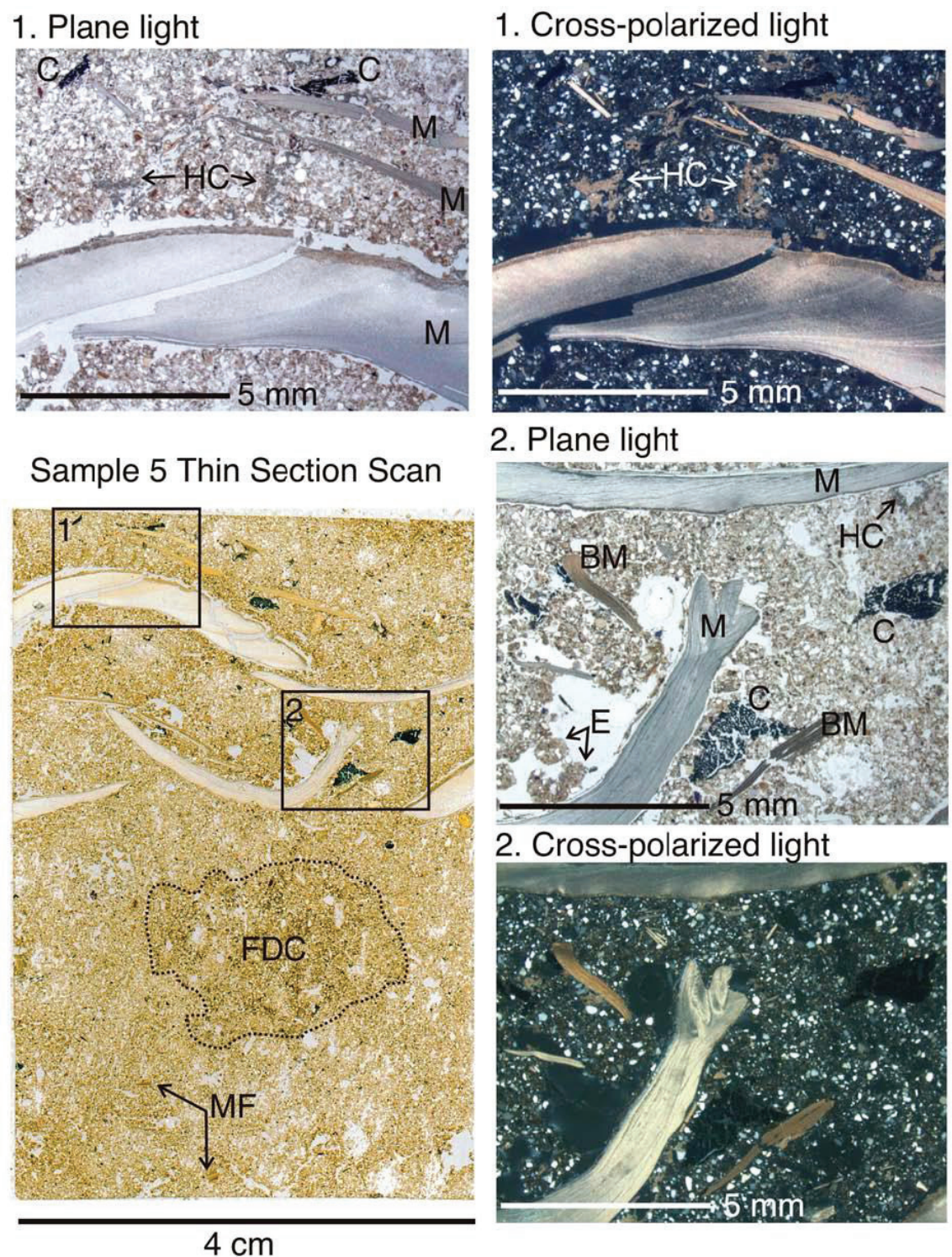

\section{Plane light}
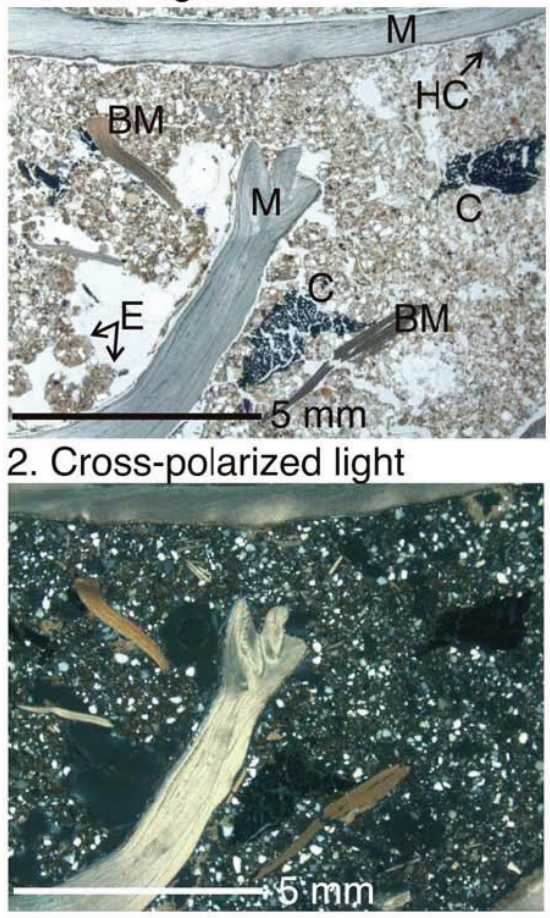

Figure A4: Bottom left: transmitted light scan of the thin section showing the relatively discrete occupation zone in the top half of the slide. Rectangles show locations of the two areas enlarged above (number 1) and to the right (number 2). Area labeled FDC is a zone of finely disseminated charcoal consistent with earthworm reworking of charcoal. MF denotes small mussel shell fragments located well beneath the occupation zone, but small enough to have been moved by soil fauna. Enlarged area 1 shows one large mussel shell (M) with several smaller shell fragments (M) and charcoal (C) fragments above it, and small hypocoatings of calcium carbonate (HC). Enlarged area 2 shows detail of the area between the mussel shells where there is evidence of faunal reworking of the soil (excrement pedofeatures (E)) most prominently immediately adjacent to the shell, but also relatively large charcoal fragments (C) and burned mussel shell (MB). One small hypocoat of calcium carbonate is visible attached to the bottom of one of the larger shells. 


\section{Appendix B Radiocarbon Data Sheets}

The information for this appendix is provided electronically on the attached CD. 
Appendix B 


\section{Appendix C Artifact Catalogs}

The information for this appendix is provided electronically on the attached CD. 
Appendix $C$ 


\section{Appendix D \\ SoIl SuSCEPTIBILITY}

The information for this appendix is provided electronically on the attached CD. 


\section{Appendix E \\ Comparable Component Ages}




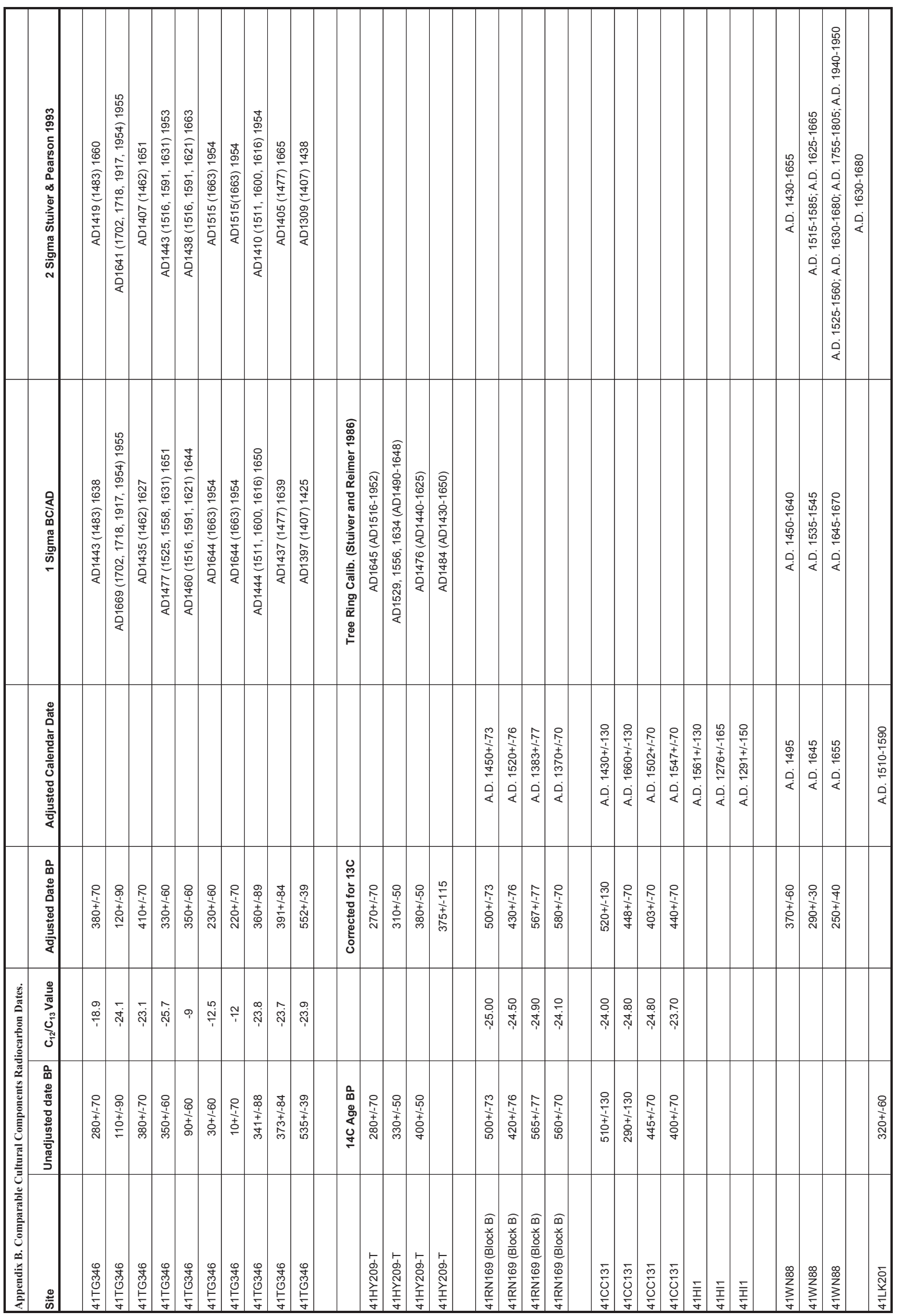




\section{Appendix F}

\section{Raw Materials}


Appendix $F$ 


\section{Joel A. Butler}

\section{Overview}

Raw materials studies assist in identifying local lithic resources utilized by Native Americans in their daily needs for acquiring, harvesting, and processing vegetable and faunal foods, as well as cooking and the containment of cooking fires. An absence of local lithic resources and the presence of imported materials found within an archaeological site indicate human transportation and trade of resources.

Lithic material samples were collected at two separate localities along Fish Creek; one downstream (Sample 1, South Robinson Road) and one upstream (Sample 2, in Fish Creek Park near Meade Drive) from site 41DL436 (Figure F-1). A general grab sample of rocks was collected at each of the two localities. Fourteen rocks were collected in Sample 1, and 17 were collected in Sample 2. Because no bank outcrops were identified in the area, none of the rocks were collected in situ, but were found in loose gravels deposited within the streambed. A table of all sample specimens is presented in Table F-1.

Materials mostly reflect local geology, originating in the Upper Cretaceous-aged Eagle Ford Group. The exceptions were imported and manmade materials, the result of local urban development. No chert or quartzite was identified within the samples, which indicates human transportation and/or trade for the sparse assemblage of lithic tools identified in 41DL436.

\section{Sample 1}

Sample 1, located 1,400 meters downstream of 41DL436, was comprised of 14 specimens, a representative sample of which are presented in Figure F-2. Ten specimens (71 percent) from Sample 1 were very fine-grained sandstones from calcareous concretions within the Eagle Ford Group. One rock was identified as a course-grained Eagle Ford sandstone concretion, and one piece of limestone was identified as Cretaceous in age (judged by the presence of a pecten fossil), but of unknown origin. Also among the sample were two non-native specimens; one piece of Chico Ridge limestone, quarried in Wise County and distributed regionally as a common roadbed material, and one cobble of stream-rounded and weathered concrete with pea gravel inclusions.

\section{Sample 2}

Sample 2, located 2,400 meters upstream of 41DL436, was comprised of 17 specimens; a representative sample photograph is presented in Figure F-3. Seven specimens (41 percent) from Sample 2 were very fine-grained sandstones, while four (23 percent) were coarsegrained sandstones. Two specimens were calcite slickensides from fracture joints in the Eagle Ford Group. Additionally, there was a specimen of thinly laminated limestone (most likely part of a limey layer within the Eagle Ford beds) and two pieces of typical Eagle Ford shale, a friable and quickly degraded clay rock. None of the Sample 2 specimens were identifiable as imported rocks. 


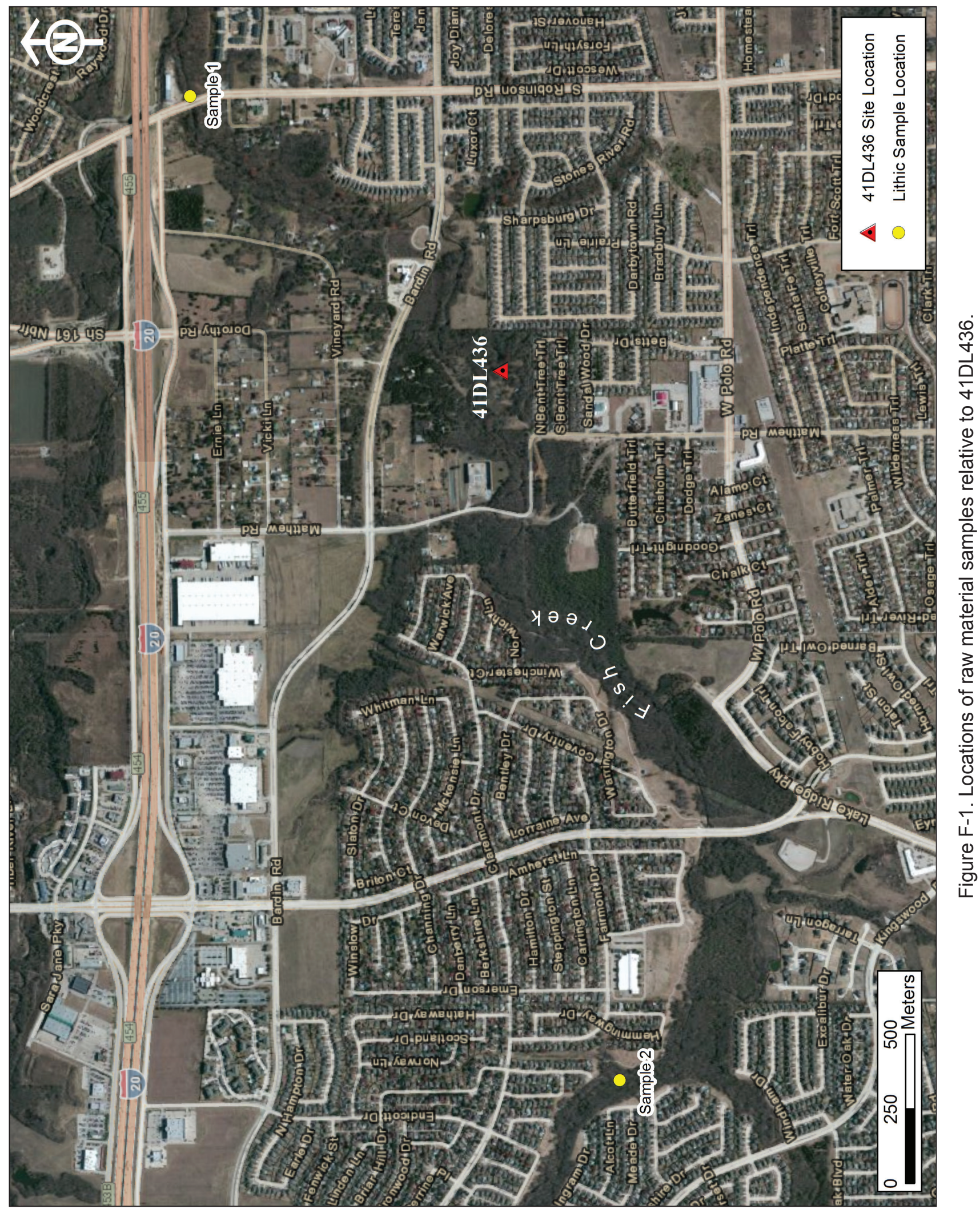




\section{Summary of Samples 1 and 2}

Of the 31 specimens collected at both Sample sites, 17 specimens (55 percent) were of very finely-grained sandstones and six specimens (19 percent) were coarse-grained sandstones. These sandstones originate as calcareous nodules within the Eagle Ford Group. Several of the coarse-grained sandstone specimens contained fragments of fossil shells. Native limestone, shale, and slickensides were represented by two specimens each, or 19 percent of the samples. Imported gravel and concrete debris made up the remaining balance of material.

Table F-1. Raw Material Specimens Collected.

\begin{tabular}{|c|c|c|c|c|c|c|c|c|c|c|c|}
\hline 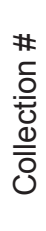 & $\begin{array}{l}\frac{0}{O} \\
\frac{0}{E} \\
\text { ָ }\end{array}$ & 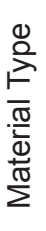 & $\begin{array}{l}\overline{\bar{d}} \\
\stackrel{\text { D }}{5} \\
\stackrel{5}{\Sigma} \\
\sum\end{array}$ & 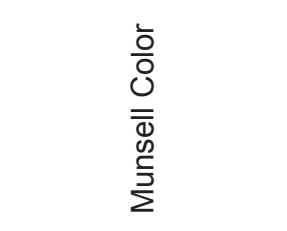 & $\begin{array}{l}\stackrel{0}{N} \\
\frac{N}{\omega} \\
\frac{5}{\pi} \\
\frac{\pi}{0}\end{array}$ & 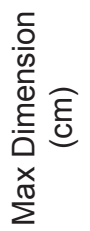 & $\begin{array}{l}\text { শ } \\
\text { ț } \\
\text { U }\end{array}$ & 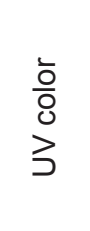 & 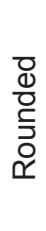 & 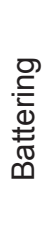 & Remarks \\
\hline A & 1 & 2 & 10YR 5/6 & Yellowish Brown & 1 & 5.9 & 1 & $\mathrm{DP}$ & 1 & 2 & $\begin{array}{l}\text { Almost chert-like - Conchoidal } \\
\text { fracture, reacts to acid }\end{array}$ \\
\hline B & 1 & 2 & 10YR 5/6 & Yellowish Brown & 1 & 4.3 & 1 & DP & 1 & 2 & UV color reddish purple \\
\hline C & 1 & 2 & 10YR 6/4 & Light Yellowish Brown & 3 & 5.8 & 1 & $\mathrm{DP}$ & 1 & 2 & $\begin{array}{l}\text { Coarse sandstone with } \\
\text { fossil shell inclusions }\end{array}$ \\
\hline $\mathrm{D}$ & 1 & 2 & 10YR 5/6 & Yellowish Brown & 1 & 5.2 & 1 & DP & 1 & 2 & \\
\hline $\mathrm{E}$ & 1 & 4 & 10YR 8/1 & White & 1 & 7.4 & 1 & DP & 1 & 2 & $\begin{array}{l}\text { Partial pecten fossil on cortex, } \\
\text { chalky, Eagle Ford or Austin }\end{array}$ \\
\hline $\mathrm{F}$ & 1 & 2 & 10YR 5/4 & Yellowish Brown & 1 & 6.9 & 1 & $\mathrm{DP}$ & 1 & 2 & \\
\hline G & 1 & 2 & 10YR 5/6 & Yellowish Brown & 1 & 7.4 & 1 & $\mathrm{DP}$ & 1 & 2 & \\
\hline $\mathrm{H}$ & 1 & 2 & 10YR 5/6 & Yellowish Brown & 1 & 3.3 & 1 & $\mathrm{DP}$ & 1 & 2 & \\
\hline 1 & 1 & 2 & 10YR 5/6 & Yellowish Brown & 1 & 7.6 & 1 & DP & 1 & 2 & \\
\hline $\mathrm{J}$ & 1 & 4 & 10YR $7 / 1$ & Light Gray & 1 & 7.7 & 1 & $\mathrm{DP} / \mathrm{G}$ & 1 & 1 & $\begin{array}{l}\text { Chico Limestone } \\
\text { (imported roadbase) }\end{array}$ \\
\hline $\mathrm{K}$ & 1 & 6 & 10YR 8/1 & White & 3 & 8 & 2 & G & 1 & 2 & Eroded Concrete Cobble \\
\hline $\mathrm{L}$ & 1 & 2 & 10YR 5/6 & Yellowish Brown & 1 & 4 & 1 & $\mathrm{DP}$ & 1 & 2 & \\
\hline M & 1 & 2 & 10YR 5/6 & Yellowish Brown & 1 & 4 & 1 & DP & 1 & 2 & \\
\hline $\mathrm{N}$ & 1 & 2 & 10YR 5/6 & Yellowish Brown & 1 & 7 & 1 & DP & 1 & 2 & \\
\hline A & 2 & 4 & 10YR $7 / 3$ & Very Pale Brown & 1 & 9.8 & 1 & DP & 1 & 2 & $\begin{array}{l}\text { Very finely laminated, } \\
\text { probably Eagle Ford }\end{array}$ \\
\hline B & 2 & 5 & $2.5 Y 4 / 1$ & Dark Gray & 1 & 8 & 2 & DP & 2 & 1 & $\begin{array}{l}\text { Very friable Eagle Ford Shale, } \\
\text { fish fossil in one fragment }\end{array}$ \\
\hline $\mathrm{C}$ & 2 & 2 & 10YR 5/4 & Yellowish Brown & 1 & 5.8 & 1 & DP & 1 & 2 & Fine stratification seen in cortex \\
\hline $\mathrm{D}$ & 2 & 3 & 10YR $7 / 4$ & Very Pale Brown & 1 & 8.2 & 1 & DP & 1 & 1 & Slickenside Cobble \\
\hline$E$ & 2 & 2 & 10YR 6/4 & Light Yellowish Brown & 3 & 6.7 & 2 & $\mathrm{DP}$ & 1 & 2 & \\
\hline $\mathrm{F}$ & 2 & 2 & 10YR 6/6 & Brownish Yellow & 3 & 9.6 & 2 & DP & 1 & 2 & \\
\hline G & 2 & 3 & 10YR $7 / 4$ & Very Pale Brown & 1 & 5.3 & 1 & DP & 1 & 1 & Slickenside Cobble \\
\hline $\mathrm{H}$ & 2 & 2 & 10YR 5/6 & Yellowish Brown & 1 & 9.9 & 1 & $\mathrm{DP}$ & 1 & 2 & \\
\hline I & 2 & 2 & 10YR 6/6 & Brownish Yellow & 3 & 6.5 & 2 & DP & 1 & 2 & \\
\hline $\mathrm{J}$ & 2 & 2 & 10YR 5/6 & Yellowish Brown & 1 & 5 & 1 & $\mathrm{DP}$ & 1 & 2 & \\
\hline
\end{tabular}




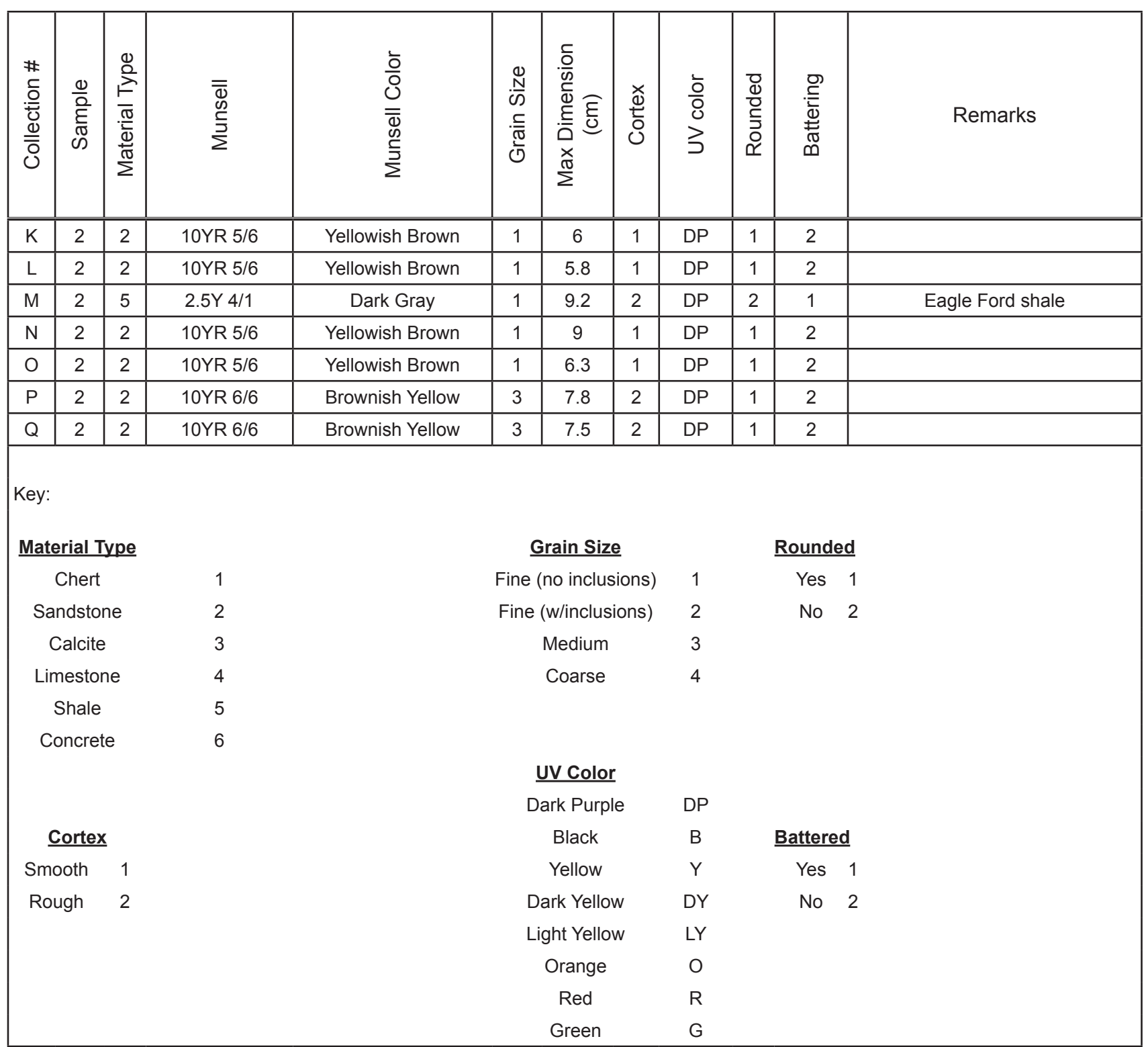

\section{Discussion of Sample Specimens}

The Eagle Ford Group, named after its type location, ten miles north of 41DL436, is represented by an abundance of laminated, friable clay-rich shale. These shales were deposited during early Upper Cretaceous time when the Interior Seaway covered the majority of Texas, extending across the Great Plains. The Eagle Ford shales are rich in fossil vertebrate fauna as indicated by its original common name, the "Fish Beds" (Shuler 1918:15). The Eagle Ford shales were deposited in a mostly calm near shore environment punctuated by regressions of the seaway, resulting in the introduction of interbedded sand concretions (Surles 1987:20). 


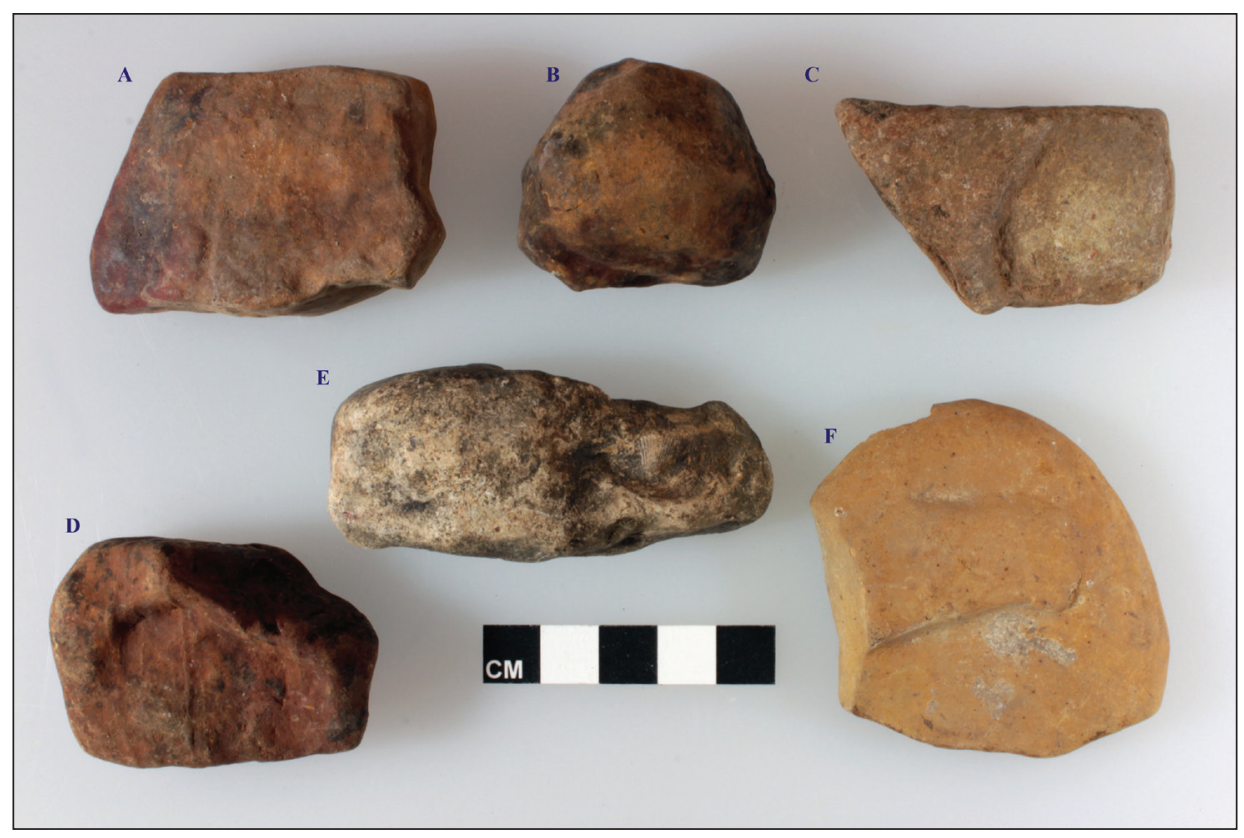

Figure F-2.

Representative sample of raw material within Sample 1 (a. fine-grained sandstone, $\mathrm{b}$. fine-grained sandstone, c. medium-grained sandstone, d. fine-grained sandstone, e. limestone, $f$. fine-grained sandstone).

Figure F-3.

Representative sample of raw material within Sample 2 (a. limestone, b. shale, c. fine-grained sandstone, d. calcite, e. medium-grained sandstone, $\mathrm{f}$. medium-grained sandstone).

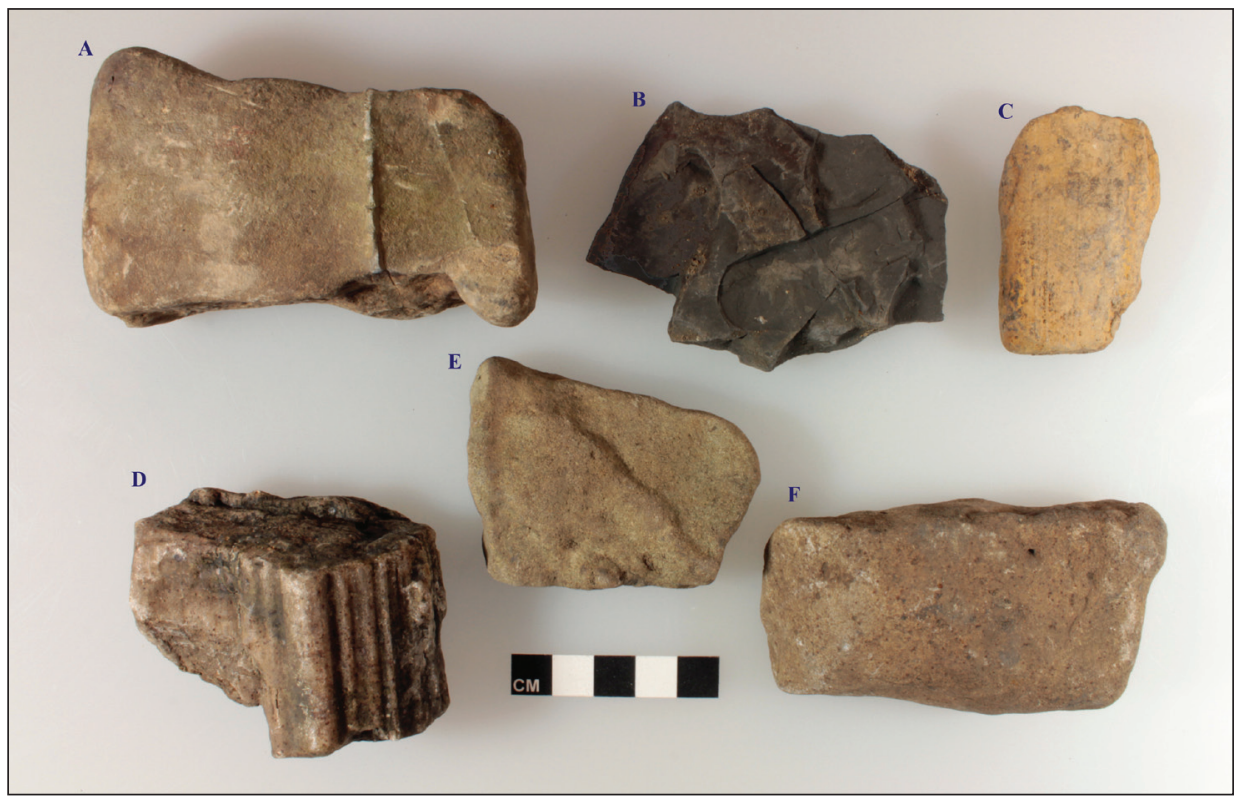

\section{Sandstone}

Interbedded within the Eagle Ford shale are small calcareous nodules of fine and coarse-grained sandstones (Stephenson 1955:53). Although forming a small fraction of the Eagle Ford Group as a whole unit, the sandstone nodules, as seen in Samples 1 and 2, are much more abundant in erosional settings where the parent shale degrades and forms sediments of dark gray clay. Of all specimens collected in sampling, only the sandstone could have been used as a functional lithic tool. The fine-grained sandstone breaks in a conchoidal fracture similar to chert, and contains very tightly packed grains. However, the grains are not cemented well enough so that it could have served the purpose of knapping without breaking in an unpredictable manner. Sandstones could serve in a limited capacity as groundstone or possibly in place of chert. 


\section{Slickenside}

Slickensides are tabular striated rocks which form by compression and friction within the joints between fault blocks. These are of interest in the context of 41DL436 due to their presence within the site's deposits. Eagle Ford slickensides are mostly formed of calcite (CaCO3) and, like their counterparts formed in Austin Group limestone, are attractive rocks, which contain translucent to transparent calcite crystals. Typically, slickensides quickly delaminate and erode into small rounded cobbles when exposed in streambeds. Several tabular slabs found in deposits at site 41DL436 suggest that an outcrop of Eagle Ford Group rocks was exposed nearby at some point during the site's occupation.

\section{Limestone}

The two specimens of limestone which were not apparently imported both exhibit fine lamination. These limestone pebbles most likely eroded from thin bands within the Eagle Ford shale. One specimen contained a partial pecten fossil, which could not be identified, but places the fossil firmly at some point within Cretaceous time.

\section{Shale}

Both collected specimens of shale were typical of the Eagle Ford Group. One piece was noted to contain a small fish vertebrate (less than $2 \mathrm{~mm}$ ). When exposed, these rocks quickly erode, delaminate, and dissolve into clay, leaving behind the harder elements of their matrix (i.e. sandstone and limestone lenses, and most fossils). The presence of two specimens at Sample 2's location indicate a nearby exposure of undisturbed Eagle Ford deposits.

\section{Ultraviolet Fluorescence}

All specimens collected in Samples 1 and 2 were exposed to ultraviolet (UV) light to check for the signature color and possibly link the specimens to raw lithic material types found in deposits at 41DL436. All specimens fluoresced in varying intensity and shades of purple with the exception of the Chico limestone, which fluoresced with a light green and purple mottling. Aside from the absence of any of the sampled specimen types at 4DL436, all observed chert artifacts at the site fluoresce in shades of orange, more typical of Edwards chert (Hurst et. al. 2010).

\section{Conclusions}

Although sandstone concretions could have served a limited purpose as groundstone or as a replacement for chert, there is minimal evidence of such uses at the site. Sampled streambed gravels from Fish Creek suggest that of the lithic tools and flakes recorded at site 41DL436, only sandstone was obtained locally. 


\section{Acknowledgements}

Our special thanks to archaeologists Antonio Padilla and Jimmy Barrera for spending a hot Saturday tromping through the brush along Fish Creek in order to find and collect raw materials for this study.

\section{References Cited}

Hurst, S., E. Johnson, Z. Martinez McCoy, and D. Cunningham

2010 The Lithology of Ogallala Gravels and Hunter-Gatherer Procurement Strategies along the Southern High Plains Eastern Escarpment of Texas, USA. Geoarchaeology: An International Journal 25 (1) 96-121.

Shuler, E. W.

1918 The Geology of Dallas County. University of Texas Bulletin No. 1818. Austin.

Surles, M. A. Jr.

1987 Stratigraphy of the Eagle Ford Group (upper Cretaceous) and its Source-Rock Potential in the East Texas Basin. Baylor Geological Studies Bulletin No. 45. Waco, Texas

Stephenson, L. W.

1955 Basal Eagle Ford Fauna (Cenomanian) in Johnson and Tarrant Counties Texas. Geological Survey Professional Paper 274-C. US Government Printing Office, Washington, D.C. 
Appendix $F$ 


\section{APPENDix G Faunal Data}

The information for this appendix is provided electronically on the attached CD. 
Appendix $G$ 


\section{Appendix H \\ Macrofloral and Microcharcoal \\ Radiocarbon Data Sheets}

The information for this appendix is provided electronically on the attached CD. 


\section{Appendix I \\ Bone Collagen Radiocarbon Dating}


Appendix I 


\title{
Bone Collagen Radiocarbon Dating of Selected Fauna from 41DL436
}

\author{
Raymond Mauldin, PRL-CAR-UTSA
}

Ten faunal samples were submitted to the Paleo-Research Laboratory (PRL), Center for Archaeological Research (CAR) for bone collagen radiocarbon dating. All samples were identified to taxa prior to submission. Radiocarbon sample preparation initially involved an assessment of the stable isotopic signature, for calibration, as well as an assessment of the carbon to nitrogen $(\mathrm{C}: \mathrm{N})$ ratio of the potential collagen sample. Isotopic preparation was initially conducted at the PRL and subsequently samples were analyzed at the Colorado Plateau Stable Isotope Laboratory at Northern Arizona University (CPSIL-NAU). Accelerator Mass Spectrometry (AMS) radiocarbon dating of samples was conducted by DirectAMS/Accium Biosciences in Seattle.

\section{PRL-CAR Sample Preparation and Isotopic Analysis}

Each bone sample was examined, and a section selected for sampling. We used a hand-held rotary sander to grind off the surface in this area. We then used a small cutting wheel to remove a section of bone for subsequent analysis. This section was placed in a clean glass test tube and washed in ultra-pure (Type 1) water in an ultrasonic bath. Following that washing, we dried the bone samples under low heat $\left(50^{\circ} \mathrm{C}\right)$ in a dry bath.

For the initial isotopic analysis of the bone collagen, a section of the cleaned, dry samples was removed and lightly crushed in a mortar and pestle into small fragments $(0.5-2 \mathrm{~mm}$ size). The resulting material was again washed in an ultrasonic bath with Type 1 water. We changed the water after each 60-minute cycle until the water was clear. We then removed and dried the samples under low heat. For each sample, we weighed out roughly $200 \mathrm{mg}$ of bone and split this into two clean glass test tubes. We added $0.5 \mathrm{~N} \mathrm{HCL}$ to each test tube, and refrigerated the capped samples at $4^{\circ} \mathrm{C}$ to decalcify the bone (see Bocherens et al. 1991; DeNiro \& Epstein 1981; Longin 1971). After 30 hours, samples were rinsed to neutral with Type 1 water. They were treated with $0.1 \mathrm{~N} \mathrm{NaOH}$ for 45 minutes at room temperature to remove humic acids and some lipids. Samples were again rinsed to neutral in Type 1 water. Following the $\mathrm{NaOH}$ treatment, samples were solubilized in $0.01 \mathrm{~N} \mathrm{HCl}$ at $70^{\circ} \mathrm{C}$ for 11 hours in a heating block. The supernatant was filtered through coarse fritted filters into glass vials. These were capped, sealed, and frozen at $-29^{\circ} \mathrm{C}$. The frozen samples were freeze-dried under vacuum to isolate collagen. Roughly $600 \mu \mathrm{g}$ of collagen was weighed into tin capsules for bulk stable carbon and nitrogen isotope analysis (see Munoz et al. 2011).

The isotopic analysis of the 41DL436 collagen was conducted by the CPSIL at Northern Arizona University. Collagen samples were analyzed using a Thermo-Electron Delta V Advantage Isotope Ratio Mass Spectrometer (IRMS) configured through the CONFLO III and attached to a Carlo Erba NC2100 elemental analyzer. Both carbon and nitrogen isotopic composition for a given collagen sample was obtained during a single run. The CPSIL uses standards from the National Institute of Standards and Technology (NIST) and the IAEA (International 
Atomic Energy Agency), along with a variety of internal standards for calibration and raw data normalization. Collagen carbon $\left(\delta^{13} \mathrm{C}\right)$ is reported in per mil $(\%)$ relative to the Vienna Pee Dee Belemnite $(\mathrm{V}-\mathrm{PDB})$ standard. Nitrogen $\left(\delta^{15} \mathrm{~N}\right)$ values are reported relative to AIR and are also reported in per mil. The CPSIL has an uncertainty of $\leq 0.10 \%$ for $\delta^{13}$ Ccollagen and $\leq 0.20 \%$ o for $\delta^{15} \mathrm{~N}$ based on repeated runs.

Table 1 presents the results of the isotopic work. Note that two separate analyses were conducted on each bone collagen sample. In the table, we reference these as Sample 1 and Sample 2, and the mean reflects the average of these two runs for carbon and nitrogen. In addition, the bone from one animal, a bison, was sampled twice (samples \#315,317), though only a single sample from this bison was submitted for isotopic analysis. Nitrogen results are not discussed here, as the focus of this analysis was on acquiring calibration data. CAR sample \#314 is a previously run standard, with an average of $-9.8 \delta^{13} \mathrm{C}$ based on previous runs. The atomic $\mathrm{C} / \mathrm{N}$ ratio is also reported in the Table. This ration is a measure of collagen quality (see Ambrose and Norr 1992; Van Klinken 1999. Collagen samples that fall below a value of 3.1 or above 3.5 are not routinely sent for radiocarbon dating. An examination of the $\mathrm{C}: \mathrm{N}$ ratio in Table 1 shows that all samples are within the acceptable range.

Table 1. Isotopic results fro bone selected fro radiocarbon dating, 41DL436.

\begin{tabular}{|c|c|c|c|c|c|c|c|c|c|}
\hline $\begin{array}{c}\text { CAR } \\
\text { C14 \# }\end{array}$ & SITE & Class & $\begin{array}{c}\text { Atomic } \\
\text { C/N Ratio }\end{array}$ & $\begin{array}{c}\delta^{13} \mathrm{C} \% \\
(\text { Mean })\end{array}$ & $\begin{array}{c}\delta^{13} \mathrm{C} \% \% \\
(\text { Sample 1) }\end{array}$ & $\begin{array}{c}\delta^{13} \mathrm{C} \% \\
(\text { Sample 2) }\end{array}$ & $\begin{array}{c}\delta^{15} \mathrm{~N} \% \\
\text { (Mean) }\end{array}$ & $\begin{array}{c}\delta^{15} \mathrm{~N} \% \\
\text { (Sample 1) }\end{array}$ & $\begin{array}{c}\delta{ }^{15} \mathrm{~N} \% \\
\text { (Sample 2) }\end{array}$ \\
\hline 307 & 41DL436 & Bison & 3.20 & -8.90 & -8.90 & -9.00 & 5.27 & 5.26 & 5.28 \\
\hline 308 & 41DL436 & Bovidae & 3.26 & -11.80 & -11.85 & -11.81 & 6.10 & 6.10 & 6.14 \\
\hline 309 & 41DL436 & Deer & 3.34 & -20.20 & -20.12 & -20.29 & 5.40 & 5.43 & 5.42 \\
\hline 310 & 41DL436 & Bovidae & 3.29 & -13.10 & -13.10 & -13.04 & 8.00 & 7.95 & 8.06 \\
\hline 311 & 41DL436 & Bovidae & 3.20 & -9.50 & -9.50 & -9.40 & 6.90 & 6.90 & 6.90 \\
\hline 312 & 41DL436 & Bovidae & 3.33 & -7.60 & -7.48 & -7.66 & 5.20 & 5.19 & 5.22 \\
\hline 313 & 41DL436 & Canis & 3.26 & -8.10 & -8.10 & -8.03 & 9.20 & 9.17 & 9.18 \\
\hline $314^{*}$ & STANDARD & Bison & 3.30 & -10.00 & -10.00 & -10.06 & 7.70 & 7.70 & 7.60 \\
\hline $315 / 317$ & 41DL436 & Bison & 3.32 & -11.90 & -11.80 & -11.91 & 5.50 & 5.44 & 5.56 \\
\hline 316 & 41DL436 & Bovidae & 3.30 & -9.10 & -9.16 & -9.13 & 6.80 & 6.81 & 6.76 \\
\hline 318 & 41DL436 & Deer & 3.30 & -20.10 & -20.17 & -20.03 & 6.60 & 6.66 & 6.60 \\
\hline
\end{tabular}

* PRL standard (Bison 1) from Planiview Texas area, previously analyzed and dates.

315/317- single animal.

\section{PRL-CAR Sample Preparation and Radiocarbon Analysis}

For the isolation of bone collagen suitable for radiocarbon date, we used an acid-base-acid preparation procedure on the 41DL436 material (see Brock et al. 2010; Minami et al. 2004). All glass wear used in the process was autoclaved prior to use, and all test tubes were also heated to $450^{\circ} \mathrm{C}$ for 2 hours to assure that no organic contaminants were present. For a given bone sample, we initially lightly crushed the clean bone with a ceramic mortar and pestle. These crushed bone samples were sonicated in Type 1 water, with the water changed after each run, until the rinse water was clear. Samples were then dried in a covered dry bath at $50^{\circ} \mathrm{C}$. Two 
$150 \mathrm{mg}$ sub-samples of clean, dried bone were weighed into glass test tubes for each of the 11 samples. These sub-samples were then decalcified with $0.5 \mathrm{~N} \mathrm{HCl}$ at $4{ }^{\circ} \mathrm{C}$ for 30 hours. After washing to neutral, we then treated each sub-sample with $0.1 \mathrm{~N} \mathrm{NaOH}$ for up to 45 minutes at room temperature, and again washed sub-samples to neutral. They were then covered with $0.5 \mathrm{~N} \mathrm{HCl}$ and again refrigerated at $4^{\circ} \mathrm{C}$ for roughly 12 hours. We then replaced the $0.5 \mathrm{HCl}$ with $0.01 \mathrm{HCl}$ without exposing the decalcified bone to air. Sub-samples were solubilized in the $0.01 \mathrm{HCL}$ at $70^{\circ} \mathrm{C}$ for 20 hours in a covered dry bath. The solubilized samples were then vacuum-filtered through individual 0.45 um silver filter membranes to eliminate larger contaminants. Samples were drawn into glass vials and then placed in a freezer at $-29^{\circ} \mathrm{C}$. Frozen sample were subsequently freeze-dried for roughly 36 hours. The sample vials were then sealed and shipped for analysis.

Radiocarbon samples were analyzed by DirectAMS/Accium Biosciences in Seattle (Zoppi et al. 2007). The collagen samples were combusted and reduced to graphite in sealed vials and measured using a National Electrostatics Corporation Model 1.5SDH-1 Pelletron Accelerator. The Direct/AMS laboratory has an overall precision and accuracy of 0.3 to 0.5 percent for modern samples (Zoppi et al. 2007).

Table 2 presents the results of the analysis. As noted above, the $\delta^{13} \mathrm{C}$ of all collagen samples submitted for dating, along with their atomic C:N ratios (see Ambrose and Norr 1992; Van Klinken 1999), were measured prior to submittal by CPSIL (see Table 1). These independent $\delta 13 \mathrm{C}$ measures were used to correct for isotopic fractionation on individual dated samples. Two samples from the same bone, samples 315 and 317, were prepared and processed independently.

Table 2. Collagen Radiocarbon results and related information for 41DL436 and Bison 1 (Standard)*

\begin{tabular}{|c|c|c|c|c|c|c|c|c|c|c|}
\hline CAR C14 \# & SITE & UNIT & LEV. & Field lot & Class & $\begin{array}{c}\text { M Modern } \\
\text { Carbon }\end{array}$ & $\begin{array}{c}\text { NAU Measured } \\
\text { C }^{13}\end{array}$ & $\begin{array}{c}\text { Corrected Radio- } \\
\text { carbon age BP }\end{array}$ & $\begin{array}{c}1 \text { sigma } \\
\text { error +/- }\end{array}$ & $\begin{array}{c}\text { Direct } \\
\text { AMS \# }\end{array}$ \\
\hline 307 & 41 LL436 & 69 & 3 & 280 & Bison & 95.49 & -8.9 & $\mathbf{3 4 2}$ & 34 & 5759 \\
\hline 308 & $41 \mathrm{DL} 436$ & 1 & 1 & 2 & Bovidae & 95.35 & -11.8 & $\mathbf{3 4 0}$ & 24 & 5760 \\
\hline 309 & $41 \mathrm{DL} 436$ & 102 & 1 & 391 & Deer & 95.67 & -20.2 & $\mathbf{3 4 7}$ & 25 & 5761 \\
\hline 310 & $41 \mathrm{DL} 436$ & 70 & 1 & 229 & Bovidae & 96.25 & -13.1 & $\mathbf{3 0 9}$ & 25 & 5762 \\
\hline 311 & $41 \mathrm{DL} 436$ & 75 & 1 & 235 & Bovidae & 97.08 & -9.5 & $\mathbf{2 1 2}$ & 26 & 5763 \\
\hline 312 & 41DL436 & 72 & 1 & 233 & Bovidae & 95.88 & -7.6 & $\mathbf{3 4 0}$ & 25 & 5764 \\
\hline 313 & 41DL436 & 72 & 1 & 233 & Canis & 96.18 & -8.1 & $\mathbf{3 0 0}$ & 26 & 5765 \\
\hline 314 & STANDARD & $\mathrm{n} / \mathrm{a}$ & $\mathrm{n} / \mathrm{a}$ & $\mathrm{n} / \mathrm{a}$ & Bison & 64.75 & -9.8 & $\mathbf{3 4 3 2}$ & 29 & 5766 \\
\hline 315 & 41DL436 & 69 & 3 & 280 & Bison & 95.74 & -11.9 & $\mathbf{2 6 4}$ & 24 & 5767 \\
\hline 316 & 41DL436 & 75 & 1 & 235 & Bovidae & 96.17 & -9.1 & $\mathbf{2 8 9}$ & 24 & 5768 \\
\hline 317 & 41DL436 & 69 & 3 & 280 & Bison & 96.66 & -11.9 & $\mathbf{2 0 8}$ & 22 & 5769 \\
\hline 318 & 41DL436 & 103 & 1 & 390 & Deer & 92.65 & -20.1 & $\mathbf{4 6 9}$ & 31 & 5770 \\
\hline
\end{tabular}

* This bison (bison 1) is from plainview area that was previously dated by Beta Analytic at $3490+/-40$.

315,317 same animal but two different runs. 
These provided results of $264+/-24$, and $208+/-22$ (Table 2). In addition, sample 314, a PRL standard, was prepared and run with these dates. This sample has been independently dated by Beta Analytic (224050) and has been dated multiple times during the PRL and Direct/AMS calibration. These previous results are presented in Figure 1. The sample run with the 41DL436 samples (3432 BP +/-29) overlaps both with the Beta date (3490+/-40) and with the majority of the previously run dates for this animal.

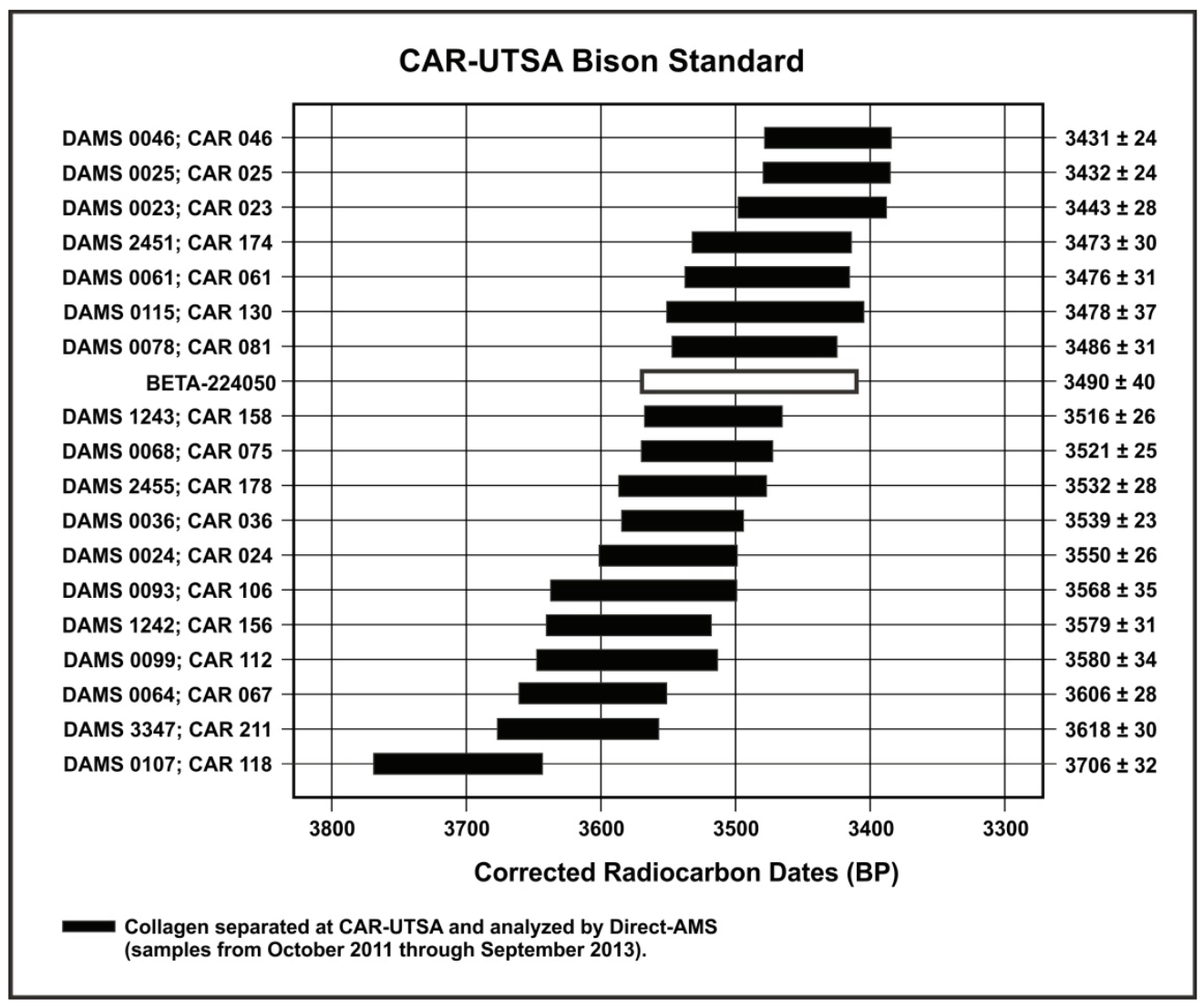

Figure 1. Bison Sample 314, PRL standard. 


\section{References Cited}

Ambrose, S. H., and L. Norr

1992 On stable isotopic data and prehistoric subsistence in the Soconusco region. Current Anthropology 33, 401-404.

Bocherens, H., M. Fizet, A. Mariotti, B. Lange-Badre, B. Vandermeersch, J. P. Borel, and G. Bellon

1991 Isotopic biogeochemisty (13C, 15N) of fossil vertebrate collagen: implications for the study of fossil food web including Neanderthal Man. Journal of Human Evolution 20, 481-492.

Brock, F., T. Higham, P. Ditchfield, R. C. Bronk

2010 Current pre-treatmen methods for AMS radiocarbon dating at the Oxford Radiocarbon Accelerator Unit (ORAU). Radiocarbon 52, 103-112.

DeNiro, M. J., and S. Epstein

1981 Influence of diet on the distribution of nitrogen isotopes in animals. Geochimica et Cosmochimica Acta 45, 341-351.

Longin, R.,

1971 New Model of Collagen Extraction for Radiocarbon Dating. Nature 230:241-242.

Minami, M., H. Muto, and T. Nakamura

2004 Chemical techniques to extract organic fractions from fossil bones for accurate 14C dating. Nuclear Instruments and Methods in Physics Research B. 223-224, 302-307.

Mauldin, R. P., R. J. Hard, C. M. Munoz, J. Z. Rice, K. Verostick, D. Potter, and N. Dollar

2013 Carbon and nitrogen stable isotope analysis of hunter-gathers from the Coleman site, a Late Prehistoric cemetery in Central Texas. Journal of Archaeological Science 40: 1369-1381.

Munoz C. M., R. P. Mauldin, D. Paul, and L. Kemp

2011 Monitoring Paleovegetation Shifts through Stable Carbon Isotope Variability in Archaeologically Recovered Leporids. Texas Journal of Science. Vol 63 (1).

van Klinken, G. J.

1999 Bone collagen quality indicators for palaeodietary and radiocarbon measurements. Journal of Archaeological Science 26, 687-695.

Zoppi, U., J. Crye, J., and Q. Song

2007 Performance evaluation of the new AMS system at Accium BioSciences. Radiocarbon 49, 171-180. 


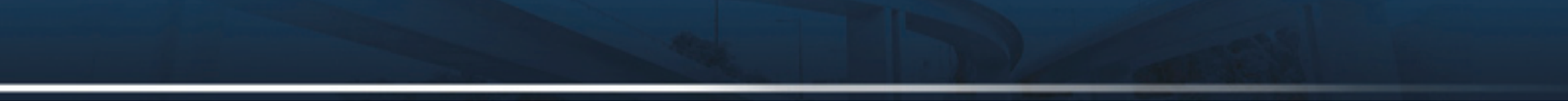

